

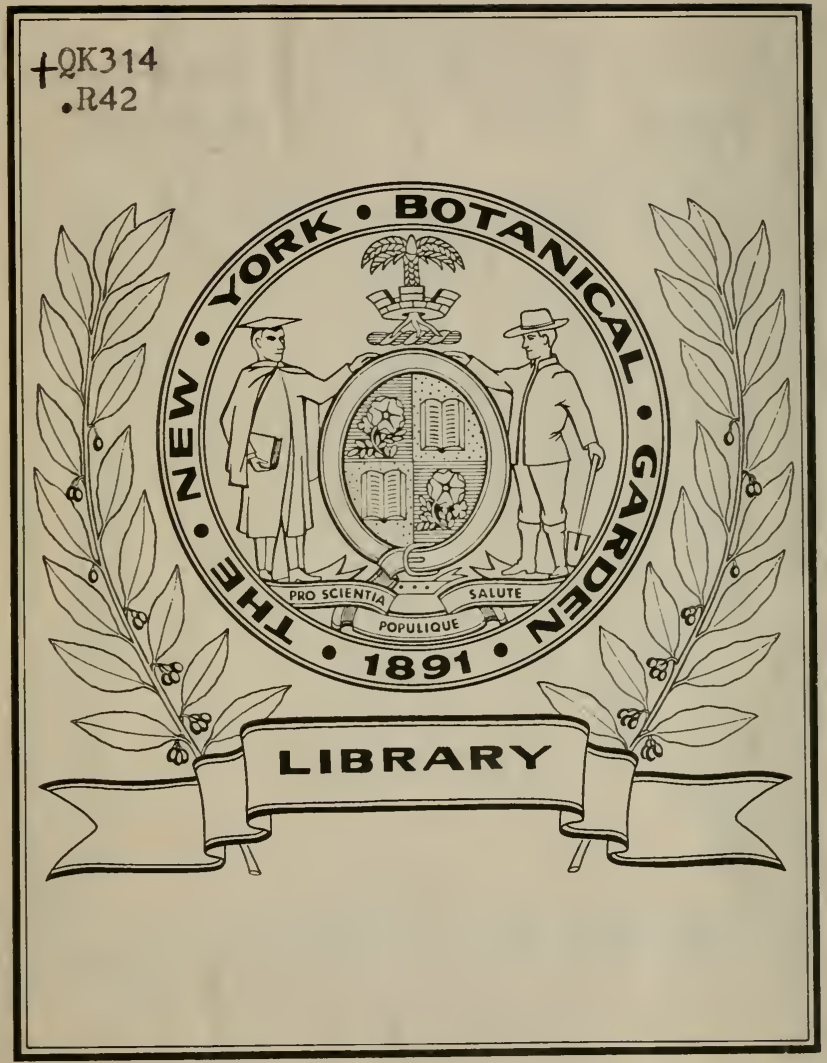






\title{
FLORA SAXONICA.
}

D i e

\section{Flora von Gadien,}

, ein botanifaces (Ercurfionabuth

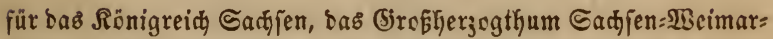

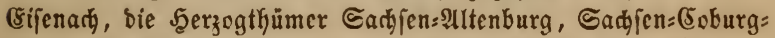

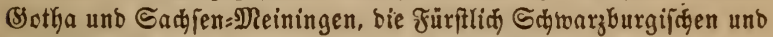

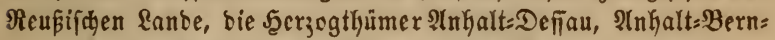

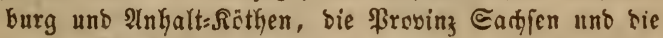
\$reußif

\section{Reb if \\ E ch I it if t} zum

erleiderten Beftimmen der Sinttungen nad)

\section{Rinme's Gexualinitem} uns

Dentifchem und Inteinifacht Regifter.

\author{
SЕ \\ ven
}

S. (5. R. Picichenbach, Oaruba

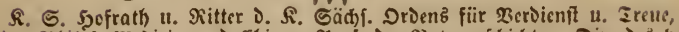

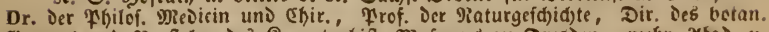

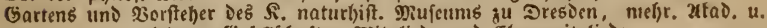
gelebrten (Esfeafinaften Mitgfieve uno Ebrenmitglieve.

Deg beutienen Sotanifers żeiter \$ano.

Dresben und Reipjib,

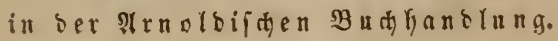

1842. 


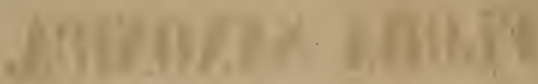

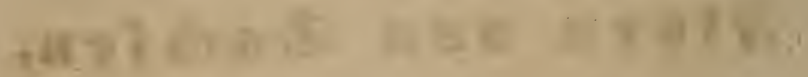

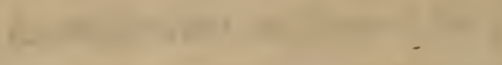

$$
\begin{aligned}
& \text {. } \\
& 10
\end{aligned}
$$

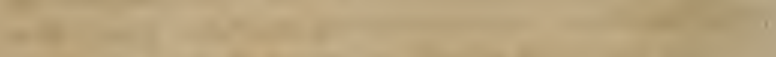

$$
\begin{aligned}
& 10-100 \\
& \text { 1.200 } \\
& 10+100
\end{aligned}
$$

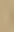

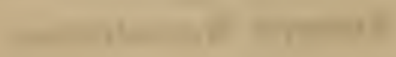

$$
\begin{aligned}
& \text { 1) }
\end{aligned}
$$

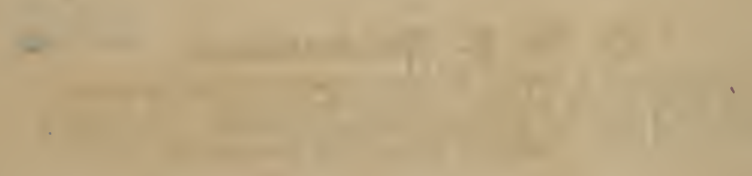

$$
\begin{aligned}
& \text {. }
\end{aligned}
$$




\section{Geiller Minjeftät}

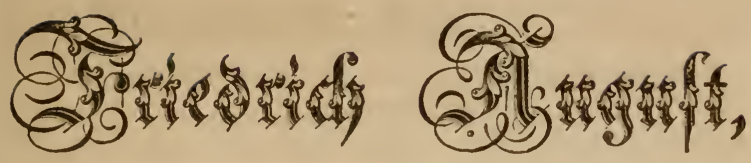

Rönig von Sadyien,

Dem erbabenen Renuer Der Ratur,

chrerbictigit geiviomet

rom

3erfalier. 


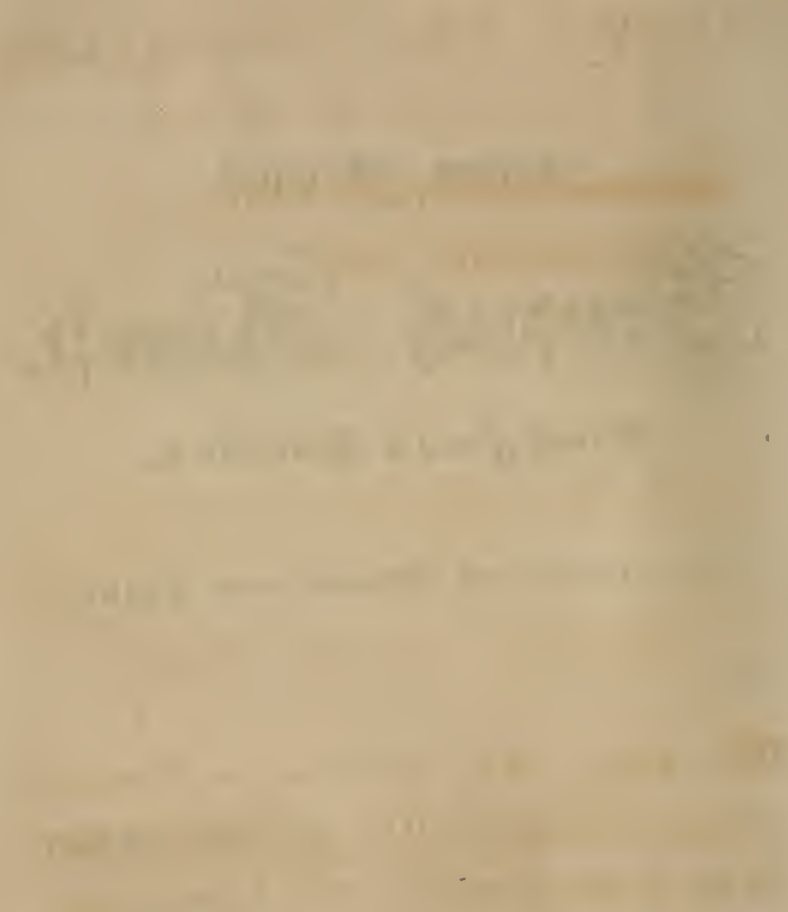

$+4+2+$<smiles>[CH][TlH]</smiles> 


\section{9flerburchlauchtigfter Söแig, :Ullergun̈sigiter ङerr!}

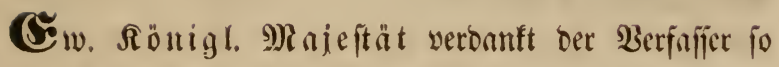

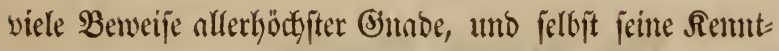

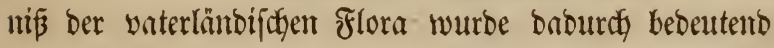

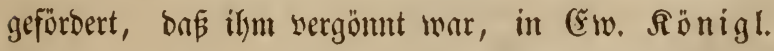

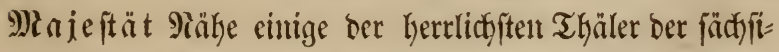

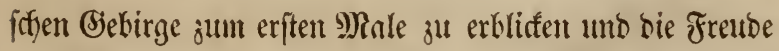

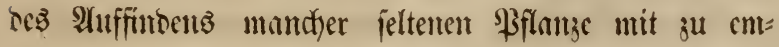
printoent. 


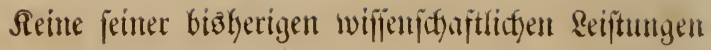
forien ifym Darum, fo wie biefe Flora von Eadjen, ge= eignet, bie Biefunumgen ber tief empfundenen Danfbarfeit

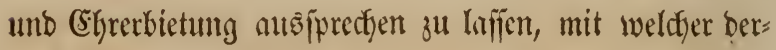
felle Zeitlebens befourret

\section{Ew. Rönigl. MRajeftät}




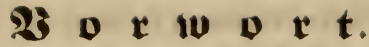

Die Bearbeitung ser flcra feines 3aterlanbes fatmebte bem Berfafier feit bem Beginnen feiner betanifiten Etubien als

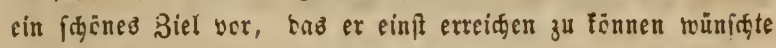
unb bofitte.

Die Entomologie, von frühefter Sugeno an in einem Rreife unvergęlidger Freunbe eifrig betrieben, fülyrte ifhn zuerft burd bie frudtbaren Befilte ber Baterfabt Reipzig unb wieberfyolt burch sie frĩanzenreicten Berge uno üppigen Thäler bes väter: lin befreunbeten Thüringerlanbed. Frühseitig exēfinneten iłm (5ors reipenbenzen unb, fo oft es geinefhen fonnte, fleine Neifen bie

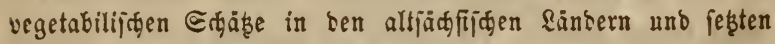
ihn in ben હtanb, bereitz im Jaḩre 1818, als \$rofeffor ber

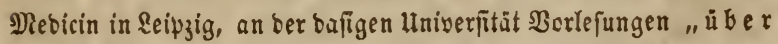

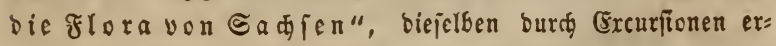
läuterno, zal Kalten. Die Berufung nart Dresben excīinnete bem

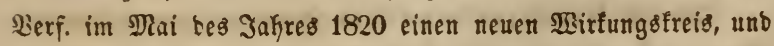
son ba an uefyrten fin bie Nittel für ciue genaue uno ppecielle 


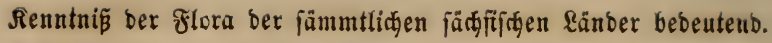
Neben ofteren, in anbere Begenben hin geleiteten Excurfionen

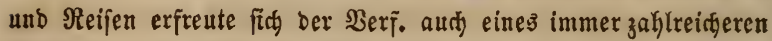

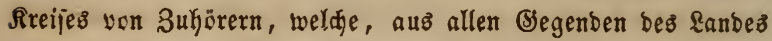
zufammenfommenb, fpäterfin fin eben fo wicber in baffelbe ver:

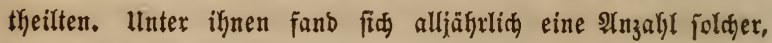
benen es zur Freube gereidte, ihre Bemerfungen ober (sntbed:

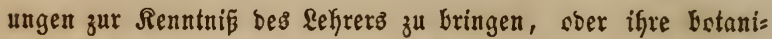

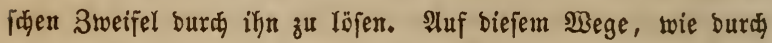
bie Nitwirfung załlreider Freunbe unb bic pääere Thätigfeit feiner beiben älteren Säkne (L. Rchb. fil. unb G. Rchb.)

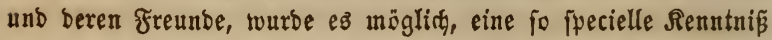
ber vaterlänbiftien Flora zu erlangen, als biejes $\mathfrak{B u d}$ feinem Rejer barbietet, auf biefem $\mathfrak{B e g e}$ allein fonnte eine fo grofe Menge yon zuberläfïgen Stanborten intrerhalb ber (3renzen aufgezeidunet

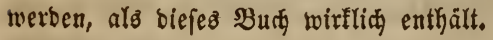

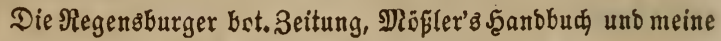

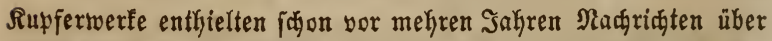
biefe meine Flora von 5 a d fen, unb fiton bamals hatte bie Strs

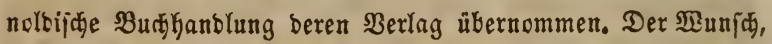
bie bereits yorhambene, in ifrem Berlage erifienene Lofalfora nod möglidfft benuben zu lafien, veranlapte inbefien yon Seiten

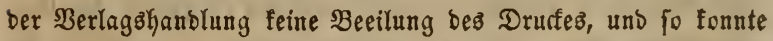

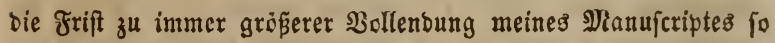
lange benuģt werben, bis endlid ein 1 mftand eintrat, ben es

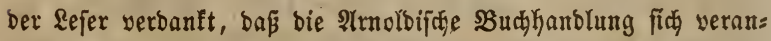

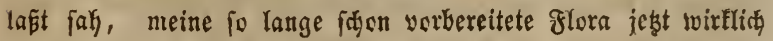
rructen ž Iaाien.

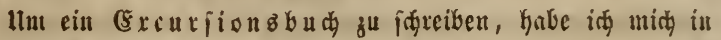

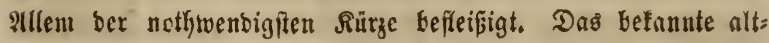




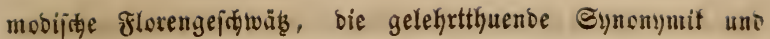
bie caballiftijuen Benennungen ber mebicinij̄ gleidgültiglen \$flamzen aus ber 3eit ber Ardimifen gehören ni at a u f curfionen, und i⿱ habe fie barum möglidft vermieben. Unjer

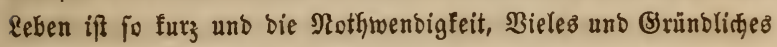

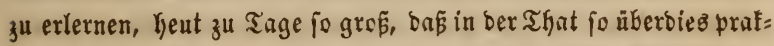
tiin) unnüß̨e Büroe z" tragen, am wenigften einem Stubirenben Der Dlebicin soer \$ुgarmacie noh 3eit uno Sraft bleibt. So wie id min bafer immer bemüht habe, yor ifnen nur \$ofitivez zu refren, fo if aud Gier alle \$olemif gänzlid befeitigt, uno felbft ben Druff Kabe id bei aller Deutfinfeit und Sefälligfeit jo compenbiös angeorbnet, baß bas Beftreben, die Bogenzahl zu verringern unb nidht zu vermefren, hervorleudtet.

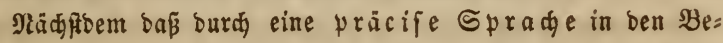

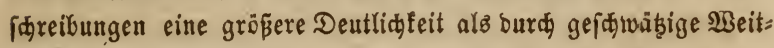
läufigleit exlangt werben fonnte, wirb bas erfte $\mathfrak{A} u f f u$ den und $\mathfrak{B}$ eftimmen ber \$ĩanjen insbefonbere burch ben voralls= gejendeten, nady bem $\mathfrak{L} i$ ueifden Sexualfyfteme abge= fapten Grifluffel gar fefrr erleidtert. Man wiro bei befien

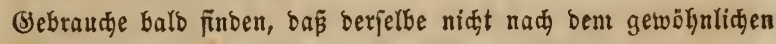
Erfema, wo nur ein einzelner (5haracter bie Battung trifit, ge= arteitet ipt. Csin berartiger ๔ajlüf̄el expheint mir immer als

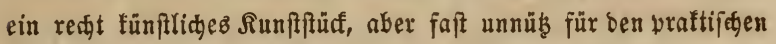
(Sebraud, benn fobald berielbe in einer einzigen Nummer fehl=

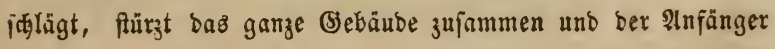
fiegt fid serlafien. Sक Gabe beshalb, wie in finon in meiner Flora germanica gethan, für jebe Sattung mefre Renuzeiden zufammengefaft und jebe abweidende (s) attung, ju fogar jebe abweiden be $\mathfrak{A} r t$ au allen Drten aufgeführt, an benen ber Infünger fie juţen bürfte. Diefe Bintintung wirb ifm mantie Nemente feiner eslen 3cit erffaren. 
Die Befátigung ber Beftimung ber gejunbeneu

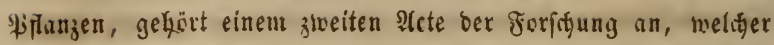

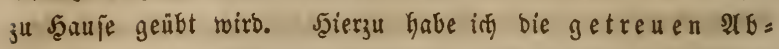
bils u u gen ber befannteften und am allgemeinften yertreiteten WBerle citirt unb bie Siummern angegeben, unter benen fit Dri=

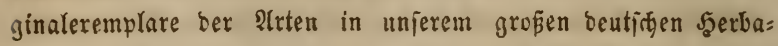
rium, in ber "Flora germanica exsiccata“, befinben, beren zweiunbzwanzigfte Eenturic io even erifheint. Ohne Rupier: werfe unb Şerbarien $3^{u}$ vergleiden, bleibt bas $\mathfrak{B}_{\text {efftmmen ber }}$ \$flanzen fefir oft now häbjt unfider, uno ofjne fie twiro tein Stubium vollentoct.

Die Rebaction ber Standorte hat mein zweiter Sofn

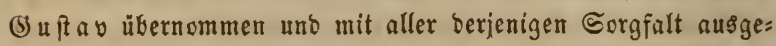

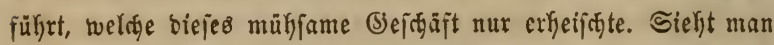
in ähnlidgen. Büraern ein puar Stanborte in willfüfrlidjer $\mathfrak{t n}=$

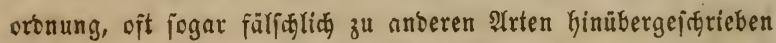

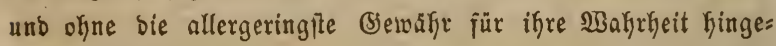
freut, jo vergleight man nit \$ergnügen Gier bie frülle von auto: rifirten Stanborten, mit Sienauigfeit unter iffe \$rovinzen georb=

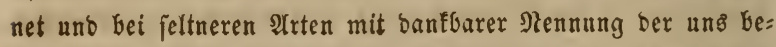
fannt geworbenen Entberfer und Finber verfełen. Allen benje: nigen, beren Namen hier lei ben Stanborten genannt finb -

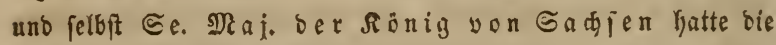

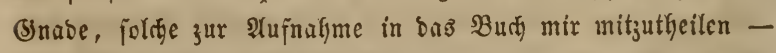

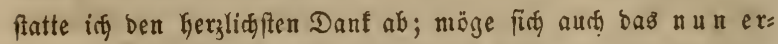
frienene Bucf ifrer weiteren Theilnafge und wünfdens: werthen Şervollfänbigung uno Berbefierung erfreuen!

Sim Regifter hielt ing für nothwenbig, Bejonbers für bie

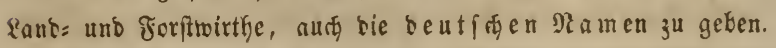

शlles sllfgemeine über \&age, Rlima uno formation bes Terraits, fo mie tiber bie $\mathfrak{B} e$ roveitung ber $\mathfrak{B e g e}=$ 


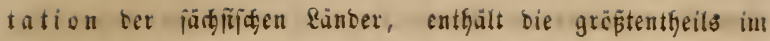
Druff vollentete (5) ăa von $\widetilde{G}$ a

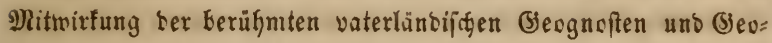

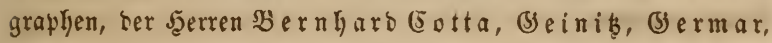
v. (5) Serlage, bulbigft exjeineint.

Die natürlife Incronung fonnte teine ancere jein

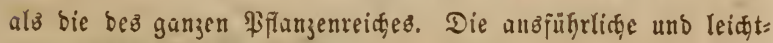

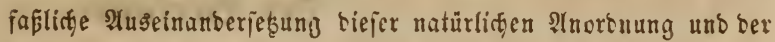

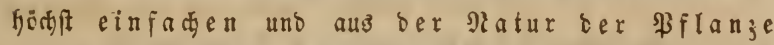
felbit abgeleiteten (5) $r$ u $n$ of folgt, Gat man in cem türzlith erjøienenen jerbarien to zmedmäfig gefunben und bañelbe hat baburty unb als ein vor= züglitges Dittel, bei Nnorbnung eines Serbariums 3 it $z^{u}$ gewinnen, eine jo freunblige Tufnabme uno fo

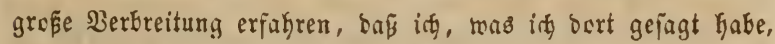
yier niat mieberbolen burite, da es jebem Rejer barin vorliegt.

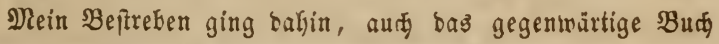

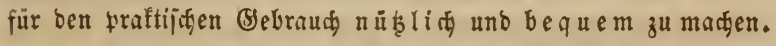

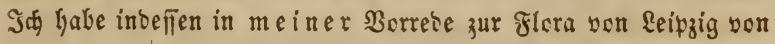
Rlett uns $\Re$ i

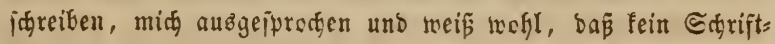

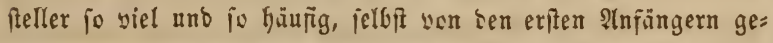
tabelt miro, als ber Jlorift. Seben segrüneten uns mafrhajte Berbeflerung bejwedfenten Tatel, fo wie alle Bufäge uno neuen

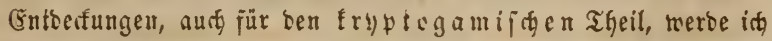

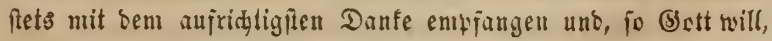
unmefy baloigit benuben.

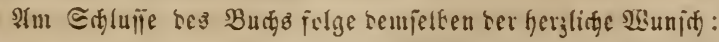

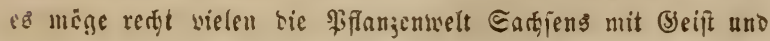




\section{$-x I 1-$}

(B) gleiter fein, uno ez möge nod \$landjen veranlafien, auf bie

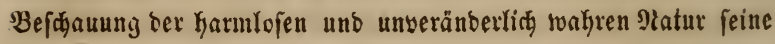
Sliffe z" ridten.

\section{Der Berfalier.}




\section{E di I il i i t}

วแกเ

erlecit)terten Beftimmen ber Bsattumenen nach

\section{Siltec's Serualinitut.}

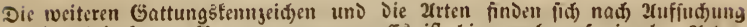
Der beigefekten Gattungsmummer. (E) ift bier aud) auf eingelne Zrten,

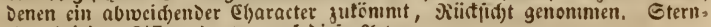
(1):"n bei Den Biffern Deuten auf Dieje 2urten.

I. Monandria. Činmännige. 3witterblüthen mit $e i=$ nem Staubgefä́ (

I. Monogynia, (sintweibige; eine Rarbe. Hippuris, Relđfam un๖eutliđ). Slätter quirlftändig. 512.

Aphanes, Reldfiaum 4ipaltig. S2lätter mit 2(d)jelblättdfen. 492.

II. Digynia, 3tweitweibige; zwei Rarben.

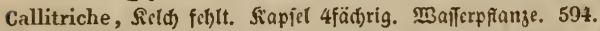

Blitum, Rel(́) 4-5tbeilig, mirb beerenartig. 9)eldenartig. 483 .

Salicomia, Reld) einceitig, baudsig. Blattlofe geglieicrte Pranje. 477.

Albersia vergl. Triandria Digynia. 489.

Polycnemun vergl. Triandria Digynia. 488.

Agathophytum vergl. Pentandria Digynia. 482.

Vulpia, ein Ġras. 61.

1. Diandria. Bweimännige. 3witterblüthen mit 3 twei હtaubgefǟ̄en.

I. Monogynia, çinmeibige; eine Rarbe.

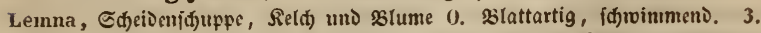
Lycopus, słtume 1blättrig, unregelmäß̄ig, faum länger als Reld). 2uirlblüthen. 4 शïßđjen. 255.

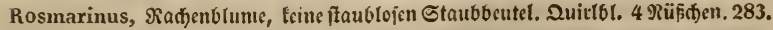

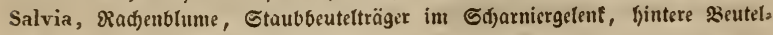

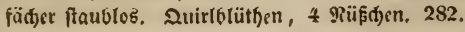




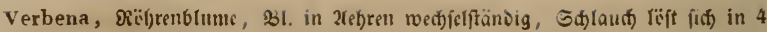
शีïßđ)en. 288.

Veronica, Rabolume (ober trifferf.) 4ipaltig, unterfter 2rofdfnitt fómaler. Sapficl 2 fäđrig. 311.

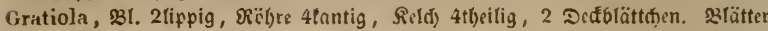
gegeniiber. 322 .

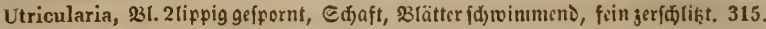
P'inguicula, 231. 2lippig geifornt, હd')aft, 3lätter ganj. 316.

ligustrum, 31. trid)terf. 4 fpaltig. 3eerenartige હteinfrud)t. 369.

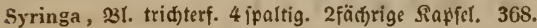

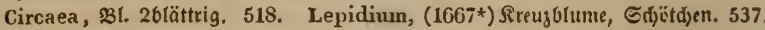

\section{I. Digynia, S weitweibige; z wei Narben.}

Anthoxanthum, Diđ)t ftraufblït)giges Grras. 29.

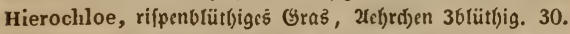

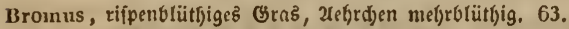

Salicornia, Glattlos, geglieicrt. 477.

Fraxinus, Baum, polnganiff(t), fpäter gliigelnus und unpaarig gefiederte 23 läto ter. 367 .

\section{Triandria. Dreintäntge. 3mitterblütfen mit}

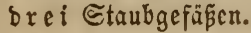

\section{Monogynia, Ginmeibige. Sine Narbe.}

Nardus, einfeitigälyrigę Graš. 40).

Valerianella, Blume tri(b)terförmig, Grud)teld() gejälsnt. 165.

Valeriana, 3lunte tridsterförmig, grut(t)teld) federartig. 165.

II. Digynia, 3weitweibig'e. 3wei Narben.

a) Şräfer.

Mibora, 2chre aแs 1 blütbigen Epelgen. 25.

Lolium, 2(eb)r(j)en vielblütbig, vertical, alfo nit ber Sante Der 2(đ)fe angebriidt. 41.

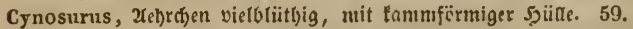

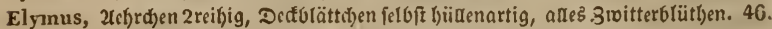

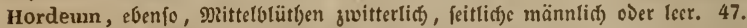

Brachypodiun, 2(el)r(j)en vielolüt(big, turjgeftielt, $2($ (t)fe ausgefd)nitten, äufere Epelge unter Der Epik̨e begrannt. 42.

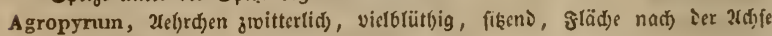
getefrt. 43.

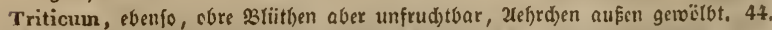

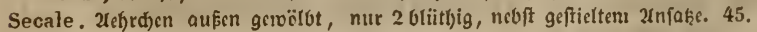

Digitaria, 2(ef)ren ziemlid) eniftänbig, gefingert. 2(cl)rd)en faarig, Epelzen voll. ftänoig. 36.

Andropogon, 2rebren gefingert, 2(ef)rdjen paarig, äupicre Spelze blus ciue Granne. 39.

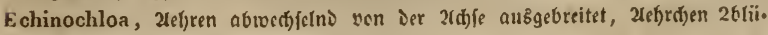
thig, unterfite $\$ 81$. leer. 37.

Agrostis, Kifpe. Spelgen 1 blütljig. 16.

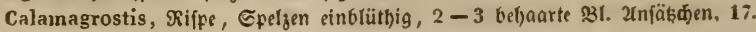


Ammophila, Straufrifipe, Epelgen 1 blüthig, 1 bebaarter 31.21 njak̨. 18.

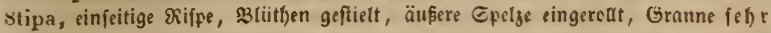
lang l)aar, sier fioerförnig. 20.

Setaria, Etraufrifpe, 331. polngantifa), innre Epelje tnorpelartig, 2lebrden mit borftigen 5ü̈đđ)en. 38.

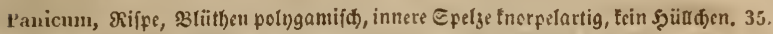

Milium, Sxippe, \$3lïthen zroitterlid, innre Epelye fnerpelartig. 34.

Alopecurus, ährenartige Etraufrifpe. Dedfipeljen verroactifen, Epelje fळlaudi. artig. 26.

l'hleun, äfrenartigc હtrauprifpe. Detipeljen fđief zugefpist, Epeljen cingefentt. 27.

Phalaris, Straufrijpe (Did)t cise fnanelartig getheilt), Dedffpelge mit fliigelarti. gem fiiel, 1 blüthig nit $1-2$ sit. 2tnfäh̨en. 28.

Leersia, Siifpe (meift in Der 23lattfd)ei১e), Dedffelge fithlt. 33.

Sesleria, äl)renartige Straufrifpe, äufere Spelje ausigefreffen, 3-5jäl)nig. 57.

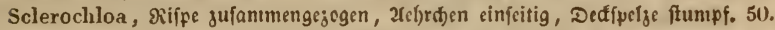

Dactylis, Rifpe tnauelartig getbeilt, 2lel)rdjen jufanumengeذrüaft, feingefpikt. 60.

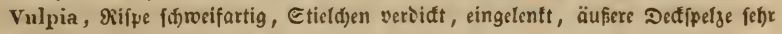
Elein, äufere Epelje langbcgrannt, enigrannig. 61.

Festuca, Rifpe, Etieldfen faienfïmig, eingelenti, 2lel)r(t)en vielbliithig, frad,, äufere Epelge auz Der Spike begrannt. 62.

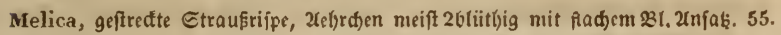

Triodia, Iraube, 2uef)r(ben 3-5 blütbig, äufere Spelje 3jäbnig. 54.

Bromus, Rifpe, 2lef)rdicn (anjetlid) zufammengebriidt, äusere Epelfe unter ber Epił̧e begrannt. 63.

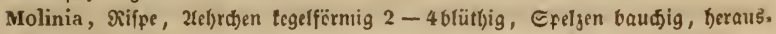
ragend, ganjranisig. 56 .

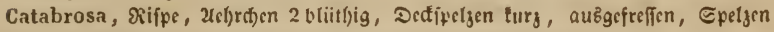
ausgeferbt. 52.

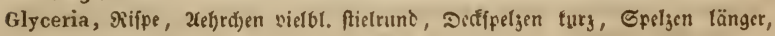
abgerunist. 51 .

Poa, Silfpe, Jef)rdyenadfie geglieiert jerbied)lid). $4 S$.

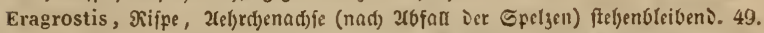

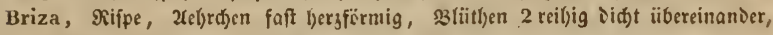
Epelzen berzförnig vauthig. 53.

Koeleria, Straufriffe lappig, 2(ebrd)en meift 3 bliithig. 58.

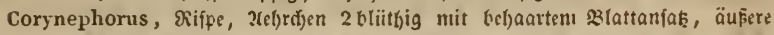
Dedffelge mit teulenförmiges Granne. 21.

Aira, riifpe, 2(cb)rd)en 2 blütbig, äufere Epelze unten nit borftenförmiger gera. Der ober gé̌niđter Granne. 22.

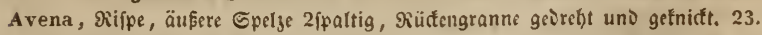

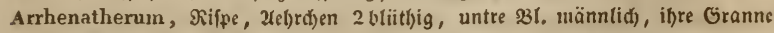
bodenftändig, getnidt, obre grvitterlich, Granne unter Der Epił̧e, geraie. 24.

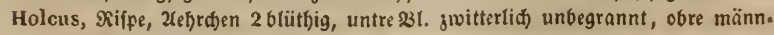
(id, begrannt. 31 .

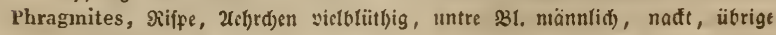
jwitterlich, 2(d)fe lang bel)nart. 19. 


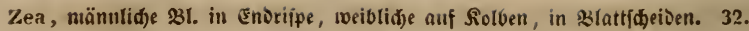

b) Eりpergräfer ntit 2 Rarben.

Pycreus, aefhrden platt, Dodbe mit 5jüle, Borften feblen. 69.

Rhynchospora, 2rehrd)en büfðelftändig, Grifel unten breit, 6-10 Reldjboriten. 66.

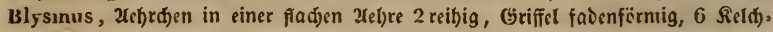
borften. 73.

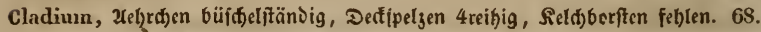

vignea, vergl. Monoecia Triandria.

c) $\mathbf{B}$ lattfeimer.

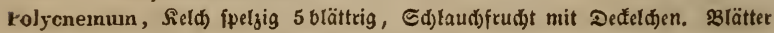
pfrientid). $4 \mathrm{SS}$.

III. Trigynia, oreitreibige. Drei Narben.

a) JrisäbnIide.

Crocus, Rarben zufanimengerodt, gezähnelt, Btüthen triđteroglodtig, aufredt. (R̈̈̈nnte als cultivirt $79 . \mathrm{b}$ folgen.)

Gladiolus, Blüthe vorgeftredt 6theilig 2lippig. 79.

Iris, Blüthe aufred)t, rëbrig verwadjen, Saum Doppelt 3 theilig, Rarbenträger blumenblattartig. 78 .

b) Eypergräfer.

Cyperus, 2abjoben platt, Dolde mit Şülle, Borften feltlen. 70.

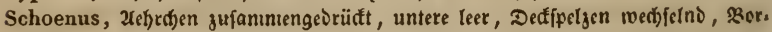
ften fellen. 67.

Holoschoenus, 2refroben fuglid, , Ieldborften fehlen. 75.

Scirpus, 2afhrden ziegelfđuppig, neift fpindelförmig. 72.

Eriophorum, 2(ef)rden ziegelf(f)uppig, zur frudttgeit quaftenartig beranzragende Seidenhaare. 71 .

Carex vgl. Monoecia Triandria.

c) 3 lattieimer.

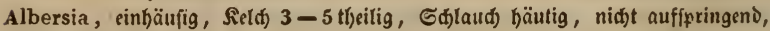
1 faanig. 489.

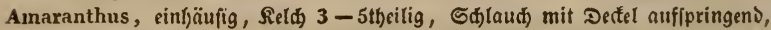
1 faamig. 490.

Elatine, (1613*) SBlume 3 blättrig. 590 .

Montia, slunte 5 blättrig verwoađjen röhrig. 475 .

Polycarpon, slunte fdl)r tlein 5 blättrig, Rapfel 3tlappig. 469.

Holosteun, Blumtenblätter 5, gizäl)nt, Rapfel mit 3ähnen auffpringento. 617.

IV. Tetrandria. Bickmönnige. 3rwitterblüthe nit vier હtaubgefäß̈en.

1. Monogynia, e inmånnige, e ine Narbe.-

a) Sieine 3 lunte:

Equisetuun, fiolben mit geftielten ₹rägern, auf ocren unterieite $\mathfrak{B}$ cutelḑen mit

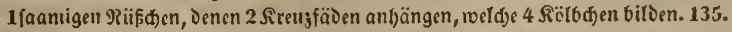

Maianthemun, Sield blumenartig weif, raoförumig 4tbeilig. 92.

Parietaria, field) frautartig 4tbeilig frci. Rarbe quafitenförmig. 156.

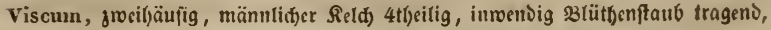

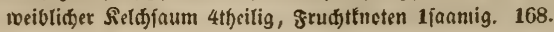


Thesium alpinum, Sield) glectig, Eaum inmentig vocif. હdaalfaanie 1 faamig. 137.

Elaeagnus, Relth gloofig, 4ipaltig, allşen filberidułpig, inmentig gelb (E. augustifolia bisibeilen angeffiangt), lïnnte 143. b. folgen.

Isnardia, Reld) glodtig, gan\} frautartig, ienı frud)tfncten angemadifen. 515. Sanguisorba, field mit 2 Deđblättjen, Deni frudjtfncten angeroadien, 4. fpaltig, farbig, Rarbe onaftenfërnig. 494.

b) S\&l u me 1 blättrig.

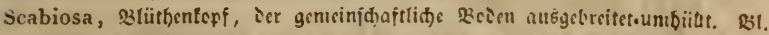
röhrig 2 lippig. 163.

Dipsacus, ebenjo, Şü̈e ftraf)lenartig, fteif, Eprenbläuțen ftedjens. 164.

Globularia, slïthentopfhültc allögebreitet 2reihig, Rseutet 1 fätbrig, Rarbe ge. fpalten. 305.

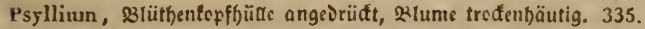

Plantago, stüthenähren, 21 . tređ́enbäutig. 334.

Littorella, (eint)äufig) welbli(t)e 831. mit 1 faamigem E(f)laud). 333.

Centunculus, Udffelblüt)en, $\mathfrak{B l} 4$ fpaltig, Raflel mit Dedfel aufipringent, riel. faamig. $3+2$.

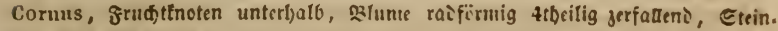
beere, Rüfd)en 2 faamig. 422.

Linnaea, fruditncten unterljalb, 2 jaamig, mit 2 Dofflättden, Blumen (2 beifammen) glơfig. 169.

c) 23 I u nue 4 olättrig.

Trapa, frudjtenoten unterbalb (ipäter 4 bërnig), giarbe tefffïrmig. 51ł.

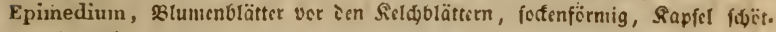
d)enartig. $5 \% 0$.

Cornus f. oben, 3lume eigentlid) 1 blättrig, nur gerfađeno. 422.

Evonyınus, Reld) frei frumpf 4 lapfig, glunenblätter ausgebreitet, Rapfel 4 5 fädrig. 634.

Gardanine hirsuta, Fel(s) aufredt) 4blättrig, Freujblunte, Ețote. 1695*.

\section{Digynia, z to eitue ibige, juei Sarben.}

Galium, Blume raifïrmig 4theilig, Doppelfकaljaame 2 faanig. 172.

Asperula, Blume trid)terfïrnig 4fpaltig, Dopfelid)aljaame 2 faamig. 173.

Rubia, 23lume raifërmig 4theilig, Eicin beere 2 faanig. 174.

Sherardia, Slume triđterförmig tipaltig, Deppelfolalfaame 2faanig, som Sildfaume gefrënt. 175.

Alchemilla, Reldyfaum vicrthcilig, 4 abıcedjfelni angernadjfene Dedorättd̆en. Bl. fel)tt, Sdjalfaame 1 faamig. 493.

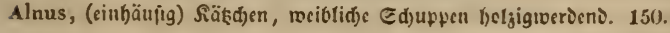

\section{Tetragynia, viertoeibige; a. vier Rarben.}

Rhannnus, Die 4 Staubgcfäse vor ien slumenblättern, Eteinbeere, Etraud). 426. Mönchia, 4 Rluntenblätter gan\}, Siaffel mit 3ähnen auffpringenঠ, 1 fädgrig. Relfenartiges̀ Siäutđ)en. 620).

Sagina, 4 (over ().) sklumenblätler gan;, finpiel 4tlappig, 1fädrig, nelfenartiges รiäuthen. 612. 


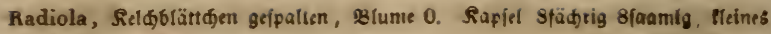
Rräuțen, Slätter gegenüber. 636.

b. vier grufitfncten.

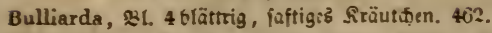

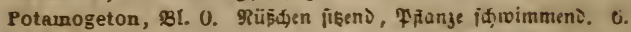

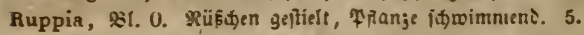

V. Pentandria, fünfmännige. Switterblüthen mib ๆ

J. Monogynia, einroeibige; eine Narbe.

A. Reldblütbe ebne \&lume.

Thesiun, Reldfaunı inmendig reiß, Edjalfaame unterbalb, 1faamig. Zer. freut.fómalbctsätterte fräuter. 137.

Glaux, Reldjiaum inmeniig roja, Rạjel frei, 5fädrig, Blätter gegenüber. 3wU.

B. $\&$ lume einblättrig. a. 4 frudtfnoten um ien Brifiel.

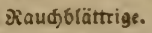

Echinan, 81. etras 2 lippig, Etaubgefäpe aufĩeigend, Ed̆lund nađt (Rarbe geffalten). 289.

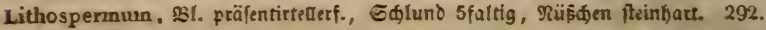

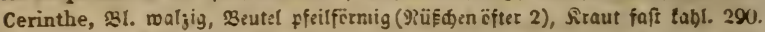

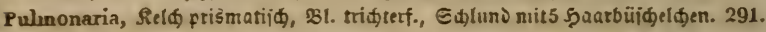

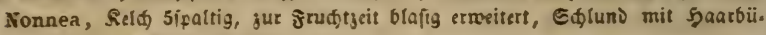
fifeldjen, Gaum Sipaltig. 293.

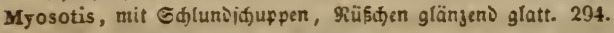

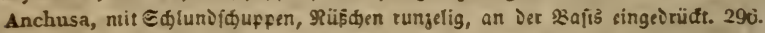

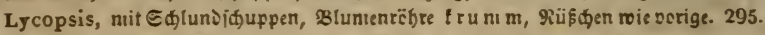

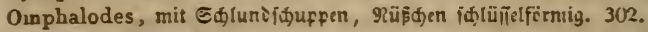

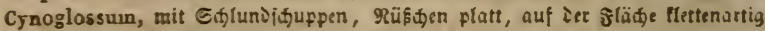
igelf́taţelig. 301.

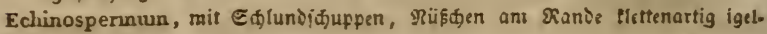
frachlig. 300 .

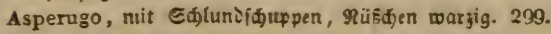

Borrago, €dglunijøuppeen frei berauŝttheno, Blume fternfërmig. 298.

Syuphytum, Sdluni iduppen lang, fulammengeneigt, Blume maljig. 297.

b. Griffel a uf Dem grudtfneten. aa. Sapfel unterbalb (eingeroadjien:).

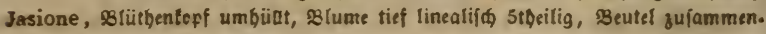
bängent, Rarbe leulig. 251.

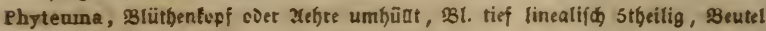
fpäterbin frei, Rarbe $2-3$ fpaltig. 252.

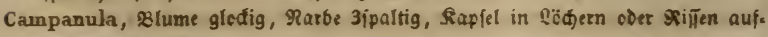
ipringeni. 254.

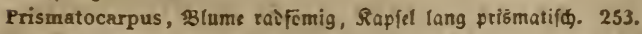

Sanolus, Slume präjentittelletërmig, Rapfel Ifährig, oben frei. 348.

bb. Srudit frei (nidjt eingervadfen).

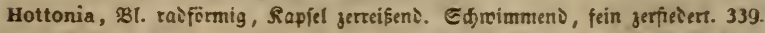

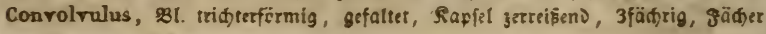
2 faamig. 304. 
Anagallis, \$I. rabferraig stbeifig, Rel(h) ausgebtentet 5tbeilig, Rapiet mit Dedel aufipringent. $3+4$.

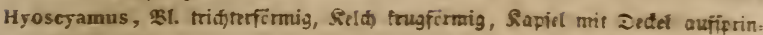
geni. 325.

Cynanchun, Sl. T̃emfömig, Etaubfaientrone Slappig, Balgfrude, Eaamen mit Geile. 359.

Asclepias, ebenio, Etaubfaientrene aus 5 Dürţen mit Şöruden iarin. 36u).

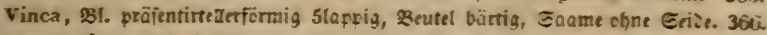
Menyanthes, 281. inmenis jetteniaierig, Rapiel 2 tlappig, Eaamentröger in Eer Nitte jeier Sapjeltiappe. 365.

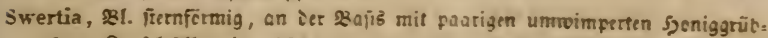
den, Rapfel 2tlappig. 364.

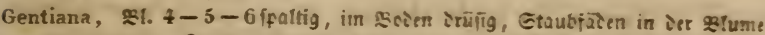
berablaufeni, Raffel 2 tlacpig, Gaamenträger raniyiänsig. 363.

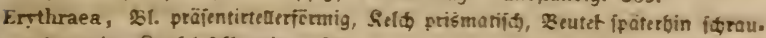
benartig, Rapiel 2 llapfig. 362.

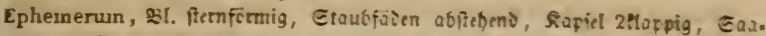
menträger auer. $3+5$.

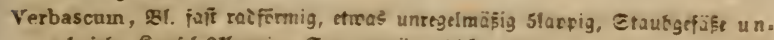
gleid, Rapiel 2llapfig, Eaantenträger sit. 319.

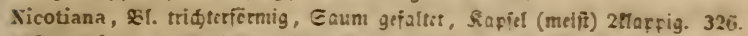

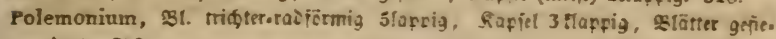
iert. 303.

Datura, st. tridgterfermig gefaltet, Feld unten abffringerts, Rafiel to tlapfig. $32 \%$.

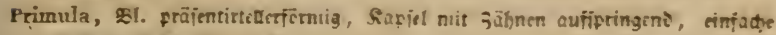
Dolte auf Edajt. 335 .

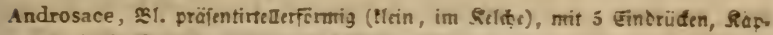
pel balb stlappig, Dore auf Edyaft. 33\%.

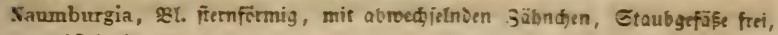
abitebeni. $34 \%$.

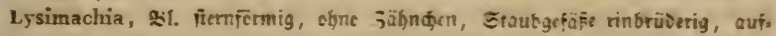
reffe. $3+6$.

Lonicera, sI. rëbrig, meit 2lippig, setre unterḩal6. 16 .

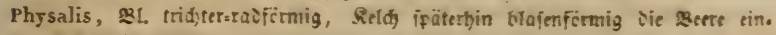

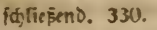

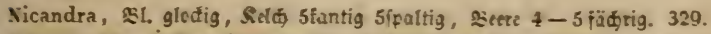

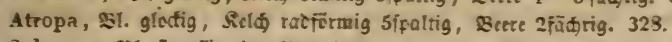

Solanun, sil. fีernfirmig, seutel ctmas jujamnenkängent, an ier Epike mit 2 sëdern aufferingend, şeere 2fädrig. 332.

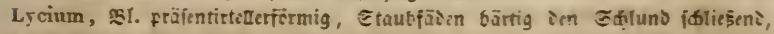
Sette 27üdrig. 331.

C. Slume mebrblättrig.

Impatiens, șl. unmgelmäsig, Reld tblüttrig, binteres slatt Egelförnig, gi. ipernt, 5 Rapielllapfen fartig, rollen fid elaitiid guiamnuen. 611.

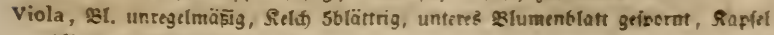
3tlaprig auffringent. $5 \% 2$. 


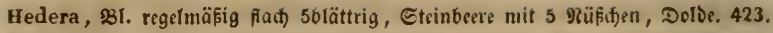
Aunpelopsis, 31. regelmäsig offen 5blättrly, Etaubgefäpe auf einem Bect)er, Gteinbeere $2-4$ faamig, DolDentraube aus Dorbdien, Widelranten. $\$ 25$.

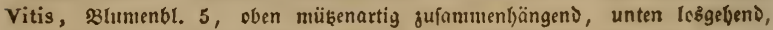
33eere 2-4 faamig, Riipe aub Doloden, MBideltanten. 424.

Frangula, Blumenbr. 5, tappenförmig aufred)t, die Staubfäton vor (id) be. Defend, Steinbeere. 496.

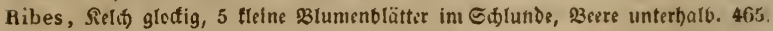

\section{Digynia, zweitweibige. 3 wei Narben.}

a. tcine Slumicntrone.

R. Bliit\}enftano inaulartig,

Uhnus, Relđ glodig, frei, fruđtfnoten fpäter ein ringšum gêtügeltes 1 faamiges Priif̧çen. Bäume. 160.

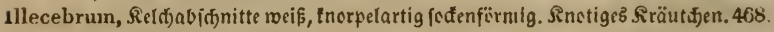

Herniaria, Reldyabfdnitte frautartig, flađ, 5 beutellofe .3wifłenitaubfäben. Rnctiges Rräuţ̦en. 467.

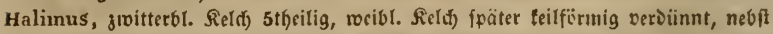

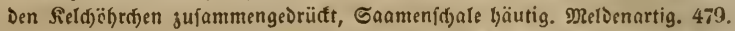

Atriplex, cbenio, weibl. Reld)tlappen rhombijd), Gaamfdale idwargtruftig. Mrelde. 478.

Chenopodiun, 3tvitterblütben, alle Felde 5tbeilig, trautartig, Caame linfen. formig, horizontal. Meldenartig. " 485 .

Agathophytum, endfändige Sieldfe 5theilig, feitlid)e 2-3theilig, 1-3 männig, (alle frautartig bleibeni). Meldenartig.

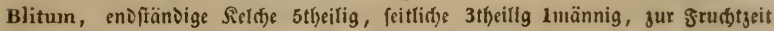
Der ganje 3 liithenbeere beerenartig (wie rethe 9Raulbeere!). Melbenartig. 483.

Beta, alle Sield)e 5 theilig, 5 männig, Die 2 bojofnitte tappenartig trautartig, zur Frud)tjeit Der ganje 3lütlyentnauel troden verwadffen. Meldenartig. 4 S1.

Schoberia, field) 5tbeilig, fleifdjig, ofne 2lnłängfel, Saame borigontal. Eaftige Ealzpitange. 486.

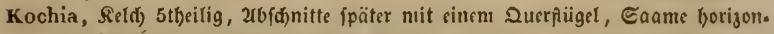
tal, Reimling ringförmig um Daร Eineiß̧. 487.

Salsola, Reld 5theilig, 2tofd)nitte fpäter nit einemı Querpiügel, Eaame borizon. tal, Reimiling fdjnedfenförmig obne Eimeif. 487.

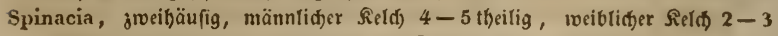
theilig, Sdflaudfaame int verhärteten Seldf, Saame aufred)t.

Aunaranthus, einl)äufig, Sicld fpelgenartig 3-5theilig, (đd)laudfrudjt mit Deffel nuffpringens. 491 ).

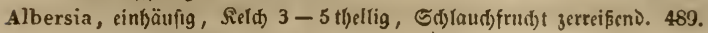

b. mit s3lumentrene.

Cuscuta, Reldi) fieiffig, Blütben in Sinäul verwadffen, Blume $4-5$ fpaltig glodig. Faienförmige Edimarokerpfianzen. 491.

Ribes, Reldi) gloctig, 5 tleine Blunienblätter im Edjlunis, Beere unter. balb. Eintlüthig oder zrauben. 465 .

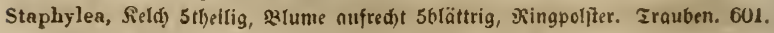


b. Blütbenftano Doloig, Srud)teneten unterbalo, Reldfaun tebr lleit1, 23lume 5blättrig, Sdjalfrutt)t löf ftd) in 2 Edaljaamen, meift rippig

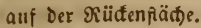

$x_{11}$. Die Shauptbeftimmung gefdieft nad Der frudt, man Durdffonneidet Die jiemtid reifen Edaljaamen quer.

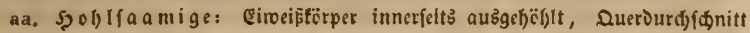
balbmondförmig.

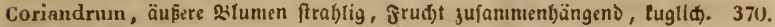

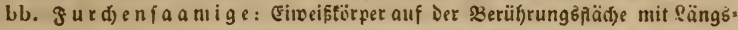

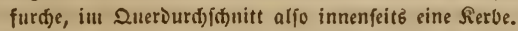

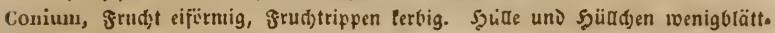
rig. 375 .

Pleurospermum, frud)t eiförnig jufanmmengebrüđt, \&ippen (đ)arf fielförnig,

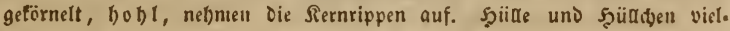
blättrig. 376 .

Scandix, grud)t langeftredt, rifpig, I a ng gefd) 11 a belt: 371 .

Anthriscus, frud)t längliđ rippenlos, હđjnabel rippig. 372.

Chaerophyllum, frudgt länglidg, rippig, ungejd)uavelt, Sd)ale mit eiugelnen Deltanülen gıvif̧)en Den Sippen. 373.

Myrrhis, frudt länglid, sitppen hol)l, Rern lofe, Edjale ofme Deltanal. 37 . Caucalis, 5 rippen fo wie Die 4 bühercu .3rifidentippen igeljtachlig. 377.

Turgenia, 3 mittlere Siften uno 4 .3wif dentipfen 3-4teibig igelitad)lig. 378.

Torilis, 5 Rippen nebft 4 3wifd)enrippen borftigffad)lig. 379 .

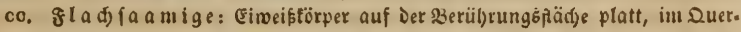
Durdbffunitte Diefe jiemilid) gerablinig.

Daucus, 31vifdentippen einreifig beftadjelt. Dolde nads Dem abolüben voget. ueftërnig. 415.

Orlaya, 3twifdenrippen $2-3$ reibig beftad)elt. 416 .

Laserpitium, 4 3wifdenripfen piïgelartig. 414 .

Tordylium, frud)trand wulftig aufgetricben. 409.

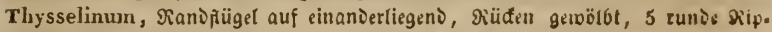
pen Did)t aneinander. 402.

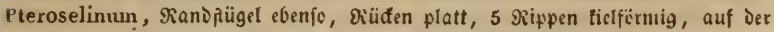

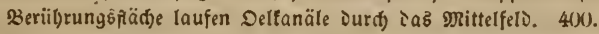

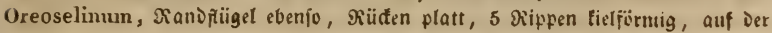

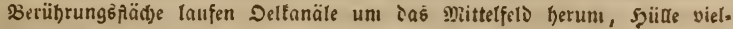
blättrig. 40 .

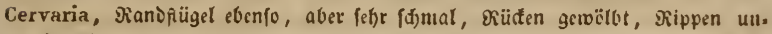
Dentlid), Deltanäle um Das Mittelfelo berum, Şülle einblättrig. 403.

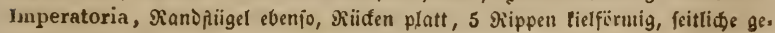

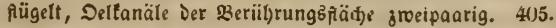

Heracleum, Ran〉ịügel ebenfo, Diliden platt, 3 Dünne Mittelrippen, 2 feltlide ctras gefiugelt, Berül)rungsîähe mit 2 qaar teulenförmigen balten Dcl. tanälen. 408 .

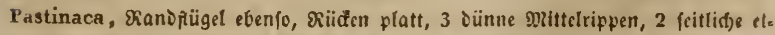

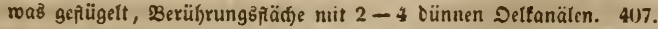

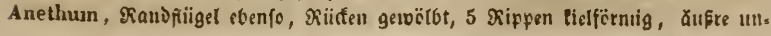




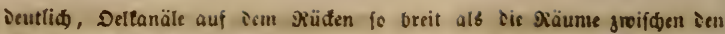
Sitpen. 406.

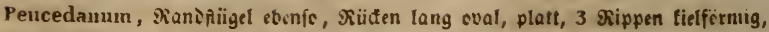
2 feitlid)e entfernt, auf ieu flügelfaume. 3lumentätt:r gelb, 3fpisig. 401.

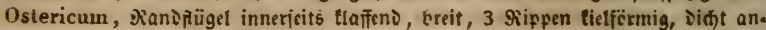

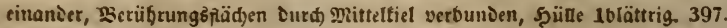

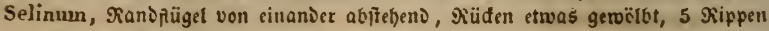
büutig gepiugelt, äuf̂erĩte breitrt. $\$ 10$.

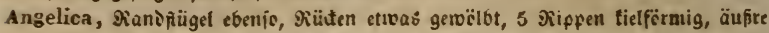

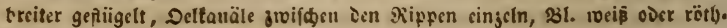
lid. Şü̈lte feblit. $\mathbf{4 1 7}$.

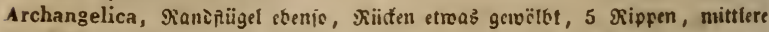

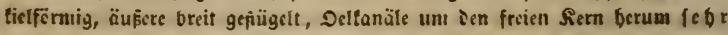

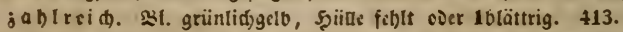

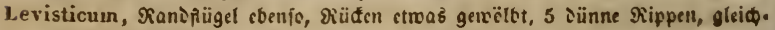
förmig fdurfrüđig, äū̌te cntfernter, Sgïlde vielblättrig. 411.

Aethusa, grudjt faft tuglid) eifirmig, 5 Rippen runi, ticlrandig, teine Dslta. näle, Şülle filflt, şüldden bängen`! 392 .

Foeniculum, fruht cif̈̈rmig, 5 গippen gleidjfïrmig getielt, Odtanäle einzeln,

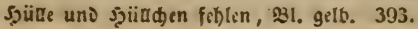

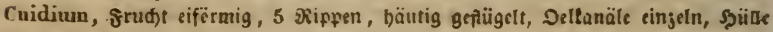

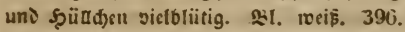

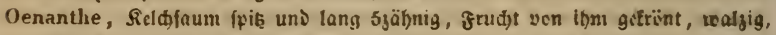

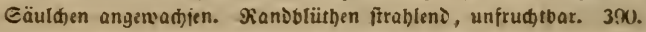

Phellandrium, cbenfo, alle Sslütfen gleid) und frud)tbar. 391 .

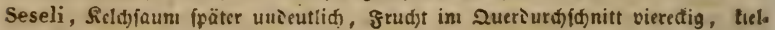

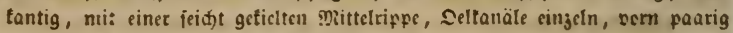
cice U. Gäuldjen frei, soülte felblens. $39 \%$.

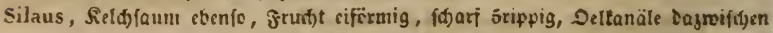

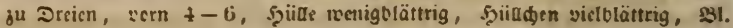
griinlidj. 398.

Meun, Rildfaum ebcnio, frudt fpinielförnig, 5 Xippen entfernt, ticlförnig, Delfanäle Iajmijd)en ju Dreien, scrn 6 , Soilde meift fibleni, Şzüldyen vielblättrig, \$21. reif, siätter fein faarjërntig jujanınıengefest. 399.

Aegopodiun, Reldfaum ebenfe, Rippen faienfirmig, felic, Deltanäle 0 , Şüle un๖ Şü̈d)en (), Blättdjen grof.

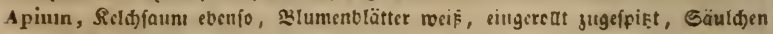
ungett)cilt. $38 l$.

Petroselinum, field̦jaun cben(o, slumenblätter gelbliơ), runolid), Epişe ein.

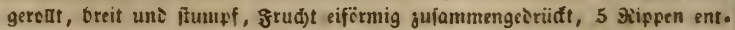
fornt, fadinfirmig geticlt, Deltanäle einjeln, sorn 2, Gaulden 2theilig Şü甘e 1-2, feitliche viclolättrig. 382.

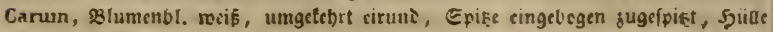

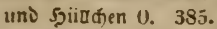

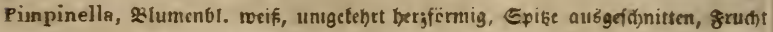
eifirmig zufanmengeoriidt, 5 Rippen entiernt, faìnförmig, Deltanäle in

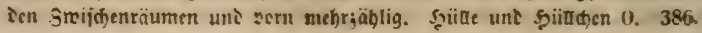




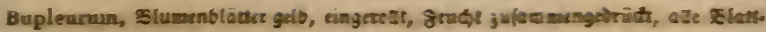

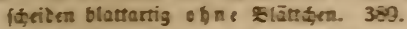

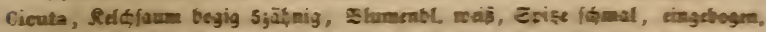

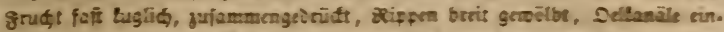

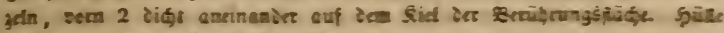
feb̆lt, Sgüldfen mentigtlätrig. 350 .

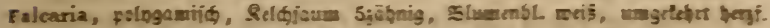

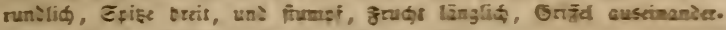

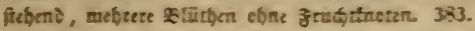

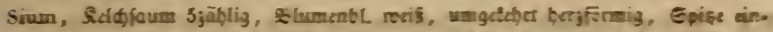

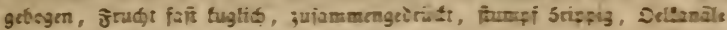

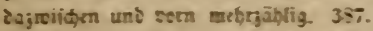

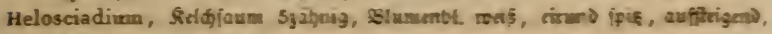
Delisnāle ringetr. 358 :

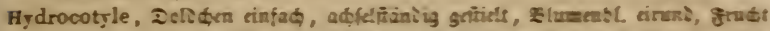

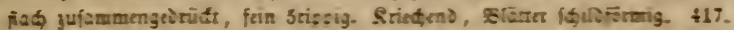

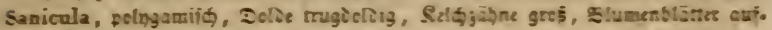

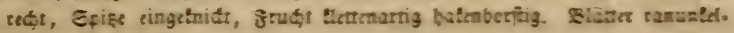
artig. $\$ 18$.

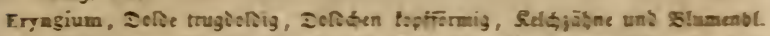

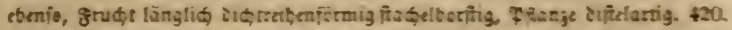

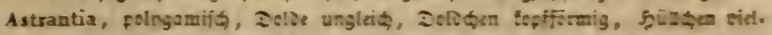

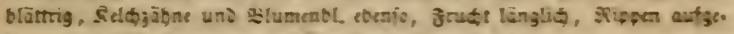

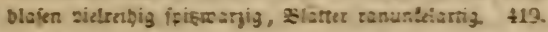

\section{Trig Inia, IreimeiEige; trei Marber.}

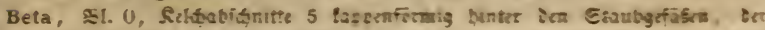

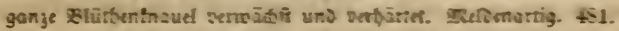

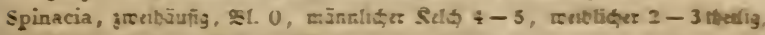

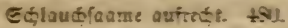

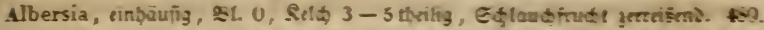

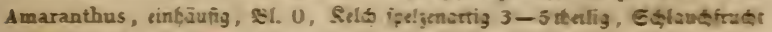
Befllartig aufiftinger:. tou.

Sanbucus, Slume ratFrmig, 5thrilig, Etenterte 3foumig. 16:.

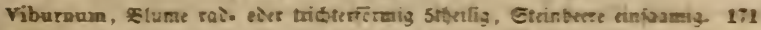

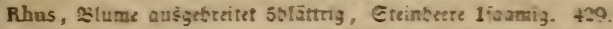

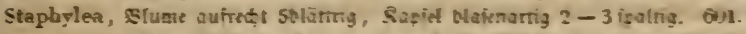

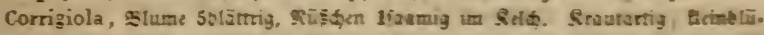

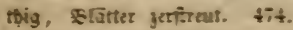

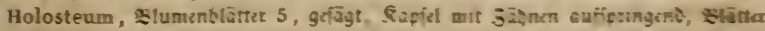
geyenüber. 617.

Stellaria media, situmentïtter 5, gripalten, Sufd wis Sihmen eufierungent slatter grgenüter. $61 \mathrm{~s}$.

IV. Tetragynia, Biertheifige: wiet Ratber.

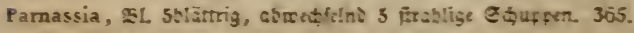

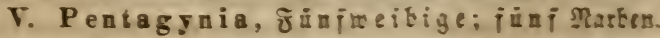

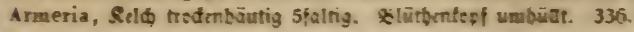


Drosera, feld 5tbcilig, 31. 50lättrig, giarben gefpalten, fiapfel 1 fäcffig vicl. jaamig. 573.

Linuun, 231. 56lättrig, Betttel auftiegenı, giarben teuleufïrmig, Fapfelfäduer ljaanig. 638.

Cathartolinum, 33lume 50lättrig, Beutel aufredt, gRarben topfförmig, Rapjel. fäd)er 1 laamig. 637.

VI. Poly gynia, Bielweibige; viele getrennte \$ifille. Myosurus, słlumenblätter rḯ)rig, gruळtboven geftreft fadenfërnig. 577.

\section{v1. Hexandria. Cech) männige. 3ritterblüthe mit} fects હtaubgefä́̈en.

\section{MI onogynia, Gintwe ibige; cine Rarbe.}

a. Grudtetnoten unterbalb.

Leucoium, ficld farbig, 6theilig glcutig, Sroicbelffanje. 81.

Galanthus, Relú farbig fitbeilig, 3 äufere Il)cilc lang, 3 inutre turj, .5̂viebel. pranje. 80 .

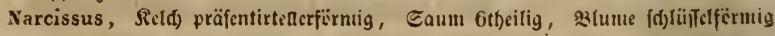
oocr glodtig. Stwiebelpitanje. (YRarbe 3tc̈pitg.) 82.

b. Frud)tinoten oberbalb. a.. Reld $n$ i (t) $t$ auşgeoreitet.

Convallaria, field) farbig glodtig oicr roaljig 6jähnig. Beerc. Sinduen. 91. Streptopus, אicld farbig glodig bithcilig. Recre. Sinollen. 90.

Muscari, Rêlib farbig, trugfërmig 6jäf)nig. Siapfct. Zlviebel. 101.

Codonoprasum, Relch farbig, glodig 6theilig, unten nebit Den Stanbgıfäfill verwađffen. Dolde bängent, Edcide 2ulättrig, fchr lang. 98.

Heınerocallis, Fild farbig trid)terf. unregeluäßig 6tbcilig, vorgeftredt. Staub. gefäfe aufiteigeni. 106.

Liliun, Sicld) farbig, regelmüsig 6tbeilig, abfd)nitte tragen in ier Witte cine bonigabfondernde Sängstiķc. 97.

bb. Sield a usgebreftet.

Acorus, Rotben Diđtblütbig, Reld frautartig. 88 .

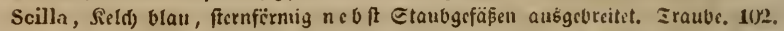

Gagea, ficld inwendig gelv, fternfërmig, હtaubgifäßc pfriemenfčrmig, Dulden. traube mit Sdcioc. 93.

Ornitlogalum, Ficld invendig rocif, ferufürmig, Etaubfäien unten bocit. DutDentranbe mit DeđGlättđ́cu. 103.

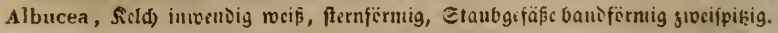
Itaube. 104.

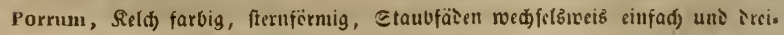
ipibig. Dolvc. 99.

Allium, Reld) farbig, ficrnfërmig, હtaubfä̀cn atle pfriemenfërmig. Dolice. 100.

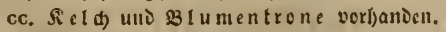

Peplis, Reldt) glectig. Siräutçı, 23lätter gegcnüber. 520 .

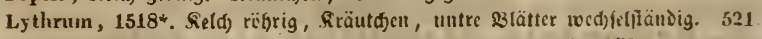

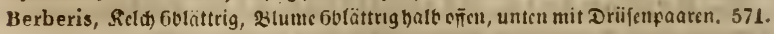




\section{Trigynia, Dreitueibige.}

a. Drei VRarben.

Luzula, Reld) 6fpeljig, Rapiel 1fäđrig, 3tlappig, 3łaamig. 83.

Juncus, Reld 6ipeljig, Rafiel 3fäđrig, 3tlappig, vielfnamig. 84.

Triglochin, 26* Reld) trautartig 2reibig 3blättrig, Siaffel 3fäifrig, 3 faamig.

sinfenartig, traubenblïthig. 7 .

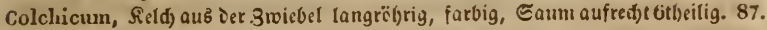

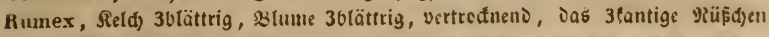
umbü̈leno. 472.

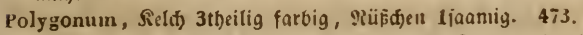

Flatine, 1614*. Reld) 3tlfeilig, sil. 3blättrig, Rapfel 3jüd)rig vielfaamig. Sats tę firäutcthen, Slätter gegenïber. 590 ).

b. Drei Piftitle, Reld) Gtl)eilig.

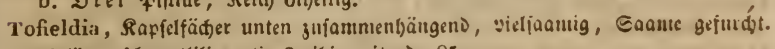

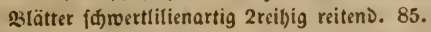

Veratrum, Rapielfädjer unten julammenbängeno, 2tlappig, Saame gethigelt. slätter nervig gefaltet. 86 .

Schenchzeria, Rapielfäđ)er frei, 2faanig. Binjenartige szlätter. 8.

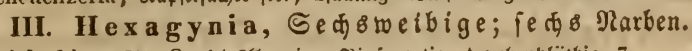

Triglochin, 27*., Rapfel 6tlappig. SBinfenartig, traubenblütbig. 7.

IV. Polygynia, Bieltweibige; mefr als fects Plarben.

Alisna, field̆ 3blättrig, 3lume 36lättrig. 10.

\section{Heptandria. Ciebenmäunige. 3witterblüthe} mit fieben @taubgęäjen.

Calla, folben Did)tblütbig, Gđ)eide iütenförmig, innen weip. 2.

Trientalis, Reld) uno silume fternförmig 7theilig. $3 \notin 1$.

Aesculus, Reld glcđ̛́ig, s3lumenblätter $4-5$, mit viagel, unregelnäßig. Co3.

VIII. Detandria. SAchtmäunige. Switterblüthe mit

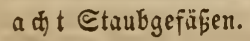

1. Monogynia, Eintweibige; eine Marbe.

Calla, ficlben Didtoliitbig, Ed)eide Dütenförnig, innen witi. 2.

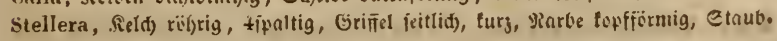
gefǖê cingefd)loten. $1+4$.

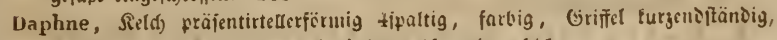
Etaubgefäfe cingeid)loilen, Steinbeere 1faanig. 145.

()xycoccus, field) uno 33 lume 4 lbeilig ausgebreitet, sicere unterljalb, tfädrig, vielfaanig. 356 .

Vaccinium, szlume fuglid ooer glodig $4-5$ jähnig, Becre unterljalb, $4-5$. fäd)rig vieljaamig. 357.

Calluna, fict(t) 4blättrig farbig mit treujitändigen Dedtblättden, sklume 4 fpals tig vertrodneno, Rapfel 4 fä̈brig natbffaltig. 352.

Erica, Reld 4blättrig iperjig, 35t. tfpaltig vertredtucni, Sapisl ttlappig, Enteite. roätic in Ser Mitte ter Slappen. 353. 
Tropaeolum, field) 5tbeitig, ge(pornt, 831 . vergeftređt., unregelniaßig 5blättrig. 6()9.

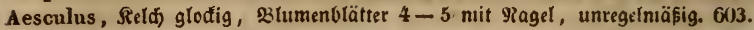
Epilobium, Reld) 4tbeilig, 38 lumentrone 4blättrig, Rapfel unterljalb, lang f́ço. tenartig. Saame haaridjopfig. 517.

Monotropa, Relă) un১ Bluntentrone 46 lättrig aufred)t, B(umenblätter unten böđrtig. Stengel fúpupig, blattlos,. 349.

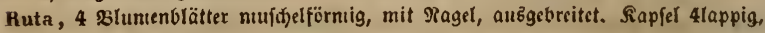
4fäd)rig. 599.

\section{Digynia, 3 weiweibige; 3 twei Narben.}

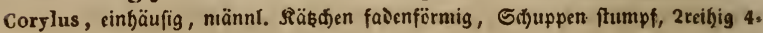
männig, reibl. 31 . ju 1-3. 152.

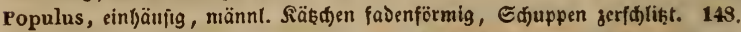

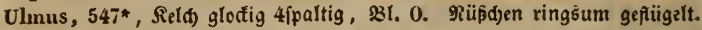

Acer, Slumenblätter $4-5$, fаб und ausgebreitet, 2 flügelnüf(t)en. 602.

Chrysosplenium, Reld 4lappig, inwentig gelb, 31 . U. Rapfel 2fønabslig, 1 fädrig. 459.

Polygonum, Relch 5fpaltig, farbig. Tiïpiden 1faamig 2tantig. 473.

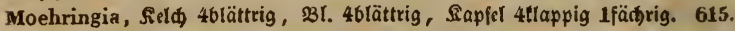

III. Trigynia, Dreitueibige; Drei Narben.

Polygonum, Reld) 5fpaltig, farbig, Riif(f)en 1faamig 3tantig. 473.

IV. Tetragy $\mathbf{n}$ a, $\mathfrak{B}$ ierwe ibige; $\mathfrak{B}$ ier Rarben.

Paris, Sielch uns 31 . Irautartig 4blättrig, Staubfäben grün, über Dte seutel l)inaubgel)end. 89.

Elatine, Reldh 4theilig, 331. 4blättrig farbig, Beutel enoftändig. Rapfel 4. fäd)rig. 590 .

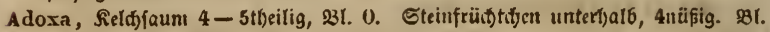
in R̈̈pfden. 421.

Myriophyllum, miännl. 2 I., Reld 4tbeilig, 31 . 4blättrig, meibl. Reldyfaum 4. fpaltig, B1. 0. Rapfel gefondert 4fäळtig. Geines slattgerüfte. 513.

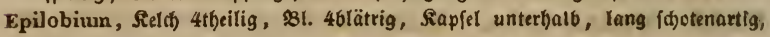
Eaamen baarfdopfig. 517.

Denothera, Sielbfaum einfeitig 4tbeilig, 31. 4blättrig, Rapiel unterbalb, ge: frreft. Gaamen naft. 516.

\section{Ix. Enneandria. N(cunmäunige. 3mitterblüthe mit} 9 Staubgefäß̄en.

I. Hexagynia, Serbeibige; nit fertg Narben. Butomus, 81 . Gblättrig farbig. Doldc. 11.

X. Decandria. 3ebnmännige. 3witterblüthen. mit 10 Ctaulgefäß̈en.

1. Monogynia, Eintweibige; Eine Marbe.

Androineda, Blume bängenঠ, Prugfïrmig, Beutel an Der Spiķe 2fpornig

Sapfel 5fädyrig. 354.

Arctostaphylos, Bl. bängend, frugfërmig, Beere glatt, 5fädrig, 5faamig. 355 
Dictamınus, 281. vorgeftredt untegelmäfig 50lättrig, Rapfel 5lappig 5fäđrig. 600. Monotropa, (Enibliitlye Der Iraube:) Blumenbl. 5, unten b̈̈đtig, aufreḑt. Stengel fojuppig, blattlos. 349.

Leduu, 31 . 5blättrig ofien; geterbtę Foljter trägt ๖. Staubgefäpe. 358.

Psrola, 231. 5blättrig gleđ̛ig, Staubf. fadenf., शRarbe 5lappig a. D. Griffel. 350.

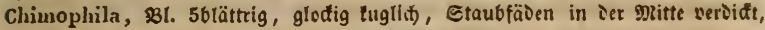
Narbe Slappig iu grudttencten eingefentt. 351.

Ruta, (Mittelblüthe rold)e juerft olübt:) Bluntenblätter 5 , mufđelförnig, nit Nagel, Rapiel 5lappig, 5fädrig. 599.

II. Digynia, 3weitweibige; 3 toei Narben.

Scleranthus, field glodig, Saum 5theilig, 331. 0. Sd)lauthfaanen in verbat: tetenı Felh, şlätter gegenüber, zart nelfenartig. 466.

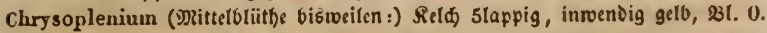
Rapiel 2 jđnnabelig, 1 fädrig. 459.

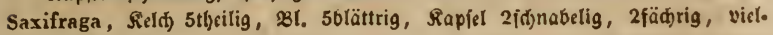
faanig. 460 .

Diantlus, field) rïfrig, unten treuji(b) uppig, Blumenbl. 5 mit langem $R a g e l$, Platte ganz alı̈gebreitet, gezät)nt oder gefranft. Rafiel 1fädbrig. 628.

Kohlrauschia, Relめ) räbrig fđuppenlob bäutig, grünftripig, fïpfden in grofen trofinen ๔đuppen. 627.

Tunica, Reld) gloďig, nit 4 Ed)uppen, trautartig hautrandig, Blumenblätter liclfïrmig, łlatte balb offen. Rapiel 1fädrig, 4fpaltig. 624.

Gypsoplila, Sield) glodig, fdjuppenlob, trautartig bautrandig, Blumenolätter tielfërmig, ¥latte halb oர̃en, Rapfel 1fädrig 4ipaltig. 623.

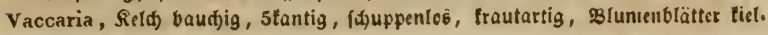
fïrmig, Flatte balb offen. 625.

Saponaria, Sicld) locfer röbrig, fd)ufpenlos, slunenblätter mit ban๖fïrnigeu

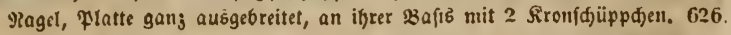

\section{Trigynia, Dreitweibige; Drei Marben.}

- Reld) 5 tlbeilig, bei leşteren 5 jäbnig.

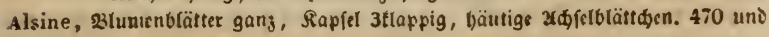
$1924^{*}$.

Sabulina, Blumenblätter ganj, Sapiel 3tlałpig, teine Xdbfelblättd)en. 61 .

Arenaria, Blunınblätter ganj, Rapf́l mit 6 .3ähnen auffpringeıt. 616.

Moehringia trinervia, \$Blumenbl. ganj, Siapfel Glappig. 615.

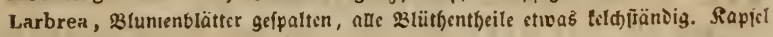
6 theilig. 619.

Stellaria, szlumenolätter gefpalten (alle sliitfentbcile wie bet den übrigen), îticlftändig frei. Rapicl 6fpaltig. 618.

** Reld) gledig coer rëbrig, $5_{j}$ äl)nig.

Silene, slumenblätter meift geffalten (oier auğgeterbt), fapfel mit 3abnen auf. ipringeno, unten gefät)ert. 629.

Cucubalus, Blumenblätter gefpalten, Sapfel beerenartig 1fäđrig. 630.

IV. 'Tetragynia, Bierweibige; Bier Narben.

Adoxa, zartez Rräutđien mit Rlütbentïpfen. 421 . 
V. Pentagynia, fủ nfroeibig; fün f Rarben, (Nield) 5 theilig ober 5 pipaltig).

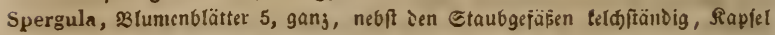
5ipaltig. Slätter quirlf̈tändig. 471 .

Spergella, ßlumenbl. 5, gan 3 (wie alle folg. fietftänoig), Rapicl 3ipaltig, 23 lätter gegenüber, neflenartig. 613.

slalachium, silumenblätter 5 , gripalten, אapfel eiförmig 1fätgrig, 3fpaltig, Rlappen 2 jäfbnig. 622.

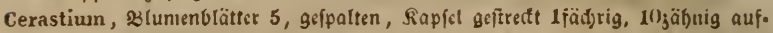
ipringeni. 621.

Lychnis, Reld häutig, trautartig rippig, 5;äbnig. 633.

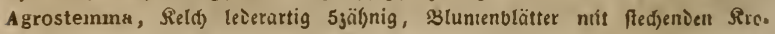
neniduppen. 632.

Githago, Reld) lederartig Sfpaltig, Blumenblätter mit langeu Mlagel obne Rro. nenf(d)uppen, 631.

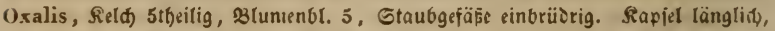
Stlappig. 610.

Sedum, 5 gefonierte frud)ttnoten. 463.

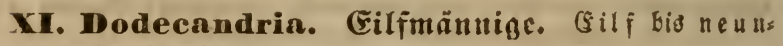
zehn $\mathfrak{n}$ ๔taubgefäß̈e.

I. Monogynia, Gintoeibige, eine Rarbe.

Asarum, Reld inivendig braunretl), glođig 3fpaltig. 162.

Portulaca, 2B1. 56lättrig, Etaubgef. 16rü̇rig, Rałfel 1fäd)rig. 476.

Lythrum, Reld) röbrig, gefurd)t, 6 siluntenbt. In Ed)lunde. 521.

II. Digynia, 3 to eitue ibige, zwei Narbett.

Agrimonia, Rraut mit unter(tod)en gefièerten Blättern, Blitthen aftrenftanè gelb. 503.

III. Trig y nia, Dreitueibige, brei Narben.

Reseda, Blumenbl. $4-6$ jerfd)likt, Rapfel 3 - 4 fpikig, oben offen. 364 .

IV. Dodecagynia, 3 to of frueibige, bis 12 ober melyr ßiptille.

Sempervivun, settplange. 464.

XII. Icosandria. Swanģigmännige. Stwitterblütfen mit 20 ober mehr Etaubgef. auf bem Rclafdrunbc.

I. Monogynia, Gintweibig, eine Rarbe.

Crataegns monogyna, grudittncten unteri)alo. 5(1)6.

Prunus, grudttnoten oberffalb, eteinfrudt, אern glatt. 523.

Amygdalus, Frudttnoten cber(jalb, Eteinfrudt, ßern grubig eingeoridt. 524.

II. Di-Pentagynia, 3 weis bis funftoeibig, znei

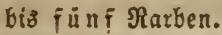

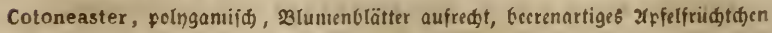
mit $2-3$ bictaufftegenien Steinternen. 5107. 
Biele @tbgf. felđftänbig. - $\mathbf{x} \times 1 \times$ - 3wei bis jünf Marben.

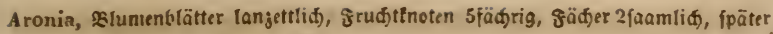

2 - 5ternige affelbeere. 508.

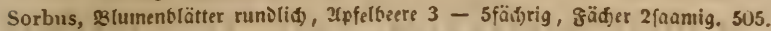

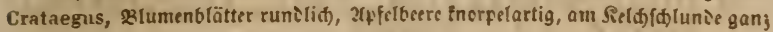
cingefd)nürt, 1 - 5ternig. 506.

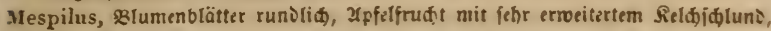
2 - 5itzinig. 509.

Pyrus, 23lumenbl. längliकh, 2rffcl (Bzirne) neijळig, mit pergamentartig 5 fädrigem

Grëps, güđ)er 2jaanig. 510.

Cydonia, eben fo, gäळer 2reihig mehrfaanig. 511.

spiraea, fapfel tređ̌en, 5füdrig, füdger atle getrennt, vielfaamig. 502 .

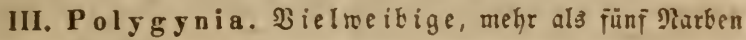
(Pị̂tille).

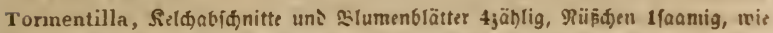
bei folgenien. 499.

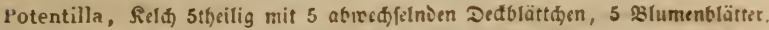

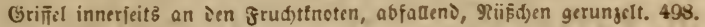

Comarum, eben fo, Grifiel bafilar, frudtboien fdwammig, Rïïtfen glatt. 497.

Fragaria, cben fo, grudtbcien meijofig werdend: Eribceren. 400.

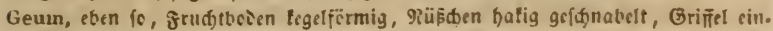
gelentt, abfateni. $5(x)$.

Rubus, -eben fo, frudtbcien tegelfirtmig, Rüsdjen adfe Etainbeeren, ju einer

\$̇renibeere (Şimbecre) vermadffen. 501.

Rosa, Ficldrët)re frugförnig, 巨aum 5theilig, Grifiel aus iem Gđlunde ragent, Syagibutte nit Etrinterndacn. 504.

Spiraea, Raffel tređten, mebriäđjrig, gäđfer alte gitrennt, ricljaamig. 5112.

\section{Polyandria. Wielmänuige. Switterblüthen} mit 20 ober mehr Etaubgễūen auf hem Blüthens boben.

\section{Monogynia, Sintweibige, (Fine Rarbe.}

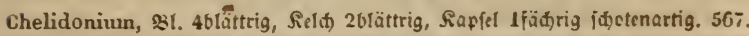

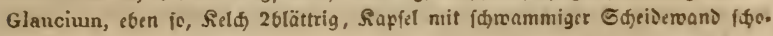
tenartig 2 fäd)rig. 568.

Papaver, eben fo, Feld) 26lüttrig, Piarben frablig reteint, fiaffel unter einem Detel mit ९̈̈dern aufipringeni. 569.

Actaea, eben fo, Reld) 4blättrig, Siscre jisent, nucbrfaunig. 592.

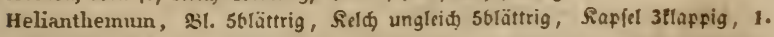
fäd)rig. 574.

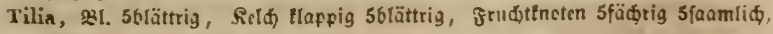
Rapfal leverartig 1 faamig. 635.

Delphiniun, Relđ 5ulättrig, farkig, geffernt. 585.

Nuphar, Reld 5 - 6blättrig, Slume einreibig tlein vielblättrig, fafiel beeren. artig, frei. 14.

Yronphaea, RelФ \& - 50lättrig, unmittelbar in die mebrreibig jiegelblättrige 
3iele Stbgf. ftielitänbig. - $\mathbf{x x x}-$ (Sine Plarbe.

Blume übergebens, Rapfel beerenartig in Den tiifenfërmigen gruøtboden ein. gefentt. 15.

II. Di-tri-pentagynia, 2 we $i=$, oreis, funftoei= bige, $2-3-5$ srifiel.

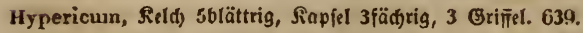

Aquilegia, Rela) 5bättrig farbig, Blumenblätter abredbfelno, raalobornförmig,

bonigtrageno, fiapfelfärt)er vieliaanig, ganj getrennt. 584 .

Nigella, Rield 56lättrig farbig, Slumenblätter 5-10, Enieförmig, 2lippig,

Rapfelfäder halb getrennt. 587 .

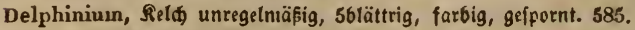

Aconitum, Reld unregclmäfig, 5blättrig, farbig, unter Der Şaube jroei geftielte 5yonigbiiten. 586.

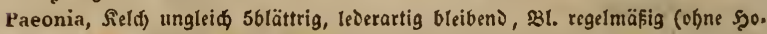
nigDüten). 593.

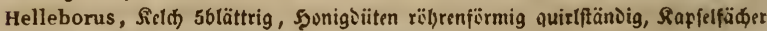
jujammengè rüđtt. 590 .

\title{
1II. Polygynia, Bieltweibige, mehr als füf Rarben.
}

\author{
a. शüfiben cinfaamig.
}

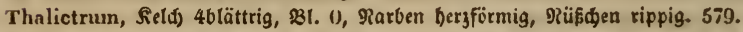

Adonis, Reld) 56 lättrig, \$lumenblätter $5-20$, शiüßđ)en geídnabelt, äbrenartig beifnnınıen. 578 .

Hepatica, Şülle teld̆artig 36lättrig, Reld 3blättrig farbig, unmittelbar in Dle

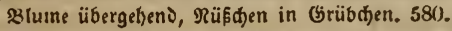

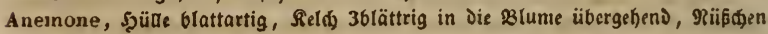
gefónabcit. 581.

Pulsatilla, Şülle blatt. oder manjhettenartig, Reld) 36lättrig in Die \$3lume über.

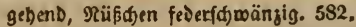

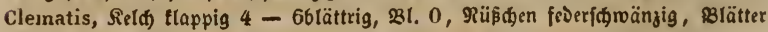
gegsnüber. 583.

Ranunculus, Reld 5blättrig, $\$ 81.5-150$ lättrig, Rägel mit Şoniggräboben, meift unter einer Sduppe. 576 .

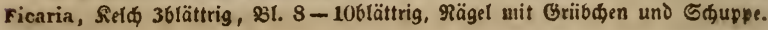
575.

b. Rapfelfäß)er getrennt, vieljaamig.

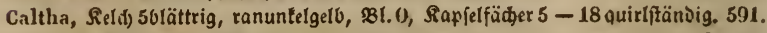

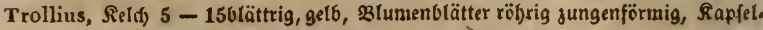
fäd)er zablreiđ, tnäuelitänذig. 588 .

Eranthis, אelch $5-86$ lättrig, ranuulelgelb, Blumenblätter $6-8$ röbrig jun. genförmig, Rapfelfädjer $5-6$ dufammengeذrüđt verwadffen geftielt, Sjülde ftrablig. 589.

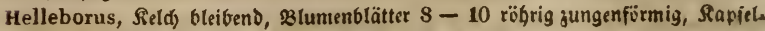
fädust 3 - 11) zufammengè rüđt, fik̨eno. $59($ ). 


\section{Didynamia. Sweimächtige. Stwitterblüthe mit}

\section{2 längern und 2 fürzern Staubgefäß̨ет.}

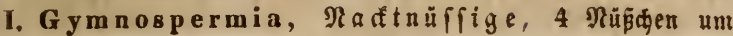 ben Briffel herum.}

Mentha, 31. taum aus Dem Rel(h) rageno, Caum tipaltig, Reld gleidförmig 5̧äblig, હđlund nađ̛t. 256.

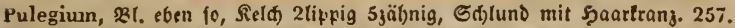

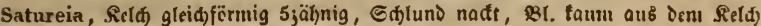
ragent, 2tippig. 259.

Origanuun, Bl. eben fo, $\mathfrak{B}$ lüthenäbren Durd) it)re Dedblättthen gapfenartig. 258.

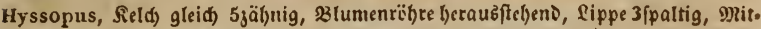
tetlappen quer. 260.

Lavandula, אeld) ftumpf zufanımengeneigt şäbnig, 5̧elm 2ipaltig. 261.

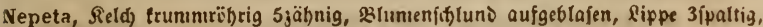
Mittcltappen ausgeb)̈blt. 262.

Glechoma, Ritd) eben fo, Staubbeutelpaare treusförmig. 263.

Laaniun, Fieldy tridterförmig geraie, Selm gewöltot, Seitenlappen Der Unterfippe 1 - 2 feinfpikige 3äbne, Mittellappen ungetehrt berzförmig. $26+$.

Galeobdolon, Relds tridjterförmig gerade, Unterlippe faft gleidjförmig fpikig 3. theilig. 265.

Galeopsis, Seld) trldfterfërnilg gerade, an Der Bafiš Der Unterlippe 2 von unten eingedrïđte boble 3äbne. 266.

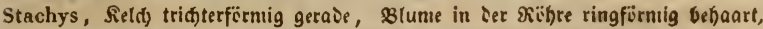
Syelnt mufdelförntig, Sippe 3lappig, Dittellappen ungetebrt berjförmig, nad Der Befrudjtung Die beiden tiirzeren Staubgefäfe aubwärtb gebogen. 267.

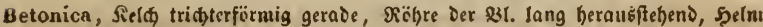
auffeigend, Sippen bängend 3lappig, - Quirt äl)renftändig. 268.

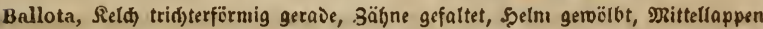
Der Unterlippe umgetefrt herjförmig, Geitenlappen abgerundet, faft einge. terbt. 269.

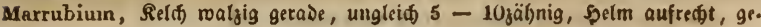
fpalten. 270.

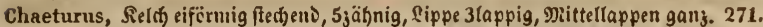

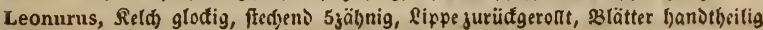
und 3ipaltig. 372.

Thyonus, Лeld rïbrig 2lippig, Dberlippe auffeeigend, Unterlippe lang 2jäbnig, Sdilund nactt, Staubgefäße oben etwas entfernt. 273.

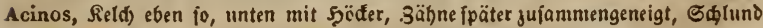
betjaart. 274.

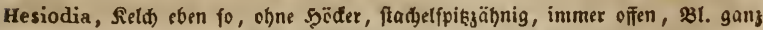

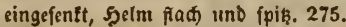

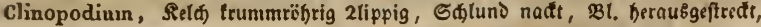
Selm und Mittellappen Der Rippe ausgeterbt. 276.

Melissa, Reld turgröbrig 2lippig, Dberlippe pratt 3jätnig, Seitenjäbne getielt, Staubgefäß̨e bogig zujammengeneigt, Quitle menigbtütblg. 277. 


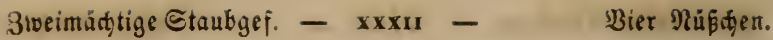

Melittis, Sielts weitglodig 3 - 5lappig, slüthenröbre weit enger, Sippen faft frad. 278.

Dracocephalum, 3Ltumenfd)luns weit aufgeblafen, Şelm gewïlbt, geffalten, un. terlippe 3 fpaltig. 279.

Prunella, Fieltoberlippe platt furs 3jäbnig, Staubfäden unter Denı Beutel mit 3abnfortfas, ఇuirle topfartig geirängt. 280).

Ocimum, Reldoberlippe fólloförmig, Unterlippe tipaltig, sl. Dberlippe 4lerbig, unterlippe ganj. 281.

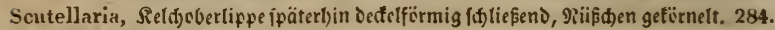

Ajuga, Reld) gleid) 5ipaltig, Spelm Der Blume quer abgeftuțt. 285.

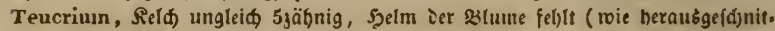
ten). 286.

Scorodonia, Relđ) aufwärtŝ gebogen, Dkerlippe rundliđ, gan\}, unterlipfe 4. zähnig, 2lume roie vorigc. 237.

\section{A ngiosperma, Bebeftiaamige, Caamen ín Rapiel, @teinjrubt nber Beere.}

Qlobularia, slüthenfïpfónen :idjt, umbüat, Sd)laud) 1 faamig. 305.

Linnaea, 83. ju 2 auf Dem Etiele eniftändig, ïberbängend, \$1. glofflg, Etein. friid)td)en unterbalb nit 2 Defblättdjen. 169.

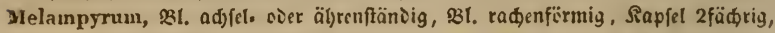
oben auffpringeno, 2 - 4 länglid)e Eaamen. 306.

Lathraea, Feld glođig 4ffaltig, BI. raḑenförmig, Blüthen einfeitig, Saamen= leiften eingeln. 323.

Orobanclie, Selit) $1-26$ lättrig, 4 - 5ipaltig, RI. radjenfïrmig, Blüthen ad. feitig, Eaantenleiften paarig. 324.

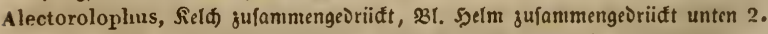
säbnig, Rapfet zufammengèrïđt, ranojpaltig. 310 .

Euphrasia, Reld roalgig 4fpaltig, 36 . Şcln gerö̈lbt gegähnt, Sipfe auछgelerfot 3lappig, Staubgefäfe eingefd)loîen, Sapiel zufammengeذrïđt. 307.

Odontites, field) glodig 4ffaltig, Şeln jufantmengcorüđt, Sippe gang 3lappig, Staubgefäp̄e beraušrageno, Sapfel aufgetrieben. 308.

Pedicularis, Reld) baudjig 4fpaltig, Ssclnt sujammengebrüđt, Sippe 3lafpig, Sapfel forjef gefđnabelt. 309.

Antirrhinum, föroenmaulblume ofne ઉporn, Sapfel nit födern aufiprin. geno. 319.

Linaria, fërenmaulblume mit Gporn, Sapfel mit .jäl)nen auffpringeno. 312.

Gratiola, field 5theitig mit 2 Dedolättden, Blumentäl)re 4lantig, Caum 4. fpaltig, 2 હtaubgefäpe unfrud)toar. 322.

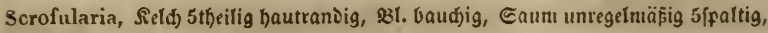
2tippig, unter Dem Şelm ein Sđuppenanią̧. 318.

Ceramantle, Seld) 5theilig trautartig, Bl. frugförmig aufgeblafen, DRiindung eng, tein Eduppenanjaks. 31\%.

Digitalis. Field) eben (0, BI. unregelnäpig glodfig, Gaum ungleid) slappig, släto ter toed̆felīändig. 314. 
Lindernia, Sluntenrïbre baudig, Gaum 2lippig, Dberlippe abgeruniet, unter. lippe 3lappig, Mittellappen auşgeterbt, Slätter gegenüber. 321.

Limosella, 31. 5ipaltig, fur子 triđterfürmig, słlätter wurzelftändig. 320.

\section{Tetradynamia. Wiermächtige. Switterblüthe,}

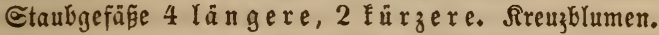

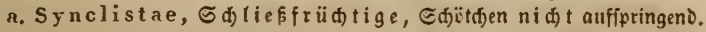
(XB. Die sage der (Eotyledonen in Eaamen wird Durdi) Etrid)e oder

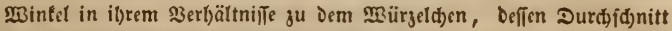
Der sing andeutet, jeder Gattung beigejeşt.)

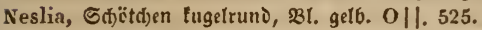

Isatis, Sđütţen platt gèrïdt, l)ängeno. 0 |1. 526 .

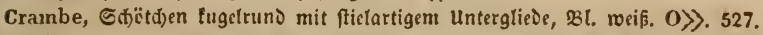
Rapistrum, Gdjötd)en eifürmig mit ffielartigem unterglie১e, s3l. gelb. O\〉. 528. Raphanistrum, Gliejerf(jote, perlid)nurartig eingefđnürt und quer gerfpringeno. $0 \gg .529$.

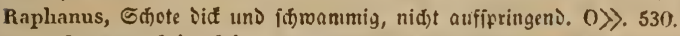

b. A in phis chist a e, G(jötd)en und Edjoten, beiderfeits aufifringent. aa. Siliculosie, ( $)$ (d) öt d)entragende.

* Ed)eideraano quer, (fit)mäler als die Sitappen).

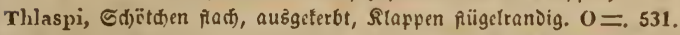

Teesdalia, E(t)̈̈țen muiftelförmig gebegen, Silappen tielrandig, Sd)eidemand fid)elförmig, türzere Staubfäden unten nit $€$ d)ufpen. $\mathrm{O}=.532$.

Hornungia, Sdjütden cben to, Etaubfäoen olyne Eduppen, sl. tegciniäpig. $\mathrm{O}=\mathbf{5} 33$.

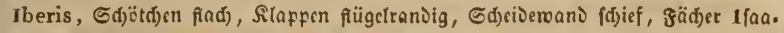
mig, 2 sluntenblätter grëfer. $\mathrm{O}=53$.

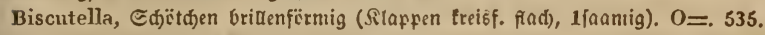

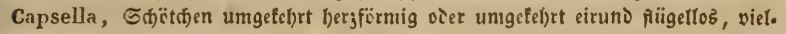
faamig. 0 \|l. 536.

Lepidium, Sd)c̈tđen flađ oval, fäd)er 1faamig. O 11.537.

Cardaria, Gdjötđen Diff herłfïrmig, nę̧grubig, fäđer 1jaamig. 011.538.

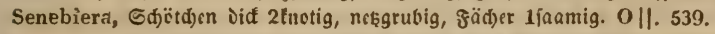

** Edeidervani den Silappen Des Edjëtđens paraull.

Draba, ๔djëtden oval, ftumipfran১ig, fäder vieljaanig, Gaamen ungefäunt. $\mathbf{O}=$. SBlumenblätter eingeterbt oier gariz, reeiß. 54 ).

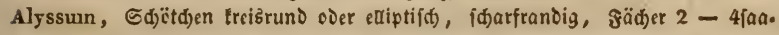
nig, Saame fiügetrandig. $0=$. \$21. gelb. 541 .

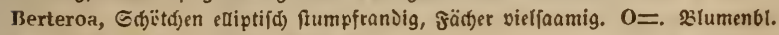
paarig geftellt, 2 fpaltig, meis. 542 .

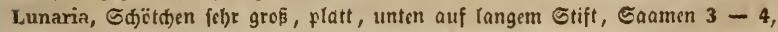
platt. $0=$. 231 . Iila, Feld) 2 factig. 543 .

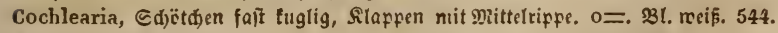
Armoracia, ভdiötḑen faft tuglig oier länglid), flappen oljne mlittelrippe. $0=$. B1. 10eißs. 545 .

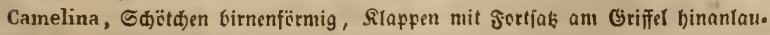
feno, รäß̧er vielfaamig. $O=.231$. gelb. 546. 
bb. Siliquosae, $\sigma$ d)otentragenos.

Arabis, אidd) alfred)t, Sd)ote gleid)breit, SIappen mit Mittelrippen, Saamen einteibig, зufammengebrïctt. $O=.547$.

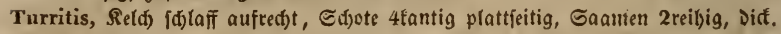
$O=.548$.

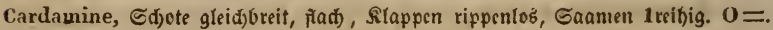
slätter gefiedert. 549.

Dentaria, S(j)ote f(d)mal lanjettlid), lang geid)nabelt, Slappe rippenloz, Sanmen 1reibig. $\mathrm{O}=$. \$3lätter jujanmenge[ç.t. 550 .

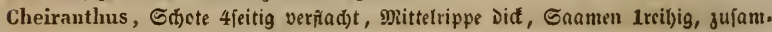
mengebrïat ftumpfrandig. $O=.551$.

Nasturtiun, Gd)ote walgig roulfig, Snamen 2reibig, fuglig, nekgrubig. $O=$. 31. meif́. 552 .

Roripa, Reld ofien, S(f)ote tuglig ober waljig, Saamen 2reiljig eingeftodgen punttirt. $\mathrm{O}=$. $\mathfrak{B l}$. gelb. 553.

Barbaraea, Sdjote 4tantig, mel)r 2fantig, SRippen mafdjig verbunocn, Gaamen 1reilsig. $O=$. 31 , getb. 554 .

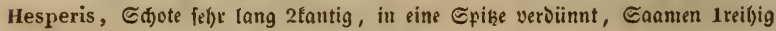

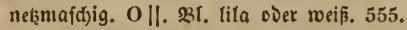

Alliaria, ๔d)ote 4fantig, in eine ๔pib̧e verdïnnt, ๔aamen 1reibig, längšfurdjig. Oll. 33 I. meii. 556 .

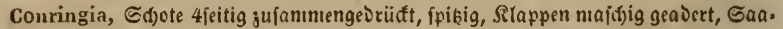
men 1reiljig, grubig punftirt. $0 \|$. 231. weif ober meiflid). 557.

Erysimum, Gdjote 4feitig, Rlappen 1rippig, Gaamen 1teibig. O II. 231. gelb. 558.

Sisymbriun, Feld ofien, Gdjote Sịcitig oder ftielruno, Rlappen 3uetvig, Saa. men 1reibig. O|l. 231 . gelb. 559.

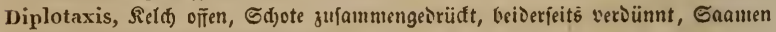
2 reilbig jufammengedriiaft. $0 \gg .560$.

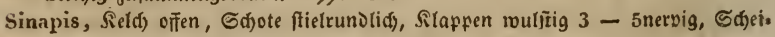
Dewano gefdnabelt, Gaanten fuglig 1reibig. $0 \gg .561$.

Erucastrum, Gd)ote fitielrunolid), ctwaz gefd)nabclt, Slappen 1rippig, Saamen zujammengèrüdt. $0 \gg .562$.

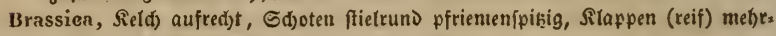
rippig, Saamen fuglig 1reibig. $0 \gg .563$.

\section{Monadelphia. Cinbrüberige. Staubfäben in} e in Bündel verwachien.

\section{Triandria, Dreimännige, brei @taubfüben ver= wachfett.}

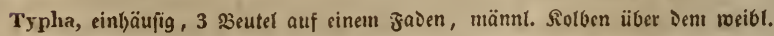
anf (đ)aft. 76.

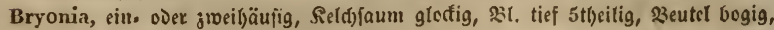
an 2 Stanbfäben Doppelt. Becre. 247.

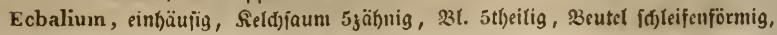
frubt) (ïft fich yon ifrem Stiel ab. 248 .

Cucurbita, einl)äufig, Sild)faum 5ipaltig, 231. gloctig, Saamen roulftrandig. 250). 


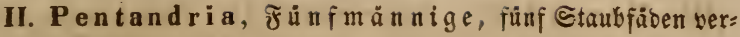
wartjert.

Cucumis, einläufig, Sieldfaum 5fpaltig, 23l. glođig, Gaamen iffarfrandig. 249. Lysimachia, Smitterblütl)e, 31. Pternfïrnig 5fpaltig, Staubfäben aufredt, Raf. fel 5 fäd)rig, 3 l. gegenüber òer quirlftänoig. 346 .

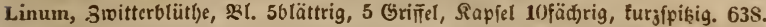
Herodium, 3ivitterblüthe, 2il. 5blättrig, 5 Griffel, Rapfel 5 fädsrig, lang gee [d) nabelt. 60)\%.

III. Decandria, 3 e $\mathfrak{y}$ mä nnige, $3 e \mathfrak{h n}$ @taubfäben ver: roadfien.

* 23lume regelnıäpig 50 tättrig.

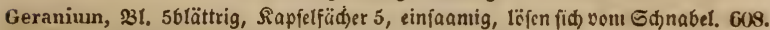
Oxalis, $\mathfrak{B l}$. 50lättrig, Sapfel länglid) 5tlappig vieljaanig. 610.

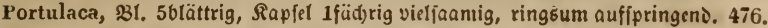
** Slume fdjmetterlingşfïrmig.

Ononis, fabne liniirt, Şïlfe aufgetricben, wenigfaantig. 448.

Ulex, Reld) 2lippig, Slume Enum länger, Şzïlie aufgetrieben, roenigfaamig. 451. Spartium, field) 2 lippig llaifend, 33l. f(t)la ĩ dīen, Grifiel pofthornförmig gebo. gen. 450 ).

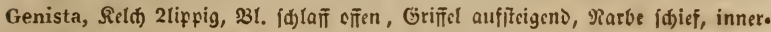
feitร. 449.

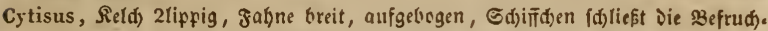

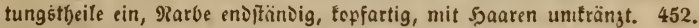

Anthyllis, Sield blafig, umbjüat die zufammengeirüđte 1 faamige Şülje, słlätter gefievert. 453.

Lupinus, Reld) tief 2lippig, 5 Beutel Eleiner uno friil)jeitiger, Șülfe lederartig เoulftig, $\mathfrak{B l a ̈ t t e r}$ gefingert. 454 .

IV. Polyandria, গielmännige, mehr als zeh̆n Ctaubiäben vermadjen.

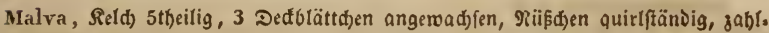
reid). 6()4.

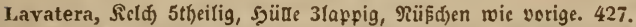

Althaea, Sild) 5tfeilig, Şülle 6 - 9fpaltig, 9ü̈ßđen wie vorige. 606.

XVII. Diadelphia. Bweibrüberige. Etaubfäben in 2 Bünbel vertwartijen.

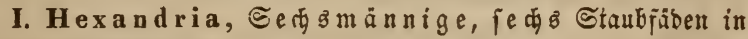
2 şüneln.

Funaria, 9üßß)en 1jaamig. 565.

Corydalis, Sapfel fuotenartig mełrjaamig. 566.

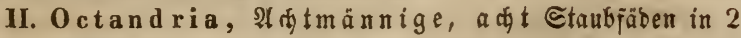
Bünbeln.

Polygala, 2 Ficldbrättđôn fiügelartig, 3lume 2lippig. 522. 


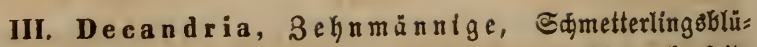
thige, zehn Ctaubfäben, unterjeits 9 sermadjen, oberjeits einer frei.

a. ธका I

\section{- 3jäblige Rlecblätter.}

Trifoliun, Blume verttod̆neno, ๔dlaudfaame òer roenigíaamige Şülie im Sield. 430.

Mlelilotus, Blume vodtommen fdnmetterlingsfërnig abfatteno, Şülfe aúfer dem Seld, 1 - 3 faamig, unvodfominten aufipringeno. 431.

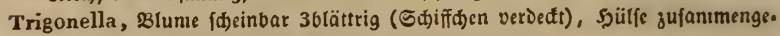
Drüđtt, lang geftredt, geidnabelt. 432.

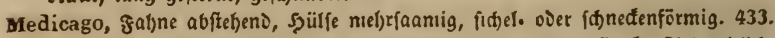

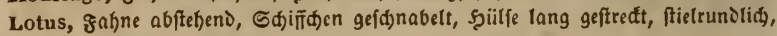
Eriffel gerade. 434.

Tetragonolobus, eben fo, Sjülfe 4tantig geîiigelt. 435.

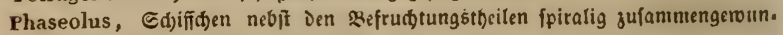
Den. 447.

* Blätter unpaarig gefiedert alfo mit einzelnem Endobättकen.

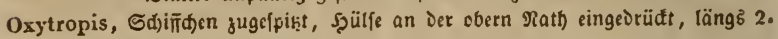
fäđrig. 439.

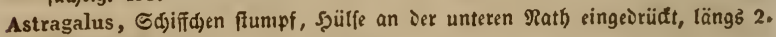
fäđrig. 441).

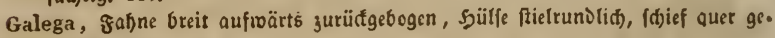
fireift. 436.

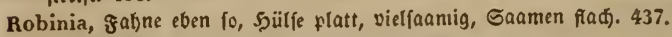

Colutea, gafjne eben jo, Şülfe blafenartig. 438.

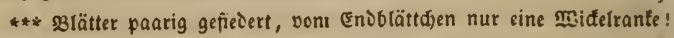

Lens, Rarbe innenfeitig, Saamen linfenfërntig. 442.

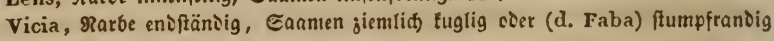
jufammengedrüđt. 443 .

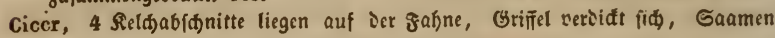
edtig. 444.

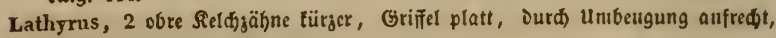
खiđéltante äftig. 445.

Orobus, eben fo, Miđetranfe einfad) vorftidj. 446.

Pisum, Seld) eben fo, Sriffel innerfeitz tielrandig, Saamen kuglig mit länglider Reimmarze, Mid̛́elrante äjtig. 441.

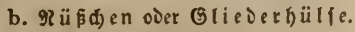

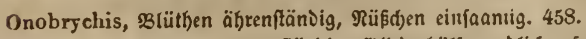

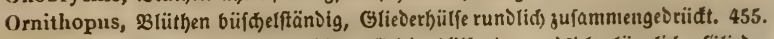

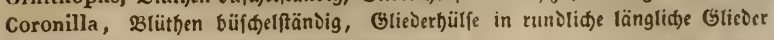
zerfpringeno, Saamen gुientid) wal gig. 457.

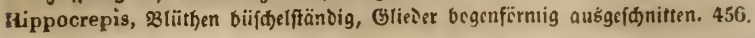


Bielbrüterige Stbgĩ. - xxxv11 - 3wei Bünbel.

XVIII. Polyadelphia. Biclbrïbcrige. હtaubge: fäß̄e in mehr al 2 Bünbel verwadjen.

Hypericun 639.

XIX. Syngenesia. 23erwahicnbentelige. Nefire Blüthen auf gemeinidaftlidiem Slüthenboren. 5 Staub= beutel verwatgfen. (NB. Reldyaum = ๔aamenfrone.)

I. A equa lis, (5) le i a. Sauter 3ungenblümđen, mcift getb.

Launsana, Șï̈blättd)en zur Frud)tjeit aufredt, אeld) faum ferblt. 212.

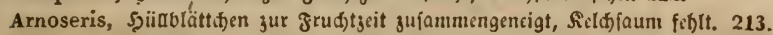

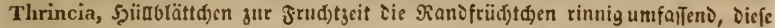

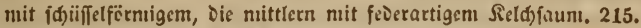

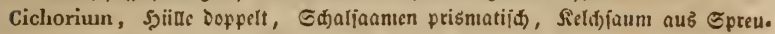

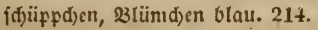

Hypochaeris, frudtboden fpreublättrig, Reldfaum fiderartig. 235.

Tragopogon, frud)tboien naft, Şülblättđen einteihig, unten verwadfen. 217. Scorzonera, frud)tboden eben fo, Şïllblättdjen jiegelftändig, Sicldfaumfedern in einanicr gefügt, Єđalfaamen ftiellos. 219.

Podospermun, eben fo, G()alfaamen mit ffjwicligem unterfak. 218.

Helıninthia, frudtboìn eben fo, J̧ürblättd)en Jeppelt, innen etroa 8, aufen 5 breitere, Єdalfaamen quer gefurdt, Seldfaum federartig. 221.

Picris, fruđtboden eben \{0, Syüablättđen jiegelftändig, Sdjalfaamen quer ge. furdit, frumint, Seldifaumifedern frei, abfallent. 220.

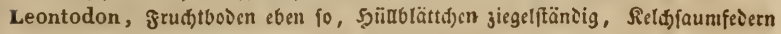
frei, bleibent. 216.

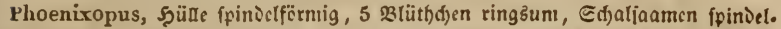
förnig, gcf́(fnabelt, Reld)faum haarartig. 22\%.

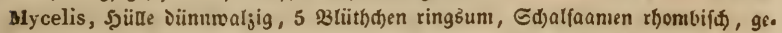
\{dnabcit, Reld)faum baarartig. 228.

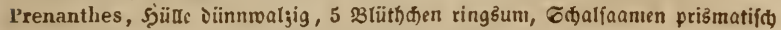
ungefdnabelt, Reld)faum baarartig. 229.

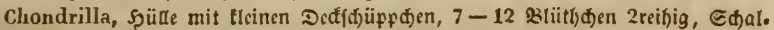
faamen mit Gd)uppentränjd)en uno Sd)nabel, Reld)\{aum baarartig. 226.

Taraxacuun, Şülle Doppelt, sicle Slüthd)en mebreibig, Gdalfaamen mit Gduf.

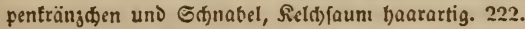

Mulgedium, Şüđe unten bauđjig, હđalfaamen ungefđnabclt, ficldfaum bräแn. lic) borftig. 225.

Sonchus, Şülle unten baudig, હdjaljaamen ungcidjnabelt, Reldfaum veiळ) roeis baarartig. 224.

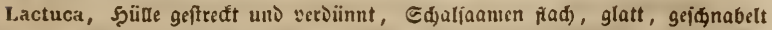
Sield) faun baarartig. 223.

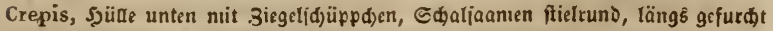
ไängliф verذünnt, Reldfaum haarartig. 230.

Geracium, Şüđe unten mit Biegelfdüppđen, હđaljaamen turs abgeftukt, ge.

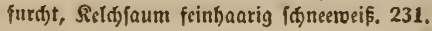




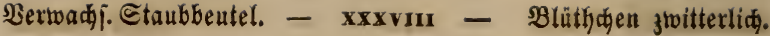

Gatyona, Siille unten baudig, sur frudtgeit luglig gej(j)lofen, äufre Cdalfaa= men geftümmt, fitigeltantig. 232.

Barkhausia, wic Crepis, Sd)alfaamen lang und Dïnn gefonnabelt. 233.

Hieracium, Şïlle gicgetfduppig, Gdjalfaamen 5tantig, Seldjfaum freiflaarig, unrein เeeistiơ). 234.

\section{b. Sauter Röbrenblütl)がen.}

* Griffelipiß̧e ungeglievert.

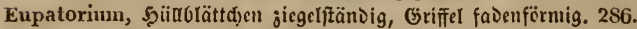

Chrysocoma, Şüablättđ́)en jicgelftän১ig, Grififel Innzettlid). 190).

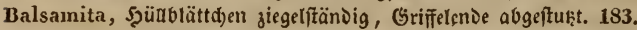

** Grifferipikise gegliedert, şülle baudig tuglig.

Serratula, Blütbenbeien boriftig fpreublättrig, Şïlle bart giegelid)uppig, field). faum baarartig, bleibent. 237.

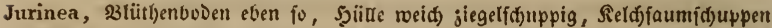
linealif(d), ungleid). 238.

Lappa, Blütbenboden eben fo, Şüldblättd)en balig, Reldsfaumborften abfallent. 239.

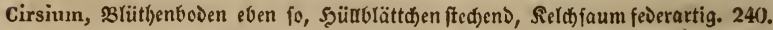

Carduus, eben jo, Reldjiaum baarartig, nebft Ringe abfalleno. 241.

Silybuun, eben fo, Sd)uppen an der sBafts blattartig uno buditig ftadjelgäbnig, Sicld)faun baarartig ipreublättrig, mit গinge abfalleno. 243.

Carthanus, Blütbenboden zeríd)lif̧t fpreublättrig, Sd)uppen blattartig, etraas fted)eno, Sieldffaum ferlit. 244.

Onopardon, frutbtocden mabenzellig, Sdjaljaamen quer gerunjelt, Feld). jaum baarartig. 242.

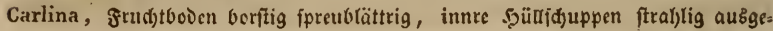
breitet, glänjend, Re(d)jaum federartig, fäd)erartig verwad)fen. 211.

II Superflua, Heberflüffige, S丸eibenblütyden röh= rig, zmitterlin, Ranbblüthden röhrig ober zungenförmig

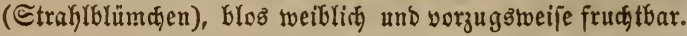

a. Reldjaum fel)lt oder trof́enl)äutig.

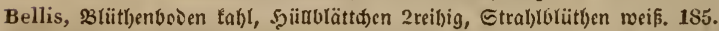

Tanacetum, SBlütl)enboden fahl, Sjüllblättḑen jiegclftändig, Strablen fel)len, Cd)aljaantert edfig, geitreift, Sieldjăam jodjeibenfïrmig. 198.

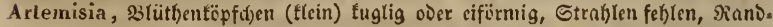
blüt)dien fadenfirmig, G(balfaumen umgetebrt ciförmig, Seldfaum [d)eibell. förmig. 197.

Matricaria, Blütbenboden nadt, legelfürmig, bobl, SRanbolündjen ftrablig. 1S4.

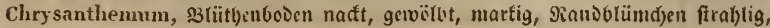
Reld)iaum 0. 181.

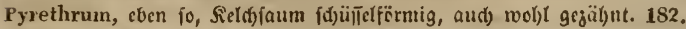

Achillea, 33liitljenbeden \{preublättrig, Etral)lell wenigjäl)lig, turz u. breit. 178.

Anthemis, 33lütbenboven fpreublättrig, Gtrablen viclgäl)lig, lang uno fd)mar, Gd)aljaamen 4tantig rmolid). 179.

Anacyclus, etven fo, Gdjalfaamen platt geiriečt, 2jäbuig. 180. 


\section{Bextvadif. Staubbeutel. - xxxix - $\Re a n b b l u ̈ t h$ t. toeibl.}

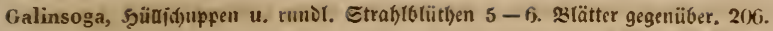
Bidens, Blütbenboien fpreublättrig, Şü̈le Doppelt, S(f)aljaamen lang, 4tantig, mit 2 - 4 Şafengrannen. 3lätter gegenüber. 207.

b. Reld)faum baarartig.

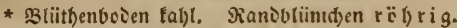

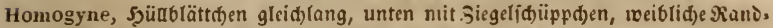

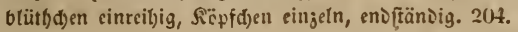

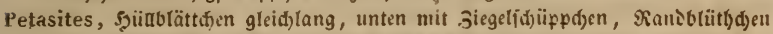

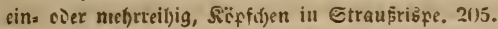

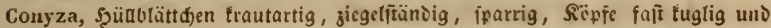

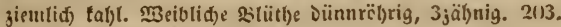

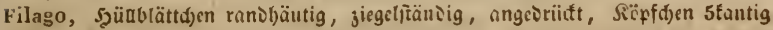
mollig. 200.

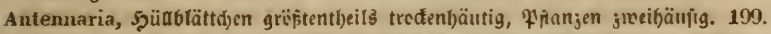

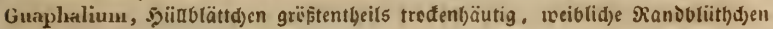
mel)rreilyig. 201.

Helichrysum, sjüLblättd)en ganj trođenl)äutig (gelb), meiblid)e Rian〉olütld)en einreil)ig. $2(1) 2$.

\section{** Sanibliimdsen frrablent.}

Erigeron, હtanbbeutel unten niđt begrannt, હtrablblütl)en ntebrreifig. 187.

Stenactis, eben fo, Feldjaum Der (d)eibenbliitb)(j) mel)rreil)ig baarartig, un. gleid), soeibl. Stral)(blütlyd)en fein uno jel)r jalylteid, Iveip. 186.

Aster, eben fo, Straljiblïtlf(jen 1-2reibig, nid)t gelb. 158.

Solidago, eben fo, Etrablolüt)d)en 1-2reilyig, getb. 189.

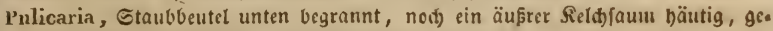

, jäljnt, Etrablen fein uno jebr jab)(reiđ), gelb. 195.

Inula, Etaubbeutel cben fo, Sel(bjoum nur baarartig, Etrablen gel6. 196.

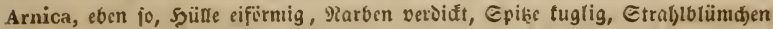
mit freien unfrudtbaren હtaubbeuteln. 193.

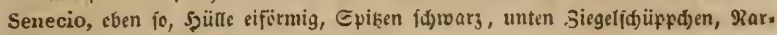
ben foffförmig. 194.

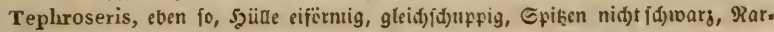
ben fepffirmig. 192.

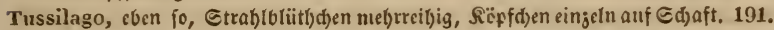

I1I. Frustanea, $\mathfrak{B}$ ergebline, ๔dgeibenblüthden räh=

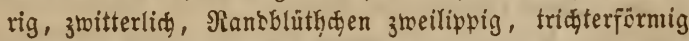

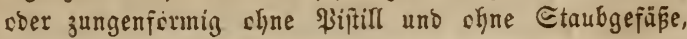
unirudt tbar.

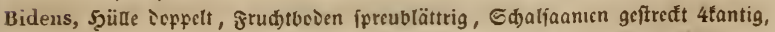
mit $2-4$ Shafengrannen, (Etralylen feblen oier fino votisanien). 207.

Heliantlus, Şïlle jiegelifuppig, verplad)t, frudjtbcien fpreublättrig, Gdjalíaa. men jujaumengeorïidt mit 2 oier mel)r abfallenden Epreujdjüppden. 208.

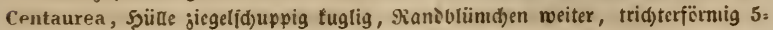
ipaltig, Reldjaum borftig. $2(1) 9$.

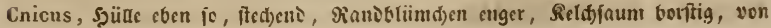




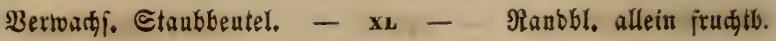

Drüfentragenden Sorften innen uno von einen geterbten Gdjüfeldjen außsen umgeben. 210.

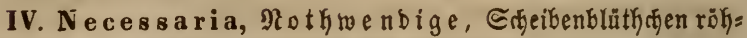

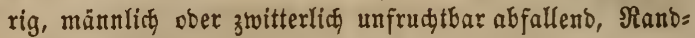
blütfdien weibliț, a fre in frudtbar.

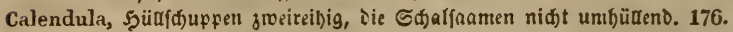

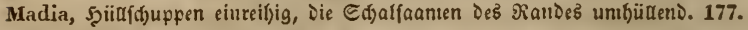

v. Segregata, Abgejonberte, Allle Blüthen zwitter= liđ, einzeln feldyartig umfyüllt.

Echinops, Der augenteine fruthtboden fugetrund. 245.

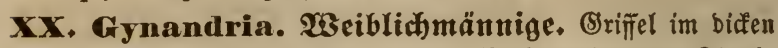
Etrukfaben eingewactfen, nur bie Rarbe unter bem Єtaub= beutel fittetbar, ober (III.) bie Beutel mehrzählig um ben (S)iffel herumgetwanjen.

1. Monandria, (Einmånnige, ein Staubbentel, zmei= färdyrig, in jebem Factje eins ber \$ollinarien ober feulens förmigen @taubförperdjen.

a. Etaubbeutel ganz aufgerwadifen. aล, Blumenlippe gefpornt.

Orchis, łodinarien auf cingefenften Drüfen, Reld helmartig zufammengeneigt. 108.

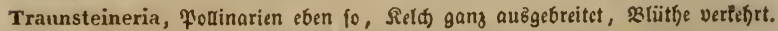
111.

Anacamptis, Follinarien auf einer freien Drüfe, Sippe breitlappig, 3fpaltig. 109.

Loroglossuin, Podinarien eben fo, Sippe fefr lang linealifw 3theilig, Mtittellap. pen tief gefpalten, Epcrn turz. 112.

Gsmnadenia, ¥ollinarien allf 2 freien Drïfen, Blüthe offen, Sippe ftumpflap. pig. 110.

Platanthera, łouinarien auf 2 freien Drüfen, szlüthe offen, Sippe banذföruig, ganj. 115.

Peristylus, Pounarien auf 2 freien Drïfen, Blüthe belmartig zufammengeneigt,

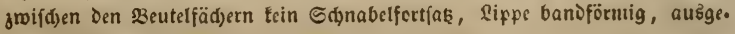
terbt 3 jälnig. 114.

Leucorchis, ¥lodinarien auf 2 freien Drüien, Blüthe tappenartig jufanımenge. neigt, jroifden ien ßeutelfäd)ern ein Edjnabelfortfak, Unterlippe 3ipaltig, פrittrllappen niđt) verlängert. 117.

bb. Silumenlippe ungeffornt.

Herminium, Sippe lincalifक), gleid)lang, 3ipaltig. 116.

Aceras, Qippe linealif(d) 3theilig, פiittellappen länger 2 ffaltig. 113.

Ophrys, Rippe breit 3lappig. 118.

b. Staubbeute! frei, nidst fefigeroadofen.

aa. silumentipłe gefpornt.

Epipogum, gเvicbeltuenig. 119. 
bb. Blumenlippe ungefpornt.

* 2̧us grvei Zbeilen gegliejert.

Epipactis, frud)tlnoten geftielt, nid)t georebt. 126.

Cephalanthera, frudsthoten fikseno, georeht. 128.

** 2น" einent Stüđe, ungeglievert.

Corallorrhiza, 3lütbe balb offen, Untertippe runotich, an Dex 3 afts mit zroei Rinnen. 121.

Sturmia, Blütle oர̃en, Sippe folef aufredt, \$eutel abfaldent. 122.

Malaxis, Blüthe offen, Sippe f(bief aufredt, Beutel bleibend. 12().

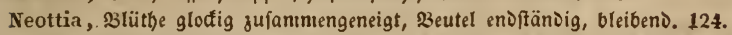

Listera, Bliuthe oben belmartig, Bcutel auf einem fortfak̨e Der Gäule, lippe baniförmig, gefpalten. 125.

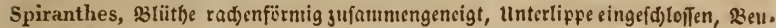
tel fikeno. 123.

Goodyera, Btütlye eben fo, Ilnterlippe eben jo, Beutel geftielt. 127.

II. Diandria, S weimännige, ztoei Ctaubbeutel (feitlich).

Cypripedium 129.

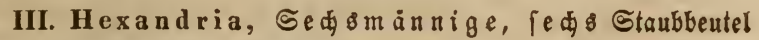
rings um ben (S)riffel.

Aristolochia 151.

XX.. Mlonoceia. Einbäuf̃ vioum theils ๔taubgefä $\tilde{B}=$, theils \$iftilblüthen.

I. M onandria, (Si in ännige, e in Staubgefä́̈.

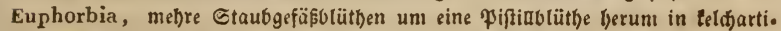
gem Şüldjen. 595.

A rum, Rolben in Gd)eide, nuf Demfalben nur unten über ben piftiden ein Rrans von Gtaubgefäpblïtbeu. 1.

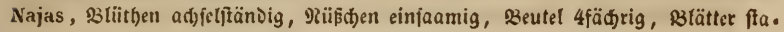

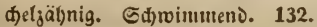

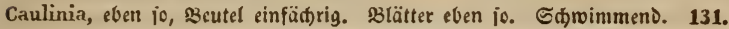

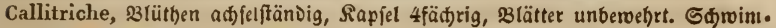
men๖. 594.

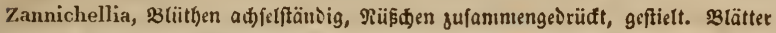
unbervebrt, fiftroimmeno. 4.

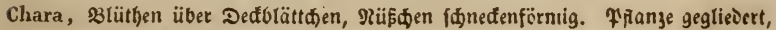
quirläftig. ఠđ)rimuen〉. 130.

Lycopodiun, Beutel niercnfërntig adjietjtändig. 137.

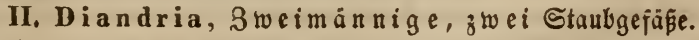

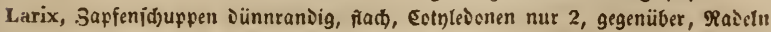
weid. $1 \pm 2$.

Abies, Sapfenf(j)ufpen Dünnraniig, fiađ), cotylèonen quirffäntig, Raicfn iteif. 141.

Pinus, 3apfenfouppen am ente rbombif́, serdift. 140. 


\section{Triandria, Dreimännige, orei Staubgefüpée.}

Typha, Rolben waljenförmig, Der obere aus Staubföben, Deren jeder $2-3$ Beutel an Der Epike trägt. 76 .

Sparganium, Rolben fuglig, Die obern männliđf. 77.

Carex, slütben äbrenftänoig, einipeljig, frudttnoten von f(blauめartiger şaut umgeben, 3 rarben. 65.

Vignea, eben fo, 2 शarben. 64.

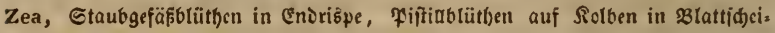
Den. 32.

IV. Tetrandria, Biermännige, vier Staubgefäß̃e.

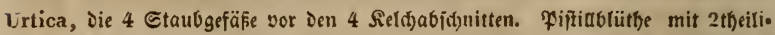
gen Sield). 155.

Thuja, Die 4 seutel auf einer @d)upe. Beibl. Slütben paarig in follaffen ธ(f)uppen. 139.

Alnus, die 4 Etaubgef. in 4jpaltigem Sieḷ), 381 . ju Dreien auf Deut Etiele Dor Räb(j)enídułpen. 150 .

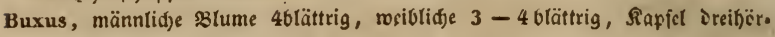
nig. 597.

Littorella, männl. 2lume präfentirtelterförnig, Saum 4ipaltig. 333.

V. Pent-Poly-andria, Fün $f=b i$ vielmänn $i g e$, 5 - 00 @taubgefäpere.

a. slunic feblt.

* Räţđđenblütbige.

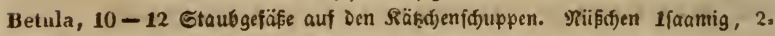
f̂ügelig. 149.

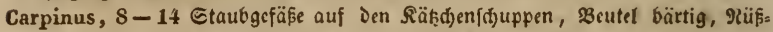
den 1 laamig, 5̧ülle blattartig, 3lappig, cinjeitig. 151.

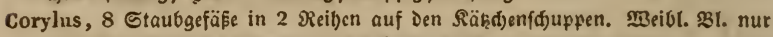

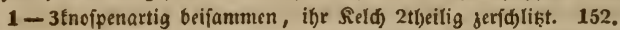

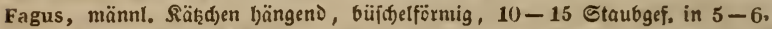

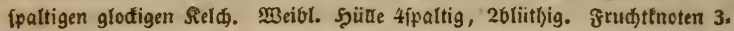
fäd)rig. 153. b. f. Seite 452.

Castanea, männl. Räbđen aufredyt äbrenförmig, 10-20 હtaubgcf. in Gipal.

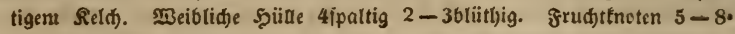
fäđrig. 154.

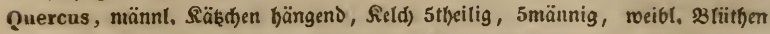
endftändig 1-3, Reld idiüifelförmig. (eidjelfrudt. 121.

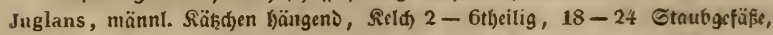

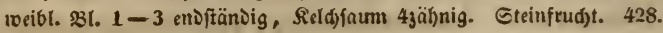

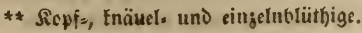

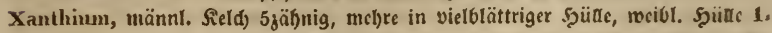
blättrig, 2fäd)rig, 2blütl)ig, 2jaanige Steinfrudt aus ১er Şüđe geviloct. 246.

Ceratophyllum, slüthen adfflftänoig, Gtaubbeutel fiß̨ent in vielipaltigem Seld), Fiftia in sielipaltigem Relds. 133. 
Atriplex, אnäuclblüthen, männl. Sielă) 5theilig 5männig, weibl. 2llappig, unten breiter, ๔aame fifwargftuftig. 478.

Halimus, eoen fo, rocibl. Seld) teilfürmig in einen Stiel verf(f)älert, Eaame läutig. 479.

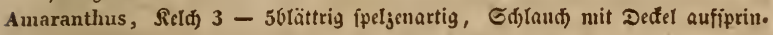
genv. 490 .

b. 3lume farbig.

Sagittaria, Reld) 3theilig, \$lume 3blättrig, Staubgef. u. Piiłtille zahlreiđ̆). 9. Myrioplyllum, Seld) 4theilig, Staubgefäfe 8, 3l. 4blätrig, abfallenঠ, reibl. Seldfaum 4jpaltig, 231. 0, Sapfel 4tbeitig. 513.

VI. Monadelphia, (sinbräberige, Etaubbeuter, zum Theil aum bie Beutel berwadien.

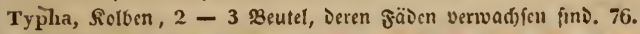

Cucurbitie, 3 ๔taubfäben und fdjleifenfïrmig getwundene Beutel verwadjfen, Saamen wutftrandig. 250.

Cucumis, 5 Staubfäoen nebit Den fifjleifenförmig gemundencu 3cutelu verwad). fen, Saanten fdarfrandig. 249.

Bryonia, Etanbbeutel frei, Bcere 3 - Gaanig. 247.

Ecbalion, હtaubbeutel frei, Beere vieljaamig. 248.

Larix, Abies, Pinus i. II. Diandria.

XXI1. Dioecia. 3tweihäuịige. Gin Эnbivibum trägt bloz Etaubfäben, cin anberes blos soifillbhüthen.

I. M on-Di-a ndria, 1-2männige, 1-2 Staubgf. Salix, Sđuppentäțdjen, $1-2$ Drüjen in Der $2 d$ fel. 147.

1I. Triandria, Dreimännige, orei હtaubgefäß̈e. Salix amygdalina (triandra) f. oben. 504*. Valeriana dioica 560 *. Empetrum, Rel(t) und Blumen 36lättrig, Rleinftraud), beideartig. 598.

III. Tetrandria, $\mathfrak{B}$ ier mănnige, vier @taubgefäpe. Salix Meyeriana f. cken, 511 *.

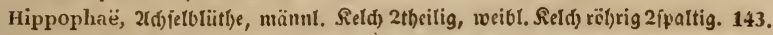

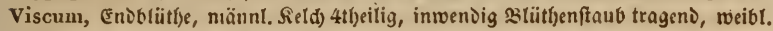

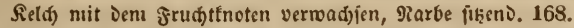

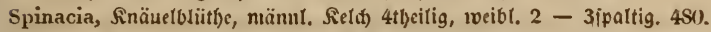

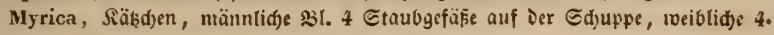
id) uppig. 146.

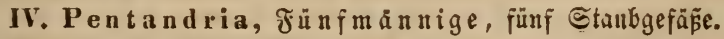
Salix pentandra f. ธocn. 512 *

Cannabis, finüuelblütben, männl. Reld) 5tbeilig, weibl. 1blättrig f(beibenartig 157.

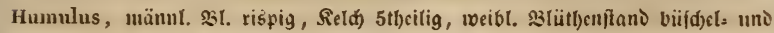

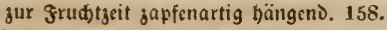

Juniperus, uännl. $\mathfrak{B l}$. in ßäfăd)

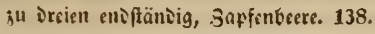




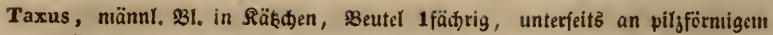
Iräger, neibl. Bl. enذftändig, Relđbeeren frugförnig. 136.

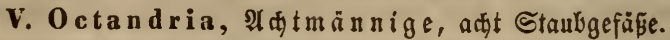

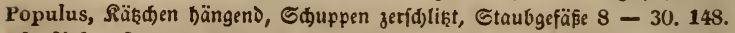

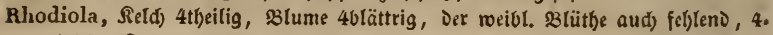
theitige Siapiel. 3ergl. 21um. vor 464.

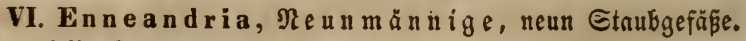
Mercurialis, Reld 3theilig, $\mathfrak{8 1}$. fel)lt. 596 .

Hydrocharis, Reld und 8 lume 3blättrig. 13.

VII. Decand ria, $3 \in \mathfrak{h} \mathfrak{n} \mathfrak{a} \mathfrak{n} \mathfrak{n} i g e$, zefn Staubgefääe. Lychnis dioica 1982*.

Silene Otites 1971*.

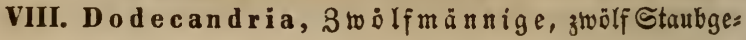
gefǟê.

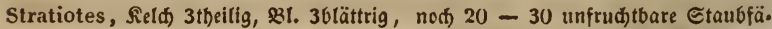
Den, roibl. 23l., frudttnoten vom אeld) unwwa(t)en, Caum 3theilig, Griffel 6, 2tbeilig, unterftän๖ige Beere 6fäđtrig. 12.

Populus, f. oben. $148 \mathrm{~b}$.

Mercurialis $1875 *$, Reld 3 theilig, 3 l. feblt. 596 .

XXIII. Polygamia. Bielehige. Staubgefäß: uno Biftilublüthen getrennt neben 3witterblüthen auf einem ober verificiebenen Snbivibuen.

xale ebedem bierber'gejäl)lte Gattungen rerien leidter und fiderer naథ Dem 23 aue ifrer 3roitterblïthen in ben obigen אlaffen aufgefudyt. 


\section{(Sintheilung Des Serrains uno Erfflärung Der Arbë̈rzungen bei ben Standorten.}

D. Degierungsbegirt Dresien.

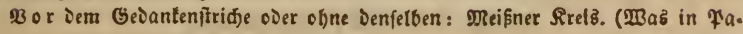
rentbefe eingefdloffen, ift bëbuif(d).)

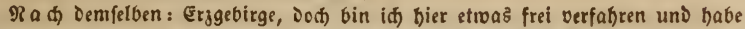
einige Drte, roclde aud) efjemals Dem Dieiß̄ner Rreife angebörten, wegen bier offenbar erjgebirgifder (Begend bierber gezogen. ( $\mathbb{B a s}$ in parentbefe

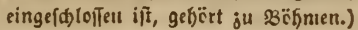

Z. Regierungsbejirt 3 wiđau.

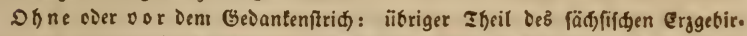
geร.. (

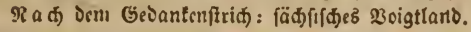

L. Regierungz̊ 6 ezirt seipgig.

(Bisrocilen eingelne Drte gu 2rnfang mit Gedantenftrid abgetrennt, aud) biefe gef)̈rten ehenials zum (Erggebirge.)

B. Siegierungzbegir $\mathfrak{B}$ au

PL. Freufifde Iaufik.

Of) ne oder $n$ a d Dem Gedantenftrid): Riederlaufie.

$\mathfrak{B} \circ \mathrm{r}$ Dentfelben preufifder Ibeil Der Dberlaufik.

A. Xnbaltinif́e fänder.

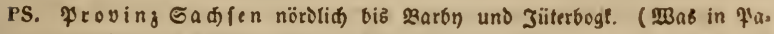

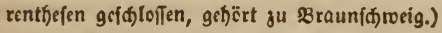

HS. Sergoglid fädfif由e fänber.

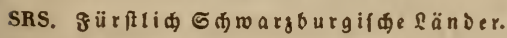

R. ร̈̈ 


\section{$\Re \mathfrak{p}$ ferwer}

\section{beren $\mathfrak{A b b i l}$ oungen citirt wurben, nebit Erläuter: rung ber Sofürzungen.}

A. Deutide, allgemeiner verbreitete unb bebhalb of ter citirte 2 erfe.

JACQ. austr. - JAcQUIN Flora austriaca, Vol. I - V. Vindobonae. 1773 - 78. fol.

W. K. - Waldstern et KrTArbex plant, rar. Hungariae. Vol, I - III. Vindobonae. $1802-12$.

Scrк. - SchкणнRs botanisches Haudbuch, I - III. Wittenberg. 1791 $-1803$.

Rcri, Deutschl. Fl. - Reichexiach Deutschlands Flora oder Icones Florae germanicae. Leipzig bei Fr. Hofmeister. In Heften zu 10 Platten. Theilweife ju erfjalten. I - V. 1837 - 42.

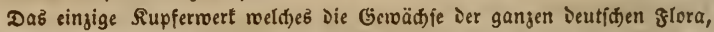

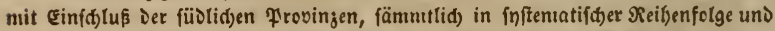

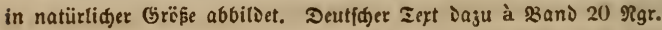

Rсnв. Agrostogr. - Rerchrxвach Agrostographie oder die Gräser. Leipzig bei Fr. Hofmeister. 1934. 4. 110 Kupferpl. mit 50() Abbild.

Rсnв, pl. crit. - Reichrnbach plantae criticae oder Kupfersanmulung europäischer Gewächse. Band I $-\mathbf{X}$. Leipzig bei Fr. Hofıneister. 1823 - 33. 4. Mit 10)( Kupfertafeln.

ST. - Strom Deutschlands Flora. Niirnberg bei dem Verfasser. 1798 $-1842$.

Haxis Arzngw. - Hayxe Arzneigewäclise. I - XIII. 1805 - 37. Leipzig in Comun. bei Fr. Hofmeister.

Drev. u. HN. - Dreves u. HAYNe botanisches Bilderbuch. I - V. Leipzig b. Voss. $1802-10.4$.

Dietr. - Diftrich Flora Regni Borussici, I - VII. Berlin b. Oehmigke. $1833-40.8$.

ZkNк. Schuchto, - ZkNker u, v. Schlechtendal Flora von Thïringen. Heft 1 - 16. Jena bei Schmidt. 1836 - 40. 12. 
Guimp, - Guimpin, Winldexow a. Haysz die deutschen Holzarten. Berlin b. Schüppel. 1815. 4.

Kerx. ük. - Kraxir Abbild, aller ökon. Pflanzen. 8 Bände. Tübingen. 1786. 4.

Kern, Bm. - Karser Besclir. d. Bäume Kiirtembergs, Stuttgart. 1783 $-1786.4$.

Reit. u. Ab. - Reitter u. Abel Abbild. von 100 dentschen Holzarten, Stuttgart, 1790. 4.

Pugxi. - Plexk icones plant, medicin. I - VII. Vindob. 1789-1803. BLAckw. - Exis. BLAcK WRLl vermehrtes Kräulerbuch, I - VI. Nürnberg. 1750,

Riv. - Rivixi ordo plant. etc. Vol, I - III. Lipsiae. 1690 - 99, fol.

Garrta. - Garrterr de seminibus et fructibus plant. I - III. Lipsiae. $1788-18() 5.4$.

N. v. E. - Nkes v. Eskxbecx genera plantaruu. Bonn Henry et Cohen, Fasc, I - XXI, sine anno. 8 .

Mrtzg. - MarzGer europäisclıe Cerealien. Heidelberg bei Winter. 1827. fol.

Mrisx, - Mrisnar Polygonpae. Genevae. 1826. 4.

Narg. - Naggetr die Cirsien der Schweiz. Zuirich, $18+1$.

Ust. Ann. - Ustrei Annalen der Botanik. I- VI. Ziirich. 1791-93. 8. Schrad. Journ, - Schradkr Journal für die Botanik. Göttingen, 1799 $-1803$.

Spr. - Sprexgrt Flora Halensis. I. II. Halae. 1806.

Wallr. ann, - Waleroth annus botanicus. 1822. Halae. 8.

Waxlr. sched. - Waxlroth Schedulae criticae. 1822. Halae.

B. গิน $\mathfrak{I}$ än felten citirte $\cong$ Berfe.

B. Mag. - Botanical Magazin by Curtis, Sins et Hooker. Vol. I - LIII. and new series I - XIII, 1787 - 1842. London.

B. Reg. - Botanical Register by Ker et Lindley. Vol. I-XXVIII. 1815 - 42. London.

B. Cab. - Botanical Cabinet by Loddigges and Sous. Vol, I XVII. 1818 - 30. London. 4. et $S$.

Engl. B ot. - The English Botany by Sinith and Sowerby. Vol. I XXXVI et Suppl, 179x) - 1830. London.

Curt. Fl. Lond. - Flora Londinensis by Curtis. Vol. I. I. London. 17i\%. fol.

Hоок. Fl. Lond. - Flora Londinens is cont. by Hooker. Vol. III. IV. 1815 - 19. London, fol.

Fl. dan. - Flor a d a nica auct. Oeder, Vahl, Homemann, Nolte. Vol. I - XIII. Hafniae. 1761 - 1836.

Srensk. B. - PAxystruch et Brllberg Svensk Botanik. Vol. I VIII. 181)4 - 15. Stokholın. 8 . 


\section{- XLVIII -}

F1. gr a c. - Srвthorp et Smitr Flora graeca. Vol. I - VI. 1806 1826. Londini. fol.

Baxb. Nocc. - Barbrs et Nocca Flora Ticinensis, Vol. I. II. 1816 1821. Ticini. 4.

Sfb. Maun, - Skbastraxi et Mauri Flora Rounana. Roinae. 1818. suppi. 1820.

Poxlns. - Pourrni Flora Veronensis. I - III. Verona. 1822-24. 8. Drix, elth. - Drllenri hortus Elthanensis. London, 1732. fol.

Camrr. hott, ic. - CaMrrarir icones accuratae plantarum in horto descriptaruun. Frcof. ad M. 1588.

Lax. ill. - LAMark illustration des genres avec 950 pl. - Paris. 1791 - 1793. 4.

Gmex. sib. - J. G. Gmenrni Flora sibirica. Vol. I - IV. Petrop. 1747 - 1769. fol. min.

Paxx. ross. - Pallasir Flora rossica, Vol. I. II. Petrop. 1784 - 88. fol.

Paxx. haloph. - Pazrasir illustratio plantarum minus cognitarum. Lips. 1803. fol.

Varzl. - Varllant Botanicon Parisiense. Leidae. 1727. fol.

Puokn, - Puukenet phytographia. I - IV. London. 1691. et Alinagestum I. ib. 1796. mant, 1700.

Amaltheun 1705. 4.

Moris, - Morrson hist. plant. oxon. I - III. Oxon. 1680. fol.

Cuus, - Cuusri rarior. plant. hist. Antverp. 1601. fol. 


\section{O I. E O P II Y T A. \\ Elaffé ber Sheidenpflanzen oder Spizgeimer.}

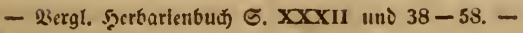

\section{Familic Aroidene, $\mathfrak{A}$ roibcen.}

- 5erbarienbud) S. XxaruI und 32. -

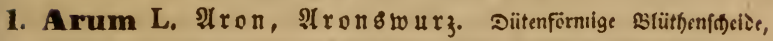

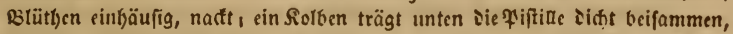
über if)nen Dic Etaubbeutcl uno bilidet ïber siffen eine nafte Seule. Etein.

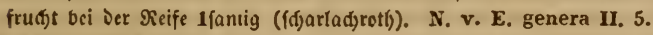

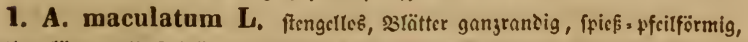
fielben tïrger alb ed)eite. Haysi Arzngew. XIII. 32. Stura 44. Murgel.

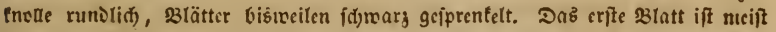

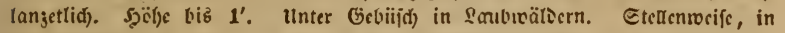

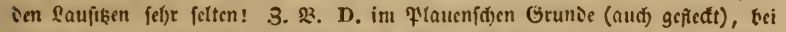

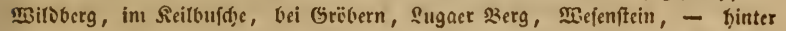

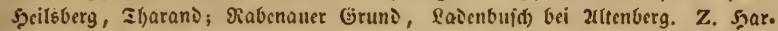

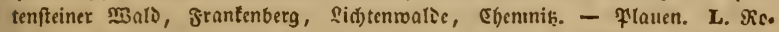

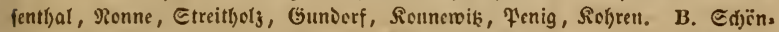

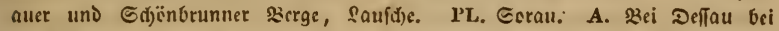
Groftiilynau in ien Eaalbergen, bei .3erbft, Scib̧tau, sar šgeroie. PS. Diaben.

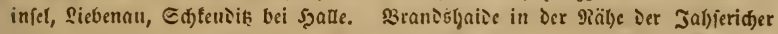

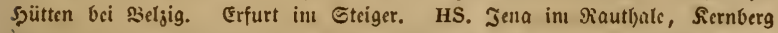

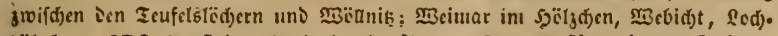
hörjdjen. SRS. צrnjêtast. Mai. Juni. 4. - Off. Radix ari maculati.

2. Calla L. Sdfangenfraut, 3 efrtourz. Duitenförmige

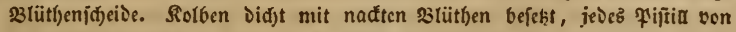
6-8 Etaubgefäßen unigeben. Eteinfrud)t vielfamig (idjarlad)roti)). N. r. E. gen. II. 4.

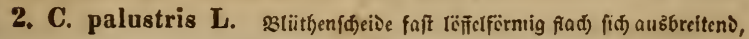

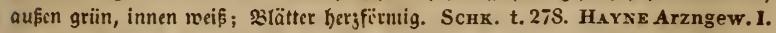

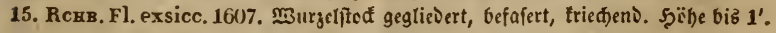

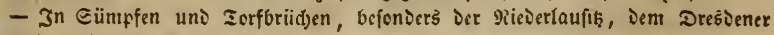
Saidelande und obern Erjgebirge eigen. D. int Morigrunie, bei Dledingen, Sallfa, Fonilall, Sangenbrüd, Mioriłburg. Griinneţe bei Glaufdaniß, Edjön. trunn. Z. in vielen Zorfmooren: Peutirdien bei el)emnik, Etodberg bei

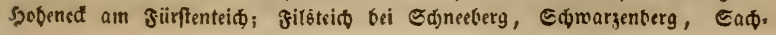




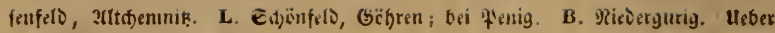

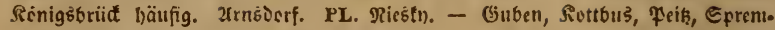

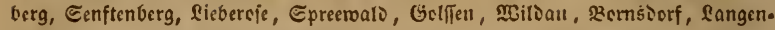
graj̃an. A. Dranienbaun, Edierau, 3erbft. PS. Edfrabenmalo bei sinten.

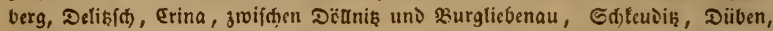

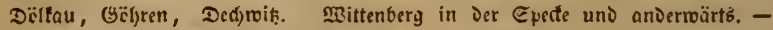
HS. Roburg, bei Mtënd)rode, Reuftait. R. Greij.

\section{Familie Potamogetoneae, Qaich) fräuter. \\ - Strbarienbud) G. XXXIII uno 33. -}

3. Lemna L. $\mathfrak{B}$ a fferlinfe. Ed)cice einblättrig, Btütbe switter.

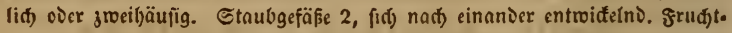
lnoten frei mit 2-6 aufred)ten Samiden, פiarbe ftumpf, Grifint furr, Srudt fd)(aud)artig. N. v. E. VI. 9. \$3itoet 4 untergattungen: Lemna L. Telmatophace Schrвid. Spirodela SchLrid. $u$. Staurogeton Rchв. Deren restere aud) in ganjen

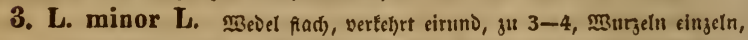

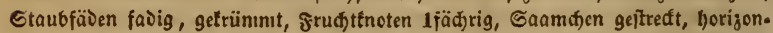
tal, balbgegenläufig, Grififel Deutlid), getrü̈ımt. Scнк. t. 281. Sт. 44. Ноок.

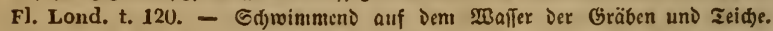

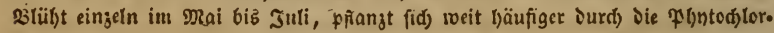
törnd)en fort, weld)e im Epätherbfte aus Dem 3ellgecwebe ju Boben falden und in srübling roièer emporfteigen, wobei fie nod) cine 3eitlang wurzellos bleiben:

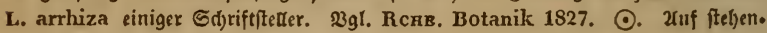

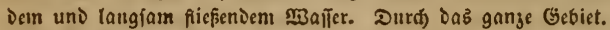

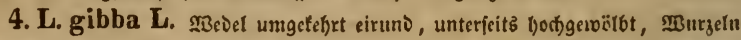
cingeln. Gtaubfäben breit, getrünııt, Grudtttnoten 1 fäd)rig, Eaamid)en 2 oder

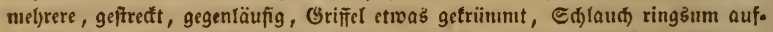

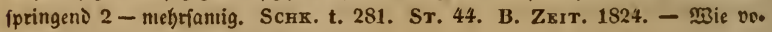
rige, $\odot$. Dod) reniger gentein.

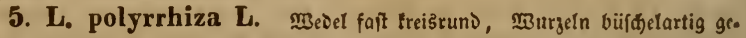
Ђäuft, ভtanbfäben veridjnälert, ๔aamden 2, gegenläufig. Scnk. t. 281. Sr. 44. - Mie vorige.

6. L. trisulca L. MBevelgliever eilangetfid, geftielt, treujartig fproffeno,

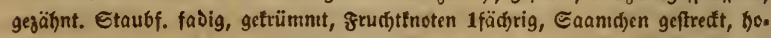
rizontal, balb gegentäufig, Griffel geftümmt. ST. 44. Engl. Bot. 926. Hоoк.

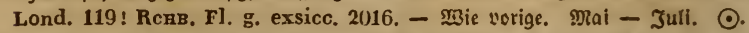

4. Zannichellia Mrch. 3 an $\operatorname{nich} e \mathfrak{l}$ ie. Edeide cinblätt.

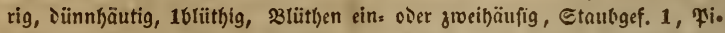
ititle geftielt, 4-8, Narbe fdjildförmig. - Etengel fadenförntig, fofminumend,

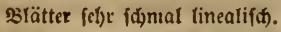

7. Z. repens BvNGK, wourzelno, etaubfaien taum länger als fruoft.

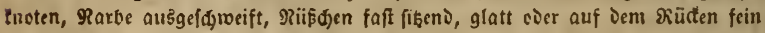

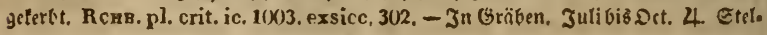


tenweife 8. 3. D. Im Canal des grofien Gartens. L. Sil. Däljig, ęue

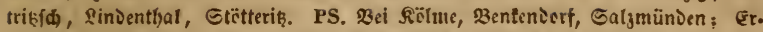

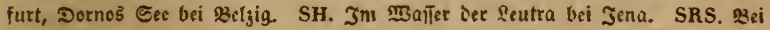
Grantenhauien.

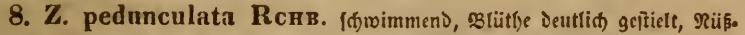

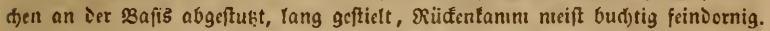

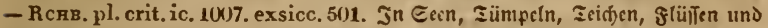
Bäđhen. Juni- Dct. 2. Geltener als vorigeš : 3. 3. D. im gr. Garten, im

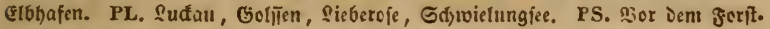
baufe bei salle.

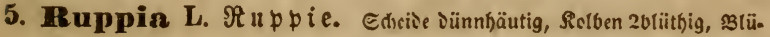
then jroittertion, 2 Staubgef. Staubbeutel groß 2fäibrig (Daber fdeinbar 4niännig), allf furjen (d)uppenartigen Ctaubfäien. Niifit)en geîtielt. -

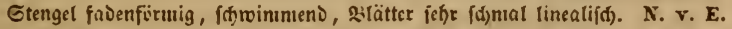
VI. 12. -

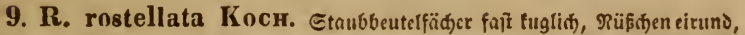

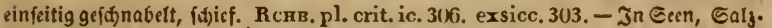
gueden. Jug. - Det. ந. Rid)t verbecitet, nur in PS. ant ufer Des falgigen

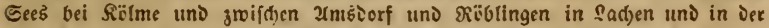
Salja. Wallroth. L. Rchb. fil. bei 2retern, siumburg. Hornung.

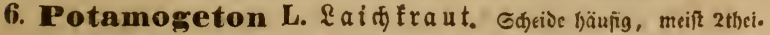
lig. Reld 4blättrig, 4 Ctaubbeutel ftßen auf Dem গagel Der Sield)blätter.

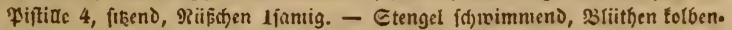
frändig. N. v. E. VI. 13.

a. pectinati, Stentpelglieذer un১ 3 lätter fełr zart, Dieje gleidjfir. mig, fáeibig, şlütlyen tnäuelartig älyrig.

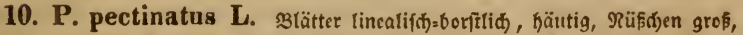

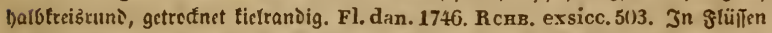
und zeid)en. Jul. Yug. 4. D. Jn Şafen, Weigelt, im gr. Gebägc, Bauer, Groh.

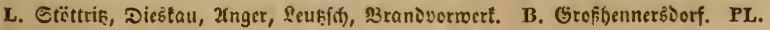
Epreeroalo, ๔d)wielungice. A. Gröbzig, sernburg, Güften. PS. Mit. tenberg, Szalle ( Saale, unftrut, Diulbe, Eliter), Ecfartsberge, Eulja, Erfurt. HS. Jetha in Der Leutra, Jljorn bei Roburg. Homung. Jin bei serta, Zenker.

In m. Diefe Franje ift P. un arinus Kocr, melde Scaptange Derfelbe roun.

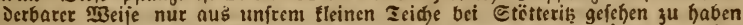
betioftet. Iob fammelte fie Dafelbft feit 1814 imner als $P$. pectinatus, wäh. reno P. marinus Lix. u. Sм. (P. filiformis P. setaceus Schuнracr. non L.) nur in grosen fandieen wö̈dft; jeine früd)te find taum halb fo grof, als Die unjerer Prianje.

b. c o m pressi, Єtengel jufammengcìrüctt, siätter bäutig, Durđ̆) (d)einens, linealif̧‘ gleiđ)artig, Blattbäutden abgetecnnt.

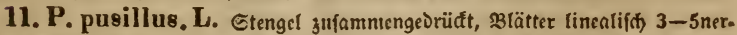
vig; sliuthenftiele $2-3$ Mlal fo lang als Die meifit unterbrod) $2 \mathrm{chre}$; Rüßs. den fibief eiruno. - Loss. priss. t. 67. Fl. dan. 1451. Gefbe äftig. Mehr

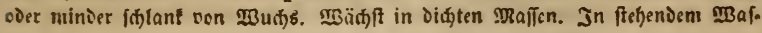




\section{Potamogetoneae. - 4 - Potamogeton.}

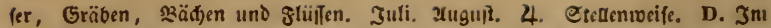
Gebäge, verm faltenfthlage, in Şaušcorf, bet Meißen, in Ealberla's zeid in Dresden. Z. Swiđau, MBerdau, MBiltenfels, Deieran. L. Sinientl)al, Mad)ern, Döljig. B. Szerenhut, Groklyenners̄orf, Rupperboerf. PL. Diefa, Görlis.. -

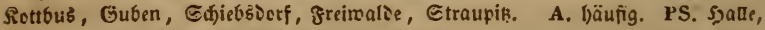

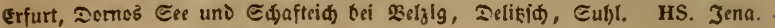
SRS. Urnitait.

12. P. obtueifolius M. K. Etengel georiidt, ftumpflantig, Blätter

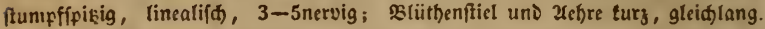

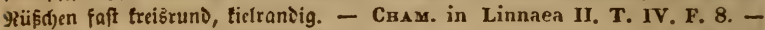
Fl. dan. 2107. gramineus Sx. Engl. Bot. 2253. - In Iciden. Juli. Xuguft.

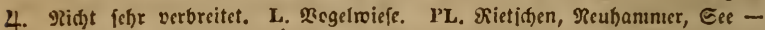

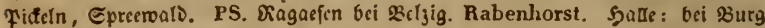
Riebenau uno mallendorf.

13. P. acutifolius $\mathbf{L K}_{\mathbf{K}}$. Etengel grirüđt, fiügelfantig. Stätter linea.

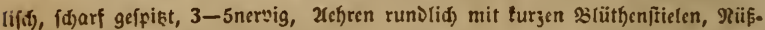

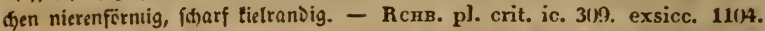

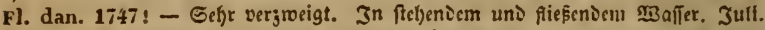
2uguft. 4. Wenig verbreitet. D. Un Der Etrape nath Firna vor Gruna.

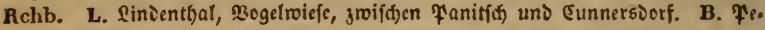

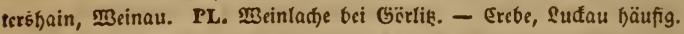

14. P. compressus L. Etengel gèrüđt, flügelfantig, siätter $3-5$ ner.

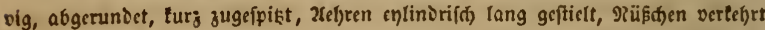
cirund, fumpf, tielraniig. Loss. pruss. t. 66. Rcrs. pl. crit. ic. 3118. P. zosteraefol. Fl. dan. 1865. et P. acutifol. 2046. excl. fret. In Sanojecn, Ieidjen uns flüiTen. Juli. Xuguft. 4. Fait Durd Das ganje Gebiet, Dod

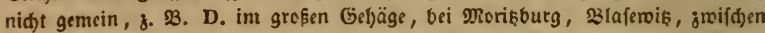

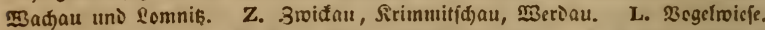

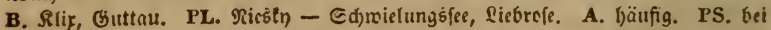
Beljig, æittenberg, Rof́leben, Szalle, Merjeburg, Eubl. HS. Eijenterg, Jena im 3cikgrund und nad) ier fröblid)en MBisicrfunft zu.

c. heterophylli. slätter verfd)iedengeffaltig, slüthen in tolbenförmi. gen ael)ren gleidymäfig vertbilt.

15. P. crispus L. Blätter untergetaud)t, balbftengclumfaĩenঠ, lineallfí) länglid), 3.nervig, tweđtenraniig, gefägt, Etengel jufantmengciriuctt, \$Bliithenftiels

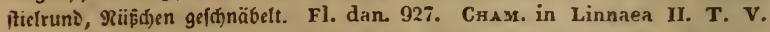

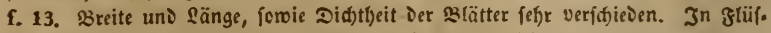
fen, Gräben, Zeidjen. Siebt letjmigen soben uni blïht nidt iiberall. Mai 3uguft. 4. Durd) ias ganje Gebict.

16. P. perfoliatus L. slätter untergetaudt, berzfïruig, balołtengel.

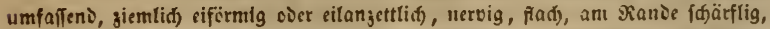

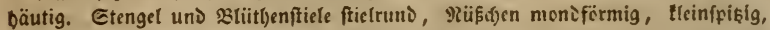
ohne Riel. - Lonskz. pruss. t. 65. Fl. dan. 196. Zntheren febr großf. In Ftüiten, Ieiden. Juti. 2luguft. 4. Sier uns Da j. \$s. D. in grosen Gebäge, in ser Elbe bei Sefdroiß, Runnersidorf. L. Srandvorwert, Sindenau, 2unger. B. 


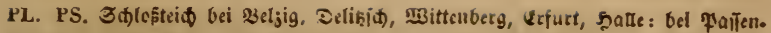

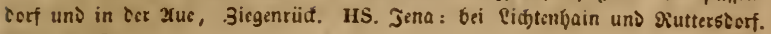
SRS. Arnftatt.

17. P. lucens L. slätter untergitaudt, bäutig, durăjiđjeinend, gefülelt,

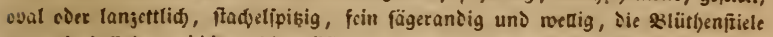

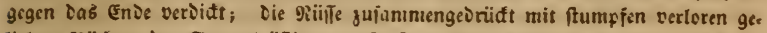
tielten Rüđten; Der Etengel äjtig. - Fl. dan. 195. Engl. Bot. 376. - 2rbart: b. Р. Ziz ii Косн. lleiner, obere Blätter flad), jđfroinınend, lederartig; gełërt nad) NoLte's Beridferung bicrber. Mbart c. a cu un in a tu s Scrox. Blätter icl)r lang uno fómal sugeípiţt. Fl. dan. t. 1337. In Gräben, flüllen, beion. Der6 in Seidjen. Juni - 2uguft. 4. Sajt allgentein, 3. B. D. ghodrit,

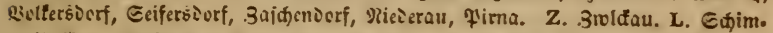

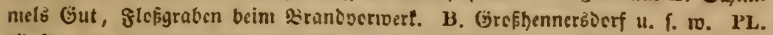

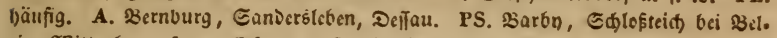

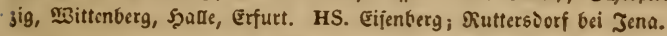

18. P. praelongus WvLF. Blätter untergetaudis, balbftengelumifai. feno, lünglid), lanzettlid, nervig, an ier Epișe fabnförmig, an Rance glatt,

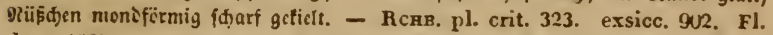
dan. 1687. - Unter ađen las anjebnlidjfte uno längfte. In fiesendem uns

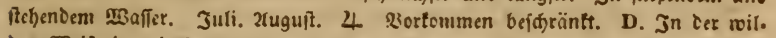
ben meiperiţ bei હdjinfelo. Fr. Avoust K. v. S. PL. In ier Eprec. In

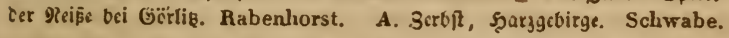

19. P. rufescens Schrad. Stengel cinfad,, bie slätter unterge.

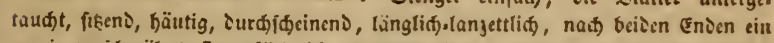

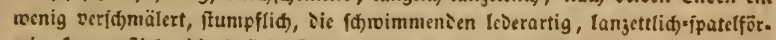

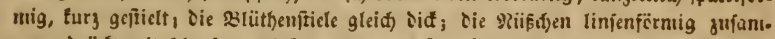

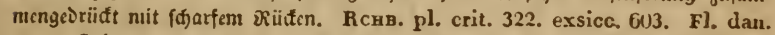
1635. fluitans Scroy. Fl. dan. 1451). et Engl. Bot. 1286. In \$3ädfen und కciđen. Juni - 2ug. 4. Niđt gemein. D. Firna. Papperitz. Saf́fenjorf,

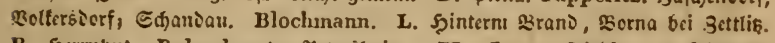

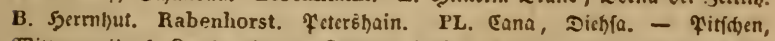

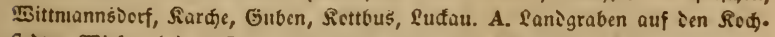

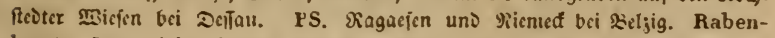

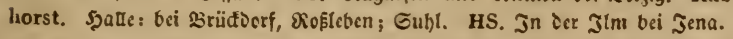

20. P. gramineus L. Etengel äpitg, ১ie ß3ätter untergetauđ)t, நäutig,

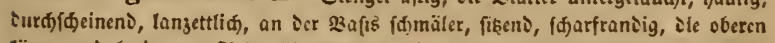

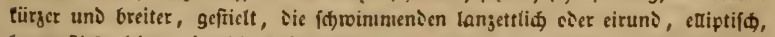

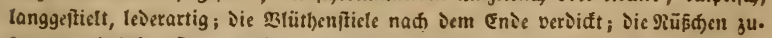

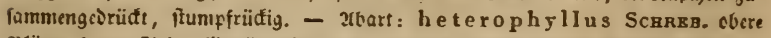
slätter langgefficlt, längliđ) cier csal, nad) beioen Enden fugefpişt, leverartig,

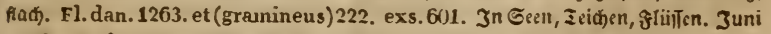

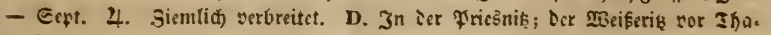
ranit: bei Saufa, Dipfelsiorf, Sídoma. L. Sinientjal, Gresbetijen. B. Fe.

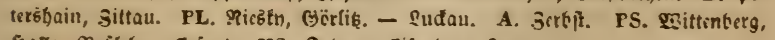
Salle, Rostcten, Exfurt. HS. Scturg, Eifentecrg, Jena. 
21. P. nitens WEB. Blätter untergetaudt, bäutig, ourdjiđjeinend, tan.

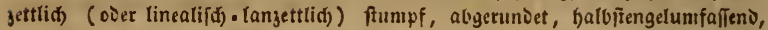

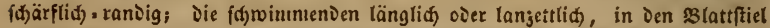

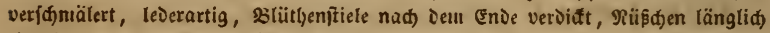

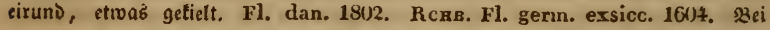

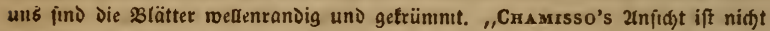
ju billigen, wenn er bjer P. lucens, Zizii, nitens uno heterophyllus verbindet, Dann müfte aud praelougus und decipiens

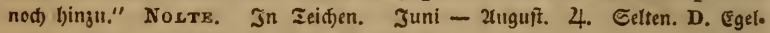
fee bei \$irna. Bucher. Rchb. PS. Wittenterg. Schkuhr.

22. P. fluitans $\mathbf{R}_{\mathbf{T H}}$, 2đte 3 lätter geffielt, fpit, Die untergetaud)ten

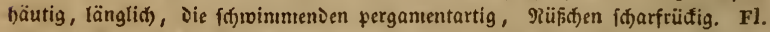

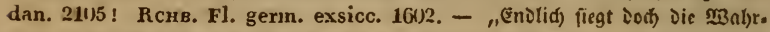
beit. Mer nur einmal P. fluitans lebend uno vorurtheilsfrei beobad)tet bat,

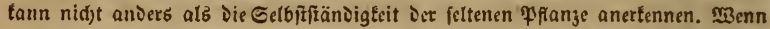
aud) Rотн auf 2tnorer 2(utorität Die Finanje enolid) jel(oft fitreicht, fo fagt mir Dod) meine 15jätrige \$eebadtung, Daß P. natans nie fI uit ans uno Dicfes nie jenes wiro." Norts. In Jliiien und Gräben. Juli. 2lug. 4. Selten. PS. Golzew vei $\mathfrak{B}_{\mathrm{el}} \mathrm{l}_{\mathrm{j}} \mathrm{g}$. Rabenhorst.

23. P. coloratus Hornem. slätter untergetaucht, lanjettfërmig, in

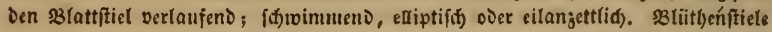

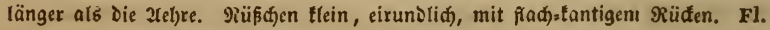

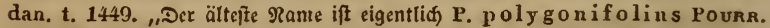
Mém. de l'acad. de Toulouse 1788, vol. 3. Chloris narbon. n. 9)1."

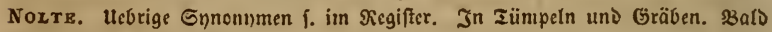
(d)wimumeno in ₹orflöđjern, balb eingefentt gwifden Sphagnum cuspidatun,

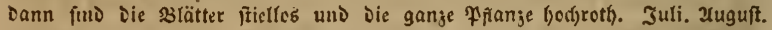

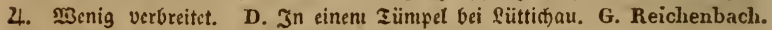
PS. In Gräben eines હrtenטruds bei Müđenberg. G. Rchb.

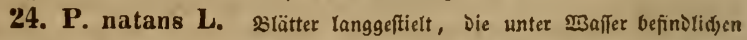

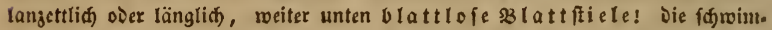

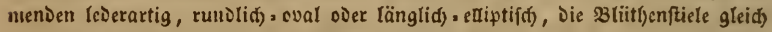

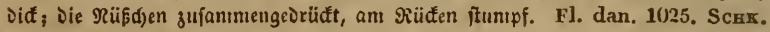

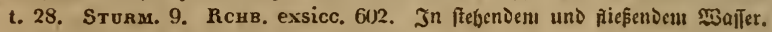
Juni - 2ü. 4. Durd) Das ganje Gebiet.

d. oppositifolii, ßlätter gegenitän১ig.

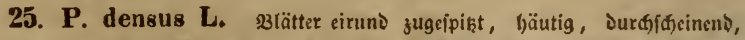

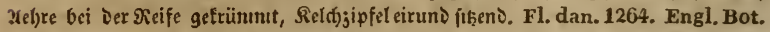
397. Rскв. exs. 1605. 2tendert ab : $\alpha$. P. o p p o s i ti fol i u s Dec. Blätter fdymal

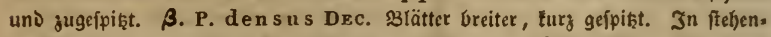

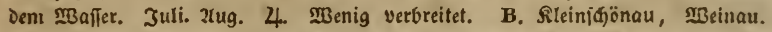

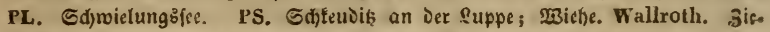

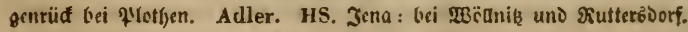




\section{Familie Alismaceae, Alismaccet.}

- sarbarienbud 5. XXXIu uno 33. -

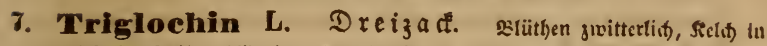

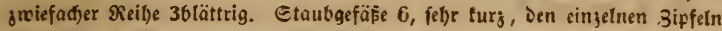

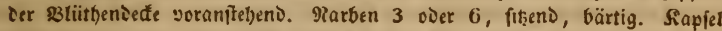
Ifärtsig, 3 over 6, an Der 23 ajis aufgehende Silafpen. N. v. E. gen. II. 8 .

26. 'J. palutre L. Siapfeln fitieltund, 3tlappig. Schx. 102. Rchв. Fl. germ. exsicc. 164. Blätter f)alb friełrund, unten fdocidig; faft rlyabarberattig

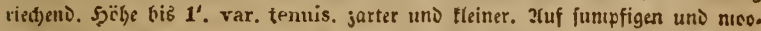

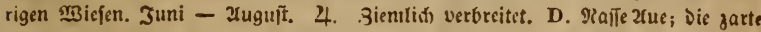

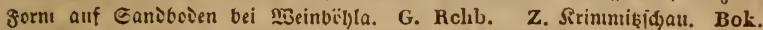
- Flauen. L. Edünefelo, Döljig. B. - NL. Nitestn, Sanban u. f. w. A.

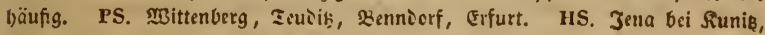

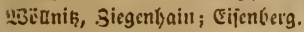

27. T. maritimum L. Rapfeln eifürnig, 6tlappig, Fl. dan. 3()6. Rсвв.

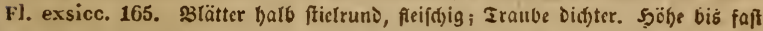

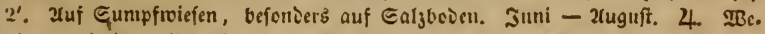
niger verbrcitet als voriger. L. R̂teindëlzig. A. Seau, Eaniersleben, Giilten.

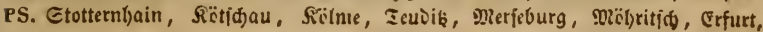
zrtetn u. f. w.

8. Scheuchzeria L. Stgeudzerie. Bä̈then gwit.

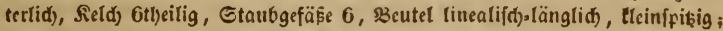

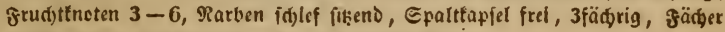
utift 2famig, aufgeblafen. N. v. E. gen. U. 9.

28. S. palustris L. Fl. dan. 6 . İßnige \$lätter, balbitietruno, rinnig,

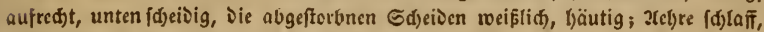

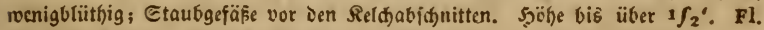
dan. 76 . Sснк. t. 1(N). Rснв. exsicc. 548. 2(uf zorfmeeren mit Rhynchosporen und Droseren, in tref́uen Jahren fef)r felten. MRai. Juni. 4. \$Bße nig verbreitet. D. Morişurg. Bok. bei Stcinbađt. Manke, Dehne, G. Rchb. 7. Johanngeorgenitait. Bok. Brunner. હarlšferd, (Gettešgabe), Jnnaberg. Weigelt. PL. Ziefenfurth, Mechrau. - Sivifden Mittreida und Seuthen. Rabh.

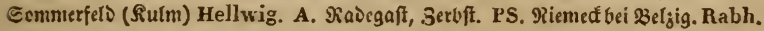

9. Sagittaria L. $\quad$ f feiff $\mathfrak{x} \mathfrak{a} u t$. Blït)en einfäufig. Sicld)

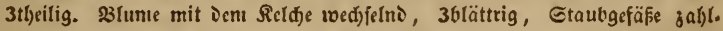
reidj. Grudtttnoten gebäuft. Epalttapjel frei, vielfäd)rig, fädjer einfamig.

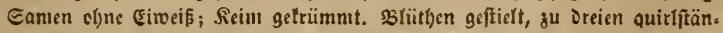
¿ig, Die untern weirtid. N. v. E. gen. VI. 19.

29. S. sagittifolia L. 23lätter tief-ffeilförnig, jugcípikąt; ๔d)aft einfach.

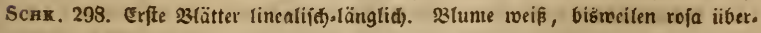

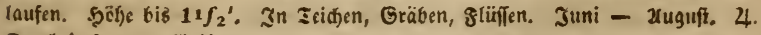
Dur(i) इaร̆ ganje Giebiet. 


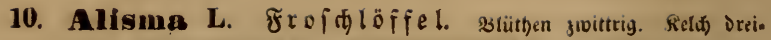

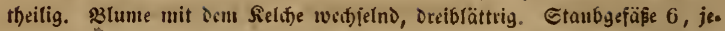

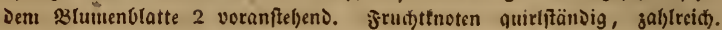

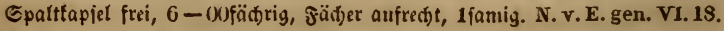

30. A. natans L. Stengel beblättert. Untergetau(t)te ß3ätter linealifø) ()äus.

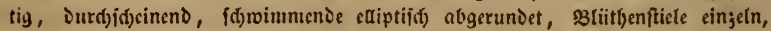
Früd)t(f)en geffreift. Rснв. pl. crit. 77. 78. Fl. exsicc. 504. Zarte Prianje;

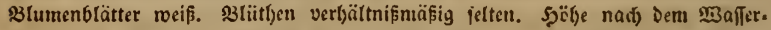

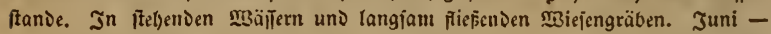

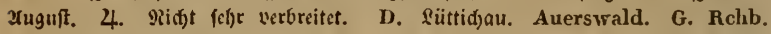

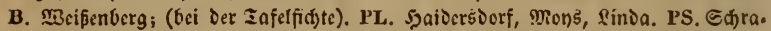

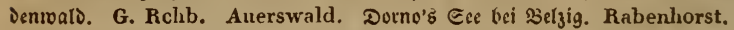

31. A. parnassifolium L. Blätter rourzetitänoig, berzförmig, eifürnig,

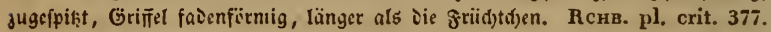

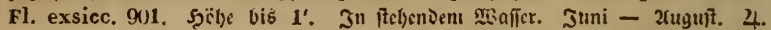
Eefyr jelten. PL. Eonnentwalie. Rabh. PS. Sthafteidy bei Betjig. Rabenhorst.

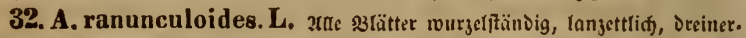

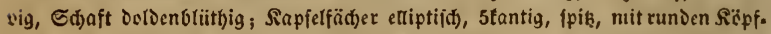

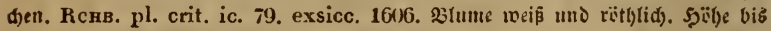
iiber ${ }^{1} \int_{2}{ }^{\prime}$. In fethenien Mä̈jern. Juni - 3uguft. 4. Selfr jelten. PS. Barby. Scholler.

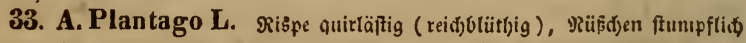

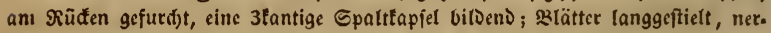
vig, berzfërmig, ciruno oder lanjettlid. SchK. t. 102. Var. lanceolatum,

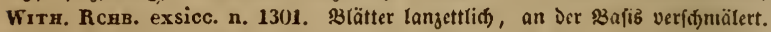
Blumen reiflio, meiff rofa überlaufen. In und an ftetenden und langfam pic.

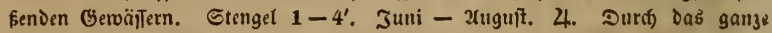

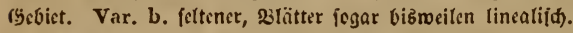

11. Butomus L. $\mathfrak{B}$ a fferviofe. B B

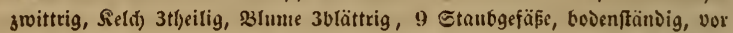
ietent Blumenblatte Deren 3, Spalttapicl Gfäd)rig, Fädjer an Der Sprlse of. fen, vielfantig, gearbe beibent 2fpaltig, Eamen gerippt, Drippen feingelerbt. 5d)aft Dorbentrageno, Blätter reitend. N. v. E. gen. VI. 20.

34. B. umbellatus L. Sснк. t. 111. Sт. 40. Blätter rinnlg, orcifcitig,

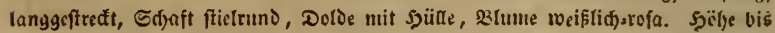
über $4^{\prime}$. In Eiiupfen, Gräben, an ₹eidgen. Juni. Juti. 4. Durd) Dab Ge.

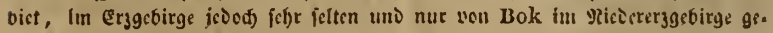
punden.

\section{Familie Hydrocharideae, গtiçenfrăuter.} - Şerbarientura) 5. XXXIV uno 34. -

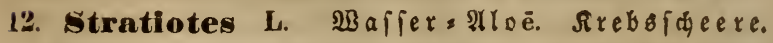

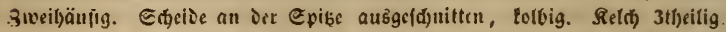

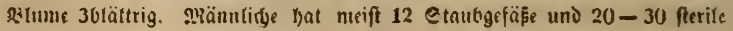


Hydrucharideae. - - - Stratiotes.

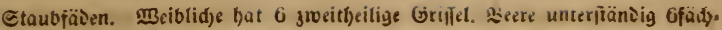
rig, vieljamig. N. v. E. gen. VI. 16.

35. S. Aloides L. \$lütter fábiverotfërnig, 3tantig, ftadlig gezäłnt. Fl. dan. 337. Scrux. 335. а. b. Silunı weif̈. Şabitued oer arlë̈ äl)nlid. In

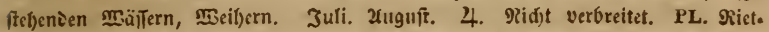

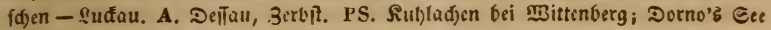

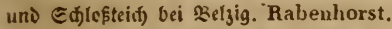

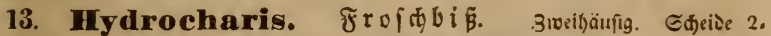

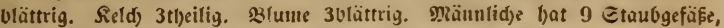

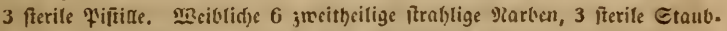

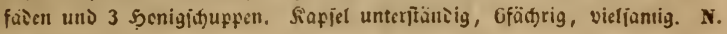
v. E. gen. VI. 15.

36. H. Morsus ranae L. slätter gętielt, treiఠrun`, nierenförnig, büutig,

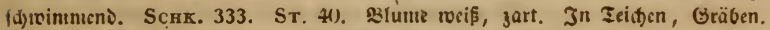
Juli. 2ugult." 4 . Durd) ias (Gebict.

14. Nuphar Sibth. Sr. Nixblume. Slütfen gritterlid. Rild 5-6theilig, frei. Slunte cinreihig viclblüttrig, fowic Die vielen @taub.

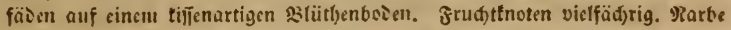

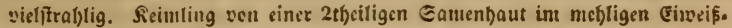
fïrper unigeben. Slunie getb.

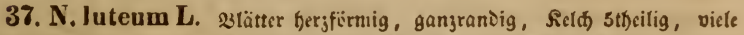
Blumenblätter, Die bersorragenden Spiscen oer Staubfäden quer

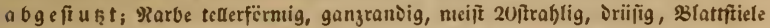

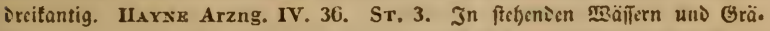
ben. Juni. Juli. 4. Saji Durd) Das ganze (bebiet; in Ibiitingen feltner, in Erjgebirge fel)len১. Jit lie und Da freilid) gleid) No. 38. nut angepîangt. D. Ge*

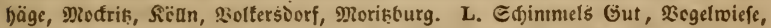

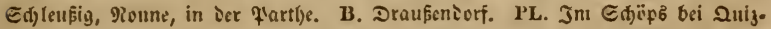

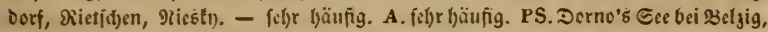
Şađe, Erfurt. HS. (Eijena(b) bei ßerta, Eij̄nberg. Orp. Radix Nympheae luteae. ânm. N. tenellum Rснв. S3tumenblätter meift 10, vertebrt, eifërmig, faî

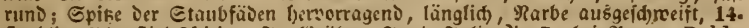

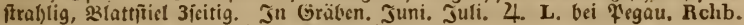
- Pluß exft ned) weiter beobad)tet rerien.

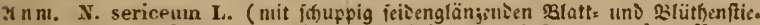
Ien uni 16-20jtrabfiger, gezäbnter Yarke) foll nat) Scratz Fl. Halberst.

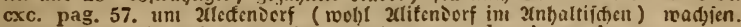
Exemplare von da falsen wir nid)t. 2igl. Rснв, pl. crit. II. ic. 233.

15. Nẏmphaea P. Seeblume 26 . Simittrid. Field 4-5.

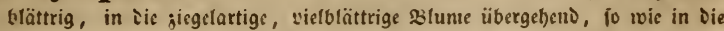
3ablreidjen Gtaubäben auf Dent killenförmigen Blumenboden. SBecre dent

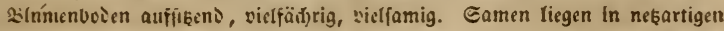

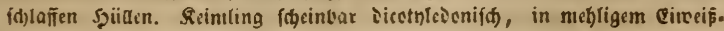
törper.

38. N. alba L, se(atter herjfërnig, ganjrantig, fielt) $\$$ blättrig, Rarten lappig, gelb, imen Etrabien 16-20, auffeigeni. Haysis Arzng. IV. 35. El, 


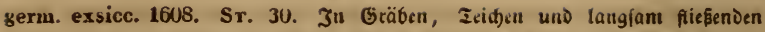
glüpd)en. Juni. Juli. 4. Stellentweife Durd' Das Gebiet, niđt felten. Die

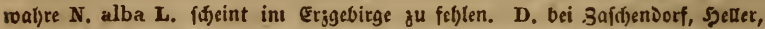

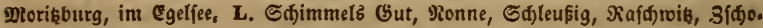

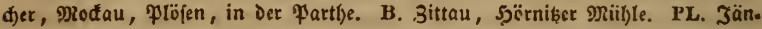

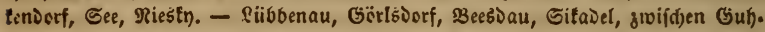

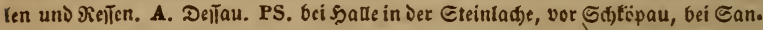

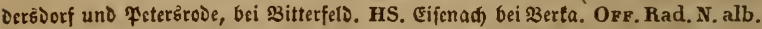
X $n$ m. Ferner gu beobadten find: $N$. interme di a Wrik. mit 8-12ftrabliger, gelber ober aud rothgeitreifter Rarbe. Z. Simbad) bci (j)eunits, Deseran.

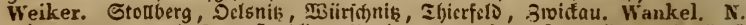

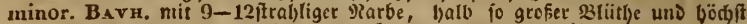
fólantem Mudfie. D. Dzoriţburg. Dehne. - PL. - Weiker.

\section{Familie framineae, Grärer. - Şcrbarienbud S. XXXIV und 35. -}

\section{Gruppe Agrostideae, SBinbfalmgräjer.}

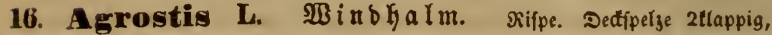

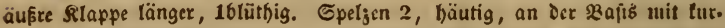
zeni Şaarbuiftsel, Granne fein oicr feblend, Evififel tury, grarben federartig.

Rcrв. Agrostogr, t. XXXII-XXXVI. N. v. E. gen. II. 3.

a. A pera Ad. P.Brauv. Untre Epelge tleiter, ein S3lütl)enftield)ent

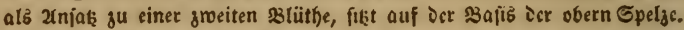
R снв. Agrostogr. t. XXXI.

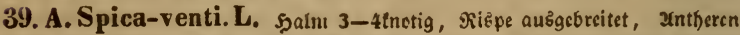

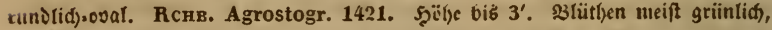
ielten bräunlid) angelaufen. Swij̄ken Der Eaat auf troćnen Geloern und auds

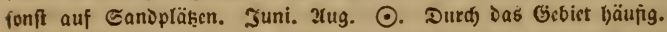

b. Trichodium Mcrx. Dbere Epelje ganj tlein, meiti feblen১. RcHB. Agrostogr. 1422-1425.

40. A. canina L. Siispe (Duntelviolet) eiförnig, fđlaĩ, Xefte fparrig,

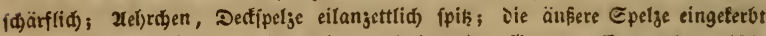

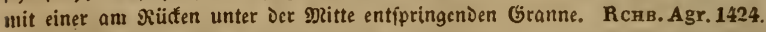
exs. 513. \$urzelblätter juíanmengerout, borftenartig. Etengelolätter faç). Şäb)

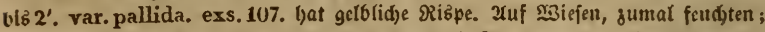
an Ieidjen, auđ) an trodnen Stellen. Juni. Juli. 4. Durđ) Daక Gebiet gemein. $\mathfrak{X}_{\mathrm{n}} \mathrm{m}$. A. rupestris Axx. (mit glatten, abftel)enocn $\mathfrak{U}_{\mathrm{c} f \mathrm{fen}}$ ) wiro yon Schwabe

fl. Anlialtina pag. 33 bei Sarzgerode, ßiamberg angegeben. S3on Dafjer

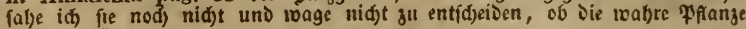
cort rähifit.

C. Agrostis P. B. Beice Dedifpeljen entroidelt. RCrB, Agrostogr. 1426-1437.

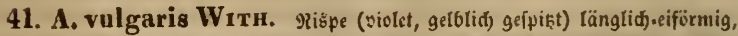

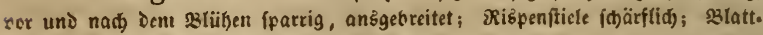

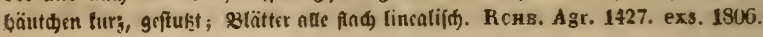


Sö̈be 1'. A. pumila L. ift ois ourdf Etaubpilge vertünumerte Pranje. A. sylvatica Poxxrck. Die aus Den 2 lüthen anefeinende. An feudjten und trod.

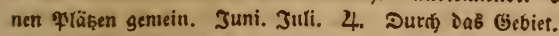

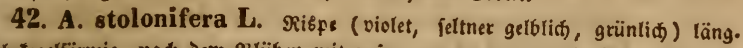

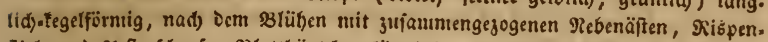

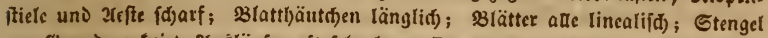
am Grunde gefniet, 2fušläufer oft fêr) lang. Rchв. Agr. 1431). exs. 1Su7. Şöhe 1 bis 4', Dann A. gigantea Roтr. Rснв. Agr. 1433. exs. 4()t. 2uf Miejen, Graspläken, fetorainen. Juni. Juli. 4. Durd) ১as Gebiet bäufig.

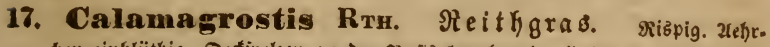
den einblütbig; Decfipelzen an der 3 afib langbaarig; äufete Deffipelje grë. fer; Epelzen tleiner, bäutig. Sdjuppen lanjettlid). Rarbe feictartig. Rсвв. Agrostogr. t. XXXVII-XLIII. N. v. E. gen. XI. 6.

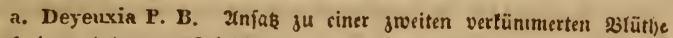
auf cincu beljaarten Etislthen.

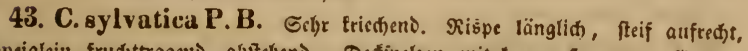

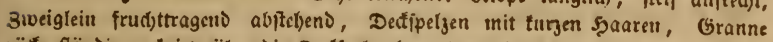

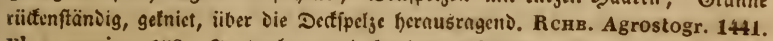
Fl. g. exsicc. 109. In trodfnin unto feudjten MB̈̈lDern. Juni - 2fuguft. 4. Durd) Daz ganje Gebict.

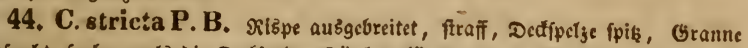

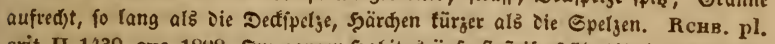

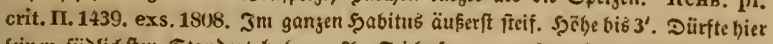
feinen füolidffen Etandort baben. 2In Ieidjufern, an fumprigen Drten. Juni. Juli. 4. Eelye folten. PL. Sei Jetfd nad) froflen gu an Dem tleinen Ieido In Gräben, bci Guben. Rabenhorst. A. Rabcgaft, Serbft. Schwabe. PS. 3ranist)eioc bei 3 etjig. Rabenhorst.

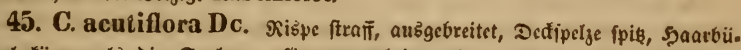
f(j)el türzer als Die Epeljen, Granne getnict, faum länget als Die Epelgen.

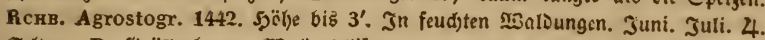
Selten. D. Griidenburger malo. Hiibner. PS. Soderbleben. Wallr. Mant. 2.

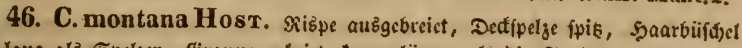
fo laug als Єpcljen, Granne getniet, taum lü̈tger als Die હpeljen. Rchв. pl. crit. I. 1443. exs. 110. In Bergrö̈loern. Juli. 2luguft. 4. A. Şarjgerods,

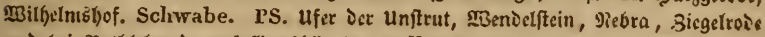

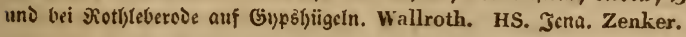

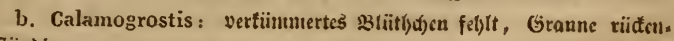
ftänioig.

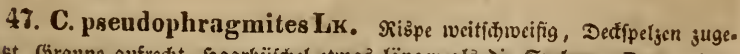

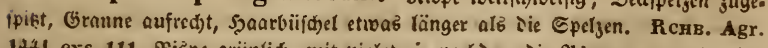
1441. exs. 111. Rispe grïnliff, nit violet, je nadjdent Die Yriange an melyr oder

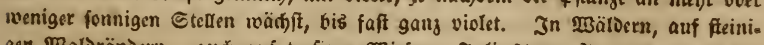

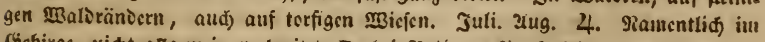

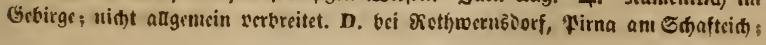




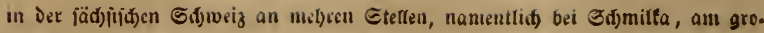

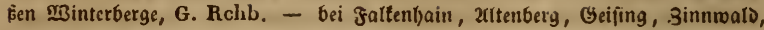

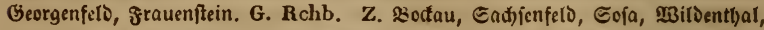

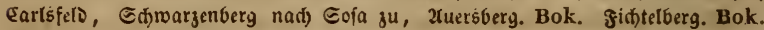

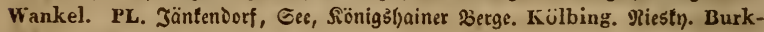
hardt. - A. Şarj l)äuñg.

c. Epigeios : vertüinmtetses \$3lütb)(ben fel)lt, Granne enDftändig.

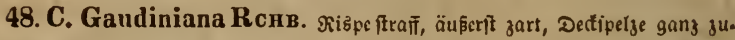

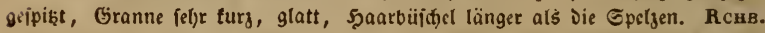
Agr. 1447. exs. 112. Unterf(j)idet fiit) von Der folgenden ourd) grïfite Bartlyeir und

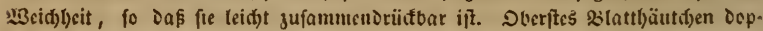

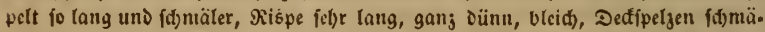
ler, länger, Granne tiirjer un১ glatt. Durd)aus nid)t Durd) fíbattigen Standort

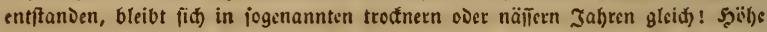

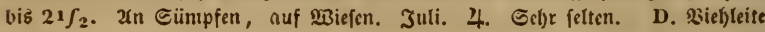
uci ¥irna. Bucher, Hiibner.

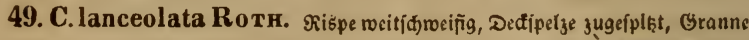

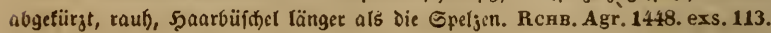
Şöble bis 4'. 2uf Eumpfwiefen, an Ieiđufern, Gräben, 3äđon. Juni, Juli. 4. Stellenweife. D. Morikburg. Hübner, Rchb. Dorf Mefjlen. Bucher.

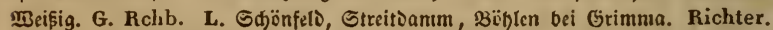

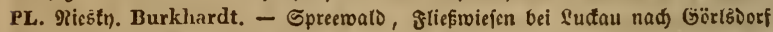

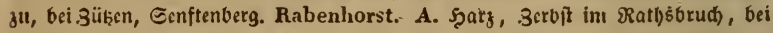

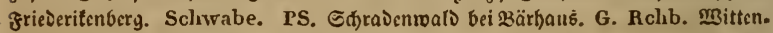

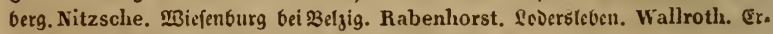
furt im zeufe'bł

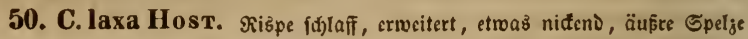
gezäl)nett, übcr Den 3äl)nen begrannt, ettwas türger als fcine Granne. RchB. Agrostogr. 1450). Rispe fchr fzart Duntclviolet. Säbse bis $4^{\prime}$. 2(n fandigen अlupufern. Juni. Juli. 4. Eebr felten. L. ufer Der Muldo bei gerøa. W. Gerhard.

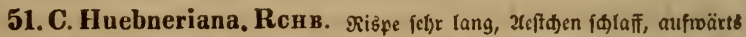

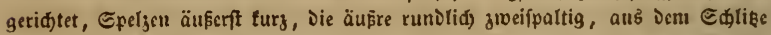
gegrannt, länger afs Dic Granne. Die innere etroas flciner, als Der Fruttttnoten, ftarter Şaarbiijdyel länger als Dic Deđ̄ipclje. RсHв. Agr. 1451. exs. 114. Şöbe

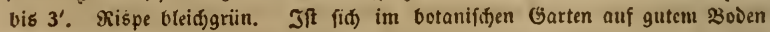
gleidgeblieben. In Radelwaldungen. Juli. 2fug. 4. Sefje fetten. D. Im

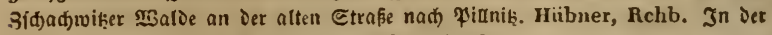
Dreşner Spei১e bei Der Friesnik. G. Reichenbach.

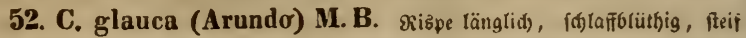

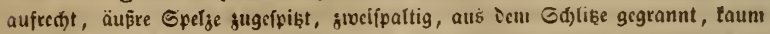
ränger als die Granne; 5̧aarbiifd)l arm, türjer als Die Epelge. Rcrв. Agr. 1357. exs. 115. Gang graugrïn, edjeiden neipł turg bel)aart, 2Kišpe blciçgrïn, fel.

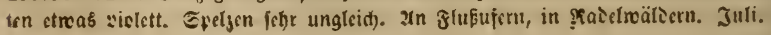


burg, Candersleben. PS. Barbn, Şalle, Diirtenberg, Reufibbitg, Raumburg

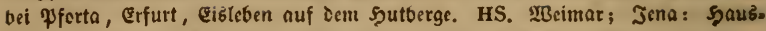

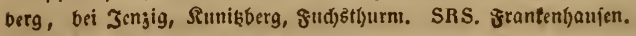

57. St. pennata L. Granne getniet, feorig, an Der $\mathfrak{B}$ afis tabl. Rсrв.

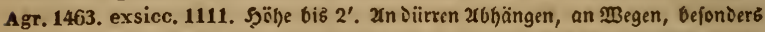

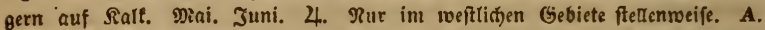
3erbit, DeiTau, Friederifenberg. PS. Brandsheide bei Beljig, MBittenberg am

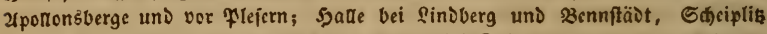

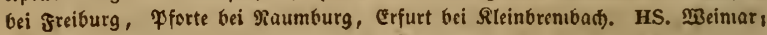
Jena am Şaußberge, bei Jengig, an funił̧berge. R. Gera. SRS: Franten. bauien.

\section{Corynephorus Beauv. Reulengras. Eispe.} zet)roben zroeiblitthlg, mit haarigem 2(njaks. Deffipcl;en paarig, faft gleió). Epelzen paarig, jede äufre an Der Baftz gegrannt, Granne teulenförmig,

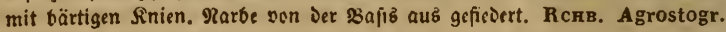
t. XCIV.

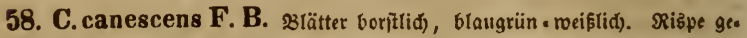
brängt, meift roeiflid, Bentel violet. Rснв. Agr. 1674. exs. 131. Ş九̈he biß 1'. Iuf Dürtem Saniboden. Juni-2uguft. 4. Dur(f) Das Gebiet, im Erzge. birge jeذod) nur fefre felten: Z. Seifigmald bei Ebemniţ. Bok.

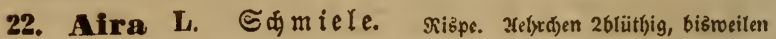

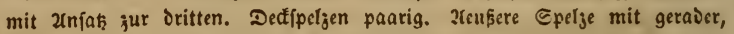
Doer nur am Grunde gebrebter Granne, innre frei, andre $23 a f i z$ nit Shaar. bïff́eln. Sdjuppen lanjettlid). Rarbe won Der Sajis aus feirig. Rснв. Agrostogr. t. XCIV - XCVI.

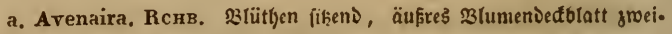
ipaltig. Rснв. Agrostogr. t. XCrV.

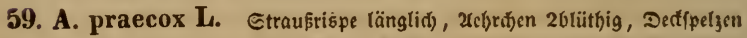
länger alz Die 3 lüthen; untere Spelze 2fpib̧ig mit einer unter Der Mitte ent.

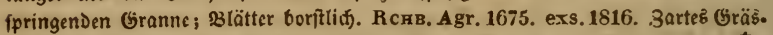

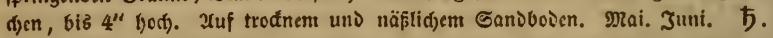
Sdjeint im reftlidften Gebiete gu fehlen, nur in Der PRieDertaufis und in 2rnbalt

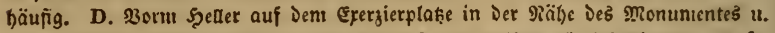

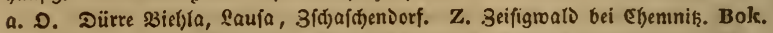

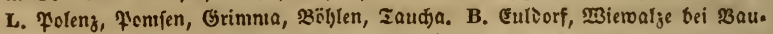
ken. PL. 2(ensoorf, Riestn - Gaiten, \&uffaù u. f. wo. A. bäufig. PS. Bitten. berg, Diiben, Belyig, Salle bei Siestau, S3ennftäbt, Galjfurtly, Benndorf. HS. Benva, Gotba.

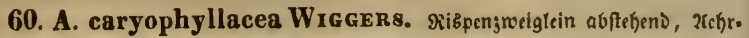

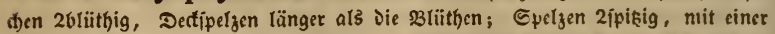
unter Der Mritte entipringenden Granne, slätter borftlió. RcHB. Agr. 1678.

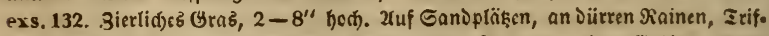

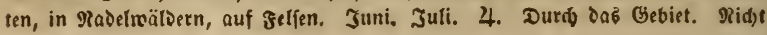


Gramineae. $\quad-13$ - Airr.

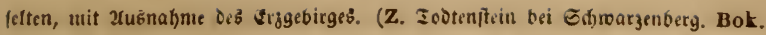
Etollberg. Wankel.)

b. Avenaria Rснв. B(iit)dyen turjgeltielt, Granne getnict. Rснв, Agrostogr. t. XCV.

61. A. flexuosa L. Riępengroeiglein abjêtben১, jart, zum इbeil geị)längelt, vor Dem 23 lül)en jufammengejogen, oben übergeneigt; Jefbrd)en 2blütbig, Deffipelgen fo lang alb Die sliitben, Epeljen 4jälsnig, nit einer nabe an Der 23 afız enjpringenden Granne; Blätter borfttid). Rснв. Agrostogr. 1678. 79.

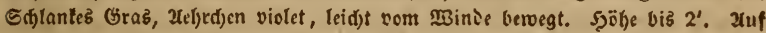

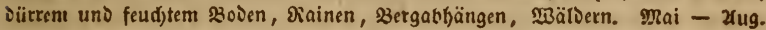
4. Durd Das (bebiet.

c. Deschampsia P. B. 2Rlïtl)(ben turgeftielt, Sranne gerade. Rcra. Agrostogr. t. XCVI.

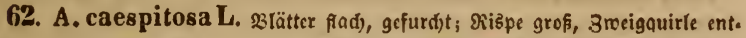

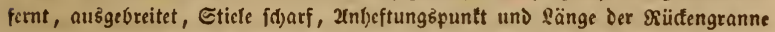

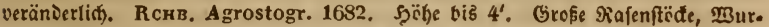

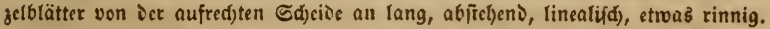
Ded́fpelzen violet. Var. ocliroleuca RichteR: Dectipelge gelblid). var. parviflora Thuill. Rснв, Agrostogr. 1686. flcinbliitlig, gelblid). inontana Rcrв. Agrostogr. 1683. nit zujanmengezogener $\Re$ izpe. A. alpina vivipara Rснв. Agrostogr. 1684. nit auśteimenden 23tïtben: Rсвв. Agrostogr. 1685. 2(uf

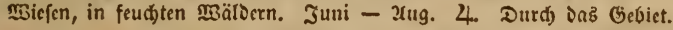

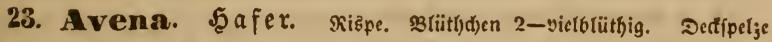
paarig. Epelzen paarig, äufere greiipaltig, nuf Dett Rïfen begrannt, Granne georebt, getniet. Rarbe vor Der Bajis. Ed)aalfamen flaunfeberig. R CHB. Agrostogr. t. XCVII-CIII.

a. Ventenata. Einiälyrig, untre slüţ̧e nur nit Enjgranne Rснв. Agrostogr, t. XCVII.

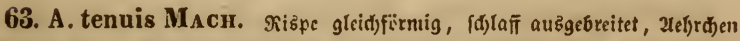
meift 3blüthis, Slütlyden über sie Dectipelge bervorrageno, Das untere an Der Spiķe unbegrannt, Das andere an Der Epiţe mit żwei lurzen graden Grannen

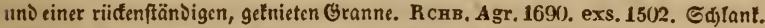

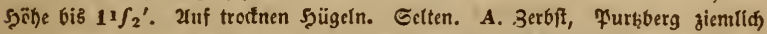
felten. Schwabe, Zenker. PS. Sei Eišleben in Ratljarinenbolye am trodnen, faft tablen 2rbljange not) Mimmelburg ju, mo Sircišfeld licgt, bier und Da. Bok. Sprengel. Bei Siegenrüía. Adler. HS. Jena.

b. Trisetum. Ueufre Epelze bei atten 2 lüthen 2grannig. RcrB. Agrostogr. t. XCVII - CII.

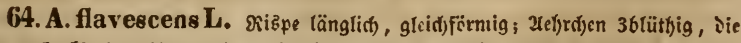
cbere Dedifpelje eilangettlid) mit einer ïber oer Mitte entfpringenden getnieten Granne; Epindet bnarig; Blätter făđ. Rснв. Agrostogr. 1694. Şöl) bis 2'. Uchroben gelblió). Var. lutescens Rснв. Agrostogr. 1695. (ćl)mgelb. Var. variegata Gaud. Rснв. Agrostogr. 1696. braun uno gelb. 2uf trodts

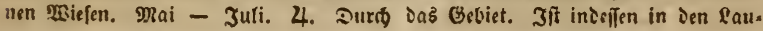




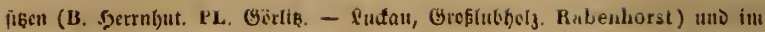
Erzgebirge (Ed)wargenberg, 2muaberg, Geier. Bok.) filten.

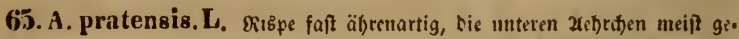

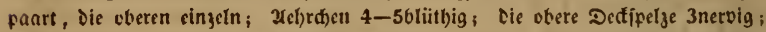
Epindel baarig, 2Blätter linealifक; G(t)ciden ftielrumb oier (đ)twad) jufammen.

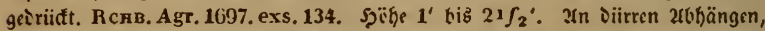

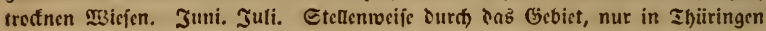
etwas verbreitet. D. Saj́dfenjorf. Z. Swidtau, Jobanngeorgenftait. L. Dïjen,

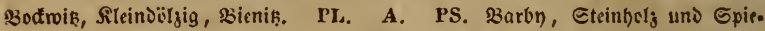
gelberge bei Spalberftadt, Şalle bei Gutenberg und Diofentjolj, Eiø̈leben, Raum. ourg, Erfurt, Siegenrüct auf Den Eaalbergen und in Den Bufd)bölgern. HS. Jena, Roburg. R. Sobenftein.

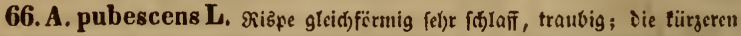
3weiglein mit einemt, Die längeren mit 2 2(ef)rdben; Die untern ฉuirle bis ju 5 ; Zebroben 2-3blüthig, Die ohere Deftipelye 3tervig; Epindel turghaarig; 33lätter

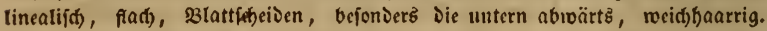

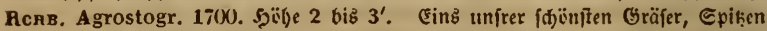
grïnlid), ein flect Derfelben und Die Granne violet. Var. glabrescens: (al)l.

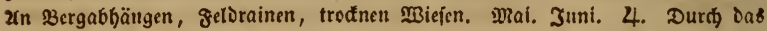
Gebiet.

c. A vena. Einjälrig. Uehroben hängend. RcrB. Agrostogr. t. CIII.

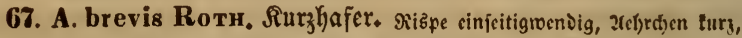

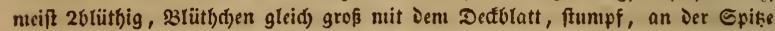
2gälnnig, Granne rüđđenftän๖ig, getniet. Rснв. Agrostogr. 17()8. Mғтzgвя, europ. Cereal. t. XVI. Şäh) bis 21 $\int_{2}^{\prime}$. Unter Dem Getreide. Juli. 2(nguft. ○. Sclten. A. Defiau, Dranienbanu, 3erbft. Schwabe. PS. Bicgentiid. Adler.

68. A. strigosa Schreb. Winbhafer, Canbhafer. æriape jicnlidy einfeitroendig; 2elerif)en neift 2blütbig; Die Dectipeljen fo lang als Die szlütben, Dic sbern 7-9 nervig; Die 3 lütl)en fol)l; Die Epeljen lanjettlid) mit getnieter Granne an $\Re$ iiden, oben in 2 begrannte Epiken geipalten; Epindel fall, an

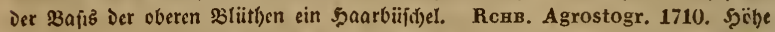
$3^{\prime}\left(2^{\prime}-4^{\prime}\right)$. Unfer Dçm Getreide, inşbefondere bäufig unter Dent Şafer, ininter

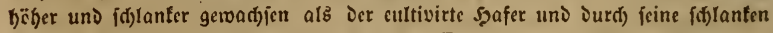
Zef)rdfen von fern ju erf́ennen. Juli. 2tug. ○. Dutch Daş Gebiet bäufig.

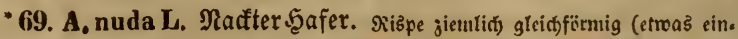

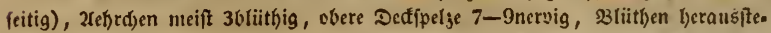
leno, tal)l, Diffnervig, jweijpişig, obere grannenlob, Epindel fall. MetzgBr, europ. Cereal. t. XVI. Untere Spelge trautartig bäutig, Die ftarten Rerven bis jur Epike vorlaufens. Sic uns ba cultivirt. Juli. 2ug. $\odot$.

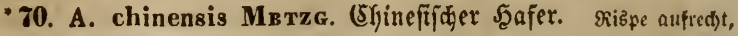

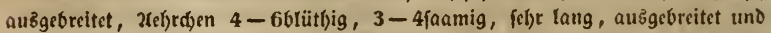
bängend, ser Saame tei Der Reife aus Den Spelgen beraubfallen১. Miktzo. 


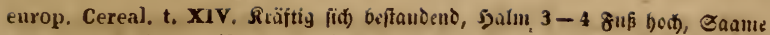

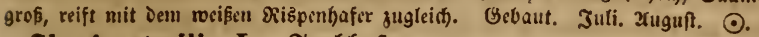

71. A. sterilis L. Taubfafer. Rcnв. Agrostogr. 1711. Heber.

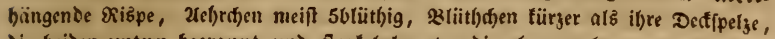
Die beiden untern begrannt uno ftart bel)aart, cie obern unbegrannt und tabl.

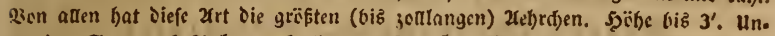

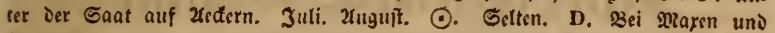
sungrik.

72. A. fatua L. Flughafer, $\mathfrak{W}$ ilbfafer. Rснв, Agrost. 1710. Mktzger europ. Cereal. t. XV. Rispe glcidförmig, offen, aet)rofen meift 36tuitbig; die obere Deftipelge 9nervig; Die Speljen unterieitz borifent)narig

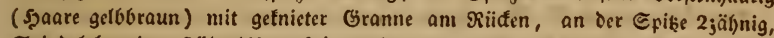

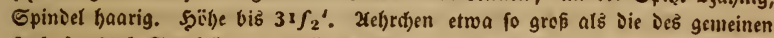

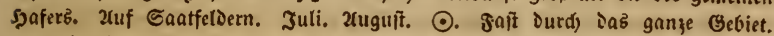
D. Szriešnik, Eotta, Rieberau, Reuborf. Z. L. Dëlzig, Dülfau, Zhouberg. B. sauķen. PL. Triebel, शeuzelle, Guben, Sieberofe, \&ïbbenau, fưfau. A. PS. Eišlcben, Şalle, Rebbad), ZenDik, Diirrenberg. HS. Jena, MBcimar, Sioburg.

73. A. hybrida Peterm. Baftarbhafer. Die bcioen untern \$lii.

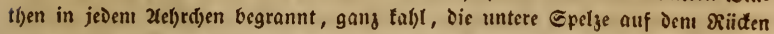
nidst braun gefärbt, Epindel in Den 2el)t(d)en zroeizeilig, weifjottig. Swifd)en

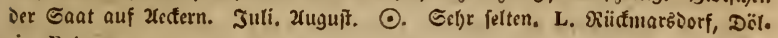
jig. Peterinann.

* 74. A. sativa L. Rispenhafer. Merzerr eưop. Cerealien t.

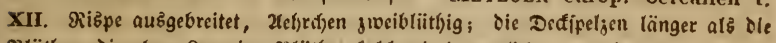

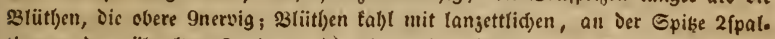
tigen uno gejäl)nelten Epelzen, Die obern olyne Granne, Die Epindel falbl, an

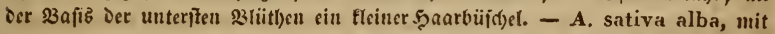
weiffen Saamen. - A. sat, nigra A. fusca ARD, wit fdowärglidıen Gaamen.

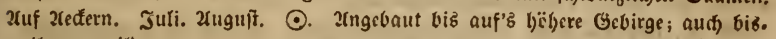
weilen verwilbert.

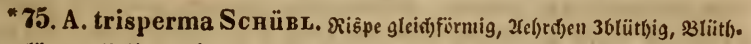

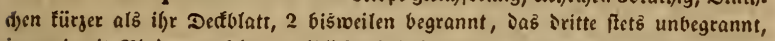
ie greei mit ßinien verfelyne, gelblidje Edjalfaamen. 2uf 2lifern gebaut. Juli. ○. L. Sei siünuarsborf gebaut. Petermann.

76. A. orientalis Schrer. Fafnenfafer. Matzgra europ.

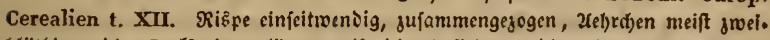
blütbig; die Deđ̛fipelyen länger als Die 3lütlyen, Die obere 9nervig; Die

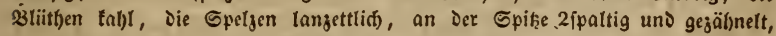
Die obere ofjne Granne; Die Epindel fabl, an Dem Grunie Der unterften \$lüthe

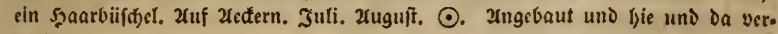
wilbert.

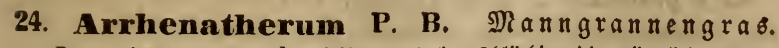

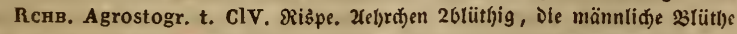

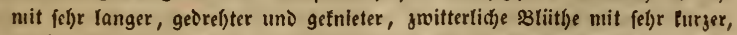

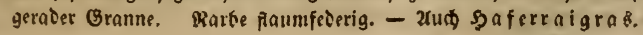




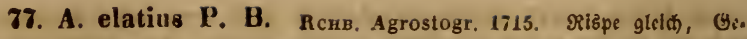

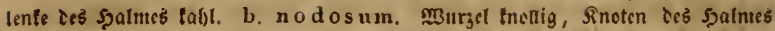

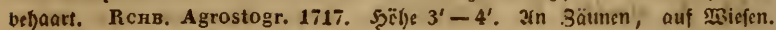

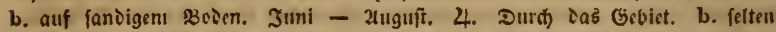

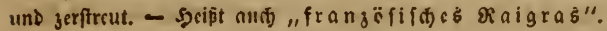

\section{(5) rappe Panicaceae, Şirfegräfer.}

25? Miborn Anxs. 3 ivergg ra 8. Rснв. Agrostogr. t. XXvı.

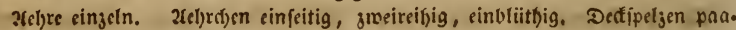

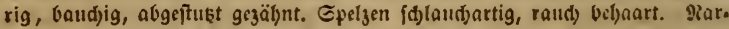
ben lang, zart, befajert.

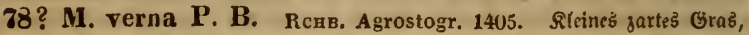
ıuit purpurfarbigen, in ier Mitte griingeftreiften Deffipelgen; Gritīel lang, füD. liक. Şäh) 1'-3'. 26uf Caniboden. Geflyr feltin. A. 23el Dranienbaum feftr fparfam nad) Schwabe. Epemplare Daber fal) idt) nidft.

26. Alopecurus L. $F$ แ

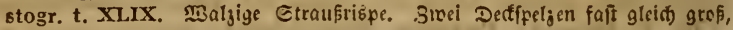

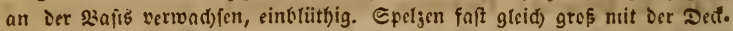

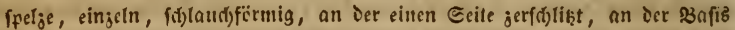
vegrannt. Grififel lang, alls Der פitte in jart fecrige giarben verlängert.

79. A. agrestis L. Rснв. Agrostogr. 1473. exsicc, 13()5. Salnte

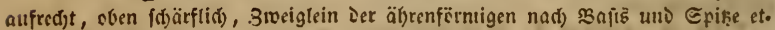

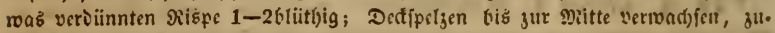

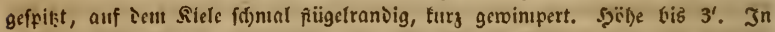

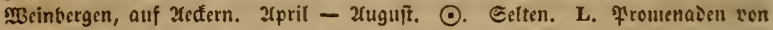
seipjig? angeblid). A. 3erbft, 33ernburg, Candersteben. PS. Freiburg,

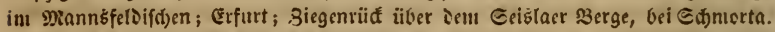
Adler. HS. Jena: Sidjtenbain, Galgenierg.

80. A. fulvus Su. Rchr. Agrostogr. 1476. Salme unten niedertiegend,

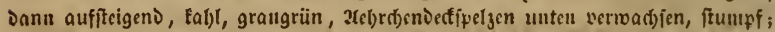

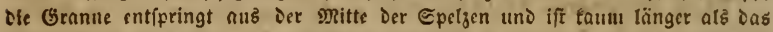

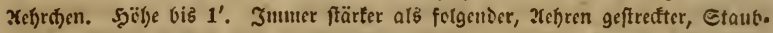
beutel erangegelo, länglióf. Stuf iiberfoiwemmiten, fumpfigen Stellen, auf feuds. tem Eande, an Gräben. Jutt. Juguft. 24. Durdi Dns Eebiet ljäufig, Das Erggebirge ausgenoumıen, wo er gu fel)len fojeint (Weiker. Wankel.).

81. A.geniculatus L. Rснв. Agrostogr. 1477. Sgalme unten niederlie. geno, talst; Dectifipelyen unten verioad)fen, ffumipf; Die Sranne entfpringt unter

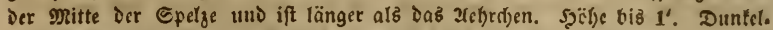

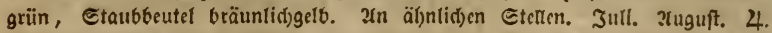
Durch Das Gibist nintit felten.

82. A. pratensis L. Rснв. Agrostogr. 1479. Burzel fafrig, Salnt auf.

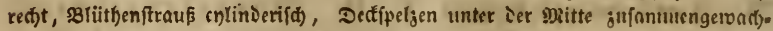

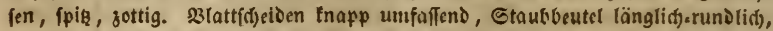

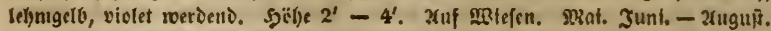

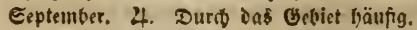


83. A. nigricans HoRx. Rснв. Agrostogr. 1478. MBurzel trictjent,

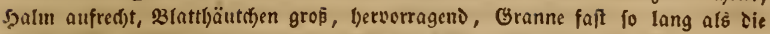
Epel3e. Slattf(j)iden baudsig; Sieutel langgeftreft, im Seben orangefarbig, bleid

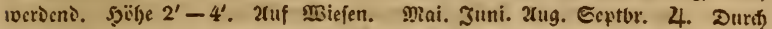

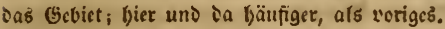

27. Phleum L. Liefiggras. Rchв. Agrostogr. t. L. und LI.

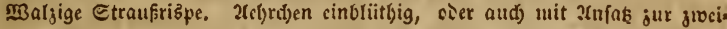

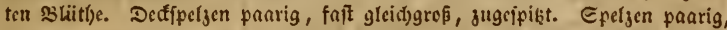
l)äutig, eingefentt, innen faft zrocifach) geticlt. Grifiel in groci Mearben ver. längert, Diefe won unten an zartfeocrig.

a. Chilochlo a P, B. Rснв. Agrostogr. t. LI. Ye(j)den mit Jufak gur gmeiten 3 zïtthe.

84. P. asperum ViLL, Rchв. Agr. 1487. exs. 703. Deff́peljen tielförmig

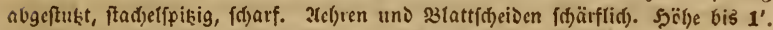

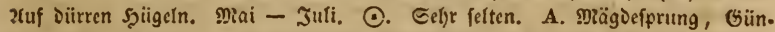
therbtterg. Schwabe. PS. Freilutrg, fcicrsicben. Sprengel, Wallroth. HS. Sisburg am Goldberg und Seftungsberg. Hormung, Eckart.

85. P. Boehmeri Wrbx. Rghb, Agr. 1488, exs. 120. Deffipelzen lan.

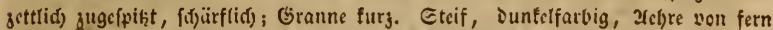

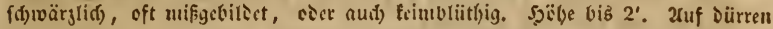

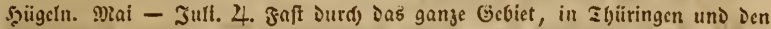

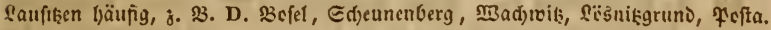
Z. Egenınik, Dederan. B. PL. A. Bernburg, Grïbjig, Serbft. P'S. \$Bitten.

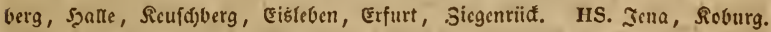
SRS. Jrmitaot, frantenijaufen.

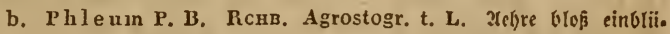
thig, elgne 2tnjaķ.

86. P. pratense L. Tfimatheugigras. Rснв. Agrostogr. 1483.

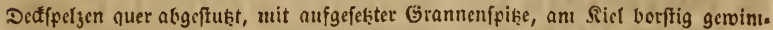

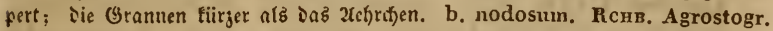

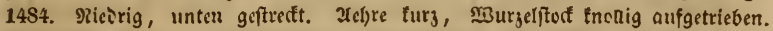
5äl)e $1^{\prime}-3^{\prime}$. var. b. nicoriger. 2luf জBiejen. 3uni. Juti. 4. Durdi das gange Getrict gemein; b. an trof́neren Etellen.

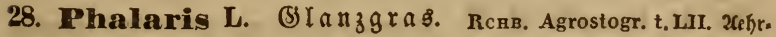

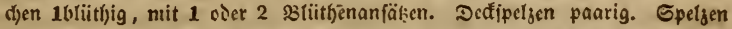
Icierattig, eingefentt, ftumipf, Die untere f(d)ual, einfad) fiefriifig. Ratbe zart, fièrig. Ganmen rindenfdalig.

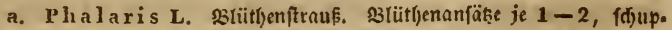
pig. Deffotätter paarig, fü̈glig getielt, bäutig, faft gleid).

*87. Ph. canariensis L. (Eanariengras. Rchв. Agrostogr. 1492.

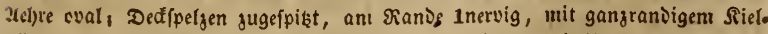
Aliigcl; Die Eperzen ier untern szliityen fein bellaart, balb fo lang als bis

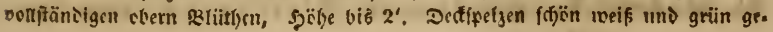




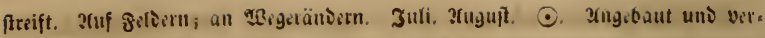
wiliert.

b. Baldingera Fl. Weтt. Snaultbeitige શiöpe. S3lütlgenan. fäßse je 2, bärtig, Decfffeljen paarig, oljne gliigel.

88. Ph. arundinacea. Fl. d. WETt. Rснв. Agrostogr. 1494.

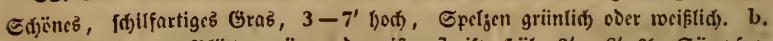

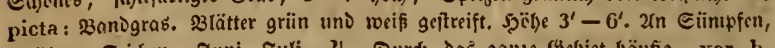
Gräben, Zeiđ̧en. Juni. Juli. 4. Durd) ১ab ganje Gebiet bäufig. var. b. in oen meiften Farţ uno ßaumgärten gebaut.

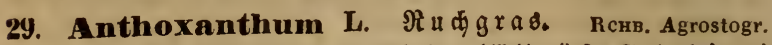

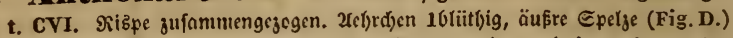
son unten aus mit langer getnidter Granne, innre (Fig. C.) von Der פitte auz mit fiirgerer Granne, cin paar (Pig. B.) an Der $23 a f i s$ verwad). fene, baudjige, aufredjte, nerwenlefe, ftumpfe Edjuppen (lodiculae)! - ober nać) Roв. Brown uno Palrs. Bkauvors ctivaz gejtoungener ertärt, aber natiirlid) yon Den meiften Peucreu angencumen: $\mathfrak{X}(\mathfrak{b}) \mathrm{d}$ )en 3 blütbig. Gele tenblütben C. D. Iecr, einipelgig (?!), Die ntittlete (B.) 2männig. Dect。

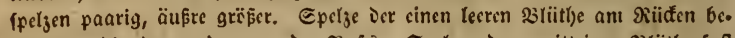
grannt, Die Der anDern an Der $\mathfrak{B} a f i z$. Epcijen ter zroittrigen 3 liitlje faft gleid), unbegrannt. ( (d)uppen alio felslend ! lodiculae c. P. B.) - Griffel und Rarben fel)r lang, federartig.

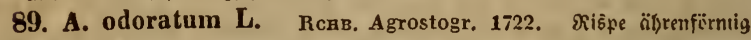

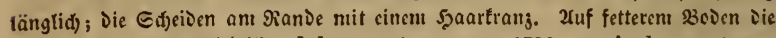

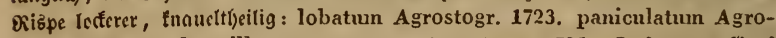
stogr. 1724. - b. villosum ThutLc.: Agrostogr. 1725. Dą gange Grą fein behaart. Dicift gelogriin. - MBurgel und slätter, bejonders getaut, ried)en

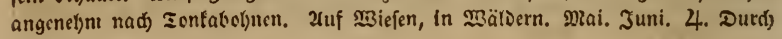
Dab Gebict.

30. Hierochloa Gu. Darrgrabs. Dla riengrab. Rchs.

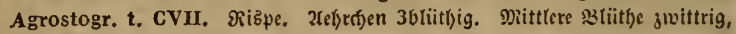

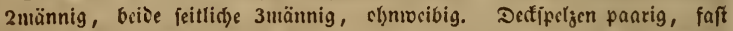

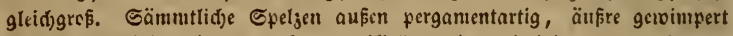
und ftachelipiţig, innre nadt, jweiticlig uno jweifpişig. Narbe fpreng. rovelig.

90. H. borealis R. S. Rcrв. Agr.1728. exs. 1819. Æiispe ein wenig tibergeneigt, 2Rliit)enfticle glatt, 2(ef)r(f)en runblid). 3witterblïtlye unbegrannt,

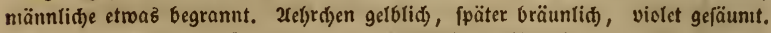

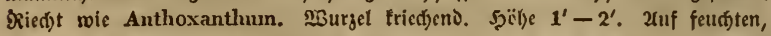

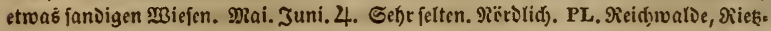
naueniorf nach) 23 arutf) zu. Rabenhorst. A. 3ei Deifau fararfam, in Den Caar.

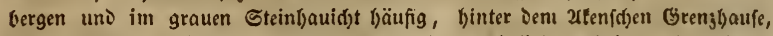

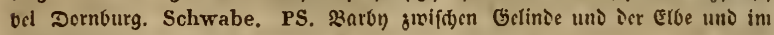
Ireugentuidi)e. Scholler.

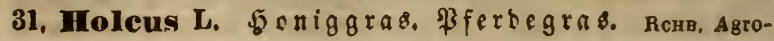


stogr. t. CV. Riępe. 2aifrofjen 2blütbig; unters slütlye guvittrig, unbe. grannt, oberc nuännliff, begrannt. Rarben sottig beljaart.

91. H. mollis L. Rенв. Agrostogr. 1721. Granne gellnix, über

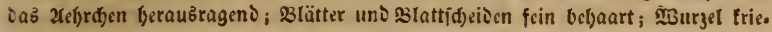

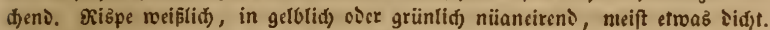

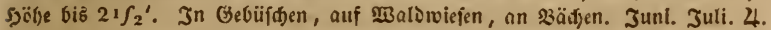
Durd) ঠas Gebiet, aber weit feltuer als folgenier. Fl. germ. exsicc. 1310.

92. H. lanatus L. Rснв. Agrostogr. 1718, 1719. 1720. fočerrižpig.

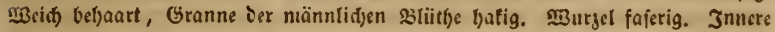
Epeljen grïn. Decfipelyen breiter uns tïrzer, weiflia, meift roja ober lita an.

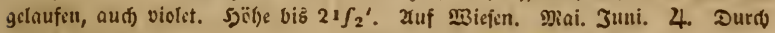
¿as Gebiet bäufig.

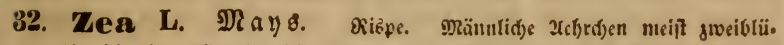
thig, die eine männlidb, bie andre leer. Dedffpelyen paarig, faft gleid). Epelge

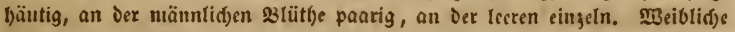

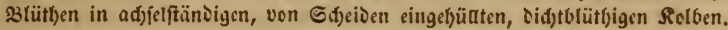

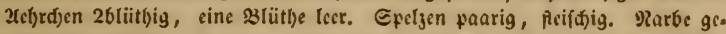
tvinıert. Grififl fel)r lang, bängeno. Edjalfaame faft luglid, ant pieifisi. gen fiolben.

93. Z, Mays L. Schк. t. 283. 3lätter ganzrandig, fifjarfransig, Dectipeljen Der nü̈nliden Blïtlyen fangettliđ):ipit, geroimpert. Gaanten iotter.

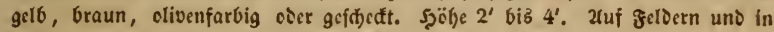

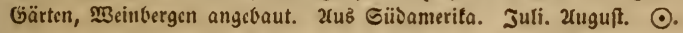

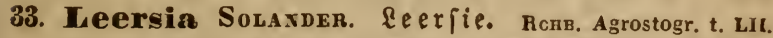
Rispe auछggebreitet. 2febrd)en cinbliitbig, auf einen Sinëtdjen obne Ded. fpelyen angclseftet. Epclyen paarig, geficlt, oljne Granuc, Die äufre traut.

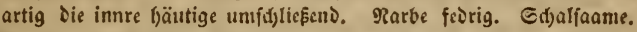

94. L. oryzoides $\mathbf{S w}$. Rcrв. Agrostogr. 1495. exs. 7u8. Qiišpc abfte.

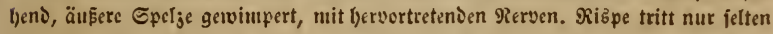

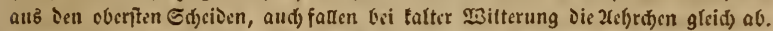

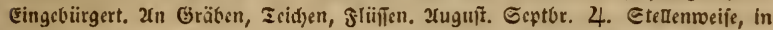

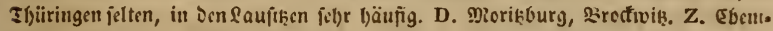

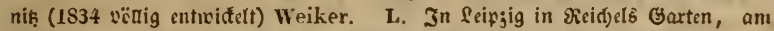

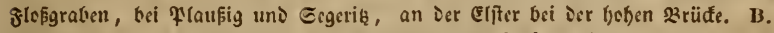

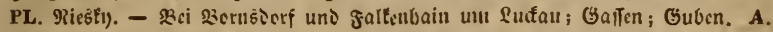

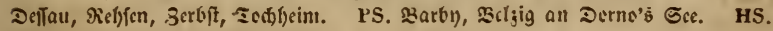
Miöndrëcen bci foburgifd) Pruftait.

34. Milium L. Flattergra B. Nilisgra 8. Rchв. Agro= stogr. t. XIV. Elizpe. Je(l)rd)en cinblütlig. De(tipeljen faarly, baudyig, iie untern etwas länger. Epeljen paurig, reierartig. Rarbe fprengresclig. edjarjaame.

95. M. effusum L. Rchв. Agr. 1450. Datfipelye fpik; Salm Eabr:

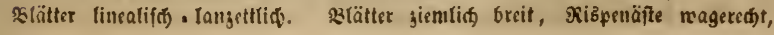




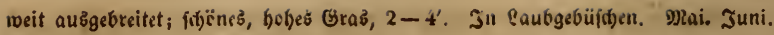
4. Dutরீ) Daš Getrict bäunig.

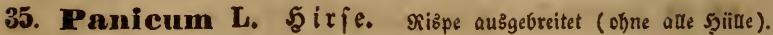

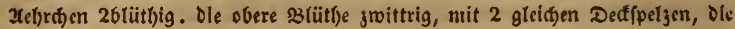
untere niännlid, over leer, mit $1-2$ Epelzen. Rarbe fprengroedelig. S(bal. faaure frit, oder Durd Die Epeljen eingeidjloffen.

-96. P. miliaceum L. Sicmeiner Sirfe. Merzo. europ. Ce-

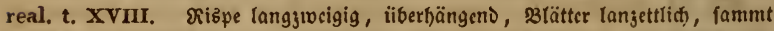

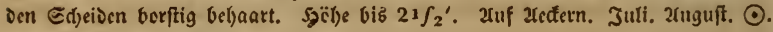
angebaut und verwilisert.

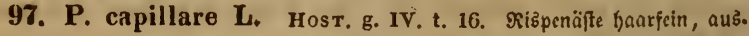
gebreitet, Deffipeljen fpis, glatt, s3lattid)elden lang, fteif beljaart. Şible $1^{\prime}$ bis

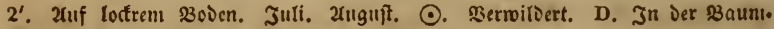
fdilule in gresen Garten. Mieth.

\section{Digitaria Scop. Fingergraß. Rcnв. Agrostogr. t.} XXVII. 2lelgen faft fingerfändig; 2ebrd)en paarig, die eine mit turzem Stlcle, Die anore fişento. Je 2 3titit)en, eine glvittrig, Die andre lcer. Deffipelyen Jer 3roitterblüt)en gleid), pergantentartig. Parbe fprengroedelig.

98. D. filiformis Koes. Rсав. Agr. 14(1)6. exs. 511. 2tefren gu 3-4;

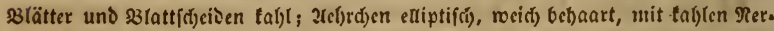

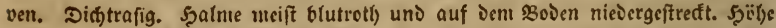

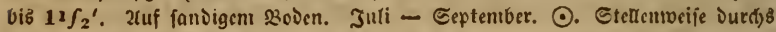
Gebiet; felstt in Erzgebirge. D. Heber Oent Şeller, ant wilden Manne, bel

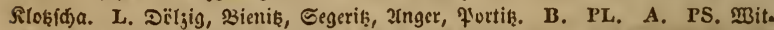

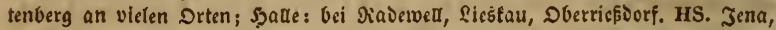
Roburg. SRS. Iilleia.

99. D. sanguinalis Scop. Rchв. Agr. 1407. exs. 512. 2tef)ten зи 4

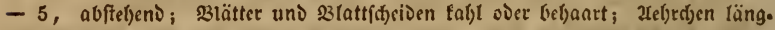
(id)=(anjettlid); unterfte Detfipelge fein belsant, an Den äuferften शerven fabl.

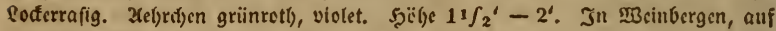

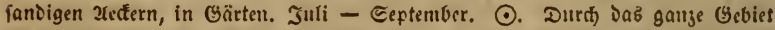
bäufig, fodscint in Erzgctoirge gn fellen.

100. D. ciliaris KoEs. Rchs. Agrostogr. 14(08. 2(ih)ren mijt зи

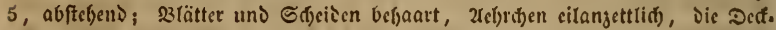

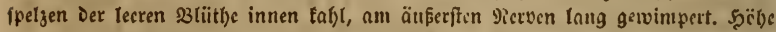

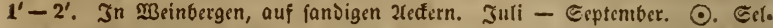

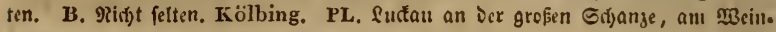
berge bei fuppen. Rabenhorst.

37. Echinochlon P. B. Gtabelfirie. Rснв. Agro-

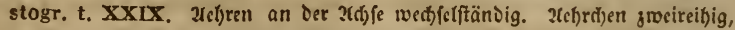

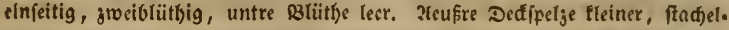
fpişig, inure fo lang als Die Switterbliitl)e, ctıos begrannt. 2leupite Epelge

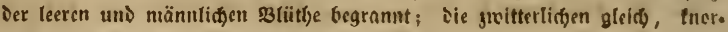
pelig, ftunipf. Rarben fprengresilig. 
101. E. Crus galli. L. Rcris. Agrostogr. 1411. 3ethen thelts wedt.

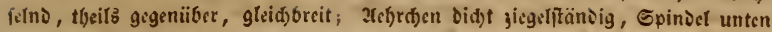
fünftantig. b. aristata Agrostogr. 1412. mit langen Grannen. Sjible $2^{\prime}-4^{\prime}$.

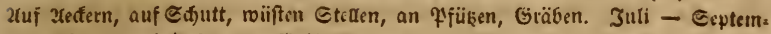
ber. $\odot$. Durd) Das gange Gebiet gemein.

38. Setaria P. B. $\mathfrak{B} \circ$ rîtengra

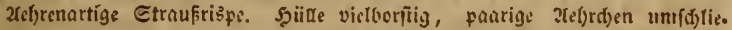

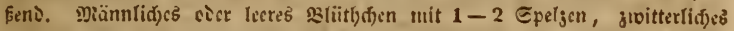
mit 2 gleidgen pergamentartigen Epcljen. Diarbin fprengiveitig. Saame von Dir Epelje unijü̈tt.

102. S. verticillata P. B. Rcns. Agrost. 1+65. 2fefte gedrängt,

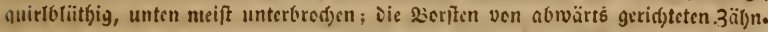

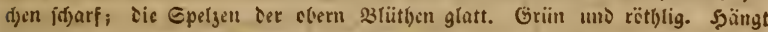

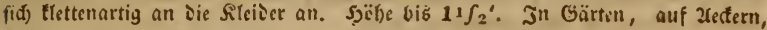

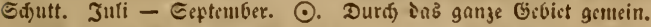

103. S. glauca P. B. Rснв. Agrostogr, 1466. Fl, g. exsicc. 516. Etraufrizpe walgig; Dic Borften aufwärtz fidarf; Epelgen ier obiren slïtl)e

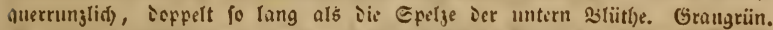

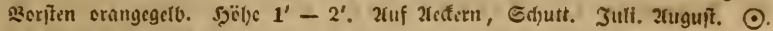

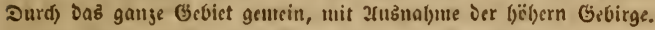

104. S, viridis P. B. Rскв. Agrostogr. 1467. F]. g. exsicc. 517.

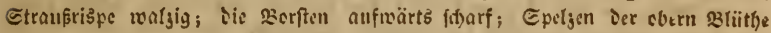

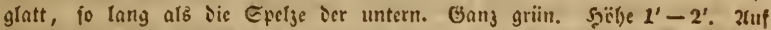

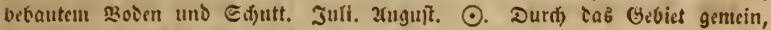

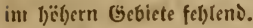

* 105. S. germanica P. B. IIosT. gr. anstr. II. t. 17. TRrs. ic.

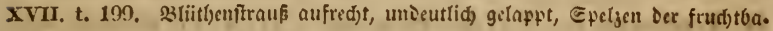

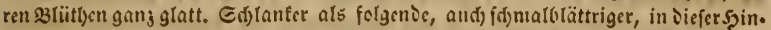

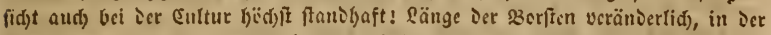

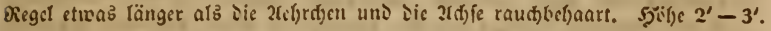

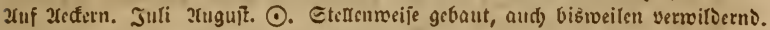

- 106. S. italica P. B. Relbenfirie. Host. gr. austr. IV. t.14. Metzger europ. Cereal. t. XIX. ßlütl)enftrauf hnauclartig jufammengefelit,

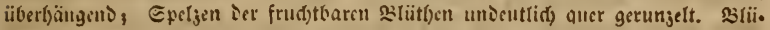

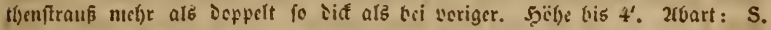
maritima R. S. Diof) or (in Ungarn genannt), Boriten türger alb Zeffrd)en.

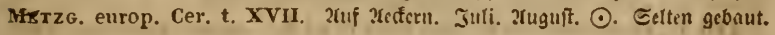

\section{(S) rupte S a c cha rinae. 3urferrofgrartige (5riajer.} 5proarienoud)'

39. Andropogon L. $B \mathfrak{B} \mathfrak{a} \operatorname{tg} \mathfrak{a} \mathfrak{a}$ b. Rchв. Agrostogr. t. LIV.

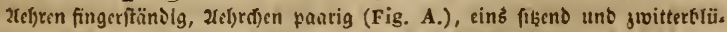
thig, ăußre Deftipelye pergamentartig, glatt, innte Dutr)(d)einend, nervig.

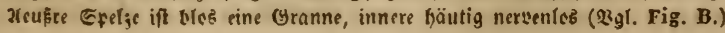


Oดs anive 2ct)r(t)en gefticlt uno männlid) (Fig. A.) uit eingclner Dedfpetze unঠ eingelner büutigen, nervenlofen ๔peljc: Fig. C.

107. A. Ischaemum L. Rснв. Agrostogr. 1500. Fl. germ, exsicc. 651. Etroas äftig, Blätter rinnenfïrmig, an Der $\mathfrak{B}$ afiß ftatt des $\mathfrak{3}$ latthäut.

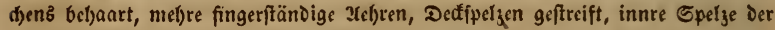
3ıitterblütbe uns Die S3lütbenan(äke weid) bel)aart. Xel)ren violst angelaufen.

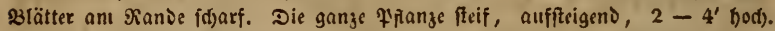

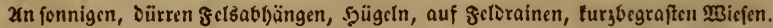

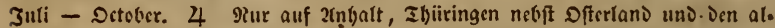

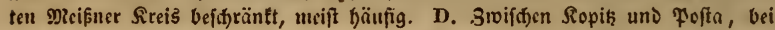

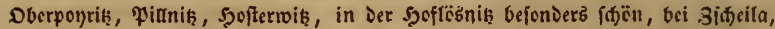

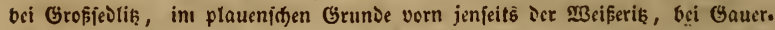

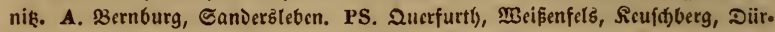

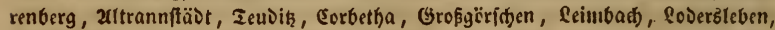
Eišleben, Gerbftäst. HS. Eifuberg, Jena.

\section{Sruppe Festucaeae a. Triticeac. Ş̧wingelgräjer.} a. toaizenartige. Şcrbarienbudi) ธ. 38.

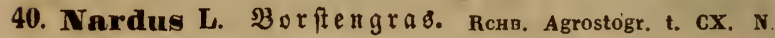
v. E. gen. X. 15. 2(cl)rd)en einjeln, einblüthig, in einer siertiefung Der Epindel eingefețt, 3lüthe ol)ue Decf́pelze. Epelyen paarig, äufre perga. mentartig, borfttig, begrannt, Die innere bäutige cinfdjlisfend. Griffect lang, in sine cinfarbe, gefftrecte, feorige viarbe vertängert.

108. N. stricta L. Rснв. Agrostogr. 1733. Blättrr zufanıntengerout, vorftig, biifdlig. Juf Ganbboben, trofinen, aud) feudten unb moorigen Micfen. Mai - Juli. 4.

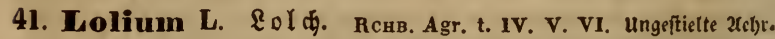

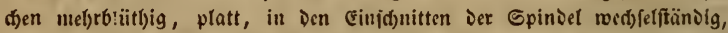
Derfelben sine Rante zutebreno. Dectipelyen eingetn, au Den eniftändigen 2it)ren soppelt. Epeljen paarig, lanjettling, untere biżwcilen bcgrannt. Gaame Durdi Die Epelge cingefüatt.

109. L. arvense Wгтн. Rснв. Agrostogr. 1337-39. Fl. germ.

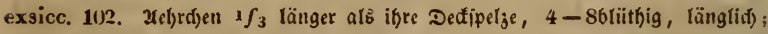

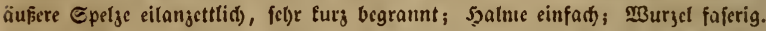

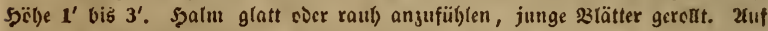

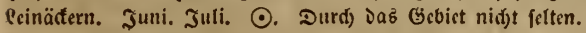

110. L. tenulentum L. Ta u melfol

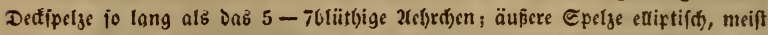
lang liegrannt. MBurzel faferig. Sä̈l)e $2^{\prime}-3^{\prime}$. Junge slätter getollt. Xunf Xeffern, befoniers unter Safer uno Gerfte. Juni. Juli. $\odot$. Durd) Das gange (sebiet, namentlid) um DresDen, Firna, Sittau bišweilen auferorbentlid) bäufig. $x \mathrm{~nm}$. 20n L. robustum Rснв. fal) id) feine (Frmplare ans Dicicm Grbiete.

"111. L. multiflorum LaM, Rснв. Agr. 1345. exs. 1108, "it ali $\ell=$

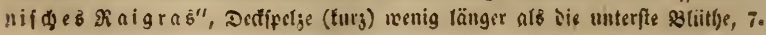




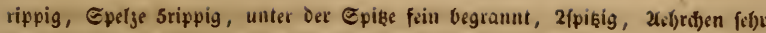

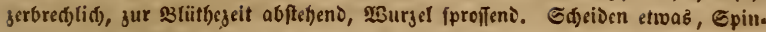
Del felbr raub), s3ätter (breiter, beller griin, weid)er und faftiger als bei $\mathbf{L}$. pe renne, jung cingerout. Caamtentorn ungefähr gleiđ) lang mit Dent von $\mathbf{L}$. arvense, aber iđfnäler uns Dünner, oben etwas teulig, madigelb; feine Epelge un $1 f_{4}$ länger. Juni. Juli. $\odot$. Im grorien $\delta$ sier faft 4 . Wirb unter obi. gen ?amen cultivirt und fammi aus @ïieuropa.

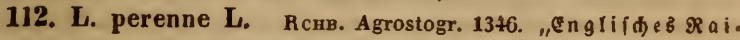
gras." Zelfrd)en länger als iłhre 9rippige Deff́pelje; äufere Epelje Ianzettlid), unbegrannt; $\mathfrak{3}$ urgel fproffentreibend. Şähe bis $3^{\prime}$. b. L. tenue Wrucd. zar. ter und (d)mäd)tiger gebaut, var. c. ramosum mit äftiger 2(c)bre: cristatum Pras. Rснв. Fl. genn. exsicc. 103. Junge \$lätter tielfaltig. Fïrner breiter, ftärter und bräunlid)er ats von $L$. multiflorum, ifre Epelye uni ${ }^{1} \int_{3}$ länger als Rorn.

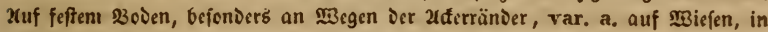
Mäldern. Juni - September. 4. Durd Das Gebiet gemein.

113. L. festucaceum LK. Rснв. Agrostogr. 1347-48. Fl. g. exsicc. 104. 2(el)rd)en vieloliitljig, Inngettlid) geftrectt, siel länger als ibre Ded. ipclje; äušre Spelje ftumpf, unbegrannt, zart getvimifert. 2abbre nidbt felten an Der $\mathfrak{B a f i s ~ a ̈ f t i g : ~ i c . ~} 1348$, Dod Dann find Die 2(efte aufred $)$ ausgebreitet. Sïbe 2'-3'. Xuf feudsten Miejen Deš befiern 3oiens. Juni. Juli. 4. Gelten. D.

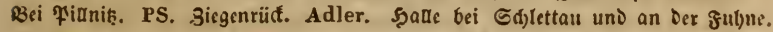
Sprengel. HS. Jena; Roburg. Horniung, Eckart. SRS. Frantenbaufen. Hornung.

42. Brachypodium P. B. $3 \mathfrak{w} \in \mathfrak{n} \in$, $R \mathfrak{u} \mathfrak{z}$ fitelden. Rснв. Agrostogr. t. XVI-XVIII. N. v. E. gen. XIV. 16. afebren

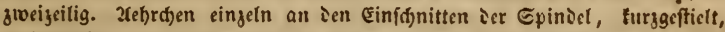
mel)rblütbig. Deffifelgen paarig, türzer als Die untern 3zlütben, Die obern länger als Die untere. Xeufre Spelge Durd) Den Sufanmenlauf Der ORerven begramut, innere gewinipert. Rarben gefiebert.

114. B. gracile P. B. Rсвв. Agrostogr. 1373-75. Fl. germ, exsicc. 508. Iraube überljängeno, cie oberen Grannen länger als sie Dectipelge,

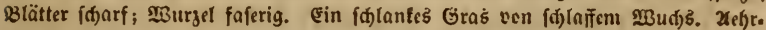
den meid) beljaart coer tabl. Ş̈̈be bis 3'. In f(j)attigen, feudjten faubwäl. Dern. Juni - હeptentber. 4. Durd) Das Gebiet nidt felten.

115. B. pinnatum P. B. Rснв. Agrostogr. 1370. Fl. g. exsicc. 704. Sraulve faft aufredt; iie oberen Grannen türger ats Das \$3tumendeffolatt.

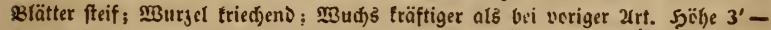

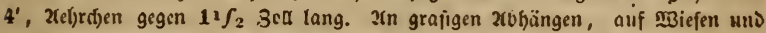
brifdsen (id)tem Gebï(d), aud) au feudten Flufufern. Juni. Jull. 4. Durd) Das Gebiet, ftellenveije bäuñg.

43. Agropyrum Gaertiv. Dueffe. Reнв. Agrostogr. 1 . XIX-XXII. N. v. E. gen. XIII. 17. achre zweizeilig. 2rebrdien ein.

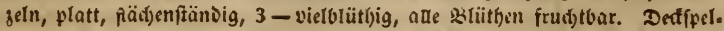

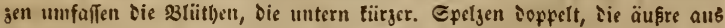
ier Epił̧e begrannt oier unbegrannt. Rarbe federig.

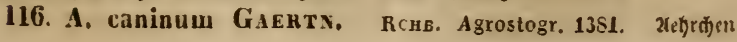




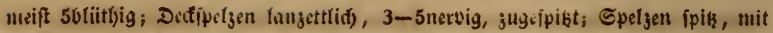

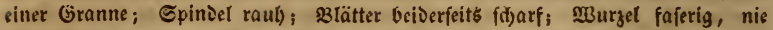
frie(f)end. Z(el)re fel)t (d) lanf, Durd) die langen Grannen ansgejeidfnet. MBit

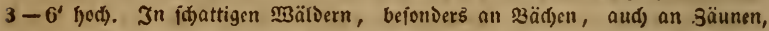
Megen. Juni. Juli. 4. Dur(f) Das̆ Gebiet nidjt felten.

117. A. repens Gakrter. Duedfe. 2(el)rdjen meift 5blittjig; Ded. ipirgen langettliđ), 5nervig, fpiß̨ig; Epelgen fpį̧ oder ftumpf, mit oder obne

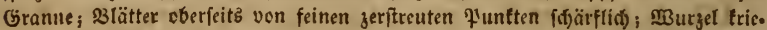

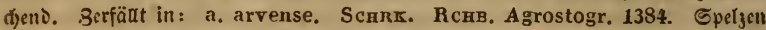
lang, fpik, unbegrannt. b. subulatum. Schrk. Rchs. Agr. 1385. Gpeljen

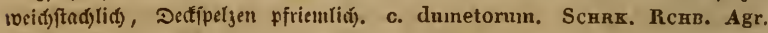
1386. Xeljedi)en ju 2 eder 3, Decf́peljen und Epeljen furj begrannt. d. Vail-

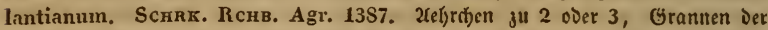

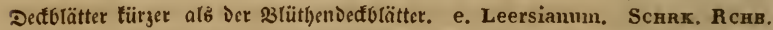
Agr. 1388. Dectipelzen uno Epelyen begrannt, Grannen ier Decfipclyen faft to

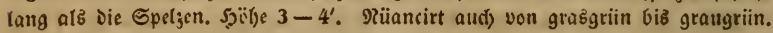

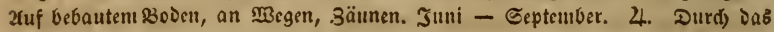
Gebict bäufig. - OFF. Radix graminis.

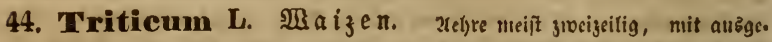

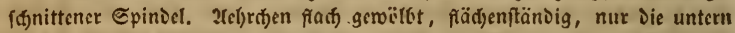
2 - 3 stiitlyen fructbar, übrige taub. Deffipelyen paarig, tiirzer ars ole 23tïthd)en, oben abgeftust. Rarbe fcoerig.

a. Gpelze oljue Eaamen, Epindel zäfe.

*.118. T. vulgare Viru. Mexzg, europ. Cereal. 2. xehre vier.

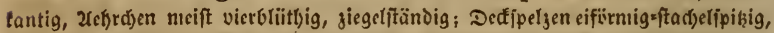
unter Der Epik̨e platt, am Rüifen gervëlbt, mit f̈umpf emporragenden Rerven. Berfäftt in: a. aestivum L. "Sommermaizen" nit meift lang begrann. sen Xefrden. b. hibernum $L_{6}$ " $\mathbb{B}$ intervaijen" mit meift unvegrannten, glatten 2(el)rdfen. c. compactum Host. mit gebrungener, breiter, begrannter

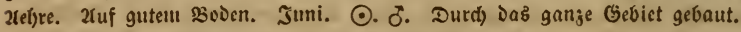

* 119. T. turgidum L. Englifiter Waizen. Meтzg, europ. Cereal. t. III. Xel)re iibergeneigt, Xel)rdben bautfig nufgetricben, meljr cier roe.

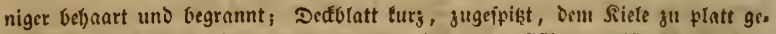
sriictt. Var. Compositum L. 2el)re an ber $\mathfrak{B}$ afı äftig, meift meid)lgaarig.

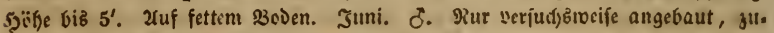
mal ex nur in roarmen Jabren gedeibt.

* 120. T. durum Dsf. Sุartförniger ஹ̧aizen. Metzo. enr.

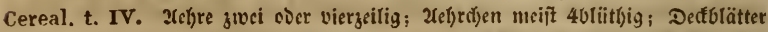

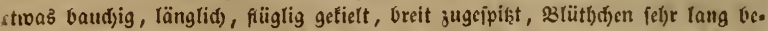

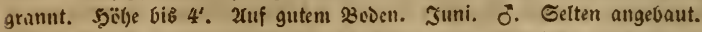

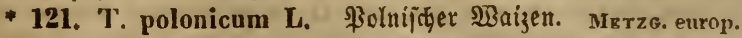
Cereal. t. V. VI. f. c. 2tel)re längliđí, unregclmäfig, sierzeilig sder platt.

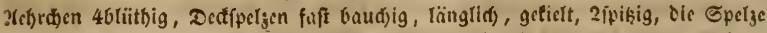

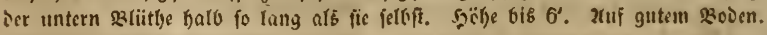
3uni. ठ. Belten angebaut. 

gebcn).

b. Epinter ipröor. Suame mit Rinde (von Dar Epelze um.

122. T. Spelta $L_{0}$. Dinfel. Spelt. MEтzo, europ. Cereal. $t$.

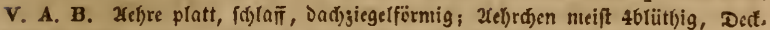
blätter geffukst, breit, eiförnig, zroeifpişig, mit erbabenem fiel, neldber in Den

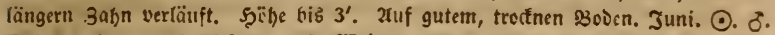
Gelten gebaut. PS. Erfurt. HS. ॠeimar. SRS. 2rnftadt.

* 123. T. dicoccum Schrk. Emmer. Metzg. europ. Cereal. t. VII. VIII. Xef)te platt; Xibrd)en 3blütbig, begrannt, Did)t, Dadjiegelfërmig, Deďblätter baudjig, 2jäbnig, frart getielt; Gaamen 3feitig, lang, gebuđelt; Şïl)e

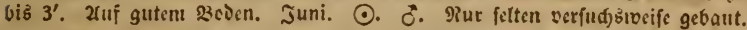

- 124. 'T. monococcum L. Cinforn. Metze. enrop. Cereal. t. XVII. Fig. C. 2(eb)e platt, Xel)rdfen eng ancinanier liegent, 3blïtbig und groar nur bie untere frud)tbar uno begrannt, Dic jroci cberen Ieer und unbe.

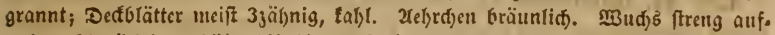

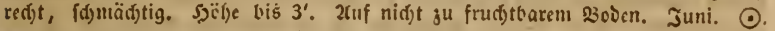
Gelten angebaut. HS. Jena; Dafelbit audi vermiliert.

45. Secale L. R oggen. Rcas. Agrostogr. t. Xariv. N. v. E.

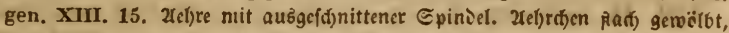

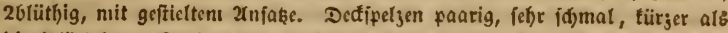

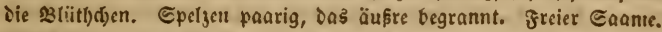

* 125. S. cereale L. Metzg. europ. Cer. t. IX. Epiniel gliedrig,

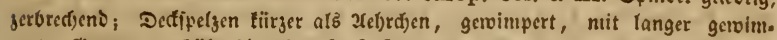

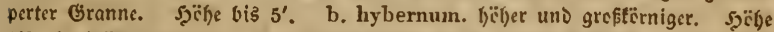
bis $7^{\prime}$. Sräpte Xbart: S. a rundinaceu m Trautr. Sdilfroggen. Xuf mittlem 3oden. "Iuni. ○. b. $\delta$. MBrD bis ins bolse Gebirge gebaut, we

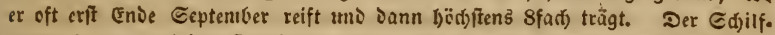
roggen D. 3. 23. bei Syofterwib von B. v. Trautretter gcbaut unb bejofrieben.

46. Flymus L. Şa a v. E. gen. XIII. 14. 2tel)re zmeijeilig. Jebroben zи $2-4$ beijanumen, in ien Einfdynitten Der Spindel fikens, 2-106liitbig. Deffipeljen ju $2-3$,

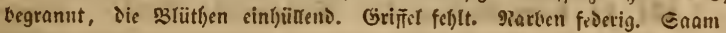
umipelyt.

126. E. europaeus L. Rспв. Agrostogr. 359. Fl. germ. Cent.

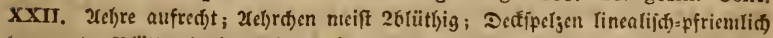
begrannt; Slätter fiad); Slattidjeioen behaart. Gan; grünes, fd)lantes Graz.

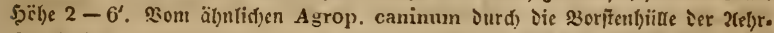

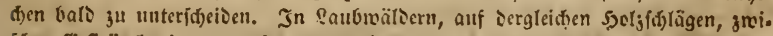
fífen Gefräuđ); immer auf gutem Socien. Juni - 2uguft. 4. Biemlid jelten. D. Conftappel. Bok. Sr. MBinterbeig. - Grauenftein. Z. Bicjentbal, Saarten.

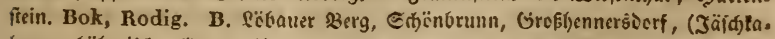

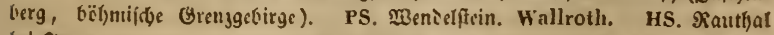
bet Jena.

127. E. arenarius L. Rснв, Agrostogr, t, X. 2rebre alifred)t, sidgt; 


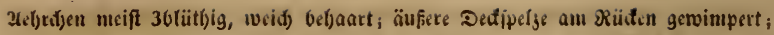

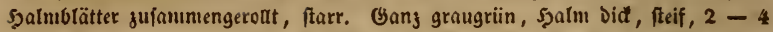
gus bod), unifocidet, 2(cl)ren oft über $1^{\prime}$ lang, Die \$lätter der Murzeltricbe breiter, mef)r fad)rinnig, Murzel weit umbertried)end. Xuf ๔anbboden. Juni. Juli. Geptember. 4. Menig verbrcitet, bäufig nur um Dres̉oen, jdjon weniger

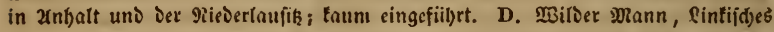

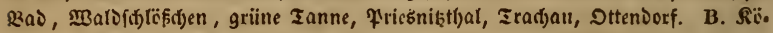

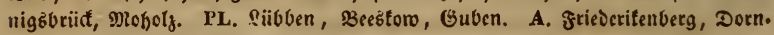
burg, Elbufer. HS. Düben, Beljig.

47. Hordeum L. (S) e rfte. Rснв. Agrostogr. t. XI. XII. N.

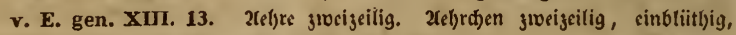
zroittrig oder mit 21nfak zur zreciten stiit)e.

a. 2ftle stiitben begrannt (fétlid)e ntännlid) over leer).

128. H, murinum L. Rchв. Agrostogr. 1362. Die mittleten Ded,

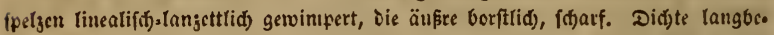

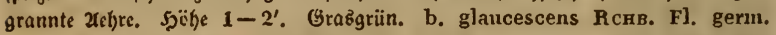

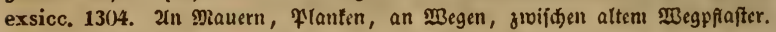
3uli - September. 4. Durdj Das gange Gebiet meift bäufig.

129. H. nodosum L. Rснв. Agrostogr. 1363. Fl. germ. exsicc. 705. 2ule Decfipelyen borfftid), fd)arf, länger alz ibre Grannen. 2lef)rdjen nadt. Sebr fd)lanfes Gras 1-2'. 2uf troďnen uno naffen $\mathfrak{B i e f e n . ~ J u n i . ~ J u l i . ~} 4$. Stellenmeife; meift \{parfan, auf Den $\mathfrak{B i e f e n ~ D e r ~ M i e r f e b u r g e r ~ S a l i n e n ~ g e . ~}$ mein. D. Raffe 2ue. L. Rlein๖ölgig, Bienis. PL. Golften. Rabenhorst. A. Defo

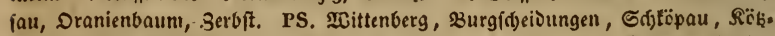

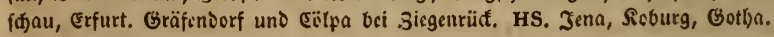
SRS. 2irnftait.

b. Seitlid) 23 tiithen unbegrannt, mämulich oocr atle jwitterlid.

- 130. H. vulgare L. Semeine Berite. Mrtzg. eur. Cer. t. IX. 2ute siätbdjen zwoittrig, begrannt; 2(eb)rdjen 6reibig, wovon zwet auf jever Seite bervorragen. 2tuf 2ectern. Juni. Juli. ○. Ueberall gebaut, Icidgt an Begen uno Dergleidyen Etellen verwitoerno.

- 131. H. hexastichon L. Sengseilige Berfe. Mrtzgra

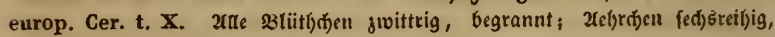
gleidfniäpig ftebeno. b. nigrum W. nit iđbrärgliđ) verbenden Eaanten. c. coe-

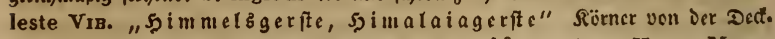
fpelze entolëst, uno Deilen nionftrëfe 2 bart: H. trifurcatu in HoRr. Monspel. "3 intengerfte". 2uf 2lectern. Juni. Juli. ๑. 2lngebaut. शRauente lid) c. feit einiger seit fclyr beliebt.

132. H. distichon L. Sweizcilige Sierfite. Mrtzgra eur.

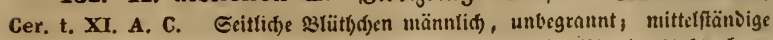
suittrig, mit angesriidten Graunen; Rïrner fantig, iad)giegelfërmig. 2luf 2redern. Juni. Jult. $\odot$. Gelten gctiaut.

* 133. H. Zeocriton L. Reiggerféte. Metzg. eur. Cer. t. XI.B.

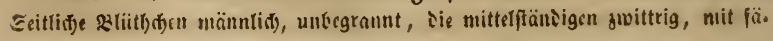




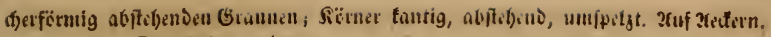
Juni. Juti. $\odot$. Selten gebant.

\section{Sruple Festucaceae b. Poaceae, Sdgringelgräjet. b. rispengrasaatige. Szerbarienbud ธ. 39.}

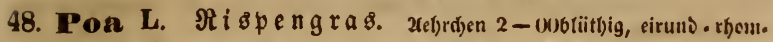

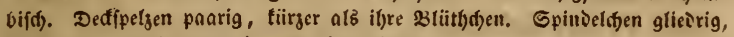
zerfadend. Epeljent paarig. WRarbent feierig.

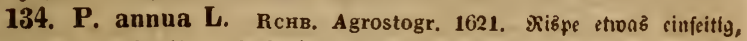
ausggebreitet, fpäterlyin außggefpreizt, 3meiglein glatt, cingeln, unten paarig;

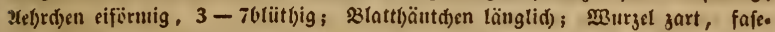
rig; Şalm zufamumengebrüăt; Spelzen ftumiftidg. Var. b. supina Schrad.

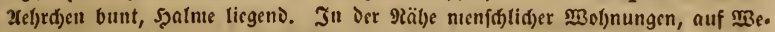

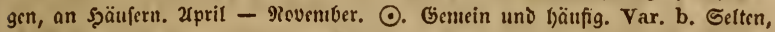
mur inu beblen Gebirge. Junl - 2uguft. ๑. D. 3inntvald. Papperitz und G. Rchib. Z. ßiefentilal.

135. P. bulbosa L. Rснв. Agrostogr. 1619. Fl. gerin. exsicc.

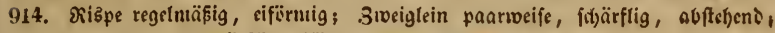

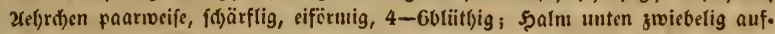

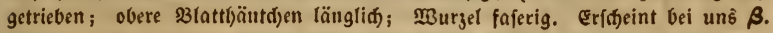

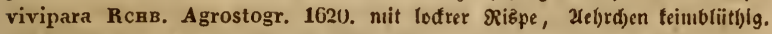

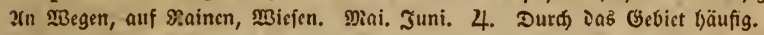

136. P. badensis HaEnke. Rсhв, Agrostogr. 1625. Fl. germ.

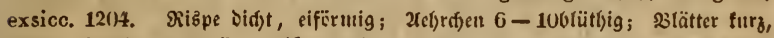

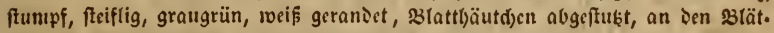

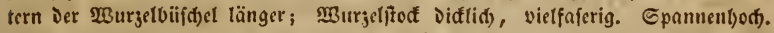
Mird als 2 erga und Şïgelform Der P. alpina L. Rchв. Agrostogr. 1626. bc.

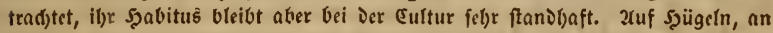

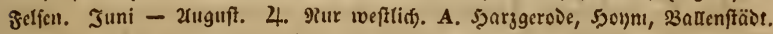

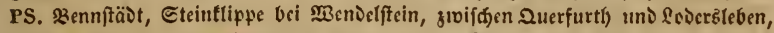
నëIme, autcben, Bottendorf, Sadjfenourg. HS. Soburg au Etaffelberg. Eckart. Hornung. R. Sgeintidjftein bei Sobenftein. Heynhold.

$2 \mathrm{~nm}$. 23on ber bald für alpina, bals für laxa augggegebenen Poa von D. galtent)ain fal) ids feitte Exemplare.

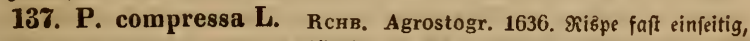

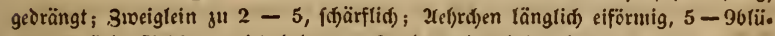
thig; 33(üt)enftiel(d)en weid) bel)aart; Eperze undeutlid) betgant; Szalme zufant.

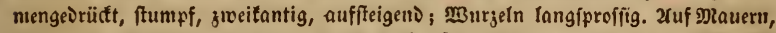

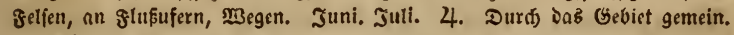

138. P. nemoralis L. Rснв. Agrostogr. t. LXXXVI. शispe regel.

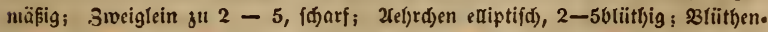

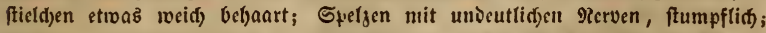

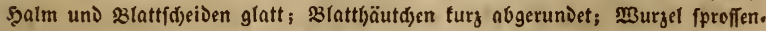
treibend. a. subuniflora ic. 1638. jartefte form, Die menigen 2tef)rdfen faft

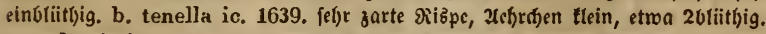

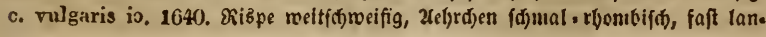


sittlid), melyrblittbig. d. montane ic. 1641. e. coarctata ic. 1642. f. firinula ic. 1643. The mit sufammengejogener Rispe. - 2the formen fins ge.

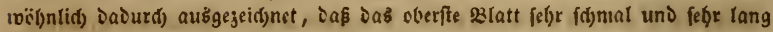

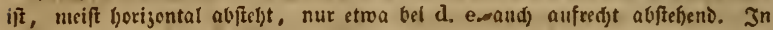

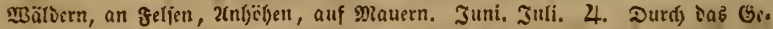
viet niçt felten.

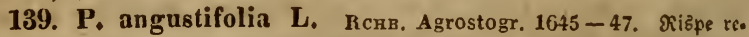

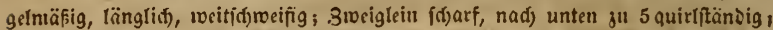

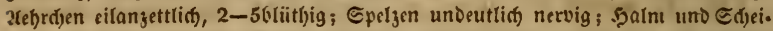

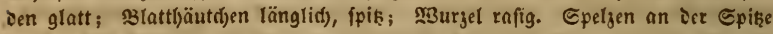

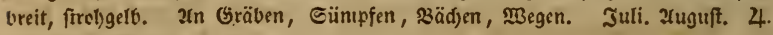
Dur() Das Gebiet.

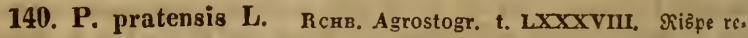

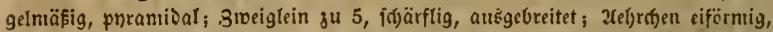

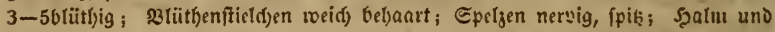

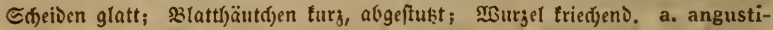
folia Pozr. Rchs, Agr. ic. 164S. b. latifolia ic. 165(). Das oberfte slatt weit fiirger als feine Cdjeice uno aufred)t. 2(ef)rdfen grïn sier bunt. c. varie-

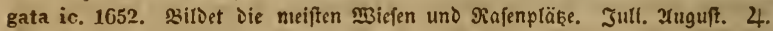
lleberall gemein uno bäutig.

141. P. trivialis L. Rсвв. Agrostogr, 1653-55. Rišpe gleidffir.

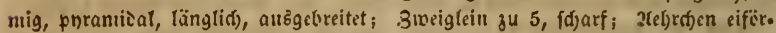

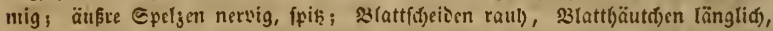

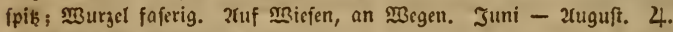

142. P. hybrida Gaud. Rснв. Agrostogr. 1656. Fl. g. exsicc.

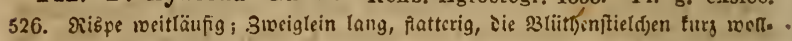

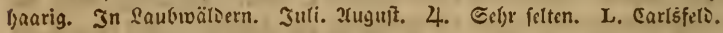

143. P. sudetica HaexкE, Rснв. Agrostogr. 1657-58. Fl. g.

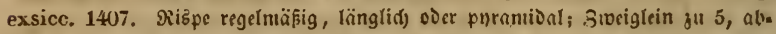

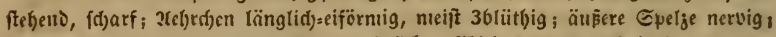

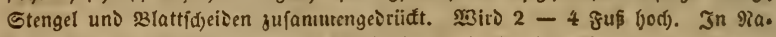

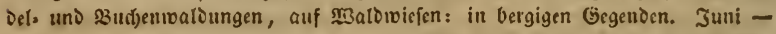
?uguft. 4. Sienulid) jelten. D. - Sinnwalo. Z. 3mifd)en (Eartšfelo und mil.

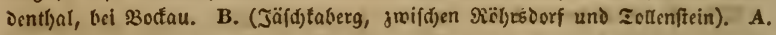

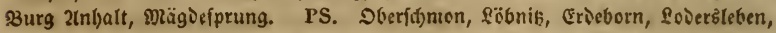

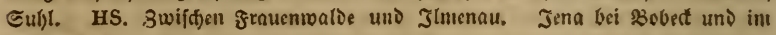
3cikgrunde.

49. Hragrostis Host. Riebeggrab. Rcri. Agrostogr.

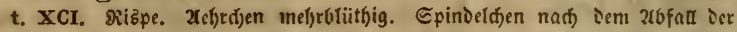
\$2titlyen fteljenbleibeno. Edjeiden an Der Miïnoung beljaart. N3urzel fafes rig, einjäbrig.

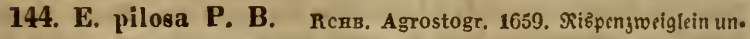

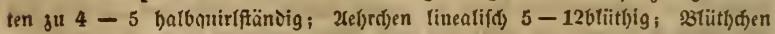
fpis, angebrii(tt; Geitennerv (d)wadi). Xuf feud)tem \$̧umus, auf Felfen. Juli -

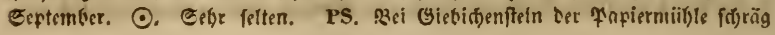




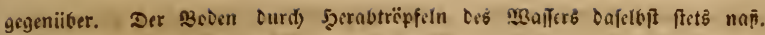
Wallroth.

145. E. poaenides P. B. Rснв. Agrostogr, 1661. Fl. g. exsicc.

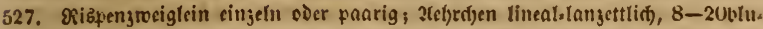
mig; Deffipelzen ftumpf, mit ftatten Eeitennerwen. Zuf Ennobsien, an \$Be.

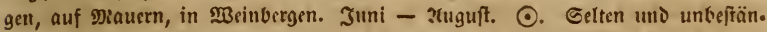
big, woljl meift ringefdsleppt. D. Im swinger und vei ier 3utirficberei 1819.

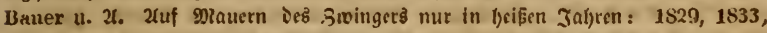

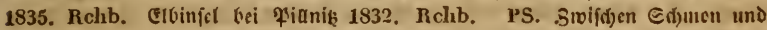
Seimbađ. Wallroth. HS. Jena um isn Sudfberg. Zenker. SRS. Zrnftait.

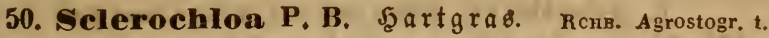

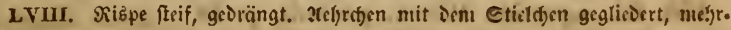
blütljig, einfeitig. Deufipelge panrig, tielrüufig, ftumpf. 2lensite Epelze ficlo rüctig, ftumpf.

146. Sc. dura P. B. Rcns. Agrostogr, 1516. Rişpe Ureit eiruno; 2(el)edjen Didjtfteljento, langett(id), ffumpf, 3-56liitljig; Epcljen 7nervig; slätter flad), brafgriin, 2" $-6^{\prime \prime}$ lang, melft liegend. 2tuf Sandboden, an und auf

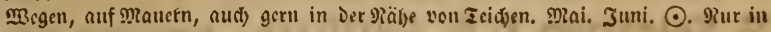
Den reftlidbern Gegenien. A. DefTau, פBalternienbutg. PS. 23arbu), MBittenberg,

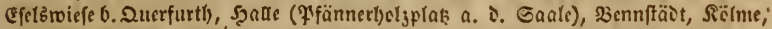

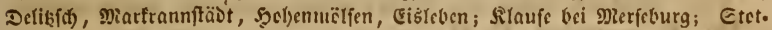
ternt)eim und ghittelf)aufen bei Eıfurt. HS. Jena (5ninberg, Sienusberg, am

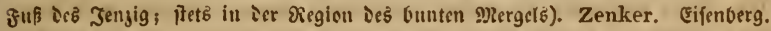
Geier.

147. Sc. rigida PAxz. Rcrв, Agrostogr. 1518. Exispenıurige

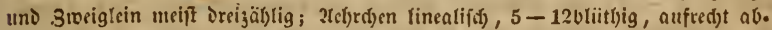

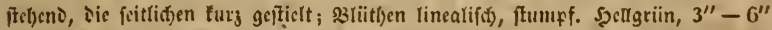

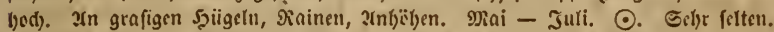

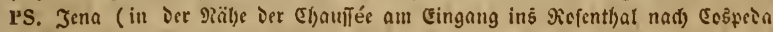
ljin; in M(ï)(t) al) Zenker.

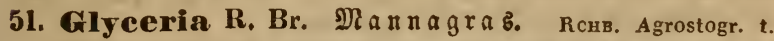

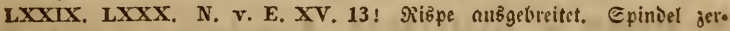

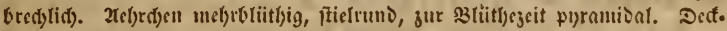

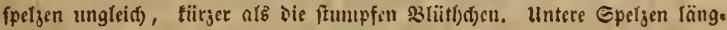
lid)srunb, ftumpf. शarben zeräftelt.

a. Glyceria: Rarben faumfederartig.

148. Gl. distans Wнив. ups. Rснв. Agrostogr. 1609. Fl. g.

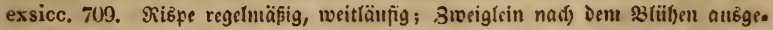

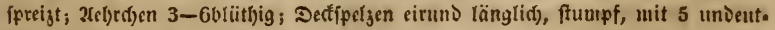
lidjen Rerven; $\mathbb{B}$ Burgel faferig. Jufíteigeno, meif̂̃ graugrüntiđ), $1-2$ '. In Gräben, Gümpfen, gumol auf Gafjboien, an Megen, auf Cđjuttpläḥen. Mai - Detsber. 4: Pidft serbreitet, namentlid) Den Ealinen eigen, fonft vielleid)t

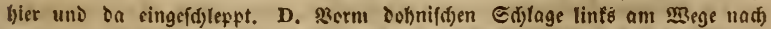

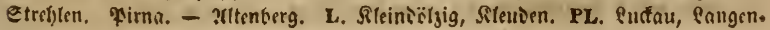




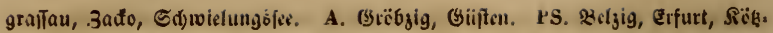

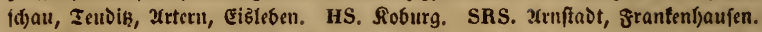

149. Gl. fluitans R. Br. Rснв. Agrostogr. 1615. Nišpe faft eln. feitig; 3wciglein jur 2 lüthezeit horizontal auşgebreitet; 24ebrd)en 6-106lütbig, Deut Sweiglein anliegent; Dectipelzen ftumpf, mit 7 turgen vorragenden Trerven.

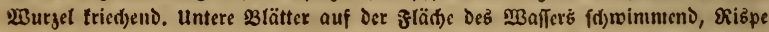
fébr weitläufig, $1-2^{\prime}$ lang. Şaln und 3lätter tweid). Saaule: "פRoor.

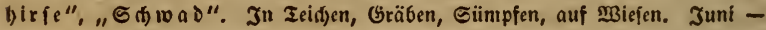
Xuguft. 4. Murde friiber aud) (3. 23. um (Eisleben) angebaut. (Sentcin Durd) Das (Gebiet, im bödften Gibirge fehlend.

b. Hydrochloa LK. Ratben pinfelartig, 2deforfien etras platt.

150. Gl, aquatica Wнкв, gothob. p. 18. Rснв. Agrostogr. 1614. Siiß̄pe groß, regelmäfig pyranioal, vieläftig; 2el)rofien 5-96lütbig; Epel. Jen ftumpf, mit 7 ftarten vorragenden Sierven; Murzel triectend. Şalm Diff, et.

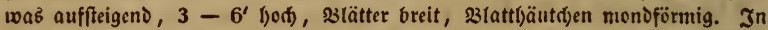

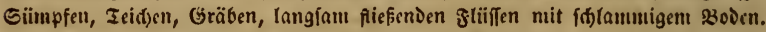
Juli. 2(uguft. 4. Gemein, nut nid)t im bobsen Gebirge.

52. Catabrosa P. B. Due $\mathfrak{l}$ gra g. Rchв, Agrost, 1608.

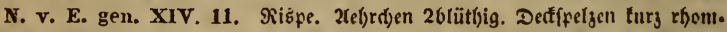

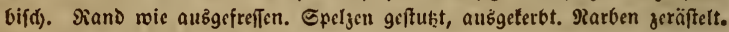

151. C. aquatica P. B. Rснв. Agrostogr. 160)8. Fl, g. exsicc.

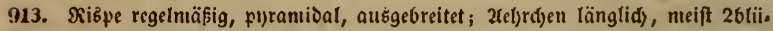
thig; Dedffpeljen längfid') ftumpf, mit 3 werragenien VRerven; XBurgel fproffell.

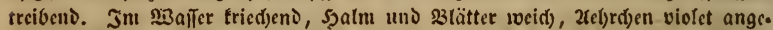
laufen, $1-2 x$. Ju Siimpfen, Gräben, nuf feud)ten Miefen. Juli. 2uguft. 4. Stellumelie, nidjt gentein. D. Grofenlyain im Staotgraben. L. Rleindër.

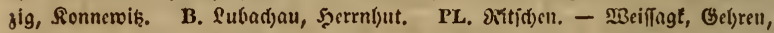

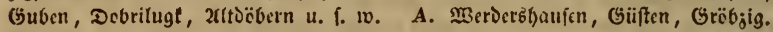
PS. Betzig; Şalle an Der Fulyne uno bcim Drcierlyaic an Der હalga, Röb. (d)au, Benndorf, Siebenau, פzöriķfd), 33atgenderf. HS. Siabla; Eulza; Jena an Der feutra und bei Den Zeufelślëdjern, fioburg.

53. Iriza L, Sittergra 8. Rchr. Agrostogr. t. XCII. N. v.

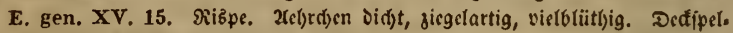
zen ticf nuifdelformig. Xeufre Spelje berafirmig baudjig, innre 2tielig.

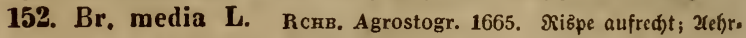

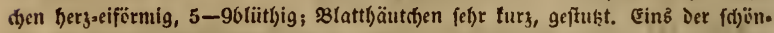

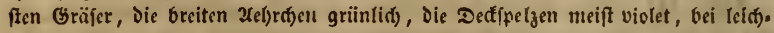

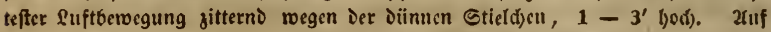
खBicfen, feldorainen. Juni. Juli. 4. Dur(t) Das Gebict bäufig.

54. Triodia P. B. Dreizahn. Rchв. Agrostogr. t. LXXI. N. v. E. gen. XV. 20. گrisppe traubig. 2(el)r(t)en ftielrunolid), baudjig, 3 bis 5blütbig. Dedfperzen fo lang als EpeIzen, äußre grëßer. Epelgen ftunipf, unten mit 2 Şaarpinfeln, dic äufre Dreizäfnig. Sanmen 3friß̨ig. 
153. T. decumbens P. B. Rснв. Agrostogr. 1572. Fl. g. exs.

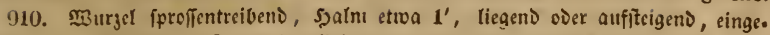

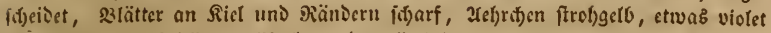

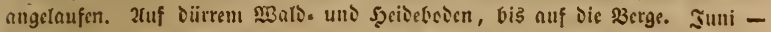
2ruguit. 4.

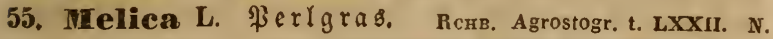

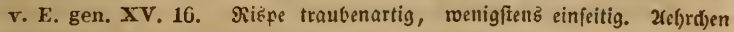

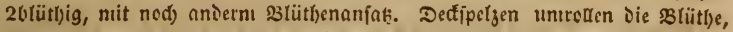
Epelyen Vart, pergamentartig, unbegrannt, innre guciticlig. Eaame frei.

a. Beckeria Brax. anno 180()! Deffifectjen eilanjettfict), äusere

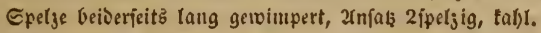

154. M. ciliata L. Rснв. Agrostogr. 14it-75. exs. 911. Siižpe

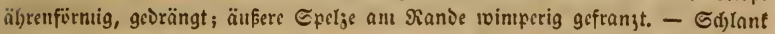

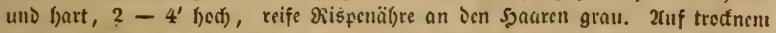

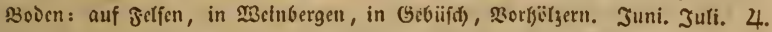

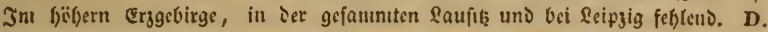

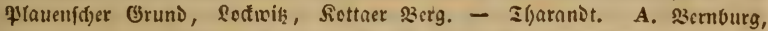

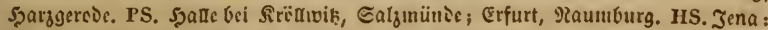

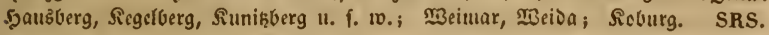
grantentiauien, 2truifait. R. Sobenftecin.

b. Melica: Decfipelgen oval coer eiruno, baudjig, ftumpf, Sper. sen tabr).

155. M. nutans L. Rснв. Agrostogr. 1577. ₹raube einfeitig, über. bängens; Xefjr(d)en mit 2 vedfonmenen silitt)en. - Epelzen violet, nad) Der

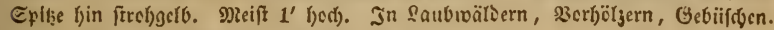
Dini. Juni. 4. Durd) Das Gebiet gemein.

156. M. uniflora Retz. Rсnв. Agrostogr. 1576. exsicc. 1812.

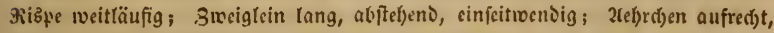

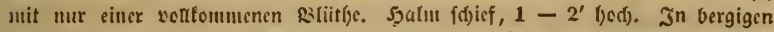

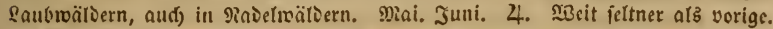
D. Ed) lottervik, Sotta; Grï̈berg, Siefpgruno, Niaikgruno, Uteroaloer Grund,

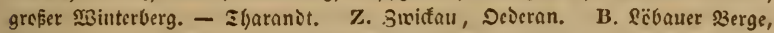

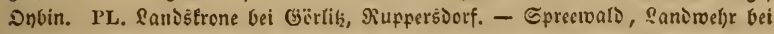

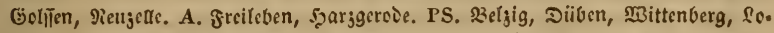

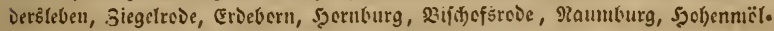
icn. HS. Jena, Reburg. SRS. 2(rmitadt. R. Sobenftein.

56. Nolinia Schrk. Steifgalm. Rснв, Agr, t. LXXVIII.

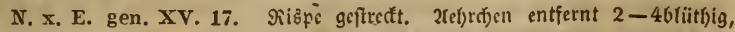

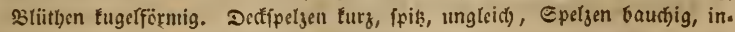
nere gefpalten. Saante frei, droeifpif̧ig.

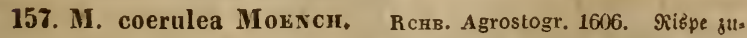

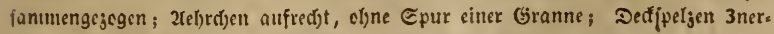

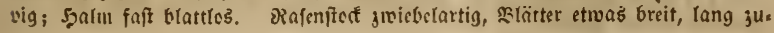




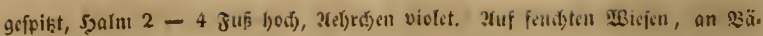
đen. Juti. 2(uguit. 4. Durd) Daś Getriet nid)t fe(tin.

158. M. arundinacea SснRк. Rснв. Agrost. (litoralis Host.).

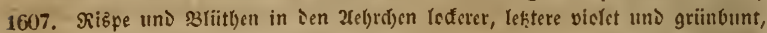

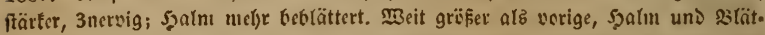

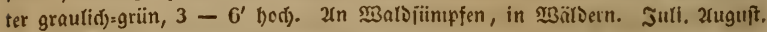
4. P(id)t felten, molst Durdy ১as ganje Gebict.

\section{Sruple Festucaceae c. Festuceae, eigentridic

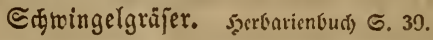

57. Gesleria Arduno. Rcub. Agrostogr. t. LVI. LVII. N. v.

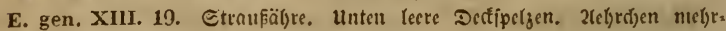

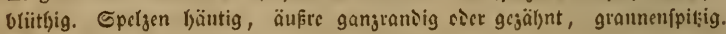
Rarben feljr lang, finumig.

159. S. coerulea ARD. Rchв. Agrostogr. 1510, Etraūiäíre läng.

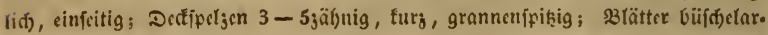
tig, lincalif(d), jung jujummengelegt, Dann lang auşgebreitet; .5alm fpannenlang,

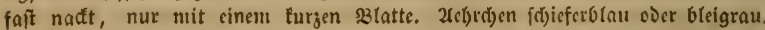

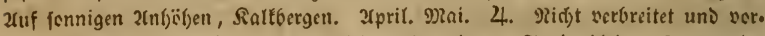

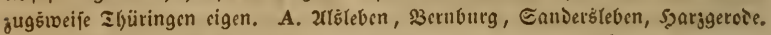
PS. Freiburg an milinen Drten, शaumburg, Erfurt, Siegenrïit, auf Den Eant.

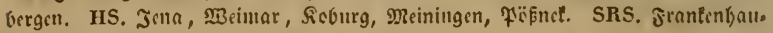
fen, ?trnjtait.

58. Koeleria Pers. $\Re a m m i$ miele. Rchв. Agrostogr. t. XCIII. Riskpe ennatitartig äfrenförmig. 2(ef)r(t)en 2-46tiitbig, platt.

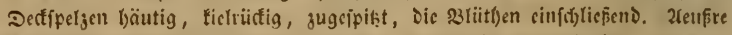
Epelge grannenififigig, innte 2fielig, 2/pişig. 9iarbe paumfederig.

160. K. glauca DEc. Rchв. Agrostogr. 1672. Fl. g. exsicc, 130.

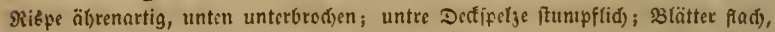

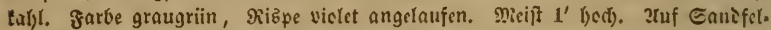

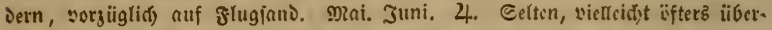

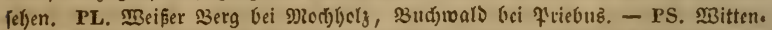
berg. Schk. San〉stl)urm, Sgchcnthurm, Лlepjig. Sprengel. HS. Soburg. Lucas.

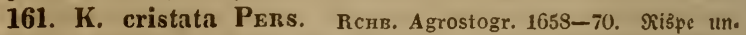

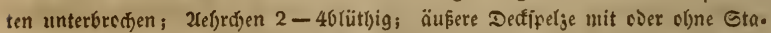

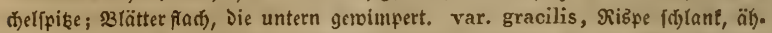

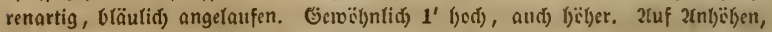
Sanopläken, Iriften, an \$egen. Mai. Juni. 4. Durit) Das Gebiet gemein.

162. K. pyramidata (Poa) LA.r. Rснв. Agrostogr. 1670. b.

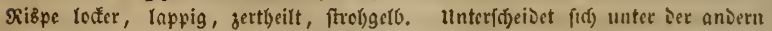
madjicns fdjon von fern surd) sie offne rappige aniers und nuf Demfelben

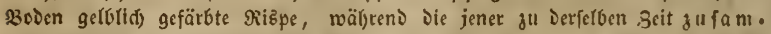
mengezogen und bläuliđ ift. MBie sorige, und oft unter ibr. Mai. Juni. 4. กB०hl Durdi) sas Gicbict. 
59. Cynosurus L. $\Omega$ a $\mathrm{mm} g \mathrm{r}$ a 8 . Rснв. Agrostogr. t. VII.

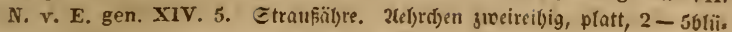
thig, cinfcitig. Swociglcin riifiwärts mit fiçerartig (Doffelfammartig) ge.

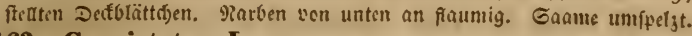

163. C. cristatus L. Rснв. Agrostogr. 1351-52. Stranfäbre

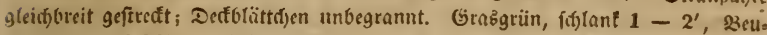

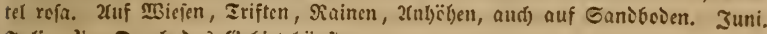
Iuti. 4. Durd) ذaß Ge(ict l)äupig.

\section{Dactylis L. $\mathfrak{R} a \mathfrak{a} \in \lg \mathfrak{r} a b$. Rchr. Agrostogr. t. LIX.}

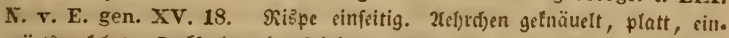

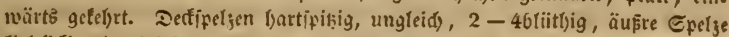
tietriiffig, Jaattipilig. Parben won unten fraumig.

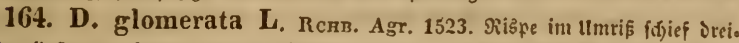

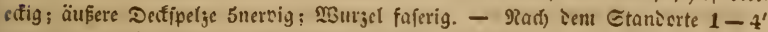

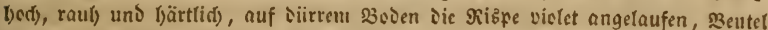

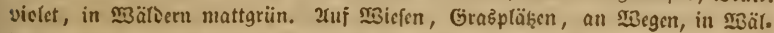

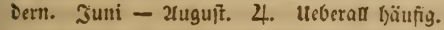

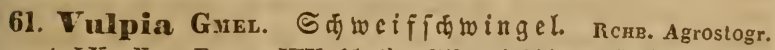

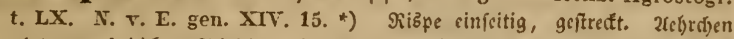

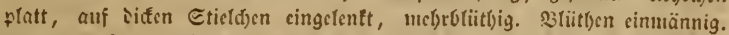

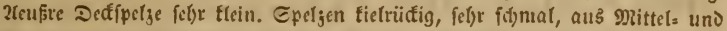
Ceitennerven gleid) lang begrannt. Ratben faumfeberig.

165. V. Pseudo-Myurus Sover Willemet. Rchb. Agrost.

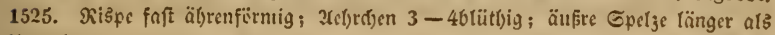

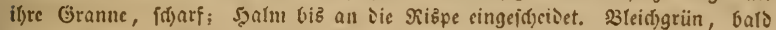

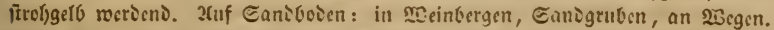

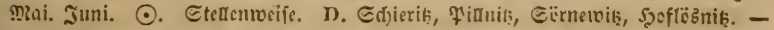

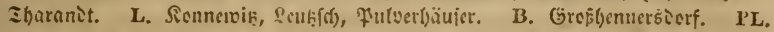

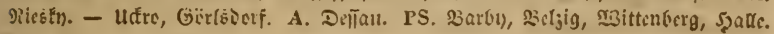
HS. Jena. R. G̈era.

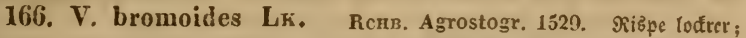

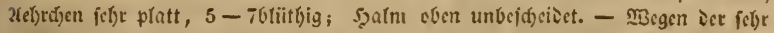

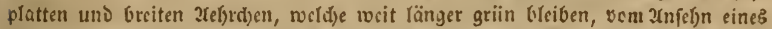

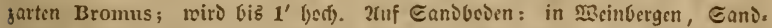

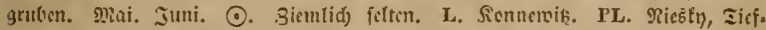

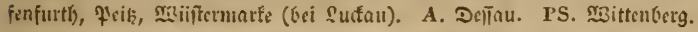

62. Festuca L. $\Subset$ thingel. Rснв. Agrost. t. LXI-LXX.

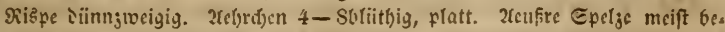
grannt, innte an beiten Sielen getvimpert. PRarken giffelitänoig.

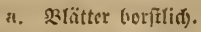

167. F. tenuifolia Siвтr. Rспв. Agrostogr. 1532. szlätter f́f)laif,

*) Nardurus lyave idf Fl. germ. p. 19. unter No. 92. zuerît benannt. 


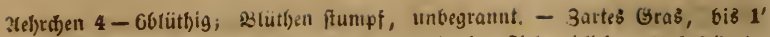
bod), frolggelb, Salm fer)r bïnn, aud) nad) oben fticlrunblid). 2(uf Şügeln. 3uni. 4. Eelyr felten. PS. Soalle. Sprengel.

168. F. ovina L. Rснв. Agrostogr. 1530. Blätter fteifoborffliç), raul),

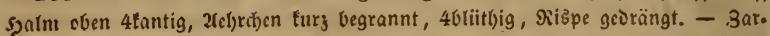

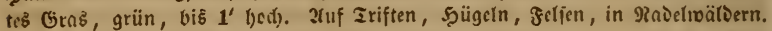
Mai. Juni. 4. D. Grïne Innne, Reppgrund, Diirre \$̇iefla. L. Bicnik, Son.

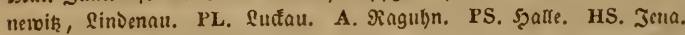

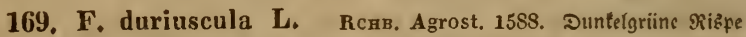

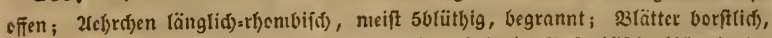

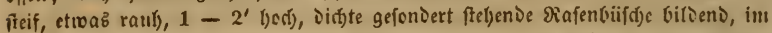

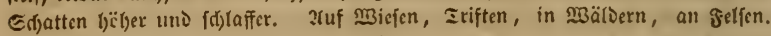
Mrni - Juli. Durdi) Das Gebiet gemein.

170. F. glauca LAм. Rсвв. Agrostogr. 1542-43. S3laugrün, be.

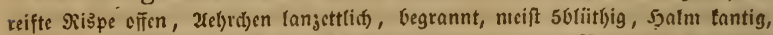

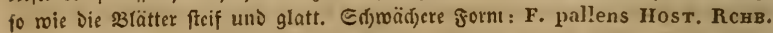
Agrostogr. 1544. Etcife, Diớtlättrige Gorm: F. pungens R. S. 2ln fonnigen Felfen, auf હaniferdern. Mrai - Juli. 4. Etellenweife. D. Flanenfder Grund, 3ader. L. Soldik. Klett. PL. Suctau. PS. Dürtenberg. HS. Roburg. SRS. Stantent)aufen. R. Robenftcin.

171? F. valesiaca GAcD. Rcrв. Agrostogr, 1547. Blangrïinliche

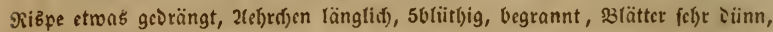

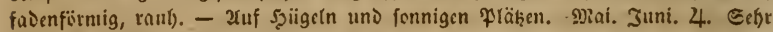

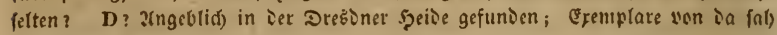
i(i) ni(t)t.

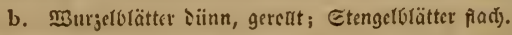

172. F. rubra L. Rснв. Agrostogr. 1557. 3łtiit)ende ORişpe ofĩen,

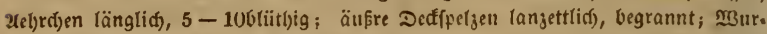

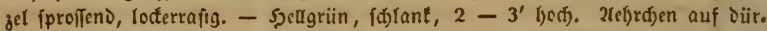

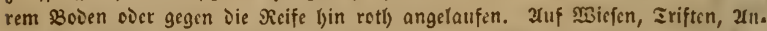
büben, in SBätbern. Juti. 2uguft. 4. Durd) Das Gcbict gemein.

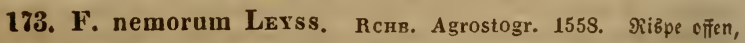

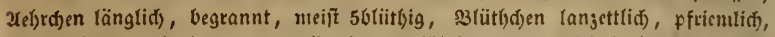

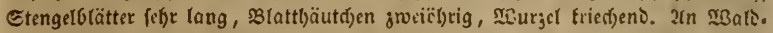
rändern, auf getirainen. Mai. Juni. 4. Durds ias Gebiet nickt felten.

c. 2rue 3lätter flad).

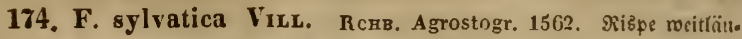
fig, aufredft oier über(jängend; .3weiglcin felfr sünn, fit)arf, Die unteren zu 3

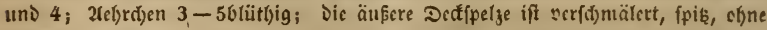

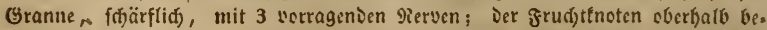

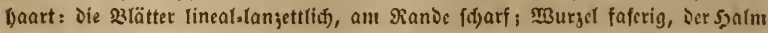

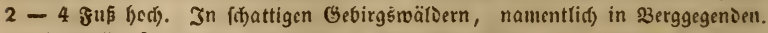
Juni. Juli. 4. PRidgt felten in Den Gebirgeggegenien. D. Ennftappel, Dret. 


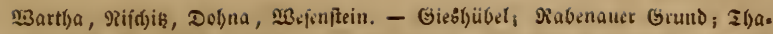

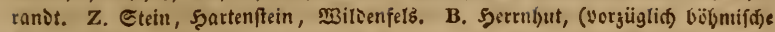

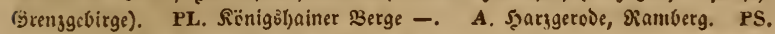
Soderb́leben, Şornburg, Erbeborn; Şclfta; ๔uft. HS. Jena.

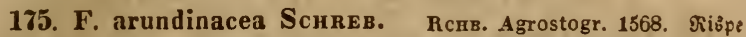

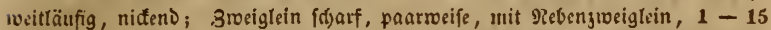

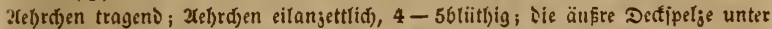

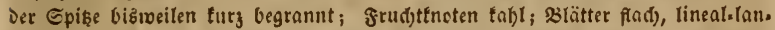

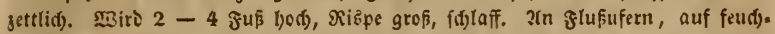
ten פ্̉iejen. Juni. Juli. 4. Etellenweife Durif ১ab Gebiet, aber reit feltner

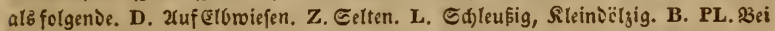

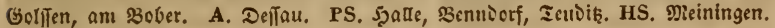

176. F. pratensis Huds. (elatior L, suec,) Rchs. Agrostogr.

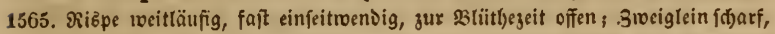

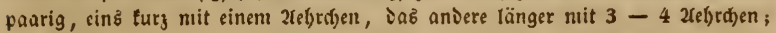
Jet)rdjen linealifá), 5-106tiithig; Deđfipeljen ftuniff; äusere Epelye an Der

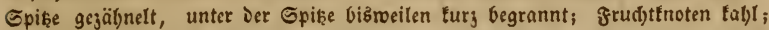

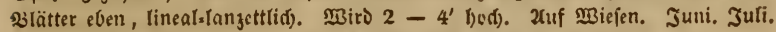

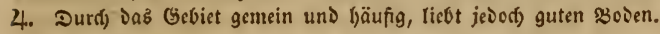

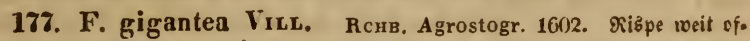

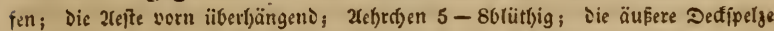
mit einer bogigen Doppelt fo langen Granne unter Der Epiķe; Blätter linealolan.

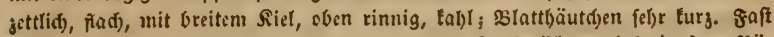
firbilfartig, $2-6^{\prime}$ hod). In fdjattigen, feudjten gaubroäldern, befonders an $33 a ̈$.

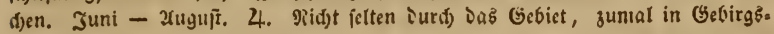
gegenien.

63. Bromus L, Tresి e. Rснв. Agrostogr. t. LXXIV -

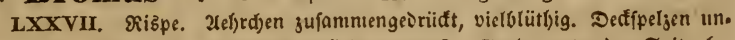

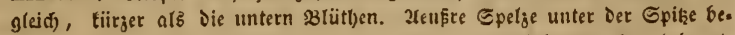
grannt, innre auf Den Rielen fteif gewinipett. Brudftfnoten oben bel)aart. Griffel feitlix). Rarben feierig.

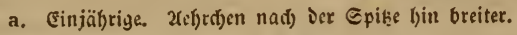

178. Br. tectorum L. Rснв. Agrostogr. 15S2. Siizłe faft cinfeitig,

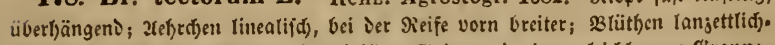

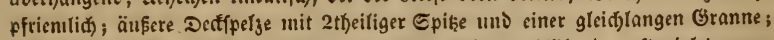
nad) oben weid) belyaart. (Etwa $1^{\prime}$ yod, bals aublübend, oft violet anges

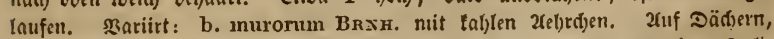

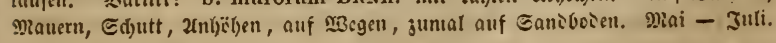
4. Durd) Das Ģebiet läufig.

179. Br. sterilis L. Rснв. Agrostogr. 1363. 2iişpe f(g)lafi, zulekst

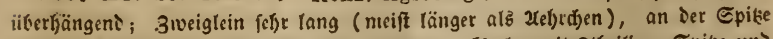

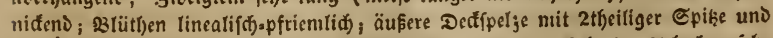

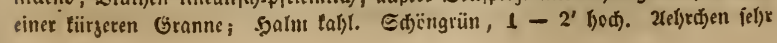


lang uns lang vegrannt. In Mauern, Planten, 2ldir + uns Malorändern, an 3ergen. Juni - 2uguft. 4. Durn) Das Gebiet meift bäufig (im Erggebirge auffallens felten).

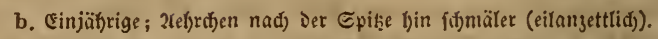

180. Br. arvensis 1. Rснв. Agrostogr. 1587. §iझpc offen, zuleţt oben übergencigt; 2(cl)rd)en fd)mal langettlidi), Dad)jiegelartig einander Deffend;

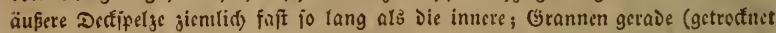

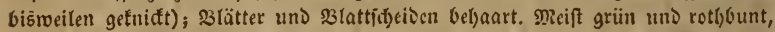

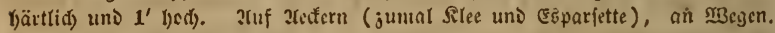

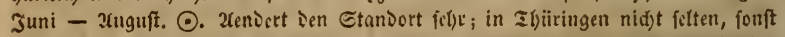

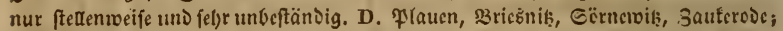

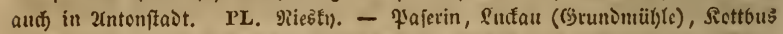

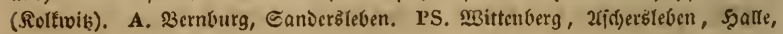

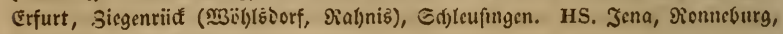
Mieiningen. R. Gıt $\alpha$.

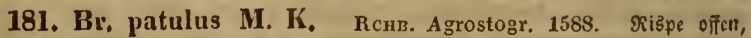

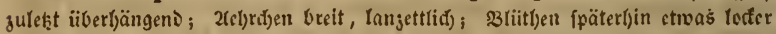
fteheno; untere Spelje beftimunt länger als obere; Grannen fpäterf)in juriictges

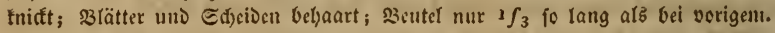
- hebestachyus, mit fein bel)aarten 2(ef)r(f)en. - Griin, 1' unD Driibcr. Xuf

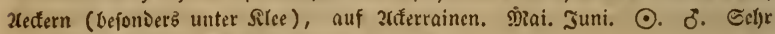
felten. D. 3wifd)en Etrel)la und Sodfwiş 1S39. Heynhold.

182. Br. commutatus Schrad. Rcni. Agrostogr. 1589. ఇiąpe

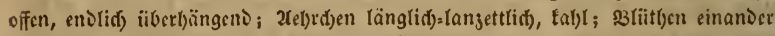

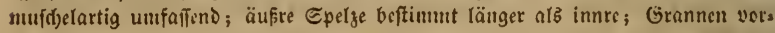
wärts geftrcfit, faft to lang als bie Speljen; unterife Ed)cioen bet)aart. Matt. grün, in graulidi) iibergelgend, $1^{\prime}$ und Dariiber. 2tuf 2teffern unter Der Gaat.

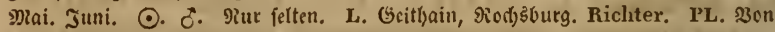

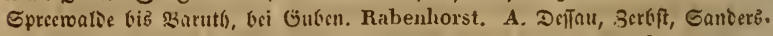
leben. Schwabe. PS. Dïbcn. Rabenhorst. Şalle. Sprengel. Riofitcben. Wallroth.

183. Br. racemosus $L^{\prime}$. Rснв. Agrostogr. 159), গiißpe wenig

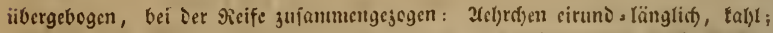

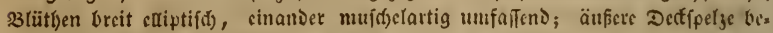
fitimunt längit als Die innere; Grannen gerade vorgeftrectt, furj; untere 33 lätter

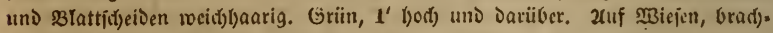

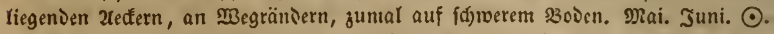

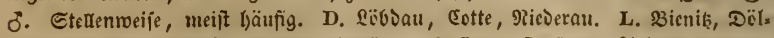

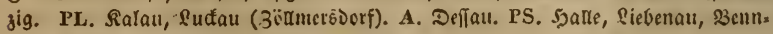

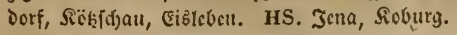

184. Br. mollis L. Rснв. Agrostogr. 1591-92. Siiłpe aufredft,

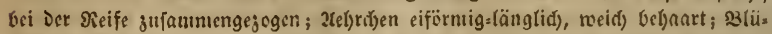

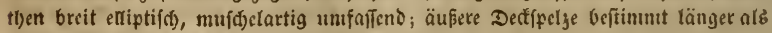

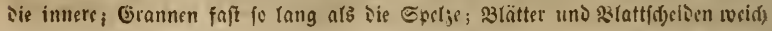




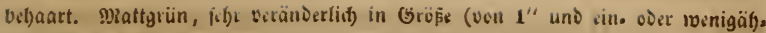

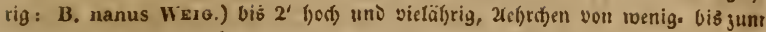

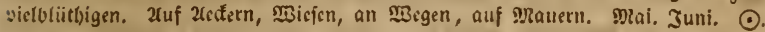
ठ. Durḑ Dab Gebiet bäufig.

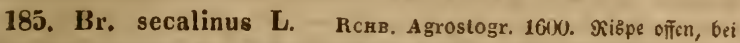

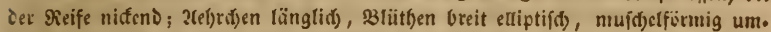
faffeno, frudittragcni runitió) meriend uno loder ftelbend; äufere Dedipelje fo lang alह Die innere; Grannen verwärtb geriđ)tet, türjer als die Epelge; Blatt. fifjeiden fal)l. 2(cniert ab: b. submuticus RcHB. Agrostogr. ib. 2(cl)rdyen tleiner, nur bie Eniblïtle furg begrannt. c. divergens Rснв. Agrost. 1601.

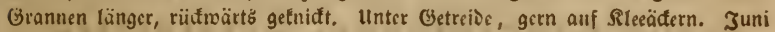

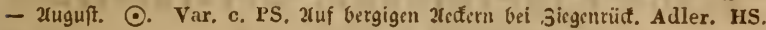
Eifenbcrg. Geier.

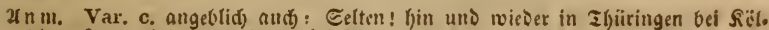
liva, \&angenjalje, freiburg, bci Jena.

186. Br. erectus Huds, Rснв. Agrostogr. 1604. Rispe aufredjt,

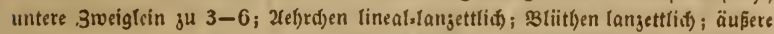
Def̌ipel3e vorn 2jälynig, mit einer lurgen Granne aub Der Mitte, 3-5nervig;

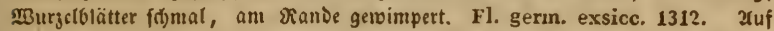
æBicfen, Iriften, Sjügeln. Juni - 2tuguft. 4. Eelten und äuferft fparfam inı

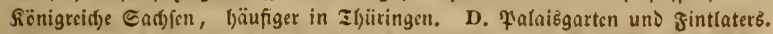
Hiibner. S(jarfonberg. Mauke. Bicberftein. L. Rchb, fil. Z. - Plawen, 20orf. L. F'aunsoorfer Selfoen 1826. Richter. A. Bernburg, Sanderbleben. PS. Bcnnftä̀t, 3appenoorf, Querfurth), Raumburg, Earsiorf, Burgideioungen,

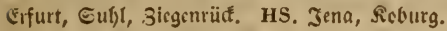

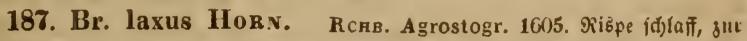

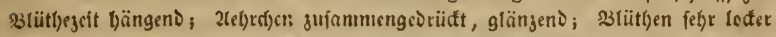
fteheno; Granne türycr als Epelje; Silätter foldaff, woid) bel) aart umo gewim. pert. Unter Gebiifid). Juni - 3tuguff. 4. Gel)t felten. D. Srauenftein. Weigelt. (Bei জBolfenftein fant id) nut B. asper.)

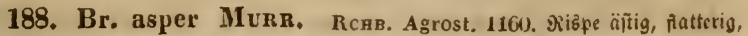

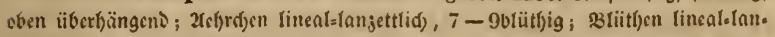

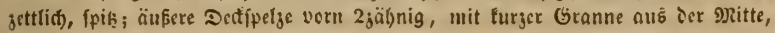

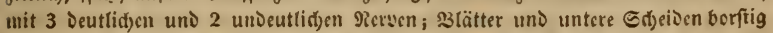

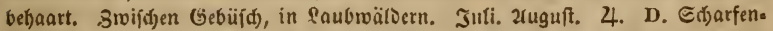
berg, Minoberg, Goblis. - Gottleute, Delia, zi)arandt. Z. Milbenfclb, Eteln,

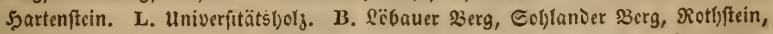

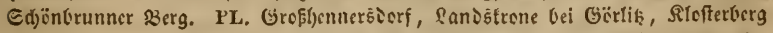
bei Sauban -. A. Deflau, Dranienbaum, 3erbft. PS. Szalberftaot, Szalle, Er: furt. HS, Roburg. Jena. SRS. Stantenlyaufen, 2ernftaot.

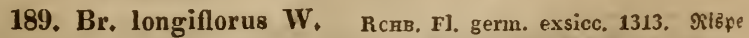

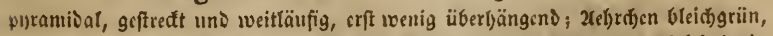

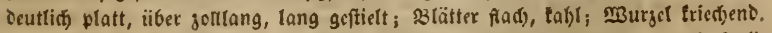

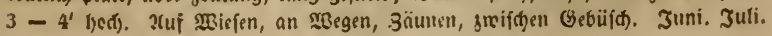


Sängt um volle 14 Tage fpäter an ju blüljen als voriger, 4. Eelfr felten. D. ßei ßurgfäbtel. Rchb. (jeit 1838 becbadjtet). Jut gropenen Gel)äge. G. Rchb.

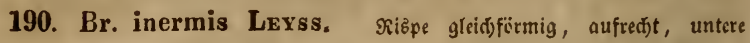
3rveiglein zu $3-6$; Xel)rdjen linealslanjettlid), äußse Dedfipelje vorn 2 jäl)nig,

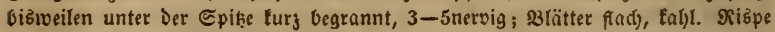
groß, nad) Dem 2loblüben jufantntengelegt, 2(el)rd)en meifit rothbunt, seutel bod)= gelb, Şalm $2-3^{\prime}$ bod). Gef́ldig auf Jeldrainen, פiauern, in Şeden, auf fet. ten Miefen. Mai. Juni. 4. Durd) Dns ganje Gebiet (in Der Gegend yon

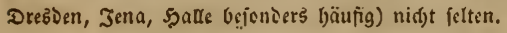

\section{Familie Cyperoideae, Eypergrälex.}

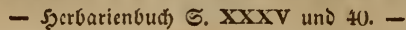

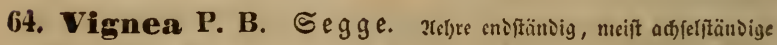
Eeitenäl)ren. Sild f(b)(and)förmig; 3 Rarben. E(blaud)frud)t platt gebriidt.

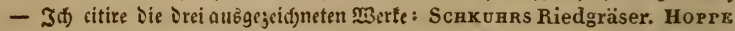
u. Stura Caricologia gernanica. Nürnberg 1835. uno Kuxze Supplemente der Riedgräser. Leipzig 18+0 und 41. sq.

a. Psylloploor a. Uếre cinz̧litänbig.

a. jiveil)äufig.

191. V. dioica L. Sснк. t. A. 1. Hpr. ST. caricol, t. 1, *). গiii .

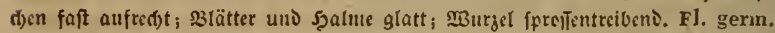

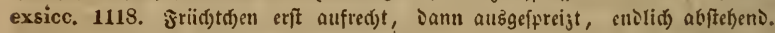
Didfrafig, sart, fadenförmig, band, bis ipannenbed). 2uf Mroerboden. 2Rai. 4. Etellentveife; faft längs Der fiiblidben Grenge fehlent. D. Sidjeila auf Der naffen atue. L. Dïljig, Bienik; Miëltikfd), Schünfeld. PL. Scutben; Guken; IBals

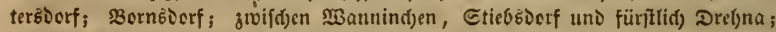
zroifden Safel uno Malbo bei Rottbus. A. 3erbft, Şar\}. PS. Şalle: Eeben,

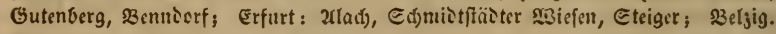
HS. Swifd)en Ëcl)lberg und 2trlesberg.

192. V. Davalliana SM, Schrk. t. A. 2. HPP. St, caric. $t .2$.

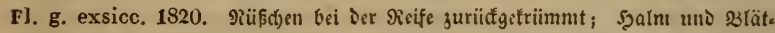

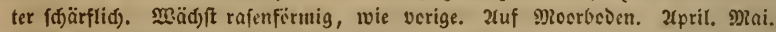

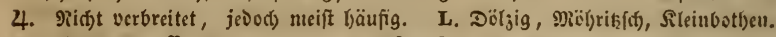
PL. Guben. Ruff. A. DeiTau, Şarg. Schwabe. PS. Syade: Geben, Gutenberg,

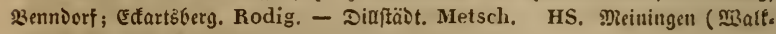
mül)le), Rauch. Roburg (Seiimannsंborf), Eckart.

bb. Mannweitig.

193. V. pulicaris L. Schk. t. A. f. 3. Hrp. St, caricol, t. 3.

* Die Begifirerung Der Infiln fu ier teefflitgen Caricologia germanica

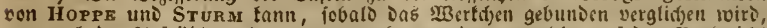
nur nad) Der 2lufjäblung Der 2irten gegeben werden, weld)e auf Den serterid)t folgt. Das 3uffudjen Eer in ien Seften jerffeuten ?uten bërt inun muf. 


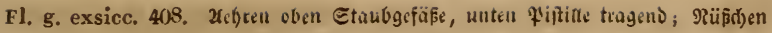

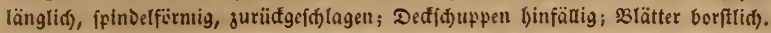
Zelyre braun, glängens. Sä̈ge biš nicift $6^{\prime \prime}-1^{\prime}$.: 2uf Sunpfroiefen, befon. Derz auf Mioorboden. Mai. 4. Edjeint im weftlid)en Gebiet jelten, fonft in

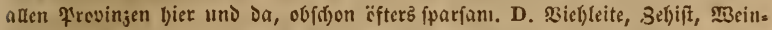

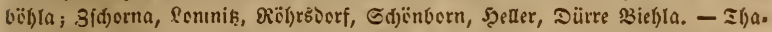
randt. Z. Dzivalogrumb bei DBirdenau, Gdivarjenberg. L. Grofpartbau, Grof.

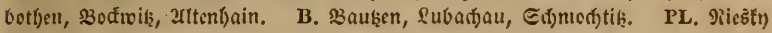
(Moljols), Gee, Devernik, 2trnsiorf. - Maldo, Friero, 33ornsiorf, Siraufnigt, Eprentberg A. Berbft, Dranientaum. PS. Detif̧id bei Bennoorf. Szitterfelo. \$zer.

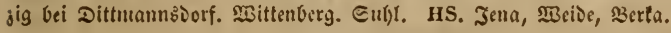

b. Heleonastes: Miffre ntannweiblidfe 2felyrdjen.

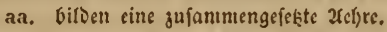

* Sriidite allfredit, Epik̨sn nad) oben geriditet.

194. V. Schreberi (Sснгк.) Sснк. t. B. f. 9. Hрр. St. Caric.

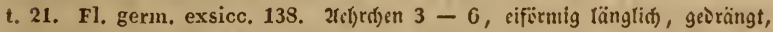

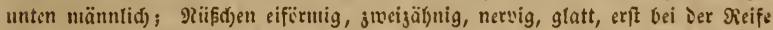

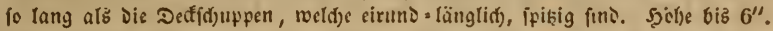

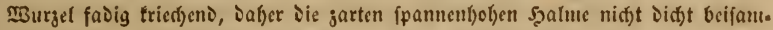

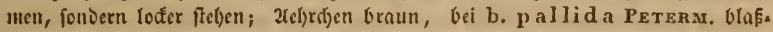

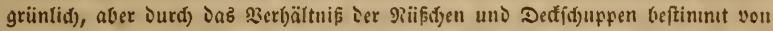

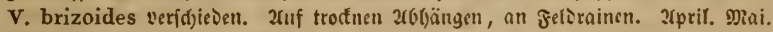

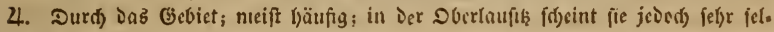
ten su fein. b. bei \&eipzig. Petermann.

195. V. brizoides (L.) Sснк. t. C. U. 12. HPP. ST, Caric. $t$.

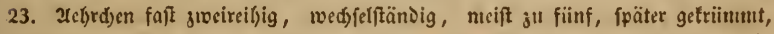
fpindelförnig, Der 2 ajis ju nünnlid); Rüf(t)en eiruno, geterbt, juveifpaltig. Sełje

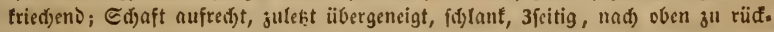

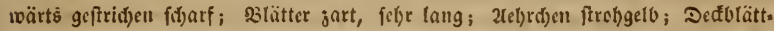

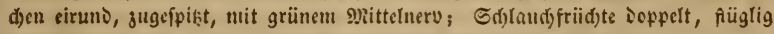

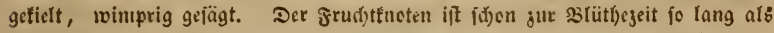

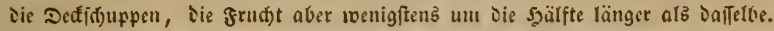

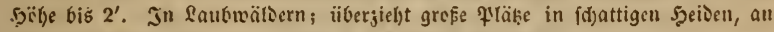

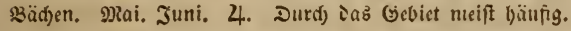

196. V. canescens (L.) Sснк. t. C. 13. Нрг. Sт. Caric. 31.

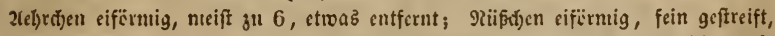
flad) erfaben, mit furjem, ungetl)eiltenı Gdunabel, wenig länger als Die Dedf:

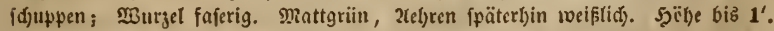

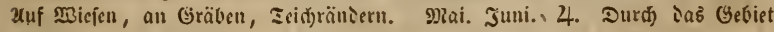
getucin uno meift läufig.

197 ?. divulsa Good. Scuk, t. Del. 89. HPr. Sr. Caricolog.

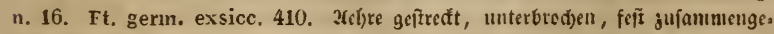

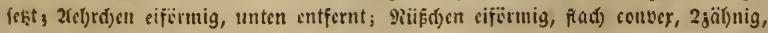

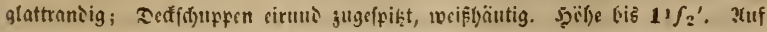




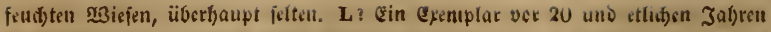
in Det Gegento von Peipjig gejantmelt findet fidi) in meinem Şarbario.

198. V. argyroglochin (HoRv.) Fl, dan. 1710. HPP. ST. Ca-

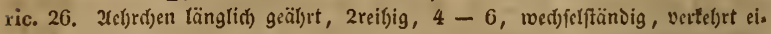

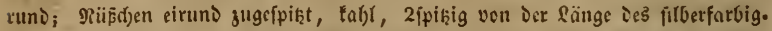

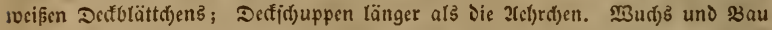

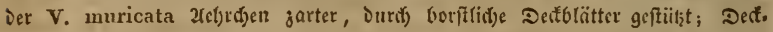

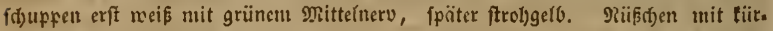

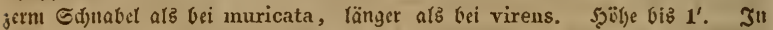
fentiften Gebiifden. Mai. 4. Eclfr felten. (D. Ripborf. Neumann.) L. Sin. ientijal. Petermann. PL. Swiffonen G̈alje uno Rajel. (C. microstaclya) Rabh.

199. V. remota (J.) Schк. t. E. 23. HPP. St. Caric. 35. Fl. germ. exsicc. 1825. Uefroben eifürntig, abgciondert, Dic untere wcit von cill.

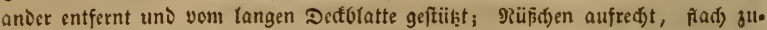

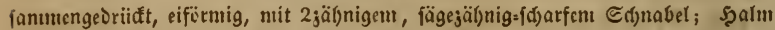

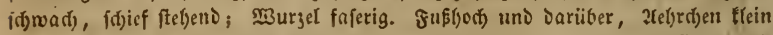

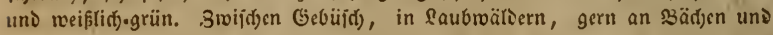
fonft an feuditen Drten. Maai. Juni. 4. Durd) Das Gebict gemein unD bäufig.

200. V. axillaris (Good.) Schk. t. R, 62. HPP. St, Caric. t. 33.

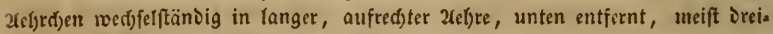

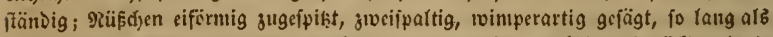

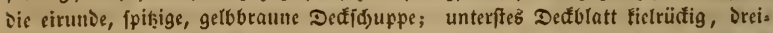

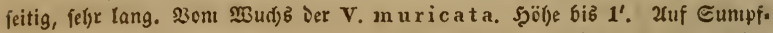
wicion. Juni. 24. Gelten. L. Seipzig (iđ) befike eine 2(ngaf)l Ëcniplare, weld)e

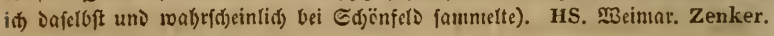

201. V. arenaria ( $\left.\mathbf{L}_{*}\right)$ Schк, t. B. 6. Harse Arzneigew. V. 7.

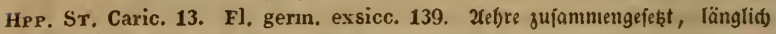
cock eiförntig, obcre 2fef)rden männlid), untere weiblid), mittlere an iffer Epiţe

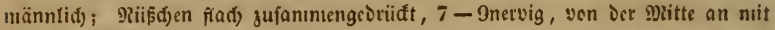

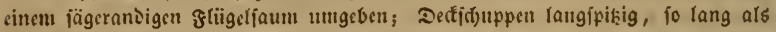

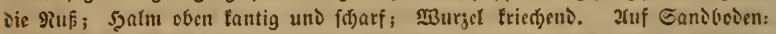

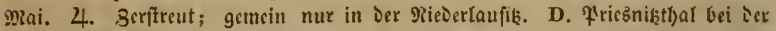

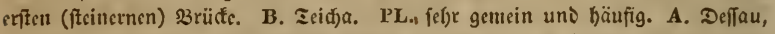
3erbft. PS. SBittenberg (2pollonbberg uno anore Drte an Det Strafie nad) Do. bien, (Elgftran)). - OFF. Rad. Caricis arenariae s. graminis rubri.

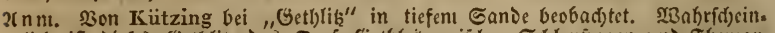

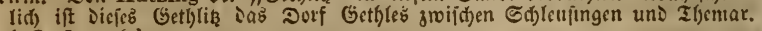
(PS. Spenneb.)

202. V. intermedia (Good.) Sснк, t. B. 7. Hрp. ST. Garic.

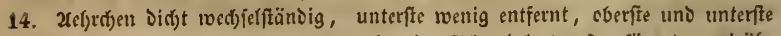

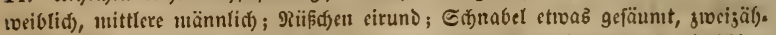

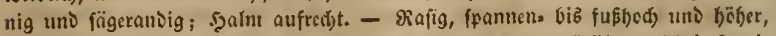

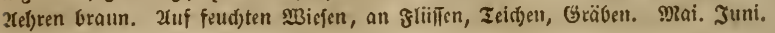
4. शi(t)t felten Durd) Dab Gebict.

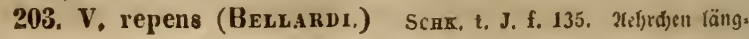




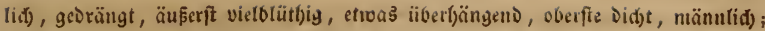

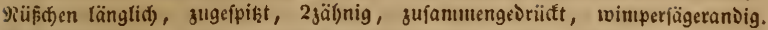

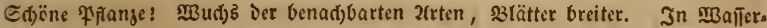
gräben. Mai. Juni. 4. Gełr felten. L. Romnewißs (V. disticha floribunda). Petermann.

** Frï(d) fparrig, Epişen na(h) aup̄en ober unten gerid)tet.

204. V. stellulata (Good.) Sснк, t. C. 14. HPp, St. Caric. t. 28. Fl. germ. exsicc. 1922. Sujammengefetite 2(ef)re; ?(ef)rdjen meift 4 , etwas

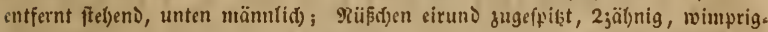
fägerandig; Deffiftupen eirund jugefpist. - Siafenfïrmig sondficns, aufredft,

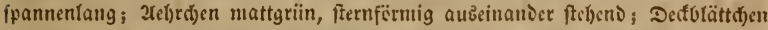

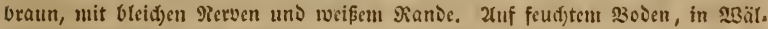

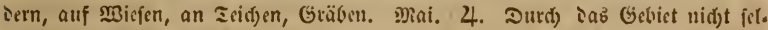
ten uns meift bäufig.

205. V. muricata (L.) Schr. t. Ee. 91. Hрr. ST. Caric. 15. Fl.

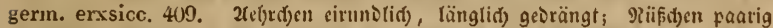

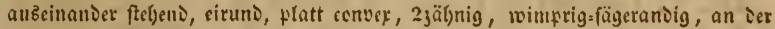

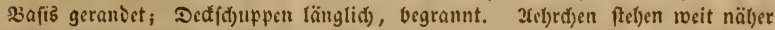

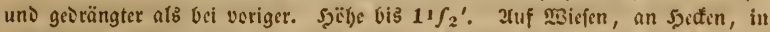

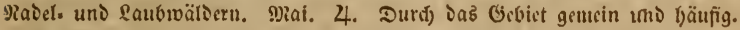

206. V. vireus (LAM. et Dc.) 2(ef)rofen $7-8$, runolid), unten

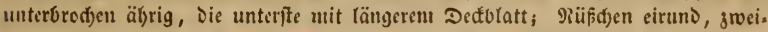

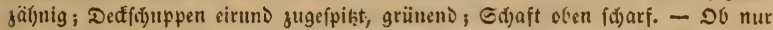

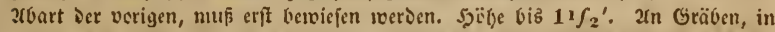
(d)attigen faubwäldern und in Dïrten Radelwäldern (wo fie $n i$ d) $t$ befd)attet

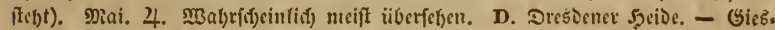

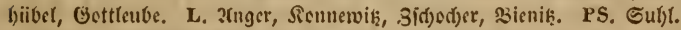

(IIII. 20 die aud) bei Pray roadffenie V. contigua Hpp. ST. Caric. 11. 10.

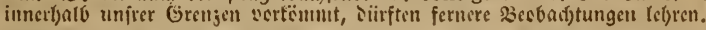

207. V. elongata (L) . SchK. t. E. 25. HрP. ST. t. 32. Fl. g. pxslce, 1826. 2(el)rdjen länglid(), genäl)ert, meijt ju 1()$-12$; Rïī̄d)en abfte=

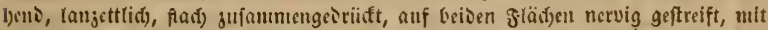

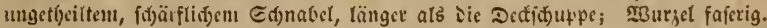

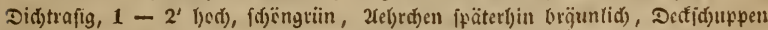

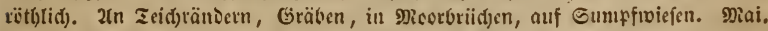

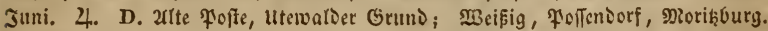

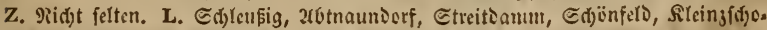
d)er, Düljig. B. Jaft überall. PL. Desgleicten. A. Deffau. PS. MBittenberg

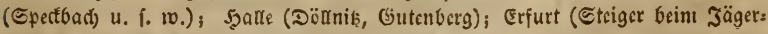
baufe). HS. Sioburg (Bentelbeide), Eifenberg.

208. V. nemorosa (REBent,) Schr. t. Dddd. 168. HpP. St.

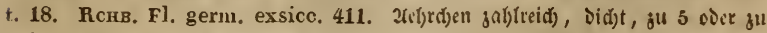

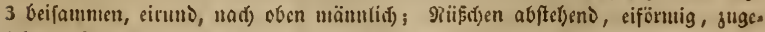

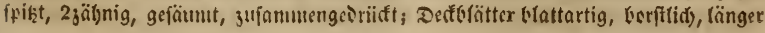




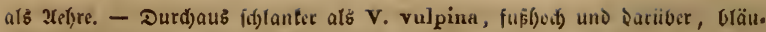
(id)grün, E(j)aft unten fticlrund, nad) oben orcienntig, 2(ef)rdfen grïn, tur\}. 3leibt fid) ïbrigens feloft bei 2ustroctnung Der Gräben gleiø, eben fo auf trod. nem Boden erjogen nni Die waljre Prange wird Jedermann leidt Durd Die an

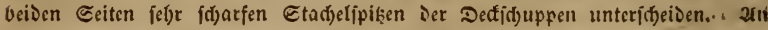

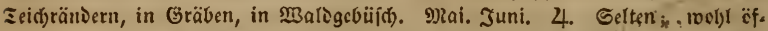

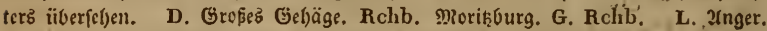

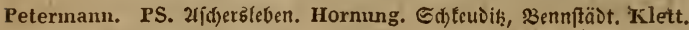

209. V. vulpina (L.) Scrk. t. c. 10. HP. ST, t. 17. 2terje Dop.

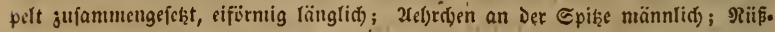
d)en fparrig auscinander ftef)end, eiförmig, fâd) gewölbt, mit 2ipaltigcm, fäge.

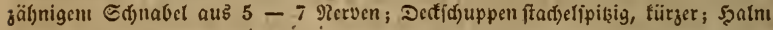

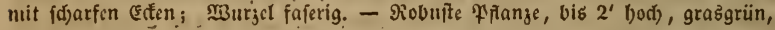

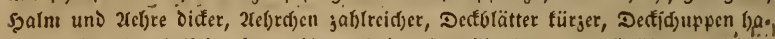

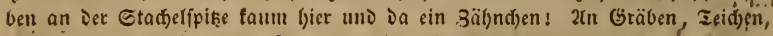
in Eümpfen. Mai. Juni. 2. Durd) Das Gebiet gemein un১ bäufig.

210. V. leporina (L.) HPr. St. Caric. t. 22. c. ovalis. Schk. t.

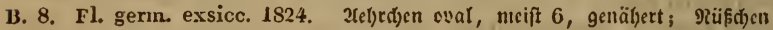

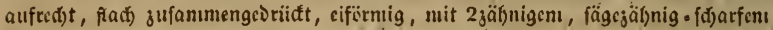
Sd)nabel und feinen 9iervenftreifen; Solm glatt; MBurgel faferig. Did)trafig,

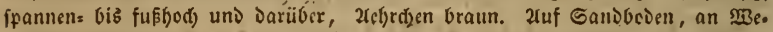
gen, Gräben, Zeidjen. Mai - Juli. 2uguft. 4. Durd) Das Geblet nidjt feltell.

bb. 3ilben eine Straufrizpe.

211. V. teretiuscula (Good.) Schk. t. D. 19. HрP. ST. Car. t. 9. Fl, gern. exsicc. 14(). 2(el)r(f)en ftrausartig, bid)t gcorängt, oben männ.

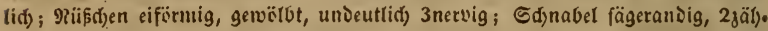

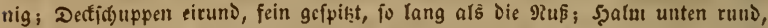

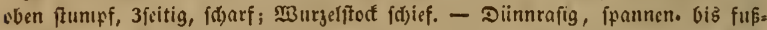

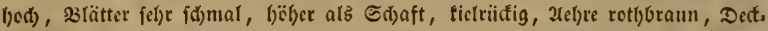

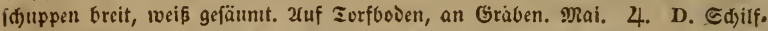

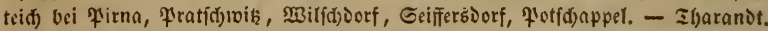

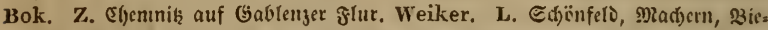

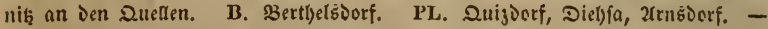
Suffau u. f. т. A. Dranienbaunt, 3erbft, Frièerifenberg. PS. Loberbad bei

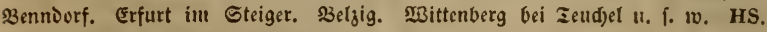
Roburg bei Rallenberg und Mï̈n(friben.

212. V. paradoxa (W.) Schк. t. E. 21. HPP. St. Caric. t. 12.

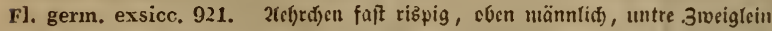

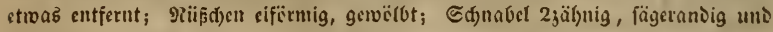
(biderfeits Deutlia) gencrvt. Dedffo)uppen fo lang als sie giiiffe. Etwas robufter,

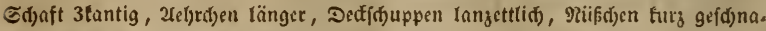

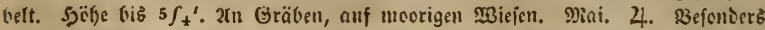
icm norö̈ftlidjen Gebiete cigen, fonft gerftent, im \$Beften felten. D. Remifen;

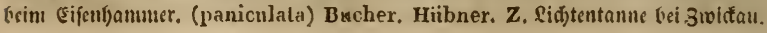




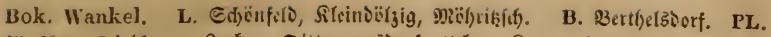

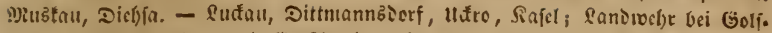

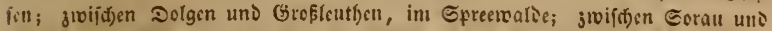
Galten, Epremberg. A. 3etbit. PS. Siestau.

213. V. paniculata (L.) Schк. t. D. 20. HPP. St. Caric, t, 19.

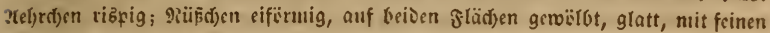

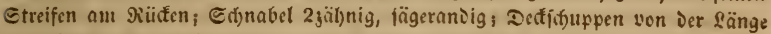

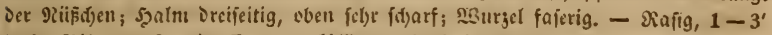

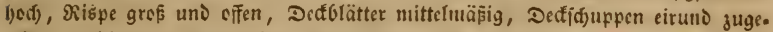

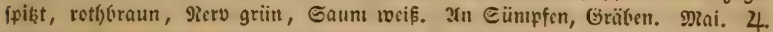
Durd) Das Gebict, Dod) jiemlidf felten: D. Firna (Bichleite u. f. w.). 3rvifdjen

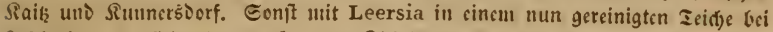

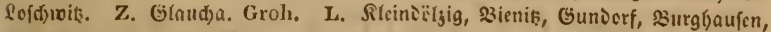

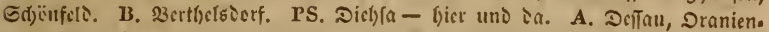
baum, Serbft. PS. Mittenberg (Debien, 21nteniubüüb)le). Dïben (Iornau).

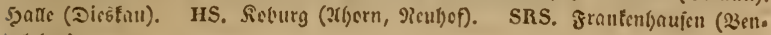
icleben).

c. Leimon astes: unäryte, rietgrabartige Eeggen, Deren untere atelyren weiblidis fint.

214. V. stricta (Good.) Scris. t. V. 33. Eе. 92. HрP. St. Caric. t. 43. Fl. germ. exsicc. 925. Die sberfte 2relfre männlid), weiblid) 2 4, feitlid), aufred)t, alle lang waljenförmig, fpisig, furjgeftielt (bibmeilen obere

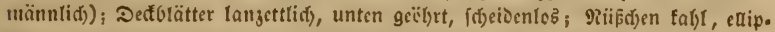

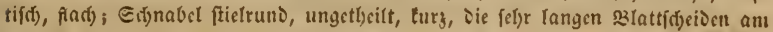

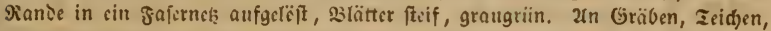

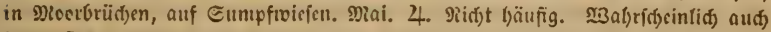

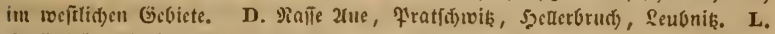
S(j)̈̈nfelo, sienif.s. B. Rioft felten. PL. Deşglcioben.

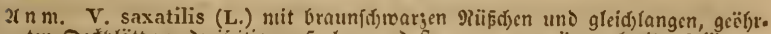

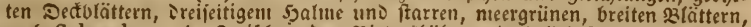

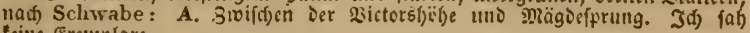
teine Exemplare.

215. V. pacifica (DrEJ.) Fl. exc. Hafn, pag. 292. Revis pg. 39.

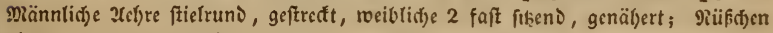

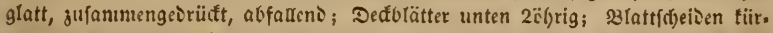

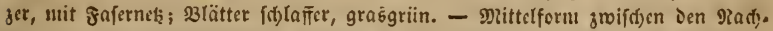
harn. - 2uf Sumpfwicfen. Maai. Juni. 4. Eelten. Bacldcidtt nur übericlyen. L. 2 m sienik, an Den Sd)ambertకqueden; an Gräben, auf ŞBiefen bei Rlcin. Dërig. (V. homalocarpa) Petermaxx. Miai. Juni. 4.

216. V. neglecta Peterm. હine zrocite Mittelform. Şalne Dïnu, (d)Iant uns fdjwantend; slätter fein; Gdjeiten nit Gafernefs, aber ofjne jene grofen braunen Edjuppen am Grunde. Silict äuserfit sidjte, grefe, runde, sia.

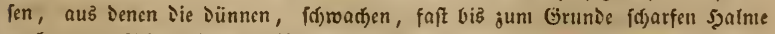

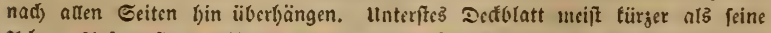
aebre. 2uf terfigen Miefen. Mai. Jumi. 4. Celten. L. Szci Xotuauniorf. 


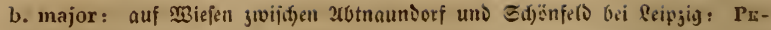
TERMANN.

217. V. caespitosa (L) Sснк. $t_{2}$ Aa. Bb. 8j, HрP. St. Caric.

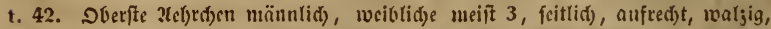

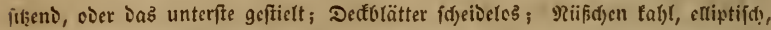

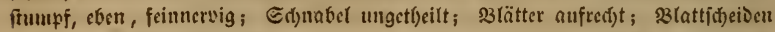

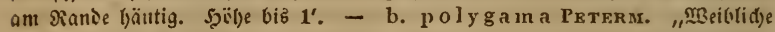

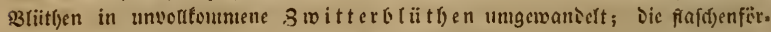

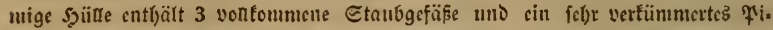

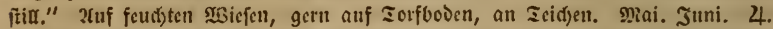
Durd) Das Geriet nidf)t felten. b. L. Rüifmaršborf gegeniiber neben Der (E)aufa fee, red)tb in Graben: Petermasw.

218. V. acuta (L.) Scrk, t. If. 92, HPP. ST. Caric, t. 44. Dic

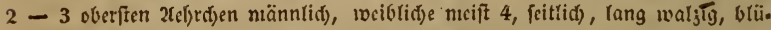

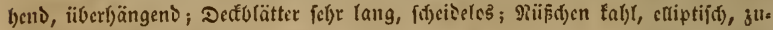

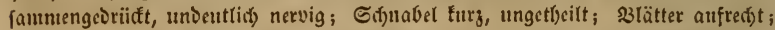

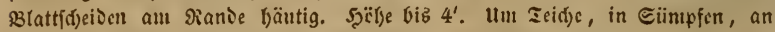

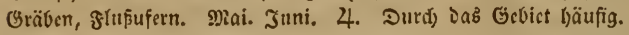

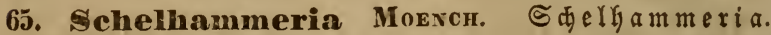

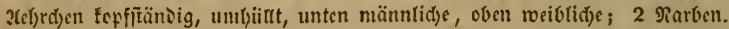

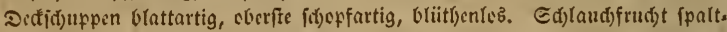

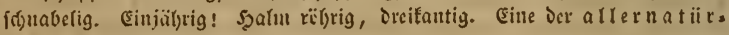

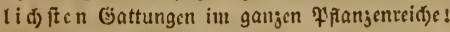

219. S. cyperoides L. Carex - Scrir. t. A. 5. Hpp. ST. Caric.

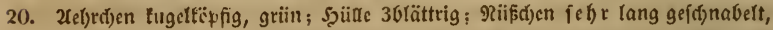

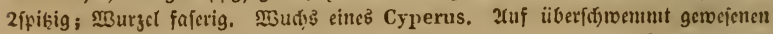

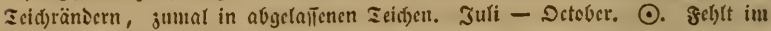

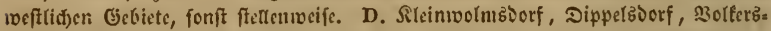

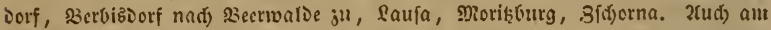
(Elbufer bišbeilen becbad)tet, Dod) Dajelbit unbeftändig. L. Brvijđ)en Pindenau

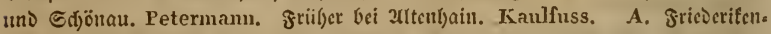

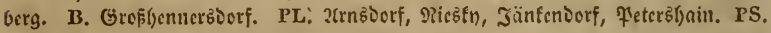

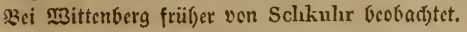

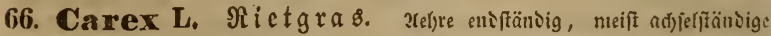

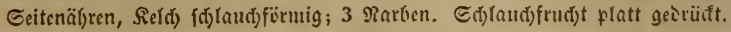
- sigl. Vignea.

a. Lencoglochin: Seggenartig; einzelne manumeiøige 2telge, ims ten meiblid).

220. C. Leucoglochin Енвн. Panciflora Lrgtf. Schк. t. A.

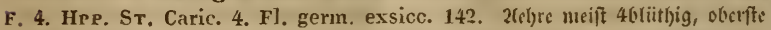

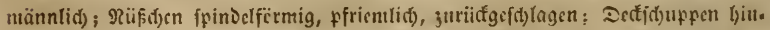

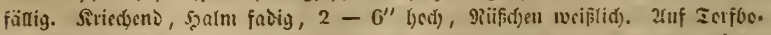
isn, namentlios nit Hypnum aduncum uno Oxycoccus, getn unter Pinus 
uliginosa. 9kai. Juni. 4. Sientid) feltill ; befonters auf bebuen Gebirgen, in

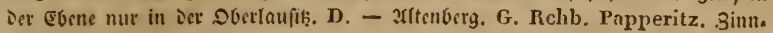
walb. Papperitz, G. Rchb. (B̈̈thnif( Sinnwals. Papperitz, G. Rchb.). Z. Joljanngrorgenfät. Bok. Brunner. (Unter Dem fid)telberge nad) Gottes̉gatie

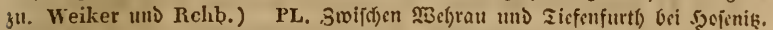
v. Albertini. - A. Giinter\$brgs, 5̧ar; nac) Schwabe. HS. Fennfteig auf

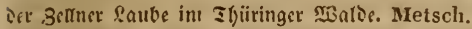

221. C. spicata Sснк. t. D. 15. Hрг, st, Caric. 3. Fl. germ.

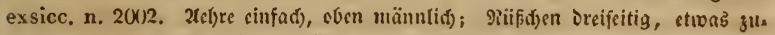

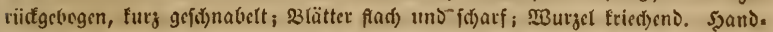

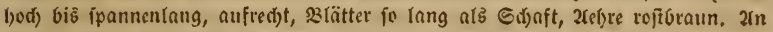

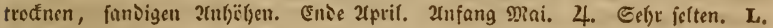
$2 \mathrm{~m}$ şicnif. Kunze. - Richter, Rossıässler, Reichenbach, W. Gerhard, Yetermann (Il, exs. 2002.).

I $\mathrm{nm}$. 24ufictom einft friiber gefunden : L. $23 \mathrm{sim}$ Gefundorunnen. Romanus Hedwig. PS. Gutenberg, Dem ₹annenberge grgenüber. Wohlleben. Dagegen Diirfte woljt Dic von Schwabe fl. Anhalt. bei Eeltentbal auf Iorfwicjen im Juni angegebne C. spicata eine anjoroginne ferm einer andern 2(rt fein, wie aud) Die won Dr. Jahn Z. bei Bcerwalde gefunine, in Sjerbar Des Soern $21 \mathrm{mt}$. mann Rodig bepinolidłc łinanze, nut eine andregyne C. panicea fift.

\section{b. Iydronastes: Seggenaltig; melfere mannmeibige 2(cl)r(f)en.}

222. C. Buxbaumii Wantxbre. Schк, t. x. Gg. 76. Hрт. St. Caric. 54. Fl. germ, exsicc. 530. Dbcritc 2(ef)ec sertefrt eifïrnig, obcn männ=

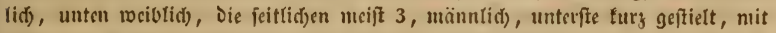

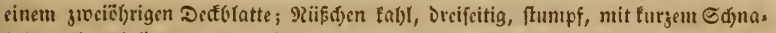

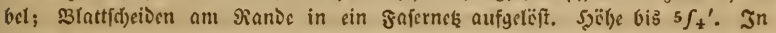

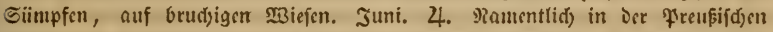

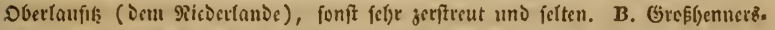

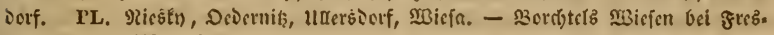
Dorf nit C. filiformis. A. Berbft. PS. 3wijđen der Sgeibe uno Dölau, Diş. tau (bri sjalle). Barby).

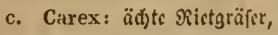

aล. 2rếren einfyäujig,

aaa. focioentragenic, Dectorattid)citen (wenigftens am rande) bäutig.

223. C. digitata L. Schк. t. H. f. 38. Hрr. St. Caric. 14. Dberfte

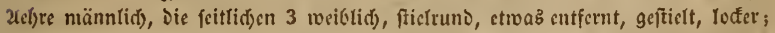

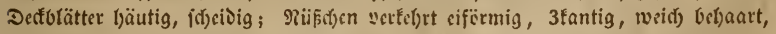

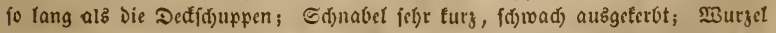

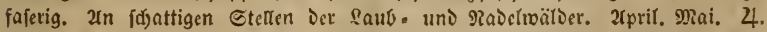
Den Gebirgen befonders cigen; in ier gricierlaufik jitumlidf jelten. Gonjt nidjt jelten.

\section{C. ornithopoda Winud. Schr. t. H. 37. Hrp. St. Caric.} n. 13. Fl. germ, exsicc, 1121. Mä̈nnlid)e 2(elfre einzeln, fiţen〉, weiblid)e

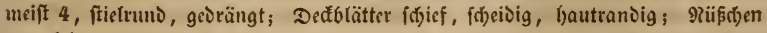
umgefelyrt sifïrnig, 3tantig, fein belyaart, gejơnabelt, länger atz sie untgefeflyrt 
citunden Deffiduppen. In liften saubrältern. Mini. 4. Siljr jetten. HS.

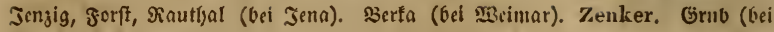
zbemar). Metsch.

225. C. humilis LExss. C. clandestina Schr. t. K. 43. HPP.ST. Caric. 15. Fl. germ. exsicc. 144. S)ännlid)e 2(el)re eingeln, gefticlt, meiblid)e 2, meift 36riithig, entfernt, fajt jikend und eingejd)lofen; Decfolätter breit bauts

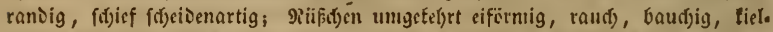

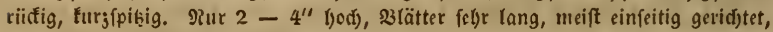
fteil. Cdjuppen Der niäunlidjen 2(el)re umgeffelyet eirumo, Der weiblidjen ciruno jugefpișt, Dunfelbraun, 9ierv grïn, Eaum breit, weifs. 2uf grafigen, fonnigen

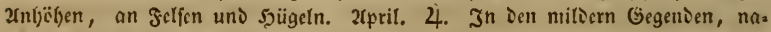
mentlic) um Dresien und Jena. D. Tlauen, Sofel, Radebeil, fößniķgruno,

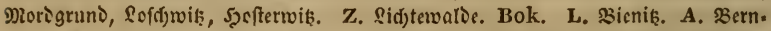
burg, Ganderslcbon, J̧arjgerede. PS. Şalle in Der Şeide, bei fangenbogen, Bettin. Erfurt am Etollberge. Saumburg. HS. Sanograf, forft, Rautbal bei

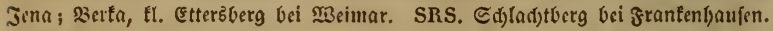

226. C. supina W. HPP. St. Caric. t. 19. glomerata ScHz, t.

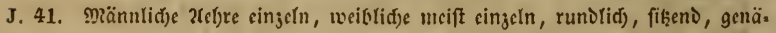

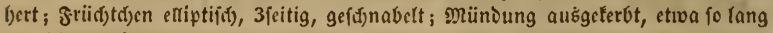

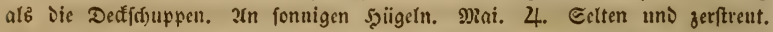

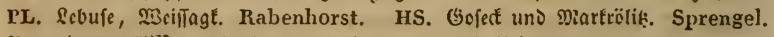
Raumburg. Miiller. SRS. Jrantenbaujen bei Ibaltsben. Hornung.

227. C. pilulifera L. Schк. t. F. 39. HрP. Sт. Caric. t. 26. Fl, germ. exsicc. 413. Dbere 2(i)re männlid), feitlide weibltd), meift 3 , genälyert,

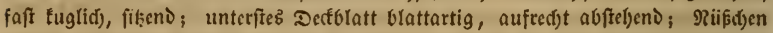
fugelig eifirmig, 3fantig, fury geid)nabeft, weid) beljaart; Dectidjuppen ftadjel.

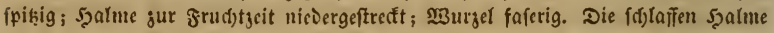

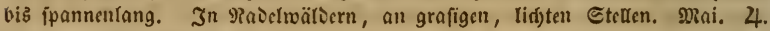
Durd) bas (Gebiet nic)t jelten.

228. C. montana L. Hrp. St. Caric. 21. collina Scuk. t. F. 29. Fl. germ. exsicc. 926. Dberfte 2fel)re männli(f), fcitlid)e $1-2$ weiblid), gc.

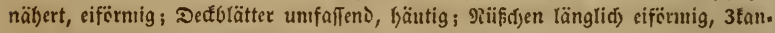
tig, mit furjem, aubagcterbtem Edjnabel, furz beljaart; Def́fil)uppen ftunipf, fta.

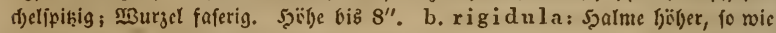
Die 3 lätter fteifer, weiblid)e 2Clyre einjeln, nit langem Deffblatt. 3lätter fel)r fd)mal, 5yalm aufred)t, fpannenlyod). - In fdjattigen faubwäloern, befoniorb in

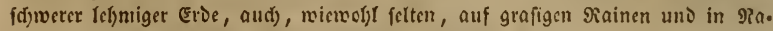

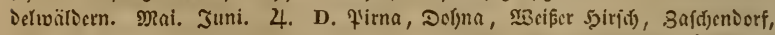

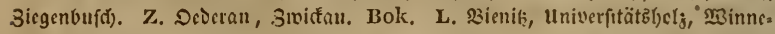

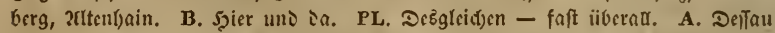

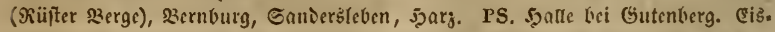

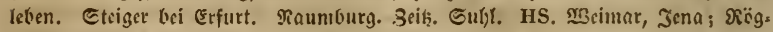

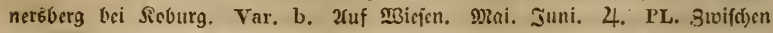

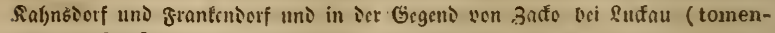
tosa). Rabenhorst. 
229. C. ericetorum Polich. HрP. St. Caric. n. 26. ciliata

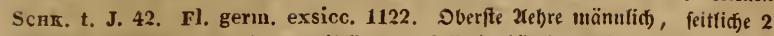

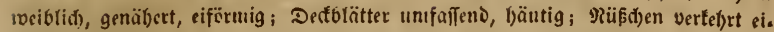

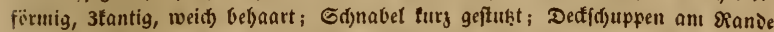
(d)wad) gemimpert, ftumpf; $\mathfrak{B}$ Burget fproffentrcibeno. - 2(ud) feuntlid) ourd Die breiten, fteifen, ausggcbreiteten slätter. Shalm bis fipannent)od). 2(uf Dürrem

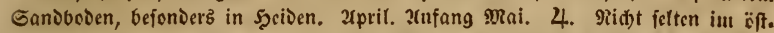

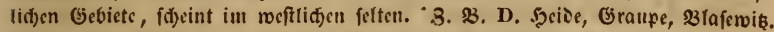

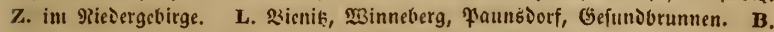

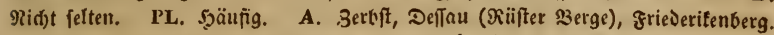

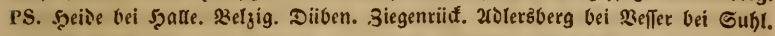

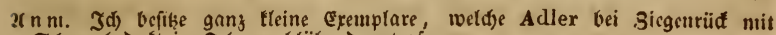
Sd)nee beorft in sebruar bliibento antraf.

230. C. praecox JacQ. Schк. t. F. 27. Hрp. St. Caric. n. 24. Docrffe 2at)re männtid), feitlidge $2-3$ weiblidłe genäb)ert, (änglid) eiformig, un.

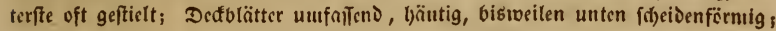

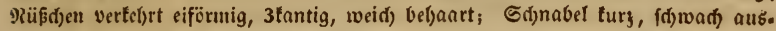

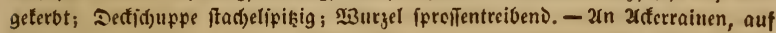

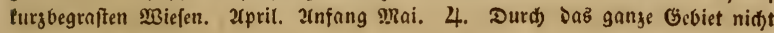
feltcu, uteift väufig.

231. C. tomentosa L. Scrk. t. F. 28. Hpr. St. Caric. n. 28.

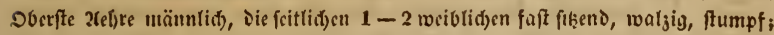

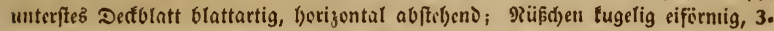

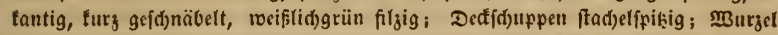

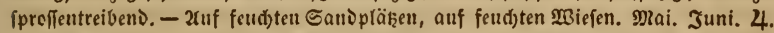

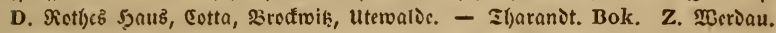

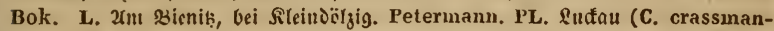
niana) Rabenhorst. A. Deifau, Dranienbaum, Berbft. PS. Gutenberg bei

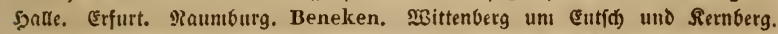

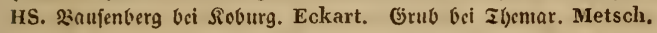

232. C. umbrosa Host. Schk, t. Ffff. 190. Hрp. St. Caric. n. 35. Mä̈nnliđ)e 2(c) fre fpindelförmig, weiblid)e $2-3$ walzig, genäl)ert, unterfte

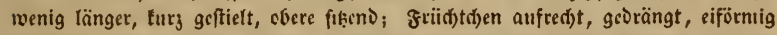
rundlid), raul); eirunde ftuntpfe Def(j)upfen gleid)lang. - 2tuf feud)ten $\mathfrak{B i e f e n , ~}$ in lidften Etellen Der Saub. und Madelwärber. Mai. 4. Mrid)t allgemein ver. breitet. D. Sofd)wiš; ver \&angenorüđ ; Pirna. Ppptz. - \&iebftadt. Z. Şarteuftein.

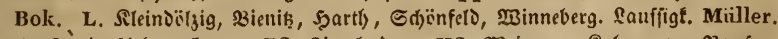
A. Canderżleben, 5zarj. PS. Sicgelrode. HS, Meintar. Soburg anı Baufen. berg. Eckart.

233? C. fulva Good. Schк. t. T. 67. Sigur renttz. Hpp. ST. Caricol, n. 41. Fl. germ, exsicc. n. 1S32, Männlidłe 2efhre ftiefrund fpindelför.

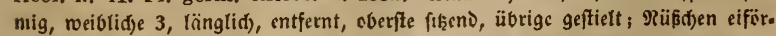

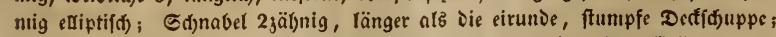
Salnı nad) oben raut). Bon folgcnder 2(rt (d)on Durds Das thetle (Briin, grofe

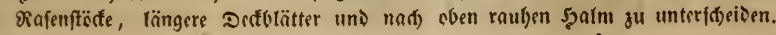




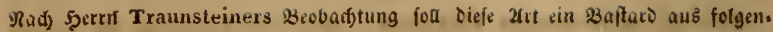
Der 2ut und C. Hava fein; abermars ein wid)tiger Sdjritt zu 23eurtbeilung Der guten 2rten! - auf naĨen $\mathfrak{B} B i e f e n$ ferten. Mai. Juni. 4. Bielleid)t an man. (jen Drten no() überfel)en. P'S. Salde bei Gutenberg nad) v. Schlechtendal (Flora 1840). 3ufcriem nod) angegeben: B. Baukzen. PL. G̈̈rtik, Eiefen.

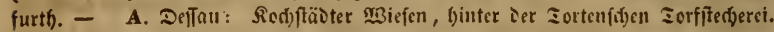
PS. 3 enniorf.

234. C. Hornschuchiana HPP. Scнк. t. T. 67. Figur lintz. HPP. St. Caric, n. 4). Fl. germ, exsicc. (C. Hosteani) 1504. Drännlid)s Zebre etwas feulenföruig, weiblid)e meift 3, untere geftielt, obere fik̨eno; Riißs.

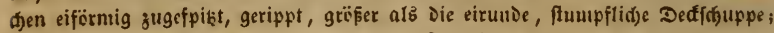
5alm glatt. - 2luf malfen Bicfen. Mai. 4. Wemiß nod an mel)ren Etelln. p. शaffe 2ue ftreffenwiije. L. SBienik, Dölgig.

235. C. distans L. Sснк, t. T. f. 68. HрP. St, Caric. n. 42. Fl. germ. exsicc. 15()5. Mä̈nnlid)e Xelyre fpindelfürmig, tculig, 3 mciolidje eiför.

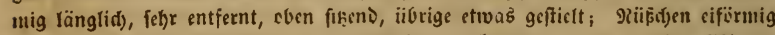

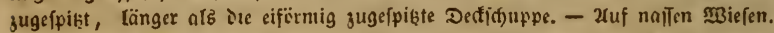
Mai. 4. Nidft felten. D. Remifen bei Eotta; Seubnib; NaiTe Xue. Sottaer Spikberg. L. Dölzig, હonnewik. PL. DeDernił, Robols - befonders weftich

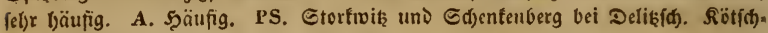

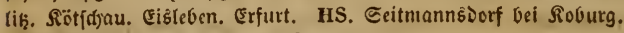

236. C. panicea L. Scrk. t. Ll. 100. .HPr. St. Caxicol. n. 33. Männlid)e acbre fpindelförmig, 2 rociblid)e, entfernt, aufred)t, locter, obere cin.

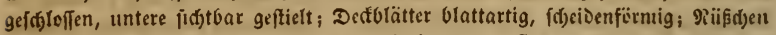

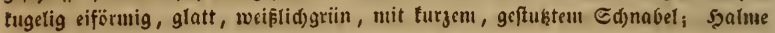

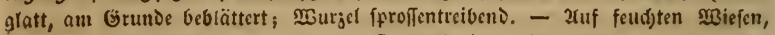
aud) auf Gandovoen. Miai. 4. Mieifĩ gemeill Durd) Das Gebiet.

237. C. glauca Scopoli. Schк. t. O. P. 57. HpP. St. Caric. n. 67. Fl. germ. exsicc. 914. 1 - 2 männlidge 2(ef)ren, Diff, ipindelförmig, 2 - 3 untere weiblidje, waljig, Did)t, lang geftielt, julek̨t bängend; Decfolätter

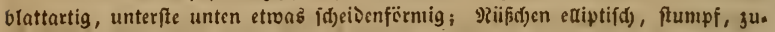

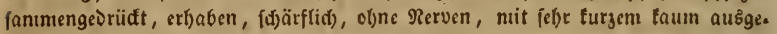

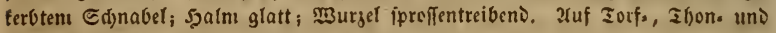

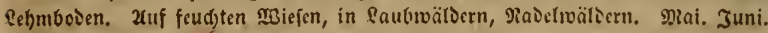
4. D. Remifen, Egelfee, Raffe ?ue, im Siegenouid) u. a. D. Z. Sier und Da. L.

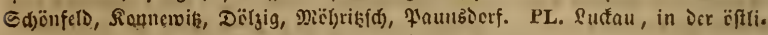

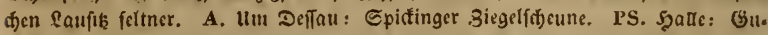
tenberg, Dëlau u. i. w. Mittenberg, Belzig. HS. Vieufrait, Reburg.

238. C. pallescens L. Sснк. t. Kk. 99. HрP. St. Caric. n. 44.

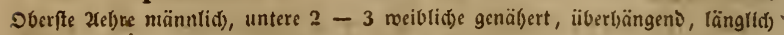
eiförnig, Didgtfrïd)tig, firftbar gefticlt; Defblätter blattartig, fdjeisenförmig;

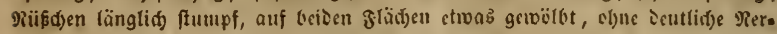

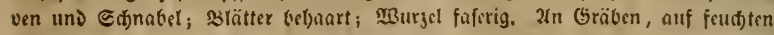
Miefen, in Radelwäldern. Mai. 4. Durd) Dab Gebist nidjt felten.

239. C. sylvatiea Huds. (Drymeia Евян.) Sснк. †. L. L(1). 
HpP. Sr. Caric. n. 55. Rännfid)e 2(ebren $2-3$ tur findelfïrmig, weiblid)e

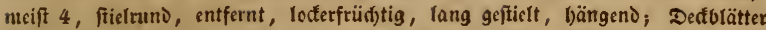
blattartig, jur Şälfte f́cidenförmig; शtiifid)en längliđ), 3tantig, ganz glatt,

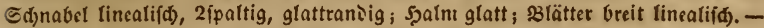

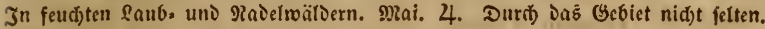

240. C. hirta L. Schk. t. Uu, 108. Hpr. St. Caric. n. 58. Smei

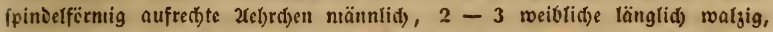
aufred)t, entfernt, unterifte geftielt; Dedf(d)uppen ftad)elipisis; unterftes Dectolatt

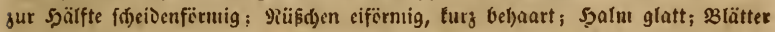

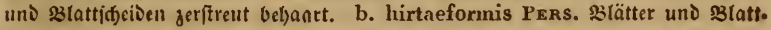

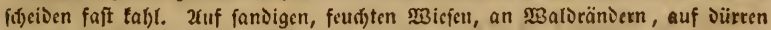

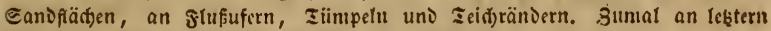
Stetlen Die 2bart. Mai. Juni. 4. Durdy Das Gebiet gentin.

241. C. limosa L. Scnk. t. X. 78. HрP. St. Caric. n. 49. F1, ger̀n. exsicc. 150. Die oberîte Uelyre ntännli(i), feitlitfe $1-2$ wenig entfernt, iiberljängeno, allf feincn Sticlen, länglid); Yiüs(ben runolid) oval, ftumpf, tin.

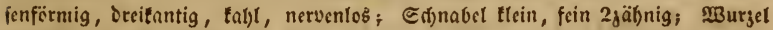
fproflent. - Jn Torfmeoren. Mai. Jumi. 4. Jn äftid)en uno nittlern Gebict

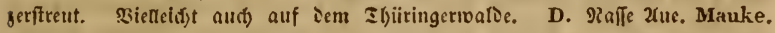

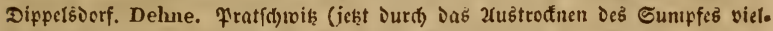

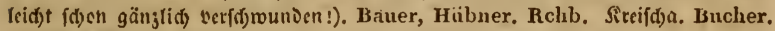
- 2utenberg. G. Rclib. Z. Jobanngeorgenftaot. Brunner. Bok. PL. Drau. fentorf. Burkhardt. Tafelfidste all 2(bhange gegen Das Speufuier. v. Alber-

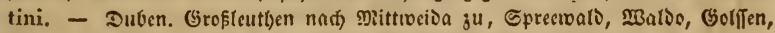

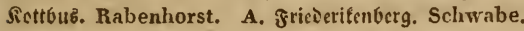

242. C. filiformis L. Sснк. t. K. 45 . HрP. Sт. Caric. n. 31. 1

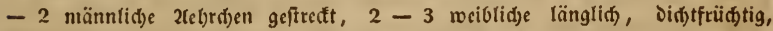

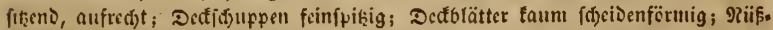
d)en länglid, eifïrmig aufgetricben, fur bel)aart; Şalm ftumpflantig, geftreift;

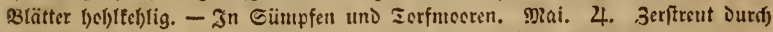

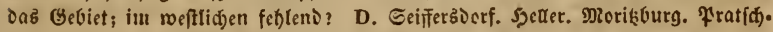
wię. Z. MBerdau. Bok. B. Tauniorf bei $23 \mathrm{ernftadt}$ Şertnlut. PL. Gee,

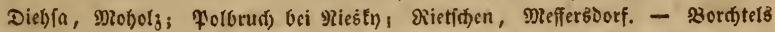

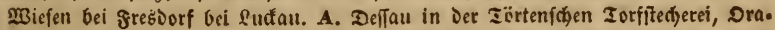
nienbaunt, friederifenberg, 3crbft. PS. Riestau, Srjmon bei Spalle. Dorno's ङee bei selgig. Drtrant.

243. C. paludosa Good. Schк. t. Oо. Vv. 103. Hрr. St. Caricol. n. 63. $2-3 x_{e}$ (j) pen ftumpfliç), $2-3$ rociblid)e, malgig, Didffrüd)tig, aufred)t, fikeno, untere geftielt; Dectid)uppen lanjettlid) feinfpißsig; Dedforätter niđ)t fd)eidenförnig;

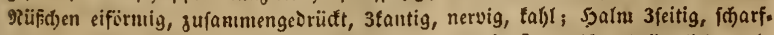
tantig. Var. Ko chian a Dec. HPP. ST. Caricol, n. 62. Männtidbe 2teh. ren $2-4$, ungleid' lang, faft bäutig, weibliche $3-4$, waljig, oben fibeno, unten geitielt; Riißş)en faft tegelförmig zugefpišt, 2 jäbnig, glatt, geftreift; Ded.

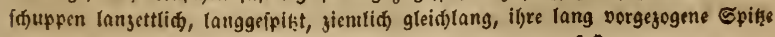




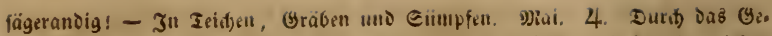
viet nidgt felten. Var. K o ch i a n a De C.: L. Stanbvorwert, Parthentviejen, Gerberwiefer, zaud)a, Bisniţ, Gropoützig. Petermann. HS. Foburg bii ¿ü̈z̨elbađ), Hornung. Eckart.

244. C. riparia Curt. Schk, t. Qq. Rr. 105. Hpp. St. Caric. n. 66. $3-5$ nıännli(ł) 2(el)ren, $3-4$ weiblid)e, roalgig, Di(ftfriid)tig,

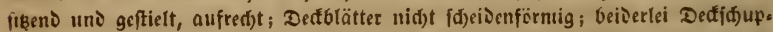

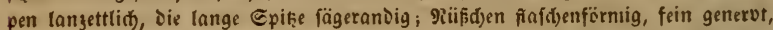

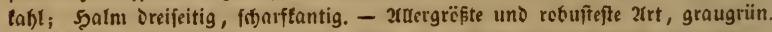
In Günpfen, an Glïifen, zeiden. Mai. 4. Durd) ১as Gebiet nidjt felten.

245. C. Oederi Retz. Schk. t. F. 26. Hpp. St. Caric, n. 23.

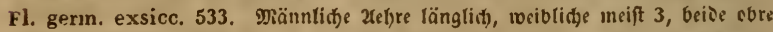
nabe und fikend, untre entfernt uno cingefdolofien gefticlt; Niifisen faft fuge

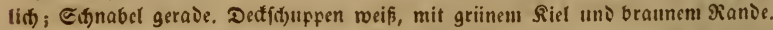

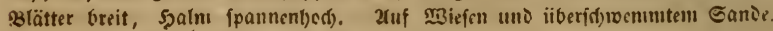
Mai. Juni. 4. Durd) Daśs Écbict nif̧t felten.

246. C. flava L. Scнк, t. H. 36. HPp. St. Caric, n. 22. Männ=

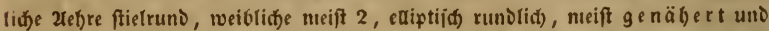

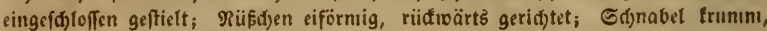

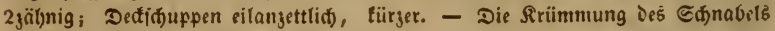

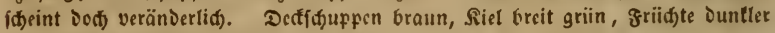
gelb, slätter fđamäler, beder grïn. Xuf nalien, sumal torfigen Miefen, an ₹ei. ijen und Gräben. Mai. Juni. 4. Mcift läurig.

247. C. lepidocarpa Tavsch, Hrp. St, Caxic. n, 25. Kunzi Suppl.n. t. XII.2. Fl. germ, exs. n, 2005. Miännlidje Xelfre eingeln empor, geftreft, weiblide $\mathbf{2}-3$, entfernt, eiförnig, unterfte geftielt, mit langem, fiteis

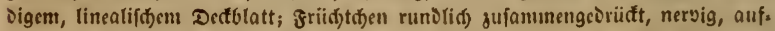
geblafen; Sđ̆nabet 2jäl)nig, abwärts gerid)tet; Dedf́d)uppen ftunıf; Szalu faft

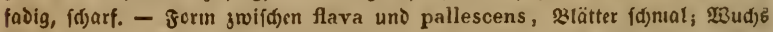
(d)lant; fpannentyod). Xuf torfigen Micjen. Rai. Juni. 4. Eelten, L. Bie.

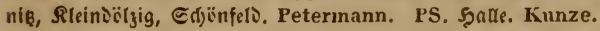

248. C. Pseudo-Cyperus L. Sспк. t. Mın. 11)2. Нрғ. St. Caricol, n. 56. Fl. germ. exsicc. 2006. Dberfte 2(el)re männlid, Die unteren 4 - 6 meiblid, walgig, Diđtfriidtig, lang geftielt und bängend; untere Dect.

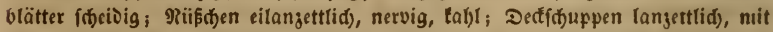

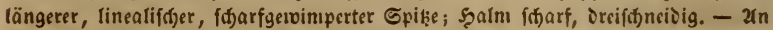

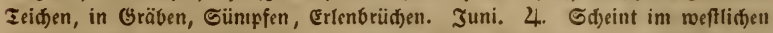
Gebiete felten, fonft ftellenweife. D. Bebift, Pirna, Mlorib̧ourg. Z. Sroiđau, sä.

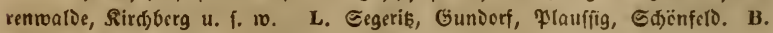
Şäufig. PL. Şäufig. A. DefTau. HS. Bittenberg. Dieśtau, 23rudōorf, Ean. nena, Bennoerf bei Şalle. Erfurt, Bei Dolftbeite in Edradentoalde.

249. C. maxima, Scop, (Agastachys Енян.) Sснк. t. Q. 6).

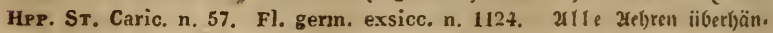
genঠ, 1 nünnlidbe jpindelförnig, 4-6 weiblicke, geftielt, febr langteulig, untre 


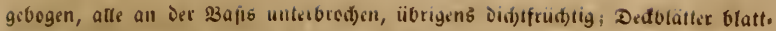

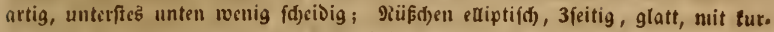

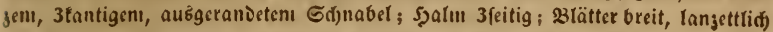

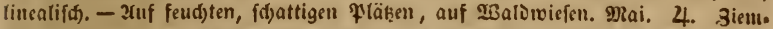
(id) fclten. B. 2(n Gd)önbrunner Berge. Külbing, Burkhardt, PL. Spree.

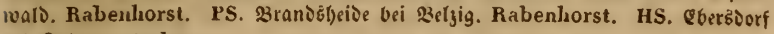
bei Roburg. Eckart.

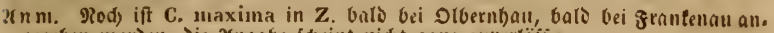
gegebelt rourden, die zungabe fideint nidjt ganj juverläfíig.

250. C. ampullacea Good. Sснк. t. Tt, 1177. Hрғ. St, Caric.

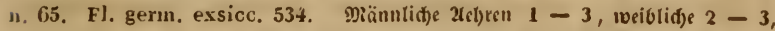
cutfernt, walzig, Didst, furg gefticlt, aufred)t abfteljend; Dedfblätter feĺr lang, fd)eidenlos; Prïst)en aufgcblafen, faft fugelig, tabl, binten nervig, mit lineali.

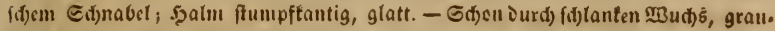

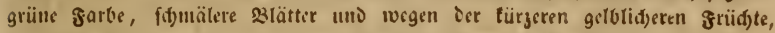

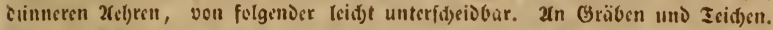

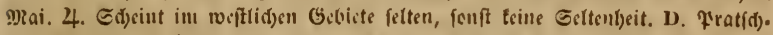

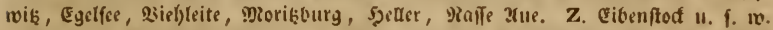

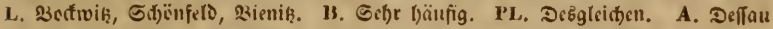

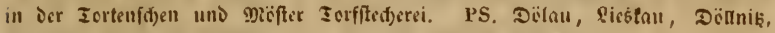

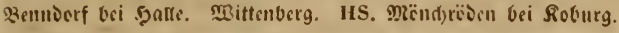

251. C. vesicaria L. Scнк, t. Ss. Ilff. HPp. St, Caricol, n. fit. F). germ, exsicc. 535. Mzännlid)e 2telgren 1-3, weiblid)e $2-3$, cntfernt,

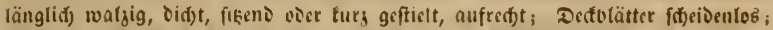

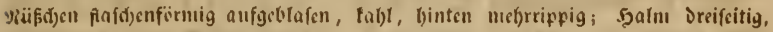

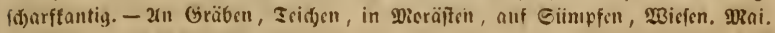
4. Durd) ธกล (๖่cbiet bäufig.

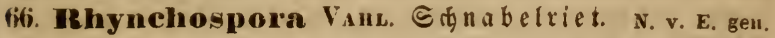

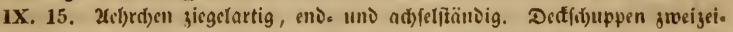
lig, core $2-3$ mit 3 tiithen, unterfte $3-4$ tïrger, Glütbenlos. Borften

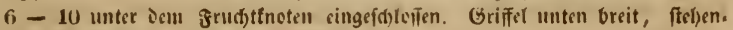
bleibent. grarben 2. Switterblütl)en.

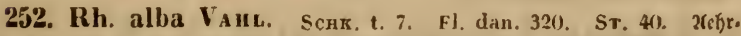
d)en faft dolentraubig, Enauclartig; Deffolätter gleich lang; 10 3orften fo lang,

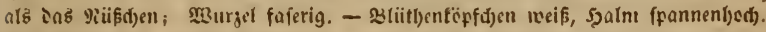

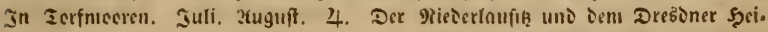
Delanie befoniers cigen, fonft gerfitrut, im weftlid)en Gebiete felten. D. fange. brüd, Dtteniorf, ?auja, פiorib̧urg, Sinocnau, Steinbad), Fenifnu, Gräfen.

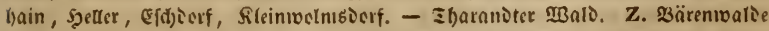

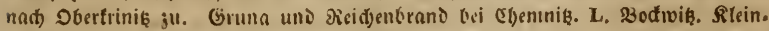

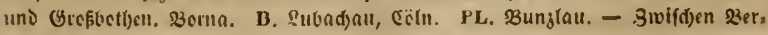

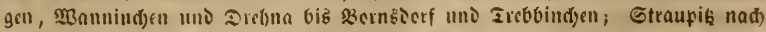

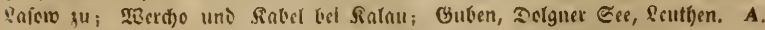

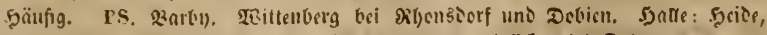

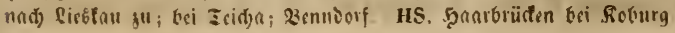


253. Rh. fusca R. Sсн. Sr. 41). El. germ, exsicc, 206. 2elfr. den lopffïrmig tnauelartig; Deđtblatt meit länger; Borften länger als Das Rüs.

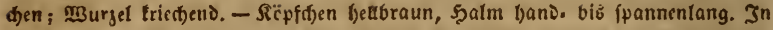
Torfmoeren, an Ieidrändern. Jufi. Xug. 4. Berbreitung wie bei voriger, Dod) felt.

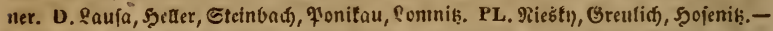

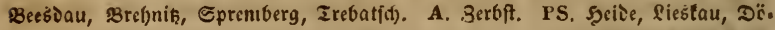

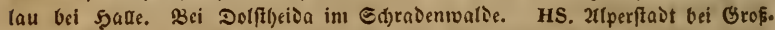
rudeftedt.

67. Sehoenus L. Ropfriet. N. v. E. gen. IX. 16. 17. Utefo.

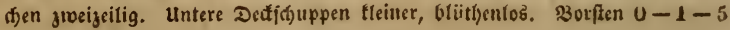
unter Dem grud)tinoten.

a. Schoenus: 2l(t)je gerade.

254. S. nigricans L. Sr. 40). Fl. germ, exsicc. 204. şalm fticl,

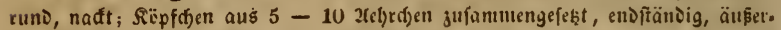

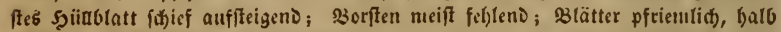

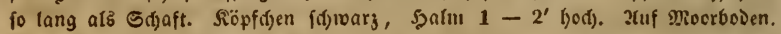

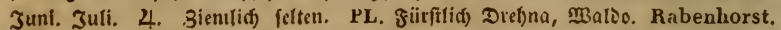
A. 3erbft, Radegaft. Schwabe. PS. Moka bei 3iegenrïđ. Adler. HS. Sinter

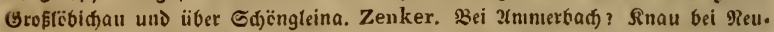
ftadt. Adler. HS. 2llperftadt bei Grofrudefteit. Hornung. Crasso. SRS. Dörnfets nach) Grieśbeim zu bei €tait Jimt. Schönheit.

b. Streblidia Lr. xđfe gèreft.

255. S. ferrugineus L. Schiad. Fl. g. t. 1. f. \&. St. 4). Fl. germ. exsicc. 205. Sgalnı ftielrunt, nactt; Sïpfdyen feitlid), au6 $2-32$ el)r.

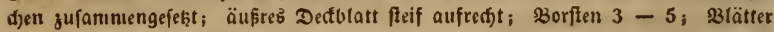

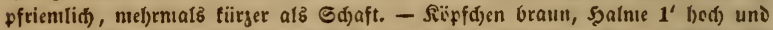

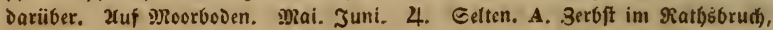

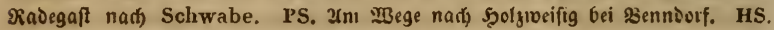
Gigend von Grofrudefted bei allperfadt. Hormung.

In m. उत) befike Epenılare von Moritz Kiistner 1811 HS. bei Stotterul)eiu! gefaminit. Daf fie fid) nad) Zustredıung Der grëßsten Dortigen 3rüde ned erf)alten babe, bejweifle ith.

68. Cladium P. Browne. গ̉ǘriet. N. v. E. gen. IX, 18. Xefjrden büfdjelartig, meift 2bliitbig. Dectíf)uppen su 6, Die 3 untern flei. ner, blütbenloz. Girifel abfatlend, 2 befaferte garben. शus bartídoalig. Gaame faft fuglia).

226. C. Mariscus P. Br. Sr. \#. Irugoctie end und adjeclfän. Dig; blattartige an Der Safı̈ fdjeidige Dectolätter, fo wie Die Slätter amı ßiande

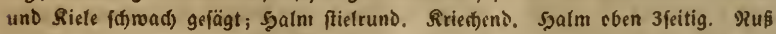

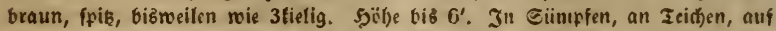
brudigen M3iefen. Juli. 2ruguft. 4. Geljr filter. PL, Guben. Ruff. A. 3erbit, Rogäjen. Schwabe. PS. Xitern. Beyer.

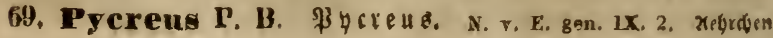




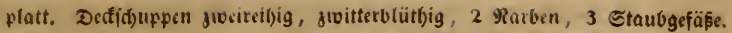

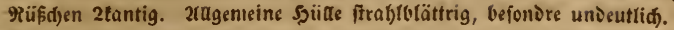

257. P. flavescens. P. B. Scrk. t. 7. Fl. germ. exsicc. 151.

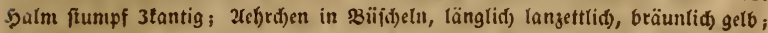

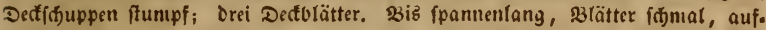

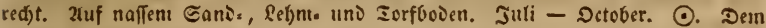
Dresoner 5cibelande und Sauftser grieierlande bejeniers eigen, fonft zerftreut.

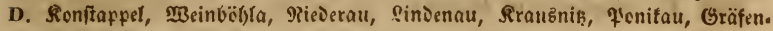

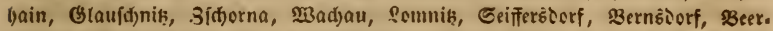

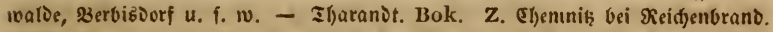
Heiker. L. Sindentlyal, Borboorf, Großppartbau, q'(auffig nad) Gegerifi zu, Grofbotljen u. f. w. B. Priđt) felten. PL. Şäufig - Dezgleidten: A. Deflan,

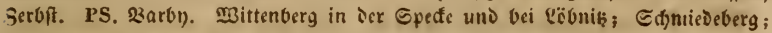
Remberg; Dïben. HS. Beitgrunt bei Jena. Serfa bci æBcinar. Reufbof bei

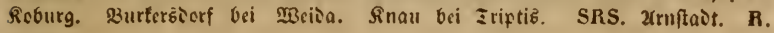
Plotben.

70. Cyperus L. (5)pergra d)en platt. Defíf)uppen jmeireil)ig, suvitterbliithig; 3 yearben, 3 Staub.

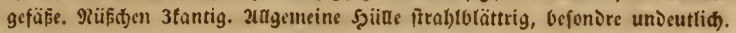

258. C. fuscus L. St. 52. Fl, germ, exsicc, 152. Salm fdarf

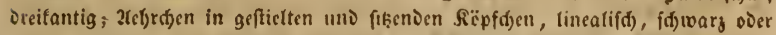
grïntid), (Dann aud) fd)lanter gebaut); Dectid)uppen fpik; 3 șïublätter. Bie fpannentang, slätter breiter, aubgebreitet. - Die 2rbart nit grïntid)en Ř̈pf. d)en (C. virescens Hoprar) ift fef)r unbeptändig, erfdgeint bištvcilen oa, wo Dab Jafre zuvor C. fuscus ftand (j. 23. D. bci Dippetsiorf). In Gräben, Ieiden, Flufufern. Siebt thonigen sicien. Juti - Detober. (.) Stentenmeife. D.

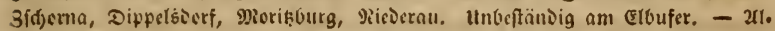

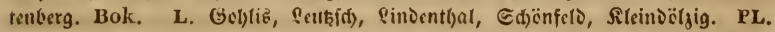

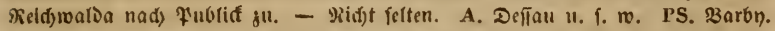
ßittenberg in ser Epefe; Ed)mieieberg, Remberg, Düben. Şafe bei Gicbid)en.

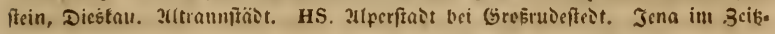
gruno. Roburg.

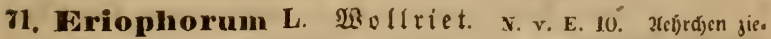
getîtänig. 3 gearben. Dectidufupen vteibent. Gur Frud)tzeit wabjen weife

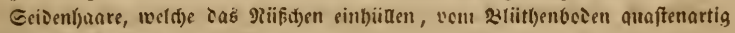
iiber Dic Dectid)

259. F. vaginatum L. Sr. 10. F]. germ. exsicc. 1410. Ђalm glatt, oben 3fantig; Gd)eioen aufgcblafen, nur vie unterfte trägt sin furges 23latt; 2al)re einjeln, nufred)t, läıglid) ciförmig; Scibenbaare gerąe. - 2uf בorf. bcien: in Moräjten, Mäliern, an Gräben. 2tprit. Siai. 4. Riorjüglia im boben Gebirge; fonft gerftreut, im veftlid)en Gibiete fparfamer. I). Sangebriä,

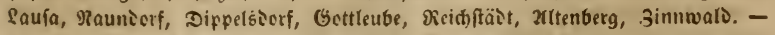

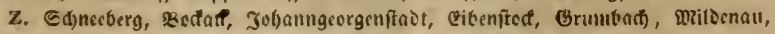

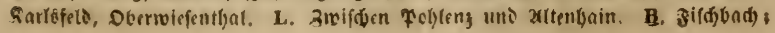




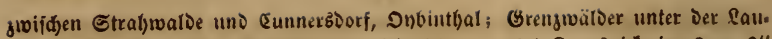
fde in unnalfe. PL. Iafelfidste - nid)t felten; "bei Rrausnid eine $2-3^{\prime \prime}$ bobe Barietät mit abrocidenden Gđuppen (hunile)". Rabenhorst. A. Cdjie. rau. PS. Femberg, Düben, Eilenburg: rotbes Şaub, SBitterfels, 5oljroeifig,

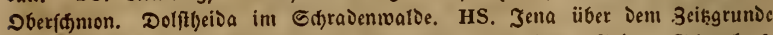

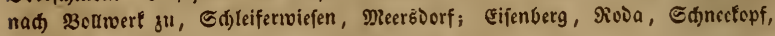
Beerberg.

260. E. triquetrum Hoppe. St. 10. F], gcrm. exsicc. 422. Şalı

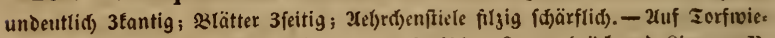
ien. 2rpril, פrai. 4. Celse felten. D? Swoiftien Sangenoriid und Piega? $B$.

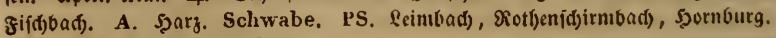
HS. Berta. NBeimar. Zenker.

261. E. angustifolium Котн. Sт. 10. Fl. gem. exsicc. 931.

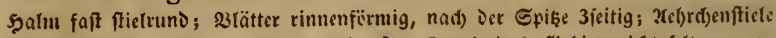
glatt. 2uf Iorfooden. 2pril. Miai. 4. Durd) Das Gebiet nid)t felten, na. mentlidi) in şeidegegenden gemeitr.

262. E. Iatifolium HoppE. ST. 10. Fl. germ. exsicc. 932. 5ुalm

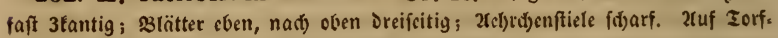
ıiefen. 2upril. Mai. 4. Durch) Das (Yctriet gemein.

72. Seirpus L. $\mathfrak{B}$ infe. diffr(b)en jiegelf(f)uppig, eingeln ober bii. id)elftändig. S3tütben zrvittertid). 3 Rarben. Sorften Kurz, 6 oder 0 .

a. Limnochlo a P. BEauv. Ffublbinfe. 2felyre endftändig, meift 63 orften. Griffel fadenförmig. Mrü 3fantig. S3lattrofe Etfeiden oder fd) aftartige 33 lütter.

263. S. parvulus R. S. Rснв. Pl. germ, exsicc, n. 419 . C(n)aft

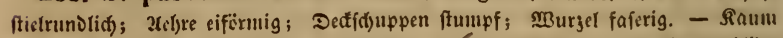

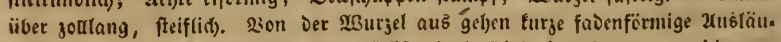
fer, weláse Sroiebelf́nollen von Der Grïße eines şirfenternes tragen, Die son

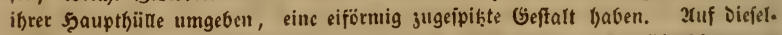

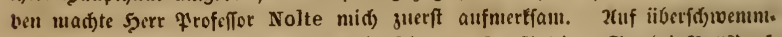
ten Stellen. Juli. atuguft. ○. Gelyr felten. PS. Satgiger See bei Rollboorf. Wallroth, Sprengel, Kegel. Pritzel u. ?. - Sriiber aud) im Rölmer Ces. Sprengel, Hübner.

264. S. fluitans L. Fl. dan. 1082. Etengel nicberliegeno, öitig, Gratt.

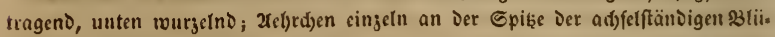

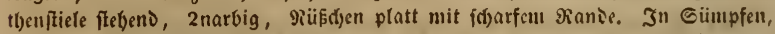
stiden. Juli - Eept. 4. Eeljr fclten. A. 3erbit, Dranicnbauu nadi Schwabe. pS. Im falgigen Gee. Wallroth Mantiss, pag. 4. Jd) foll) Dal)er feine (Epentuplare.

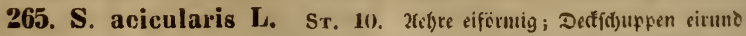

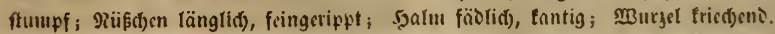

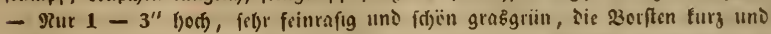

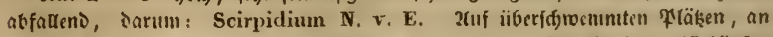

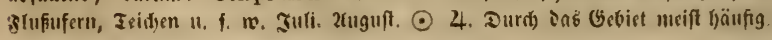




\section{S. Baeothryon Ebrh, Drew, u. Hayse 1. t. 22. N. v.} E. gen. IX. 12. ST. 16. (nidft Fig. F.). Fl. germ. exsicc. n. 539. 2(ch)re tiirzer als Die unterfte abgerundete Dectif)uppe und von iljr umfafit. Etroa 2 $3^{\prime \prime}$ bis fpannenlang. 2luf fumpiggen, befonders torfigen \$Biejen. Juni. Juli. 4.

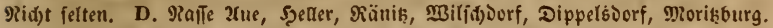

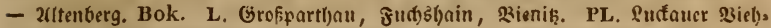

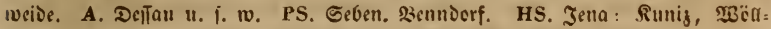

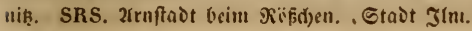

267. S. caespitosus L. ST. 11). Fl. germ, exsice, n. 929. Diع oberite Sd)eide trägt ein furjes s3latt; Dic unterite grëste Dectifituppe fo lang als Dic 2ebre uno fie unifaifeno, Deren Stad)eljpikze Diff uno griin. - Xuf toriggen

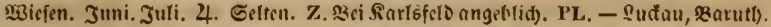
Rabenhorst, A. Nicgälen. Schwabe. PS. 23clzig. Rahenhorst. HS. Jena: bei E(t)leifereifen, Miencsiorf, Slefter ?aušnih, nad) Dittrich. Ed)neetopf. Metsch.

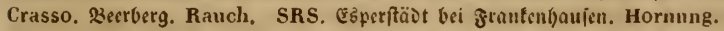

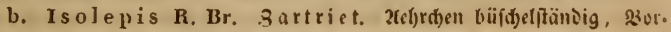
ften 0,3 lätter fur\}, fdscidig, Griffel fàenfïrmig.

268. S. setaceus L. St, 10. Fl. germ, exsicc, n, 416. 3(ch)t=

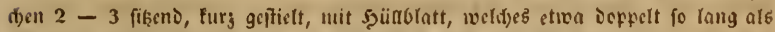

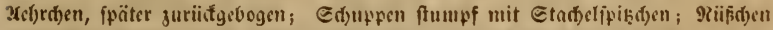

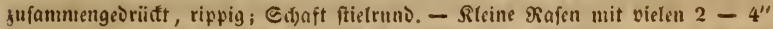

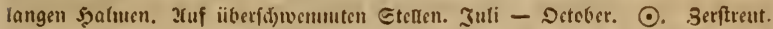

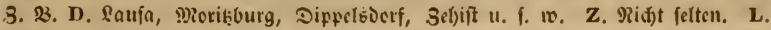

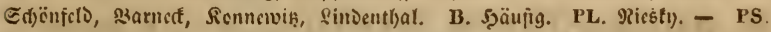

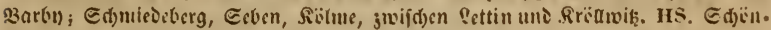
gleina, Scibgruni bei Jinu. Ditpperg bei Roburg.

269. S. supinus L. Schrad. Fl, germ. f. 1. 2(el)rdiden $2-8$;

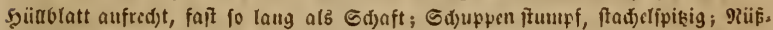
d)en 3tantig, nuctrunjelig, 巨d)aft ftiefrumb. - In aden zlyeilen Differ als serige

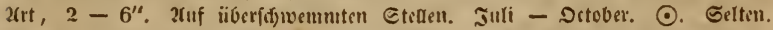
PL. Sürftlid) Dreljna, Solfmik. Rabenlorst. A. MBerbersbaufen, Giiften. Schwabe. PS. Xidjersliben. Hornung. Sarby? fübcjïn bei Sattau. Schwabe.

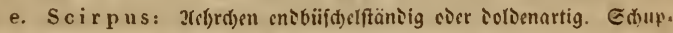
pen ausgeterbt. Serften 6. Griffel fadenfïrmig, abfallend.

270. S. lacustris L. Fl, dan. 1142, ST, 36. Salm fticlruni; ilc

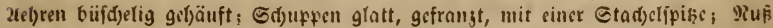
3tantig, glatt; 3orften rïđuërts wimpetborîtig. In tiefen scidjen. Juni. Juli.

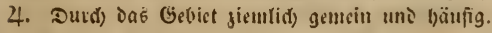

281. S. maritiuus L. Scнк. t. 8. F1. dan. 937. Sт. 13. 5alıt 3tantig; stätter am etenger uns unter ser zrugiolie linealifd, fiad); Die 2tefr.

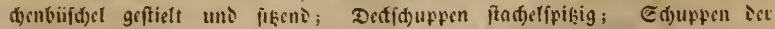

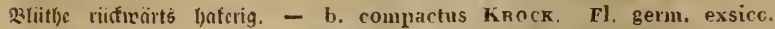

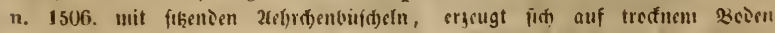
sier in troffnen Eonmern, 2n Jlufufern, Eern, इeinen, Padien uno 
Gräben. Eđfjeint Ealjboien ju lieben. Juni-2uguit. 4. Stellenvelfe ourdo

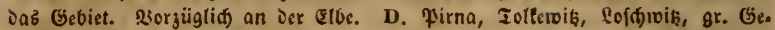

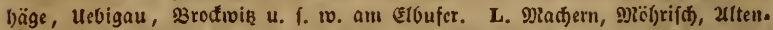

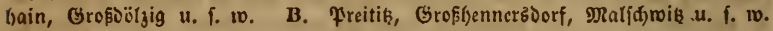

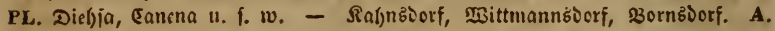

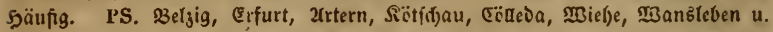
f. 10. HS. Jena bei Sulga, Sauba. Itmmeritaot bei Roburg. SRS. Urnftadt.

d. T a phroget on Rcrs. Zrugoolse eniftäniig, iel)s äftig, mit ftralyliger șülle. Sduppen jugefpişt.

272. S. silvaticus L. Fl. dan. 307. Lerrs 1. f. 4. ST. 36. 5̧alı! ftumpf oreifantig, beblättert; Blätter an Şalme uno unter ier Irugoolde ebcn;

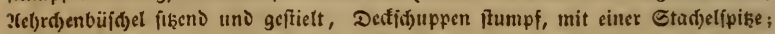

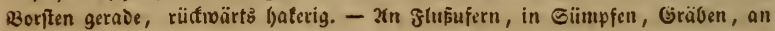

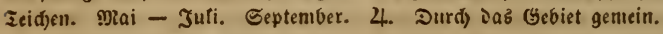

273. S. radicans Sснк. Sт. 36. Fl. germ, exsicc. 542 . 53alı ftumpf 3tantig, beblättert, Die slätter am Şalne und unter Der ₹rugboloe

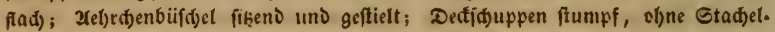
fpike; 3orften glatt, georebt. - 2n flufufirn, in Ieid)en, Sad)en. Jult - Gep.

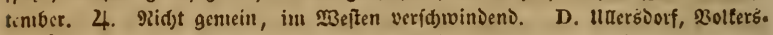

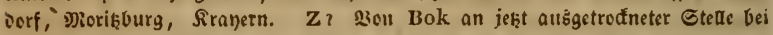

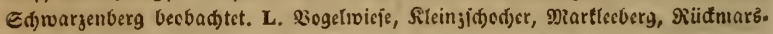

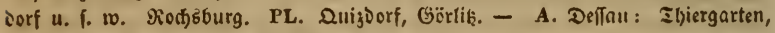
Gecrgengarten น. f. to. PS. Stille Elfter bei Dientorf.

73. HIysunus Panzer. Duelltiet. $r$. v. E. gen. ix. 9.

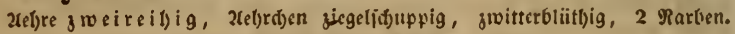

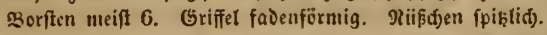

274. B. compressus Panz, Leers t. 1. f. 1. N. v. E. 1. c. 2fil)r.

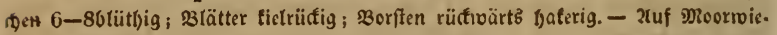

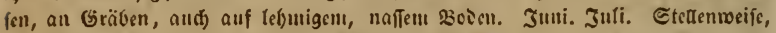

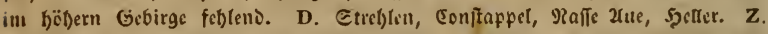

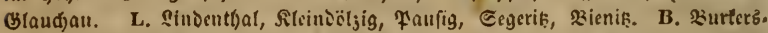

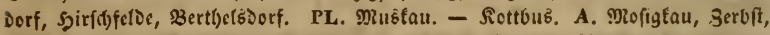
Eaniersleben. PS. Beljig. Guten:erg, Rietleben, Granau, Siçfau, BBanšleben. erfurt. Grosmonnra. HS. Xnmmerbad) bei Jella. SRS. Frantent)aufm.

275. B. rufus Paxz. Schrad. Fl. germ. t. 1. f. 3. N. v. E. 1. c.

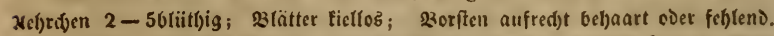
3uf feudtem, fanoigent Boben; tiebt Sarzboben. Juni - 2uguft. 4 . A. San. ierbleben, 3erbft. PS. Rülne, Mank̇lcben, Dič́tau.

74. Heleocharis Lestib. (Eleocharis R.Br.) Te id riet.

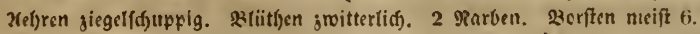

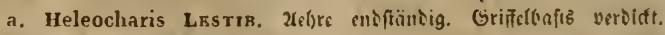
शriišçen oben mit fuctigem 2 (nfak.

276. H. ovata Lestib. Sr, 10. Fl, dan, 372. Fl, germ. exsic'. 


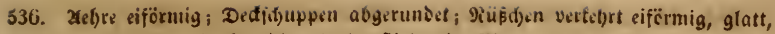

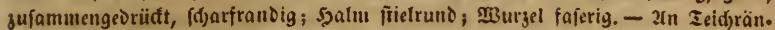

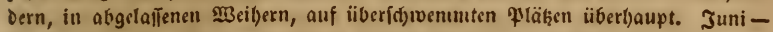

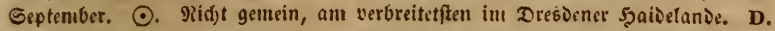

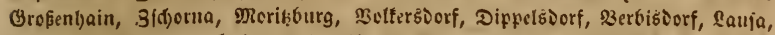

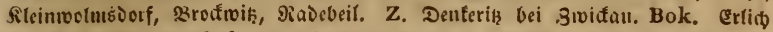
bei șildenfels. Wankel. L. Seukfts, Barnet, Xttenl)ain u. f. w. Grimma.

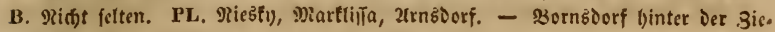

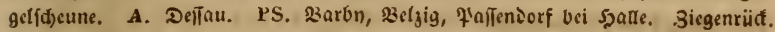
Dolftbeide im Edjradenwalie. IIS. Un Jena.

277. H. uniglumis LrNк. Rснв, Icgr. pl, crit. 11. 319. Sт.

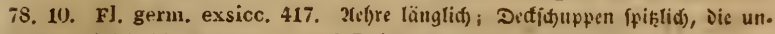

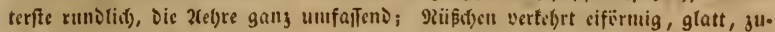

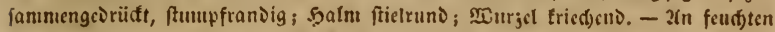
Eteden, foudgl auf Eorf., als Eano. uni fef)mocien. Juni - 2uguft. 4. Durd) Das Gebiet nid)t felten.

278. H. palustris Lestib. LeERs t. 1. f. 3. F]. d. 273. St. 9.

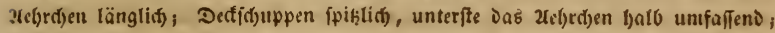
Rüfof)en vertelgtt eiförmig, glatt, jufaumengesrïft, ftumpfransig; 5̧aln fticl.

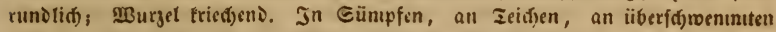
Plähent. - Mai. Juni. Juli - Geptember. 4. Dur(t) ১as ganje Gebiet gemein.

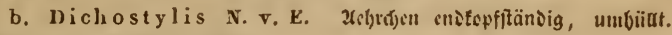
Borften 0 . Riüf(ben ipişlitf).

289. H. Micheliana (Scirp. - L.) N. v. E. gen. IX. 7. F1.

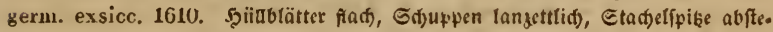

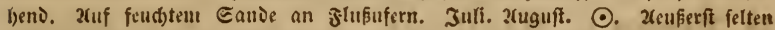

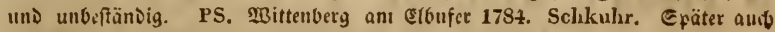
iafelbif von Prof. Nitzsche bcobadtet. Bribo. Schwabe.

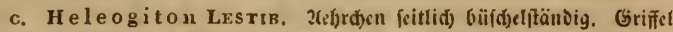

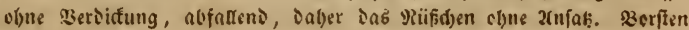
utcift 6 .

280. H, Tabernaemontani (GMeL.) TABkRx. Kräntb. p. 366.

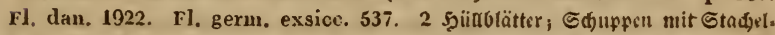

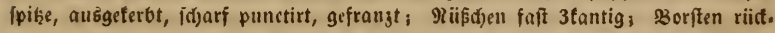
wärts baterig! Єđ)aft fitielruno. b. virens. Fl. germ. exsicc. 538. - Sm खBud) fe äbntid) Dcm Scirp. lacustris, aber robufter uno unterfetiter, Der \$alu unten oft fingersidf uno Dod) nur $2-3^{\prime}$ jod). 2(u uno in ₹eid)en uno Grä. ben. Juni. Juti. 4. 3erftreut, Iod) fetten. L. G(jënfels. Dberbalb ies Gdjail. cert im Graben an oer gicrofeite ier Ebaufee bäufig. Petermann. PL. sิmi.

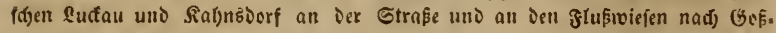
mar zu. Rabenhorst. A. Merierą)aufen, Grëbzig, Miajegaft. Schwabe. PS.

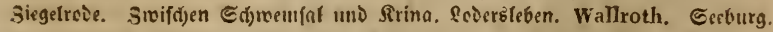
w. Gerhard. 2trtern. Rchb. HS. Etotternbeiu bei Grofrutoffett. Hornung

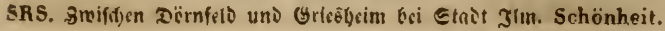


281. H. trigona (Scirp. - Rотн,) Sc. Duvalii Sr. 36. Şй̈.

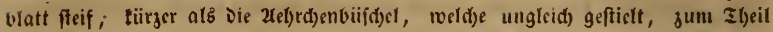

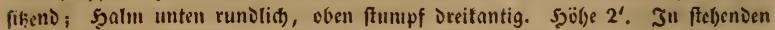

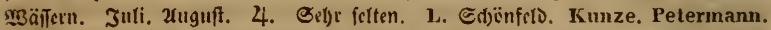

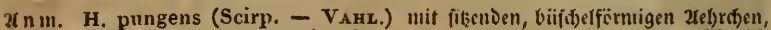

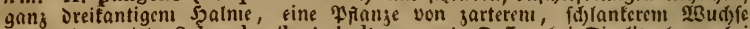
als vorige, giét Schwabe 11. Anhalt. an: A. DefTau bei Sieglikgerberg, bei

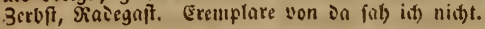

75. Holoschoenus LK. $\mathfrak{R}$ ugelriet. N. v. E. gen, IX. 6.

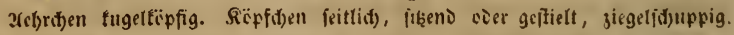
Grififel faoig, abfalleno. 3 yarben.

282. H. exserens Rснв. (N. v. E, I. c.?) R̈̈̈f()en volfoumen

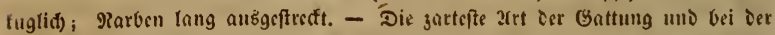

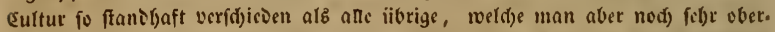

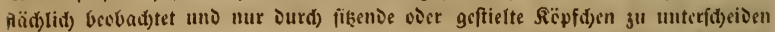
veriud)t bat, wäb)rsti Die in Der Fl. germ. erxsicc. p. 76. gegrbenen Rennjeri. d)en weit ridstiger mio fo ftandbaft find als irgend ein Sennzeidfen an andern

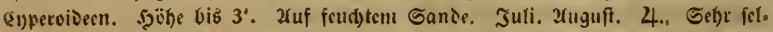

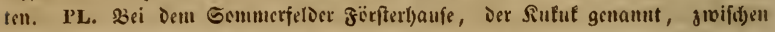
Gaffen uni Dolgig. Ruff., Blase, Rabenlorst. A. Dornburg am MBeg nad)

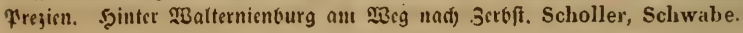

\section{Familie Typhaceac, Robrfolbcu.} - Şerbarienbud, G. XXXV uni 43. -

76. Typha L. Rohrfolbe. N. v. E. gen. II. 1. Stenget um,

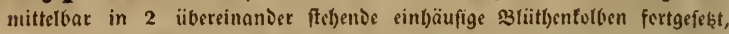

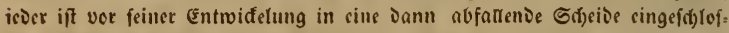

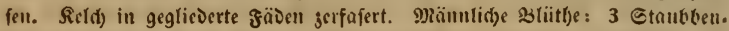

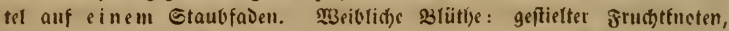
G(j)laudjanme nit Griffelfurtfak.

283. T. angustifolia L. Fl, dan. 815. FJ. germ. exsicc. 711. 28tätter taum

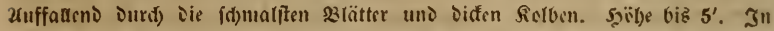

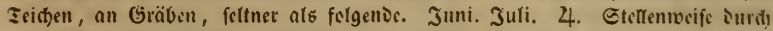

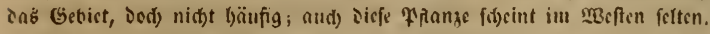

284. T. elatior Bungit. (gracilis Suhr!) Fl. germ. exsicc. No.

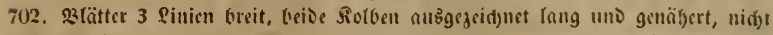

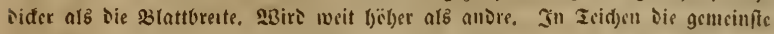

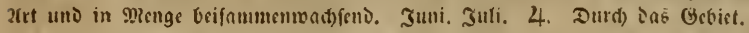

a $\mathrm{nm}$. Mer dicje 2(rten zu Souncerten gefaumelt bat, wiro fid) Durd) Kochs Synopsis nidst abbalten leifen, in bet freien ratur fie ju ertenuen.

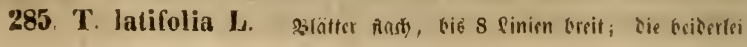




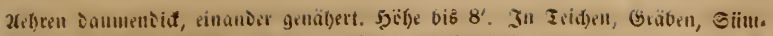

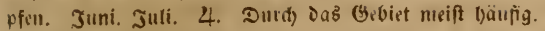

78. Sparganium L. Sgel sfo!ben. Blutbentïpfden ein.

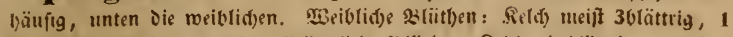

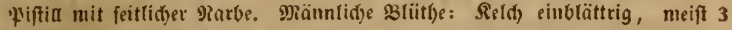

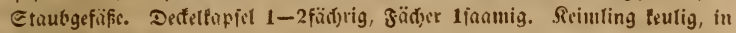
mel)ligem Esimeip.

286. S. natans L, Fl, dan. 260. Fl. germ. exsicc. 543 Błlütben.

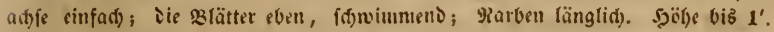
Var. terrestre etwas nieierliegeno, in aften $₹$ f)eilen id)mäd)tiger, entwidfelt fid)

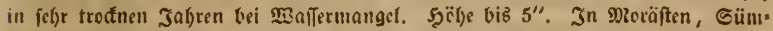

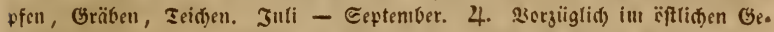
biete, ntcift bäufig. D. Eteinbad), Diorik̨burg, Saufa, Dtteniorf, Grofnaunborf,

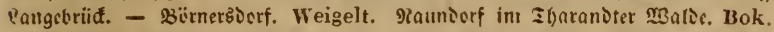

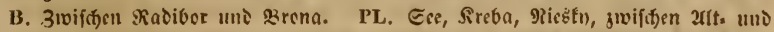
Meuliebel. - nidst jelten. A. 3ctbft, Dranienbaum, Deffau bei Der Zïrtenjiben

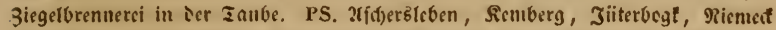

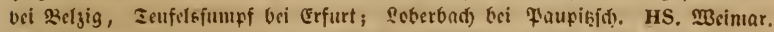

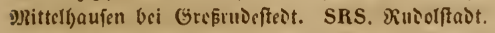

287. S. simplex Huds. Scrik. t. 282. S(üt) ter unten 3/đjneibig, mit ebenen Geitenpäd)en; Rarben lincalifid). Şöbe $11 \int_{2}$ '. In Gräbcn, an Icid)en. Juti. 2uguft. 4. Durit) Das Gebiet nidbt felten.

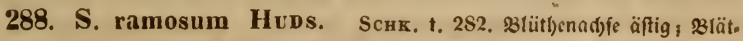

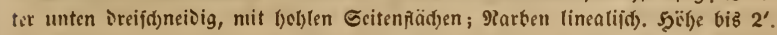
In Gräben, an Icit)en, in Siinıfen. Juli. 2tuguit. 24. Durd) Das Gebiet, เocit f)äufiger als sorigcè.

\section{Familie Irideac, Sch toertelgetoäd ie.}

\section{- 5jerbarienbud, ธ. XXXVI uno 43. -}

78. Iris L. Sकwertel, ك屯toertlilie. N. v. E. gen. V. 18. 23tiitlen aufred)t! corcuinific), unten verwadficn. Saum 6tbeilig, 3

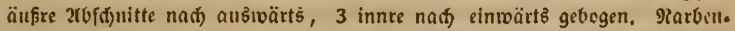
fräger 3, blumenblattartig. Etaubgefäse 3, unten in bie Sröbre geroadjien.

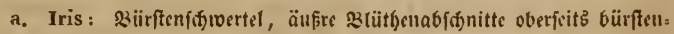
artig befafert.

289. I. pumila L. ST. 44. FI. germ, exsicc, 1213. Slätter fffroert.

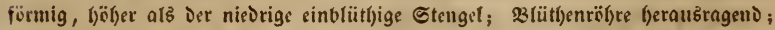
slütbenabid)nitte länglid) ungetebrt ciruno. - Die grofe slütbe violet, abändes:

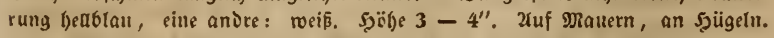
april. Mai. 4. Diefe uno vie folgenden arten fünnen füglid gleid, Sempervivum tectorum und andern Pranjen nur als cingebürgert betradjtet werden. 23gl. Hornungs intereftanten 2થufiał̧ Flora 1832 p. 297. D. Meiß̧en in Iries 


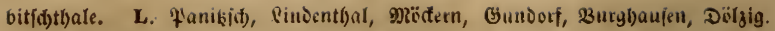

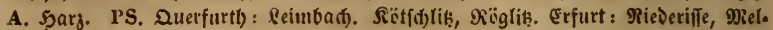

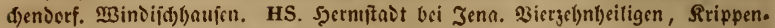
Dorf bei $\mathfrak{B c i n t a r . ~ S R S . ~ 2 t r n f t n o t . ~}$

290. I. lutescens LAM. Rснв. Icgr. pl, crit. X. ic. 1238, słät,

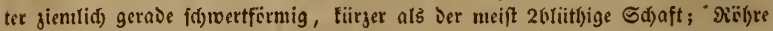

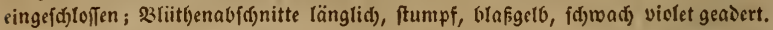

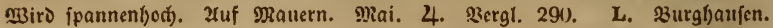
Petermann.

291. I. sambucina L. Bot. Mag. 187. Jacq. h, vind, t. 2, 2Blät.

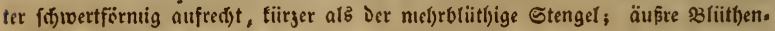
abfditte fiad) uno ausgeterbt, violet, an Der $\mathfrak{B}_{3}$ afts gelb gendert, innre unrein

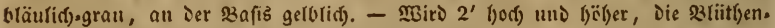

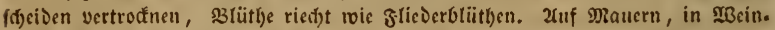
bergen. Mai. 4. Bergl. 290. 1'S. Şïl)nftuit, freiburg, Saudja, Sïlme.

292. I. germanica L. Rснв, Icgr. pl, crit. X. ic, 1245. Fl, germ. exsicc. 1612. Blätter fd)wertfërmig, fïrzer alz Der mel)rbliit)ige Stengel; Sabei.

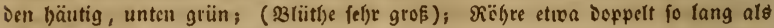

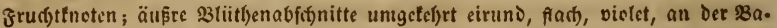

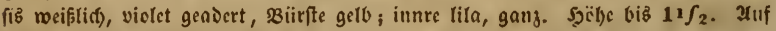
Mauern, in MBeinbergen, nuf Gražplähen, in Şainen. Mai. 4. \$ergl. 290.

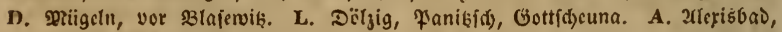
Raadenftedt. PS. Szalle: Dïlau, fiesfau, in Der \$3rennau, Diofécn. uno Mittel:

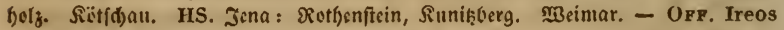
nostratis radix.

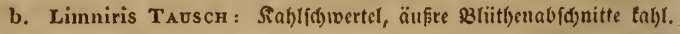

293. I. sibirica L. Rснв. Icgr. pl. crit. ic. 1232. 23lätter linea.

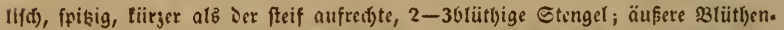

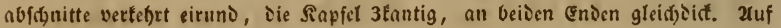

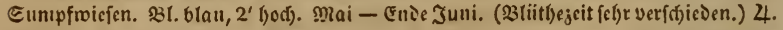

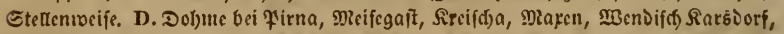

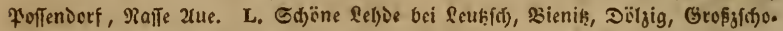

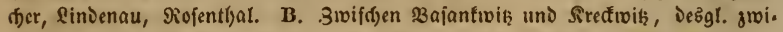
(d)en Bauken und Preufdumik. PL. Guben. A. Mofigtau, Berderşbaufen, Aten. PS. 3arbn bei פzonplaifit; Szalle bei Eeben, Dölau, Rietleben, in Der

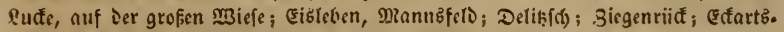

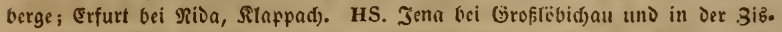

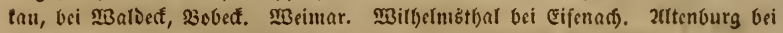
Griva. Mittelf)aufen bei Groß̂rubeftedt.

294. I. Pseud-Aeorus L. Scrк. t. 5. а. b. Blätter (đ)ıertfïrmig;

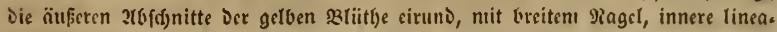

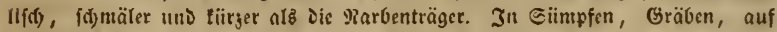
Eumffwiefen, an Ieid)ränvern. Mai. Juni. 4. Durd) Das (Gebict meift nidbt

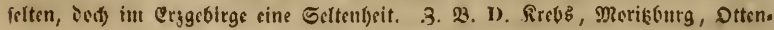




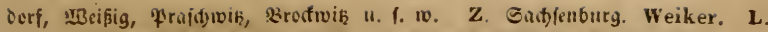

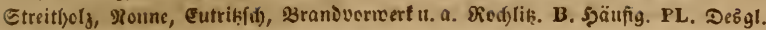
A. Deogl. PS. Barbn; Fallendorf, Geben, Dëlau, gietleben u. i. w. Gci Şalle.

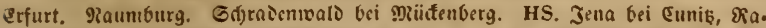
fonnitilyle, Foburg. SRS. Z(rnjtatt.

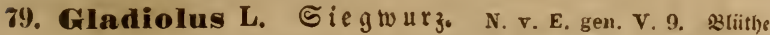

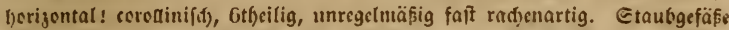
3, aufizteigend. 9iarben 3, länglič), jujammengelegt. Saamen etwaś piï. getrandig. - 3wiebeltnolle. Blätter fidswertförmig. Siliitben in einfeiti. ger asefre.

295. G. palustris Gavd, (Imbric. Rchв, pl, crit. V1. 818.) \&a. fern Der Rnottenliüle fart, bogenartig gefrïmmit Durd) einander greifend, nad) oben

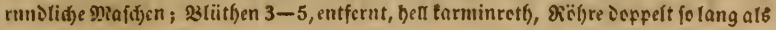
Jrud)tEnoten; untre Slätbenabidynitte meit länger, mit lanzettfïrnigem, meifen

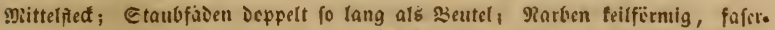
warzig. 2uf Eumpfwiefen. Juni. 4. Etcllenweife, meift fparfam, da Die sant.

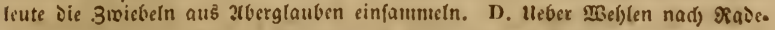
walbe zu. Bucher, Bauer, Hornberger. शajfe 2ue bei Grïbern. Mauke u. $\boldsymbol{x}$.

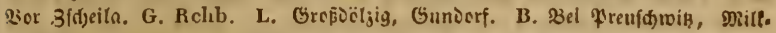

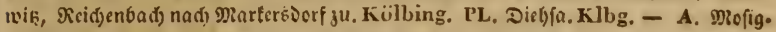

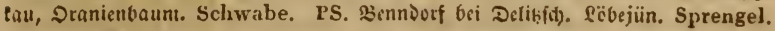

? $n$ ur. Red) find folgende angaben su bemerten, won Denen id) serumuti)e, Das fie

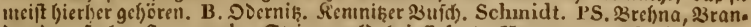
Dercocr şolj. Sprengel. Etcigermalo bei Erfurt. Horuung. HS. Jcna am

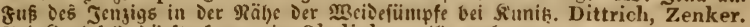
3ci Siart6felo biirfte foum ein Gladiolus wilo vortsmumen.

- 296. G. communis L. Rснв. Icgr. pl. crit. VII. ic. 817. Dis Saforn ier Sucdenfiitle jientidg ftart, paradel uno nad) oben jufommenlaufeno;

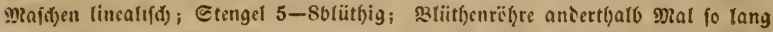

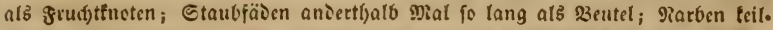

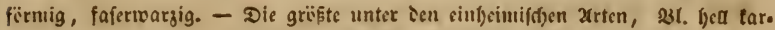

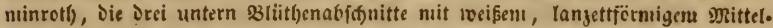

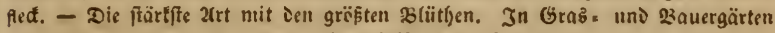
allgefirangt. Juni. 4. OFF. Victorialis rotundae radix.

297. G. imbricatus L. Fl. germ. exsicc. n. 2009. snodentiüte siơt baftartig, glatt; 23 littgen $6-12$ nalge beifanınten ftelgend; Stütbenrëfre faft Drcintal fo lang als grud)thoten, untere weif gendert, ade gleid)lang; Staub.

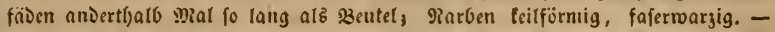
Die foflantite und zartefte ier einfjeimififsen arten; in ungarn findet fids ned) sine robuftere form. 2uf trodfnen Biefen, in Saubgebiifd). Juni. 4. Eel)r

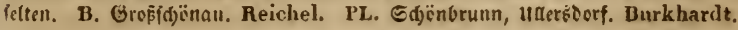




\title{
Familie Nareissineae, Marzilïnichwertel.
}

\author{
- Scerbarienbuti) S. XXXVI uno 44. -
}

80. Calanthus L. S di neetr op fen. sklitt)e corodinifd) (über

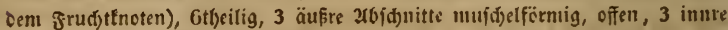
weit tiirzer, platt, aubgefertot.

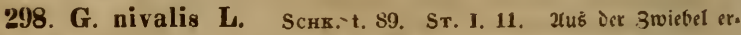

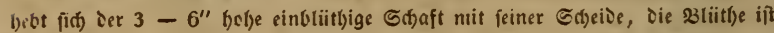
iiberfängenD, f(f)neeroeiß, Die fürjern innern 2(6fd)nitte oberbalb grabgrün, 2

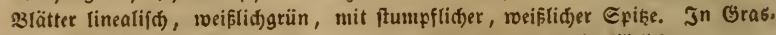

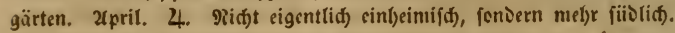

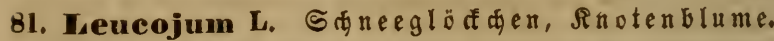

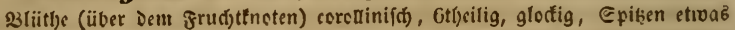

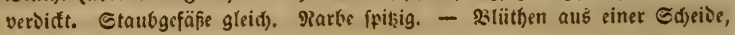
iiberl)ängen๖.

299. L. vernum L. Schx. t. 89. ST. I. 11. Eqfeite cinblïtlig,

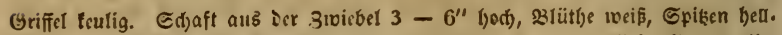

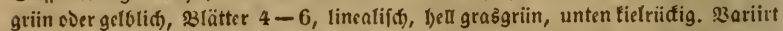

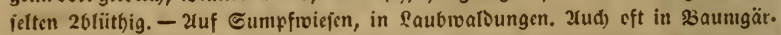
ten angeprangt. Xpril. 2enfang Mai. 4. Eteđenweife Durd) Das̆ Gebiet. D.

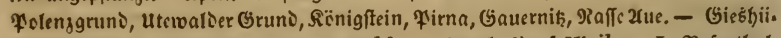

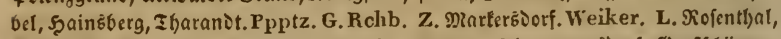
Ed)leufig, Guniorf. B. Dftrik, Şz̈rnik, EulDorf, Dberrennersoorf, Groffd)önau,

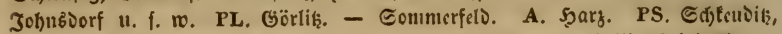

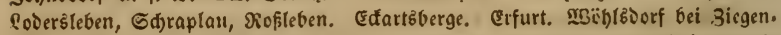

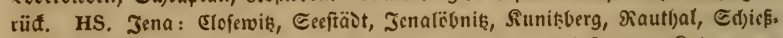
baukbolz. Segefelo bei \$Beinar. Eijenterg. 2litenburg bei Saucn. Roburg ant Etaffels uno Boldoerg. SRS. 2trmftait.

300. L. aestivum L. Fl. dan, 1265. Fl, gernn, exsicc. 1129.

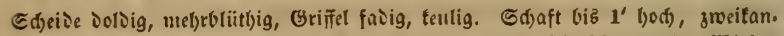

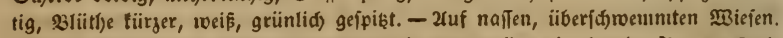

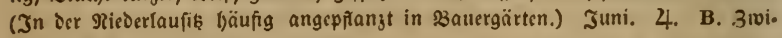
fojen Dftrik uno 23 tumberg. Preuss.

$\mathfrak{i n ~ m . ~ W o b e r ~ K o c h ~ D i e ~ 2 u n g a t e ~ : ~ ( E r j g e b i r g e ~ ( S y n o p s i s ~ p a g . ~ 7 0 3 . ) ~ g e i d f e ̈ p f t , ~}$

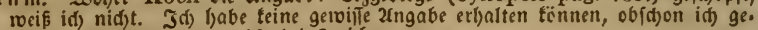
riid)tswoife hërte, es twadje bei 3ridfau.

82. Nareissus L. $\mathfrak{R} a \mathrm{r} z$ iffe. Säuthe (iiber bem frudttnoten)

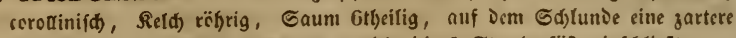

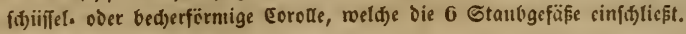

301. N. poëticus L. Borl. herb. t. 306. Fl. gerın. exsicc. 1510.

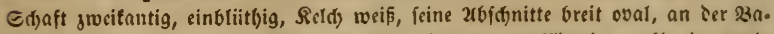

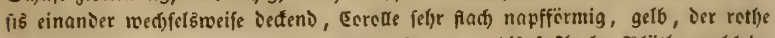

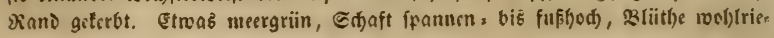




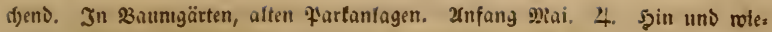
oer verwiloert.

302. N. Pseudo- Narcissus L. Taberx. 1002. f. 2. 3. Blätter

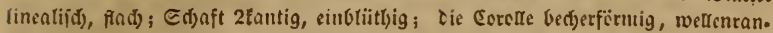
rig uno ungleidf) geferbt, fo lang als Die Reld)a(bf)nitte. - stiitl)e groß, gelb,

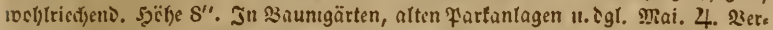
witvert, fogeint aber roeit belier zu gedeiben, alš vorige. 3. 3. D. Grofer Gar=

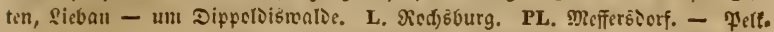

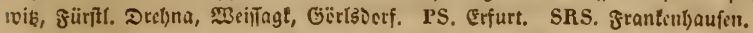

\section{Familie Juneaceae, Simfenlilieu.}

- Şerbarienbud ธ. Xaxvil uno 46. -

a. Junceae, હimien, fpelabluthige.

83. Luzula Desv. Şainfimfe. N. v. E. gen. 11. 7. Blïthe

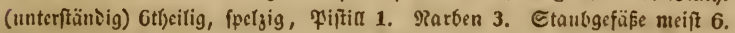
Sapfel 1 fürthrig, 3tlappig, 3jaamig. - Sïpffjen eine Dolie cier eine zrug. Dolve. Silätter graßăartig.

303. L. campestris DEc. ST. 77. LeERs t. 13, f. 5. Blüthentïfiden

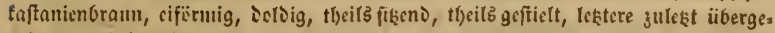

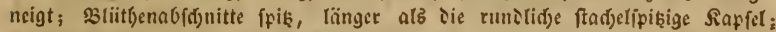
Etaubfäben 6, fo lang als bie Etaubbentel; Blätter am Sianie beljantt, enolid)

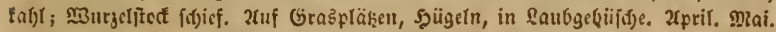

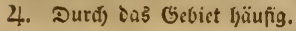

304. L. sudelica W. Blitt)enfieffiden fajt fuglid), f(d)wargbraun,

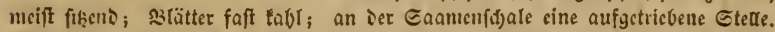

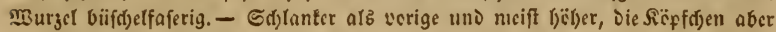

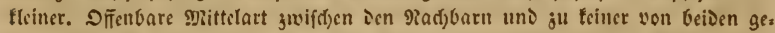

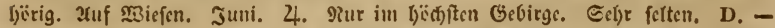
Sinnwato. G. Rchb. 1S41. Z. SidftelGerg. Bok, Weiker und Rehb.

305. L. multiflora LEJ. ST. 77. Blïtlentüpfden eiförnig Dorbig,

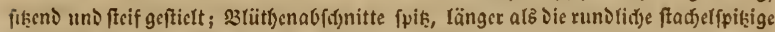

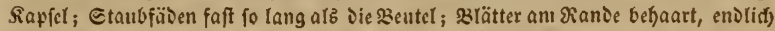

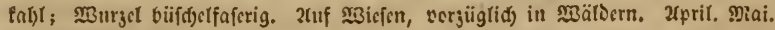
4. Durd) Das Gebict nidjt felten.

306. L. albida DEc. St, 44. Fl. g. exs, 1838. zrugiorbe zu=

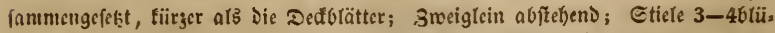

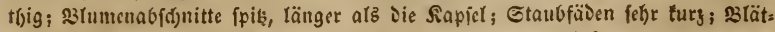

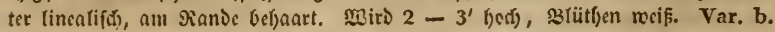

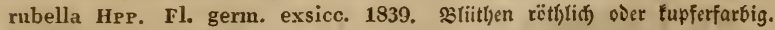

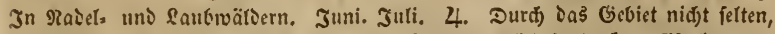
namentlid) in gebirgigen (jegenien; var. b. namentlid) in trednen waloungen.

307. L. maxima Dec. Sr. 44. Fl, g. exs, 935. zugiclie mefr. 


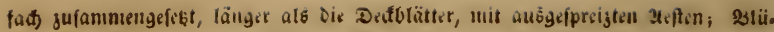

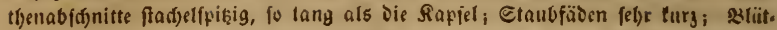
ter limealzlanzettlit, at! $\Re$ ande beljaart. Die fdjënen breiten slätter geven Der

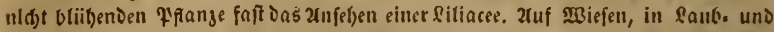

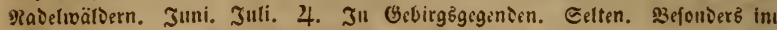

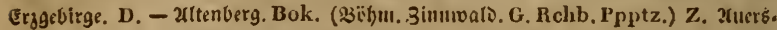

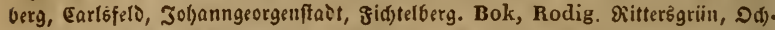
fentopf bei szotau, Gitjeibenberg. Wankel. A. Sharjgeroie. Schwabe. HS. 3ella. Metsch. Jena im serfte. Zenker.

308. L. pilosa WiLLd. Sr.77. Dolientraube jienutid) einfa(t, nit orit. bliitbigem sroeiglein, obere ffäter zuriidgefdlagen; Slütben einjeln, Caame an ber

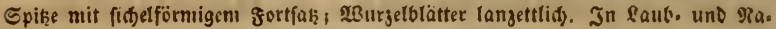
celwäloern. 2(pril. 4. Durd) Das (Gebict nid)t felten.

A $\mathrm{nm}$. Schwabe fl. Anhalt. gicbt nod) all: Luzula spadicea Dc. A. Mä̈g. ocfprung. L. Hlavescens GAUD. A. Sharjgerode. - Ja) jab teille Ereniplare

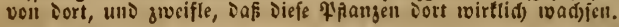

84. Juncus L. N. v. E. gen, 11. 6. 3lüitle fpelgig, Gbättrig. esaub.

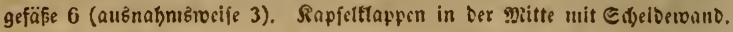
Caamen zar)lreid).

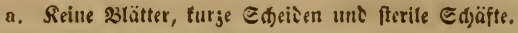

309. J. conglomeratus L. LeERs t.13.f. 1. Fl. dan. 1094. ST. 43. Sḑaft naft, zart lintirt; Irugrolise feitliob, Enauelförmig, s3lïtf)enabfd)nitt lan. gettlid), fobr ipiß̨; 3 Staubfäten; Sapfel umgetifyrt ciförmig, auzgefd)weift;

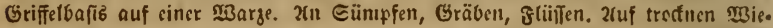
fen, an Megen. Juni. Juli. 4. Durd) Das Gebict.

310. J. effusus L. LeErs t. 13. f. 2. F1. dan.1096. ST. 43. હđaft nadt, glatt (nur troden fein tiniirt); Irugoclde feitlid), Ioćer; 33 liitbenobfdynitte lan. bettlid, febr fpibig; 3 etaubfäben; Sapfel ungetebrt eiförnig; Grifelbafis in einer Grube, sisie yoriger.

311. J. glaucus EнRH, Leerst.13.f.3. Fl. dan.1195. St. 43. Fl. germ. exsicc. n. 546. Cđ)aft nact, tief geftreift; Mart fä()crig unterorod)en;

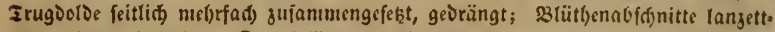

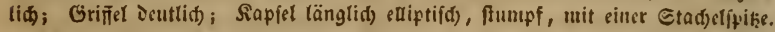
- 2n Gräben, auf Eumpfwiefen. Juni. Juli. 4. 9Rid)t alggentin verbreitet uno meift fparfam. D. RaTe 2lue, Milcberg, હotta. Z. Johanngeorgenftadt.

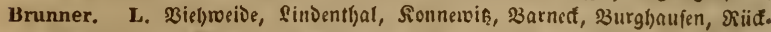

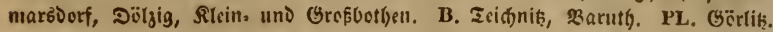

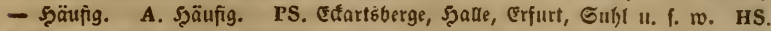

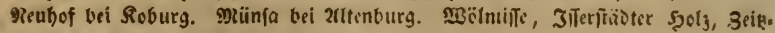
grund bet Jena. SRS. Xrnftnot.

312. J. filiformis L. Lekrst.13. f.4. Fl.dan, 1207. ST, 43. Fl. g. exsicc. 1412. Sđaft nadt, fadenförmig, cben iibergeneigt, glatt; Irugoolie

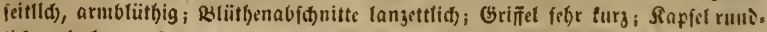

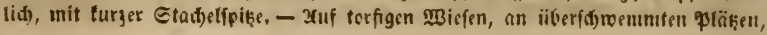




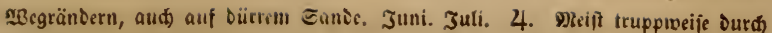

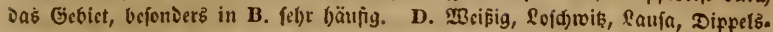

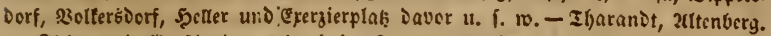

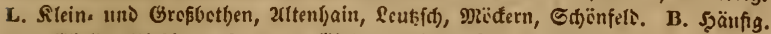

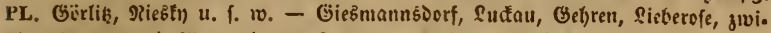
fifen Iugani und Dialleudjen u. f. vo. A. Defau, 3erbft u. f. tv. PS. Dber. fifmon, Benniorf, Ërfurt, NBiclse, Dïben, Subl. HS. Sd)leifereifen und Plcerb. iorf bei Jena. Reburg bei Szaarbrïten. Reuftadt. Eijenad).

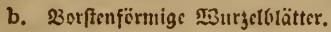

313. J. capitatus WeIGEL. Fl, dan. 1690. ST. 43. Fl.g. exs.157.

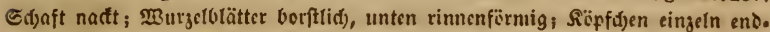
fänıig (aud) rochl ned) cins geftielt); 23 (üt)

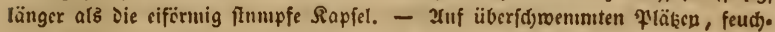

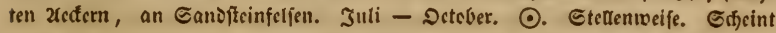

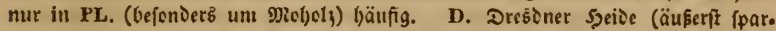
fam). G. Rchb. 1839. Z. Sulti(fí) na(t) Rirdjberg zu. Bok. PL. Profjols. Burkhardt. - Şäufig. Rabenhorst. A. DêTau, Bernburg. Schwabe. PS. Bittenterg in Der Epcte. Schkulur, Nitzsche. HS. Jena: bei Roda (an ๔and.

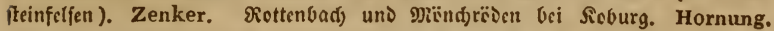

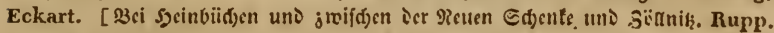
Reuerlid) wiciergefunden ?]

314. J. supinus MoEvсн, Fl. dan. 1099. Sт. 43. Fl. g. exs. 547. Sd)aft fadenföruig; 33(ätter faft berftliđ), oberfeits fd)mal rinnenförmig, unterfeits erbaben; Sïpfd)en auf meift sinfadjen 3weigen, quirlartig, orei Staubfäben! sliitbenabid)nitte langettlids, äufre fpis, innre ftumpf uno ftad)el. \{piłig. - In un๖ an Sunıfgräben, an ïberfd)wenunten łläłen, auf torrigen

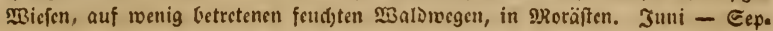

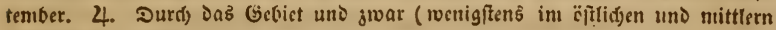
Gebiete) nidjt felten.

315. J. nigritellus Dov, ST. 78. Єe (๖)

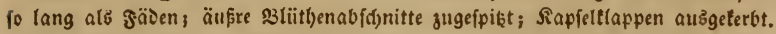
- Borigem äl)ntid), aufredst, (pannentjod). 2(uf überfdrommtem Sanoboien. Juni - 2ugujt. 4. Gelit feiten. D. Bei Saufa. Rchb.

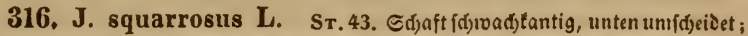

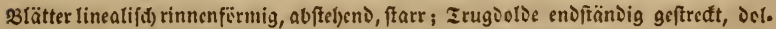
Dentraubig; s3lüthenabfonitte fo lang als Die ungetefrt ciförmige, ftumpfe, fta. delfpißzige Rapfet. - 3efonders auf Iorfboden, auf zorfoiejen, in feudjten, tor. figen Mäldern, in Micräjten. Juni. Juli. 4. Jm bübern Erggebirge, fowle in Det intern Dreşoner Sgeide an mand)en Etellen mit Eriophoruun vaginatum verberrfdjent; aud) fonft Durd) Das ganje Gebiet ftettentoeife nidjt felten.

c. Stengelblätter vorbanien, niđ̛̣t geglièert.

317. J. bufonius L. Lesrs t. 13. P. 8. Sr. 36. Stengel beblättert,

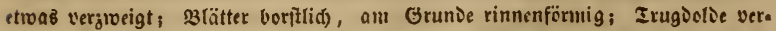
längert, gabeläffig, nufred)t; BItiitf)en cinjeln, entfernt; Blütbenabjđ̆nitte langett. 


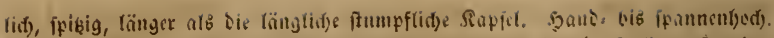
2u ๑. Durd) ¿̀s Gebict gemein und läufig.

318. J. Tenajeia Енвн. Fl. dam. 1160. St. 43. F1. g. exsicc. 424. Stengdbätter $1-2$, rorffig, unten rinnig; Irugoolbenjweige geftrect,

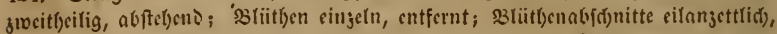

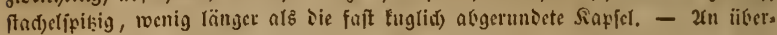

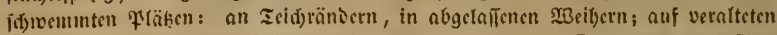

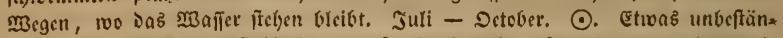

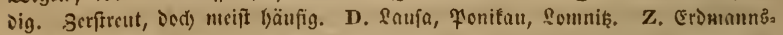

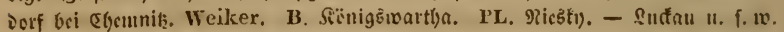
A. 3erbit, Jrieicrifenterg. PS. S3ittenberg in Det Epeffe. S3c/jig. Dfontorf, Dïnnik, গ̇ißansłeben. Erfurt. Diajtäot.

319. J. Gerardi LoIs. Wahlnb. (bottnicus) lapp.t.5. St, 43. Fl.

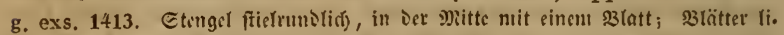

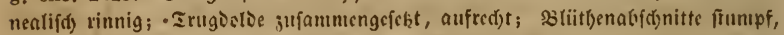

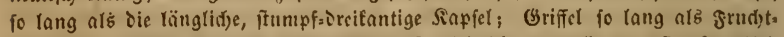
tnoten. 2uf Sumpfwiefen, namentlid) auf faljlbaltigen. Juli. 3tuguit. 4. Est ten. PS. Sïtidiau, Diesfau, Sangenbegen.

320. J. compressis J ICQ. (bulbos.) Fl, dan. 431. Lenrs t, 13. f. 7.

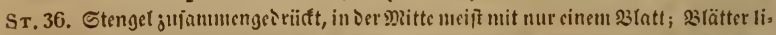

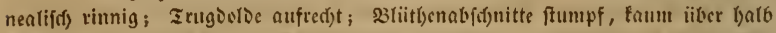

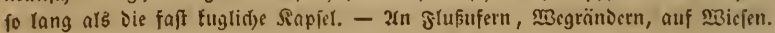
Juni - Eeptember. 4. Tiid)t feiten. 3. 23. D. Elbufer, Eotta, Siotta, 9riciocrau

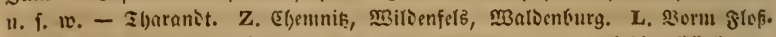

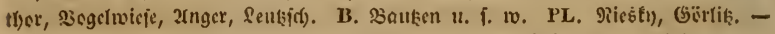

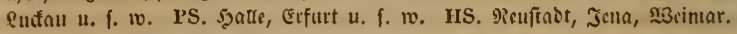

d. Etengerblätter verbnnoen, glicoerartig a rigetțeilt.

321. J. alpinus VILL. (ustulatus HPr. Anleit, Grïs. z, trockn.

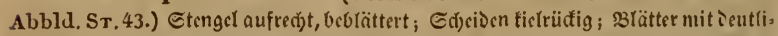

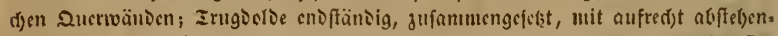

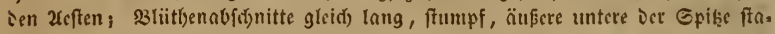

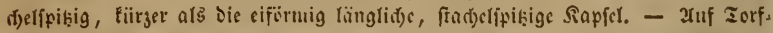

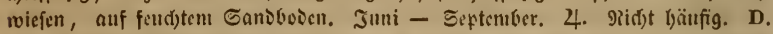

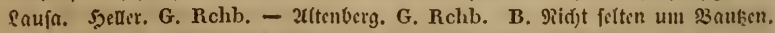

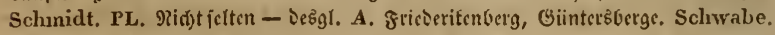
PS. Eur)!. Metscl. HS. Bïndjriten uno giotteniorf bci Sicburg. Hornung. SRS. Eingcr forff. Schönheit.

322. J. articulatus L. (lamprocarpus EnRH, St. 43.) Fl. g. exs.

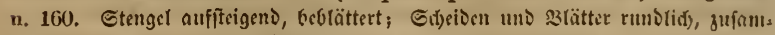

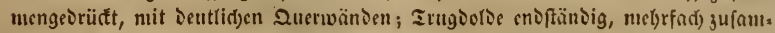

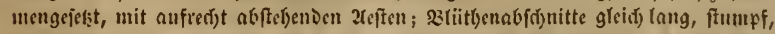

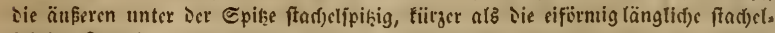

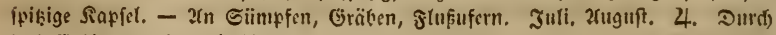
১as Gcbiet gemein uno bäufig. 
323. J. melanauthos Rснв. Fl. germ, exs. 650. 5alu aufred)t,

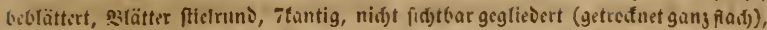

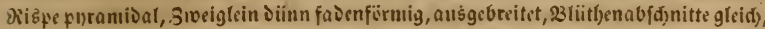

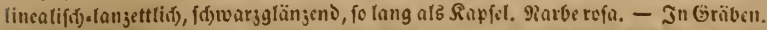
Juli. 2ug. 4. Eclin feltin. L. bei \{cutid) u. Guniorf. J. septangu]us Petrru. $18+1$.

324. J. acutiflorus EнRH, Fl, dan, 2112. Sylvat. Sт. 78. 5alı!

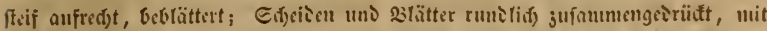

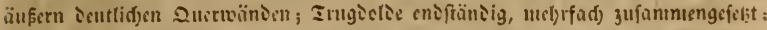

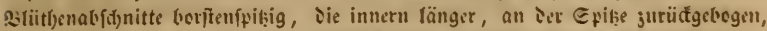

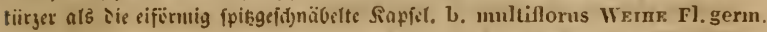

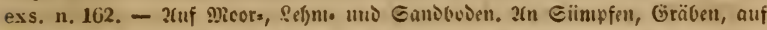

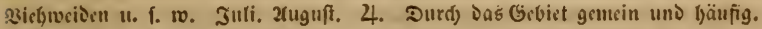

325. J. obtusiflorus ЕнRн. Fl. dan. 1872, Sт. 77. Fl, g. exs.

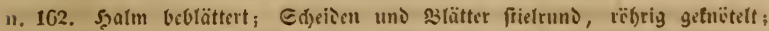

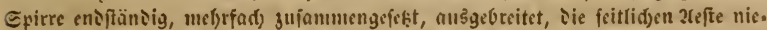
Dergetred)en; Sipfel ier \$lumenlyäle gleidffirmig, sorn gerundet, fo lang als

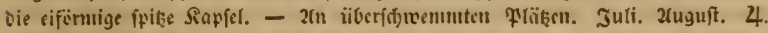

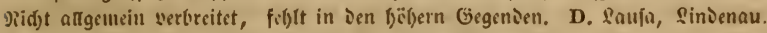

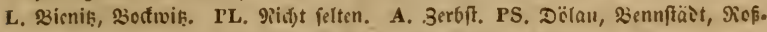
Irben. IIS. actperfteit bei Grofrudeftiot. SRS. Etait \$Imt.

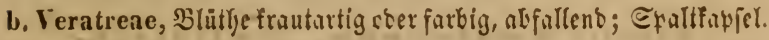

85. Tofieldia Huds. Tofielbie. N. v. E. gen. II, I1. siti: the Gtheilig. Etaulgefäfe 6. Gä̀cn lang, sientel turs, rundlid), in 2

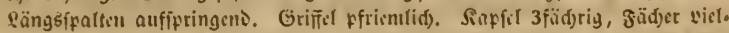

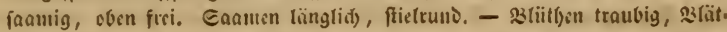
ter reiteno.

326. T. calyculata Whuxbg. Fl, dan. 36. Fl. g. exsicc. S11.

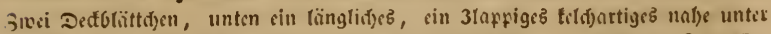

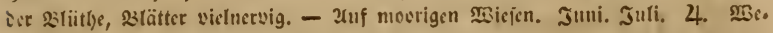

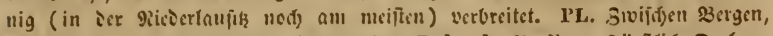

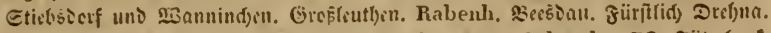

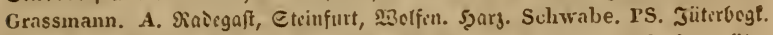

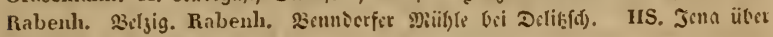
Edjünglcina. Zenker.

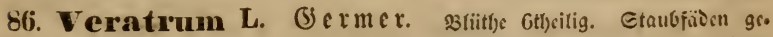

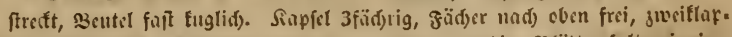
pig, vielfaamig. Gramen ginitigelt: - Viizpr tranbig, słätter faltenrippig.

327. V. Lobelianum Berxh, Lob. Stirp. p. 168. F]. germ.

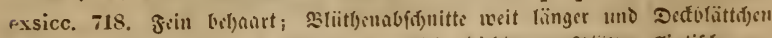

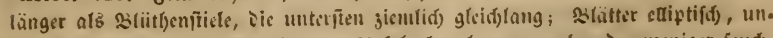

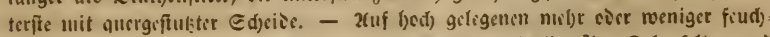

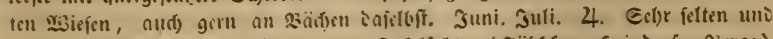

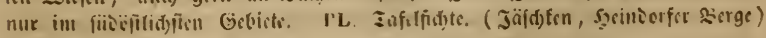
Külbing. - 
c. Colchiceae, zeitlojenartige; Brüthen corollinijđ, Gintwelfeno; 2ืfdnitte aufeinanber liegend; Beutel aufliegenb.

87. Colchicum L. Se it fofe. N. v. E. gen. VI. 7. Blitthe

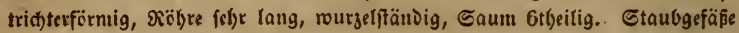

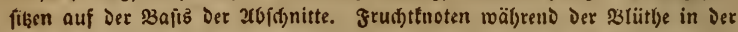

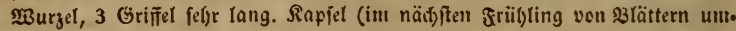
geben emporfteigeno) aufgeblajen 3fädgrig, gädser ipäterlyin an Der @pitzi auseinander get)end, innerfeits aufipringend.

328. C. autumnale L. Schr, t. 101. Hayxe Arzneigew. v. 45 ,

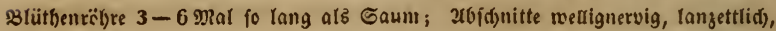

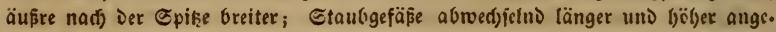

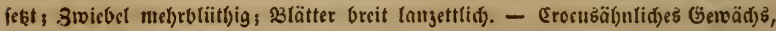

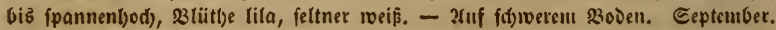

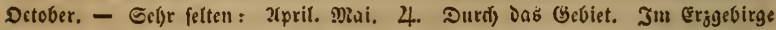
ielten. (Pöbla bei Gdjwargenberg. Bok. Joljanngeorgenitaot. Brunner. \$Bit.

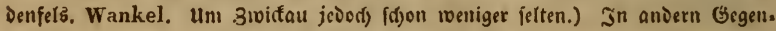
Den Dagegen, 8. 3. um Jena (Saalwiefen) und Dreşden (3idjoner Grund u. i.

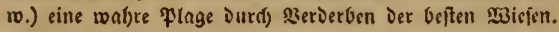

\section{Samilie Smilaceae, Smilacen. \\ - 5ctbarien6uty ธ. XXXXVII und 47. -}

A. Acorinae, wieberbolen vorige Familte.

88. Acorus $L$. $\Re \mathfrak{n} \mathfrak{m} u$ bे. $\quad$ N. v. E. gen. II. 3. Solven am

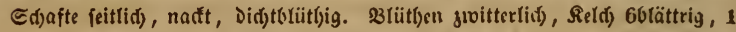

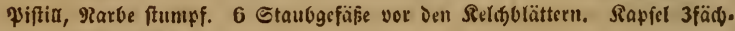
rig, vielfaamig.

329. A. Calamus L. Schk. t. 97. Hayne Arzng. vi. 31. MBur.

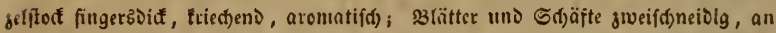

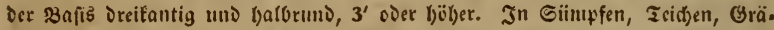

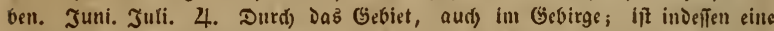
urfprïnglidi orientalijaje Fianze, "gl. DierBach Bot. Zeitg. 1828. 545-52. OrF. Radix calam, aroun.

B. Parideae, Blüthe enbitänbig, 4 - 5 srififel.

89. Paris L. Einbeere. N. v. E. gen. 11. 10. 3witterblithe.

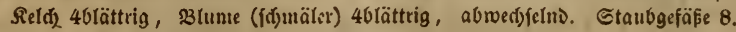

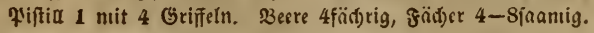

330. P. quadrifolia L. Schr. t. 109. HAYNE Arzneigew, III. 7.

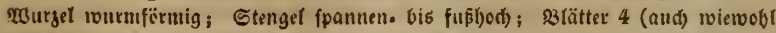

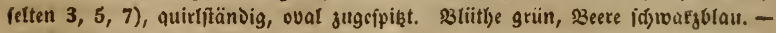

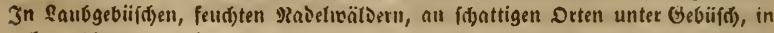

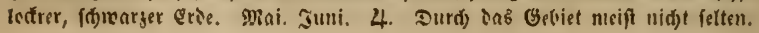




\section{Convallarieae, Blütf̧en nţjelftinbig, 1 Esrifịel, Blätter nervig.}

90. Streptopus Мichayx. $\Re$ ॥ $\nu$ te

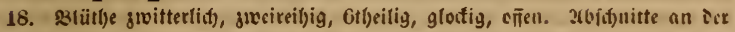

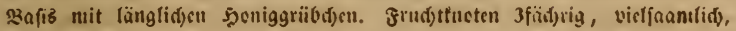
Ylarbe frumipf.

331. S. amplexifolius DEc. Sснк. t. 93. Sr. 41. Fl. germ.

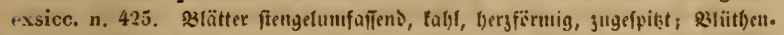

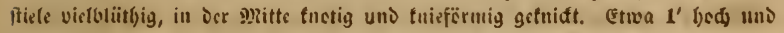

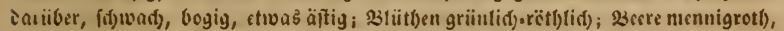

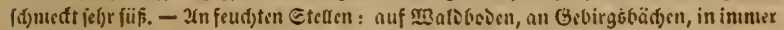

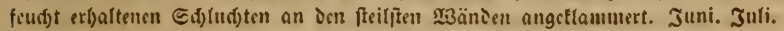

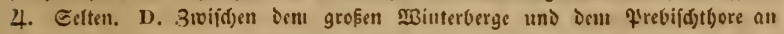

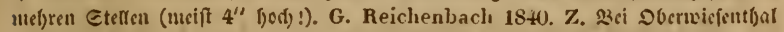

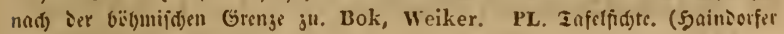
Berge, Jäjđ)tabırg.) Külbing.

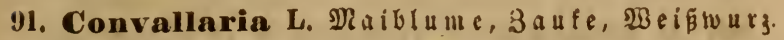

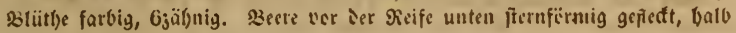
3fäd,rig, Bädjer etwa Gianuig.

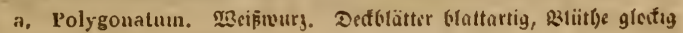
warjenfïrmig.

332. C. Yolygonatum L. Fl. dan. 337. Harxi Arzng. III. 19.

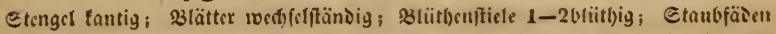

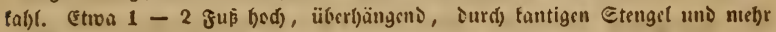

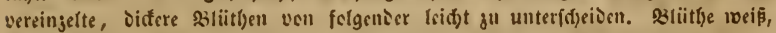

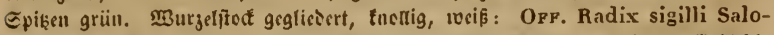

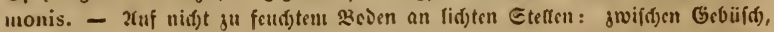

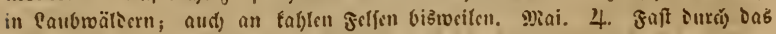
ganje Gebict, uteiff nidjt feiten. Ederint jeicd) in obern uno mittlern (Erggebirge

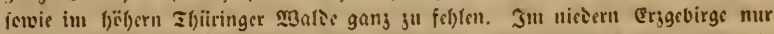

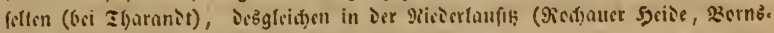

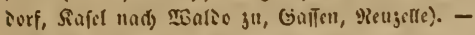

333. C. multiflora L. Schk. 1. 97. Fl, dan. 125. Harxs Arz-

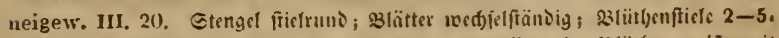

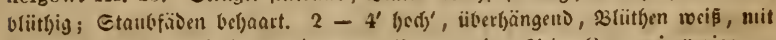

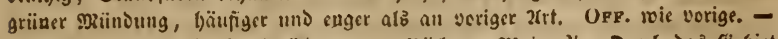

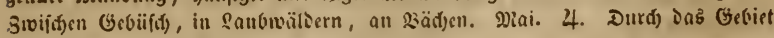
nidft felten uno bäufiger als vorige.

334. C. verticillata L. Etcngel aufredst, tantig; 33ätter anir.

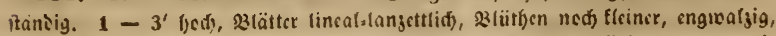

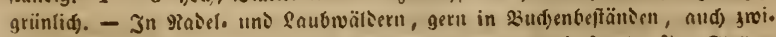

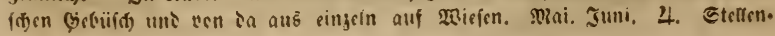




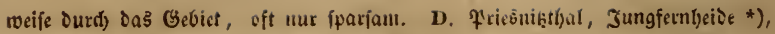

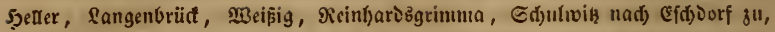

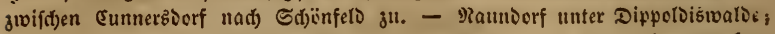

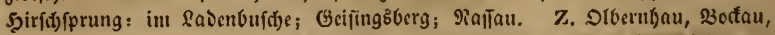

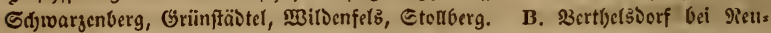

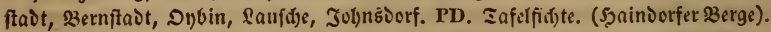

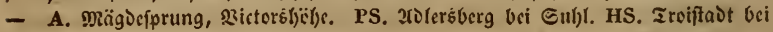

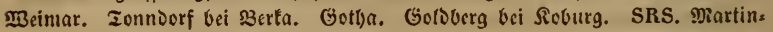
rode, Mellenbad). R. S3urgt. Lobenftein.

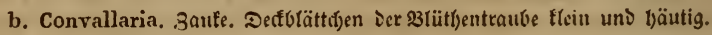

335. C. majalis L. Schк. t. 97. Hayxe Arzngw. III. 18. 23lii.

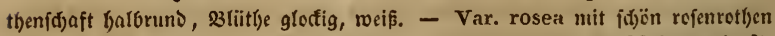

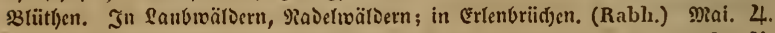
Durd) Das Gebiet meifł l)äufig. Var, rosea. D. bei sintlaterz. F. Leonhardi. L. u. G. Reichenbach fi].

92. Majanthemum Wiggers. 3 weiblatt, Sigatten=

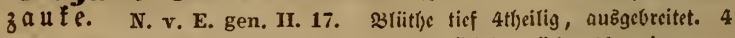

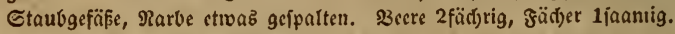

336. M. bifolium DEc. Fl. dan. 291. ST. 13. Swwei geftiefte, fyery.

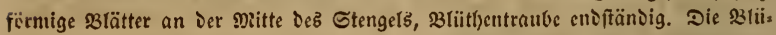

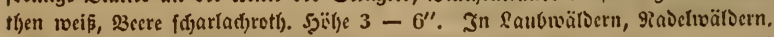
शRai. Juni. 4. शicit felten.

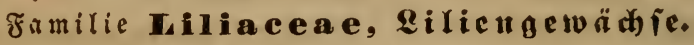

\section{- Sorbarienbud) ธ. XXXVII und 48. -}

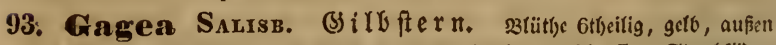
uit grünen mittelftrcif, (bei beitrem ฐage) iiber Der $23 a f i z$ offen. Staubfäben pfricnlid), $\mathfrak{B}$ cutel aufred)t. Sapiel Drcifäct)rig. Saanten faft fuglid). -

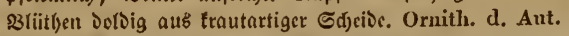

337. G, stenopetala (Fr.) Rснв. F1. germ, exsicc. 942. Ein

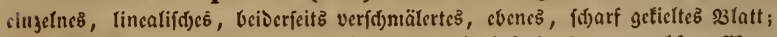

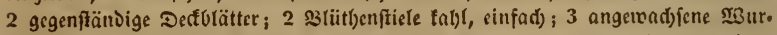
gelfnouen, Die beiben jälsrigen feulenförmig. S3latt graugriin, 33 (ït)

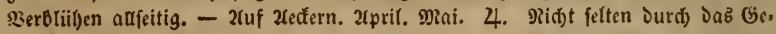

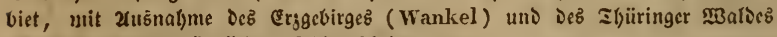
(Metsch), wo fie gänglid) ju felblen (d)eint.

337. b. G. pratensis (PERs.) Косн. F]. g. exs. 2012. 3(iit) $\mathrm{cn}$ nad) Dem abblüben einfeitig, Die beioen cinjälyrigen Sncuen e if örmig. 2uf

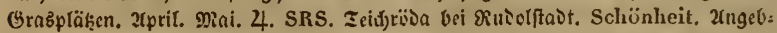

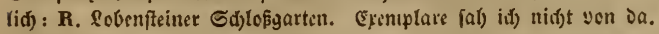

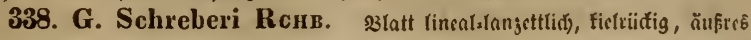
gintlaterb. 
Defolatt fidseibig, an einer Eeite berablaufend, gettig gerwimpert; S3(üt)enfticle

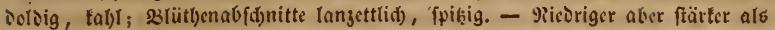

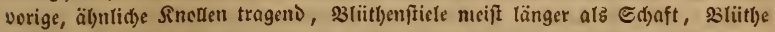

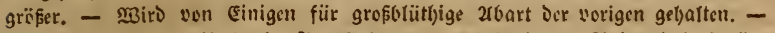

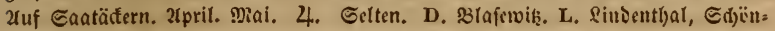
fels, Metteribif(t).

339. G. minima (L,) Schult. (Ornith Sternbergii Sт. 23.) F1. germ. exsicc. 943. (Fin eingelucb, aufred)tez, linealific)

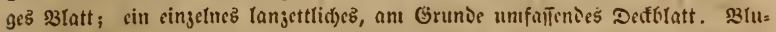

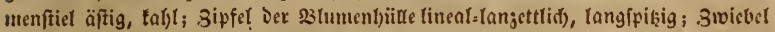

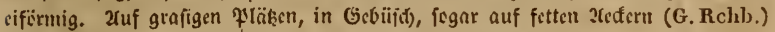

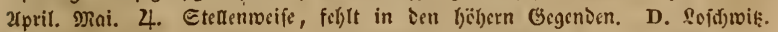

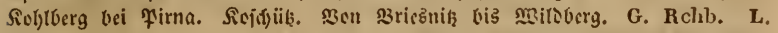

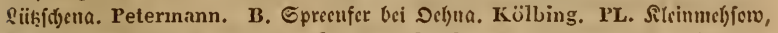

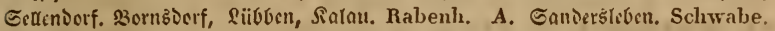

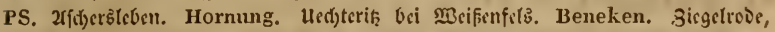
Gatterftet. Grimberoda bei giorobaufen. Wallroth. HS. Jena int Rautlyal.

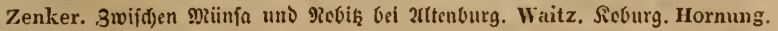

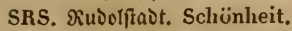

340. G. arvensis (Pers.) Schult. (Ust. Anual. V. t. 1. St. 12.) Fl. germ. exsicc. 945 . Sıvei linealifoche, rinnenfirmige, ftumpf getielte,

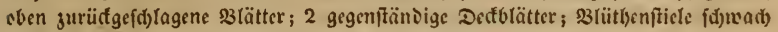

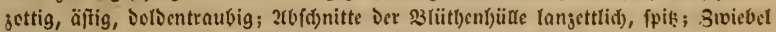

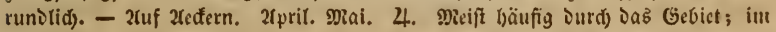
Gebirge jebed) nur fetten.

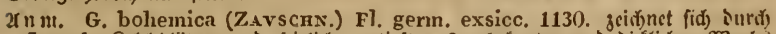

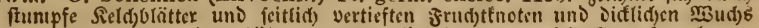
aus. Sie erreidst eine 5ïbe son $1-2^{\prime \prime}$. Jd) mage nidjt fie nufunclymen,

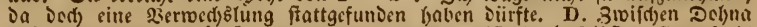

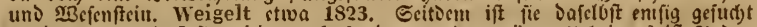
worben, olyne ذaf́s fic wisber aufgcfunien werien wäre. llebrigens ift sicoen uno Gebirgart ies frïbern 5yautitanoort3, Jer \$oobaba bei 7'rag, ganj ver.

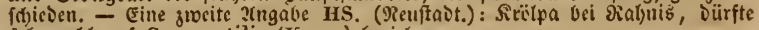
(id) wolyl auf $\mathbf{G}$. saxatilis $(\mathbf{K} \mathrm{OCH})$ bejieljen.

341. G. saxatilis (Косн.) Fl, germ, exsicc, n. 1S 43 . פ̇urzcl.

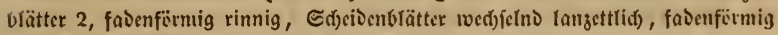

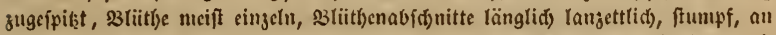

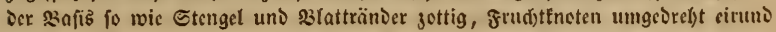
länglid), Snotre runolid). - Die blütbige G. arven sis unterf(f)ieden Durd) fal), Ien Sd)aft, gegeniiberfteljende Sd)cibenblätter, $3-4$ gar rängere şrüthenfitiele,

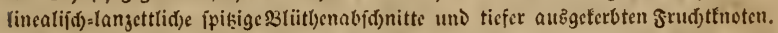

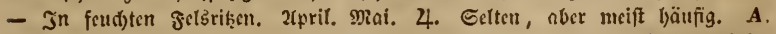

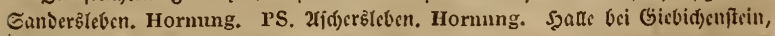
Sirüatwik, yor Dcu seibeljauje.

342. G. spathacea (Havne) Schuct. Ust. Annal. XV. t. 1. ST. (O. Haynii) 26. \$3urgelblätter 2, aufred)t, fabonfirmig, balbrunt, cbcn faci) ober (d)wad) rimig, Gdjeibenblatt einjsln, rangettlid), cingerent, etwas cnts

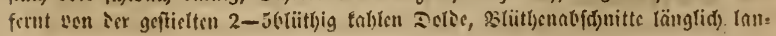




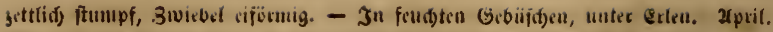
gRai. 4. Etellenmeife, meift fparjan bliibent. D. Dippeloborf. Delme. L. Rchb. fil, G. Rchb. L, Ronneıvik. Cichorius. Peterinann. B. Rlein.

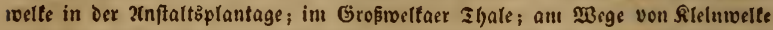

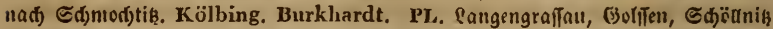
(bei altö̈bern) и. f. w. Rabenhorst. A. Sanjeršlcben. Schwalse. PS. Brants. baide bei Belyig. Rabenhorst. Ed)teubih, freiburg. Sprengel.

343. G. Iutea Ker. Schк, t. 34. Fl, dan. 378. Fl. g. exs. 577.

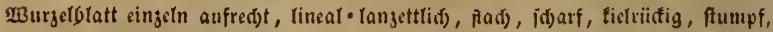

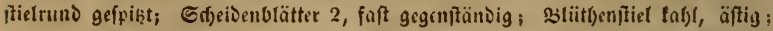
Bliitbenabfd)nitte länglid), ftumpi; 3woicbel sifirmig, einfad). - Die grïfte 2(rt.

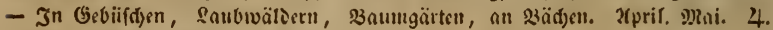
Durd) ১aส̉ Ġebict gentein un১ bäıfig.

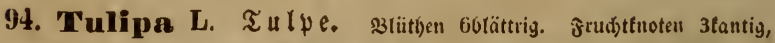
Rarbe fiţento, 3lappig. Eaancn platt. - 3rviebel, Bltïtf́e endfündig. Gd)arige 3wieber.

344. T. sylvestris L. Sr. 29. Stengel fabl, cinbliitbig; Sinospenitind; dic

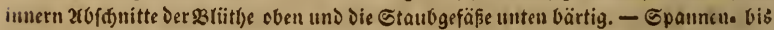
fül)od), 3liitbe Eleiner alz nn folgender, gelb, wolg(ried)end. - In Fartanlagen,

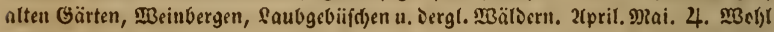
nur verwitbert, obfdoon nantentlid) bei Seipjig ganj eingebiirgett. D. Gr. Garten,

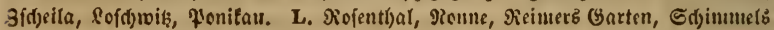

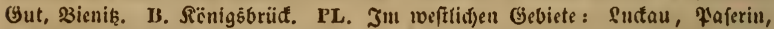

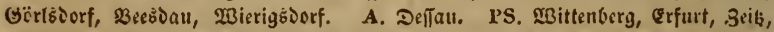
PRaumburg, Şalle. Ërfurt. HS. Jena: Gonnenberge. Eijenberg. אicburg. SRS. 马rantenlyaufen. 2rinftads.

345. T. Gesneriana L. B. Mag. 1135. etengel tabl, einbluitlig ;

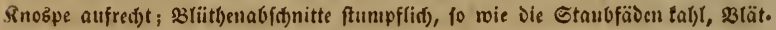

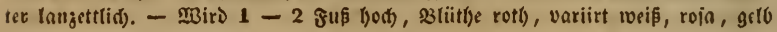
uni bunt. - In Gärten angefitangt. MRai. 4.

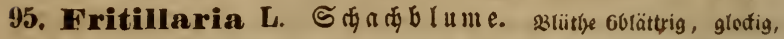
bängens, S3luntenblätter

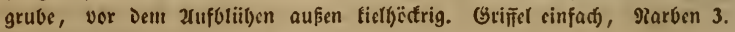
Rapfel ffumpffantig. Saante platt. - Sd)uppenywiebel.

346. F. Meleagris L. Sсrк. t. 92. Sт. 18. Fl. germ, exsicc. 947. VRad) coen jerftreute, linealifdie, rinnige 23 tätter, 3 tütbe meift eingeln, ells.

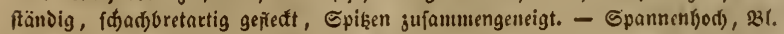

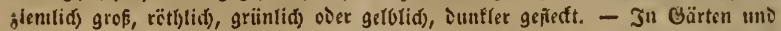
Partanlagen angepranzt uno zufülig verwilbert, fo s. $\Omega^{4}$. L. auf Der gropen MBiefe im 2iofenthale. Rchb. D. Fonifau. Anerswall.

96. Petilium L. Ruiferfr one. sliitbe 6blättrig, glectig, silu.

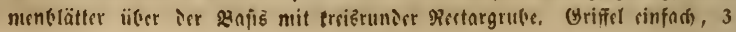


Narben. Sapiel itgarf Gtuntig. Eaamen platt. - Buvicbel fituppig, Blï. then uแ einen \&lätterígeff berum quirlftändig, bängent.

*347. P. imperiale L. B. Mag. 194. \$Birs $2-4^{\prime}$ bed), iteif auf.

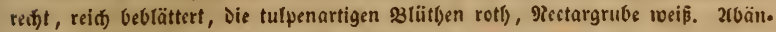
Derung blïl)t gelb: B. Mag. 1215. In Gärten. 2(pril. Maai. 4.

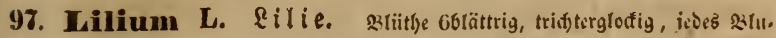

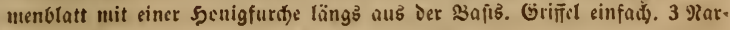
bell faft fopfartig vereint. - E(t)ppenjuviebel.

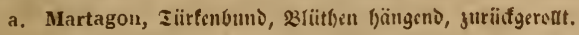

348. L. Martagon L. HAYsk Alzngw. VIII. 29. 3lätter งuur.

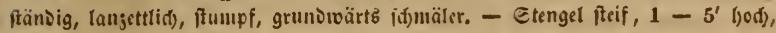
gefprentelt, peofig, retl) angelanfen, Slätter iuntelgriin; 231. weniger 1-3, cDev

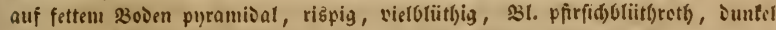
punftirt. Var. glabrum SPR, Etengel raul), fơtenloz, s3(ätter länglid), fpif̧.

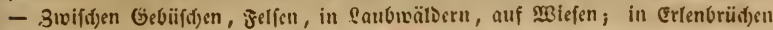
(Rabenhorst). Juni. Juli. 4. Etellenweipe, Dod) meift fparfam; am bäupig. ften in Ibiringon. Blïbt mandse Jalje faft gar nid)t. D. Flawenfd)er Gruno,

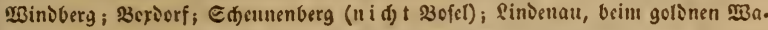
gen u. f. w. - Delia. Z. Erla bri હdwargenberg. Pidstenwalis. - Zlauen.

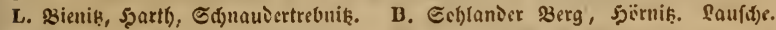

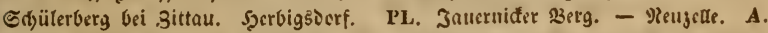

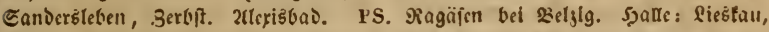

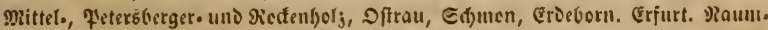

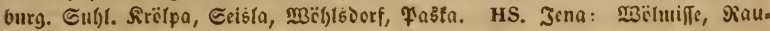
thal, gerft. Weimar. Grub bei Ibentar.

b. Lilium, filie, słütb)e aufredgt (nidjt surüdgcrout).

349. L. bulbiferum L. Scвк, t. 91. 3lätter zerfftreut, tänglid) langettliđ), Blunenblätter innen befafirt. Etengel fteif, $1-2$ fuß̉ bed), Blät.

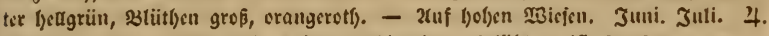

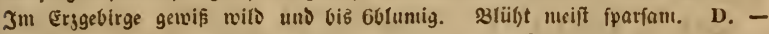
Bei \$ärenftein. Frimdrich August König v. Sachsen. zutenberger Ctadt* wiefent. Geifinģberg. Bok. Bucher u. 2t. Geifing. Bok, G. Rchb. Z. \&au.

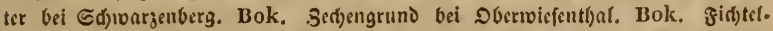
berg. Rodig. PS. Erfurt im Stciger. Bernhardi. HS. Eijenad) auf ism (Saul.

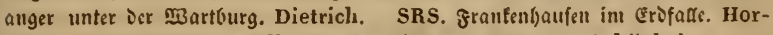

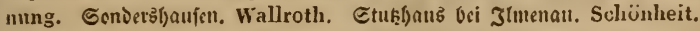

*350. L. candidum L. Hayse Arzngw. VHI. 26. 33ätter lanjett.

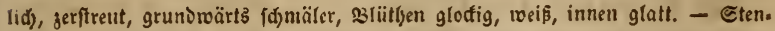

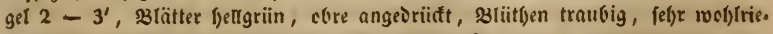
Ђens. - In Gärten angeprangt. M2ni. Juni. 4.

98. Codonoprasum Rснв, (5) foff $\mathfrak{e}$ la

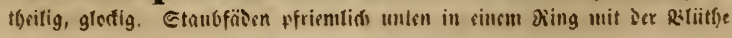




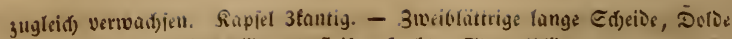
bängeno, frud)títiele verlängert, fteif aufredjt. Etengetblätter.

351. C. oleraceum (L.) Rске. pl. crit. V. 601. 33lätter rël)tig,

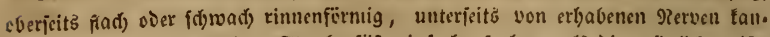
tig; Doloe jwiebeltragent; Etautrgefüfe einfad), fo lang als Die grïnlid)sucip̈e,

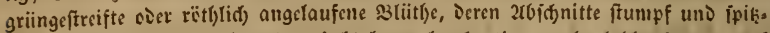

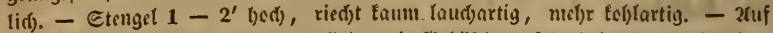

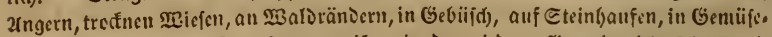
gärten. Juni. Juti. 4. Etellenveije, in Det nicbern Gegent nidjt felten und

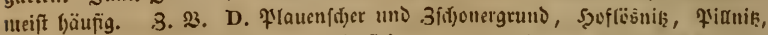

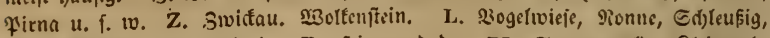

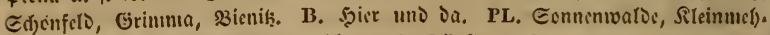

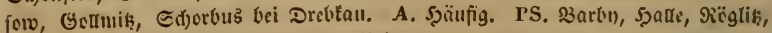

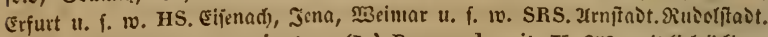

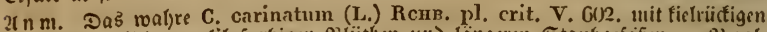
Blättern, fleineren tilafarbigen sliülhen und längeten Etaubgefófen - Sergl. Fl. germ. exsicc. n. 559. - wädift wobl nidit in unferm Gicbicte.

99. Porrum Tounnef. Po r rey. satithe ticf Gtjeilig, (bei bei. terem כage) offen. Gtaubfäden abıxedjfelno plattläutig, jeberjeits mit ciner Episc. Sapfel fapt tuglid), 3furdjig. - Doloc; Edjeibe baudjig, auf einer Ecite aufplab̧ents. - Allium Der in Farentlyeje beigefosten 2utoren.

a. Cepa T. S3lätter tïßrig.

* 352. P. ascalonicum (L.) Cஞ̆alotte. Kenser t. 31)\%. Etill.

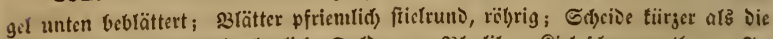

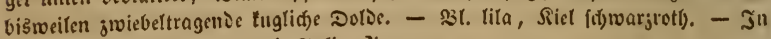

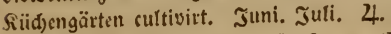

353. P. sphaerocephalum (L.) Gaud. helv. Il. t. 31. Gtrngel

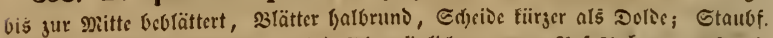

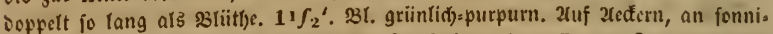

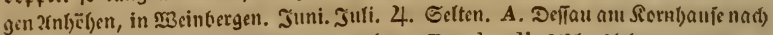

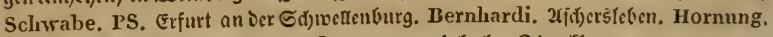

* 354. P. Cepa (L.) Sommerzwiebel, Sipolle. Tabern. 870. 1. 2. Gaud. helv. I. t. X. G(baft nadt, weitrïbrig, unten baudjig, böbser ale Die ftielrunden 3lätter. - Sroicbel brotfïrnig, bei einer 20bart länglid),

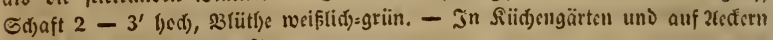
cultivirt. Juli. 2luguft. 4.

b. 23lätter galb ober gang fad).

aa. Dolbe zwiebeltragens.

355. P. vineale (S.r.) Rснв, pl, crit, V. 590. 3lätter ฤal6fticl.

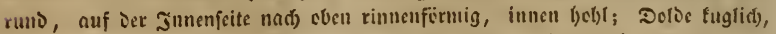

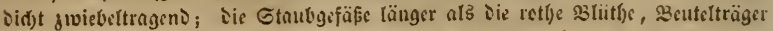

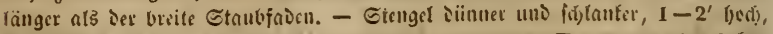

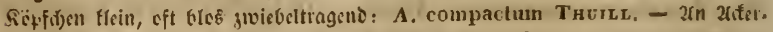

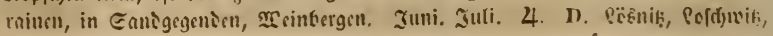




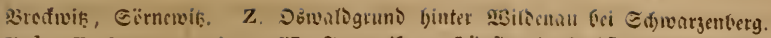
Bok. B. Sinuten u. f. w. PL. Jnuernit. - 5äufig. A. Jcrbit, Dranienbaum,

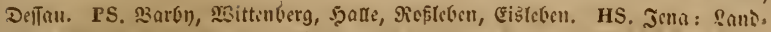

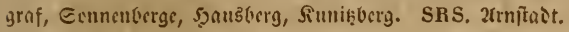

356. P. Scorodoprasum (L.) Recambele. 3lätter fad), fin.

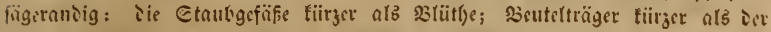

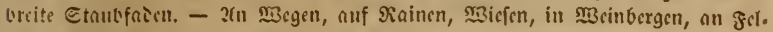

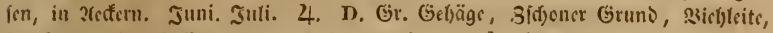

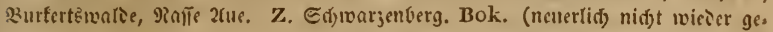

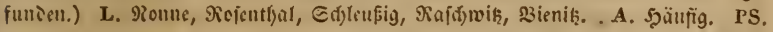

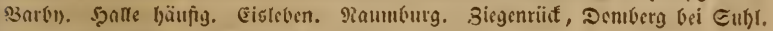

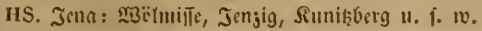

* 357. P. Ophioscorodon ( $\mathbf{L K}_{\text {. }}$ ) Perljwiebel, Stengel uer iem

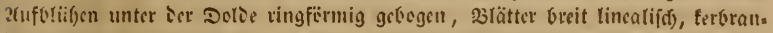

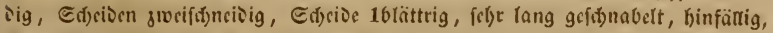

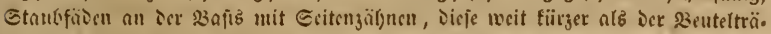

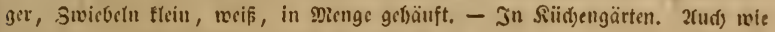
werige ?trt: "Recombolc". Juli. 2uguft. 4.

* 358. P. sativum (L.) Rnoblauf,. Scrк. t. 91. Harxe Arzneigw. VI. 6. Etengel fitielrund; Slätter brcit (anzettlid), pandi), f(d)wad) rin. uenförnig; Ed)cioen lsinfänig, lang gefdunabelt; Dolde gwicbeltrageno; Gtaub.

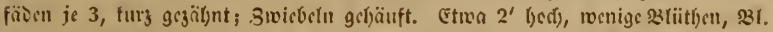

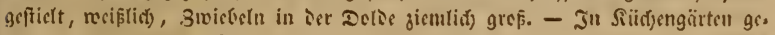
rout. Juli. 2tugut. 4.

\section{bb. Delide fapfeltrageni.}

359. P. strictum (Schrad.) Rснв. pl. crit. V. 591. Fl. germ.

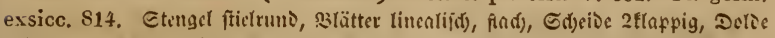
fajt fuglids, Gtaubfabenjät)ue weit tïrjer als sicutelträger, 3miebelidfale fpäter: bin netzfajerig. Etengel fteif, 1' yod), s3l. retl), sidfttëpfig. - 2(n fonnigen Fela icn. Juli. 4. Eclje felten. PS. 9icbra. Sprengel. SRS. Siffläufer. Wallroth.

360. P. rotundum (L.) W. K. t. S2. Etengel fticlruno, s3lätter

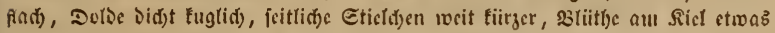

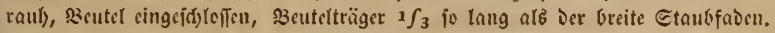

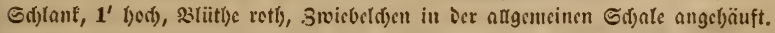

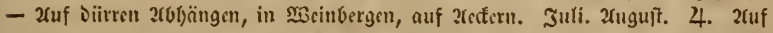

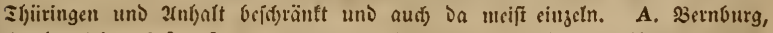

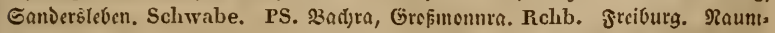

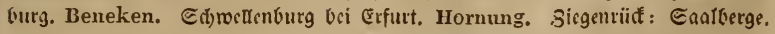

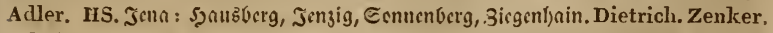

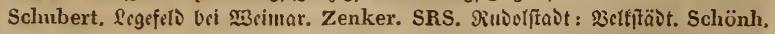

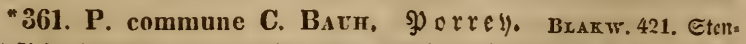
gel fitistruns, sitätter fiad), Dolie fuglid), \$3liitl)e raut) getielt, Etaubfäien etroas

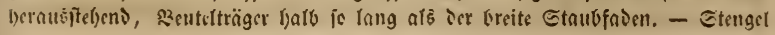




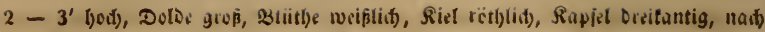

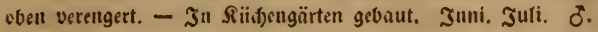

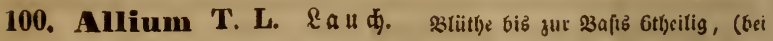
beitrem zage) ausggcbreitct. Stnubfäbsu einfad), frei. Siapiel fuglid), 3fur. djig. Dolbe, Gdicise 2blättrig.

\section{a. Sఏjaft Didft, 33lätter balb ooer ganj ftictrund.}

362. A. Schoenoprasum L. Sł̆nittlaud. Sснк. t. 91. Fl. dan. 971. Sd)aft ftielrund; Blätter ftielrund, rübrig; Sd)cibe fo lang als Dolbe; stütbenabidnnitte eflanjettlid), fpiß; GtaubäDen unten breiter; Sapfel

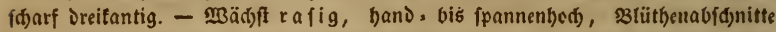

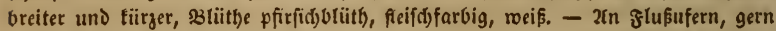

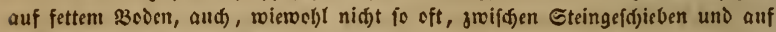

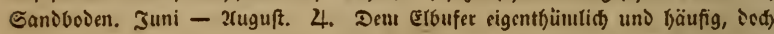

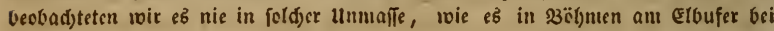

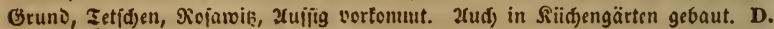

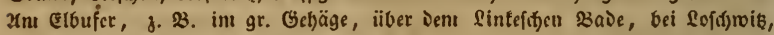

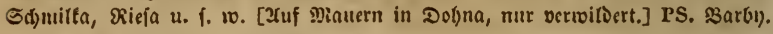

363? A. sibiricum W. Sđaft an Grunde blättertragend; Slätter

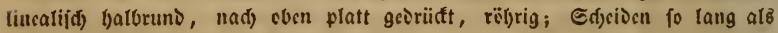

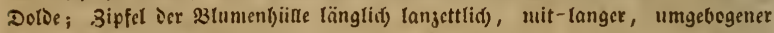

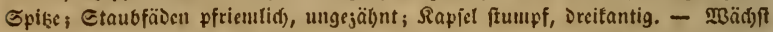

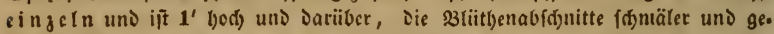

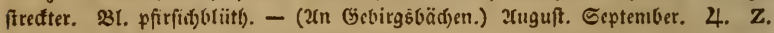
1839 in Gaulen; in Egaujeegraben. Wankel. Ob nun vielfeid)t von cinen ut. fpriinglid)en Stalloorte Dabin getonumen? oocr als Sdjnittlaudg gebaut und vervo.?

b. Sd)aft und \$rätter rocitrëbrig.

* 364. A. fistulosum L. Stenget unten beblättett, in Der פritte auf. geblafen ; 23lätter röbrig, baudjig; Dolis fugetig. - Stengel 1-2' bod), Dolbe

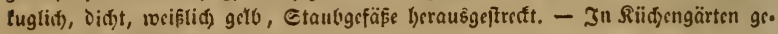
baut. Juni - Esptember. 4.

c. 33tätter baloruno oder fiad).

aa, Didftbliitbige.

365. A. fallax Don, Gdjaft oben fdharf einfantig, blattlos, Blätter lincalif(d), flads), unterfeits unieuttid) nervig, tiellos; Dolie faft tuglid); Staub.

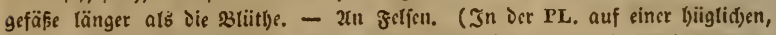
trodnen Miefe: Ruff.) Juli. 2uguft. 4. Sol)lt im obern uno ntittlern Erage. birge, forvie im bäfern Ibüringermals, fonft ftedenweife und neift bäufig. D.

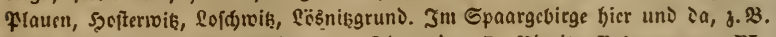

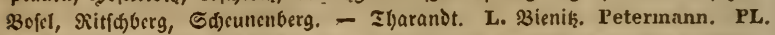

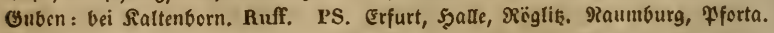
HS. Jena: Şaubbrrg, গRautbal, Forft. MBeinar: Legefelt. Eifenad) : NBartburg

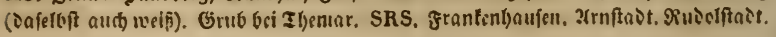


366. A. acutangulum Schrad. F1, germ. exsicc. 588. 1620.

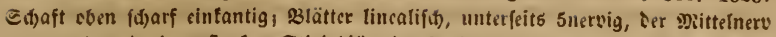
vorrageno und einen farten Etict bildent; Edjirn sben faft cben; Staubgefäpe

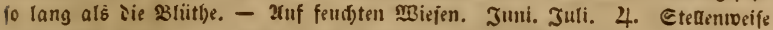

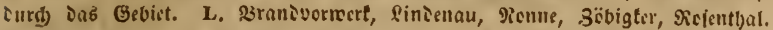
PL. Szen Suffall bis gur ifflidgen Grentze folten. A. Deīau. PS. Barbn. Mit=

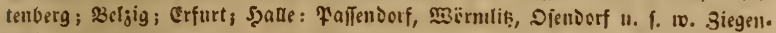
rïf. HS, פittelf)aujen bei Grefrubeftedt.

367. A. Victorialis L. Blakw. t. 54t. Havaz Arzngw, V1. 5.

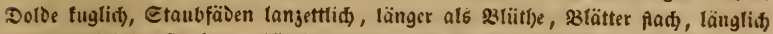

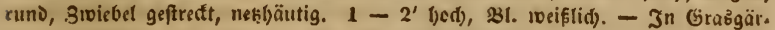

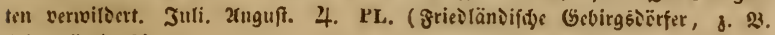
Dbergrängoorf.) -

-368. A. nigrum L. Kenx. t. 4t. Eđaft nadt, ftieltuns, slätter

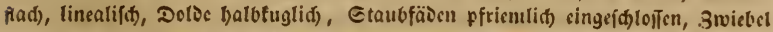

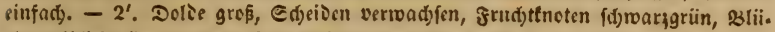
the getblidgriin, - 3tud) fiatt stiitgen mit Swiebeln in Der Doloe: A. magi-

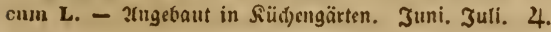

\section{bb. Lođterblïtbig.}

369. A. ursinum L. Fl. dan. 75\%. ST, 41. હđaft ftumf, 3tan.

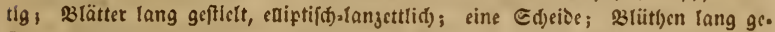

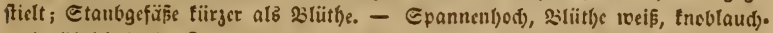

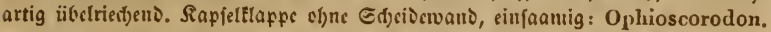
Wallr. - In Raubwäliern, gern unter \$zuifen. Mai. 4. Etcdentucife, am

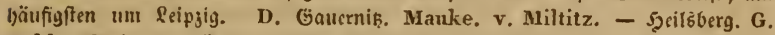

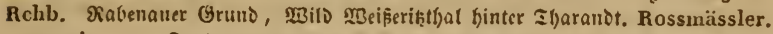
Papperitz. Z. Sncblaudffilfen im Şartenfteiner Mals. Bok. Rodig. Wankel.

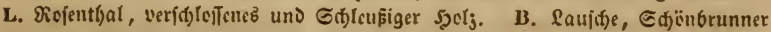

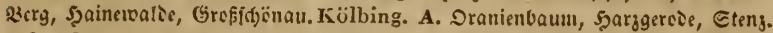

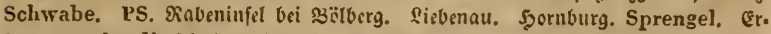

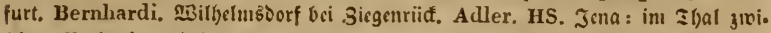

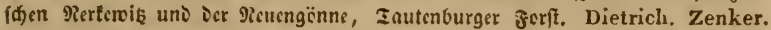
Beimar: II. Ettcrbberg. Zenker. Sisburg: Etafictberg. Hornung. Martinreie. Schönheit.

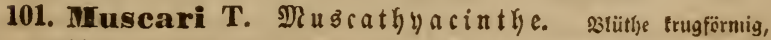

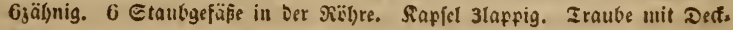
blättchen.

370. M. botryoides MiLl. Kars, 201. St, 7. Fl. germ. exs. 416. Briithen faft luglid), glcidyfürmig, unterfte entfernter, 3lätter fteif, linea.

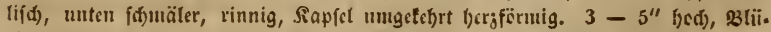

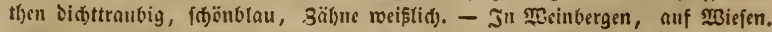

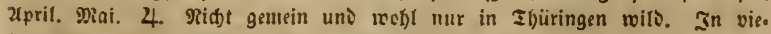
ten Baum. uno Gragä̈rten verwiltert. PS. Şatbc nidjt fetten. Sprengel. surgwenion, Grofmionnra an G̈ortenterge. Rchb. Maumburg. Beneken, 


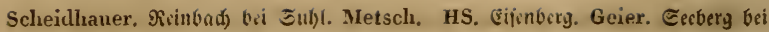

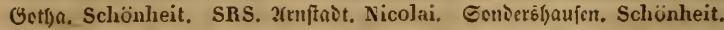

$211 \mathrm{~m}$. L. bei Solgren mir angegeten; of iort wirflid) wirl ?

371. M. racemosum Micl. Jc2, aust, 187, B. Mag. 122. 3lii,

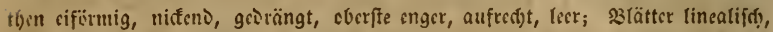

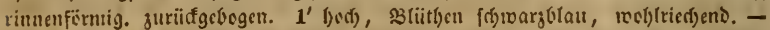
In Sỉeinbergen, auf 2exfern. 2pril. Nai. 4. Sn Der Dberlaufit nur eingeln

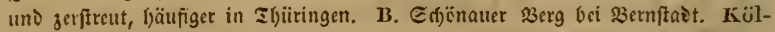
bing. Sycinriđşberg bei Serrnfyut. Kölbing. Scliwabe. PL. Sanıstrone bci G̈̈rlif̧. Kölbing. - PS. Ceeburg bei şađe. Sprengel. Marbađ) bei (Erfurt. Bern-

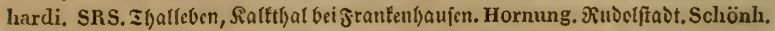

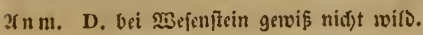

372. M. comosum MILL. Jc2. aust. 126. B. Mag. 133. Die S(ït)sen fantig walgig, untere entfernt, löblig abftel)eno, cbere länger geftielt,

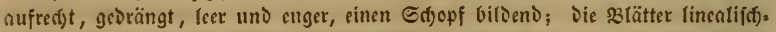

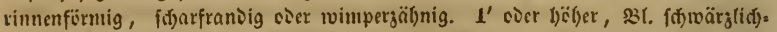
blau, oberfte fö̈̈nblau. - 2uf 2lečern, in Meinbergell, Gebüfó)en. Mai. Juni.

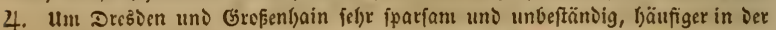

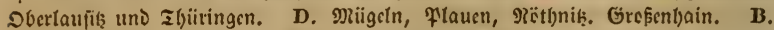

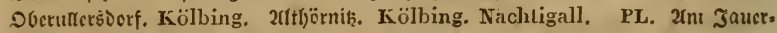

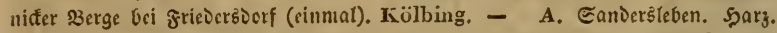

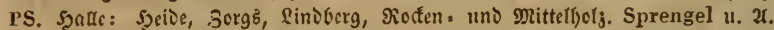
Raumburg. Beneken, Etartzbergc. Rodig. Erfurt: Eteigcr. Bernhardi u. $\mathfrak{x}$. 102. Scilla L. Sternfyacinthe. siüthe Grlättrig, ausgc: breitet. Etaurgefäfe Der sajis ierfelben alljängent, Beutel aufliegeno.

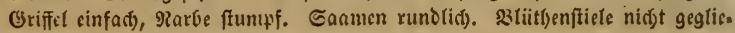
Dert. - 23liitlje DolDentraubig, mit Ded́flättern.

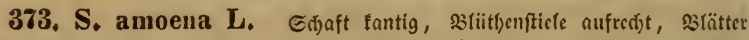

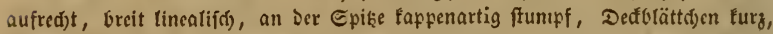
geftukt. Şandfod). 331. Dunfelolaut. In alten Gärten, Farfanlagen, 3aumigärs ten. 2prif. Mai. 4. Serwitbert. D. 3m fonft v. Mäberidjen Garten. L.

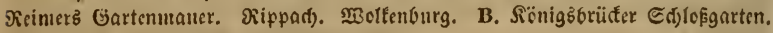
PL. \&ữau. PS. Şalle. HS. Eijenberg.

374. S. bifolia L. B. Mag. 746. F]. germ. exsicc. 209. 33tütter

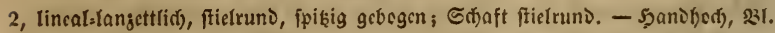

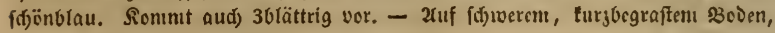
getn in 3aumigärten. 2tpril. 4. Niint gemein, Dod) meift läufig. 'D. Sängs Des Eloufers Diçt an Demifeloen, 3. 33. Ropih. Fr. Avgust K. v. S. 5eibenau. Ficinus. G. Rchb. Papperitz. Uctıer 2 riçniţ. Reichel. Ppp. Gaucrnik̨. Mauke.

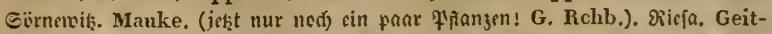

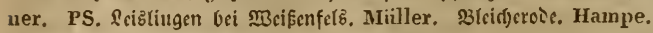

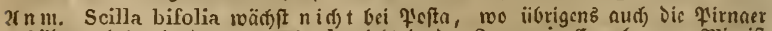

Fälyre nidf) t laniet! - Koch giebt in Der Synopsis Ergget. an. Mir ift yon ba nie cin Etanoort betannt gevoorden, aud) zweifle ids) unbedingt an dics

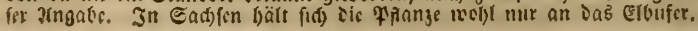


103. Ornithogalum L. $\mathfrak{B} \circ$ gel ft e $\mathrm{r} \pi$. Blüthe bis jur $\mathfrak{B a}$.

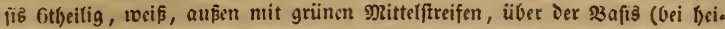
term ₹age) aubgebreitet. Staubfäben unten breit, frei, 3 cutcl auflisgento.

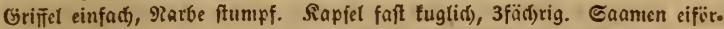

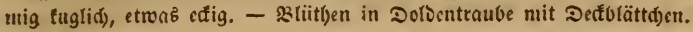

375. O. umbellatum L. Scrk, t. 94. Doldentraube gegipfelt;

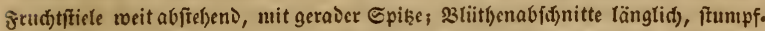

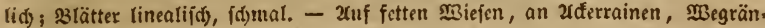

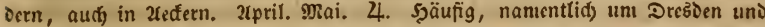

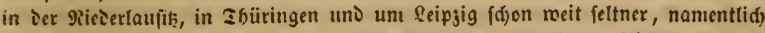

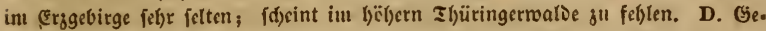

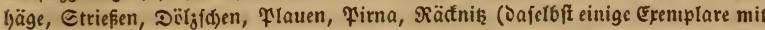
idsncemeifer 3 lume. G. Rchb.) u. f. w. Z. Ehemnis auf Den Edjwentblviefen.

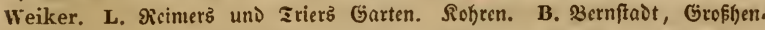

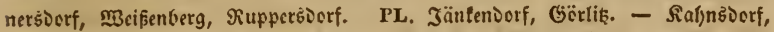

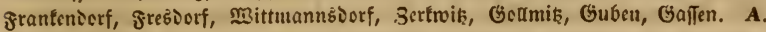

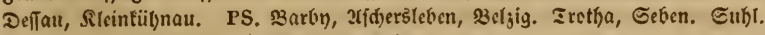
Siegentiiđ. HS. Eifenberg. SRS. 2urnitadt.

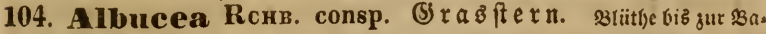
fis Gtheirig, weif, unten mit grïnen Mitteliftreifen, (Gci beiterm zage) über Ocr \$afis auşgebrcitet. Etantfäien platt, Dreipipisig, mittlere Spiß̨e bcuter.

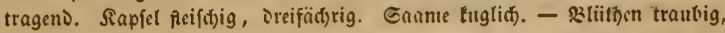
Def(t)(ätț)en りäutig.

376. A. nutans (L.) Jeฯ. FI. austr. 301. B. Mag. 269. Iraube

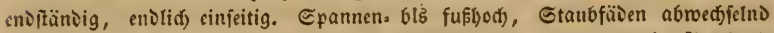

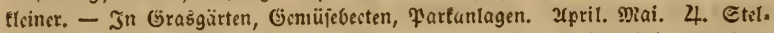

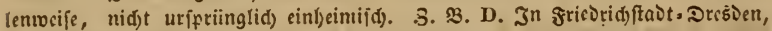

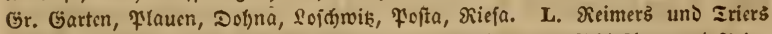

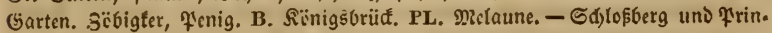

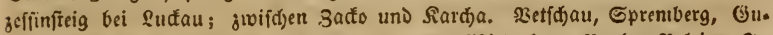
usn; Dffig bei Eommerfelo. A. Deiাau. PS. Mittenberg, 2antby, מelyig. In Salle. Freiburg. PRaumburg. Şeringen. HS. Eifenberg, Jioburg. SRS. 2ernftadt.

105. Anthericum L. 3 a unlilie. Blütl) 6blättrig, ausgge. breitet. 6 Etaubgefäße, Etaubfäien fadig, Eaflt. Narbe feulig. Siapfel bit.

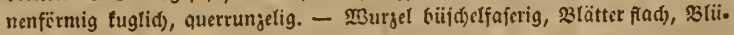
then traubig, weis.

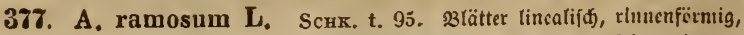

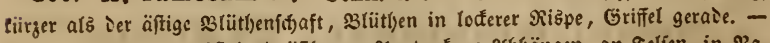

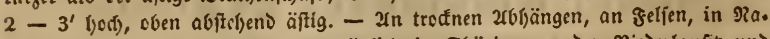

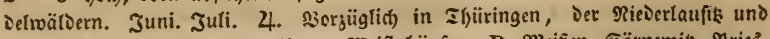

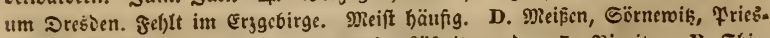

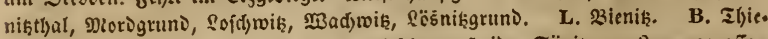

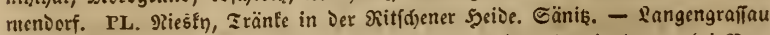
auf ien şüuenbergen; bi szabben; bei Sübben auf Jem Marienberge; bei Reus 


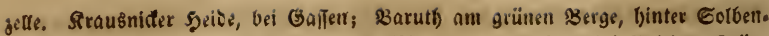

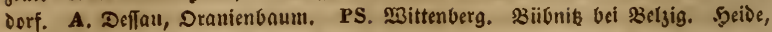

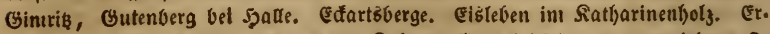
furt. HS. Jena, Meintar, Eifenberg, Roburg. Grub bei Zbemar u, an vielen a. $D$. SRS. Franteni)aufen, 2rnftadt. R. Gera.

378. A. Liliago L. Fl, dan. 616. B. Mag. 914. SBlătter rinnig, Ed)aft eillfa(t), Griffel abgebogen aufiteigend. $-1-2^{\prime}$ (joch, Bliitl)e Doppelt fo

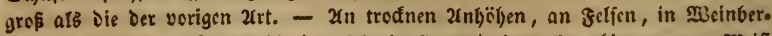
gen. Mai. Juni. 4. Seljlt Der Dberlaufith und Dem Erggebirge ganz. Meift bäufig. D. Säusliks, Sörnewoik, Roftebaude, Sofd)wiks, MBad)wił, Rlcin(jofter:

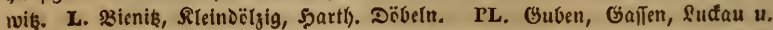

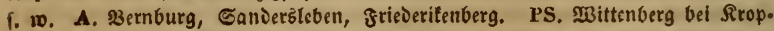

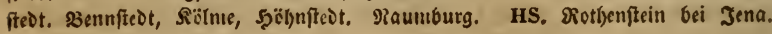
SRS. Jrantentjaufen, 2urnftadt.

106. IHemerocallis L. $\mathfrak{L}$ a glilie. stïthe Gtheilig, tridter. glodig, unregelniäsig. 6 Stanbgefäfe abgebogen aufizeigenb, నapfil ftumpf 3 tantig. - Rnouten angebäuft, Bliitlbe vorgeftrectt.

* 379. H. flava L. Scrr, t, 98. Sт, 7. 33 rätter oreit linealifd,

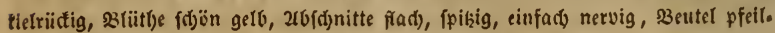

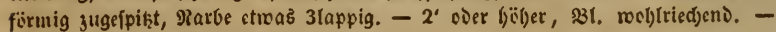
Jn জ̈ärten angepitanzt. Mai. Juni. 4.

-380. H. fulva L. B. Mag. 64. Blätter lincalifó), tietriidig, szlütbe gelbroth, innre 2rofd)nitte ftunıpf, toellenrandig, äftig geavert, 23cutel länglid),

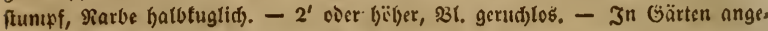
pfanjt und verwilderno. Juli. 2tuguft. 4.

107. Asparagus L.

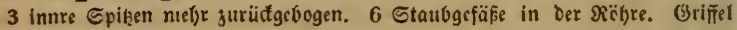

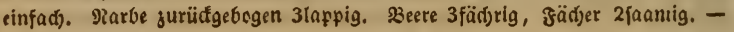
- Wurgel äftig.

381. A. officinalis L. Scru. t. 96. Hayxe Arzngew. VIII. 29. Etengel trautig, pyrantioal äftig, 33ätter tabl, borftenförmig, gerabe, 32tiitben

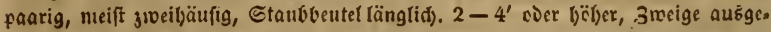

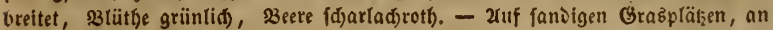
Malorän১ern. 2ud) in \$Beinbergen bäufig angebaut. Juni. Juli. 4 . Ser. ftreut, meift eingeln, faft Durd Das gange Gebiet, int Erggebirge feblent.

\section{Familie Orchideae, $O$ r hibecu.}

- 5̧erbarienbuch G. XXXVII und 47. -

A. Coniorchideae. Pollen fraubartig.

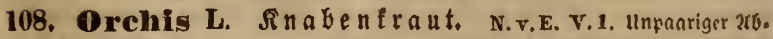

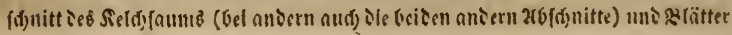


awelter Reif) belmartig jufammengeneigt. Sipfe aubgcbreitst, 3lappig, un. ten gefpornt. Eäule fótäg aufred)t, fel)r tur\}. Darauf Die längerc 2(n.

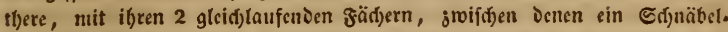

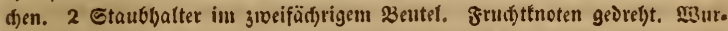
seln 2, tnculig.

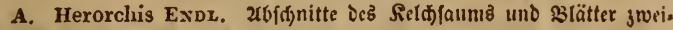
ter Reibe zufammengeneigt. Rnoden runbrid).

382. 0. coriophora L. Rcrв. pl, crit. 773. Sippe 3fpaltig, iie lappen fofief abgcftukt, Mittellappen gangrandig, Seitenlappen abftebeno, ge. terbt. Sporn balb fo lang als Der Srudttnoten, abfteigend. - Stengel ftcif.

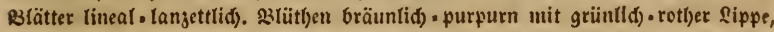
(päter braun bis gelolid); rie(j)en roangenartig, ftel)en in bidfter 2(el)re. Şöbe bis 1'. - 2uf trodinen uno etwas feuditen Micjen. Juni. 4. Etcllenweife

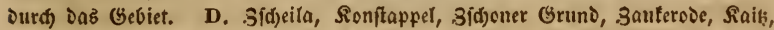
Pianik, sebift, Groffelik, Meifegaft. - sjaranot, altenberg. Bok. Z. Mils

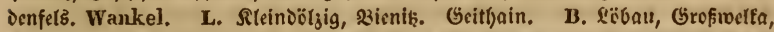

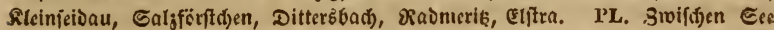

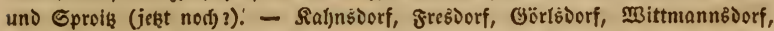
æBanninden, Pitjden, §ïbben, Salau, Epremberg, Gorau, Drebtau, Senften.

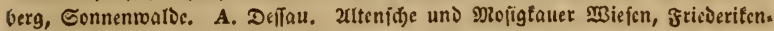

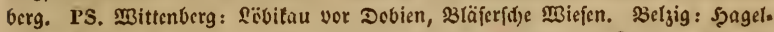

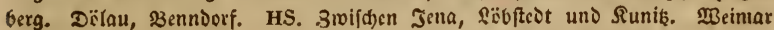
binterm

383. 0. ustulata L. Rснв. pl. crit. 775. Sippe 3thcilig, פzitter. lappen 2theitig; Lappen lineal, mit fd)arfen Puntten. Eporn getrümmt, 3 Mal

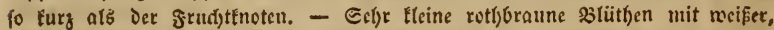
rotbpunttirter Sippe ftelgen in Didjter erfít topfförmiger, Dann länglidjer 2(cł)re.

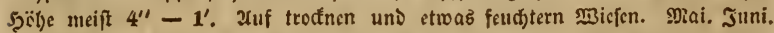

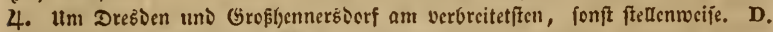
Sd)arfenberg, Sonfappel. Mauke. N3abnsiorf. G. Rchb. Sfifoner Gruns.

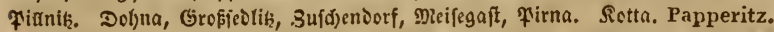

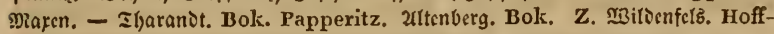
mann (viclleid)t aus̈gerottet!). B. Şainervaloe, Sgërnil̨. Sroflyenners borf: 5̧olberg, langer \$3erg, Rälberberg, Sdjünbrunner serge. Sdj̈̈nauer Şutberg bei Bernitadt. Grofidjënau. Flach. PL. Sิmifden Goliten und Dabme. MBiefen

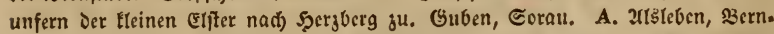
burg, ๔anberšleben, Gefren. PS. Rotbenburg. Iorgau. Löber. HS. Eifenađ̆),

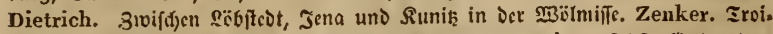
ftedt bei Meimar. Zenker. Miüna bei attenburg. Waitz. SRS, Galgenberg bei Srantenfjaujen. Hornung. Sillodftadt. Beyer.

384. 0. variegata L. Zexk. Fl. Thïrg. II. Lippe 3fpattig, Die Sap, pen fdicf abgeffust, Der Mittellappen 2ipaltig, Eporn getriimnt, balo fo lang als Der fru(t)tencten. - Xebre fopffïmig, mit Did)ten feiffifarbig = purpurnen

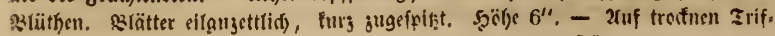


ten; in olten MBcinbergen. Diai. Juni. 4. Im weftlitgen Gebiste; meift par.

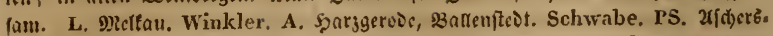
leben. Hornwng. Erfurt. E(t)mon, Erbeborn. Freiburg. Kegel. Rauntburg. Beneken. Stolze. Scheidhauer. Efartşerge. Rodig. S3urgwenden. Fest. altrannftäbt. Richter. HS. Ucber fïberfdibi im इautenburger forft, bei Sinnił bei Jena. 3wiffuen Einstorf uno Jarrnftnot. Zenker.

385. O. militaris L. Rcus, pl, crit. 34). Sippe 3tficilig, raul)

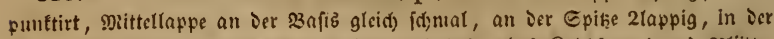

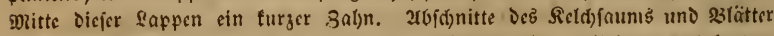

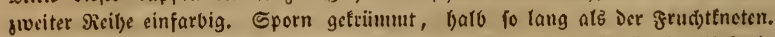

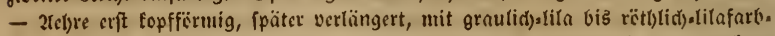

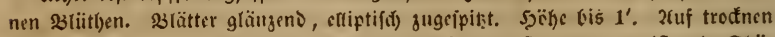

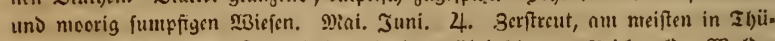

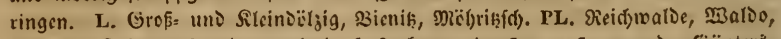

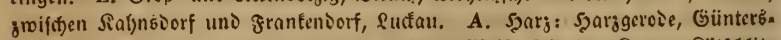

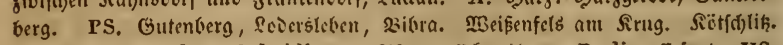
Rauntburg. Beneken. Scheidhauer. Fforta, હfartsoerge. Rodig. Erfurt. HS. Jena. Eifenberg. Geier. Serfa bei \$Beimar. Zenker. Etaffelberg bei Sioburg. Ekart.

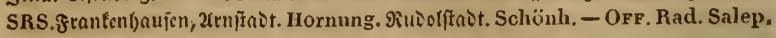

386. 0. fusca Jace. Stura 41. Sippe 3tícilig, raul) punftirt, Mittellappe an Der 3 afis feilförmig, an Der Epitze 2lappig, in Der Mitte Diefer

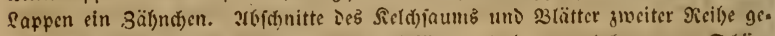
fedt. Gpern jiemlid) geraie, $2-3$ Mial fiirzer als ber grudsttneten. - Gdjüne

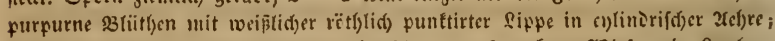

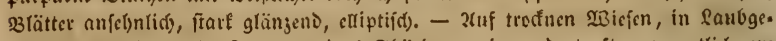
büfóten. miai. Juni. 4. Befonders sljitringen cigen, iort oft, namentlid) unt

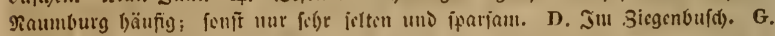
Rchb. 1841). Papperitz. A. Janij. Schwabe. PS. Erfurt. Erieborn, Edimon. sibra. W. Gerhard. Gdiulpforte, פiaumburg. Beneken. Scheidhauer. Edtarts. berge. Rodig. 23urgmenicn. lest. Rchb. Dolmar bei Rültniouf bci Edrwarga.

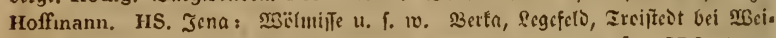
mar. Zenker. Syeilzberg. Martintwoc. Schönh. Mkiningen. Rauch. SRS. gran ienijaufen. Hornung. Ruiolitait. Beyer. 2(rnftait. Szlantenburg. Schönheit.

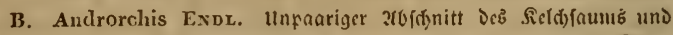

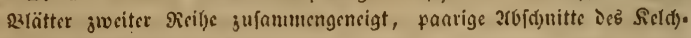
faums abjtelfens.

a. Snollen runolion.

387. О. Morio L. Schк. t. 271. Sippe 3lappig, Ditteflappen auz.

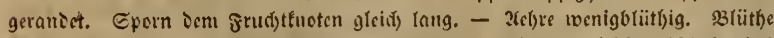

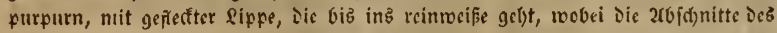

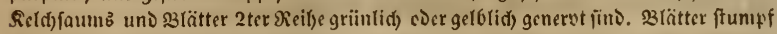

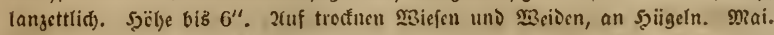
3uni. 4. Ju bïl)ern Enggebirge fel)r felten (बd)wargenberg, Sd)neeberg, MBil. Denau), f(d)eint im bëbern sljüringerwalie zu feblen. Sonft nidjt felteut und meift trupprocije. - OFF. Rad. Salep. 
388. O. palustris $\mathbf{J}_{\mathbf{A}}$ Q. R $\mathbf{R}$ сн8. pl. crit. 1122. Sippe setfet)rt eiförmig,

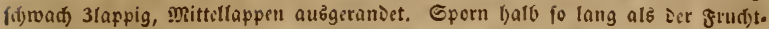

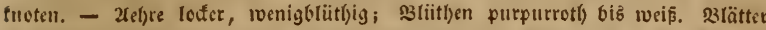

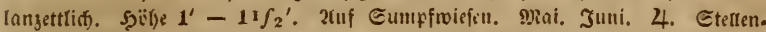

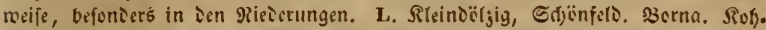

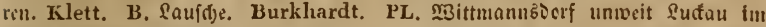

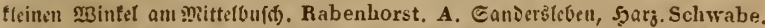

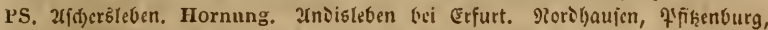

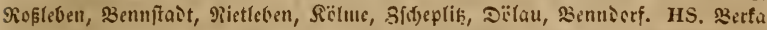

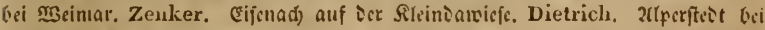
Gropruoffest. Hornung.

389. O. pallens L. Rснв, pl, crit. 1093. Sippe fófwad) 3lappig,

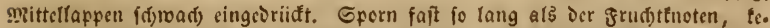

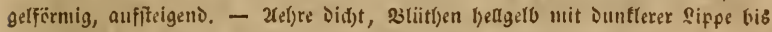

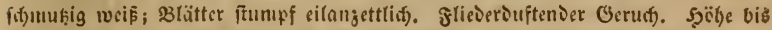

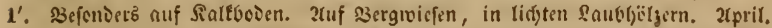
mai. 4. 3efonoers in weftliffen Gebiete. Sicreingelter Etandert in Der 9icc.

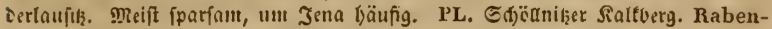
horst. A. Şarjgeroie, Giintersberg. Schwabe. PS. (EIfurt. E(j)men, Mart. rötiḩ. Piaumburg. Beneken. Stolze. Scheidhaner. હffarţ6erge. Rodig. Burg.

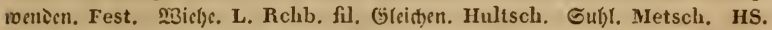

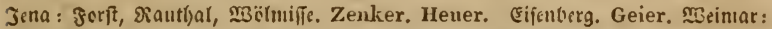

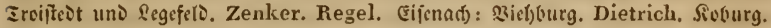

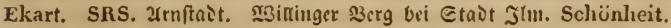

390. O. mascula L. Rcrib. pl, crit. 768. Sippe 3tappig, fdjwad) geterot, sitteflappen länger, 2ippaltig. Eporn ftumup, meift auffítigeno, Dent

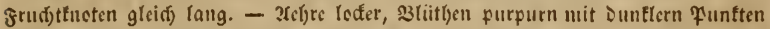

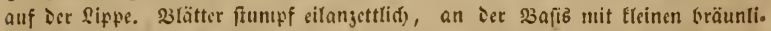

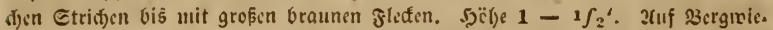
fen. Mai. Juni. 4. Befenderb in Thiiringen und bei Dreşen sen Dofjna

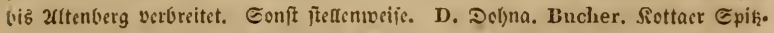

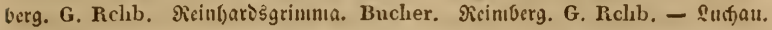

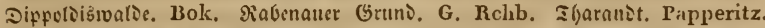

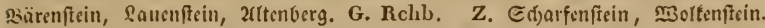

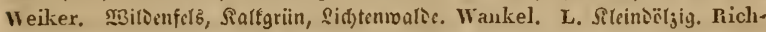

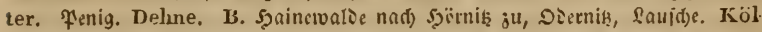

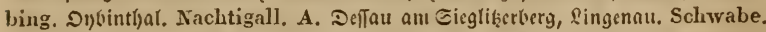
PS. Soberšlebul, Gutenticrg. Sprengel. Erfurt. Gieiđien. Hultsch. Großs. monnra. Rclıb. Panuburg. Beneken. Scheidhaner. Effartstirge. Rodig. HS.

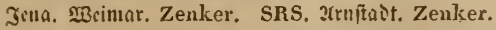

b. Sincaen দanifërmig oier geidfwänjt.

891. O, sambucina L. Rсвв, pl, crit, 1094. 1095. Sippe 3/ар.

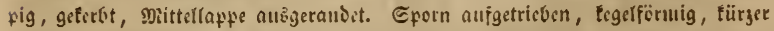

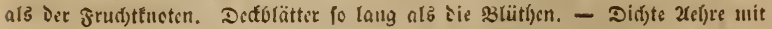

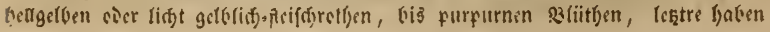


nuf Der Lippe an Der 23 afis einen gelben rotbpunttirten Sted. Sitüben rieḑet

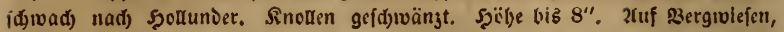
jmifden Gebiifd. Juni. Juti. 4. Etellentvelfe; bei Scipjia worsl verfdjwun.

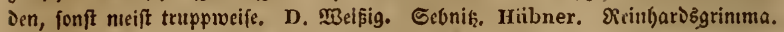
- Pu(jau. Frick. Zbarandt. Papperitz. Z. 23reltenbrunn, S(jroarjenberg, Peubori, Gdjeibenberg. Bok. Fidftelberg. Bok. Wankel. L. Bienik, nod) 1830 Rchb. Jek̨t vielleid)t ganj verf(jwunDen. Siriphäne? Dbergräfenljain bci Sun.

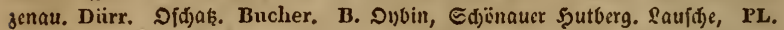

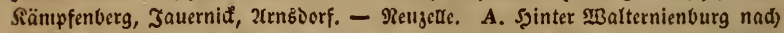
- Gefren zu. Scholler. PS. Gleiđjen. Erfurt. Räbejün, 23ifhofstrode, Martrïlik.

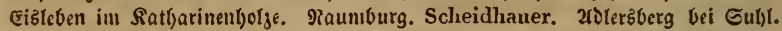
Metsch. HS. Jena: Siautbal, Mölniile. Sienioa. Roburg. SRS. Zeidjroie, Sikzeniorf. R. Robenftein.

392. O. maculata L. Rcur. pl. crit, 772. Sippe 3lappig, fein ge. terbt, Seiteulappen größer als mittcllappen. Sporn faft fo lang als frudjttno.

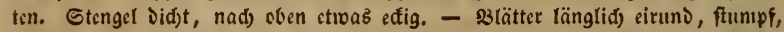

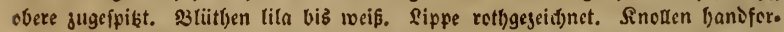

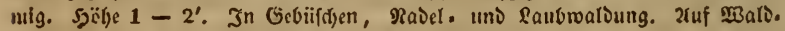
เviefen. Эuni. ふuti. 4. Durd) ১as Gebict bäufig.

393. 0. Iatifolia L. Rcns, pl. crit. 769. Sippe undeutlid) 3lappig, wenig geferbt. Faarige abid)nitte Des Seldffaumb aufiteigeno. Gporn fürger als Srud)ttnoten. Stengel rël)rig. Blätter langettlid) fteif, aufred)t, ntit langen

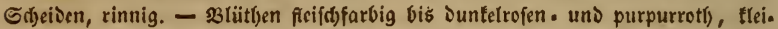
net als bel O. majalis. Defolütter lang, Innjettlid) jugefpitst, eingebogen, griin und braunrot). S3lätter neift ungefectt. Rnollen bandförmig. Jut ganjen Şa. bitus fräftiger un১ fteifer als folgende. Şëlye $8^{\prime \prime}-15^{\prime \prime}$. 2uf torfigen M̉iefen.

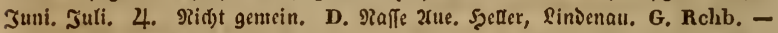

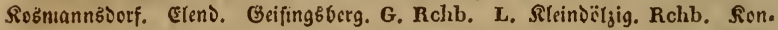
neıviķ. Petermann. PS. Dëlau, Gutenberg. Dierfeburg. L. Rchb. fil. Єut)l. Metsch. HS. Jena: binter Groflïbiđau, Zenker.

394. O. majalis Rcнв. Rснв, pl, crit, 77). Sippe Dentlid Drei.

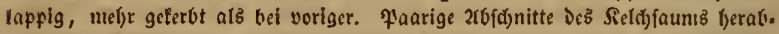

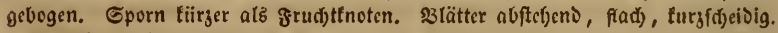

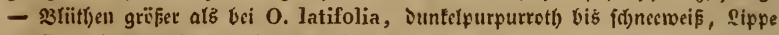
meift weniger gegcid)net alz bei voriger. Dectulätter lang, lanjettlich), eingebogen,

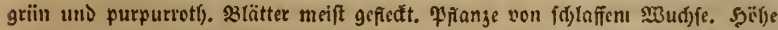
bis 1'. Var. abnorm. Sippe ungefpornt! - \$3efonders auf naffen, Do() all auf troffnetn Miejen. Brai. Junl. 4. Gentein uno bäufig. Var, abnorm. L. Döljig. Petermann.

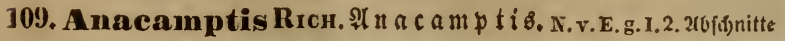

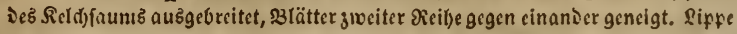

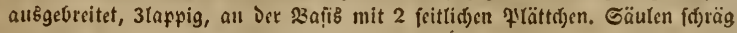
aufred)t, furz. 2zeibe Follenträger an cinem bereinten brbeuterten Etaubbal. scr. Frudglfncten geirel)t. MBurget 2 fnouig. 


\section{A. pyranidalis (L.) Ricr, Rснв, pl, crit. 766. §ippe} 3lappig, פxittellappen ausgeferbt. Cporn Dünn, Denı frut)ttnoten glcid) lang.

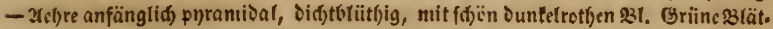
ter bevedten Den Eterigel. Fnollen runolid). Şäbe biz 2'. 2fuf sergwiefen, in Saubroaloungen; gern auf Salffocin. Junl. Juli. 4. Selje felten, nur im weft.

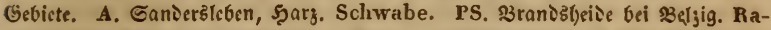
benhorst. Mendelftein, 3iegelroie, Sïlue, 3idjeqlik, 23ibra. Wallroth. 23urg.

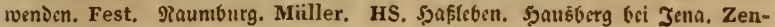
ker. Ionndorf. Mcintar. Zenker.

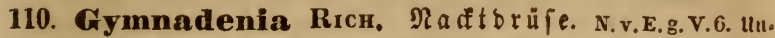

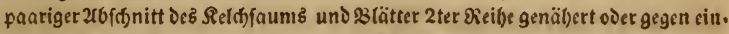

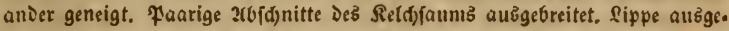
breitet, 3lappig, gefpornt. Gäule fehr turz. Bwiffsen beiDen Bentelfädjern ein Gortfał bes Gdjnäbeldens. Unbebeutelte, gejenderte, reitlidge Etaubbar. ter, frud)tfnoten gedrel)t. $\mathbb{3}$ uryel 2 fnodig.

396. G. odoratissima (L.) R. BR, Rснв, pl, crit, 814. §ippe 3lappig, NRitteflappen länger, fpișer uno breiter. Eporn getriinıntt, etwas tiir. zer alb Frud)ttnoten. - $B$ (tiit)en tlein, in Did)ter, länglidjer 2(ebre, Suntelpurs

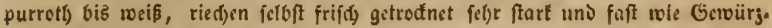
nelten. Bierlid); (d)lant grwadjien, mit fel)e (d) ualen lincalif(d)en siättern.

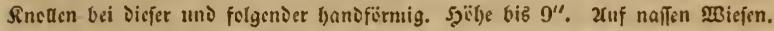

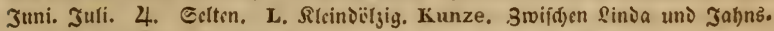
bain bei Grimmua. Sc foren. Klett. A. Şarggcrodc, Gü̈ntersberg. Schwabe. PS. Edjinnarie. Schkuhr. HS. Jena binter Šroflitididau. Zenker. SRS. Butuclftait. Schünheit.

397. G. conopsea (L.) Rich. Rснв. pl, crit. 815. Sippe 3lappig, geterbt, Geitenlappen meift breiter. Sporn beppelt fo lang als ocr Srudttnoten.

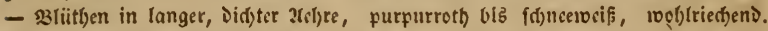

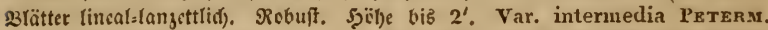
Fl. des Bienitz. pag. 30. Eporn taum fo lang als Drr grudttneten; geţört

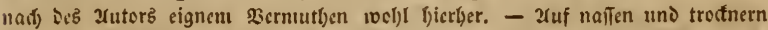
Miejen, an Marbräniern. In Gebiifd) folbr felten. Juni. Jufi. 4. Durdi)

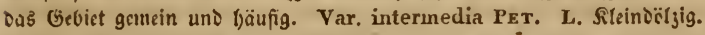

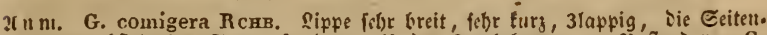
lappen abftelyeno. Eporn io lang als der grudtitnoten. - sáftaro von G. conopsea uno Orchis latifolia? - Sinçpen yiel fiirzcr a1s. Drétulätter, Da. ber Dicfe einen ftarten Edjopf bilien. $\mathfrak{B}_{3} u d s$ weit fräftiger ats bei Der ftärtfften

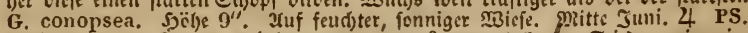

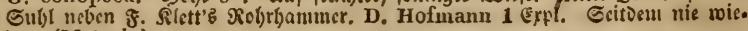
ier. (Metsch.)

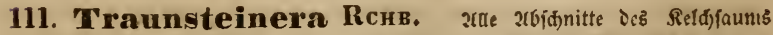

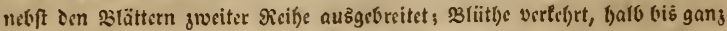
ungeorelst, Sippe 3lappig, geffernt. Frudetfucten georel)t. Gäule wie lei Orchis. MBurgel 2fncdig.

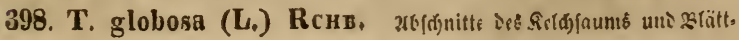




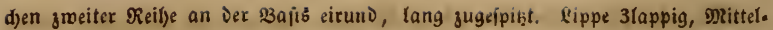
lappen abgerundet fpik. Sporn balo fo lang als Der frrudttnoten. - 3lütljen

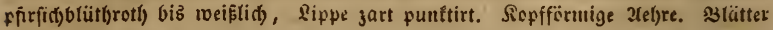
verfelyrt eiförmig, längliț), jugefpił̧t, ftengelfändig, auf Der unterfeite feegrün.

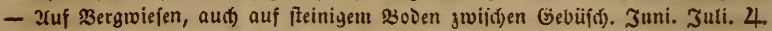
Geiten, nueift in Gebirgs̈gegenden. D. - Deliengruno. Fr. August K. v. S. salfenbain. Papperitz. Lauenftein. G. Rchb. Geifingsberg bei altenberg. Bucher. B. \&au(d)e. Kölbing. Flach. PS, ßarby. Scholler.

xnm. Cine 2angabe SRS. Siaftbal bei frantenl)aufen Dürfte su Anacamptis pyranidalis gelsören.

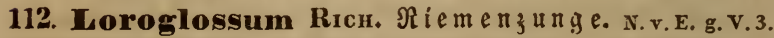

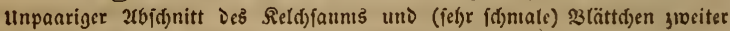

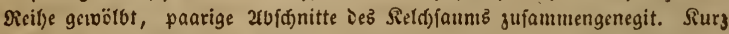
gefpornte Sippe lineal, 3lappig; Der mittlere Sappen fef)r lang; fänınitlid)e

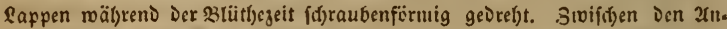

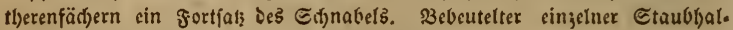
ter. Frudttinoten georef)t. $\mathfrak{B}$ Burgel 2 fnodig.

399. L. hircinum (L.) RІсн, Z Z lappen Der 3lappigen sippe an Der $\Xi_{\text {pił̧ }} 2$ fpaltig. S3(ït)en in anfét)n(id)er 2(el)re;

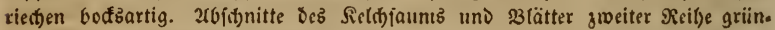

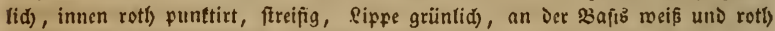
funttirt, firghaarig, Deffolätter ragen über Den Frułtäneten beraub. Blätter eilan. jettliđ). MBurgeltnollen eifïrmig jugeipiçt. - 2luf jonnigen Miefen, an Mald. rändern, forobl auf Sand: alz אalfboden. Mai. Juni. 4. Eelten, nur in

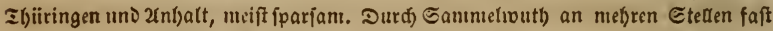

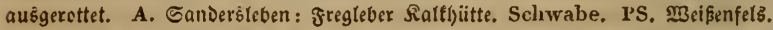
3eigefelo. Iiegel. Freiburg. Kiitzing. Stolze. Scheidhaner. ł' forta. Beneken. Efartsberge. Rodig. HS. Eifenait). Dietrich. Jena: zwif́t)en Suniţ uno Sajan; unter Der Diebeśfrippe, in Gïr\{tenbrumuentbale. Dietrich. SRS. 尺iuoolftait. Zeuker. Beyer. Schünheit.

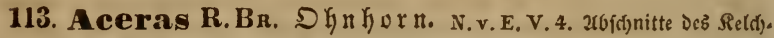

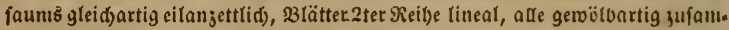
ntengeneigt; Sippe lineal, 3theilig, Rittellappen länger, 2fpaltig, aber an

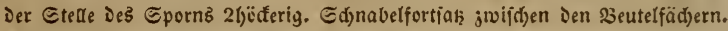
Gtaubbalter gufammengemadifen, bebeutelt. Rarbe berjförnig. Gieireliter Frutittnoten. $\mathfrak{B}$ urgel 3 tnotig.

400. A. anthropophora R. BR. Sipfe länger alz Der frudtttno.

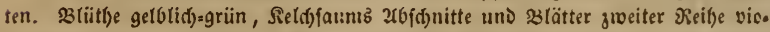

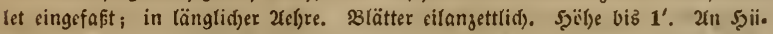
geln, auf furzbegraftem $300 \mathrm{cn}$. Mai. Juni. 24. Eeljr jelten. PS. Biegelrode. Wallroth. [HS. „Berta bei SBBcimar angeblid) gefunden." Zenker bricflid)].

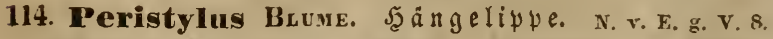

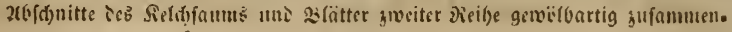


geneigt. Sippe gefpornt. Swififyen ien antberenfädyern tein Edjnabelfortfą̧; Etaubbalter grundfändig, fdjeibenfïrmig, unbebentelt. Frudjtfneten geirel)t.

401. P. viridis (L,) Lrvor. Synops. Brit. Rснв. pl. crit. 813.

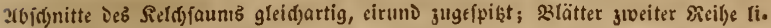

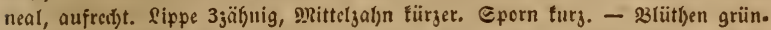
(iø), oft bräunliç, Sippe gelb und griin. Slätter verlel)rt eirund, ftumpl. Snor.

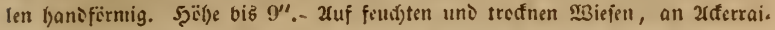
nen; jroifden Gebïijd). Juni. Juli. 4. शamentlid) in Gebirgšgegenden. $\mathbf{D}$

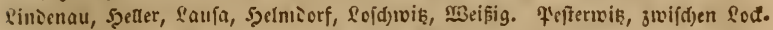

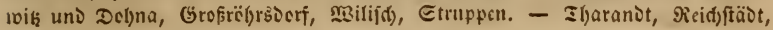
DberfrauenDorf, Gieśljïbel, Sicitenau, zlltenberg, Sinnwald, Giorgenfelo. Z.

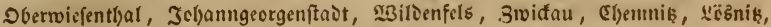

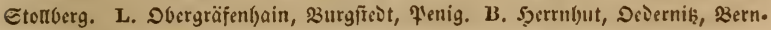

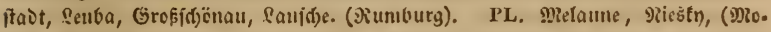

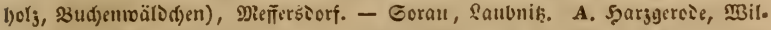
belmabcf. PS. 23randathaice bei 3elyig. X3inercoe bei Erfurt. Cuhl. HS.

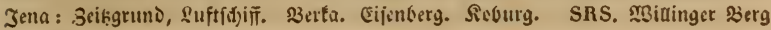
bci Etadt Jlu. R. Qobenftin.

115. Platanthera Rich. \$łatanthere. N. v. E. v.7. un.

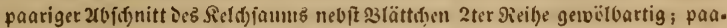

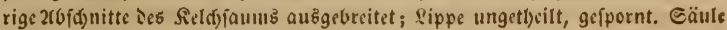
furg, aufred)t, ofjne Ed)nabel. 2(ntberen aufred)t, uit 2 alseinanier fteben. ien Fädjern. Ctaubfjalter unbebeutelt, ein wenig feitlió) an oen Etaubträ. gern. Frudfthoten geirelft. SBurgel 2 thollig.

402. P. bifolia (L.) Rгсн. Rснв. p], crit. 1144. 2(ntberenfädjer

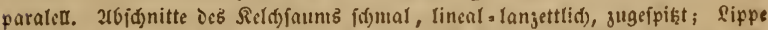
fo lang, Eporn 3-4 Mial fo lang als Der frud)tEncterl. - 2 länglid)e, ftumpf:

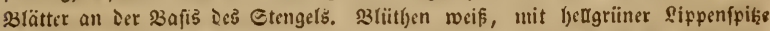

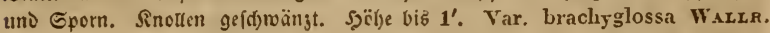
Rснв. pl, crit. 1144. Rarbe ausgerandet. Sippe fiirger als frudjttncten. -

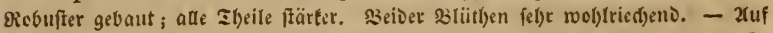

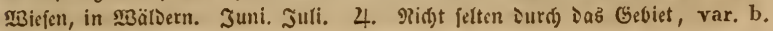
an foudteten Gtelten.

403. P. Wankelii G. Rснв, 2(nt)erenfätter ungleiđf (aufend, an

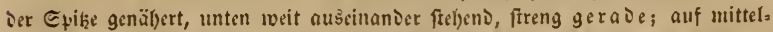
breiter Güule. Eporn soppelt fo lang als̄ frưftfnoten, unten jufaumengebrüdt

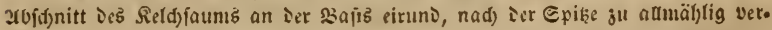
längert, ftunıf. Slütben ganj wvif, Sippen uno Eporn bunfel z̈lgrïn; S3lütben

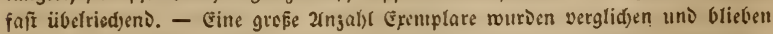

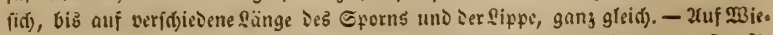

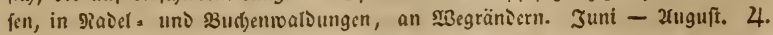
Eiltelt. Dit unter voriger. D. - Raffau. G. Rchb. Papperitz. Z. Marterz. Dorf bci É()enniş. Weiker. Ilı Etcuberg. Waukel. Ilnweit Fïbla. Wankel.

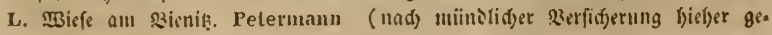
()ërig). 
404. P. chlorantha (Cestor,) RснB, b. Mosssx, u, pl, crit, 1145. a(nt)

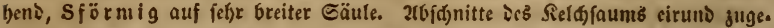
fpist, Sippe breit. Eporn faienförmig, feulig, faft Doppelt fo lang als Der

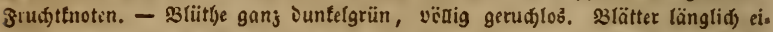
runt. - In Radelwältoern. Mai. Juni. 4. 3eitiger als vorige. - Eebr fol.

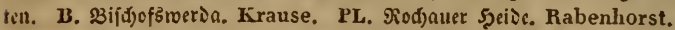

$\mathfrak{x} \mathrm{n}$. PS. Sulfl. Metsch. HS. Maartinroie. SRS. MBiđinger $\mathfrak{B} \mathrm{crg}$ und greseb

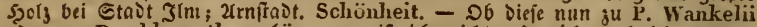

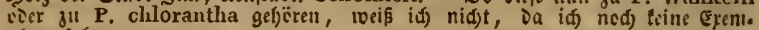
plare jaf).

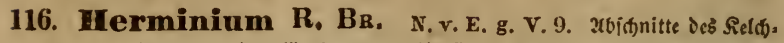

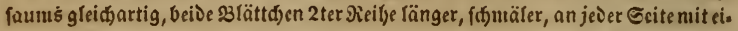

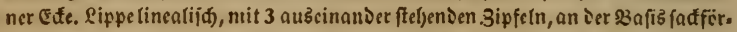

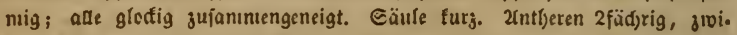

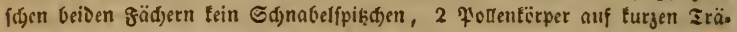
gern; große, fappige Fodenlyalter unbebentelt. Frudjttncten georeljt. \$3urzel uit eutfernt fichenien Sinotlen.

405. H. Monorchis (L.) R. BR. Zkxx. Fl. Thüring. II. Elü. then flein, gelofid)sgriin, bijanartig Duftend, in verlängerter Xef)re. Deffolätter

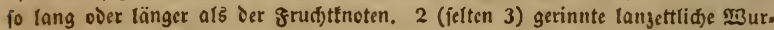
jelblütter, ant Ctengel cin einzelnes lineales 3 latt. Der cinzelne Sinoue treibt an Jangem Etiele einen netuen, entfernt ftelyenden. Syïl) bis $5^{\prime \prime}$. Xuf trofnen

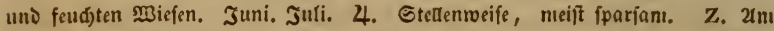
अidftelberg. Schwägrichen. (feit১ent nidft wièer gefunden!). 2(nnaberg. Wei-

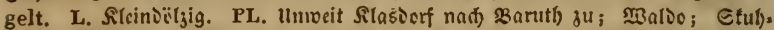

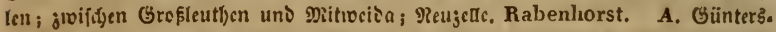
berg. Schwabe. HS. Jena: Zmmerbah), griid)en Sgainberg uno Denn gorfte,

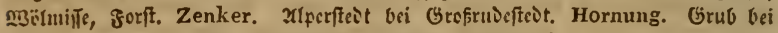
Ilycmar, Metsch. SRS. Niutolftaot. Zenker. Schönheit.

117. Heucorehis E. MEYer. $\mathscr{B} e$ i

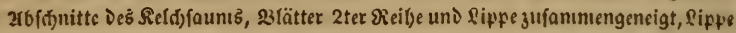
3 fpaltig, unten an Der $B$ afib furg bejpornt. Unbebentelte, grunoffünoige, getrennte

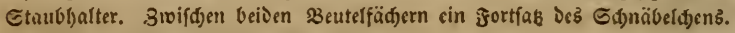

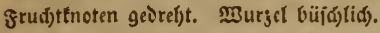

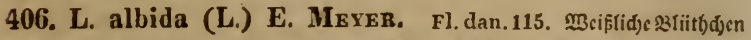

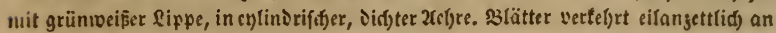

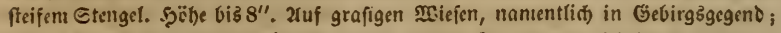
gern uit Melum athamanticum. Juni. Jufi. 4. Ramentlid) im Erjgebirge;

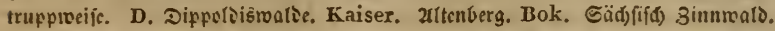

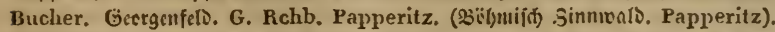
7. Sidjtelberg uno fonft bei Dberwiefntifal. Bok. Wankel. Rchb. 3oofau,

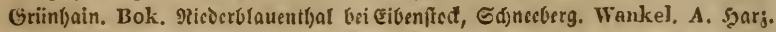

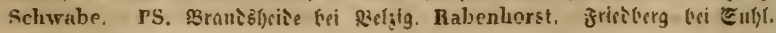
Mntsch. HS. vicia, Honer. 


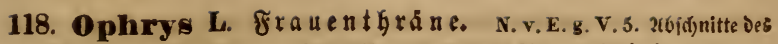

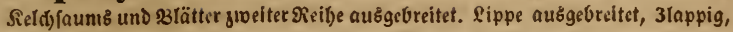

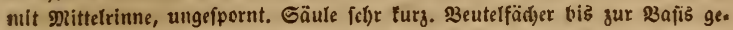
trennt. Staubljalter in 2 Beuteldsen. Grusittnoten gerade (nid)t gejrefit). Murzel 2tnollig.

407. O. Myodes JacQ. 'Rchв, pl, crit, 1146. Zexx. Fl. Thii-

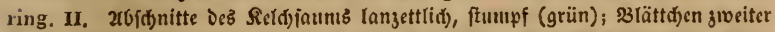
Ereilge lineal (braun). Sippe 3lappig, mit augegefidnittenem Mittellappen, famnts

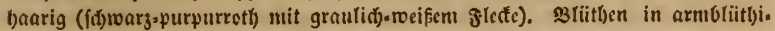

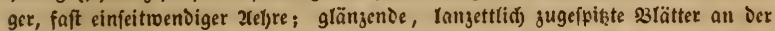

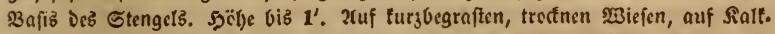
voden. Mai. Juni. 4. 2uf Ibiiringen und 2(nt)alt bef(d)räntt, necift cingeln. A. 2llsleben, Bernburg, Biendorf. Schwabe. PS. Gutenberg; ant Syagen bei

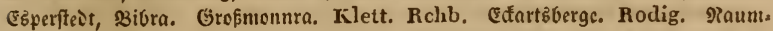
burg. Beneken, Stolze. Scheidhaner. Sdjulpforte. Maidroia, Eteigerwarb bei (Erfurt. Ed)warza. Metsch. HS. Eif(pnad). Dietrich. Berta, Zonndorf bei

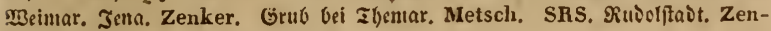
ker. Beyer.

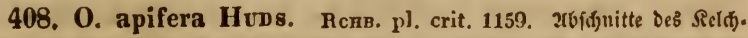

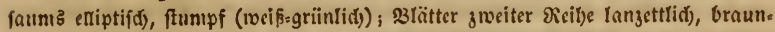
zottig; Sippe 3lappig, Geitenlappen Ianzettlio), braunjettig, Mittellappen vertebrt

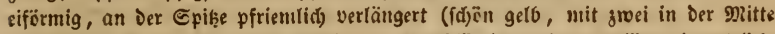

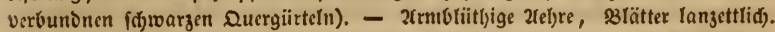

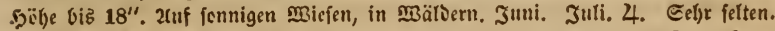

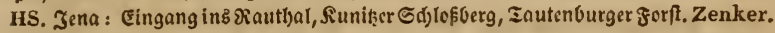

409. O. aranifera SM. Rснв. pl. crit. 1154. ج(6if)nitte Des Seld)faumb ftumpf langettlid) (grïn=wei巨), 3lätter zıeiter Bieibe lineal, ftumipf (Graun), Sippe verfelirt eiförmig, an ber Epise ausgcrandet (braun), mit 2 falg.

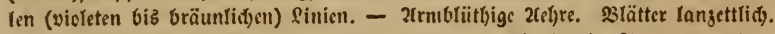

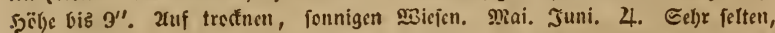

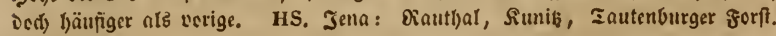
Zenker.

119. Epipogum Gr. $\mathfrak{B} a$ na ne tr or

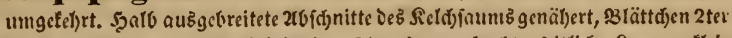
Seilfe gleidjartig. Sippe Enicbogig, 3lappig, aufredt, feitlidje Sappen Elst. ner, abfteleno, mit aufgeblafenem, furgem ๔porne. Cäule längliob aufred)t, mit for)r grofer, oben abgeftuster 2(ntl)crengrulbe, worin Die turggeftielte, 2e fäd)tige, längs aufipringente 2(ntt)ere. Beibe Fodinarien an bafíth verein.

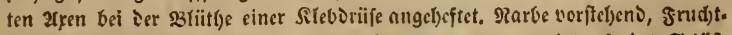

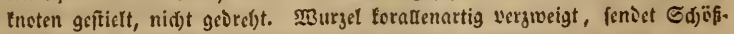
linge aแz, weldje ftengeltreibende 3roicbeltnetten ausbițen.

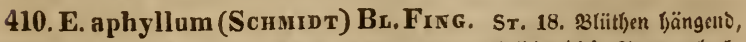

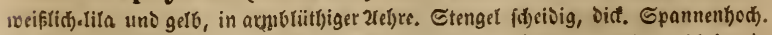

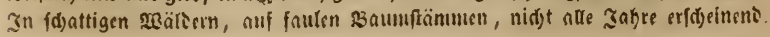




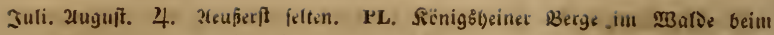
Eulenftein (nur einual, aber in mel)ren Exemplaren all finfter feut)ter Etelle gefunden, feitDell inmer vergeb(id) gefud)t). Kölbing. - 1'S. Belgig in Der 3ranţ̧) be beint Cakteidy. Rabenhorst.

\section{B. Ceriorchideae. Pुollen waţฺ̧̆tig.}

\section{Malaxis Sw. $2 \mathbb{B}$ eitffraut. N. v. E. gen, v. 16. Sli.} the verfef)rt, geftielt, ganj ofien. Sippe ganzrandig, unbeipornt, an Der $\$ 3$ afis sic furge, ftieltunde Gäule umfalfent. Intbere eniffändig, frei, undeutlid) 2 fäd)rig, in jedem Fadje 2 Podentërper, beldje an Der fiddjorüje Eleben. Pinibe unter Der 2untjete an Der Epiţe in Eurges Cdinäbelifen endent.

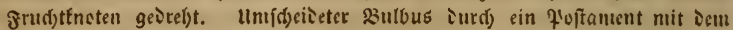
verjübrigen serbunien.

411. M. paludosa (L.) Sw. B.Ztg. 1838. I. T. 2. 231ätter 2 ter æieiłe flelner

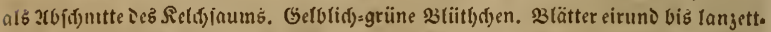

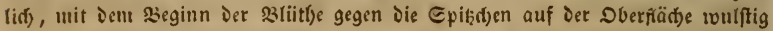

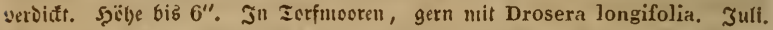
3uguit. 4. Eel)r felten. D. Etcinbar) (nur 1 (Epeuplar!) Deline 1840. L, fioldik. Miiller. PL. Debrilugf, Epremberg, Guben (Ruff.), Dolgig bei Gaf. iill. Hellwig. Saubnił bei Eobrau. Blase.

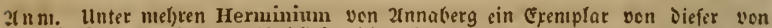

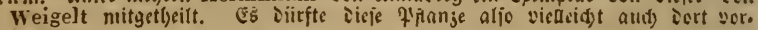
fonunen!

121. Corallorhiza Hazl. N. v. E. gen. X. 10. 2(6fd)nitte

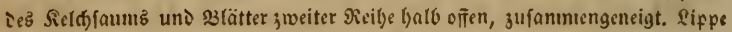

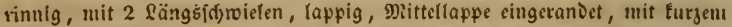

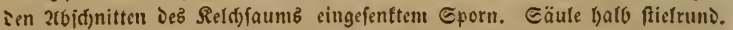

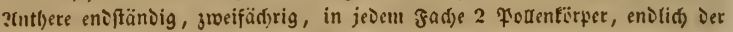
Sileboriife anj)afteno. Frudittnoten gerade. NBurgelftef forallenartig.

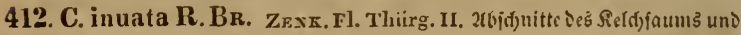

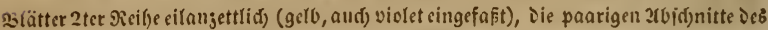

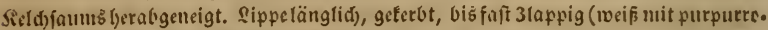

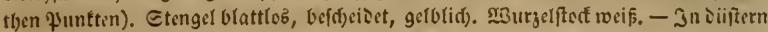
Saub. und siabetwäliern; nuf bemocften Eteinblïfen (G. Rchb. Papperitz.) Juni. Juli. 4. Gelten. D. - 2ltenverg. G. Rchb. Papperitz. (Ju vï)mi,

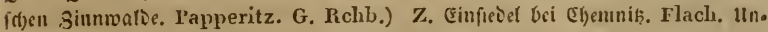
terblauentbal bei (Eibenftof. Scheidhaner. Beim 2uersberge. Weiker. B. Şill.

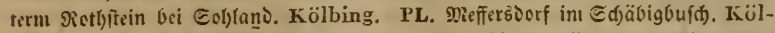
bing. - [PS? Sciersileben uno Siegeltwide. Dafelbft ncuerlidi) nidyt mef)r gefun.

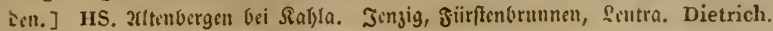
Lenker.

129. Sturmiat Rchв. Sturmie. N. v. E. gen.x.13. 3little

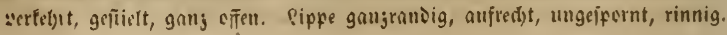




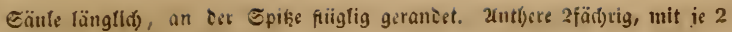

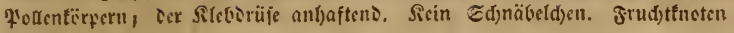
geraide.

413. S. Loeselii Rrch. Fl. dan. 817. T(bid)nitte Des Reldf (aum!

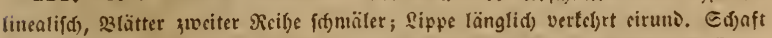

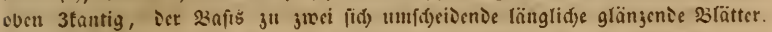

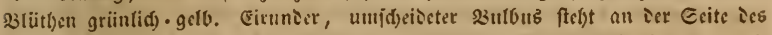

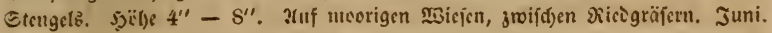

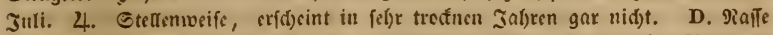
Uue. Bucher. Mauke 1806. Hiibner 1832. G. Rchb. F. Leonhardi, 1St1). Şiller. Papperitz. Rüber. Gr. Rchb. PL. Dutuen und Saden, altgolīen, Grefs.

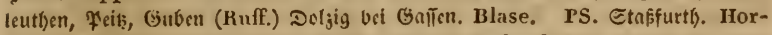

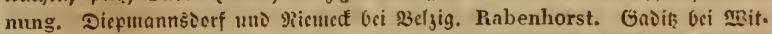

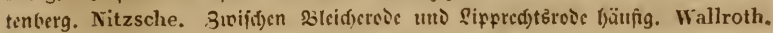
\$3enniorf vei Delikifd). Sprengel. Hiibner. (wenigftens fonfit). HS. Jena: bin. tcr Grofläbiส่nn. Dietrich.

\section{Spiranthes Rrcir. Drehordib̉. N. v. E. gen. v.13.}

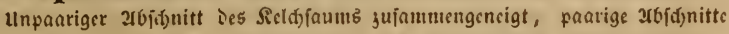

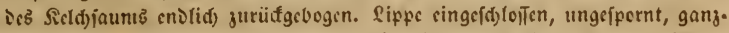

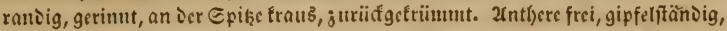
nit 2 entfernten Südjern. 2 2tbeilige łodtentörper enolid) au Der Epił̧e Der

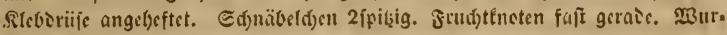
jel tnollig.

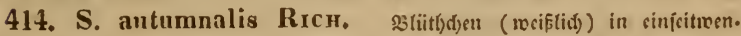

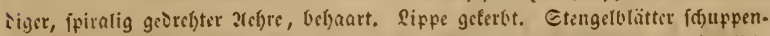

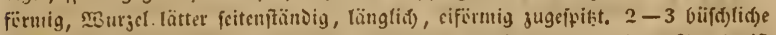

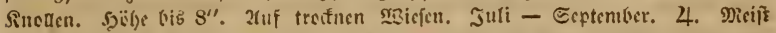

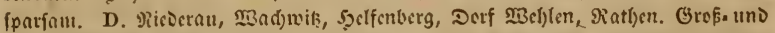

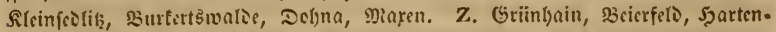

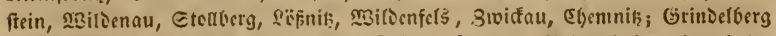

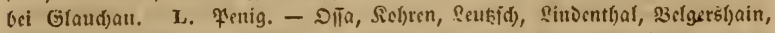

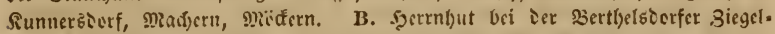

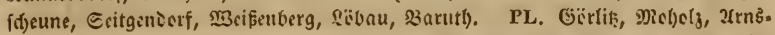

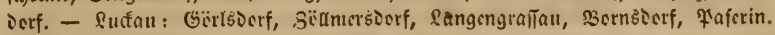

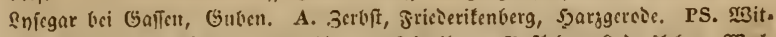

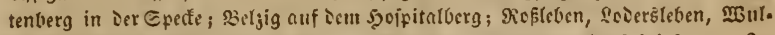

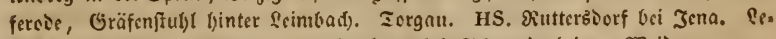

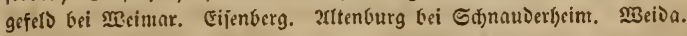

124. Neottia L. Neft tourz. N. v. E. gen, v. 15. xGfdnitte

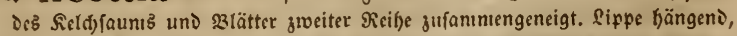
an ier Siafis jadff̈rmig eingejentt, unDeutlid) 3lappig, mittelfappen 2ipaltig.

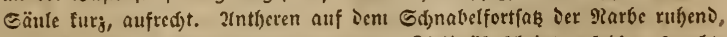

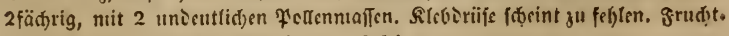
fnoten gerade. Mnurzel serfid)lungen, fofrig. 
415. N. nidus avis Rrcr, Fl. dan. 181. Stengel tlattlos, ve.

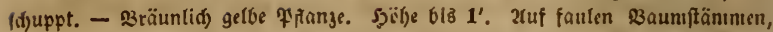

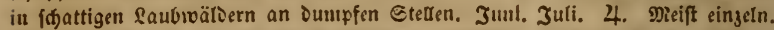

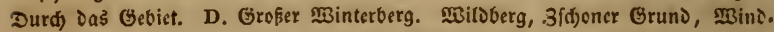

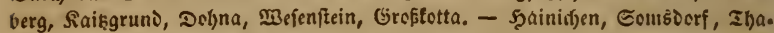

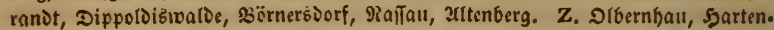

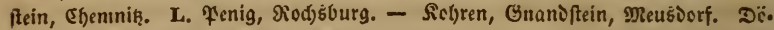

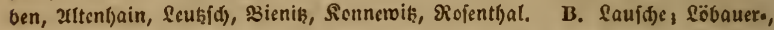

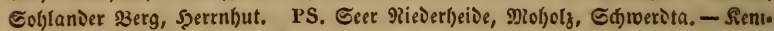
lik̨er Şeide, Etrablau, untrer Spreenalo. A. Berbft, 3eik, saltenfteot. PS.

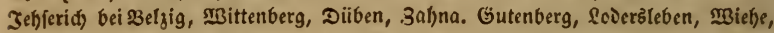
Ed)nton, surgmenien, 2rtern. HS. Eifenad). Jena: \$B̈̈lnifle u. 1. w. Eifen,

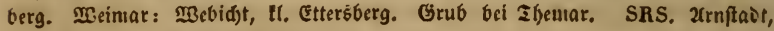
Srantentiaujen. R. Sobenitein.

125. Listera R. BR. 3 weiblatt. N. v. E. gen. V. 17. Blii,

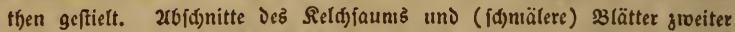
Sieibe etrą zufanmengeneigt. Sippe bängend, lappig, unbefpornt. Säule

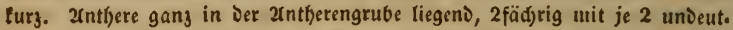

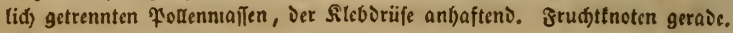

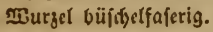

416. L. ovata R. BR. Rснв. pl, crit. 812. Sippe lineal, 2 fpaltig.

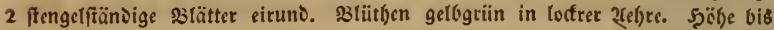

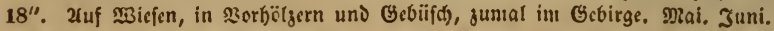
4. Durd) Dak Gebiet nidft felten.

417. L. cordata R. BR. Sw. Bot. 4i2, \&ippe 3ipaltig, Mittcls зipfet 2ipaltig; 2 gegenftändige, herzförmige Blätter. - Sileine rothgrïne Blü. then. Sarte Priange. Şäl)e bis $8^{\prime \prime}$. 2uf Micorboien jroifden Sphagnum in

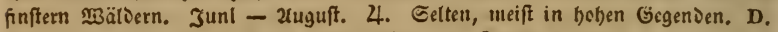

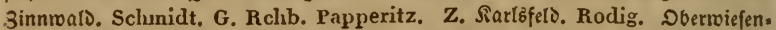
thal. Bok. Johanngeorgenitadt. Brunner. B. Zeida. Kölbing. ̊aufd)e. Rei-

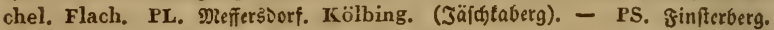
Metsch. HS. Jena bei Der frëblidfen Miedertunft. Zenker. Ed)nectopf, \$är. verg. Metsch. SRS. शieu氏aus. Schönheit.

126. Fpipactis $S w . S u m p f \mathfrak{u r} z$. N. v. E. gen. v. 10.

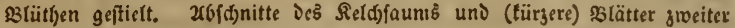
Sieilfe halb offen. Sippe ungefpornt, tniebogig, Das untere Gfico hol)t, Das cbere offen, an ier Bafis 2f(d)wielig. Säule rundlid), aufredjt. 2(nttheren

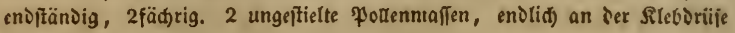

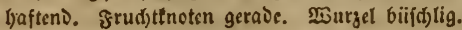

418. E. latifolia Sw. Engl. Bot. 269. §ippe runotich, turg зugc.

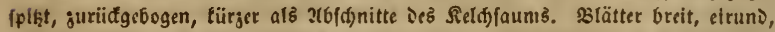

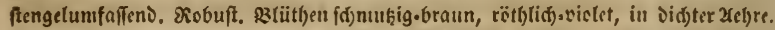

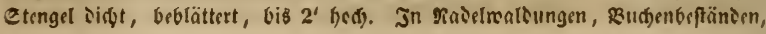




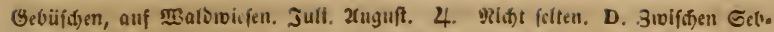

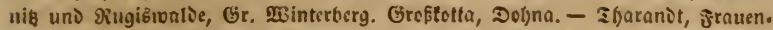
ftein, Raffall, attenberg. Z. Gadfenfers, Eibenftod, 3roidau, 3fdjopauthal bei Sopfgarten, WBitoenfels, Ridjtenwalie, Elyenunis, Syartenftein, Breitenbrunn. $\mathbf{L}$.

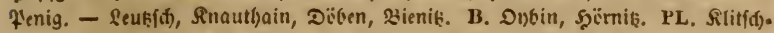
Corfer Seice, untrer Epreewals. A. Deffall: Gecrgengarten, Entenfang. PS. Belgig. Szatle. Grofmionnta. Raunburg. Euhl. HS. Eifenad). Jena. Mzei. mar. Eifenterg.

419. E. viridiflora Sw. Rснв. pl. crit. 1142. Oberes Sippenglte

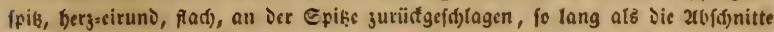
¿es Sieldffaumb, ganjranDig. Blätter meift fđ)nüler als bei voriger. MBud)s fd) (ant. 23tütben bedgrün, Das untre Glieo Der Sipfe roth), Das cbere weif, in ber mitte rofenrotb. Sgäbe bis $18^{\prime \prime}$. In Ravelwälbern an fdjattigen Pläken. Juli - Gepteniber. 4. Eeltner als verige. D. Jungfernbad, Sofbrwiß, Dber.

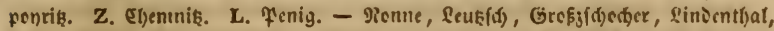

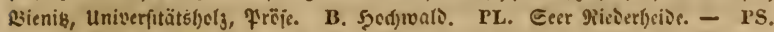

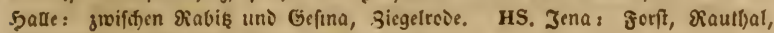

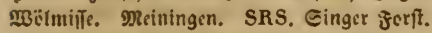

420. E. atrorubens Hofry. Rcnв, pl, crit. 1141. Dbcres Sip. penglied berjförmig, lang jugefpibt, icn cirumben abfónitten iss Reldjiaums

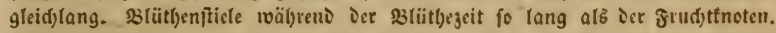
Bliithen Dunfelroth, beftänsig, Ileiner als bei verigen. Slätter ciruno jugeffif̧t,

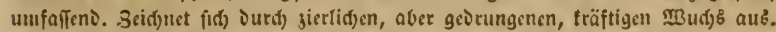
- In giabel. und Saubrealiungen. Juli. 2luguft. 4. Siemlid) filten. L.

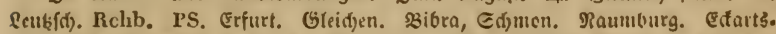

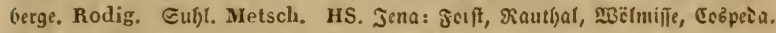
SRS. 2rmftait, rubelitait, frantinijaufen, Gonberabaufen.

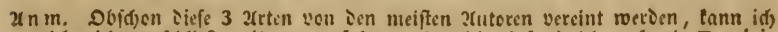
nidi) nid)t entfd)licfen, if)nen zu folgen. 2aderbings fand id) ned) nie E. viridiflora und latifolia unter einanier, aber eben fo venig fab ids, tres ber ge. ringen unterid)eibungsumertmale, ie aud) ien geringften llebergang. E. latifolia rö̈d) bei uns auf Dem Sottaer $3 \mathrm{erge}$, auf Dem 23 interberge an ien

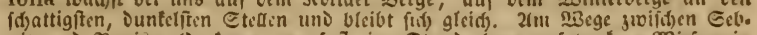

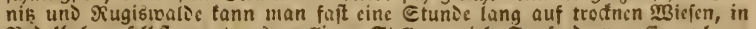
Ravelbely, fethit an etwas quettigen Stetlen, viele Jaufende ven Erentflaren ven ibr becbaditen; uno iod) ließ fid) bei angeftrengtem Eudjen aud nid)t E in Eremplar finoen, Das cinen Uebergang Ju viridiflora gezeugt bätte. $3 \mathrm{cn}$ E. atrorubeus ift bei ¿resisen nie eine Epur wab)rgenenmen werden. Gleid) conftant blieb fid) Die E. viridiflora. Sefenders in Eeben Diirfte man bel ier unterf́djeibung Dicfer 3 arten wobl nie in Berlegenbsit fomnten.

421. E. microphylla Sw. Wazdst. Kit. 270. Docres fippenglled eirund zugefpilkt, geterbt, ien refoffnitten ics Reldffaunis faft gleidjlang. Eten.

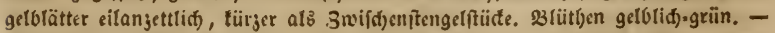

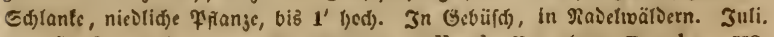

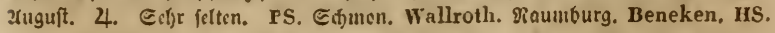
Zena: Sautijal. Zenker. Hener.

422. E. palustris Sw, ST. IV. 13. Doeres sippenglico ftuntpf, 


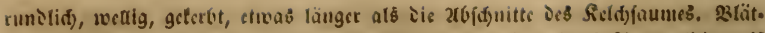

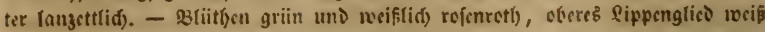

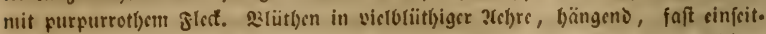

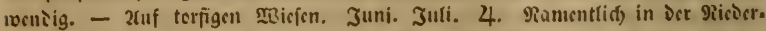

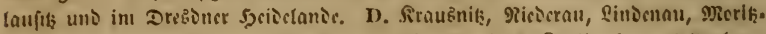

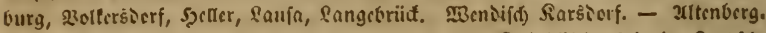

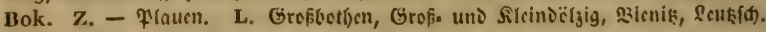

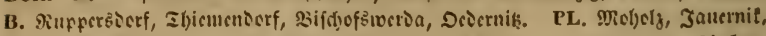

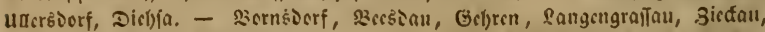
Golīen, Sirdglyain, Genftenberg, G̈uben, Doljig. A. Dranienbaum, Pingenau,

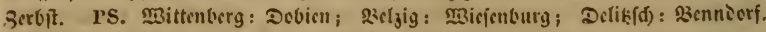

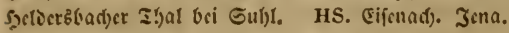

127. Foodiera R. BR. N. r. E. gen, X. 11. Btütben foffe turg

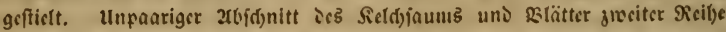
aufred)t, genäl)ert. łaarige abidnitte Des fieldjaumb abjtebeni. Sippe vor.

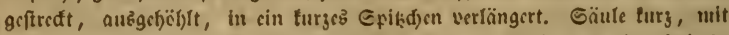
aufred)tem, 2l)ërnigem E(b)

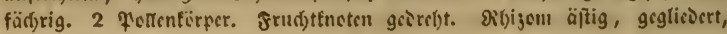
tried)eno.

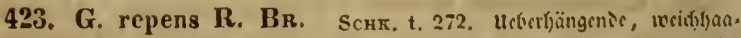

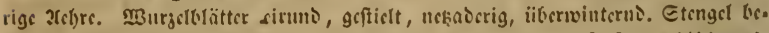

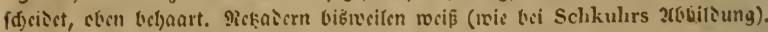

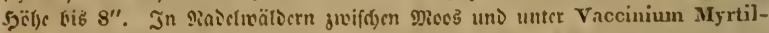

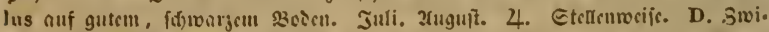

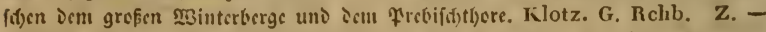

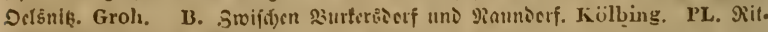

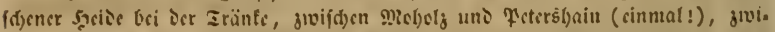

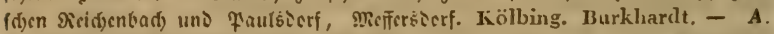

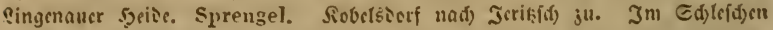

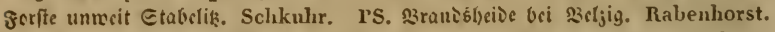

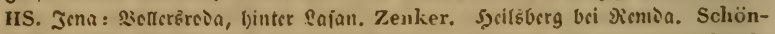

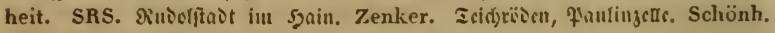

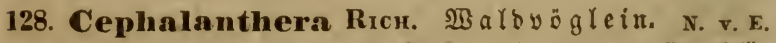

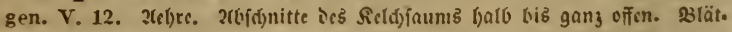

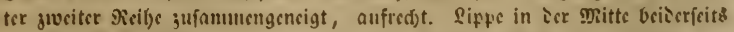

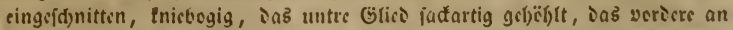

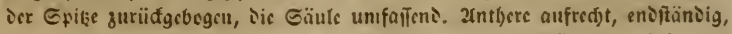
berocglitb, on cinem Eticldyen ier Epike Der aufred)ten Eäule angelieftet, 2. fäd)rig; ¥ollentërper 2lappig. Sicin Ednabelfortfas. Frudttneten geirebt. खुuzelftor friedsent, fajerig.

a. Dorycheile Rскв. Bliitlyen ofīen. Siffe zugcfpilst, länger als

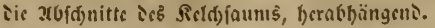

424. C. rubra Rich. Fl, dan. $3+5$. 2tof(d)nitte sce Reld)faums und

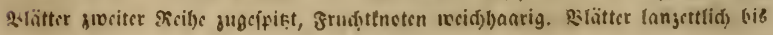


linealolangettlid) jugefpikt. Blätbe f(j)ën purpurrotb, fippe nit $6-11$ ethabee

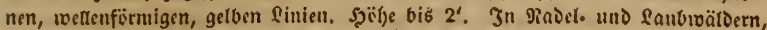
auf Malowicfen. 3uli. 4. Ramentlic') in Ifjüringen, fonft nut felten und fparfam. D. Sangebriiffer Şcide. Fr. August K. v. S. Dipper3Dorf. G. Rchb.

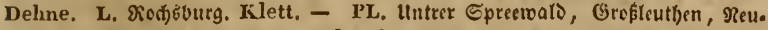
getle. Rabenhorst. A. 5̧ary. Schwabe. PS. \&agäfen bei 23elyig. Rabenhorst. Erfurt. Sdimon, Erbeborn; Rebra, Steintlippe. Raumburg. HS. Ei.

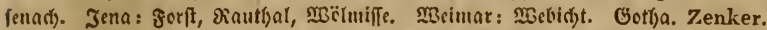
Roburg. Hornung. Grub bei కhcmar. Metsch. SRS, 2tenftadt. Midinger Birg bel Staot 3Im. ¿eid)t. Schönheit.

b. Cephalanthera. Blïtben balb offen. Sippe ftumuf, eürger als

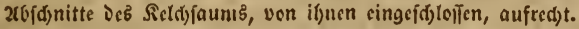

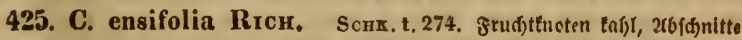

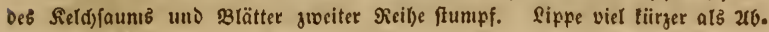

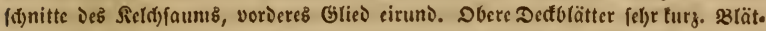

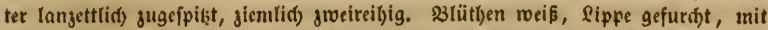
gelbent flett. Şäbe $8^{\prime \prime}-1$ '. Jn snub. uno शadelwäldern. Mai. Juni. 4. Saft Durd' Das gange Geblet, meift cinzeln, fel)lt bisiveilen Jal)re lang und et. fifeint Dann in Mienge wleber in warmen, feuditen Jaljren, wie aud) folgenie

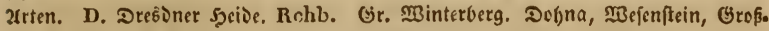

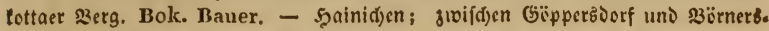
Dorf. Weigelt. Z. Şartcnftein. Bok. Wker, Mildenfels. Wanke], L. Siol)ren. Klett.

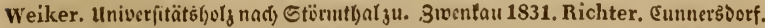

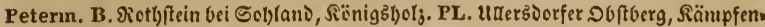

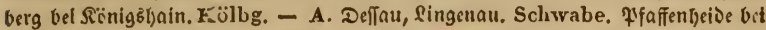

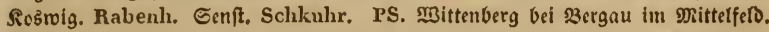
Schkulhr. Erfurt, 3iegelrode. Memileben. Sđjmon. Rodig. Erbeborn. Edart36erge. Bok. HS. (ifєnad). Dietrich. Jena. Zenker. Eifenberg. Geier. Mzartinrode bei Jinte. nau. Schönheit. Meida bei Rleinfalfe. Rossmässler. Soburg. Hornung. SRS. \$Bidinger serg bei Gtaot Jim. Schönheit.

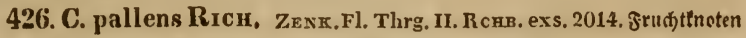

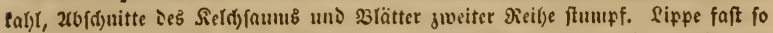

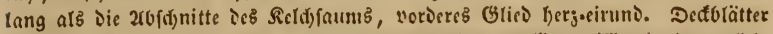

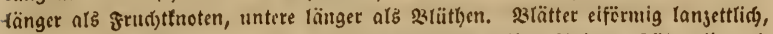

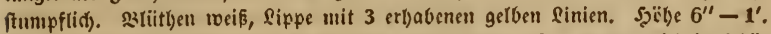

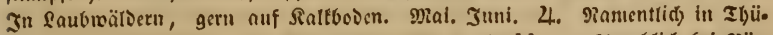

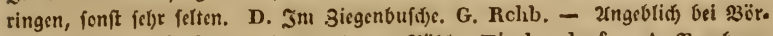

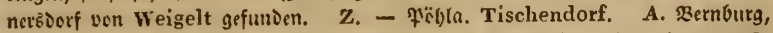
Satzgerode. PS. Erfurt. Gutenberg, Edimon, 3iegelrode. Traunturg. HS.

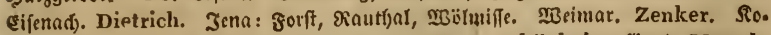
burg. Hornung. artenftein. Hultsch. Şell̋̈brg. Schönheit. Grub. Metsch. SRS. Frantenbaufen. Hornung. L. Rchb. fil. Siudolftaot. Zenker. Zeldjel, Miduinger Berg bei EtaDt \$Im, 2trnftait. Schönheit.

\section{Cypripedium L. Sla a}

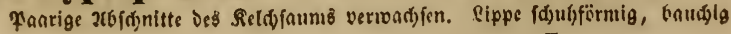




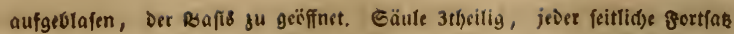

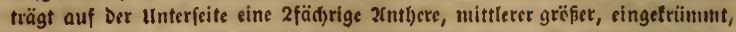

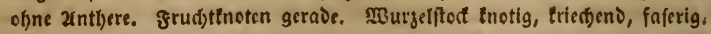

427. C. Calceolus L. Schк. 275. Rскв, exs. 179. 26fd)nitte det

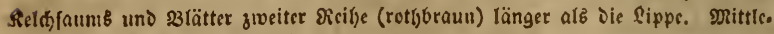

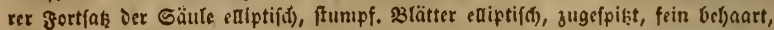

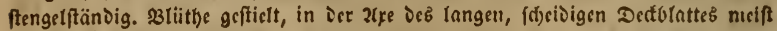

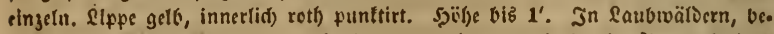

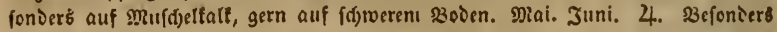
in Iyüringeu. Ureprünglid) wobl an Den meiften Steden nidjt felten, jeşt Durdচ Gärtner neeift verniniert ober ausgerottet. D. Sonft in Dof)na's Sirchen. bolze nidjt gar felten, jek̨t roobl ganz auzgerottet. L. Gcitljain. Seidel. A. Stedun, Sary. PS. Erfurt. Erbebern, 3ibra. Fforta. Eibleben. Bok. నï.

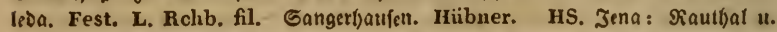

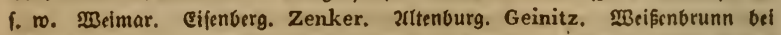
Roburg. Hornung. Spilebcrg bel Remia. Schönheit. SRS. 21mftadt; fran. tenbaufen im Snltbal. Hornung. Sudolftait. Beyer. Stadt Ilu. Schönheit. 


\title{
S Y N CHLA Y Y I A A E.
}

\section{(5) affe ber 3 toeifetblu $\mathrm{m}$ igen. \\ - 23ergl. Şerbarienbud) ๔. XaXIX und 59-71. -}

\section{Familie Characene, Itrmleud̆tergerwäd)ie.}

\author{
- Serbarienbud G. XL. und 59. -
}

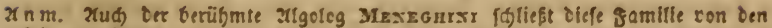
XIgen aนs: -

130. Chara Vaitr. Armleudfer. Sügelden: unootlem. menes fibeniç 3mitterblüthdsen, beftebt auढ (6) rëbrigen frud)ttnoten, roelde rethe fïrner enthalten und Dreiedige, fdjifteformige Rarben tragen,

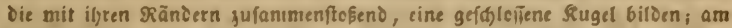
Bereinigungşpuntte der Jruđttnoten entfpringen jarte ßä̌en ( Borbiltung

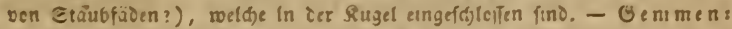
ven einer meifit fünfolätrigen sjütte ffirallg umwadjfen.

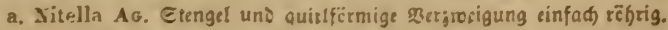
. aa. Stügeldgen und Gemmen adjfelftäniig.

428. Ch. flexilis L. 3reigtein cinfad) oier cinmal bis greeimal geo

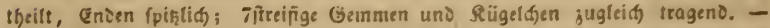

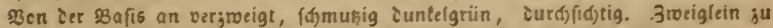
$6-3$, ungeglieiert. Sjäbe $6^{\prime \prime}-1^{\prime}$. Zn fiéfjenten Gräben. Junl - Eeptem• ber. ๑. PL. Sudau, Siotrbus, Guben, Rabenh.

429. Ch. syncarpa Thtrll. Rcвв. pl, crit.1073-79. exs.95.96. Dbere.3roeige Sügelden tragend. Quirle nueift getnäult. 3roeiglein gett)eilt, zie Enden mit turjer Etadjelfipise. $2-3$ zufanumenfitefende faft tuglidje Benmen Gifreifig. Gefenierte Efrmplate adein Eügelden tragend. - S3en ier Bafú an getfeilt, sroeige nueift wedsfelftäntig. Var. Nit, opaca AG. ftreifing incruftitt. - In at. ten serfadenen felgnigruben, zeidjen. Juti. zugujt. С. D. Grefeš Gebäge. Rchb. Z. હhemnis. Weiker, PL. Siebercje, \&udau, Solīen, Guben. Raben-

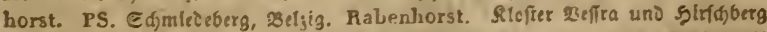
(foll wobl beifen SjirfdbaG)) bei હufft, Kützing. Var. opaca. L. Edjimmels Out, Rchb. Branewiefen. Petennann, PS. Düben. Rabenhorst.

430. Ch. mucronata Ax. Braty. Rcr8, pl, crit. 1071. exs. 38. 3weiglein ier eberften 2uirle gmeimal getheilt, die Enden mit langer Etachellpike.

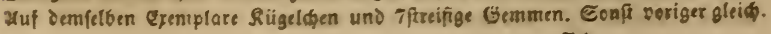


- In Zeiden, ZünıeIn. Juni - Eeptember. ๑. D. Moriß̧burg. L. Edjim.

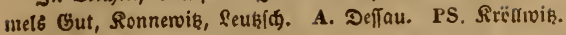

431. Ch. gracilis Sr. Rcвв. pl, crit. 793. 3weiglein meift orei. nual getbeift, in loferen, 63rocigigen Quirlen; ifre Enden 2gliebrig, mit abgefet?. ter Stadjelfpiłze. Gemmen längliă, meift ju 2. 2ruf Denfelben Eremplaren Rü. gelden uno Gemmen. - Xeuperft jart, von Der Bafis aus vielfaç) vcräjtelt. 3

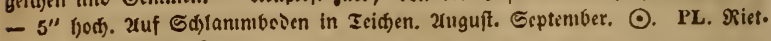
(d) ener Soide. Rabenhorst.

432. Ch, tenuissima Desv. Rcrв. pl.crit. 1065-67. exs, 100, 3meig. tein Dreinal getbeilt mit ungegtiederten EnDen und feiner abgefețter Stadjelípią

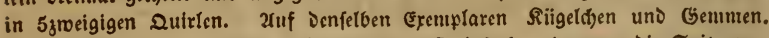
Gentmen 9/treifig. - 3roeige fadenförmig, faft einfach, nie gegen Die Spiçe ver. äftslt. Xfftquirle getnäult. Şöhte bis $3^{\prime \prime}$. b. exigua. RABExr. Flora 1837. 131. Quirle auร nur $3-4$.3reiglein beftelyend; 31veige gabelfërmig verältelt. c. batrachosperma THUnL. Rсвв. pl. crit. 1070. Duirle genähert, gufam. mentlebend aus Den gabltreiden, Did)t quirffändigen 3roeiglein beftehend. - In

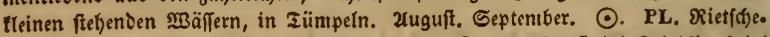
ner Şeide um Daubis, Lữau. Rabenhorst. - b. PL. Sonft bei Stiebs̄dorf bet Sud́au. Rabenhorst. - c. D. Moriłburg. v. Zeng. L. Sindentbal. Rchb. PL.

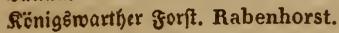

433. Ch, stelligera Baver. RcrB, pl, crit. 1887. Smeiglein meift 2-3theilig, Das Mittelftüc längcr, meift 2glièrig, Die Seitenftüđe 1 glicorig,

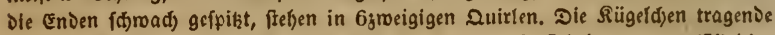
Pfianye trägt 5 - 7 fternfürmige elfenbeinartige, faft fteinl)arte wurzelftändige

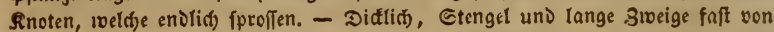

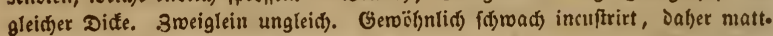
grün. Meeift $1^{\prime}$ bod. In zeiden. Juti. 2luguft. ๑. PL. 巨d)wielungbfee. Rabenhorst.

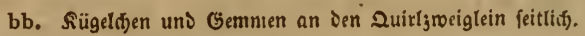

434. Ch. barbata MEYex, Rcri, pl.crit. 1080-81. exs. 97. 3ineig.

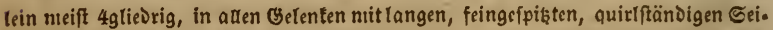

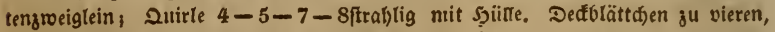

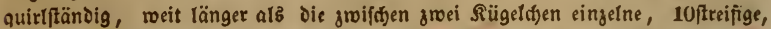
fpis getrönte Gemme. - Etengel äftig, Durdsfdeinent. - 2uf überfd)wenum.

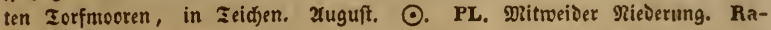
benhorst.

435. Ch, scoparia BAver. Rchs. pl, crit. 1082-1085. 3weiglein vädig unberindet, mit fein gefpikten Seitengweiglein, etroa von Der Sänge Der Gemme, an adtent Getenten und eben foldhe an iffer $B a f i z$, einen $\mathbb{R}_{\mathrm{ran}}$ am

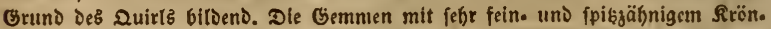
den 10-11ftreifig. Sïigeldien und Semmen auf Derfelben Yrange. Stengel

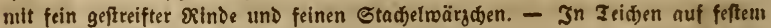
goden. Xuguft. ๑. PL, Sieterofe, Rabenhorst. 
b. Chara: Stengel und Sroeige aus meloren umeinander gelegten Rïl)ren jufanmengefekt.

436. Ch, vulgaris LIN. (foetida BRAUn.) Fl. dan. 150. BIsсноғв t. I. f. 14. Sweiglein zu 8, quirlftändig, lineal, ftumpf; um Die Gem. men je 4 ungleidje, borftidfe Rebenzmeiglein; Diefelben fuid meift fo lang als Die 13ftreifige Gentnte. 2luf Denielben Exemplaren Gentnien und Rügetí)en.

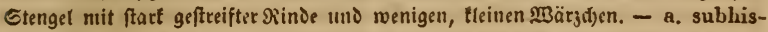
pida Braun. Etengel mit jieniliof ftar"en, gedrängten Ctadjelmargen, table Ënogliedar Der 2lefte türger. - b. subinermis longibracteata elongata Braux. Orobuft, ftärler incruftirt, als serige, Daber inuuter weißsograu, fajt obne Etadjet. wargett, mit langen Seitenäften, icl)r genäl)erteıl afțuirle. $-c$. inermis brachytela et brevibracteata parva BrAux. Dhne Etadjelwarzen, mit lurgen Ent.

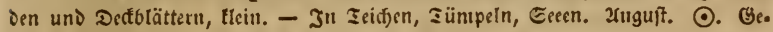
ueiu. Var. a. PL. \&uffau. Rabenhorst. PS. \&elyig. Rabenhorst. Var. b. PL. Rönigsిwarther ferft. Rabenliorst. Var. c. PL. Iorfgräben bci Jüterbogl. Rabenhorst.

437. Ch. longibracteata Krz. Etengel äfig, verfoditen, fur. d)lg geftreift, glatt. 3weiglein Der Quirte 8ftändig, faft einfeitwendig, 5-6. glievrig, Die Gelente jujanmengejegen. - Deftblätter gul 4, ungleich, die Benme 6-8 Dzal überrageni. Gentute 9ftreifig, turs getrënt. Unteríbei. Det fid) von Ch. vulgaris, ju Der fie A. Braun jieht, aud) Durd) meit geringere

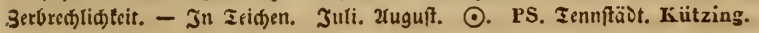

+ 438. Ch. stricta KTz. Bot. Ztg. 1834. 707. Etengel fteif, felse get.

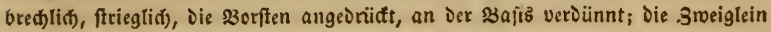
Der Quirle jı 8 ; Dectblätter einfeitig, zu 4, 3 mal fo lang als Die ovale Gettl. me; Rügeldfen bleibeno. - In ftebenden G̈räben. (Juli. 2luguft?) ○. PS.

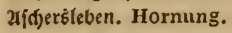

+ 439. Ch. refracta Krz. Bot. Ztg. 1034. 707. Etengel ftad(id), 3weiglein Der Quirle zu 8, an Den Glicoern berabgebogen; Das lekte Glied ias tiirgefte, Dectblattartig, Dectulätter jiemulid) quirrftändig; Die inneren 4 grëßer, etıas länger als Die faft ellipioioifa)e Gentnte, Die äufern 4 felbr tlein. - In ftce

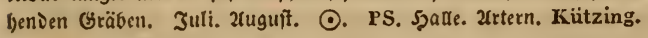

440. Ch. ceratophylla Warur. (toment.) Fl. exs. 92. Etengel f(s)r

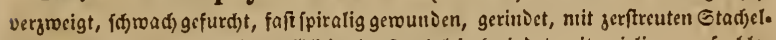
twargen. Die untern frud)tbaren Glieder Der.3rociglein berindet, wit quirligen, aufgebla.

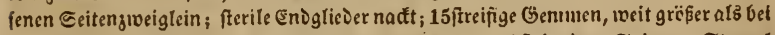
Chara vulgaris, haben ein אrënđ)en utit 5 furjen abjtefenden Spiß̧en. Stengel

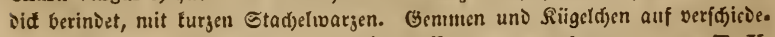
nen Jndivibuen. - Setfäut in: a. microptila Braun. Wallr. annus T. V. Stcifer, mit georängten, fel)r lurjen Etadjelwarzen ain ticfgefurdjteu Stengel, lurger EnDipişe Der Sweiglein un১ eurzen, eiförmigen, jugefpikßten Seitenzweiglein. - b. macroptila Braus. Ed)lafïr, mit renigeren, längeren Stadelwargen am

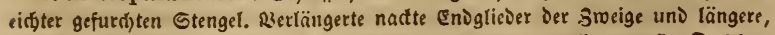

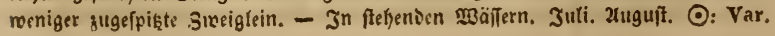


a. A. Merderbłjaufen. Schwabe. PS. Stnß̈furt. Schwabe. WBanšlıben in Der פitterö̈nefe. Wallroth. Sprengel. Rchb. Var. b. PL. Şoffnungśbai. Rabenhorst. A. Badej. Schwabe. PS. Im Mannefeldifiden. A. Braun.

+ 441. Ch. papillosa KTz. Bot. Ztg. 1834. 707: Gtengel diđtich, meiđwargig, je 6 fïnfgliebrige 3weiglein, an Denen Das lebte Ǵlico Das längfte; einfach rïbrig, Diđ̛er, ftad)elipişig. Defolätter lineal, ftumpf, quirlftändig, etroas

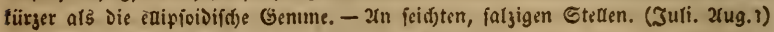

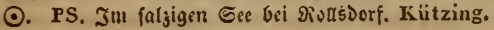

+ 442. Ch, equisetina KTz. Bot. Ztg. 1834. 706 : Stengel feffr Did, georeht, nad) unten ju fteifl) a arig (hirtus), oben etwas ftad)elig. Siveiglein

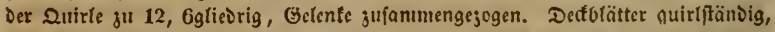
зи 6; Die 3 äufern grïfer. - In einem tisfen Gumpflode mit fel)r flarem $\mathfrak{I}_{3}$.

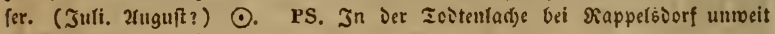
Eڤteufingen. Kützing.

443. Ch. hispida L. Wallr. ann. T. IV.R R gebreft, mit vidften, langen, Dïnnen ङtad)eln. S1veiglein zu $8-10$ guirlftändig,

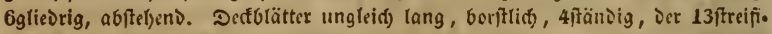
gen, ftart gifrënten Genume faft gleidf) fonument. Gelse gres, ftart incruftireno. Die Gräßte vou alten. - In ฐeidjen, Gräben. Juli. 2unguft. ○. D. Egelfee, Raffe 2łuc. L. Bei Dem szieniş. PL. Suffau. A. Radegaft. PS. Etaffurth. Bel.

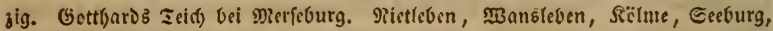
Diestau. HS. 2uperifteit u. Etctterbeim bei Grofirucepteot.

444. Ch. aculeolata KTz. Fl. germ. exsicc. 426. Etengel faien. förmig, äftig, geftreift, Dur(f)if(f)tig, nađ) oben Diđgt mit biifdselftändigen Gtadjefn

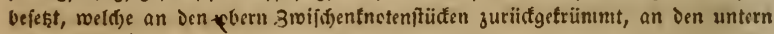
aufredst gerid)tet; Die Sweige Der Quirle zu 8 - 10, ftiefruns, 5-6gliebrig, futy. 23racteen all 5, Die länglid) eifürmigen Geumen faft un Das Deppelte

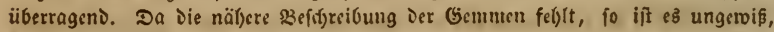
ob fie nidjt vieldeidjt, wie A. Braun sernutbet, зu Ch. hispida gebören Dürfte.

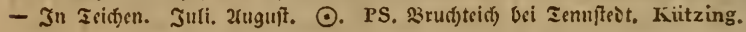

445. Ch. fragilis DEsv. Waxlr. annus II. Fl. germ. exsicc.

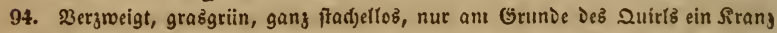
von tleinen, angeoriiften, zweitleiligen Fapiaten. 3weiglein meift z" 8, rineal

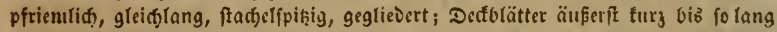

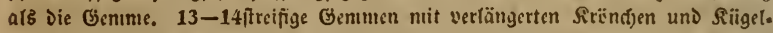

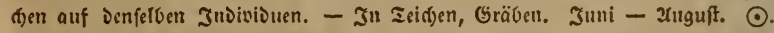
D. Gruna. Rchb. Rlicben. Mauke. L. Bogelivicfe. PL. Pididt felten. Rabenhorst. A. Deifau bei Den 7 Jufeln. Schwabe. P'S. Betjig. Rabenhorst. Rietleben, Golirauter. Wallroth.

446. Ch, crinita W. Wallr, ann. T. 11I. Sebljaft grïn. Etenger berindet, Did̄t mit feinel, langen Stadjeln bejät. Stweige beriniet, ju $8-10$, 6gliedrig, an jedem (Śliede nit feimen 31velglein und gleid) an Der $23 a f t s$ einen Did)ten Sranz am Gruns Deb Quizlo bilbend. Benumen mit furger, abgeftuster

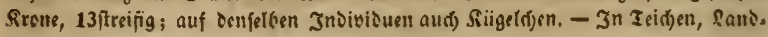


feen, gern im ealgrvaffer. Juli. 2uguft. (. A. Đröbjig. Schwabe. PS. Gtaffurth). Schwabe. Banbleben, אölne. Wallroth.

+ 447. Ch. pedunculata KTz. Bot. Ztg. 1834. 706: Etenget Did.

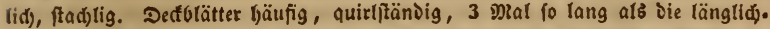

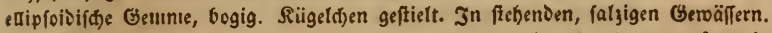
(Juli. 2uguft?) ○. PS. Unweit bes faljigen MannžfetDer Ece's unter Ch. crinita. Kiitzing.

448. Ch. aspera W. Waslr. annus T. VI. Fig. 3. Sd)lant, faft

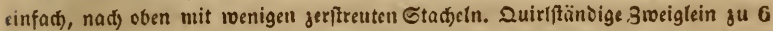
- 8 pfriemlid), gegliebert, mit ic 4 Def́tolättern, เveldje türger find alb Die Gent.

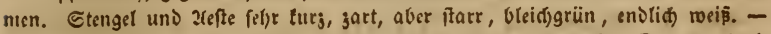

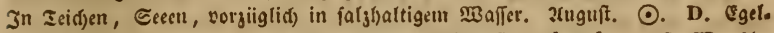

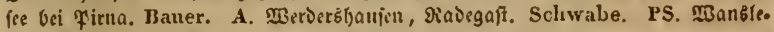
טen, 2tmbiorf. Sprengel. Sï̈me. Wallroth.

ann. 23ei Diefer Gattung bin id) A. Brauns und Kiitzing's fpeciellen au. jiid)ten fait Durdigängig gcfolgt.

\title{
Familie Ceratophyllene, Sorublattgewäd)ie.
}

\author{
- Sacrbarien(udi) S. XL uno 59. -
}

2 $\mathrm{n}$ m. Das̃ Die Elafífication Der Pranjen nid)t unnittelbar auf Der Ucbereln. ftininung Der Cotylcoonen berubt, fagt f́fon Mirser.

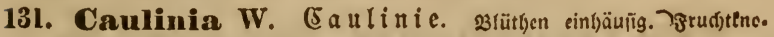

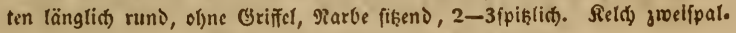
tig, (đ)laudfïrmig. 2(ntb)ere einfäd)rig, son Reld)e bedcdtt.

449. C. fragilis W. Scнк.t.296. Rснв. exs.91. Etengel fadenförmig, greitheilig. Stengelftünذige 2 lätter gegenftändig, abftelyeno, ju Dreien, Die oberften ge.

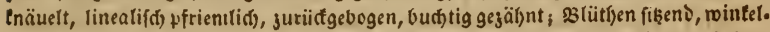

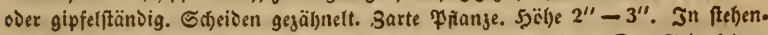

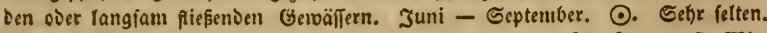
PL. Edjroielunģ̧fee. Rabenhorst. A. Dranienbaum. Schwabe. PS. Mit. tenberg: yor Dem Elbthore auf Dem 2unger, nethen Der erftẹn 23 rüfe lints. Sclikuhr.

132. Najas L. $\mathfrak{N a j a b e . ~ B ( u ̈ t ) e n ~ \jmath w e i f a ̈ u i g . ~ M B e i b l i d ) e ~ n t i t ~ f a f t ~}$ treifelförnigem grudttucten, obne Griffel, nit fitiender, ftumpfer Rarbe.

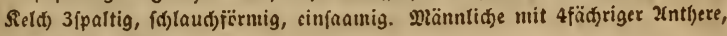
เem $\Omega(d)$ be bedect.

450. N. marina L. Lixwata IX.T.7. Rснв, exs.560. Stengel2tlyeilig.

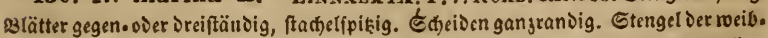

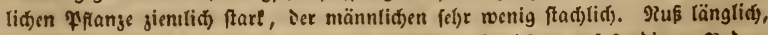

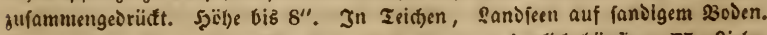
Juli - Eeptember. ○. Echr felten, um Deffau jientich häurig. PL. Siebe. rofe, Baruth). Rabenhorst. A. Defín: im Riil)nauer See, vorgüglidy am Safjn.

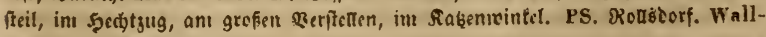
roth. $\mathbf{r}$. Schlechtendal. 


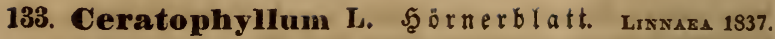

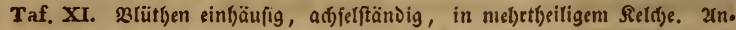

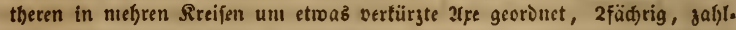

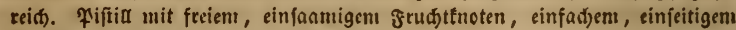
Griffel. Einfädrige, cinjaantige פ?uß.

451. C. submersum L. Lrwn. 1830. T. IV. Fig. A. B. Rснв, exs. 1419.

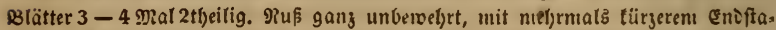

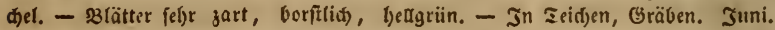
3uli. 4. Sel)r felten; fructificirt, wic folgenie äußserft fparfam. L. Seuţfó. Peternann. A. Dellau im Siil)nauer @ee naif Sclnwabe.

452. C. demersum L. Livisaka 1829. T. V. Blätter $2-3$ stal

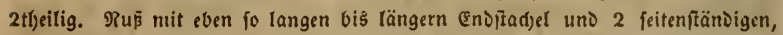
getrümmten હtad)eln, oval. Blätter ftarr, Duntelgrïn, Diďct als̀ bei voriger. -

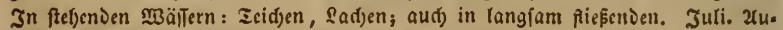
guft. 4. Durd) ias (Sebict nidjt felten.

453. C. platyacanthum Cham. Linaea 1829. T. V. Fg. b. a.

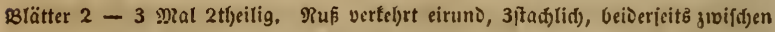
Den Etadjeln geptiigelt, feitlid)er Ctad)el platt georüift, endlidjer länger als Die Drus. - In ftelbenden und langfam fiefenden Gewö̈jern. Juli. 2ruguft. 4. Eelik felten. L. Bogetruiefe.

\section{Jamilie Lycopodiaceae, Şärlawpgetvächíe.}

- Şerbarienbud) ธ. XL uno 6). -

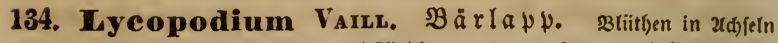

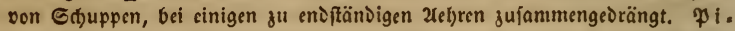
ftill: fuglid)e, raube frudfthoten. Staubbeutel in befoniern Blattadfeln,

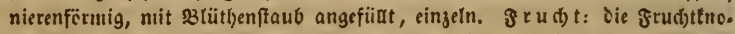
ten fpringen bei Der פeife tlappig auf und entbalten 4 (aud) nur 2-3) Saanten nit grünlid)em Reintling. Blütbenftaub brennbar.

a. Plananthus P, BEAuv. 2(ntheren adjfelftändig, frudititioten fet. Ieno, \$3ermefjrung nur Durd) Genmen.

454. L. Selago L. ST. 5. Smeige paraud auffeigens, gleid) hed). Blätter Steibig, Dadjzieglid), (anzettlid) ffriemlid), (d)wad) gezäbuelt. (大d)ën

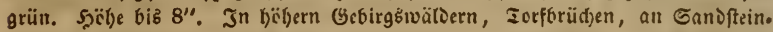
felfen angetlammert, auf Felablëđen. Durd) Daš ganje Jaljr. 4. Rautintlid

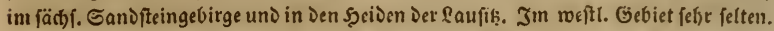

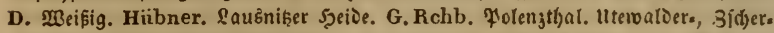

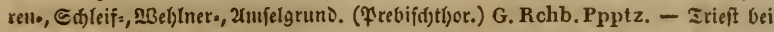
Eenda. G. Rchb. Z. Joljanngcorgenftadt. Brunner. Bodau. Weiker. Sidjtelbcrg. Wankel. L. Penig. Dehne. - B. Sod)wals unweit 9ieuftadt. Frick. \&au.

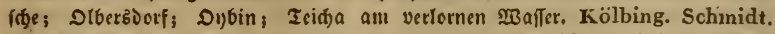

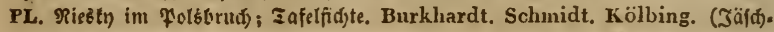

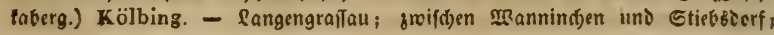


2Büftermart; Rodjauer Şeide; Marienterg bei \&übosu, Sorau. Rabenhorst.

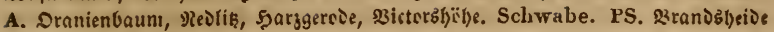
bei ßeizig. Rabenhorst. Sufjl. Metsch. HS. Zena : juvif́(jen \&aasoorf und Bodebra. Zenker.

b. Lepidotis P. BEAUv. 2(el)ren enoftändig, männfi(f), Berntel)rung Durd) Gitnmetr.

455. L. alpinum L. Sr. 5. Bwelge aufíteigend, glcid) bot), Dicht vergıeigt. Blätter 4reiljig, iadjzieglid), fpiß̨, fticlrunde 2lebren fikent. S3leids, ftarr. Şïbe bis 3". Iuf wenig begraften Etellen. Juli. 2ruguft. 4. 2uf Den

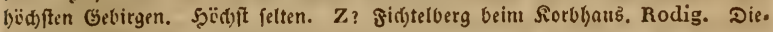
fez Rorbbaus if aber nid)t mefre vorbanden und Die gange Gegend urbar ge.

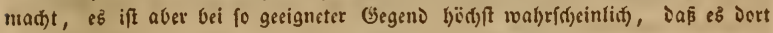

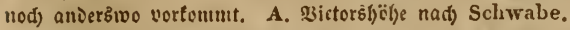

4j66. L. complanatum L. ST. 5. Stenger und 3reige fädjerartig ver. zueigt, frad)-geDrüđt. Blätter alif Det einen Seite 3teifig, verwadffen, auf Der

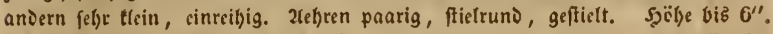
In Şeibewälsern. Juli. 2uguft. 4. In Den grëpern Şeiden, namtentlid' im

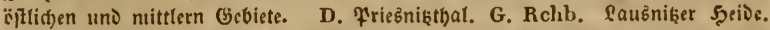
Delune. G. Rchb. Dresoner Şeide. Rchb. Z. El)enıniß bei Rleinalbertboorf. Stange, Etodberg. Wankel. B. szauken. Kölbing. 5̧od)wald bei 3ittau. Sod)ftein und Şengftberg bei Şerrnbut. Debfobiiker Sjeideberg (wo getegen ?).

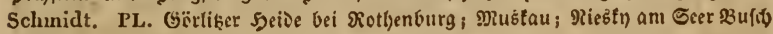

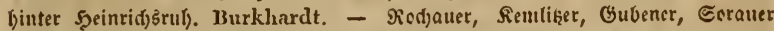
Sjeide. Srattznict, Drebtau, Sittbuz, Gailen. Rabenhorst. A. Dranienbaun, Rosmig, Piedlik, Serbft, Şarg. Schwabe. PS. Sirandzhcide bei 23elgig. Rabenhorst. Dïben. Soders̈leben. Bennshaujen bei Gul)t. Metsch. HS. Diennives

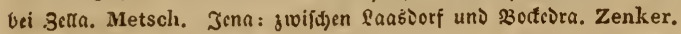

457. L. clavatum L. ST. 5. Sang bin triedjent, sweige aufítcie

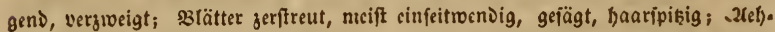
ren fticlrund, paarig, lang gefticlt. - In Şelderö̈ldern, auf Dürren Steden

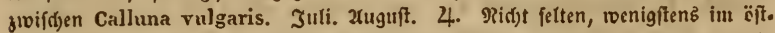
lidjen und mittlern Gcbiete, namentlid) in Der faufis bäufig. Cdbint in weft.

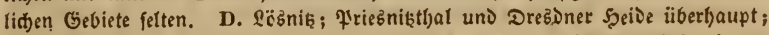

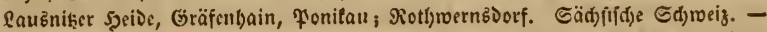
Sinnwalo, SGeorgenfelo. Z. Joljaungeorgenftaot u. f. w. L. Penig. - Univer.

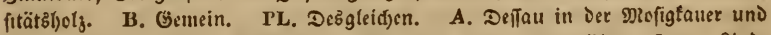

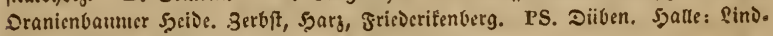
berg, 3orgz. Eefurt in Eteiger. Eulyl. HS. Jenn.

458. L. annotinum L. ST. 5. Stengel fried)end, felfr verglveigt, 3roeige auffteigeno, an Der 3 afis 2-3theilig; Blätter Dadjsieglid, 5reibig, li. neal.langettlid), ftaçel(pikig, ganz abftcheno, cinnervig, ftarr, fd́road) fägetandig

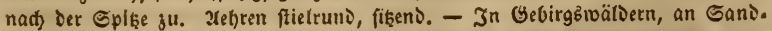
fteinfelfen augetfammett uns von ibnen berabrantens; an meofigeu Etellen, gern fwiftgen Polytrichum, frustificirt fparfam une roobl nur an trectnen, founigen 


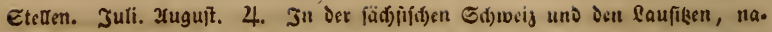

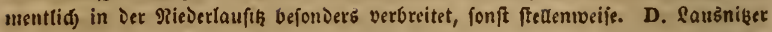
Speide an mefren Stellen (faus̆nik, Grefnaunjorf u. f. ro.) Delane. L. und G.

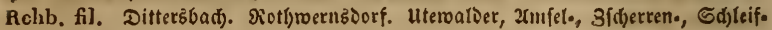
gruns. R̈̈nigftein, Sitienftein. Minterberge. (Frebifd)ther). G. Rchb. - Irieft bei Sanda. G. Rchb. Papperitz. Z. Jchanngeorgenftadt, Brunner. B. S2od).

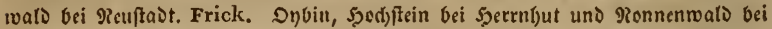

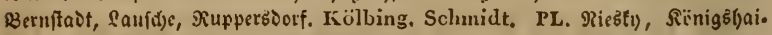
ner 3erge. Burkhardt. - 5ödenberge bei \&angengrnjau. Siirftlid Drefna,

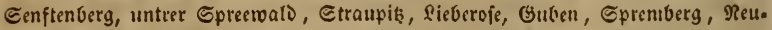

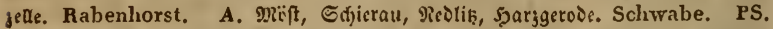

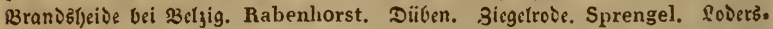
teben. Wallroth. Sulgl. Metsch. HS. Jena jwifósen faasjorf uno sodtedra. Zenker. Eijenberg. Geier.

459. L, inundatum L. Sт. 5. Rсnв. exs.1513. Etengel tried)ent, 3reige

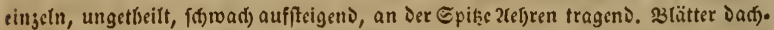
jieglid) pfrienulid), 5reifig, lincal, ganjrandig, einnervig. Sd)uppen Der 2el)ren und Blätter gleid) geftaltet, an Der 3 afis verbreitert. Meijt getogrün. Szëble $2^{\prime \prime}-4$ ". zuf überjd)rominiten Sande, auf feud)ten, moofigen IBicfen, in torfigen syeiden unter Calluna trupproeife. 2ruguft - Detober. 4. In Dem Saufiker PRicder. lande befonder, in Der Dreboner Scide fdoon reniger verbreitet, fonft felten. D.

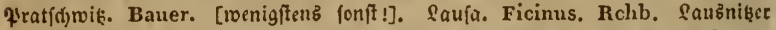
Şcibe. Dehne. Somnił̌. Awd. Gräfenţain, łonitau. G. Rchb. Awd. B.

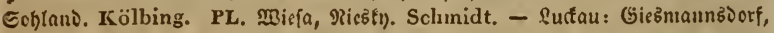

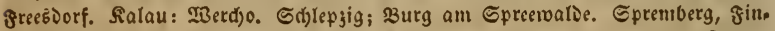
fterwalde, Guben, Gorau, פtitweioa, attoibern, Rënigsmartbe. Rabenhorst.

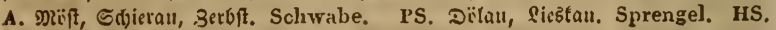

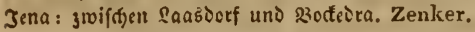

c. Selaginella uno Stachygynandrun G. BEAUr. 2(ef)ren eno.

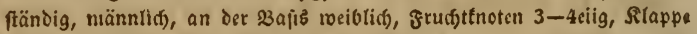
gientid') 3lappig.

460. L. selaginoides L. ST. 5. Rснв. exs. 1136. 3reige, aufredit,

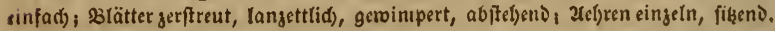
- In f́fjattigen Mäldern gwifdjen Mloob. Juni. Juli. 4. Gebr felten. Z. BorDerer fidfteiberg. Rodig. A. Dranienbaunı, Szarg nadi Scliwabe. HS. 3rikgruni bei Jena. Zenker.

$\{\mathrm{nm}$. L, helveticuun L. Blätter jroeireibig, eirun১; 2rebren paarig, geftielt. In Der Bot. Zeit. 1834. pag. 559. SRS. T'aulingeller forft angegeben. $2 B 0 h 1$ viedeidft (5)reibfel)ler für $L$. selaginoides? Jd) lah teine Eremplare von caber.

\section{Familic squisetaceae, $\sigma_{\mathfrak{c}} \mathfrak{a}$ d telbalm.}

- Şetbarienbud) S. XLI und 61. -

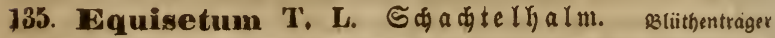

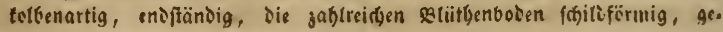


ftielt, unterfeits in Itmitrife mit $4-7$ @äudben verfeben, weldse naćs Dem Dittelpuntte bin mit einer Epalte aufipringen und mit sablitridoen Btvitterbliithen erfiiat fins. Grudtfneten febr tlcin, fpcrenartig, fuglia), fpį.

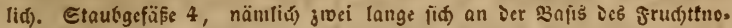
tens Durdftreujenien fäben, weldje an ibren enten tie teulen. oier fpatel. fërmigen Etaubbentel tragen.

461. E. Telmateja Eнr. Eteriler Etenget einfang jmeigig, 3meig. lein idjatf, adjtedig, ier fruḑttragenise mit bedferförmigen, jugefpik̨ten, ein. gefd)nittenen Edjeiben. Der Etengel elfutbcinartig, reislid) gelb. 3eid. net fid) Durd) fefre robuftem szau und beträd)tlider Grëse wen Den folgenden

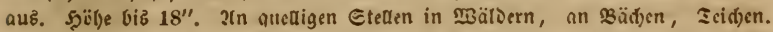
2(pril. Mai. 4. Gel)r felten. Z. Sol)nftein. Bernhard. A. Deî̃au in Sïil).

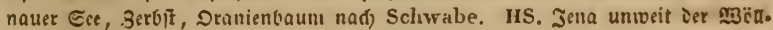

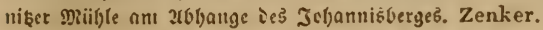

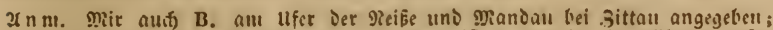
iff jaf ven Da teine Epemplare. - Dagegen ift er neuerlit) in 3 ïfomen auper icnı (Sebicte bei Zetfden bänfig von G. Rchb. gefunien.

462. E. arvense L. Scrk. t. 167. Etcrilcr Etengel cinfact) stweigig, S1weige aubgebreitet, idfarf, viertantig. Sruthtbarec zeitiger, einfad), glatt, mit

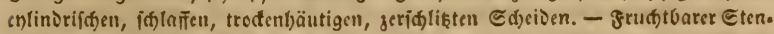

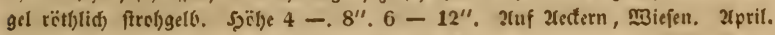

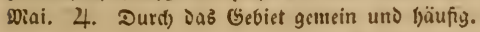

463. E. silvaticnm L. Scrk. t. 166. Ettnget Doppelt ziveigig, Swreigc viertantig, (f)ärflid), berabgcbeugt, Smeiglein jiemlidi 3tantig. Ed)ciben

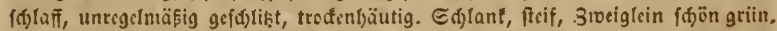

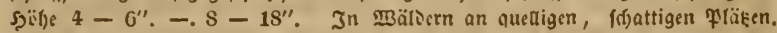
21pris. Miai. 4. Durd) Das Gefiet nidft felten.

464. E. palnstre L. Schr. t. 169. Etengel melit Gtantig, jroeigig oicr einfad), glatt, gefurdst; 3tocige abftelyent, 4-5-6tantig, oft äbrentrageni.

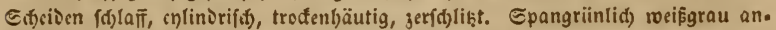

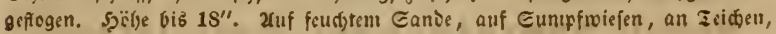

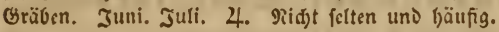

465. E. pratense L. Fl, dan, 1182. Rснв, exs. 1418. Eteriler Etenger

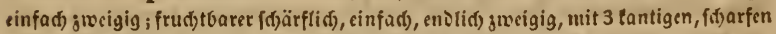

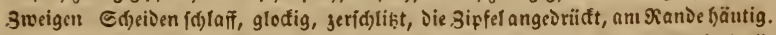

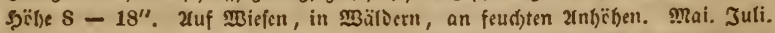
4. Eethr felten. PL. Şoncromeria. - MBBeitagt bei Suffan; Marienberge beim Dolgener Sec; graunoorf bei Edjliebrn; un Genftenberg, Mautenoorf. Raben-

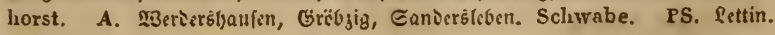
Sprengel.

466. E. limosum L. Engl. Bot. 929. Scrk. t. 171. Stengel sill.

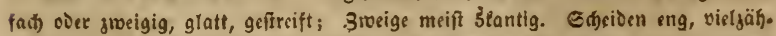

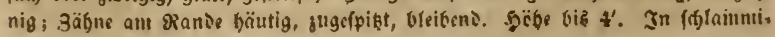


gen Ieiden, Sïmpfen, Gräben; auf na)ten Miefen. Mlai - Juli. 4. Duró Das Gebiet bäufig.

467. E. hiemale L. Scrx. t. 172. Etengil einfact, börbft felten

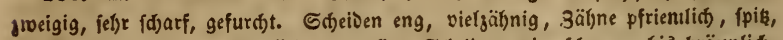
enolid abfattend. - Sientid meergrïn, Edjeiden rein fdotoars biz bräunlid.

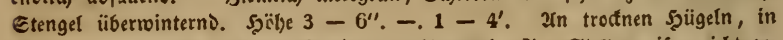
Mälbern; gern in feud)teul Sanbe. 2(pril. Mai. 4. Stellenmeife, nidbt ges

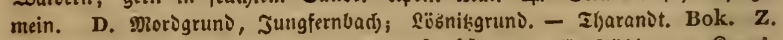
Elyentnik, Sdnneeberg. Bok. B. Sittau. Sclumidt. PL. Groflübbenau; నraub. nidf; Groprabden; fuistid) von Butota bei Iriebel. Rabenhorst. A. Deffau inı grauen Eteinbauid)t, 3erbit, Dranienbaum, 5̧ary. Schwabe. PS. \$3arby bei פonplaifir. Scholler. Düben. Rchb. Edutu, Sgoljweifig. Sprengel. Erfurt. Bernhardi.

\section{Eamilie Taxineae, Eibeu.}

- 5̧сrbarienbud) ธ. XLII uno 61. -

136. Taxus L. Fibe. 3reilyäufig. Gruđttnoten som trugför. migent, endlid) fleifdigem, abgeftukt randigent, offenen fieldbe umgeben, ein. eiig; शarbe fisens. 2intberen zalg(reid), $3-4$ auf einem Sdjilde, dis

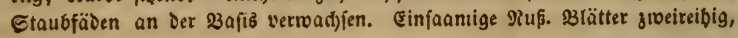
leberartig.

468. T. baccata L. Scнк. t. 339. \$lätter leierartig linealifd), ipik, ge.

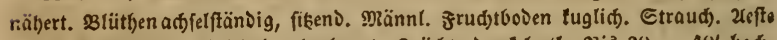
meift quirlftändig, endich ljerabgebeugt. Srüd)te Duntctrotl). $33 i z 30-4()^{\prime}$ hod).

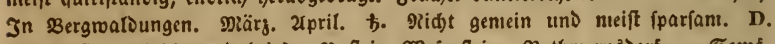

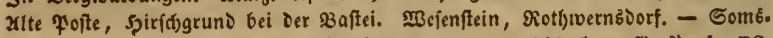
borf [ 06 angepranjt?]. B. Gol) [ander 3erg. PL. 3fdjod)au, Gerzborf. PS.

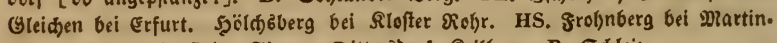
rode. SRS. Silloolftait, Eingett, Ditterboorf, Reilfau. R. Edjleij.

\section{Familie Santalaceae, Santalaceeu.}

\section{- Szerbarienbud) S. XLVI uno 62. -}

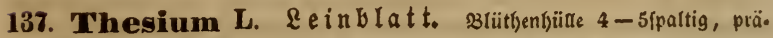
(entirtetlet. ober trid)terförnig, fteljen bleibens uns die einfaantige Gteinfrud)t unigebens uns trönent. Etaubfäben ven cinem \$ganrbïfdjel unigeben. Bluitben bellgrün, innen reiß.

a. 3 tüt)en mit einem Dectblatte; Die oberften Deçblätter ofne şlï. then, fdopprig.

469. Th. comosum Rotr. Rснiв.pl.crit.649. exs.14. Blätter 3.

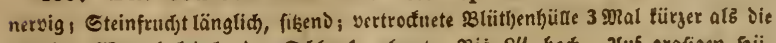

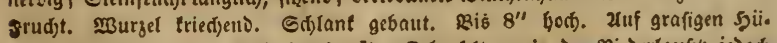

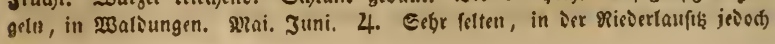


jienlid) verbreitst. PL. Mablboerf; Duben; Raltenborn bei Guben, Reriniß, Babben, Solpin im 2ucrbals. Rabenhorst. Galien. Blase. A. Groptiifnau, 3erbft nad Schwabe.

b. 23(üt)en mit 3 Def́blättern tranbig oier riffig.

aa. Bertredncte 3 lïtbentjiille eben fo lang oder länger als bie Eteinfrudst.

470. Th. alpinum L. Drew. u. HArse 121. Rсrв, exs.15, sititben

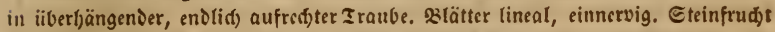
jlimling fugelrund. (Erft meergriin, fpäter biß gelblid) merceno. Dectblätter felbr lang. 3tweige visıveilen veräjtelt. MBurgel fpindelförnig. Şz̈bse $4-9^{\prime \prime}$. $2 x_{n}$

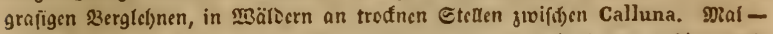
Juli. September. Detober. 4. Un Dresien nidt felten, Ded) nur auf Dent red.

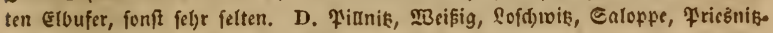

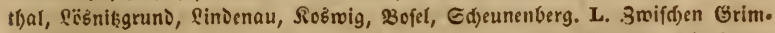

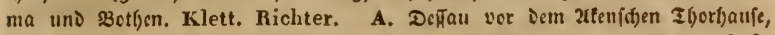
Dranienbautu. PS? [Bien Gecburg aus unguvertäfígen 2uetten.] Son Scholler "Dornburg red)tb an Der Ctrafe nad) \$urg bei $\$ 3 a r b \eta^{\prime \prime}$ angegeben; cb bierber ge. bërig ? HS. 23on Grblberg unter T.pratense erbalten.Schönh. R. Eberboorf.Geinitz.

471. Th, pratense Eнr. Rснв, pl, crit. 647. ¿raubig bia rispig. 8ruđttragenie stocige jorijontal bis beratigeneigt. 3 lätter lanjettlid) lineal, ver. loren 3nervig. MBurgel fpintelförnig. Slliitbentiilde auffalleno grof, aufen gelb. lidjgrïn. Etcinfrud)t zientid) fugelruns. (Selblidgrï̈. Şöbe $6-14^{\prime \prime}$. 2uf खुalotwiefen. Juni - 2luguft. 4. Get)r felten. D. - 2uttenberg an flciner

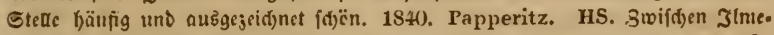
nau uno Elgcrsturg. Mlartinrode. Schönheit. Git)lucrg in 2rut 3cua. Metsch. SRS. शReubauz. Schönheit.

bb. Bertrodnete 3 (iiitlenbïlle faft 3 gral türger als die હteinfrudt.

472. Th. Linophyllum L. Sr. (intermedium Schrad.)

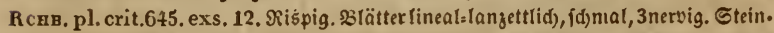
frud)t eirun১ bis länglid) eirund, geffielt. W3urgel fried)end. Şelgrün, etroas

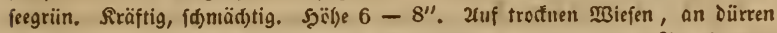

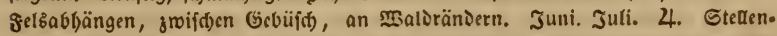
meife, nid)t gentein. D. 3adel 1841. G. Rchb. [in Frc. Flora angegeten: „Bo-

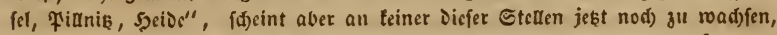

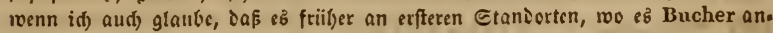
gab, vorgetontmen fein mag.] L. Bienik. Dit)ak. PL. 2fuf Den sergen bei Duben an Dcr \&ucfauer Edjäferei. Drebna. Rabenhorst. A. Deffau auf den Eanbbergen binter Den 2finfid)en Iborl)aufe. Schwabe. PS. Beljig jwifden

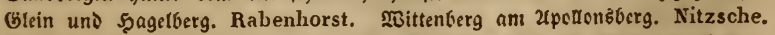
Srüumis, פittell)oly u. f. ro. bei Şalle. Raumburg. HS. Grub bei Ibemar. Metsch. Jena. Zenker. SRS. Jrantent)aujen. Fest. L. Rchb. fil.

473. Th, montanum EHR. Rснв, pl. crit, 644. Fl. gern. ex-

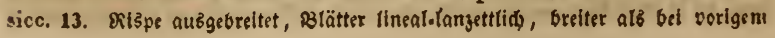


Imeift 5nerbig. Bertrectnete Bliitlenbiille auf Dor fiBenden coer geftielten Etein.

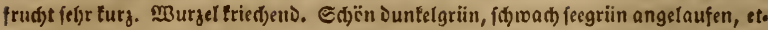

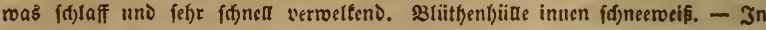

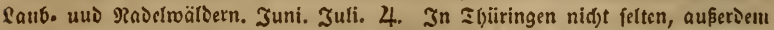

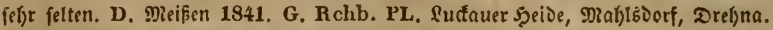

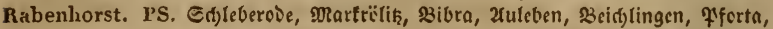

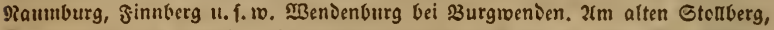

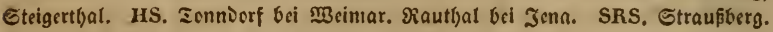
Eonders̄baufen.

I nnt. 1. Thesium ramosum Hayss, Rchв, pl, crit. 646. Murgel fpino. lid); Ctengel von Der \$3urgel an verjmeigt, traubig, äftig. Frudjttragende 3roeige aufred)t aoftehend. Etaubfäben balb fo lang als Die 2untheren nad) Der Sefrud)tung. S3lätter lanjettli(b)=lineali( (d), meift 3nervig; Cteinftu(b) läng.

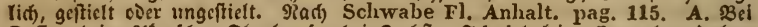

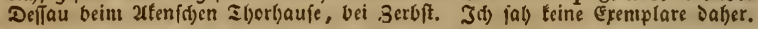
I nn. 2. Sprengel in Der Fl. Halensis fül)rt Th. intermediun ScHnAd. und Th. pratense EнRн, auf, und citirt bei vitien oie rid)tige abbiloung. Denno(t) fommit mur erfteres bci Şalle vor.

\section{Familie Coniferae, $8 \mathfrak{a} \mathfrak{p}$ fen $\mathfrak{b} a ̈ u m e$. - Sperbarienbut) 5. XLIII uno 60. -}

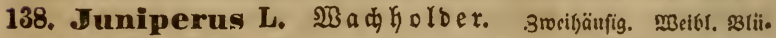

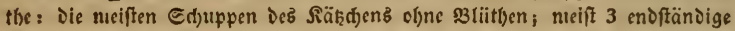

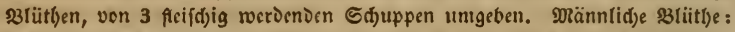

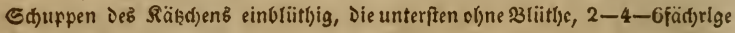
2(ntb)ren. S3cerenjapfen.

474. J. communis L. Gurare. 206. B(ätter zu Dreien, abftel)eno,

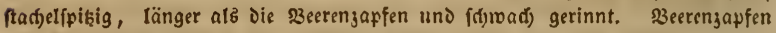
eiruno, fidmargolaut angelaufen, reifen crft in grbeiten Jabre. 2(ufterfter Strand). Şäbe meift 3-4'. * Var. suecica. S3lätter länger, 23aunt. - 2luf Diirren,

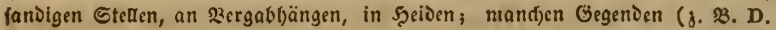
Dem Strid)e von (Sräfent)ain bis Sinz, Pianitz) ganz befonderz eigen. März Dial. b. Var, suecica in Parfanlagen angeppanjt. 2lpril. Miai. 5.

- 475. J. Sabina L. Gurmp. 205. Rchi. exs. 1846. Blätter gegen.

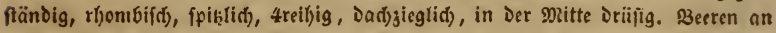
getrünıten Etielen, blau. Etraud). $23 i \overline{5} 5^{\prime}$ hodj. In Baumgärten, Partan. lagen angepfanjt. Itpril, Dal. b.

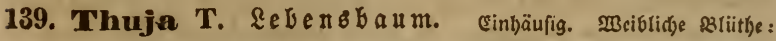

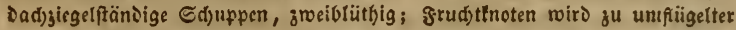

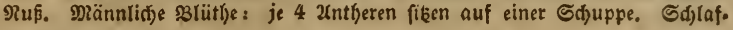
fer $3 a p f e n$.

- 476. Th. occidentalis L. Scrr, t, 309, afeftdjen fiadjged riidt,

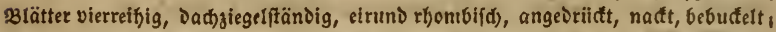
3apfen verfefirt ciruno, innere Sdjuppen abgeftukt, unter ber Spise budtidg.

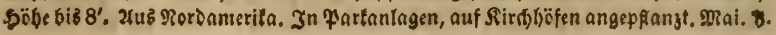




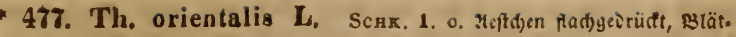

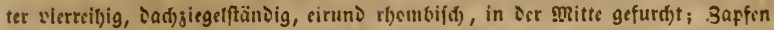
eiruno, innere Ed)uppen abgeruubet, unter Der Epiß̨e ftadjelipikig. Wefte jar.

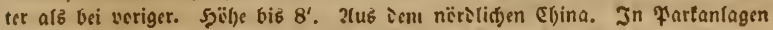
u. Dergl. angepiranjt. Miai. के.

- 478. Th. sphaeroidea Rrch. Schr. t. 310. 2reftd)en ஈangse.

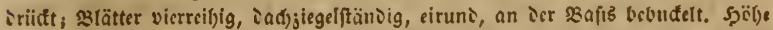

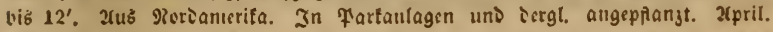
Mai.

\section{Pinus L. Riefer. Eintüupig. Gd)ufpen iss 3apfens siå,} benabelt, mit je jroel abroärts get(l)rten હaamen. Räßğ)en traubig, gefäuft,

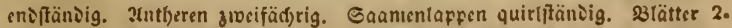
ober metbroüfd)lid), nabelförmig.

479. P. sylvestris L. Riefer, F̌̉hre. Raistn ftar, paarig; 3apfen vor Dem Deffnen eilcgefförntig, mit zurüđgetrimıntem Etiele; 3affen.

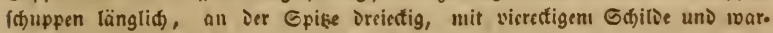
zenfërntigent Yrabel, innen locl)l, iis unteren Edjuppen ftets anliegent. Slügel 3 Drat fo lang als die 9iuß. - Edjlanter Baum. Rinie iffuppig, rotl). Sä̈he

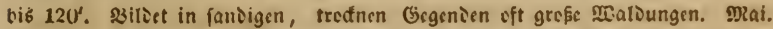
Ђ. In ien neciften 9Ricocrungen uno Gebirgen, Burd) Forfttultur jedod) in mall.

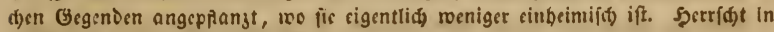
Den झुäloern rectits von Der Elbe vor.

480. P. obliqua Sauter. Seffiefer. giadsin farr, paarig;

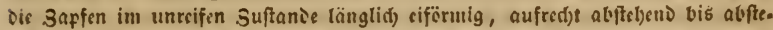
beno, im rsifen eifërnig, abifebeno. Sत)uppen im rsifen suftande borigental

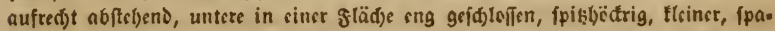

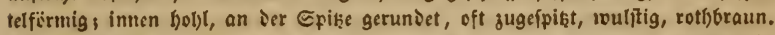

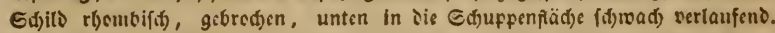

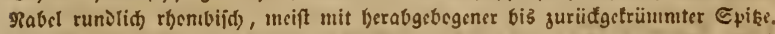

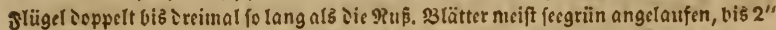
lang. 3affon mifen im jroeiten Gonumer, $1^{\prime \prime}-5 \int_{t}^{\prime \prime}$ lang; an ber fidstfeite

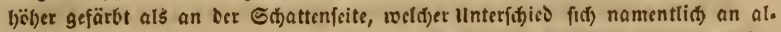
ten, melbrjäbrigen 3apfen jeigt, wo Dann Der giabel auf Der ङdjattenfeite weiflich,

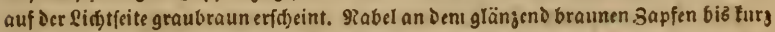

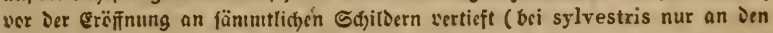
unteren). Sinde in Der Jugeno glatt, afthgrau, Dann bräuntid), riffig. Sgols fshr

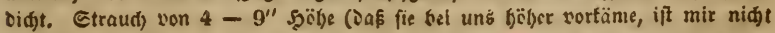

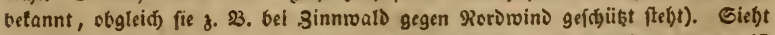

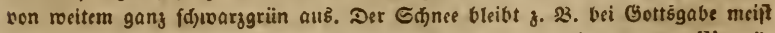
$6-7$, ja 8 Monate liegen, obne Daßs Der $\mathbb{B} u(j)$ fín Dem Der P. Punilio nä̈ bert. - In Zorffirgen, wo Sphagnum unঠ Hypnum aduncum, fluitans üppig gedeiten, aud) Andromeda, Carex leucoglochin 11. Dergl. vortonmen. Mai. Juni. क. Im bädften (ङ

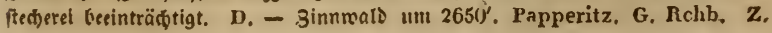


(grolfd)en Gottzggabs uno Platten um 3050" "Ruiebel3". Bok. Wankel. Weiker. Rchb.). Jolsanngeorgenftait an Şenneberge um 20(y). Brunner. Bok.

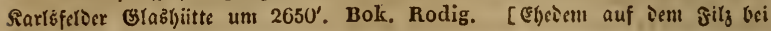
Edjnecberg um 1700'. Bok.]

* 481. P. Strobus L. Whetsmutfifiefer. Wanerne. B. t. 1. f. 1. Raicln zu 5, Dünn, 3apfen malgis, länger als Die Nadeln, follaff, foup. pig. Solter, f(t)lanter $23 a u m$, biz 60 ' Sö̈be. In Parfanlagen 11 . Jergl. ange-

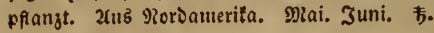

141. Abies T. Tanne, Fidte. (sintäufig. Meibl. srü.

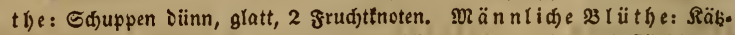
đ)en einjeln, Beutel 2fädrig. Saantenblätter mebrzäblig, quirlftändig. 9radcln.

482. A. pectinata DE C. Eoeltanne, Weif̧tanne. Gurmp.t. 159. Rabeln fiad), an Der Spike ausgerandet, eingeln, glveireißjig, unten feegriin mit 2 weisen Sinien; 3apfen aufred)t. Sduppen ftunipf, angebrüft, falten ab, ibre zre bleibt. - Rinde glatt, weifgrau. Rabeln fdrwarjgrün. 5jober, fdjöner, ge.

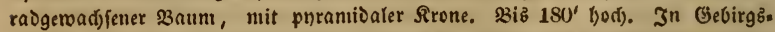

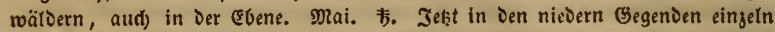
in Mäldern uns taum roirflid) wild; melyrentbeils mit Fagus berrfidbe grofe

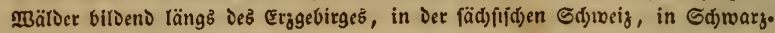

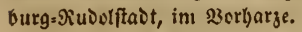

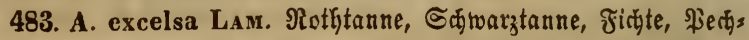

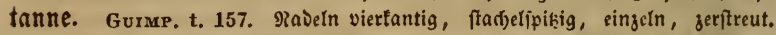

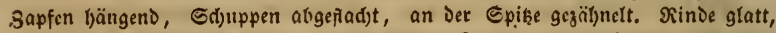

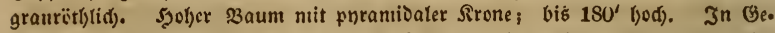
birgbiväldern, aud) in Der (Ebene. Mai. ち. Mie vorige uno gern ntit ij)r, fd)eint aber weit empfindlid)er, indent fie an bol)en, Stïmten aubgefeksten Stellen (3. 33. D. - auf Der Sitppe Des Rablenberges bei altenberg $2800^{\prime}$ ) nidat neffr gut geveibt.

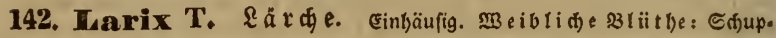
pen Des కapfens zart, glatt, mit je 2 Frud)tfncten. Männlid) 23 lüt be:

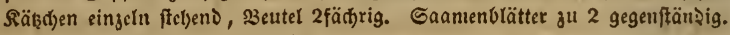
- Radeln abfatletio, zart, fillafi.

484. L. europaea DE C. Gormp. t. 155. Radeln biif́d)elftändig, fađ̆, (d)wad) gerinnt. Sapfen eiförutig, nit ftumpfen an Det Spike umgebogenen

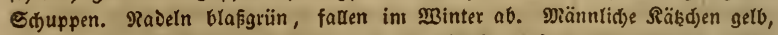
meiblid)e roth. Sd)ह̈ner Baum nit bogenförmig nad) unten gencigten 2(eften,

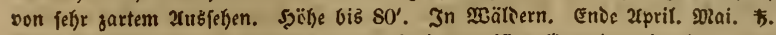
X118 Sübdeutf(hland angepflangt. Jekt in Den meiften Gegenden eingeln, auts in grösern Beftänden, 3. 8. B. auf Dem Dybin, bet Zornsborf. 


\section{Fumilie Proteacene (Wlaeagneae), \$roteacen (Elängueen).}

- Şcrbaricnbud) S. XLIII und 64. -

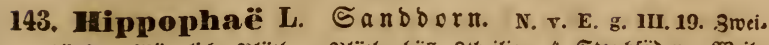

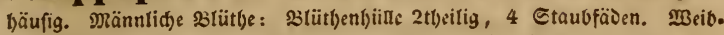

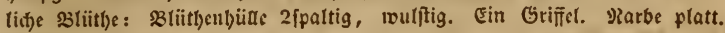
Eteinfrud)t.

* 485. H. rhamnoides L. Guimp. 199. SchK 321. Silätter tinealalanjett.

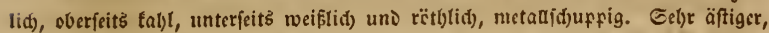
Dorniger Straud). Xefte berabgeneigt. Blüt)en flein, getblid). In Partanlagen und Dergl. D. angeppanjt und tier und Da verwilierno. Meärs. Xpril. ち.

\section{Familie Thymelaeaceae, Scioclu. - Setbarienbud) G. XLIII uno 64. -}

144. Stellera L. Stelfere. Siüthenbü̈le ftehenbleibend, die

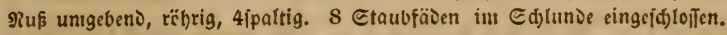

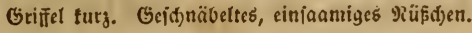

486. St. Passerina L. Schk. t. 107. Gtengel tahl, şätter lineal,

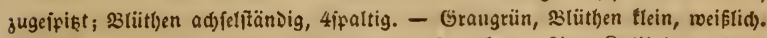
Sä̈be $6^{\prime \prime}-1^{\prime}$. 2un trodnen abbängen, auf Zeatitn. Siebt Raltboven. Juli. 2(uguft. $\odot$. Gel)r jelten. A. \$ernburg. Schwabe. PS. Swifden mansleben und 2misoorf. Wallroth. Ed)raplau. Sprengel. Sennitsit. Sprengel. Kegel.

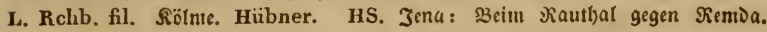
Rupp. Zenker. Zngsblid) aud) Dafetbitt "bei Єpiknafens (jut".

145. Daphne L. ๔eibelbaft. N. v. E. gen. VII. 2. 2lü.

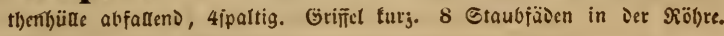
Etcinfrud)t mit weidjem Fleijđje.

487. D. Mezereum L. Gurmp. 48. Schк. 107. Stütt)en gu 3-4,

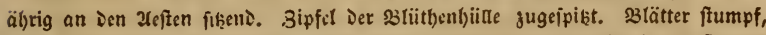

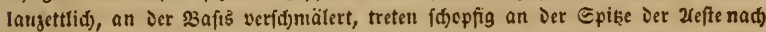

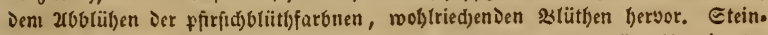

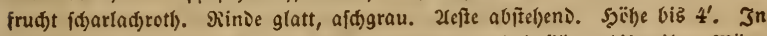

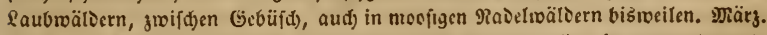

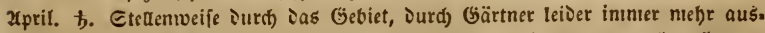

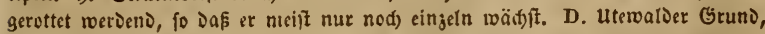

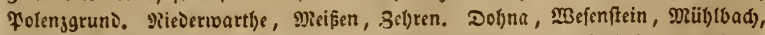

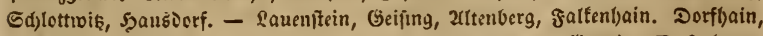

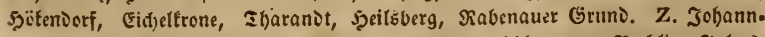

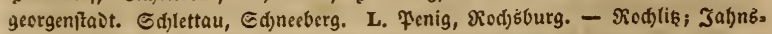

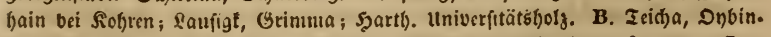

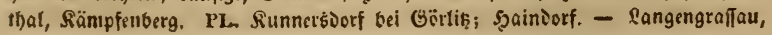




\section{Thymelaeaceae. - 114 - Daphne.}

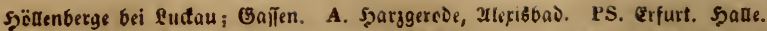

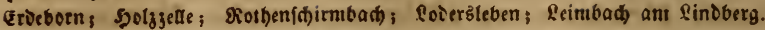

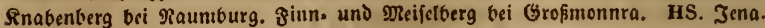

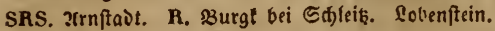

\section{Gamilie Myricaceae, ginnicacen.}

- Şerbarienbud) ๔. XLIV uno 65. -

146. Myrica L. (5) a gel. N. v. E. gen. III. 1. 3weil)äufig. Räkzdenartige slittbe. Sđ)uppen 1blütbig. Miännl. sklïthe: 4-6 Staub. fäben, genäl)ert oder verwadfou auf ier 3 afís Der Erjuppe.

488. M. Gale L. Gurup. 200. Scuк. 322. slätter lanjettlid, an der Epiচ̨e etwas gefägt, unten teilförmig. S()uppen Det Räkzd)en zugeipik̨t. शieòrer Etrauth.

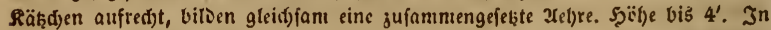
Moorbrüđgen meift utit Erica Tetralix und Ledum. 2xpril. Diai. t. Sel)r

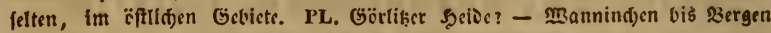

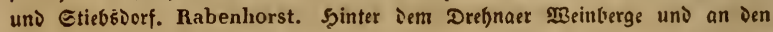
Zeidyen iu nafien şujo. Grassinann.

\section{Familie Amentaceae, $\Omega$ äthenblütblex.}

\section{- Serbatienbud G. XLV uno 66. -}

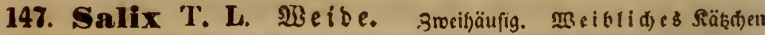

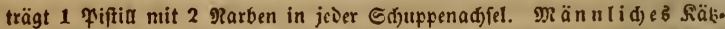
d)en trägt 2 Staubgcfäfe (bei einigen arten $1-3-5$ cier nebrece) nebft eincr Drüfe (vertüntnterten frudttncten). Sapiel einfäđrig, 2tlapłig, Saa. nten nit $\mathbf{B}$ nufd)opf.

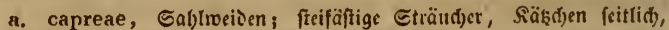
gruচbtfneten Deutlid) geftielt, 2 હtaubgcfäfe.

$\alpha$. argenteae, Gilberweiden, fleine Cträud)er, Siäkşben turz, 3 lätter unten fitberglänjent.

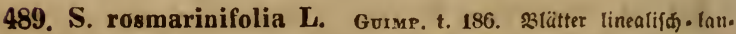

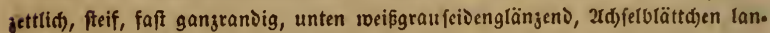
zettlid), gerave, Rapieln eifürmig verDünnt, firzig, lang geftielt, Griffel turz, Rar. ben ciförnig, gefpaiten. - xuf Moorwicfen. 2ipril. Miai. b. Sebr felten. D. Grofentjain. v. Zeng. PL. Rafel, Dolgener Eee, Sorau. Rabenhorst, A. Deifau. Schwabe.

490. S. repens L. Gurmp. t. 183. säätter cual cier lanjettlid́), ganz.

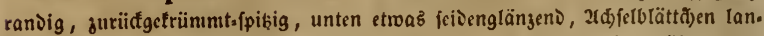

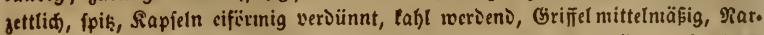

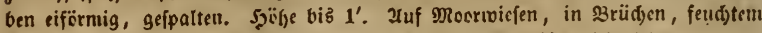
Sanic, an Stufufern. 2(pril. Mai. b. Durd) ias (Sebiet nid)t felten.

491. S. ambigua Енвн. Blätter unterfeits meiß, fitgig, runzelig,

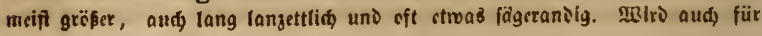


Baftaro von $S$. repens mit $S$. aurita gebalten. Sÿ̈be $1-11 \int_{2}$. Xuf Mloorwiefen. 2rpril. Mai. b. Eel)r felten. D. Sïnigftein. Bauer. Raufa. Rchb. G. Rchb. शafie 2ue. G. Rchb.

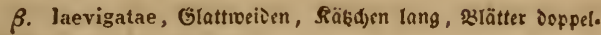
farbig, glatt (nid)t gerungelt).

492. S. bicolor Енгн. Rсnв. Fl. gernn. exsicc. 1629-1630.

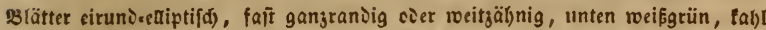

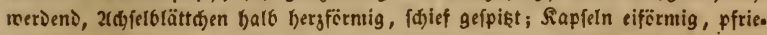
menipisig; Ctiel $2-3 \mathrm{Mal}$ fo lang alß Drüje, Griffel geftedt, mit 2 jpaltiger Rarbe. Sö̈be bis 6'. Eetten angepĩangt uno nerwildernd. D. Eeiffersoorf. Rchb. 2pril. Nai. b.

$\boldsymbol{a} \mathrm{nm}$. Ein Exentplar, leider ofnne Blätter, von Dr. Peternann L. jwifd)en

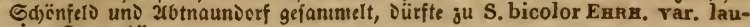
rina SAr. gebören.

493. S. nigricans L. Rснв. Fl. germ. exsicc. n. 568. (Aman-

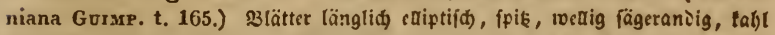
werdent, unten graugriin; stattftiele lang und fo roie i ie 3tweiglein fein be.

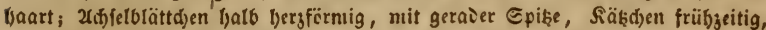
Rapjeln (fabl oder behaart) eifërnig, verdïnnt, gejtielt, Grifel lang, Rarben ge. fpalten. - 2luf Micfen. 3pril. Mai. b. Gefr felten, aber nidt f́parfam. L.

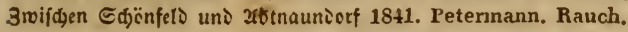

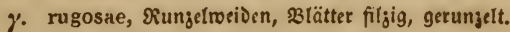

494. S. aurita L. Gurmp. t. 1S8. \$lätter umgetehrt eifërmig, Epiß̨e

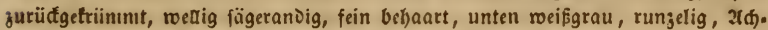
felolättđen nierenförmig, faft ganjraniig, Griffel furg, Rarben cifïrmig, ausge.

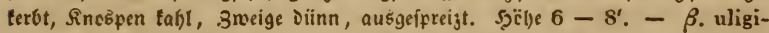
nosa W. Ş̈̈berer (Etraud), in aluen Ibeilen grëfer, mit längeren, aufred)ten

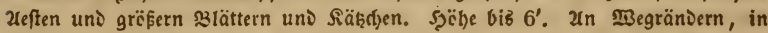

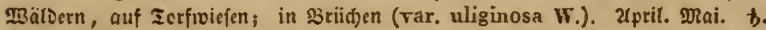
Durd) Das Gebiet nidjt felten.

495. S. cinerea L. Rснв. Fl. geran, exsicc. n. 1140. (aquatica Gurmp. t. 191.) 3lätter ungefebrt eilanjettlid) over caiptif́), etwas fägeranis,

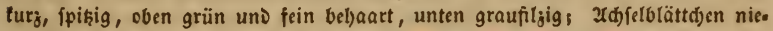

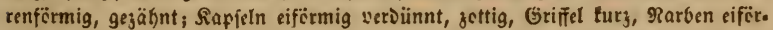

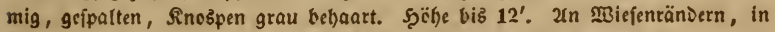
Gebüid), an glufufern. 2(pril. Mais b: Durd Das Gebiet gemein.

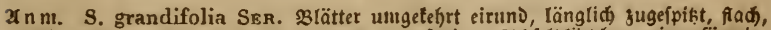

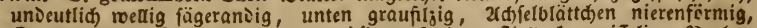
Sinospen tabl, Sapieln ciférmig verdiinnt, filjig, gefitielt, turjgrififelig, Rarben

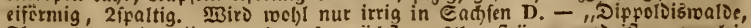
zharanot, freiberg" angejeigt, ite räd)it an zafenftrëmen uno ift gu vergleie' d)en: Fl. germ. exsicc. n. 729 .

496. S. caprea L. Gurmp. t. 192. Haysiz Arzngew. XIII. t. 43. Blätter eiförmig, ediptif́), geraDfpiḳig, mellenrandig geterbt, eben tabl, unten ftart runzelig und graupilgig, 2kibiclblättd)en nierenförmig, Sapieln eiförmig 


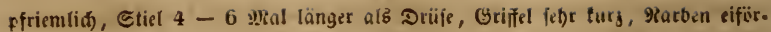

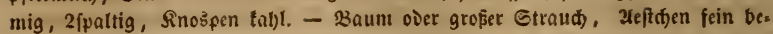

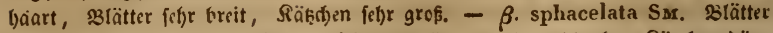

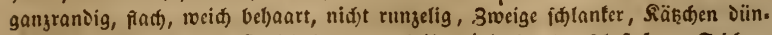
ner. Edyeint faft cine ftandr)afte 2rt. \$3is $30^{\prime}$ bod. 2In Flufufern, Zeidsen, Gräben, in Gebiijđen. Märj. ?tpril. Ђ. Ђ. Gentein.

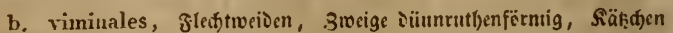

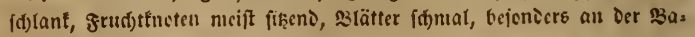
iิs jurüđgeront.

497. S. acuminata Su. Gurmp. t. 193. \$3lätter länglid) lan= zettlid, allgefpist, wellig geranoct, íbload) gejäl)nelt bis ganzrandig, unterfeits filjhaarig, Rebenblätter nicren=l)erjfïrnig, jugefpikt, Rapfeln eirunt, verengert, Griffel verlängert, Rarben fadenfïrnig, ungetheilt. Şäbe bis 15'. 2In flußs:

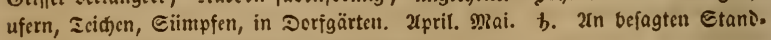
sten in Der Saujik angefíanjt. Rabenhorst.

498. S. mollisima Енгн. Rснв, Fl. gern, exsicc. n. 957. \$3lät.

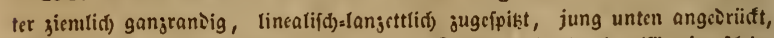

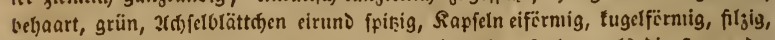
fibend, Grifiel lang, Parten linealifd jweifpaltig, fo lang als Die Spaare Der

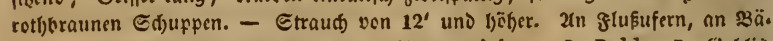
d)en. 2(pril. Mai. b. Gelten. D. Uebigan. Ficinus. G. Rchb. L. Gol)lis, Supfe, vor (Ebrenberg. Relib. Petennann. PL. ?n Der Eprce, Serfte, Reife. Rabenhorst. PS. Iettin uno Rrïđmiķ. Sprengel,

499. S. viminalis L. Gursp. t. 194. s3lätter fapł gangrandig, fo

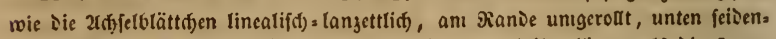

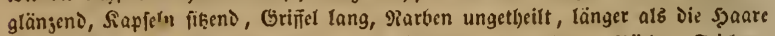

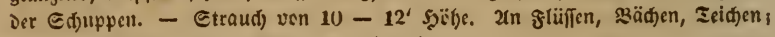

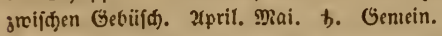

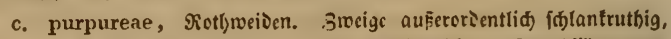

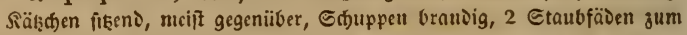
El)eil oier gan; verwad) fen, 3eutel farminreth coer f(f)iörglia).

500. S. rubra Huds. Gurmp. t. 171. Gifpalten 2 männig. Slätter

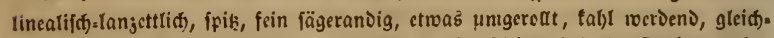

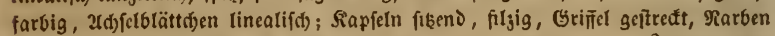
längliđ). - Etraud)= ober baumartig, $6-12-18^{\prime}$ bod. $-\beta$. Forbyana Sx. Engl. Bot. 1344. Gurap. t. 172. Miarben lang, fadenförnig. Şöbe biz 12'. In fluşufern, Bäđjen. Mai. b. Seljr felten, meift ganz sinzeln. D. ¥ofta, SBirfwik, łiuniķ 1820. Bauer. Uebigau 1839. G. Rchb. PL. Eebr

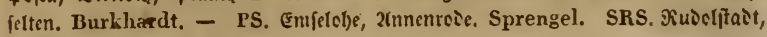
๔ingen. Schönheit.

501. S. purpurea L. ST. 25. Rснв. Fl. gern, exsicc. 1141. Ein: Münnig. SBlätter ungefel)rt cilanjettlid), fein gefägt, flad), tabl, Sapfeln fiß̨eno,

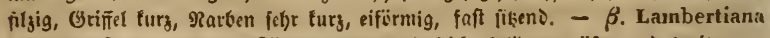
SM. Engl. Bot, 1359. Räßd)en ioppelt fo Did, słlätter grëper uni veciter. - 


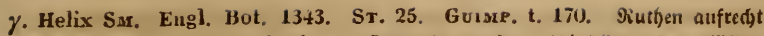

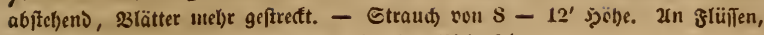

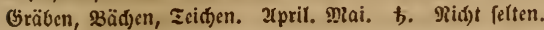

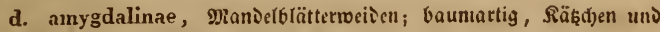
uns Sapieln geftielt, Edjuppen gleidffarbig.

502. S. hippophaëfolia Thuгs. Rскв. Fl, gern. exsicc. 959.

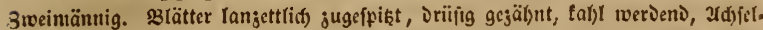

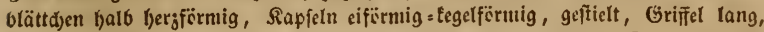
Rarben 2fpaltig. - Räß̧đ)en nur ljalb fo groß alß Die Der S. undulata. Şöbe bis 15'. In Gräben. 2tpril. b. Xeuferift felten. PS. Eprecioalo bci 33urg. Rabenhorst.

503. S. undulata Енвн. Gurmp. t. 160). Rснв. Fl. germ. exsicc. n. 960. Drciniännig. Blätter fanjettlid), fel)r lang jugcfpik̨t, unten frumpí,

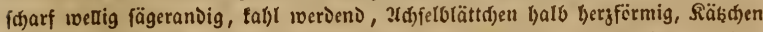
gleiđ)zeitig, אapfeln geftielt, länglid) versiinnt, Griffel lang, Jarben 2fpaltig. - Zur 23 lütf)egeit Der S. viminalis fef)r ä()nlid). 10 - 20' bod). 2(n griif(en,

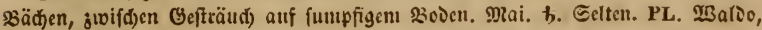
Spremberg, G̈uben. Rabenhorst. A. De|Tau, Mörlik nađ) Schwabe.

504. S. amygdalina L. Dreimännig. 3lätter langettliđ) ränglid),

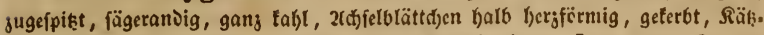
benfd)uppen an Der Spitie, fo toie Die ei = fegelförmigen, ftumpfliden Rapieln

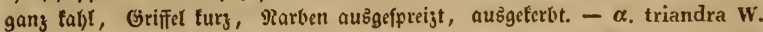
St, 25. Gurmp. t. 159. Hayne Arzngw. 13. t. 39. 32lätter" veiderfeits grün.

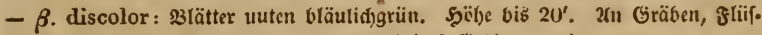

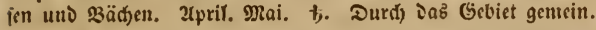

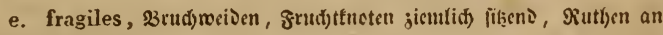
Der $\mathfrak{B a f i b ~ b r u ̈ d ) i g . ~}$

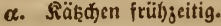

\section{* 505. S. daphnoides VILL. Fl. germ. exsicc. n. 569. (prae-} $\operatorname{cox}$ Wrucp.) Sr. 25. Gurmp. t. 168. Blätter breit, lanjettliđ jugefpik̨t, irüfig gefägt, falll, unten bläulid)grïn, jung fo roie die jungen 310ciglein jottig,

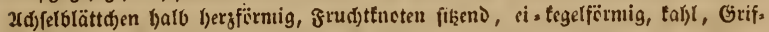

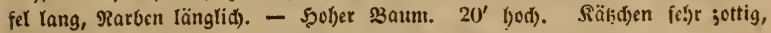

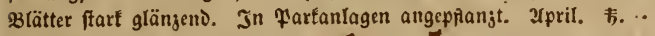

* 506. S. pruinosa WESDL. Sิıeiüährige 3ıveige blau bereift; slätter lineal=lanjettlid), fel)r jugefpik̨t, gefägr, fabl; ; Rapielu cirun১, verengt,

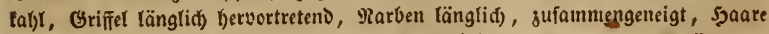

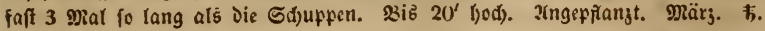

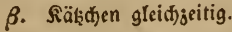

* 507. S. babylonica L. s3lätter lịtcalalanjettlid), jugefpibt, fäge.

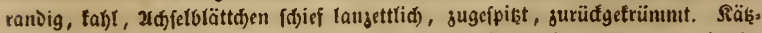
d)en gebogen, Grudytencten eiförmig, fikent, talyl, Griffel furł, Rarten ciförmig, 


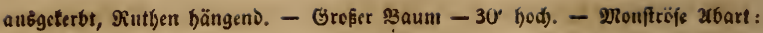
annulata: Blätter ringförmig riiđiö̈rts gebogen, fogenannte Rapoleonbెweibe. In Partanlagen, namentlia) an Ieidjen, angepinanzt. Xpril. Mai. ‡.

508. S. alba L. St. 25. Hayne Arzngw, 13. t. 42. Guimp. t. 197. Slätter lanzettliđa) jugefpikt, fein gefägt, beiDerfeitz reeiß feidenglänjend,

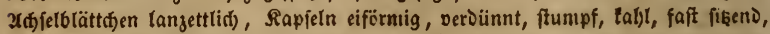

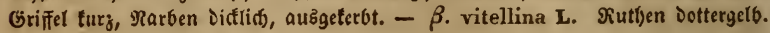
- $\gamma$. coerulea Sm. Engl. Bot. 2431. Blätter tabl reerdend. - Şühe bis 30'.

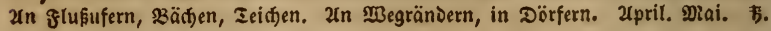
Durd Das Gebict gemein.

509. S. Russeliana SM. Engl. Bot. 1908. 3rocimännig. Slätter

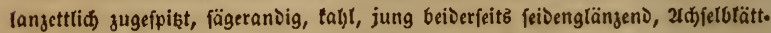
deen fdjief, balb berzförnig, zugeipikt, Rapieln eiförmig verdïnnt, tabl, geffielt, Griffel mittellang, Rarben Did̛́lid), 2ipaltig. Şäbe biz $30^{\prime}$. 2in glusufern, an

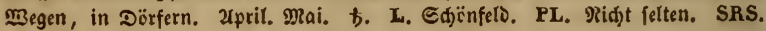
Singen, Rubolftadt.

510. S. fragilis L. Rснв. Fl, germ. exsicc. 1143. Harne Arz-

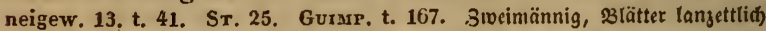
jugefpişt, gleiđfarbig, tabl, 3älyne eingebogen und oriifig, 2(d)felblätţ̦ell balb

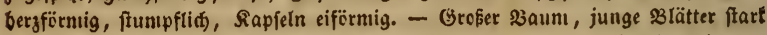
gemimpert und etroas zottig, gelblidggriin, Rätd)en lang. Ş̈̈be bis $30^{\prime}$. In Slupufern, auf MBiefenräniern, an B̉egen, in Dërfern. 2pril. Diai. b. Gemein.

511. S. Meyeriana WruLd, Rcnв. Fl, germ. exsicc. 1144.

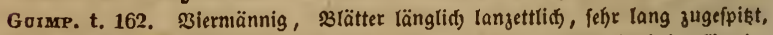
eng gefägt, falsl, Blattfticle nađ̆ oben Driifig, Xd)felblättçen balb berzförmig,

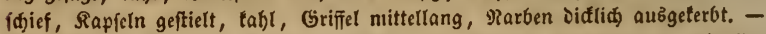

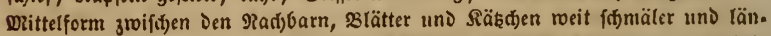

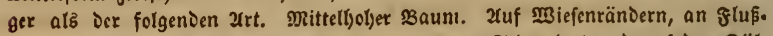
ufern. Dai - Juni. ђ. Gefr felten. L. 2um G(j)ambert uns auf Den Döl.

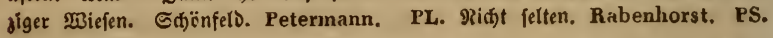
Düben. Rchb. 1816.

512. S. pentandra L. Rснв. Fl. germ. exsicc, 1423 . Gurmp. t. 161. Hayne Arzngw. 13. t. 40. Sünf-vielmännig. Blätter oval, beiderfeits verf(d)mälert, Diđjt, fein geterbt, fart glänjend, 2ldfelolättd)en eiförmig, gerabc, Blattfiel nad) oben vielorüfig, Rapieln turz gefticlt, tabl, Griffel mittellang,

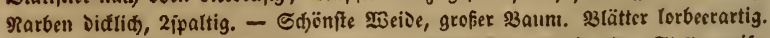

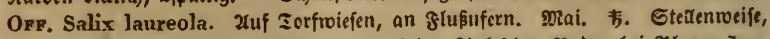
neift fpariam. D. Dofna. [2ngepranzt beim Sintefden sabe, bei Plauen.] -

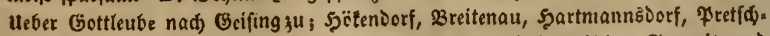

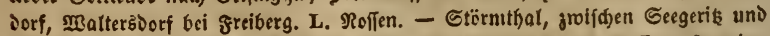

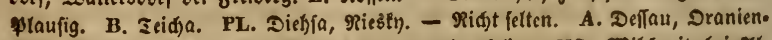
Daum, 3er6ft. PS. Soderbleben, Solgjelle, sitterfelt. HS. MBildgwib̆ bei are tenburg. 
148. Populus T. L. э̧appel. Stweithäufig. Räbitenf(t)uppen

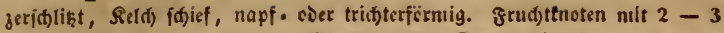
tief gettgeilten grarben. Ctaubgefäße 8 - 30. Siapiel Ifädorig, vielfaamig. Eaanten rodjdopfig. - Räßden vorzeitig. -

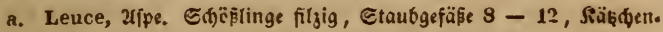

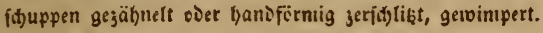

*513. P. alba L. Guimp. t. 202. Engl. Bot. 1618. 2lätter berj.

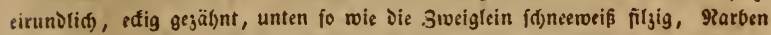

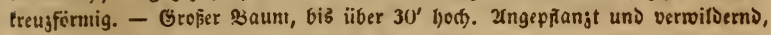

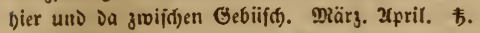

- 514. P. canescens Sx. Rchв. Fl. germ. exsicc. 2018. Engl. Bot. 1619. (alba Scre. t. 331). b. f. 1.) Stätter oval runolid, eđ̛ig ausggc.

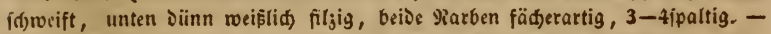

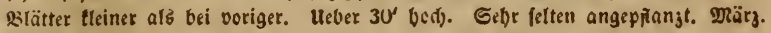
april. 5 .

515. P. villosa LaNg. Rchb. Fl. germ. exsicc. n. 1633. Blätter

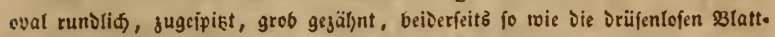
îticle und siveiglein feidengottig, unten grau, taf)l werdend. - Baum von 12

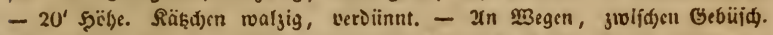

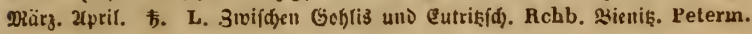

516. P. tremula L. Schr, t. 330). ค. Guisp. t. 201). 33tätter faft

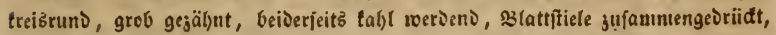

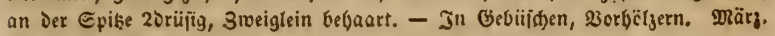
aprit. 5. Gemein.

b. Populus, Fapper. Eđjä̈rlinge taht, Stanbgefäfe $12-30$, Räb̆ đenfduppen unregetunäpig jeríf)likt, nidt gewimpert.

517. P. nigra L. Sснк. t. 330. a, Harse Arzngew. 13. t. 47. Guimp. t. 20)4. $\mathfrak{B}$ tätter 3ectig, veiDerfeits jugeipikt, fügerandig, länger als breit,

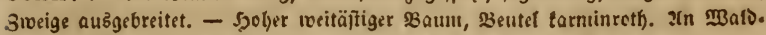
ründern, Megen, in Dërfern angeprianjt. März. 2epril. 5. Gemein.

- 518. P. balsamifera L. Waxgrah. nner. t. 28. f. 59. Blät.

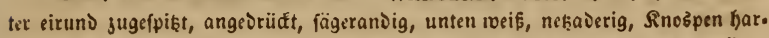

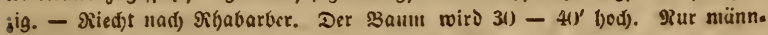

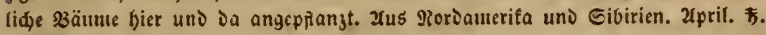

-519. P. dilatata L. Hayse Arzngw. 13. t. 46. Siveige aufa

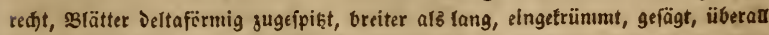

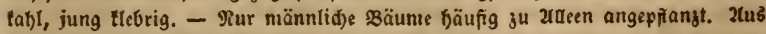
Jtalien. Märrg. 3(pril. क.

* 520. P. monilifera Ait. Scrк. t. 330. b. f. 5. Blätter an

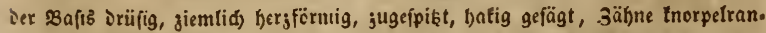

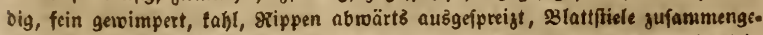

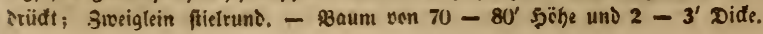




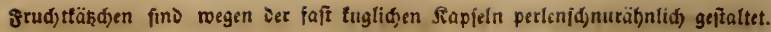

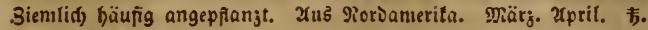

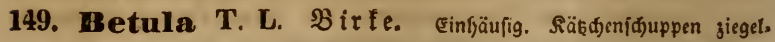
artig angeorüđt, meift 3lappig, 2-36lüthig. Reld auferhalb Der Befrud),

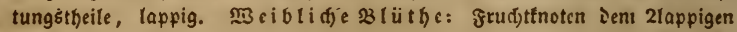
Reldje angetwadjen, 2 bängende Eaaniden, 2 borttige Rarben. Neänn.

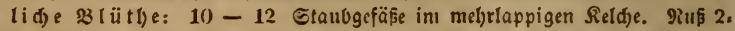

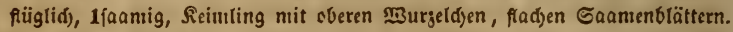

521. B. nana L. Fl, dan, 91. Gurmp, t. 148. Rснв, Fl, gern. exsicc. 1634. Blätter (thein, glänjeno Duntelgrün) treibruno, geterbt, tal)l, un=

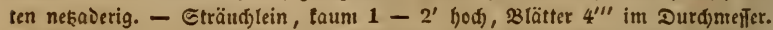
Zuf Mioorboom, gern auf Mioorfilgen. Juni. Juli. b. Jm bëdften Gebirge. Gefre felten. Z. (Smifden Sottesgabe uno Dem sidftelberge. Bok. Rodig. Weiker. Rchb.) A. ramberg nad) Schwabe.

522. B. carpathica W, K. (alba HoRv. Fl, dan, 1467.) S(ät, ter thembifif), ungleid) fägerandig, fpik; rierad)ieln fein bethaart; Inospen läng, (id) fo roie Die Stociglein tabl, teintig; weiblidte Eduppen gerointpert, ungleiđ)

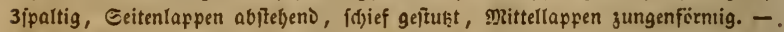
Etraut $=$ und baumartig. -2 uf \$icorfil 3 en mit pinus obliqua. Juni. $\mathbf{b}$.

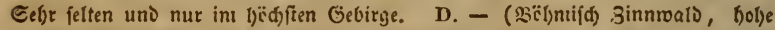
Bäunte. Papperitz. G. Rchb.). Z. (Ģottes̆gabe. Hofınann. Weiker. Rchb.).

523. В. pubescens Енкн. Gurмp. t. 146. Slätter lyerz = eiruno,

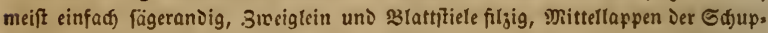

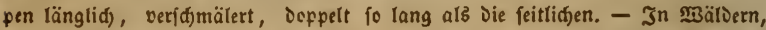
gern auf Mioorgruno. Mai. Iuni. Ђ. 5. Serfteut Durd) Das Gebiet D. Ira: d)au, Fonifau, Flauenjd)er Gruno. - Il)arandt. Z. Etedberg. L. \$ienik,

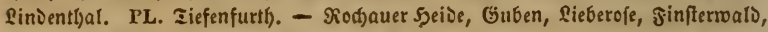
Ffërten, Gorau, Drelyna, Mariso. A. Zörten, Mëft. PS. Soberstebcn. Subt.

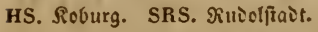

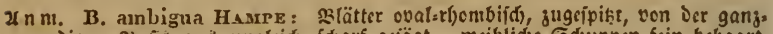
randigen sajis aus ungleidy f(j)arf gejägt, weiblid)e Edjuppen fein beljaart,

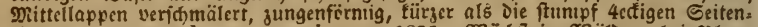

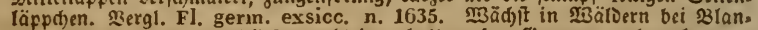
fenburg am Şarge und Dürfte wohl innertjalo unfrer Grengen aud vortomulen Eönnen.

524. B. alba L. Schr. t. 2S8. Gursse. t. 145. 2lätter ieltaförnig, fpisig, Doppelt gefägt, talyl, Eeitenläppden Der Edfuppen abgerundet, Mittels

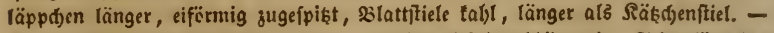

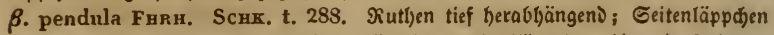
Der Edjuppen abgerundet, in Das länglidje Mittelläppden binarlaufend. -

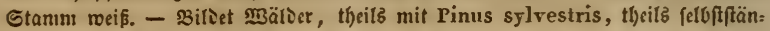

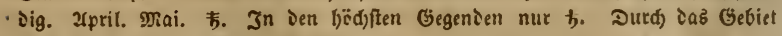
meift bäufig, feltner mälter bilieno.

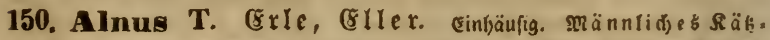

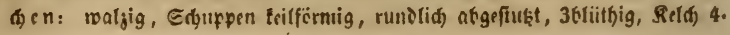




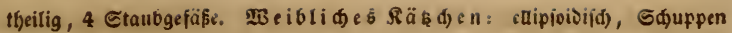
verboljeno, ausgefpreigt, teilförmitg abgeruniet, 1. bis nefbrblütbig; frud)t.

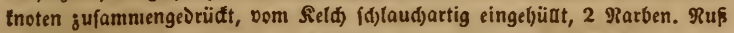

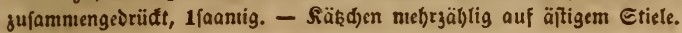

525. A. incaua W. Rchв. F1. germ, exsicc. n. 1352. Gursp. $t$.

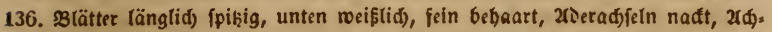

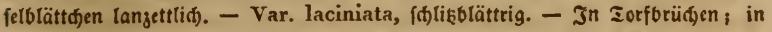
trodnen Wäldern wabridjeinlid nur angepriangt. Xpril. Mai. Eepteniber. $)$.

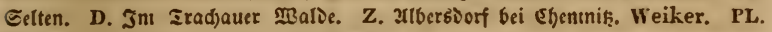
Muśtau. - gürftt. Drebna, G̈̈rtšorf.

526. A. glutinosa GAERTs. şätter teilfịrnig runolid, etroas ausgefdjweift, bogig gefägt, leintig, żerad)feln unterfeiţ bärtig. $-\alpha$. emarginata. Gormp. t. 180. mit auछgeferbter Spike. - $\beta$. quercifolia, eidenblatt. artig gebudftet. - $\gamma$. laciniata, fd)lişblättrig. - In brudjigen Gegenden, biz.

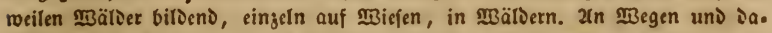

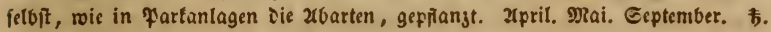
Şäufig gerftreut, felten.

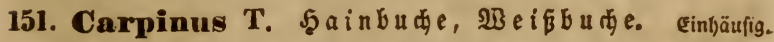

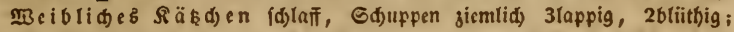

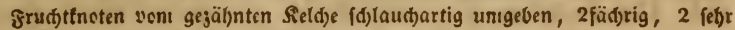
lange paradele Rarben. Männtides Sähd)en: Sd)uppen cirund, Staubgefäße 8-14. Scutelfäळer getrennt, aufrecht, an ier Spiß̨c bärtig. Ruß einfäđrig, einjaantig.

527. C. Betulus L, Schк. t. 3(14. Gurmp. t. 150), S3lätter ciruns

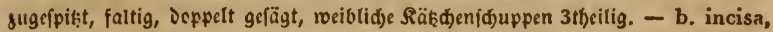

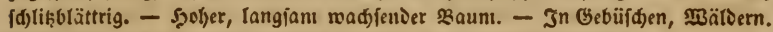
april. Mai. ち. Durdf Das Gebiet felten, gern in Gebirgşwäldern.

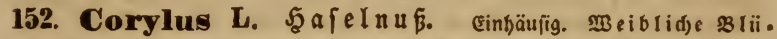
the u mel)rere Enospenartig beijantnten, Reld sweitheilig, jerfd)lişt, frudtst.

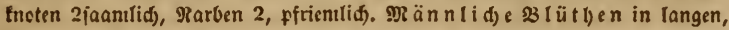

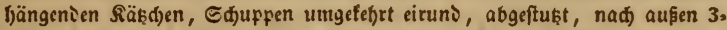
ea̛ig, innen erbebt fid) eine sängsleifte, veld)e auf jever Ceite 4männig iff.

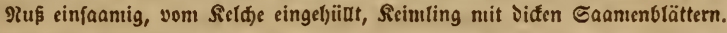

528. C. Avellana L. Scek. t. 305. Gurmr. t. 151. গū ciför.

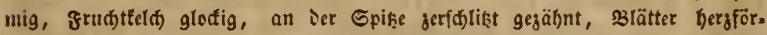

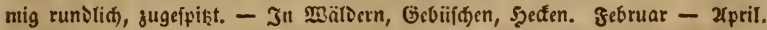
b. Durd) ১ab Gebiet ljäufig.

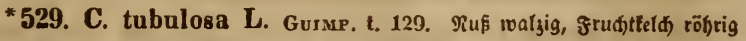

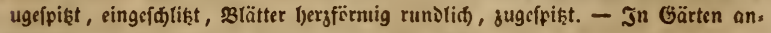
gepiangt. (2us ungarn, Deftrcid), Stalien.) 2(prir. b.

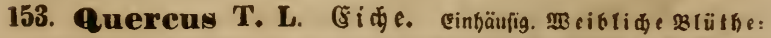

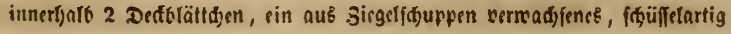




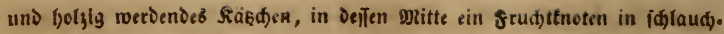
àrtigen Relđe, Grifiel mit 3 turgen, ftumpfen Rarben. DRännlid)e 81 .

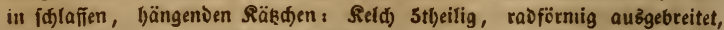

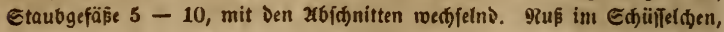
Gaante gleidtfïrmig, Eaamenblätter tił.

530. Q. Robur L. Schк. t. 301. b. Harsis Arzneigew. 6. 35.

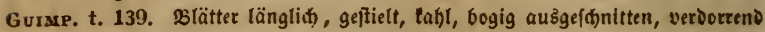

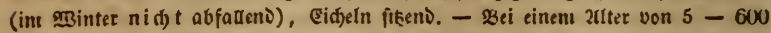
Jabren bat ber Stanim $15-20^{\prime}$ Unifang und fojon narb 200 Jabren eine

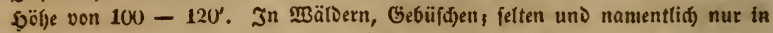

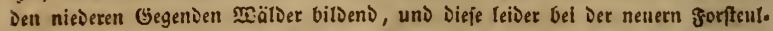
tur an mandjen Drten ju Gunjten Det RaDelfjöljer ausgercttet. Xpril. Dlai (12 - 14 Iage yer folgender). Ђ. Durd) Dab Gebiet, in Den oberjten Gegenden verjojmindent.

531. Q. pedunculata Енгн. Schк. t. 301. Harnis Arzngw.

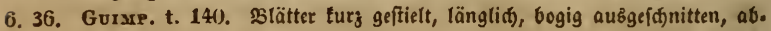

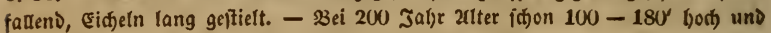
18 - $25^{\prime}$ bid. Goll nur $4(0)$ Jabr alt metben. Borfommen, roie bei voriger,

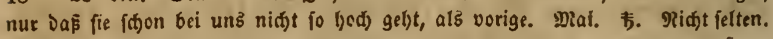

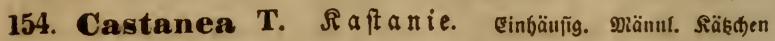
trägt an Der $\mathbf{B a f i s}$ weiolid) $\mathbf{B}$ I. meift 3 , in 5 - 6tbeiliger, igelftadhlider

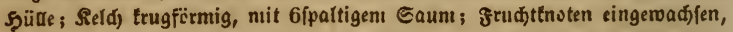
6fäd)rig, 12 hängende Saanţen; 6 शarben, auf Dem Saume unfrudtbare

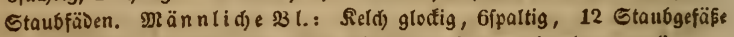

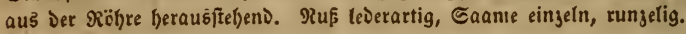

*332. C. vesca GaERTN. Gormp. t. 144. Blätter länglid́) lanjetto

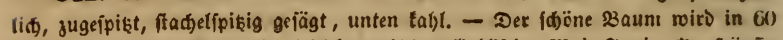

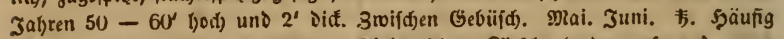
in \$einbergen (nantentlid) D. un Giebeneiden, Rötf(jenbroda u. f. w.) ange.

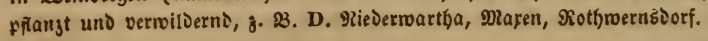

\section{Familie Urticaceae, grefielgevä die.}

\section{- Serbarienbud) S. XIV und 66. -}

155. Urtica T. L. Reffel. Ein. oder jueilänig. NBeiblide

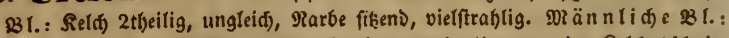

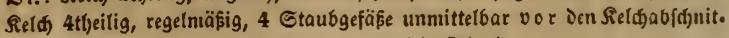

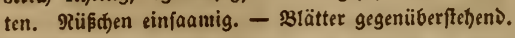

533. U. urens L. Fl. dan, 739. sklätter eđiptif́, faft 5uetvig, fđarf

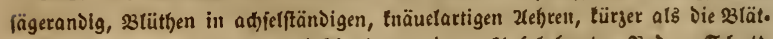

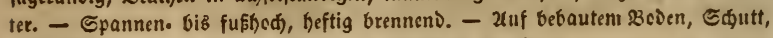
an פrauern. Juni - Rovember. ○. Uleberall gemein.

534. U. dioica L. Fl. dan. 746. slätter bergförmig, fägeransig, 


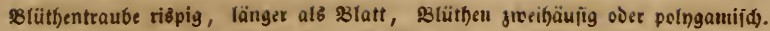

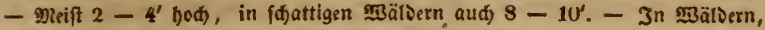
zwifłten (Gebüif), an Megen, auf Edjutt, Brandfätten. Juni - Drtober. 4. Ueberad gentein.

535. U. pilulifera L. Scrk. t. 289. Fl. germ. exsicc. n. 22. Blät。

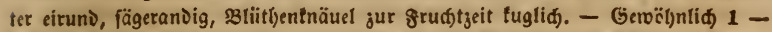

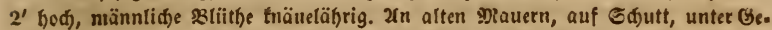

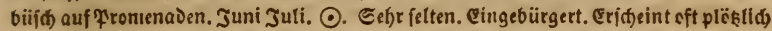

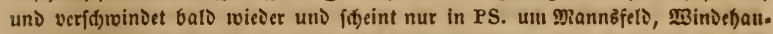
fen und Seringen Etand ju halten. D. Fidnik (eimmal). Fr. AUgust K. v. S. Brođfroik (einnıl). Mauke. PL. Suđåu. Känmerer. Leidolt. Schwerdtfe-

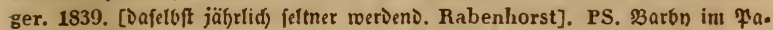

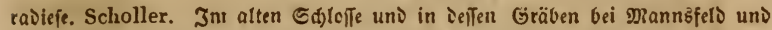

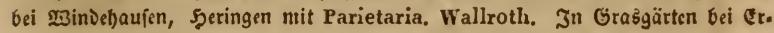
furt. Buddensieg.

156. Parietaria L. (S) I a \& $\mathrm{f} \mathfrak{a} u$ t. Folngantifo. Reld glodig, an Der 31vitterblütbe enjlid) vertängert; 4 Staubgefäße, bei Der sefruđtung

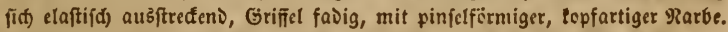
Meiblide Blüthe clyne Etaubgefäfse. - Blätter jerftreut, Dreifađ) nervig.

536. P. officinalis L. Scak. t. 34t. Harve Arzngw, V. 12, F1.

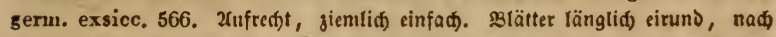

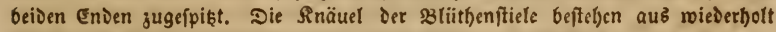

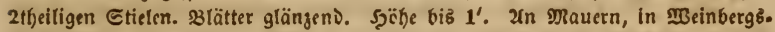
gaffen. Juli - September. 4. Stellenweife, neift bäurig. D. Pitna, Sofd.

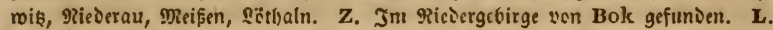
In Der griinen Gaffe binter Den Reblgärten, bei Sederbaufen, Sindenau an Ieidje,

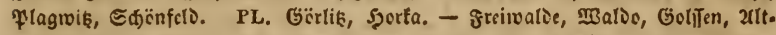
goliten, Goljig, Guben, Eonnenwalo. A. 3erbit. PS. 23arbn. Şalle. Raum.

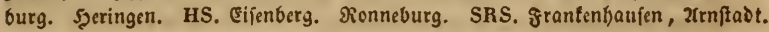

537. P. diffusa M. K. (P. judaica Schx. t. 3ł6.) Fl. gernn. exs.

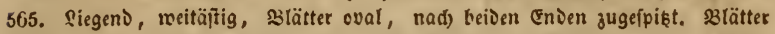

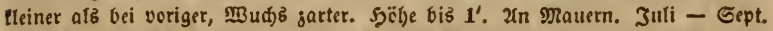
4. Sefr felten. D. Meisen. L. Rchb. fil. PS. Eilenburger હd)lofmauer. Richter.

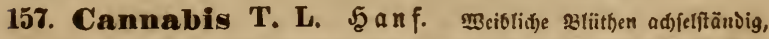

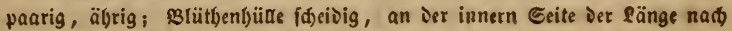

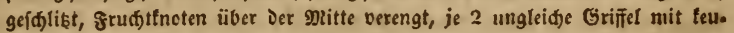
liget Rarbe. Männlidje 32 liithen ađjfelftändig traubig, bängeno, Blütben.

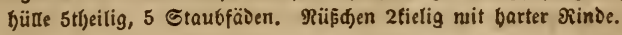

538. C. sativa L. Haxxz Arzngw. VuIl. 35. Blätter gefingert,

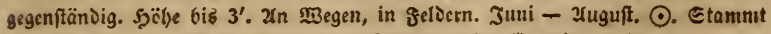

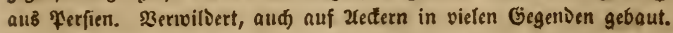

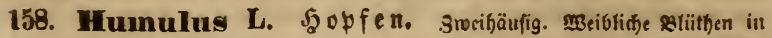

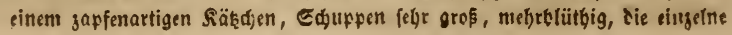




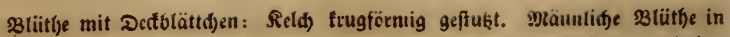

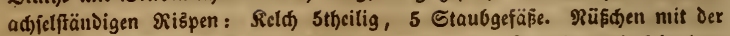
Spițe aus Dem binweltenden Reld) bervorragend; Feimling mit fef)e lan: gen, quer fpiraligen Saamenblättern.

539. H. Lupulus 1. Schx. t. 326. Hayse Arzngw. ViII. 36. Stengel roinvent, fantig, 3lätter gegenüber, geftielt, bersförnig, 3-5lappig, fä.

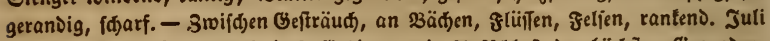

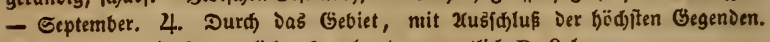
3ußserben, bejonders neuerlid, oft gebaut, nanientlid) D. Sobmen.

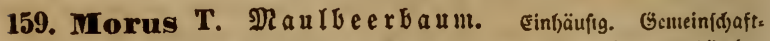

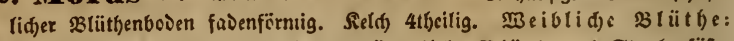
Fruđttnoten 2fäđrig, 2 Rarben. Männlid)e $s$ liitbe: 4 Staubgefäßse.

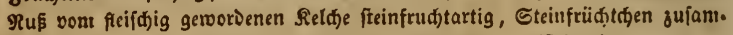
menbängenঠ. - Saamenblätter parallel, Wiirgelden aufiteigenj.

-540. M. nigra L. BAкw. t. 126. Blätter łergförmig eirun১ oder

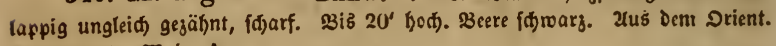
zingepflangt. Mai. b.

- 541. M. alba L. Schk. t. 290. Gurmp. t. 13s. S3lätter fóbief bergförmig, etroas lappig, auđ) ungetl)eilt, ungleid) ge[ägt, jientlid) glatt. 23aum von $20-30^{\prime}$, c̈fter ftraud)artig gejogen. Beere rei巨. \$is $20^{\prime}$ bod bei uns. Xus Dem Drient. Xngepflanjt. Xpril. Mai. †.

- 542. M. rubra L. 3lätter bergfërmig, zugépiḩt unذ 3lappig, glcid).

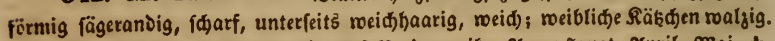

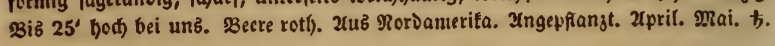

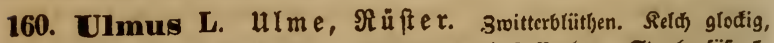
5ipaltig, bei andern 4fpaltig; frudjtfnoten mit 2 शarben. Staubgefäße 5, bei andern 4 oDer 8 . Rüßđ)en ringšum perpendiculär gefiiigelt. - Blütfen

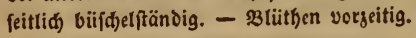

543. U. campestris L. Hayne Arzngw. 111. 15. Gurmp. t. 27. siätter Doppelt gefägt, an Der $\mathfrak{B}$ afis ungleid), şütt)en faft fikend, tnäuelartig,

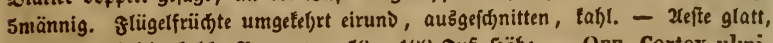

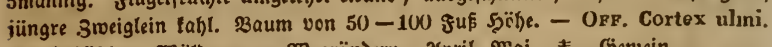
In Gebüfdjen, Wäldern, an Megrändern. Xpril. Mai. ち. Gentein.

544. U. montana (BaUн.) Sи. Engl. Bot. 1857. slätter eiförnig,

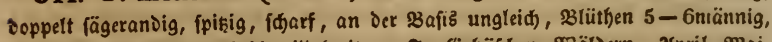

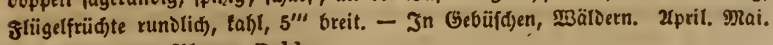
Ђ. Gelten. D. Plauen. Rchb.

545. U. suberosa EhrH. Hayxi Arzngw. II. t. 16. Gunm.

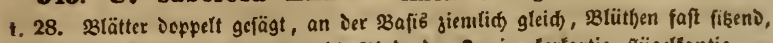
Inäuelartig, 4männig, friidjte tafjl, אinde der Sweige fortartig, fïgeltantig. -

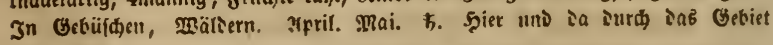
nirft fiften. 
546. U. major Sn. Engl, Bot. 2542. Slätter länglit,, Doppelt ges

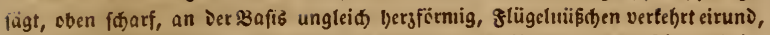
tafl. In Fartanlagen, Bältern, Gebiiften. Xpril. MRai. Ђ. Şier und Da allgeprianzt oDer verwildert, 3. 3. D. Sileinhoffertibis.

547. U. ciliata EнRн. Hayxz Arzngw. III. 17. Blätter doppelt gefägt, an Der $\mathfrak{B a f l b}$ ungleid), Blüthen 8männig, Slüthenfticle lang und fd)laff,

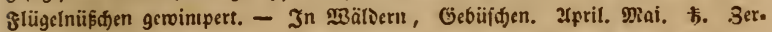
frett Durd Das Gebict.

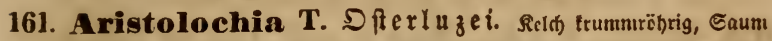
lippenartig. 6 Staubbeutel auf Der Etaubfäbentöbse. Sapfelfädger vielfaa. ntig, ๔aanen Dreictig, platt.

548. A. Clematitis L. Schk, t. 276. Hayxz Arzngw, IX. 24.

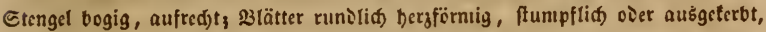

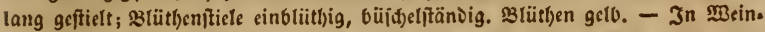
bergen, an Mauern. Juni - 2tugujt. 4. Eingebürgett. Etedentveife Durd

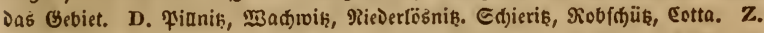

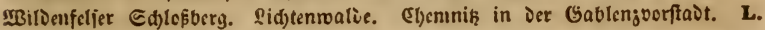

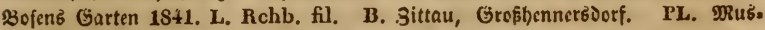

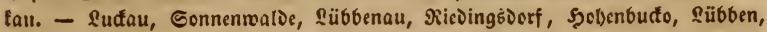
Siottbub. A. DefTau, 3erbjt, Bernburg. PS. Barbn bei Enprena, ans Ihierberg.

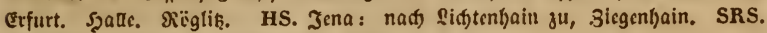
atmftait. OrF, Rad. et Hb. Aristol. vulg.

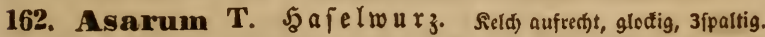
12 Etauligefäße, Etaubbeutel unter Der Epike Der Etaubfäben aufgeroadjo. fen. Siapielfädjer 3-4faamig, Gaamen ungetebrt eiförmig, vorn außgges

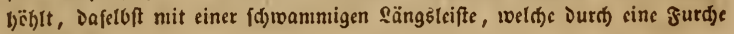
getbeilt ift.

549. A. europaeum L. ScrK, t. 127. Haysr Arzngw, I. t. 44. Mit 2 nicrenfërmigen, ftumıfen 3 lättern. - Siried)end, Blüthe untcin (d)wärz.

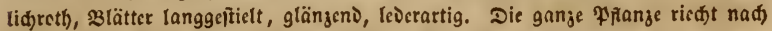
Samufer. - Opr. Radix Asari, - Unter Gebüfd). 2(prit. פiai. 4. Eteulen. weife Durd ১ab Gebiet, nantentlid in gebirgigen Gegenden, in 9tieverungen Da.

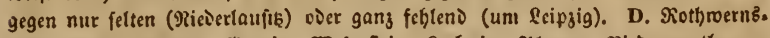
Dorf, Firna, Dolna, Gamig, Mcfenftein, Soffwik, Flauen, Ricverwartha. -

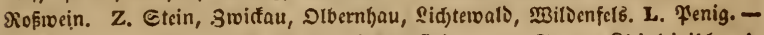
B. Gdjënauter Şutberg, ß3urgberg bei Bernftadt. PL. Sorau, Sileinleipifd. A.

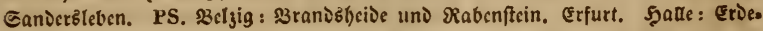

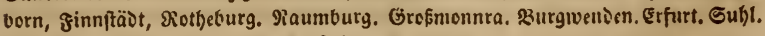
HS. Jena, sifenberg. SRS. 2tinftait. R. surgt. 


\section{g Y N P T A I A E.}

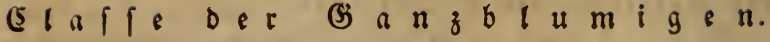 \\ - Bergl. Syerbarienbua 5. XLVIII und 72. -}

\section{familie Dipsaceae, Dipiacen.}

- sperbarienbud) ธ. XLVIII uito 72. -

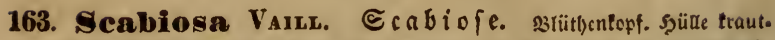
artig ausgebreitct, sweireiljig oder giegelartig in Epreublättben übergeheno.

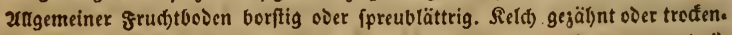
väutig auşgebreitet. Eaantentrone $8(-16)$ borjtig. Bluntentrone unregeinuä. fig, 4-5ipaltig, 4männig.

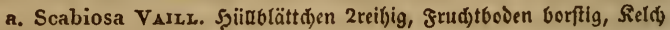
4jäbnig, taum über Den §rud)ttnoten emiporragent, 巨aantenfrone beđen. förnig tief şälynig, şlïndđen 4 fpaltig.

550. S. arvensis L. Schx, t. 22. Hayse Arzneigw. V. 38, Fl. germ. exsicc. 2021. Etengel raul), $\mathfrak{B}$ lätter gan $\xi_{3}$, einge[d)nitten oder fieder(pale

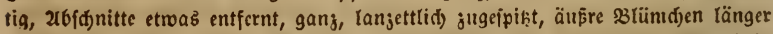

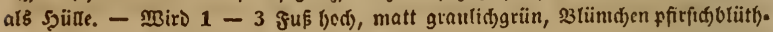
roth) *). - b. trivialis Scux. Fl, gern. exsicc. 2022. Elänzend Duntelgriin,

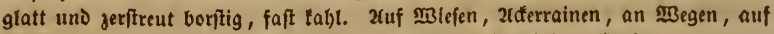
\$alorändern. Juni - Geptentber. 4. Gcmein Durd) Dą Gebiet.

551. S. silvatica L. JAcQ, austr. t. 362. Fl, gern, exsicc. 213.

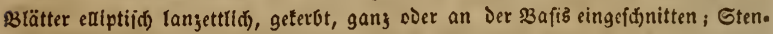
gel feeif befaart, oben weidh befyaart; äufre slüm(jen etwa fo lang als Sjülte.

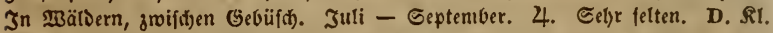
Eeolik. Dittınarsch. Edjandau. Groh. Rchb. A. Sjarggercoe. Schwabe. PS. Euljr. Metsch.

b. Asterocephalus Varnx. Sü̈abtättdjen 2reihig, Frut(t)tboden fpreu. brättrig, Seld)faum trođ์enläutig, Saamentrone fdüiffelförmig, rang 5 . borftig, 3lümonen 5 ipaltig.

552. S. suaveolens Desf. Rснв, pl, crit. ic. 76. El, germ.

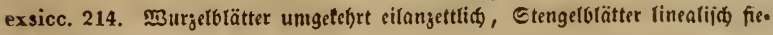

*) Baer bat jemals ,flores coerulei" gefelien? - 


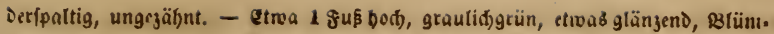

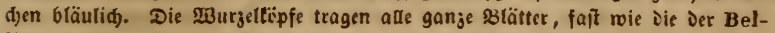

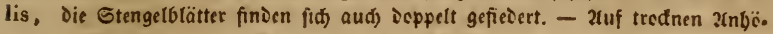
ben, an Megen. Juli - September. 4. Etellenweife; nantentlidy in ier reft.

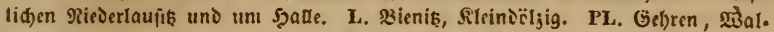

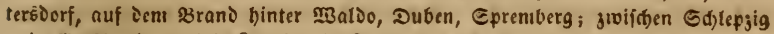

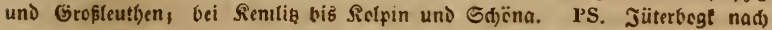

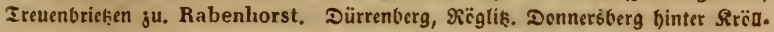

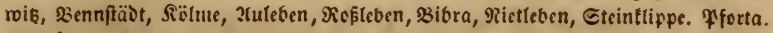
Beneken. Erfurt bei હduvedenburg. Hornung. SRS. 2rnftait. Schünheit. Srantenlyaufen. Schünheit.

553. S. Columbaria L. Rснв, pl, crit. IV. ic. 535. शुurgelblät. ter geftreft teierfïrmig, menige unjertheilt, Stengetolätter neift fiederipaltig, Sield)berften unten jufanımengebriiat, netvenles, $3-4$ Dial fo lang als Sield-

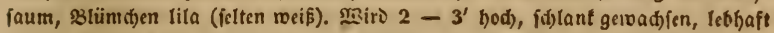

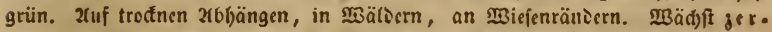

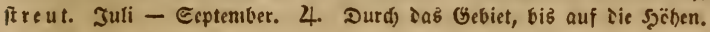

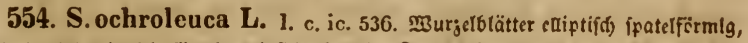
geterbt, folgende leierförmig unذ fièerfpaltig; Reld)borften unten zu\{amimengèrüdt, nervenles, $3-4$ פlal folang alś Reldfiaum; Slïmden edjergelb. MBird $1-2$

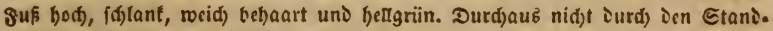
crt ergeugt, indem an melyren Ctellen sie vorige 2trt unter ifbr wäd)ft. Gie än. Dert aud bei Der 2usfaat niemals bie Sarbe, nur \$aftarie groifden beiden ge. ben 3lüm(ben, weld)e Den llebergang in Die Silafarbe nadiweifen. 2luf Xderrai.

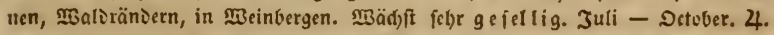
Etedlenmeife Durd) Das Gebiet, feblt in böbern Gegenden; namentlid) um Drcs. Den an vielen Etcllen febr läufig. D. Rojdjüb, \&aubegaft, Firna. Fianis, şo.

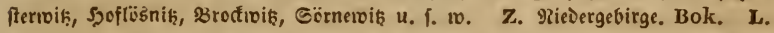

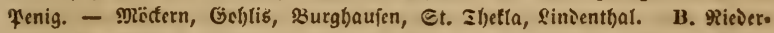
gubrig gegenüber. Kölbing. Sittau. Reichel. PL. Görti६ am ufer Der Reife. - Dobrilugt. A. Deifau, Redfteit, Sanjersteben. PS. Barby. Jiiterbogt. Szalle. Rauniburg. Eibleben. HS. Jena an Der (E)auffe im פriibltbal zmifden Der Del. und ¥apiermüble. SRS. Ifrnitadt.

c. Spongostemma, wic vorige, ier trođ̌enbäutige ficldjaum aber mit şuljtrani.

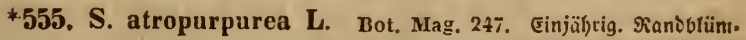

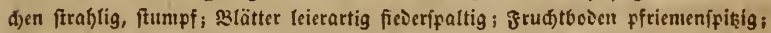

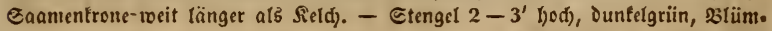

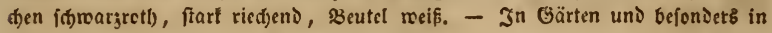
ibnen verwildert. Juni - September. $\odot$.

d. Succisa VAILx. Şünblättdyen jiegelfändig in ১ie Spreublätter

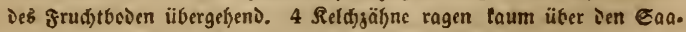
men binaus, 23lümd)en 4ffaltig, Saamenterne botftig.

556. S. Succisa I. HAYxR Arzngw, V. 37, Etengel jiemitid ein. 


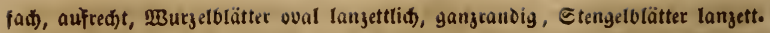
lid) (meift ganj), s3liithenfipf(hen faft fuglid). - Etwa $2^{\prime}$ bod), lebbaft fattgrün,

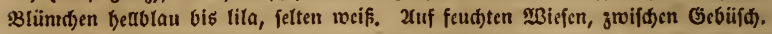
Juti - September. 4. Gemein Durd) Das Geviet.

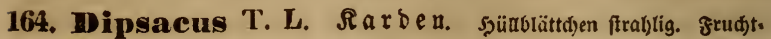
boden fted)end=fprcublättrig. Seldjsäl)ne taunt über Den Saanten binaufra. gen๖, 3lï̈nd)en 4\{paltig. Saamentrone näpfdjenartig.

557. D. pilosus L. BLAKw. t. 124. Fl. dan. 1448. Blätter geftielt,

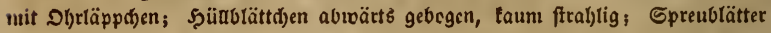
umgefel)rt eirund, borftig gewintpert, gerade, grannenfpikig. S3erbiniet Die Scas biofengeftalt nit folgenden, $2-6^{\prime}$ bod), 31veigs fteif bebaart, 3lümónen weif.

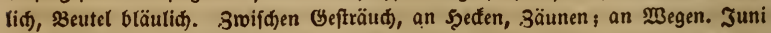

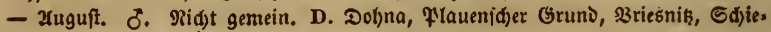

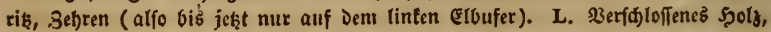

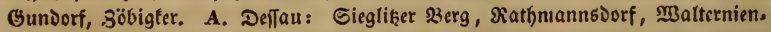

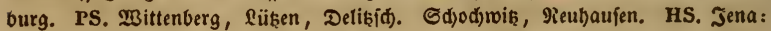

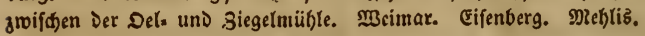

558. D. sylvestris MILr. Fl. dan. 965. 23lätter fikend, ferbig ges

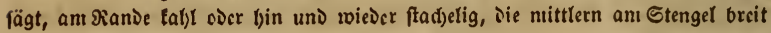
verwadjen, ungetbeilt oDer fiederfpaltig; Die Şüllblättthen bogig aufíteigend; Die Spreublättd)en biegfam, länglid) verf́cbrt ciförnig, fein grannenfpił̧ig, geràe, länger als Die slümd)en. Steif, $2-4$ fus bod), betlgrïn, turz und trumm=

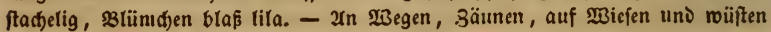
Stellen. Juli - September. $\delta$. Ju Den bëbern Gegenden felten, bis gan fel)lend, fonft nid)t felten. D. Firna, Mägeln, Etrel)len, Mü̈blbad), Plauen.

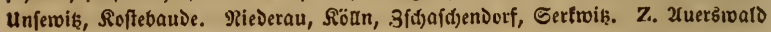

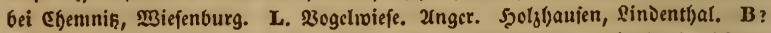

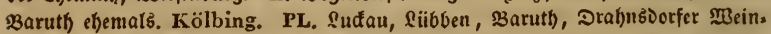

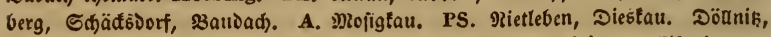
Mallendorf. Burgivenden. Erfurt u. f. r. HS. Zena, Meimar, Eifenberg u. f. w. SRS. 2urnitadt.

* 559. D. Fullonum L. Schк. t. 21. 33tätter fik̨en〉, ter6ig ein, gefdnitten; Stengelblätter breit verıvadfen, ungetநeilt; Şüublätter borizontal auf=

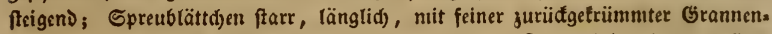
fpise, fo lang als Die sliint(jen. Steif, $2-6^{\prime}$ bod, Sopf minder bod getwölbt

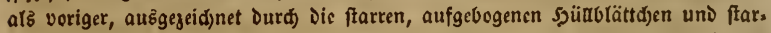

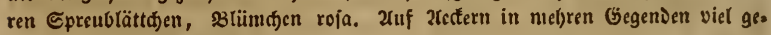
baut. Juli - Sipteniber. $\delta$.

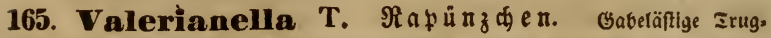
Dolde oder Sïpfiben. 3lume trid)terförmig, 5jpaltig. 3 Staubgefüße. Rapfel

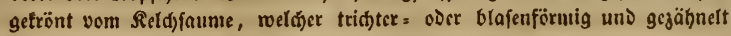
ift, 3fäđ)rig, 2 Geitenfäđ̆er leer, nittletę 1 faamig.

560. V. olitoria Moexcn. Rснв, pl. crit. I. ic, 121. Sisthfaum 


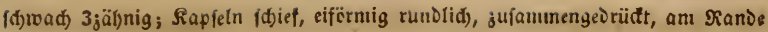

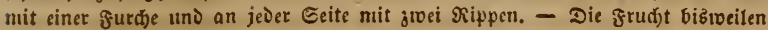
fein bel)aart b. lasiocarpa Rснв. ic. 122. - Lebhaft grïn und labl. Siätter taum gewinipert, unigetel)rt, eilanjettlid), fpatelfïrnig ober jungenfërnig, oberfte

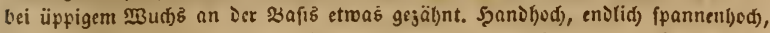
3lïthe blafilila. - c. costata Der fäd)fifd)en flora gehört nur als saar. bierber und ift nid)t Stevens Prange. - 2tuf 2tefirn. 2upril - Juni. 2tuguft - Ds. tober. $\odot$. Nantentlid in Den nieberen Eegenden, in Den bödjten febleni.

561. V. carinata Lors. Rснв. pl. crit. ic. 123. exs.573. Rapfeln

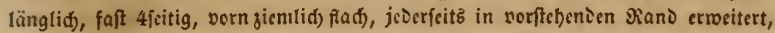
binten tief winnig, Seld undeutlid) einjät)nig. Sgïbe bis 6". 2uf Xectern. 3pril - Juni. ○. Selten. D. 33riç̄ik. Rchb. B. S3ertbelsjorf, Şerrnbut.

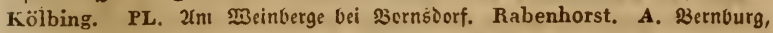
Gandersteben. Schwabe. SRS. Frantenlyaufen. Rchb.

562. V. eriocarpa DEsv. Rснв. pl. crit. ic. 132. Rapfel eiförntig, binten conver, fubtil 3rippig, vorn jientlid) fiad, Mlittelfelo jwifden den erljabe.

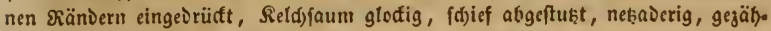
relt, 3reiglein sidf, Did)tblüthig. Sapfeln meift raudfftreifig oder gang raud). -

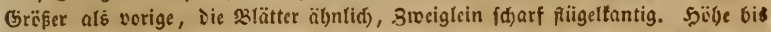

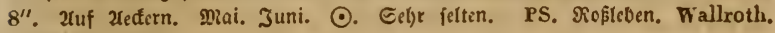
\&aucfitüt. Rchb.

563. V. Morissonii DE C. Rснв, pl. crit, ic. 124. exs. 182. Rapfel eiförnig, legalförmig, binten gewölbt, fein 3rippig, vorn jiemlid) platt, 9)ittelfelo

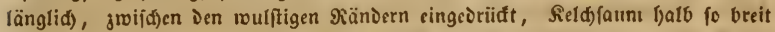
als Siapfel, fdief abgeftust, fpikig, gejäl)nclt; S10ciglein ausgebreitet. Rapfef

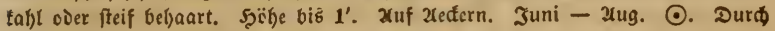
خas Gebiet, in böbern Gegenden feíten cier feblend.

564. V. Auricula DE C. Rсвв, pl. crit.ic. 128-29. exs.10. Sapfein

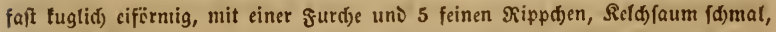
f(j)ief geftukt, linterer 3al)n aufred)t, lang und ftuntpf, vorderer fel) tlein. -

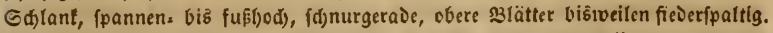
grud)t taljl, fetten bel)aart: dasycarpa ic. 130. Ş̈̈l)e bis 12". Uuf Xedern. 2tpril - Juni. Gepteniber. ○. Etellenmeife Iurd Daz Gebiet.

565. V. dentata DE C. Rснв. (trident.) ic. 131. Rapfeln faft fuglidf eiförnig, fein 5rippig, vorn 4rinnig; Reldfaun $1 \int_{3}$ fo breit als Sapfel, in einen breiten, 3ectigen, fpikigen Şintergal)n ïbergebeno, Bordergäl)ne febr llein.

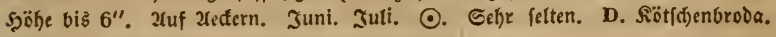
Rchb. L. Burghaufen, 3orsoorf. Petermann.

566. V. coronata (VAHL) DE C. Renв. pl. crit. ic. 133-135.

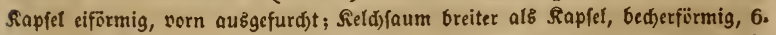

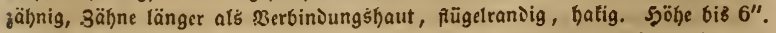

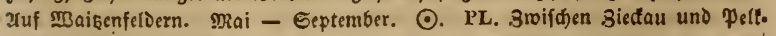
soį̧ naफ Rabenhorst. 
166. Valerinna T. L. Ba aldrian. Erugdolde (vei andern

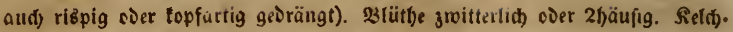

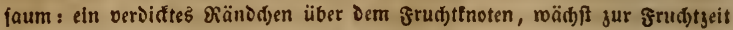

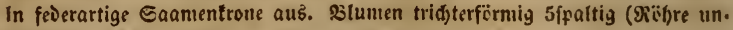
gefpornt). Staubgefäpe 3. Edaliaamen.

567. V. dioica L. Hayne Arzngw. 11I. 31. St. 9. SBätter dir 20urgeltïpfe lang geffielt, fpatelfïrmig, untere Etengelblätter clliptif(d), cbere fic. ocrpaltig; Murgel fprotentrcibento. Stengel $6-8^{\prime \prime}$ foct). Blunten weik, weib.

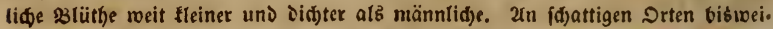
len zwitterblütfig: V. silvatica ScHar. - 2uf Sumpfiviefen truppiveife, auc

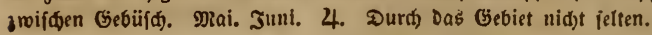

568. V. officinalis L. HaysB Arzngw. III. 32. ST. 9. Blätter gefiedert, 7-10paarig, Blättd)en tanjettlid), gezäl)nt; Etengel gefurd)t, Fronen. röl)re fo lang alb ber Saunt; Murgel mit Eproffen. Şäl)e bis̆ 18". V. exaltata MrK. mannshod), olyne Sproffon. OFf. Valerianae minoris radix. - zuf

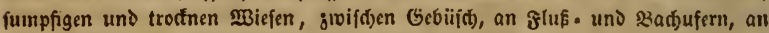
Zeiden, Bergen. Juni. Juti. 4. Durd) Das Gsbict nidgt fetten.

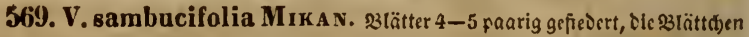
grob fägegähnig, Die unteren eiförmig, Die obercn lanjettlid); RTronenrëbre länger alb ber Saum; Murgel fproffentreibeno, etengel gefurdft. - 2un Stüfen, zrol.

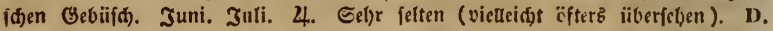
Dobna. G. Rchb. PL. 2xm ఇutis. Rabenhorst. -

167. Sambucus L. Flieber, א̧ollunber. stugoolie. Reldfaum oberbalb, 5jälfnig. Blume radfürmig, 5 fpaltig, 5 Etaubgefäß̄e.

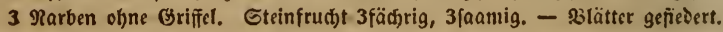

570. S. Ebulus L. Sсrк. 83. Haxns IV. 15. Rснв. exs. 1426. Єtengel

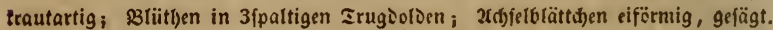

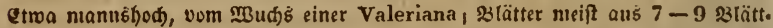

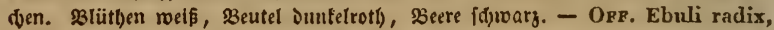
cortex interior, folia, flores, baccae. - Sroif(d)en (Sebliif(d) an 3ergablängen,

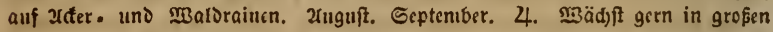
Iruppen. 9iidt algemein. D. Sofdivik (einual). Rchb. - Grauenftein. G. Rchb. Papperitz. 2ungeblid aud bei altenberg uno Sauenftein, Dafelbft neuer. lid) nidt bentertt. A. Dranienbaum, Sjarjgerobe. Schwabe. PS. 23arbn beim

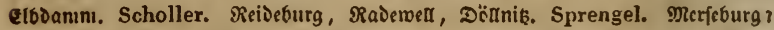

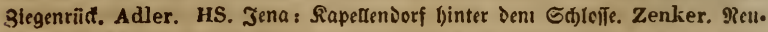
brunn bel Meiningen. Rauch. R. Sobenftein im Gottliebsithale.

571. S. nigra L. Schr, t. 83. HaYss Arzneigew. IV. t. 16.

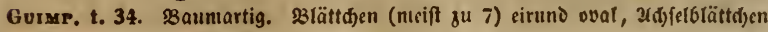
wargenförmig, zrugbolie 5theilig. - 3 (ütthen weiß , Becutel gelb, Beere fđywarg. 3ar. chlorocarpa, grïbeerig, leucocarpa. weiffeerig. - OFP. Saunbuci cortex interior, folia, flores, baccae, semina. - In .jecten, Geviildsen, in Dör.

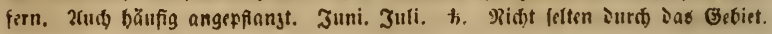


572. S. racemosa L. Вснв. exs. 1427. Guisp. t. 35. Etanim fraun.

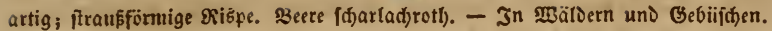
3pril. Mai. ち. Befonders in Gebirgs. und Spiigelgegenden nißht felten, in Ebenen aber feblend (reftlidje Ricocrtaufik, un feipsig u. f. w.).

\title{
Ganilie Caprifoliosae, Ģeisblattgewäd)
}

\author{
- Serbaricnbud S. XLVIII und 73. -
}

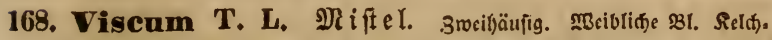

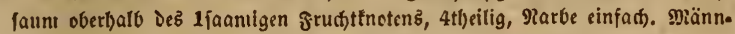
lidje 21 . Reld) 4theilig, allf Der innern Geite Den slütbenftaub trageno. 巨teinfrud)t 1faanig. - \$3lätter gegenüber.

573. V. album L. Schk. t. 320. St. 8. Harse Arzngw. IV. 24.

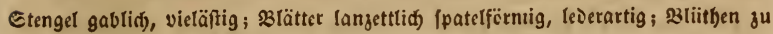
$3-4$, endftändig. Steifer, rundlid)er, inunter grüner Gtraud) von $1-2$ ' \$äbe.

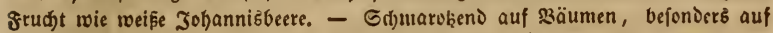

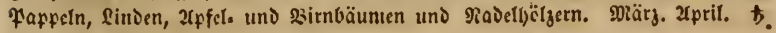
Durḑ Daś Gebiet meift nidjt felten.

169. Iinnaea Groxov. $\mathfrak{R}$ in năa. Frudthtnoten unterftänsig, nit

2 Deđfulättd)en. Sicldfaunt 5theilig. Slunte gloctig, 4niännig, 2ntädjtig. Etcinfrud)t trođen, 2 fäd)rig, jäđ(jer 1-2 jaamig. -

574. L. borealis Grov. Schk. t. 176. Hayxis Arzngw. IV. 13.

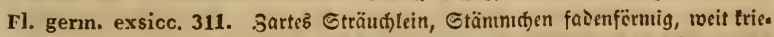

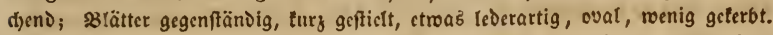

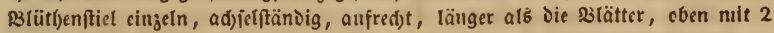

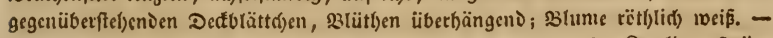

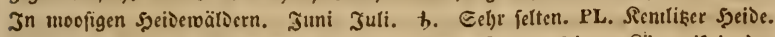

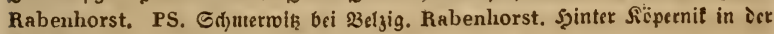
Rropftäiter Scioe. Schkulır. Erdinann.

I $n$ ın. * Diervilla canadensis W. mie Lonicera, abcr Sapfel, 22I. gelb.

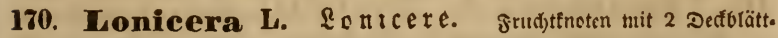
()сn. Sield) obcrfalb ذes grudttnotens $4-5$ jäl)nig. 23łunte trid)terförmig,

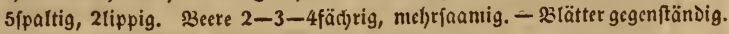

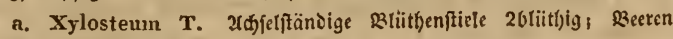
meift gang verwadjín.

575. L. nigra L. Gormp. t. 8. Fl. germ. exsicc. 184. 3lüthen. ftiele 26tütbig, tahl, länger als Die länglid)=clliptijd)en, anfangs recid) belsaarten,

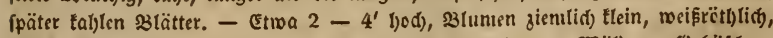

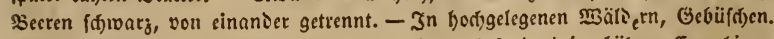

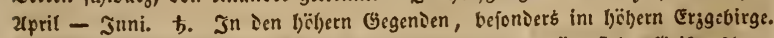
b. Sileiner \$interberg. - Gđmisbeberg, Jrauenftein, särenftein, Gieifingsberg, Geifing, altenberg, (b̈̈buif() Sinnivalo). Z. Jobaungeorgenftabt, Gbeibenberg,

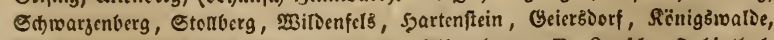

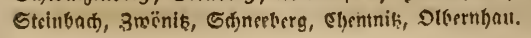

B. \&aufrie, Dnbintbal. 


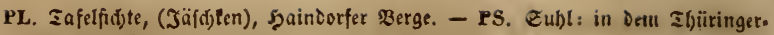
wald. HS. Roburg. SRS. Lauterticrg. Paulingelle, Singen. R. Iobenftein.

576. L. Xylosteum L. Gurarr.t.9. 23lüthenftiele 26lütrjig, fein ve.

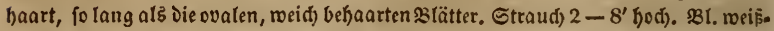

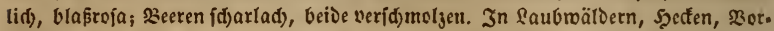
bëlgern. Mai. Juni. b. Um Ieipjig und in Den Saufişen fehlend, fonft nidjt felten.

- 577. L. tatarica L. Bot. Mag. 31. slätter ferg.eirun১, taf)! stiutbenfticle 2blïtbig, faum fo lang als 3lume; siseren (f́f)arlad) oder gelb)

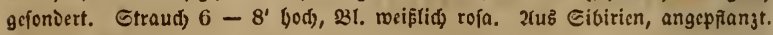
פai. to.

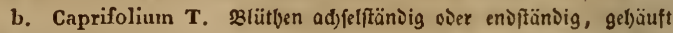
fikeni, Beeten getrennt.

578. L. Periclymenum L. Schк. t. 41). Haysx Arzneigw. 38.

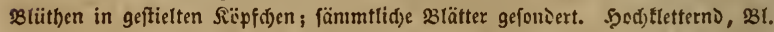
langrël)rig, auš odjergelb rofa biß rëtl)(id). 2eeren mennigrotb). - In Gebüfdi)en, ஐBälDern, Szef̌en. Juni. Juli. b. Bientlid) felten und rosbl nucift nur vet.

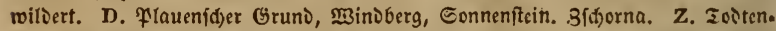
ftein bei Sdjwarzenberg. Bok. L. 2attent)ain. Sindentf)al. PL. Grofradoett, \&uctau, Guben. A. Dranienbaum, \$̧arg. PS. Erfurt. HS. Ylaffenfteig bei Jena. SRS. 3rnftadt. 5̧orba.

* 579. L. Caprifolium L. Gurmp. t. 6. Brittyen in Quirlen un১ Rëpfd)en; / Das eniftäniige Röpfiten fiķent; Die oberen Slätter paarig zufanl. mengemadjjen. - 2(ngeppanjt und bier und Da verwildernd. Mai. Junt. $b$.

- 580. L. sempervirens L. Bot. Mag. 781. Blätter tabl, unten

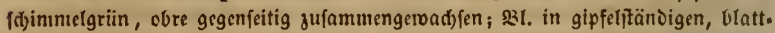

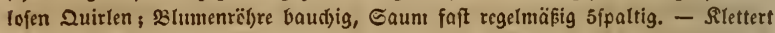

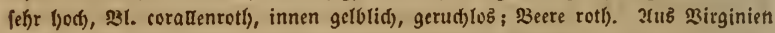

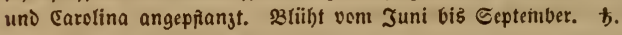

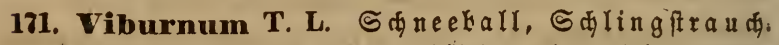

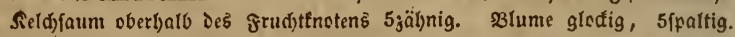
(Unfrudtbare Ṡlume raDfërmig.) 5 Staubgefäfe. 3 Yrarben olsne Griffel. 1 Eteinfrüd)tđjen bcerenartig, 1 faanig. - 23 lätter gegenüber.

581. V. Opulus L. Scrк. t. 81. St. 27. Gurmp. t. 32. 3lätter

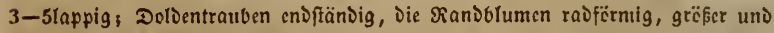
unfrud)tbar. - *b. globosum: alle slumen fo wie in wilden Suftanie nur Dic Ranoblumen, szlïtf)enitano tuglict). - Etraud) bis $8^{\prime}$ lyod), 23lütben weis,

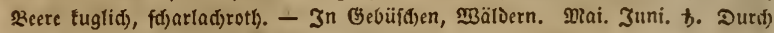
Das (Gebiet niđjt felten. Var. b. angepranjt.

582. V. Lantana L. Gưmp. t. 31. Bzlätter berłförmig, cirun১ läng= liø, fägeranDig, fternl)aarig, unten rungelig, filjig; Irugboloc mit Süublättchen. - Etraud mit jälsent $50 l_{3}, 4-8^{\prime}$ bod, 281 . weifs, grüd)te eifïrmig gufan.

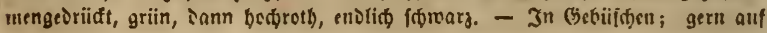




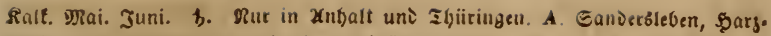
gerode. PS. Raumburg. Finnberg bei Grof̈monnra. Gutenberg, Ëperf́täbt in Şagen, Mlartrüliķ. HS. Eifenberg, Jena.

\section{Familie mubiaceae, Rubiaccen.}

- Şerbarienbud) E. XLIX uni it. -

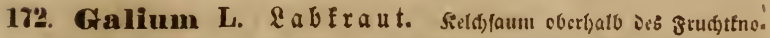
ten febr thein, 4jälsnig. Blunuen radfïrmig, 4ipaltig. C(blaut) 2tuglid),

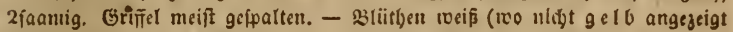
wiro). Blätter quirlfïtïnoig.

a. Aparine, Rleblräuter; einjäl)rig, etıas faftig, leid)t jerbredlid!.

583. G. saccharatum ALL. (Valantia Aparine L.) ScrK. 345.

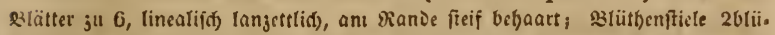

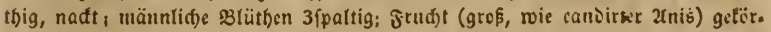
nelt. - Rieberliegent, etwa bis $7^{\prime \prime}$ lang. 2tuf Eetreiscfelicrn. Juli. 2uguft.

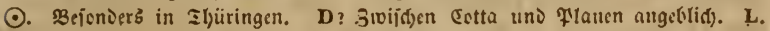
Dëlgig. Richter. Petermann. A. Bernburg. Schwabe, PS. Mierfeburg. Rich-

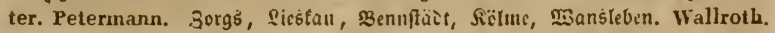
Sprengel. HS. Jena. Zenker. Buddensieg. SRS. Sdyroarjourg felten. Schönheit.

584. G. tricorne With. Varl. part. IV. f. 3, a. Fl. gern. exsicc. 321. 3lätter neift ju 8, riiđwärts feinftad)liđ); \$(iit)enfitiele 3blütljig;

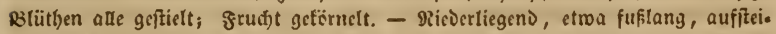

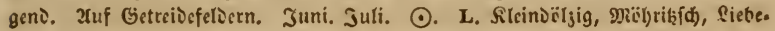
nau. Rchb. Richter. Petermann. A. Deffau. Scliwabe, PS. ßelgig. Ra-

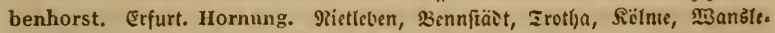
ben. Wallroth. Diffiüot bei Gul)l. Metsch. HS. Roburg. Hornung. Jena.

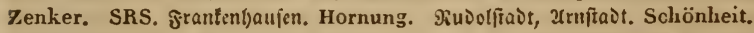

585. G. A parine L. silätter zu $6-8$, lineal lanjettlid), einnervig; gian১ un১ Ricl, fo mic Dic 4 Sianten am Etengel rïufiörtb ftadyclig; finoten jottig. Silettert $2-4^{\prime}$ (yod) und bängt fid) tlettenartig an: SIcbfraut. -

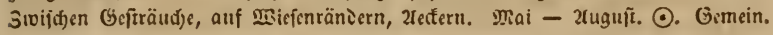

586. G. spurium L. (infestum) W.K. t.202. s3lätter tueift 6, linea.

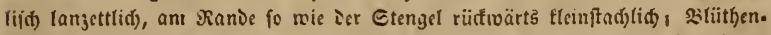
fitele äjtig, ausgefpreizt; Frü(f)te nierenförmig, glatt (talyl cier fteif bebaart). Epannen. biz fußf(jod), liegeno oder Eletternd. - 2luf 2ledern, namentlid) auf

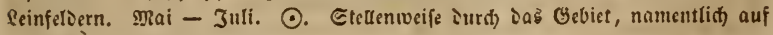
scinfelièn faft Durdigängig.

587. G. anglicunn Huds. Engl. Bot. 384. F1. germ. exsicc. 428. ßlätter meiff ju 6, linealifd) lanjettliđ), feingc(pikst, verwörts geftielt, turj, Eten.

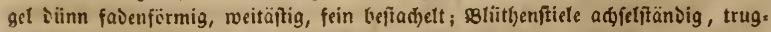

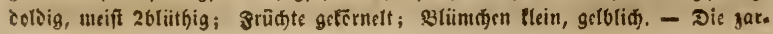


tefte 2urt. - Xuf Xeđern. 3uni - 2uguft. ○. Şauptiädliđ) in Ifiiringen.

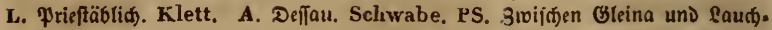
fäbt. ¿eutjąenthal unذ sppt)aufen. Wallroth. Sennftäbt. L. Rchb. fil. HS. Traßsorf unweit Elgersburg. Schönheit. SRS. Ibälendorf; Däuftäot, Gingen, ఆrod̆เvis, G̈̈ifelberg. Schönheit.

b. Galiuun, perennirend.

aa. Cruciata: Blätterquirl 46 lättrig.

aаa. Bliitben ađjelftänbig, polngamijiđ).

588. G. Cruciata Scop. ST. 7. SBtätter gu vier; 28 tïtl)enftiele ard.

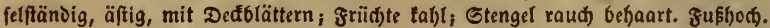

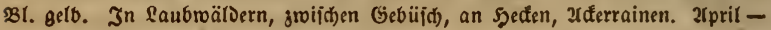
Juni. 4. Dutch das Gebiet neeifi bäupig.

bbb. Blüthen guvitterliđ, ađjfelifänoig.

589. G. palustre L. Fl. dan. 423. Fl. germ, exsicc. 1324. \&lätter

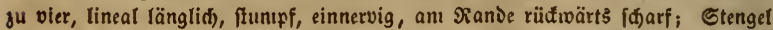
viertantig; Blüthenftiele weitläufig rispig; grudtftiele red)trointelig abftebeno;

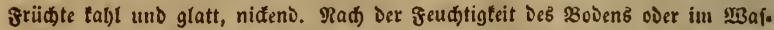
fer felbft $1-2^{\prime}$ bod), aud f(f)rinmmend. - 2uuf Sumpfiviefen, an Gräben,

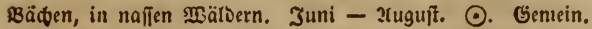

\section{ccc. Blüthen' groitterlid), enjeftänoig.}

590. G. rotundifolium L. Blätter zu vier, oval, orelnervig; Eten.

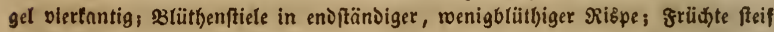
voritig. - Gdjlanl, auffeteigeno, etwa $\mathbf{1}^{\prime}$ hod. - In moofigen, nid)t algutrod. nen Ravels uno \$udenwäloern. Juni. 3uti. 4. Stedenteeife Durds das Ģe.

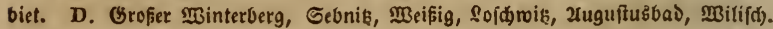

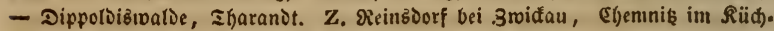

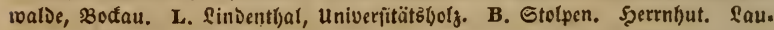

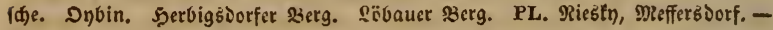
Rremliţ̧er und Siod)auce Speide. A. Shatzgerode, Gernrode. PS. Wittenberg: binter Räpnit, in Edjlej(hen forfte. Brandşheibe beim Eatiteid) bei Betgig.

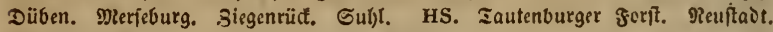

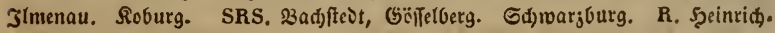
fein bel Sobenftein.

591. G. boreale L. Fl. dan. 1024. Fl. germ, exsicc, n. 429. 83lätter zu vier, lanjettlin, Drcinervig; Stengel fteif, aufredt, viertantig; Blii.

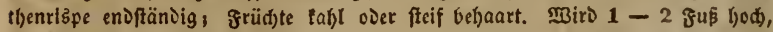

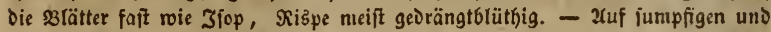

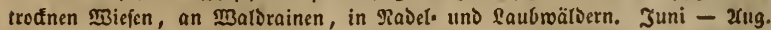
4. Etellenteife, namentlid) in ebenen Giegenden. D. Gr. Get)äge. Sjetler, Exer.

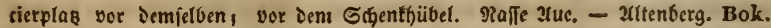

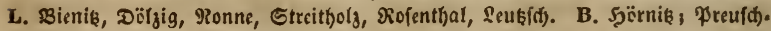

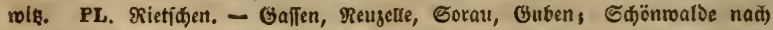

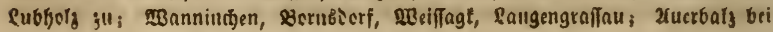


Müftermart. A. Dellau. PS. Barby. WBittenberg. Eolgon boi Relglg. Erfurt.

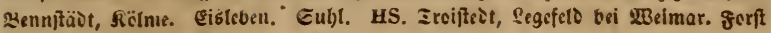
bei 3ena. Eifenberg. Roburg. SRS. \&rantenbaujen.

\section{bb. Diollugoartige. Blätter ju $5-8$ quirlftänsig.}

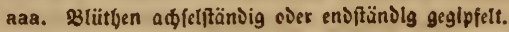

592. G. uliginosum L. Fl. daz. 15()9. Fl. germ. exsico. 1325.

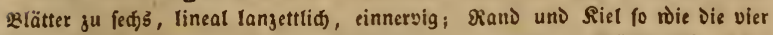

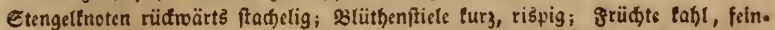

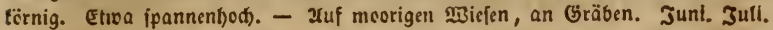
4. शiđt allgemein verbreitet. D. शafte 2ue. Mlorişburg, Şeller, Laufa. -

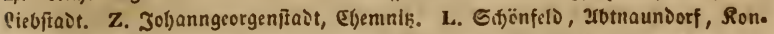

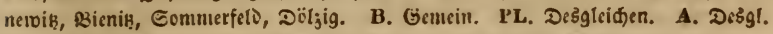

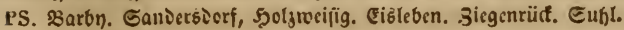

593. G. saxatile L. Fl. dan. 1633. ßlätter ju fe(ో) в, cinnervlg, fta. delipisig, untere verfebrt ciruns, ebere verfebtet eilanjettlid); Gtengel viertantig,

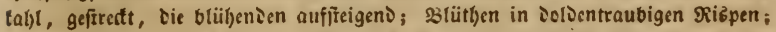
Grüd)te gefërnelt. Bon ${ }^{1} \int_{2}$ bis über $\mathbf{I}^{\prime}$ bod), nad) unten bizmeilen fein bebaart.

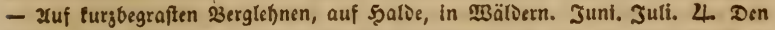
(ëhern Gegenien eigen, aud) in Şeiden auftretend. D. Friešniktbal. Marterb. bađ, Reimberg. - DippoldisibalDe, Grïllenburg, Ilyaranit. Gottleube, 3ten. berg, 3innıalo, Gcorgenfelo, Bärenftein. Z. Iederbäufer, \$iejenthal, Johann. georgenftait, Reuborf, Gdjneeberg, Stein, Goja. L. Rleinct Eteinbrub im

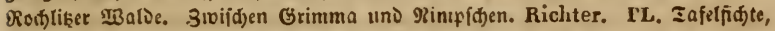

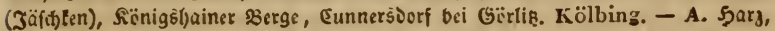

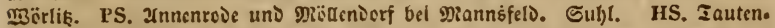
burger forit. Zenker. SRS. Sđjwarjburg. R. Sobenjtein im frantenwalt.

594. G. sylvestre Pouricr. Fl. gern. exsicc. n. 430. Blätter

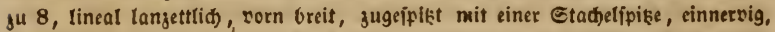
Die unteren vertefort cilanjettlid), Stengel nieverliegent ober auffeigens, vieredig ;

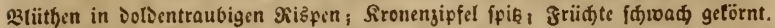

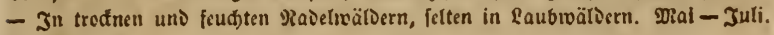
4. Gentein.

595. G. sylvaticum L. ßlätter ;u å̆t, längling ftumpf, mit ciner Etad)

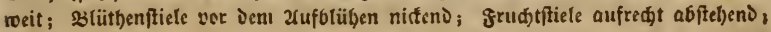

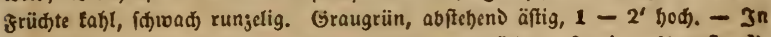
faubrö̈tsern, aud in feudten Raveliväldern, an Bädcn. Juni - 2uguft. 4. Ridit felten.

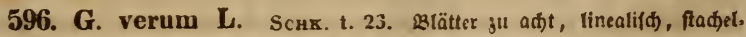

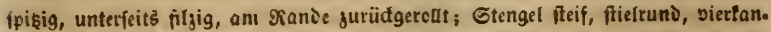

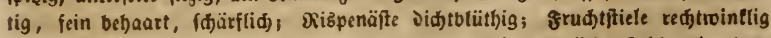
abftebend, Srenengipfel ftumpf, nit gang turger Spike; früd)te tabt und platt.

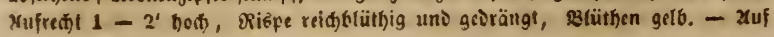




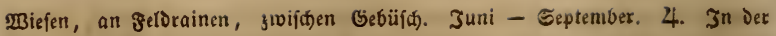
Dbestaufing felbr jelten, fonit ljäufig.

597. G. Mollugo L. Fl. dan. 455. B(ätter zu 8, (anjettric), naç

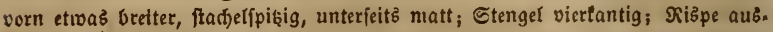

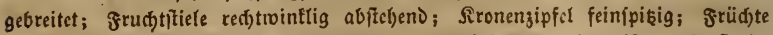

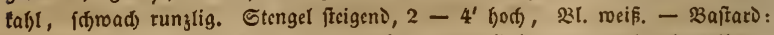
G. vero Mollugo ScHrede, yom Şabitu弓 gegentwärtiger 2rt, $\mathfrak{B l}$. ođjergetb. -

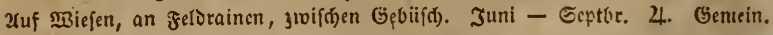

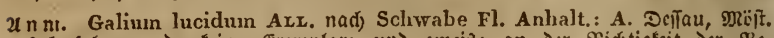

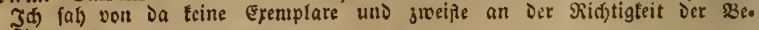
itimnung.

173. Asperula $L$. $\mathfrak{W} \mathfrak{a}$ İ $m$ e ifter, Reldfaum oberbalo des Frudftenotens tlein und 43äbrig. 33lunte trid)terförmig, 4ipaltig.

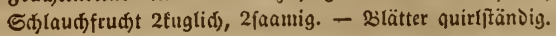

598. A. arrensis L. LOBEL ic. S01. Fl. gern. exsicc. 312.

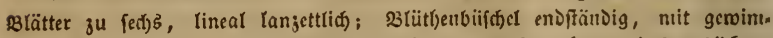

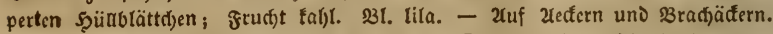

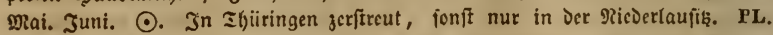
3ieffau bei \&uđfau. Rabenhorst. PS. Erfurt vor Dem alten Gteiger. Bern-

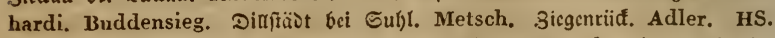
Jena bei Ziegenl)ain. Zenker. Soburg. Mieiningen. Rauch, (jrub bei Ibe。 mar. Metsch. SRS. Siudorftaot auf Den meift tyorfliegenden Jedetn. Schönheit.

599. A. cynanchica L. Fl. gerun. exsicc. Cent. XXI. n. 968.

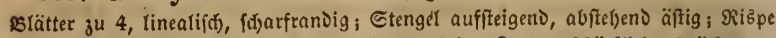

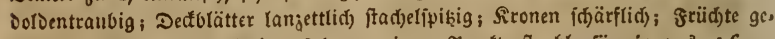
tërnelt. Siscle Etengst breiten fid) von eincm łuntte ftrablenfïrmig aus, $1 \int_{2}-$

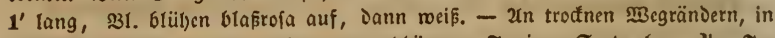

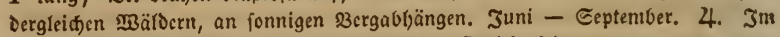
bübern Gebirge uno Der Docrlaufit felflend, fonft nidft ferten.

600. A. gatioides M. B. (Gal. glauc.) Jc2. I. 81. Fl. germ.

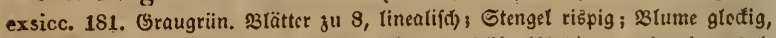

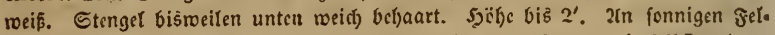

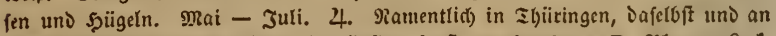
nef)rern Cteten um Dresden fé)r l)äufig, fonft nur fparfam. D. Plauen, sod.

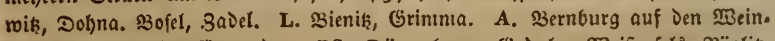

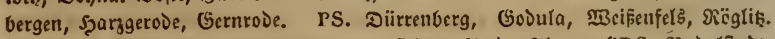

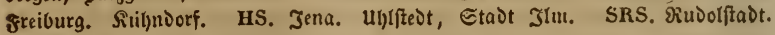
2tenftait.

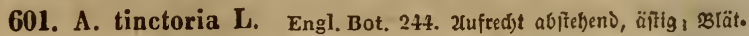

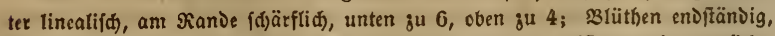
oolbentraubig, mit räbrigen Deftblättern; Blume glatt, meift 3\{paltig; grüळte glatt. - Ueber fufhod), B1. weiß. - Xuf trodenen, bewaldeten Şügeln. Juni.

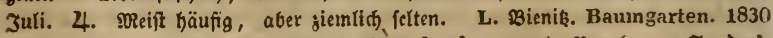
Richter. Petermann. PL. Eententorf. Rabenhorst. A. Bernburg, Sanderbs, 
leben, Syarjgerode, Bađlenftäst. Schwabe. PS. Barón: Bufd) bei Breitentbagen

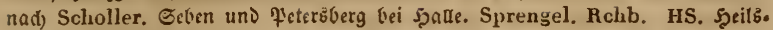

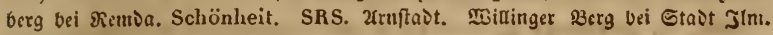
Schönheit.

602. A. odorata L. Schk, t. 23. Fl. dan, 562. S3lätter z"l 6 uns

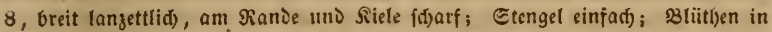
gefticlten DolDentrauben; friid)te nit batigen Sorften beickt. - Epannen. bis

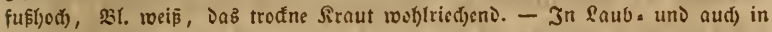
Radelwäldern, jwijden Gebüf(d). Mai. Juni. 4. Stellenmeife. D. Sriferšs

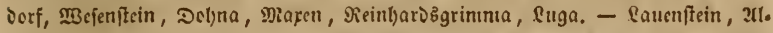
tenberg, Ibaranit, Rabenau. Z. Şartenftein, Jobanngeorgenfait, Breitenbrunn,

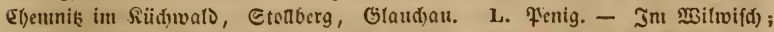

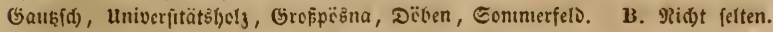

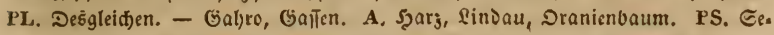
ben, Petcrbberg, Єubl. HS. Zautenburger Forft. Jlmenau. SRS. Rubolftadt.

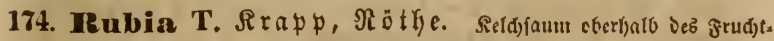

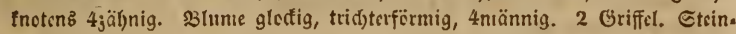

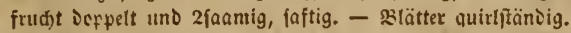

- 603. R. tinctorum L. Scrk. t. 23. St. 3. Haxie Arzngw.

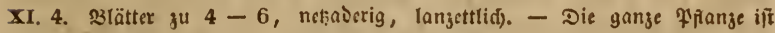

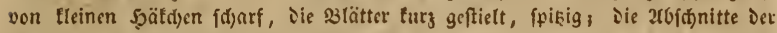
Blumentrone etwaz fdrwiclig. Etengel $2-3^{\prime}$ bod, slunte gelb, Stcinfrudt

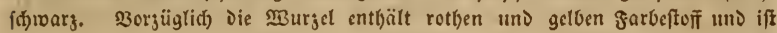
febr fd)arf. OFf. Radix Rubiae tinctorun. - Xuf 3edfern gebaut. Juti. 2(uguft. 4. शlantentlid) in Elyüringen.

175. Sherardia L. ভherarbie. Seldyaum oberbalb ocs

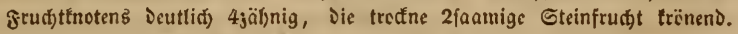
Blune tridfterförnig 4fpaltig, 4 männig. Griffel ctwas gefpaltig.

604. S. arvensis L. Scнк. t. 22. Fl. dan, 439. Sirautartig auf*

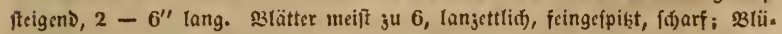

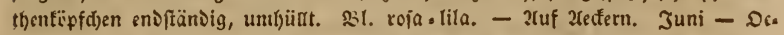
tober. ○. 2ieift gemein; im sacugebirge und um šeljig (PS.) felten.

\title{
Familie Synanthereae, Berwadjenbeutelige.
}

\author{
- 5̧erbarienbud) 5. XLIX uno 79. -
}

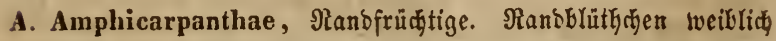

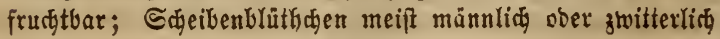
un Frurgtbar.

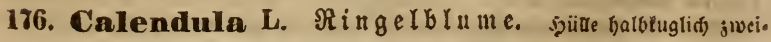
reib̧ig, greidgbättrig. Sriffeläfts naç oben seriümut unt fein befafert, in 


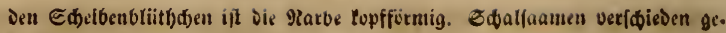
ftaltet, getrümnit, fpikböđerig ober gezälynt.

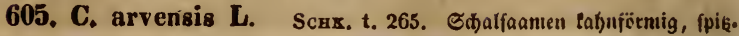
bëđerig, eingetrünınt, ole äusern fămmal, langettliđ) pfrientliđ), Die Blätter ellan. jettlith, gezäl)nelt. S3lütben belgelb. Stengel auffeigens. Şöbe bis $8^{\prime \prime}$. 2uf

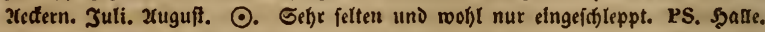

* 606. C. officinalis L. Shaljaamen eingetrümnt ftad)litg; die äu.

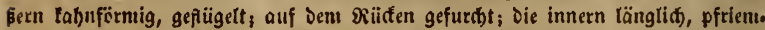

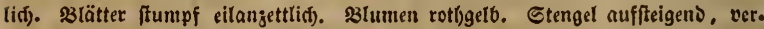

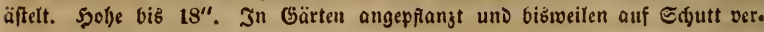
wilbert. Juli, 2ruguft. $\odot$.

177. Madia Momina. Ml a bie. Şülde faft tuglid), lteilgig, Sduup. pen ziemlidy gleid)lang, $10-12$, fo viele als to eibl $i$ dje Etrablolüthd)en,

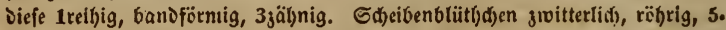

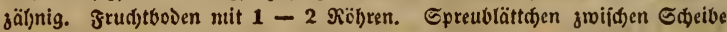

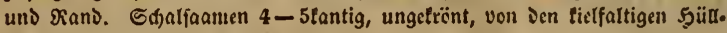
f(f) uppen umgeben.

- 607. M. sativa Mor. (inellosa.) Jç̨, h. Schönbr.oHI. t. 302. Etcngel $2-4^{\prime}$ bođ. Blätter lineal (anjettlid), unterfte gegenüber, ïbrige roed). felns, balb umfaffens, ganjrandig, fo mie Die gange Pranze orüfig uns tlebrig.

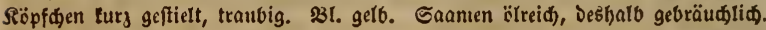

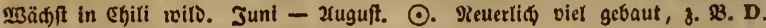
um Drešen.

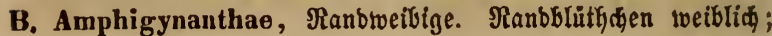

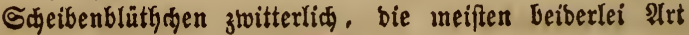 frumbtbar.}

ж. Anthemideae: Briffeläfte abgeftukt, teine Shaartrone.

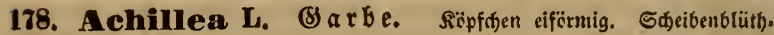

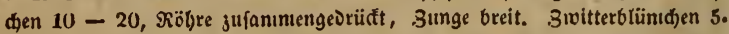

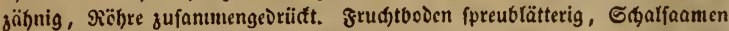

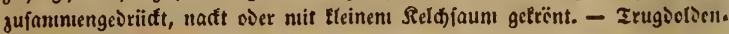
artige Doldentraube.

608. A. nobilis L. Morrs. sect. 6. t. 11. f. 4. Fl. germ. exsicc.

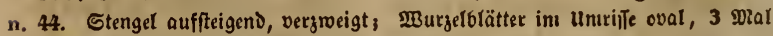
geficoert, Stengetblätter 2 Mal gefiedert, salptifđ), die Säppđ)en alle lineal, ge.

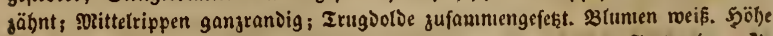
bib $1^{\prime}$. 2un bufbigen Sergabbängen. 2uf Mhauern. Juli - Septeniber. 4. Eelten. Rur in Ibüringen und 2infjalt. A. Sarzgerode. Schwabe. PS. Saalle:

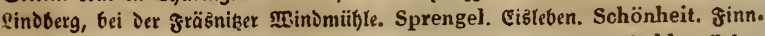
berg bei Grofmonura. Klett. ¿urturt. Rchb. Sangerbaufen. Rchb. Erfurt auf Mauern. Bernhardi. Buddensieg. HS. Eulja, Geier. Bintel bei 2a. feot. Zenker. SRS. grantenhaufen. Hornung. 
609. A. setacea IV. K. ST. 80 . 5jellgrün. Blätter Doppelt fiever. theilig, gieذerdifen borftenfïrmig fo geftent, Daß Der Untis bes Blattez (wie ein

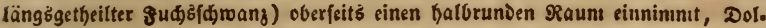
Dentroube Dints. 231. reeif. Saum fpannenlyod). Sie iff, fobalo man einmal

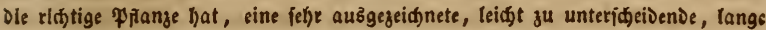

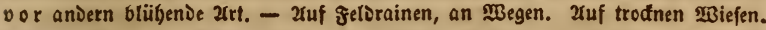

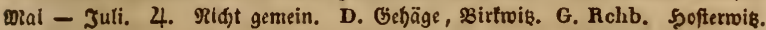

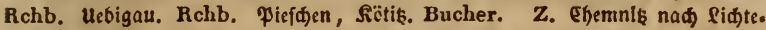
roalbe zu. Bok. (jekt nod)?). B. Strombery; (Suttaet Steinbrud. Kälbing. A. Bernburg; Sandersteben auf Dem Stiefiberge. Şary. Schwabe. PS. Baron auf Dent Diühlinger Berge. Scholler. Eižteben auf demt Şutberg. Bok.

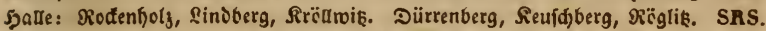
Riffäufer. Schönheit. Rattenberg, Rattberg, żhalteben bei grantenbaufen. Hornung.

610. A. Millefolium L. ST. I. 10. Harnx Arzneigew. DX. 45.

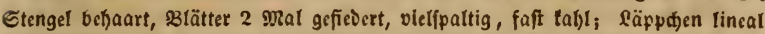

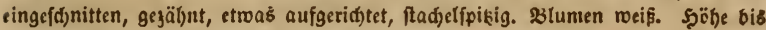
18". 2roänderung pfirfidjolüth. Bliithenftano fdjon gegipfelt, wenn Die Sinožpen nod) tlein fino. (2igl. lanata.) Xuf Miefen, an Diainen. Juni - Xuguft. 4. Gemein.

611. A. magna L. Rосн Bann. f. 68. Bä̈tter dreifad) gefiedert, tury be.

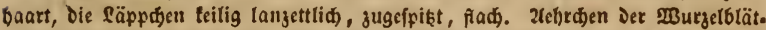

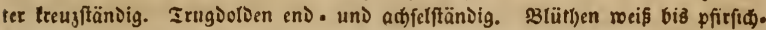

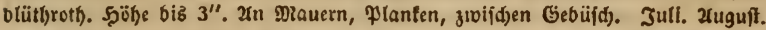

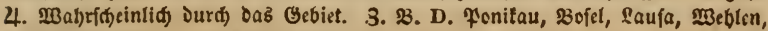
Sösnik̨: Strefłten. PS. Dürtenberg.

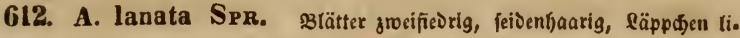

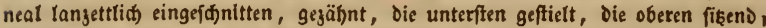
in Untrelife zugefpist lanjettlid). TrugDorde Diđ)t (bis turj vor Dem 2ufflü)en

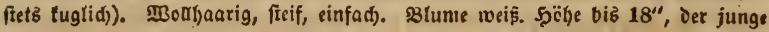

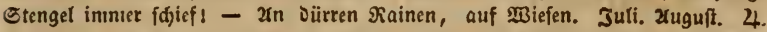

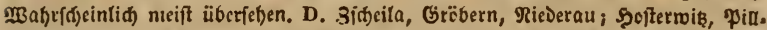

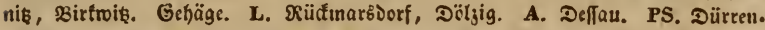

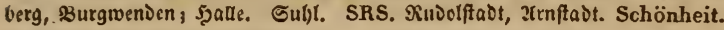

613. A. Ptarmica L. Sr. 1. 10. Blätter linealifđ, fđatf gefägt, taht,

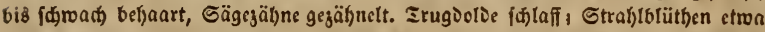

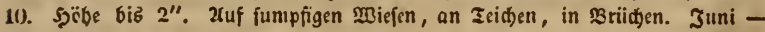
Septentber. 4. Gemein.

179. Anthemis L. Ramille. Randotïmbengungen geftredt.

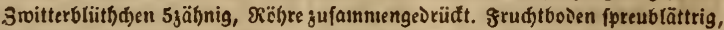
gevölot. Edalfaante nađ̆t ober fur; getrënt. - Blätter einfadj jufant. nicngefest.

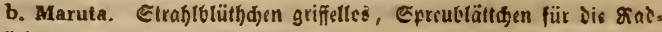
slütbden feblen. 
614. A. Cotula L. süütjenboien tigelfïrmig, uut linealija) borfitlitgen

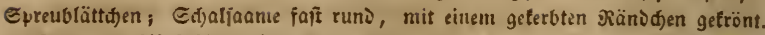

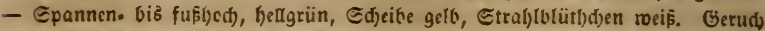
wiorig. - Hb. et Fl. Chanomillae foetidae s. Chamaemoli canini. - In

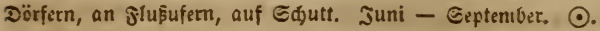

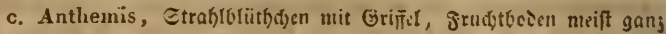
fpreublättrig.

615. A. austriaca JACQ. JAcQ. austr. V. t. 444. Bgätter icppelt

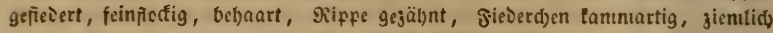
gleiú), ganj uno ftad)elipişig, Frudtboven fajt bafbtuglid), Epreublätter läng.

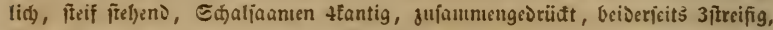

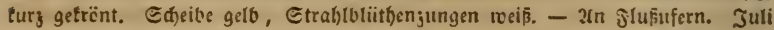

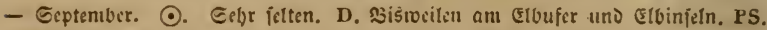
sittenberg. Nitzsche.

616. A. arvensis L. Schк. t. 254. Harss Arzngw. 1. 5. Blii.

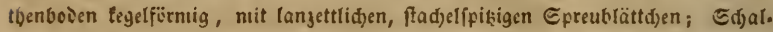
faumen fłuntpf vieredig, Die äusern nit einem toulftigen, Die innern uif cinenı (í)arfen Rröndfen. Ricierliegeno cier aufitzigeno, iuutelgrün, Gtengel fpannen. lang. Gdeibe gelt. Sungen reif. - A. agrestis Wall. feiner gefievert,

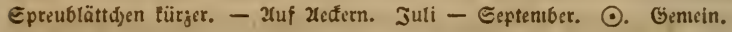

* 617. A. nobilis L. Hayxr Arzngew. X. t. 47. Etengel äjtig,

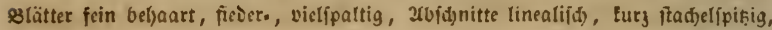

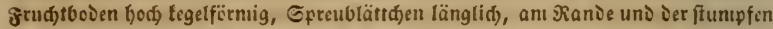

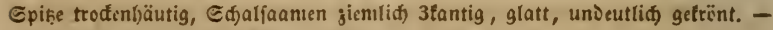
Xngebaut : "römifde $\Re$ a mille". Juni. Juti. $\odot$.

618. A. tinctoria L. Fl, dan. 741 . Eteif, aufredt, äftig. B(iitben. boden fait balofugelig, mit Ianjettlid)en, ftadbelfpişigen Spreublättd)en; SRiife sierfantig jufammengcirüđt, fđarf getrënt. $-1-3^{\prime}$ hod), 3meige aufred)t

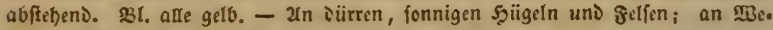

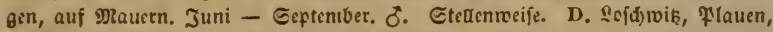

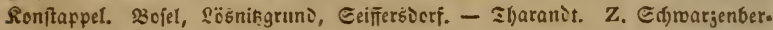

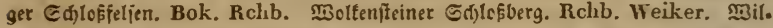

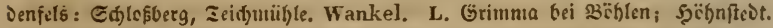

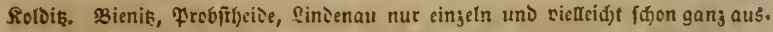

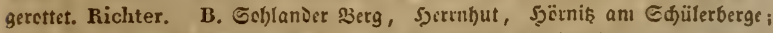
Dubraute. PL. Epremberg, Guben. A. Saarjgcrode, Ganderblıben. PS. 2arby.

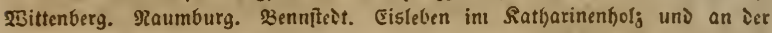
Şünenburg, Jer Ginne. Erfurt. Cubl. HS. Eifenberg. SRS. 2ruffadt u. f. w.

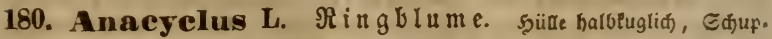

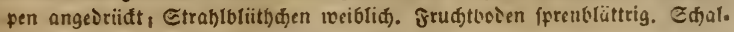
faamen platt, flïgeltantig, 2 jäbnig, ungetrënt.

* 619. A. officinarum L. Hayse Arzngw. IX. t. 40. 2ufred)t

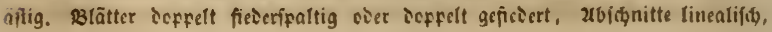




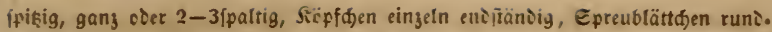

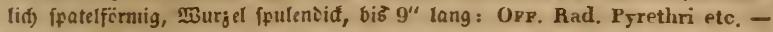

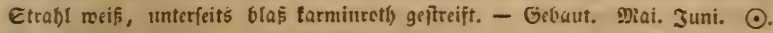
Fantentlid in इbüringen und im şcigtlanie.

181. Chrysanthemum L. $\mathfrak{W} u$ iter $b$ lume. syille balb.

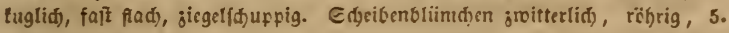

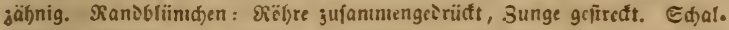
faame ungefrënt.

a. Leucanthemun T. Friefterfraufe. Exhalfaante gleidförmig runi.

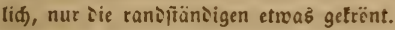

620. C. Leucanthemum L. Schx. t. 253. Sr. I. 2. Sį̈fden einjeln am Enie ies Gtengets cier Ier joseige; untere \&lätter lang giffielt, ver. tebrt ciffatelformig, cbere lineal längliđ, gefägt cder eingefdnitten: $\beta$. incisum.

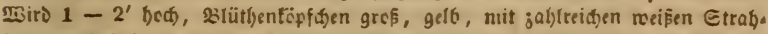

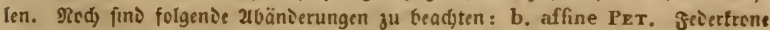

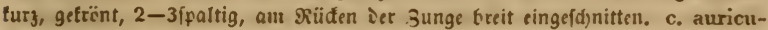

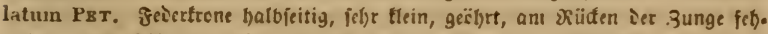

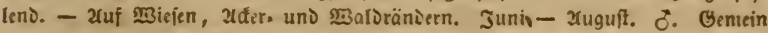
(nur in ien b̈̈đjiten Gegenien feltner). b. 3tuf grafigen rbblyängen. L. Sin.

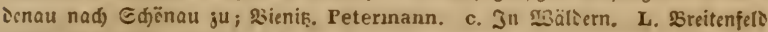
finter finienthal. Petermann.

b. Chrysanthemum. Eigentliđe æuđerblume; raniptäniiger Eđal.

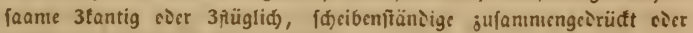
runilid, innerfsits jđđntal gệügelt.

621. C. segetum, L. §ëpfó)en eingetn auf ier Epike Der Uefte; Blätter lineal lanjettlid), cingeid)nitten gejälsnt, sorn breiter, am Grunde umfaffent,

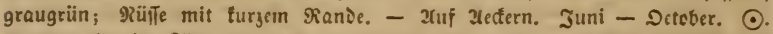

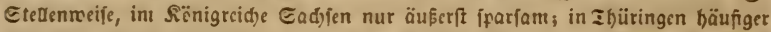

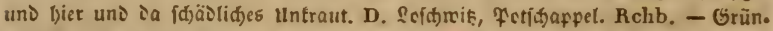
bainid)en bei 2ruguftusburg. Stange. L. ¥anik̨id. L. Rchb. fil. PL. Smifd)en

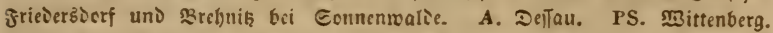

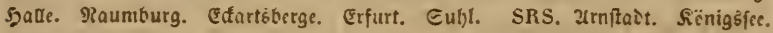

622. C. coronarium $L$. Scrx. $t .253$ (₹rudt). stätter Joppelt

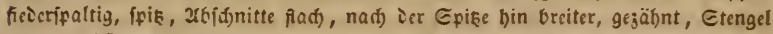

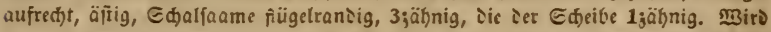

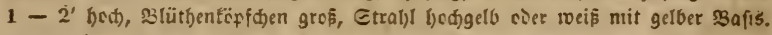
- 2us ieni fïbliden Eurepa f̂amnieno, in G̈̈rten, son ১a sertvilierno auf Maurern, an Megen. Juni - Detcber. $\odot$.

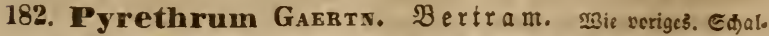
faamen tantig, mit bäutiger, aud mobl gejäbnter Rrone. - Edeibe gitb, Etrabicn recis.

623. P. Parthenium Su. Harss Arzngw. VI, t. 20. 23litthen 
Synanthereae. $\quad-142-\quad$ Pyrethrum.

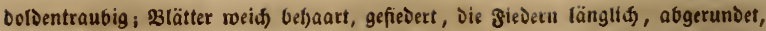

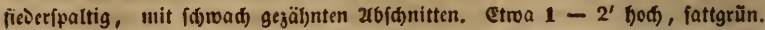
Etarf ried)end: OFr. Hb. et Fl. (summitates) Pyr. Parthenii Matricariae s.

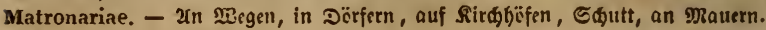
כuti. 2uguft. ठ઼. Gicuncit.

624. P. corymbosum L. Jç. austr. 379. Scr.x. t. 253. siütben Doldentraubig; 3lätter gefiedert, Die fièern Der untern fiederfpaltig, ntit fpiß̨er gejägten 2 b (d)nitten; äusere Saamentronen bed)erförmig, gejät)nt. - 2n trod.

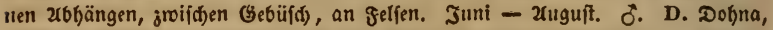

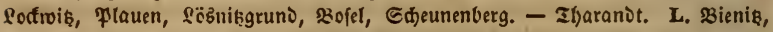

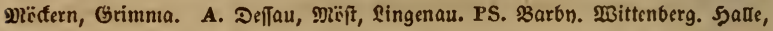

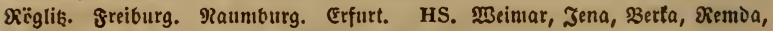
Eifenberg. Grub bei इbcmar. SRS. Urnftadt.

625. P. inodorum L. Scrx, t. 253. Harsz Arzngw, 1. 4. 3lät. ter 2-3fad fiederfpaltig, nit linealifd) fadenförnigen 26jđnitten; Edalfaamen mit bäutiger, tellerförmiger firone; Slititbenboden balbtuglid, narbig. $-\mathfrak{B c m}$

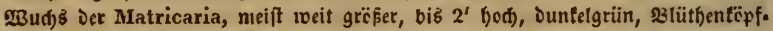

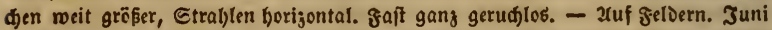
- 2uguft. ○. Durd ১aš Gebict meift bäufig. - $\beta$. salinun Warcr. bid. blättrig, an Galinen.

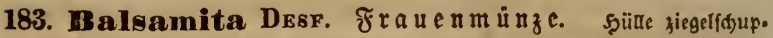

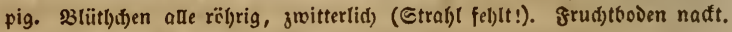
Ed)aljaame nit turger Eaautenfrone.

- 626. B. major Desf. Schк. t. 240. Hayar Arzneigw. II. t. 5. Sirnutartig, unten trie(t)ent, wurgelno, 2 - 4' hod), szlätter ferbjäl)nig, untere

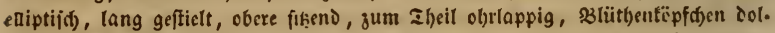
Dentraubig. Salfaniíf ftarl ried)end. OFr. Hb. s. fol. et Summit. Tanaceti gentilis s. Balsamitae inaris etc. - In Gärten angeppanjt. Geptem. ber. Dstober. $\odot$.

184. IIatricaria L. Selmer (f) $\mathrm{n}$. Şïlle balbtuglid), fumpf

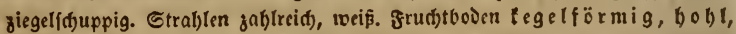
na đf. Sdjalfaamen ungefrönt.

627. M. Chamomilla L. Schr. t. 253. b. Hayse Arzngw, 1. 3. 33lätter Doppelt gefieders, nit lineal fadenförmigen abid)nitten. Gerwäbnlid) $1^{\prime}$ bod), aufred)t. Geitenftengel auffeigend; Sraut bellgriin, ftart ried)end. Orf. Hb. et flores Chanomillae vulgaris. - 2fuf Xefern, an \$Begen. Juli Drfober. O. Durdf Das Gebiet meift gentein, in menigen Gegenden feflend.

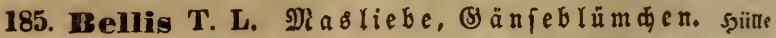
balbfuglid), viclfduppig, cinfadj. Etrablentlütben jablteid). frudjtbeden tegelförmig, nadt. S(j)aliaamen nadt.

628. B. perennis L. झुurgel frieđ)ens; 3lätter fpatelförmig, gelerb́t; Sgïllblätthen ftumipf. Bliitbentipfdyen auf $2-6^{\prime \prime}$ bebem Sdjaft, Stralylen melis, meift tarminroth angelaufen. In Gärten monjtrös gefiiat, weís, rofa coer 


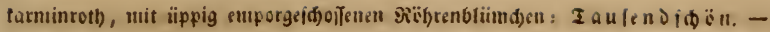
zuf NBiefen, an X̉egen. Jamuar - December. 4. Gemein.

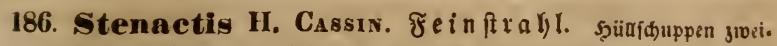
reibig. Weiblide Straflblumen felbr fein jungenförmig, zroeireibig. Edjalfaamen zufamntengebrüdt, Saantentrene haarig, mefreigig.

629. S. annua H. CAss. Fl. dan, 4S6. Fl. germ, exsicc. 1331. Eteif, DolDentraubig, bel)aart. Untre Blä̈tter eirund fpatelförmig, gefägt, sbere

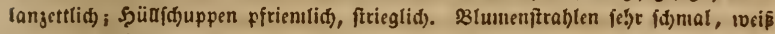

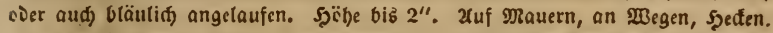

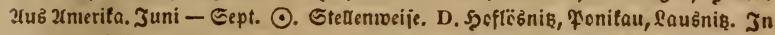
Der 3tntonftast. Zuf Den Mauern Dę swingers. Ronftappet, Rlipfl)aufen. -

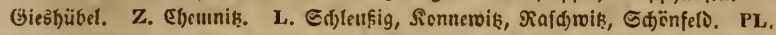

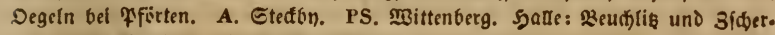
ben. HS. Eifenberg. SRS. Rilidolftait.

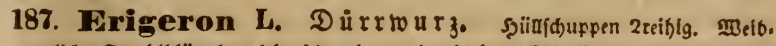
lide Etraflblümdjen felfr fdjmal groeireibig. Eddalfaanten zufantnenge.

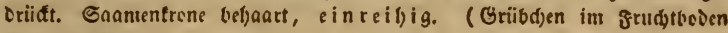
taum Deutlidy.)

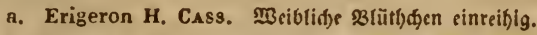

630. E. canadensis L. Fl. dan. 1274. Sđjnurgeraic. æiispe viel.

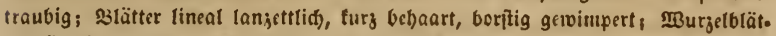

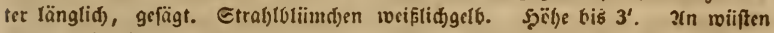

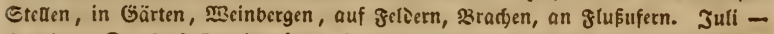

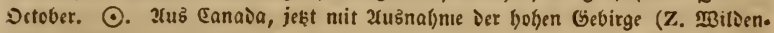
fels ant Muldenberg beint 2unguftweg mur fefr fparfam.) überall gemein uno fehr gefollig, oft eine mafre qlage.

b. Trimorphaea H. CAss. Weiblithe 2 lïthden 2reibig, innre röh. rig, äußre ftrablig.

631. E. acris L. Scri. F. 241. Fl. gernn. exsicc. 586. Sï̈pfolen traubig oDer Doldentraubig; Blätter lineal lanjettlid, rauh befaart, $2 B$ urgelblät.

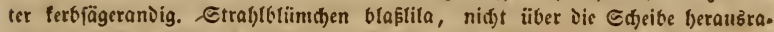
gend, gederfrone meiffid. Syäbe viß $1^{\prime}$. - b. serotinus Wrrнs. Fl. gern.

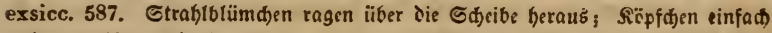
DolDentraubig. Feiertrone brauntoth, slätter klein, reellig gerandet. Şöhe bi६

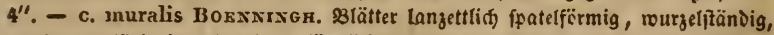

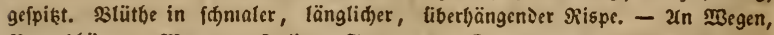
3ergabbängen, Mauern. Juti - September. $\odot$. Durd Das Gebiet nidjt fel. ten, meift gentein. Var. b. Zn trođ́nen 23ergabbängen. September - Novem. ber. Var. c. Xn fandigen Znbäben. Mai. Juni. L. Geitewił 1828. Richter.

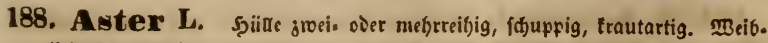

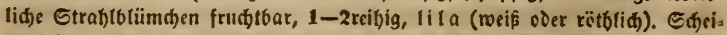
benblimthen ( $g$ elb) rïbrig, 5jäfnig, meift frudtbare stoitter. Bstiitbento. 


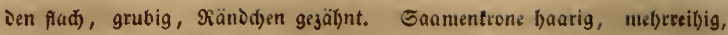
ungleidf).

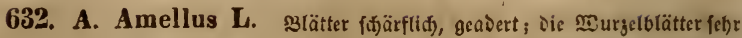
groj, eirund ipatelförntig, gefägt, Stengelolätter oval, lnmgettlid), fpiß, verloren

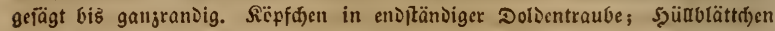

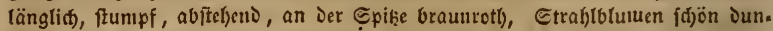

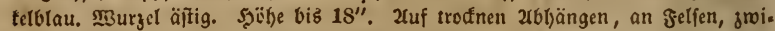

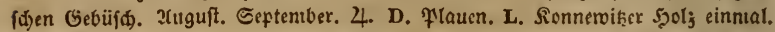
Schubert. PL. Saltenborn bei Guben. A. Şarggerode. PS. Sogelberg bei Bennfäbt, शaumburg, freiburg, Efartsberge, Burgivenden auf Der Finne u. f. w. HS. Jena. Eijenberg. Meiningen. Grub. SRS. Granfenlyaufen; 2rnftadt.

633. A. salignus W. ScHoux. Fl. barb. Suppl. slätter lanjett.

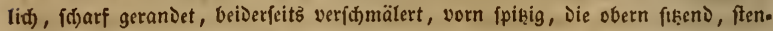

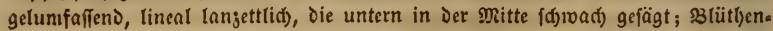

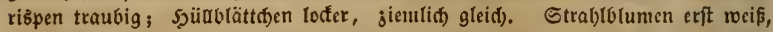

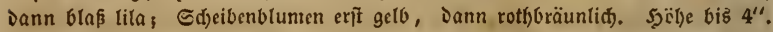

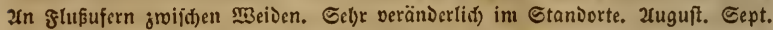

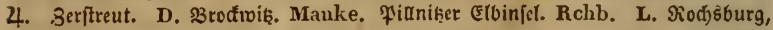

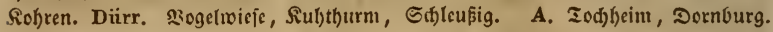

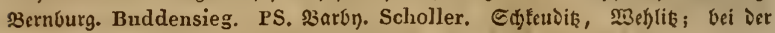
Strïuribįcr fäbre.

634. A. 'Tripolium L. El. dan. 615. Fl. gerim, exsicc, $\$ 32$. 3lätter lineal (anjettli(i), jientliđ) fieif(t)ig, 3nervig, am Rande verloren gefägt;

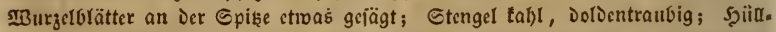

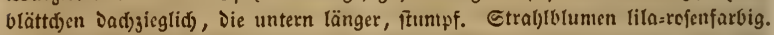
Szöl) bis 3'. Var. discoidemn, obne Strablbliití)(f)en. Fl. germ. exsicc. 833. Zuf Miefen um Salgquelten. Juli - Eeptentber. 4. Meift in grofen Iruppen, nidft gentein. A. Seau. PS. 3arbn : ๔alja. Scholl. 巨taffurth. Hornung. 2uttern.

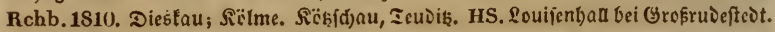
Buddensieg. Galjungen bei Meiningen. Rauch. SRS. Frantenbaujen. Hornung.

- 633. A. novi Belgii L. Blätter langettlin, ftengelumfâteno, zu=

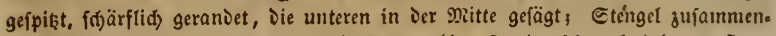
gefett bis vielfad) zufanmengefest, Doldentraubig; 3weige f(f)road) behaart, ftart,

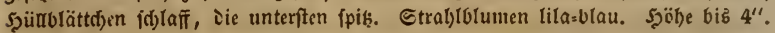

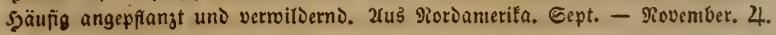

* 636. A. laevigatus W. slätter länglid) langettlid), ftengelunı.

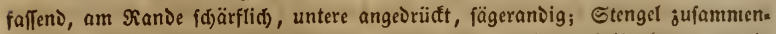

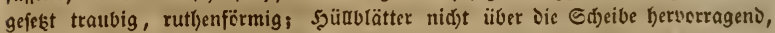

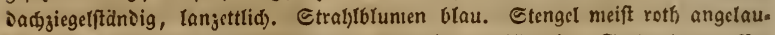
fen. Şäge bis 4". Şäufig angepfiangt und verwilderno. Eeptentber - 9io. vember. 4. 21ив storvamerifn.

637. A. mutablis AIT. 23lätter länglid̆ langettlid), jugefpiett,

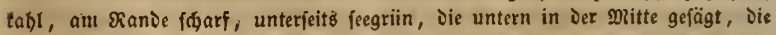
obern gangraniig, ftengelumfaffeno. Etengel tabl, von Der $\$ 3 a f 13$ an risptg jus 
Synanthereat. $\quad-145-\quad$ Aster.

fanmengejetst; Smeige abfelyento, Diøt Doltentraubig. Etrablblumen blau bis purpurfarbig; Sd)eibenblume gelb bis purpur. - 5̧äufig angepĩangt un১ ser. toildernd. Septentber - शrovember. 4.

* 638. A. bellidiflorus W. S3lätter tanjettlid), angèvrïăt, gefägt,

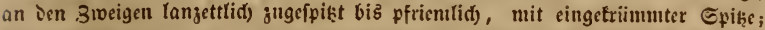
Stengel fteif traubig biz vielfad) zujammenge(est, , fdmmär)tig, nad) unten ganj tabl, weisffreifig bis purpurn angelaufen; Şüublättchen Dad)jicglid, lineal, fpib; oie unteren meift an Der Epilse gefärot. Etralstblumen weiflid), balo lila. Sÿ̈lye biß 5'. Zengepianjt uno leidst verwilderno. 2uguft - Detober. 4.

* 639. A. concinnus W. S3lätter lanzettliđi, ftengelunifafteno, ents

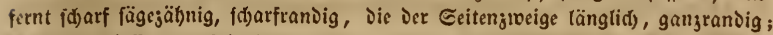
Gtengel fdylaff, etwas Doldentraubig; 3wecige rutlyenförnig, jweitlyeilig rispig; Şüablättd)en Did)t Dad)jiege(îtänsig. Etengel purpurn angelaufen; Strahıblume

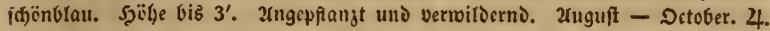

- 640. A. laevis L. Blätter lanacttlid, ftengefumfaleno, tabl, fdarf. randig, Die untern forwad) gefägt; Stenget traubig zufammengejest; Ceiten=

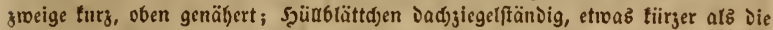

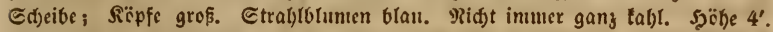
2ingeprangt und verwilbernd. 2uguft - Detóber. 4.

641. A. alpinus L. ST. X. 37. Fl. gerın. exsicc. 1657. 3lätter ganjrandig; $\mathfrak{B}_{3}$ urgetblätter lanzettlich) fpatelförmig; Etengetblättix lanjettlid); 5. Sünblättd)en fd)laff, lanjettlid); Etengel cintëpfig. Etrablblumen violetbrau.

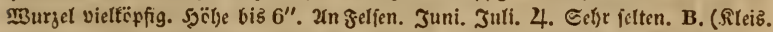

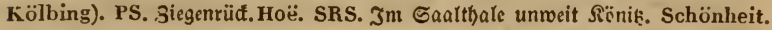

- 642. A. chinensis L. untre 23 lätter fpatelförnig, geftielt, mitts

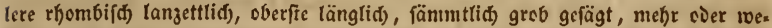
niger geminipert; Şüublättd)en blattartig, etroas fparrig, lang gemimpert; Etengel einföpfig. Strablblume weiß̄, blau, lita u. f. w. Şähe $8^{\prime \prime}-1^{\prime}$. şäufig angeppranjt, aud) verwilbernd. 2(uguft - Detober. 4."

189. Solidago L. (5) olb $\mathfrak{r}$ ut $\mathfrak{h}$ e. Mic Aster, Etrabtotümdten (gelb) gleidffarbig mit Den G(j)ibenblümđ)en.

643. S. Virga aurea L. Hayne Arzngw. VIII. t. 12. Etengel aufred)t, ftielruno, oben traubig coer rispentraubig; Irauben aufredst; Etengel. blätter bel)aart, eilanģettlid, in einen gefügeiten Etiel verfd)mälert, gefägt;

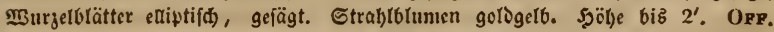
Herba Virgae aureae - b. alpestris W. K. Blätter lanjettlid) ediptifd,

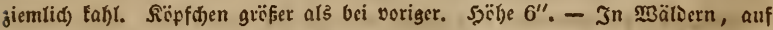

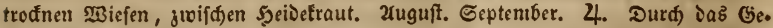
biet meiff gemein. Var. b. 2fuf Bergwiefen, an Belfen. D. In Der fädfififden

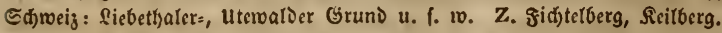

- 644. S. canadensis L. Puur. alın. t. 263. Etenget aufrectit, be:

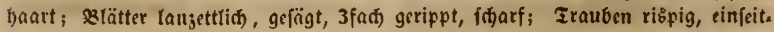




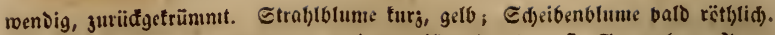
Şöbe bis 2'. Şäufig angepriangt un১ verwiloerns. 3uguft. September. 4.

- 645. S. arcuata TAUsch. Schx, t, 246. Stengel fteif; Blätter langettlid) jugefpikt, gefägt, 3fad) getippt, j(barf, unten ftriegelbaarig; כrauben enoitänoig, rispig, fdlaff, bogenfürnig umgebogen, an Der Spik̨e veroünnt;

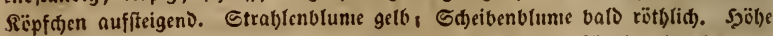

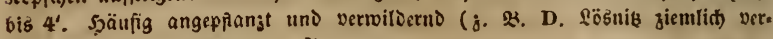
oreitet). Juguft. Siptember. 4.

190. Chrysocoma L. (5) ol $b$ ha a r. Siitle giegelfappig, balb.

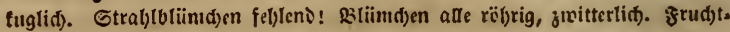

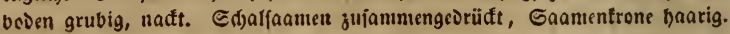

646. Ch. Linosyris L. Fl. germ. exsicc. 224. Stengel aufrect,

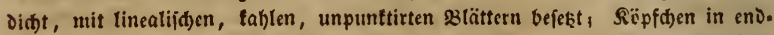
Föndiger Doldentraube; Şïafduppen fparrig abftel)ent. Stral)ls uno Edjeiben. blume gelb. - 3uf trof́nen abbängen. Juli - Eeptentber. 4. Jeblt im gan.

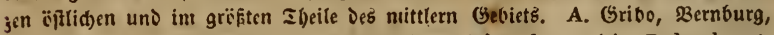
Sharjgerode. PS. Mittenterg am 2rpođonsberge. Nitzsche. Selgig. Rabenhorst.

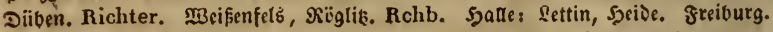
Scheidhauer. Naumburg an ¥fortaberge. Rchb. Beneken. Eđartšberge. Rodig. 23urgreenden am finnberge. Rchb. Fest. HS. Jena. Zenker. SRS. grantenkaufeut. Hornung. arnftadt. Schönheit.

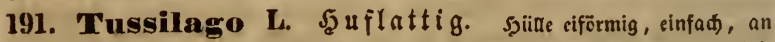

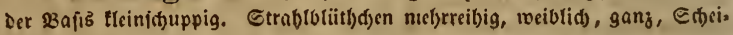

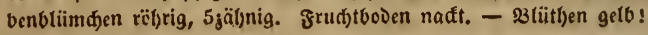

647. T. Farfara L. Harsi Arzngw, I1. t. 16. Edjaft einfïpig,

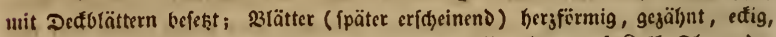
unterbalb reeid bebaart. Szïbe Des Sdjafts bis $6^{\prime \prime}$. Sern auf Salf, Ihon oder Päner, Dod) aud) auf Sandvoden: auf 2ectern, an Saltbrüd)en, an Bäden, flufufern. Märs. 2tpril. 4. Meift gemein, im Dbergebirge feltner. OfF. Rad. et Hb. T. Farfarae.

192. Tephroseris Rснв. If Sd)uppen zablreid), gang trautartig, gleidjlang. Strablen $15-20$ (over

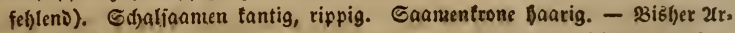

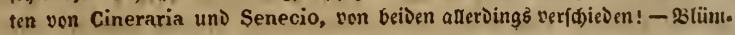
(j)en gelb oder orange. -

a. Heloseris: Sđalfaame ungleid) vielrippig. Saamentrone febr vielbaarig. Dolbentraube veräftelt.

648. T. palustris (L.) Scнк, t. 246. Fl. germ. exs. Cent. XXI. sebaart, Rëpfoben sotDentraubig; 23lätter lanjettlich, balbumfaffend, Die unteru budbtig gejähnt. Blïnțen bleid)getb; Etrahlen etra 20. Sgähe $18^{\prime \prime}-3^{\prime}$.

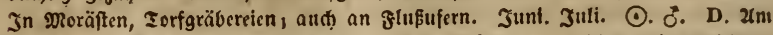

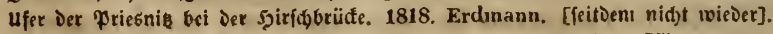

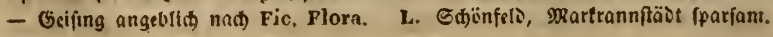




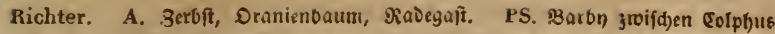
und Enprena. Scholler. MBittenberg: binter Thomäbreite an Der çlbe bištweilen,

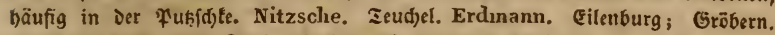

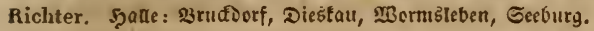

b. Tephroseris: Effaljaanen gleid)rippig, "Saamentrone minter vielbaarig, Doldentraube einfad).

649. T. spatulaefolia (GM.) Rсrв, pl, crit. 240. Fl, germ. exsicc. 219. \$lätter gezälsnt, bebaart, oben fpinnroebenfiodig, unten wollig bee

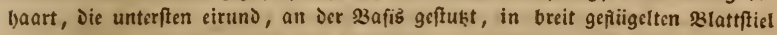

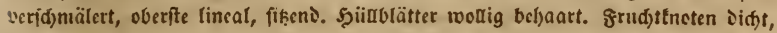

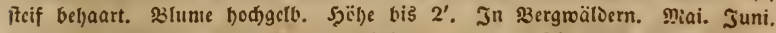
4. In Ifjüringen: PS. Finnberg bei Grefntonnra. Rchb. Ectartsberg. Rodig. Freiburg. Scheidhauer. Drlabcrg, sibra am Spikbutberg, Sdloß seidtingen.

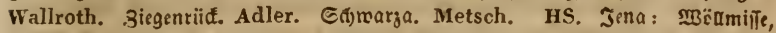

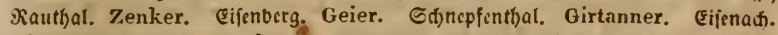
Dietrich. Gotobcrg bei Soburg. Hornung. Grub bei Ibenar. Metsch. SRS. ※udolftait. Scliönheit.

650. T. campestris (RETz.) Rchs, pl. crit, 251-55. Blätter flodig belsaart, \$urgelblätter länglid) cirund, Ctiel gepiigelt, oben längliđ) und

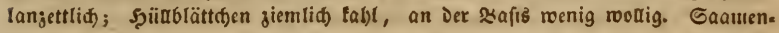

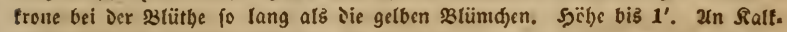

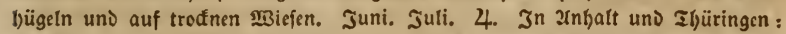
A. Sarjgerede, Bernburg. Schwabe. PS. Botteniorf, Bennftädt an Bogels.

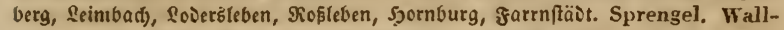
roth. SRS. S(gladjtberg uno Saltberg bei frantenljaujen. Klett. Hornmug. arnitait. Klett.

651. T. crispa (JAcQ.) Fl, austr. 2. t. 178. R̈̈̈fd)en in einfa. d)er Dolientranbe; s\&lätter tabl, gejäbnt, untere ljerzseiförmig, bic oberen nit

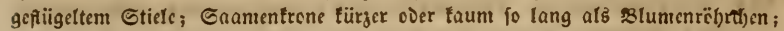

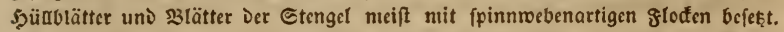
3lunien gelb. Şöbe bis 2'. Serfäut in folgende unterarten: a. genuina. Rснв. pl. crit, 214. Etiele Der Stengclolätter fełbr breit geriügelt, Diefe und die $\mathfrak{B l a ̈ t . ~}$ ter grob gęäl)nt, tratts. Dif, faftig. - b. rivularis (W. K.) RснB. pl. crit. 215. Şü\#blätter grün; Ctielc Der Stengelblätter gęäfnt bis gangrandig. - c. sudetica (Косн.) Rснв, pl, crit. 212. Şülulätter an Jer Epik̨e ojer gans rotl) angclaufen; Etiele Der Etengelblätter gejälynt bis ganjrandig. - d. Schkuhrii. Rснв. pl. crit. 216. Doloentraube renigblitithig; untre Blätter

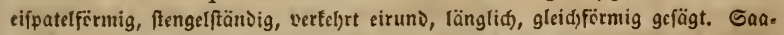
mentrone tïrzer als Blumenrs̄bre. - 2 ก quedigen Drten, in \$B̈̈lDern, auf Balowiefen, in Zerfgräbereicn. Ende Miai bis \uli. 4. Nur im Erzgebirge, in Der Dberlaufie uno Dom Ibiiringer $\mathbb{B}$ alde; uno jmar: Var. a. Cebr fer. ten. D. - In cincr Zorfgräbcrei in Jcr Gegeno von Frauenftein. G. Rchb. Papperitz. Var, b. D. - Deliengrund. Fr. Avgust K. v. S. 3innwalo. G. Rchb. Papperitz. Z. (unweit Eeiffen, fdon in ßäbmen. Leonhardt). B. "Im Gehirge". Rabenhorst. - Var. c. D. Dorf Sanoa. Diirr. Frick. Pap- 


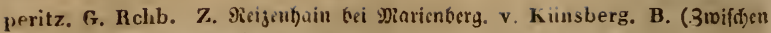

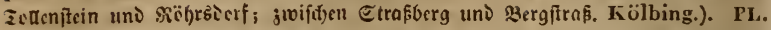

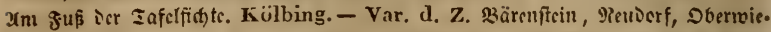
ienthal. Bok. Rodig. B. Şcrrutbut. Burkhardt. PS. Eulyl. Metsch. Buddensieg.

193. Arnica L. Wुolverley ( $25 \circ$ fluerleif) Sohan= nifblume, Fallf $\mathfrak{a}$ ut. Szülte fur cifïrmig, Gduppen 2rcibig,

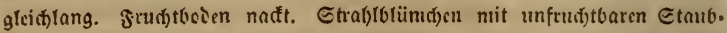

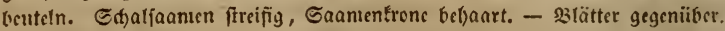
Rearben Der switterblüthd)en verdifft, ihre Epił̧e tegelförmig, fein vel)aart.

652. A. montana L. Schk. t. 24S. Havis Arzngw. vi. t. 47.

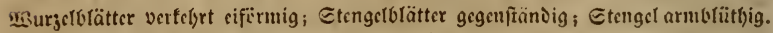

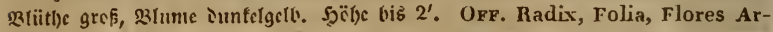

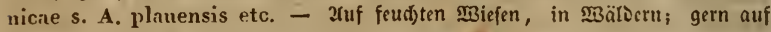
Mrocrboden. Juni - 2uguft. 4. Mantentlich in Şcide. und Gebirgsgegenden,

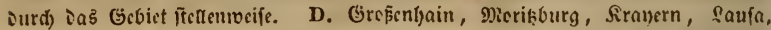

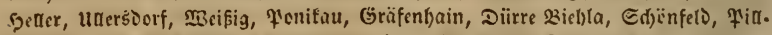

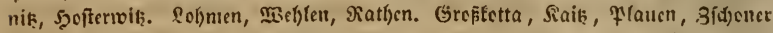

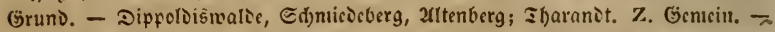

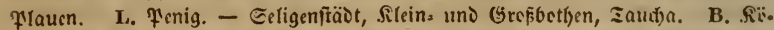

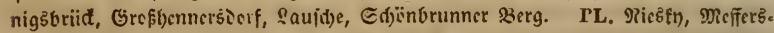

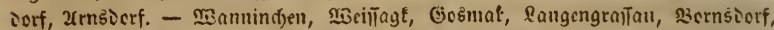

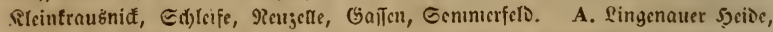

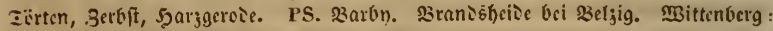

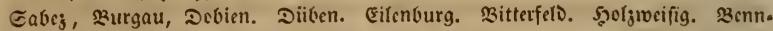

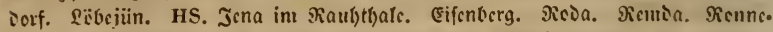

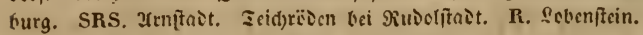

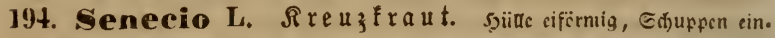

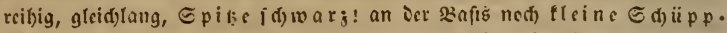

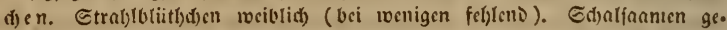

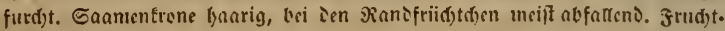
boicn nadt.

\section{a. Etrablen follien.}

653. S. vulgaris L. Fl, dan. 513. Harxb Arzneigew. Vill. 10.

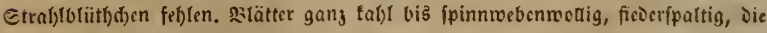

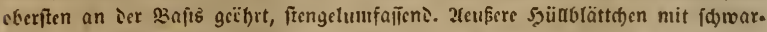

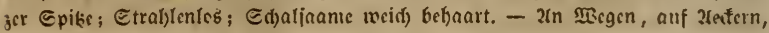
in Gärten u. j. w. Januar - Decentber. ๑. Esentcin.

\section{b. Etraflen juriidgereat.}

654. S. sylraticus L. salätter ticf ficicripaltig, jart f́pinnme(beni)aa.

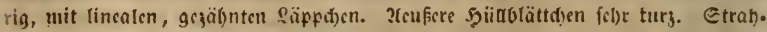
lenblïmd)en zurïifgeront; Ed)aljanmen frin behaart. Sï̈pfiten colisentrautig. 


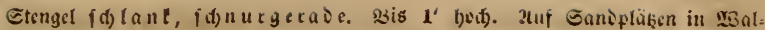

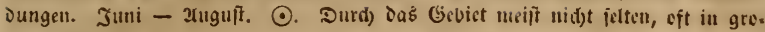
हैen Exupten.

655. S. viscosus L. F], dim. 1230. FI. germ. exsicc. 590. \$lütt't

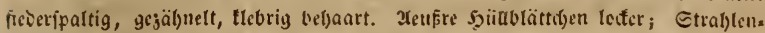

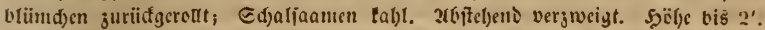

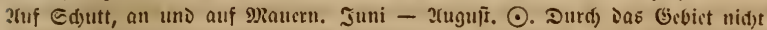

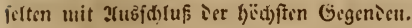

\section{c. Etrab)len aubigsfiredt.}

656. S. tenuifolius JAcQ. JAcQ, austr. 278. Rснв, pl. crit. IV. 516. Etrablen lincalija) lünglid); Slätter alle jeocripaltig, unten fo wie tie grrudttnoten fein bel)aart; slattabid)nitte lincalifd) lanjettlid), ipikig, wes

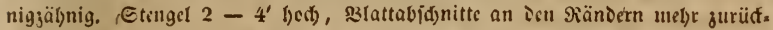

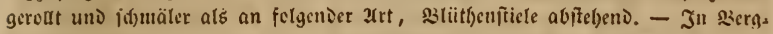
wäloern, an গ̇̉aloräniern. Xuguft. Eeptember. 4. Sicnlid) felten, bcjonicrs

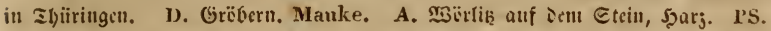
3ibra. Rchı. Gutenberg, Sarš̉orf. Sprengel. Erfurt. Bernhardi. Lucas.

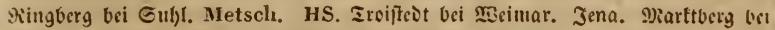

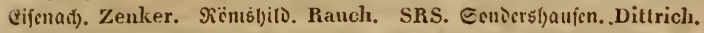

657. S. barbareaefolius Krock, Etrab)t lanjettlidg; frut)tetuc. telt labl weriens, untre siätter lang gefticlt, ciruno, cingejđgnitten gejägt,

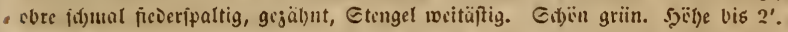

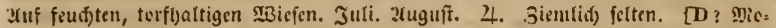
ritiourg angeolid); id fal) son ia uno fano nur cine form son Senecio Jacobaea.] L. Edjünfels, Ed)leupig, siranoyorwort, Etreitfolj, Vionne, giojentjal,

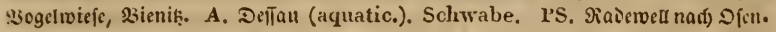
sorf ju. Dïnnik. Bitterferto.

658. S. Jacobaea L. Engl. Bot. 1130). M3แtrjels uni untere Silätter

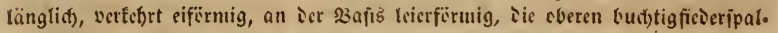

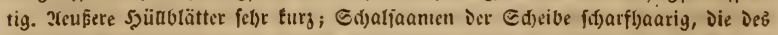

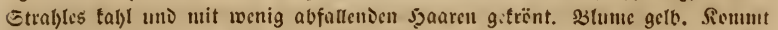

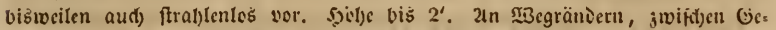

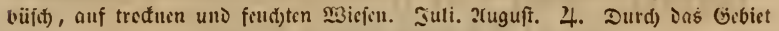
gentcin.

$2 \mathrm{~nm}$. S. alpimus Scop. nat) Sprengels Flora Hal. 1'g. 357. PS. G(f)mcu uni Soocrsleben. J(t) bejweifle Die Rid)tigteit ict 2ugabe.

659. S. saracenicus L. Rснв, pl. crit. ic. 466 . F]. germ. ex-

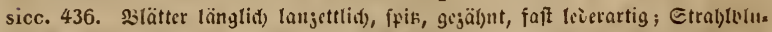

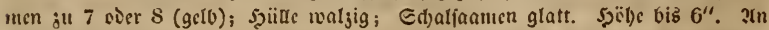

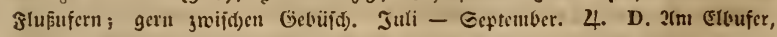

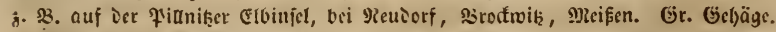

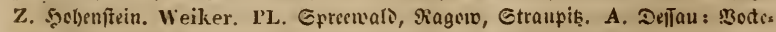
roier forît, Siegliberblerg; Dranientinum. PS. SBittenberg. Sjalle an ier Erale.

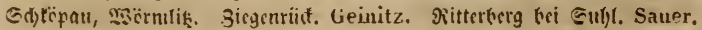


660. S. nemorensis L. Rchs, pl, crit, ic, 467. Fl, germn. ex-

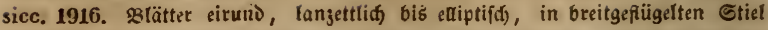
veringmälert, von beiden Ceiten over nur von utten mel)r ooer weniger turz bes

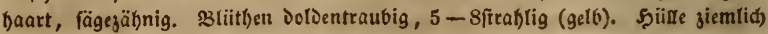

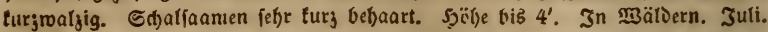
3uguft. 4. In Berggegenden. D. Roht6erg, Rothwernsoorf, Rotta, Dohna,

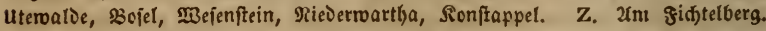

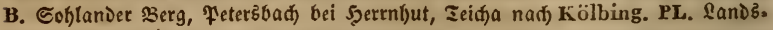
trone nad) Kölbing. A. Şargherove, Baflenftedt, syonm nad Schwabe. PS.

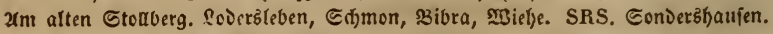

661. S. Fuchsii Gmez. Rснв, pl, crit. 466. Blätter fómal lan= zettlid), ge(ägt, nur Die unterften eiruno, tab). B(üt)en Doldentranbig, lang 5 .

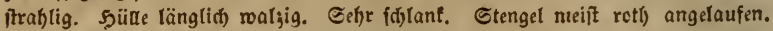

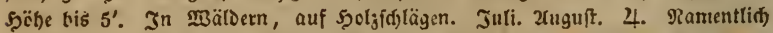

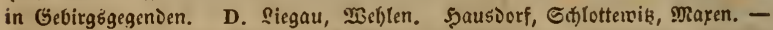

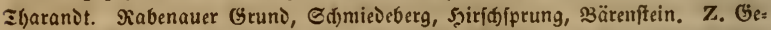
mein. B. Cohlander Berg, Feteršbad) bei Serrnfut, Zcid)a na(h) Kölbing.

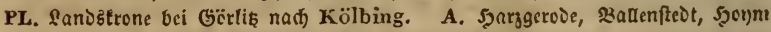

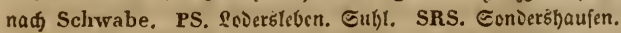

662. S. paludosus L. FI. dan, 385. Fl. germ, exsicc, 1332. Steif,

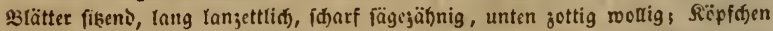

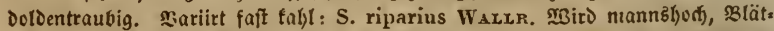

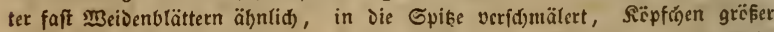
als bei Senecio Jacobaea. - In flusufern, in \$iefengräben, in 23 rü. den. Juli. Zuguff. 4. MBenig verbreitet. PL. Untrer und obrer Epreeroald. Rabenhorst. ziltwafler, ভonumerfelo. Blase. A. 3erbft, Foleimuilyle, Dranien. baum, Szectingen. Schwabe. PS. Barbn in Der Ententudfe, bei Monplaifir.

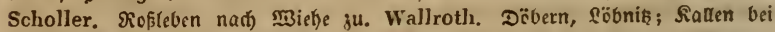

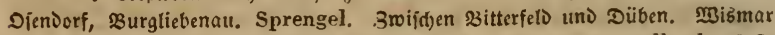

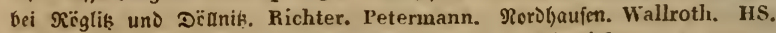
פittellbaujen bei Ġrefruieffèt. Bernlıardi. Eijenađ̆. Dietrich.

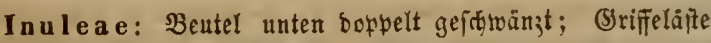 fumpf; Sheibenblüthdien frutbtbar.}

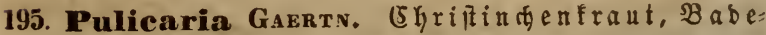

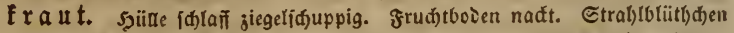

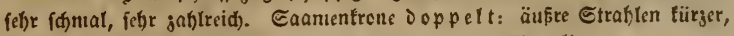
bäutig, gejälfnt, innere 10 - 20 ffjarfe sjaare. - \$il. gello. -

663. P. vulgaris GaERTN. Fl. dan. 613. Etrablulümd)en fellyr furs, Die äukre Gaamentrone bäutig, in berftige Bälyne gerrififen. Stengel fpan.

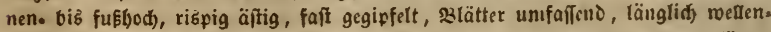

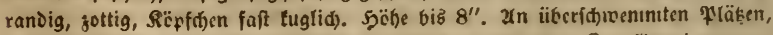

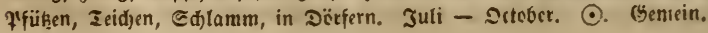


664. P. dysenterica Gaertan. Fl. dan. 410. Schk. t. 247. (frudt.) Harne Arzneigew. VI. 46. Fl. germ. exsicc. 585. 3lätter unt.

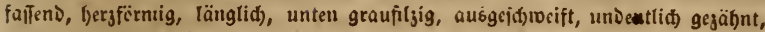
Ecitenzroeige übergipfelig, abftebenis; Şïßid)uppen fsin gefpikt. \$3is 2' jod).

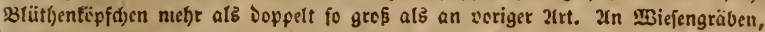

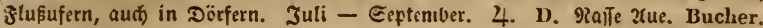
Mauke. Rchb. L. Bienil, Surghaufen, Guniorf, Dëljig. PL. Pangengrañau, \$iiftermarte, Bees১au, Stranpik, Sottbuz, Iricbel, Scrau. A. Eanderšleben.

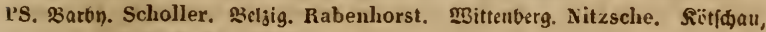
zeubik. HS. Eifenberg. Geier.

196. InuIa L. $\mathfrak{A} \mathfrak{l a} n t$. Sjüle jicgeli(f)uppig. Frudistboien nadt.

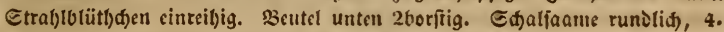
fantig. Eaamenfrone einteibig, (fifarfl)aatig. - 31. gclb. -

665. I. germanica L. JAç. austr. t, 13ł. Fl. gerın. exsicc. ҰU. Blätter baltounfalfent, h)erz. unt eilanjettlid), iffarfrandig, juriifgetriinumt, oben

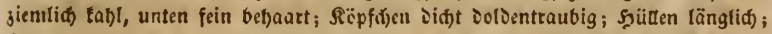

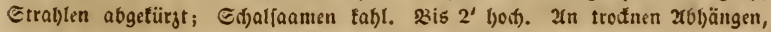
an $\mathfrak{B}$ einbergen. Juli - Ecptentocr. 4. In shuiringen und anbalt. A. Bica

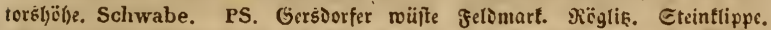

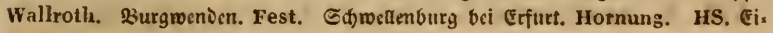
fenberg. Geier. SRS. armftait nad Nicolai.

666. I. britannica L. Scrk. t. 277. Etengel wellig fottig, 2-5s

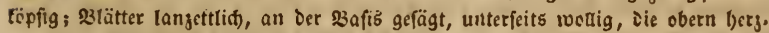

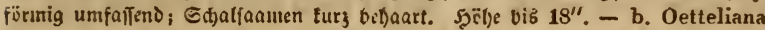

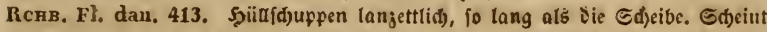

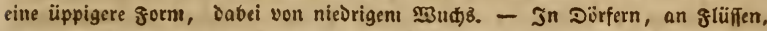

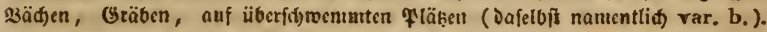
Juli. 2tuguft. 4. Mecift gemein Durd) Das Gebiet, (d)eint isn Erggebirge 3u feblen.

667. I. salicina L. Fl, dan. 786. 23lätter längliđ lanjettlld), Die obern

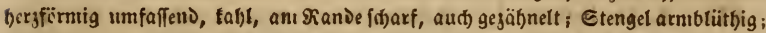

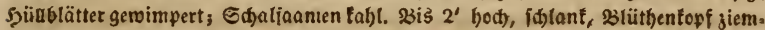

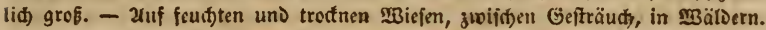

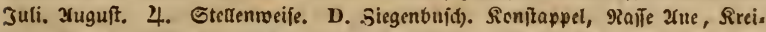

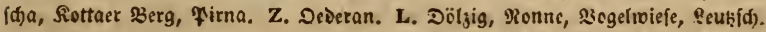

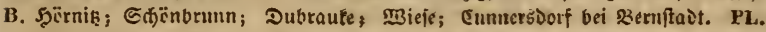

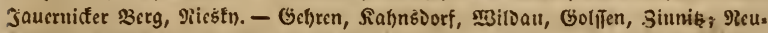

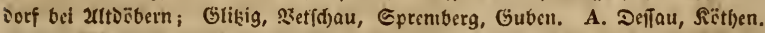

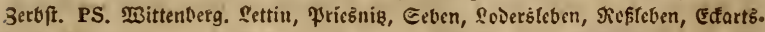

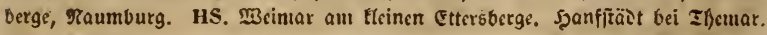
SRS. Xrenftait.

668. I. hirta L. Jacr. austr. t. 358. Fl. germ. exsicc. 2038.

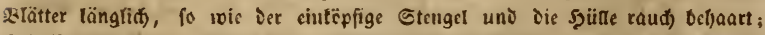

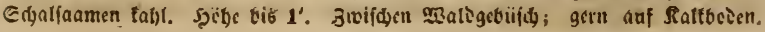




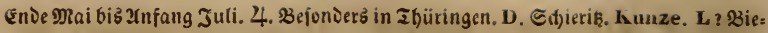
nił̨ pormals. A. Şarggerode, Zlerisbad. PS. Mittenberg anı 2pollonšberg. Schkuhr.

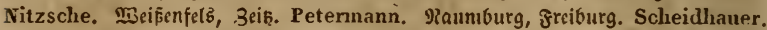

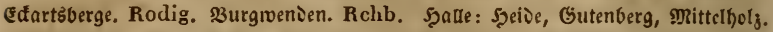
HS. Weimar, Jena. Rchb. Zenker. Berta. Zenker. Eijenberg. Geier. Şeils,

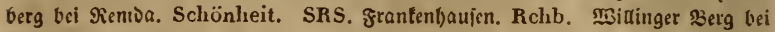
Gingen. Schönheit.

* 669. I. Helenium L. Fl. dan. 728. Hayxe Arzneigew. VI. 45.

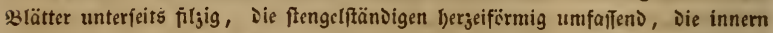
Şïublätter ipatelförmig; Edjaljaamen fabl. - Gtengel diff, fteif, $2-4$ ' bod,

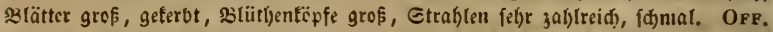
Radix Enulae. - In Dërfern, an 3äunen, in Grasggärten. Juli - Septen: tember. 4. Durd) Den unbau verwilbert.

197. Artemisia L. $\mathfrak{B} \in$ i $\hat{f} u \tilde{B}, \mathfrak{B} \in \mathfrak{r m} u t \mathfrak{h}$. Şülle jiegelídup:

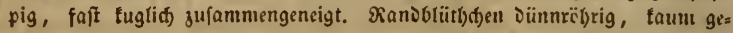

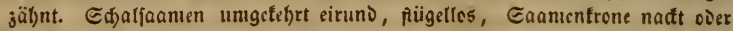
ein tleines Gdjiloden.

a. Artemisia, Beifuf. Fruđtboden nadt.

680. A. campestris L. Schr, t. 240. Haysz Arzngw. II. 9.

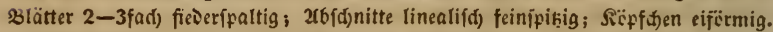

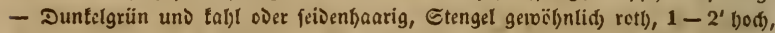

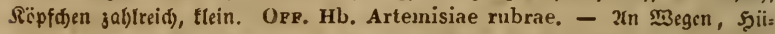
getn, Felfen. Juli - Eept. 4. Feblt in bübern Gebirge, fonj̃ niđ)t felten.

* 671. A. Abrotanum L. Hayne Arzngw. XI, 22. gaft ftraud): artig. Etengel und 3roeige gerade aufred)t; Blätter neêrfad jufammengefest, tabl, unterfte Deppelt, obcre einfad) gefiedert; siedern faft fadenfërmig linealif();

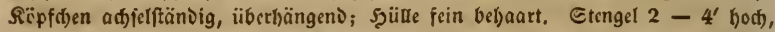

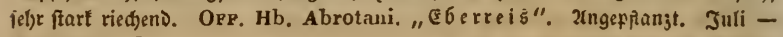
Geptemiber. 4.

672. A. laciniata L. (Mertensiana.) Wallr, sched. t. IV. Eins fad, tabl werDenD; 3lätter Deppelt gefièert; Sièern länglid), ftumpf, etwas

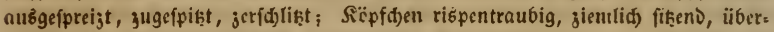

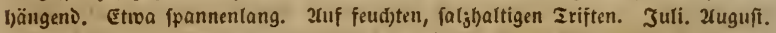
4. Gehr felten. A. Bernburg. Buddensieg. PS. આ(d)ersleben. Hornung. Bortsteben bei zrtern. Wallroth. Schünheit.

* 673. A. Dracunculus L. BLAKw. t. 116. Rab) ; slätter tanjett.

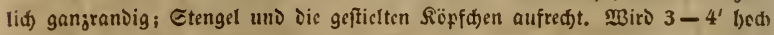
und ift rutbenäftig, ffarf ried)eno: "Dragun". Xtus Sibitisu, angebaut. Juli - Ęeptember. 4.

674. A. maritima L, Fl. dan. 1655. 23 (ätter Defpect uno oreifad)

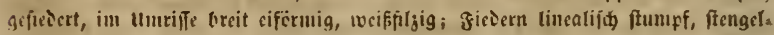

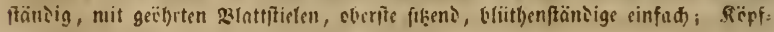




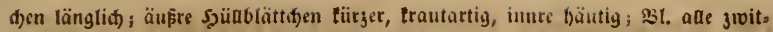
terlid); R̈̈pf(j)en aufred)t; 3rveiglein niđfeno. - b. salina W. Fl. gerın. exs. n. 1851. Sï̈ffden nideno; Etengel aufftigeno; fuflod), fterile Edj̈̈stinge. In Galinen auf loferrajigem Boden. Juli - Eeptember. 4. Gilten. A. Seau nad) Sprengel Fl. Hal. PS. Gtaffurti). Schwabe. 3rvif(t)en Sangenbogen uni Gceburg an Galjfee. Sprengel. Wallroth. Rchb. 2irtern. Rchb.

675. A. pontica L. Hayne Arzngew. II. 10. Blätter rojenartig,

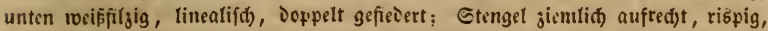
nadt. Sïpfd)en fât fuglid, niffent. Epannen, bis fusbod). - 2n MBegen,

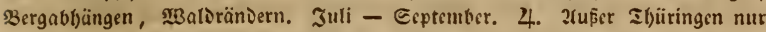

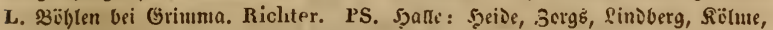

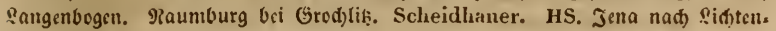
bain ju. Zenker. Buddensieg. SRS. Frantenbaujen am Galgenbirg. Hornuug.

676. A. vulgaris L. Hayxe Arzneigw. 11. 12. S3ätter unterfeits

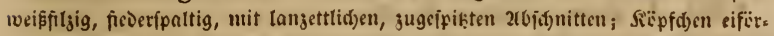

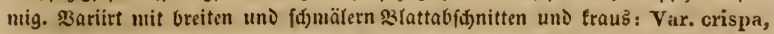

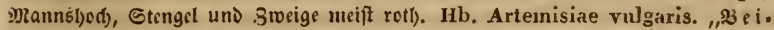

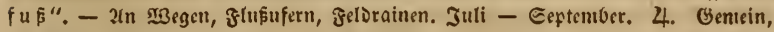
iu bëbern Gebirge nur felten (Z. Eitberiftrafe, soutra bei şwiffau, Gtodberg,

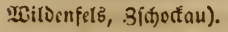

\section{b. Absynthium T. MBernuti). frudt)tboien vorftig.}

677. A. rupestris L. Fl. germ. exsicc. 41. WALLH. sched.t. V. 2tufiteigent. Etengelblätter Deppelt gepiebert; Fievern lanjettlid linealija, blii.

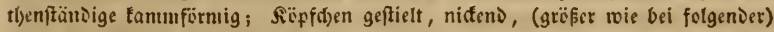
fein bchaart. Epaunenlang, fdü̈n grün. - 2luf faljbaltigem 23coen. Juli. 21u= guft. 4. Geljr felten. A. Bernburg. Buddensieg. 1S. Etaffurtl). Scliwabe. Bertsteben bei ?trtern. Wallrotl.

678. A. Absynthium L. Fl. dan. 1654. Harxe Arzngw. II. 11. slätter feitenartig weifgran, 2-3jad) fic̀erfpaltig, mit lanjettlid)en 2(bid)nitten;

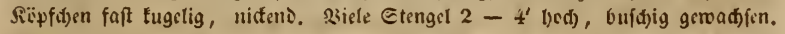

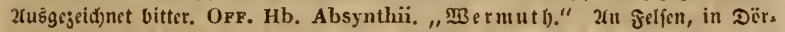
jern, an 5yedfen, Ed)utt. Juli - Eep. 4. Durd) Das Gibiet meift nid)t felten.

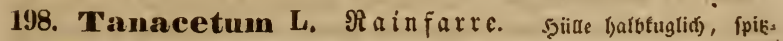

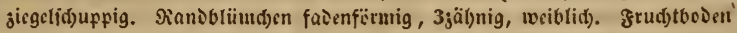
tegelförmig, naft. Ed)aljaame tantig, geftreift. Sirone fel)t tlcin oocr feb. leni. - 331 . galb.

679. T. vulgare L. Fl. dan. 871. St. 10. Harze Arzngw. 11. 6. Blätter Doppelt fieberfpaltig, mit gefägten Sipfeln. Die gref̌en gelben Röpfd)en Der Dolbentraube Did)t beifanmen in einer fläd)e. Stengel $2-4^{\prime}$ bod). -

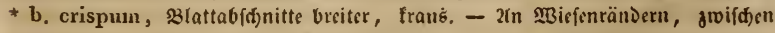

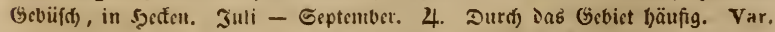
crispa bäıfig angcpก̂nแat, - OPF. Hb. summitates et semiı Tanaceti. 


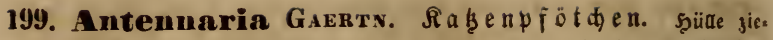
gelïuppig, vielblumig, 2häแfig (over gemifht). Sil. 53ätnig. Frudtboden gervälbt, grubig. MBeiblidge Saamentrone fadig, mänulidje teulenförntig.

a. Antennaria: Sienılid vodtonımen 2 bäufig.

680. A. dioica Gaertn. Fl. dan. 1228. St. 38. Hayns Arz-

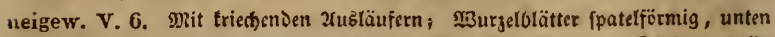

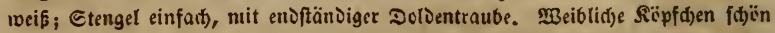

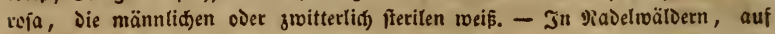

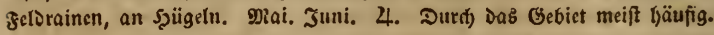

b. Margaripes DE C. *) Switterlide Ripfonen nit einteibigen, weib.

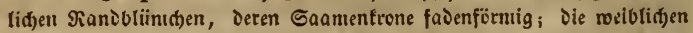

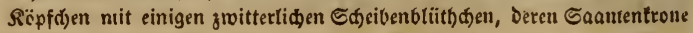
an Der Epiļe verdictt.

* 681. A. margaritacea R. Br. Sr. 38. Sirautartig, aufredt ;

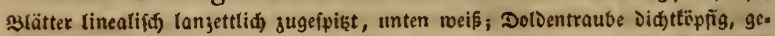

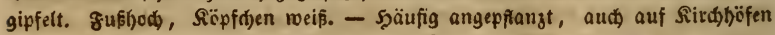
uno in Dërfern verwildert. Juli. 2uguft. 4.

200. Filago L. Sqimmelf $\mathfrak{a} u t$. R̈̈pfdien vielvlüthig, פit. tclblümळen zum ₹(ycil männlid). Frud)tboden feulig, nit ङpreublättd)en (roie Şü̈lfid)uppen, Die äufern fogar wodig). Eaamentrone baarig, auf Den

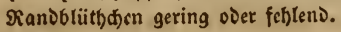

682. F. germanica L. ST. 12. Gabelipaltig, äflig; Röpfóen in

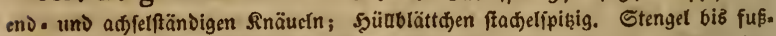
t)od, aufred)t oder gewö̈)nlid aufferigend und länger ats bie auffeigenden 3weige. Das ganje Siraut weip̧woltig, fo fart wie F. arvensis; Blätter linea=

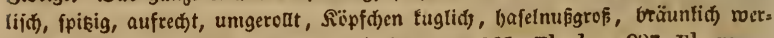
Dend. - b. pyranidata. (F. germ.) Scнк. t. 265. Fl. dan. 997. Fl, gerin. exsicc. n. 1329. Stengel niejrig oder von Der $\mathfrak{B}$ urgel aus in tangen 3tweigen

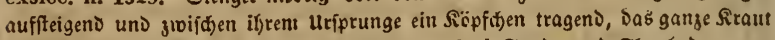
getblid) grün, $\mathfrak{B}$ lätter breiter, ffunupflid. - Xuf Gand. und zhonboden, an

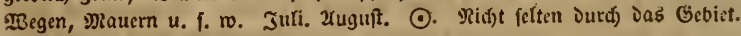

683. F. arvensis L. (F. montana Wahlnb.) Fl. dan. 1275. St. 38. Didt, meift moltig; Stengel rispig; Die אïpfden in fciten. und endftändigen

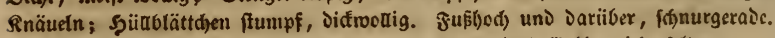
- 2ruf 23 raden. Juli - Eeptember. $\odot$. Durdy Daß Ectiet nidst felten.

684. F. montana L. Fl. dan. 1276. Sr. 38. Fl. germ. exsicc. 2035. Silzig; Stengel mit gablid)en अepten; Die Sï̈pfden in adffls, feitens uno

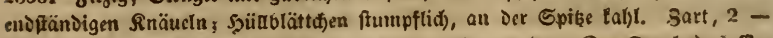

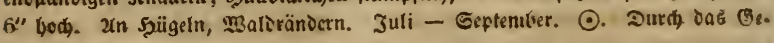
(riet nid)t felten.

*) Midyt Margaritaria, Isnn fo beift (4hon cinc Pinncifitte Ealtung. 
685. F. gallica L. Morıs. sect. 7. t. 11. f. 1\%. Blätter linealifít,

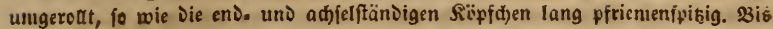

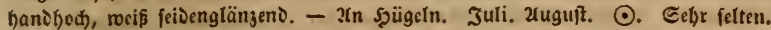
PL. Settin, Srö̈wik. Wallroth. Id fals teine Exemplare von Da.

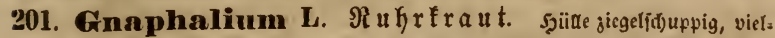

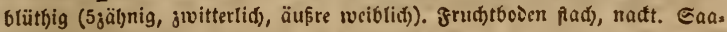
mentrone baarartig.

686. G. uliginosum L. Fl, dan. 958. Єtenget vom Grunie all ver.

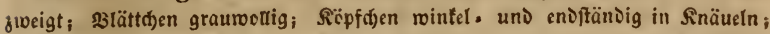

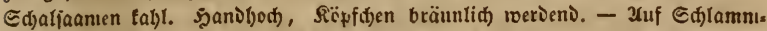

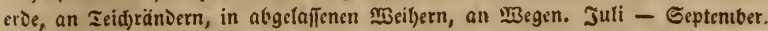

๑. G̈entein.

I n m. 2uf G. nudun Horrm. Rснв. pl. crit. VIII. 999. Fl. g. exs. 1429. jarter, gans griin uno tabl, Saamentrene wenig bel)aart! Dürfte innertjalb Der Greugen ju ad)ten fein.

687. G. silvaticum L. Fl. dan. 1229. Schr. t. 234. Stengel auf:

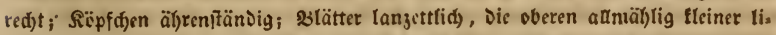
neatifक, unterfeits weiffilzig, oberbalb zulest tabl meroend. Steif aufredt, über

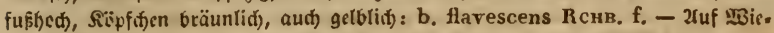

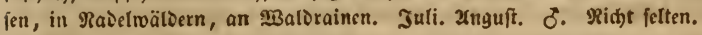

688. G. norvegicum Guxv. ST, 38. (fuscatun P.) Fl, germ.

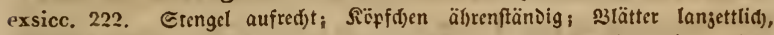

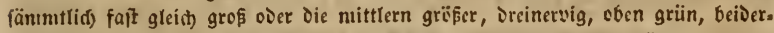

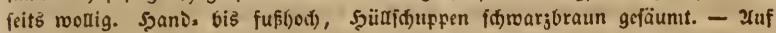

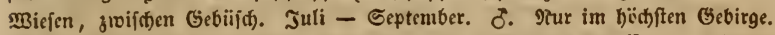
D. - Geifingsberg am Sulfe angeblid. Z. Sidtelberg. Weiker. Jobanns georgenftadt. Brunner. PL. ¿aferfiđfte; (כäfd)ten). Kölbing.

689. G. luteo-album L. St. 38. Fl. dan, 1763. Fl. germ, exs.

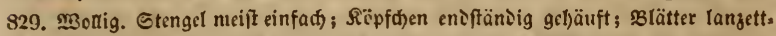
lich unffalfeno, untere nad) vorn breiter uno fîntpf; Edjalfaamen fein getörnelt.

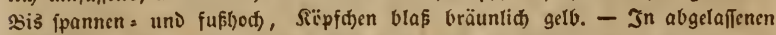

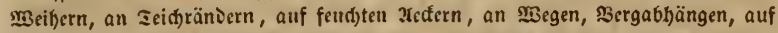

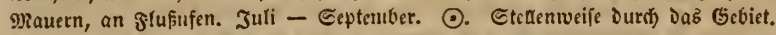
Rantentlid) Dent Dresoner Scioelanie und Der Drtranier Gegend (PS.) eigen.

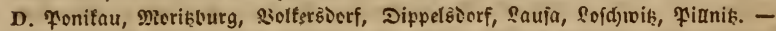

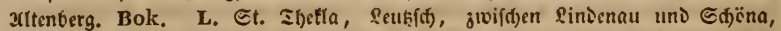
Grinuma, Grofer ettinberg. B. 9tidt felten. PL. Değgl. A. DelTau. PS.

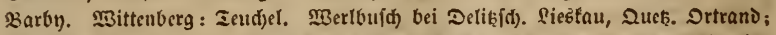

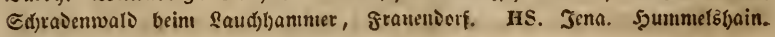
Mcion. SRS. Sdivarjburg, 氵eid)rïben.

202. Welichrysum Ganrtin. Smmottelle, Smmer:

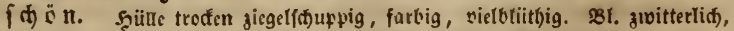

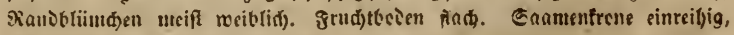
baarartig, ídürrftids. 
690. H. arenarium DE 1:. Fl. dan. 647. ST, 38. Hayne Arz-

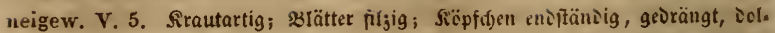
Dentraubig, citronengelb oict b. aurantiacuun: crangefarbig. Epannell. bis

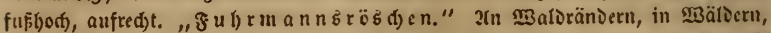
auf Gandpä̈ben. Juli - Eeptember. 4. Ed)eint in Erggebirge ju fellicn, fonjt meifit bäuịg: var. aurantiacum icitner.

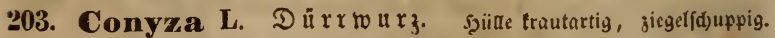

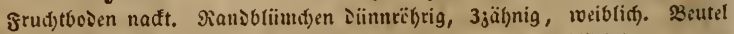
unten Doppelt gefdowängt. - Gleidjfam Inula obne Etrabiblütl)(j)en.

691. C. squarrosa L. Fl. dan. 622. Etengel äftig; Räpfđjen Dol. Dentraubig; SBlätter clliptij(t) lanjettlid), Die unteren in einem Gticle verf́d)mälert.

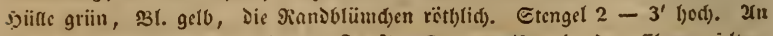
Dïrren Sergabbängen. Juli. 2uguit. 4. Etellenweije, in Den Ebenen iclten.

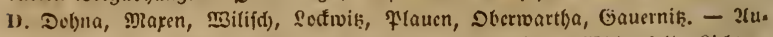

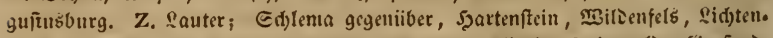

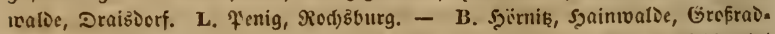

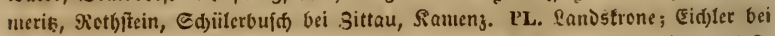

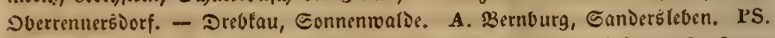
Beid)lik, Fiebauien, Geeburg, హreiburg, Burgmenien. Sicgenriict. HS. Jena, Ëifenberg. SRS. Atrnftadt. - OFr. Herba Conyzae vulgaris.

Pe ta s i te a e DE C.: weibl. Bl. röfrig, Şüllfđuppen gleidfang.

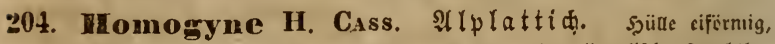

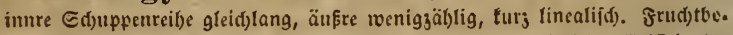

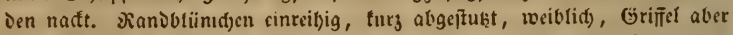
Dent ier switterbiütbd)en gleid) (Yiarbenjweige rinnenartig Driijig). Cdjale faamen fpindelfërmig, gefurdft, Gaanentrone fib̧ens, baarartig.

692. H. alpina H. Cass. SchK. t. 242. St. 21. Murjelbä̈ter langgefticlt, nicrenförmig, terbjäl)nig, unten an Den zsern fein bel)aart; Etenger fd)aftartig vis ffannenbod, weđig, unten mit eineul geftieften 3latte, iibrige 1

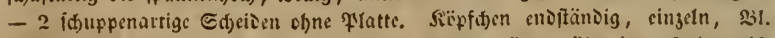

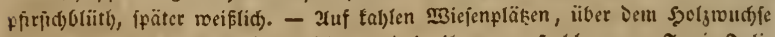

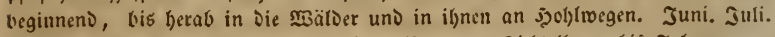

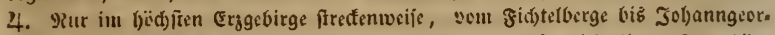

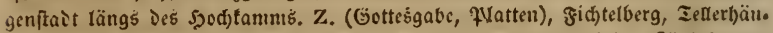

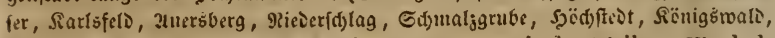
Caljung, Jol)anngicrgenifait. Bok. Brumner. Weigelt. Weiker. Wankel. Rchb. Miiller.

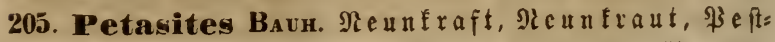

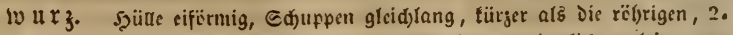

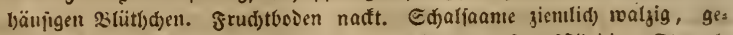

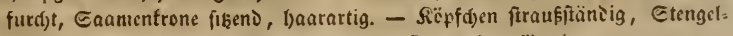

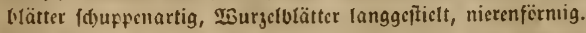

6993. P. Vulgaris DESF, Fl, dan, 842, Haxa Arzngw, M, 17. 


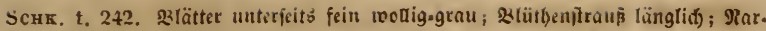

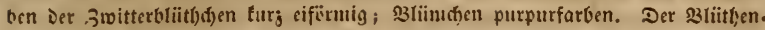

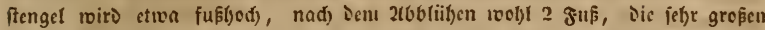

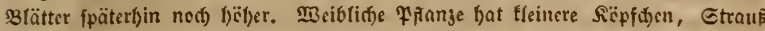

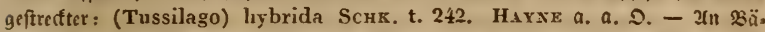

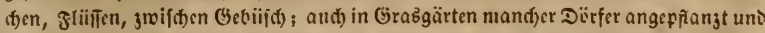

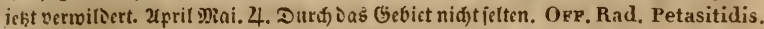

694. P. albus Haller. Fl. dan. 524. Schк. t. 242. St. 21.

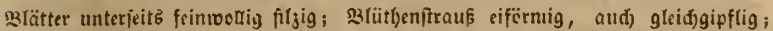

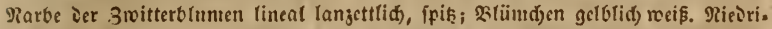

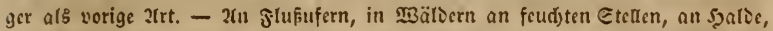

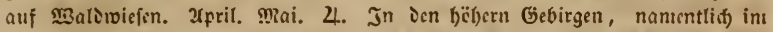

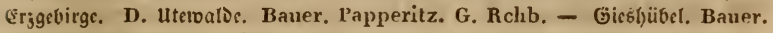

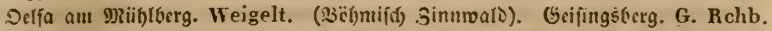
Papperitz. Sauenftein. G. Rchb. Edfmiejebcrg, falfinlyain. Rchb. Ihatanit.

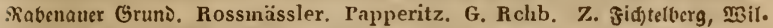
ienţal. Wankel. (Eibenftod, Bielberg, Gtcinbad). Weigelt. B. Saufde. Köl-

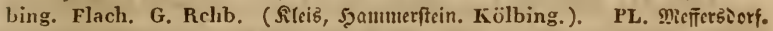
Burkhardt. PS. Subl. Metsch. HS. Jena bci Safan. Zenker. ̊änmertberg bei Jintenau. Schönheit. R. Sobenjtein.

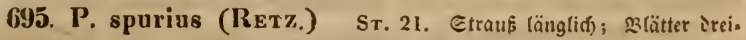
eafig, hersfïrnig, ungleiđ) gejül)ut, unten bid)t moiffill;ig; Sajilarlaffen einge: trïmnt oier lappig eingcid)nitten. Der jwitterblütbige Etraus Diđft georängt,

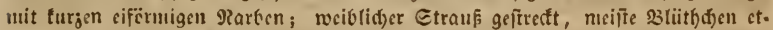

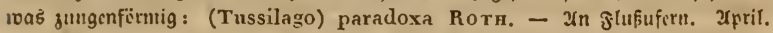
Mai. 4. Gelje felten. A. ŞB̈rlit, Defau, fricocrifenterg. Schwabé.

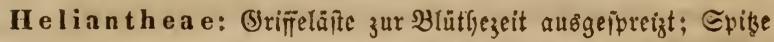

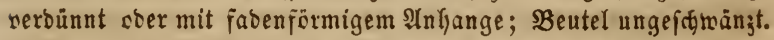
Eriulfaame zujammengebrüft, vierfantig, meift fouppig gefrënt.

206. Galinsoga Rz. Pav. (b) alinisga. suimfinuppen 5 -

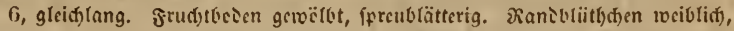

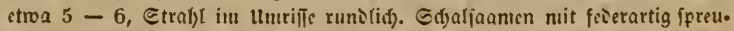
blättriger Sirenc. - Blätter gegeniiber.

* 696. G. parviflora Cav. Car. ic. 281. 3icmlida taf) ; 33tätter

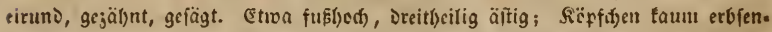

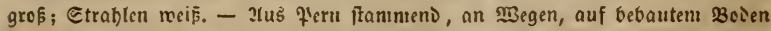

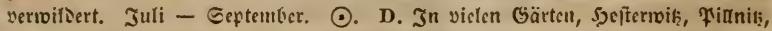
sorni fdroarjen abore u. f. w. L. Xutumaundorf.

207. Bidens T. L. 3 ineizaly $n$. syïlfínfpen gleidlang, mit . siïd)en. Frudftboien fads, ipreublättrig. Gdaliaanten 4tautig, 2-4gran.

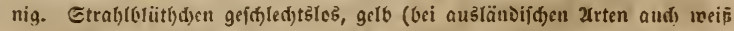

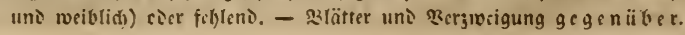


697. B. tripartita L. Engl. Bot. 1113. 3lätter oreitbeitig; $X 6$. idfnitte lanzettlid, einge(d)nitten, gezäbnt; Rïpfden röbrenblütbig, aufred)t. Var. pinatifida, Blätter fièerfpaltig. Stengel äfítig, $2-4^{\prime}$ hoch, aud) oft nur bandhođ). 2un Gräben, Eümpfen, auf überfđrwemnitem Bcien. 2uguft. Sep= tentber. $\odot$. Eemein uni gejetrig. Var, pinnatifida D. Sauja. G. Rchb.

698. B. cernua L. Fl. dan. 841. Schx. t. 235. St. 1. slätter

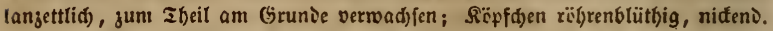
- b. radiata: fdjön gelbe, große, zungenfïrmige Gtrah)(blümıd)en. - Ģröfe wie vorige. Sroergekemplare: B. uninima L. - In Gräben, an Sünıpfen, auf über: finwemmtem Boden. 2uguft. Septeniber. $\odot$. Sentein und gefettig. b. Meijr

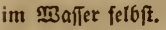

208. Helianthus $L$. Sonne $n$ b $\mathfrak{I}$ ume. Şüabrättçen jiegel.

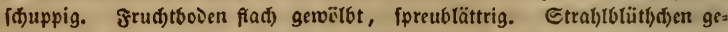
(d)led)tslos. Ed)alfaamen gleid, Caamentrone 2, cocr melbridjuppig, abfals teno. - 23l. getb. 33tätter jerffreut.

- 699. H. annuus L KxorR del. 1. 1. s. 1. Blätter (gefftielt) betj.

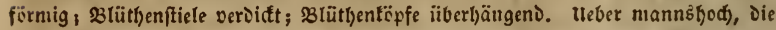

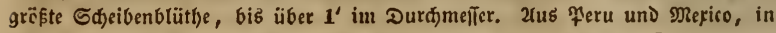
Särten und auf SelDern gebaut unঠ verwițerno. Suli. 2uguft. $\odot$.

* 700. H. tuberosus L. Scrk. t. 258, untere 23lätter Gerzeiförmig, obere längfid) eiförnig und langettlid). Stengel über mannshod), Sïpfdjen tlcin,

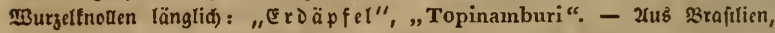
bäufig cultivirt. Detober. Provenber. 33 liil)t nur in warnten Şerbften. 4.

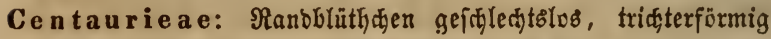
ober rölyrig, 2lippig. Saamenfrone mehrreifig, borftig.

209. Centaurea L. Flo ff en $\mathfrak{I} \mathfrak{I} m e$. Şülle żiegelfduppig.

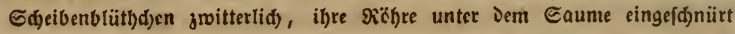
abgejectit.

701. C. Jacea L. Fl. dan. 519. Schк. t. 261. (รrud)t.) Şüufd)up=

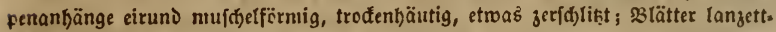

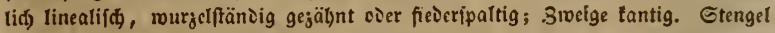
$2-3^{\prime}$ bod, auch zwergartig, Blütljentëpfd)en Dann faft auf Der $\mathfrak{B}$ urzel. $\mathfrak{B} 1$.

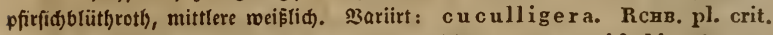
ic. 1239. Ed)uppenantjängfel Eappenartig gefb̈̈blt; a ngustifolia ScнRк.

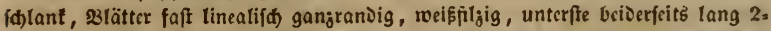

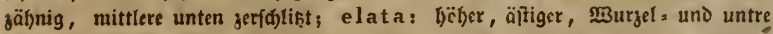

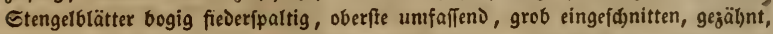

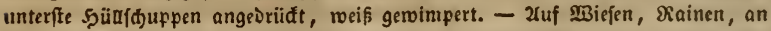

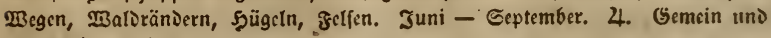

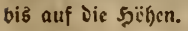

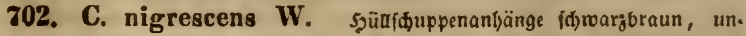

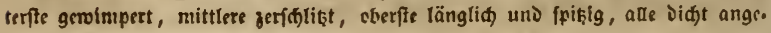


Drüđt. -3weige DolDentraubig, aufred)t. - 2uf झeiefen. Juli - September. 4. D. S3orgüglid, nädit Der Etbe bei DresDen.

703. C. decipiens ThunL. Rсвв, pl. crit. ic. 1316. Fl. gern. exsicc. 2030, 2031. Şiidj(d)uppenantänge bräunlid gelb, untcrfte etras abfte. beni, fo wie Die mittleren tief gemimpert, oberfte furg, winperartig jerfd)likt. Blätter lanjettlid) oder fpiçartig, Die unteren aud) feserfpaltig. \$\$. wie vorige, blcibt fid mıs Saanen ergrgen gleid). - 2luf \$Biefen Der Gicbirgstbäler. Juli - September. 4. D. um DresंDen; wehl Durd Das Gebict.

804. C. pratensis ThurLL. Rсrв. pl. crit. ic. 1294. Fl. germ. exsicc. 2032. Şüufd)uppenanbänge braun, unterffe feinfpibig verdünnt, febr ab. itebeno, fo wie Die etwas jeritreut entfernten nittlern runjlidgen gewinipert, oberfte berjförntig, jeridgliķt. Catt Duntelgrïn, fräftiger gebaut, faft toie C. ni-

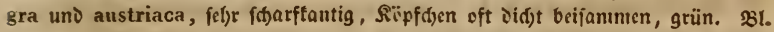

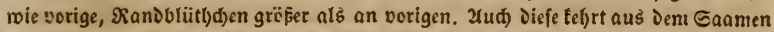

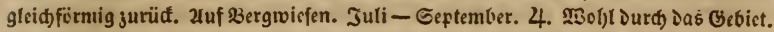

705. C. austriaca W. Spec. pl. Rcнв. pl. crit. IV. 554. *) Şül.

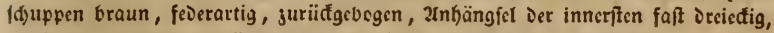
gewintpert, aufred)t; slätter oval uno cirund, fd)ärflid), grob gejähnt. 2(ufred)t

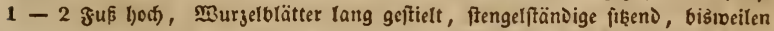
aud) bud)tig oDer an ier şajis eingefdyitten. Sïpfd)en greß̧, wie perüđenartig

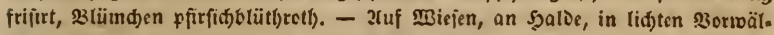
Dern. Juli - September. 4. Sgauptiäd)lid) in Den Gebirgsgegenden, aud fefor felten in Der Ebene. D. Dolyna, MBrfenftein, Mapen, Miüllbad); Gd)(ctterviß,

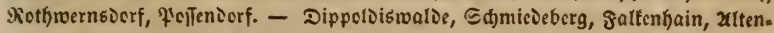

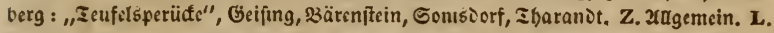

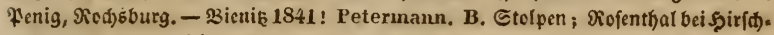

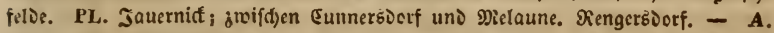
Şarggerode, Badenftedt. PS. Loverbłcben. Sprengel. Erfurt. Buddensieg.

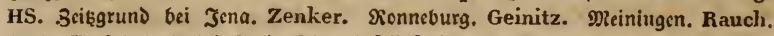
SRS. Gropes Spols bei €tàt Jlm. Schönheit. R. Sobenftein.

706. C. Cyanus L. Rornblume. St. 4. Haxis Arzngw. ViI.

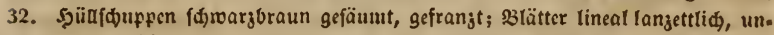

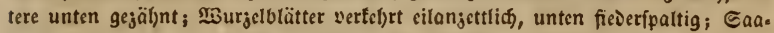
mentrone fo lang als ser Sdjalfaame. 23l. ajurblau, variirt recis und bei ber Eultur * violet, furpur, refa. - 2luf Geldern givifden Der Gaat. Juni - Gep=

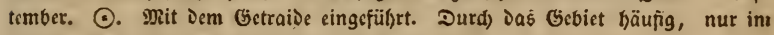
bädfiten Gebirge feltner. - OrF. Flores Cyani.

707. C. montana L. Bot. Mag. 77. Jc2. austr. t. 371. Şüllffjup: fen grün, Der fđłwarge Saum gefägt; slätter lanjettlidf, ganj, berablaufen১,

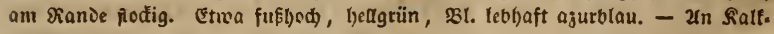

a) Bergl. Die 2(nm. in Der Fl. gerun. exsicc. ju No. 2034. Die rabre C. phrygia L. ift die Jipenpianje, von poldaer Wrucd. eıne Var. discoidea: C. nervosa genannt hat. ङ. pl. crit. ic. 554 . 
bergen. Juli, 2uguit. 4. Gelten; une in zbïringen uno 2tubalt. A. Ballen. iteit. Schwabe. PS. Gđmon. Sprengel. Sicgentïí, Kunze, Geinitz. HS. (jotf)a. Buddensieg. SRS. Cing๕n, Grieş)ein. Schönheit.

708. C. Scabiosa L. Fl.' dan. 1231. Hayxi Arzngw. VII, 33.

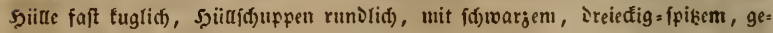
franjten 2(nbängicl; Eannentrone fo lang als Der Ed)alfaame; 3lätter einfach) oDer ioppelt fiècripaltig, ntit lanjettliden 2(bjod)nitten; Etengel gefur(f), äftig.

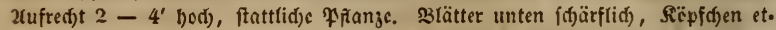

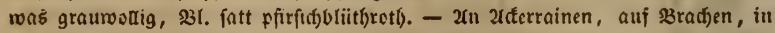
Mcinbergen, an Sö̈geln. Juli. 2uguft. 4. Durd) Daß Gebiet nidft felten, aber

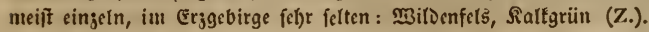

709. C. paniculata L. நุü[f(f)uppen ciruns, nit braunem, oreicđi. geix, gefrangtem Xnbängiel; Eaamentrone balb fo lang als Der Sdalfaame;

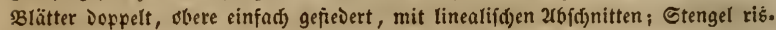
pig äftig. Eteif aufred)t, $1-3^{\prime}$ bod), 3weige aus̈geipreijt, alle tragen 23tüthen.

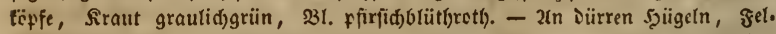
fert, Felorändern, auf Rauern. Juti - Eeptember. ¿. Durd) Dab Grbict nidift felten.

710. C. solstitialis L. Sснк. t. 261. S̈̈̈lfduppen mit 3 હtad) cln,

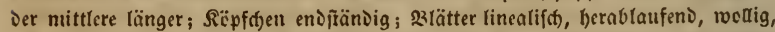

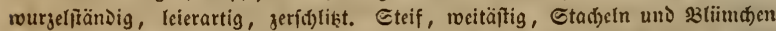

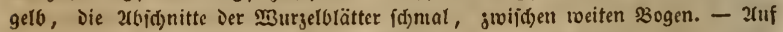
2tđerräniern, an 21nfïb)en, unter Den Getreide. Juni - 2tuguft. ○. Gclten, nut in weftlicfen Ëcbietc. L. Saufigt. Miiller. Gautid). Petermann. A. San. Derīleben, Bađtenftèt, Şarj. Schwabe. PS. Baarby vor Dem Gnej. Scholler.

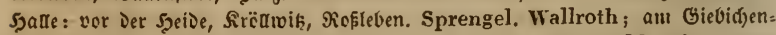

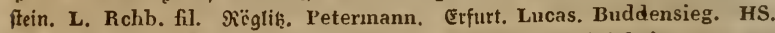

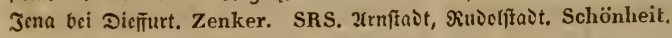

711. C. Calcitrapa L. St. 4. Drev. n. Hayse t. 147. R̈̈pfden fikiend; Etadteln 3 Mal fo lang als Ed)uppen, aubgeipreizt, an iłjer $23 a f 15$ nit Seitenftacheln; Gaamentrone fchlt; $\mathfrak{B}$ lätter fieverfpaltig; 3bfd)nitte unglcidf fä.

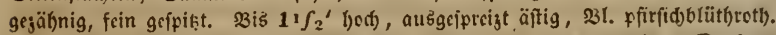

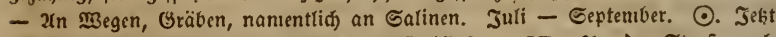

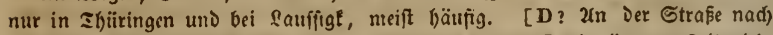
Pirna jroifajen Drésden und Gruna. Bucher. Dafelbft jeit längerer 3eit nidft máfr.] L. Snufígl. Miiller. A. Canicríleben, Siötben, Rojefelt. Schwabe. PS. Delikifit), Faupikj(t), șalle.

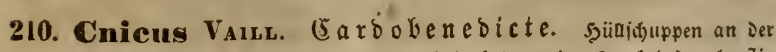

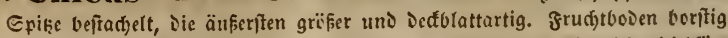

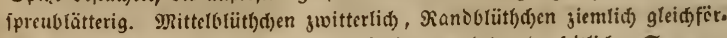

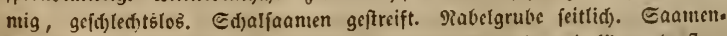
frone Dreifad) : (diüfelfërmig geferlit, lang verftenfërmig uno fürger borften. fërmig irüientragent. 
812. C. benedictus L. Harxu Arzngw. VII. 34. Wiptig, voblät.

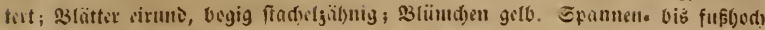

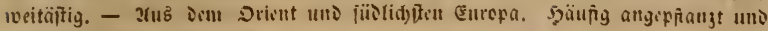
cultivirt. Juni. Juti. ¿.

\section{Carline ae, Earlineen.}

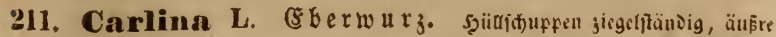
pecerartig beftadyelt, innte treffenlyäutig, glänzent, ftrab)enartig aubgebreittr. VRarbe sueilippig jufanmengencigt. Fru(t)tbooen borffig ifreublättrig. Sd)al.

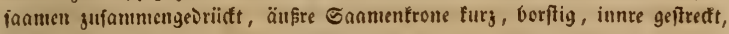
foicrartig, fä (i)erartig verwa (t) fent -

713. C. vulgaris L. Scнк. t. 232. Etengct alf fred)t, bet(ättert, ovent

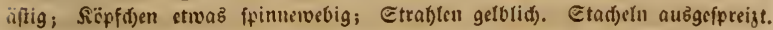

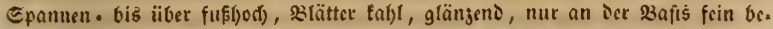

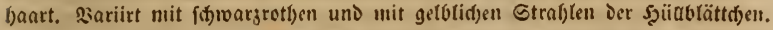

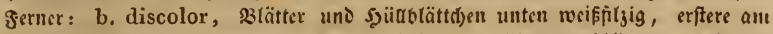

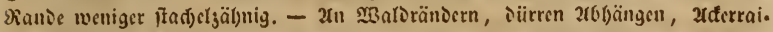
nen. Jufi - September. ठ. Meift gemcin. - b. Z. sici Sïjefau am ufer. Rchb. Neiker.

714. C.'acaulis L. Harse Arzngw, X. 45. Etengil cintopfig, fur;

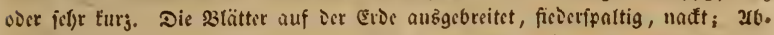

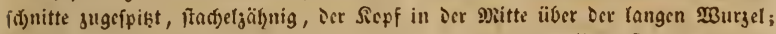

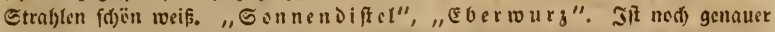
3n teobaditen, ob Die ftengetlofe Pronnge wirtlid) 3u b. C. caulescens fid) fortbitiet.

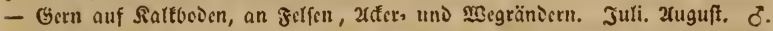

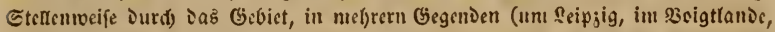

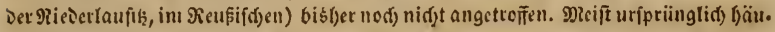

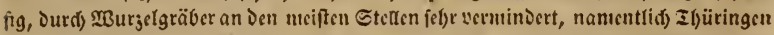

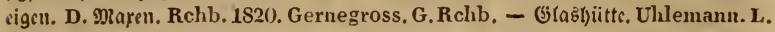

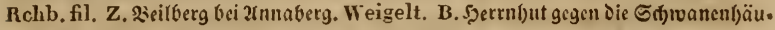

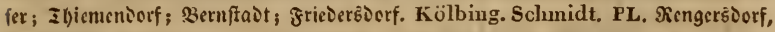

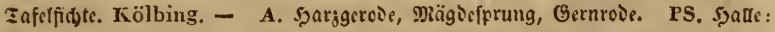
B3erge an Der unftrut, 33urgideidungen. 23i6ra. Querfurth). Erfurt. Eubl. HS. Jena, Beimar, Eifenberg, Eijenad). Soburg. SRS. Srantenbauten, zerne

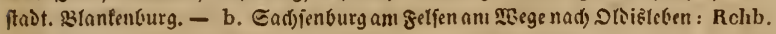

\section{Cichori a ce a e, Cinforiceen.}

212. Campsana $T$. Re inf oh 1 . süuf(d)uppen g(cid)lang, ctiva

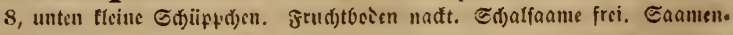
frone filfit. (Lapsana L.)

715. L. communis L. Fl, dan. 500$)$ S(нт, t, 225. (ङrud)t.)

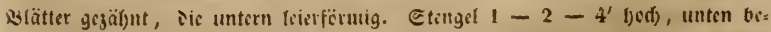

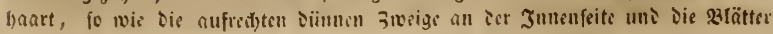




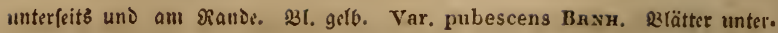
feitz didjt graupilgig, nièriger uno geirängter getvadjen. - 3wifd)en Gebuifd), auf bebautem SoDen, ઉd)utt. 2ruguit. Eeptember. (. Die var. bišmeilen auf bod)gelegenen, fonnigen 2ledfern.

213. Arnoseris Gaerts. Lămmerialat. Sjiufduppen gleid)(ang, jur frud)tjeit vouffig zufammengeneigt. Frudftboien nadt. E(d)al.

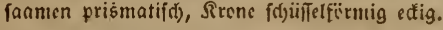

716. A. pusilla Gaertw. (Hros, minima L.) - Schk. t. 224. Fl. dan. 201. Eđaft 1 -3tipfig; Etiele teulenförmig veroif́t ${ }_{3}$ Burzelblätter

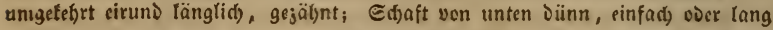

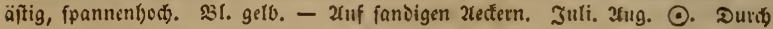
Das Gebiet nidft felten, in Den Gebirgs̆grgenden verid)windent.

214. Cichorium L. (Sid̆orie. Sä̈le Doppelt, innere gleid).

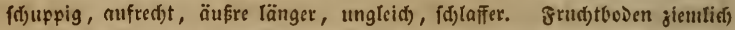

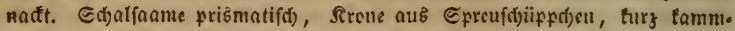

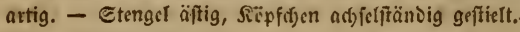

717. C. Intybus L. St, 6. Scrix. t. 226. Hayare Arzngw. II. 24. Swei und mol)rere, theits fikende, theil(3 geffielte Sïpfiffen beijanmmen, obere

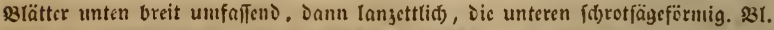

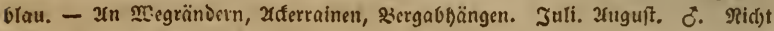
felten. Im Givbirge felten.

- 718. C. Endivia L. Brakw. t. 378. SBïtbenftiele zu gixcien adjo

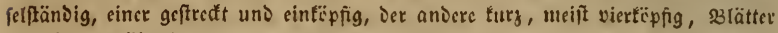

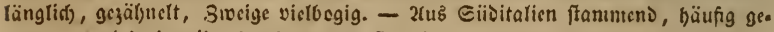
baut, "Endivien". 3uni-2ugutt. ठ.

215. Thrincia Rотн. Thrimcie. sä̈mfupfen gleintang, s

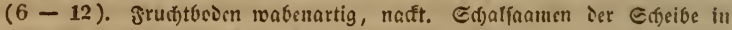
einen Etift verï̈nnt, Srone fecerartig, Die Des Siandes nit trectent)äntiger,

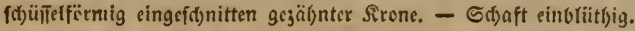

719. T. Leyseri Wallr. Rснв, pl, crit. VIII. ic. 990-992, 23ä̈.

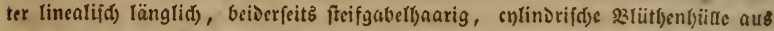

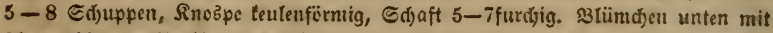

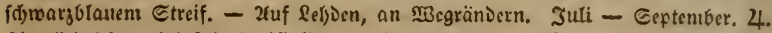

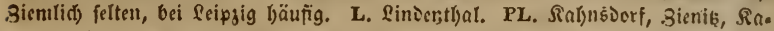

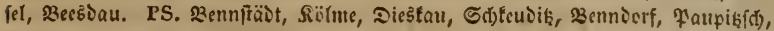
รัc̈glik.

720. T. hirta Rотн, ") (Aparg.) Scrк. t. 220. Rснв. (hispida) pl. crit. VIII. ic. 990). Blätter fagmal länglít), fteifgabel(jaarig, Edjaft vier.

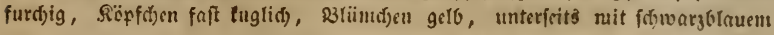

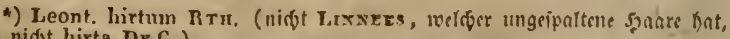
auk) nidft hirta $\mathrm{Dz} \mathrm{C}_{\text {, }}$. 
Etrcif. - auf feudten Eriften. Juli - Esptember. 4. Biemlitif folten, in

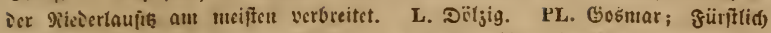

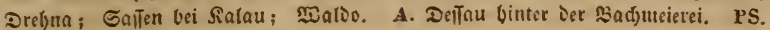

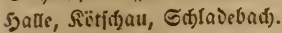

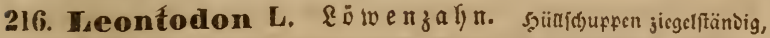
angeiviidt. Frudftboien zicntid̆ nadt. Eaamenfrone bräunli(i), feicrartig, uittlere Edjaljaamen in einen Etift verdiinnt.

a. Leontodon, G(jaft cinblütbig, Gaamentrone unglciđ), nittlere

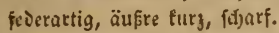

721. L. hastilis L. JAc2. austr, 16t. RcnB, Fl, germ. exsicc. 439. \$lätter länglid) langettlid), in einen Ctiel berablaufeno, gejät)nt ober fie*

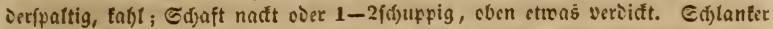

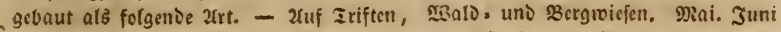

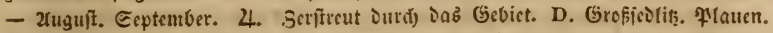

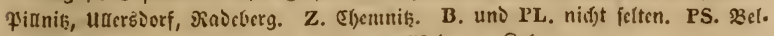

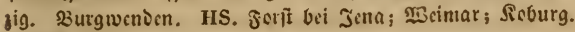

722. L. hispidus L. Scrk. t. 220. 23lätter unigefélyt ciruns, räng.

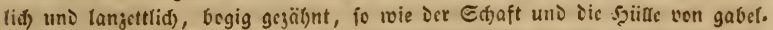

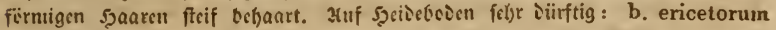

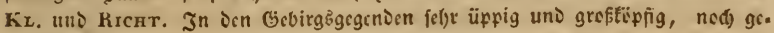
nauer ju becbadten! - 2uf Iriften, Misiçen, 2(nlj̈̈l)en, Syciben. Mai. Juni 3uguft. Scptember. 4. Gemein Surd) Das Grbiet.

b. Oporima Dox. G(j)aft äitig, aud) Dic vianijaamentrone fejcr. artig.

823. L. autumnalis L. ฮd)aft äftig, 2-5fïpig; Gtiele nad oben

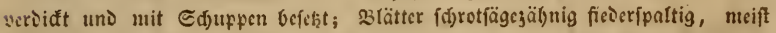

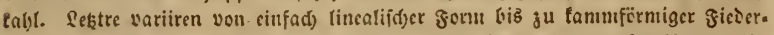
ipaltung. - b. L. pratensis Lrxk. Syülle zottig belsaart. - 2uf Zriften, feli. rainen, 5yïgeln. 2ruguti. September. 4: Gemtein in ier Etene wie in Gebirgs.

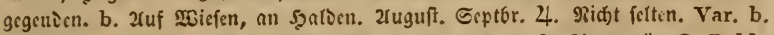
D. Ilauen. Rchb. - Gecrgenfeld. Fr. August K. v. S. Sinnivalo. G. Rchb.

\section{Tragopogon T. $\mathfrak{B}$ of $\&$ bart. şümiduffen $8-12$,} gleidflang, unten baufjig werwadjicn. Frufftboien naft. Edaliaamen längsfftreifig in einen Gtift verlängert. Caamenfrone feierartig, gegenfei. tig verwebt. - Gewölsnlid') beblätterter, äftiger Etengcl, Blätter faft gras. artig.

724. T. pratensis L. Scrax. t. 214. (Frud)t.) SB(iithenftiele glcid)

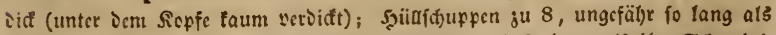
Dic slüm(j)en; Gdjalfaamen am Sianie tërnig forarf, fo lang als if)r હdjnabet.

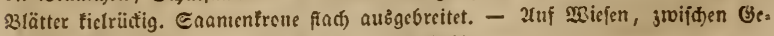

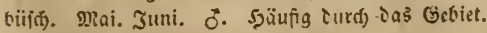

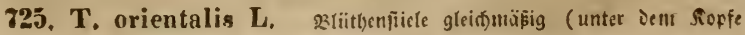




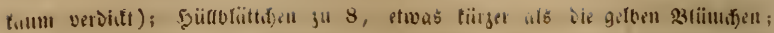

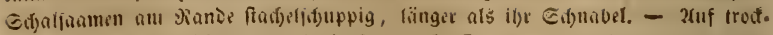

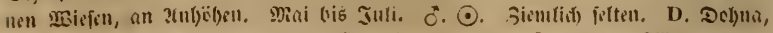

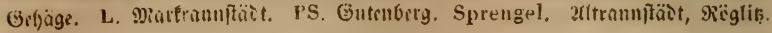
retermann.

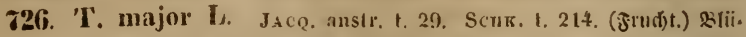

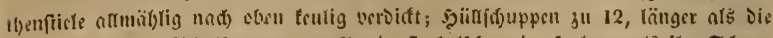

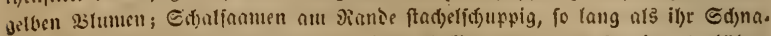
wel. Etengrl 2-4 Jus bod). Sanutentrene glodtig gebegen. 2(n fonnigen 2(nbäb)en,

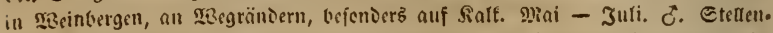

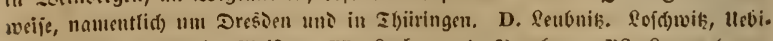

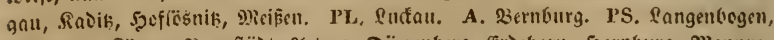

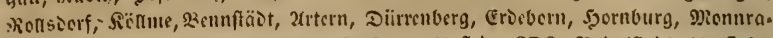

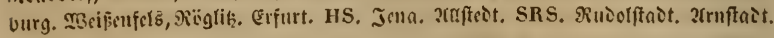

727. T. porrifolius L. Scrk. t. 214. S3lïthenfticle aumäblig nad)

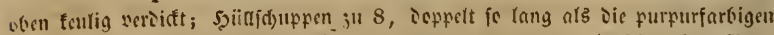
slumen; S3lütter pad), auşgeftrefft; Dic Cd)alfanmen am $\Re a n d e$ fduppig gefïrnt,

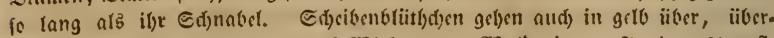

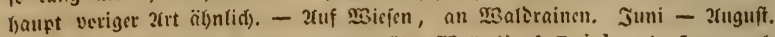

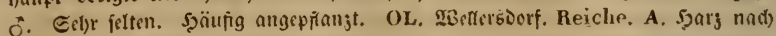
Schwabe, PS. Gutenberg. Sprengel.

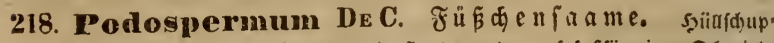
fen jiegclftänsig. Ed)alfanmen abgeftukt, unten nuf fuffömiger Edismicle. - Sitpfit)en wor seu 2ufbriilsn stantig, 33\%. gerb.

728. P. Inciniatum DEC. (Scorz, octang. Гтн.) Fl, germ. exsicc. 1163. Ed)lafi nufred)t; ๔eitentengel nuffreigeno, äftig; Jieisrat,

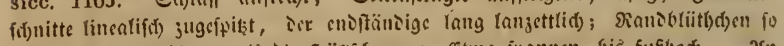

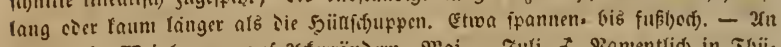

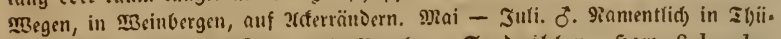
ringen. PL. Galien. Blase. A. Sernutrg, Eandersileben. Saary. Schwabe. PS. Sarby. Scholler. Beljig. Rabenhorst. Mietleben, Eeben; Eistelien an

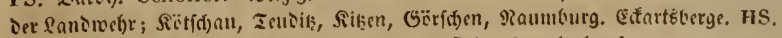

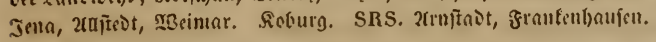

219. Scorzonera L. Şiilf jiegcliduppig. grudtthoien naft. Ed)ar.

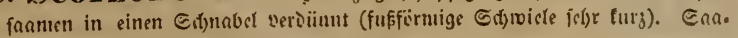
mentrelle gleid)föruig, feicrartig verwebt.

729. S. purpurea L. JAc2. austr. t, 46 . 33lätter lincaliīd) coder

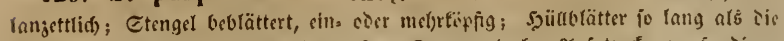

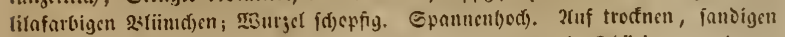

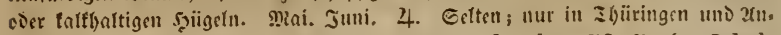
balt. A. 3ernourg, 5arggercie, Ennderiteben. Schwabe. PS. 3ant(1). Schol-

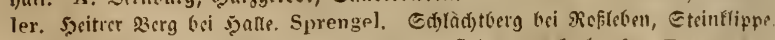

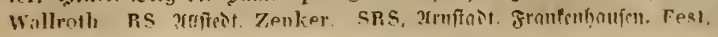


730. S. plantaginea Sсисетсн, *) Fl, dau. 1653. Fl, germ.

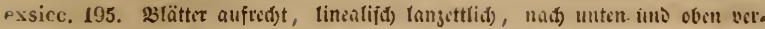
id)mälert, nervig, Etenger eins cier wenigtipfig, untere Gd)uppen Tanjettlid) uno

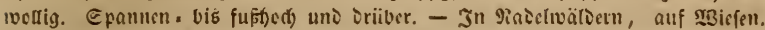

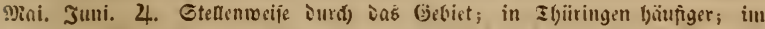

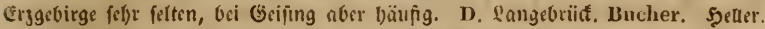
Rchb. Deesoner 5sioe. Rchb. Sotta. Bauer. Blajeıik, હarsourf. Fic, - 2lten.

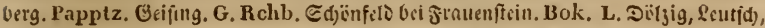

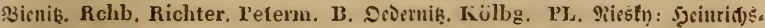

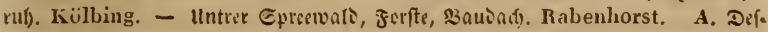

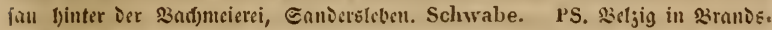

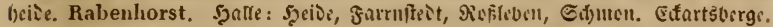

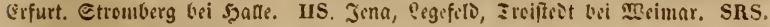
seidfrïben bei siludulfait.

731. S. glastifolia IV. (Sc. mir. pamn. 1.) Ceus, hist. pag. cxxxVIII. Fl, germ, exsicc. 738. Etengit etwas äpitig; silätter linenliớ)

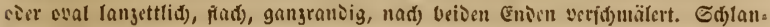

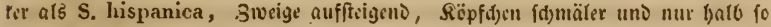

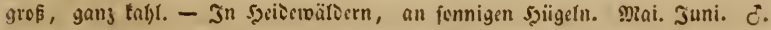

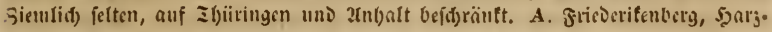

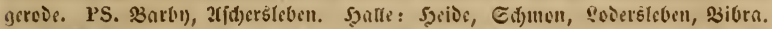
Erfurt. Buddensieg. Euly, Metsch. IIS, Martintcic. SRS. Itrnftnit. Etnit Ilı1. Schöuheit.

* 732. S. hispanica L. Cuvs, hist. pag. cxxxvn. Etengel

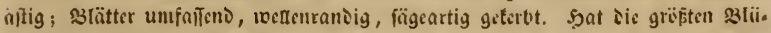
thenfëpfe uno Greiteften Gdjuppen. Etenget $2-t^{\prime}$ bort). 2(us Epanien, bist uni ia angepinanjt. Mini. Juni. 4.

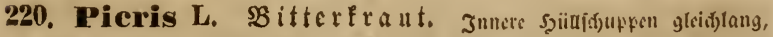

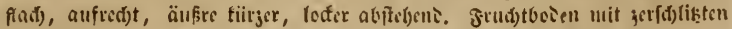

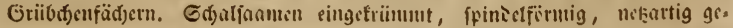
furd)t. Enaumentroue fik̨ent, fiotrartig. - 331. gitb.

733. P. hieracioides L. Scnk, 1, 216. Fl, germ. exsicc. 1661. Ettif bel)antt, äftig; Sïpfden Doronnutig; Silütter länglid) Ianjottlid), budstig

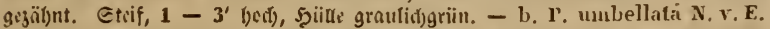

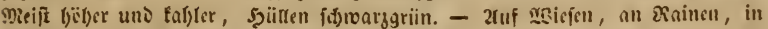

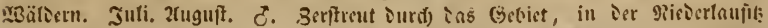

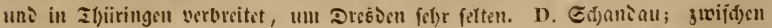

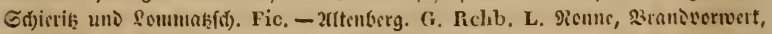

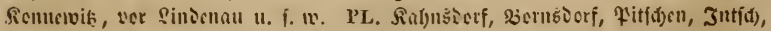

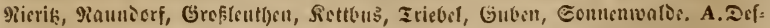

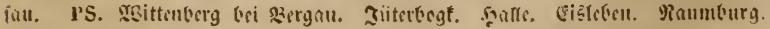

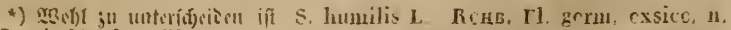
12:7, nit fityofiger Mgurjil. 


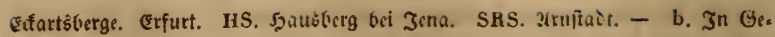

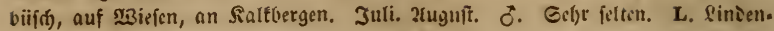
thal. Petermann. PS. Nï̈gliţ. P'etermam. 23erge in ier G̈egend won Sï̈llon. Reichenbach.

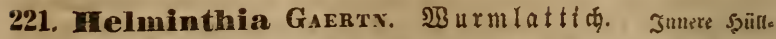

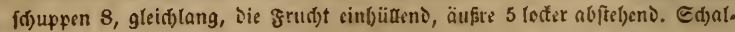
faanen auer gefurdit, Saamenfroue fiocrartig, gilitielt. - 23 l. gelb.

734. H. echioides Gakrtr. II. t. 159. f. 2. Fl. germ. exsicc.

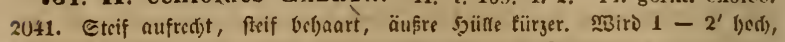

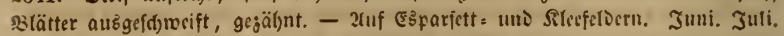

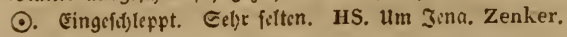

222. Taraxacum HaLr. Ffaffentöbrlein, fettens

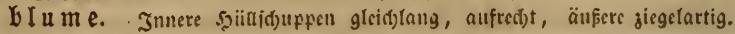

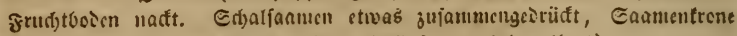
banrartig, gefitielt. - Edjaft rïbrig, cintïpfig. - 31 . gett. *)

735. T. officinale WVrgg. Scrix. t. 219. Hayse Arzngw. II. 4.

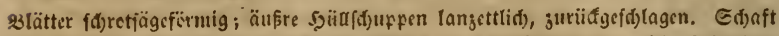

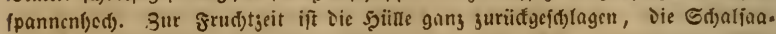

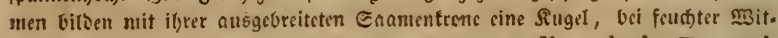
terung zicht fit) wicicr allez zufaumen. - Ofr. Radix et herba Taraxaci.

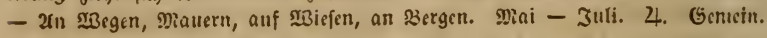

736. T. Iaevigatum DEC. (Leont. alpinns HPP.) ST. 41. Fl.

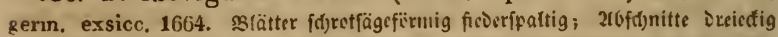

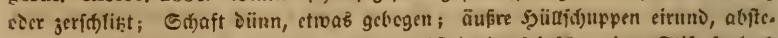

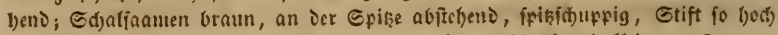

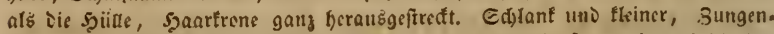
blïmden unten uit olivengrünem હtrcif. - b. T. corniculatum (KIT.) bie äl.

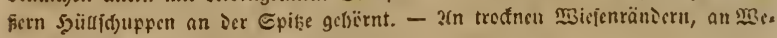
gen, felfen. Mai. 4. gitifit felten.

737. T. palustre DEC. Engl, Bot. 553. Fl. germ. exsicc, $20 * 3$. 3(ätter linear länglid), gejäl)nt; äufre șïablätter breit eifërmig, an Die innern

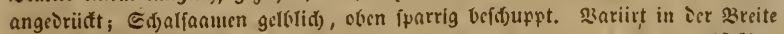
Der słätter, fo wie in Deren Salynung, bišmcilcn ganjrandig: a. temuifolius Hpr. ST. 41. odcr gejälnt: b. salinus Hpr. St. 41. - 2unf Eumpfivicfen,

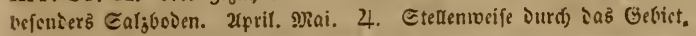

738. T. Scorzonera (Leont.) Rотн, El. dan. 17u8. 33lättcr

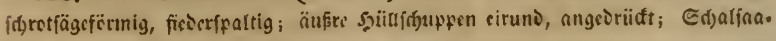

* Die arten Diejer Eattung bleiten bei Ser Ergengung aus Gaamen in Den

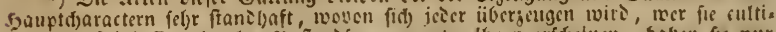

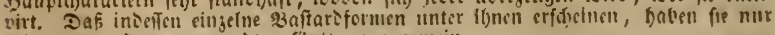
nit aflen nniern sermanten Gattungin giusin. 
Iten oben turj unt jerftent befffuppt. - Xuf હuntpfwiejen. \$nai. 4. Etef. Ieniveife Durth Das Gebict.

739. T. glaucescens (Leont.) KIT. B̉tätter sïnn, tulfl, bogig

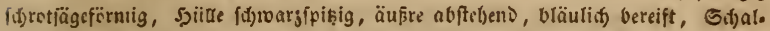

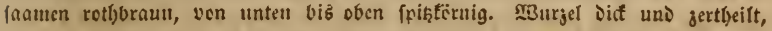

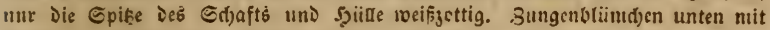
breitem, otivengriinem Strcif. - 2uf zerfocien. Mai. Juni. 4. Z. Glaue (j) au. Grols.

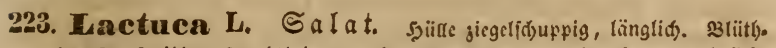

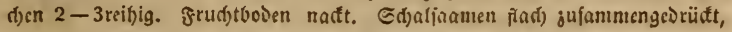
rbombifo, Eaamentrene haarartig auf fadenförnigem Etifte.

740. L. saligna L. Rupr. Fl. Jen, ed, Hall. t. 4. JAc2, austr.

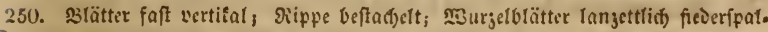

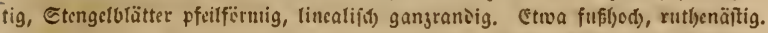

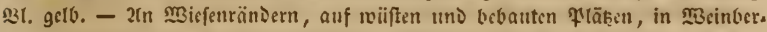

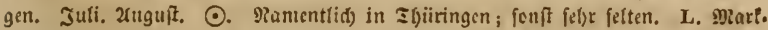

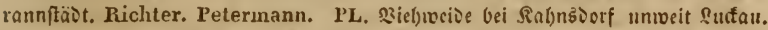

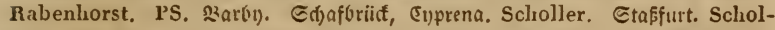

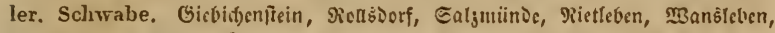

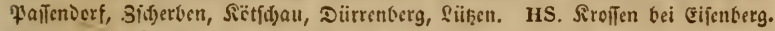
Brimat. Zenker.

741. L. Scariola L. HArsr Arzneigew. I. 46. Blätter vertilal,

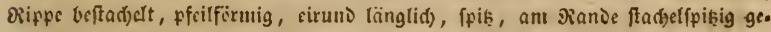

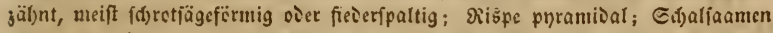

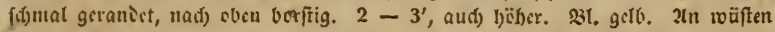

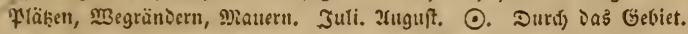

742. L. virosa L. Harxe Arzneigew. I. 47. 23lätter borizontal;

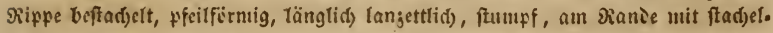

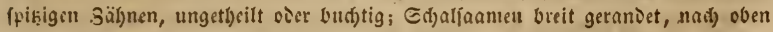

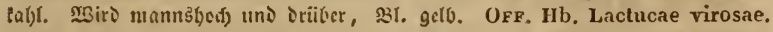

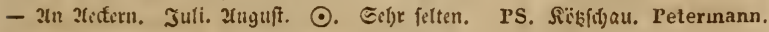
SRS. Galjgraben bsi frantent)aufen. Hornung.

* 743. L. sativa L. Harse Arzngw. vir. 30. 33lätter all Ricl

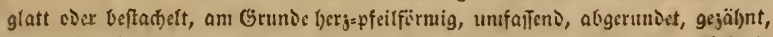

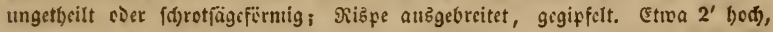
231. gelb. S3ariitt aud) unit fraujen uno gerjofliktin, mit gleidffarbig griinen,

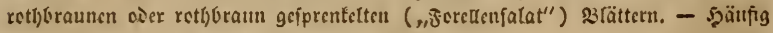
angebaut und verwilderni. Juli, atuguft. $\odot$.

744. L. striça IV. KIT, t. 48. Unterifte \$ä̈tter teierfërmig oicr

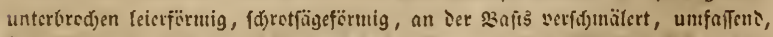

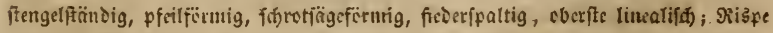

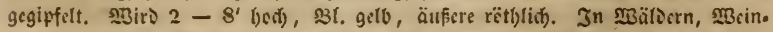

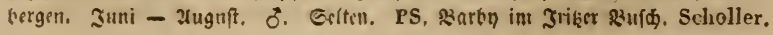




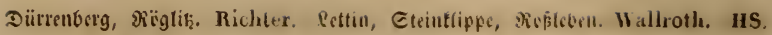

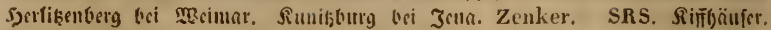
Reichenbach.

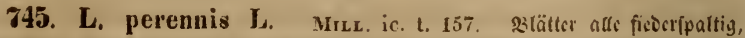

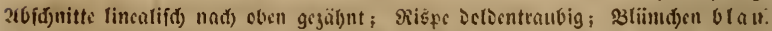

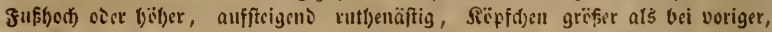

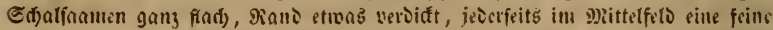

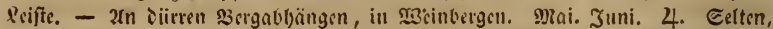

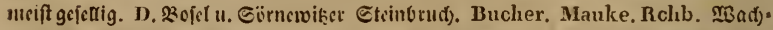

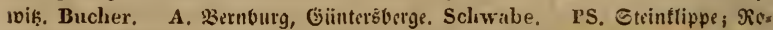

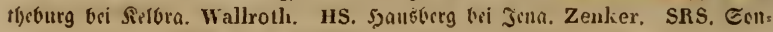
ierşbaufen แei Ju(t)aburg. Wallroth.

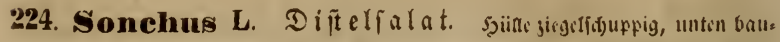

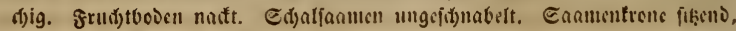
banrförmig, merí). - 231. grib.

746. S. oleraceus L. Scuк. 1. 256. (qunt)t.) Hayse Arzugw.

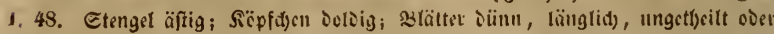

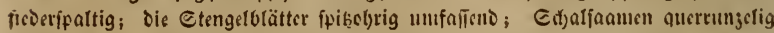

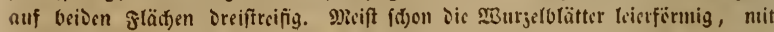

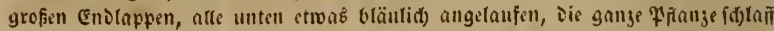

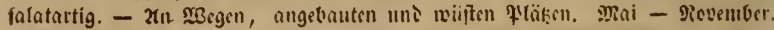
๑. ठ. Gencin.

747. S. asper Vichars. Schк. t. 256 . (frudt.) Fl, dan. 843. H. gem. exsicc. 1165. Etengcl älitig; Die R̈̈pfd)en iolsig; 3lätter länglid)

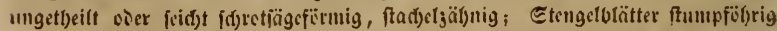

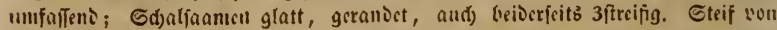

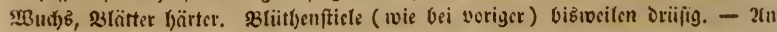

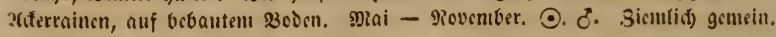

748. S. arvensis L. Schk, t. 217. (Fru(t).) Fl. dan, 606. Einfad);

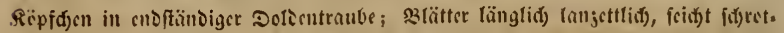

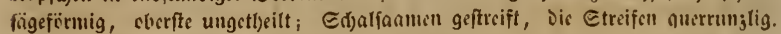

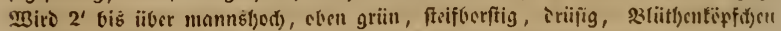
fobr groforiitbig. - 2uf 2toditn. Juni - 2uguft. 24. Gsucin.

749. S. palustris L. Fl, dan. 1109. Sснк. t. 217. (ริtud)t.) Sïpf: d)en uno ifse Eticle faft iofis, fdowargorifig lonarig; szlätter ticf ffcilförmig,

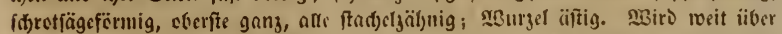

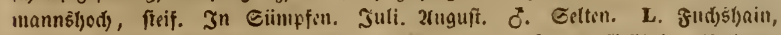

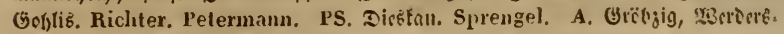
vauín, frau, Eanterklsbin. Schwabe.

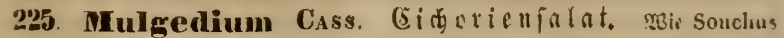

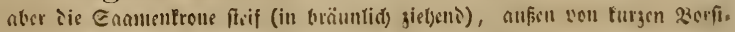
bon une eincm Ringe umgrben (mic fri Lactuca). - 251. Mfau. 
750. M. alpinum Lessixg. Fl. dan. 182. Sitüttir ffociförmig,

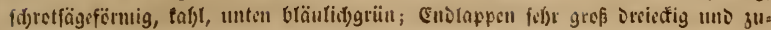

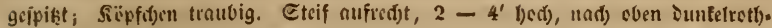

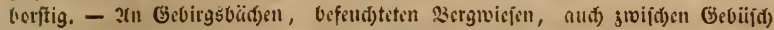

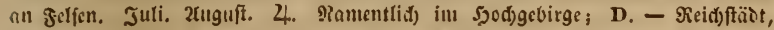
altenberg, 3innwalo, graffau, \&rauenftin, Edjënfils. Z. (Gottesgabe, Platten),

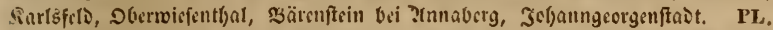

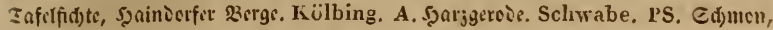

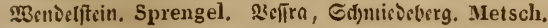

296. Chondrilla L. Rnorpelfalat. Syüajuppen ctwa

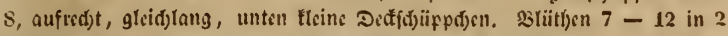
Sieifen. S(j)alfaamen unter ism ๔đjnaber mit Siränzdsen uni fdjuppenar:

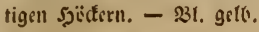

75̃1. C. juncea L. JACQ, anstr, t, 427. GAERTN, II, 158, f, 6.

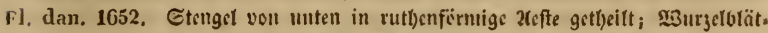

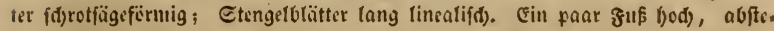

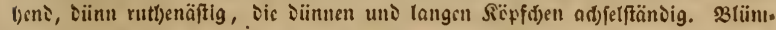

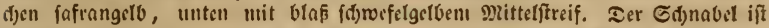

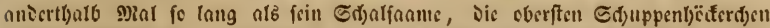

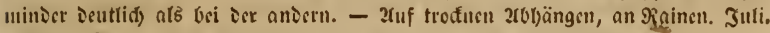

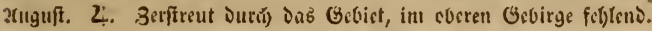

752. C, acanthophylla Вовкн. (Ch. juncea.) Scнк, t. 218.

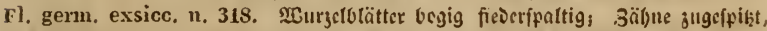

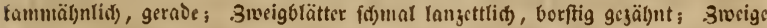

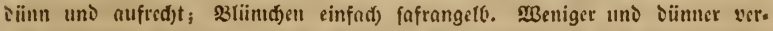

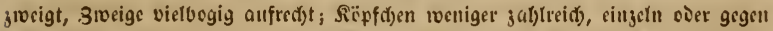

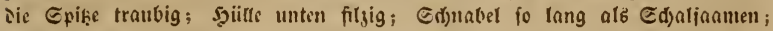

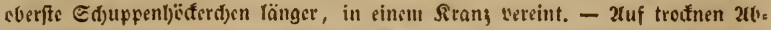

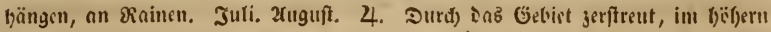

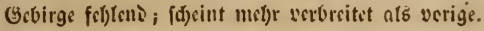

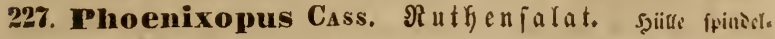

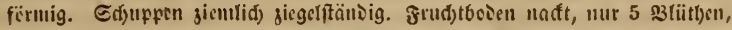

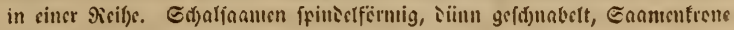
baarartig. 331. Grafzerte.

753. P. vimineus Rснв, JAc2, austr, t. 9. Fl. germ. exsicc. 11. 598. Siätter blaugriin, Gerablaufint, unterfte tief fammartig ficosrfwaltig;

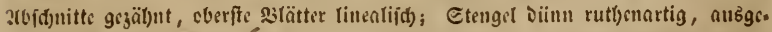

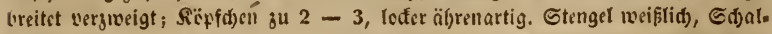

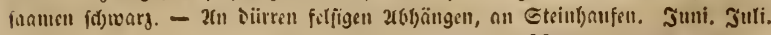

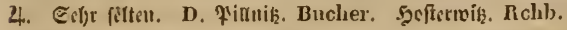

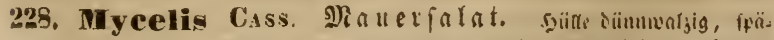

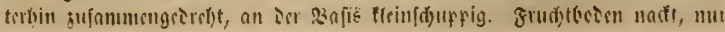




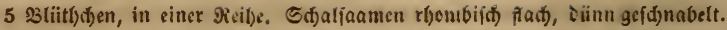
๔aumentrone baarartig. \$31. getb.

754. M. muralis Rchв. (Pren. mur.) Sснк, t. 218. Fl, dan, 509.

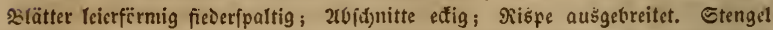
fd)lant, 1 - 4' bod), s3lätter grïn, Dïnn falatartig. - 2fuf Maucrn, E(futt,

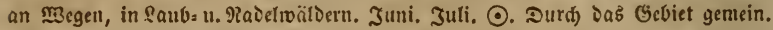

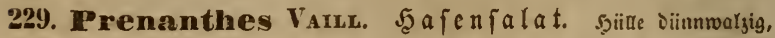
Gduppen in 2 rciben, unten mit tleinen G(jiipfd)en. Fruditbooen nadt, nur 5 stiutbden in eincr Reil)e. E(f)alfaamen prismatifd, Caantentrone fi h̨en D, haarartig. Sl. tarminrotl).

755. P. purpurea L. JAc2. anstr. t. 317. SchK. t. 218. (รruđft.) Fl. gerın. exsicc. n. 1337. Blätter länglid) langettlid), budhtig ceftig, cliere lan.

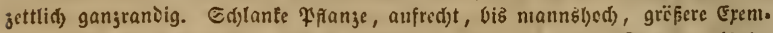

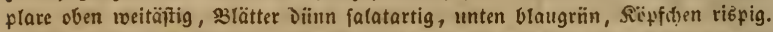

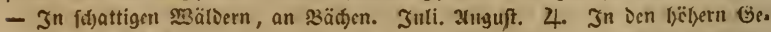

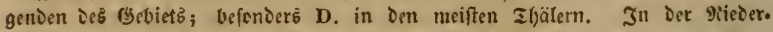

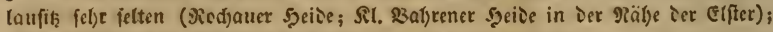
un Peifjig uno in 2unl)alt fellent.

230. Crepis L. (5) $r u n b f \in f e, ~ \Re i p p a u$. syillfduppen nit

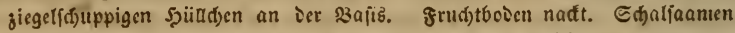
gleidffirmig, ftielrund, lä̈gs gcfurd)t, an icr Spif̧̨e verdïnnt. Saanens

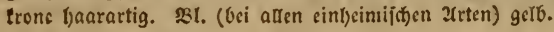

756. C. tectorum L. Fl. dan. 501. ScнK, t. 222. (frntdit.) Fl. germ, exsicc. n. 226. 2ufred)t, nad) oben afdgrau filbig und Doloentraubig; Murzelolätter bud)tig gegäl)nt soer frederfpaltig, obcre ffeilfïrnig linealif(b); äu. fere Sünfdüzpden anliegeno; Gdjalfaame 10rippig, oben verdiunt. Epannen.

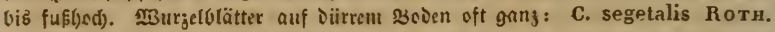
- 2uf Mauern, 2ledfern, an Megen. Juni. Juli. ○. शRidjt felten Durd) Das Gebiet, fdeint im Groirge zu fel)len.

757. C. virens VILL, (C. tectorum) Engl.Bt. 1111. 2uffiteigent ober allfre(b) tal)l; 23 lätter tabl, bu(b)tig gezälsnt oder f(b) rotjägeförntig fiederfpaltig;

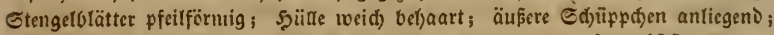
S(j)alfaamen 10rippig, nad) oben ein wenig verdünnt. - a. pinnatifida WruLd. 11. germ, exsicc, n. 33. Zufred)t, bis über fufl)o(h, nur cinige Eeitenftenget aufftcigeno. - b. adscendens. Fl. germ. exsicc. n. 32. Sgetbftform, ieren

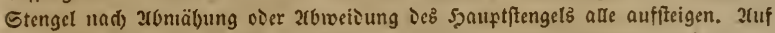
trednen 2ecfern erfdjeint fie jel)r Elein und jartäjtig: Lapsana capillaris L. -

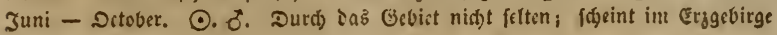
gul fel)len.

758. C. agrestis W, K. t, 220. Fl. germ. exsicc. no. 34. 2uff

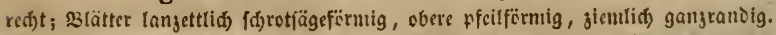
23 tiitlyenfticle uno Szïllen sriifig bebaart. Gröfer als vorige, faft wic folgente,

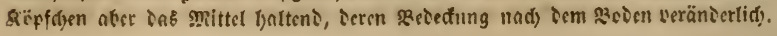




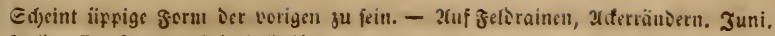

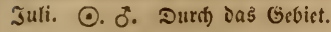

759. C. biennis L. Engl, Bot. 149. Scrk. t. 222. (\$rudt). Etengel aufred)t, rispig, gefurd)t, unten fteif belynart; B(ätter f(d)retfägefërmig oier fieier:

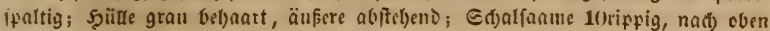

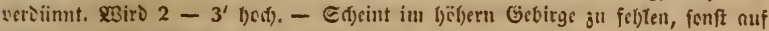

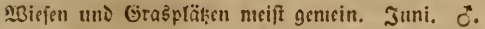

760. C. lodomeriensis Bess. Gu. sib. II, t. XI. Etengel auf. redi)t, gefurdjt, to woie tie fifrotägefërmigen, bigig ficoeripaltigen uno (nad) oben)

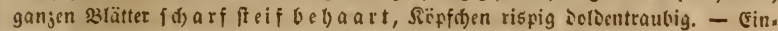

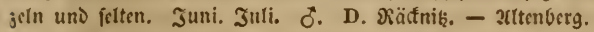

\section{Geracium Rснв. in Monss. Handb. Eperbers}

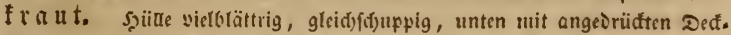

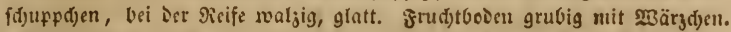

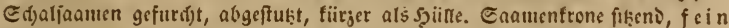
b) a arartig, fdueeweif. - s3ätter zart falatartig, 31. gelb. -

761. G. praemorsum (Hierac.) L. Fl. dan. 9+2. ST. 39. Fl. gerın. exsicc. 1439. Slitthen in enoftändiger Iraube auf eincul

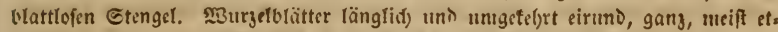

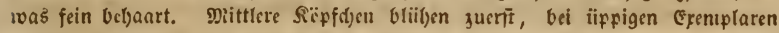

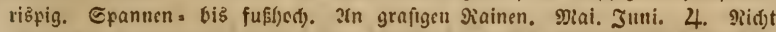
alfgencin. D. Safdentorf. Bucher. Ë̈rncivik. Manke. Siegenbufd). G, Rchb.

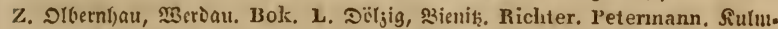

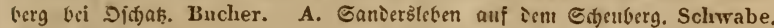

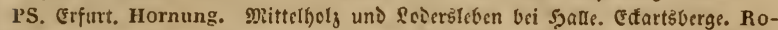

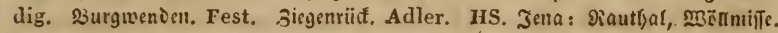

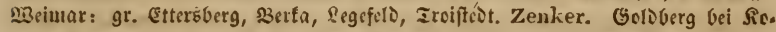
burg. Hornung. Grub bei zif)emar. Metsch. SRS. Frantenl)aujen. Hornung. Siuioljtait. Schünhleit.

762. G. succisifolium (Hierac.) ALc. H, integrifor. Sx.

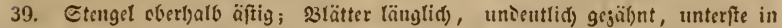

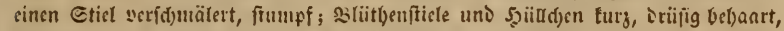

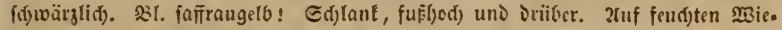

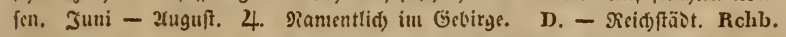

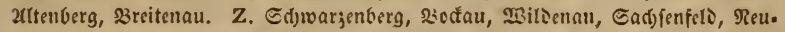
Durf. Bok. MBolfenftein. Weiker. L. Dïtzig. PS. Esfurt. Hornung. Budden-

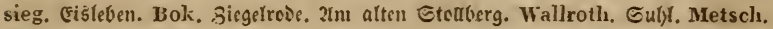

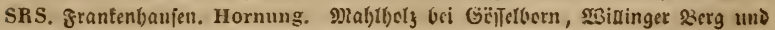

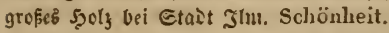

763. G. paludosum (Hierac.) L. Scrk. t, 221. F1. dan.

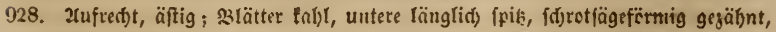
sbere sirund tänglid). Sdlank, $1-2^{\prime}$ bod). Xuf Gumpfwiefen, in Gebuif(')

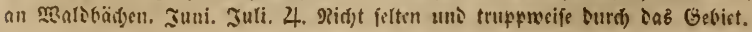


r64. G. prenanthoides (Hier.) Vile, Gtingd auficet)t (meifit cinfad),

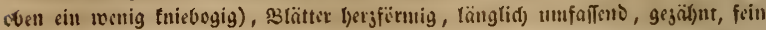

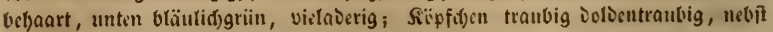

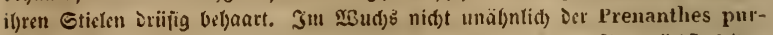

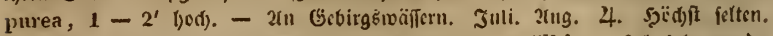

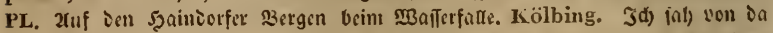
feine Exemplare, fano is aber in sicejengebirge jelbit uno balte Den Ctaniert fiir wal)rf(f)cinlid). Bergl, Fl, germ. exsicc, 1n, 228.

232. Gatyona H. Cass. (5) aty one. Siife unten bauthig,

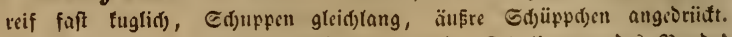

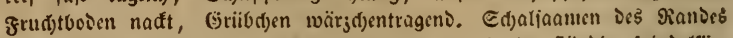

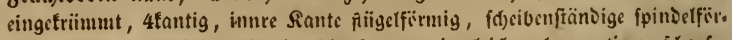
mig, Dïnn geid)nabelt, gefurd)t, fif)arf, alle uit gleid)er, lyanrartiger, iff)arfer Gaamentrone.

765. G. Dioscoridis (Crepis.) L. Sснк, t. 222. 2ufredt, äftig, $1-2^{\prime}$ (jod), 3lätter Diinn falatartig, untre fdjretfïgcartig leierförmig, core

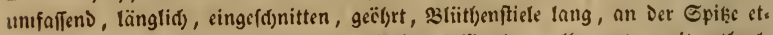

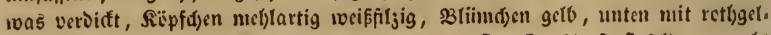

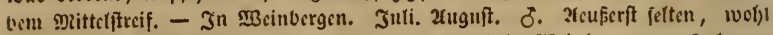

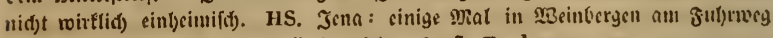

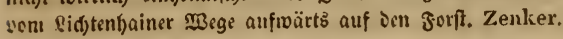

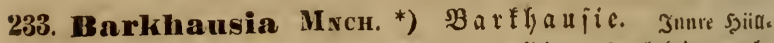

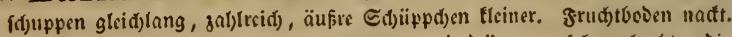
Ed)alfaamen fpindelfërmig, alle lang unD oï nn gef(t) nabelt, Die

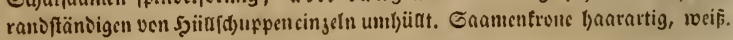

766. B. foetida De C. (Crepi8.) Engl. Bot, 406. G.1ertx. Il. t.

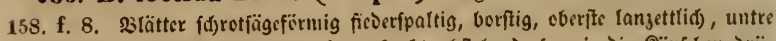

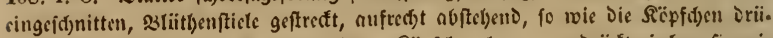

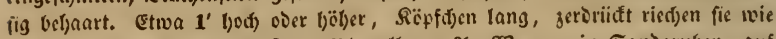
sie Blätter son Prumus Padus, 231. gitb. - 2un Megen, in Conigruben, anf

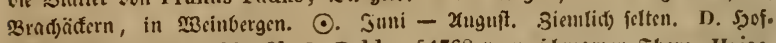
tösniķ. Dehne. L. Rchb. fil, G. Rchb. [ 1768 vorm idbonrjen sl)orc. Heise.

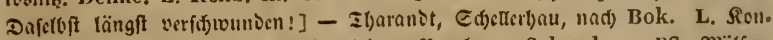

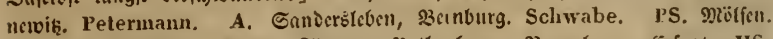

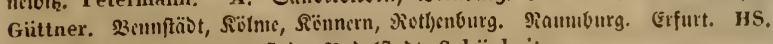

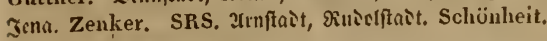

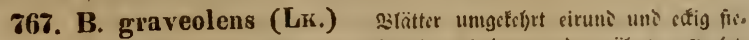

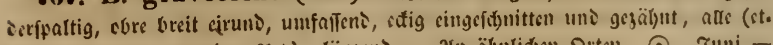

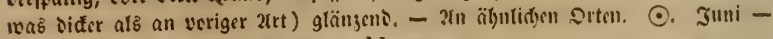
?tuguf. PS. Gegent ven Ëttria. Relib.

*) Gonannt nad): ,G. Barkna(:s: specimen inang sist, lascit. planlaxum ex Flora Comiläus Lippiaci, Cǘting. 1775." 
234. Hieracium L, ๖a

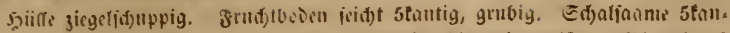

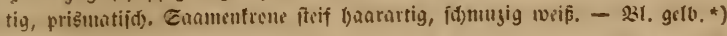

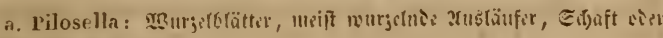
fuif blattrojer Etengel.

768. H. Pilosella L. Fl, dan, 1110. St. 27. Harxe Arzngir.

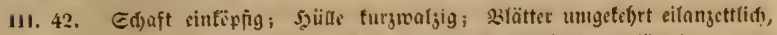

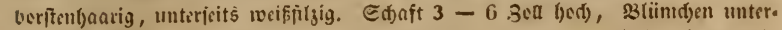

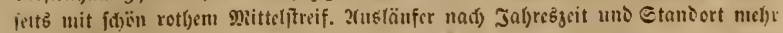

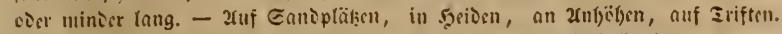
Mai. 2uguft. Eeptemerr. 4. Gentin uno grielig Durd) Das Gebiet.

769. H. Auricula L, Fl, dan, 1111. (dubium Sx.) Engl, Bot, 2332. Eçaft groci. bis vierfïfig (biswerilen mit eincm fleincn \&latte) ge•

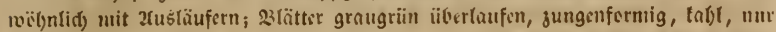

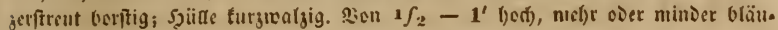

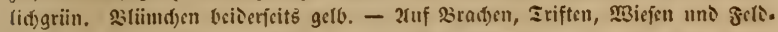
raincn. פRai. Juni. 4. Gemcin uno gefellig gruppirt.

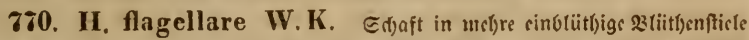

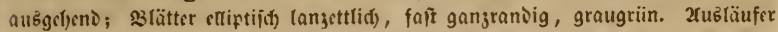

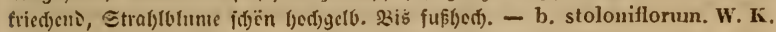

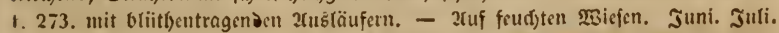

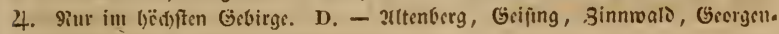
fats. Rchb. G. Rclib. Papperitz.

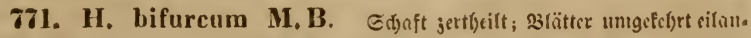

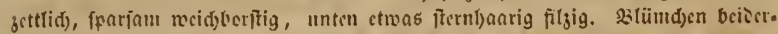

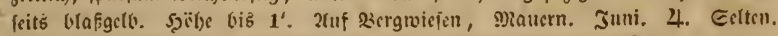

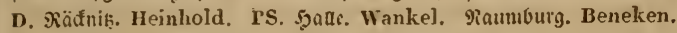

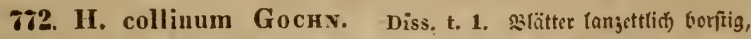
Etengel untin wenig brättrig, trugodoig Doloentraubig, Şütte grau bel)aart,

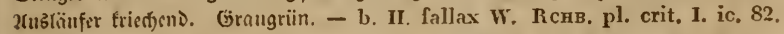

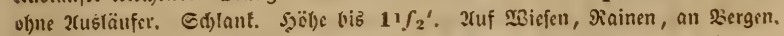
Miai. Jumi. 4. SBob) jiemlid) vertureitet in Den sisrggrgenien. D. Grefent=

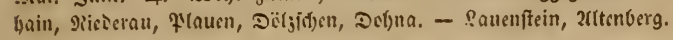

783. II. setigerum Tsсн. (Н, echioides non Lозх.) W. К. t. 85. Stengcl unten wenig blättrig, fo wie tie (anjettlid)en selätter jottig, raud) o\&: baart uno filjig; Dolientraube gegipfelt; אï̈pfit)en graujottig, jerftreut, langbor.

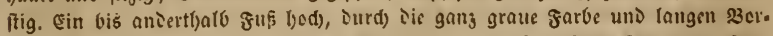

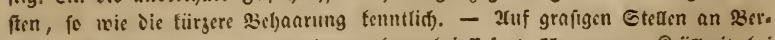

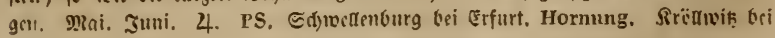

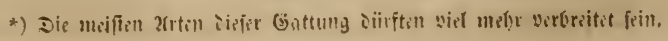




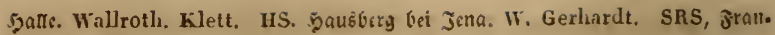
bentiaufen. L. Relib. fil.

774. H. cymigerum Rснв. Рснв. (cymos. 3. ) pl. crit. I. ic. 116. Etenget unten beblättert, hod), fo wie Die länglid) (anjettlid)en siätter grau, friu bebaart uno jerftreut lang bef)aart; Irugiolve regelmäfig gegipfelt (feine 2ub.

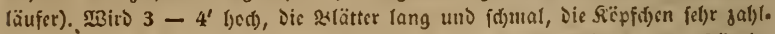
reiळ. - b. Vaillantii Tscr. mit 2rußläufern. - 2uf Micjen, an Şiigeln.

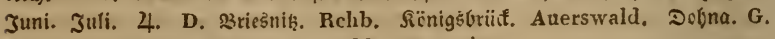
Rchb. - 2rttenberg, Geifing. G. Rchb. Papperitz.

775. H. praealtum ViLL. Rспв. pl. crit. I. ic. 114. Sgetgirün, Blätter ungetef)rt eilanjettlid), etwaz bläulid) überlaufen und fo wie ber unten toenig bebtätterte Etengel Pabl, nur an Der 2 afis lang gemimpert; Irugoolie

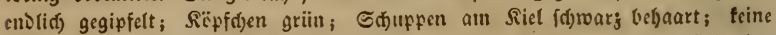

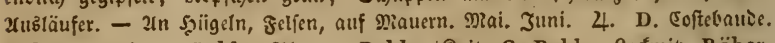

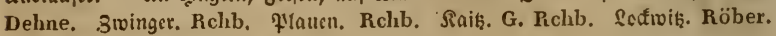

776. H. obscurum Rснв. Rснв, pl, crit, I. ic. 115. Dunfel blät.

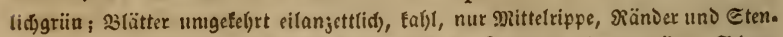

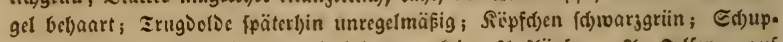

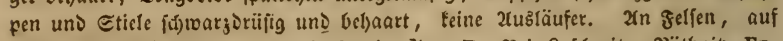

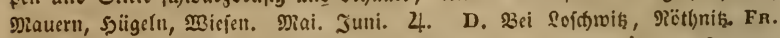

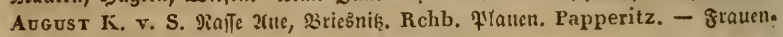
ficin. G. Rchb. Papperitz. PS. 3enndorf. Rchb.

777. (786 ?) H. glaucescens BEss. 23(ätter (angettliđ́), Gläuliđ́) grüı,

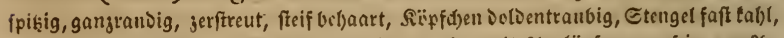

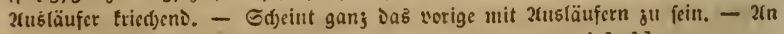
afferrainen. Maai. Juni. 24. Gef)t felten. D. Flancn. Heinhold.

778. H. radiocaule Tscr. Etengel unten roenig befjaart uns we.

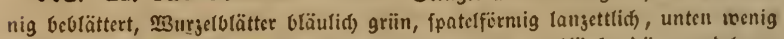

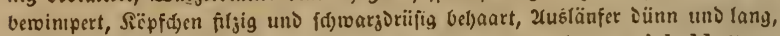
meift blütbeutragend. - Juni. 4. D. Sgetlenioerf, attenberg. Heinhold. Papperitz. G. Rchb. Salfenbain. Papperitz.

789. H. Bauhini Schtut, Baur. hist, II. p. 1040. 3lätter lan.

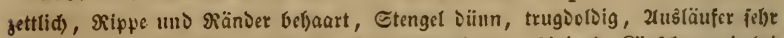

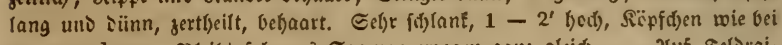

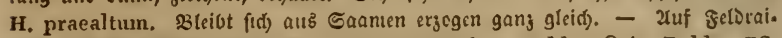

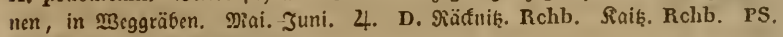
Bci Rauniourg. Scheidhauer.

* 780. H. aurantiacum L. Jce. austr. t. 410. ST. 39. Etengel unten beb(ättert, weid) raud) beljaart, sben brüfig uno f(j)ror's beljaart; 33lätter unigete(j)t ciruns länglid) oier lanjettli(t), (ang, weid) bef)aart, of)ne Stern(jaate;

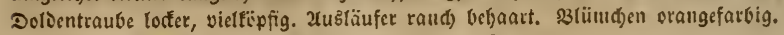
angepfianjt (arfen, Riefangebirge). Miai. Juni. 4.

781. H. pratense Tscr. (cymos.) Sт, 39. Etenget untin (meifit 


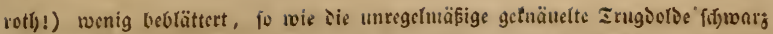

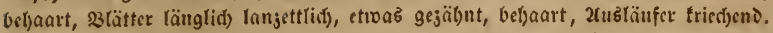

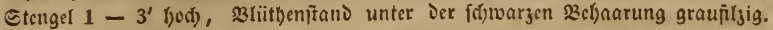

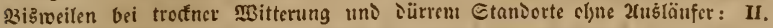
pseud-auricula Tsch. eine tiimmertidje forn nuf Binuern coer Ibonboden,

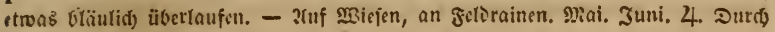

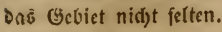

782. H. cymosum L. Rснв. pl. crit. I. ic. 34. Ctengel unten wea

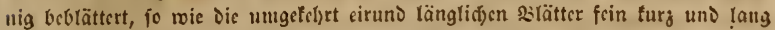
bchaart, Dunfilgrïn, Zrugoolde fel)r regelmäfig, gegiffclt, R̈̈pfifen gettig. Dun.

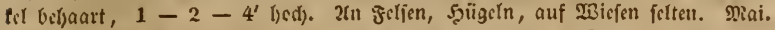

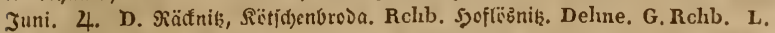

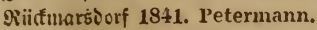

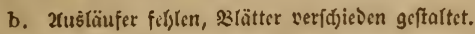

783\%. ? II. Schraderi DE C. (H. alpin. W. ST. 37.) Etcngel uncijt

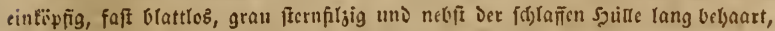

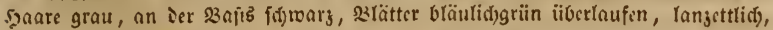

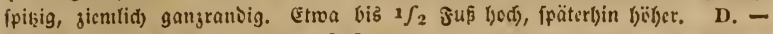
In Geifingsherg einmal 1S20. Sclubert.

$26 \mathrm{~nm}$. Hierac, alpinum L. Fl. germ. exsicc. n. 73\%. (pumilum HPP. ST.

37.) nad) Scnwabe Fl. Anhalt. pag. 342. A. Bictorsljübe, פeügoejprung. Id) fals teine Exentplare ven ba.

784. H. Sohmidtii Tасsсн, (rupestre Fl, germ, exs, n. 1658.) Stengel unterhalb 1-20lättrig, mit wenigen iolicutraubigen Siëpfónen, grau

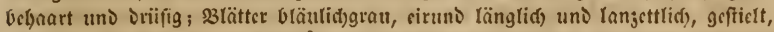

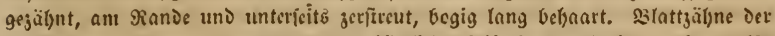

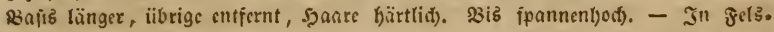

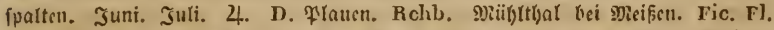
Z. Geifien bei Drbernlyau. Leonhardt. Ed)roerta uno Snetenitein. Weiker. PS. Gaalberge bci Siegenriid nad) Gaalfolo gu. Schönheit. SRS. Rird)felfill bei Silantenburg. Schünheit.

785. II. incisum IoPPE. St. 39. Fl. genn. exsica, n. 1160).

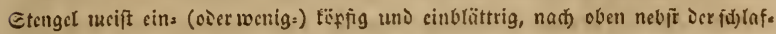

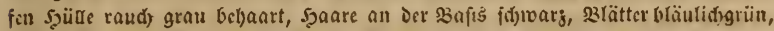

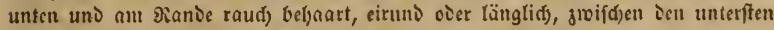

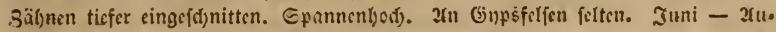
guft. 4. HS. Frofne uno şcrnonicnberg bei Riartinrede. Schönleit. SRS.

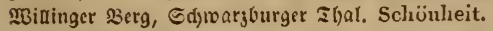

886. H. mwrorum L. ST. 39. etengel unten 1-26lättrig, sufitei.

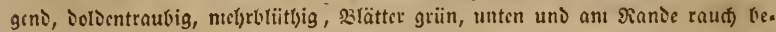

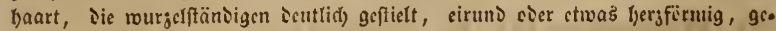

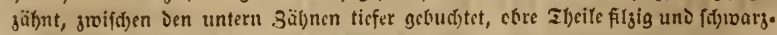
iriilig. - b. nemorosum Pers. fdjlanfer, boller griin, Etengelolätter mil) lìg, formäler, fpilzig. - c. sylvaticum L. Gäber, slätter breit, etengelotätter

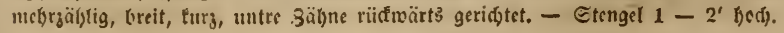




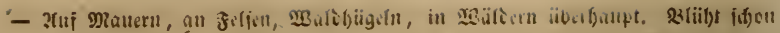

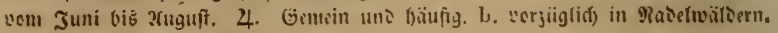
c. in suntlen Saubuiätirn.

887. H. Lachenalii G.ı. (H, muror. ALs. ped. t. 2). f.1.) §tı.. get anfred)t, bet)aart und beblättert, langäffig uni yon sinem 33latt zum andern

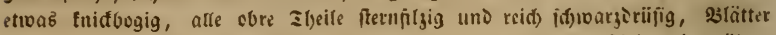
griin, unten uns am sanie rand), ciruns, meift cilanjettlid) geftielt uno gezäbnt,

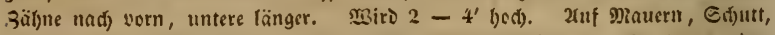

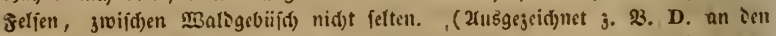

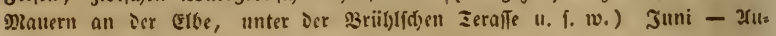
guif. 4.

788. 11. asperum Sсицеich. Etengel fó)arf, beblättert, äftig, riò

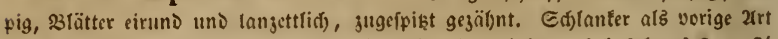

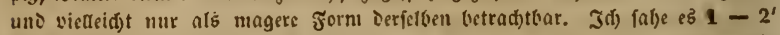
hod) und mit fdrweigerifden (Epeniflaren (H. scabrum GAUD.) iibercinftimment. - 2fn Mauern, selfen. Juti - Eeptember. 4. 3erftecut. D. Meiffig, uders. Derf, פieifner \$3ad u. a. D.

789. H. laevigatum Wruxd. hort. Berol, t. XVI. Etengel anf: red)t, f(j)lantäftig, beblättert, s3lätter (änglid) langettlid), falsl, geftielt, in ber

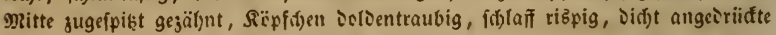
Soülle an Dor $\mathfrak{B} a f ı$, fo wie ibre Eticle graufilgig. - In $\mathfrak{B}$ äloern. Ju!i - Erf. tentber. 4. Berfitrut surd) ias Gebiet.

790. II. umbellatum L. Eteif aujred)t einfad), 23 (ätter biđłtiftelens,

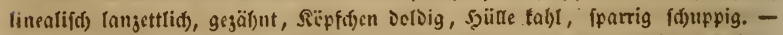
(stroa $2-4^{\prime}$ hod), gelbgriin, bärtlid). Rad) 2umä(bung tonmen sïnne Seiten. ftengel, weld)e oft wenigblättrig uno wenigfëping, fogar einfëpfig fino; ilbre Rlät. ter fino breiter, aud) ftumıf uns Die Senngeidjen palfen nidjt meffe auf Dic

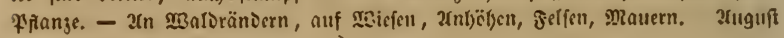
- Detcber. 4. Gemein.

791. H. sylvestre Tatsch. Moris. III. sect. 7. t. 5. f. 62 . Gtcif

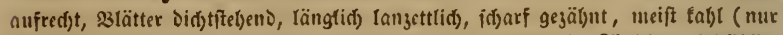

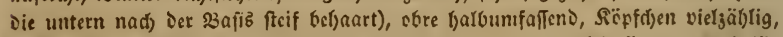
ioldig rispig, Etiele graulid), Şïlle angeorü(ft, tals, Duntslgriin. - 2(ud) für Dicfe ?rt gilt Die bci H. umbellatum gegebene semertung. $2-6^{\prime}$ (jod). Sivi.

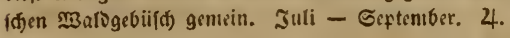

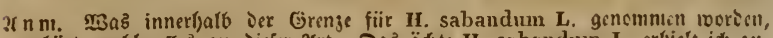

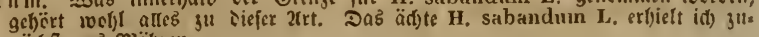
näd)ft aub Miäl)ren.

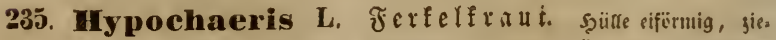
geliduppig, äuferfte follt flem. Frudthoien if reublättrig! Edjalfaa.

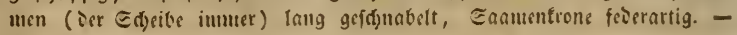
\$3. gilt. - 


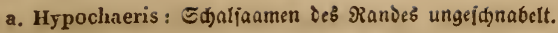

792. H. glabra L. F]. dan. 424. Gaertx. I. t. 160. f. 4. Scra.

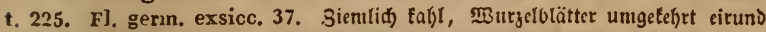
länglid), budjtig gezähnt, Etengel blattlos, äftig, Sjüublätter fo lang als bie ranoblümden. (Etwa $1 \int_{2}^{\prime}$ bis (pannenbod). Xuf Candfeldern unter Dem Ge. treibe. Juni. Juli. (.) G̈mtein.

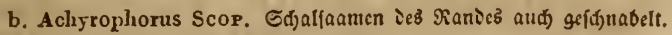

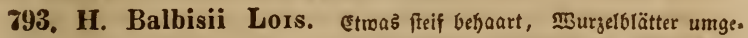

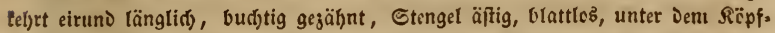

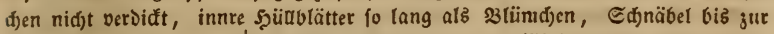

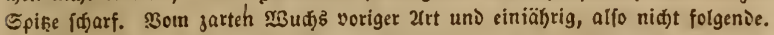

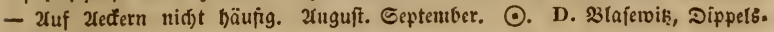

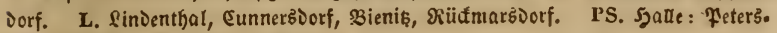
berg, mittelbolg, Siestau. Richter.

794. H. radicata L. Fl. dan, 150. GARRTr. t, 160. f. 6. श्Bur=

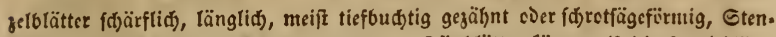

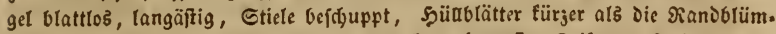
d)en, Sd)näbel nad) oben glatt. - 2uf turg begrajten Iriften, গiainen, an

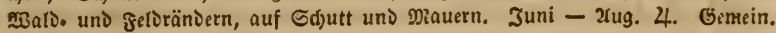

795. H. maculata L. Sснк. t. 225. HAyxe Arzneigew. VI. 43.

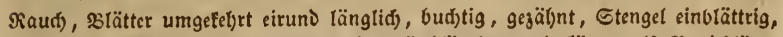

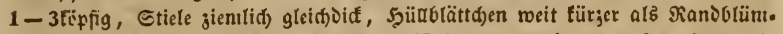

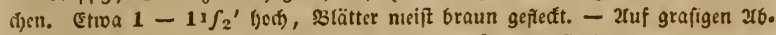

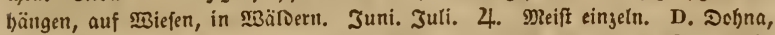
Saik, Sidjoner Gruns, Sieberwartbe, Dberwarthe, \$Beiftropp. Bucher. Bok. Rchb. G. Rchb. - Delfengruno, Delia. Fr. Augus T K. v. S. 2litenberg. Bok, G. Rchb. PS. Dolgner See, 2uerbal; bei \&angengraitau, Duben, Gafien. A. DeTau auf Den SanDbergen binter Dem 2ttenid)en ミborbaufe, Dranienbaum, Singenau. PS. Epittellyolg bei Bergau, 2pollonbberg bei \$Bittenbcrg. Nitzsche.

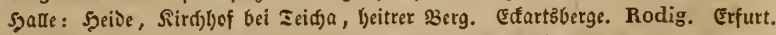
Hornung. HS. Jena. Zenker. SRS. Ztrnftadt, Franfenljaufen. Hornung.

Eu patorin a e: Blumen alle röhrig, żitterlich, Beutel unge= fdrwänzt, Griffeläfte felyr lang, won unten an feit befaart.

236. Eupatorium L. $\mathfrak{B} a$ f $f$ ex b of

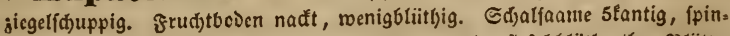
ielfürmig, 厄aamentrone fiseno, haarartig. - \$l. pfirjidjblüt)roth). B(ätter gegenüber!

796. E. cannabinum L. H.YXE Arzngw, VIII. 4t. SchK. $t$.

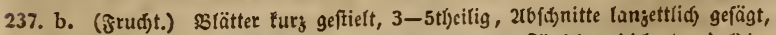
Der mittlere länger. Etcif aufred)t, $2-6^{\prime}$ hoof), Sï̈ffden sicht trugboldig.

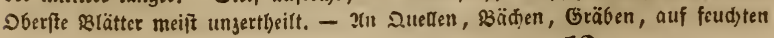




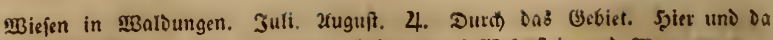

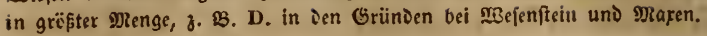

\section{Cyn a roceph a l a e: Blümđen alle röhrig, Briffel oben gelentig, hart.}

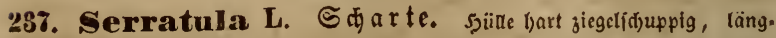
(idi), Sd)uppen Didi)t nngevriift, roeif(id) ge(äunt. Grud)tboden borftig fpreu. olättrig, vielorïtlig. Ganntentrone mełrreibig, baarartig, innerfte Rieilye ant längften. - $\mathfrak{B l}$. bläulid) Earminroth).

797. S. tinctoria L. şätter (đ)ärfliç, f(đ)arf gclägt, eiförnig, unzer. tbeilt odor lcierförmig, fiederfpaltig; Sïpfd)en Doldentraubig. (ङtwa $2-4^{\prime}$ bod,

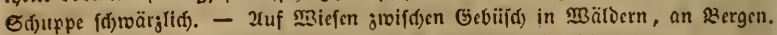
Juti - September. 4. Durí) Das Gebiet jerftreut uno nidit felten.

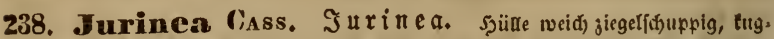
lid), fparrig. Frudytboden borffig fpreublättrig, viclblütbig. Sdjalfaamen

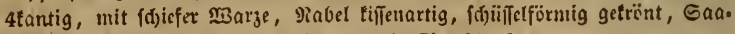
mentrone fisent, fel)r ungleid) linealifd borftig, fdarf.

798. J. cyanoides DEC. (Carduus.) Spr. Fl. Hal. t. 11. Schx. t. 228. Slätter jebr zart berablaufeno, liucalifid) frederfpaltig, umgerolut, unten firgig, Stengel meift cinfëpfig, Şïldid)uppen ftadjelfpif̧ig, abftelsend. Dieift $1^{\prime}$ bod) oder bïber und rangäftig, Sï̈pfe einzeln, filgig. - 2uf Şïgeln. Juli. 2ru. guftz 4. Eefir felten. A. Defiau auf Den Gandbergen binter Dent 2fenfdisen

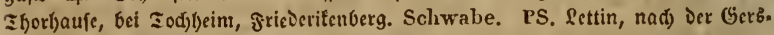
Dorfer soiijten פiart ju. Wallroth. Sprengel.

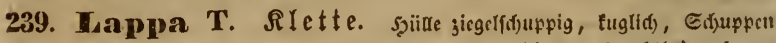

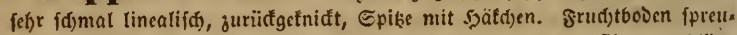
Glättrig. S(j)alfaante rippig, Saamentrone furg, ungleid), borffig fpreublätt.

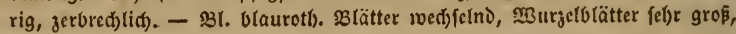
b)erzförmig.

799. L. tomentosa LaM. Şüu(d)uppen diđ)t fpinnıebig, äufere ba:

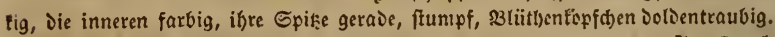
2-4' (jod). 2(n खegen, Diauern, Ed)utt. Juli - Eeptember. 4. Durd) Dab (sebiet, Dod) etrab feltner, als folgenie. Int Şod)gebirge feflent.

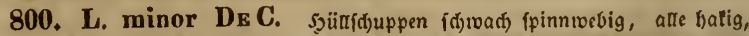
Die iunern farbig; stüttyenfëpfe traubig gedrüngt. Steif aufrectit, $2-4^{\prime}$ hod).

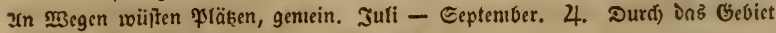

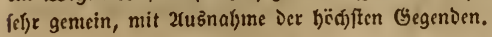

801. L. major Gaertn, II. t. 162. f. 3. Arct. Lappa L. Haynr

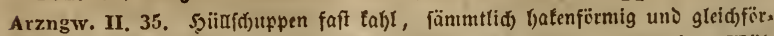

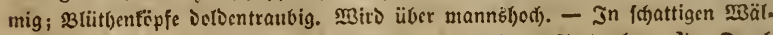
Dern, in Gelviif(t), an 3äumen. Nidjt felten. Juli - Eeptember. 4. Durd)

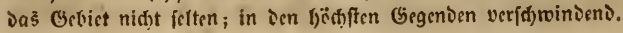


240. Cirsium T. Sirabg Edappen ftedend. Srudtboden forftig fpreublätterig. Edjalfaamen glatt, Gaamentrone weid' feDerartig: - Unter Carduus bei Linnée.

- \$3lätter oberjeitz zienilid tabl (of)ne etriegelborften).

a. Breea Lessrsc. 3weil)äurig, untre 3roeige unftud)thar, 22tüttet

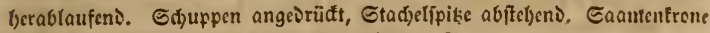
weid), länger als Die untre 5 ipaltige \$lume. 4.

802. C. arvense Scop. Fl. dan, 64t. 23tätter fikend soer wenig

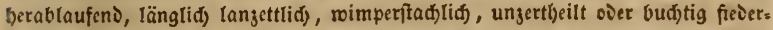

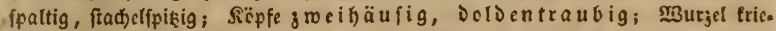

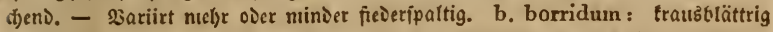
und reider beftadjelt. Etengel $2-4^{\prime}$ cier bä̈)er. - Xuf Xedfern unter Ge.

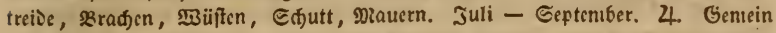
uni gefellig.

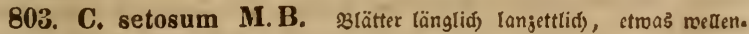
rantig, meift unten meiffrizig, bogig und beftadcelt gejät)nt, audb begig einge* fd)nitten, Die 26f(d)nitte länglid), gan\}, borftig geroimpert. $-4-8$ bod, cbre

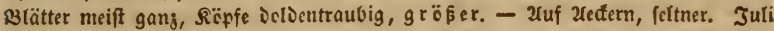

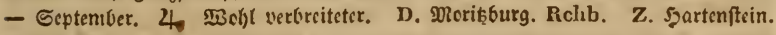
Wankel.

b. Helocirsium Rснв. *) 33t. Jerablaufend, Edjuppen angedriidt, Etadelipitąe abftelyeno. 33. purpur dier feifdfarben. $\delta$.

803 b. C. palustre Scop. Engl. Bot, 974. ScrK. t. 229. (ફrruđt.)

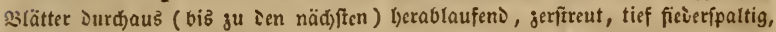

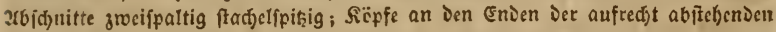

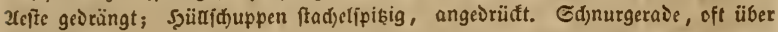

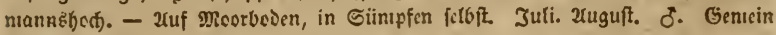
aber vereingelt.

804. C. Chailletii Gaud. Naggert Cirs. d. Schwz. tab. Ir.

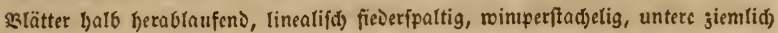
tabl; Sïpfden traubig gedrängt, unten fo wic Die turgen Etiele weiffir $y_{j} i g$;

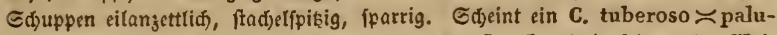

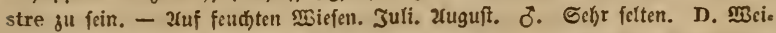
fig. Gust. Reichenbach. - 2ltenberg. G. Rehb. L. ß3ienifz. Petennann. PS. Benniorf. Richter.

805. C. lanceolato palustre NaEgeLI tab. VIII. Blätter cbir.

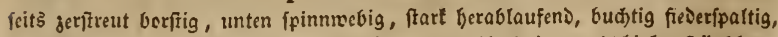

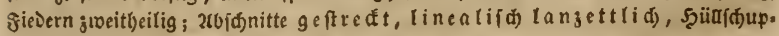

*) Pterocaulon Naegelr (fúfon ExLrot, yergl. unier Herbarienbuch 1 .

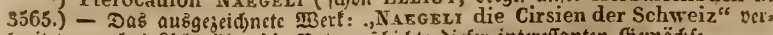

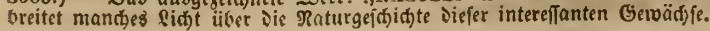




\section{Synathereae. $\quad-180-\quad$ Cirsium.}

pen naderipişig, etmas gebogen abitebend. - 2uf feud)ten आ3iefen. Juri. 2u. guijt. 4. In Jer sä̈lje von C. lanceolatum. Eelyr felten. D. Laufa. Rchls.

c. Microcentron NAEGELr. BI. fişend, Gdiuppen eirund angeiriift,

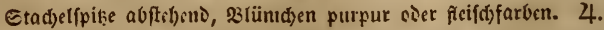

806. C. acaule Arc. Fl. dan. 1114. Schк. t. 229. (Frud)t.) ST. 24. Blätter (al)l, lanjettlid), Gud)tig fiederipaltig, abf(t)nitte eiruno, edtig, 3fpal.

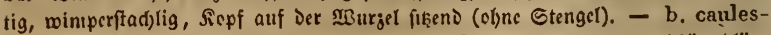

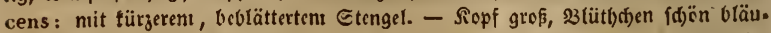

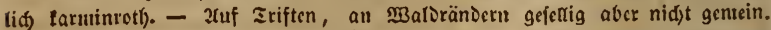

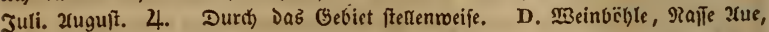

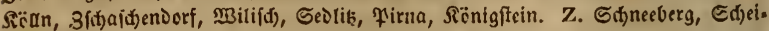

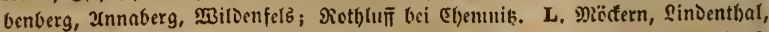

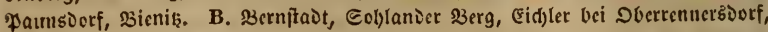
Sjod)berg bei Grofblynerborf. PL. Etromberg, \&andstrone. - A. Frieverifenberg, Sanderšleben, Şar\}. PS. IBittenberg bei Ieudel, Siropitäbtel. Gegend you

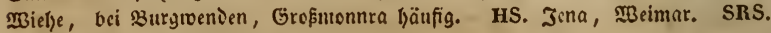
Irnffnot.

807. C. medium Axx. ped. t. 49. Blätter fiǩ̨eno, in ttnuriß lanzett.

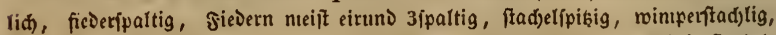

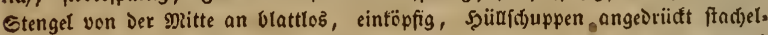
(piłkig. - Mittelaut zmif(t)en Den Mad)barn, (C. Zizianum Kocr anno 1837.) Dod) nađ Nägeli a. a. D. nid)t 23aftard. - Xuf Malowiejen. Zuti. Zug. 4.

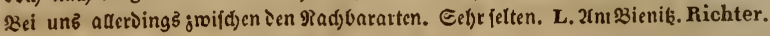

808. C. tuberosum ALx. Card, bulb. inonsp. Cxus. CXIX. Fl. gernn. exs. 229. Burjel tnodenfajerig, 23rätter umfaleno, fièeripaltig, 2ro.

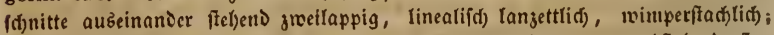

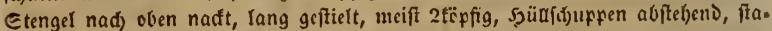
d) 3uli. 2luguft. 4. Selten. L. Sienik, Dölzig, Siriphäne, Grofftuget. A. Difo fau: Sodffifteter und Mlofiglauter M̉iefen. Schwabe. PS. Erfurt. Hornung.

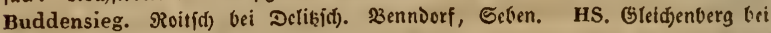
Soburg. Hornung. SRS. Singen. Schönheit.

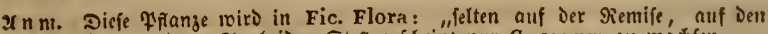

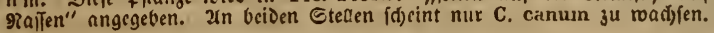

a. SBtündien bed tarminrotb).

809. C. canum ALx. JAç. austr. t. 42. 43. 23lätter länglich lan. jettlich, wimperitad)lig, buthtig gejäbnt, untere Etengelblätter herablaufend ; Stengel vicllëpfig ober langäitig, clyne Defulätter; \$Burjelfafern gébüfdelt, fpin. Delförmig vervidut. - b. pratense LAM. JAce. austr. t. 43. S3lätter einge-

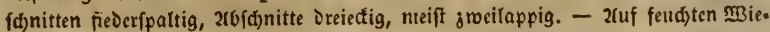

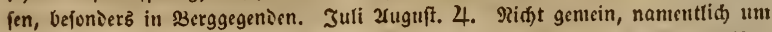

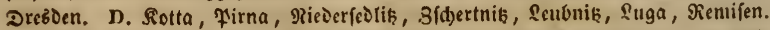

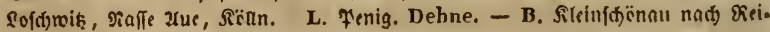
berfiorf su. Kölbing. Nachtigall. 
810. C. heterophyllum ALL. ped. t. 34. Fl. dan. 109. Fl. germ.

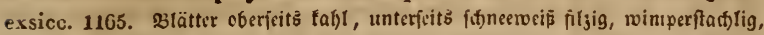
umfaffend, elliptifit), langettlid, langipişig, ungetlyeilt coer Die uittlern yon Der

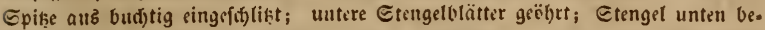

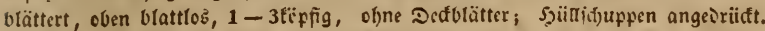

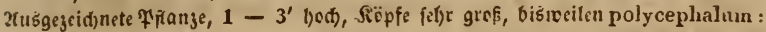

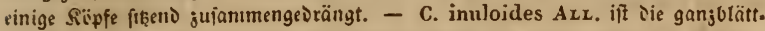
rige Fern. - 2uf Bergriefen Der bëberen Gegenien. Juli. Xuguft. 4. Ma.

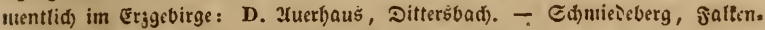

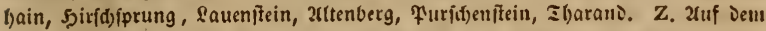

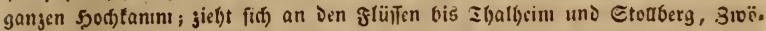

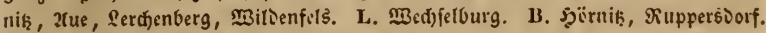

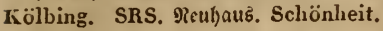

811. C. rivulare (CARD.) JAcQ. austr. t. 91. Blätter fił̧eno, ge.

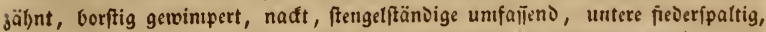

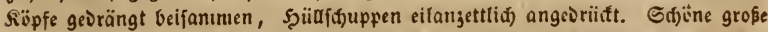
Franje, wic vorige. - 2uuf Gebirgbrwiefen. Juli. 2uguft. 4. PL. Gorau, Gu.

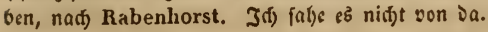

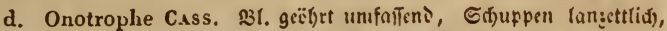

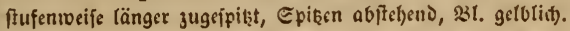

812. C. oleraceum Alt. Fl. dan. 860. Schk. t. 229. (abnoriu.)

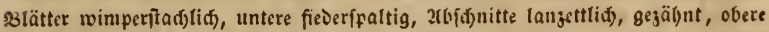

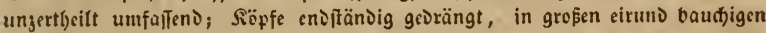

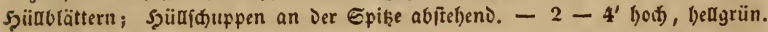
- b. integrifoliunn: $\mathfrak{B}$ urgetblätter oyal tängliff), feid)t oudtig, in Den Eticl verfd)ntälert, Etengetblätter oval und eirund, fpisig, alle mit Etad)ellorften ent.

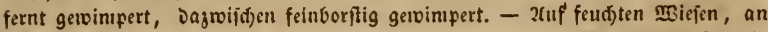
Sïupfen, Gräben, Bäd)en, glufufern. Juti. Juguft. 4. Gemtein, var. b. fét)r jetten. D. Plauen 1838. G. Rchb.

813. C. rigens Artion. Gavd. ha Grix, act. helt. IV.t. 16.

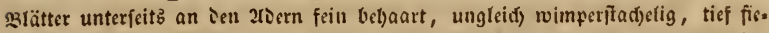

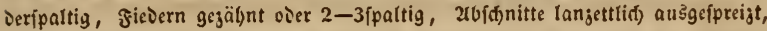

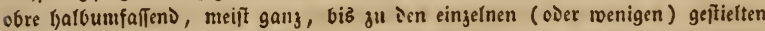

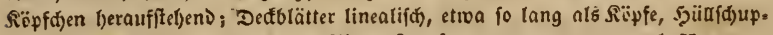
pen ftadeljpitigig. - (C. Lachenalii et decoloratun Koch, vergl. NAgGELr S. 120. tataricun $D_{E}$ C.) C. acauli oleraceum SchiedE. - Etengel 2-3'

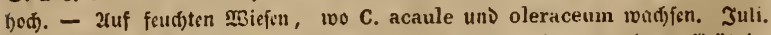

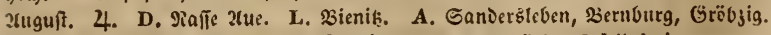

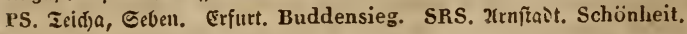

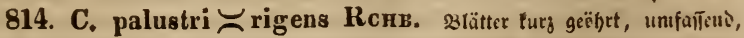

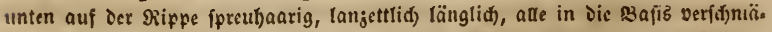
rert uno budstig edig, an Den unteren ausb gejäbnt; Sïpfe la 1 g geftieft, 
cinjeln! Deftolätter borjtig gcuvimpert, f(bmal linealijit), taum balb fo lang als Ropf; Sd)uppen aufred)t, taum fted)end. - Die B(ätter Deuten audi) in Der ganzen Icytur auf C. palustre, wäbrend Der Ropf von C. rigens ift. હॄ nä. bert fid) einigcrmapien Deur C. oleraceo bulbosum NAEGELI, ift aber jogleid)

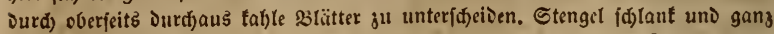
gerave, $1-2^{\prime}$ lood). Unter Den Staniniättern. Juti. Xugnft. 4. D. RaाTe

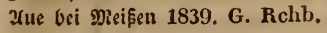

815. C. oleraceo $\asymp$ bulbosum NAEGELI. $\mathfrak{B}$ Burgelfajern etwaa verdift, Stengel (wird hod) etwas verjweigt, slätter oberîeits jerftreut behaart, unten etıaš fpinnıebartig beljaart, lanjettlid) länglid), fièerfpaltig, fievern

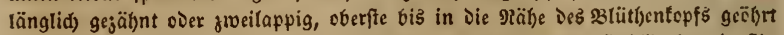

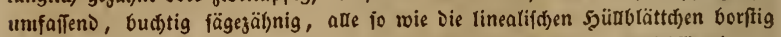
Doppelt gewimpert; Sđjuppen borîtenipikig. Slättex aljo fel)r ungleid)förntig! -

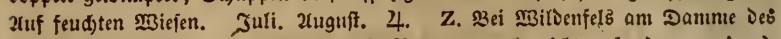
grofen (Ertidfteidjes (wo jebod) C. bulbosmun nod) nid)t gefunden morben). Wankel.

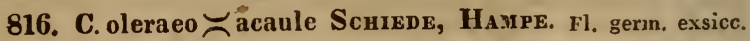
1671. S3lätter bud)tig fieverfpaltig, fievern 2-3lappig, oberfite furj geḯrt, ums

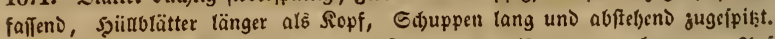
In Staniorten, wo C. acaule uno oleraceun beifamnten vorfomnicn. Zuf

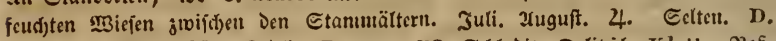

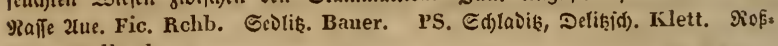
leben. Wallroth.

817. C. pallens (bulbosum b.) WALLR. \$urgel büiøelfajerig, 33 ätter fiţens, fieذcripaltig, 2lbid)nitte jreilappig, Sïpfe einjeln, lang geftielt. Sod) uns (d)lant, unten beblättert, nad) oben blattlos, şä̈tter adue gleid)förnig,

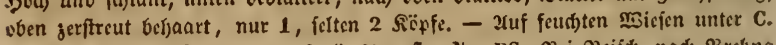
tuberosum uno oleraceum. Juti. 2tuguft. 4. PS. Bei গioijd) nad) Bref)na

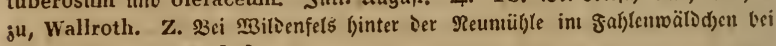
Dem Saltid)ad)te. Wankel.

818. C. hybridum Косн. oleraceo $\asymp$ palustre! Blättce an ocr

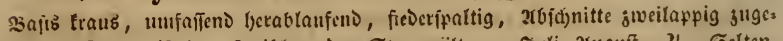

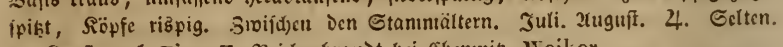
D. Sicnftappel. Fic. Z. Sicid)cubrandt bci (l)cnmis. Weiker.

819. C. oleraceo arvense NAEgeur t. IV. Blätter fabl, unten bläulid überlaufen, geäl)rt, etroas berablaufend, feft, bogig feidjt wedtig, fiècr.

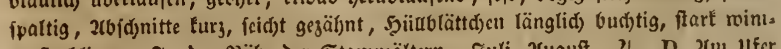
perftad)lig. - In Der siälse Der Stammältern. Jult. 2uguft. 4. D. 21m ufer

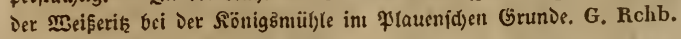

820. C. palustri oleraceum RchB. oleraceo palustre. NAEGELT t. IV. S3lätter oben giemulid) tal)l, unten etroas fpinnmebig, ctroab buđ).

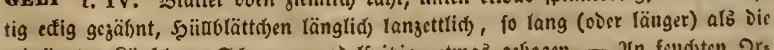
gecrängten Sïpfíten, Gduppen naielfpilsig, etwas gebogen. - 3in feudiften Drs 


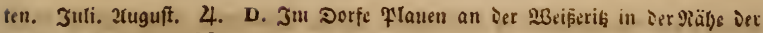
פ(ü)โŁ. 1839. G. Rchb.

821. C. tataricum (L.) Jaç. austr. t. 92. Jrorigc cintëpfig, 3lätter länglid lanjettlich, mimperftad)lich, gejäl)nt, ungertfeilt o১er Die untern

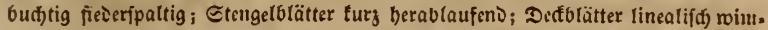

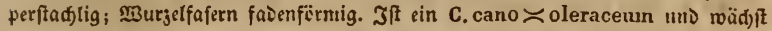

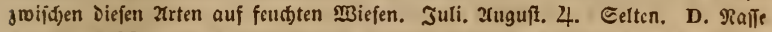
\{ue. G. Rchb. PS. Erfurt. Hornung. HS. Eifenad). Zenker.

822. C. oleraceo-heterophyllum NaEgel S. 138. Einfarf;

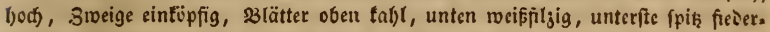
fpaltig, obre oreit herbförmig unifaftent, gefägt uno borîtig getvinipert, Ed)uppen

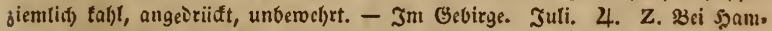
mern jwifd)en MBiefenthal uno Bärenftein an cinem \$ado. Weiker.

** Blätter oberjeitz ftricgelborftig.

e. Epitrachys DE C. SBlätter நerablaufens, Sd)uppen langipilig ftes

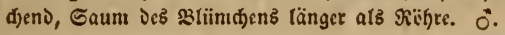

823. C. lanceolatum Scop. Fl. dan. 1137. Blätter bcrablaufent, oberjeits fteifer beftackelt, unterfeitb Dünner, fpinnwebig, tief fieieripaltig, 2 r. f(c)

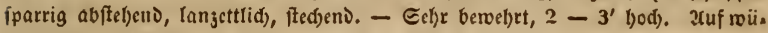

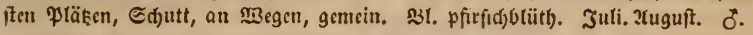

824. C. nemorale Rснв. slätter balb berablaufeno, fiederfpat.

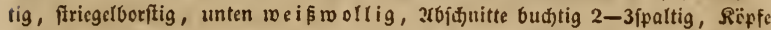

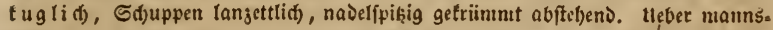

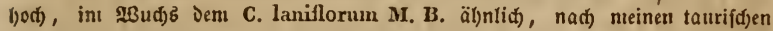
Exemplaren Diefer 2rt aber Daven gänglid) verfdièen. - b. unbraticum. C.

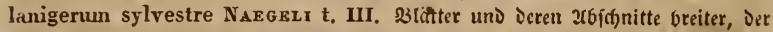
filj mel)t grau, Die ganje Pranje ninder follant und weid)lättriger, Şicrzu C. angustatum PeTERx. ein Exemplar, iciTen Etengelblätter an Der \$afis lang

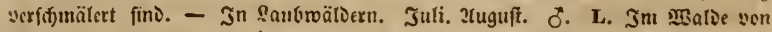
Sindentl)al (nad) Brcitenffio ju) bei Peipzig idjon 1810 beobaditet uno aut 13. 3uli 1817. benannt. b. L. 2In iemfelfen Drte uni C. angustatum im MBalise binter Gunborf. Petermann.

f. Eriolepis Cass. 3lätter jiǩent. Sđuppen frautartig mut Gta: ()) clipitie.

825. C. exiophorum Scop. Jac?. austr. t. 171. Sälätter unter= feits filgig, oben ftriegetborjtig, fikeno, obre untfajeno, tief fieveripaltig, 2loj(f)uitte

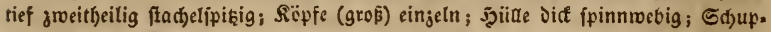

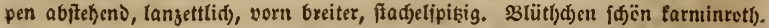
- 2in Saltbergen. Juli. 2uguit. Septentber. $\delta$. Selten, nur in 2infjalt uno

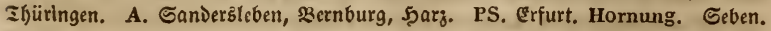
Wallroth. Şüneburg bei Eišleben im Seffcl. Bok. HS. Magbala [Saalborn, rocraberg], serta, Eifenad). Zenker. Reburg. Hormung. SRS. Gegend' yen 
Miel)e: bei Burgroenden an Der Müble. Rchh. fjon 1811, Dann roicder 1841. SRS. Strantenbaufen. Hornung.

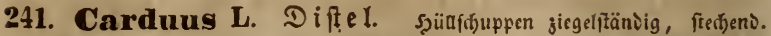
Srudbtboden borftig fpreublättrig. Saamentrone baarfërmig, gegäbnelt, un. ten in cinen $\Re$ Ring verwadjen, abfadeno.

\section{a. Sïpfdsen einjeln.}

826. C. defloratus L. JAç. austr. t. 89. HAxx, ic. helv. t. IV. slätter balb berablaufen১, eingeidnitten gejägt mintperborfitig, nadt, rourgelftän. Dig unjertbeilt, slütbentopfítiele filjig, Edjuppen linealifđ), ftadjelipisig, ven Dex Mitte aus abftebeno. - Sebbaft grün, $1-2^{\prime}$ bod), ändert ab nit fiederipalti.

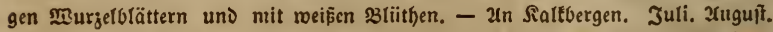

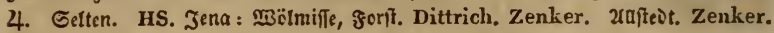
S.titsberg bei Remida. Schönheit. SRS. 2rmftadt. Schönheit.

827. C. nutans L. Fl. dan. 675. ScHк. t. 228. (gruăt.) Blät. ter herablaufens, tief fiejerfpaltig, abid)nitte oreiffaltig, wimperftad)lig, ftarf fa.

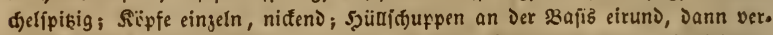

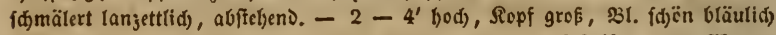

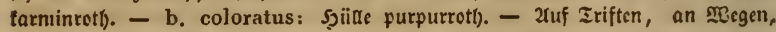

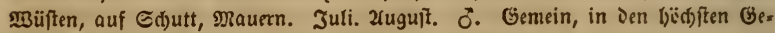
genien veridjwinieni.

\section{b. R̈̈ffĭen beifammen.}

828. C. Personata JAcQ. austr. t. 348. SBlätter நerablaufenঠ, uts. terfeits fpinnwebig firjig, borftig gewimpert, obere unjertfyeiit eirund oder lanjetts liđ), fäge;ätnig, untere brcit ciruno, bis auf Die פittelrippe fiederfpaltig; Sï̈pfe

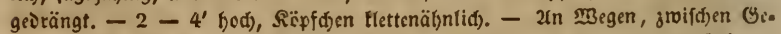
büfd). Juli. 2tuguft. $\delta$. Gel)r jelten. B. Grottau. (5ammerftein). Külbing.

829. C. crispus L. Scнк. t. 228, (ஓruđt).) Fl. gerın. exsicc. 1608. Blätter berablaufend, unterfeitz roeiffilgig, längliơ), osal, jum Ibeil budłtig fic.

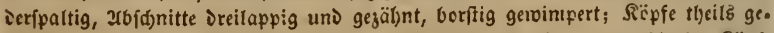

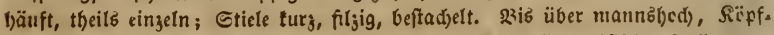

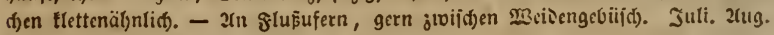
4. Sinft felten, im bïbern Gebirge veriffroinient.

830. C. acanthoides L. JAcQ, austr. t. 249. Rcre. pl. crit. X. 1319. Slätter berablaufens, länglid) lanjettlid), budytig fieieripaltig, mintper.

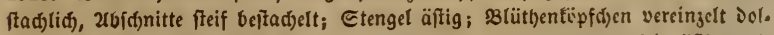
Dentraubig, Etiele beftađjelt uno fraus gefiügelt. $-2-4^{\prime}$ bod, felor äftig. Die Sjiiafd)uffen nebmen nad) und nad) an \&änge ab, Die salätter fins Dünner, blaf. fer, Die Rerven roeifer. - b. squarrosus Rснв. pl. crit. 1320. fteifer, fitter, Sopf gröfer, oberfte Sdjuppen fef)r beftimmt länger. - c. collaris Rснв. pl. crit. 1321. Die abfebenden Şäaja)uppen febr lang und fparrig, Dic übrigen an.

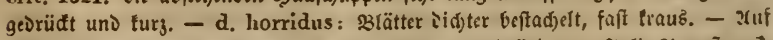

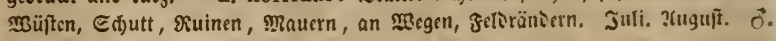
खic scrige, Dcá bäufiger. 


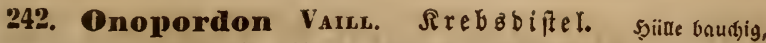
S(buppen ziegelftändig, abftchent, fted)ent. frudbtboden wa benzellig! Sdjalfaame quer berunjelt. Saamentrone baarartig, fdicarf, fitiens, abfallent.

831. O. Acanthium L. Fl. dan. 909. Schk, t. 230. HAYXx: Arzneigew. VI. 34. S2lätter herablaufent, wollig filsig, bogig ectig ober ge.

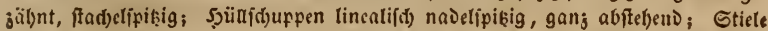
meift viertantig gepiigelt. Malerifđe ¥ranje, 2' bis iibcr mannsbod). (Eine tleinete form ift melst mollig und etwas traus, eine grëfere melje bellgrün. - 2tuf

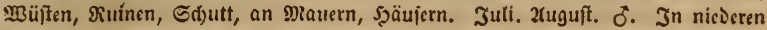
Gegenden febr gemein, in büberen feltner.

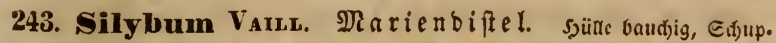
pen jiegelfänoig, an Der \$ajis blattartig Didit angebriiđt, von Da nad) au. fen gefnidt, buditig itad)eljät)nig, nadelfpibig. Frud)tboden fpreublätterig. Ed)alfaame glatt. Gaantentrone baarartig fpreublätterig, nebit cincu ringe abfalteni.

* 832. S. marianum GAERTN. t. 162. (frnt)t.) HAYNE Arz-

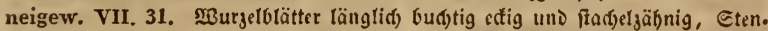
gelblätter umifa)ien〉 ipiesfïrmig ficocrfpaltig, alle glänjeno glatt, weiß geaicrt. Son 2' bis nannif)od). - OfF. Sem. Cardui Mariae. - 2uf 巨dutt verwoil. Dert. Juli. 2uguft. $\odot$.

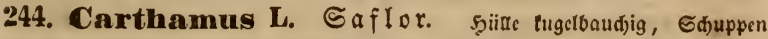
jiegelftändig, blattartig, ctras ftedjeno. Srudftboden trägt borftig jerid)lik̨te Spreublättben. Edbaljaame glatt, ol)ue Saamentrone.

-833. C. tinctorius L. Sснк. t. 233. slätter ciruns, gang, beftađjelt gęügt. Stcif, 1' oder böber. 23l. faīrangelb. - OpF. Sem. Carthami s. Croci hortensis. - Miro in इhiiringen und im Soigtlanie cultivirt und verwilbert. Juli. 2uguft. $\odot$.

Ech inopsideae: fugliager Fruatboben überall mit $\mathfrak{B l u ̈ t}$ s

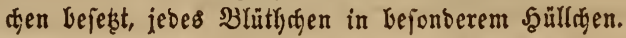

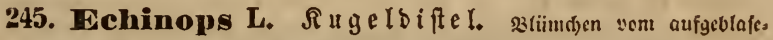
nen Gd)lunte aub tincalifí) 5theilig. Eaamentrone bäutig, gefranzt.

834. C. sphaerocephalus L. B. Reg. (paniculat.) t. 356. 厄ten.

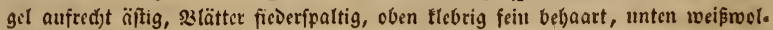

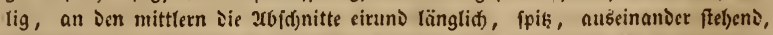
oberffe berzcirund, adte budtig und fadelfpitig. - \$Bird 2 - 4' bod und bö. ber. 3liinuden weif. - 2en fteinigen Drten, in MBeinbergen. Juti. 2tuguft. ö.

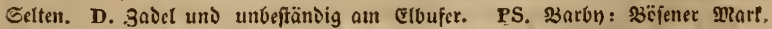

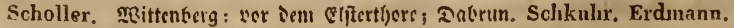




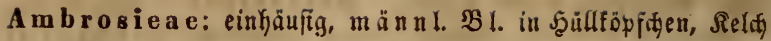
cinblättrig, flappig fünfzähnig, Staubgefäăe $4-5$, meît eins brübrig, Bentel frei. $\mathbb{3}$ eibl. $\mathfrak{B}$ I. 1 ober 2, Fructitnoten im Frudtboben eingefenft, (5riffel geipalten. Trofne Cteinfrurbt.

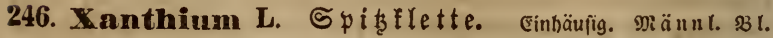

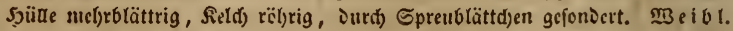

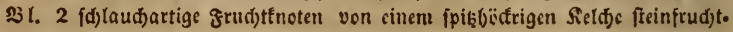
artig umwadien.

835. X. strumarium L. Fl. dan. 979. Schk. t. 291 (lints.) Sten. get un১ s(ätter unbewel)rt, untere slätter berjfürmig, oreilappig. - Die ganze

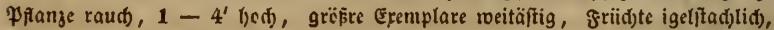

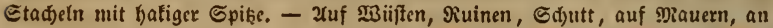

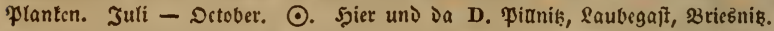
L. S3or Dem Gerbetthore. B. Şier unD Da. PL. Suctau. A. DeiTau, WBofferode,

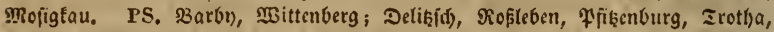
Röume, êtartsuerge. HS. Jena.

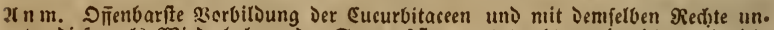

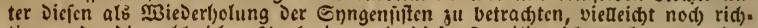

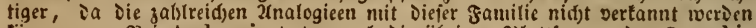
temen. - BBei Ambrosia tteten aud) Die übrigen 2ilattfornten Der Cucurbitaceae nod Deulid)er auf.

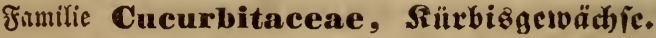

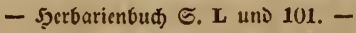

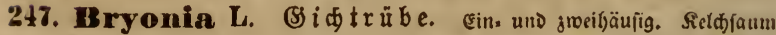
gloctig 5ipaltig offen. 33lume ticf 5theilig. $\mathfrak{B}$ eibl. 31 . Sriffel geipalten,

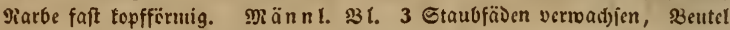
logig, an 2 Etaubfäben ioppelt, Gteinfrudyt beerenartig, glatt, Gaamen

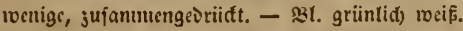

836. B. alba L. Fl. dan. 813. Schk, t. 316. Hayxs Arzngw.

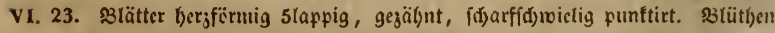

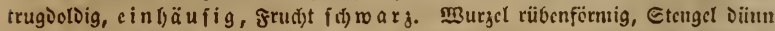

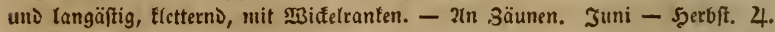

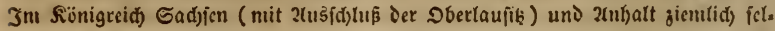

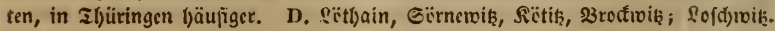

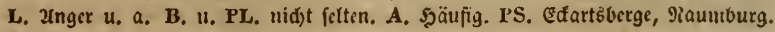
HS. Eifenberg, Jena, Dornburg.

837. B. dioica L. BLAKw. t. 37. Havxi Arzneigew. vi. 24.

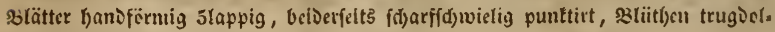

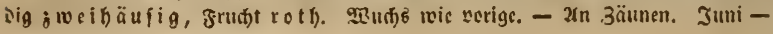




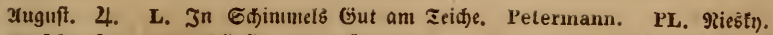
Burkhardt. - A. J̧äufig nad Schwabe.

248. Febalium Rich, Sprüg̨gurfe. Einbäufig. Sich).

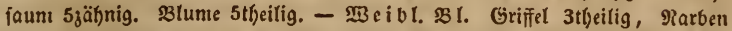

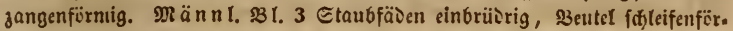

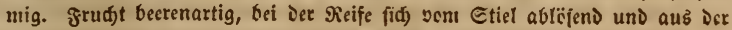
entifandenen Deffnung Die Saamen heraušipriß̨eñ.

* 838. E. agreste (Blkw.) Rснв. (Momord. Elaterium.) Schix. t. 313. Hayxe Arzngw. VIU. 45. 2(ufredt), etwa fuflocd), oier nic.

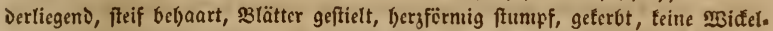

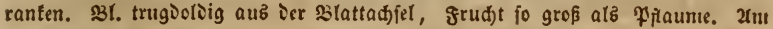

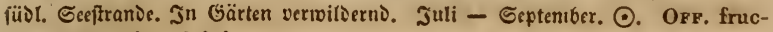
tus Cucuneris asinini.

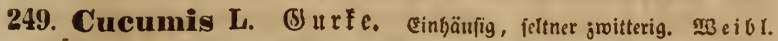

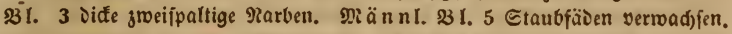
frud)t 3fädrig, nidst aufipringend. Saame 2reibig, zufammengebriữt fdi a rfrandig. - 331 . gelb.

- 839. C. sativus L. BLAKw. t. 4. Etengel feif bellaart, tetterno,

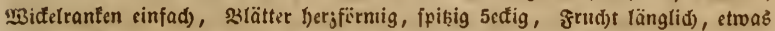

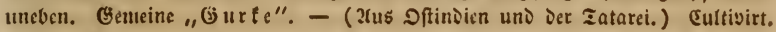
Juli - Eeptember. $\odot$.

840. C. Melo L. BLaKw, t. 329. Blätter runolid) eftig, frutd)t

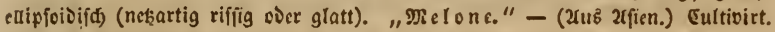
Juli - Eeptember. $\odot$.

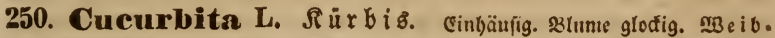

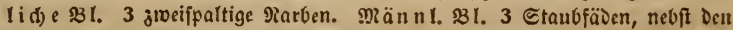

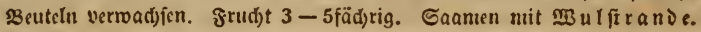

* 841. C. Melopepo L. J. Baun. hist. II. 224. Morrs. Secl.

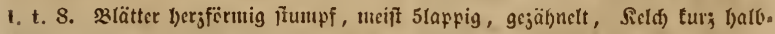

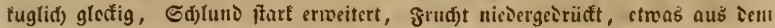

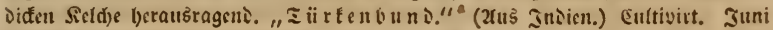
- Eeptemter. $\odot$.

842. C. pepo L. LAsr, ill. t. 795. f. 1. 33lätter herryfürmig lappig, (d)arf, Slume (glocfig) unten verengt, Gaum aufred)t, grud)t feijdjig fuglid) ober

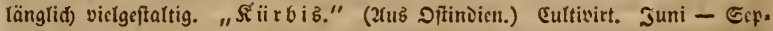
tember. $\odot$.

* 843. C. maxima Duch. Lов. ic. 641. f. 2. 3lätter f̧erjförntig, runzelig; Stiele fteif beljaart, 3 lume von Der $\mathfrak{B}$ ajis an gloctig, Saum zurüđge.

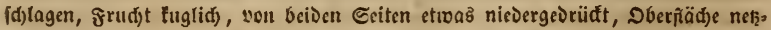

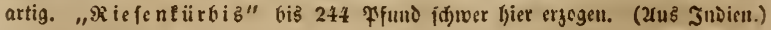
Iuni- - Eeptember. $\odot$. 
Campanulaceae. $\quad-188-\quad$ Jasione.

\section{Familie Campanulaceae, G̈löcter.}

- Sjerbarienbud) ธ. LI uno 1(1)2. -

251. Jasione L. Safí one. słtüthentëpfợen (enojiändig) in viel.

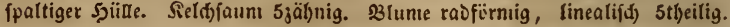
Bcutel zufammenţängeni. Rarbe feutenförmig. Siapiel eingewadjfen, balb 2fäd)rig, vieliaanig, an Der Epił̧e aufipringeno. - Bl. blau.

844. J. montana L. Scur. t. 266 ST. I. 9. Oł)ne 2tustâuffer, 3lät.

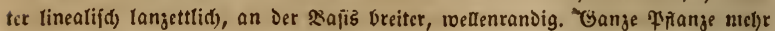
- oder ninder fteif bel)aart. 1-2' hod). 2fuf Eaniboden gemein unt gefenig.

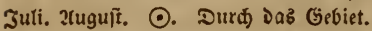

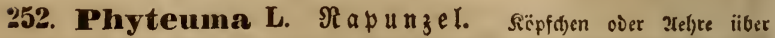

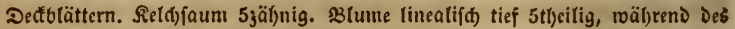
3rufblithens nod) all Den Epiß̨en zufanınenbängent. Trarbe 2-3fpaltig. Siapfel eingerwadj)en, 2-3fäd)rig an Der Geite. Durd) Sëduer auffipringend. - \$3urgel rübenartig.

845. P. orbiculare L. JAcQ. austr. t. 437. gig. ređjts. Fl. germ.

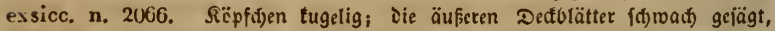

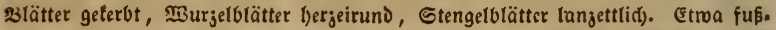
bod), BI. Dunfelblau. - b. fistulosum Rchr. JAcr. austr. t. 137. ßig. lints,

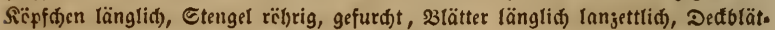

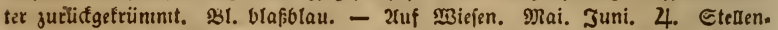

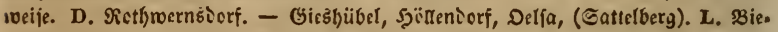

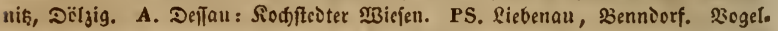

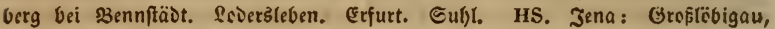

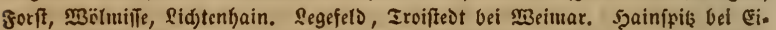

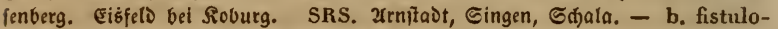

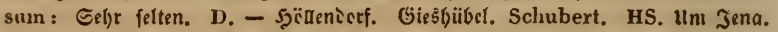
Zenker.

846. P. spicatum L. ScHK. t. 39. Fl. dan. 362. B(ïtl)enäl)re (äng.

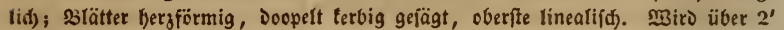

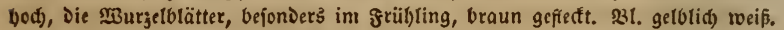

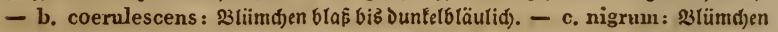

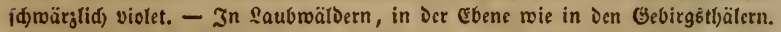
Mai. Juni. 4. b. uno c. minier verbreitet, als Die Grundart, Die Durd) Das Gebiet meift niđjt felten ift. b. coerul. Z. Gibenftoct; Jägerbaus bei ṡofau, \&auter. Bok. - c. [Blülyt alleroings um 14 Iage zeitiger!] D. Gr. Garten;

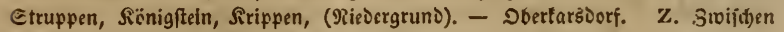
Gilberfitrafe uno \$ogenftein; Ffannenftiel, Sauter. L. Fenig. - Grimuma; zwis

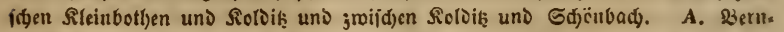

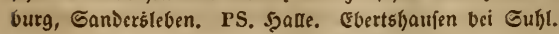

253. Prismatocarpus Hentr. $\mathfrak{e} \mathfrak{n} u \mathfrak{b}$ f 


\section{Campanulaceae. $\quad 7189-\quad$ Prismatocarpu*.}

raDfïrmig 5jpaltig. Etaubgefäfe auf 5 Drüfen. Rapjel langgeftredt prib. matija), an Den Eeiten aufreiseni.

847. P. hybridus Herit. Engl. Bot. t. 375. Geraise aufredt, et.

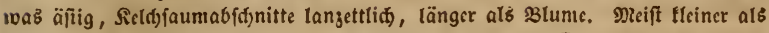
folgende 2urt. - Xuf Raltä̋̆ern im Getreide. Juni. Juli. ○. Ecljr felten. PS. ^olyr, Sülyndorf. Metsch. HS. Grub bei 氵hemar. Metsch.

848. P. Speculum Herit. Bot. Mag. 102. Fl, genn, exsicc. II.

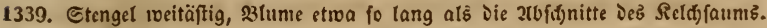
Epannenljod). SBlume violet, in Der Mitte weiß, feltner ganj weißs, slätter läng.

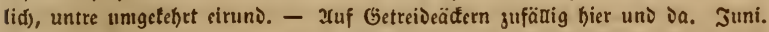

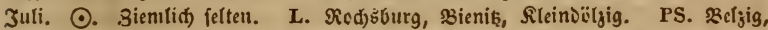

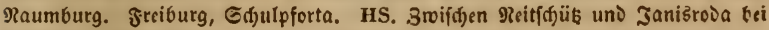
Eifenburg. Ramburg.

\section{Campanula L. (5) I o f e n b Iu me. SBlume glodig, 230.}

Den von ber breiten \$afis Der Etaubfäben bedeft, şonig abjonierno. Rarbe 3-5ipaltig. Rapfel 3-5füdrig, untell an Den Geiten aufipringen১. - Mur. del meift rübenartig.

849. C. rotundifolia L. Fl. dan, 855. DRev. u. Harre 42.

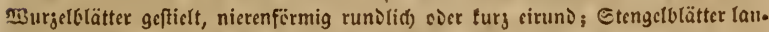

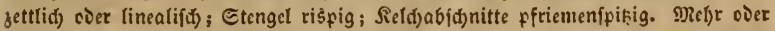

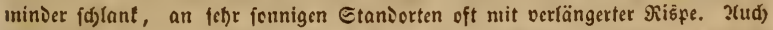
mebr oder minder grefolïtbig. - Juf Siainen, Iriften, an MiBegen, Seljen, פiauern. Grofblütfig befoniers in bübarn Gebirge. Mai - Juti. 4. Gentein.

850. C. persicifolia L. Fl. dan. 1us2. şätter entfernt \{ägejäly.

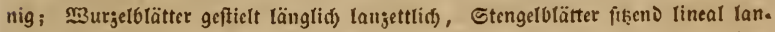
zettlid); Iraube loffer armblütljig; Seld)faumabfdnitt: lineal lanjettlidg. 2(endert ab : Inaxima Bot. Mag. 397. felgr grof̧blüthig; hispida Les. nit freif behaar. ten frud)ttnoten, aud weiß blübeno uno vertünmert fdaftoliitbig, mit grofen lanjettlidjen Sieldabfdjnitten: pumila Scнм. f. Rснв. pl. crit. I. ic. 157. In tiđten LaubroälDern, an grafigen Şügeln uno \$ergen. Miai - Juli. 4. शid)t felten. Var. hispida: D. Flauen u. a. Rchb. L. Bieniķ. W. Gerhardt. rS. 3roifden ఠdbroarja uno siensifaujen. Metsch.

851. C. Rapunculus L. Scrk. t. 39. Fl. dan. 855 uno 1326. Fl. genn. exsicc. 322. Slätter gefertrt; $2 B u r$ żlblätter geftielt länglid) eirund; Gten.

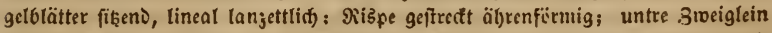

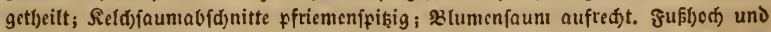

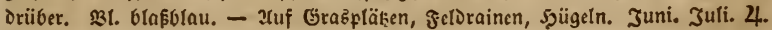
Eelten. D. Grofentjain. Schwabe. [Gtreblen angeblid).] L. Geithain. Sei-

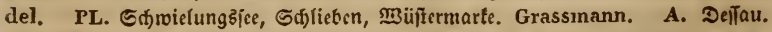
Schwabe. PS. Fretf(t). Rabenhorst. 23arby im Ginez. Sclioller. Salle.

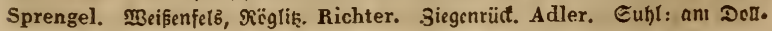

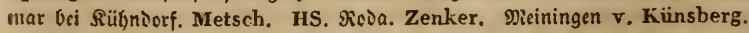

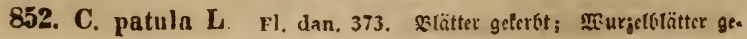




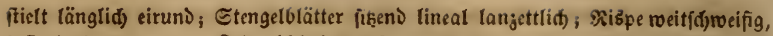
faft Doldentraubig; Reldjabidjnitte pfrientenipitig; sluntenfaum nad) aus.

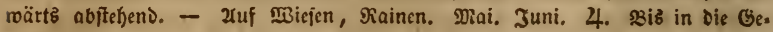
birge häufig.

853. C. Cervicaria L. Fl. dan. 787. Rснв. pl. crit. VI. ic. 778. Fl. gerın. exsicc. 1677. Steif bebaart; Slätter fein geterbt, Die untern ge:

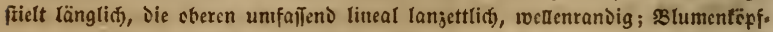

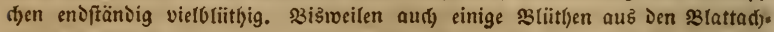
feln. Stengel $1-2^{\prime}$ soer ljëljer. 33lume tlein, blaf̧blau. Var. violacca, Rснв, pl. crit. VI. ic. 780. 781. mit gröperer violetolauer \$Blume. - In Mäl. iern, bejeniers in serggegenien jivifden Gebiujo). Juli. 2(uguft. 24. Sechlt in

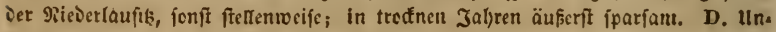

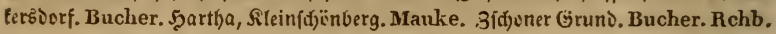

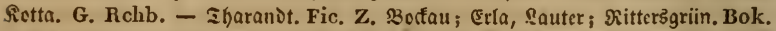

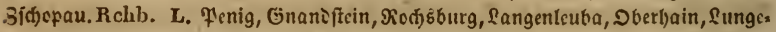

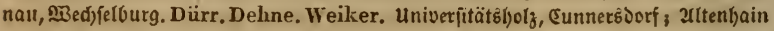

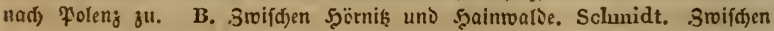

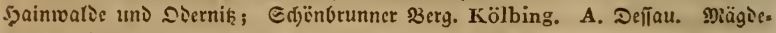

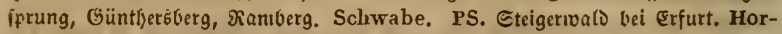
nung. HS. Jena: Döbritjđer Forft. Swijđjen Magoala und \$olleršroda. Zen-

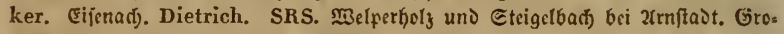

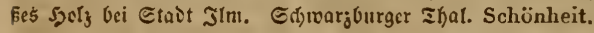

$2 \mathrm{~nm}$. 1. Die malyre C. lingulata W. K. t. 64. Fl. germ. exsicc. 1907. fiel)t

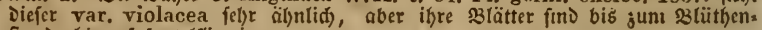
ftanie binauf ifatelfitrnig.

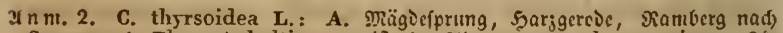
ScHWABE's Flora Anhaltina! - ifit eine đIpenpianje. Fl. g. exsicc. n.24.

854. C. glomerata L. Rснв. pl. crit. VI. ic. 752-755. Slätter

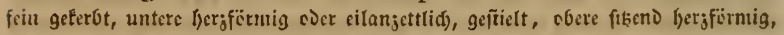

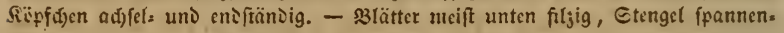

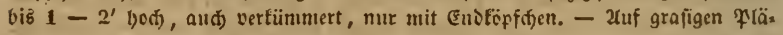

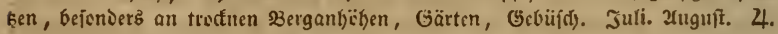

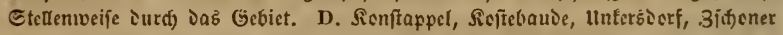
Gruno, நartlya. Merigrun১, Röbnikggruno, Gröbern, sojel. - Ilyarandt. L.

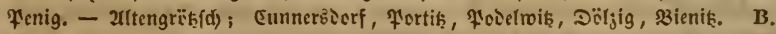

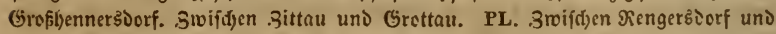

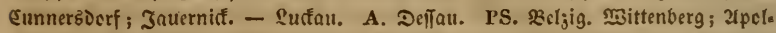

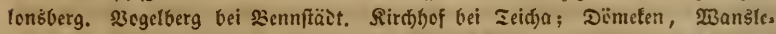

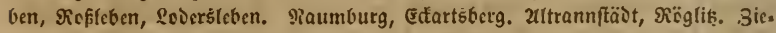
genrüđ. Edjroarga bei Sulyl. Erfurt. HS. Soburg, Jena, Meimar, Gitub bei shemar, SRS. Jrantent)aufell, 2(rnftadt.

If $n$ m. Die wafre C. aggregata BaxB, et Nocca rl. Tic. $t$. V. RchB. pl.

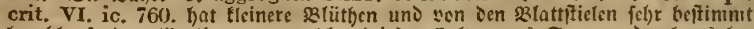
berablaufenis glïgelfanten, welche bei ier eultur aub Eaanten durdaus bis ftänis bleiben, won ilje find nir jur Seit ned) feine immerbalb unfrer Urengen geiammelte Erintilare vergefommen. 
855. C. rapunculoides L. Fl, dan, 1327. Rcrr, pl, crit. VI. ic. 700. B(ätter ungleich) ge(ägt, turg behaart, untere lang gefficlt, hergförmig läng.

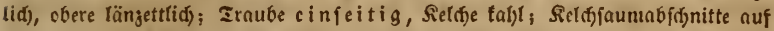
ocn (änglid)en grud)ttnoten langettlid), juleşt jurüfógebogen. Der Etengcl

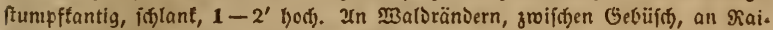
nen, auf 2teffern. Juni. Juli. 4. Ġmein.

856. C. trachelioides M.B. Rerв. pl. crit. VI. ic. 701. Eteif

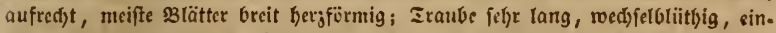

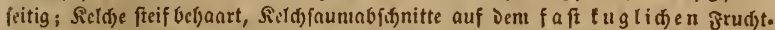
tnoten ausggebrcitet jurüđgefdjlagen. Etengel gefurd)t 5tantig, $2-4^{\prime}$ bed), bie

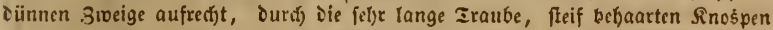

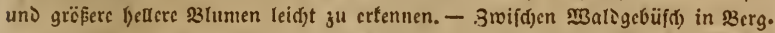

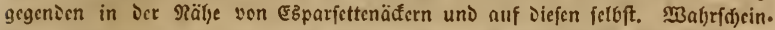
lid) Durd Onobrychis sativa eingefü̈)rt. Juni. Juti. 2(uguff. 4. Eel)r felten. D.

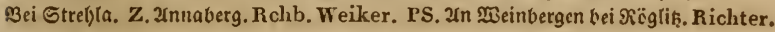

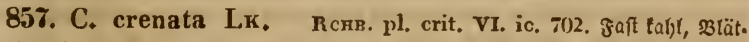

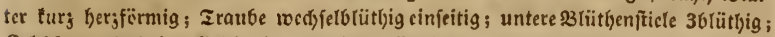

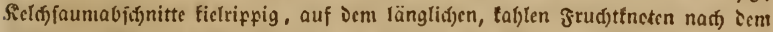
צchliif)en aufredjt jufanmmengeneigt. Siahler, glatter und fílantic als anore, 1

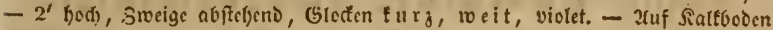

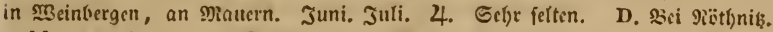

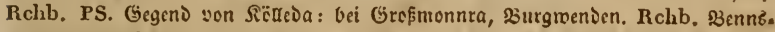
haufen. Kuitzing.

858. C. Innariaefolia W. Rers, pl. crit. VI, ic. 750. Etcif auf.

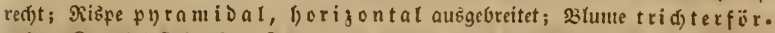

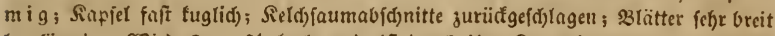

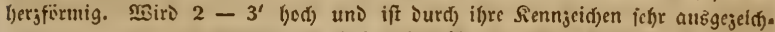
net, alid) fifon ven CurTis (C. infundibuliformis B. Mag. 2632.) und von nir (C. pyraunidiflora Rспв. Cat. host. Dresd. 1S22.) unablängig von ier

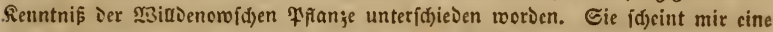

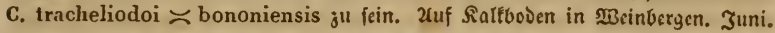

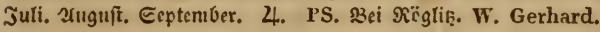

859. C. bononiensis L. Rcrв, pl, crit. II. ic, 221. Fl. germ. exsicc. n. 1S64. 3lätter geferbt, unterfeitz graupirjig, untere lang geftielt, berz= formig, obere fusend eirund zugefpist; Iraube gientlid) adfeitig, einfad) soer ris.

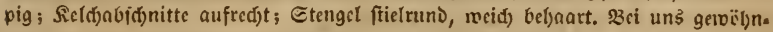
liñ) nur Die zroänderung b. simplex DEC. (C. Thaliana WALtr.) Rcrs. pl. crit. II. ic. 222, mit einfad) lang geftreffter ₹raube und unterfeits jier. (id) tahlen 3 lättern. - 2uf Salfboden in \$̇eintergen. Juni. Juli. .4. A.

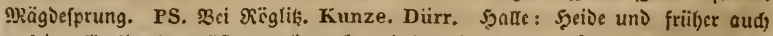

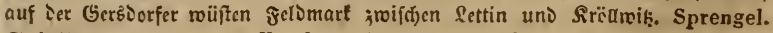
Etcinklippc, Rofleben. Wallroth. Effartsberge. Rodig.

860. C. latifolia L. Fl. dan. 85. Brätter turgefftieft, ciruno lan.

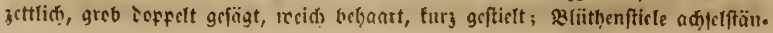




\section{Campanulaceae. $\quad 192-$ Campanula.}

Dig einblüthig, traubig; Seldjaumabid)nitte eilangettlid); Stengel undetlid tan. tig. Stcif aufredt, $1-2^{\prime}$ bods, 31. großj, betrblau. - In fisattigen Gebirgs.

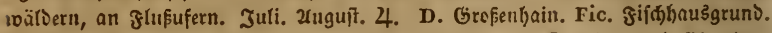

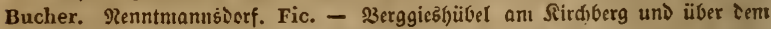
Bitriolwert. Bucher. Iharanot. Rossmässler. Dorfbain. Papperitz. B. 3ri.

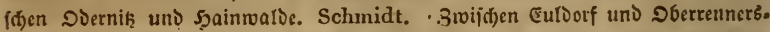

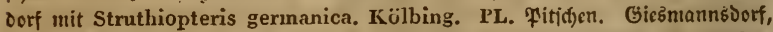

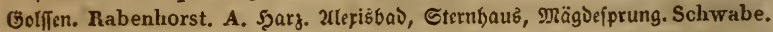

861. C. Trachelium L. Fl. dan. 1026. Blätter gréb Doppelt ge. lägt, furg fteif bel)aart, Die unteren lang gefticlt hergeiförmig, obere fikent, läng.

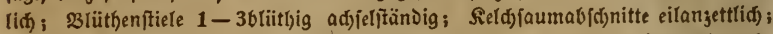
Stengel idjarffantig. - b. urticifolia Scrur. Blüthen cinjeln in Den \$lattad).

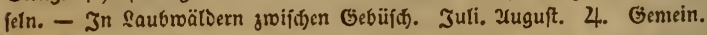

* 862. C. Medium L. Clus. Hist. CLXXII. stätter ungleiă) grob

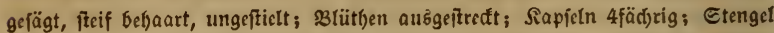
oben vergmeigt, beblättett. 2Blume großß, fdjën blau biz weiß. - Şäupig cultivirt

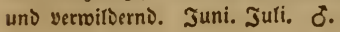

\section{Gamilie Labiatae, Sippenblütblex.}

- Şetbarienvud) E. LII und 104. -

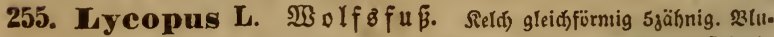

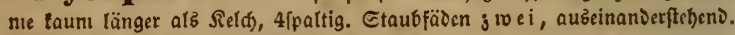

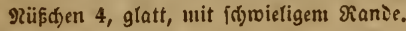

863. L. europaeus L. Scrk. t. 4. Fl. dan. 1081. Blätter eilan.

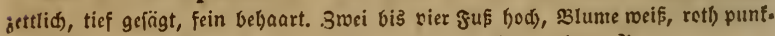
tirt, Elein. - $\mathfrak{U n}_{n}$ Günıffen, in Gräben. Juli - Eeptember. 4.

- 864. L. exaltatus L. Fl. gern. exsicc. n. 955. Blättcr in Uus

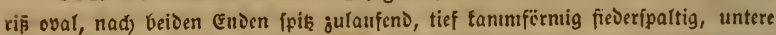

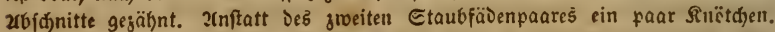

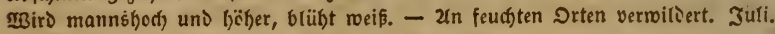
Juguft. 4. PS. WBittenberg. Schkuhr. Nitzsche.

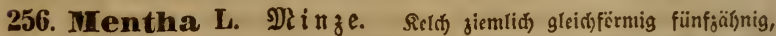

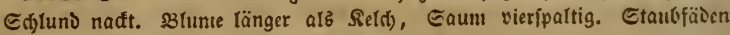

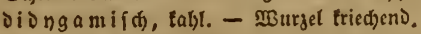

a. SBlüthenquirle Glattachielfiäntig.

865. M. arvensis L. Engl. Bot, 2119! Rснв. pl, crit. X. ic.

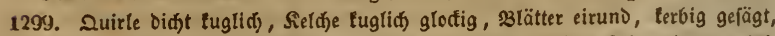
unterfte rundlid, faft gangrandig. Fieldye und Eticldien furg feif beftaart, 28 , rola, ভtaubfäben meifî eingef(j)loîen. - b. lanceolata ib. ic, 130r). Tall. jettblätterig. - c. parietariaefolia Brck. ib. ic. 1301. rigombija) Lanzetteläto terig. - d. prucox Sore. nicirig, freif, aufredst, slätter eral (anjettlits, fo mie 
Die Reldfe jottig, Eticle jumlid tabl. - e. ngrestis Soxk. Engl. Bot. 2120. Rснв: pl. crit. 1302. 23lätter breit cirund entiftifó), grob terbjüljinig, runzelig,

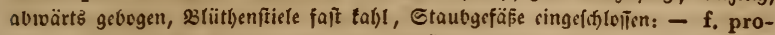

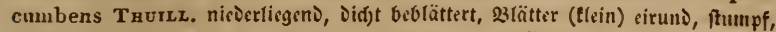

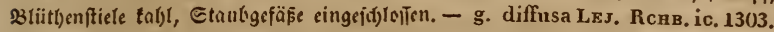

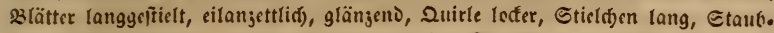

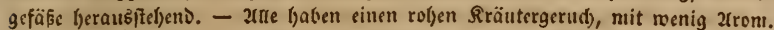

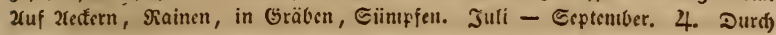
Dab Gebiet gentein.

866. M. gentilis L. sp. Engl. Bot. 211s! Rснв. pl. crit. X. іс. 1395. Quirle entfernt, tnäulartig, graulid), Reld) tegclfïrmig glefig, Blunte taum länger. Blätter alle gefitielt, oval elliptij(র), f(d)arf gefägt. Boriger äl)n. (id), $2-4^{\prime}$ bod), ftrif aufred)t, Quirfe Elein, feitlid), oberfte oft werfümmert. -

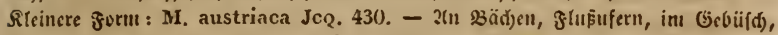
in હiimpfen. 2ruguft. Eeptember. 4. Eitten. D. Tlauen. Relib. PS. Elfterau, Dftrau.

867. M. sativa L. sp. Hods. Ss. Engl. Bot. 448 ! Fl. germ. exsicc. n. 2()48. Quirle entfernt, gefticlt, Sield) röbrig, 3ülnne gcivinpert, Blume Dofpelt fo lang, 3lätter geftielt eiruno cier oual, fol)arf gefügt. Quirle

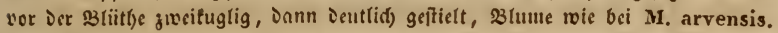

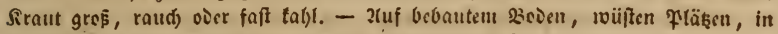
(Gebüf(d), an 23äd)en, Slii)en. 2rugnit. Eeptenber. 4.

868. M. rubra Huds. Engl. Bot. 449! Quirle entfernt, Etieldjen

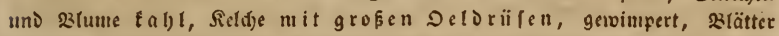
filįc no länglid) lanjettlid). S()lant gewa(t)ien, (gracilis S.r. int index!),

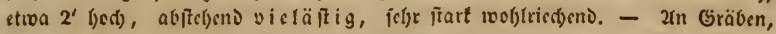
Fliilfen, Sïnıpfen, bejenters in Bergwäldern, feltner als anire. Juli - Gep.

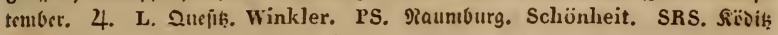
unter Rïnigfé; Eingen. Schünheit.

869. M. palustris Mхск. Rснв. pl. crit. X. 1307. 厄tcif auf,

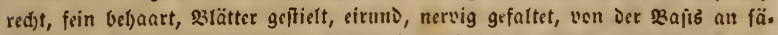

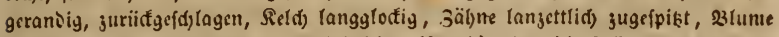
Deppelt fo lang, fein beljaart. Quirle Didjt (jhend). Sgat Die fö̈ne grofe silume Der M. aquatica, Das Siraut ift oft violet angelaufen, Der Stengel $1-2^{\prime}$ hod).

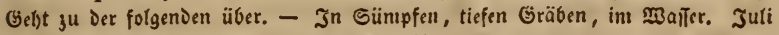
- Eeptemiber. Stellenweife Durd) Das Gebiet.

b. Bliitlenquirle enditänذig, fopfartig gèrängt.

870. M. aquatica L. Rrv, monop. irr. t. 49. Engl. Bot. 447!

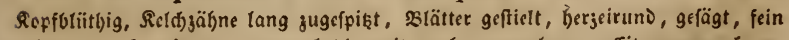
bol)nart. - b. citrata EнRi. (al)!, nit nod) angenelmeren (sitronengerudj. In Eïmpfen; Malfergröbcn. Juli - Eeptember. 4. Etellenvocife Durd) das Scroict.

* 871. M. crispa L. Ilayxs Arzneigew. XI. 30. Sänglid) toff. 


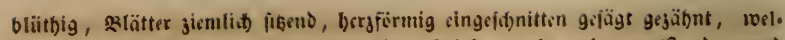
lig uno blafig uneben. Etart rietbend. Edeint aนธ̇ vorlger entitanden uno toninit nur sultivirt vor. 2rnguft. Eeptember. 4. - Ufr. Ib. Menthae crispae.

c. Blït) mqulrle enঠītündig, äfrenartig nerlängert.

* 872. M. piperita Huds. Harxe Arzngw. XI. 37. Jeffren un,

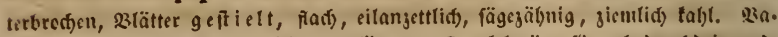
riirt nit breiteren coer f(f)müleren siättern. Duntelgrïn, Gerud) Durd)oringent. OFp. Hb. Menthae piperitae. - MBild in \$zaden, vergl. Fl. gerın. excurs. p. 859. 2093., bel uns nur cultivirt. Juli. 2tugut. 4.

873. M. viridis L. Engl, Bot, t. 2424. Harse Arzngw. XI. 3t;

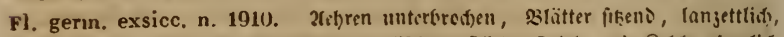

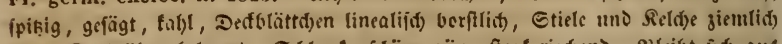

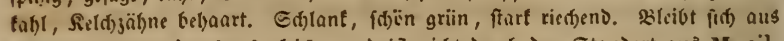
Gaanen erjegen Durdfaus gleid), uno ift nidft Durd) ien Etaniort aus M. silvestris erjengt, ia fie nit iffr an gleid)en Drten müd)ft, iennod) foumuen mit.

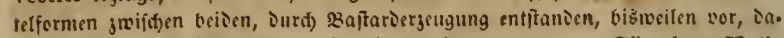

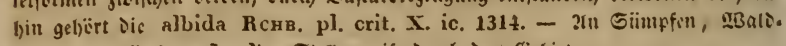
räd)en. Juti. Augujt. 4. Stentenweife Durd) Das Gebiet.

* 874. M. crispata Schrad. Hayse Arzngw. XI. 35. 2aelren

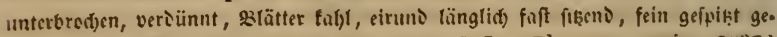

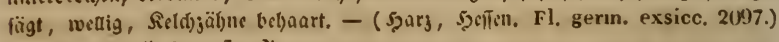
ฮultivirt. כuli. ?tuguf. 4.

If $n$ m. Da heut 3 u ₹nge iie roalye M. crispa feltner vortomut, fo baten mand)e sicée gegenıuärtig bäuñgere, fiir jene genenumen.

875. M. silvestris L. Engl. Bot, GS6! Hayxr Arzngw. XI. 34. Rснв. pl. crit, X. ic. 1313. Fl. gernn. exsicc. (var.) B. 42. 2aelfen faft un.

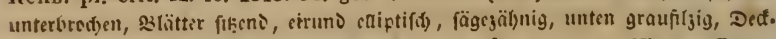
bättf̧en ffriemenffitig, filld) ganj bebaart. - b. nemorosa Willd. Rснв.

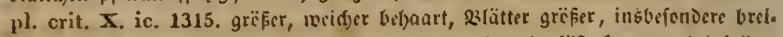

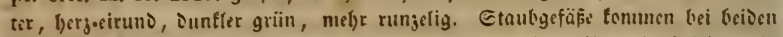
formen fowobl türjer als länger vor als bie silume, biblweilen, Ded) felten, in

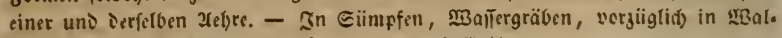
iungen. 2lugujt. Geptember. 2. Durá) ias Gicbict.

876. M. undulata W. Fl. gerın. exsicc, 1911. 33tättet cirumı, tutrs

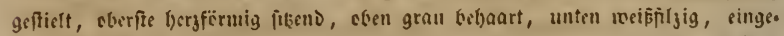

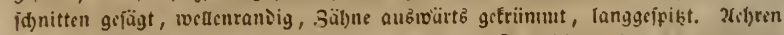

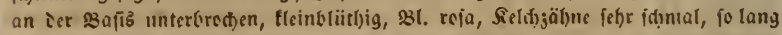

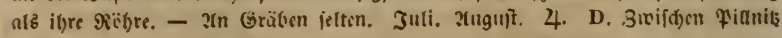
uno 5ofterniç. G. Rchb.

877. M. rotundifolia L. Engl, Bot, 446. Fl. germ, exsicc. 6r4.

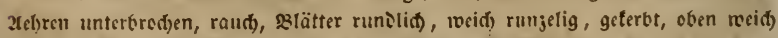

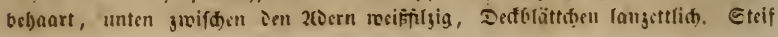




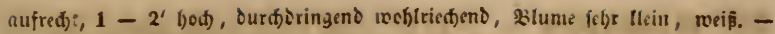
Ju Grtäbcn, Eimpfen felten. 2ruguit. Eeptentocr. 4. Eebr felten, nur im wefftidjen Gebiete. L. Etërmithal nad) Petermann. PS. Rieicburg, Soidjiorf, Burgliebenau, SRS. ๔đłıarzburger ミljal. Schünheit. J. Beier.

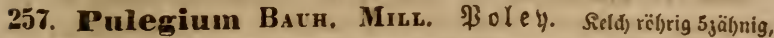
Doerlippe (Drei 3äl)ne) etıos aufroärts getrïntmit, Gd)luno yen sinem

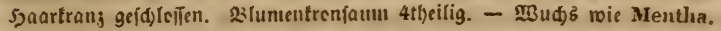

878. P. vulgare Mich. Harxs Arzneigw. XI. 39. Rlätter ei. runo, ftunipf, etwas getertit, Relche grau belaart. 2tufiteigeno, fpannenlang, \&lätter fât trie bci Origanum, Quirle tugliđ), SL. tlein, rcja. - 2uf nietrigen,

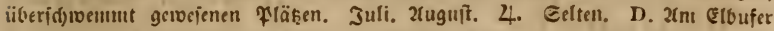

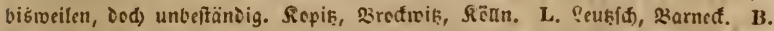
Grofbennersoorf. PL. Ed)wiclungsice, Epresibalo, Guben. PS. 23arby. Ed)to.

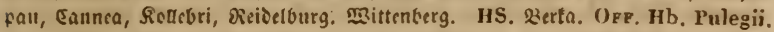

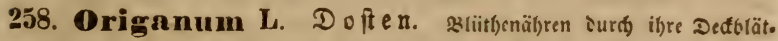
ter japfenartig. Reld) etıas̉ ungleid 53äl)nig. Slunte faum berauşftebens,

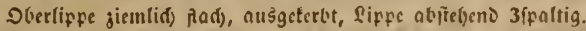

ค. Origanum, Rel(t) $5_{j}$ äbnig.

879. 0. vulgare L. St. 3. Harre Arzngew. viII. 8. Sliitben. äbren faft tuglid, riß̨pig, Dectolätter ciruno, farbig, Sield) bärtig. Etcif auf. red)t, unten etwos aufĩcigeno, Etingel uno Dedoläster ifibargretl) angelaufen, Dedblätter länger als Sicldy, 2il. frirfid)blütb), feltner weiß̄. - b. thyzniflorum Rскв. Dedulätter türger nls icr bärtige Sisld); nieiriger, nufiteigeno, jettig, 23lütlie tleiner, blaīer. - In Rerggegenien, jwijđjen Gebüfd), an Felien, rai.

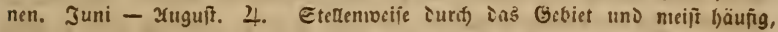
fiblt aber bei scipjig. OPF. Hl. Origani vulgaris.

b. Maiorana BAvr. Seld balbeitig, gaf)nles oier 3jübnig, unter. feits geffalten.

- 880. 0. Majorana L. Harxe Arzngw. VIII. 9. \$2lütb́näbren gef̂tielt, faft luglid), ju Dreien georängt; slätter geîticlt, frumpf, jientid) tal)l, IBurget einjäl)rig. Graugrïn, $\mathbf{l}^{\prime}$ bod) ooer-bël)er, ftart toeb(ricd)ent. Orf. Hb.

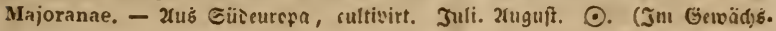
baufe auf b.)

259. Satureia L. Sa turei. Sicldo 1(bîtreing, gleidförmig jugc.

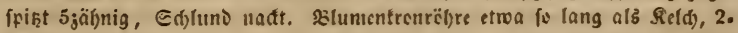
lippis, Docrlipfe etivas aufred)t, flad), anbgeterbs, Interlifpe breiter, 3lap. pig, Dittcllafpen ausgelerot.

- 881. S. hortensis L. Schк, t. 156. Harsi Arzneigew. vi. 9. sinjäl)rig, armförnig meitäftig, Blätter fdynal lanjettlid), ganjranìg, slütben

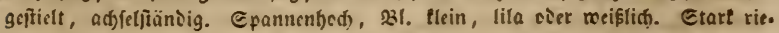
dent. OFr. Hb. Satureiae. - Xuf velautem Reien, in Eärten. Suli Eeptember. $\odot$. Gebaut. 


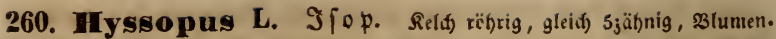

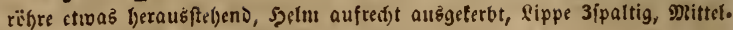
lappen jeverfeits quer verlängert, ausgetertot.

882. H. officinalis L. SchK, t. 156. HAYNe Arzneigew. VI. 18. Fl. gerın, exsicc. 13+0. Blätter linealifd) langettlid, Bliitthen quirltraubig ein. feitig. Unten holgig, $\mathbf{1}^{\prime}$ hod, 3l. blaul. OFF. Hb. Hyssopi. - 2uf Mauern, Ed)utt, bier und Da verwilDett. Juni - 2uguft. b.

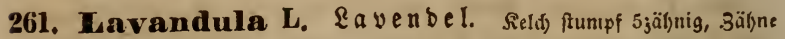
zur $\mathfrak{F}$ rudgt feit zufa un engeneigt. Blune: Doerlippe 2fpaltig, un. terlippe 3fpaltig. Fiftule und Etautgefäfe in $\delta$ er $\Re$ ö brc. Beutel mon $D$. förmig einfädrig.

- 883. L. Spica L. Scrk. t. 157. Fl. germ. exsicc. 134t. HАy g

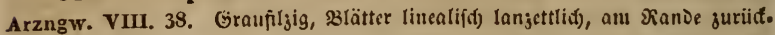

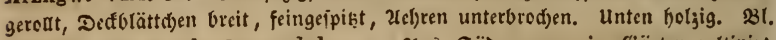
graublau. OFF. Hb. Lavandulae. - 2ub Siideuropa, in Gärten cultivirt. 3uli. 2luguft. b.

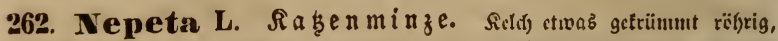

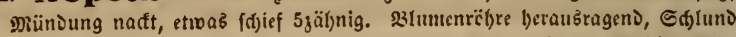

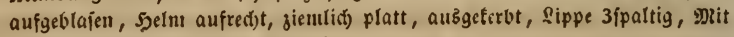
tellappen gani, fiad) nuifdelffremig.

884. N. Cataria L. H. Arzgw. IV. 8. 23lätter gejłticlt, her jaciruno grob fäge.

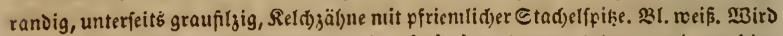
$2-4^{\prime}$ ()od), ricd)t unangene(jut. - b. citriodora BALB. 23lunic rotl) punftirt,

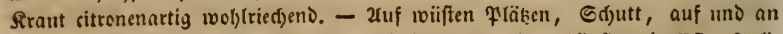
刃auern. In Den meiften Segenden und Dann gefertig, bäufiger in PS. Juli. 3rıuाt. 4 .

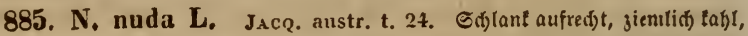
Quirle gientlid) fikeno, wenigbliitbig, Blätter grïn, untere furz gefitielt, berj.

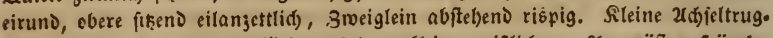

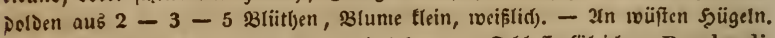
3uti. 2uguft. 4. Gebr felten. PS. Bei Erfurt am Edjleffe G̈Teidten. Bernhardi. Bei Eišleben. Bok.

263. Glechoma L. (5) u n bermann. Seldi röbrig 5yät)nig. Dberlippe Der Blume fad), mit Einf(d) nitt. Mittellappen der Unterlippe um. geterbt herzförmig. Etaubfäben parallel, Die Beutelpaare freubförnig.

886. G, hederaceum L. Schk. t. 152. HaYNe Arzngw. II. 8. Rried)eno, Blätter nietenförmig, terbrandig; aufíteigeno, ipaunentang uno län. ger, fd)ön grün ooer rotl) überlaufen, aud) wolsl gan; braunrotl), Seldsjät)ne ci. runo fein jugefpik̨t. 23l. blau. - b ? heterophyllum OP. untre Blätter nic.

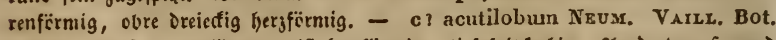

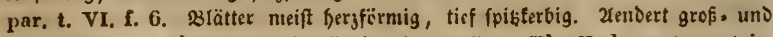
fleinblïthis und ginßs uno tlcinblättrig $a b$. - OFr. Hb. Hederae terrestris. 
- 2uf bebautem Boden, in id)attigen Mäbern, an Mauern. 2tpril Soerbif. 4.

264. Tamium L. Taubenefiel, Bienen $\mathfrak{x}$ ug. Sold

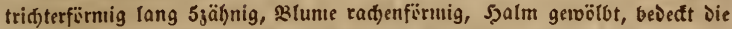
paralleten Etaubgefäße. Mittellappen Der Unterlippe untgetelgrt herjfërntig,

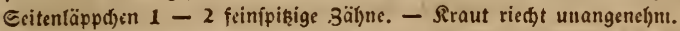

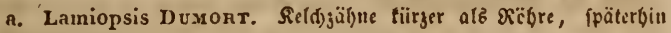
suianintengencigt.

887. L. amplexicaule L. Schx, t. 150. Rснв, pl. crit. III. ic. 373. Blätter rundtid) nicrenfïrmig, ftumipf getcrbt, Die oberen ftengelumıfailent, faft gelafpt; $\mathfrak{B}$ lumenrëbre geraic. 231 . tarmintotl). - b. clandestinun Rснв. pl. crit. VIII. ic. 950. 23 lume im Reld) verfïmmert. - 26uf becoutent 300 en,

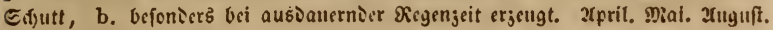
Esptrilber. $\odot$.

888. L. dissectum Wıтн. Вснв, pl. crit, III, ic. 37(). Brätter

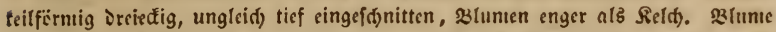
farninrotf. 2tufittigeno, (pannent)od). - 2tuf bebautem 230ien. 2(prit. MRai.

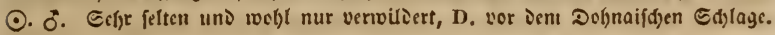

b. Lamiun, Rel(d)jätrue lang, ofien ftetlent.

889. L purpureum L. F], dan. 523. Scнк. t. 169. Säätter si.

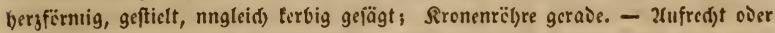
meift mel)r(tenglid) auffiteigend, bis ipannent)od, meift Stengel und obre pyra. misal geffectte 3iätter braunrotl) angelaufin, Blume tarminreth), felten blafroth)

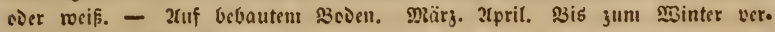
singelt. $\odot$. Gentein.

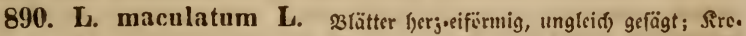

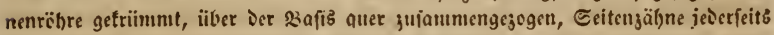

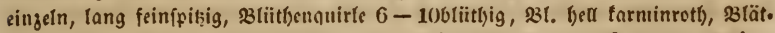
ter eigentlid) mit weificm \&ängšftrteif : n. vittatum Rснв, Fl. germ, exsicc. 742. pl. crit. III. ic. 362. Sisei unz Dic \$3lätter meift ungenefft, ganz griin: b. nemorale Rснв. Fl. gerın. exsicc, n. 845. - In Saubwäliern, in Gi。 viifd. Xrprit. Mai. 4. Durd Daß Gebict nidgt futten.

891. L. album L. T], dan. 594. ST, 8. Hayse Arzngw. VI. 41.

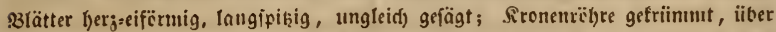

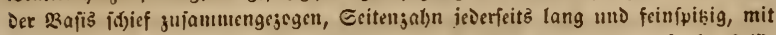

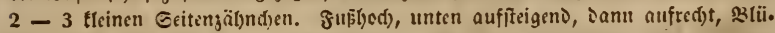

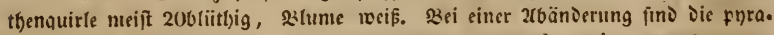
miDal geffellten Deftblätter vraun angelaufen. OFr. Fl. urticae morlune. -

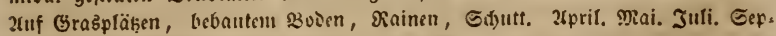
tember. 4. Eerjer gentein.

265. Galeobdolon Hods (S ilbnefiel. Mie Laminu,

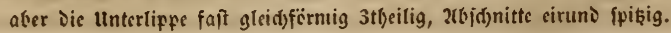


892. G. Inteum Sr. Engl. Bot. 787. Schк. t. 157 (23(üthe). Drkw. u. Hayse t. 20. F], germ, exsicc. n. 1680. 2(uffigeigent, fup̈lood) und bïber.

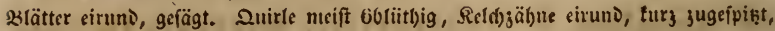

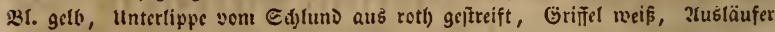

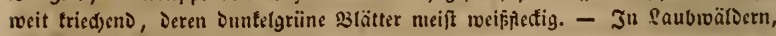
an fd)attigen Drten. 2(pril. Maai. 4.

898. G. montannm P. Fl. germ. exsicc. n. 1681. D৮re Blätter eilanjettlid), Die Der ?ustäufer gref, weid), eingei(fnitten Dreifad) ge(ägt. Sield).

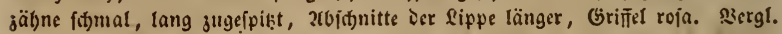

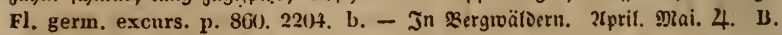
Bei Niciederfriedersonrf. Neumanu.

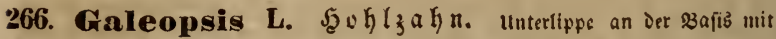

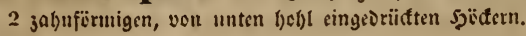

н. Ladanuin Rrv. Blunten aufredt), Stengel tnotentos.

894. G. angustifolia Енвн. Rснв. Fl, gern. exsicc. n. 1679. ST. 62. Etenget rüđúwärtb meid vel)aart, \$lätter lineal lanjettlid), von Der Mitte auls ungleidf) entfernt gefägt; Seld)e graul. - 2un feligen Etellen in 23 erg. gegenden, bäufiger auf Sialtboien, aufierient felten. Julli - Eeptember. ๑.

895. G. Ladanum L. Schr. t. 161). ST. 62 . Etengel rïđwärts vel)aart, Slätter oval over länglid) (anjettlid), gleidffürmig (ägejätnig; Setd)e

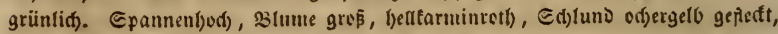
ielten ganj weiß̄. - ?uf 3eťern. Juli - Eeptember. $\odot$.

896. G. ochrolenca L.M. Rснв. pl. crit. I. ic. 98. Riïđıärts

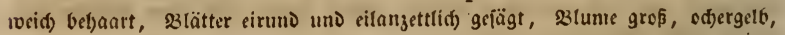

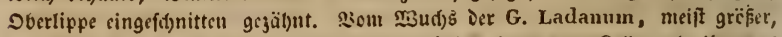
IDer edjluno 1)odggelb. OFF. „Hb. Galeopsidis, Sieberfder Rräuterthee”. Zuf

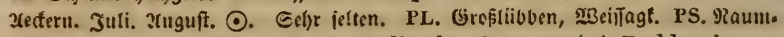
burg. Beneken. Nisfleben, Mebra. Wallroth. Edywarjatjal. Buddeusieg.

897. G. intermedia Vıcx. Rснв. pl crit. I. ic. 99. Fl. germ.

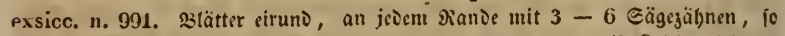
wie Der Etengel foin belfaart, 23fume taum ieppett jo lang als Sietd, $\mathfrak{B}$ ud)

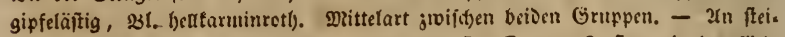

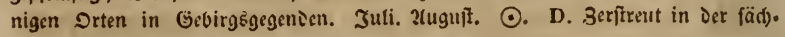
fifd)en Edjtoriz.
b. Galeopsis, \$3tumen vorgeftredt, Etengel Enctig.

898. G. pubescens Bess. Пснв. pl. crit. I. ic. 100. 101 . Fl.

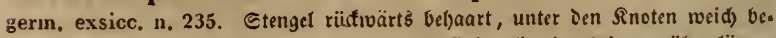

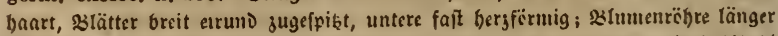
als̀ Der Reld); Mittellappen Der Unterlippe fein geterbt. Epannentod) bis 2'

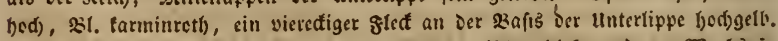

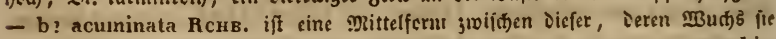
bat, and iie entfernten Quirle, aber Dis fteife befharung ven G. Tetrahit. 
Cie ift viedteidst Baftaro: - 2uf Єdytt, an Wegen, Seljen, Mauern, Flantin. 3uli. 3uguft. $\odot$.

899. G. bifida Bvigh. Rснв. Fl. germ. exsicc. n. 236. Sr.62. Etengel fteif beljaart, S3lätter eiruno länglid), fpisig, 23lumenrïb)re ganz einge.

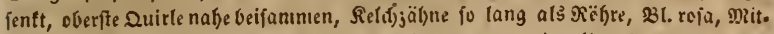
tellappen Der llnterlippe ungetel)et berzfirmig ungercat, Dunfler, 2 gelve Flecten.

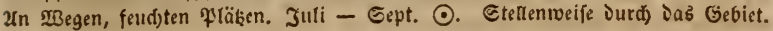

900. G. Tetrahit L. Stenget fiteif befaart, slätter eirun১ längliđa,

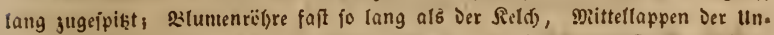

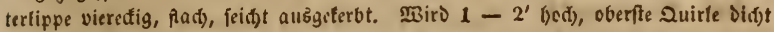

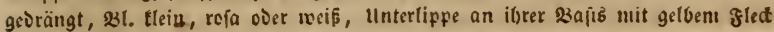

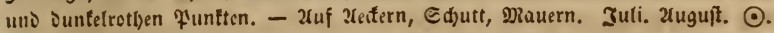
Dur() ¿ab Gebiet gemcin.

901. G. versicolor Cunts. Rcrв. pl. crit. 1. ic. 117. Fl. germ. exsicc. n. 450). Etengel fteif bihaart, 23lätter eiruno länglid), lang jugefpiß̨t;

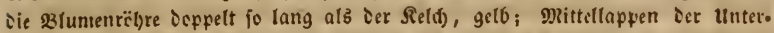

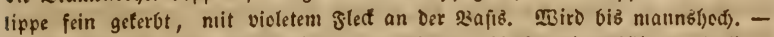
3ı feudjten Drten an \$alorändern, an \$äd)en, bänfiger in इbälern. Jull Eeptemiber. ○. Durd) Das Gebiet nid)t filten.

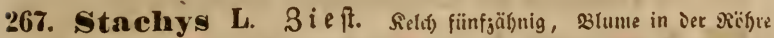
ringförmig ochaart, J̧eln nuidgelfïrnig. Sippe 3lappig, mittellappen ant

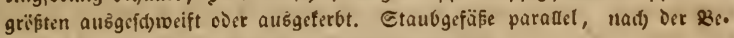
fruditung Die beiden türgere"l nad) auß̄en umgebogen.

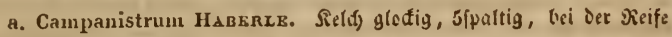

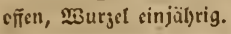

902. S. arvensis L. Rснв. pl. crit. X. ic. 1298. Quirle 66lütblg, Etengel aufrect)t, fteif bet)aart, Slätter bers=eiruno, untere geftielt, ftumpf, ge. terbt, f(d)wad) behaart, Selí) faft io lang als bie Sirene, mit eilanjettlidjen, fta.

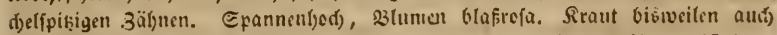

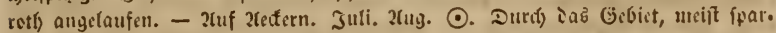

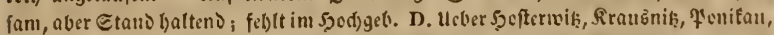

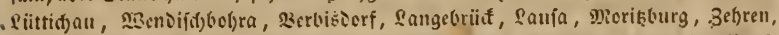

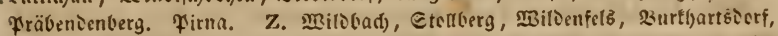

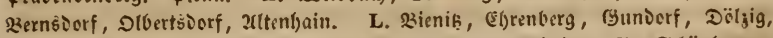

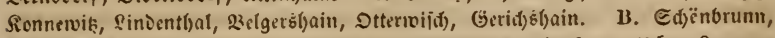

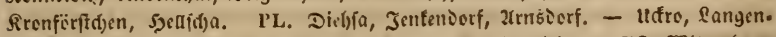

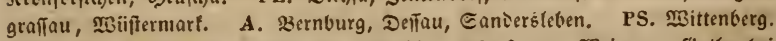

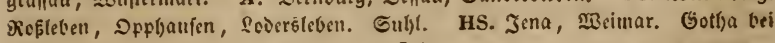
S(b)argljaujen, Zannrode. SRS. Ruodftait.

903. S. annua L. Sснк. t. 161 (231. un๖ frud)t). JAcQ. austr. 1. 360). Fl. germ. exsicc. n. 448. 2uirle 4-66hiitbig; Gtengel oben weid) be. baart; Blätter lerbfägejäl)nig, geftielt, cilanjettlid) over efliptif(i) länglid, die cberen langettlld), ganjranoig; Seldbe jottig, nit fein bel)aarter Etndjelfpib̨e. - 
Spannenbod) und bïber, $B I$. groß, berausffebend, odergelb, Sippe roth punttirt.

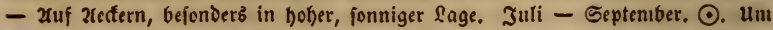

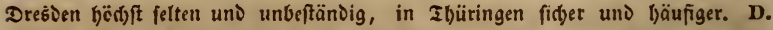
Şaubsorf. Fr. August K. v. S. Sertervih; Seflberg bei Firna. Bucher. Bok. Gr. Gefäge. Rchb. - 2tuguftüburg. Bok. L. Gundorf. Peterinann. PL. Zriebel. Rabenhorst. A. DeiTau, Bernburg, Sandersleben. PS. \&übnifz

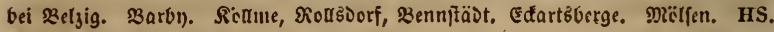
Eifenberg, Jena, ঙrimar, Eifenad).

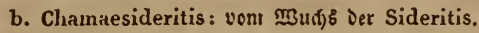

904. S. recta L. Schk. t. 161. Haysk Arzngew. IV. 12. Quirle

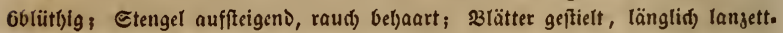
lid), terbig gefägt, obere eirund, zugefpişt, ganjrandig; fieldje raud) bel)aart, mit gelber Stadjelfpik̨e. MBiro bis $3^{\prime}$ hod), hellgrün, 31. odjergelb, Sippe roth punt.

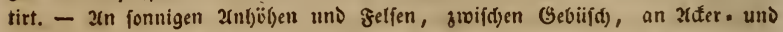

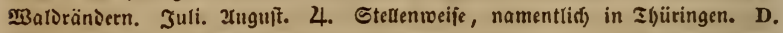

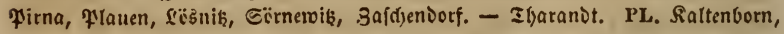

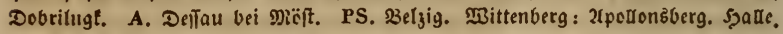

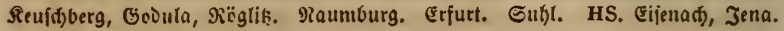
SRS. Jrantenliaujen, 2trmftait.

c. Eriostachys LK. Eteif aufred)t, 3[. rotf), meiff zottig.

905. S. palustris L. ST. 18. Hayne Arzneigw. III. 40. Quirle 6-12blütbig; Gtengel tabl ober furz bebaart; Slätter berbfömig langettlid),

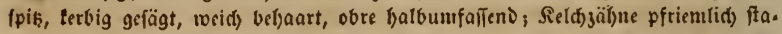
d)elfpițig; SBlume Doppelt io lang als Der Reld), rofa, earminrotl) gefieft. - b. segetuin HAGEx. 3lätter feidenbaarig, Quirle Did)t. - In Sïmıfen, Bräben, auf feudtin 2ledern. b. auf trodtuen 2feffern. Juli - September. 4. Durd Das (sebiet nid)t felten.

906. S. ambigua S.r. Ricrв. pl. crit. III. ic. 369. Fl. germ.

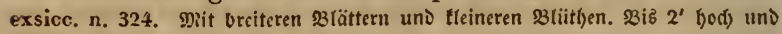
bäber, Mittelart jlvif(d)en Den शRad)barn, fonft für 23 aftaro gel)alten. - In $\mathfrak{B} a ̈ l$. Dern. Juti - September. 4. A. Deffau: Sieglikzer 3erg nad) Kützing. PS. 3wifdjen Edjwarga uno Diaftüot. Kiitzing.

907. S. silvatica L. Hayre Arzneigew. IV. 11. Quirle 6blï.

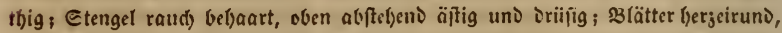

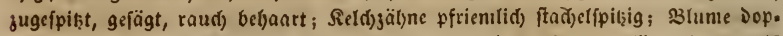
pelt fo lang als Der Seld), farnuinrotl), Dunt(errotl) punftirt. 3lätter im Uniriß

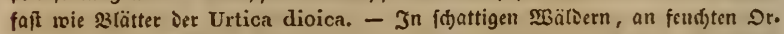
ten, an szäd)en, Eümpfen. Juni - 2uguft. 4. Durd) Das Gebiet nid)t felten.

908. S. germanica L. Rснв. pl. crit. X. ic. 12S(). Fl, germ. exsicc. n. 646. Quirle vielbliitl)ig; Stengel Didyt modjottig; \$Blätter bergeirun১

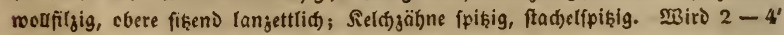
bod), 231. rofa, tarminrot) punttirt. - 2(n fonnigen, fteinigen zrbljängen, gelfen,

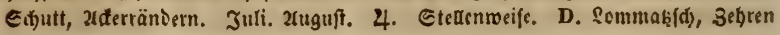




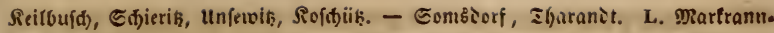

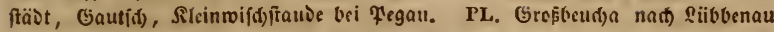
ju; 9Renjetle. A. Sermen, grieveritinberg, Sandersleben. PS. Sarby bei Gref. roicnburg. Szelyig. Mliidgelı, Erumpa, Sranderode. Beneljaujen, Bormbleben. Erfurt. HS. Berfa, Grra. SRS. Frantenbaufen.

268. Betonica L. Betonie. Relds legelfömig, seisnnervig,

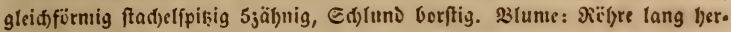
ausiftcheno, Sgelm nufiteigens, Cippe ljängens 3lappig.

909. B. officinalis L. Rснв. pl, crit. VIII. ic. 052. ब(t) (ant, seta)

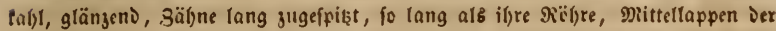
Itutcrlippe auer, Єeitenläppdisn furz. - b. hirta LeYss. Rche. pl. crit. VIII. ic. 953. G(t)lant, gcraje aufred)t, Feld) oben bel)aart, .̧äl)ne lanjettlid) (pis, balb fo lang alb ibre Rïbre, Mittellappen ier llnterlippe runblid), geferbt, feit. lidje anliegend. - c. stricta AIr. Rcrib. pl. crit. VIII. ic. 954. Etürter, gea

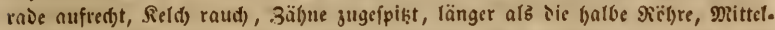

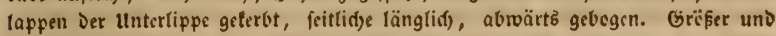

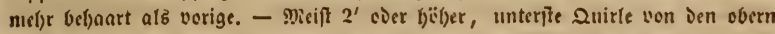
entfernt, Stinget mur nit wenigen slattpanren, faft nadt. 33. tarminroth. -

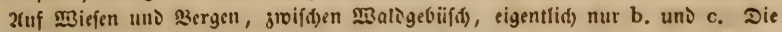
lable form tonumt bei uns nid)t vor. Juli. 2uguit. 4. Durd) ¿as Gebiet, in ien bïdjen Gegenien verfiftwiniens.

209. Ballota L. $\mathfrak{B}$ a $\mathfrak{l}$ o te. Sild) ribrig gloctig, Gd)luns nadt,

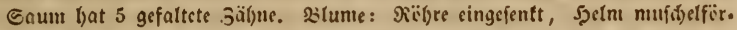
mig, Mittellappen Der unterlippe umgefelyrt berzfïruig, Geitenläppdjen ct.

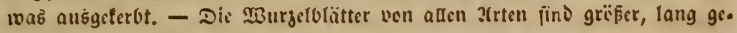
ftieft, nierenförmig runolid), giterot.

910. B. nigra L. Rснв. pl. crit. VIII. ic. 1039. Fl. germ. ex-

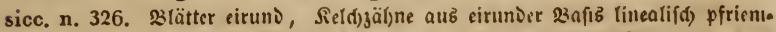

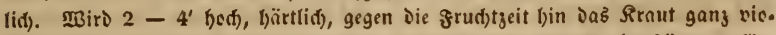

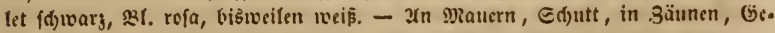

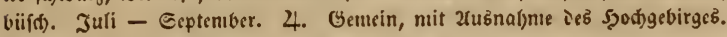

911. B. urticifolia ORt.r. Rснв. pl. crit. VIII. 1010. Eđ(nnt,

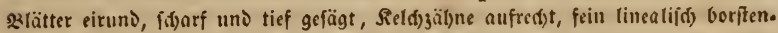

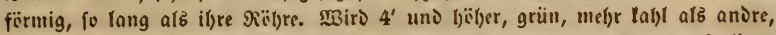
23lätter im tmurís wie Die von Urtica urens. - 2(n Mauern, Sd)utt. Juli Giptemiber. 4. Scrifteut.

912. B. foetida LAM. Rснв. pl. crit. ic. 1()41. Fl. germ. exsicc.

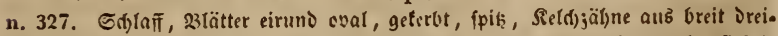

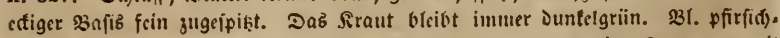
bliitl)rotl), felten weifs: B. alba L. 2uls હpätling tonnt cine form ver mit leilförmig uuigetel)rt eirunden, wenig geterbten 2 lättern: marnbioides, Fl. germ. excurs. p. 325. - 2u פlancrn, Säuncn, auf C(1)utt. Juli - Giptor. 4. 3erftreut. 
270. Marrubium L. 2t noorn. Sitd falt waljig, feif 5 10järlnig, Ed)luno mit eincm Şaartranje. 23(ume: Jiäbre feeft int Sieldje, Dberlippe linealiid), geipatten, aufredt), Unterlippe 3lappig, fappen auzgc. lerbt, ber mittlere ant grḯten.

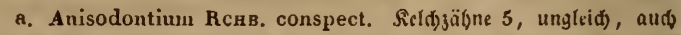
3ur grud)tjcit aufre(t)t.

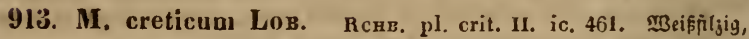

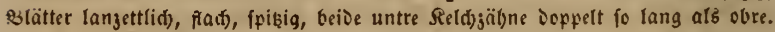

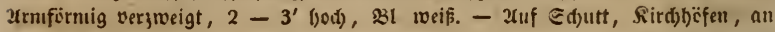
Wö̈lent, Megen. Juli - Eeptember. 4. Gelje letten und weljl cingebiirgert. PS. Erieborn.

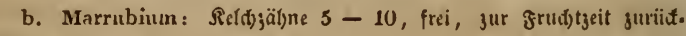
gebogen.

914. M. pannonicum CLUs. Rснв. pl. crit. II. ic.-473. \&lätter

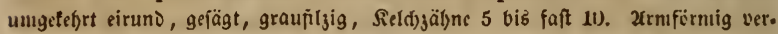

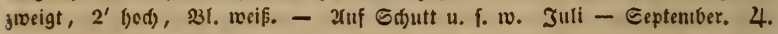
Echr feften. PS. Erbeborn.

915. M. vulgare L. SchK. t. 162. HAYNB Arzngw. XI', 4). 厄tell.

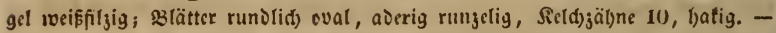

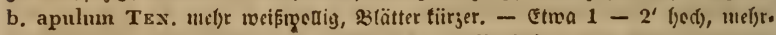
ftenglig, äjtig, 23l. weiß. - OpF. Hb. Marrubii albi. - 2lı Niauern, Flall.

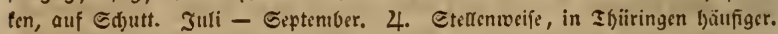

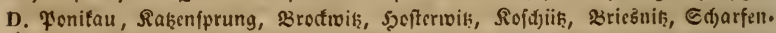

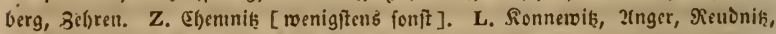

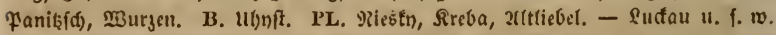

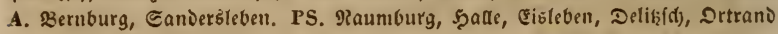
und umgegend. HS. Meimar, Jina, Gera, (sifenad). SRS. 2(rnjtadt.

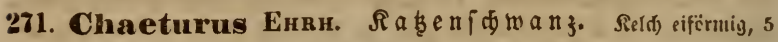

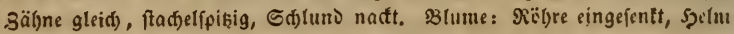
unffd)elferrnig, vorgeftridt, Sippe 3lappig, Mittellappen ganj.

916. C. Marrubiastrum Rснв. JAc२, austr. t. 425 . Schк, t. 162. Blätter länglid), greb gefägt, 2uirle Did)t, S3lume flein, meiß̧. SRraut auf,

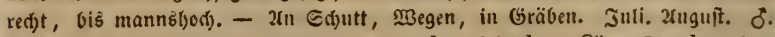
Gelten uno unftanohaft. D. Priederau. Bucher. Mauke. Sïan. Mituke. [an

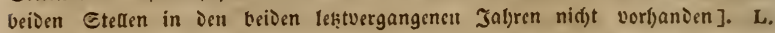
rofentlfal feit Ludwig. PL. Cee, cinmal auf Dem Rirdfbefe. Külbing. -

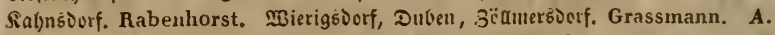
Deliau: an jenfcitigen Elbufer; Friederitenberg. Schwabe. PS. Barbn ant Gnes uno fonft nidgt feiten. Scholler. MBittenberg: Fratau, Frolfteigarten,

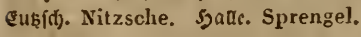

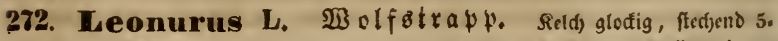

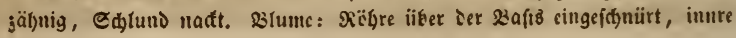




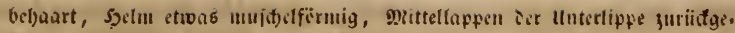

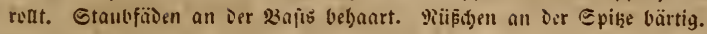

917. L. Cardiaca L. Scnk. t. 162. Sт. 9. Haxжi Arzneigew. 111. 41. Die untern 23lätter bantfürmig stbeilig, eingejđ)nitten gr(ägt, Die sbern tcilfërnig länglid), 3ipaltig. Mud)s plyrantiol, Dis tleine Slunte rofa, tarmin. rotl) punttirt. - 2tuf હdutt, nn Diauern, Planten, Süunen, Ffïb̨en. Juli Septeniber. 4. Durd) Das Gebict meijt gemein.

273. Thymus L. Thymian, 2 uen lippe aufíteigent 3jäl)nig, - Unterlifpe aufïrigens lang 2 jäl)nig, હ(t)luno

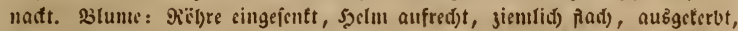
Sippe 3tt)eilig.

* 918. T. vulgaris L. Schк. t. 167. HAy 2ufred)t, arufërmig äpīig, Blätter eiruns oocr lincalif(d), umgerout, Blïtl)en quirläbrig, ounfilgrïn, bandbod) vis ifannenbod), 231. blaşlila. - OrF. Hb.

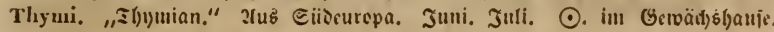
b. J゙ Gürten.

919. T. angustifolius Schreb. Rскв. F]. germ. exsicc. 186.

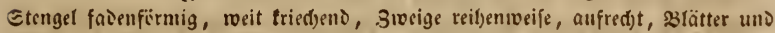
Dectolätter lincalijd) Ianzettlid), frumıf, nervig, fpäter ri un en a rtig, sliitl)en

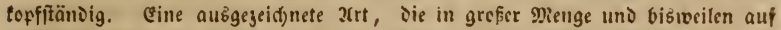

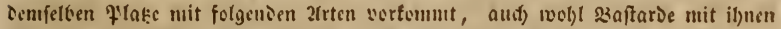
vilben riag, ju(t) aber fonlt aus Eaamen erjogen gleid) bleibt. - 2uf Eanobc.

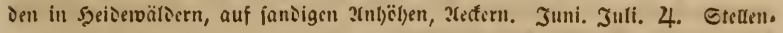
weije, jumal D. l)äunig in alten Eanigegenden auf oer teiften Ëlofeite.

920. T. pannonicus ALL. Rснв, Fl, germ, exs, n. 1534. હ(f) $(a)$

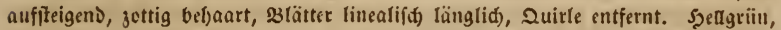
fel)r twoblried)end, $\mathfrak{B}$ l. rofa. - b. Jamuginosus Mrcs. Blätter länglid) ellip.

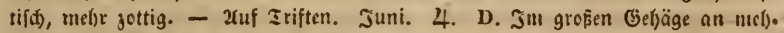
rail Stellen. 3ngetids aud) bei Siopik.

921. T. humifusus BrNH. Etengel folft lang tried)ent, fo wie sie 3 weige uno Sï̈pf()en zettig bef)anrt, slätter treistuno uno elliptijd) fpatelfürutig gervimpert. Slätter nur 2 - 4 Sinien lang. - Juf Saltboien, an founigon

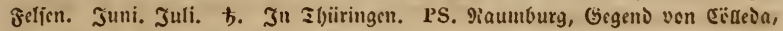
Finnberg u. f. w. Erfurt. HS. Jena, Meimat.

922. T. Serpyllum L. Nieocrliegend, aufiteigeno, 'Etenget turij und fraus bel)aart, silätter uno Dectblätter f $f(a d)$, länglid́), oval, eiruno, ftumpf, Quirle tëfrig, Die untern entfirnt. - a. Serpyllum L. Fl. dan, 1165.- Engl. Bot. 310. Rснв. Fl. germ. exs. n. 187. Stengel fadenfïrmig lang tried)ent, 3meige reiljenweife, nufred)t (ïteiflid) uno siffer alz an Th. angustifol.). $-\mathrm{b}$. Chanaedrys Fries. Rснв. Fl. germ. exsicc. n. 188. 189. Rrummiätig auf。 fteigeno, 3roeige 2reil)ig furj grau bej)aart, 3lätter gefitielt eiruno. Sjierber ge.

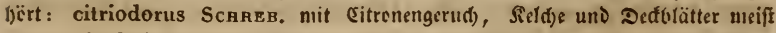

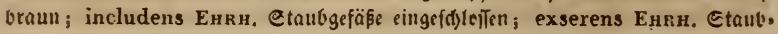




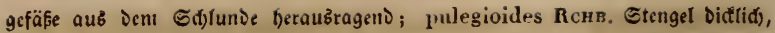
4lantig, 2 fritig weiffiljig, Duirle vielulütbig, alle entfernt; silvestris SCHRкв. Srweige Dïnn fadenfirmig, nebft Blöttern tal)l, Quirle alle entfernt. 2uf Feld, rainen, Iriften, Şïgeln. Juli. 2uguft. b. Micift gemein. OpF.Hb. Serpylli.

274. Acinos Moench. ß3afilienthym. Reldy an Der $3 a f i s$ unten nit Şïđer, rël)tig, Doerfippe begig orcijälsnig, Unterlippe groeipaltig,

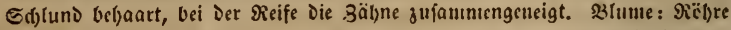
etwas aufgeblaien, 5jelm jicnulid) fad), Sippe 3inppig. Untre Parbe frunm,

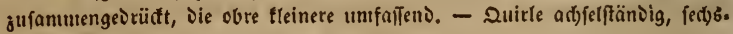
bliitbig.

923. A. thymoides Mксн. 23lätter eiruno, gciägt, fpił̧ig. Eten. gel allfec(t)t coer alffifeigend, ffannenlang, wenig bel)nart oder b. villosus PERs.

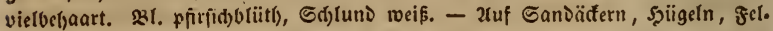

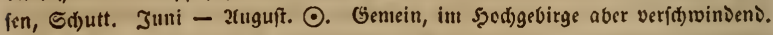

275. Hesiodia Mмсн. Sefíobia. Seld rübrig, Dberlipue ftad)elfpishig 3jälsnig, Unterlippe lang 2 jälsnig, bei Der Dicife offen. Blume: Röl)re ganj eingejentt, Şcim fiad, gan\}, fpit, fippe abgerundet 3lappig. Untre garbe fad), breiter, unfaft Die obre fieltunoe.

924. H. montana Dumort. (Siderit. - L.) Sr. 4. Schk. t. 158. Rснв. Fl. germ. exsicc. n. 1231. 2(ufrect)t oder rocitäftig aubigebrei. tet, jottig, Slätter gefficlt (anjettlid), nad) Dor Epif̧e gejägt, Die blïtbenftänذigen ganyrandig, 31. ed)ergelb, ffäter Der Gaum braun. $3 i \xi$ fpannenlang. - 2tn fonnigen Gand. und Saltbügeln felten. Drai. Juni. $\odot$. PS. Gegend von Sgalle vei syornburg, (Everzrode nad) Wallroth.

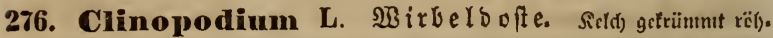

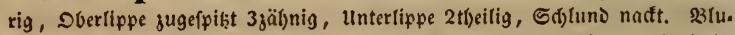

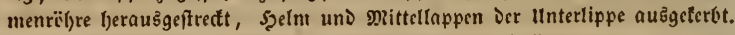
- Quirle Didbtolütbig mit vielen berftenfpikigigen Deffolättd)en.

925. C. vulgare L. Fl. dan. 930. Scrk. t. 163. 2(ufredt, weids bebaart, Quirle alle zien!lid) gleid) vielblütljig, 5̧ülle fo lang alb Die field)c.

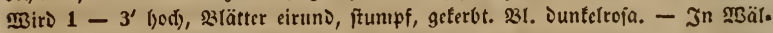

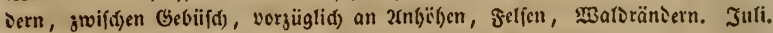
Yuguft. 4. -ridst felten.

277. Mélissa L. Me liffe. Sild offen, Dverlippe turg 3 jälsnig, Scitengäl)ne fielrippig, Unterlippe lang 2jäl)nig. Blume: Dberlippe etroas mujđ)clfërmig, aušgeterbt. Unterlippe 3lappig. Etaubgefäfe bogig, gegen Die Gpiken roieder jufammengeneigt.

- 926. M. officinalis L. Sснк. t. 165. Rснв. F]. germ. exsicc. 1237. Hayse Arzneigew. VI. 32. 3lätter ciruno, fpik, gęägt, Dectblätter

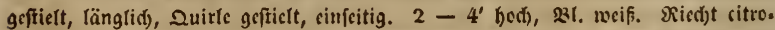
nenartig angenel)m. "હitronenmelifie." OFr. Hb. Melissae. - 2ů̊ Sïbentopa. Juli. 2luguft. 4. In Gärtcn. 


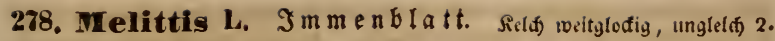

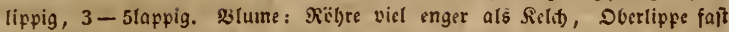
naad), tiiryer als Die grofe 3theilige Unterlippe, Der grefe Mittellappen umge. tel)rt eirund. EtaubfäDen unter Der Unterlippe aub Der $\Re$ äbre aufifeigent, beiDe zätser Der obern $\mathfrak{B}$ cutel übereinander, Die Der untern nebeneinander.

927. M. grandiflora Sy, Rсnв, pl, crit, III. 397. Fl. germ. exsicc. 607. ScHK. t. 166. 23Jätter eirund länglid), Seld) nteift unregelunäfig

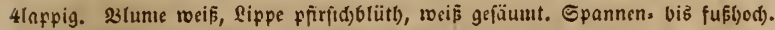
- In id)attigen Mäliern. Juli. Juguft. 4. D. Dol)na, Esitik. Bucher.

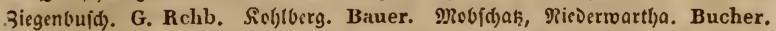
Seifferth. Edjierih, 3afdenoerf. Hanke. L. Medjielburg. Klett. Sparth,

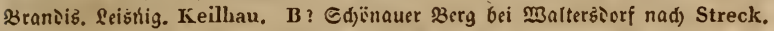

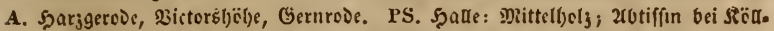

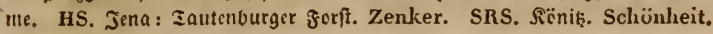

I $\mathrm{nm}$. Die roafre M. Melissophyllum iff fehr verffficien, sergl. pl, crit, ic. 396. uno Fl. germ. excurs. n. 2247. vorjiiglidg in Dejtreid).

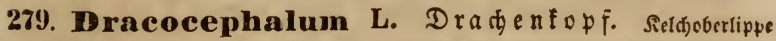

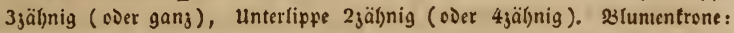
Ed)lund aufgeblafon, Syeln gewölbt, gefpalten, Unterlippe 3ipnltig, פittel. lappen verfelyrt -jergfïrnig. Etaubgefäße unter Der Dberlippe vorwärts gevogen.

* 928. D. Moldavica L. Hayse Arzueigew. vili. 32. Quirle

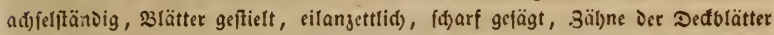

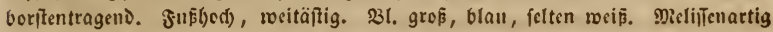
ricd)endę Sraut. OFF. Hb. Melissae Moldavicae s. turcicae. - (Mroldau.)

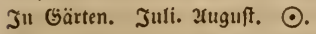

2 n ur. Dracoc. Ruyschiana L. A. Dranienøaum. Schwabe Fl. Anhalt., id) (al) ftinc Epeniplare von Da.

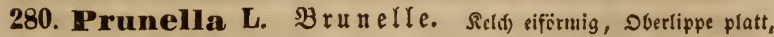

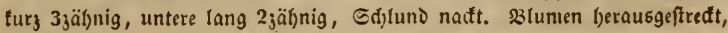
Dberlippe muffelförnig, gan, Itnterlippe 3lappig. Etaubfäden unter DetI Beutel mit 3alinfortias. - Quitle Didft topfartig.

929. P. vulgaris L. St, 5. Hayxe Arzngw, Vi, 10. Die län.

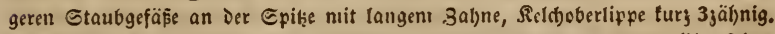
2rufizeigeno, fpannentgody, 33. geftielt eiruno, obre lanjettlid). S3lunte lila, felten

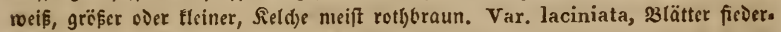

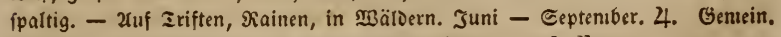
Geltner var, laciniata: PS. Barby in Der Đurgel. Scholler.

930. P. grandiflora L. Scrk. t. 168. Fl, germ. exsicc. n. 328 , Die längeren Etaubgefäfe an Dicr Epik̨e nit cinem Ş̈̈đerzal)n, Dbertippe Dis

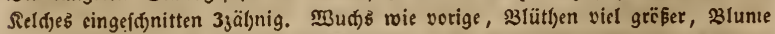
violet, wol)l vierntal fo lang als Reldf. - 2tuf trodinen, fandigen und fteinigen

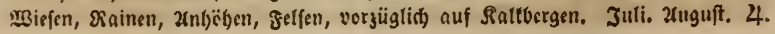




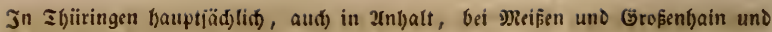

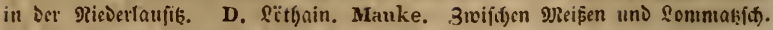

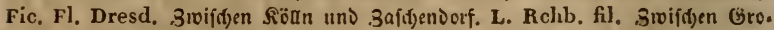
Eenbain uno Streljla. Schubert. L. Siteinö̈ljig, Bienit, Ct. Sbefla. PL.

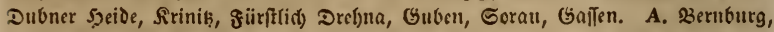

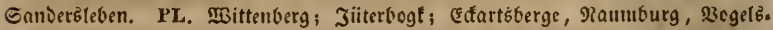
berg bei şennfäbt; Eiß̌leben, Ed)ulpforte. Eteiger bei Erfurt. HS. Eifenberg,

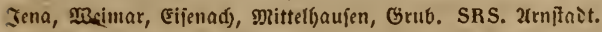

931. P. alba Paxc. Rснв, pl, crit. III. ic. 393. Fl. germ. exsiç.

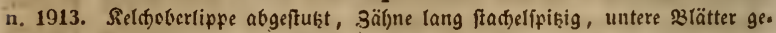
fielt, cirund länglid), obere eingejd)nitten ober tief fieverfpaltig, 2(cl)re unten be.

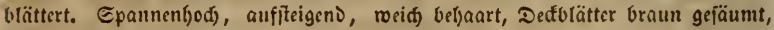

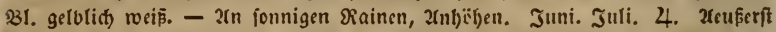
felten. HS. G(t)nepfentijal. Lenz. Etaffelborg bei Roturg.-Eckart.

281. Deymum L. BBa i i lif u m. Seld): Docrlippe fdjilofërmitg, ganz, unterlippe 4ipaltig. slune: Dberlippe 4ferbig, unterlippe gan\}. Etaubgefäfe rufjen allf Der Unterlippe. Sicutel cinfädsrig.

- 932. O. minimum L. Scrк. t. 166. 33ätter eiruno, meił ganj.

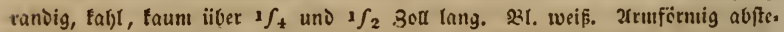

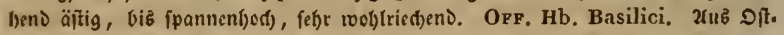
insien, iiberall auf Gartenbeten uno in Söpfen gezogen. Juli. 2uguft. $\odot$.

* 933. O. Basilicum L. Hayxr Arzneigew. XI. 3. siätter ge.

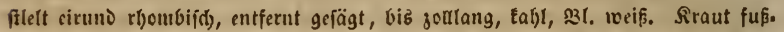
bod), grün, rotb)(raun angelaufen ober ganj rotbbraun. IBobltiedent. OrF. Hb. Basilici.

282. Salvia L. Salbei. Sield): Dberliłpe ganj ober 3 jäbnig, unn. terlippe 2jäbnig. 3lunte: DVerlippe fid)elförntig, rinnenartig jufanmenge.

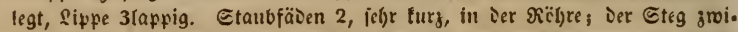
fdjen Den Bcutelfüifern fel)r lang, Dur(f) Edjarniergelent am Etanbfaien beicitigt.

934. S. pratensis L. IIAYxe Arzngw. VI. 2. Sirnutartig, Quirle

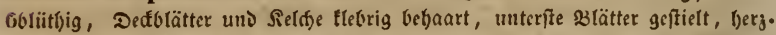
cirutto, Doppelt ferbig gefägt, obere fiker:, ungetbeilt ober Dreilappig, alle run. jelig, unten reid) bebaart. 2' bod), slume großs, violet, feltuer roeis, nod) felts ner bell farminrotb) - b. rostrata Scru, böhnn. Abh. I. t. 1. Blätter an Dex $\mathfrak{B} a j i b$ eingejd)nitten lappig. - c. dumetorum Axvrz. Slumen Elein, Dber.

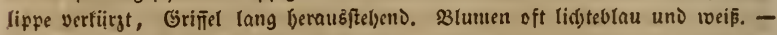

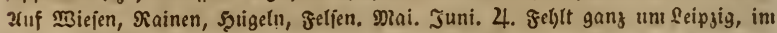
Erggebirge, Boigtlano, in Der grieberlaujik nur bci łitiden, süboen; in Der Doer. laupî́ bei Jauernič́; fonit neiff niđjt feften. Var. b. rostrata fefje felten. D. Etreblen. G. Rchb. Var. c. dumetorun. D. Icutervik, Debna. G. Rchb.

935. S. verticillata L. Cuvs. hist. $\mathrm{xxrX}$. f. 3 . Rснв. Fl. 8 . exsicc. n. 1082. Sirautartig, Brätter faft 3efig bergfïruig, ungleid) geterbt, sis 


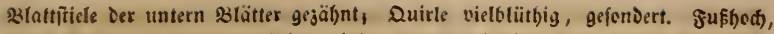

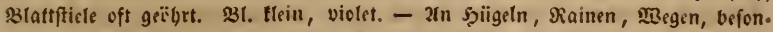
Ders auf Ralfboden. MRai. Juni. 4. Maunentlid) um Dresoen. D. 3ajdjen.

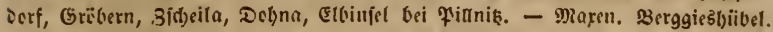
PL. Sauban an Eteinberg. - PS. Erfurt. Buddensieg. HS. Jena. Zenker.

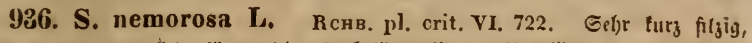

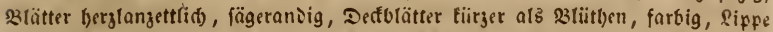

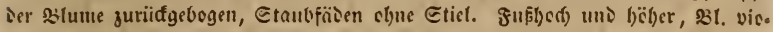

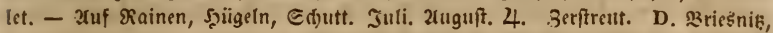

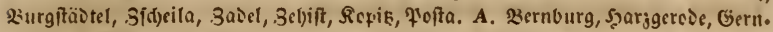

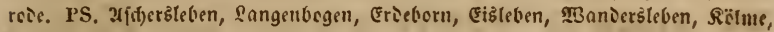

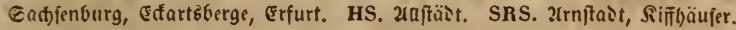

* 937. S. officinalis L. Schк. t. 4. St. 9. HaYxe Arzneigw. VI. t. 1. RcHB, Fl, germ, exsicc. n. 1912. Şalvitraud)ig, 23tätter cilanjett.

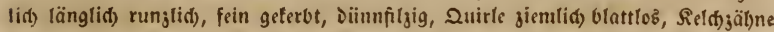
itachelfipitig; Fronenrëbre inmenoig mit einem Sgaarringe. Suflbod) und Drüber, 2il. viclet, feltner weiß. Opf. Hb. Salviae. - Eiiieuropa. Mai - Juti. t. In Gärten.

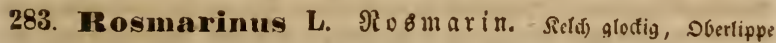

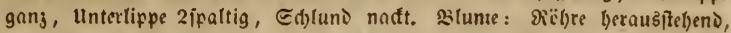

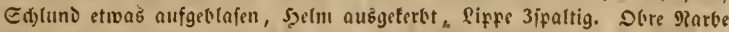
(el)r furj. Bentelfü̈t)er paraftet.

* 938. R. officinalis L. Hayse Arzneigew. VII. 25. Strand)

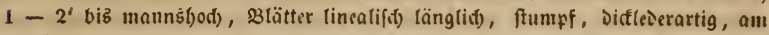

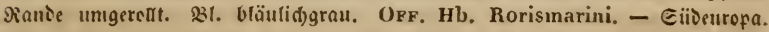
Miärz. Ifpril. Diai. Juni. b. 23ei uns in Gürten.

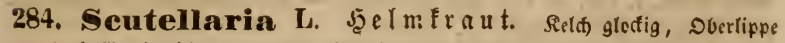

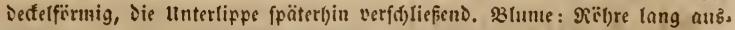

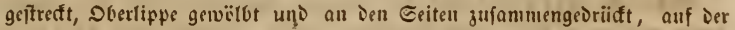
ireilappigen Sippe auffiegent. Dberfte Etaubfäen mit balben Etaubbeu.

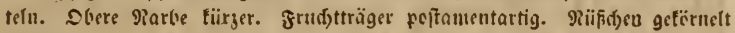
warzig.

939. S. minor L. Engl. Bot. 524. Rснв, Fl. gern. exsicc. 1537.

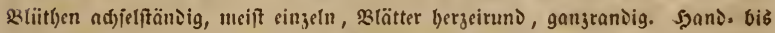

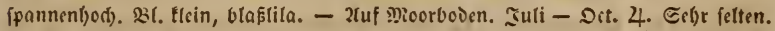

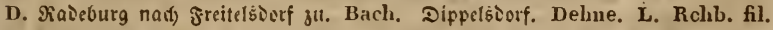

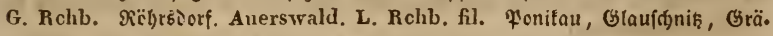
fent)ain. Auerswald. G. Rchb. A. Dranienbaun. Schwabe.

940. S. galericulata L, Schr, t. 167. Hayar Arzneigew. III.

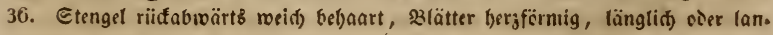
jettlion, terbig gefägt; selüt)en adjfelffändig, paarig. Spannen. biok fuffod), 
f(f)lant und langäpìig, Blume lila. Eb)mals OfF. Hb. Tertianariae. - In

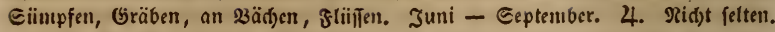

941. S. hastifolia L. Rrv. monop. irr. t. 77. Rсвв. Fl. germ. exsicc. n. 47. Etenget aufwärts toeid)bebaart, s3lätter nteift fpiesförmig, unten

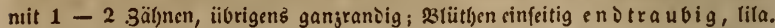

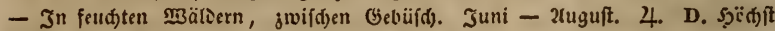
wanoclno. Falaisgarteuwall früber. Weigelt. Talfe tue angeblidg. L. Ro. fenthal, Nonne, Guniorf, 3icniti, El)renberg, Dïljig, Rilcinlicbenau. PL. Reu. getle. Fischer. A. DeTau. PS. Mittenberg in Der Probftei. Schkuhr. Gnes, Enprena bei sarby. Şalle: Irebiķ, griebeburg.

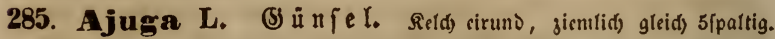

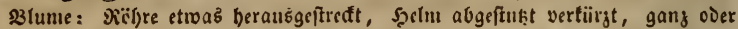

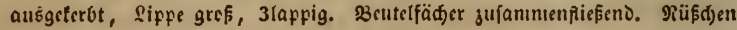
nekgrubig.

a. Ajuga: 23rïthenquirle vielotiitbig traubig, in Der Säbre ber s3lume fern.

942. A. reptans L. Hayx Arzneigew. IX. 17. פit 2๕uสläufern. Meift taf) voer rocnig befbaart, $1 \int_{2}^{\prime}$ bod), Quirle Didft, meift (d)on in unterften

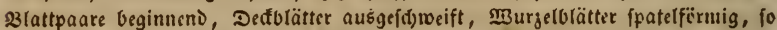
wic Dic flkenten berg = ooer eirunben Etengelblätter geferbt. S1. Dunfelblau, fel. ten tociß̧. - 2uf Graspläß̨en. 2upril - Juni. 4. Gımcin.

943. A. montana (Bujula -) Drcles. (A. genev.) Hayse

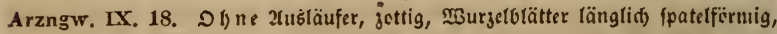
fo toie Die Deffolätter, türger als uittlere Blattpaare, beren getö̈bnlids $2-3$

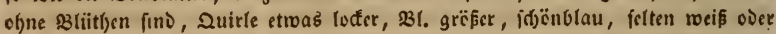
rofa: $\boldsymbol{A}$. genevensis L. - A. foliosa Tratt. ift cine ïppige form ntit gro. Ben 3 lättern und Detfolättern. Scḩtere fincen fid) aud 3ipaltig: A. pyramidalis Scвк. t. 155. $-{ }^{1} \int_{2}{ }^{\prime}$ (jod) uno bëber. - 2uf Sandvoien, 2e(fern, Shü. geln, 3ergen. Maai - Juli. ठ. Ġoncin.

944. A. pyramidalis L. Harxe Arzneigew, IX. 19. Rchв, Fl.

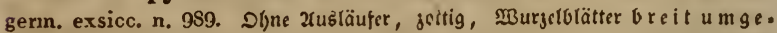
ébrt eirunD, Blütbenquirle von unten beginnend, alle Dectolätterpaare pyramibal tlciner werieno, oberfte ganjrandig. S2l. tlein, beablau, Dectolätter meift braun angelaufan. Etra ljanb. bis $11 \int_{2}^{\prime}$ bod). - In Şeiderbäldern.

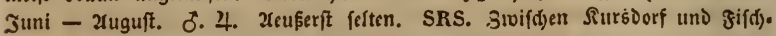
lad)sııiefe. Schönheit.

b. Chamaepitys T. 3 r. adjfelftänoig einjeln gegenüber, in Der

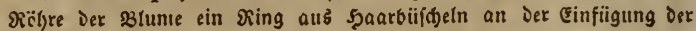
Staubfäden.

945. A. Chamaepitys Schres. (Teucrium - L.) Rснв. Fl. g. exsicc. n. 2049. HaYsir Arzneigew. VIII. 1. Soccift weitäftig niçerliegent, etwas auffeigend, (f(d)wäd)fte Efemplare einfad), aufredt), Burjelblätter linealifis) lanjettlid) ffatelfërmig, ïbrige 3ipaltig und Die Dedolätter linealifd) 3theilig. 
bel)anrl, banis - $1 \int_{2}$ ' coer ipanneulaing, s3l. octergelb, Sippe tarmintoth punt. tirt. Siraut tlebrig und fart ricd)end. OFF. Hb. Chamaepityos. 22n trodnen 2t6.

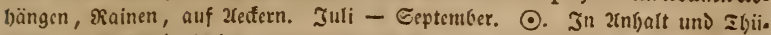
ringen. A. Sanberbleben, Sernburg, Syarjgeroie. PS. Sinabenberg bei Raum. burg. Bennftät. Siurgivenden, finnberg. Relib. Silappad). Hornung. Echt.

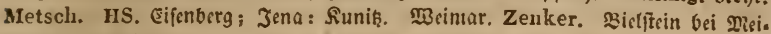
ningen. Rauch.

286. Teucrum L. (5) a m a n ber. Sild ungleid) fünfzälinig. Blunte: Vï̈l)re eingefentt, Dberlippe fefft (mic berausgefd)nitten), Unterfippe

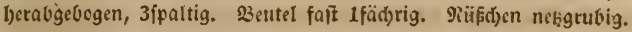

946. T. Botrys L. Hoffu. Fl. germ, ed. 1. t. 9. r]. gern, exsicc. n. 2050. Slätter faft icppelt linealifid) fieicrfpaltig; satüt)ennuirle 2-6.

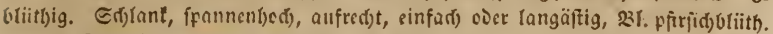
- 2uf Saltboien jroifd)en Gebiif( an šcrgen. Juni - 2ugujt. (.) In Ibii. ringen fjet und ia. D. Sonfrappel. Dittmarsch, Mlarin. G. Rchb. Ricnt.

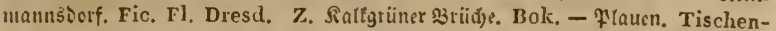
dorf. A. Bernturg, Sarjgercie, Gernreie. PS. Edfraplau, Burgmenten.

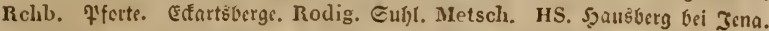
Eifenbrg. Zenker. Ronneburg. Geinitz. M̉eida: Silcoranüble, Miniobrg. Rossinässler. Diciningen: am Rirujterg. Rauch.

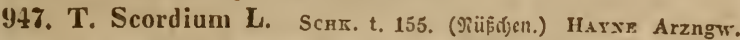

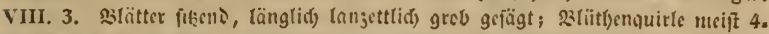

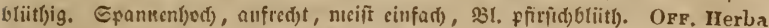
Scordii. - 2uf Dicerwiefen, in Giintfen. Juli - Eeptentber. 4. Berftreut

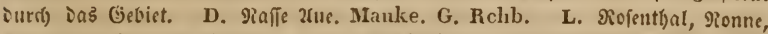

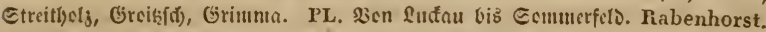

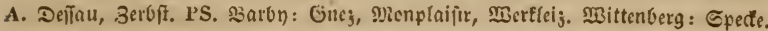

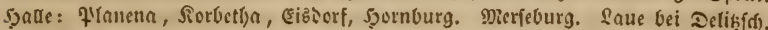

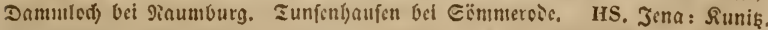
ङd)(ofvippad), હd)wanfie.

948. T. montanum L. Crus. hist, 363. f. 1. 2. Rснв. Fl. germ. exsicc. n. 447. Rleinftraudig, slätter lincalif() langettlid) ganjrandig, unten

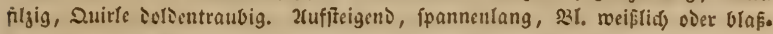

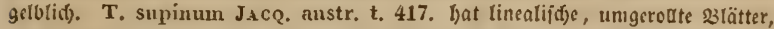
Die Sel(bjälfne finden fid) an beiben formen jugefpişt. - 2rn Salffelfen. Juni

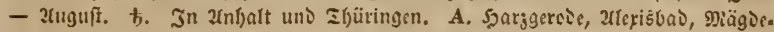

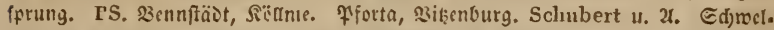
Icnburg bi Erfurt. Hornung. HS. Sud)fal)rt bei IBeinar. Jena: Sanografen.

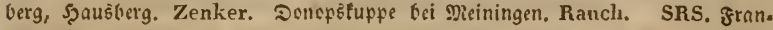
ent)aufen. Hornung.

949. T. Chamaedrys L. Schx. t. 150. (эRüfđ)en.) Harse Arz-

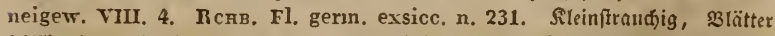

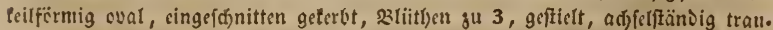

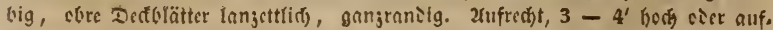




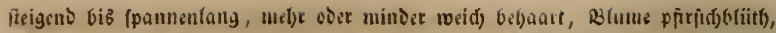
Reldie und Deftolätter auf fomigem $8300 \mathrm{en}$ Duntel rotjbraun. OFF, Hb. Cha.

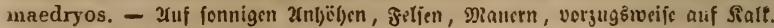

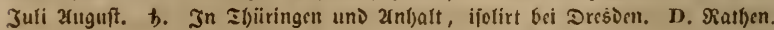

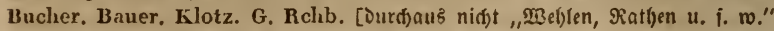

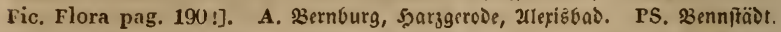
3urgivenien. Rchb. Fest. Fforta. Efartßberge. Rodig. HS. Dbernilifa bei

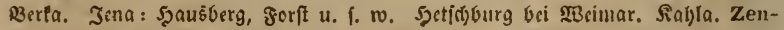
ker. SRS. Frantenl)aulfen. Hornung.

88. Scorodonia Mxch. Scorobonie. Seld alfförts gefiegen, oberlippe runolid), ga nz, unterlippe 43äl)nig, aufítcigeno, 23lu.

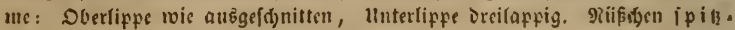
10 a $\mathrm{r}_{\mathrm{z}} \mathrm{ig.}$.

450. S. heteromalla M хсн. (Teucr. Scor, L.) F]. dan, 485. Rспв. Fl. germ, exsicc. n, 232. 2ufredjt, şätter gefticít, bergfïrmig, run.

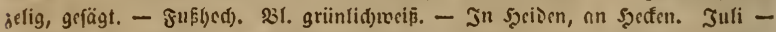

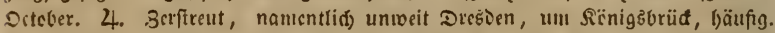

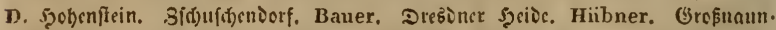

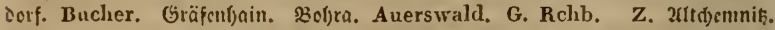
Bok. Erfinjolag, Einjiciel, Gref̈aucrbad). Weiker. B. Santenz. Schmalz.

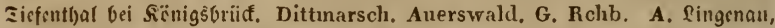

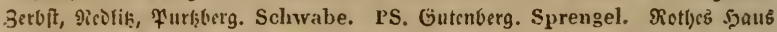
bel Düben, Sitterfild, 2ranicrcic. Beylitz. SRS. Blantenturg. Sđ'margburg. Hornung.

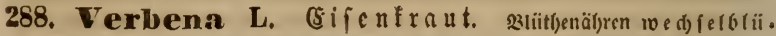

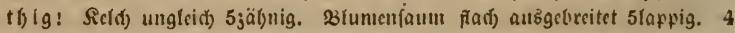

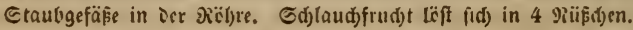

951. V. officinalis L. Sснк, t. 3. Sт. 3. Harxz Arzneigw. V. 42. Uef)ren follant und Dïnn; untere slätter oual ipatelfïmig, ooppelt einges id)nitten gefügt, folgenoe fiècrartig 3-5tl)eilig ungleids gefägt, obetfe uteift 3.

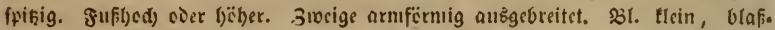
blau, feltner weif. Opf. Hb. Verbenae. - 2luf Ed)utt, an Mauern, ¥Yan. ten, in Gräben, läufig an Dorftcidjen un๖ Gänfstriften in Dërforn. Juli Esfember. ๑. In ien bëdjffen Gegenien feblent, fonft gemrin.

\title{
Familie Asperifoliacene, Raubblättrige.
}

\author{
- Şerbaricnbud) S. LII uno 111. -
}

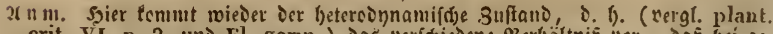

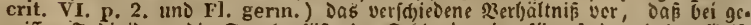
miffen Insivisuen tie Staubgrfäpe in Edjlunde cingefügt fund und Der Erif.

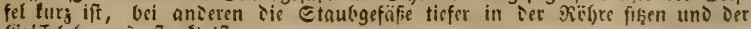
Griffel lerausgepêtedt ift. 


\section{A. Echieae, whue (B)}

289. Eehium L. Natte $\mathfrak{r}$ to $\mathfrak{r}_{3}$. 23tume unrcgetmäfig, fait

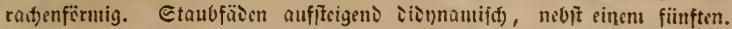
Diarbe sertifal gefpalten.

952. E, vulgare L. SchK. t. 32. Sт. 18. HAYxe Arzheigw. I.

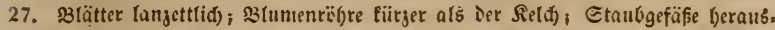

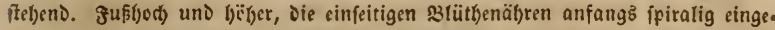

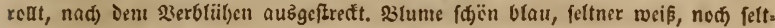
ner refa. - b. Werzbickii Haberd. Rссн, Fl. germ, exsicc. n. 1919. 21 .

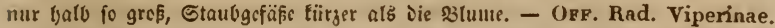

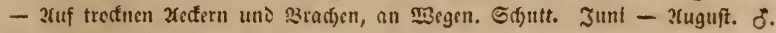
(G)แcin Durd) Das̆ Ģ่biet.

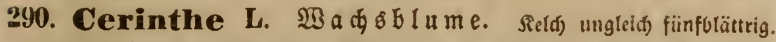

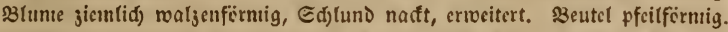

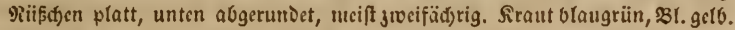

953. C. minor L. Rснв, pl. crit. VI. ic. 481. Fl. gerin. exsicc. n. 610. 3 tunten biß $1 \int_{2} 5$ fpaltig, mit nufres)t gegeneinander geneigten 3äbnen; Etaubfäten viermal türjer ats Der Etaubbeutet. - 2tuf thenigen Xeffern, an

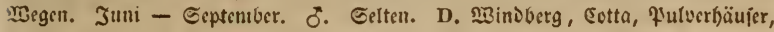

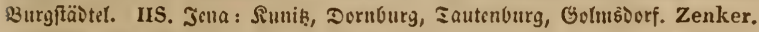

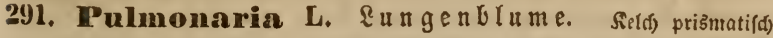

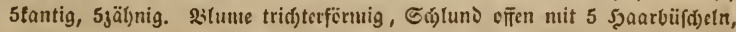
Saum eingef(d)nitten 5lappig. Sarbe 2lippig fuglidy. Miüs(d)en freifelförnig, glatt, unten abgeftutit.

954. P. officinalis L. Rсnв, pl. crit. VI, ic. 699. 23urjetbrätter geffielt, berjfërmig; untere Etengelblätter länglid), Die cberen cin wenig berab. laufend; Etenget borftig und Driifig. Epamenlyod), 331. rofa aufb(ühend, Dann

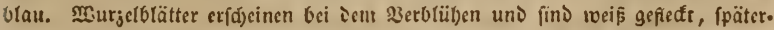
bin Die Etengelolätter meift eben fo. - OpF. Rad. et Hb. Pulmonariae maculosae. -3 wifden $\mathfrak{M}_{3}$ alogebiifd) in Der Ebene wie in Den 3ergen. März Mai. 4. Durd Das Gicbiet bäufig.

955. P. angustifolia L. Rснв, pl. crit. VI. ic. 695. Fl. germ.

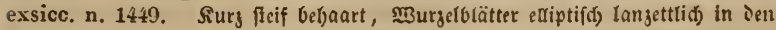

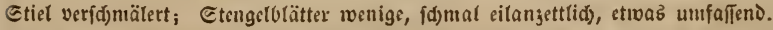
Der wenig beblätterte Etengel unterid)ciDet fic aul beften ven folgender 2rt. -

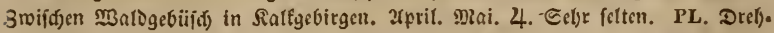

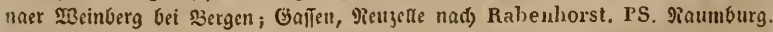
Miiller. HS. Jena: Jorft. Zenker.

956. P. azurea Bess. Rснв. pl, crit. VI. ic. 69t. Fl, germ.

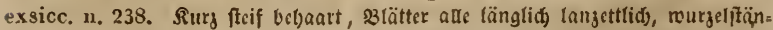

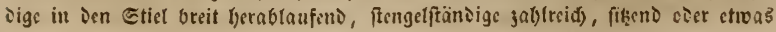


Asperifoliaceae. - 212 - Pulmonaria.

berablaufend. Sgetler grün, 23tume leblafter Glau. - 3wifacn MBartegebiifó). zprif. Mai. 4. Celten. L. Sieniß̧ fparfau,. A. Pingenau, בërten, Draniın. baum, Şarggerode. Schwabe. PS. Spalte: Şeibe, Dölnu, fiçtau, Mittilboly. Qübcjün. Freiburg. Raumburg. Erfurt. HS. Jena, Eifenads.

292. Fithospermum L. Cteinfa ame. Silf fünftbsilig.

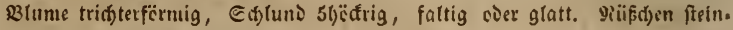
lyart, an Der 23 afis abgeftukt.

957. L. arvense L. Fl. dan. 456. Darw. n. Haris V. 4. Etel. gol oben äftig; 3lätter lineal lanjettlid); Riif(t)en runjeligförnig, vraun. SBis

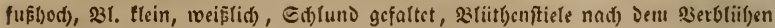
verDifft. - auf 2edtern. Diai. Jumi. Juli. (.) Durd) Das Getist gemein, bis in Die bïbern Gegenien.

958. L. officinale L. Schk, t. 29. St, 5. HaYxe Arzngw. V1. 29. Rспв. Fl. gern. exsicc. n. 153S. Etengel fel)r äftig; ß3lätter lanjettlid),

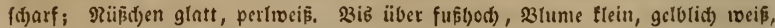
Ed)luno Durd) (Eincriide 5ljidfig. - OFF. Semina Lithospermi officinalis. - In (Scbïfd), an jtcinigen Drten, an Jelien, Ed)utt. פai. Juni. Juri. 4.

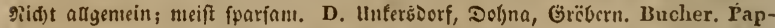
peritz. G. Rchb. Z. Garnsiorf bei (s)cnuniḩ. Weiker. A. 2iernburg, Gan.

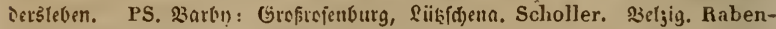

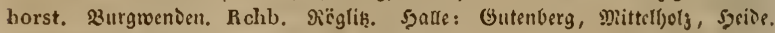
HS. Jena: Jiautbal. S3crfa. Zenker. SRS. Jranfenljaufin. Fest.

959. L. purpureo coeruleum L, JAcQ, anstr, t. 14. Rснв. Fl. germ, exsicc. n. 608. Inten faft bol;ig; unfrud)tbare Stengsi eried)eno, sliitbenftengel aufredst; Silüttir lanzettlid), fpik. S3lume etroa Doppelt fo lang

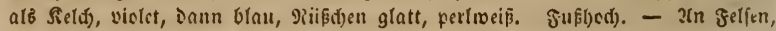

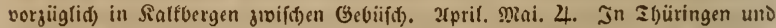

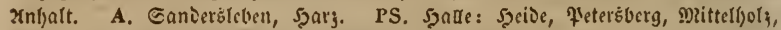
Ed)non, Erbeborn. Raumburg. Efartbberge. Finnberg, Meifelberg, Gartenberg.

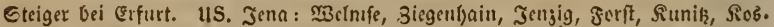
peon. Eifenberg. Beimar. Zenker. Straudblyain bei Soburg. Hornung. SRS. ruiolftait, 2truftait. Schönheit, Salttbal bei franfenljaufen. Hornung.

293. Nonnea Medic. Nonnea. Seldi) 5fpartig, fpäter ver. grësert, wie aufgiblaicn. Blume triđgterfïrmig, Caun 5lappig, offen,

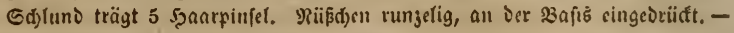
frud̆t lyängend i

960. N. pulla DEC. JAç, austr, t, 188. RсHв, F]. germ, exsicc. n. 239. Gtengel unten cinfad); 23 lätter lanjettlid) ftriegelbaarig; 33lumell.

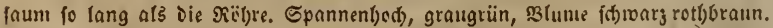

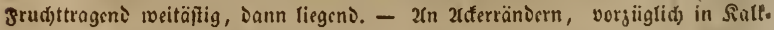

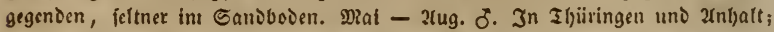

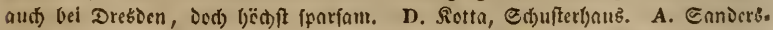

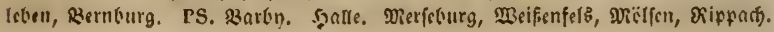




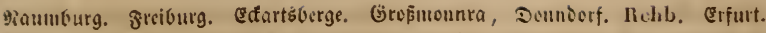

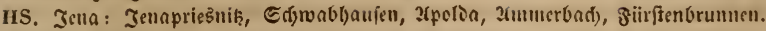

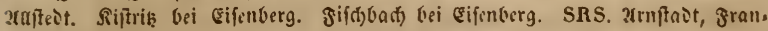
teni)aufen.

\section{B. Borragineae, mit Betwölbițufpen im Eatlunte.}

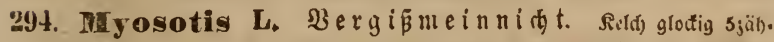

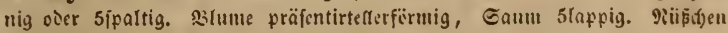
glänjeno glatt. - Blume cntwicfilt fict) rofafarbig, wiro bimulblau.

a. Blumenfoum nur abftebend (nid)t faad) auzgebreitet).

461. M. arvensis Sibth. Engl, Bot. 2558! Rснв. in St, 4?.

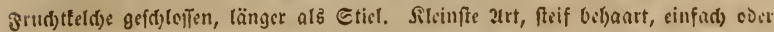

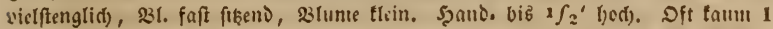

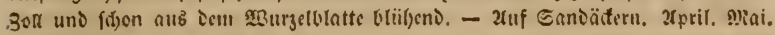
zuli. 2uguft. ๑. Gemein.

962. M. intermedia LK. Rснв. in Sт, 42. Fl. gerın. exsicc. 1.

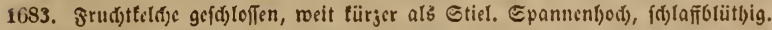
Der Seld) bat 5 range 3älyne. Durd) Das Preflen werten bie giffitolfenen Seldje

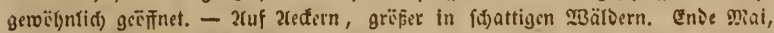
Juni, einzeln zuguft, Septeniber. ठ. Nidist folten.

963. M. collina Ehrhart. Rсhв, amoen, 1820, in St, 42. Fl, gerın. Exsicc. 612. S3lätter afle einzeln, f̧rudtfteld) offen, Blume blau, Griffel

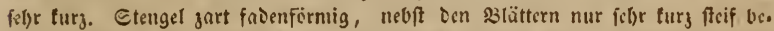
baart, Bluute Elcin. W. Mejer wial- nur M. versicolor aus Ehrharts நano

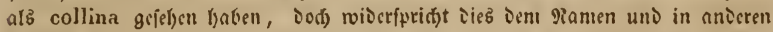
(Exemplaren von Elhharts Sammilung fand fit) Dod) Diefe art alb M. scorp.

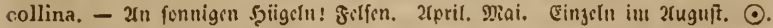
Sirffrcut, ntrift nirbt felten.

964. M. versicolor Su. Engl. Bot. 430 (linf3, Der PRame bei 2558!).

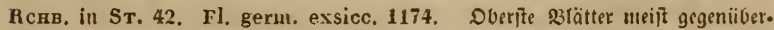
ftel)eno, 2Blume gelb! fpäter blau, Grifict feljr lang. - b. alle 231. gelb. - c.

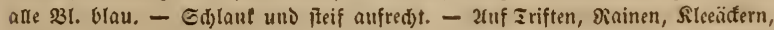
iiberbaupt melbr an ctwas foud)ten Drtell. Dai - Juli. (. Durd) Dab Gi:

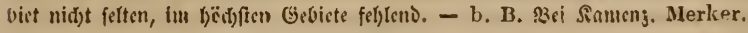

b. Blumenfaum fad) auछgebreitct.

965. M. sparsiflora Mix. Rсив, in ST. 42. Fl, germ, exsice. n. 1175. Stengel rïđwärts ftcif bchaart, Sicld) regclmäfig ticf 5ipaltig, unten

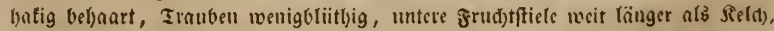

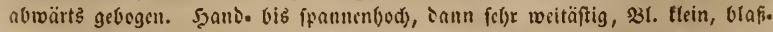

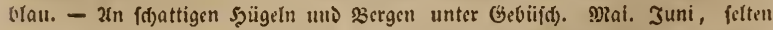
in 2uguft. ○. D. Flaucn, Gr. Garten, 3rieżnił, Sd)arfenberg, Ronftappel.

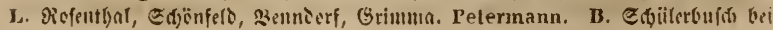




\section{Asperifoliaceae. - 214 - Myosotis.}

3ittau. Schnidt. PL. Sandźttone bei Gïrliţ. - Hatro, Epreewald bei der

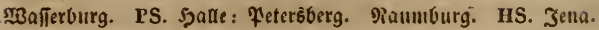

966. M. cespitosa Schucz, Rснв. in St. 42. Fl. gernn, exsicc. n. 849. Frudjtteldfe regelniäfig, tief stbeilig, ftumff, jo wie Der Stengel geftrie.

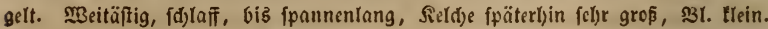

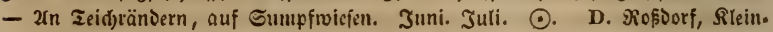
bolmbitorf̣, Mioriḩburg. L. Sinicntbal, Etïtterik̨. PS. Benniorf. Sul)l. HS. Jena.

967. M. silvatica EнRн. Rскв. in St, 42. Fl. germ. exsicc. n.

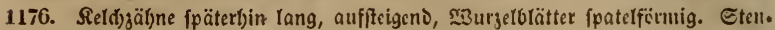
gel aufiteigend, bis fpannenlang, 33\%. grïfer, föjön blau. - b. lactea BxxGH.

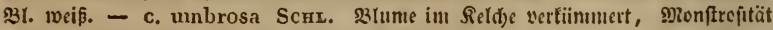

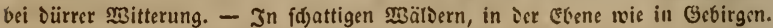

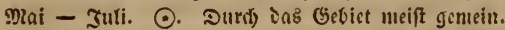

968. M. repens Dov. Rснв. in St. 42. Engl. Bot. suppl. 27() 3$.

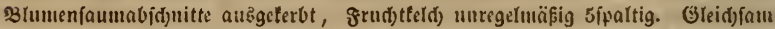
Dittelform uno vielleid)t $\mathfrak{B}$ aftaro aแz M. silvatica uno palustris, Sield), \$3lät.

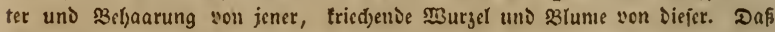
unfre Frange nit Der englifdien Diefelbe iff, berveift Sowerax's Beifaks, excellent" bei Dem sitate meiner robiloung. - Ju Sd)lamme in fdattigen faub. wälDern, felten. Juli - Eeptember. (.) D. Siei פorib̨burg. Rchb.

969. M. strigulosa Rспв. in Sт. 42. (5nare falfa)!) Fl. germ. exsicc. 11. 2051. Etengel unı şätter gefit ri c gelt! Reld) gloufig, 5jäl)nig, silı.

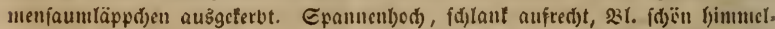
Wlau, feltner weis. - b. parviflora, szl. balb fo gres, Duntelolau. - 2luf feud). ten Miefen, Mlocrboien, Iriften. Mai. Juni. 4. Gemein.

970. M. laxiflora Ronв. in Sx. 42. Etengel geftriegelt, 3ucige

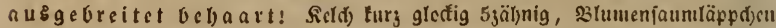

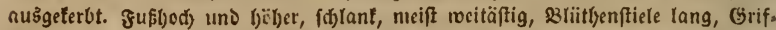

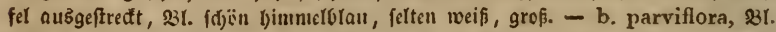

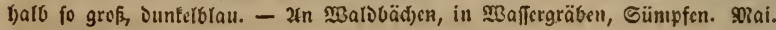
Juni. 24. शidot felten.

971. M. palustris WIтr. Sr. 42. exs. 2055. Etengel a us gefreitet

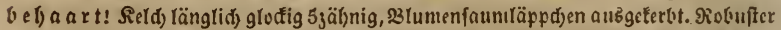

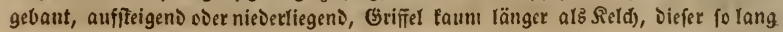

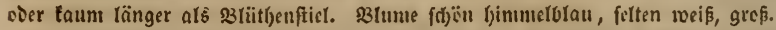
- b. parviflora, 31 . Lalb fo groß, Dunfelblau. - 2ln fumpfigen Grätien, nuf Sumpfwiefen. MRai - JuYi. 4. Durti) Dab Gebiet meift gemein.

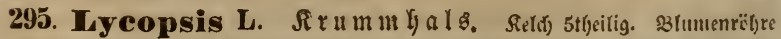

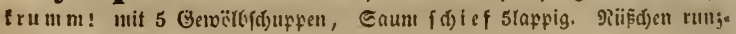
lid), unten cingeiriicťt.

972. L. arvensis MB, Scha, t, 31, Dner, u, Haxis V. 4. SRro 


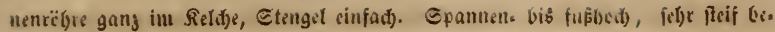

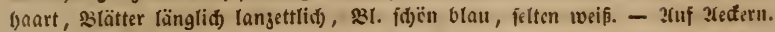

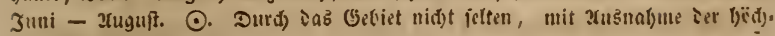
iften Gigenion.

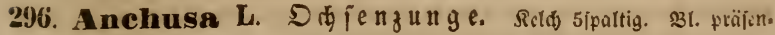

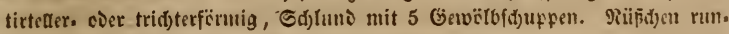

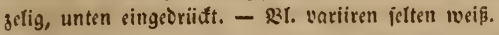

973. A. arvalis Rснв. pl. crit. III. ic. 470. frudtteldye entfernt fis:

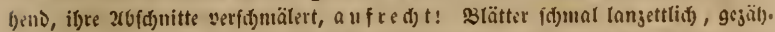

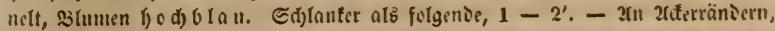

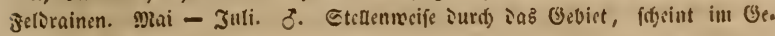
virge 3 ll fill) len.

974. A. officinalis L. HАумв Axzngw. 1. 25. Rснв, pl. crit. III.

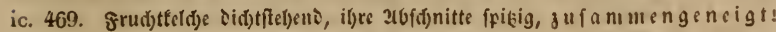

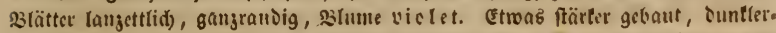
grün, Reld)e ctiolida faft blafig (A. lycopsoides Bess.), - b. nitida: tal)l uns glänjens grasgriin. - Ect)cint mit veriger Saftarie zu bilien, fegenannte "lle bergänge". - Orf. Rad, et Hb. Anchusae s. Buglossi. - In atifer.

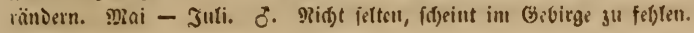

297. Symphytum L. B cinte ell. Sield) 5jüfnig. silume wa.

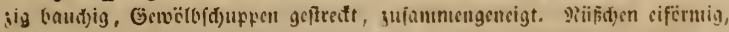

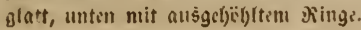

975. S. officinale L. Fl. dan. 1564. TBurgel siclipindetig, Stinget

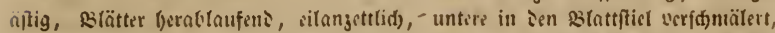

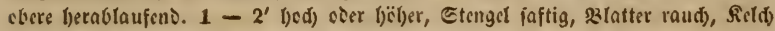

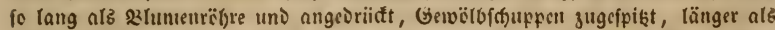

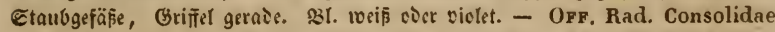

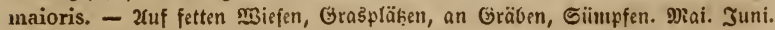
4. Ger)lt im Gebirge uno verwilbert nur aub Dorfgärten (3. B. Z. Stonberg. Wankel.) fonif nidft fciten.

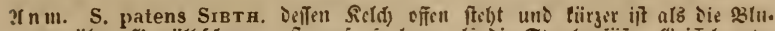
menrëbre, Gemïlbfd)uppell ftumpf, to lang als bie Staubgeföpse, Grifel unter ier 9arbe getnidt, fonmt aud) bei uns vor, ift aber ned) genauer zu beobad). ten und Die Standorte fu beftimumen.

976. S. tuberosum L. Jaç, Austr. t. 225. Rснв, Fl. germ. exsicc. n. 705. \$3urgclitef äritig, enctig, Etengel einfad) cier chen getbeilt, Blätter balb bcrablaufend, untere ciruno in sen silattftiel verfifmälett, sbere ellip.

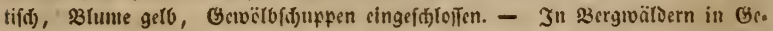

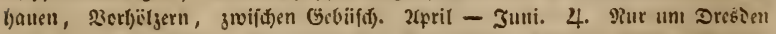
verbreitet. D. NBeblen. Firna: Egelfee, Foblnüille. Flauen. Sffjoner Gruns.

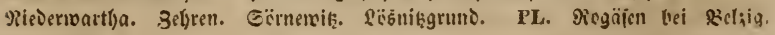
Rabenhorst.

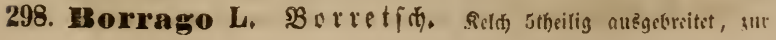




\section{Asperifoliaceae. $\quad-216$ Borrago.}

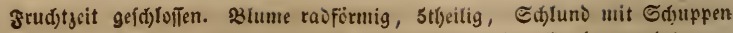

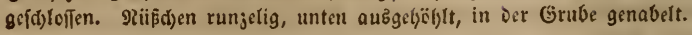

* 977. B. officinalis L. Schr. t. 31. ST. 8. Haxxe Arznei-

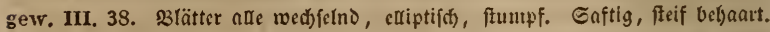

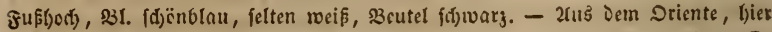
uno Da auf bebautem Beden und Edfutt verwilbert. Juli - Eepteniber. @. unbeftändig.

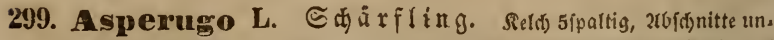

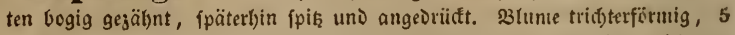

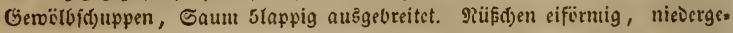

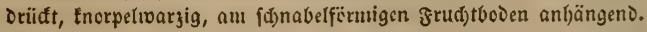

978. A. procumbens L. Scrк. t. 31. Rснв, Fl, gerin, exsicc.

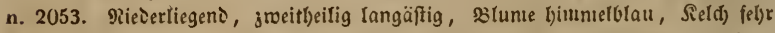
groß, wie fammartig, $4^{\prime \prime}-18^{\prime \prime}$ lang. -2 uf Єd)utt, an Miauern. Miai -

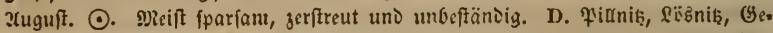
bäge (menigftenz fonft!). B. Bauken. Eđjülerberg bei Bittau. PL. Sữ̛u, Siibben, Siebenau, Eonnenwaloe, Eenftenberg, Sottbus, Guben. A. Deflat.

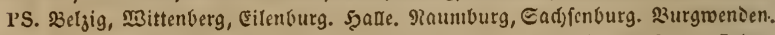

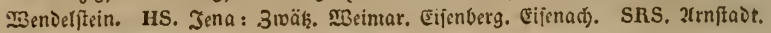

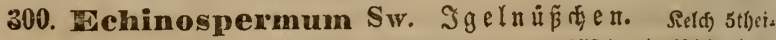

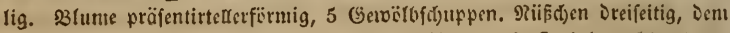
Grifel aubängend, am Sianie mit 2 vieiben Szatenftadteln, tletten. artig!

979. L. deflexum Scнм. Rснв, in ST. 43. frudititiele abıärts grbegen. Stengel (đ)wad), jung wie Myosotis collina, fpäterbin fpannentang,

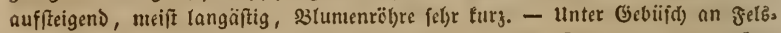
vorfprïngen. Juni. Juti. ๑. ๔el)r felten. Z. - 3ei Elftetterg. Rossmässler.

980. E. Lappula Leн., Rспв, in St. 43. Fru(t)tftiele aufred)t, Staut weifgrau vehaart, (Wahlenberg!) 3weige faft gegipfelt, Sield)abid)nitte to lang ats 23tumentribre. Epannentang, ganz übereinjtimmıeno nit Linnées f(j)wedifder Planje! 33. ftein, henblan. - 2luf Mauern und Edjutt. Juli. 2uguft. $\odot$. In If)üringen nidyt felten, fonft fparfam. D. Sïnigftein, Firna,

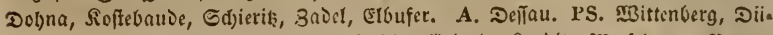

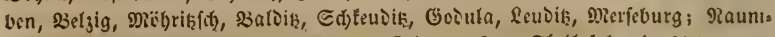

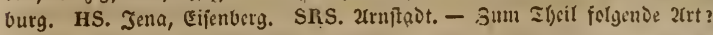

981. E. squarrosum Rснв, in ST. 43. Frudteffiefe aufred)t, Siraut

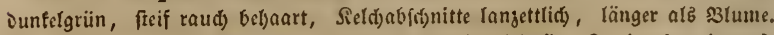
Epannentang und fuflyed), weit feifer betsantt, Duntelgriin, smeige fpartig aub.

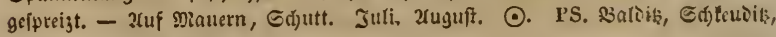
Delisif(d), Zcuoik, Gooura.

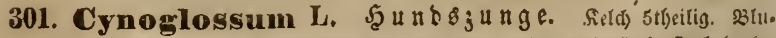

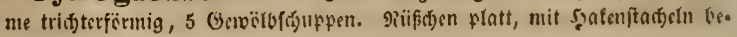


\{eşt, flettenartig! am idonabelfömigen frudotboden anbängeno. Fru(j)t nitfeni.

982. C. officinale L. Schк. t. 30. Harxe Arzneigew. I. 26. 23 lätter Dïnn filgig, untere ellipti(i) fpatelfömig, obere (anjettlid) balbumfalfend;

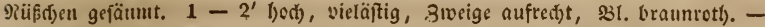
b. bicolor, 23t. meifs, in Der MRitte rett). - OpF. Rad. et Hb. Cynoglossi. -

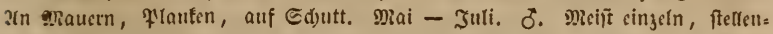

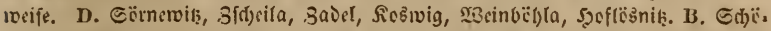
nauer Şutberg. PL. Suffau. A. DelTau. PS. 23arby. ȘBittenberg. Szalle,

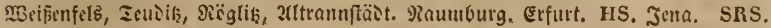
struftait. R. Robenftein.

983. C. montanum Lax. Engl. Bot. 1042. \$lätter glänjens grïn,

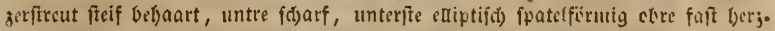

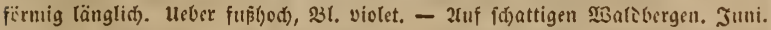

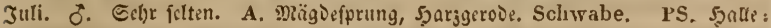

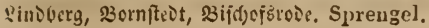

302. Omphalodes T. (J) eb e nfemein. Setd stritig. 23r.

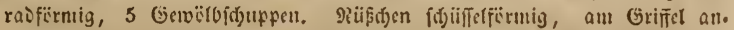
längenv.

984. O. scorpioides Lеи., Sт. 21. Rснв. F], germ. exsicc, и. 25. Etenget nicderliegend? MBurgelblätter fpatelfïrmig, obre Etengetblätter Ian.

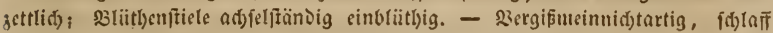
langäïtig, 231. beablau. - Unter Gebiifíf) an befid)atteten Felfen. 2tpril. Mai.

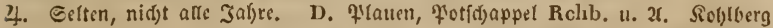
bei Firna. Baner. Ecifersdorf. Fritsclıe. - El)arand, Papperitz, B. Sol). lano, \&äbau. Burkliardt. PL. Jaucrnider \$crg. Burkhardt. - Siltugenberg ๒ci Doljig. Hellwig.

* 985. O. verna Mxch, Bot, Mag. t. 7. ST. 21. Drew. u.

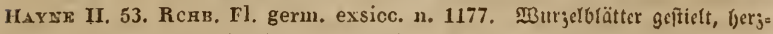

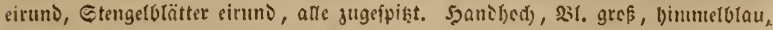
Die Säppd)en wedfeln utit weisen falten. - In fiiolid)en Sergwäloern, bei uns im Gartenloien verwilderno. 2tpril. mini. 4.

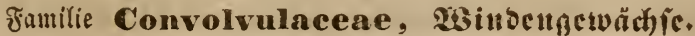

- Şarbarienbud ธ. LUI uno 113. -

303. Polemoniuma L. Eper $\mathrm{f}$ raut. Serd 5(paltig. 2it. furg tridterfïmig aubgebrcitet, Saum 5lappig. Staubgcfäfs 5, auf Sdiuf. pen in Edflunde. Sapfel 3flappig, 3fäđfrig, vicljaamig.

986. P. coeruleum L. Sснк. t, 38. Sт. 27. Rснв, Fl, germ,

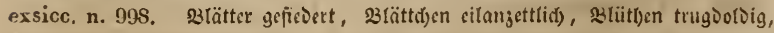

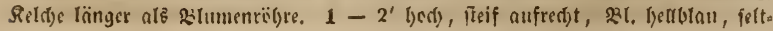




\title{
Convolvulaceae. $\quad-218-\quad$ Polemonium.
}

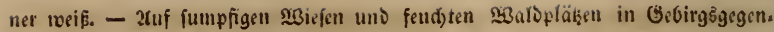
Don. Juni. Juli. 4. Eefor felten. R. Pobenftein.

304. Comvolvulus L. W in $b$ e. Şlume triđterfürmig 5 fartig (in Der Snespe georelft). Rarbe 2lippig. Sinfil 2-3fä(t)rig, Sätifer 2 faa. mig. - Etengd (bei unfern Xrten) win

987. C. arvensis L. Fl, dan, 459. Drew, n. Hayse t. 12. 3lüt. tex pfeilförmig, unten fpik̨ectig; Dedolättd)en flcin, von Den şrïtlen entfernt. 31. weißs oice rofa. - C. prostzatus Schm. niècrliegeno, Blume rofa, Falten unten grïn. - C. obtusifolius v. Halz, Blätter beiberfeitz ftumpf, Sticle

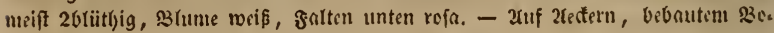

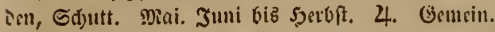

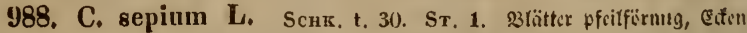

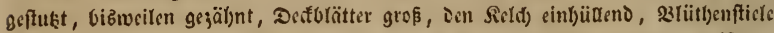

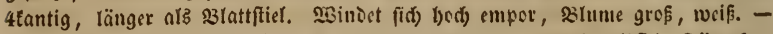
2n 3äunen, Grbiifd, befonders an feud)ten Drten, Ifern uno felbft in Sïmpfen. Iuli - September. 4. Gismcin.

\section{Familie Globulariacene, Globulntincen.}

\author{
- 5ุcrbaricntud) 6. LIV uno 114. -
}

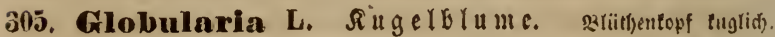

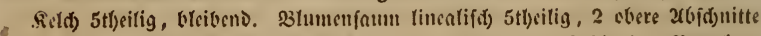

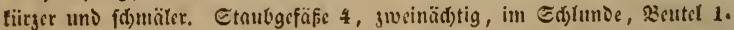
fäd)rig, aufliegend. Frud)tnoten 2 fäd)rig, Sinrbe vertiful 2 ffaltig. Sinpicl fd) Iaud)artig cinfaamig !

989. G. vulgaris L. Scнк. t. 21. Sт. 17. Rrautartig, MBurger. blätter umgetel)rt eirund fpatelfürmig, Stengelolätter lanjettliđ) fpişig, Seld) res

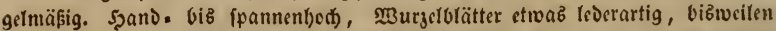
aub̧getcrot, aud) mit einem Rittelgal)ne, Stengelblätter tlein, $6-13$. 31 . blau. - 2uf fonnigen 2unljäben und Jelfen. Mai. Juni. 4. Galjr falten. A. Bern. burg, Sanberbleben. Schwabe. PS. S3ennftäbt, Sïlme, Greburg, fangentogen. Sprengel. Shcipliß̨ bei freiburg. Klett. Raumburg. Beneken.

\section{Jamilie Personatae, Raveublüthlex. - 5perbarientud) ๔. LIV uno 115. -}

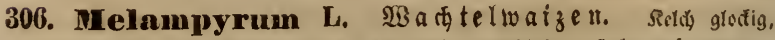
2lippig 4fpaltig. 33lume rël)rig, Gd)lums aufgeblafen, Spetu zufammenges

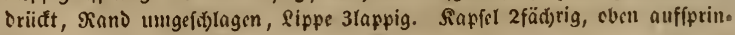
gend, Fäd)er 1-2fanmig, Snamen faft waizentomförmig, glntt, aufredist.

990. M. nemorosum L. Scнк, t. 170. 231. u. fr. Fl, dan. 305.

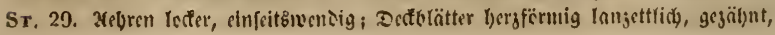




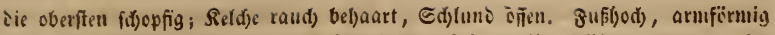

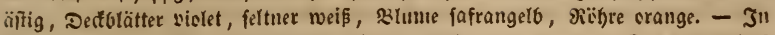

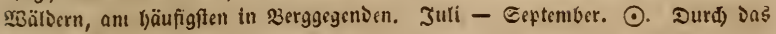
Gebiet nueift genein.

991. M. silvaticum L. Fl. dan. 145. Fl. germ. exsicc. n. 615. 2a.ljen loder, einfeitioendig; Destolätter faft linealijd), gangraniig oder unten faft fpiefförmig; Reld)sipfel faft gleid), uit ungetoutem RanDe; S3lumentëlyre

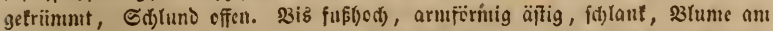

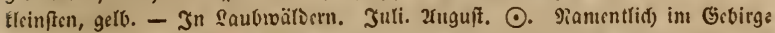
tuno sljüringerwals, aud) fenft jerftrut. D. Edharfenberg, Eicteneidjen, Gaucr.

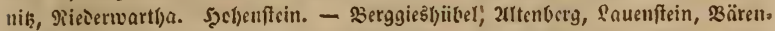

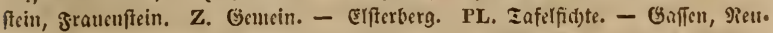

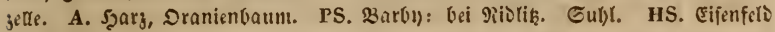

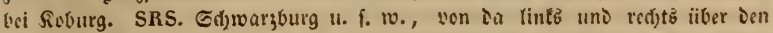

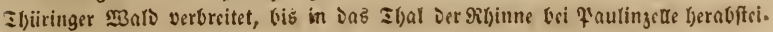
grno; ปäufig bci Ëlgeršburg.

992. M. pratense L. Scнк. t. 17). 2(c) fren focter, einfeitmentig;

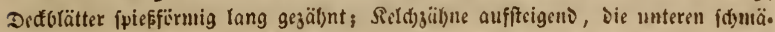

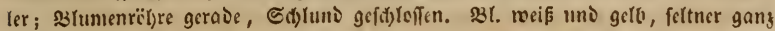

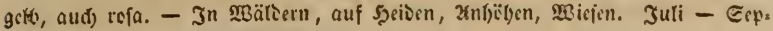

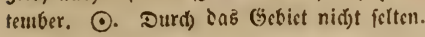

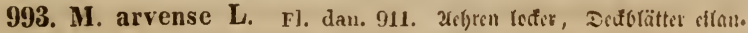

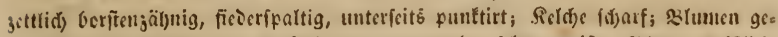

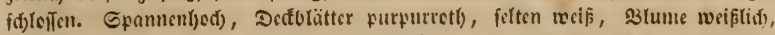
Seln furpurretb), Gatm gelo. - 2uf 2tectitn, nantentlid) im Eenmergetreios.

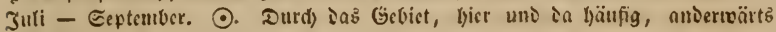
fil) reni (Bcrjig. Rabenlıorst. Erjgcbirge.).

994. M. cristatum L. Fl, dan. 1104. Fl. germ, exsicc. n. 61\%.

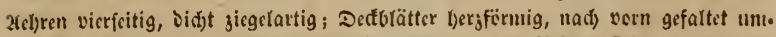
getrogen, lammartig gejäl)nt, Єd)luns gefd)loten. Dectblätter fteif, purpurretls,

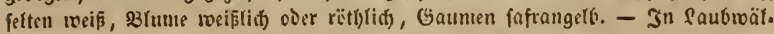
Dern. Jult - Eepteutber. ๑. Etcuenweife. D. Bofel. Bucher u. 2x. Mein.

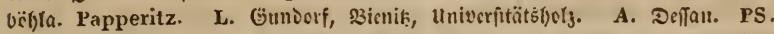

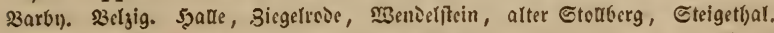
3wifden. Gadjenburg unb Dbišlcbsn. Ectartsberge, Raunburg. Dierfeburg. HS. Jena: MB̈̈rmilie. 2rperiteit. SRS. Irmftaot.

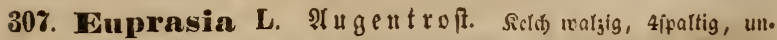

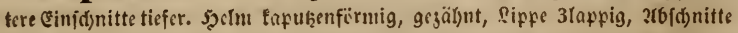

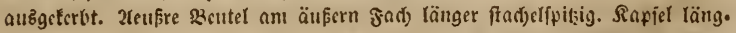
(id), 2fäd)rig, 2klappig, viclfaamig, Sanutn ipincelförmig, längs gefurift.

995. E. micrantha Rснв. F], germ. exsicc. n. 342. Eilft (d) (anj:

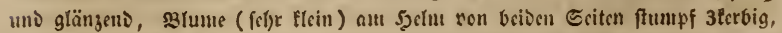

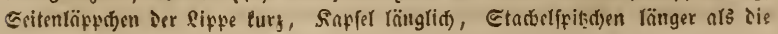


Rerbe, 23lätter lanjettli(b), weniglerbig, tiir;er als slütt)e uno studbt. -2 bis

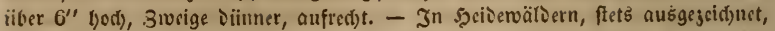
abgerunoet uno aubgeterot, aud) unter ien übrigen 2trten vortomnteno, alio tei.

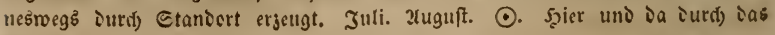
Gebict.

996. E. officinalis L. HAYNE Arzngw. IX. 8. Rснв. F]. germ.

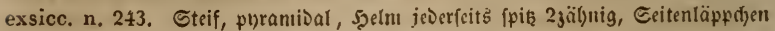

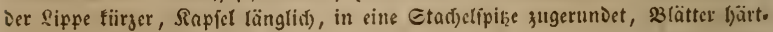

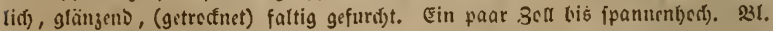

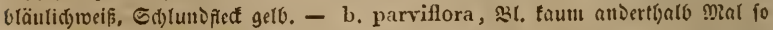
lang als Sicld). Etengel oft graulid) bebaart, slätter Dunfelgrïn, mef)r coer

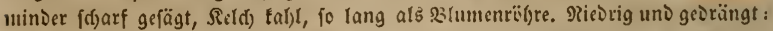
E. curta Friss. - Ju Sciben, trof̌nen Iriften, an Malorändern. Iuli Exptember. ○. Durd) das Gebiet nid)t felten.

997. E. pratensis Schecchz. (E. offic.) Fl. dan. 1037. St. 3 Sснк. t. 169. Rснв. Fl, germ, exsicc. 11. 244. Єd)lafi, 3tveige aufiteigeno,

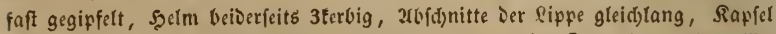

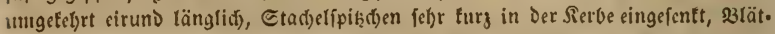
ter fein bel)aart, (getrof́net) fiad) und matt. . S3tume fijinneis, Ed)luno getb,

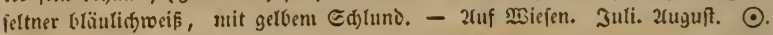
\$iEmocilen mitten unter verigen und nid)t iurd) Etanictt erjeugt! Gentein iurd) Das Gebiet, biz auf Dis böd)ften \$2ergtriften.

308. Ddontites (Rueru.) Hazer. Dbontite. Sield) glodtig, fait gleid 4 fpaltig. Şelm jufanmmengeoriidt, fipfe 3theilig. Etaub.

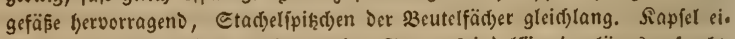
förnig, 2tlappig, 2fäđrig, vieljaamig, Gaame fpinخelförmig, längs gefurd)t.

998. O, verna Bexuardi. Rchi. Fl. germ. exsicc. n. 1750. F1.

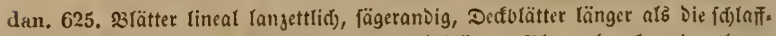

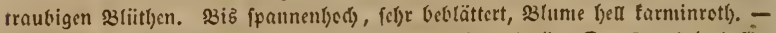

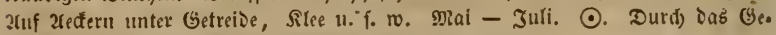

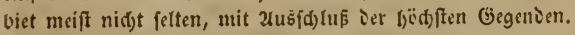

999. O. serotina LA.r. Rснв. Fl, germ, exsicc, n. 750. Cor. Ecplır. p. 202. Barr. ic. 278. 2. Blätter lanjettlicl) gefägt, Defforätter faum

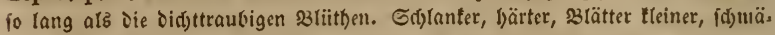

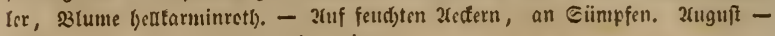
Detober. ๑. Şict uno ia voie vorige.

1000. O. Iutea L, Rсив. Fl. germ, exsicc. n. 245. Cor. Ecphr.

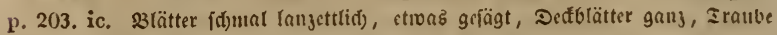

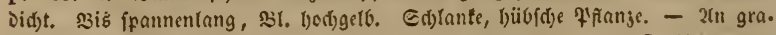

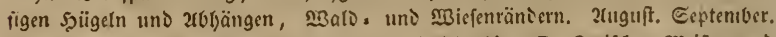

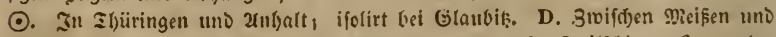
Glanbik. Ficinus. A. 23enburg, Eanierbleben. PS. ฉuilfdina, fangenbo=

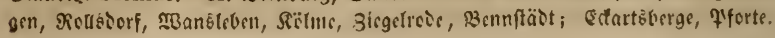




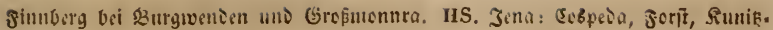

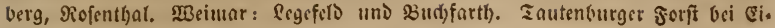
fenterg. SRS. Frantent)aujen, 2trnftait.

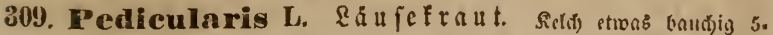
ipartig, cberjter 3aljn am lleiniten. 33. radjenfïrmig, 5ुelu zufanmenge.

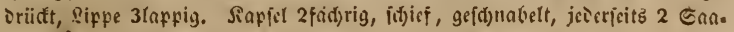
uncnleiften, vielfanmig.

1001. P. silvatica L. Schk, to 171. 231. u. ริr. Hayxe Arzngw. VIII. 34. Sт. 13. Mit aufifreigenion Gritenftengeln, Sield 53äl)nig, Die säbue oben blattartig, gejäl)nt; 3latter geficiert mit froerfpaltig gelappten 26fd)nitten.

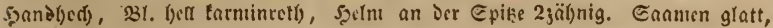
puntritt. - 2luf Iriften uno Balbwiefen. Juli. 2tuguft. 4. Durd) Das (bes bict nucift nidjt jelten.

1002. P. palustris L. Scrk. t. 171. Harne Arzneigew. ViII. 33. Etiif aufred)t, tyramioal äptig, Seld) jweilappig, trauz; Blätter gefiebert,

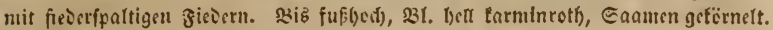
- 2uf Eumpfivicju, mecorbcisu. Juli. 2uguft. 4. Durd) sas Gebict, in

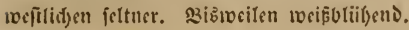

310. Mectorolophus HaLer. $\mathfrak{g} a \mathfrak{h} \mathfrak{n} \mathfrak{n} \mathfrak{f} \mathrm{mm}$. *)

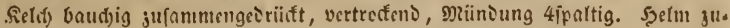

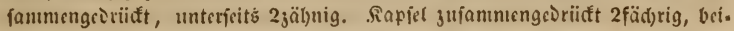
Derfeits aufipringeno. Eanmen jal)(trid), reibenweije gefdjidjtet, sufammen. griviidt, glatt.

1003. A. minor Енгн, Rснв, pl, crit, VIII, ic. 973. 974. F].

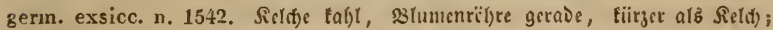
Dherlipfe uit 2 turjen, eifërmigen, getben 3älsnen; Grifel eingeld)loten; Gaa.

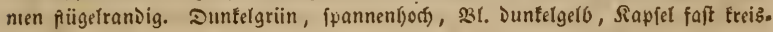

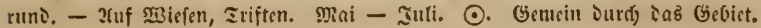

1004. A. angustifolius Gr, Rснв. FI, germ, exsicc, n. 1686.

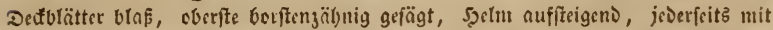

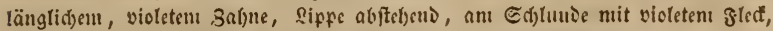

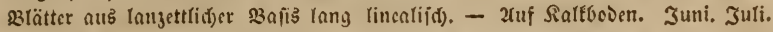

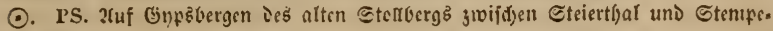
sa. Wallroth.

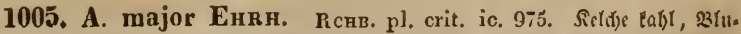

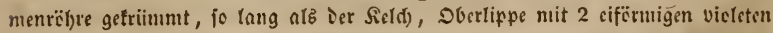

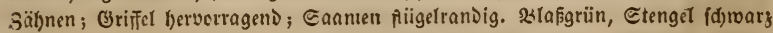

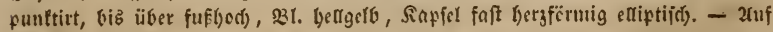

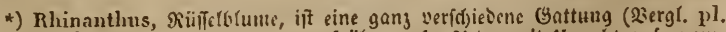
crit. VIII. ic. 972.), in rolde man friilser un(re 2fiten mit Inted)t aufgenom. ntell bat. 


\section{Personatae. - 222 - Alectorolophus.}

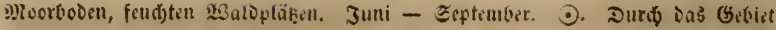
nioft felten biš felgr gemtein.

1006. A. hirsutus ALL. Rснв. pl. crit, ic. 976. Fl. germ. exsicc. n. 1543. Saamen ungeflügelt! - Subl)od) und Drïber, blafgriin.

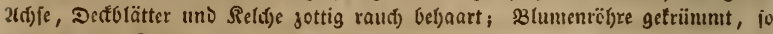
lang als Der Feld); Dberlippe mit 2 eifürmigen Bälfnen, Grif̄el bervorrageno.

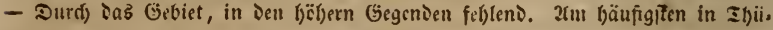
ringen, aber aud) in ber ङbene um Seipsig. - \$an lefe Bot. Zeit. 1819. S. $655-662$.

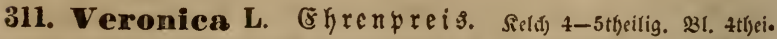

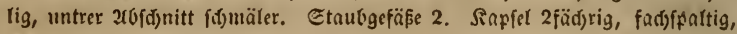
Saamenträger fidi) abfenierno.

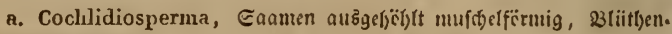

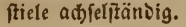

1007. V. hederifolia L. Fl. dan, 428, säätter bersfïrmig runi.

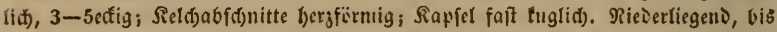
fpannentang, Bliitloujtiele cinzeln in Den Blattadjefln, Blume betrolau, tleincr alह Silţ. 2fn bürren Drten biŝtweilen Die Blätter nur 3lappig: V. triloba Oprz, auf fettem 230Den jelse üppig: V. Lappago ScHnk. Caaule grof, in jes Dem zad) 2, fuglid) gewölot, querrunzelig. - 2uf 2refern, Ed)utt. \$ärz mai. Int Şctofte fparjanter. $\odot$. Scmein Durd Das Grbiet.

1008. V. polita Fries, Rchr, pl, crit. III. ic. 40t-405. Fl. gern. exsicc. 11. 24S. 33litt)enftiele fo lang als Daz 33latt; 3lätter eiruno

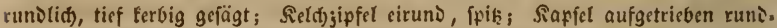

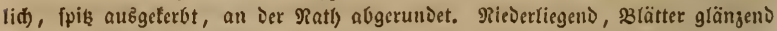

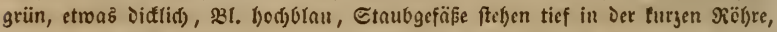
Saante ciförntig gewölbt. - Sacrbffform Fl. germ. exsicc. n, 249. ift mel)r aubgebreitet unD fein bef)aart. - 2(uf 2(ectern, Schutt, in Gärten, an Mauern,

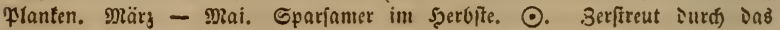
Gebict.

1009. V. opaca Fries. Rchs, pl. crit, III. ic. 441. Fl, germ. exsicc. n, 247. 33lätter bersfïrntig runذlid), runzelig, Sicldabfd)nitte fpatelför.

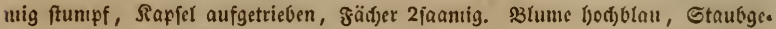

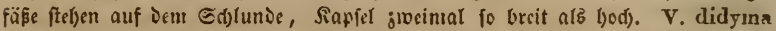
TENORE, weifGlïlend. - جfuf bebautem Beven, verzüglid in Dërfern, an

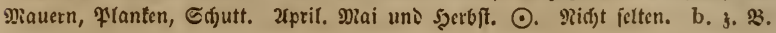
D. Uci Sallfa.

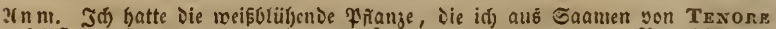

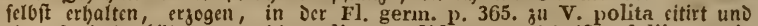
even fo irtig bält Kо с hirsutiusculis" und ats "plinta molliuscula villosiuscula pallide virens" wie fie Texore syll. p. 13 und 14 fertolt nennt, gänjlid) verf(f)ieden,

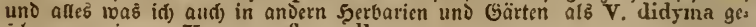
felyen, war inmer V. opaca flore albo. 
1010. V. Buxbaumii Ten, Rснв, pl. crit. III. ic. $430-31$.

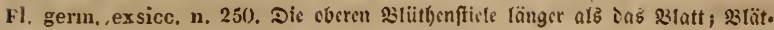

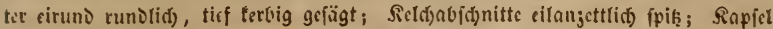

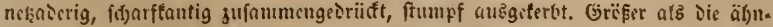

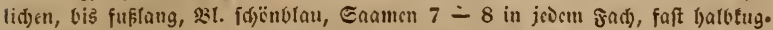

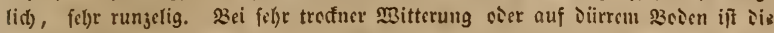
Fritange aufrect)t, fablant und flcinblätterig. - Xuf bebautem sioben, rocniget

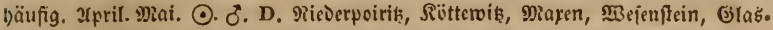

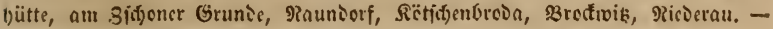

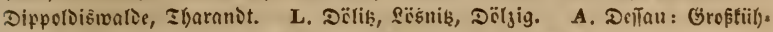

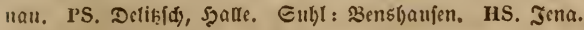

1011. V. agrestis L. Rснв, pl, crit. III. ic. 440. Fl, germ, exsicc, n. 251. Silütyenfticle jo lang als Dab silntt ; 3lätter länglid) eirund, țr.

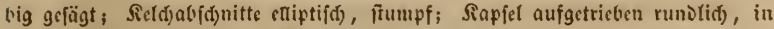

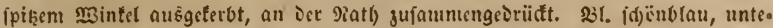

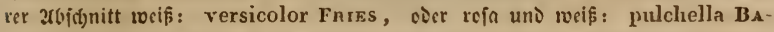

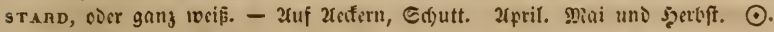
Berftreut Durd) Das (jeciict.

1012. V. praecox All, auct. t. 1, f, 1. Hagexb, Bas, t. 1. ?uif-

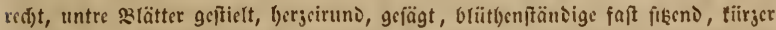

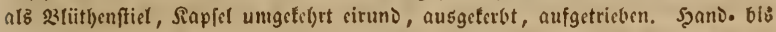
ipannentyod), meift von unten suf langäftig, rotl) angelaufen, sil. blau, Gaante

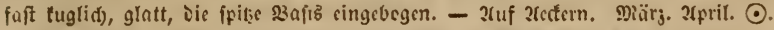

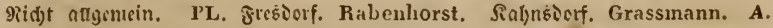

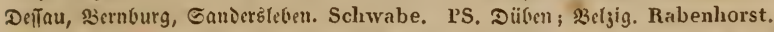

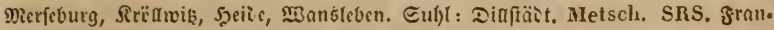
tenbaujen. Hornumg. Eingen, ?trnînat. Schönheit.

1018. V. triphyllos L. Fl, dan. 627. ST, 8. S3tätter fingetfïrmig 3theilig, unterfite eiruno ungetheilt; Stengel äftig; ¿rauben lodfer; Sapfeln auf.

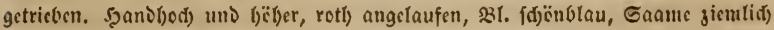

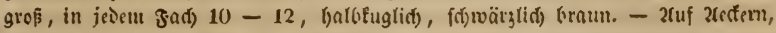
mautern. Märs - Mai. $\odot$. Gımcin.

b. Veronica: Caamen plancouner.

aа. Einjäbrige.

1014. V, verna L. ST, 13. Etcif aufrchit, 3lätter ficierfpaltig, unt. terfte ciruno ungctfcilt, cocrife langettlid): Etengel aufred)t äritig; stauben

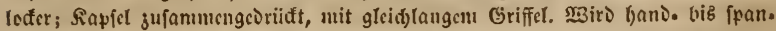

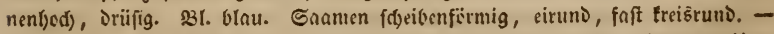

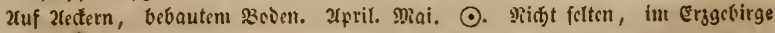
ncuerlitif nidit gefunicn.

1015. V. arvensis L. Fl. dan. 515. 2(ufrect)t, Blätter fyerascirund,

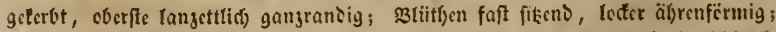

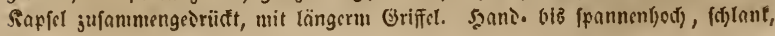




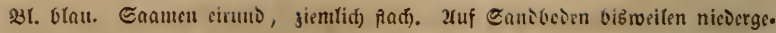

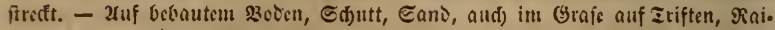
11en. 2tpril - ふ̇uni. ๑. Gentcin.

\section{bb. 円erennircnie. \\ - 23rüthentraube adjefffändig. \\ aаa. Sel(t) 4 tbeilig.}

1016. V. officinalis L. SchK. t. 3. HАYNB Arzneigew. IV. 3.

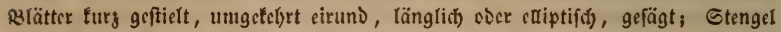

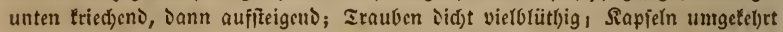

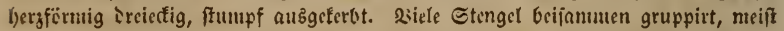

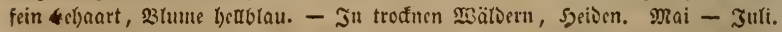
4. Gentcin.

1017. V. montana L. JAC2. austr. 2. t. 10S. Fl, dain. 1201. Fl. gerın, exsicc. n. 21. 33lätter langgeffielt eiruno, eingefd)nitten grferbt; Sten. gel an Grunde frictiend, mit jerftrenten Şnaten; Sapicl flatt, fel)r bteit, bci.

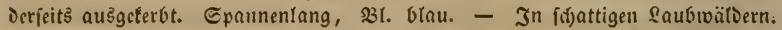

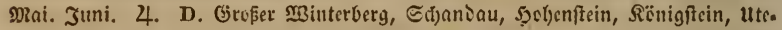

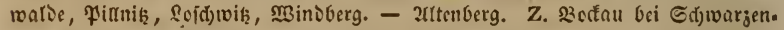

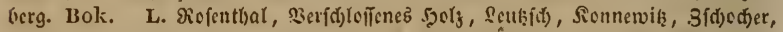

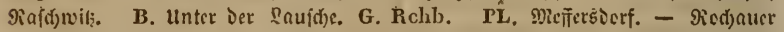

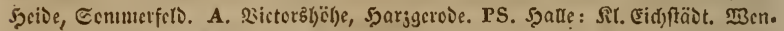

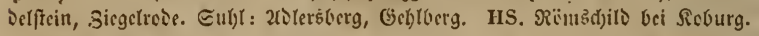

1018. V. Chamaedrys L. Fl. dan. 448. Harxe Arzneigew.

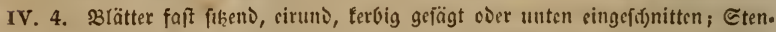

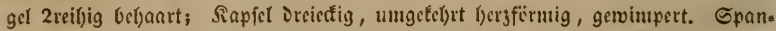

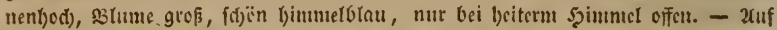
Graspläken, 2iainen. Mrai. Juni. 4. Gemein.

1019. V. scutellata L. Fl. dan. 209. Rcrs, Fl. gerın. exsicc.

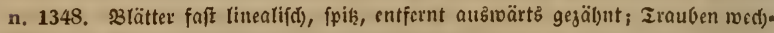

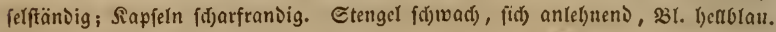
Stiele fabenförnig, lang, ausgefpreigt. - In জ̈räber:, Sïmpfen. Mai. Juni. 4. Durd) Das Gebict nid)t felten.

1020. V. Anagallis L. Fl. dan, 903. HAyxe Arzneigw, IV. 1.

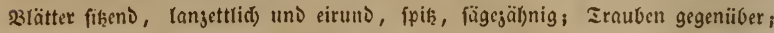

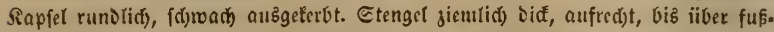

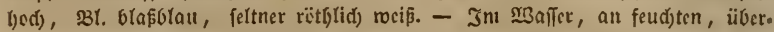
fdiwenunten Gtellen. Juni - 2tuguft. ठ. 4. Durd) Ias Gebict nucift gentein.

1021. V. Beccabunga L. Fl. dan. 511. Haxne Arzneigew.

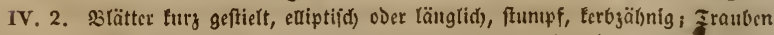
grgeniiber; Rnpfer runDlid), fd)wad) ausgetterbt. Etengel ricgeno, wurgelno, fients

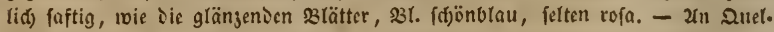

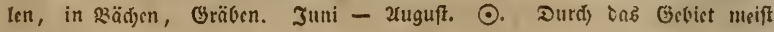
gemein. 
bbb. Oberfiter fünfter Reld)abf(f)nitt iel)r tlein.

1022. V. prostrata L. Rснв, FJ. gerın, exsicc. n. 618, 2uffel.

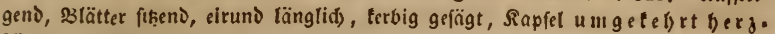
förmig. 3ariirt mit faft lincalif́c)en, ganjranঠigen 3 lättern: V. saturejaefolia TuRP. - Etenget band. bis faft (pannentyod), fein bebaart, salunten bellblau, felten weifs, feltner roja. Jumner an Den bedublauen Blumen uno der form Der

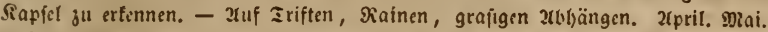

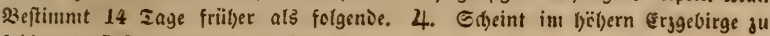
ferblen, fonft ftedenweife burd) bas Gebiet.

1023. V. latifolia L. Rснв, Fl, germ, exsicc. n. 620. 3lätter flseno, lergeiruno ober länglid), cingcid)nitten gciägt; Ctengel aufred)t (unten ein voenig gebogen); Sapicl treišrund! angeterbt. Fufled), 23t. f́djënblau, troffnet fich etroas viclet. - 2fn fonnigen, grajigen Bergabbängen uno Sjïgeln.

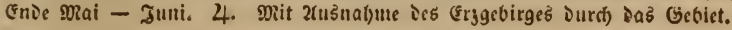

\section{** 3riitbentrauben enঠf̣ändig.}

1024. V. serpyllifolia L. Fl, dan. 492. Xufifteigeno, stätter ei. runo ober länglid), etwas getertit, untere fleiner, runolid), oberffe lanjettlid),

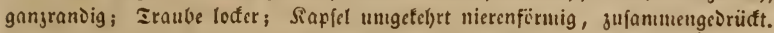

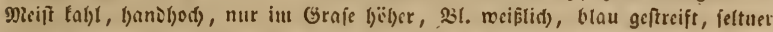

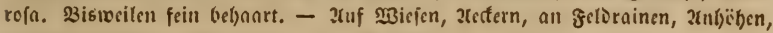
zroifdsen Gebiif(t). Diai. Juni. 4. Gientein.

1025. V. spicata L. VArL. par. t. 33, f. 4. Slätter gegeniiber, unterfte länglitf) fpatelfïrutig, obre cirunb, länglid) oocr laujettlid), terbig gejägt, nad) Der Epiz̧e ju ganzrandig; Irante Did)t äbrenfirmig; Sinpfol runofid), auf. getricben, aubigcterbt, Epanuen= biछ fuflycd) uno orïber, fdlaut uno fteif, fein bebaart, 2fef)rentraube meift einjeln, 231 . o unfel formblumenblau, feften weif. 2(n 8 ergen und gelien, fonnigen 2 (n) Sandboden. Juli - Septentber. 4. Tamentlid) in slüringen und Der शie.

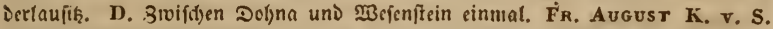

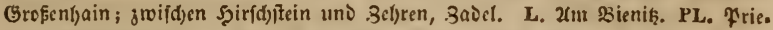

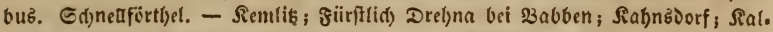
tenborn; Sdrrielungs[ee, namentlid) bei Saue, Sittlik, Eprenberg. A. Deflall.

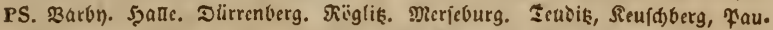

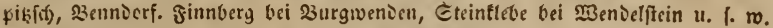
IIS. MBcinar, Jena. SRS. Miiib)(berg bei 2(rnftait.

2f n m. Unfre ¥ianje iit nid)t iic V. spicata Fl. dan. t. 52. , foniern elgent. (id) V. squamosa l'R. a. Vaillantii Fl, germ, p. 370.

1026. V. spuria L. Rснв. Fl. gerın. exsicc, n, 1005. Waldst. Kit. (foliosa) t, 1(12. Spr. Fl. Hax. t. 1. Etcif aufred)t, 3lütter gu $2-5$

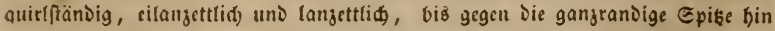

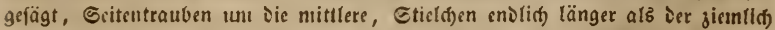
regclmäfige Sicld) und dic Decf(lättd)en; Rapfel rundlid, aufgetrieben, aubge.

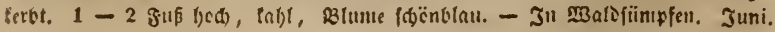




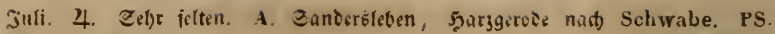
Mittelfol3, Biidofsiccie bei j̧alle. Sprenge].

1027. V. argnta Schrad, comment. t. 2. f, 2. 3ufred)t, Blätter

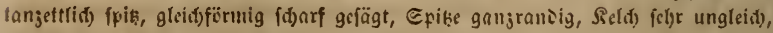
länger als frin Etiel, Sapfel runolid) ausgeferbt, itharf tielrandig. Untre Blär.

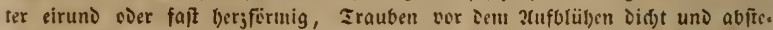

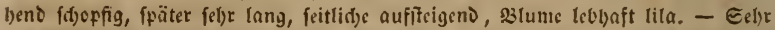
ielten in Gräben. Juni. Juti. 4. PS. Siegenriiaf. Adler.

1028. V. longifolia L. Schrad. comment. t, 2. siätter gi:

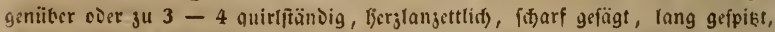

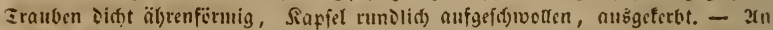

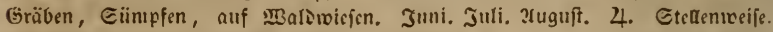
Uum Dresien uno in ier Dberlaufifí forfr felten, an Den andern Drten l)äupiger. D. Saubegajt. Fr. August K. v. S. Şinter ier Siegelijgeune bei Fianik, aud)

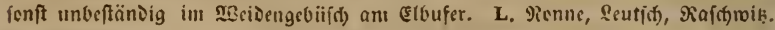

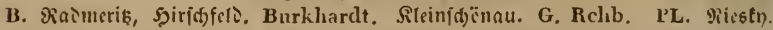
Rabenhorst. A. DeiTau. PS. 3arby, నittrnberg, Sade.

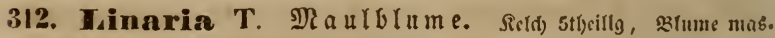
tenförmig, unten gefpornt, Gaumen gefpalten. Siaffel 2fäd)rig, nit Sält)nen aufipringend. - Peloria beift ¿ie (utenîtrïs) regelmüfage \$lunte mit 5 Epernen.

a. Sapier 2tiappig, Slappeit ganj.

1029. L. Cymbalaria MrLx. Rснв. Fl. germ. exsice. n, 1351. Blätter herjförmig 5lappig, fafl, Rapfel 2flappig. Etengel fadenfïrmig berab. bängeno, 23lätter faft epfreuartig, sit. Elein, Gaumen gelb, lila uno weiß, einjeln lang gefticlt. - 2(n Mauern. 2(pril - Dec. 4. 9iif)t uripriïnglict) cint)einifd), verbrcitet fid) aber inmer me()r. Faft Jurd) ias ganje Gebiet, am bäufigiten in Drek. Den und Der umgegeno, felten in 2inl)alt (Dranienbaum am dinejiff)en Şaufe),

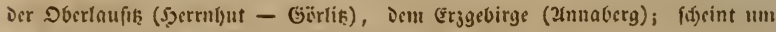
5alle und in der gicierlaufít ju felylen.

1030. L. Elatine Micr. Fl. dan. 426. Rerb. Fl. gerin, exsicc. n. 623. Slätter sirmo, Dic vocren unten fpiçï̈rmig, Etengel faoenfërmig, gro

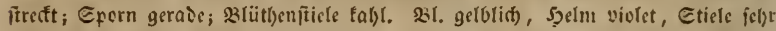
lang, faienfïrmig. - Xuf Eaniäforn. Juli - Eeptember. $\odot$. Şier uni in;

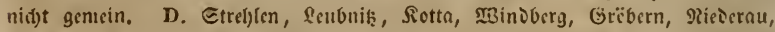

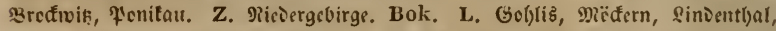

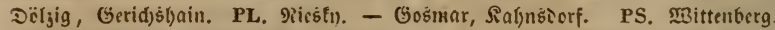

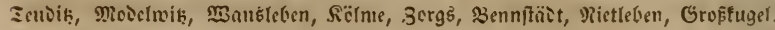
HS. Zliperiteit. Jenn.

1031. L. spuria Mrck. Fl, dan. t. 913. Siätter eiförnig, faft ganjrandig; Etengel fä̀lid), geftrefti; Eporn gettümnit; 23luntenfticle zottig. Iluf bebautem ßseden, Gemiijeätern. 2ruguft. Eeptember. $\odot$. In Ibjiringen

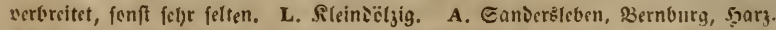

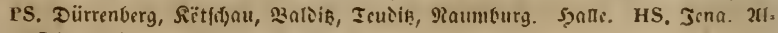
perffeit. Ricierfïrthad bei Reburg. 
b. Siapfel in 3ät)ne auffpringeno, Saanten stig.

1032. L. minor DEsf. Fl. dan. 5U2. Rchв. Fl. g.exs. 624. Driifig be baart, S3lätter f(d)mal (anzettlid), ftunıpf, sic unteren gegenüber; Slütben einjelı in Den 23 (attadjicln faft traubig; Saanten länglid), gefurd)t. ŞanD. bis fpan. nentbođ), Stweige aufiteigent. \$3l. Elein, tila, Gaumen gelblid), Sippe reiflid). - 2uf bebauten Boien, Ed)utt. Mai. Juni uns wiever iut Spcrbft. ๑. Edjeint in Der Dberlaufti uno bem bëbern Gebirge ju fel)len, fenft meift nidht felten.

1033. L. chloraefolia Rснв, pl. crit, v. ic. 627. Fl, germ. exsicc. n. 626. Stcif aufređ()t, bläulid) bereift, B(ätter jerftreut, cilanzettlid),

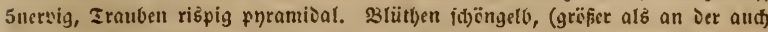
in $\mathfrak{Z}$ Bud)

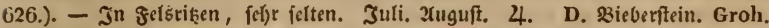
L. Rchb. fil. [Bormals auf Der jef̧t untgebauten Mauer Des prinjl. Gartens auf Der äufern pirnaifdyen Galie.] B. Etclpen. Papperitz. Frick. Weiker. [Ed)cint jekt ia verfdrwumien gu fein.]

\section{c. Siapîl in .3älyne dufipringeno, Saamen piügctrandig.}

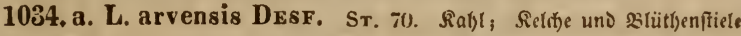

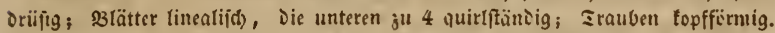
Spanten(yod), bläulid)grün, 23\%. tlein, blau, Gaum weiştió), violet geabert. 2uf 2reftern. Juli - Eeptember. 24. Serftreut. D. Tima, łianif̌, Dberpoi.

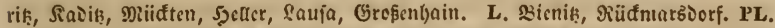

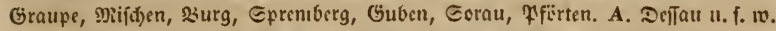

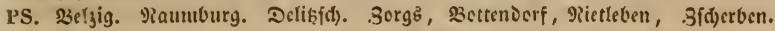
HS. Segefelo bei Mcinar. Gd)ufendorf bei Sivburg. SRS. ?trnftadt.

1034. b. L. vugaris Batr. Antirrh. Lin. L. HAy xe Arzng. VI. 33.

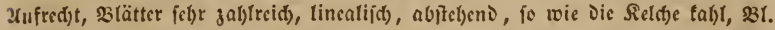

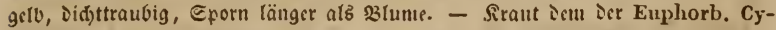
paristias älunti(t), Gaumen fafrangelb. - 2tuf felorainen, Ganiboien, felfen, פauern. Juli. 2ruguft. 4. Gentcin.

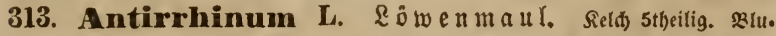
me naśfenfïrmig, unten budflig, Gaumen gefpalten. Fapfel 2fäd)rig, an ier ङpik̨e mit ̊̈̈d)ern auffpringens.

1035. A. Asarina L. Bot. Mag. 902. Nicictfirgent uns wurgelno,

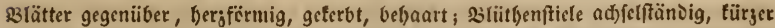

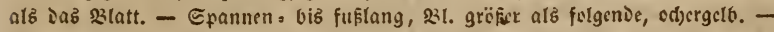

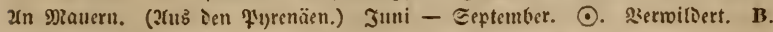
5ainwaltor. Reichel.

1036. A. Orontium L. Sr. 27. 2(ufred)t, Reld)abfonnitte (anjettlid), länget ałs Dic \$3łume; Stengd armblütl)ig, \$lütl)en entfernt. Spannen. bis

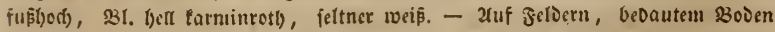

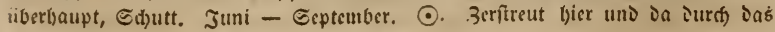
Gebiet, jelbit bis inz mittlere Ẽrzgebirge.

1037. A, majus I. Dict. st. nat. cah, 2. Seld)abf(t)nitte siruns, 


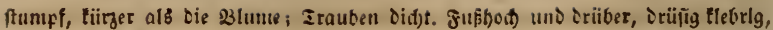
231. roth, Gaumen gelb, jelten weißß, aud) rotl) unb weiß̄. - ?uf gauern, Dä. đern. Juni - 2luguft. ठా. Sier und oa serwilbert.

314. Digitalis L. Fingerfut. Sel(b) 5theilig. Blunte baudblg oier glocfig. Niünoung ungleid) 53äbnig. 4 frud)tbare Etaubfäden, Beutel 2tlappig, Rapiel eifërmig, 2fädrig, Rlappen in Den Diđ̛en Saanienträger bineingebogen. - 3 lätter jerftreut.

1038. D. grandiflora LAм. Rспв. pl. crit. 11. ic. 289. \$2lätter länglid) langettliđ), gefägt, reid) belyaart, cbere balbumfafend; Sild)ab(d)nitte faft linealifó); 3lume bel)aart; Die Säl)ne Der unterlippe fpișig orciectig. Uteber

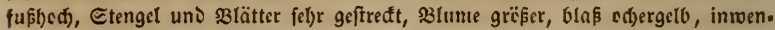
Dig bräunlid) nek̨artig gegeid)net. - 2n Selfen, im ur. uno Ralfgebirge. Junt.

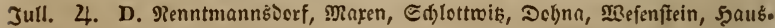

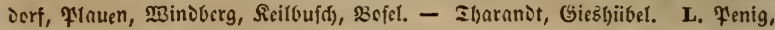

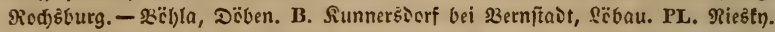

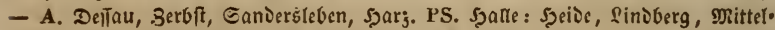

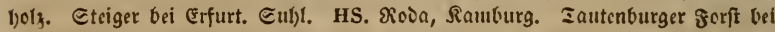
(Eifenterg. Etfenad). SRS. Frantenlyaulen, 2runiant.

1039. D. ochroleuca JcQ. austr. t. 57. Rcris. pl. crit. II. ic. 290).

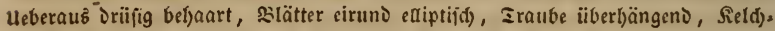

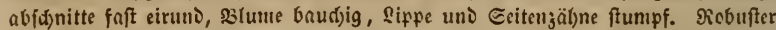
gebaut und Driifiger. Blume tïrger und enger, Duntler gelb, inwendig bräunliç) neķaderig gejeid)net. - 2n Jelien wie veriger. Juni. Juli. 4. \$obl weiter verbreitet. D. Flauen. SRS. Eiudolftadt.

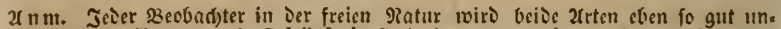
terf́ciden fënnen, wie Schönheit fie in ier Bot. Zeit. 1834. 540. fo unter. f(jieden bat, wie id) fie fidon a. a. D. Dargeftedt hatte.

1040. D. purpurea L. ST, 11. HAyse Arzngew. I. 45. Blätter cilanjettlid), geterbt, unterieits filgig, rungelig; SBlunte ausen fabl; Die 2rbidjnitte Der unterlippe furg eiförnig, gerundet. Gegen 2', fpäter aud) böher. 33l. bell farminrotl), inwendig weißs gefectt, augenartig mit fdjwargen Pupillen. - b.

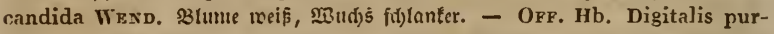

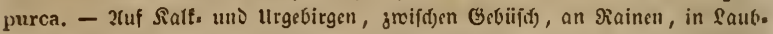

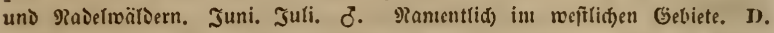

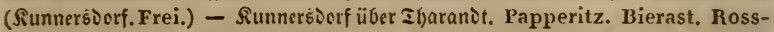
inässler. 2uttenberg. Bucher. Bok. Do neuerlid) Dajelbft gefunien? ? A. Sarage.

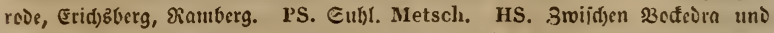

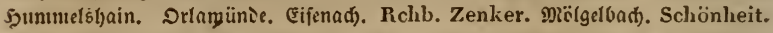

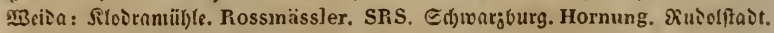
Schönheit. R. Sobenjtein.

\section{Scrofularinae: @trubbeutel ein fädrig.}

315. Utricularia $L_{0}, \mathfrak{B}$ a fferffla u

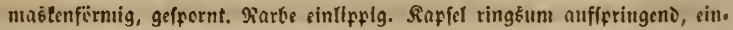


fäarig. Gaamen zahtreiđ). - Slafd)enförutige slajen bängen an Den Blät.

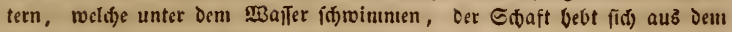
2Ba Ter, bevor er oie 23lütben entwiffelt. 231. getb.

1041. U. minor L. ST. 17. Dakw. u. HaYne t. 9u. Blätter von

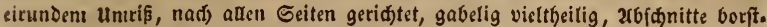

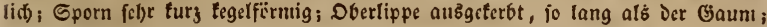
Srudifftiele jurü(fgef(j)lagen. S(j)aft nur $2-3^{\prime \prime}$ (jod). Sraube menigulüt)ig. - In Günpfen auf Dicorboden. Juni. Juli. 4. Eparfant, namentlid) in

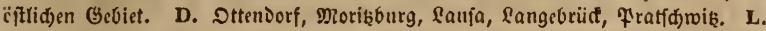
R̂ein. und Grofbotten. Fartbau. B. Doernik. Kölbing. PL. Rreba, Sorfa.

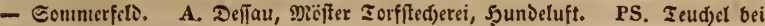
Mittenberg; Dorno's Gee bci 2actjig; Bennoorf. HS. Tnutenturg, RoDa. Zenker.

1042. U. intermedia HaYNe. 6т. 17. DREw. u. HAYNe t. 89. Fl. dan. 1262. 23lätter von nierenförnigem Ilnuri)fe, 2reibig, vieltbeilig; 26. (d) nitte borftlid), fein gejäl)nt; Eporn fegelfïrnig; Dverlippe ungetbeilt, Doppelt fo lang alढ Der Gaum; Grud)titiele aufred)t. - In Gümpfen, Gräben. Juni. 4. Seltener als vorige. D. Seifiersoorf. Bok. Grïtberg. Bucher. Dttenjorf.

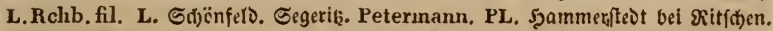

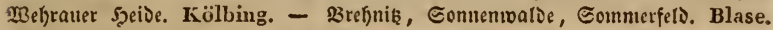
Straupiķ. Rabenhorst. A. 3erbft, Şundeluft. Sclıwabe. HS. G̈ëfen unঠ Şain. fpik bei Eifenberg. Zenker.

1043. U. vulgaris L. Scrk, t. 3. DREw. n. Hayne t. 88. 3lät. ter von cirunien uluriß, nad) allen Geiten geridtet, fieberartig baarfirmig, viel. theitig, fein ftad)elipiłzig; Eporn fegelförmig; Oberlippe fo lang als Goumen. Sd)aft faft fpannentjod). - In Gïmpfen, Gräben. Juni. Juli. 4. Tament.

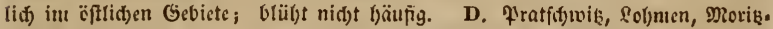

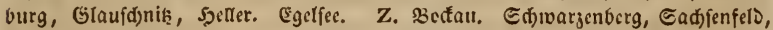
Gdi)neeberg, Mildenfils. L. Geitbain, Grofbotben, Grimma. Diđak. Streit. bolg? B. Sittau, Etolpen. PL. Picstn. - Dubcn, MBittmannborf, \$3urg,

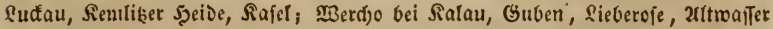
vei Eonmerfeto. A. Groftïbnauer Gee; DeiTauer şicrgarten. PS. 23arby. 3is*

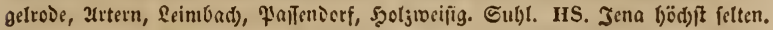
altenburg. R. Gera.

316. Pinguicula L. Fettfraut. Reld) 2lippig 5ipaltly. 33lume 2lippig, gefpornt, 5̧clm auṡgeterbt, Sippe 3lappig. Siapfit einfäd)rig,

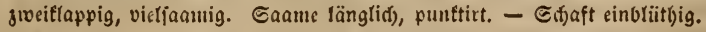

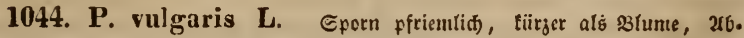
(d)nitte Derfelben gefondert, Rapfel eiförntig s Murgelblätter oval, meid), bedgrün,

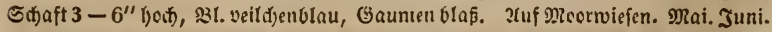

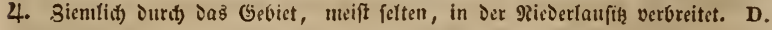
fangebriif. Bucher. Löber. Fr. August K. v. S. M̉eifig. Papperitz. G. Reichenbach. - Dippclbiätonloe. Frick. altenberg. Schunidt. G. Rchb. Pap-

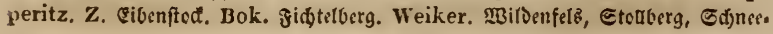




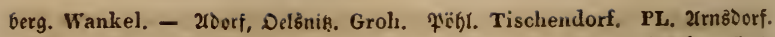

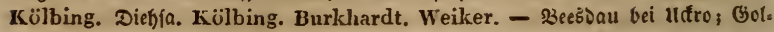

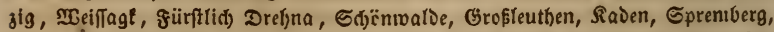

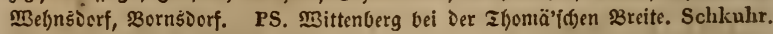
Nitzsche. Belgig, ๔dnniedeberg. Rabenhorst. Şolyenfeld bei Erfurt. Hornung. Gufl. Metsch. Bauer. HS. Jena : bei Der fröbliden Micierfunft, Gunibeira.

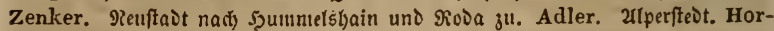
nung. Zonndorf. Bernhardi. SRS. Zeidrïbell bei §illoolftait.

$2(\mathrm{~nm}$. P. flavescens FLokrк. Rснв. pl. crit. I. 186. A. Mitfelmibl)of nad Scliwabe!

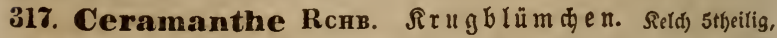
ganz trautartig. 31. trugförmig a uf geblafen, Mtinoung eng. Das mittlere ๔taubgcfäfpaar an Der Bafiz nabe beifammen, Dann aubeinander laufend. (Sieine Epur von fünftem etaubgefäß.) ๔aanı gcfurdit uno Durd) fdarfe Duereinoriide genuffert. - Blätter gegeniiber. (Diefe Eattung ift nit Calceolaria verwanot.) \$ergl. fifen FI. germ. p. 376.

1045. C. vernalis Rснв. (Scrof. vern, L. Schr. t. 163. Sт. 23. Rснв. Fl. gern. exsicc. n. 255.) S3lätter leerzförnig, runolid) eirund,

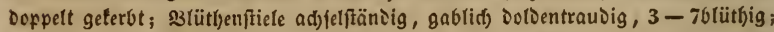

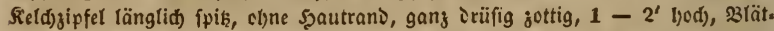

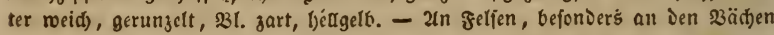

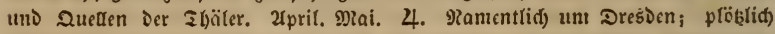

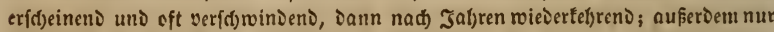
feffr fêten. D. Recif(r)a. Lüber. Firna. Bauer. Sr. Sarten. Bucher. Dres.

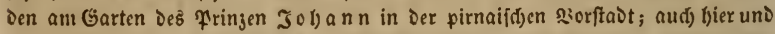

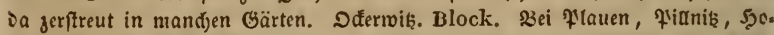

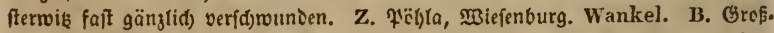
henners̄orf. Kölbing. PS. \$3ittenberg. Schkuhr. Nitzsche. HS. Jena. Schubert. SRS. atmftaot. Schönheit.

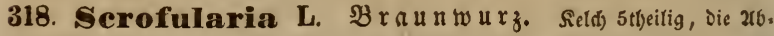
(d)nitte bautrandig. S3lunte stroas baudjig 2lippig, ungleid) 5lappig, ant

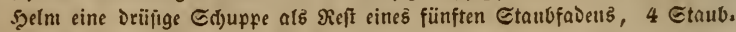
fäben Dioynantifd), paraftel. Sapfer 2fä̈d)rig, STappen in Den Dif̌en Gaamten. träger singebogen, - 23 lätter gegeniiber.

1046. S. nodosa L. St. 20. Hayss Arzneigew. v. 35. Brätter

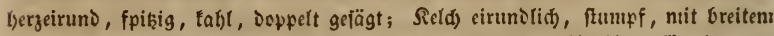

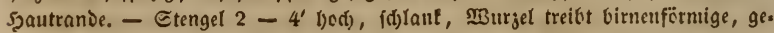
ringelte Sitroden, 23t. blafgrüntid) mit braunem Szelü, Etaubfäben gerade. -

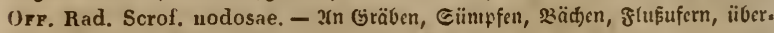
yaupt feudjten, fdjattigen Drten. Juni - Geptember. 4. Gentein.

1047. S. aquatica L. ST. 23. Harss Arzneigew. v. 36. ฮtcl,

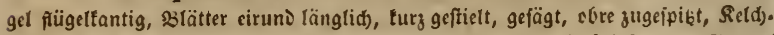

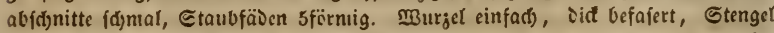
$2-4^{\prime}$ bod), 321. braun. - 2n Gräten, Sïnıfen, 23äd)en. Juni - Eęt. 4. 


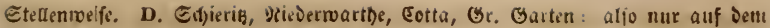

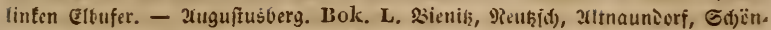

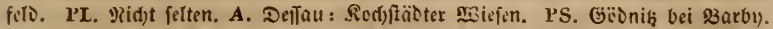

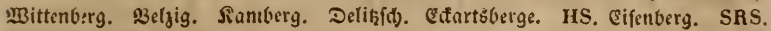
irnftait.

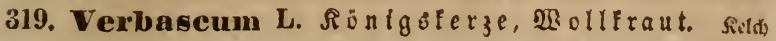
5theilig. Slumte raifïrmig, stwas ungleict) slappig. Etaubgefäp̄e 5, un. gleid), gegen Den seutel verdidt. Siaplet 2 fäd)rig, 2 tlappig, Silappen in ien Diden Saamenträger cingebogen.

1048. V. phoeniceum L. JAcQ, anstr, t. 125. Bot. Mag. 885 .

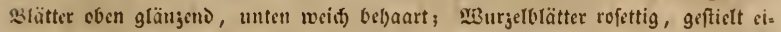

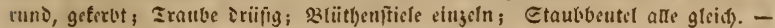

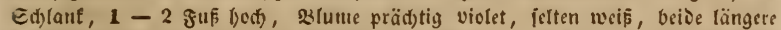

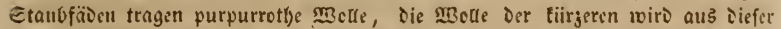

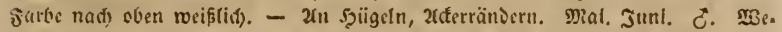
nig verbreitet und zerftreut. D. E(t)ierik. Manke. v. Rümer. 3rifften Giv.

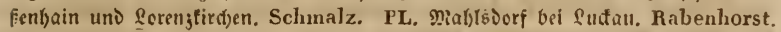

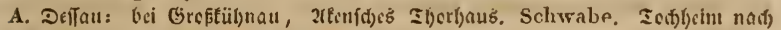

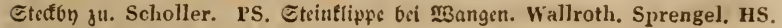
Runiķburg. Schmidt.

1049. V. Blattaria L. Engl. Bot. 393. S3lütter Eabl, untere unge.

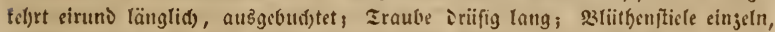
cntfernt, Doppelt to lang als Dedfolätter; Etnubbeutel alle gleidffirmig. $2-3^{\prime}$ be(t), 231. gelb, MBodle Der Gtaubfäden siolet. Var, V. glabrum Mick. ic. t. 67.

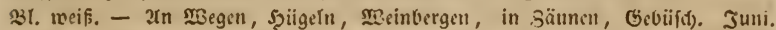

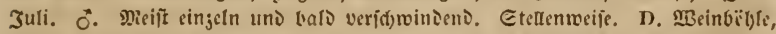

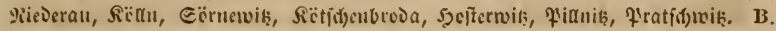

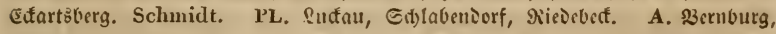
2rexişbav, Difau. PS. Sarbu. Iretła, Mertben. Var. b. D. Ueber Irachau. G. Reichenbach.

1050. V. nigrum L. Fl. dan. 1uss. şlätter geferbt, obcrfeite faft tulbl, unterfeits sünnfiljig, untere lang geftielt, Etengelblätter länglid̆ berzeiför. utig, obere eirun১ längliø); Gtingel obcn f(i)arffantig, mit virlängerter Iranbs; Etaubfäbon purpurwedig. 1 - 3' jod), Etengel violetbraun, getrodnct idjuarj,

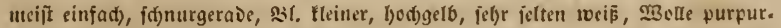
rotl), filten serfiüuntert uno fel)leno: V. gymnostemon. - $2(n$ getbrainen,

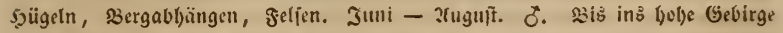
nid)t feltin.

1051. V. Lychnitis L. Fl. dan. 586. Blätter geterbt, eberfeits tabl,

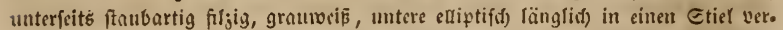

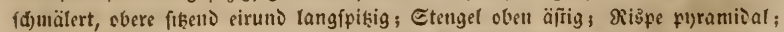

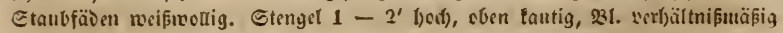

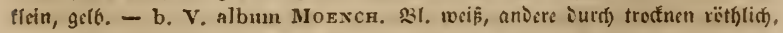

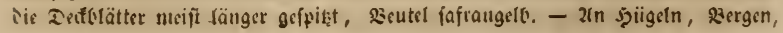




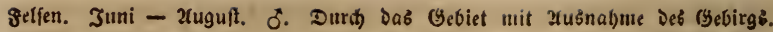
b. D. Plauen. PS. MBendelftein. L. Rchb. fil.

1052. V. Schottianum Schrad. mon. II. t. 3. f. 2. Blätter alt.

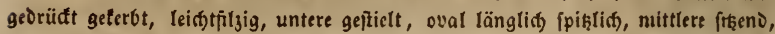
längliơ), fpiksig, oberfte fạt berzförmig, etroas untfaffeno, eiruno zugefpilst, Irau. ben rispig, Eticle doppelt fo lang al( Seld). Mud) von V. Lychritis, abec Die Mode Der Staubfäben violet, Die slätter aud) oben ftaubfilzig; getrodínet find Die slätter ganj fad) und fafrwarz, wie Die ganje ¥itange, Die Reld)afo.

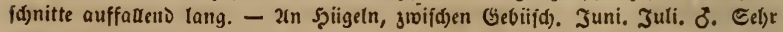
jelten. D. Etruppen. Klotz.

1053. V. ramigerum LK. Schrad, inon. t. IV. 3lätter unten graufilzig, oben leid)t ftaubfitzig, untere länglid) lanzettlid), grob geterbt, fiengel. fändige eirund fpis, etras berablaufeno, Doppelterbig, oberfte faft ganirandig

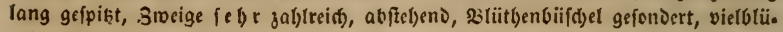
thig, 2 seutel länglid). $4-6$ ' bod), @tengel Dicf, ftielrund, oben etwaś tan.

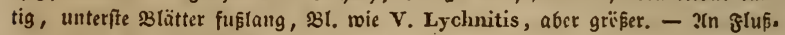
ufern, Şügeln, unter V. Lychnitis uno thapsus. Juni. Juli. ठ゙. Esbr felten. D. Solnmen. Rchb.' Şefterwik. Rchb.

1054. V. nemorosum Schrad. mon. t. 1. f. 2. slätter filzig, ge• terbt, fpib̨ig, tourgelffändige länglid), nad) beiben EnDen verjơniälett, ftengelftätts Dige lanjettlid, länglid) lanzettlid) und längliø, oberfte wenig berablaufeno,

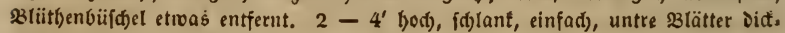
filzig, iibrige Dïnnfilzig, intnter fd)mäler als an folgender 2urt, Blunte etwas

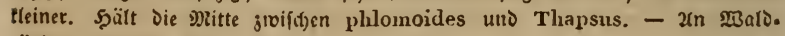

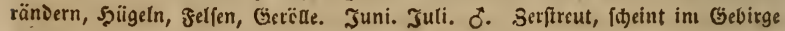
ju fólen.

1055. V. phlomoides L. Hayne Arzngw. XII. 40. 33lätter gi.

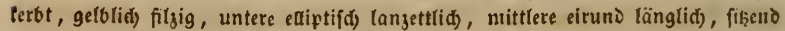
und balb unifaiteno, oberfte cirund jugefpist; Iraube unten unterbroffen; siliis thenftielden felgr turz; slume (fehr großs) rabfornig; Die Staubgefäfe un. gleiđ): 2 länger nit länglid)en Etaubbeutcln, woran Der @taubfaien fabl uno Doppelt io lang als Der Staubbeutel ift. \$3is $2^{\prime}$ bod, feltner äftig, \$lätter run.

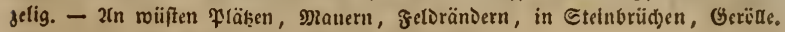
Juni. Juli. ठ઼. Tidjt felten, felftt in Şodjgebirge.

1056. V. australe Schrad. mon. 1. t. II. siätter geterb̂t, filzig,

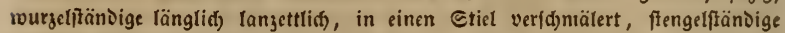
läng(id), fpik̨ig, herablaufeno, vberfte breit eiruno, berablaufeno, lang gefpişt,

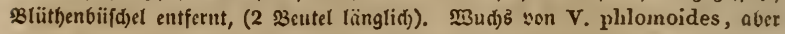

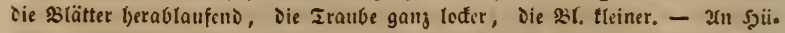
geln, Gelbrainen. Juni. Juli. ठ. ๔el)r felten. D. Reljia bei Grofent)ain. Schinalz.

1057. V. condensatum Schrad. mon. t. III. Blätter filgig, unten elliptifd) länglion, an Der $23 a f 15$ verf(t)mälett, ungleid) Deppelt grlerbt, ftenger. fän๖ige tänglitb, fpikig, geterbt, oberf̣te eirunitiơ), lang geffik̨t, etmas berablaus. 


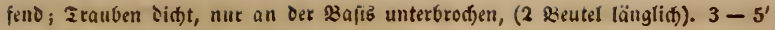

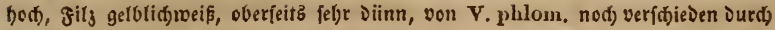
Die tief eingeferbten untern un১ oie berablaufenden sbern slätter. - 2an wüften Drten, in Eteinbriiden. Juni. Juli. ठ. Sebr jelten. D. Mtelfen. Rchb.

1058. V. Thapsus L. BLAKw. t. 5()2. thapsiformu Schrad.

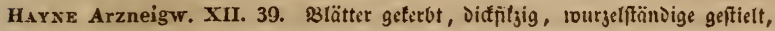
a tre berablaufent und verjđnnälert, ipibig; meift eine einjelne zraube, Didft;

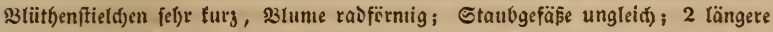
mit länglidgen Stallbbeuteln, Deren Staubfäben faljl und Doppelt fo lang als ber

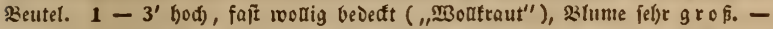
Opp. Hb. et Fl. Verbasci, aud) von andern 2rten gefammelt. - 2uf Edutt,

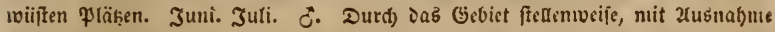
Des 5ुod)gebirgez.

1059. V. cuspidatum Schrad. unon. t. I. f. 1. Dïnnfirgig, cbote

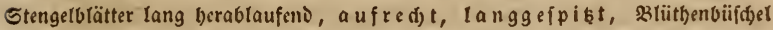

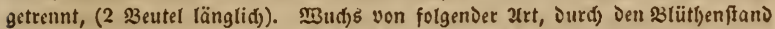
unD Die lang jugefpişten Slätter zugleid) unterjd)ieven. - 2n fdattigen Şiigeln

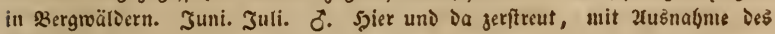
Gebirges.

1060. V. elongatum W. anno 1809. V. Thapsus Fl, dan, 631. Schк. t. 52. Haxxe Arzneigew. XII. 38. Slätter fein geferbt, Dünn, gelb. (id) filzig, ade berablaufeno, oberfte fpiblid) coer ftumpf; sliitlentraube einjeln,

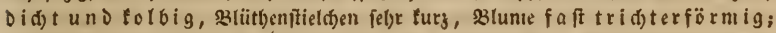
2 längere Staubgefüfoe mit längliđoen @taubbeuteln, Deren હtaubfaben viermal

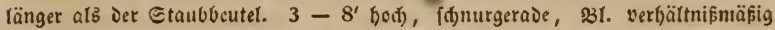
tlein, gelb eder weifs: elongatum W. Ex. - 2uf Sd)utt, woïften Pläk̨en, auf

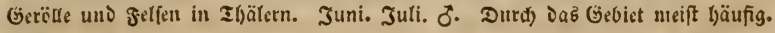

320. Limosella L. Rimofelfe. אeld) 5ipaltig. 2 b. tridtets

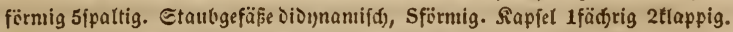
Gaantenträger teulenfïrnig, Gaamen zal)lteiđ), länglid), längs̉ gefur(f)t, quer runjelig.

1061. L. aquatica L. slätter lang geftielt, fpatelfïrmig. Sileines

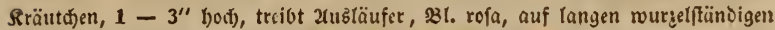
Sticlen, seutel fátwarjblau. Var. b. L. tenuifolia Horfs. siätter linealifd).

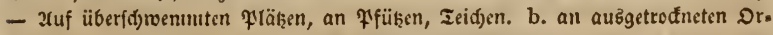
ten. Juli - September. 4. Durd) Dab ganje Gibict.

321. Windernia L. Rinbernie. Reld 5theilig. Bl. bautjig rǘrig, 2lippig, Dverlippe abgerundet, Unterlippe 3lappig, Mittellappen aus.

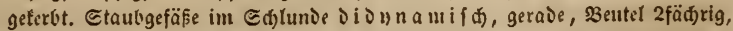

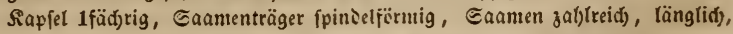
rängs gefurd)t, quer gerumgelt. Blätter gegenü ber.

1062. L. Pyxidaria L. Scra. t. 175. Ricoerticgeno, glätter fį́en

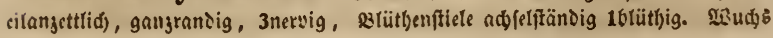


toie Gratiola, Eetengel bünner, 231. tleiner, rofa. - 3n \$lusufern uns zetd).

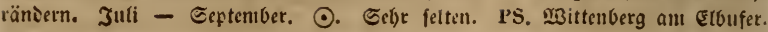
Schkuhr.

322. Crratiola L. (5) n abenf $\mathfrak{r a} u t$. Seld, 5theillg, mit zwei Def́blättd)en. 23l. vierfeitig rëbrig, Gaunt 4ippaltig, Deerlippe fiad), juriid, gebogen. Staulogefäfe Dionnamifa), 2 unfrud)tbar, ßeutel 1fäd)rig. Sapfel 2fä̈brig, Eaamenträger lïft fid) neoft ber Edjeitewano ab. - 2iätter ge. genüber.

1063. G. officinalis L. Hayne Arzneigew. III. 13. Brätter fiţeno,

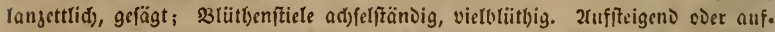

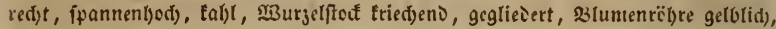
๔aum rötthlidjweif. Opr. Rad. et Hb. Gratiolae. - Iuf Æumpfiviefen, an

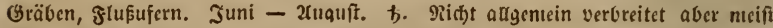

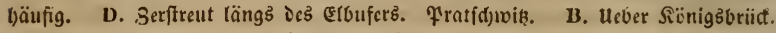

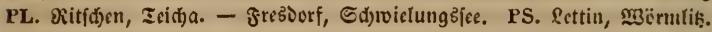

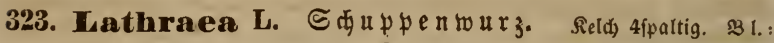
Oberlippe ganz, Sippe 3yälynig. Sapict 1fät)tig 2tlappig, 巨aantenträger

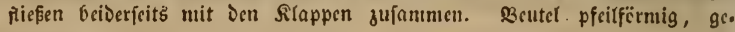
wimpert.

1064. L. Squamaria L. Schx. t. 70. ङpannentod), feif(f)ig, weiß.

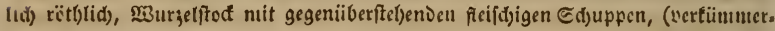
ten s(ättern ), 3liitl)cn zalslreid), einfcitig, überlängeno. - 2un Duntelen Drten

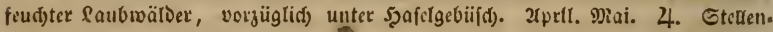
เveife Durd) Das Gebiet.

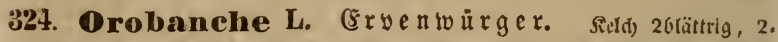
fpaltig ooer 1blättrig 5ipaltig. 33lume radjenfürmig, vertroúneno, Syetu auşgeterbt, Sippe 3lappig. STarbe quer 2lappig. Sappel 2tlappig, vertifal

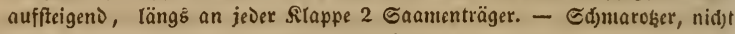
grün, Blätter zu fđjuppenförmigen $\mathfrak{B l a t t f t i c l e n ~ v e r t i i n ı n e r t . ~}$

๑. Orobanche, Sieldi) ge(onvert 2brättrig.

1065. O. minor Sutr. Rchв. pl, crit. VII. ic. $876-880$. Fl. germ. exsicc. n. 15t1. Gd)lant, (nièrig, eft bogig), Sield)brätter eirunt, (d)mal zugefpilazt meift 2ipaltig, etwa fo lang ats die siël)re Der marjigen 33 lume,

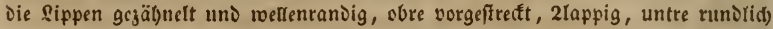

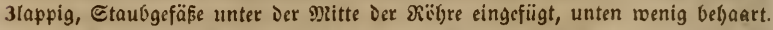

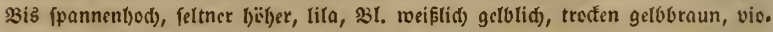

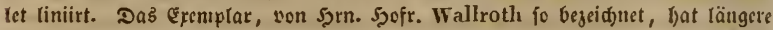

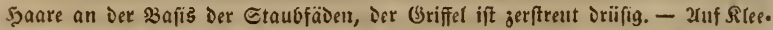

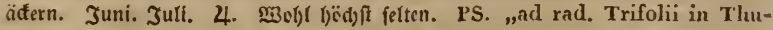
ringia." Wallroth.

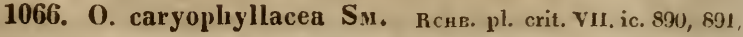
895 : 1127: Fl. germ, exsicc. 60. 62. Narbe ausgeffreizt 2fuglid), Griffel 


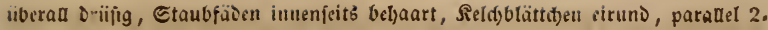
ipaltig, Blunte groß, Dünnbäutig, walgig, borizontal vorgeftrefft, Sippe

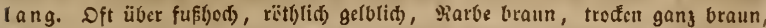

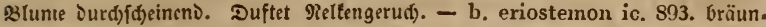
(id) rëtllid) gelb, Gtaubfäben langjottig bebaart, Blume weit, Sippenabj(d)itte

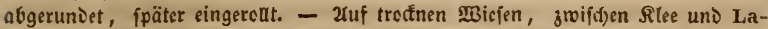
thyrus pratensis. 2Infang Juni. 4. D. S3orm Dobnaijd)en Sd)lage; bei

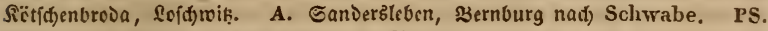

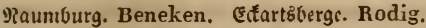

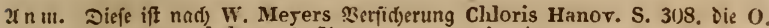

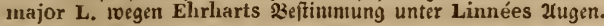

1067. O. galii Duby. Varcren pl. 7. Rchb. pl. crit. ViI. ic.

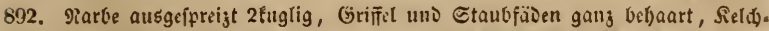

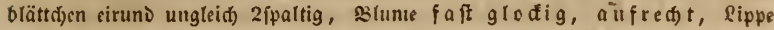

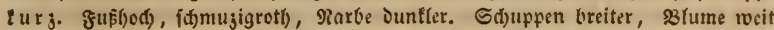
tï rjer. Gerud) f(dwad) netfenartig. - 2uf troďnen M̉içen, auf Galinm Mollngo. Juni. 4. D. Dresten yor Dem Dofynaif(d)en Ed)lage. Rchb. Hübner.

1068. O. adenostemon Rснв. pl. crit. ic. 894. श2arbe ausgefpreijt

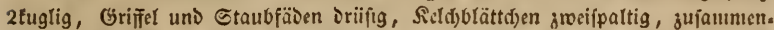

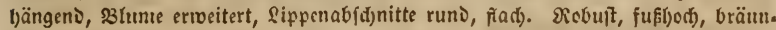

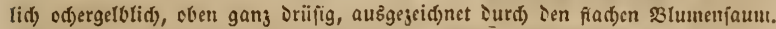

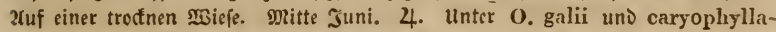
cea einmal vor Dem Dofnaiffen ๔đlage bei Dresocu gefunden.

1069. O. torquata Rснв. pl. crit. $\mathbf{X X}$. ic. 1128. शrarbe ausgcturitet

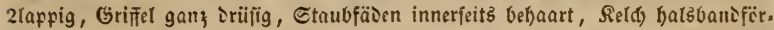

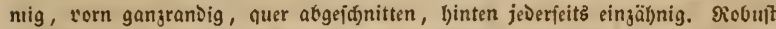

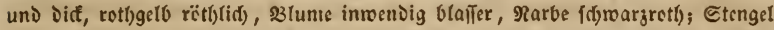
unten mit fel)e breiten Biegeli(s)uppen, faft von unten auf jerfitreut blüthig, szlüthe

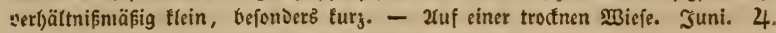
D. Peur cinnal gefunden auf Derfelben Mirje. Rchb.

1070. O. rubens WallR. (elatior) Rcri, pl. crit. VII. ic. 901. 902. Seldgblätter vielnersig, brcit sirund, pfriemlid) jugcipişt, vorn uno binten mit eincm Saltne socr ungleid) 2ipaltig, fo lang als bie s3tuntenrïbre, (vorn mel)r oDer ninier verwadffen); $\mathfrak{B}$ lume aus getriinmter $\mathfrak{B} a$ fiß rïbrig glofig, Sï̈đđen gerade, Dann abgencigt; Sippen ungleid) gejälynt, obere abftebeno

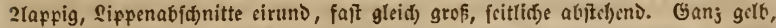
Die 23lume viro Daun bläutid), trofen rotbbraun, wie bie ganze Franje. Die

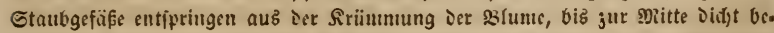
haart; Narben obne erhabenen Diand. Sicht nelfenartig. O. elatior Surt ift alteroings Diejectoe \$rînze mit Eal)lem Griffel, vergl. Chl, hanov. - Zluf Me-

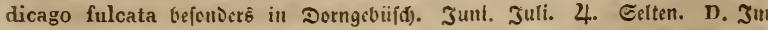

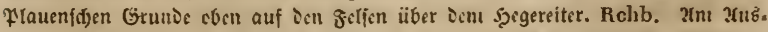

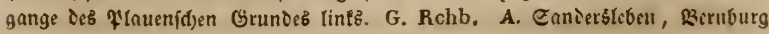




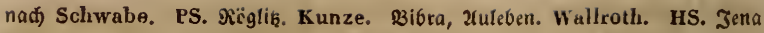
Hornung. SRS. Rubolftadt. Schönheit, 巨ondersbaufen. Wallroth.

1081. O. strobiligena Rchs. pl crit. VII. ic. $905-907$. शiarbe abfteryend 2lappig, Grififel und Etaubfäden brüfig, Reld)blätter ungleid) zrwei. fpaltig, verwad)fen, Ed)uppen breit uno gugefpişt, unten zapfenartig gef)äuft, ftengelffändige und Deč́lätter lanzettlid) Jugefpitit; Sippenabid)nitte abgerundet, gleid)groß, fo lang als Dberlippe. Єd)ën meiß, Durd) Die Mienge von Drüfen getb (d)eineno, Narbe hodgetb. (Unter vielen Eremplaren felle felten f(j)arlad)roth,

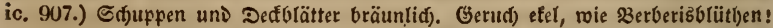
- Bıifd)en Vicia sepium und cracca auf einer trodnen $\mathfrak{B}$ iefé. Juni. Juli. 4. D. Zor Dem Dobnaifden ๔ajlage bei Dreboen, in feudjten Jabren Dafelbit nidjt felten.

1072. O. laxiflora Rснв. pl. crit. VII, ic. $908-910$ und tab. DCLI. SRarbe abftet)eno 2lappig, Griffel unD Etaubfäben orüfig, Sieldjblätter ungleid) 2 fpaltig, unten vertwa(j)ien, unterfte. E(j)uppen linealif(d) länglid), zisgel.

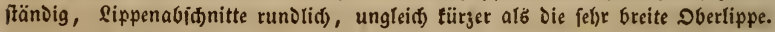
1 - ${ }^{1} \int_{2}{ }^{\prime}$ hod), oft bogig, blafrëtbling ober ganz weißs: Sabb. h. Rom. III. t. II. Parbe innen braunroth), (Gerud) fel)r wenig neltenartig. Irodén braun uno Durd feftere 33 lume von 0 , caryophyllacea zu unterfdecioen. - Xuf einer

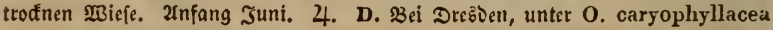
vor Dem Dolynaifden Sdilage.

1073. O. speciosa DE C. Rchв. pl. crit. vil. ic. 914. 915. आie vorige, aber 2 gefonterte einfpişige Reld)blätter. Bielleidft 2rbänDerung von vo.

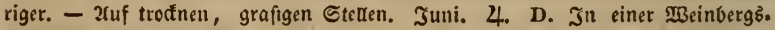

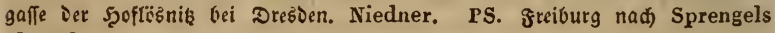
Fl. Hal.

1074. O. loricata Rснв. pl. crit. ic. 917. शarbe aubgebreitet 2 .

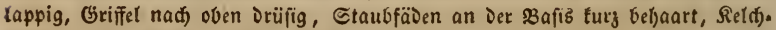

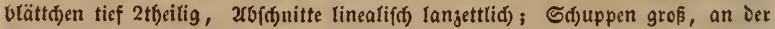

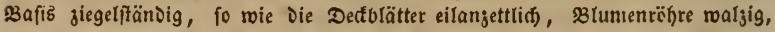

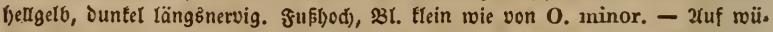
ften bergigen Drten auf Artemisia campestris. - PS. Bei Xffderઈโtben. SRS. granfentaufen. Koch. Sprengel.

\section{b. Kopsia : §eld) 10lätttig 5fpaltig.}

1075. O. caerulea VirL. Rcrв. pl. crit, VII. 928. O. Millefolii

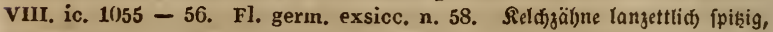

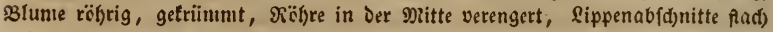

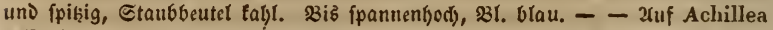
Millefoliun. Juni. Juti. 4. Gelten. D. Etolpen. Rodig. Plesch. G. Rchb. Papperitz. PL. Reujede. Fischer. A. Bernourg, Sdjadentl)al. Schwabe. PS. Raumburg. Beneken. SRS. Granlentjaufen. Hornung.

1086. O. arenaria Bonкн, Rснв. pl, crit. VII. ic. $929-931$.

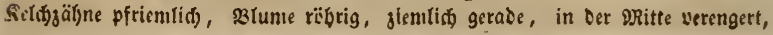




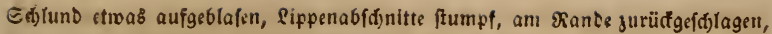
23eutelnath) rocubnarig. $23 i 3$ (pannenbod), 231. graublau. - 2(uf Artemisia campestris. Juni. Juli. 4. Gelten. D. Bofel. Hïbner 1804. G. Rchb. 1840. PS. 5alle. Sprengel. SRS. Siர̈lyäufer. August Reichenbach.

1077. O. ramosa L. Rcrв. pl, crit. VI. ic. 933 - 934. Fl, germ. exsicc. n. 57. Sieldjä̈l)ne 4, cirun১ ireiectig, pfriemenfpişig, હtaubbcutel tahl, Stengcl äftig. 3liitben faum balb fo grof, graublau. - 2fuf Şanf uno Iabal,

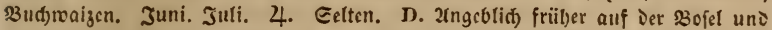
aud) nat)e bei Reifen gefunden. A. Furķ6erg, Şundelıft. PS. Bottendorf,

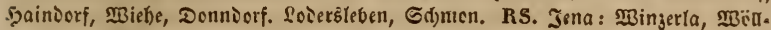
nib. SRS. Rutiolftadt.

\section{Framilic Solanaceae, Nachtichatten.}

- Şerbarienbud) S. LV uno 121. -

\section{Hyoseyamus L. $\mathfrak{B} i\lceil\lceil\in \mathfrak{n} \mathfrak{f} \mathfrak{q} u$ t. Sield) trugfërmig 5.}

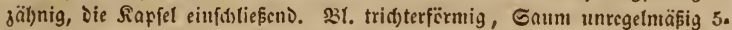
lappig. Etaubgefäpe 5, cingebogen. Sapfel 2fädjrig, ntit Deffel a uf. fpringeno:

1078. H. niger L. Schr. t. 44. St. 3. Hayxe Arzneigw. I. 28. Silätter eirund länglid), buđ)tig fièerfpaltig, Dic unterfîen geftielt, Dic ftengcl.

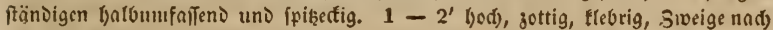
ier 23 (üt)ezeit lang, onnn cinjeitig traubig. 231 . fd)muzig offergetb, violet geabert. - b. annuus: nicorig, mit fcid)tbud)tigen s3lättern uno blafigclben situnın. H. agrestis W.K. - OFF. Hb. Hyoscyani nigri. - 2uff müften ¥läken, G(f)utt, b. vorgüglid) auf Mauern. Juni - 2uguft. ठ․ b. (.) 3erftreut, im Gebirge feltner.

326. Nicotiana L. Ta $\mathrm{b}$ af. Reld gledig 5ipaltig. Blume tridj. terförnig, Saum gefaltet. Staubfäben 5, eingebogen. Sapfel zmei = biz mebrfäßrig, jmeia bis mebrtlappig, Saanten fel)r jaljtreid).

* 1079. N. rustica L. BLAKw. t. 237. s3tätter geftielt, eiruno; 231 .

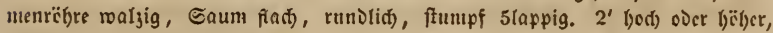
flcorig, 23\%. rispig, grïnliđ) gclb. - 2lus 2fmerifa, auf 2tectern cultivirt. Juli. 2uguft. (.)

* 1080. N. Tabacum L. Bцакw. t. 146. Schk. t. 44. Hayse Arzneigew. XII. 41. 3lätter länglid) lanjettlid), langipitbig; Cd)lun১ baudjig

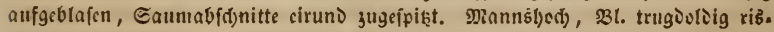
pig, bell farmintoth. - Orr. Hb. Nicotianae. - Xuf Xecfirn cultivitt. Juti. auguft. (.).

- 1081. N. latissima Mrus. Blätter faft gec̈brt eiruno zugeipişt, berablaufend, Sd)luii baudig aufgeblafen, Saumabfif)nitte eiruno zugefpląt. Dannbl)ed), Blätter febr breit, Błlume roja. - 2luš 2uncrita, auf 2ectern cultis virt. כuli, 2uguft. (.) 
327. Datura L. Ctectapfel. Reld) prismatifa tantig (bei an. Dern rïbrig oder baudjig), ipäterbin an oer 23 afi rings berum losgebend und abfallend! Blune trid)terförmig 5faltig. Sapfel 4, fä (d) rig, 4 tlappig:

1082. D. Stramonium L. Hayxe Arzneigw. IV. 7. 23tätter ge. ftielt, fabl, budjtig fpifzedig: Siapiel aufred)t, igelffadbelig. 1-2' bod ober

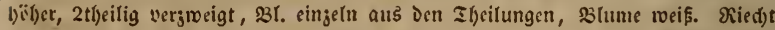
ctell)aft. Orp. Rad. Hb. Sem. Stramonii. - 2tus 2merif́a, auf Sđutt, Ģe.

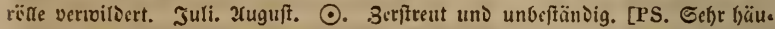

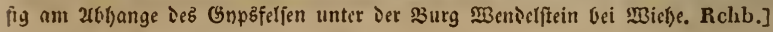

1083. D. Tatula L. MeErs, t. 13. Siaffit ciförmig aufred)t,

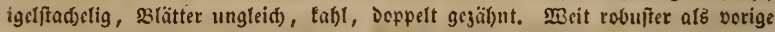

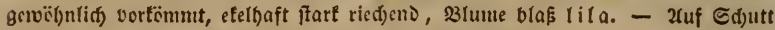
verwilbert. Juli - Eeptember. ๑. D. In Drešcn.

328. Atropa L. Tollfirífe. Seld) 5theilig. 3 Iume glodig. Ctaubgefäße aubeinander ftet)end, Dionnauifd) nebf einem unpaa. rigen. 3eere fait tuglig, 2 fäđ)rig in vergrësetten Sield)e.

1084. A. Belladonna L. Scrk. 45. 3lätter eirun১ ganjrandig, ein

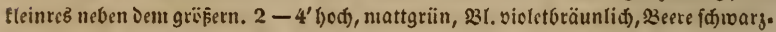

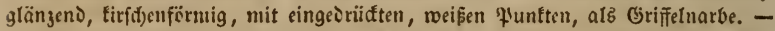

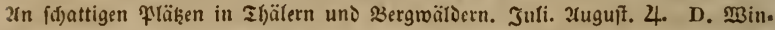

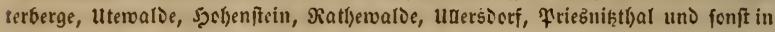

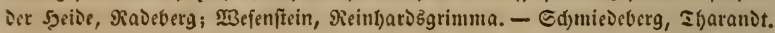

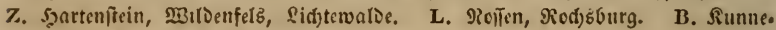

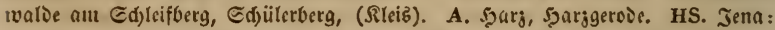

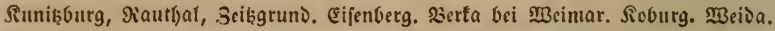

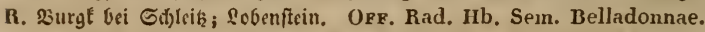

329. Nicandra Adars. (5) iftbeere. Seld 5fpaltig, tantig. 32l. glofig. Etaubfäben unten breiter. S3eere bis 4-5fä d) rig. Saa, menträgetleiften wed)feln mit Den Gdeidocränden.

1085. N. physaloides Gaertr. t. 131. Sirautartig, 2-4'

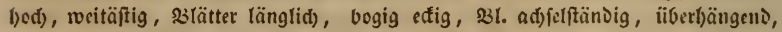

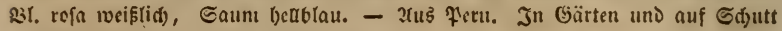
verwildernd. Juli - Esptember. $\odot$.

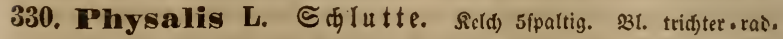
fïrmig. Etaubgefäße jufanumengeneigt. Bicere 2 fäd)rig, umgéen vem alf. geblafenen Seldje.

1086. P. Alkekengi L. BцAKw. t. 161. HaYse Arzneigew. VI. 4. Scrk. t. 45. Frautartig, slätter ju jiveien, ganjrandig, ipiß̧ig. Eten.

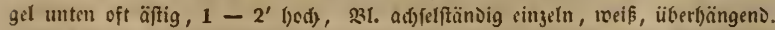

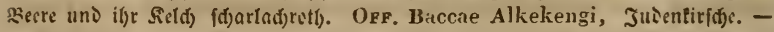

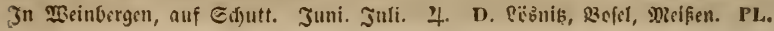




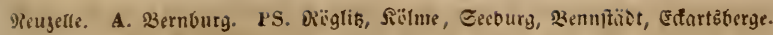

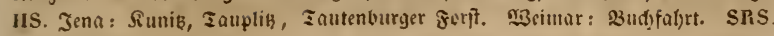
ङrantent)aufen, 2rmftait.

\section{Tycium L. $B$ o f 80 orn. Seld glodig $2-5$ fpaltig. Ri!.} trict)terförnig, Gaum 5lappig. Etaubgrfäpe 5 in ier orïbre, fíliefen mit ibren 3ärten Den @d)luno. 23cere 2färffrig, viclfaantig.

1087. L. europaeum L. TrEw. EHRH. t. LXV1II. Fiel(d) 5 . 3üt)nig, 3roeige ftictruno, sornig, szlätter länglids fpatelfürmig, હtaub. fï̀cn taum bärtig, Scere faft fnglig. Swocige jung aufred)t, fpäter bän. geno, slätter jung wellenrandig, \$1. violet, weiß geadert, Becre mennigrett), fel. sen gelo. - 2ub Eiidenropa, angepianjt uno vertoitoerno. Juni - Gept. b.

1088. L. barbarum L. Schk, 46. Gaerts, t. 132. f. 2. Dict. sc. nat. 41. Seld) 2ipaltig, sweige tantig, fẫ Jernlos, ştätter gefticlt, ellip.

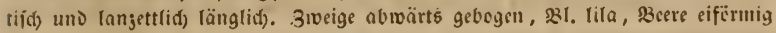

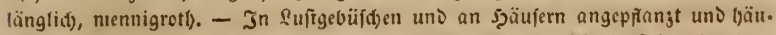

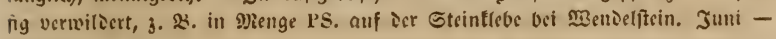
Septimber. t).

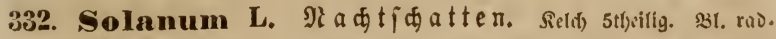

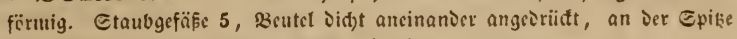
uit 2 sït)ern aufipringent. S3ecre 2 füidgrig.

1089. S. nigrum L. Hayxr Arzneigew. 11. 4). Renв, pl, crit. ic. 1283. Sin bel)aart, slätter bu(btig gezäl)nt, secren (d)warj, saliitl)en in Doldenf̈̈rnigen Irauben, Die Frudtiticle an Der Spilse veroidt, nievergetrogin.

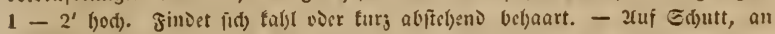
gauern, Planten. Juli - Eeptember. $\odot$. Durd) ¿as Groiet bäurig, im Ge. virge filtner.

1090. S. pterocaulon Duv. Rснв.pl. crit, ic. 128t. 310eige (d)arffautig, Ranten ftadjeljül)nig, S3lätter eiruno rlyombifd) vielbud)tig, Dolocn übcrbän.

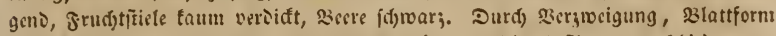

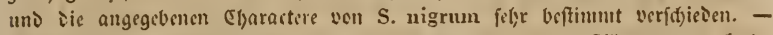

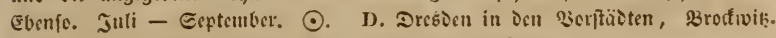

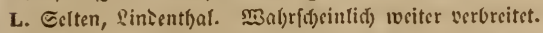

1091. S. viridescens Kóstex. (humile.) Rснв. pl. crit. $\mathbf{X}$.

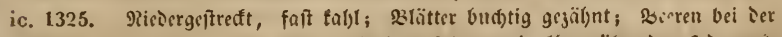

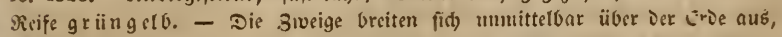

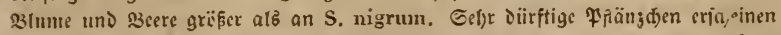
aud) uit gangrandigon sitättern. Salj: S. Juunile Brxн. oocr an trodtnin Drten fury belpart. - Ebenjo. Juli - Eeptember. ○. D. In Dresoen uno finen 2iorftäiten. - b. S. nodillorum JAcr. Etengel uno 3roeige ftielruni;

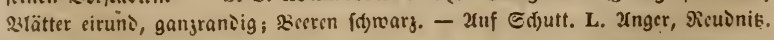

1092. S. villosum Lax. Harxi Arzneigw. II. 41. 3imeige taum tantig, meid) befhaurt, salïtter eiruni lünglid, fein bel)aart, secen gelb. Stocige 
Solanum.

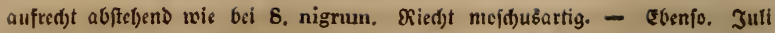
- Septenber. ○. PS. Barby, Selgig. Szalle. RL. Rleinleine.

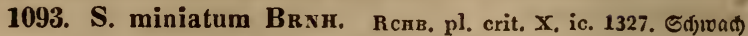
jottig (auf fettem $\$ 30 D \mathrm{en}$ tal)l). SBlätter bud)tig gezäl)nt, 23 laltftielränder an Den

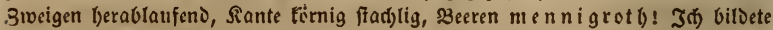
iie jientlid) fable form ab, Die Finanje tommit nidjt felten fo vor. 2fusgebreitet sergibeigt wie S. pterocaulon. - Ebenjo. Juli - September. ○. D. Röt.

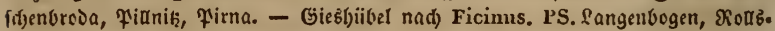
Derf. Rauniburg. Erfurt.

1094. S. Dulcamara L. Hayer Arzngw. II. 39. St. 18. eten.

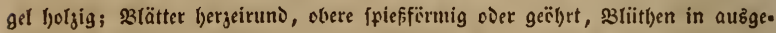
Greiteten IrugDolDen, 3eeren eiförmig. Rlettert $10-12^{\prime}$ bod), 331. violet, jeber 26fd)nitt an Det $\$ 3$ ajis mit sin paar grïnen 5oniggrübd)en. - OFF. stipites

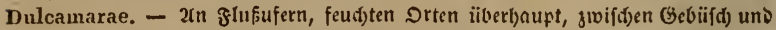
an 3äunen, aud) auf Felfen uno Ed)uttland. Juni-2uguft. b. Durd) Das Gebiet lyäufig.

* 1095. S. tuberosum L. Brakw. t. 523 unذ 587. S3lätter un.

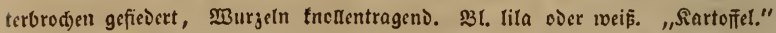

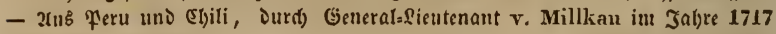
in Cadifen eingefiibrt.

\section{Familie Plantagineac, Flantagincen.}

- 5erbaricnbud) (Plumbagineae) G. LV uno 122. -

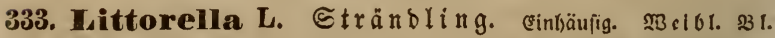
in Der 2 (d) fel Der $\mathbb{B}$ urgelolätter paarig neben Dem männtid)en 23 tütbenid)afte.

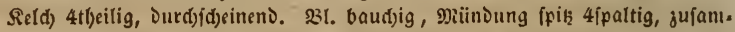
mengejogen. Fiftill nit fel)r langen pfriemtidjen, befaferten Griffel. פR än n.

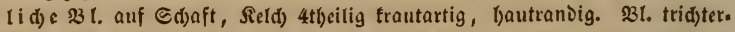
förmig 4fpaltig. Etaubgefäse 4, lang berausftebeno. Sd)laud) 1 famig.

1096. L. lacustris L. SchK. t. 287. Sт. 41 . Rснв, Fl, g. exs 455.

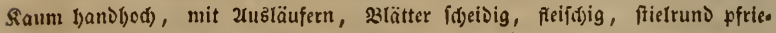
menfpibig, Єdjäfte faft gleid)lang, 1Glütbig. - 2ulf überid)wenmten Sandboden

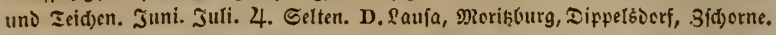
PL. MBannind)en, Bernsiorf, Sieberofe, Gdivielungsfee. A. Groftiilynauer Gee.

334. Plantago L. $\mathfrak{B} e g \mathrm{r} i$. 231 . gmittertia. Seld 4theilig. 33r. häutig vertročneno, präjentirtederförnig, Gaum 4theilig. Ctaubgefäfe

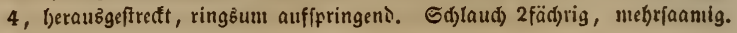

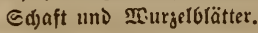

1097? P. Coronopus L. Fl, dan. 272. Rchi, Fl, germ, exsicc. n. 10008. St)aft fielrumb, 8 lätter Diđtlid), fiederfpaltig ooer Doppeltpederfpaltig,

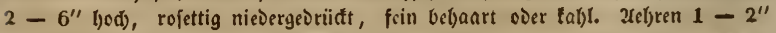

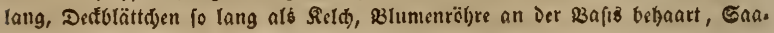


menträger treujfïrmig, Sapfet Darum 4fäđrig, 4faamig. - Eigentliđ Strani:

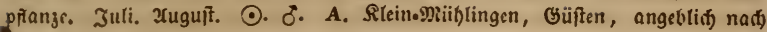
Schwabe.

1098. P. lanceolata L. Hayse Arzngw. V. 15. Sr. 7. Blätter geiftedft langettli(f), fd)wad) gcjäl)nt, 3 - Gnervig, tabl over bebaart; Ed)aft ge. furd)t; 2ebre eiförmig cier eiförmig roaljig; Dedfolätter eiförmig jugefpistt,

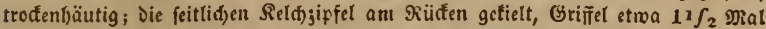

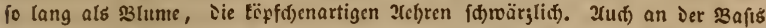
Der salätter rocubaarig: P. lanata Kocr. - b? humifusa Brexr. Cat. d.

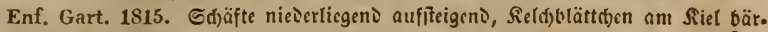
tig, Griffel mebr als Doppelt fo lang als sie slunte, lang befajert. -

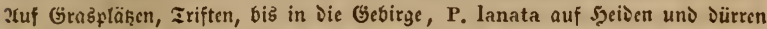

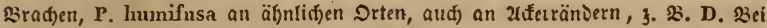
Diaren. Mai - Geptember. 4. Gentein.

1099. P. media L. Haysr Arzneigew. V. 17. Blätter (¿em $\mathfrak{B c}$.

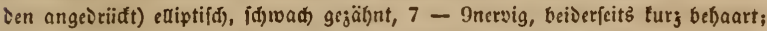

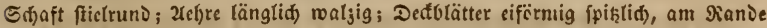

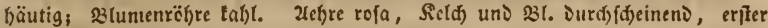
grïnnervig. - 2uf Grašpläken, zriften, Siainen, bis in iie 2ierge. פai atuguft. 4. Gentein.

1100. P. major L. Sснк. t. 24. IArxa Arzneigew. V. 13. Blät.

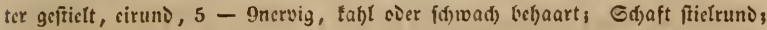

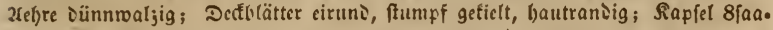

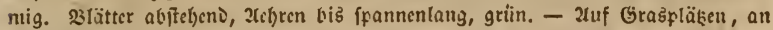
জ̇egen. Juni - Detobet. 4. Gentein.

1101. P. maritima L. Fl. dan. 243. 1634. Rснв, Fl. germ. ex-

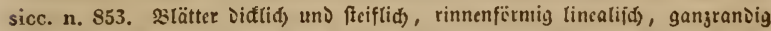

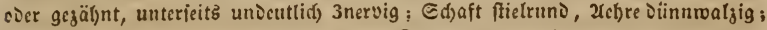

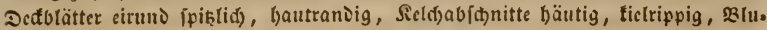
ntentäbre furz bebaart. Spannenl)od), mattgrïn. - 2tuf æBiefen uno Saljbo. Den, vorjiiglids in Der $\Re$ äbe Der Salinen. Juni - Eeptember. 4 . Siemlid felten, aber bäufig. A. Scaul. PS. Barbn: Rulbwerder, Däben nad) Scholler.

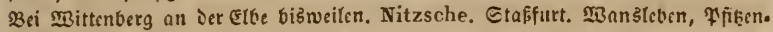
burg, Rodffäot, Dëlau, Dicstau, Sangenbegen. 2rtern. HS. Louifenlyall bei Etotternbeint. SRS. grantenbaujen. Hornuug.

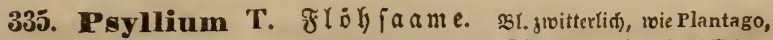
aber (d)laud) in jebem gad) 1faamig, 231. in Rëpfd)en auf 2(d)felblütl)en. fitielen, Etengel nit gegenübetîtélenden silättern.

1102. P. arenarium (Plant. -) IV.K. t. 51. HAxsz Arzneigew. V. 16. Sr. 7. Rснв. Fl. germ, exsicc. n. 255. SBchaart, 23lätter li. nealifd); 2(kלten eiförmig länglid); Die vorierften Sield;ipfel fdief fpatelförmig, ftumpf, Sic bintern lanzettlió) fpik. Spannenbod, bei trodner mitterung aud? nur hanthech. 2tud son Diefer xrt: Orp. Sem. Psyllii. - 2tuf Eandplähen. 


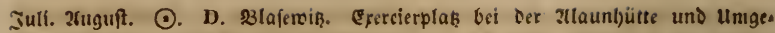

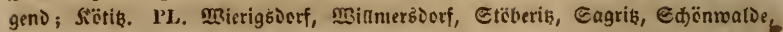
Grefraiden, Rraušnict, Dobrilugt, ginftermaloe, Raundorf, Rübben. A. Fröba, Qübs. PS. Rlonplaifit bel Barby. Mittenberg.

3366. Armeria W. (S) ra s nelfe. Süpfden mit Şülle, vor Dem 2ufoliiben in siner Sdbeide, welde Dann zurüdid)lägt. Blütbenbèen fłrel.

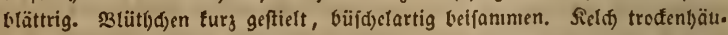
tig 5 äl)nig, 2 l. tief 5 tbeilig, (faft 5 blättrig). 5 etaubgefäßs. Frudttnoten

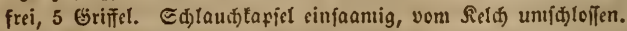

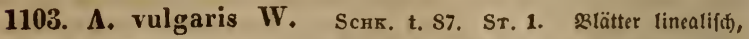

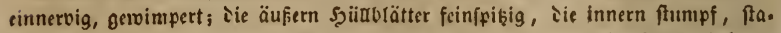

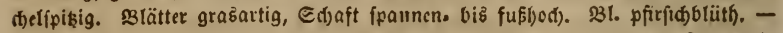
Juf Rainen, Iriften, $\mathfrak{B}$ iejen, bis in bie Berge. Mlai - Eeptember. 4. Eefbr

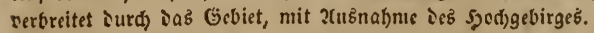

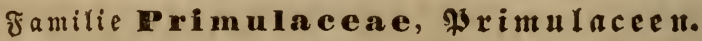

- Szerbarienbud) G. LVI unD 124. -

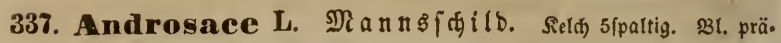
fentirtederfïrnig, હejlund jufamntengejegen, mit 5 ven unten eingedrüđten Szäđern, Caum 5lappig. Siapfel bis unter Die Mitte 5lappig, 5 - vieliaa. mig, Eaamen ectig. - Ed)aft mit Dolise.

1104. A, elongata L. Schx. t. 33. Sal)l, siätter lanjettlid) ges

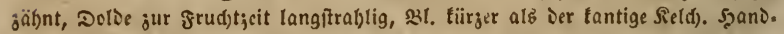

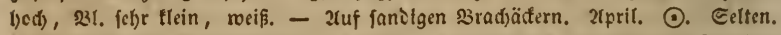

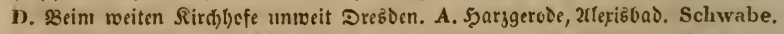

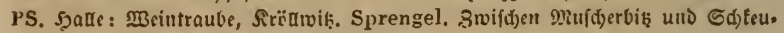
Dik. Klett. Erfurt. Sonder. Buddensieg,

1105. A. septentrionalis L. Fl, dan. 7. 'Bot. Mag. 2021. 33ät.

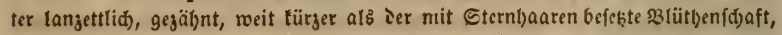

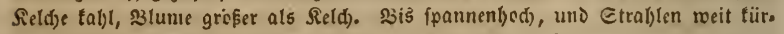

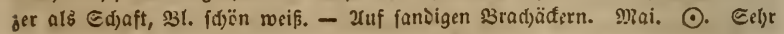
felten. D. Brbijhen Dresien, Dem weiten Sirchlyofe und Striefent truppiveife. - Gię̧lübel, Sieb(tadt, nad) Fic. Fl. Dresd.

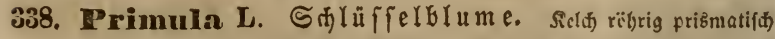
(oDer freifslförnig gleđig). 23t. präfentirtıđerförmig, Gaun 5lappig, \&appen

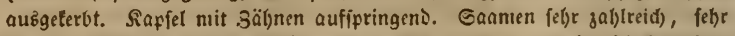
Elein. - Mie bei Den Asperifoliaceae find aud bier entweier Die Staubge.

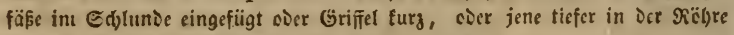
und Der Grifīel berauşftetyend. Fl. germ. p. 401.

1106. P, elatior L. Haysis Arzngw. III, 35. 23lätter eirund, un.

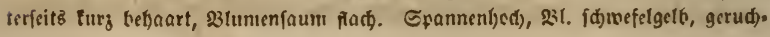




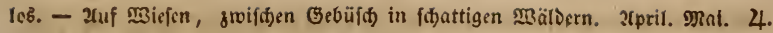
Durd Das Gebiet nidgt jetten, meift bäufig; fdecint aber in Der giederlaufts uno Dem Dberlaujtier Siebcrlande ju feljlen.

1107. P, veris L. Schk. t. 33. Hayxe Arzngw. III. 34. 23lätter eiförm!g, unterfeits sïnn fammtfilgig, silumenfaum ulyrglabartig eingebegen. Neift niebriget, 31. bod)gelb, nit orangegelben \$unften, wel)trie(t)ent. - OFF, Fl.

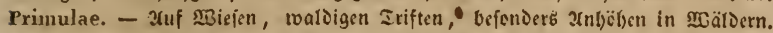
2(pril. Drai. 4. Durd) Das (Gebiet meift läufig; fd)eint aber in Der fäd)îfod)en oberlnufis böd)ft felten (einmal an fteilen ?lbl)ange Der Mandau bei Şörnils ge. funten! Kölbing.), in Der preufijdyen Dberlaupis auf Der Sandśtrene und Dem

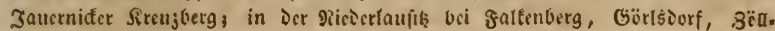
แteršouf.

1108. P. acaulis Jcę. Sт, 14. Fl. dan, 194. salätter gełältht, run. zelig, Dolde f(j)aftles, szlumenfaum flad). Sicle Mittelfaläge mit sorigen. Utr.

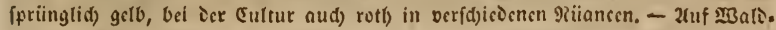
miefen. פiäry. 2tpril. 4. Eelbr felten. PS. Surgliebennu, Slcinliebenau fparjam. Sprengel. Јd) fab fcume Eximplare von Da.

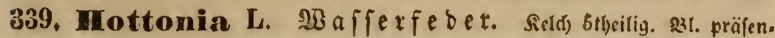
tirtenterfirmig, Enumtappetl ausgctertst. giarbe tepffïrntig. Siafict tuglig, nit Sälynen nufipringeno.

1109. H. palustris L. Sснк, t. 35. sitätter untergetaudt, tamm.

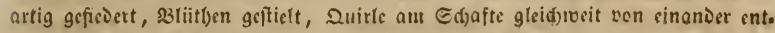

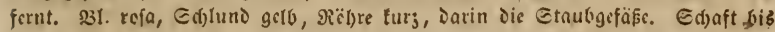

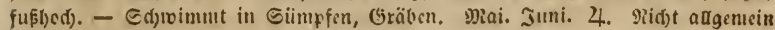

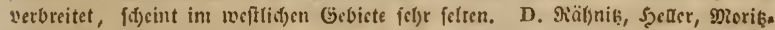

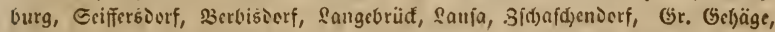

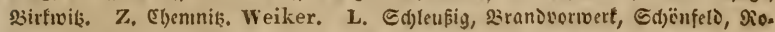

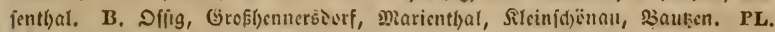

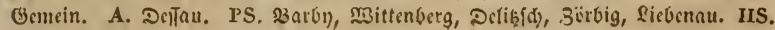
Silbig bci Eifenberg. Zenker.

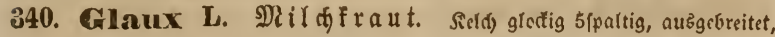

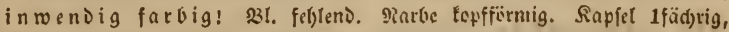
5tlappig, Eaamenträger fuglid), Eaamen cớig, friafterfteinartig gevrängt.

1110. G. maritima L. Scнr, t. $60 ., \mathrm{Fl}$, dan, 548, Fl, germ, ex-

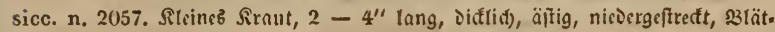

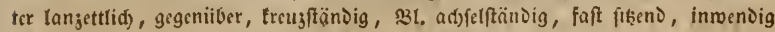

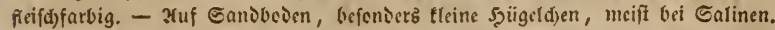

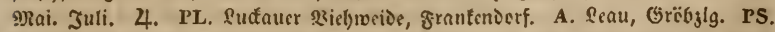

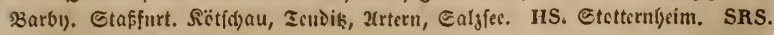
Srantenl)aufen. Hornung.

341. Trientalis L. Cif benft $\mathfrak{a} \mathfrak{h} \mathfrak{l}$. Seldi) und 231. raoför. mig 7 thjeilig. Stautgefäfe 7 , aušgebrcitet. Sapfel 1 füdjrig, zetreifeno, Saa. menträger fuglig grubig, Saanten pâfterfteinattig gevrängt. 
1111. T. europaea L. Scнк. t. 103. St. 17. Rснв, Fl. germ. exsicc. n. 1442. Etenget Dünn, $4-6^{\prime \prime}$ hod, tabl, unten ein oder Dab andre

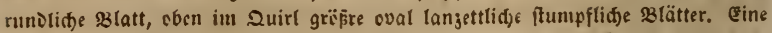
oder 2 aufrefft langgeftielte \$Blüt)en, 31. Fernfërmig, roeiß, Rapfel erbjengroßs. - In Saubrärdorn in Dem Gebirge, in lofter Sauberde, zmifhen Eteinen. MRai - Juli. 4. Etellenmeife Durd) Dab Gebiet, namentlid) int Grbirge. D. Bofel,

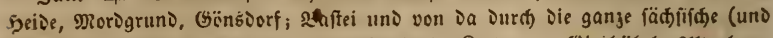

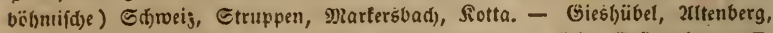

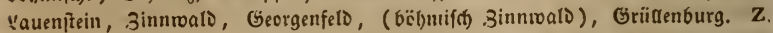
Bocfau, Eiben|tod, Johanngeorgenitait, Doermiefenthal, Seilberg, Znnaberg, 3̈̈b•

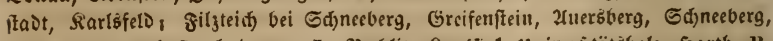

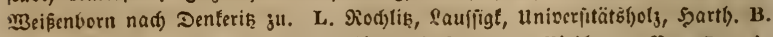

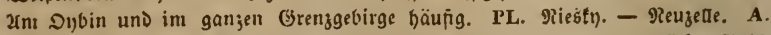

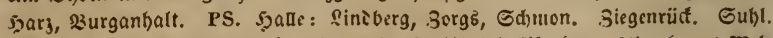

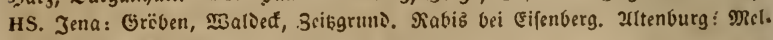

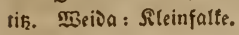

342. Centunculus L. Rle $i \mathfrak{n} \mathfrak{l}$ ing. Sieloh 4theilig trautar.

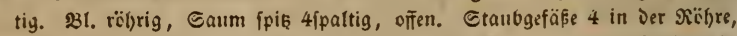
abjetheno, herauzragent. Sapfel fuglid) zugepiłt, ringsum aufipringeno, vicliaanig.

1112. C. minimus L. Sснк. t. 24. Fl, dan. 176. ST. 30. Rснв

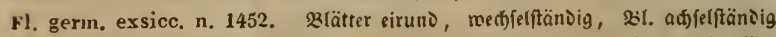

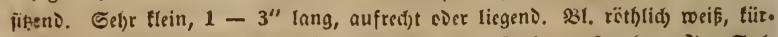
jer als Reld). - 2uf Siradjä̈tern, an Megen. Julti - Detober. 4. Ste\%. lenweife, namentlit) um Seipzig. D. Fonifau, Sindenau, Siranern, Szrodivik,

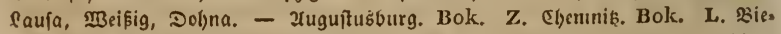

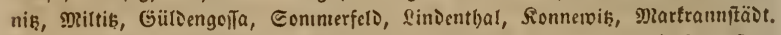

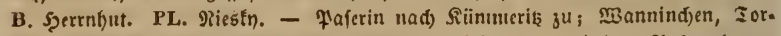

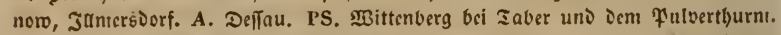
Sodersteben. Biegenriit. Drtrano. HS. Jena: jwijden ier nenen Edjente uno Paasborf. Roburg. SRS. 2trnitait.

343. Jirasekia Schmot. Tirafetic. Sield trautartig 5. theilig. BI. tridttrfürmig, Gaum 5ipaltig, Sappen gefaltet, in Der Rnospe jufammengedref)t. Etaulogefäße 5, aufred)t, jottig. Grifiel bleibend. Siapfel tuglig, ringšum auffpringend, vielfaamig.

1113. J. tenulla (Anagall. -) L. Fl. dan, 1085. Rснв. Fl,

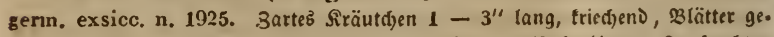
ftielt, runilid, fpislid), 31 . adfelftändig, geftielt, pieifdfarbig. - $\mathfrak{Z}$ n feudten

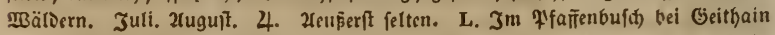

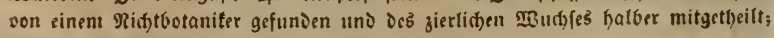
cann aber mef)rmals vergeblid) geind)t. B. Seidel.

344. Anagallis L. Ga 
331. rabförmig, aus̊gebteitet 5lappig. Etallogefäfe 5, aufred)t jottig. Girif̄el abfallend. Siapicl tuglig, ringšun auffpringend, vieliaauig.

1114. A. arvensis L. Hayse Arzngw. 11. 45. Sснх. t. 36. ST. 1.

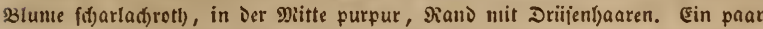
Soll bod) und aufredt, oder nad) feudfter Mitterung üppiger, verzweigt und nie.

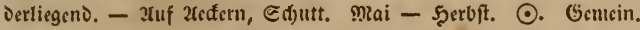

1115. A. coerulea Alc. Hayne Arzneigew. II. 46. Rсhв, FI.

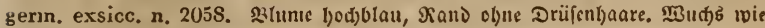
vorige, Dod) öfter aufred)t, nur int ïppigften Suftande liegeno. - 2(uf 2e(tern, aud) auf Sialtboden. Juli. 2luguft. $\odot$. In इhüringen und 2(nl)alt oft büufig uno nidjt felten, fonjt nur jelten und cinjeln. D. 9iur bëdjft felten uno einjeln

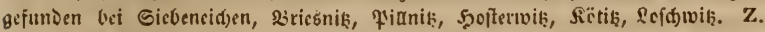

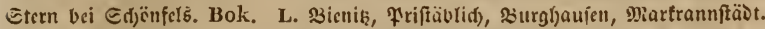
B. Serrnlfut. Schmidt, PL. Gosmar, Riècbect, Reujelle, Bornsiorf. A. Bern.

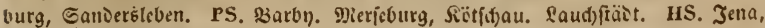
Meintar. SRS. 2urnftait.

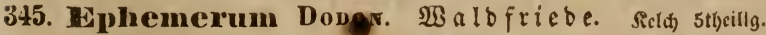
81. radförnig 5ipaltig. Staubgääfe 5, frei, etwas aubeinanderftelyend. Siapicl 2flappig, wie bei Den Gentianeen IIt Serreisung Deb (3) riffels a uffpringend: Saantenträger $z$ u a mu enged rü dt! Saa. Ite $(\ddot{n} n g$ (id), grubig.

1116. E. nemorum (Lysimach. -) L. Fl. dan. 174. Sr. 1.

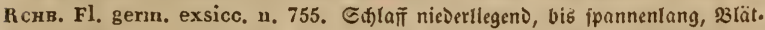

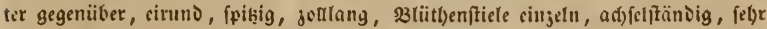

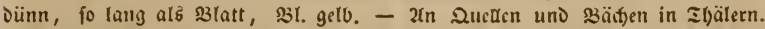
Juni. Juli. 4. Stellenweife Durd) Das Gebiet, in ier 9iieverfaujth felyr felten.

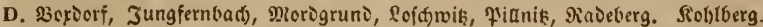

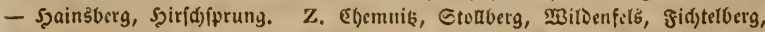
Jehanngeorgenftadt. L. Fenig. - Gnandftin, Fotflik, Grimma, Goljern. B.

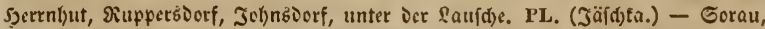
Irietlel. A. Şarjgerode. PS. Sederb̄leben, Şiegctrode. Etciger vei Erfurt. HS.

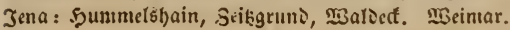

346. Iysimachia L. Ryfimante. Sielit 5theilig. Bl. rao. förmig 5ipaltig. Etauggefäße 5, aufred)t, unten verwadffen! Rapfel

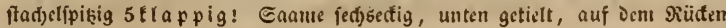
gewöltut.

1117. L. Nummularia L. Schk, t. 36. Hayxe Arzheigw. VIIl.

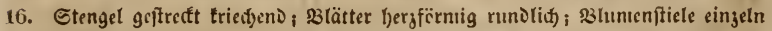
in Den 3 lattwinteln fur\}. Leber fuflang, 31 . grof, gelb, Sapfel fel)r felten rei.

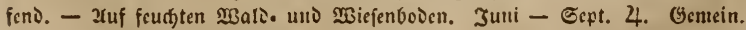

1118. L. vulgaris L. Fl. dan, 689. Haysi Arzngw. II. 59. 2uf.

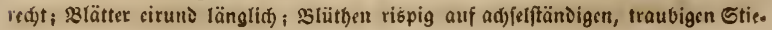




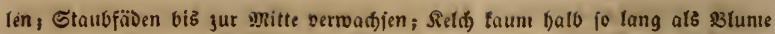
uno fürzer als Sapfel. $2-4^{\prime}$ bod, 31 . bed)gelb. In Eümıfen mit fefr lan. gen گusläufern: L. paludosa Bausa. - In flufufern, Gümpfen, Gräben. Juli - Sept. 4. Gintein.

1119. L. guestfalica WEIHE. Jufrect)t, stätter beftimmt ge=

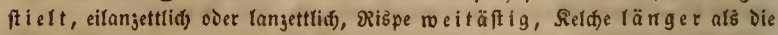

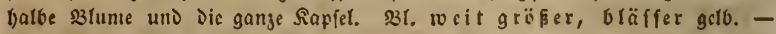

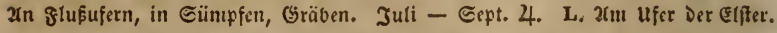

347. Naumburgia Mхch. $\mathfrak{R} u \mathfrak{m b} u \mathfrak{r g}$ ie. Se(d) $5-6$. theilig. 231. ausgebreitet, 5-6thcilig, nit 31vijđ)enzäl)nen. Etaußgefǟe $5-6$, frei, abjefhend. Rarbe berdidt. Sapfel 5tlappig, Eaamenträger tu. gefig nicbergetriït.

1120. N. thyrsiflora (Lysim. - ) L. Fl, dan. 517, 1 biß $2^{\prime}$ bod), 3lätter gegenüber fd)mal lanzettlid), $2-3^{\prime \prime}$ lang, szlütl)en in adjfelftän. Digen Irauben, jahlteid), 31. gelb. - In Eümpfen, Gräben. Juni. Juli. 4. Etellenweife, in weitlid)en Gebiete verf́ftwintent. D. Sídjorna, Miedingen, Dio.

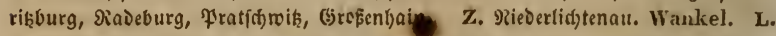

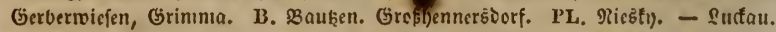

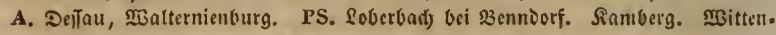
berg: S̈̈bigfau, Tanigfau, Єpedt.

348. Samolus L. \$ُ tnoten angewad)fen. S3l. präfentirtetterfërnig, Caum 5lappig, mit 5 a b. roedielnoen eingevogenen $3 a ̈$ i) nen. Etaubgefüpe 5 in bet giobre. Sapfel nur bałbfrei, 5 jälbnig anfipringend, vieljanmig.

1121. S. Valerandi L. Fl, dan, 198. Sснк, t. 40). 2(ufred)t, 3lät. ter ungefel)rt eiruno fpatelfïrnig, gangrandig, Endtraube ctroas rispig, 3lïtben. ftiele unter Der maitte mit Dectolättd)en. (Etwa fuFl)od), gany (al)l, 231. meif. -

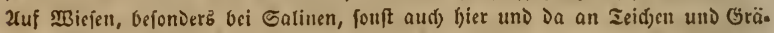
ben. Miai - Juli. 24. Berftreut. L. Dïljig. Petermann. 1'L. Doljiger Sce. Semlik̨er Şeide. A. Grḯjig, Seau. Giiften! Gnadau nad) Dïben ju. PS.

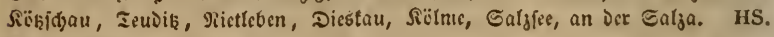
Etotternbeim.

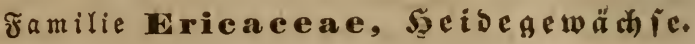

- 5orbarientu(t) ธ. LVI uni 125. -

349. Monotropa L. Dhnblatt. Seld́ $4-5$ tättrig. 3 l.

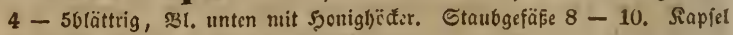
4 - 5tlappig, 4 - 5fä̈frig, Gđjeitewände in Der Mitte Der Jitappen, von Der Mittelflappe abfpringeno, Saamenteiften aufifeigeno, vielfaamig, Eaa.

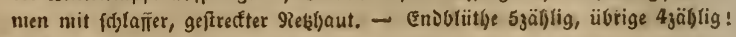

1122. M. glabra BrNh, Rснв. pl, crit. V. ic. 675. Sснк. t. 166. 
ST. t. 13. Gtanbfäien tabl, Rapfel faift tuglig. $3-6^{\prime \prime}$ botb, (einem dünnen

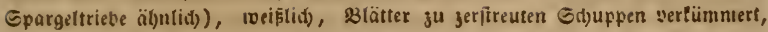
Iraube überbängent. Gstrodnet braun. - Ed)uarekeno auf Budbenivurgeln. Juni. Juti. 4. Gel)r jelten. PL. Gorau. Rabenhorst. PS. Siegetrede. Wallroth. Erfurt. HS. Jena: \$ođerకrodact Jొorft. Zenker.

1123. M. Hypopitys L. Rснв. pl. crit. V. ic. 674. Fl. dan.

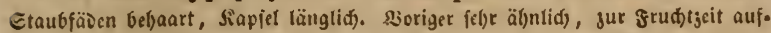
redt, bis fpannentang. 3on Orobauche leid)t surd) Die regelmä̈jige, mebrblätt.

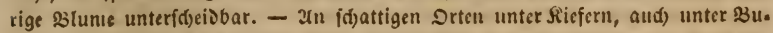
d)en. Juni. Jull. 4. Etedenweije Durdy Das Gebiet; oft truppiveife. D. Tonitau,

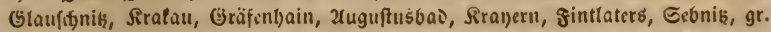
Minterberg. Slafewiks. - Ełaranit. Z. Jobanngecrgenftait, Eibenftod, Gtouberg.

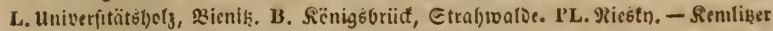

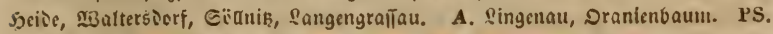

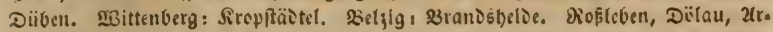
tern, Burgivenden. HS. Eifenberg. Jena. \&aue bei 2lttenburg. SRS. Zrmptait.

350. Pyrola L. Birnf $\mathfrak{r}$ a ut. Seld 5/paltig ober 5theilig, $\mathfrak{B} 1$.

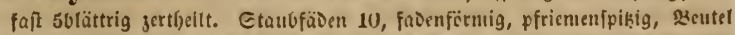
gelo, unten 2ljërnig, an Der Epișe mit tëd)ern aufipringento. Girifel aus. geftredt. Siapfel 5 fäd)rig, unten aufipringens. Caante gal)lreid), mit f(blaf.

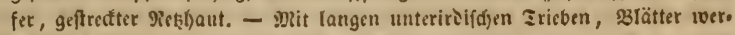
ien lederartig.

a. Moneses Salib. Mioozauge. Gtengel sinblïthig.

1124. P. uniflora L. Sснк. t. 119. Fl. dan. S, Fl, germ. exsicc. n. 1699. Seld 5tl)eilig, B1. ganz oficn. 2-4" 1)od), Slätter unten,

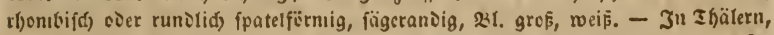

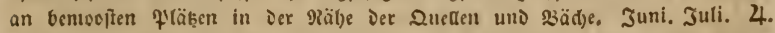

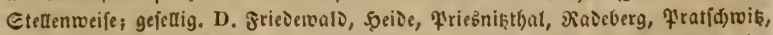

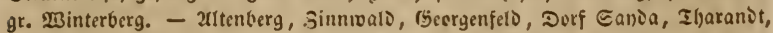

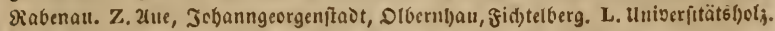

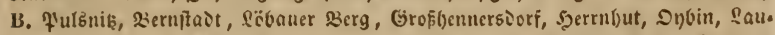
f(t)e, Grenggibirge. (Gd)ludtenau). PL. 2trnsiorf. - Ecraucr ŞciDe, Rottbus,

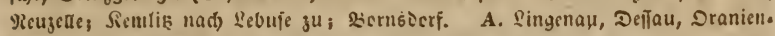

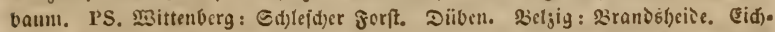

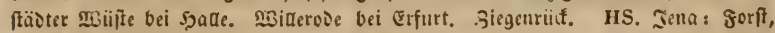

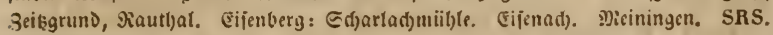
હdrarjourg.

b. Iyrola: Etengel traubenbliitlig.

1125. P. secunda L. Fl. dan, 41)2. Sr. 13. Eraube cinfeitšrecn.

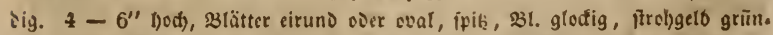

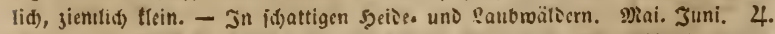
Etedenroeife, meijt nid)t felten. D. Gräfenhain, Glauf(t)niß, હd)enthübel, ssicbla,

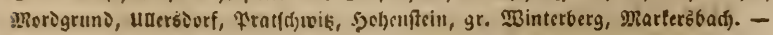


Berggieşübel, Ibaranit, Simntvalt, 2ttenberg. Z. Jat ganjen Dbergebirge,

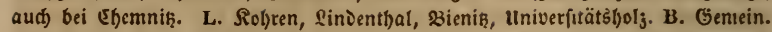
PL. Deßgleiden. A. Singenau. PS. Mittenberg: Rüibnberg; Düben; Brands.

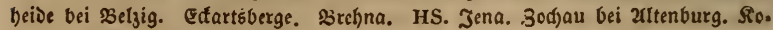
burg. Meida. SRS. Piubolftadt, Gdiala.

1126. P. rosea S.r. Rad. diss, t. II. minor. Fl, dan. 55. Fl. germ. exsicc. n. 461 . Sild) 5 fpaltig, 33. gloffig fuglid, fo lang alb Der ge. rade Grifiel. Blätter grof, oval runolid, geterbt, 231. großj, roja iiberlaufen,

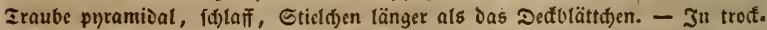
nen Saub. uno giadclwäldern trupprocije. Mai. Juni. 4. Etellenneife, in

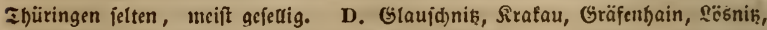

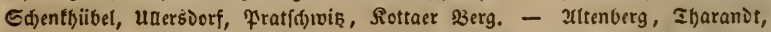
Grauenftein. Z. Faft allenthalben. L. Sol)ren, Seuba, SBienis, Sindenthal, uni.

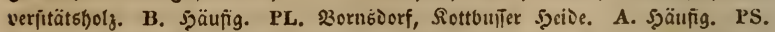

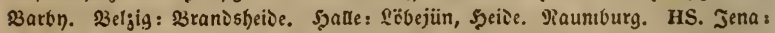

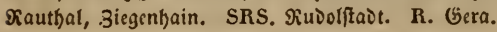

1127. P. minor L. Rad. diss. t. I. St. 13 (aujer Fig. E.) HAYNE Arzneigew. IV. 230. Seld) 5fpaltig, 32. glođtig offen, Grifiel eingejdiloîen, Zraube Didjtralgig. In allen Iheilen fleiner, Blumenblätter an Der Epişe $\Delta i$ d $t$ zufanmengejogen, $\Delta$ ïnner uno fpişer, Seldjabid)nitte tiefer ge.

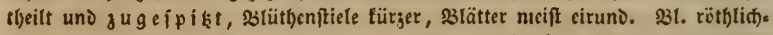

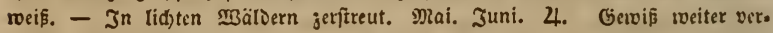

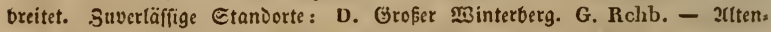
berg. Mrafau. G. Rchb. PS. Ednnieicfero, Midjtsbaujen. Metsch.

1128. P. rotundifolia L. Schr. t. 119. Bl. u. Grud)t. Hays Arzngw. IV. 21. Sield 5theilig, 3lume of̃en, Etaubgefäfe und Grifīel a bge. bogen a uffiteigend. Epannen. bis fuftod), B1. oval rundtid), feidt geterbt, Єdaft mit $5-7$ Eduppen, Davon 3 unten genälett, Iraube viclblittjig, Etiel.

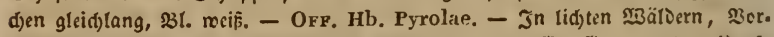

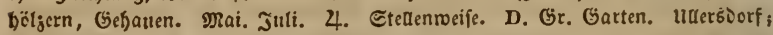

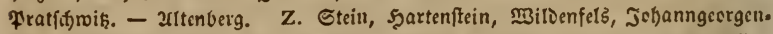

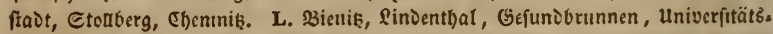

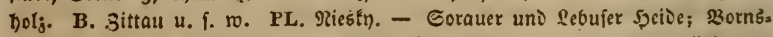
Dorf, Gallen. A. Dranienbaum, গRedlik, Singenau. PS. Şalle: \$3urgliebenau. Eisteben: Şünenburg, Bifdjofsrode. Erfurt: Eteigerwalo. HS. Jena. SRS. Ruoolfait.

1129. P. media Sw. Rad. diss, t. III. Rche, Fl, gerin, exsicc. n. 1871. Reld 5(paltig, sil. glodig fuglig, Girifel berausragend, berab.

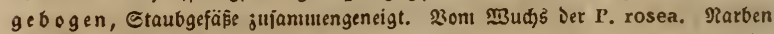

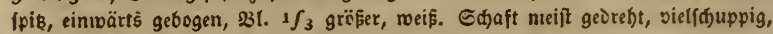

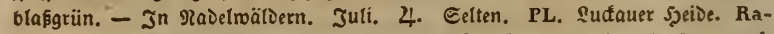
benhorst. A. Bictorsib̈be, Dranienbaum. Schwabe. PS. Foud). Sprengel. Eufl. Metsch. HS. Injelsberg. Nolte. Metsch. Grub. Metsch.

1130. P. chlorantha Sw. Fl. dan. 1693 (media). Hayse Arz- 
neigew, IV. 22. Rсив. Fl. gerin, exsicc. n. 1872. Relth Sipaltig, Bluue gleatig offen, $g r$ ï $n$ ! Griffel $11 \int_{2}$ Dial fo lang als 3lunte, nebft ien Etaub. gefäfen aufĩteigens, zraube wenig $(3-8)$ blütbig, gleid)mäpig. Sileiner, $4-6^{\prime \prime}$

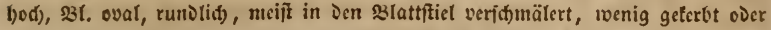

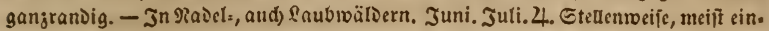

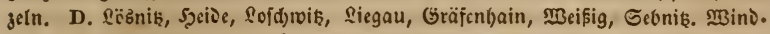
berg. Z ? ßoftall 1797. Bok, auf längit bebauten Şiigel. B. Seritreut. Kilbg. PL. Rentliķer, Erauer Şeide, Reujelle, Guben. A. DelTau, Bobbau, Dranien.

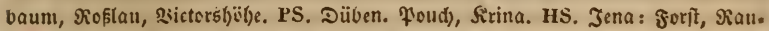

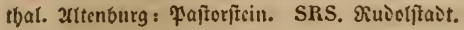

351. Chimophila Pesch. 23 intergrün. Setd) und 21 . wie Pyrola. Etaubfüden in Der Dritte breit, Seutel siclet. Grifel fellt, Tarbe eingefentt. Siapfel an Der Epiķe aufipringent. Slätter quirlītänis, 21. îfueinioldig.

1131. P. umbellata L. Fl. dan. 1336. Rснв. Fl. gerın. exsicc.

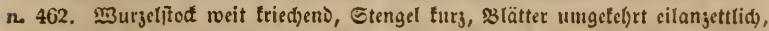
leverartig, Duntelgrïn, 3lütl)enträger $2-4^{\prime \prime}$, Delocutranbe $2-86$ lütbig,, 31 . cfen, roja. - OfF. Hb. Pyrolae umbellatae. - Jn Berg. und Syeidewäloern truppweife, jwifden Şeide und tleinen Gebüfd). Juni. Juli. 4. Etedentweife,

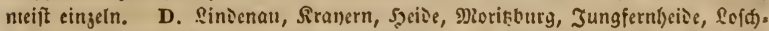

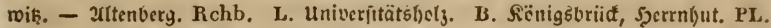

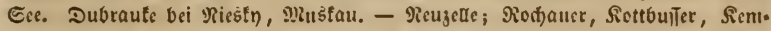

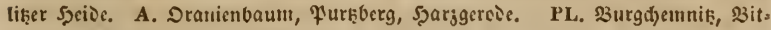

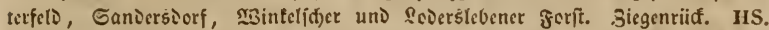

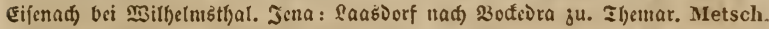

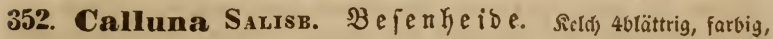
freusförmig Deffblättrig. 3lunie glodtig 4ipaltig, sertrofinens, Ctaub.

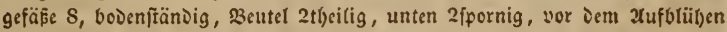

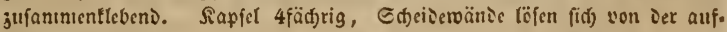
ipringenden $\Re$ att).

1132. C. vulgaris Salisb. Hayse Arzneigew. IV. 17. (Erica - L.) Schк. t. 107. ST. 1. 2fufiteigender, tleiner Straud), $1-3^{\prime}$ bod), Slätter taun 1 Sinie lang, gegenüber, cid)t jiegelartig, unten ffeilförmig, nabel. artig, oreifcitig, bart. 23 . in einjeitigen EnDtranben, ffirjidjb(üt), feltner roeif. - b. pubens, fein behaart. Orf. Hb. Ericae valgaris. - Uebergieft fandige Etrecten, bcionoers in Märbern bis in Die Gibirge, b. in Micorboicn. Juli Ecpt:mber. b. Ëentcin.

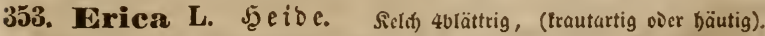
3 lume mit 4ipaltigem Saum, sertrodneni. Staubgefäfe 8 , bodenfä̈ñig. Sapfel 4llappig, Edjeiderwänie in ier Mitte Der Slappen.

1133. E. Tetralix L. Fl. dan. 81. Gurmp. t. 46. Fl, germ. exsicc. n. 1455. Etaubbeutel geipernt, \$lume lang frugfërnig, 3lätter зи $3-$

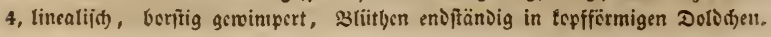




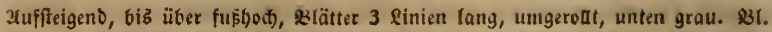
4 Sinien lang, roja, feltner weis̄, Beutel fporen. lammartig, Rapfel feidenartig

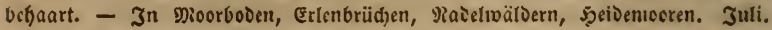

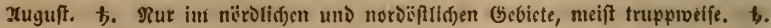
D. Sinz, Medipanda. Auerswa]d. G. Rchb. [angeblid) aud) bei Rratau]. PL.

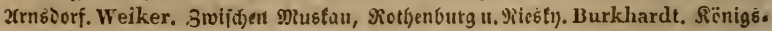

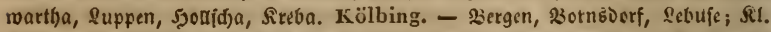

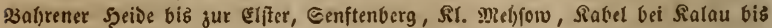
Solpin, Epremberg, Gaften, Beesiau. A. Deflau in Der Bï̈fter Zorfftecherci, Malternienburg. Schwabe. Srieicrifenberg. Scholler. Swifden शiagul)n und Deffau. Sprengel. PS. Jüterbogf. Rabenhorst. MBittenberg: TiuDerżorf,

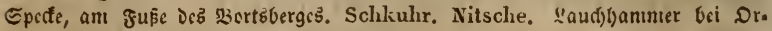
trano. Dittmarsch, G. Rclib. Anerswald.

1134. E. carnea Scop. Jace, austr. t. 32. Gutmp. t. 47. Rснв.

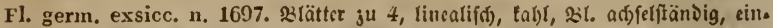

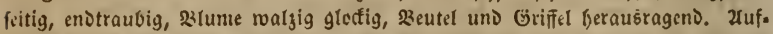

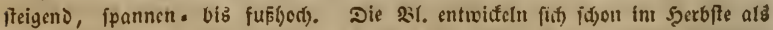

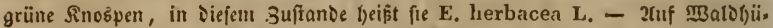

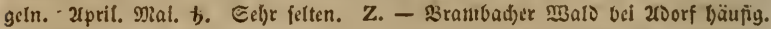
Biener.

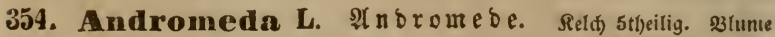

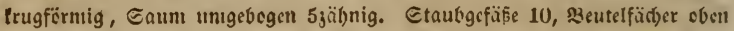

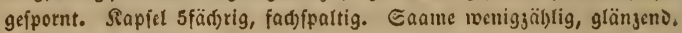

1135. A. polifolia L. Schk. t. 118. Harxr Arzneigew. III. 22. Gurmp. t. 55. Rснв. Fl. germ, exsicc. n. 1698. 23lätter leverartig, lineal

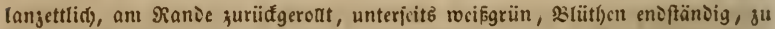
3 - 6 beijammen, geftielt, niffeno, 23l. eifürmig, weiflid), Єaum roja. 2(uf. ftcigend, ctwa fufljod). - In Moräften. Xpril. Mai. b. D. Dttendorf. Dehne. 1839. L. Rchb. fil. G. Rchb. - (33̈̈bmif( 3innwalo 1841. Papperitz. G.

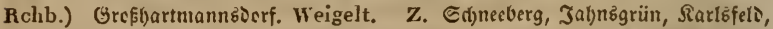

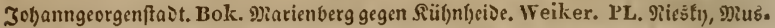

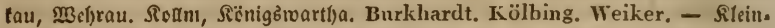

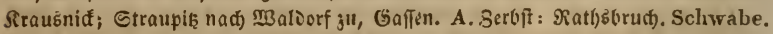

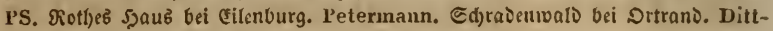
inarscl. Auerswald. G. Rchb. HS. Erinectopf.

335. Aretostaphylos Adans, Båa $\mathfrak{i} \mathfrak{n} \mathfrak{t} \mathfrak{a} \mathfrak{u}$ be. Sield 5 . theilig. 231. Erugförmig, હaum jurüfgebogen 5jäl)nig. Etaubgefäfe 10, Beutelfänjer gejpornt. Szeete 5füdjrig. 5 Gaamen an jer Mittclïütle.

1136. A. officinalis W. GR. 'Schк, t. 118. ST, 6. Gursp. t. 37. Hayxz Arzneigew. IV. 20. Rснв. Fl. germ. exsicc. n. 1016. Blättck länglid) ungefefort eiruno, ganjrandig, netiabcrig. शieocrgeffredt bis über fuf. lang, 3lätter benen bon Vacc. vitis Idaea äbnlid,), aver länglidjer, unten ni(d)t punttirt, iung ant Rande fein bebnart, SBtïtben $3-8$ an Jen Epişen Der

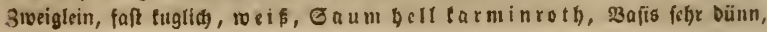


faft Durdffibelneno, 3eutel purpur, an iex Epikze gefpornt. Beere erbfengroß̄,

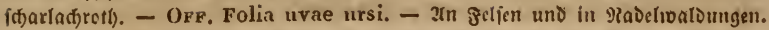

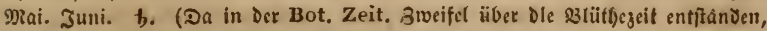
bemerte id), Daf in Diefem Jabre die Pranje in biefiger Gegend ant 5 . Mai blïbte. Snospen zeigen fid) fit)on im şerbfte.) Etellenweife im ëftlidsen uno

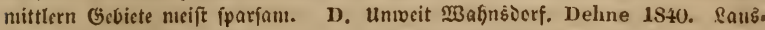

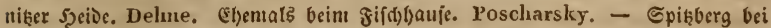
Delfa nad) Ficinus. PL. Pliesfy. Burkhardt. Kölbing. - Nod)aucr 5̨eide,

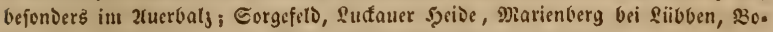

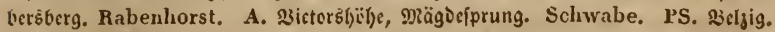
Rabenhorst.

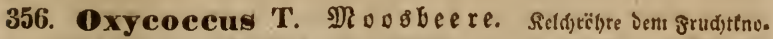
ten angewadjen, Eaum 4 fpaltig. S3lume aušgebreitet 4theilig. Etaubges

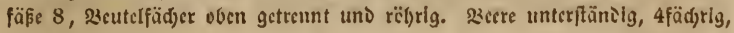
viclianimig.

1137. 0. palustris Pers. (Vaccin, - L.) Schk, t. 107. Harnk Arzneigew, IV, 18. Rсив, Fl, germ, exsicc, n, 730). Etengel trledinn,

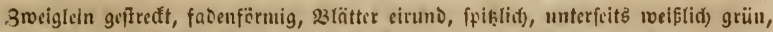

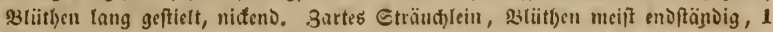
- 3, Eticle in Der Mitte mit Deffulättden, \$31. refa, Becre hod)roth). - In Mworbriid)en, auf Den ₹orfntoofi. Mai. Juni. b. Etellenweife, namentlid) im

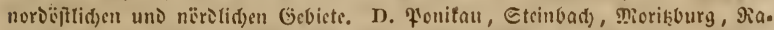

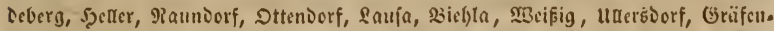
hain. - 2lltenberg, Sinnwalo, Gcorgenfelt, Griiltenburg. Z. (Gotteşgabe), MRa.

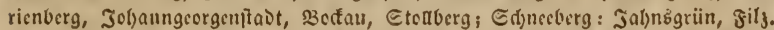

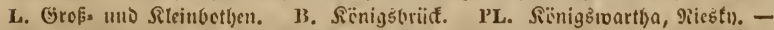
WBannindjen, Dubener Eic, Dolgener Eec binter Dem Miatienberge, Guben, Sott. Gus, Epremberg u. f. w. A. Exfierau, Z̈̈rten, 3erbit. PS. Mittenberg: Do.

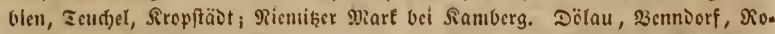
thes Şaus bei Düben. Gdjradenwato, befonders bei Dolīileibe. HS. Scua:

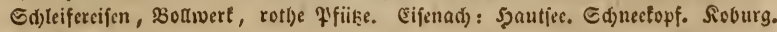
R. Gera.

\section{Vaceinium L. Şefbelbeere, \$reifelbeere.} Seld)rïbre Dem frudtetneten angewaad) fen, Saum $4-5$ jälynig. SI. freu;.

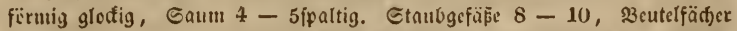
oben getrenut, Ginten gefporut. Secre unterfändig, $4-5$ fäd)rig, vielfaamig.

1138. V. uliginosum L. Fl. dan, 231. Gurmp, t. 43. ST. 12. Rснв, Fl, germ. exsicc, n, 731. Blätter bäutlg, umgetef)tt eirund, ganzean.

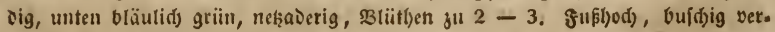

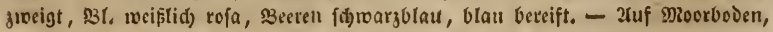

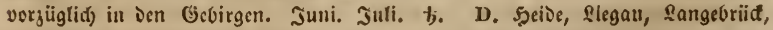
Morikburg, Dttendorf, sausniţer 5zeiDe. - zettenberg, Georgenfeld, 3innwald,

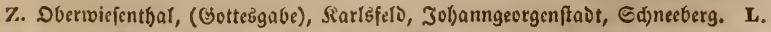

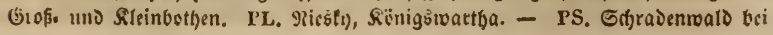




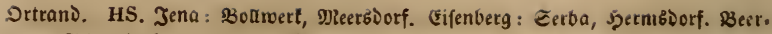
virg, Єdyneetopf, Siennfteig. Roburg: Rettcnbach).

1139. V. Vitis idaea L. HAYxe Arzneigew. 1V. 19. Guimp. t. 43. SBätter lèerartig, umgetelgrt eiruno, unten weis̈lid, ountel punttirt? Blütben in nidenien Enitrauben, Blumen glofenförnig, \&cutel ungefpornt. Beere erbfengrof̂, f(f)arlađjroth). Var. acutifolia, \$3lätter fein jugefpişt. - Ueber. jieft nafte Sandiftreden in Şeidewäldern, an felien. Mai. Juni. b. Un Şalle und Selzig febr felten; fenft robl überall gemein. Var. acutif. D. Ueber Lauja. G. Reichenbach.

1140. V. Myrtillus L. Schk. t. 107. \&. Haxxe Arzneigw. 1I. 7. Gurmp. t. 41. Slätter frautartig, eiruno, fägcrandig, fpißig, Stenget tantig,

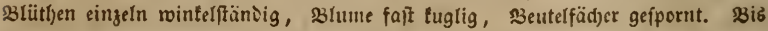

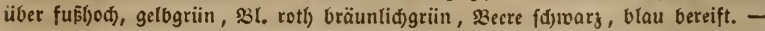
Orf. baccae myrtilli. - Uebergiebt \$3alojtreden, auf Şeibeboden. MRai. Juni. b. Gentcin.

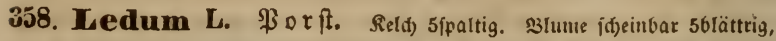
aubgebreitet. Etaubgefäfe 5 - 10. Beutel an Der Epis̨e mit fdjiefen \&̈̈. dern, feitliđ) nuffpringend, ungefpornt. Sapiel 5 fädtrig, bängeno! Silap. pen an ১er 3 afiz abfpringend. Gaamen feilfaubäbnlidg. - sil. in Dolbigen Enobüfdjeln.

1141. L. palustre L. Schк, t. 117. HaYse Arzneigew. HI. 21.

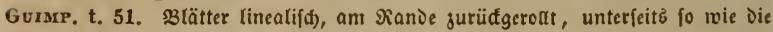
iungen 3roeige rofenroth filjig. Straud) von $2-3^{\prime}$ Şäbe, bufdig verjweigt, 33. reif. - Var. latifolia. 23(ätter jeb)r breit, Diđ)ter befilgt. - OrF. Hb. Ledi

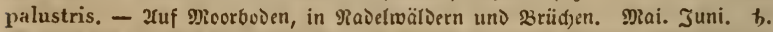
Etcllenweife, namentliđ) nërolid) und norbëitlid); im weftliđen Gebiete ver. fdrwindeno. D. Laufa. Bucher. Dttenoorf. Dehne. Glaufdniľ. G. Rchb. Ponifau. G. Rchb. Awd. M̉el)len. Hornberger. 2mifelgruno. G. Rchb. Ppptz. Minterberge angeblid). (Prebijđthor. G. Rchb.) Z. Jobanngeorgenftadt. Brun-

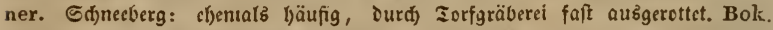
Scheidhauer. B. Rënigsbrïđ. Schmalz. PL. Rođm, Bođersiorf. Weiker.

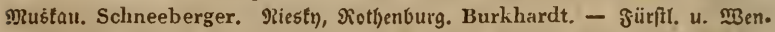

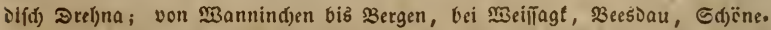

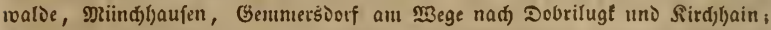
Nod)auer Sceide; Marienberg bei Süboen nađ) Dent Dolgener Gee zu, Galien, Gubcn. Rabenhorst. A. Dranienbaun, Serbft, \undeluft. Schwabe. PS.

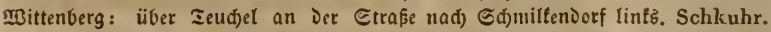
graueniorf bei Jüterbogt nad) Ireucnbrieşen zu. Diepmannbiorf bei sBelgig. Rabenhorst. Shalle: Foud), Irina, Edjwemfal. Sprengel. Sd)radenivalo bei Ortrano. Dittmarsch. G. Rchb. HS. Sdjeifereifen bei Jena. Zenker. Mit. telpöanił̧ nađ) GangelDorf ju. Adler. R. Gera angeblid). Var. Iatifolia. PS. Gdjradentuals bei Drtrano. G. Rchb. 


\section{Familie Asclepiadene, Afflepiadecu.}

- Sperbarienbud) 5. LVII und 128. -

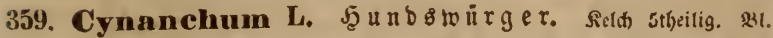

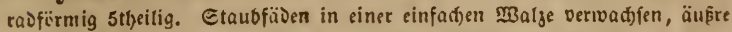
allogefditten, 5lappig gettheilt, aufred)t, eingebogen. Baalgfapfeln glatt. Saanten jeidenijtoprig.

1142. C. Vincetonium Pers. Schr. t. 55. Ilaynr Arzneigew.

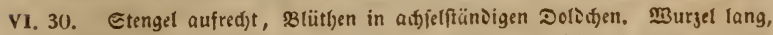
aud) büfdelfaferig, Etengel $2-3^{\prime}$ bod, Blätter gegenüber, hergeiruno, zugeo

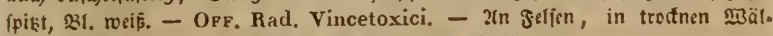
Dern. Diai. Juni. 4. Gentein, in Erjgebirge biß Etcin.

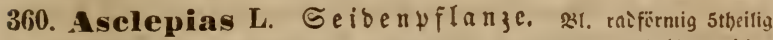
3urïifgefdlagen. Etaubfäben 5 , tronenfürmig verwadffen, nad) binten jeber

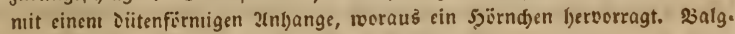
tapfel glatt oder fpisivarjig, Gaamen feioenfitopfig.

-1143. A. syriaca L. B Lakw. t. 321. Sснк. t. 56. (B̈lütbe.) Dict. sc. nat, cals. 9. Bzlätter tur geftielt, oval, unten firlig, Doroen febr viel. blütlig, überlyängeno, 23 lgtapieln aufred)t fpik roargig. Usber mannshad, mit

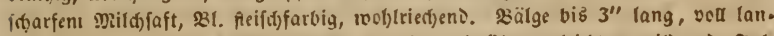
ger Ecibe. - ?tus Entien, läufig sultisirt und überall teidtt dermitoerno. Juth - Eeptember. 4.

\section{Familie Contortae, Drebblüthler.}

\section{- Sectbaricnoud) C. LVIII und 132. -}

361. Menyanthes $L$. Sotte $\mathbb{b} \mathfrak{l}$ me. Reld 5ipaltig. $\mathfrak{B}$. tricfterfïrmig, inp̧endig jottig befajert, Eaum 5theilig offen. Sapfer 1fädt). rig, 2tlappig, Saanıenträger längs in Der Mitte Der Rlappen.

1144. M. trifoliata L. Schr, t. 35. St. S. Hayne Arzngew. 1II. 14. Etengel geglievert, tricd)eno, Blattiticle fiseisig, oben runo, orei ovale

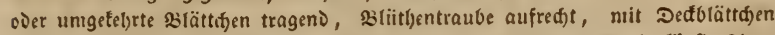
vielbliithig, 23(ume weiflid) Neifdffarbig, seutel mennigroth), Rarbe töpfig 2lap. pig, Sapfel erbengrós. - Ofp. Hb. Trifolii fibrini. - Juf Eunıfwiefen, in Micräften. Mai. Juni. 4. Etenenweife Durd) Daß Gebiet; in weftliden uno

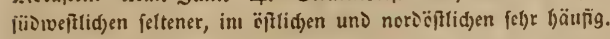

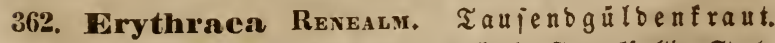

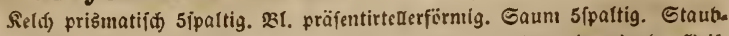

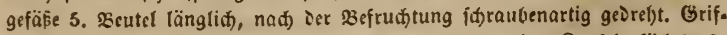

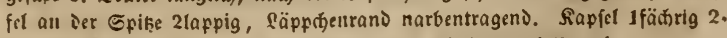
Hlappig, Gaamentrïger an ien eingebogenen Kändern, vielfaanig. 
1145. E. linariaefolia Pers. Rers, pl, crit. 1. ic. 185 - 189. Fl. gerın, exsice. n. 26ł. Stengel jufammengèriictt, Ranten (d)ärffliđ), siät.

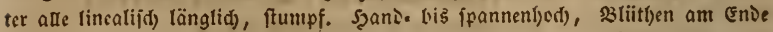

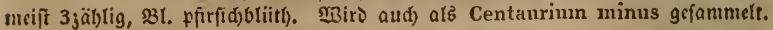

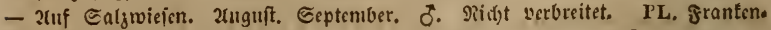

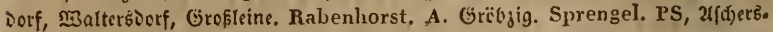

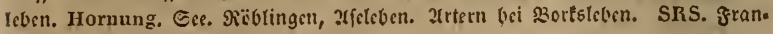
fentiaufen angebfid).

1146. E. pulchella Fries. Hayxz Arzneigew. 1. 30. Rенв,

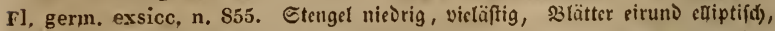

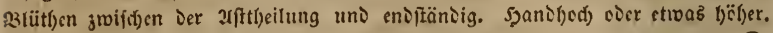

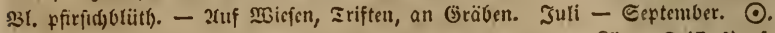

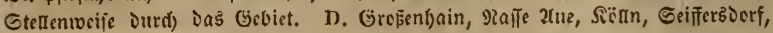

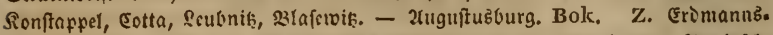

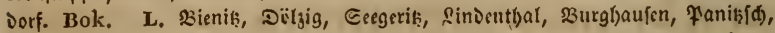

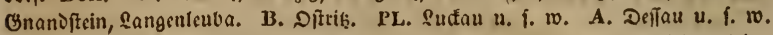

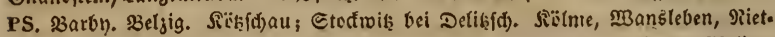

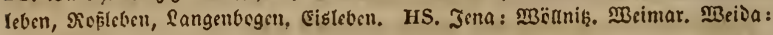
33 urferbiorf. इlymar.

1147. E. Centaurium Pers, St, 12, Harase Arzneigw, 1. 29.

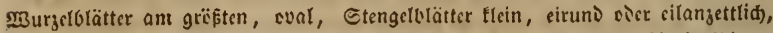

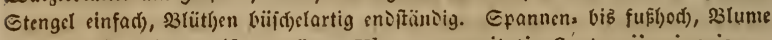

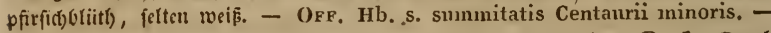

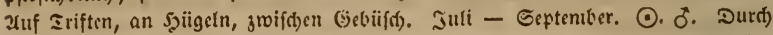

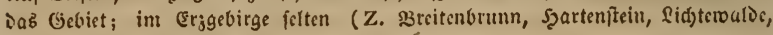
(e)enunik, sitiopau.).

363. Gentiana L. (ङ $\mathfrak{n}_{3}$ ian. Sicld) aufred)t, 231.5 (bci menigen $4-6$ ) fpaltig, im $\$ 300$ en 5yonigoriijen. Staulbefäß̄e 5 (bei venigen 4 -

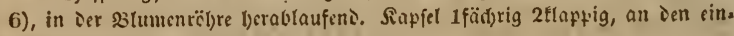
gevogenen Rändern vielfaamig.

a. Gentianella Columas, Saumabfdnitte gewimpert.

1148. G. ciliata L. JAcQ, anstr, t. 113. ST, 23, Rсвв, Fl, germ.

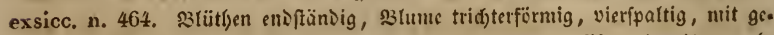

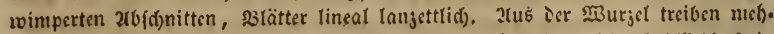

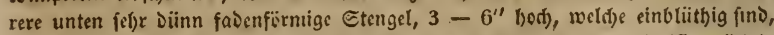

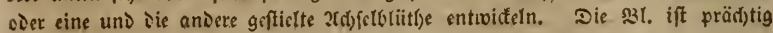
blau. - 2en grajigen zrobängen Der Sialtgevirge, зmiidden Gebuild). Juli -

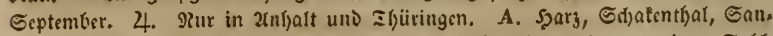

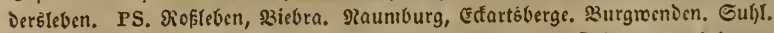
Erfurt. HS. Jena: Siautlyat. Dtfamünde. Eifonberg. Sofurg. Meiningen. SRS. atrnftadt, grantenbaufen, siudolftadt.

b. Eurrthalia Rraealas: Sdjlund bärtig.

1149. G. campestris L. Fl, dan. 367. Rснв. Fl. germ. exsicc. 
n. 463. 23lume 4fpaltig, iie Reld)nff(t)nitte ungleid), 2 äufre brelt elliptifth, 3lätter silanzettliđ), Die MBurzelbätter verfelyrt eiruno, geftielt. Şani: bis fuf. bed), ein. cier mel)rblütbig, weift von unten auf violet angefaufen, 33lume joule

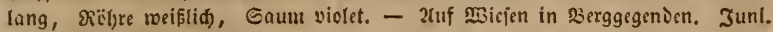
(Schönheit.) Juli. Detober. ○. Etellemmeife, felslt in Der Pitederlaufik. D. meipig, Spelfenberg, fobnten, - Griiffenburg, 2lltenberg. Z. 2rnnaberg, sBären.

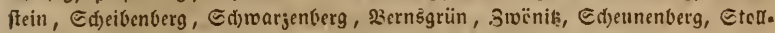

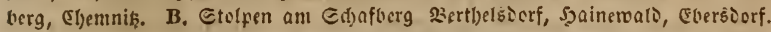

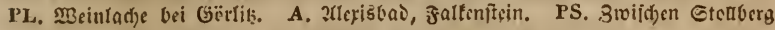
uno şeringen. foderśleben. Eubl. SRS. હdmargburg, frantenbaufon, fiurb̆. Serf, Micifelbad, Siiflyäufer. R. Sobenftein.

1150. G. chloraefolia N. v. E. Slume 5ipaltig, Reldabid)nitte türger als Deren SR̈̈bre, frad), 3 ranjettlid), 2 breite eirund, Şlätter eirund Drei.

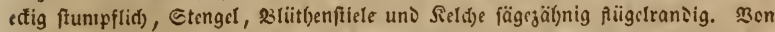
unten auf äftig, słätter Dünner, słume bläfer als bei vorigcr. - 2an grafigen 2ubbängen ier Ralfberge. 2tuguft. ○. Ecl)r felten. '1'S. Erfurt im Eteiger. Kïstner. HS. Jena: M̈̈umîfe. N. v. E.

1151. G. Amarella L. Rснв. pl, crit. X. ic. 118, 119. \$lume 5.

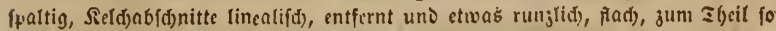

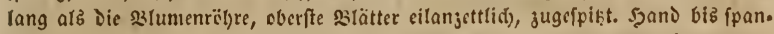
nen(f)d), renig, ober vielblüt)ig: lancifolia RAFx. und pratensis Frokx. Rснв. pl. crit. II. ic. 250). Siraut Duntel, s3l. Elc in, violct, शï̈fre reififid). - 2tuf feu(t)ten MBiefen und Iriften. 2fuguft - Detober, ○. Eel)r felten. B.

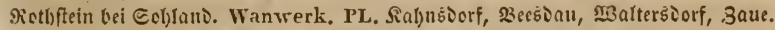
Rabenlorst. Gajen. Blase. A. Brtbft au 3 utterianm. Kreyss.

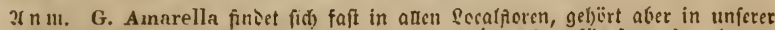

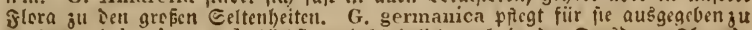
werden. (Fl. Lips. Hal. bïdfft walfridgeinlid' aud) in ier Drebiener flora.)

1152. G. pyramidalis N. v. E. ST, 54. 23lume 5ipartig, Seld) wenig ïber Die Mitte jertlgeilt, abfdynitte cilangettlid), Ctengel wen unten auf

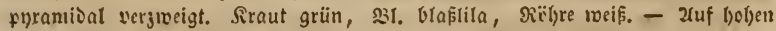
3ergtriften. Juli! ๑. Eelje felten. D. - $3(\mathrm{~m}$ Geifingsberg bei 2artenberg, nid)t ljäufig.

1153. G. spathulata Barte. Rchв. pl, crit. I. ic, $195-197$. Blume 5ipartig, zof(d)nitte f(j)mal (anjettlid), Sicldjabidjnitte ctros ungleid), wähs. rend Der 33 efrud)tung fo lang als Die 33 (umenrëbre, Stengel cinfad), fdjlant, 3lattpaare felfe entferut, unterfte Blätter fpatelförnig, folgende länglid) und

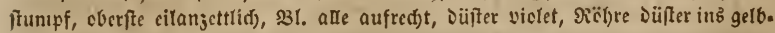
lidje gielyeno, Siraut violet angelaufen. - 2u uf bohen 23ergtriften. Juni. Juli. 14 Zage vor pyramidalis (Rchb. G. Rchb.). ๑. Eelyr felten. D. - Xm Geifingšberg bei altenberg.

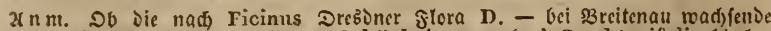
(uno Die mir PS. bei Єub) von Schönheit angegeben) G. obtusifolia bierber

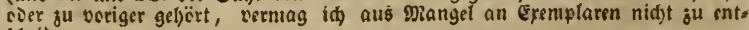
fifeiden. 
1154. G. germanica W. (G. Amarella.) ST. 23. Blunte 5fpaltig,

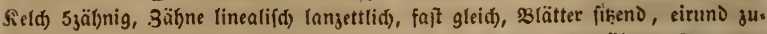

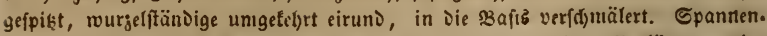

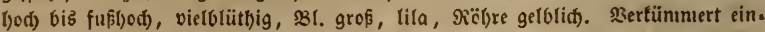

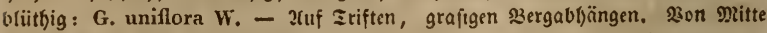

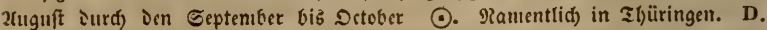
Id) befibc früher um Dreşen als G. Amarella gefanmelte Erenuplare, welde

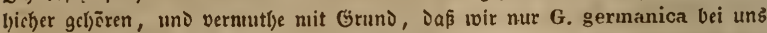

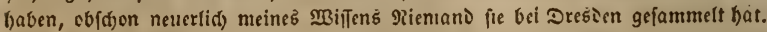
Fic. giebt an: Weifig. - Delia, Sicuifaut, artenberg, Bärenftein. L. 3rifden

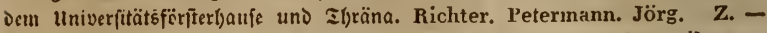
Flauen. Tischendorf. [A ? 2son Schwabe als Ennonym ju Amarella gego. gen utit 2ungabe: "häufig auf אaltbergen".] PS. Şalle: Sogelsberg bei \$Benn. fäot; zroifden Dem Riofen. uno \$ittelfolz. Burgmenden. Querfurt. Rchb.

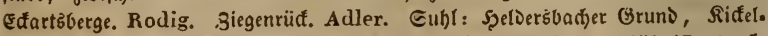

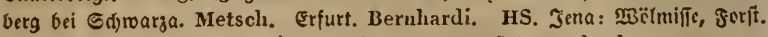
(Eifenady. Zenker. Meiningen. Rauch. SRS. Jinftadt. Hultsch.

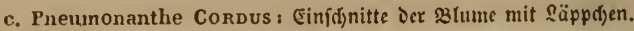

1155. G. Pneumonanthe L. St, 31). Rснв. Fl. germ, exsicc.

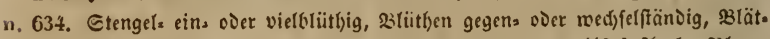

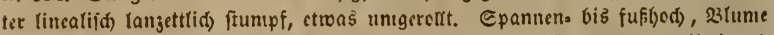

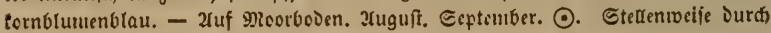

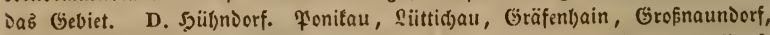

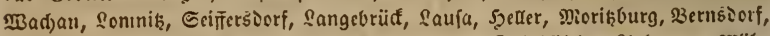

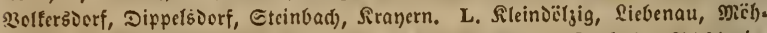

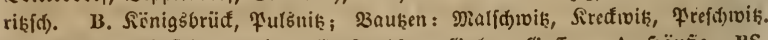
PL. Sựau, sürfftid) Drelyna, Grofmetjow, Guben, Galien. A. Şänig. PS.

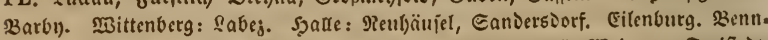

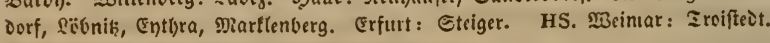
Eifenberg. Eifenad). SRS. ๔djwarjburg.

1156. G., asclepiadea L. JAc2. austr. t. 328. Bot. Mag. $1(1) 78$. Sr. 54. RcHB. Fl. gern. exsicc. n. 635. S3ätter umfaifento eilanjettlid, zll-

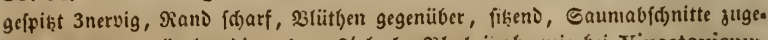
fpist, Saanten plïgelrandig. $1-2^{\prime}$ bed, 321 . beinabe wie bei Vincetoxicum,

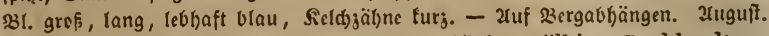
Eeptentber. 4. Gelje felten. PL. ¿afelfidste läufig. Kölbing. Burkhardt.

1157. G. cruciata L. JACQ. anstr. t. 372. B(iitl)en quirlfändig, Błume vierf́paltig, mit teulenförmiger 9iëbre, 33lätter langettlid), 3nervig, unten

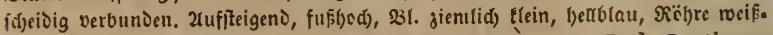

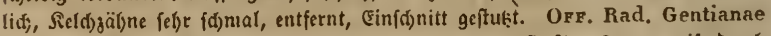

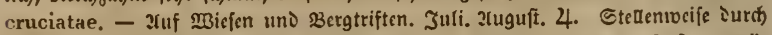
Dasิ Ëebiet. D. Siottaer ßerg. Dittınarsch. G. Rchb. Maken. Schulz. Friiber aud) einnal auf Der Rallan 3 Epemplare. Mauke. L. Dëlzig. Rchb. Pe-

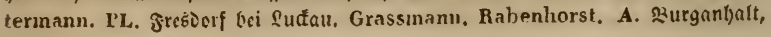




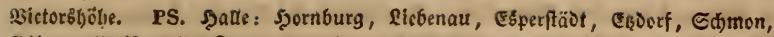

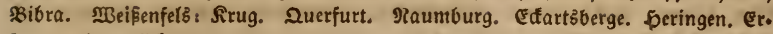

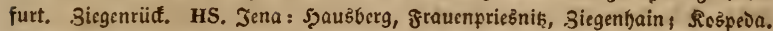
Meintar: Mebiđt, Belvedere. Reburg. Meiningen. Grub bei Ilemar. SRS. Zrmptadt, Frantenlyaufen.

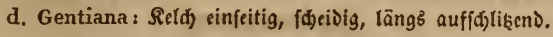

1158. G. lutea L. Hays Arzneigew. I. 28. Rсrв. Fl. gern.

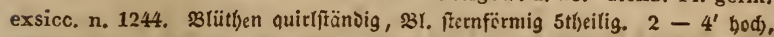
Blätter oval, vielrippig, $\mathfrak{B l}$, gclb. Saame oval, îïgetrandig. - OFF. Rad: Gentianae rubrae. - Zuf 3ergtriften. Julti. Zuguît. 4. Eefr felten, faft

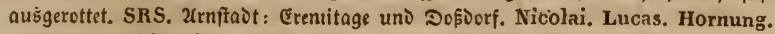
Hultsch. Buddensieg. um. (̇teid)en gan aušgerottet। Schönheit.

364. Swertia L. Stwertie. Seld 5theilig ofien. 31. fternfürmig 5theiliB, jeder X6jd)nitt an Der Bafis mit cin paar Şoniggrübden, weldhe unuvimpert find. Siapfel 1fäd)rig 2tlappig, Saanie piügetrandig.

1159. S. perennis L. SchK. t. 58. Rchs, pl. crit. IX. ic. 1129. 1130. Fl. gern. exsicc. n. 466. Blütl)enftiele faft pügelig vierfantig, Eten. gel einfad), \$Burjelblätter elliptifd), geftielt. 21 . Düfter violet, Duntel punttirt. Xuf fumpfigen, quedigen Moorwicfen, nit Pinus obliqua. Juli. 2ug. 4. Selhr felten; truppweife. Z. Sidftelberg. Bok. Weiker. Rchb. Siarlşfêt angeblidg. (3ıiidden Gottesgabe und Flatten. v. Hoffmannsegge, Wankel, Rchb.)

365. Parnassia L. (sin $\mathfrak{b} \mathfrak{l}$ att. Seld 56lättrig. Slumenblätter 5 , vor iffnen 5 firalylig zeriffliktte Ed)uppen, Die Etrahlen tragen Drüfige S̈̈pfdgen. Staubgefäße 5, গtarben 4. Sapfel 1fäd)rig, oben 4llappig. Gaa. nte nit id)lafier פictilyaut.

1160. P. palustris L. SchK. t. 86. HaYxr Arzneigw. II, t. 42.

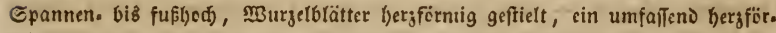
miges Etengelblatt. B1. weiß, Blumenblätter nervig, Drïlen gelb. - OFr. Hepatica alba. - 2uf Eunipfwiejen, Moorboven in Der Ebene bis in Die Gebirge.

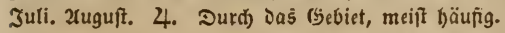

366. Vinca L. $〔$ inngrủ̉n. Seld) 5tfeilig. 33r. präfentirteder.

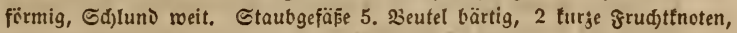
(Grifiel einfad), cben in cine Edjeibe ermeitert, Marbe in Deren Mitte ftern. förntig fajerig, 2 ftieltunde 3 älge, Saame längliđa) Fietrund.

1161. V. minor L. Sснк. t. 54. Gurmp. t. 26. Blütţenftengel auf-

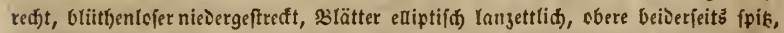

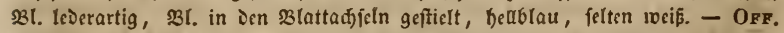
Hb. Vincae Pervincae. $-2(n$ iffattigen $\mathbb{B}$ alobuigcln. 2(pril. Mai. b. Stel.

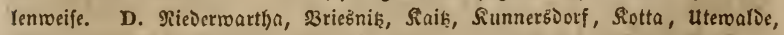

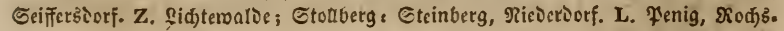

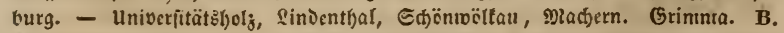

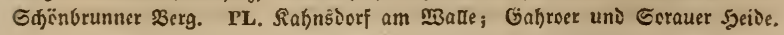




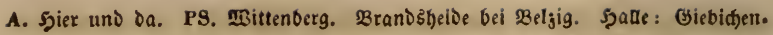

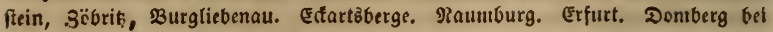
ธubl. HS. Jena: Rloferoik, Runik.

\section{Familie Sapotacene - Jasmineae, Sapotacen - Jasimineen.}

- Şerbarienbud) G. LIX unঠ 135. -

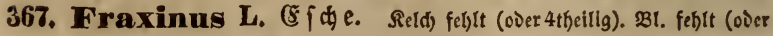

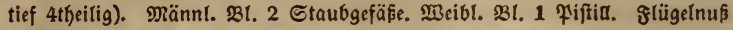
2 fäđ)rig, 1 laantig. - Blätter unpaarig gefièert, gegenüber.

1162. F. excelsior L. Schr, t. 357. GorMr. t. 214. ST, 44. 2Bät.

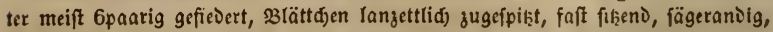

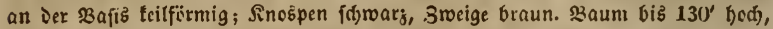
zrweif)äufig ober polnganif(d), audi) einljäufig. - Opp. Cortex Fraxini. - In

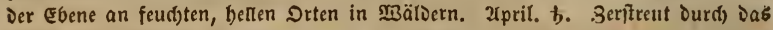

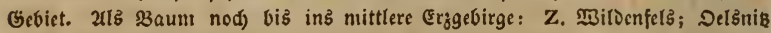
bei Etolltberg; Egemniţ.

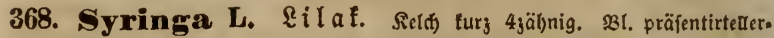

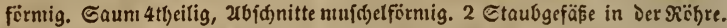
Rarbe gefpalten. Rapfel eifornig jujammengeòrüđt, ęugefpiţt, 2fäd)rig, fadj). fpaltig 2tlappig, EdjeiDewand lëft jüf in Der Mitte länge ab uno bleibt auf

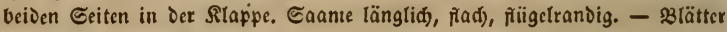
gegenüber.

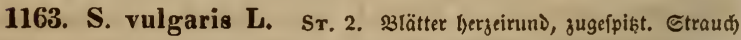

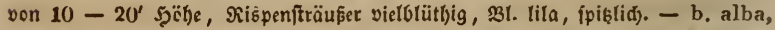

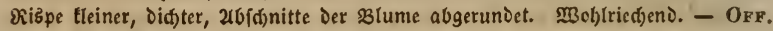
Fructus Syringae. - 2uङ Ferfien unঠ ungarn (Fl. gerın. p. 866 n. 2898.)

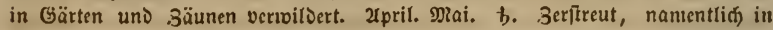

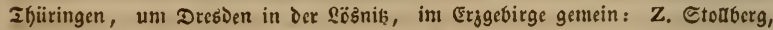
Etein, ঙ̧BitDenfels u. \{.m.

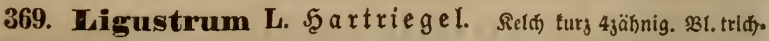

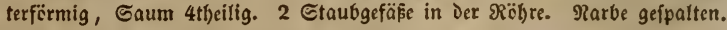
Steinfrud)t 2nüïïg, 2 - 4jaamig. - 31 lätter gegenüber.

1164. L. vulgare L. Sснк. t. 2. St. 14. Hayns Arzngew. v. 25. Gursp. t. 1. Blätter länglid lanzettlid), tabl; Blütben in enoftän১igen

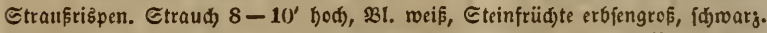

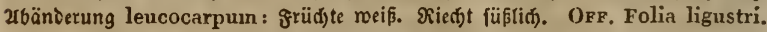

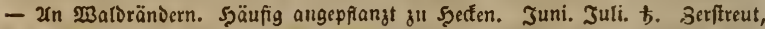
im Erggebirge nur bier und Da angepfanjt; wobt an weniger Etenten wirtling

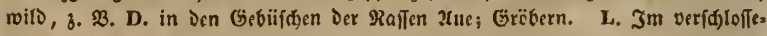
nen Syolje u. a. $D$. 


\title{
C A I Y C A N T H A E.
}

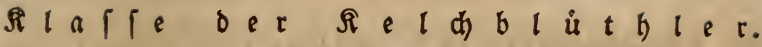 - 3ergl. sjerbarien6ud) ๔. LVIV uno 138. -}

\section{Jamilie Umbelliferae, Dolbengewäd)ie.}

\author{
- Şerbarienbud ธ. LX un১ 138. -
}

\section{A. Eigentlitife Dolbengetwädje.}

370. Coriandrum L. Corianber. grudit fuglid, Sectro.

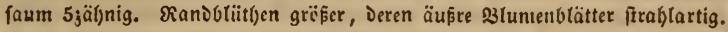
Dorde 3 - 5ftrablig, faft büđenloz, şl. เveiß.

1165. C. sativum L. Scrix. t. 72. Harss Arzneigew, VII, 13.

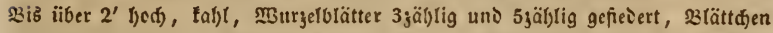
ciruno runblid), einge(d,ynitten, Etengelolätter linealifá) jujanımengefeḅt. Etinft manjenartig. OFF. Sem. Coriandri. - Şäufig gebaut, nantentlid) in Ifiirin. gen; aud) verwilierni. Juni - 2luguft. $\odot$.

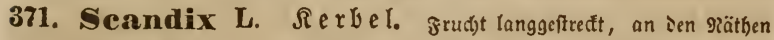
zufanmmengebrïct, fel)r lang gefd) nabelt. - Dolve gipfelartig, sjülde

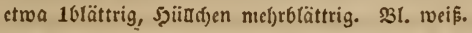

1166. S. Pecten L. JAcQ, austr, t. 263. Scrk, t. S. grudt. Rснв. Fl. germ, exsicc. n, 18i3. Slättdjen linealifíf vieltheilig, Dolde nteift 3iftrah. lig, Sttablen turj, frud)tidynabel iiber $1^{\prime \prime}$ lang, 2 feitig fein betjaart. Gpannen.

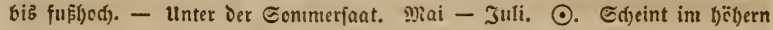
Gebirge und Den Sauftįen ju fel)len, fonft Durd) ias Gebiet, namentlidy in Ibü. ringen. D. um Reißsen läufig. 2entert ftets ien Gtandort.

372. Anthriscus Pers. Sifettenferbel. đruatt lang geo fredft, an Den Rätben jufanınıengeiviidt, rifpenlos, gef́dnabelt, 厄dinabel

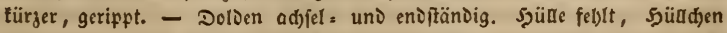

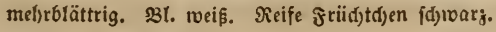

1167. A. vulgaris PERs. JCQ. austr. t. 154. Schk. t. 80. f.

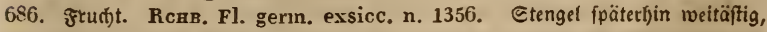
faft tletterno, tabl; şlätter Dreifach gefiebert, unterfeiţ an Den Siippen jerfteut bebaart; Frud)t eiförmig, mit pfriemlid)en, eingebogenen Etad)eln bejeķt, Dreimal fo lang als Der Sd)nabel, 5̧ürblätțen $2-5$, eınjeitig. - 2uf Edutt, an 3äunen, Mauern. Juni - Eeptember. ○. Sier uno Da gemein in Dörfern: 


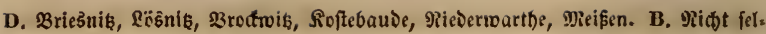
tet. PL. Gemeiu. A. Gemein. PS. Şalle, Erfurt. HS. Jena.

1168. A. Cerefolium Hoffu. t. 1. A, f. 21. JAcQ, austr. t, 390. Hayne Arzneigw. VII. 14. Stengel über Den Gelenfen wellig bebaart, 3reige aufred)t abjtebeno, Blätter Dreifad) gefiedert, Fiedern im umriß ciruno

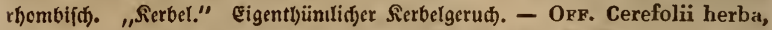
semina. - 2uf bebautem 230 en, an 3äunen, faft überafl verwilbert. Miai. Juni. (๑)

373. Chaerophyllum L. Sả $\mathfrak{l}$ berfrobf. frudt lang ge.

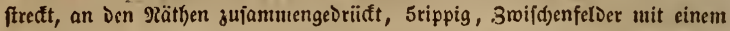

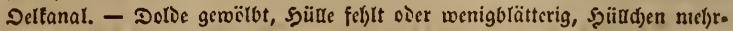

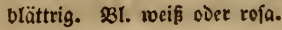

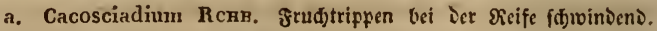
gruatist Dann glatt.

1169. C. sylvestre L. Hayss Arzngw. I. 33. Etengel unten raư̆ bel)aart, 231ätter unterfeitz an Den Sauptrippen fein boritig belbaart, Doppelt gez firdert, Blättchen fiederfpaltig; Früđ)te länglid) glatt, viermal fo lang als Der

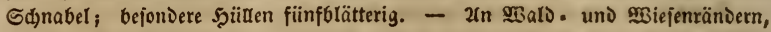
Rainen, an Säunen, Diauern, Єdutt. Dai. Juni. 4. Gemein.

b. Chaerophyllum : frudjt Deutliđjer 5rippig.

1170. C. temulum L. Hayne Arzngew. I. 34. Etengel unter Den Gelenten angefđ)woden, unten fteif bel)aart; 3lätter Doppelt gefiedert, 3lättd)en fiederfpaltig, ftumpflappig, Griffel untgebogeu. 2' bod) oocr ljöbcr, Duntelgrïn,

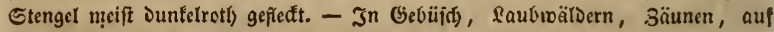

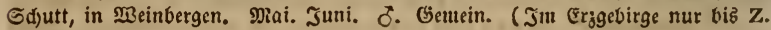
vei Mirbenfels.)

1171. C. bulbosum L. Hayse Arzngw. 1. 32. Etengel unter Den Gielenten aufgeidjwoden, unten fteifborftig, oben falyl. SBätter mebrfad)

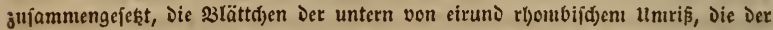

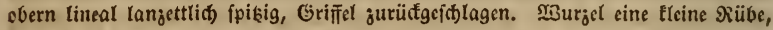
Stengel biß mannsh)o(), neeift unten rotl) geriedt, s3lätter glängen১ grün, 3latt=

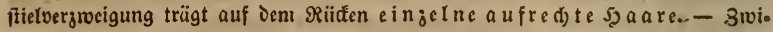

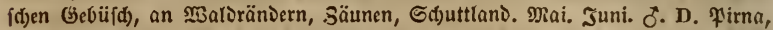

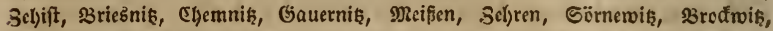

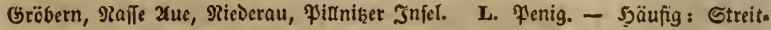

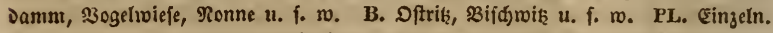
A. Şäufig. PS. Şatle: Rabeninfel. Raumburg. Ecfart3betige. Erfurt. HS. Jena, Roburg. SRS. 2rnftait.

1172. C. hirsutum L. JAcQ. austr. t. 148. Scrk. t. 80. f. 692. łrud)t. Rснв. Fl. gern, exsicc. n. 1021. Stengel faft gleid) Diff. Blätter im Umriß̧ berzförnig 3eđtig, Doppelt georeit, slätter faft fiederfpaltig eingefd)nit. ten gefägt, Griffel aufred)t, $1 f_{3}$ fo lang als Frudst., $1-3^{\prime}$ bed, raud) be: 


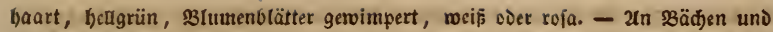
feudten Drten Der Berggründe. Juni - 2uguit. 4. 21n foldgen Stellen bei Dresden bäufig. D. Nievirwartba, Softebaude, Sfdjoner Grund, Raik, Sodrwik,

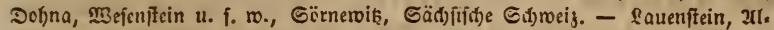

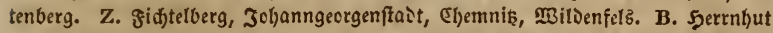

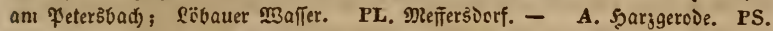

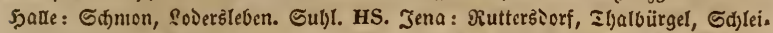
fereifen, গoDa. Soburg.

1173. C. aureum L. JacQ, austr. t. 64. Rсnв. Fl. germ. exsicc.

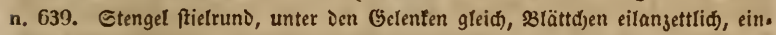
geiđjnitten geiägt, an Der Bafis fiederfpaltig, Epik̨e gefägt, gewimpert, unten an oen 2uern uns Stielden leid)t betjaart, Şüßd)en oval jugefpik̨t, gemimpert. Gđ)lanfer, gelblid) grün. Etengel meift purpurrotb gefledt. \$3l. Ilcin, weiß,

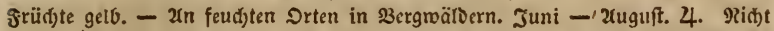

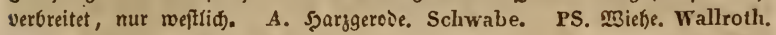

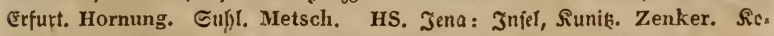
burg. Hornung. SRS. 2rnftaot. Hornung. Gonders̄baufen. Wallroth.

1174. C. maculatum W. Rснв. Fl. gerın. exsicc. n. 64). Gtell. gel gefurdt, unter Den Gelenten aufgetrieben, Sweige eintantig, slättđjen cilan. zettlid, eingejdunitten gejägt, Єpiḳe gejägt, gemimpert. \$origer älsnlid), $2-4^{\prime}$

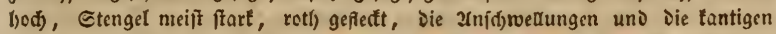

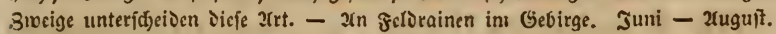
4. Jnt Dbergebirge in Minge: Z. ๔dneeberg, ๔touberg, હdeibenberg, ఠdjuar. seltberg, Docrwiejentbal. Bok. Weiker. Wankel.

1175. C. aromaticum L. Rcri, pl, crit. VI. ic. 707. Fl, germ. exsicc. n. 80. Gtengel unter Den Gelenten gefd)wclen; Slätter Dreifad) georeit,

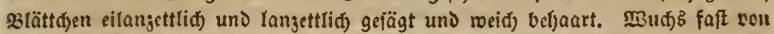

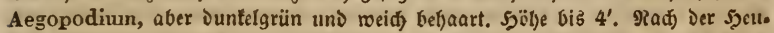
crnote bringt es oft tiefer cingefdinnitten gefägte uno zerfolikte Gtengelblätter.

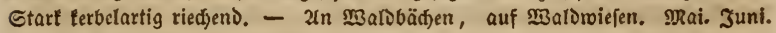
3uguft. Septentber. 4. Un DresDen uno in Der Dberlaufik nidft felten, ver.

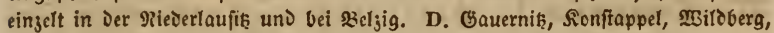

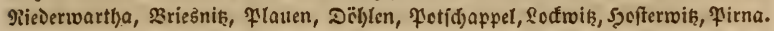

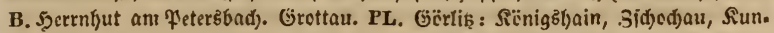
nerşorf. PRiešty, 2(rnşorf. Kölbing. Burkhardt. Schmidt. - Siod)auer

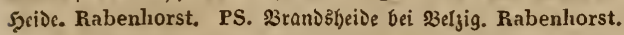

374. Mrrrhis Scop. Neyrthenferbel. Grifel nad Der $\mathfrak{B a}$.

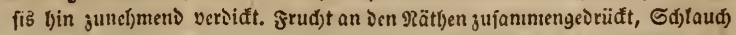
vom Rexn gelc̈ft, 5rippig, Siippen loohl, Swijdentäume ofne Delfanal. -

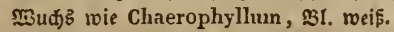

1176. M. odorata Scop. JAç, austr. V. t. 37. Scnk. t. 80. f. 683. frudjt. Rcrв. Fl. germ. exsicc. n. 1022. Stengel $2-3^{\prime}$ bod), Iem Chaer. aureum äbulid), Dic ganje Franje fein weidh bebaart, slätter nabe $\mathbf{j}^{\mathrm{u}}=$ fanmengefest, grudt fajt zollang, ffiniclfirmig. - OrF. Myrrhiflis odoratae 
herba. - In Graşgärten verwilDert. Mai - 2uguft. 4. Jnsbefondere in Den G̈ebirgsठörfern Der Dberlaufik.

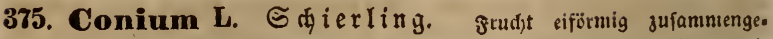

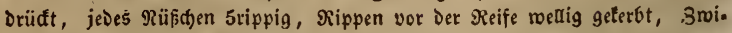
f(j)enräumre geftreift, olyne Deltanal. - Dolde vielfítrablig, Ștïlle 3-56lättrig,

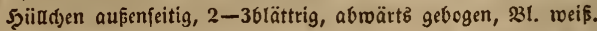

1177. C. maculatum L. Schк. t. 62. Haynk Arzneigw. I. 31.

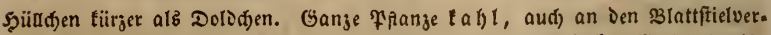

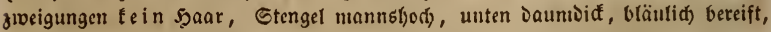
roth) gefieaft, wie beipriibt, glatt, nur unten fein gerieft. Blattfiele röbrig.

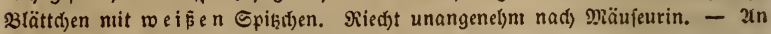

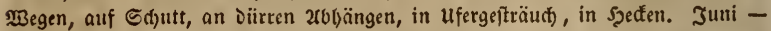

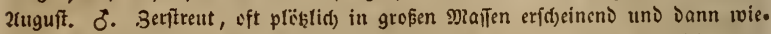

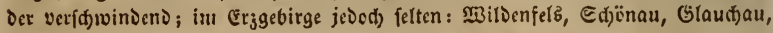
Sidjtenau.

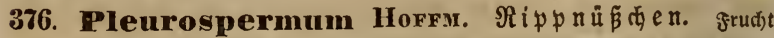

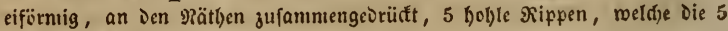

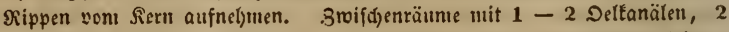
auf Der Jnnenfä̈)e (commissura). Sanmı vorn mit einer holylen Simne.

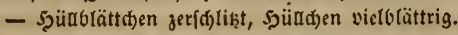

1178. P. austriacum HoffM. JAcn, austr. t. 151. Etenger fteif aufre(d)t, gefurd)t, oben aufrefi)t äftig; unterfte 33(ätter Deppelt Dreijäl)lig, ftengel-

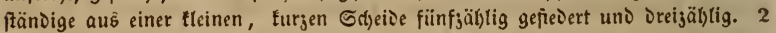

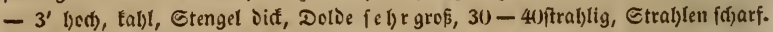

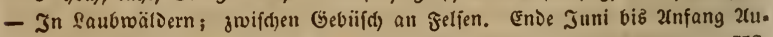
guft. 4. Eelten, nur in ₹ljiiringen. PS. Steiger bei Erfurt. Hornung. HS. ßeimar: Regefeld, Iroifteoter forft. Zenker. Roburg. Hornumg. SRS. Zrms ftaot bei Der Erremitage. Schönheit. Grantenlyaulen. Hornung. Grofeß Şolz

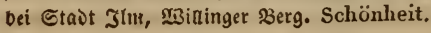

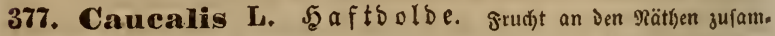

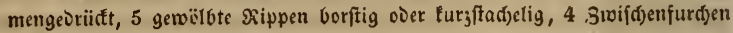
in einfacher פicilje furziftadyetig, inmenoig nit Delfanal.

1179. C. daucoides L. JAcQ. austr. t. 157. ST. Fl. Blätter 2 - 3fad) gefiebert, Die Etadjeln Der grebcnrippen batig, ctroa fo lang als Der

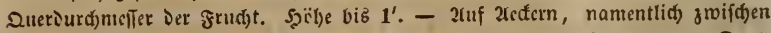

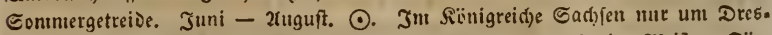
Den beobadytet (D. Etrel)len, Eotta, Seutewik, Briesnik, unferwik, Mieí̄en, Eör.

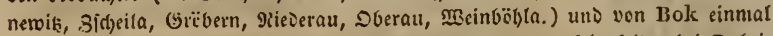
in PRiebererggebirge angetrofien; in Der Picoerlaujif nur felyr felten bei Dobris lugf, Spremberg. In 2fnljalt und Dem ehemaligen Ehurtreife bier uno Da, in Thüringen bäufig.

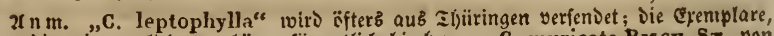

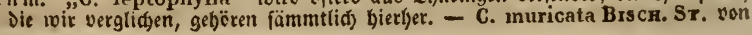




\section{Umbelliferae. $\quad-263-\quad$ Caucalis.}

Mien, hat viel türgere Etadeln, Dürfte vielleidt nod innerbalb unferer Gran. zen aufgefunoen werden.

378. Turgenia Hoffu. Turgenie. gruht von der Geite ju.

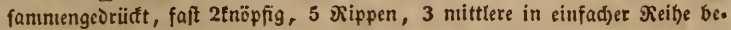

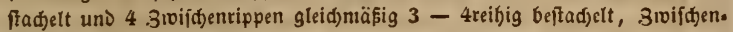

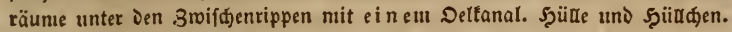

1180. T. latifolia Hofry. Scнк. t. 79. f. 627. Frutht. Rснв.

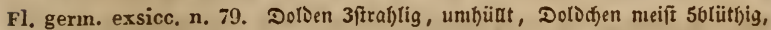

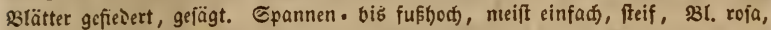

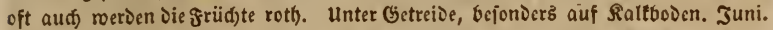

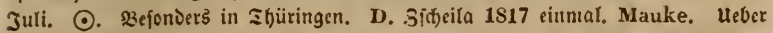
Riederau 1840. Fr. August K. v. S. Grïbern 1841. G. Rchb. A. Şargge. rode. PS. STrifden (Steina u. Éberstoda, Ed)leberode, freiburg, 23ibra, Eđarts. berge. Erfurt. Benşhaufen uno Diajtäot bei ভuhl. HS. Jena. Meimar. Ro. burg. Eifenad). SRS. 2urnftadt.

379. Torilis ADaxs, $\mathfrak{B}$ orft b olbe. Grudit an Den räthen zu. fanumengezogen, 5 Rippen fur 6 borffig, 3wifdentäume beftad)elt, mit cinem

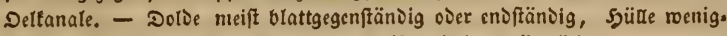

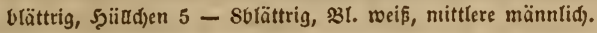

1181. T. helvetica G.r. JAcQ. h. Vind. UI. t. 16. 2ußgeipreizt

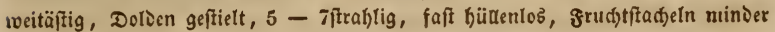
batig, Blätter Doppelt zufanımengejekt, voerfte Dreijählig, sicierd)en jufamınen.

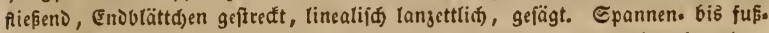

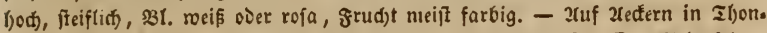
boden; auf Xferrainen, zroifden Eteint)aufen. Juti. Xuguft. ๑. Gefhr felten.

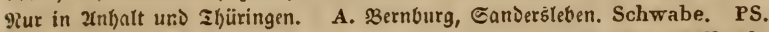

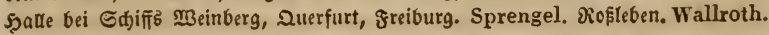
RS. Roburg: Seftungzbcrg. Hornung.

1182. T. Anthriscus G.aents. Haxam Arzneigw. 1. 36. : Blät. ter Doppelt gefiedert; Dorden lang geftielt, 5 - 12ftrablig; allgemeine Şüule 3

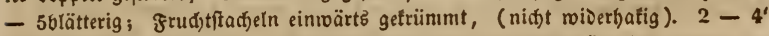

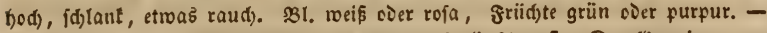

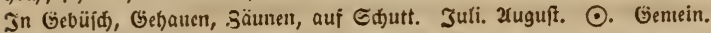

380. Cicuta L. $\mathfrak{S}$ ủ ther $\mathrm{i}$.

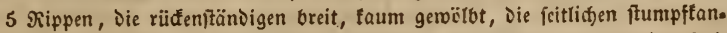
tig, 3roijdenräume nit eingetnem Deltanal, Jnnenfää)e mit 2 nahen Del.

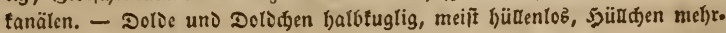
blättrig, 3 1. weif.

1183. C. virosa L. Hayne Arzneigew. 1. 37. Schk. t. 71. u. 80). f. 679. Grud)t. Etengel röl)rig; 3rätter Dreifad) gefièert, nit lineal lanzettliden

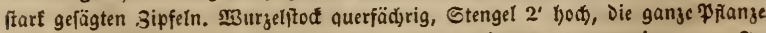
bellgrïn glänzenv. - OFF. Rad. Hb. Cicutae virosae s. aquaticae - $3 n$

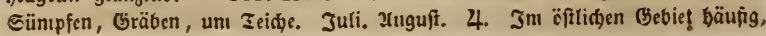




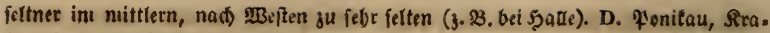

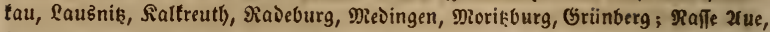

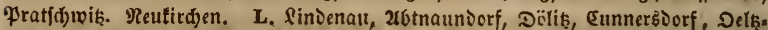

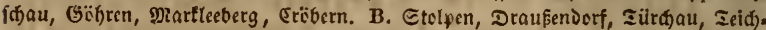

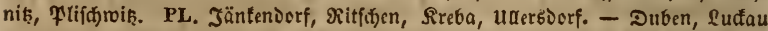
u. f. เo. nidft fclten. A. Berbft u. f. r. PS. Barbn: Göonis. Mittenberg

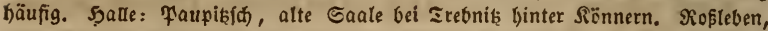

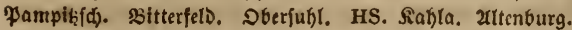

381. Apium L. Epyig, Sefferie. fruntht faft tuglig zus

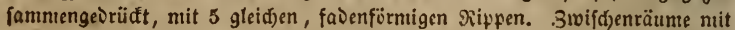
1-2 - 3 Deltanälen. Cäuldhen ungefpalten. - Doloe gegipfelt, meijt fprofleno, saüle blättrig, an jen Endooroen neeift feblend, Şü̈dden feblend. 81. reif.

1184. A. graveolens L. Haxxs Arzneigew. VIr. 24. Etenger

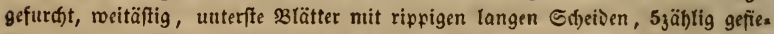

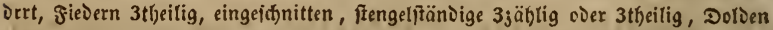

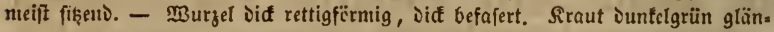

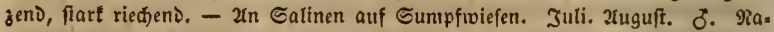
mentlid) um Die Calinen. PL. Duben bei Sufau nad) Grassmann. A. Seau.

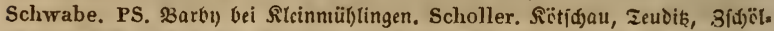

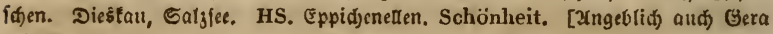
vei Iimenau.]

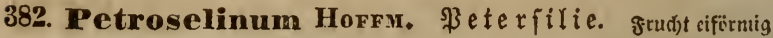

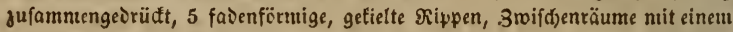

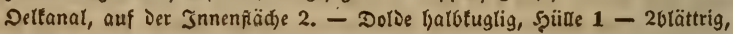
Şüßd)en mefłrolättrig, flcin. 21 . grüntid) wei巨.

* 1185. P. sativum Hofru. Haxne Arzngw. VII. 23. Schk. t. 80. f. 722. fruđ)t. Etengel Eantig; siätter glängeno, Dreifad) gefièert, mit teilförntigen, cingefdlişten Brättđ)en, - b. heterophyllum, "Eđjnittpeterfilie",

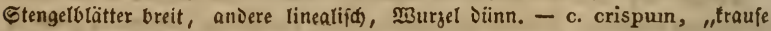
¥.", B1. franb. - (Etwa $2^{\prime}$ hod), 3weige fd)lant, etwaz aufíteigeno. Siraut cis

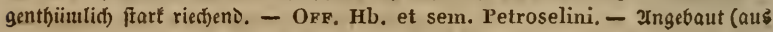

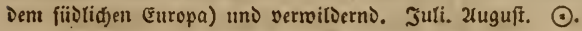

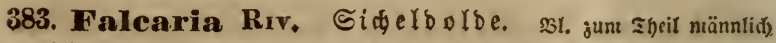

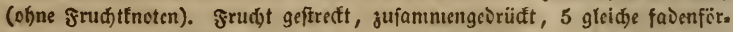
mige Siippen. Säuld)en geipalten. Smijđenräume nit cinem Delfanal. Dalうe gegipfelt, Şülle unذ Şülldjen unglcid) roenigblätterig, borftenförmig.

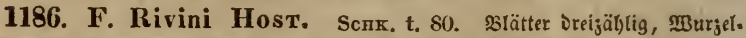

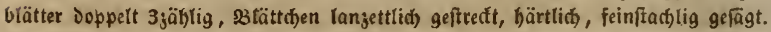

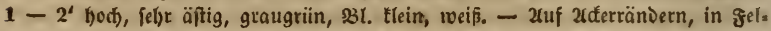
dern. Juli. 2uguft. ठ․ In Den Laufiken (B. Bauken, 3ittau. PL. Sübben, Pưfenail) nur felten, fonft wobl überaft nisf.t felten; in frudftbaren Gegenien gemsin. 


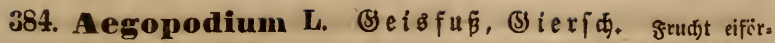

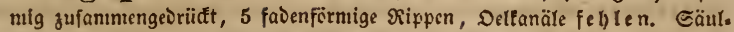

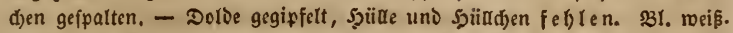

1187. A. Podagraria L. Sckx. 79. Murzelblätter Doppelt gèreit;

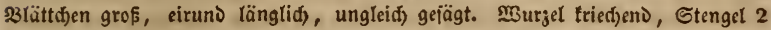

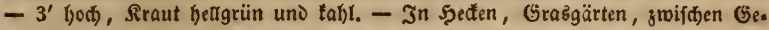
büfd), an Planten, Bäd)en, Gräben u. f. w. Juli. 2uguff. 4. Sentein.

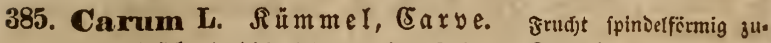

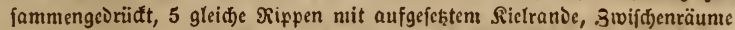

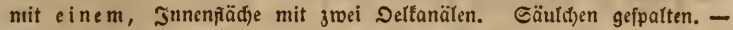
Dolde gegipfelt, 32 . weiß, mittelife olyne frudgttnoten, Şülle etrva 16rättrig, ober wie sie Spü̈ld)en meift feb) (end.

1188. C. Carvi L. Hayxr Arzneigew, ViI, 19. Scrk, t. 77. ßlät: ter Doppelt gefiedert, Brättchen fieverti)eilig linealifon vielfipaltig. Fufthon und

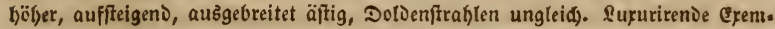

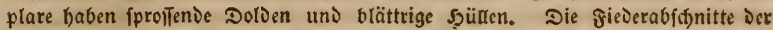
Stengetolätter fino weit länger gef̂tređ̆t und Iofrer geftent ats Die furjen uno

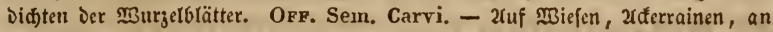
WBegen. Mai. Juni. Geptember. 4. Gemein.

386. Pimpinella L. $\$$ impineIl e. grudt cifïrnig zufam.

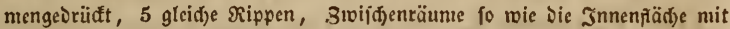
meligen Delfanälen. Gäulden gefpalten. - Dolde und Doldden gegipfelt,

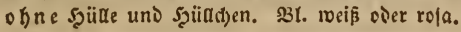

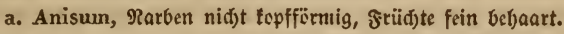

* 1189. P. Anisum L. Hayxe Arzngw. VII. 22. Burzelblätter

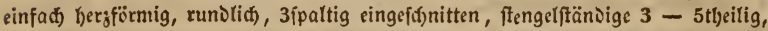

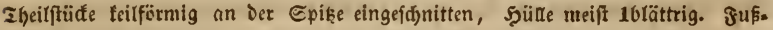

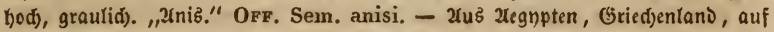

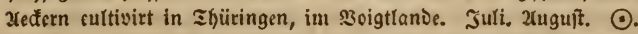

b. Pimpinella, शarben topfförmig, friid)te faht.

1190. P. Saxifraga L. Hayxe Arzneigew. vil. 20. 33lätter gi:

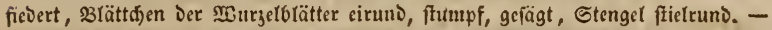

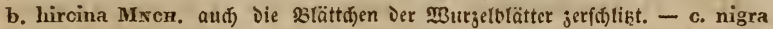

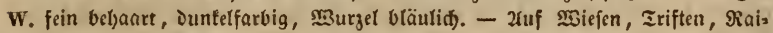
nen. Juli - Eeptentber. 4. Gemein.

1191. P. magna L. Hayne Arzneigew. VII. 21. 33lätter gefiedert,

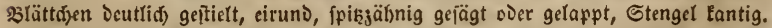

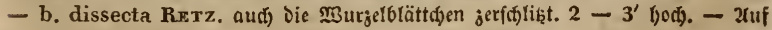

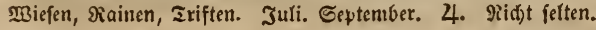

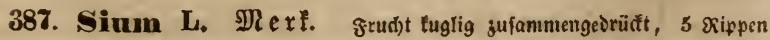

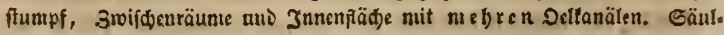


d)en getbeilt, angeroadjien. - Dolde balbluglig, şiille uno şüldden mebr. blättrig, skl. roeiß.

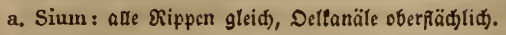

1192. S. latifolium L. Hayse Arzneigw. I. 38. Etengel 5lantig,

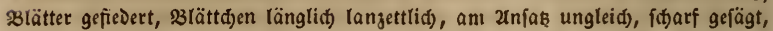

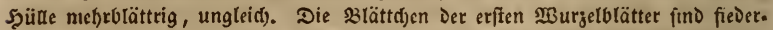

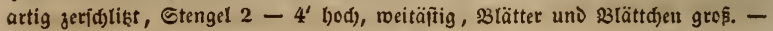
In @ümpfen, Gräben. Juli. 2uguft. 4. Jill Erggebirge jedod nur felten, fonft gentein.

- 1193. S. Sisarum L. Scrк. t. 69. S3lätter gefièert, Griitlenftän.

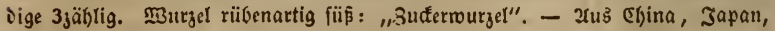
Xttai auf Xecfern gebaut. Juli. 2uguit. 4.

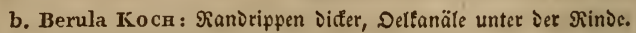

1194. S. angustifolium L. Harse Arzneigw. I. 39. 3lätter ges

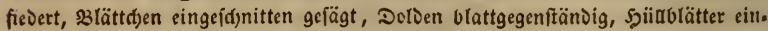

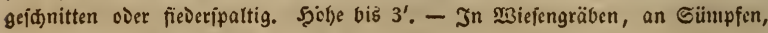
Zeidyen. Juli. 2uguft. 2. Sel)lt int Gibirge, fouft nid)t felten.

388. Helosciadium Koch. Sumpfoold

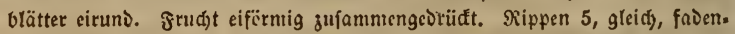
förmig, Swif́) cnräume nit einem Deltanal. Cäuld)en unzertbeilt, frei.

1195. H. repens L. Fl. dan. 1514. 尺riedjen১, slätter gefièert, જie. Dern eiruno runolid, ungleid) gefägt over eingef(j)nitten, DolDen blattgegenftän. ১ig, türjer alz ił)r Sticl. Epannenlang, 33lätter gleiđgeftaltet, Şülle $2-5$.

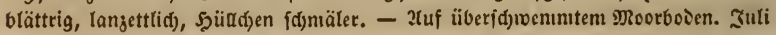
- Geptember. 4. Geljr felten. PL. 3arutb, Sanimelir bei Goliten. Rabenh. A. Sdjierau, 3erbft. Scholler.

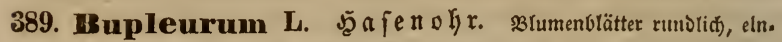
gerout, Spiçe abgeffuk̨t. Grudft 2tnotig ober eiförmig, zufantntengeorüđt,

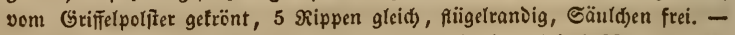
Deltanäle feblen bei 1196 uno 1197, fino vorbanden bei 1198 und 1199.

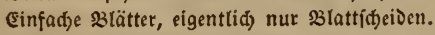

a. Trachypleurum Rснв. consp. friidjtðfen gefïrnelt.

1196. B. tenuissimum L. Rсвв. pl, crit. II. ic. 29s. Fl. germ. exsicc. n. 1876. 21ufred)t oder aufiteigeno, meitäftig, Dolden endfändig 3 -

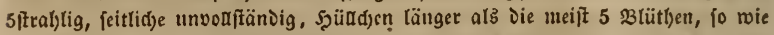
Die 3 lätter linealifd, jugeipiţt. Epannenlang, Dünnjmeigig. - 2luf Galzboden swifd)en Dem Grafe, an Miejengräben. Juli - Septentber. (O. Rantentlid) an Den Galinen. A. Seau, Güften. Schwabe. PS. Barbr): ¥öntelte. Scholler.

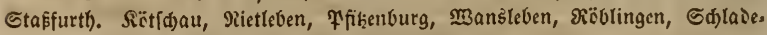
bach, Dürrenberg. Zrtern. SRS. Frantenljaufen.

b. Bupleuruun : Früđdtđjen auf Den 3ıifdjenräumen glatt.

1197. B. rotundifolium L. HAYNe Arzneigew. VII. 1. Blätter 


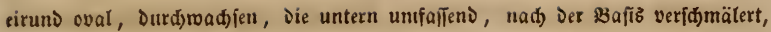

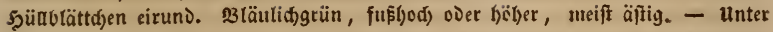

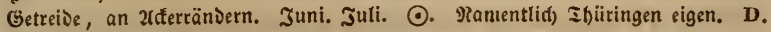
Bizmeilen bier und da elne jerftreute Pranje. PL. Desigleiden. A. Bernburg, Sanderšleben, Şarggerode. PS. Barbı. Beljig. Mietleben, Sic̈lnte, Bennftäot. Raumburg. HS. Jena, M̉eimar, (jotl)a. SRS. 2rmftadt. R. Gera.

1198. B. longifolium L. Canerar, hort. ic. 38. 23lätter eirund länglid, Die untern fpatelförmig, Die obern herjförntig unifalienD, Ђ̧üưblätter

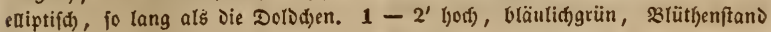

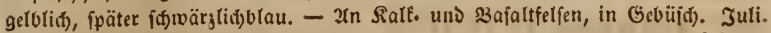
3luguft. 4. গRamentlid) in Ifü̈ringen. D. - Epiłberg bei Delia. Ficinus.

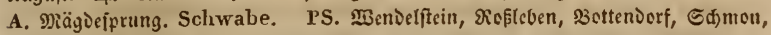

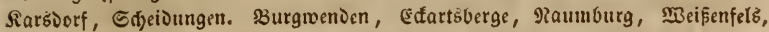

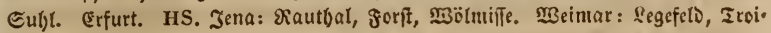
ftedt. SRS. Itrnjtait, frantenlyaufen.

1199. B. falcatum L. JAcQ, austr. t. 158, Rcrib, Fl, germ, ex-

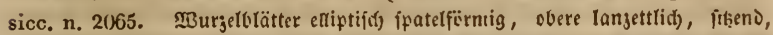

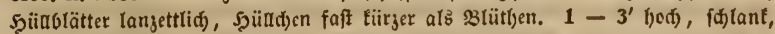

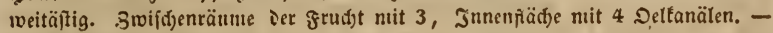

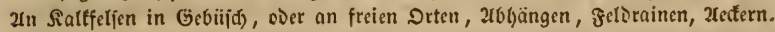

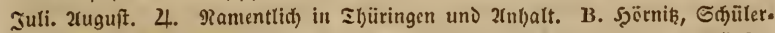

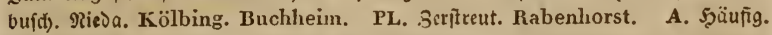

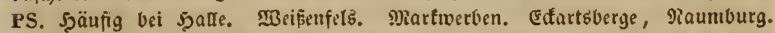

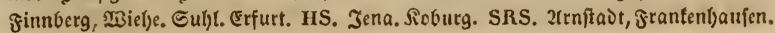

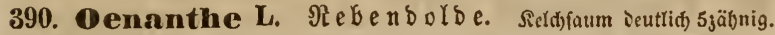

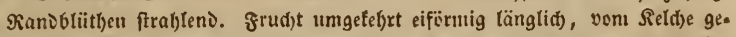

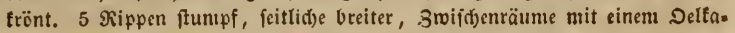

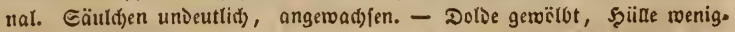
brättrig, 3il. weī̧.

1200. O. fistulosa L. Schк. t. 70. Mुurget büfdelfaferig, fafern

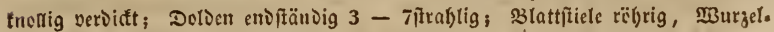

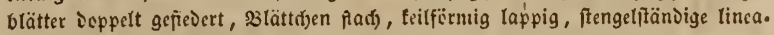
lija) fadenfürmig gefiedert. - Xuf Sumpfwiefen in Bicraftboden, Đoräben. Zuni. Juli. 4. In Den Sumpfebenen nidft felten, int bäbern Gebirge felfleno, int weftt.

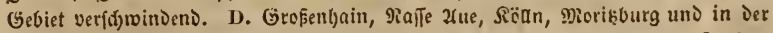

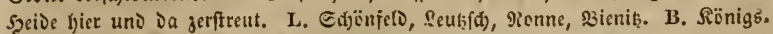

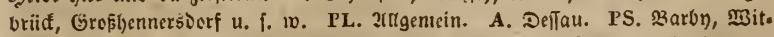

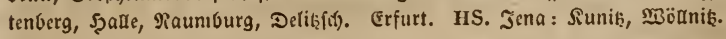

If nnt. Oenanthe peucedanifolia PoxL. nad) Koch Synopsis in ₹füringen.

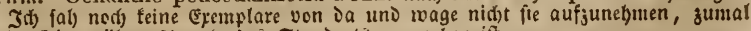
Da feine näbere 2rngabe Des Stanoort's angegeben ift.

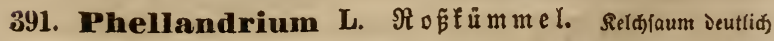
5̧ä̆lynig, Blütben gleidfö̈rmig. Fruht eiförnig vem Seldhe getrënt. 5 breite 


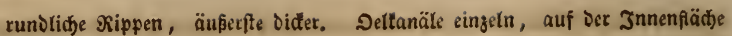
groei.

1201. P. aquaticum L. Hayne Arzneigw. I. 40. MBurgel fpind lig; Stengel fefre äftig; Slätter $2-3$ fach gefiedert, nit fièerfpaltigen $\mathfrak{B}$ lätt.

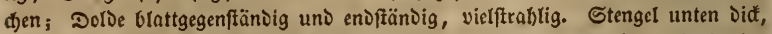

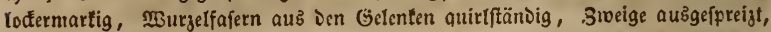
Dolven jienılid) Elein. OfF. Sem. phellandrü. - In Sümpfen, Ieiđen, Grä.

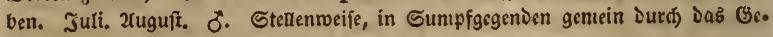
bict mit 2ušnabme Des bëhern Gebirger.

392. A ethusa L. (S) Ieife. Frudjt eiförmig tuglig, Rippen ১ič,

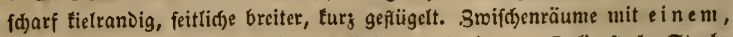
Jnnenpää)e mit jrei Deltanälen. Cäuld)en gefłalten. - Dolde frad), Strah). len mit bäutigem, fägeartig gemintperten Innenrande, Şülle meift fel)lend,

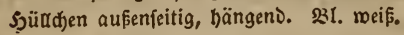

1202. A. Cynapium L. Haxas Arzneigew. L. 35. Şü̈dđen Der Doldd)en zu oreien, länger alङ Diefelben; Die äusern frud)tftiele Doppelt fo lang als Die Srud)t; Die Delfanäle Der Jnnenfäđde unten entfernt. Sabl, Dunfelgrün,

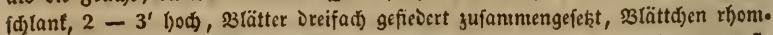
bifd), cingefóditiąt, unten glänzeno. - b. segetalis BNwgr. nièrig, unterf́te

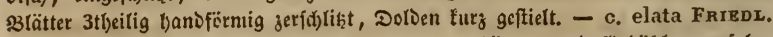

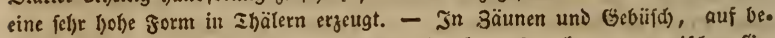
bautem Garten = uno feldboden, Sd)uttlano. b. auf 2edfern. c. jmif́chen Ges biijit) in shälern. Juni - Eeptentber. ๑. Durd) Das Gebiet gemein.

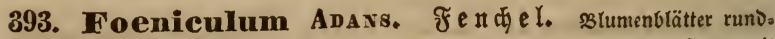

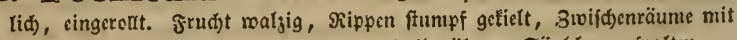
eincm, Innentäd)e mit 2 gebogenen Delfanälen. Gäuld)en gcipalten. -

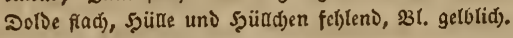

* 1203. F. sativum ArL. Schк. t. 80. f. 712. Hayne Arzneigew. VII. 18. Stengel unten ftielrunD, abid)nitte Der \$3lättđjen lang linealifó) fadenfermig, Dolocn $10-30$ ftraf)lig. $4-6^{\prime}$ bod), ausgeseidjuct Durd Die langen $\mathfrak{B}$ lattfd)ei Den, über Denen Der turge SBlattfiel geöbrt ift. - OFr. Rad. et sem. foeniculi. - 2lus Sübeuropa, auf feldern und in Gärten ges baut. Juni. Juli. $\delta$.

394. Seseli L. Sefel. Fruđ̆t länglid maljig, Grifiel zurüđgebc, gen. Sippen ১if, rinذig. Swifđjentäume mit $1-2-3$ Delfanälen.

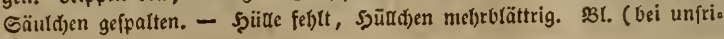
gen) tweif.

1204. S. bienne Crantz. Schк. t. 80. f. 697. Rсrв, Fl, gerin. exsicc. n. 1460, Stenget gefurdt)t, Blattíd)eiden lang uns baudjig, slattitiele

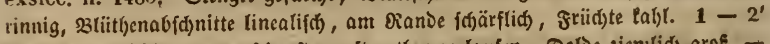
boch, feltmer äftig, unten f(b)opfig, oft roth angelaufen, Dolbe gienilid) großs. -

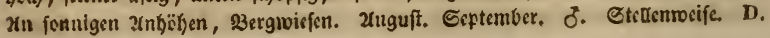




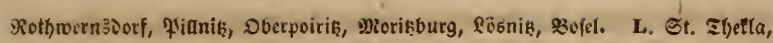

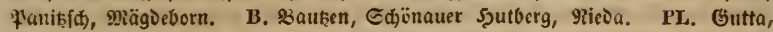

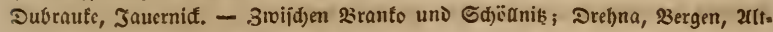
geliten, Sirugau, SommerfelD. A. Deîau, Sanjerbleben, Bernburg. PS. Sarbu).

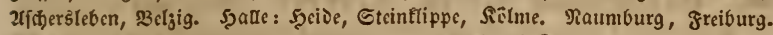

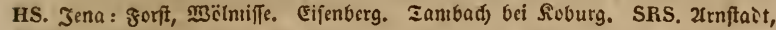
grantent)aufen.

1205. S. Hippomarathrum L. ScHx. t. 75. Etenget glatt, Brätts

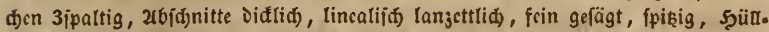

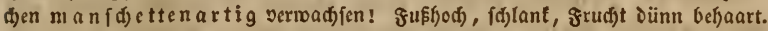
- In fonnigen Şügeln, vorgüglid auf Salfboden. ऊuli. 2uguft. 4 . Gel)r

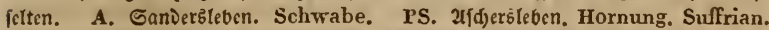
Eiżlebcn. Bock. 2uctfurt. Wallroth. Sïlme, Seeburg. Sprengel.

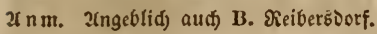

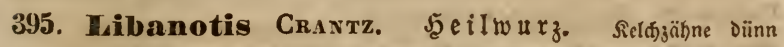

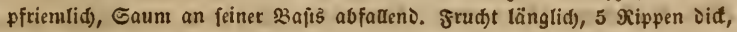
rindig, äußre breiter, mittlere 3mifd)enräume nit einem, feitlidje mit groci,

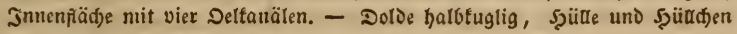
vielblättrig. 331. weiß.

1206. L. montana ALr. JAcQ, austr. t. 392. Rcrs, Fl, gerin. exsicc. n. 1360. Slätter Doppelt gefiècrt, 26uid)nitte feilförmig rfonıbifd), breit langettlid $3-5$ fpaltig, Die meiften berablaufeno zufammenfiefenend, unterfte 3lättdenfaare an Der Mittelrippe einander freujeno, friid)te furg bel)aart. 2 -

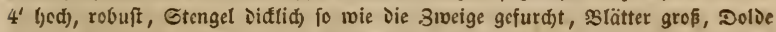

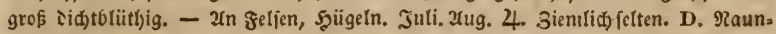
Dorf. Dehne. L. Rchb. fil. G. Rchb. Papperitz. Bei ̊angebrüff. Ficinus. Gefr felten bier und da einmal ganz einjeln. PS. 23ibra. Wallroth. Sauda.

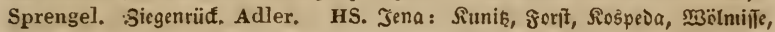
Diautljal. Schubert. Zenker. Dornburg nach frauenpriešniţ zu. Schwaegrichen. Segefeld, Zroifteot bei MBimar. Berfa. Zenker. Eifenberg. Geier.

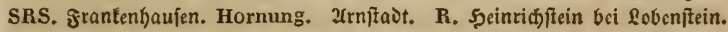

396. Cnidium Cusson. $B$ renno old

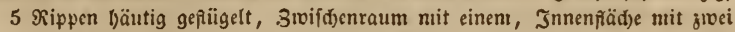

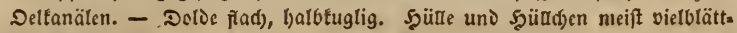
rig. 31. weif.

1207. C. venosum Косн, SPr. Fl. Hal. t. 2. (Ses. dubiun). Scrk. t. So. f. 698. నaht, 1-2' bod, einfad) ober wenigäftig, oben son Den

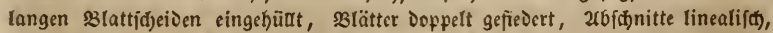

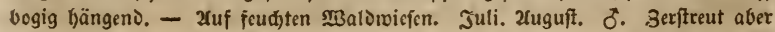
jelten. L. Nonne, verfd)lofienes Şoly. 1841. Petermann. PL. Şinienberg.

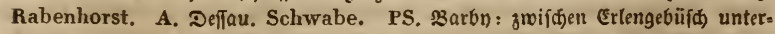

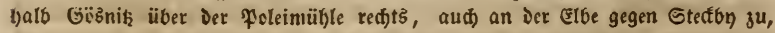

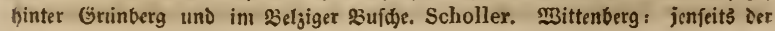




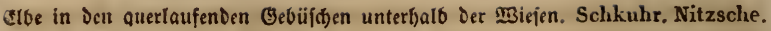

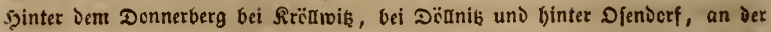
खeft

\section{Ostericum Hoffm. Dfterif. S̊cld oreit fünfłäbnig.}

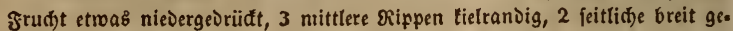
flügelt. Şmiff)enräume nit einem Delfanal. - Dolbe halbfuglig, Şiille necift febleno ober ein pfriemfïrmiges 2 lättđen, Şü̈đen vielblättrig. $2 B 1$. meif.

1208. 0. palustre Bess. Rснв. pl. crit. V. ic. 5s8. Stengel uns

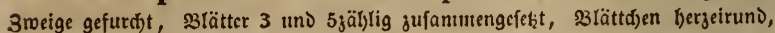

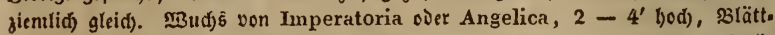
den geftielt, eingeíanitten gefägt ober grob geterbt. - Xuf Sumıfroiefen. Juli. Uuguft. ठँ. Cebr felten, aber Dann meift bäufig. PS. Dfendorf, Dent Drcierbaufe gegenüber. Ranena. W. Geranus. Sprengel. HS. 2rlperfä̈t. Bernhardi. Buddensieg. \$ăffenourg. Buddensieg.

398. Silaus (Phinius.) Besser. Silau. Seldfaum undeut. liđ). Slunenblätter umgetel)rt eirun১ längliđo, Spiß̨e eingebogen aušgeterbt.

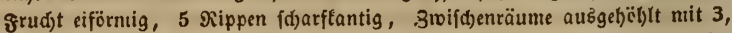
Jnnenfäđd)e nit 4-6 Delfanälen. Dolde gegipfelt, Şülle roenigblättrig, Şüldden vielolättrig, 23lüthe grünlidg.

1209. S. pratensis JEss. Schк. t. 79. f. 638. frudt. HAyne Arzneigew. VII. 5. Stengel oben tantig und gefurd)t, abftebende sweige; Blätter 3 - 4fad) gefiedert; xbjd)nitte lineal lanjettlid), ftad)elfpişig, geavert.

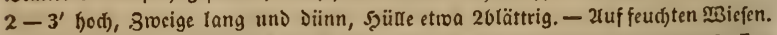

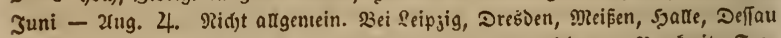

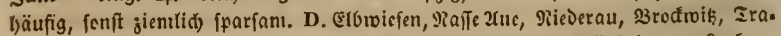

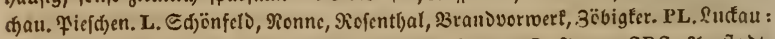

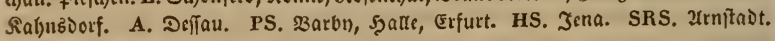

399. Meum Riv. $\mathscr{B} a ̈ r \mathfrak{v} u \mathfrak{r}$. Sieldfaum undeutlid). 23lumen. blätter oval, Epişe fiad, eingebogen. Frud)t fpindelförmig, 5 rippen ent. fernt, Eielranoig, 3roifd)enräume jientlid) fiad), ntit 3, Jnnenfä̈(je mit 6 Deltanälen. - Dolde gegipfelt, Şüle meift felllend, Şü̈lden vielolättrig. 31. roeif.

1210. M. athamanticum JACQ. austr. t. 3()3. HAYNE Arzngew.

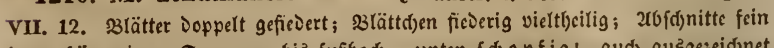
baarförmig! Epannen, bis fuffod), unten fdopfig! aud) aub̈gejeid)net surd) Die febr fein jertbeilten silätter. - 2luf ₹riften ier Gibirge gefellig. Juni - 2luguft. 4. Jn obern Eragebirge uno zljüringerwalde befonders büufig, fonft bier und da jerfteut. D. Sheide bei fintlaters. G. Rchb. Şeller. Rchb.

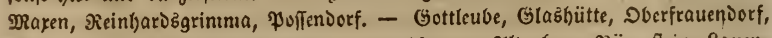
Eleno, Dippoldišroalde, Faltenl)ain, Şirfd)fprung, zrltentorg, Bärenftein, \&auen. ftein, Binnwalo, Gicorgenfels, sharandt, Somborf, Rilingenberg, freiberg. Z.

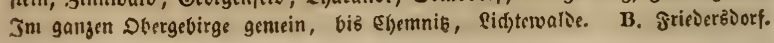


Schınidt. PL. MBei Tagt bei \&udau. Grassmann. A. Saarjgeroie, Giintersberge.

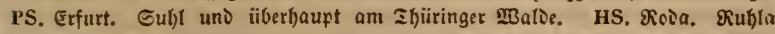
bei (Eifenađ. Zenker. Jlmenau. Hornung. SRS. Edroargburg. R. Lobenftein.

400. Pteroselinum Rchв. ap. Moessx. Flügelfilge.

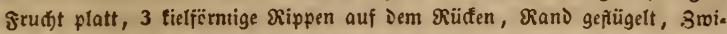
idfenräume mit $1-3$, Jnnentäđge auf ifrem Dittelfeloe nit $2-4$ Del.

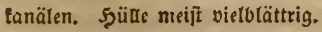

1211. P. alsaticum (Peuced. - L.) Rснв. JAcQ, austr. t. 70. Sсвк. t. 79. f. 639. §rudtt. Rсвв, Fl. germn. exsicc. n, 17)3. \$lätter

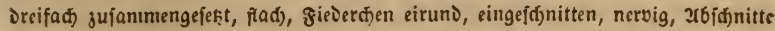

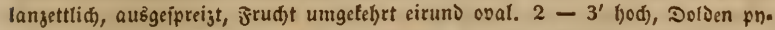
ramioal rizpig zujammengeftedt, BB. geiotid. - 2un fonnigen grafigen Drten.

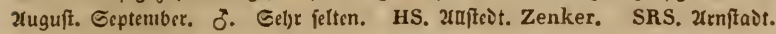
Nicolai, Oswald, Lucas.

401. Peucedanum L. $\mathfrak{5} \mathfrak{a} \mathfrak{a} \mathfrak{r}$ ft $\mathfrak{r} \mathfrak{a} \mathfrak{g}$. Grudt platt, 3 tielför.

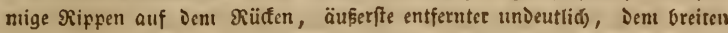

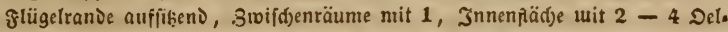

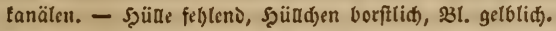

1212. P. officinale L. Schr. t. 63. Hayse Arzneigew. VII. 4.

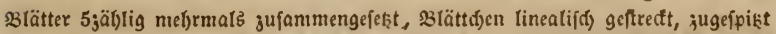

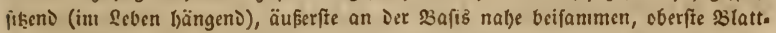

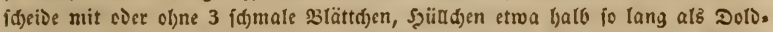

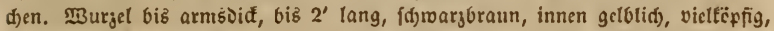
Sraut tabl, Etengel $4-6^{\prime}$ hod, Dolden grof, loffer. 3ivcige idjlant. Orf. Rad. Peucedani. - 2uf trof́nen, fteinigen æ̋alowicien. Juni. Juti. 4. [D.

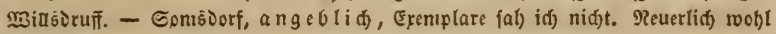

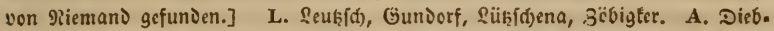

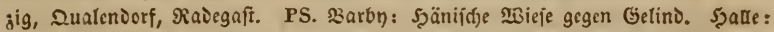

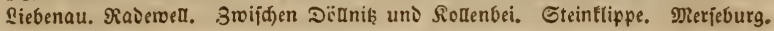
Erfurt : Eteiger. HS. Jena : gleid binter Der Fapiernü̈ble und einjeln im Siob. peoaer Szols. SRS. Zrnftait, frantenbaufen.

402. Thysselinum Dodox. Thyffe $\mathfrak{i n}$. frudt plan.con.

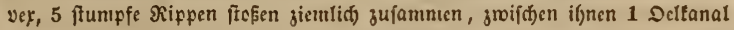

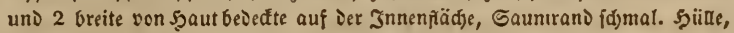
\$3t. weiß.

1213. T. palustre HoffM. SchK, t. 63. Etengel gefurcht, $\mathfrak{B l a ̈ t =}$

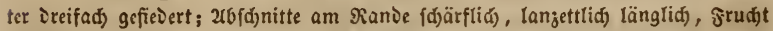
eiförnig. M̉urgel oben einfad), nad) Der Epike bin getheilt, Etengel 3-4' hod) unD Drüber. (Selin.) silvestre JAcQ. austr. t. 152. 26 fífnitte und 3lätt.

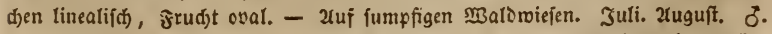

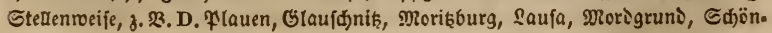

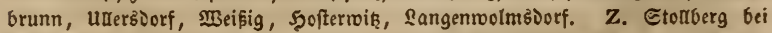

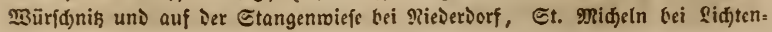




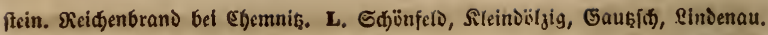
B. Serftreut. PL. Nidłt falten. A. Şäufig. PS. Nisittenberg in Der Specfe. Diestau. হodersteben. Erfurt im Steiger. HS. Jena. Meimar : Iroiftedt. Ci. fcnberg. शëndjröDen bei Roburg.

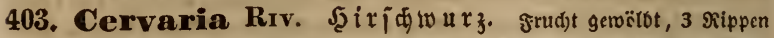

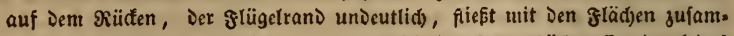

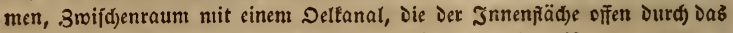

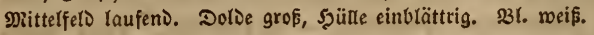

1214. C. Rivini Gaertw. t. 21. SchK. t. 79. f. 641. frud)t. JQ.

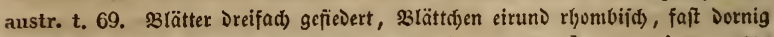
gefägt, Die Delfanäle Der Inneniäaj)e parallel. Ofr. Rad. Cervariae. $-\mathfrak{X}_{\mathfrak{n}}$

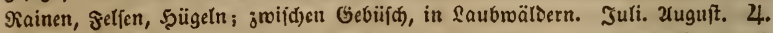
Etenenweife, fel)lt in Dem (Erggebirge und Der Doerlaufik. D. Madjwih, sofel,

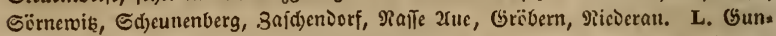

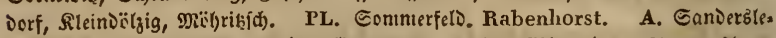

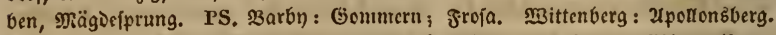

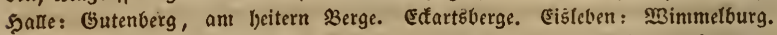
Erfurt. Siegentiif: : Saalberge. HS. Jena: Sorft u. f. w. Meimar: Segeferd, Irvifteot, Budjfalyrt. Eifenberg. Sioburg. Şenfizäot, Edjnecleim bei zhemar. SRS. 2urmftadt, franfenlyaufen.

404. Dreoselinum Cuus, (b) u nof

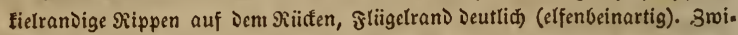
fdjenräume nit 1 Delfanal, Dic Der Jnuenpäd)e fidjtbar, um Das Đittelfelo

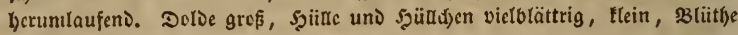
เฉeiิ̄.

1215. O. legitimum M.B. Hayne Arzneigew. VII. 3. Schr.

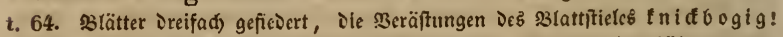

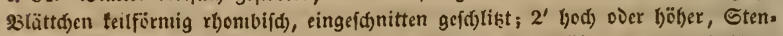
gel geftreift. OFr. Hb. Oreoselini. - Xuf grafigen 2nnbïben, $23 e r g e n$, Iriften. 2uguft. September. 4. Stellenweife, fit)eint in (Ergebirge zu fel)len. D. 230.

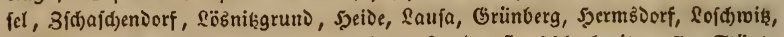

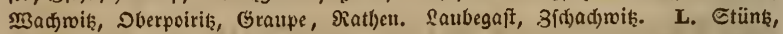

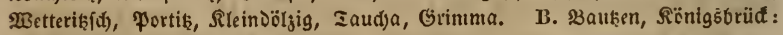

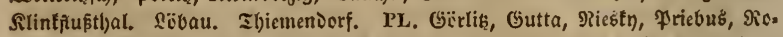

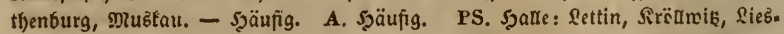
fau. BennDorf. Beerenoorf bei Delikid). Drtrano. HS. Jena: Dorf Seutra, altenberge; zwiftsen Siafla und Gumberda. \$Beimar. SRS. Zrnftadt.

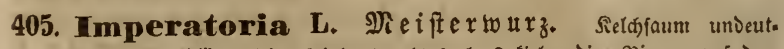

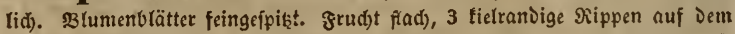

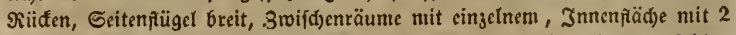

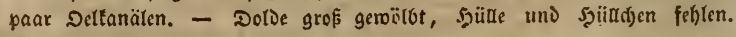
Bliittle meif.

1216. I. Ostruthinm L. Schr, t. 74. Hayne Arzngw. VII. 15. 
Fl. gern. exsicc. n. 170ł. Blätter Doppelt Dreizäblig, Blättd)en breit umgelehrt

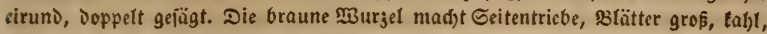
Etengel unten gefurd)t, Dann geftreift, Frudst in uniri)Te runolid), beiderfeits augggeterbt. OFr. Rad. imperatoriae. - In fteinigen, variüglid) quelfigen Dr. ten Der Gebirge, an einigen $\curvearrowright$. uriprünglid, cultivirt $u$. vermilDert. Juli. 2tug. 4. b. - Faltent)ain, 2lttenberg, Sinnwars, Georgenfels, Derf Gay১a, Frauenftein. Z. (Gottȩgabe, Єeifen bei Flatten.) Giđtelberg, Johanngeorgenftaot, Rarls.

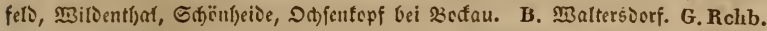

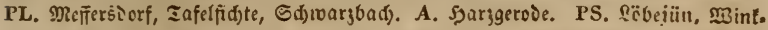

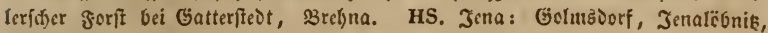
९öbejdıų̈.

406. Anethum L. Dill. Seld) unذeutlid) gejähnt. slumenblatt.

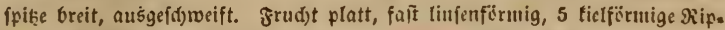
pen, Die äusern auf Denı flügetrande. Sıvijdenräume wen Den Delfanälen

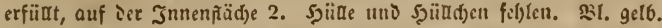

1217. A. graveolens L. Scrк. t. 77. Harss Arzueigew. VII. 17. Blätter Doppelt grficذert, 3lättđen lang fadenfirmig orcitbeilig, \&rudt breit gepiügelt, oyal runolid), an bcioen Enien ausgeterbt. $2-4^{\prime}$ bed), fd) (ant, wont

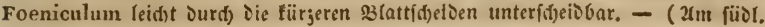
Secjtrande.) (ultivirt uno verwilbert. Juni - 2uguft. ๑.

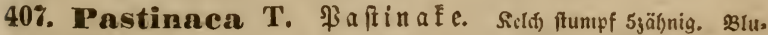
menblätter oval, Epike breitlich) eingercat. Frudft platt, 3 entfernte Sieltip.

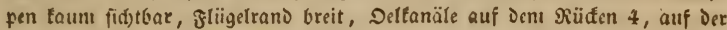

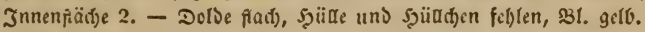

1218. P. sativa L. Scrk. t. 76. Hayxz Arzneigew. VII. 16.

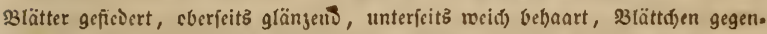
iiber, cirunb, eingef(d)nitten lappig uno gejägt. $2-4^{\prime}$ bod, aud) b̈̈l)er. - b.

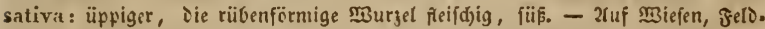
rainen. Juni - Eeptember. ठँ. Jm b̈̈bern Errgebirge feblento, fonit gentein.

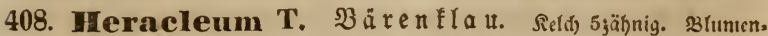
blätter ungctel)rt bergfïrnig, Die feine Epiłe eingebogen. grudyt platt, Dünn 3rippig, શans gefiügclt. Deltanäle von sben über Dic Şälfte berab.

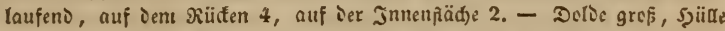
tocnigblättrig, abfalleno, Şüđden vielblättrig, 231. wciß, roja, gclb.

1219. H. Sphondylium L. Haxxe Arzngew. VII. 10). Blättex f(t)arf raud) befaart, 5;ältig gefiebert, Blättit)en geftielt, eingef(b)nitten und ge.

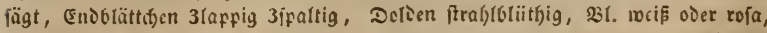
fruchtencten fein bcl)aart, früd)te oval, ffumpf, ausjgeterbt, tabl. $2-4^{\prime}$ bod

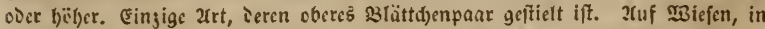

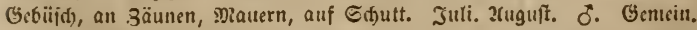

1220. II. elegans JACQ. austr. t. 175. LAs. ill. pl. 200. (Panax sphondylii folio C. Băuh. Moris. t. 17. f. 3.) ßsätter unteríeits feit bes

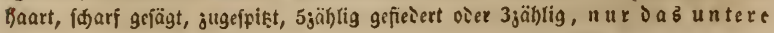




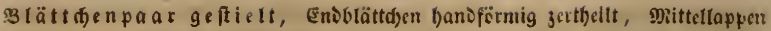
3 - 5ipaltig in Die feitlid)en freujfërmig fieserfpaltigen berablaufend, Grunt

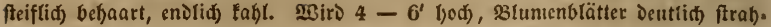

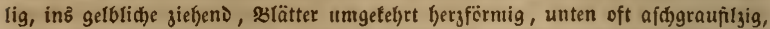

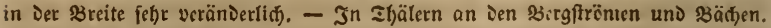

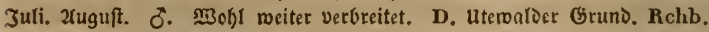

1221. H, angustifolium $\mathbf{L}$. Sv. Bot. t. 363 . S3lätter unten fiteif

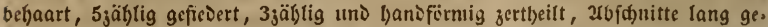
ftrefft, freusförnig, bogig ficberipaltig, greb uno angedriictit gefägt, s3lumen gelb,

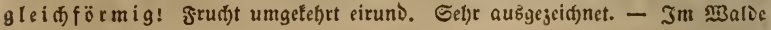

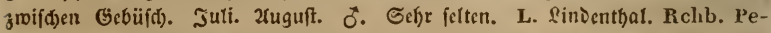
termann. PS. Erieborn, Marfrëlif, Şornburg, Edjmon. Sprengel. Erfurt an. geblid. HS. 3erta bei \$3cimar. Schubert.

409. Tordylium L. 3 irmet. Sieldfaum $5_{j}$ ä̆lnig. slumenblät.

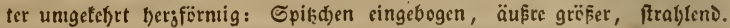

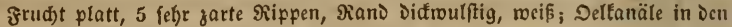

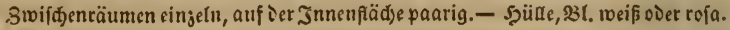

1222. T. maximum L. JAcQ. austr. t. 142. Stengel riidfroärts

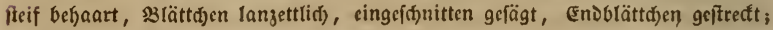
Szülte fïrzet als Die Didftblüthige Dolde. Etengel unten cinfach, $2-3^{\prime}$ hod),

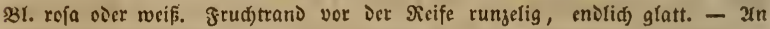

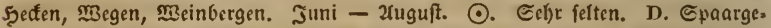
birge auf jmei ßerglÿ̈len unweit Eërnemilk. Mauke. Rchb. L. Rchb. fil. G.

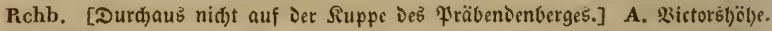

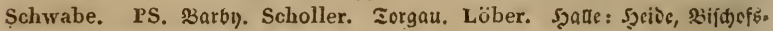
berg. Sprengel.

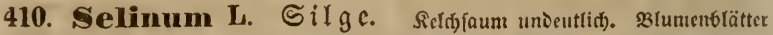
umgetefret berjförmig, Spi(je cingebegen, frud)t ctwas platt, 5 pïïgelfäutige

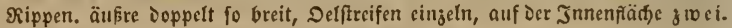

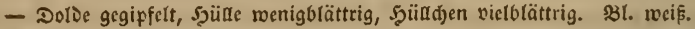

1223. S, Carvifolia L. Fl, dan. 676. JAcr, austr, t, 16. Sснк.

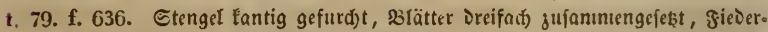
Wen (Elcin) eilanjettlid) ficierfpaltig eingefdynitten, zuid;nitte langettlid) linealijo, an Der Spiţe fdjuvielig ftad)elfpitig, Sjülle 2 - 3olättrig berftenförmig, abge-

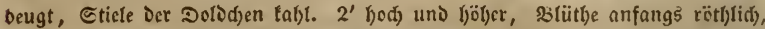

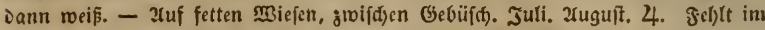
DVergebirge, fonft nicht felten, aber nteift einjeln.

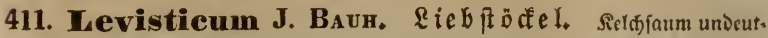
liđ). Blumenblätter (anjettliđ), fpikig, eingcfrümmt. §rud)t etroab platt,

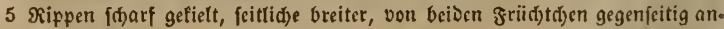

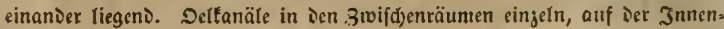

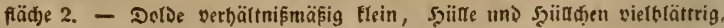
Br. getblid). 
1224. L. vulgare J. BaUh. Schк, t, 68. Harsz Arzneigew.

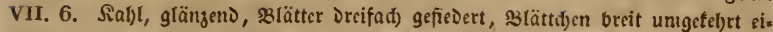

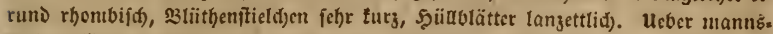
b)d), 3lättd)en Denen vont Cellerie etıvas äbnlid, aber bellgrün. - Orf. Rad.

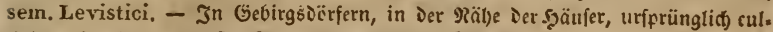
tivirt. Juni - Xuguft. 4. Mamentlid in Gebirge.

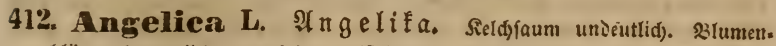
blätter lanjettlid), jugeipist aufíteigend. Frud)t jientlid) flatt, 3 mittlere

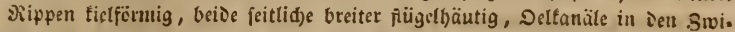

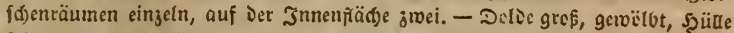

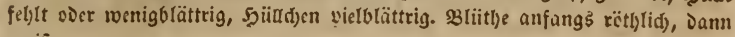
เoei

1225. A. sylvestris L. Schк, t. 6s. Hayne Arzneigew. VII. 9. Etengel gefur(j)t, oben gefftrift, fein bebaart, Blätter Dreifad) gefiècrt, \$3lättd)en

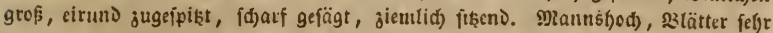

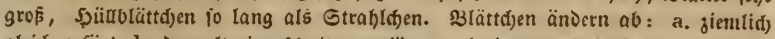
gleid) gefägt, b. Doppelt eingeid)nitten gefägt, c. brciter, grob runilid) geferbt ge=

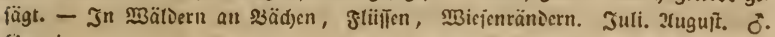
(jentein.

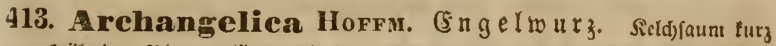

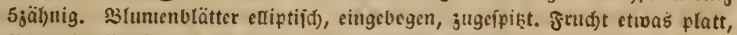
Matl) jientlich in Der Diitte, 3 nittlere Rippen fielfïrmig, jeitlide urcit ge. fiügelt. Sern frei, ringšun nit Deltanälen Did)t ungeben. - Detoe balb.

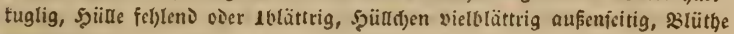
grünlid).

1226. A. officinalis Hoffu. Schk, t. 80). f. 663. grudt. HAYNe Arzueiger. VII. 8.' Etengel geftreift, S3lütter Doppelt gefiedert, mit grofen,

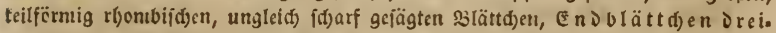
theilig; obere şlatti(d)eiten blafenfïrmig, Şüldd)en glatt, fo lang als Doli.

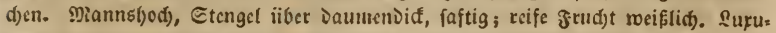

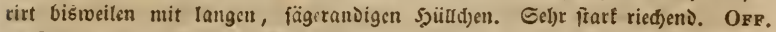
Rad. sem. Angelicae. - Jur Gebitge an \$äd)en, in Der viälse Der Saäufer ur: iprünglich cultivirt. Juli. 2luguft. 4. 3crftrut. PS. Dverftaot bei ङufl, swar woht wits nad) Dr. Metsch, icd faum glaublid).

414. Taserpitium L. Lajer. Sieldjaum $5_{j}$ ällynig. Błumen.

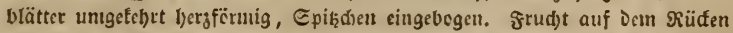

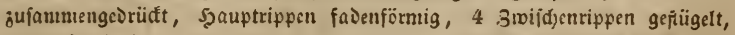

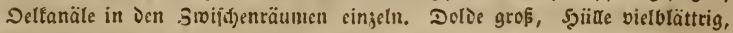
331. wei f ooer gerblid).

1227. L. pruthenicum L. JACQ, austr, t. 153. ScHK. t. S0.f. 651. (ङrudjt.) Eteif belsaart, Etengel tantig, Blätter Doppelt fieveripaltig, fiedern ei:

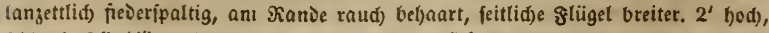

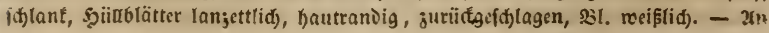




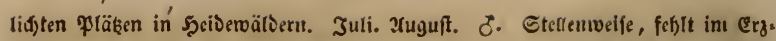

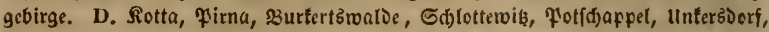

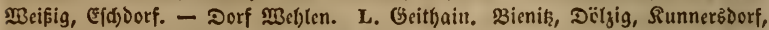

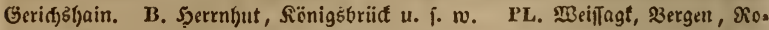

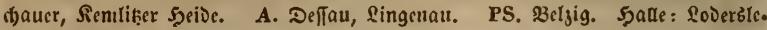
ven, Siegelrode, beitrer ßerg, SandersDorf. Raunburg. Erfurt. Sulgl bei Robr. HS. Jena: $\mathfrak{B}$ ëlniffe, forft. Weintar: \&egefelo. Einboorf bei 2uffedt. Eifenberg.

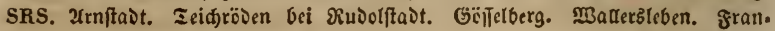
tentyaufen.

1228. L. latifolium L. ' Jacr, austr, t. 146. Sспк. t. 67. Stengel

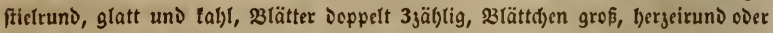

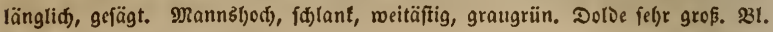
meis. Orf. Rad, Gentianae albae. - b. asperum CrTz. Blätter unterfeit3

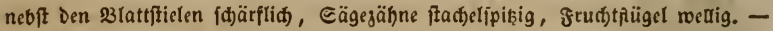
In Salffelfen, smifden Gebüfd). Juli. 2luguft. 4. 3efonderb in Iljïringen,

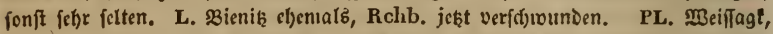

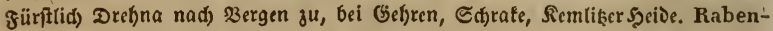
horst. Baruth. Grassinann. A. Ganderb̈leben, Şarzgcrode. Schwabe. PS.

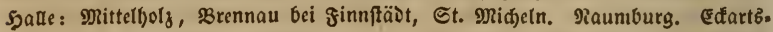

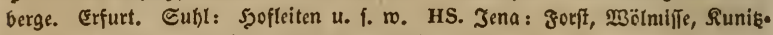
burg, Siegenljain, Rautbal. SRS. Frantenljaufen.

415. Daucus $L$. $\mathfrak{X}$ öf re. Seldfaum 5jäbnig. Slumenblätter

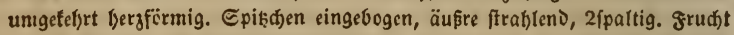

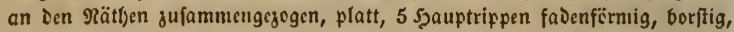

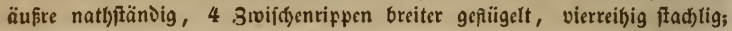
Delfanäle einzeln unter Den 3wiffenrippen. - Sü̈lle fi e Derfpaltig ! $8 \mathrm{Bl}$. meif, im Drittclpunfte cine unfrudstbare grëfere fdjwargrotb. Dolbe gut Frud)tgeit vogelneff oै $\mathrm{rmig}$ ! -

1299. D. Carota L. Schr. t. 61. Hayne Arzneigew. VII. 2. Stengel fteif bebaart, Blätter matt, 2 - 3fađ geficoert, ந̧üablätter fiçerfpaltig ober 3tfeilig, fo lang als Die Dolde. $1-2^{\prime}$ bod), bei ber (Sultur aud) $3-4^{\prime}$, iul erîten Sabre mit rübenförmiger, faftiger, rotbgelber 23 urgel. - Orf, sem. dauci silvestris, Rad, dauci sativi. - Xuf trofnen Miefen, Dürren Felorai.

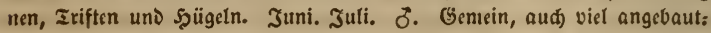

416. Drlaya Hofrm. Drlaya. Mie Daucus, aber Die 3ri. fdenrippen 2 - 3reifig oeftad)elt, äufre 3roifdenrippen breiter, batig befta=

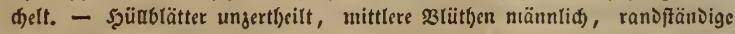
jroitterlid), furggrifelig, in anderen Doloen weiblid und langgrifielig. Gi rö f te DolDenblïtben!

1230. 0. grandiflora HoefM. Schк. t. 70.f.625. (ఫrud)t.) 2uf.

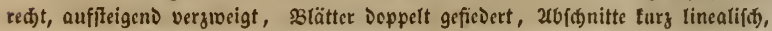
fpiş, DolDen 5 - 10ftrablig, DolDden vielblütbig, Jrud)t mit eingetrünmten pfrientenfpikigen Stad)efn, taunt balb fo lang als if)r 2uerourd)nteffer. - 2ruf Ifefern, 6efonders Saltboden. Juni. Juli. $\odot$. In Thïringen bier und sa, in 
Znbalt fefre feften. A. Eiptenfelie, Reuborf. Scliwabe. PS. 3roifdgen Duerfurt uno Gdjmon. Wallroth. Erfurt. Hornung. 3isgenrïđ. Adler. Dilftäot. Metsch. HS. Jena : Fiospeia, 5auzberg, am Forfte. Bergern bci \$3erfa. Mag. Dala. Zenker. Soburg. Hornung. Grub. Metsch. SRS. Zrmitaot. Nicolai. Lucas.

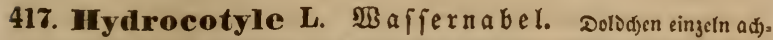

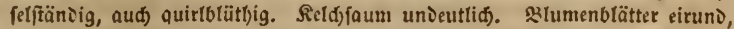

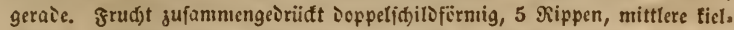

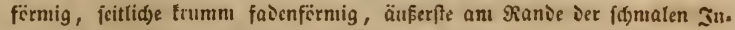

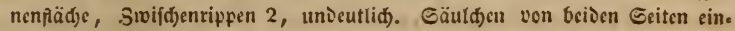
gewadjien. -

1231. H. vulgaris L. Fl, dan. 90. Dolıden quirt. unঠ topfförnig,

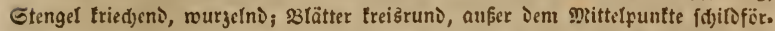

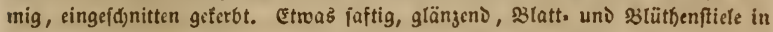

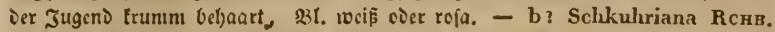

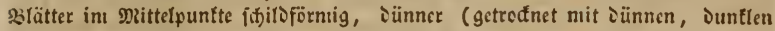

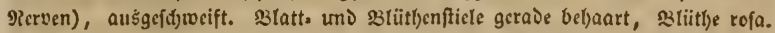

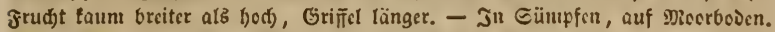
Mai. Juni. 4. Jnt weftlidjen und mittern Gebiet nidjt fetten, im mofftidjen

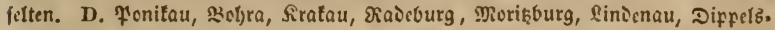

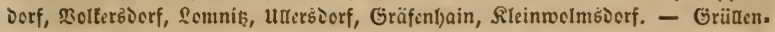

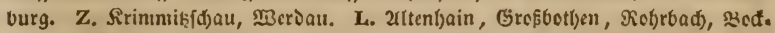

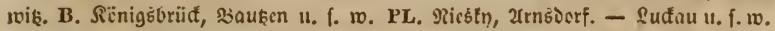
A. Şäurig. PS. 3arb\%. Wittenberg. Düben. Eilenburg. Siçtau. HS. Şain. fpik̨ bei Gijenberg.

418. Sanicula L. Sanifel. Sieldfaum Brattartig 5 theilig. 231 .

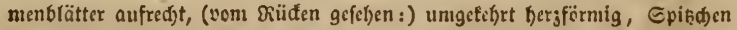
lang gefaltet uno eingetniatt, fpaltipikig. Frud)t faft fuglig, verwadfin, ha. fig beffadelt, Deltanäle zahlreid). Gaante treifelfirmig. - Dolds trugocloig, 33. wciß, polı) $g$ a mi i d).

1232. S. europaea L. Schк. t. 6). Hoppa. t. I. A. f. 1. Mut,

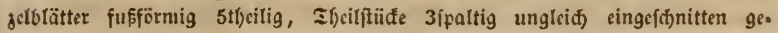
fägt. Duntclgrün, glänjend, fuß̧bod), Blätter lang gefticlt, Etengel fdaftartig

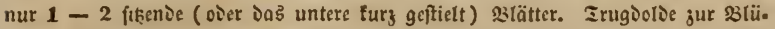

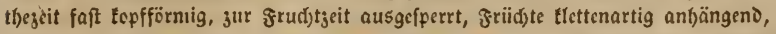

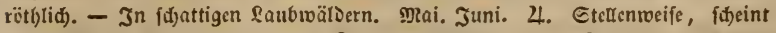

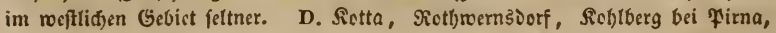

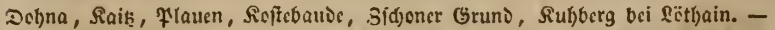

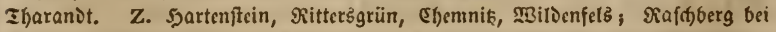

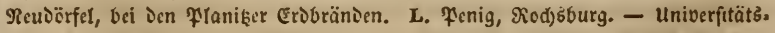

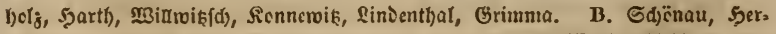

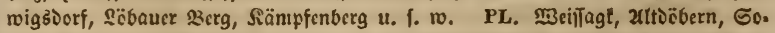
rau, Syjegar bci Gaffen, 23ornsborf. A. Qualenoorf, 5arjgerode. PS. Barby. 


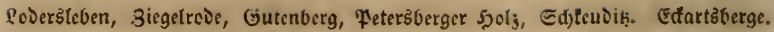
Sulyt. Biegentüf. SRS. 2rmftatt.

419. Astrantia L. Tha ffern. Лeldjaum faft trodenljäutig,

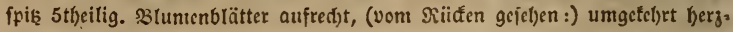
fïrnig längliơ), Spiße lang, gefaltet eingctnidt. Frud)t fpinoclförmig, 5 Sippen aufgeblajen querrungelig, fpäterbin jiegelartig wargig, inmendig mit

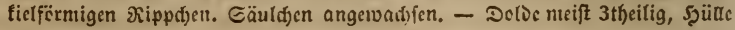
blättrig, Doldd)en büf(jelartig, untbïat. S3l. weiflid), polygamif(b).

1233. A. major L. Schk. t. 6). St. I. 29. Hayns Arzngw. I.

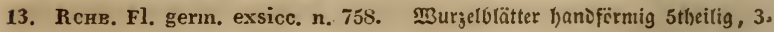

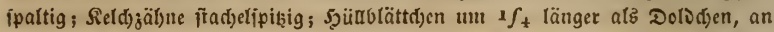
Der Safiz iđ)mäler, Dafelblit nid)t aneinanderliegeno, roeiflid) ober roja, griin ges

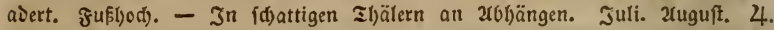
Etellenmeife, in Erjgebirge jef)r felten, in Den (Ebenen jeذcd aud feflend. D.

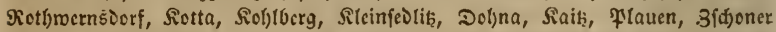

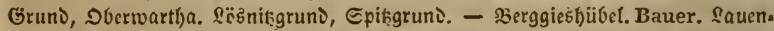
ftein, Geifingsborg. G. Rchb. Z. Ctoltberg in obern হucrenbad). Wankel,

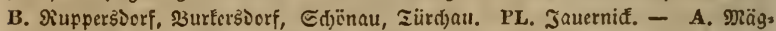

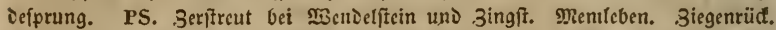

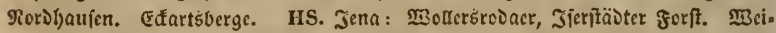
mar: Etterzberg.

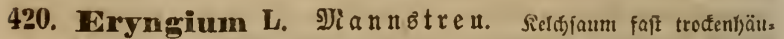

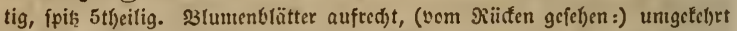

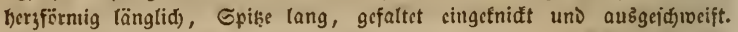
Grud)t freifelförmig, Did)t aufred)t befrad)elt, planconver. Cäuld)en einge:

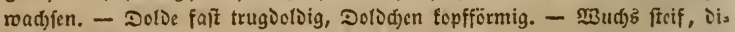
ftelartig befitadjelt.

1234. E. campestre L. Schк. t. 59. HAxxe Arzneigew. II. 1.

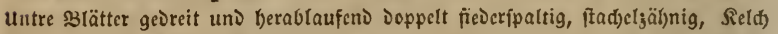

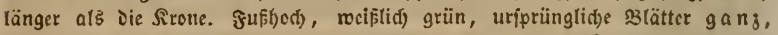

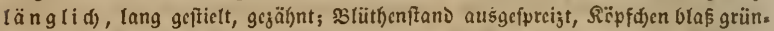

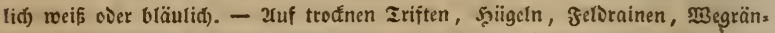
Dern in Der Ebene. Juni - Eeptentber. $\delta$. Jn Den saufiţen jefre jelten, (B.

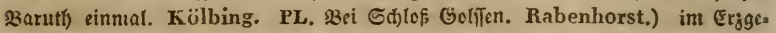

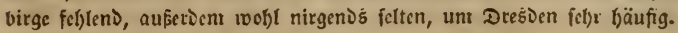

\section{B. Araliaceae: Frudyt ungetfeilt, mefr als 2 griffelig.}

421. Adoxa L. B̉î́a m $\mathrm{r}$ a t. Reldfaum blattartig 4-5tfeilig. Silume feblt. Ctaubgefäje 8 - 10 paarig vor Den Sieldabidjnitten auf cis

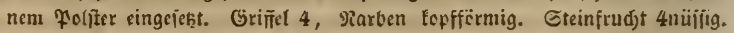
- Blitt)en topritänioig.

1235. A. Moschatellina L. Sснк, t, 109. Fl, dan, 94. Murzicl 


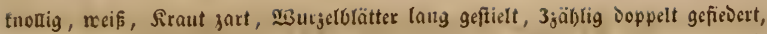

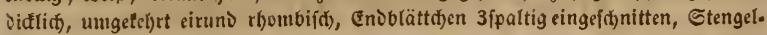

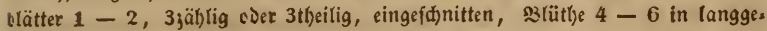

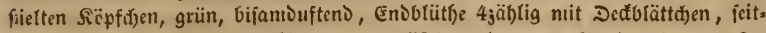

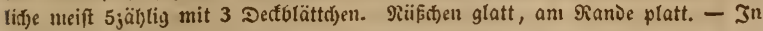
fóattigen Borbëljern, Gebauen, in loďrer Lauberde. 2(pril. Siai. 4. Durd) خ৭B Gebict nifft felten.

C. Corneae: Şlüthe 43 ählig, Fruditfnoten 2 jamlid, Rerne verwatafen, Lei 522 3l. 5 jählig, Rerne 5.

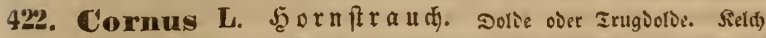
43äl)nig. \$3l. auşgebreitet 4blättrig. 4 Etanbgefäse. 1 Griffel. Steinfrud)t mit 2fäd)rig 2jaamiger গiuß. Slätter bei unjern, Yrten gegenüber.

1286. C. mascula L. Scнк, t. 24. Gurmp. t. 10). Sgülle fo lang

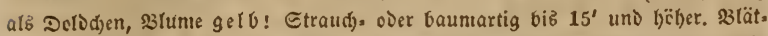
ter oval jugefpist, nervig, veiberfeits fein (d)arfoerftlid), \$l. vorzeitig, Steinfud)t

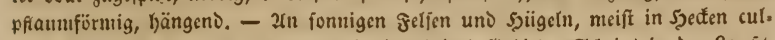

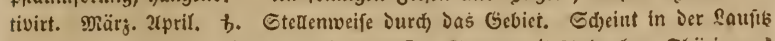

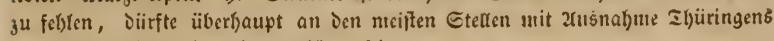
und Der Dribinet Gigents vermilbert fein.

1237. C. sanguinea L. Fl. dan. 481. Gurmp. t, 3. Rснв. Fl. germ. exsicc. n. 82(). Irugbolbe flad), 3lätter cirund oval (gegenüber), 33tu=

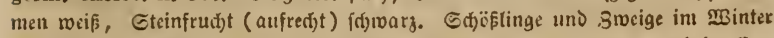

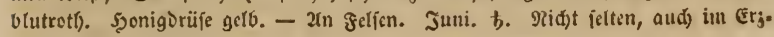
gebirge biz Milbenfelz.

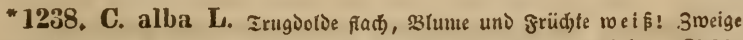
zurüifgetriimmt, sslätter brcit oval, unten graulid). Straud) $6-S^{\prime}$ (jod). Sirfd)=

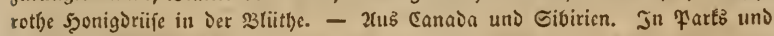
verwilbert. Juni. b.

423. Hedera L. (Fџheu. Sichjaum undeutlid) bogig 5jähnig.

5 frad)e Salumenblätter. 5 Etaubgefäfe. 1 Grifïl verroadjien, 1 Rarbe. Etriufruরiłt mit 5 runjeligen $\Re$ RüFd)en.

1239. H. Helix L. Schk, t. 49. Hayxe Arzneigw. IV. 14. Eten,

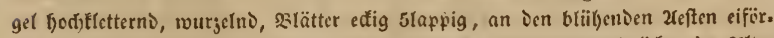

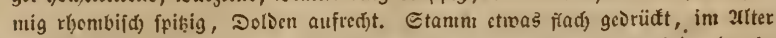

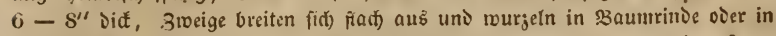
Mauern $40-50^{\prime}$ hod) uno bïber. slüht nur in 2llter, in fonniger Lage. 31. grün, Stcinfrüd)te f(j)marj. - In Märbern meift nidjt bliibend auf Dem

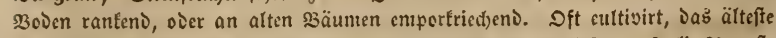

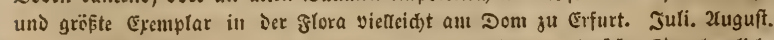
h. Dur(t) Daś Gebict. \$3(iil)t j. S3. D. Plauen 1S42. G. Rchb. [Der berrlid)e

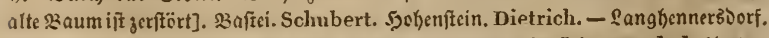
Reichel. Z. Sđfwarjenberg. Bok. Sidjterwalbe, Dberrabenftein. Wankel. (lektere

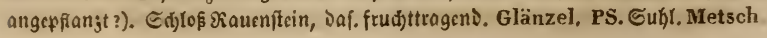




\section{Viteae: Fruhtfnoten frei $2-5$ faamig.}

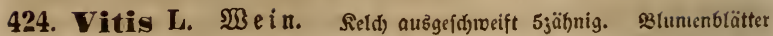

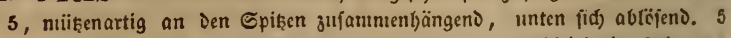
Etaubgefäpe auz einem oriifigen siecter, weldher abrwed)felno in Edjuppen

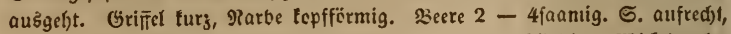

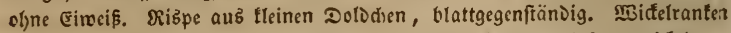

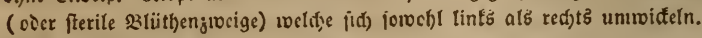

1240. V. vinifera L. Haysz Arzneigw, X. 40. Rche, Fl, gern. exsicc. n. 1464. S3lätter her jfërmig bogig 5lappig eingeid)nitten gefägt, jung

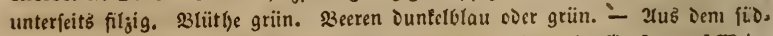

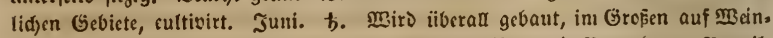

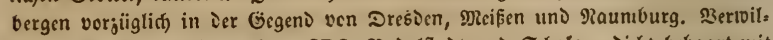

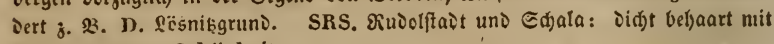
herven šecrd)en. Schünheit.

425. Ampelopsis Michaux. $3 a \mathfrak{n} \mathrm{rebe}$. Reld ausges

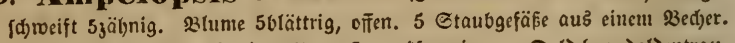

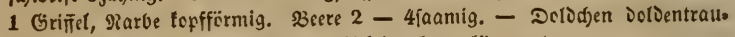
big blattgegenitünoig, oberfte jur Miđ̌ctrante vertünmmert.

- 1241. A. quinquefolia (Hedera - L.) M. KerN. t. G05. Blätter 5 jäblig gefingert, 23lättd)en fur; geftielt, oval lanjettlid), grob (ägeranoig, fabl, Doloentrauben gabeläftig. Rilettert feb) ljod), wurgelno an \$3äumen uno

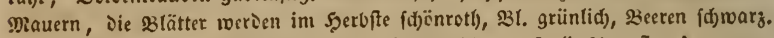

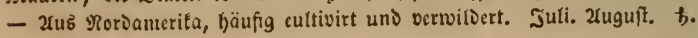

\section{Gamilie Rhamneae, Sireuzoorngeroähfe.}

- Sूerbaricnbud) S. LXI uno 143. -

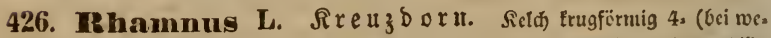
nigen 5s) fpaltig. 2rof(d)nitte nad) Der 33 efrudjtung abfaulend. S3lumenbläts ter fifmal, flein. 4 Etaubgefäfe (vor den $\mathfrak{B}\{$ umenolättern!) herauss

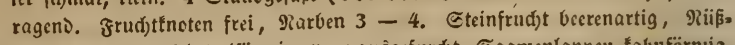
d)en $1-4$ umgetef)rt eifïrnig, vorn auşgcfurd)t, Eaamenlafpen tal)uförnig.

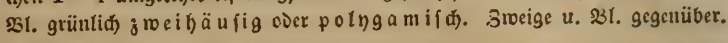

1242. R. catharticus L. ScrK, t. 46. Hayxe Arzneigew. V. 43. Sweige Dornipiļig, abltel)eno, siätter oval geferbt gefägt, core Cägejäthne in ciner Drüfe endend, 2z(iithen folngamifá, Eteinfrud)t 4nüifig. $6-8^{\prime}$ bed),

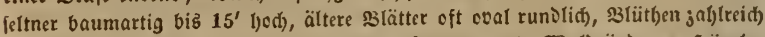

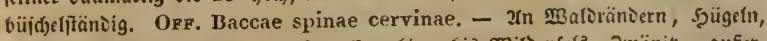
in 3äunen. Mai. Juni. b. Jm Erjgebirge biß Mitbenfols, Swönił; auker. Dem Durd) Das (Gebict nid)t felten.

427. Frangula Dovov. Fau $\mathfrak{I} \mathfrak{a} u$ m. Fild frugförnig $5=$

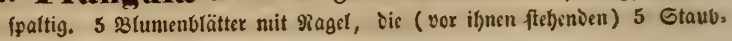


gefäfe lappenartig cinbüllend. Rarbe lgpffürmig. Steinfrud)t becrenartig, Siïßð)en 1-3, oreiefig runolid), fiad), unten genabelt, Saamenlappen fiach).

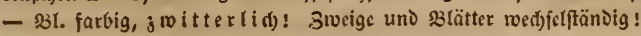

1243. F. vulgaris Rснв. Schк. t. 46. Hayne Arzneigew. v. 44. Sabl, Blätter oval, ganjrandig, taum auşgciđ)rocift. Strau(j)artig 8-12'

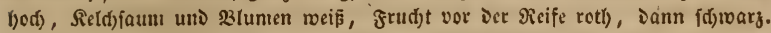
औiïfđ)en bleigrau, mit toeifem Tabel. OFF. Cortex et baccae Frangulae s. Alni nigrae. - In feudten Maloungen, auf Sumpfivicfen, an Gräben, Iei. (b)en, 3äunen. \$Rai. b. Gemein Durd) Das Gebict.

\section{Familie Terebinthaceac, כcrebinthacen.}

\section{- Şcrbarienbud) 5 . LXI und 145. -}

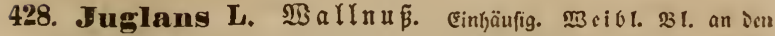

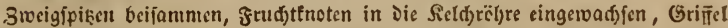
in 2 ausggefpreijte Tarben gefpalten, Feldfaum 4jäf)nig, Slunce trautartig

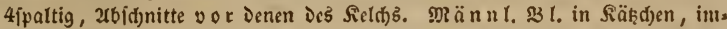

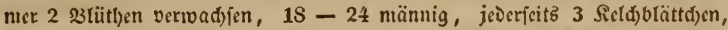
Staubfäben blumenblattartig, Scutel in Der Mitte aufgeroadjen 2fä(brig, gleid)fant Doppelt. Steinfrud)t mit 2tlappiger $9 i u \hat{\beta}$, Gaanten nit febr großen runjelig jufamintengelegten Saanienblättert.

* 1244. J. regia L. Sснк. t. 302. Harxe Arzneigew. XIII, 17.

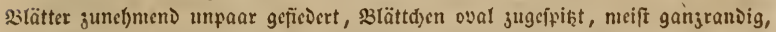
tabl, grudjt längliđ fugclig, glatt. Stanım in $50-60$ Jalsen $60-8()^{\prime}$ hod), wiro aber melyre 100 Jalye alt uno $2-3$ Fus Diff. \$l. grïn, cbenjo Die Frudt. - OFF. nuces juglandis immaturae, cort. s. putamen nucum ju-

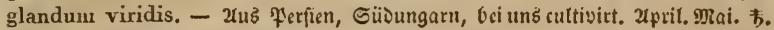

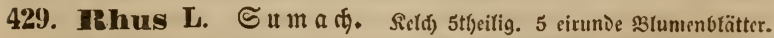
5 Staubgefäfe (med)felfän๖ig). Srud)tnoten einfäđrig. Rarben 3. Stein.

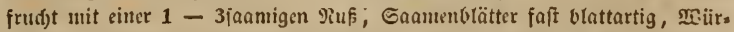

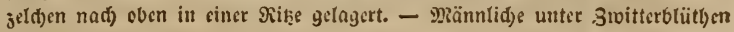
berinolid).

* 1245. R. Cotinus L. Jaç. austr. t. 210. Gurmp. t. 30. 33tät.

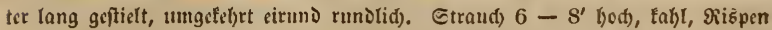
enoftänoig, loffer, fpäterbin Die langen bel)aarten Etield)en surd)einander gewad). fen: "Perü đen ba un". Orf. Cortex Contini. - Xus Eibirien, Ungarn. Eultivirt. Juni. Juti. b.

* 1246. R. typhina L. Durax. ed. Ir. t. 47. salätter 8 - 10.

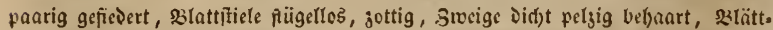

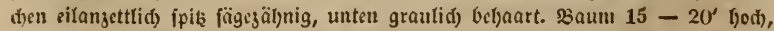

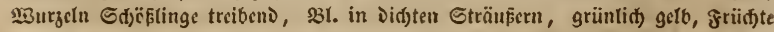
raud), roth), Dann läpt fid) Der Gtraus mit Sobrtulben verglciḑ)en, Daber (von

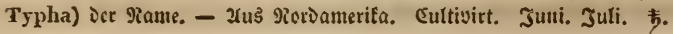




\title{
Familie Papilionaceae, Edhntetterlingsblüthige.
}

\author{
- Şerbarienbud) G. LXII unt 147. -
}

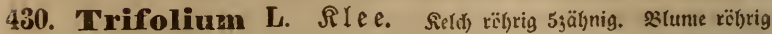

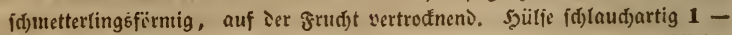

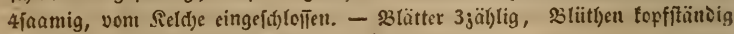

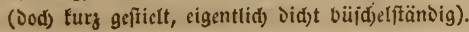

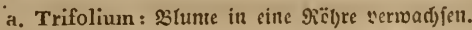

1247. T. fragiferum L. Fl. dan. 10+2. ST. IV. 16. Siricđjent,

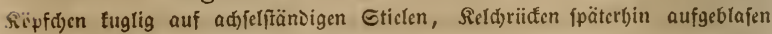

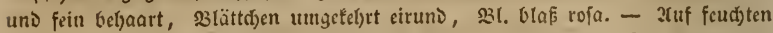

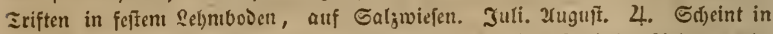
Der Dberlaujiţ uno itl erjgebirge jul fel)len. D. Etrefla, Setbuitz, Siebtau, grie. Derau, Gröbern. L. Sangenleube, \$3ienis, Dïlsig. PS. Stứau u. f. w. A. Seau, Dranienbaum, Sandersteben, 52arz. PS. Ynger bei \$arby. Mittenberg:

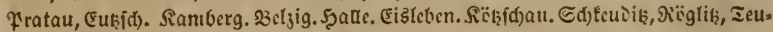
Dik, Dürtenberg. Mecrfeburg. Erfurt. Grofintonura ut. a. D. HS. Eijenberg, Siegent)ain.

1248. T. striatum L. Fl, dan, 1171. ST. IV. 16. Rснв, Fl,

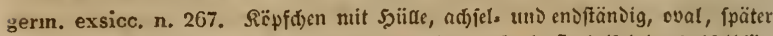

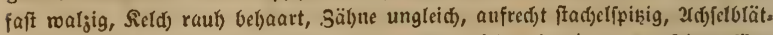

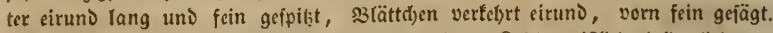

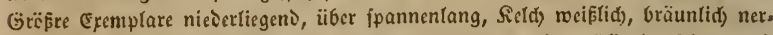

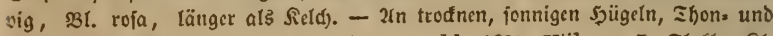

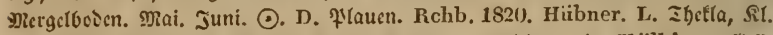

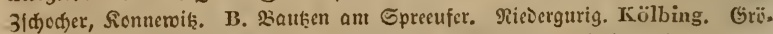
Dik̨, Ebersbađj. Rabenhorst. PL. Gutta. Kölbing. - Gabro, Giuben. Ra-

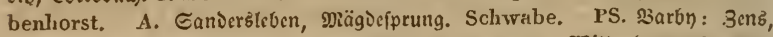
Doben, Bromberg. Scholler. 2(jd)erbleben. Hornung. M̉ittenberg: Fratau,

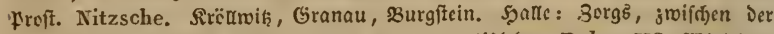

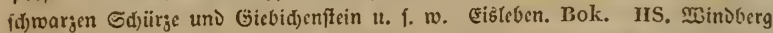

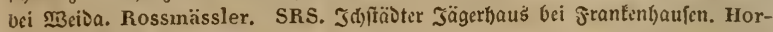

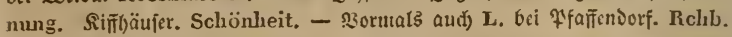

1249. T. arvense L. Fl. dan. 724. Sr. 16. Fein bet)aart, fidtant,

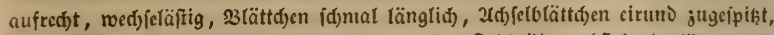
Sïpfd)en einjeln, oval, Dann waljig, feinjottig, Sisldf)

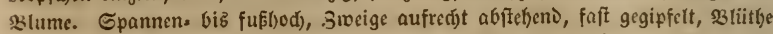
t(ein, meiflin). - b. gracile Thuxц. Rснв. Fl. germ. exsicc. n. 1363. jar,

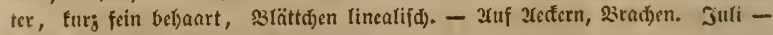
Eeptember. ○. Gintcin un๖ bäufig.

1250. T. ochroleucum L. JAcr. austr. t. 40. ST, IV. 15. Rснв.

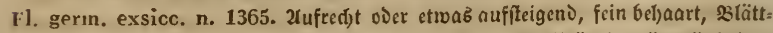

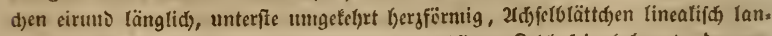

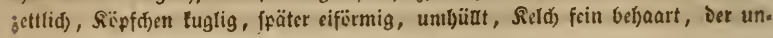




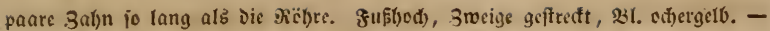

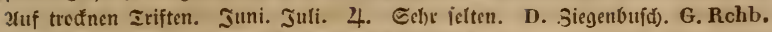
(jropsobrik. Schubert. शiaाাe 2ue feit Bucher.

1251. T. pratense L. Scrk. 210. Sт. 15. 2tufíteigend, Did)tmarfig,

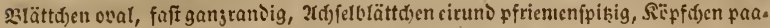
rig, fuglig, untlüut, Sield) fein belyaart, Säl)ne fadenfïrmig, gevinipert, fo lang

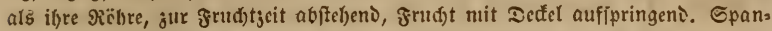

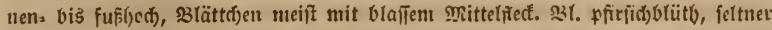
Ulafrofa woer wetf. - 2uf İiefen. Juni. Juli. 24. Gemein.

1252. T. sativum MrL. ST. 15. Etenget allfre(t), gefurd)t, rä().

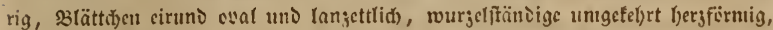

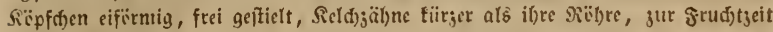

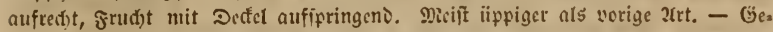

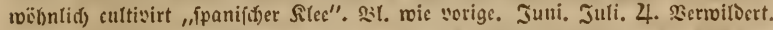

1253. T. expansum W.K. t. 237. 2tufiteigeno, leió)t geffreift, Did)t,

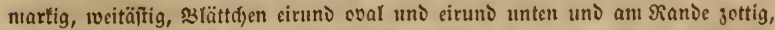

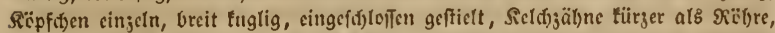

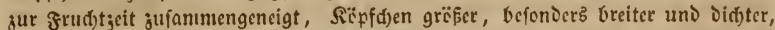

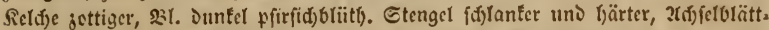

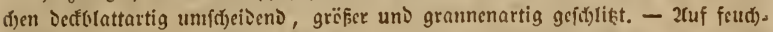

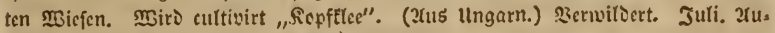
guft. 4. Sclyr felten. PS. Rïlleior. Rehb.

1254. T. medium L. Fl. dan. 1273. ST. 15. Stenger aufĩeigens,

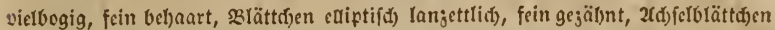

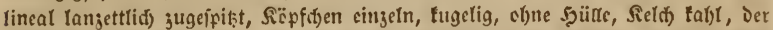
unfaare Sal)n verlängert. Tur in l)obem Grafe viro Der Stenget Durd) Die ttm: gebung neffr aufred)t, fonft nicoerliegend. Fëpfđ)en grof und Dunfeler pfirfid):

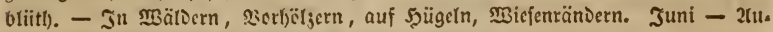
guft. 4. ふ3is inş hołe Gebirge fteđtenwcife häufig.

1255. T. alpestre L. JAc?. austr. t, 433. ST. 15. Etengel ftcif aufre(b), einfađ), siättd)en längliđ lanjettlid), fein gejügt, 2(d)jelb(ätter lanjetts (id) pfrienulid, Sïpf(ben fugelig, umbüüt, meift pantig, Seld) jottig, ier uns paare 3al)n verlängert. Stengel hart, bis fuFl)ed), s3lätter $4-5$, 23l. Duntel. rotl). - b. bicolor Rснв. $\mathfrak{B}$ l. wocí, Ral)nblättđjen rotb. - c. robustun, vicl

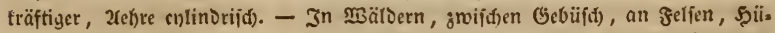
geln. Iuni. Juli. 4. D. - Ibaranot uno ant. D. Z. Sei .3wictau, aus ferdent nid)t felten, folflt in 5eibegegenten. - b. fano id) sor 18 Jaf)ren $D$. im

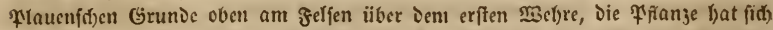
feitoem iut botanifáen Garten erhalten. - c. biex umb Da, namentlid) D. in Der Meifner Gegent. Die geröb)

1256. T. rubens L. JAC?. austr. t. 385 . ST. 15 . Rснв. Fl.

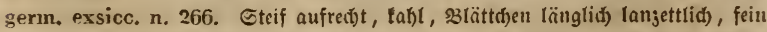

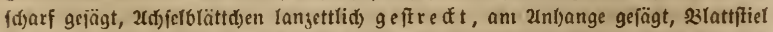

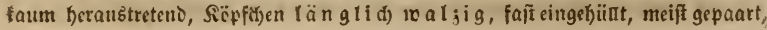




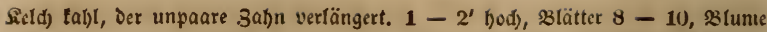

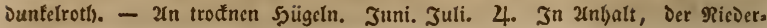
Iaufib und Ifüringen. PL. Reuzelle. Fischer. Raftenborn, Guben. Rabenhorst. A. Sjarzgcrode, S3ictorsbël)e. Schwabe. PS. 33urgroenden. Rchb. Fest. Éfartśberge. Rodig. Erfurt. Bernhardi. HS. Jena: Zautenburger Forft, Wöl. uiîe, Runiǩburg. SRS. Frantentyaujen. Hornung.

1257. T. montanum L. Fl. dan. 1172. Sr. IV. 15. Etengel faft

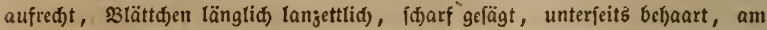

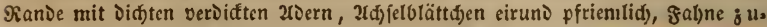

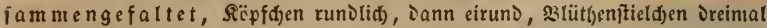

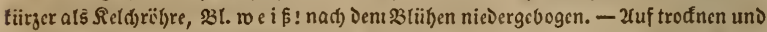

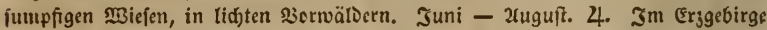
jelten (D. - Il)aranit. Papperitz. Xttenberg. G. Rchb. Z. (5)emnik̨. Bok. miefentf)al. Wankel.), auf(r)

1258. T. parviflorum EнRH. W. Krt.t. 252. (strictum Schrez.)

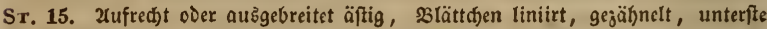

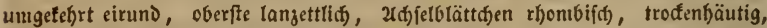

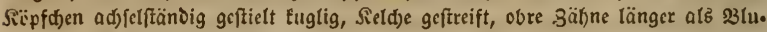
me, Frud)tteld) abmärts gebogen, Bähne tief gefpalten, langsttlid), aufroärts ge.

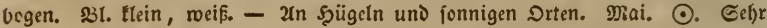
filten. A. Sarz. Schwabe. 3wiften Flö; und 1 Balternienburg. Scholler.

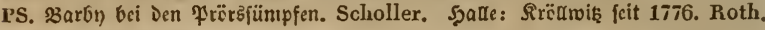
Granau. Wallroth.

1259. T. repens L. Fl. dan. 990. ST. 15. Sriedfenb, 2djfelblätt.

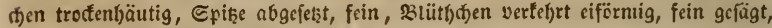

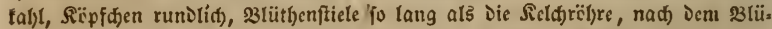
lyen niedergebogen, falyne jujammengelegt, sjülfe 4;aantig. Siclde tociflid), vic.

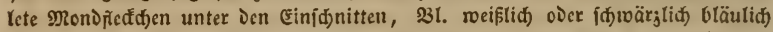
angelaufen. T. anomalum Schrк. monftrëz mit blattartigen Reldj̧älynen. - b ? pentaphyllum: \$lättţen meift gu 5, ganj oicr im Mittclfeloe id)toarg.

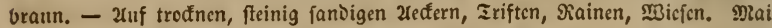
- 2uguft. 4. Gencin bis ins Gebirge. - b. cultivirt.

1260. T. hybridum L. Fl. dan. 1706. Sr. 15. Etengel auf,

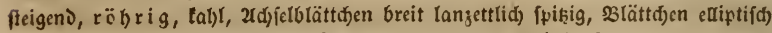
rautenfërnig, fcin gefägt, fabl; Sïpfdjen faft luglig, slütbenjticldjen $2-3 \mathrm{mal}$ länger als Dic Reldrr̈bre, nađ) Dem Blüben nicDergebogen, fabne jujammenges

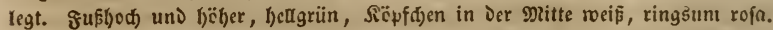

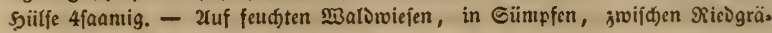

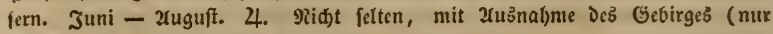
3wiđ̌au, (๕)cnniß̨ und Untergebirge).

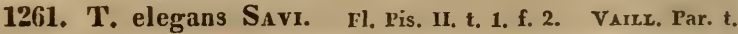
22. f. 1. Etengel aufiteigend, a $u$ şgefültt martig, slättdfen länglid), fein

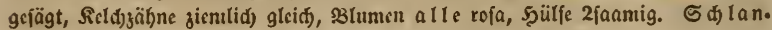
fer als yoriges, bie Sïpfdien ta um über balb fo grof, ganj rofa. - 
2uf M̉ufbicfen. Juni - 2uguft. 4. Sel)r fetten. B. Bet 3ittau. Reichel.

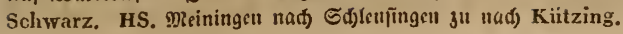

b. Lotophylluin (Rchs. ic. exot. anno 1S24. n. 7.) 3lunte vell.

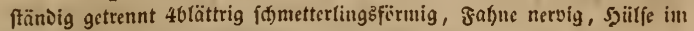

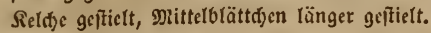

1262. T. filiforme L. Fl. dan. 1707. Sr. 16. 2(ufre(t)t, aufifeigens

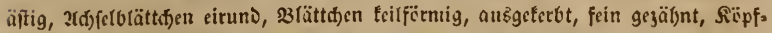
(d)en feitlid), lang geftielt, büf(t)elförnig, Blüt)enfitiele nad) Dem Blïil)en nieierge. bogen, Reldie tabl. Bartefte einbeimifid)e 2rt. Etengel alterdings faienförmig,

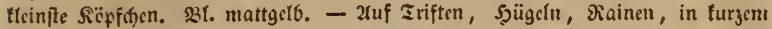
Graje. Mlai - Juli. ○. Gimein Durd) Das (Gcbict.

1263. T. agrarium L. Fl. dan. 55S, ST. 15. (aureum) Scнк. t. 210. Rснв. Fl. germ. exsicc. n. 762. 2(ufredt, fuff)odf, 2(b) felblättd)en läng.

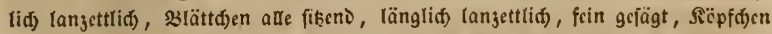

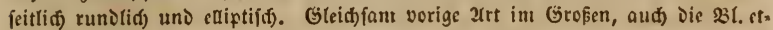

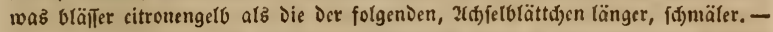

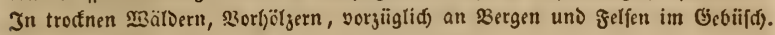
Juni. Juli. ठ. 5ier und Da Durd) Das Gebict.

1264. T. campestre Sснгев. St. 16. agrariun Scrk. t. 210. xufred) $t, 3 w c i g e$ aufitcigens, నïpfd)en grof, citrongelb, (abgeblübt gelblit). braun), Rëpfd)enftiele etwa fo lang als Die ungcfelfrt cirunien \$lättḑen. Sweige

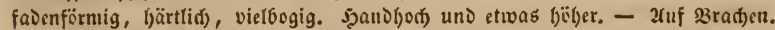
Juli - Eeptenber. ○. 9Rid)t felten Durd) Das Gebiet.

1265. T. procumbens L. Fl. dan. 796. ST. 15. Etcuget und Die

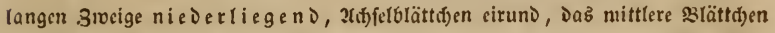
länger gefticlt, Sïpfófen Ileiner, feitliơ), runolió) und cliptifd), citrongelo (abges bliibt gelbbraun). Bismeilen fuflang, vielbegig. - 2luf \$Biefen, Iriften, feut):

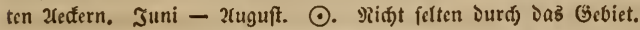

1266. T. spadiceum L. Sr. 16. Rспв, Fl. germ. exsicc. n. 763.

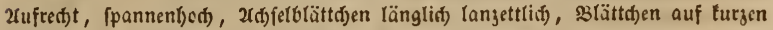
gleid)langen Etielen, Die Der unteriten $\mathfrak{B}$ l. umgefelyrt her,jf̈̈rmig, Die Der oberiten

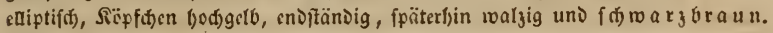
slütbenfitield)en nad) Dem 33 lüben niedergebogen. Sabl oder fein bet)aart. - 2tuf

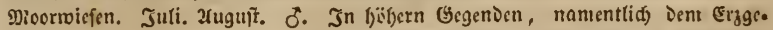

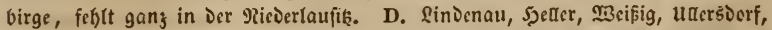

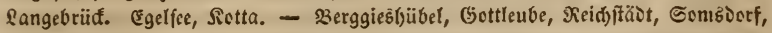

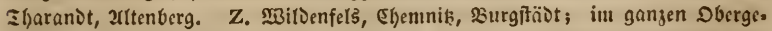
birge. L. Penig. - 3orna, finienau. B. Soblander 23erg. Swijden Serrn= but uns Euloorf. PL. 114ersoorfer Doftberg. A. Dranienbaum, 5arz. PS.

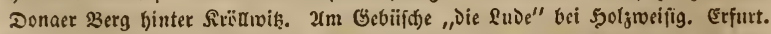

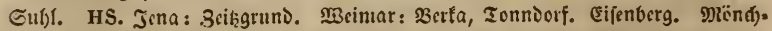

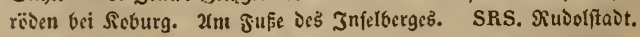

$x n$ m. T. scabmun. A. Walternienburg, Mägbefprung, Şarzgeroie. Schwabe. 


\section{Papilionaceae. $\quad-286-$ Trifolinm.}

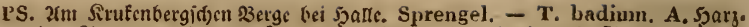
geroie, Singenall. Sprengel. Jd) jweiple an Der rid)tigen 23eftimmung Dicfer Prianjen.

431. Relilotus T. Axx. NR e fot enflee. Sieló) gloctig, stwas

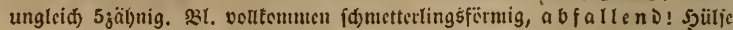
aus Dem Sieldye berausragend 1 - 3inamig, aufgetricben, unvodtonumen

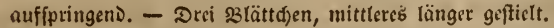

1267. M. dentata W. W.K. t. 42. ST. 15. (Kochiana W.) HArxR Arzneigew. II. 34. Rснв, Fl. germ. exsicc. n, 648. Silättd)en länglidł lan.

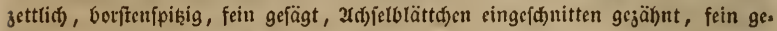

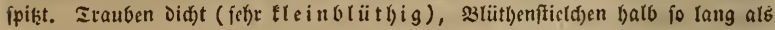

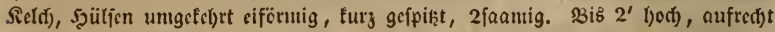
oder Die ๔eitenftengel auffteigend. - 2luf far jhaltigen Eumpfiviefen. Juli -

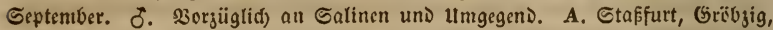

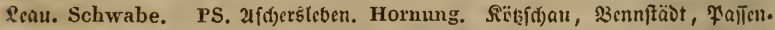

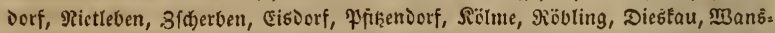

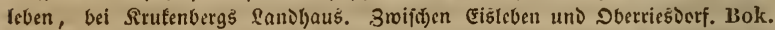
Xrtern. Hornung. Kchb. HS. \&ouifentall. Bnddensieg. SRS. Frantent)aufen. Hornung.

1268. M. macrorrhiza Pers, W. Krit, t. 25. 2fufifeigend, 23lätt:

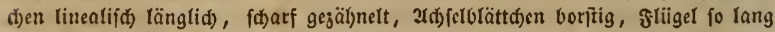

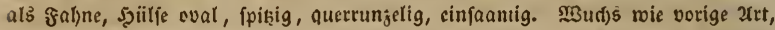

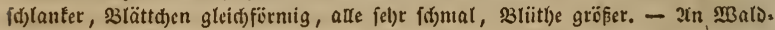

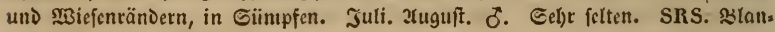
fenбurg. Schönheit.

1269. M. Petitpierreana Hayne, Arzngw. II. t. 33. anno

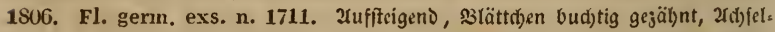

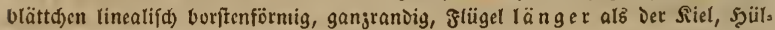
fen oval, quertunjelig, 1faamig, Eaamen of)ne 5jöđer. $1-2^{\prime}$ l)od), Irauben roffer, 3l. citrongelb, 2 Gaamtjen verfiimmert. OFF. Sumnitates Meliloti. -

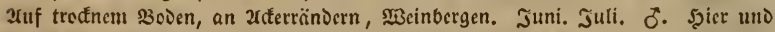

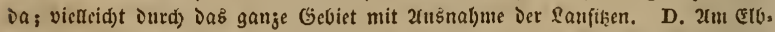

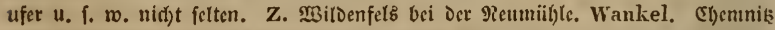

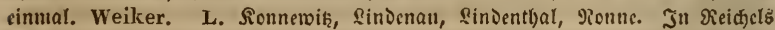

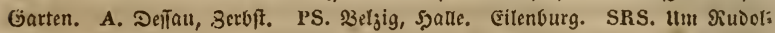
ftaot felyr verbreitet.

1270. M. officinalis Wilud. Fl. dan. 934. Haxe Arzueigew.

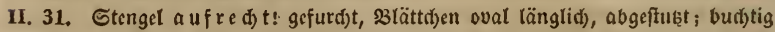

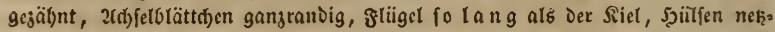

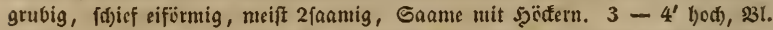
weit größer als an aden andern, bod) gelb. OrF. Summitates Meliloti. -

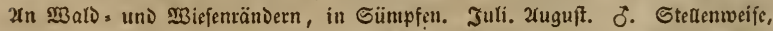

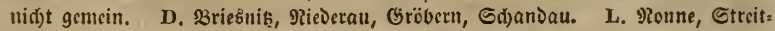

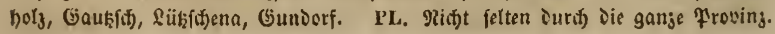




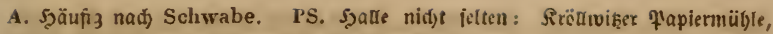

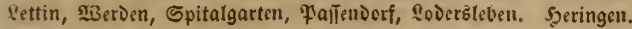

1281. M. alba ThumL. (vulgaris W.) Hayxe Arzngw. II. 32. Erengel aufrefft, siätter etwas geftukt, budjtig gejälnt, Die Der unterfen 21. faft rloombifd, Die Der obern lanzettlid), X(d)felblättd)en ganjrandig, flügel län. ger als̆ ier Sicl, Ş̈̈lfen vertel)rt ciförmig, ncţgrubig, c injaanig, Gaante obne

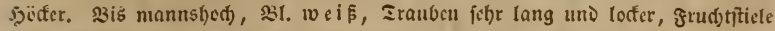

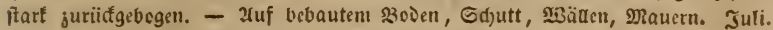

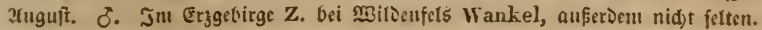

1272. M. arguta Rснв. 2rufredt, slättchen alle gleidfförmig

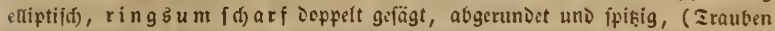

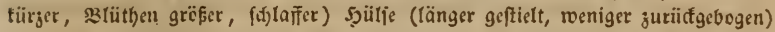

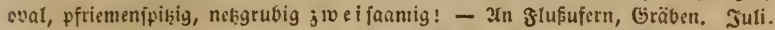

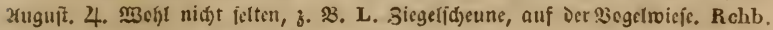

1273. M. coerulea LAM. ST, 15, Fl, germ, exsicc, n. 1029. ฐrau. ben feffförmig. 2ufre(t)t, $1-2^{\prime}$ bod, słlätt(t)en läıglith, Slüthe blau, Șiilfe

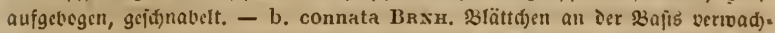

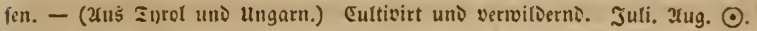

432. Trigonella L. Trig une (le. Seld glodig fünfjälnnig.

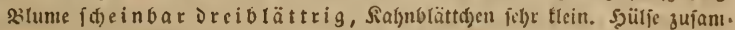

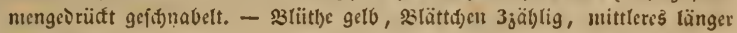
ge|̃ielt.

* 1284. T. Foenuin graecum L. Schк, t. 211. Harne Arz-

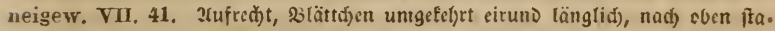

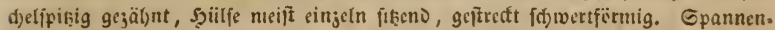

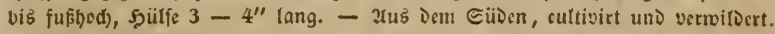

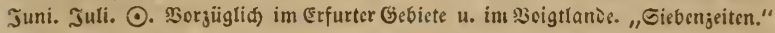

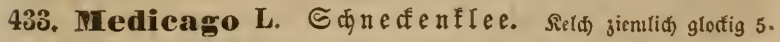

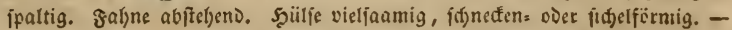

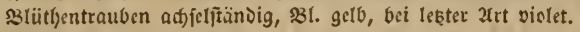

1275. M. Iupulina L. Fl. dan. 992. Schк. t. 212. Irauben Didt vielolütbig, Şüljen sen $1^{\prime \prime \prime}$ Durd)meler, nictenförmig, Epiß̧e getvunden, aufs getrieben, concentrif(t) àcrig, Tängliđ() neţnınf(fig, e in faamig. Sabl over fein

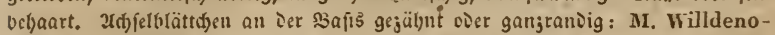

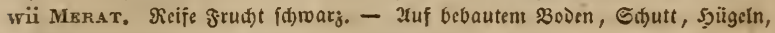

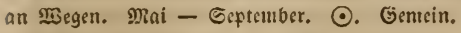

1276. M. minima Lax.' Sснк, t. 213. Fl. germ, exsicc. n. 270.

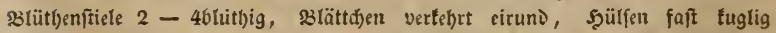

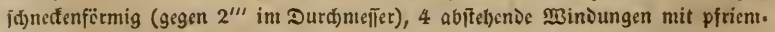
lid)en, fdjef 2reilbigen, etroas gefrïmnten bafenipibigen Stad)eln, weld)e tïrger

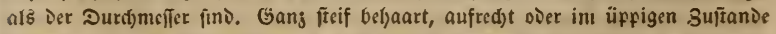

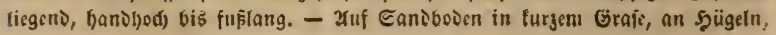




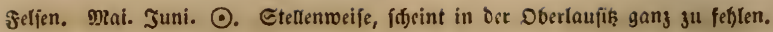

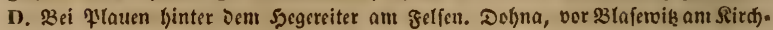
bofe, 2llaunfiitte, Rïtik. - 2uguftusburg. Bok. Z. Dedcran. Bok. L. 21t. rannftäbt, Segerik. PL. Sprentberg, Guben. A. Sernburg, Gandersłeben. PS.

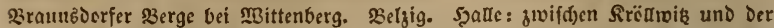

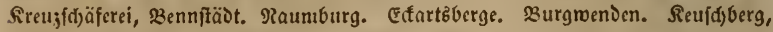

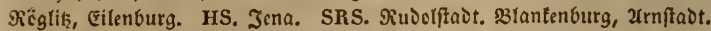

1277. M. denticulata IV. Rскв. Fl. germ. exsicc. n. 1944. 3lü. thenfticle 4- Sotüthig, Şüljen (2"“ Durd)meîer) 3windig, flad) neţaderig, Sta.

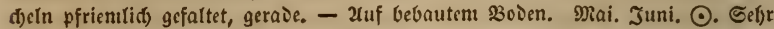

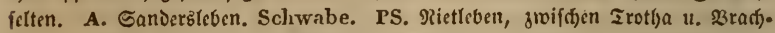

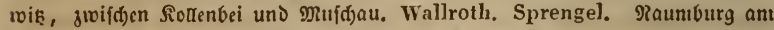
Bege naর্(b) Der Grofjenacr Bäl)re. Beneken. Miiller. Buddensieg.

1278. M. procumbens BEss. Riederliegend, Zrauben vicrblütbig,

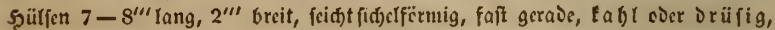

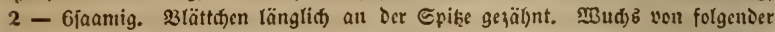
$2 \mathrm{rt}$, Szülfe weniger gebogen, 31 . lebraft gelb, Saame eirund. - 2uf trodfnen Şügeln unذ MBiejen. Juli - Eeptember. ๑. Etellenweife.

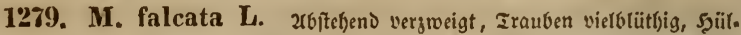
fen 5"' lang, $11 \int_{2}{ }^{\prime \prime \prime}$ breit, fid)elförmig, ftriegelig bef a art, 5-Sjaamig. Cten.

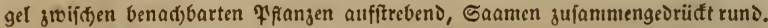

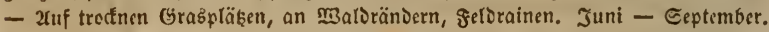

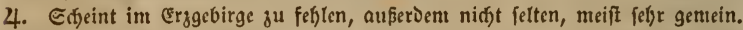

1280. M. media Pers, (Falcata.) Rrv. II. t. 83. Falc. Gakrt. t. 155. Sснк. t. 212. Fig. A. 2uffíteigeno, ₹rauben vielblïtbig, Blunte grïn. gelb, in violet fiefjeno, Ssüljen $3^{\prime \prime \prime}$ lang, $2^{\prime \prime \prime}$ breit, fid)elförmig balbtreisbogig,

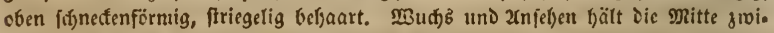

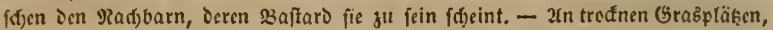

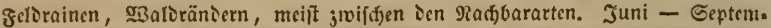
ber. 4. Eiđer weiter verbreitet. D. Elbufer. L. Sindentbal. PS. Diirrenberg,

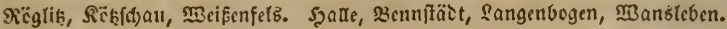

1281. M. sativa L. Scrк. t. 212. ¿rauben längliđf, vielbliitfjig,

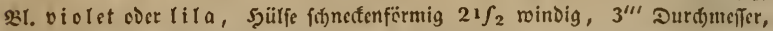

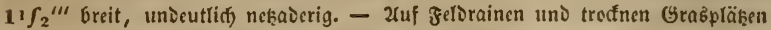
vermilbert "fujerne", auf 2ecfern cultivirt. Mai - 2uguft. 4.

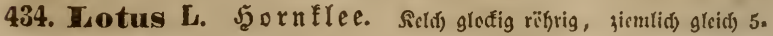

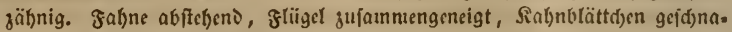

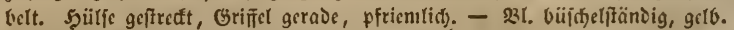

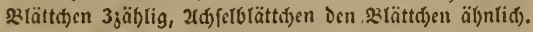

1282. L. tenuifolius Poxs. Engl. Bot. 2615. Etengel fadenfïr.

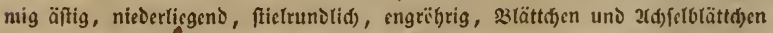

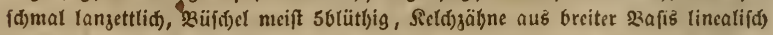
fadenfïrmig, gerade, șüllfen $2-3$, ftictruno, $9-10^{\prime \prime \prime}$ lang, $1^{\prime \prime \prime}$ dif, aub der 


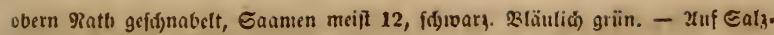
เoiefen. Juli - Septembcr. 4. Selten. L. Riiiłnarsborf. Petermann. PS.

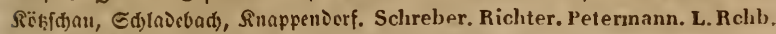
fil. HS. Foburg. Hornung. SRS. Srantent)aujen. Hornung.

1283. L. corniculatus L. Fl, dan, 991. Engl. Bot, 2(196). ar-

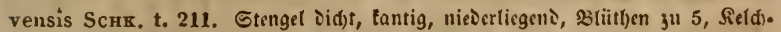
jäl)ne na(t) uno nad) verf(b) routenförmig jıijđ)en oen fliigeln vortageno, sjülien $3-5$ fitelruno, $8^{\prime \prime \prime}$ lang,

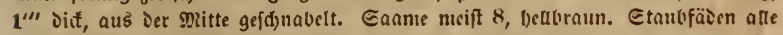
breiter weroeno. Slättd)en ungetef(t) eiruno, Didlid), fattgriin, fabl. - b. villosus Trurzl. Etengel, ß3lättden un১ Relde zettig. - Uuf trofuen Gras.

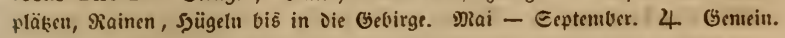

1284. L. major Scop. Engl. Bot. 2(y91. uliginosus Sснк. t. 211.

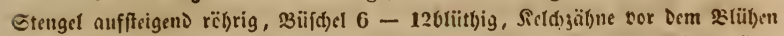
jurüđgelıcgen, bärtig. Syülịen siinn, ftlitruno, 10-12"' Iang, faum ïber ' $f_{2}$ '" Did, Eaamen meift 20, braun. (Gewöbntid) weit grëfer als voriger, fatt。

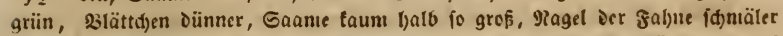

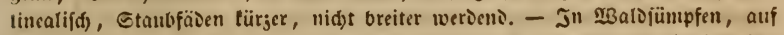
Gunpfuicjen, an Ieid)en. Juli- September. 4. Durd) Das Gebiet nidjt filten.

\section{Tetragonolobus Scop. Epargelerbie. Sidt}

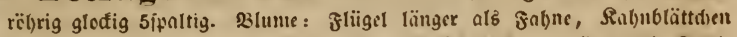
gefit)nabelt. Grifiel vogig. Syiilie fteif, geftreft, 4 tantig geriügelt mit Edyei. Dewän๖en, viđtjaanig.

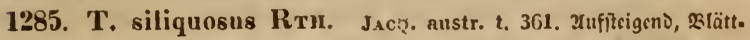

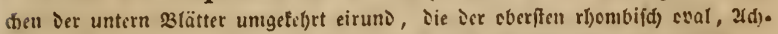

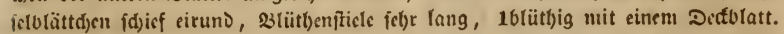

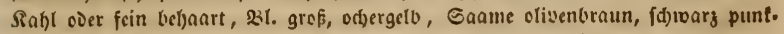

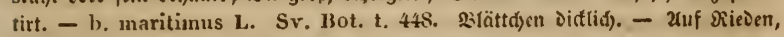
Eumpfruitén. b. auf Enljwiefon. Mai. Juni. 4. Biemlid) felten. L. Bice

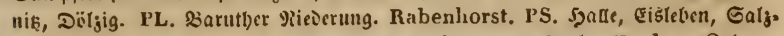
ice. Elfurt. Hornung. HS. Jna: 2iabis, \&uțid)en. 23crta. Zenker. Roburg. Hormung, Eicbclebener sico bei Getba. Regel. SRS. Jrminat, grantenlan. fen. Hornung.

436. Calega L. (5) $e$ i \& $r$ a u t $e$. Sold jienlid) gleidförmig pfrient:

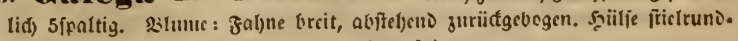
(id), idjicf gcĩtrift. - Slätter uupaarig gcỉedcrt.

1286. G. officinalis L. Schr. t. 208. Havxr Arzneigew. VI. Rснв. Fl. germ. exsicc. n. 1719. stättd)en lanjettlid), 6-3paarig, ftadgels ipişig, falst, Irauben vielblïtbig. $2-4^{\prime}$ hod), xd,(elblättd)en lanjettlid), balb pfeilförnig, 乏rauben adjfelfändig, länger als siätter, \$21. rofa lila, sabne sunt. lex, feltner gans weiß. - Euiolid)er auf feud)ten MBiefen, bei uns in Gärten cul. tivirt uno jufänig vernoilocrt. Juni. Juli. 4 . 
437. Robinia L. Robinie. Selđ) 5(palttg, säbne lanjettliđ, obere näber beifammen. Blume: Saline breit, abftelseno zurïđgefallagen. Etaubgefäfe abfallenv. Sriffel vorn bärtig. Sjïlfe platt, vielfaantig, Ratb faumartig, Saame gufammtengrorïaft. - Blätter unpaarig gefiedert.

- 1287. R. Pseud-Acacia L. Waxgratr. B. t. 7. f. 19. ఇit udfeloornen, 3roeiglein fabt, zrauben taum fein bel)aart, gefitredt, faflaffblittbig Bängend. Brtannter 22aunt, Blättđigen $15-25$, meift reedffelftändig, tur ge०

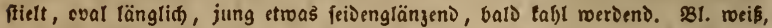

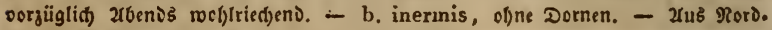
anterila. Diai. Juni. b. Ueverall angepiangt.

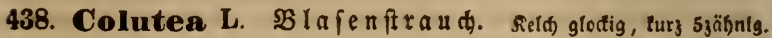

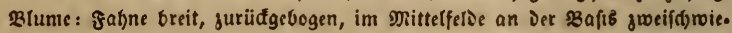
lig. Sriffel innerfeits platt uno fein bel)aart, Epiß̧e lyatig, Rarbe topffär. nug zurïđgebogen. Şülfe in einen Stiel veroünnt, a uf $g$ eb la fen. Blätter unpaarig gefiroert.

1288. C. arborescens L. Bot. Mag. 87. Blättdi)en oval, an det

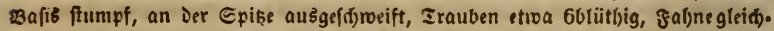
farbig, Szülfe länglid) ge(d)loîten juge(pist. Etraud) 10 bis $15^{\prime}$ hod), 31 . gelb, sjülfen blafgrün, etras über Doppelt jo lang als Diď. - 2lus SïDeuropa, über. all in Parts uno Suftgebuiiden cuttivirt und verwitDerno (namentlid PS. Dür. renberg, Sülme. SRS. Frantent)aujen). NRai - Juli. t.

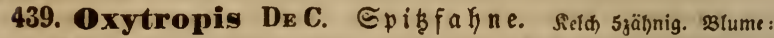

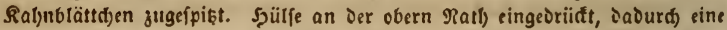

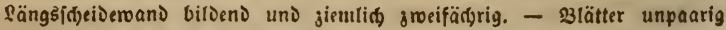
gefiedert.

1289. O. pilosa DE C. Bot. Mag. 2483. St. 49. Ŕснв. Fl. germ،

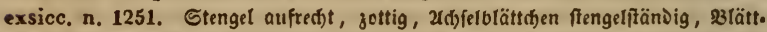

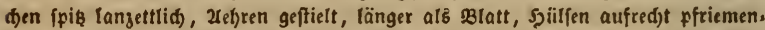
fpişig zottig. Epannen, bis fufbod, ganz zottig, 31. odergetb. - 2uf Sano.

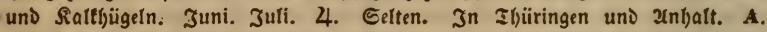

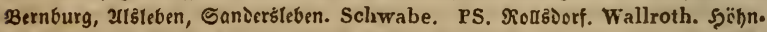
ftäbt, Seeburg, Saublingen, Eroeborn, Sönnern. Ed)wedenburg bel Erfurt. Buddensieg. SRS. 2trnftaot, frantenl)aufen. Schönheit.

440. Astragalus th. Traganth. Sielđ fünfzätnig. Blume:

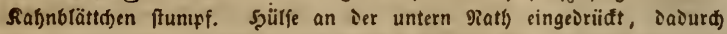

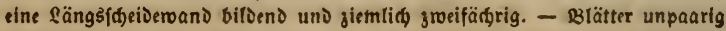
gefievert.

1290. A. Cicer L. JAcQ. nustr. \&. 251. St. 49. Scrx. t. 209.

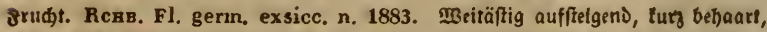
obere 2(d)felblätter verwadjen, Die $8-12$ paarigen topfförmig, Blätter gegen. über, Blättd)en länglid lanzettlid, ftumpf, ₹rauben lang geftielt, tänger als lobr sBlatt, \&rudettnoten fehr tur\} geffielt, Şülfen faft tuglig aufgeblafen, faft fisent, 


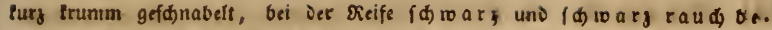

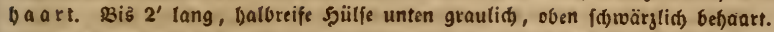

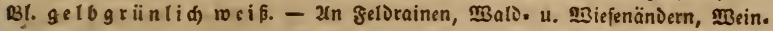
bergen, Sjüge(n, vorjüglid) in Eandboven. Mai - Juli. 4. D. Gr. Giebäge,

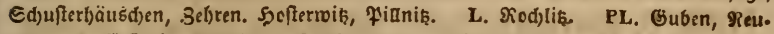
zelle. A. Gröbjig, sernburg, Eanذeršleben, RägDefprung. PS. Barbn, Benn.

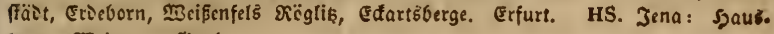
berg. Neintar. Grub.

1291. A. glycyphyllos L. Fl. dan. 1108. Scmx, t. 209: §ruđtst.

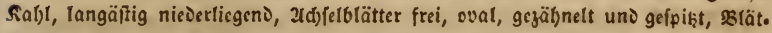
ter 5 - 6 paarig, $\mathfrak{B}$ (ättd)en ciruns elliptif() ftumpflid), Irauben ge(ticlt, türger als il)r Blatt, şül(fen fajt ireifantig, bogenförnig. 2 - 4' lang, sl. grünti (a) gelolid). - 3roifden Gebüld, an lid)ten Malifteden und Miefentändern. Juni - 2uguft. 4. Jm Erjgebirge nur: Z. MBildenfels im Erłid); bei M̉eifen. vorn uni Swidall. Wankel. 2ufferiem meift gentein.

1292. A. Hypoglottis L. Engl. Bot. 27f. arenarius PAxz. t. 34. F1. dan. 614. Sel)aart, Etengel aufiteigert, obcre 2(d)felb(ättç)en vermad)fen,

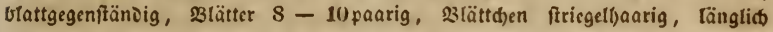
ftuntpf, Die unteren aušgerantot, 2lebren eiförmig tepfförmig, eticl länget als

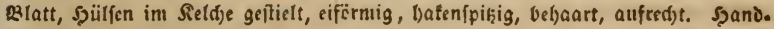

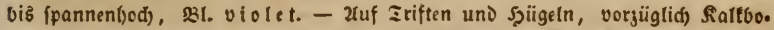
Jen. Juni. Juli. 4. A. Eanicršleben, Jricieritenberg. Schwabe. PS. aijłerb.

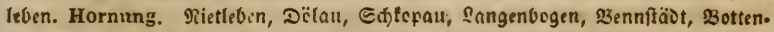

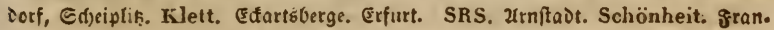
Penifaufen. Hornung.

1293. A. arenarius L. Schк. t. 208. b. ST. V. 19. Rcre. Fl. germ. exsicc. n. 271. Etengel nieberlicgend, 2rdjiclolättç)en bäurig, zreifpale tig, slättđonen 3 - 4paarig, linealijid) jufanmengelegt, fridenljaarig, Zrauben etıa 6blütlyig, länger als $\$ 3$ latt, Şüllen länglid), abftebend, grau, fein beljaart. Epannentang, szlume rofafarbig. Cdiant und jart. - b. glabrescens, ganj

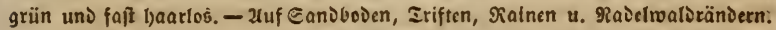

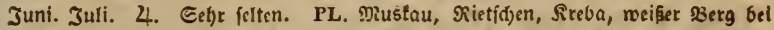

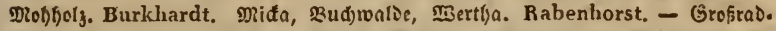

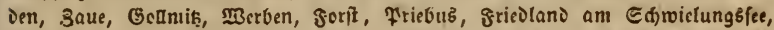
Feuzelle. Rabenhorst. PS. bci Drtrand 1842. Papperitz. G. Rchb. nut var. b.

1294. A. exscapus L. Hayse Arzneigew. VI. 12. Rcrв. Fl.

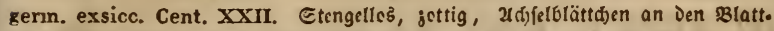

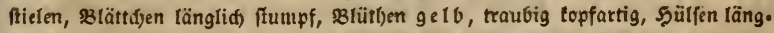

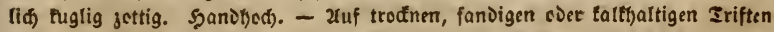
uns Şügern. Mrai - Juli. 4. Selten, nur in Inthalt und shüringen. A. Grëbjig, \&aublingen, Ganderšleben. Schwabe. PS. Mü̈letiorf, Seeburg, 5̧ell. fteit, Rënnern, Rothenburg. Ed)raplau, Erbeborn. Bikenburg. Sdieplif̧. Klett. Eteintlippe uno Mettin. Wallroth. SRS. Sattenburg bei franlenbaufen, Fornung. - Orp. Rad, Astragali exscapi. 


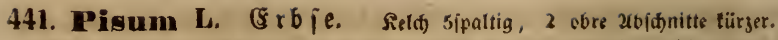

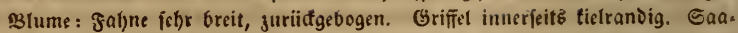

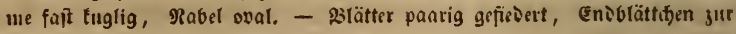
MBidelrante vertiinmert.

*1295. P. sativum L. Rıv, t. 36. Binttpticle runs nit 2 panr 83 tät.

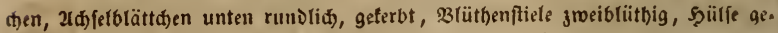
rade, fpäter waljig, Ename fuglig, rötl)fid) gelb. - b, majus: „Sontanells, Sluntererbfe". - c. hunile: "3werge, grangerbife". - Eultivirt uno verwit.

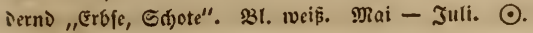

1296. P. arvense L. ST, 1. 4. Blattftiele mit $2-3$ Btït)enpas.

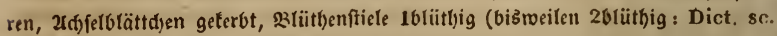
nat. cah. 8.), şä̈tt)en meift unten bogig geterbt, Fal)ne bläulid, glïgel uno Rahnblättţen purpur. Şülfe gernde, Saame fuglig, enffernt, graugrün, braum punttirt. - 2uf 2edfern unter Eommergetreioe "Eteferbfe". Baftaro aus Vicia sativa uno Pis, sativum? -

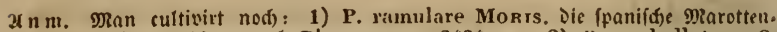
erbfe, grïne Erbje, vergl. Fl. germ. n. $3434 .-2)$ P. umbellatum $C$.

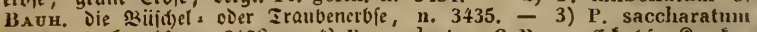
HORT. 3uffererbie, n. 3436, - 4) P. quadratum C. BaUH. E⿺ferbie, Rnoffer. erbfe, n. 3437. - 5) P. leptolobum Camer. 5̧onändifide Sufererbje, Sidjel. erbie, n. 3438 .

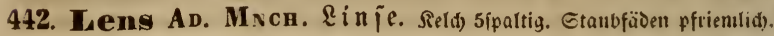
Briffel fadenfërmig, Narbe i nne nfeitig, unter ilys innenfeitig längs be.

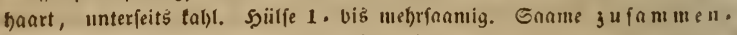
geDrüft. - 32t. gepebert, nit midetranten ani Ende.

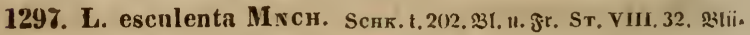

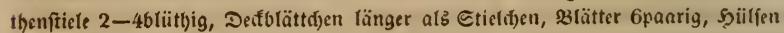

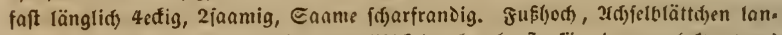

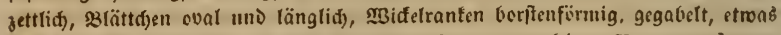
behaart. Saame grëfer, röttllid) gefb, aud) fdjwarz punffirt: E. punctulatum Новт. - Xus Den Driente, bäufig cultivirt: „Ffenniglinfe“. Juni. Juti. $\odot$.

1298. L. disperma (Roxв.), Rrv. t. 35. Silüthenftielé 1-20lii.

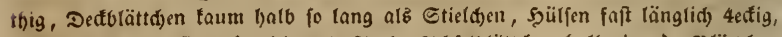

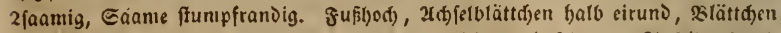

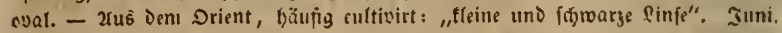
కuli. $\odot$.

443. Vicia L. $\mathfrak{B}$ i ffe. Seld) gluđig 5ipaltig, $2-4$ obre 36iffnitte liegen auf Der zalbne. Etaubfäben pfriemlid). Erriffel faienfërmig, unter Der enditändigen $\Re$ arbe bebnart. Szilffe jufammengeoriift, Saame

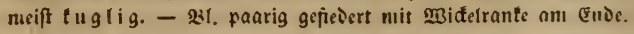

a. Ervum L. Griffel faienförmig, belyaart.

1299. V. tetrasperma Lо18. Sснк, t. 2012, ST, VIII, 32. 33tïthchs 


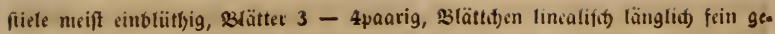

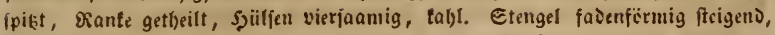

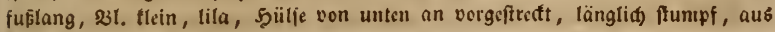

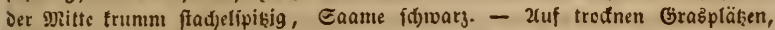

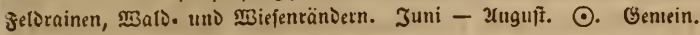

1300. V. gracilis Lors. Fl. gall. t. 12. Fein ftriegelffaarig, siätt.

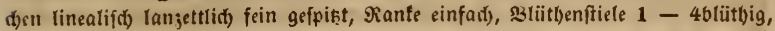
wcit länger als 23latt, 5jülfen länglid) tabl 5 - 8jaanig. - 2xn grajigen Şii. geln. Juni. Juli. $\odot$. Eelyr felten. PS. MBalterboorf vei MBeifenfee. Hornung.

1301. V. monanthos RETz. ST. VIII. 32. Sinll, zd)felbrätțiten

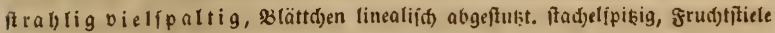
länger als il): 3latt, Şïlfen aufgetrieben 3jaamig, tabl. Grüber als Die übrigen, 33lume tila, 4nial jo lang als Sield), ভaante odjergelb, fdjwars punttirt. - 2In

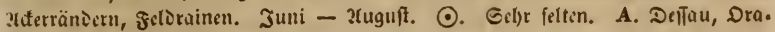
nienbaum, Bernburg, Eandersleben, Sjarggercie. Schwabe. PS. MBittenberg. Nitzsche. Eangerbaujen. Wallroth. Settin, Irotha. Wallroth. Sprengel. YBetliķfd) bei Gdteusił 1S29. Richter.

1302. V. hirsuta Kосн, Fl, dan. 639. Sснк, t. 202. Sт. VIII.

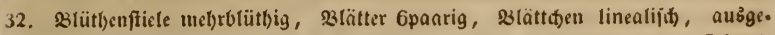

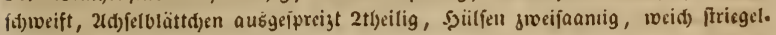

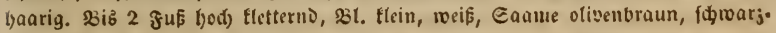
braun marmorirt. - Jnt Getteioe. Juni - Jetbft. $\delta$. Gemein.

b. Cracca Riv. Griffel unter ier Rarbe teulenfitmig, silitbenftiele traubig, soülfen inwemis glatt.

aล: Şülfen furs, faft länglid) viertifig.

1303. V. cassubica L. St. VIII. 31. JAç. anstr. t. 229. Rснв. Fl. gernn. exsicc. n. 275. Erauben tiirzer als ihr Blatt, Blättúfen vielpaarig abnel)meno, länglid) uno (anzettlid), liniirt, ftumpf, unterfeits fein betaart, 21d. felblättdjen balb pfeilfürnig, gangrandig, Şiilfen faft rautenförmig. Ueber $1^{\prime}$

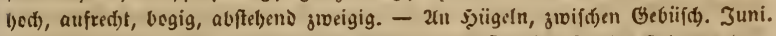

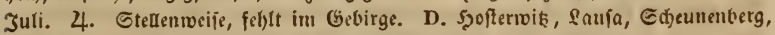

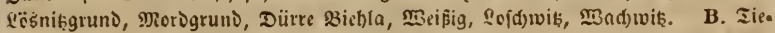

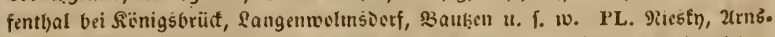
Dorf. - Guben, setíd)au nad) Sinlau ju. A. DeTau, Iörten, Canderbleben.

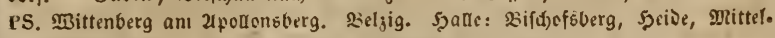

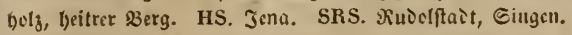

1304. V. villosa Roth. St. Vin. 31. Rснв. Fl. germ. exsicc.

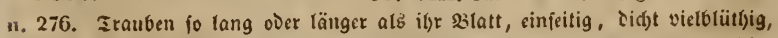

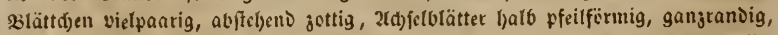
Flatte Der Gafne tïrger als il)r Ragcl, Şültjell $1^{\prime \prime \prime}$ lang, länglid) rautenfër. mig, an Der Epiąe bafig, 5 (? - 63) janmig. $2-3^{\prime}$ bod), tletterno over fdlaif

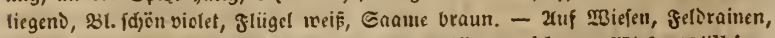
in feltern. Juti. Juli. 4. Eelten. D. Gr. Gerjäge. Rclıb. B. M̉icja. Kölbing. 


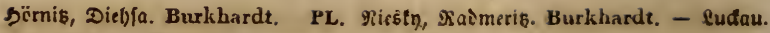
Grassinann. Rottbus, Epremberg, Eonnentoalde. Rabenhorst.

1305. V. Cracca L. Fl. dan, 804. ST. VIII. 31. Iraube fo lang

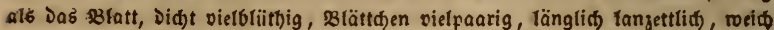

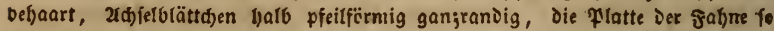
lang als ifr Ragel, sjülfen fómal länglid, $8-9^{\prime \prime \prime}$ lang, taum über $3^{\text {'w }}$ breit,

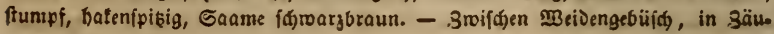
nen. Juni. Juli. 4 Gemein.

bb. Şülfen geftređt fidroertfërmig.

1306. V. tenuifolia RTH. Sr. VIII. 31. Irauben etroas foflaff,

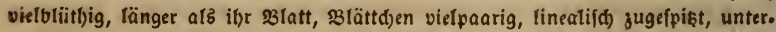

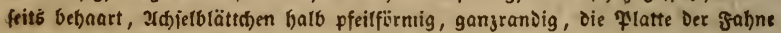

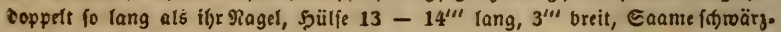
(idb. Tufred)t, $2-4^{\prime}$ bod), ftärter gebant, Irauben geftredter, galyne febr lang,

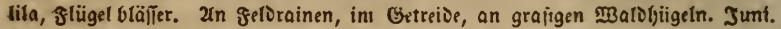
suli. ठ. Sd)eint im (Erjgebirge zu feblen, auperDem Durd) Das Gebiet nidgt felten.

1307. V. sylvatica L. Fl. dan. 277. Sr, VIII, 31. Rche. Fl. germ. exsicc. n. 1038. ¿rauben länger als ifre Blatt, Blätțen Spaarig, oval

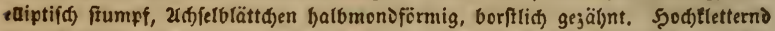
über Gebiifde, 231. reis, Jabne violet geftreift, Rabnblättci)en violet gripist,

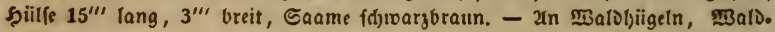
rändern, bäufiger in Berggegenden. Juni. Juti. 4. Seritreut. D. Gauerniß,

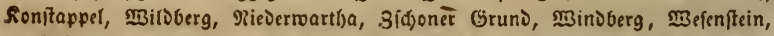
gr. Minterberg. - Ibarandt, 2lttenberg, Z. Erla, Ethroargenberg. Bok. L.

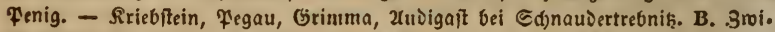

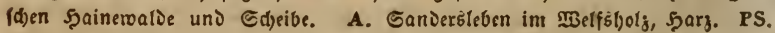
5aLe: Loderbleben, Erieborn. Effartsberge. Erfurt. Eubl. HS. Bsiniar: Zroi. feot, Regefeld. Roburg. Et)renbain bei xitcnburg.

1308. V. dumetorum L. ST. VIII. 31. SPR. Fl. hal. t. 7. Irau. Den fd) laffblütlig, fo lang als ifjr \$latt, siättd)en 5paarig, cirund, fiumpf, Dis unterften yom Etengel entfernt, oberfte unpaarig, 2udfelbtättdjen balomoniför.

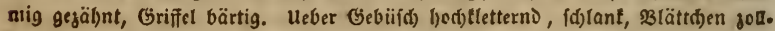
lang, über $1 \int_{2}$ " breit, 23 . violet, Spülfe gelblid) braun ïber $11 \int_{2}$ "lang, $4^{\prime \prime \prime}$ breit, in einen Stiel verbïnnt. - In (d)attigem $\mathbb{B}_{3}$ aligebüi(t), bäufiger in sèrg. gegenden. Juni. Juli. 4. Sjier und Da. D. Gdarfenlierg, Sonftappel, MBirbberg, Fot-

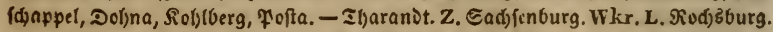

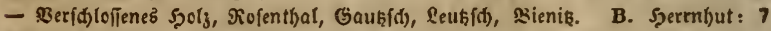

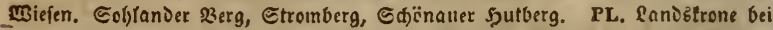
Oörtił̧. - Dreffnaer Beinberg bei Bergen. Rabenhorst. A. Sanderšleben,

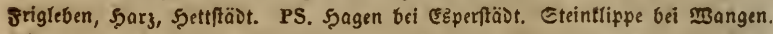

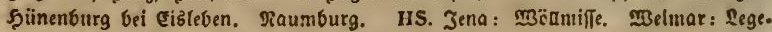
fero. Roburg: SEleidberg.

1309. V. pisiformis L. JAcQ. austr. t. 364. ST. VIII. 31. Trau. ben türger alb ib̧r 8 latt, Rlättdoen 5paarig, breit eirumb fitadelipitig, ftumpf, 
(ab), Die unterften Did)t am Etengel fik̨end und bie gezäłnten balo pfeilförnigen

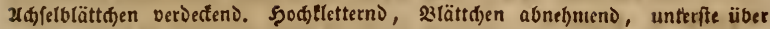
follang, über $3^{\prime \prime \prime}$ breit. Baftb fकief balbeirunb, turs geftielt, Saame Duntel.

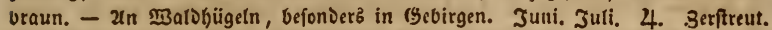
D. Iriebifdthal bei Mteißen, MBinberg, Pefterwik, Sd)lottewik, Fianiß, Sd)an.

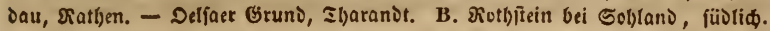
PL. Lanذb́ttone bei Görliķ. PS. Betgig. Jüterbogt. Şalle: Sfinton, Sporn. burg, Erdeborn. Efartbberg. Exfurt. Subl. HS. Jena: Rautbal, ஐ̈̈lmife. IEcimar: Segefelo. Soburg: Georgenberg. SRS. Jrantenljaufen, 2ruftait.

c. Vicia Rrv. Griffel unter Der grarbe äuserfiţ mit einer Şaarbüue,

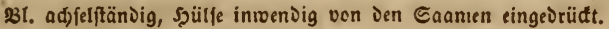

1310. V. lathyroides L. Fl. dan. 58. St. VIII. 31. Rсrв. Fl.

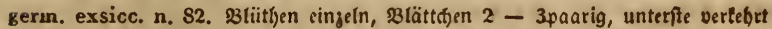

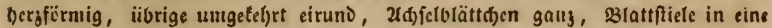
Epif̧e endigend, Sjülfen linealifd), tahl, Eaame getörnelt. Şandbod), fpäter. bin niederliegend fpannenlang. - 2uf grafigen Şïgeln, felorainen. 2tprit. פrai.

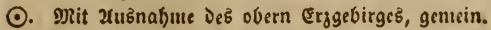

1311. V. angustifolia Rтн. 23tït)en $1-2$ turs geftielt, 2xdyfelo blättben balb pfcilförntig gejälbnt, Blättden 2 - 4paatig, Die Der untern vet. feljet eiförnig, vorn augeterbt, Die Der cbern lineal lanjetslid), ftumff over ab.

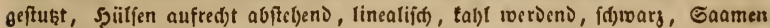

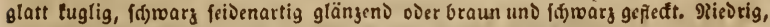
aufred)t, ffäterbin ausggcbreitet, 23l. jientlid) greß, lebbaft tila. - 2luf jandigen

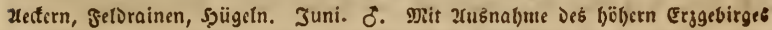
nldt felten, namentlid) in sbiiringen und D. unt gieifen.

1312. V. segetalis Thuin. St, VIII. 32. Rскв, Fl, germ. ex-

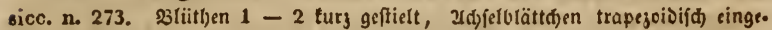

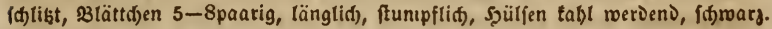

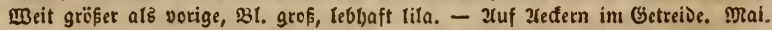

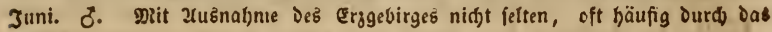
Gebiet.

1313. V. sativa L. Fl. dan. 522. St. Vill. 31. Rснв. Fl. germ. exsicc. n. 274. Blunien paarweis faft fikeno, Xd)felblätthen cingefdonitten

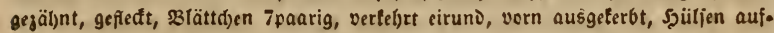
red)t, länglid), reid) bebaart, 巨aamen fd)rvad) jufanımengedrïđt, glatt, (d)rö̈rj(iđ). - b. erythrosperma: Saanten rötblid). - c. ochrosperma : Saamen od)ergelblid). Gews̈l)ntid) veid) bebaart, Şülfe jung feidenbaarig, reif braun. -

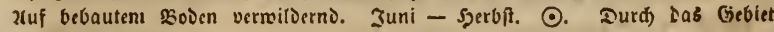
meift nidjt felten.

1314. V. sepium L. Fl. dan. 699. Sr. viII. 31. Sliitben ju 43, faft fişens, 2dđfelblättder: gesäbnt, 3lättden 5paarig, brsit oval, ftumpf, ab.

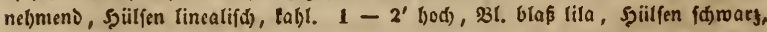

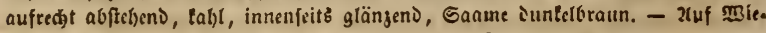
len, Grabpläs̨en, in Gebürd). 2lpril - Detcber. 4. Gemein. 
Papilionacene. $\quad 296$ - Vicia

d. Faba T. Eteif, jaftig, Diarbe fajt 2lippig, syulfe gefduwellen.

*1315. V. Faba J. Brakw. t. 19. Haynz Arzngew. XI. 4S. Blii.

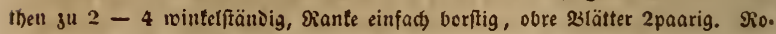

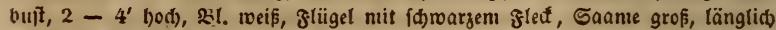

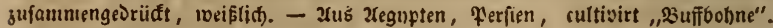
3uli. 2uguit. (.).

* 1316. V. equina (Faba) Baur. (V. Faba.) Sт. Vur. 32.

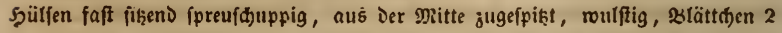

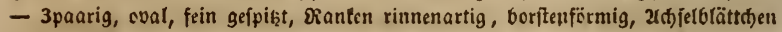

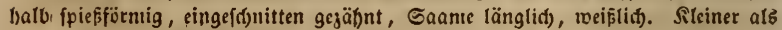

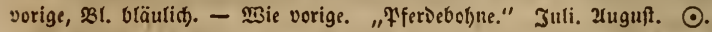

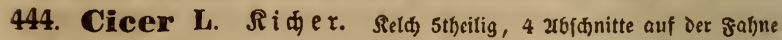
liegeno. Etaubfäben abwed)jelns, unter Der Epike verdidt. Grifiel gcht ver. diớt fi(f) in eine abgeftuķte Rarbe. Sjiilie baudjig, roenigfaamig. Caane Midoerfopf älsnlid).

-1317. C. arietinum L. Scнк. t. 202. unterite Fig. i. k- o. \$ïlfe

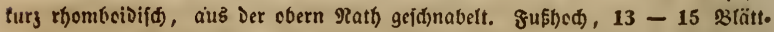

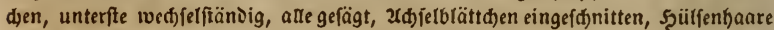
gegliebert, 231. unঠ Saane röthlid). - 2us Dem SüDen, cultivirt. Juni. 2u. guit. $\odot$.

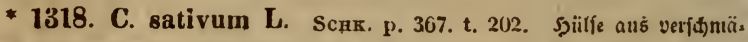

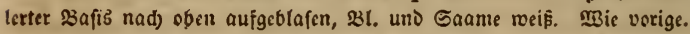

I $n$ m. 2iergl. C. physodes Fl. germ. p. 532.

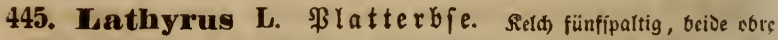

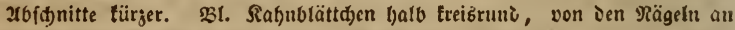
cingebogen. Griffel platt 2tantig, von Der $3 a$ fỉ tnieförmig aufred)t. Sjülfe

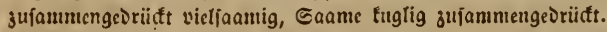

1319. L. Aphaca L. Engl. Bot. 1167. Rснв. Fl. germ. exsicc.

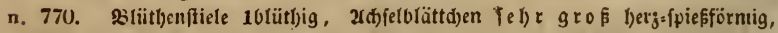

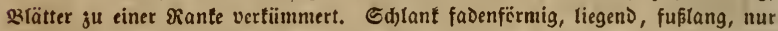
nädît Der Murgel $2-2$ einpaarige 3lätter, \$1. Elein, gelb. - 2uf 2fedfern. Juni. Inti. ○. Şëctift felten. L. Sauffigt. Miiller. Şwifdjen Erottendorf und

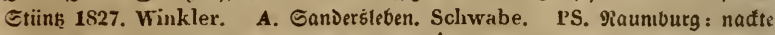
Senne. Mïller. Scheidhauer. Eula. Sprengel. Sibru nad) Röjen zu. Wallroth. Æđart6bergc. Rodig. Erfurt. Schönheit. HS. Gotba. Schünheit.

1320. L. Nissolia L. Engl. Bot. 112. athe 33lattficle blattartig

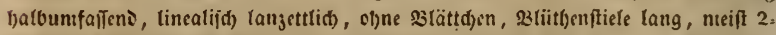

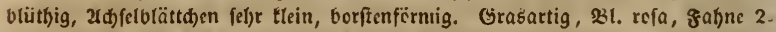

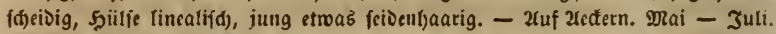
○. Şc̈đ)ft felten. A. Sanderšleben, Şarjgerode. Schwabe. PS. Burglicbenau,

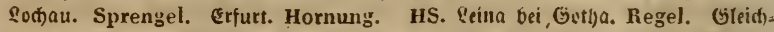
berg bei foburg. Hornung. 
" 13221. L. sativus L. Bot, Mag. 115. Einbtït)ig, stättdicn lineas

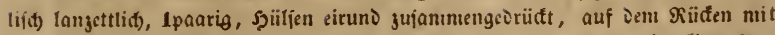
Doppelt getielter গatl), $\mathbf{B l}$. lang geftielt, hellblau, Ename von ier vierećigen $\mathbf{B a}$.

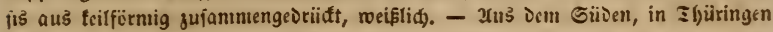
gebaut: "Deutid)e Sid)er, weife Erve, Erbis". Imt. Juli.

1322. L. hirsutus L. Engl. Bot. 1255, 23liitlyenftiele lang $1-2$, Ulüthig, 23(ättd)en lanjettlid) 1 paarig, Shilijen jottig, Eaame numgelig förnig. 21 .

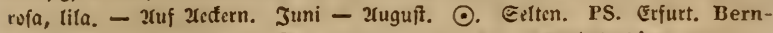
hardi. HS. Ġleidjberg bei Sioburg. Hormung. Edfnepfentlyal. Girtanner.

1323. L. pratensis L. Fl. dan, 527. Silüthenfticle viclblütbig, län.

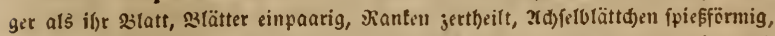

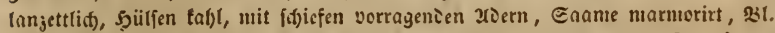
gelo. Salt tabl coer feltner weid) vihaart, Etengel idjarftantig. - b. microphyllus Кснв, in aden zlycilen weit tleiner, Ranten unjertbeilt, 2ldffelblättd)en

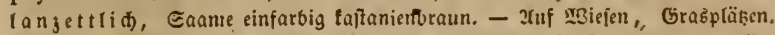

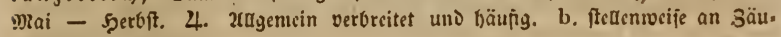
nen und im Gebiifd.

1324. L. tuberosus L. Bot. Mag. 382. 23litt)enftiele viełblïthig,

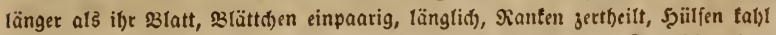

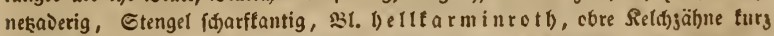

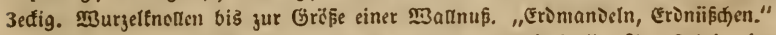
- Xuf Xefern unter Getreide, felten in Gebiiif. Juni. Juli. 4. Gd)eint in

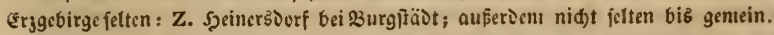

1325. L. sylvestris L. Blitthcuffiele victolïtthig, länger als ias

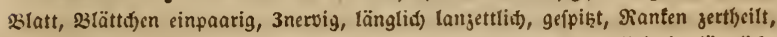

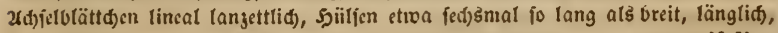
6-10iaamig, glatt, Etengel und 23lattfiele piigelfantig. - a. angustifolius

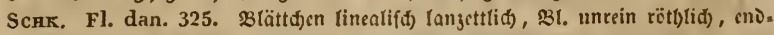

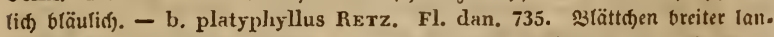

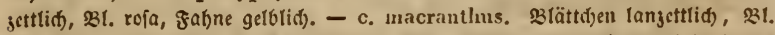

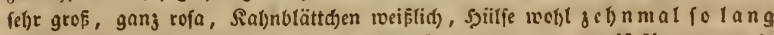
als breit, 15-20faamig (in ier Fl. germ. ju L. ensifolius gejogen).

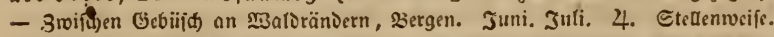

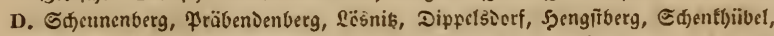

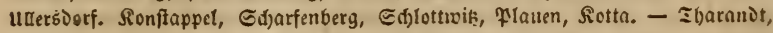

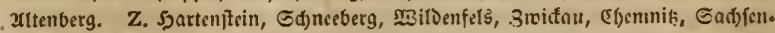

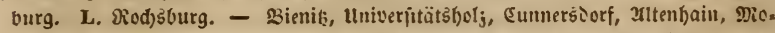

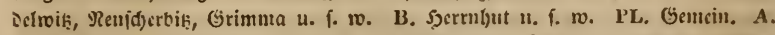

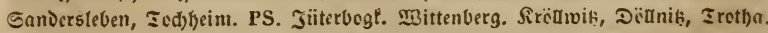

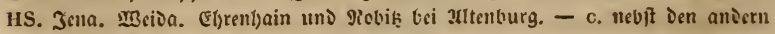
formen D. in Flatenfiden (srunde gegen zharants.

1326. L. heterophyllus L. Rснв. Fl. gerin. p. 869 . Fl. geru, exs. n. 1466. Btittyenftiele 5 - sutütbig, stättdyen ein. uno jwe i paarig,

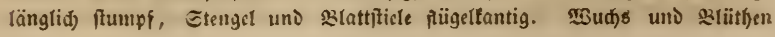


Papilionaceae. - 298 Lathyrus.

voriger 24t. - 3roifaen Gebürd in 23erggegenien. Diai - Juli. 4. Södfft felten. HS. Roburg. Eckart. SRS. Eonjersi)aufen. Eckart, 2trnftait bet Der Erentitage. Hornung. Blanlenburg, \$iđlinger $23 \mathrm{erg}$, frebnverg. Schönheit.

- 1327. L. latifolius L. Engl. Bot. 1108. S3tütbenftiele fteif gee

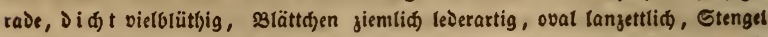

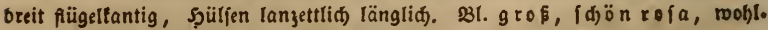

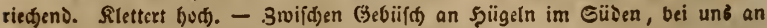
Cauben cultivirt und verwilberns. Juni. 3nguft. 4.

1328. L. palustris L, Fl. dan, 399. Rснв. Fl. germ. exs. Cent. XXII. Etengel oben fü̈geltantig, 3lätt(d) 2 - 3paarig, lanjettlid fein ge. fpist, 2dbfelblättd)en balb ffeilfïrmig. 3lütbenftiele $3-6 b$ tütbig, länger als Blatt. Etengel fdrrad), 1' oier bïljer, bišrecilen etroas äftig, BI. fdjön lila. -

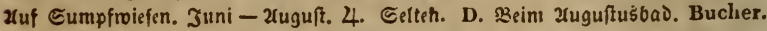

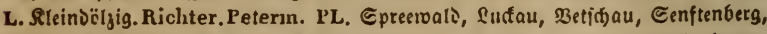

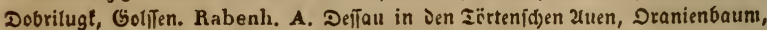
Berbft. Schwabe. PS. 2 fidjerb̂lebcn. Hornung. BeIgig. Rabenhorst. Dfendorf Dem Dreierbaus gegenüber. Sprengel. Sicbenau, Döđniş. Richter. Petermann.

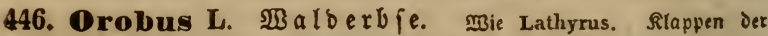
Der sü̈lje ireben fid) nad) Dem xuffpringen jujanimen. - Blattftiele mit einfad borftenförmiger rante.

1329. O. vernus L. Fl. dan. 1226. ST. I. 7. Etengel meif́t ein. fach, slütbenftiele 4 - Golïtbig, türger als iljr Blatt, 3 lättdłen 2 - 3paarig. ciruns zugefpiķt. Maigrün, Slütf)en präd)tig purpur, int 2066tübsen und కrod. nen blau werbens, Gaante roeīlid gelb, purpur punttirt. - b. albiflorus. Blume roeis. - In făattigen Snubrö̈tdern in Der (Ebene und nod) bäufiger in Den Ibälern. 2rprit. Mlai. 4. Durd) Das Gebiet neift gemein, in Der PRieذer. laufik felten: PL. Epremberg, Sorau.

1330. O. tuberosus L. Sснк. t. 200. Sт, I, 21. Etengel nicift eln. fach), s3tütbenftiele 4 - 6blumig, länger als ibr Blatt, 3lättdjen 2 - 3paarig, länglid) langettlid. Mattgriin, faft graulid), Blumen bläulid) rofa, Saame

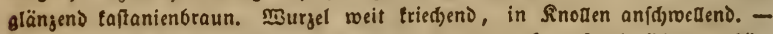
b. tenuifolius Rтr. Blättden linealifd). - In trođinen Saubrö̈ldern, bäu. figer in Den Ibälern. 2rpril. Mai. 4. Gemein.

1331. O. niger L. Fl. dan. 1170. Scuk. t. 200. Fig. k. 1. Sten. get weitäftig, tantig, slïthenftiele mebrblütbig, Blättrỉen 5 - 6paarig, oval

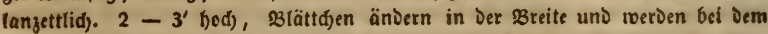

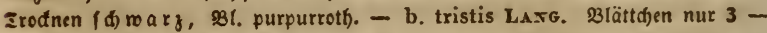

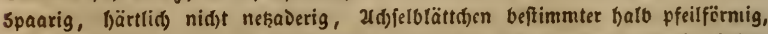
Blütbenftiel türger als fein slatt. Syärter und faft nidjt färoar werdent. Sdjon von Schkuhr unterfdieden t. 2(x). nad) innen Fig. 8. uno k. 1. - In trod. nen \$äldern und zbälern. Juni. Juli. 4. Edjeint im Erggebirge faft gan\} ou feblen, bişer nur L. æBedjelburg - in Den Saufiken nur: PL. Dubraute, Eunnersoorf. - Dorgig, Gajien, Drefnaer \$Beinberg, fangengrafiau, Gefren.

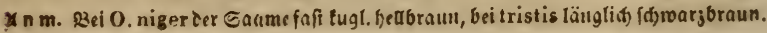




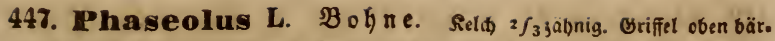

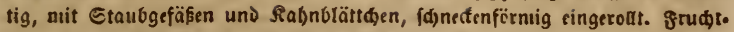
tnoten unten mit Edjeide. Siülfe zmildsen Den Eaamen fámanımig. Eaame nit geftrefter शabelwarge. - Blättden einpaarig, nsbft Ensblättden, Blü. thenftiele an Der sraube paarig.

- 1332. P. multiflorus W. HaYxs Arzneigew, XI, 45. M̉n.

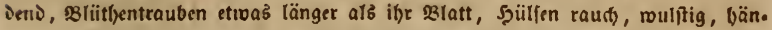
gend, meift fidfelförntig. - b. coccineus LaM. vulgaris SchK. t. 199. Blütbe

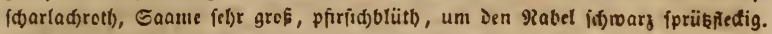

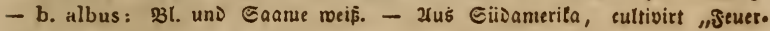
bobne". Juni - 5̧erbit. $\odot$.

* 1333. P. vulgaris L. Harne Arzneigew. XI. 46. Mindend,

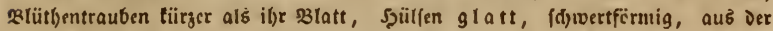

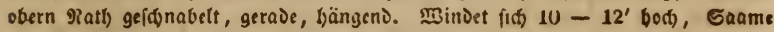

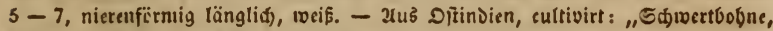

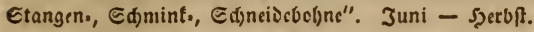

* 1334. P. nanus L. Hayse Arzneigw. XI. 47. Stengel niedrig,

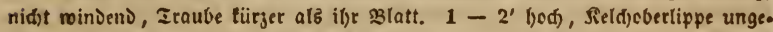

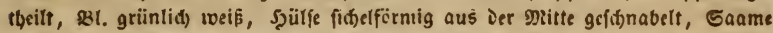

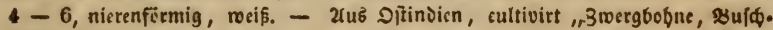
bobne". Juni - Şerbft. $\odot$.

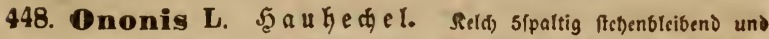
offen. Safjne fralylnervig. Salnblättd)en fpikf(d)nabelig. Şülle wenigfaanig,

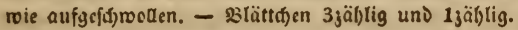

1335. O. spinosa L. HAYxr Arzngw, XI. 43. RchB, Fl, gerun. exsicc. n. 652. Etcngel aufred)t, weitäftig, 2epte Dornig, ein. over jreireihlg

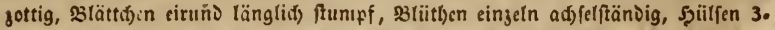
faamig, türjer als Seld). $1-2^{\prime}$ (jod), 23t. rofa, slügel weíltid). - 2uf fan.

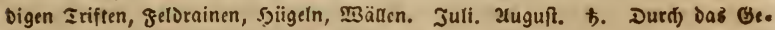
biet, nit Xušnalyme Der bïd)ften Gebirge.

1336. O. repens L. Hayxs Arzneigew. XI. 44. शièergefitredt, un.

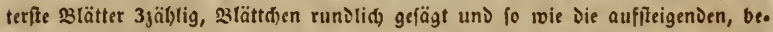

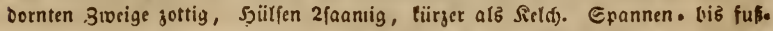

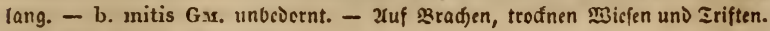
כuli. 2uguit. क. Wic vorige.

1337. 0. hircina JAcQ, horind. t. 93. HaYvi Arzneigw. XI. 42. Rснв. Fl. germ. exsicc. n. 1721. Gteif aufred)t, ringsum jottig, 32t. paarig langtraubig, unterffe \$lätst)en 3̧älltig, oberffe einfad), fägetandig, giemtid) taht,

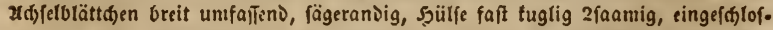

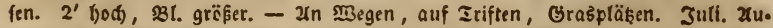

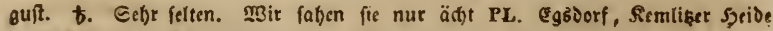
naw) Rolpin ju. Rabenhorst. 


\section{Papilionaceae. $\quad-300-1$ Genista.}

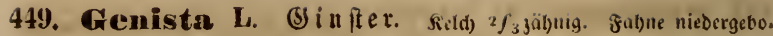

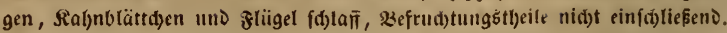
Viarbe fdjef einwärts feitlid)! Şiilfe jufanumengevrïđt. - 331. gelb.

1338. G. sagittalis L. JAcr. austr. t. 209. Guisp. t. 117. Rснв. v1. germ, exsicc. n. 469. Bel)aart, 3weige 2tantig geptiigelt, gegliejert, Blätt. then einfad) cilangettlid), 3Blïtben äbrentraubig. Siegent, Smeige aufredt), fpan. nentang. - 2ln Şügetn in Radelwäloern. Miai. Jumi. Ђ. Gel)r felten. A. DelTau, Mtongtauer Sycide. PS. Bitterfelo. Sprengel.

1339. G. tinctoria L. Fl. dan. 526. Gunp, t, 118. Zufffeigeno,

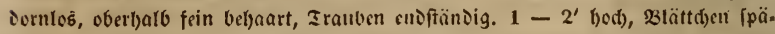

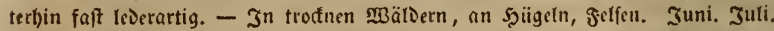

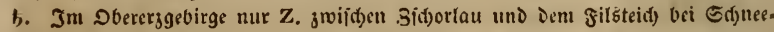
verg, in Deittelgevirge Z. bei Bogenftein, aufertoem bäuñg.

1340. G. pilosa L. Jaç, anstr. t. 208. Sснк. t. 195. Rснв, Fl.

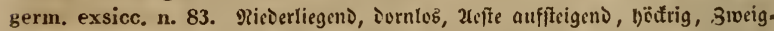

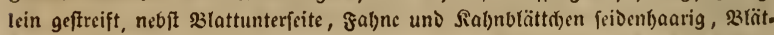

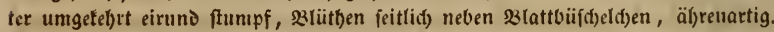
Epannen. bis fuflyod). 2(n (d)attigen Drten aud) obne Eeidenglanz. - Th Şei. Dewäldern unter Madelgebüfth und an 2nbël)en Dafetbft. Juni. Jull. 4. Etels

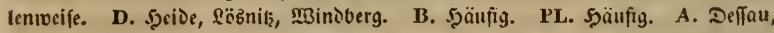
3erbft, Dranienbaum. PS. Swif(t)en Pregien uno Gommern bei 3arby. Mit.

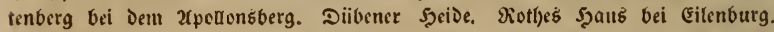

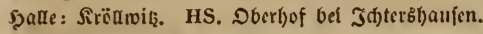

1341. G. germanica L. Schк. t. 195. Sт. 12. Etenget Dornig, unten blattlos, oben äftig, jottig, 33tätter geffictt eifangettlid), Bz(üt)entrauben

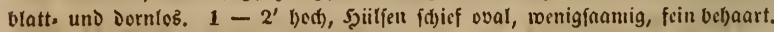

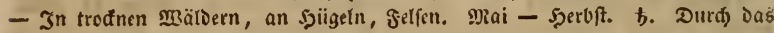
Gebiet niđjt felten.

1342. G. anglica L. Fl. dan. 619. Gurap. t. 121. Rerв. Fl. geru. exsicc. n. 864. Xufred)t, faf)t, Dornen einfad) und zufammengefelt

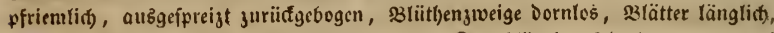

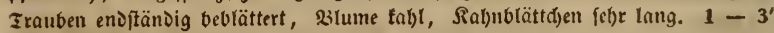

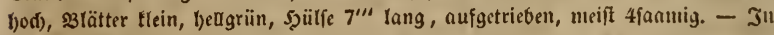

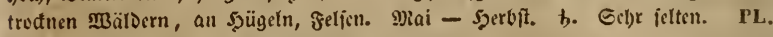
fudau. Rabenhorst. A. Serbit. Scliwabe.

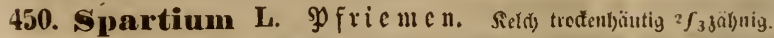

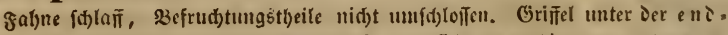
if ändigen naften Marbe verdift, pofthornartig umgebogen.

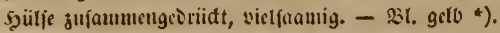

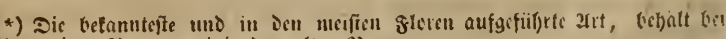
zbeilung eince Gattung vittig Den alten Finnin. 
1343. S. scoparium L. Fl. din. 313. Schк, t. 195. Hayxe Ar7neigew. 1X. 10. Etranch $2-4^{\prime}$ bod, 3fefte rutbenförmig befenartig, silätter ireizäblig und sinfad, umgetebrt eirund, sliithen adffelftändig, grof, bodgelb.

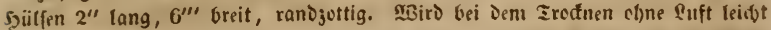

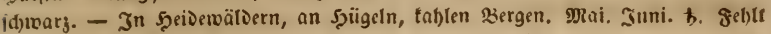
in Dhererzgebirge und bei Seipjig, fonft wolkl ïberall nidst felten.

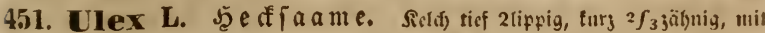
2 Dețblättchen. Slume weenig länger. jä̈lile aufgetrieben, wenig berauEra. geno, wenigfaanig, Eaantennaber nusgef)ël)tt. - Jm 2ltter blattlos, reid). (iid) fteif bejornt. 28l. gelb.

1344. U. europaeus L. Fl. dan, Ghs. Schк, t. 196. Gurmp 1. 123. Всив. Fl. germ. exsicc. и. 653. Gein vef)aart, Slättdyen (anjettlidt) tinealij(t), erfite Dornen ftark uno fteif, firielruno und gefurdt, folgende ausge. ipreijt gernde, ungleid) jweitheilig, Sild) feidenartig belbaart. $4-5$ boct), Dorne

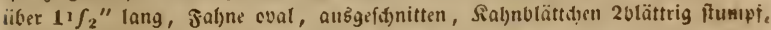

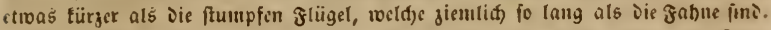
- 2uf fandigen Spcisen, an Szügetn. Miai. Juni. b. Gebr jelten. D. Rob).

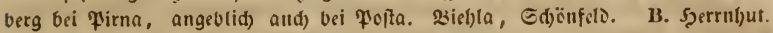

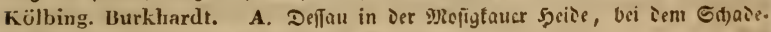
walidgen şyorlyaub. Schwabe.

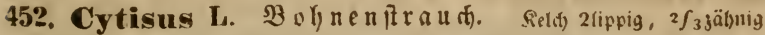

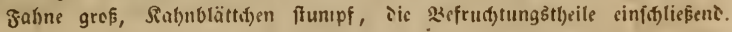
Marbe enoftändig topffërmig von 5aaren unigeben. Sgillfe

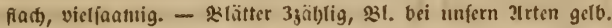

1345. C. nigricans L. JAcr. austr, t. 387. Guisp, t. 129. ST.

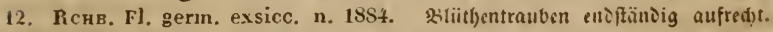
Gtraud) $2-3^{\prime}$ ljod), siätt(t)en elliptif(d) und ranjettlidy, unten fo wie Die fur.

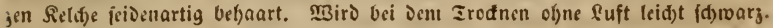

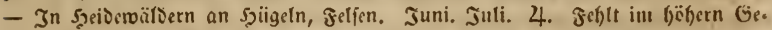

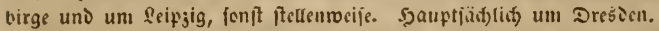

1346. C. laburnum L. JAcQ. austr. t. 306. Sснк. t. 203. 23tï.

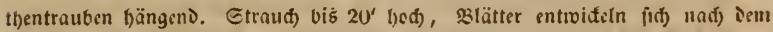

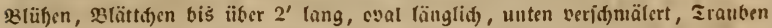
iiber fpannentang, ,golioner $\Re e g e n "$. Die şülien fino jung feidenartig behaart,

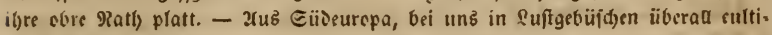
virt. Ende Ifprit. פrai. क.

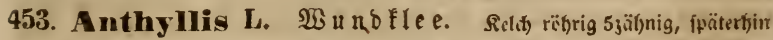

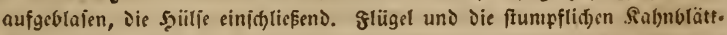
d)en ziculidid gleidjlang. - 231. gefiebert. 31 . getb und reth.

1347. A. Vulneraria L. Scrk. t. 196. Siurz fein befjaart, s3lätter

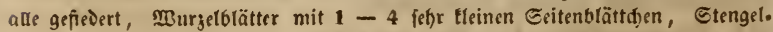

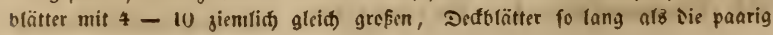


Papilionaceac. $\quad-302-\quad$ Anthyllis.

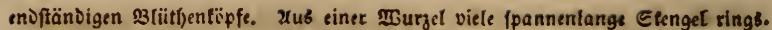

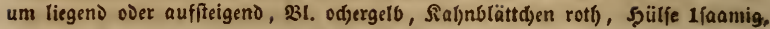
ü ber il)rer $23 a f i z$ geftielt, obre Ratl) bogenförmig. - 2luf fandigen, fteinigen

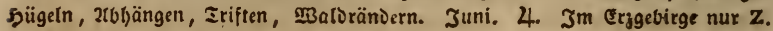
bei Gtouberg, fonft bäufig.

454. Iupinus L. $\mathfrak{W B}_{0}$ If $\$$ b o h ne. Seld tief 2lippig. Griffel auffeigend. Narbe topfförmig. 5 Etaubbentel tleiner, faft tuglig und friib.

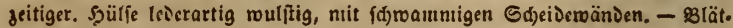
ter gefingert! 33 l. traubig, verid)iesenfarbig.

- 1348. L. albus L. Bxarw. t. 282. Btüthen getfreut traubig, Sielch obne 2(nl)ang, Dbertippe gallg, unterlippe 3 jäl)nig, 3lume weif. Meid) befjaart,

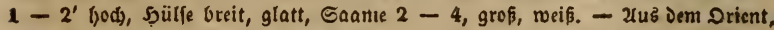
cultivirt als ₹utterfraut und als હaffeefurrogat. Juni. Juli. $\odot$.

- 1349. L. hirsutus L. B(ït)en gerftreut traubig, Selti) mit Dect. blättĐen, $2 \int_{3}$ fpaltig, 3lättđ)en lanłettlid) fpatelfërmig, auf beiben Seiten raud

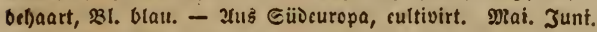

* 1350. L. Intens L. Scrx. t. 198. Quirlblütlig, Selţe mit an. Dängenien Dedulüttdjen, $2 \int_{3}$ jäl)nig, 33l. getb, wol)lriedtens. $1-2$ ' bod. zus Ciideuropa, bäufig cultibirt. Juni - 2ugujt. $\odot$.

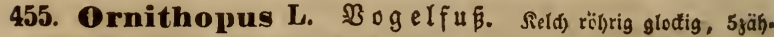
nig. Gliederlitilfe jufammenge vrïđt, Gliedcr rungelig nervig. - \$lätter viel. paarig unpaar gefiedert. $\mathfrak{B l}$. in Enobüfdjeln.

1351. O. perpusillus L. Schк, t. 206. Rснв, Fl, germ. exsicc. n. 278. Sein bel)aart, slütbenftiele länger als Die geficierten Blätter, Şïlfen $3-4$, bogenfïrmig, neift fein bebaart, Gliejer jiemtid( gleid)lang, nad) beiden Enذen verid)mälert. 3artę Siraut, vielftenglid) enolid), oft biz (pannenlang,

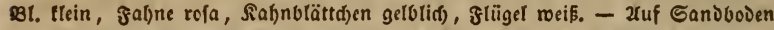

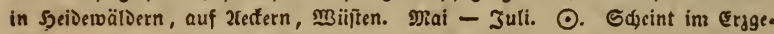
birge gu fel)len, fonft nid)t felten.

456. Hippocrepis $L$. ذu

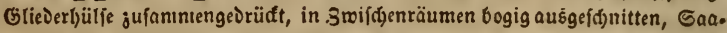
men an Den 2(usjđ)nitten befindlid), geftünınt. - Blätter unpaar gefiedert, 81. in EnDbüidjeln, gelo.

1352. H. comosa L. JAce. austr. t. 431. Rcrs. Fl. germ. exsicc. n. 279. Srautartig, grün, reitäftig, Blütbenftiele länger als ibr \$latt, süfidel DolDenartig, Soülien und Glieder feid)t bogenförnig, raul), Gelente eingejogen, tabl. Bis fpannenlang. - In Saltgebirgen, an fonnigen trodnen Drten. MRai - Juli. 4. Nur in Jnjalt uns כhüringen. A. Bernচurg, Minberfteot, 巨an.

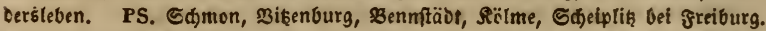
Burgronien. Efartaberge. Erfurt. HS. Jena: Szubberg. IBeimar auf oem Eteinbruăc. SRS. Urnftadt, frantenbaufen.

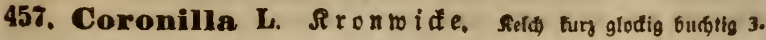




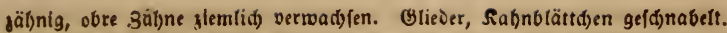
Şülfe fticlrunذlidh, Glieder länglid. Saame faft ralgig. - Blätter unpaar gefiedert. 331 . in Enobïfdeln.

1353. C. varia L. Scrk. t. 205. Sr. 49. Bz tättchen $9-15$, täng. (Id) langettlid), ftumpf, tahl, 2r(d) (elblätter frei, lanjettlid), Büifd)el vielotütlslg,

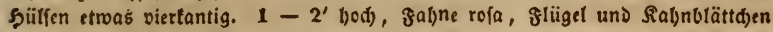

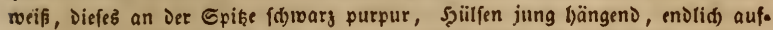

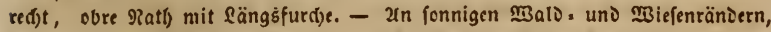
Nainen, Şiigcln, gelfen. Juni - 2uguft. 4. Durd) Das Gebiet bäufig, nue im Erjgebirge felten.

1354. C. vaginalis LAM. Rснв. pl. crit. I. ic. 65. Fl. germ. ex-

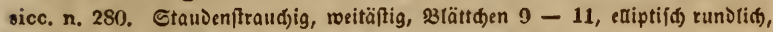

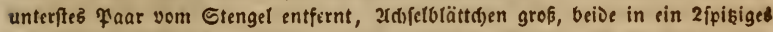
verwadjfen, Biifdjet 6 - lublütbig, Sjülfen idjarf 4tantig. Epaunenlang, aufo fteigens, bläulid) grïn. - 2ln trodinen Iriften und Sialtbiigeln, felfen. Mai -

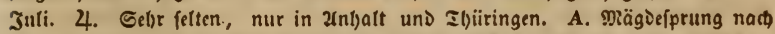

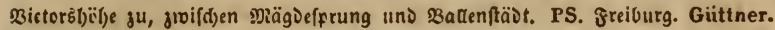
Beneken. Erfurt. Bernhardi. HS. Donopstuppe bei Mieiningen. Rauch. SRS.

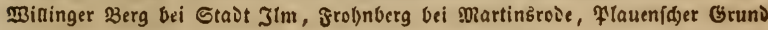
bei arnftadt. Schönheit.

1355. C. montana Rrv. Rснв. pl. crit. I. ic. 68. Fl. germ. exsicc. n. 654. Srautartig, aufred)t, meift einfad), 3lätt(b)en $11-13$, oval, un.

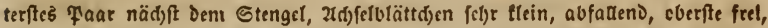

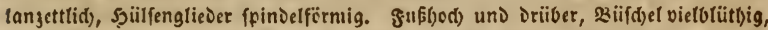
Murgel fried)end. - Swifden Gebiifd) an Raltbergen. Juni. Juti. 4. In 2nbalt und Ibüringen. A. Sanderbleben. Scliwabe. PS. Freiburg, 巨dmon, faud)a. 3ibra. Naumburg bci Fforta und in Miordtbal. Beneken. HS.

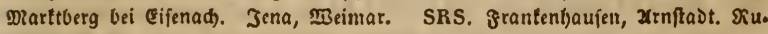
Dolftadt. Beyer.

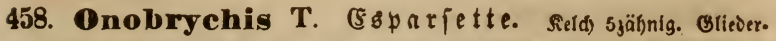
bülfe nur niißj)enartig 1glièrig, 1)aamig, grubig. Saane nierenförmig. Blätter unpaar geficoert, Blütl)en traubig, Stiigel febr tur\}.

1356. 0. sativa Toxmef. Etenget auffteigeno, slätțen teilförnig

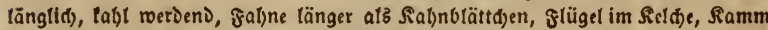
- Der fein beljaarten Şüllfe beiderfeitz erthaben punttitt. $2-3^{\prime}$ hod, 36. rofa. -

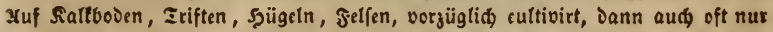
verwitDert auf selorainen. Juni. Juli. 4. Seblt im Ërzgebirge, im Boigitande und Den faufisen, auferoent ftellenweife. Eine var, macrodonta Perzrs. wird Durd felitr lange Seldisät)ne unterf(d)ieden. 


\title{
Fumilie Corniculatae, Gehörntfrühtige.
}

\author{
- 5̧arbarienbud) હ. LXIII uno 157. -
}

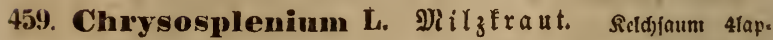
pig, inwenisg farbig. Silume feblt. Driijenpolfter (um Den grutttfnoten)

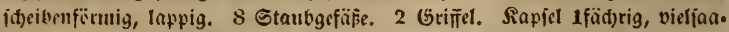
mig, zweif(d)nabilig, nad) Dem 2lufipringen ganz oர̄en liegenD, Saamenträs

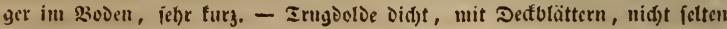

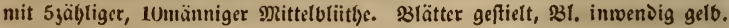

13557. C. alternifolinm L. Fl. dan, 366. Sснк, t. 1(18. St. 12.

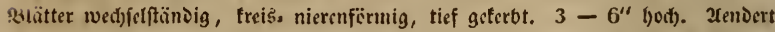
ab mit runolidfen und feilförnig umgetef)rt eirunben, an Der 3ajis ungeterbten Dedfolättern. - 2in fiud)tin, fif)attigen Drten, befonders 2uellen, Säden uno

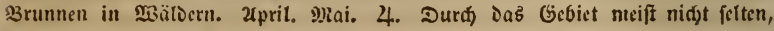
iı Ëcbirge febr bäufig.

1358. C. oppositifolium L. Fl. dan. 365. Sr. 4. 23rätter gegen。

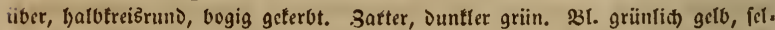

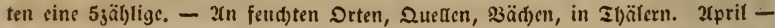
Juni. 4. $x_{n}$ gecigneten Drten ziemlid) büufig, fel)lt Dagegen in Der (5vene. D.

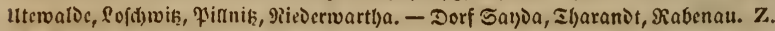

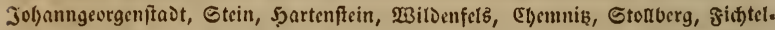

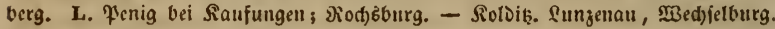

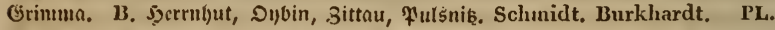
Riestı). Burkhardt. - A. Gandersleben, Sarz. Scliwabe. PS. Sdjteudik. Sprengel. Sulyl. HS. Eifenbery.

460. Saxifraga L. Ctein bxert. Seltffaum 5theilig. Salume

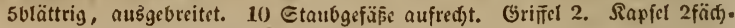
rig, vielfanmig, 2jđ)nabelig, jwif(t)en Den Sđjnäbeln aufípringeno. Caamen. träger an Der Sd)eiderwand angerwadjern.

1359. S. tridactylites L. BuArw. t. 212. Rchr, Fl, gernn. exsicc. n, 1374. Sт. 33. Schx, t. 119. Mßur jel cinfad) Dïnu, Etcngel beblät. tert, oriifig belhaart, meift äftig, unter|țe Blätter ipatelföımig; ungetheilt, ১ic näd). ften 3fpaltig, chere 5ipaltig, fironenblätter wenig länger als Der Reldt). Şani.

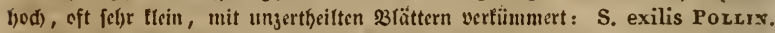

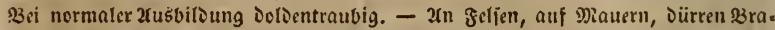

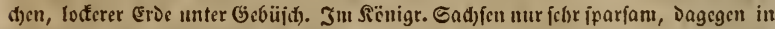
F̧üringen nifft gar felten. D. Dolna, Eonnenftein, Pirna. S(jarfenberg. Sjirr

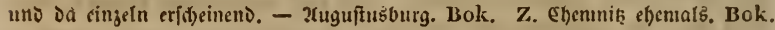

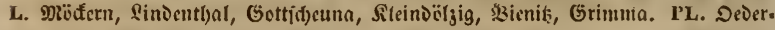

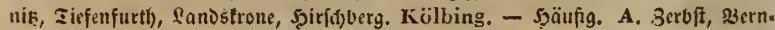

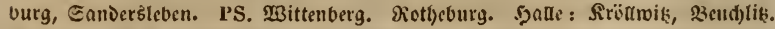

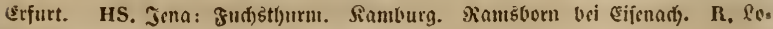
benitein. 
1360. S, granulata L. Schk, t. 119. ST, 6. HAYNe Arzhgw. III 23. Wurzet nit törnigen Sinöld)en, Etengel cben äfrig Dolventraubig, untere 3lätter geftielt nictenförnig, lappig getirbt, Blumenblätter Deppelt io lang als Der Seld). Fuflocd, bel)aart. - Xuf Felorainen uno grafigen 2unt)ïhen, MBiefen,

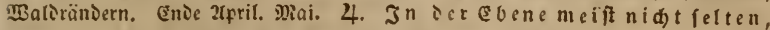

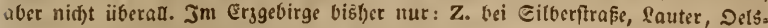

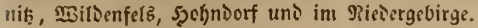

1361. S. Hirculus L. Fl, dan, 20), Sr. 35. Rснв. Fl, germ. exsicc. n. 473. Stengel fölant aufred)t, mit faienförmigen Zušläufern, Blät=

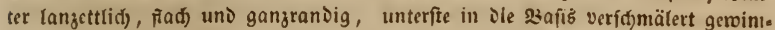

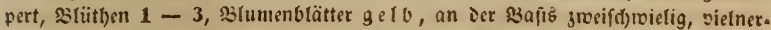
vig. Spannentoot). - 2uf ₹orfmorr. Juli - September. 4. Eel)r iclten. PS. Bct 3 ig bei greversiorf. Rabenhorst. Sinem. Hübner.

1362? S, caesia L. ST. 33. B. Cab. 421 . Etct foliterurtig sidft.

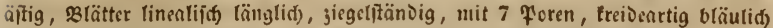

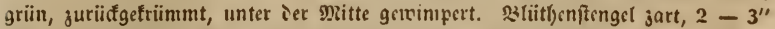
hod), wenigblättrig, 1 - wenigbriitfig, 3luntenolätter rundtid), nit 9?agel. -

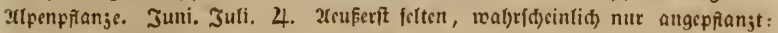
HS. $x_{\mathfrak{m}}$ Jnfelberg über Misinterftein 2 Epemplare. Prof. F. G. Dietrich.

1363. S. decipiens Енви. Stris, t, 23. St, 27. Rснв, Fl. genn. exsicc. n. 1261. Soctig, 23 lätter 3 - 5ipaltig, 2(b) fd)nitte linealifd) läng.

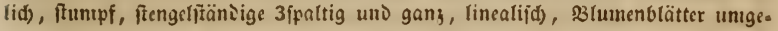

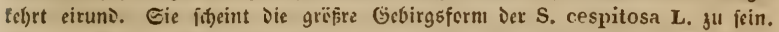
B1. und Seldje Duntelgriin, \$llitt)e weißs. - 21n fonnigen gelfen. Miai. 4.

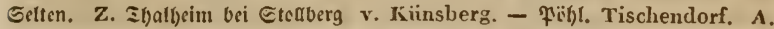
Mä̈defprung. Schwabe. HS. W̉scida in Etciniķ. Rossmässler. R. 23urgl, Dem \&urghamuner gegentiber. Dïrr. Edsleig am felfen Der \$zurg. Kunze.

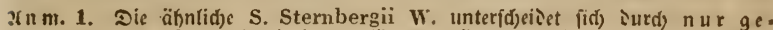
wimperte, fitadelfpiłige szlätter, längere bellgrüne Reldjab. idinitte.

$3 \mathrm{~nm}$. 2. S. controversa Stвg. Rснв. Fl, germ, exsicc. n, 1050. eine ?ll.

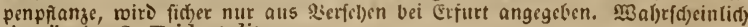
cine üppige $\mathrm{S}$. Tridactylites.

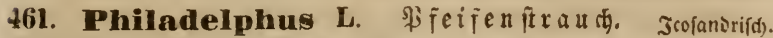
grudtfneten frcifelfïmig, eingewadjfon. Seldjaum $4-5$ theilig. Blument.

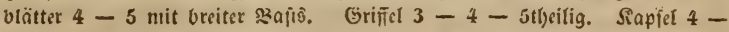

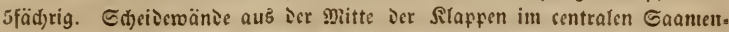

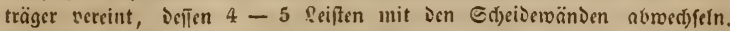

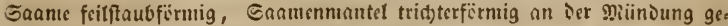
franft. - Bä̈tter $g \mathrm{eg} \in \mathrm{n}$ ii $\mathfrak{b} \mathrm{er}, \mathfrak{3}$ t. wocif.

* 1364. P. coronarius L. Scrk. t. 131. Sт. 3. S\&lätter eniptijø

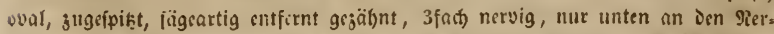

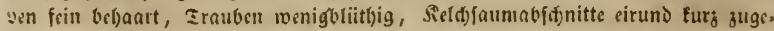

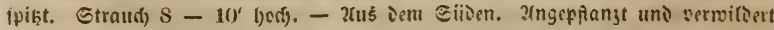
,irutidgr Jašmin". Endi Mai. Juni. b. 
462. Eulliarda DEC. Bulliarbe. Seld 4tbeilig. Blunie 4brättrig. Etaubgefäp̈e 4, mit 4 linealifđen Sdjuppen wedffelno. Rapfel 4tlyeilig, fäd)er mel)rfaamig. $\rightarrow$ Bie tlcines Sedun.

1365. B. aquatica DE C. Usteri Annal. II. t. 3. 2tufredtt oder lies

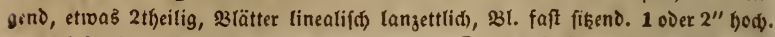
- Xuf feuchtem Sande. 2uguit. September. ๑. 2euferft felten. A. Sosmig, Gribo. Schwabe. PS, M̉ittenberg an Elbufer. Schkuhr, Iorgau. Löber.

\section{Sedum L. Fetthenne. Ficld stheilig, 2(6f(d)nitte feifitig} wulffig. 231. 56tättrig. Staubigefäße 10, Deren 5 vor Den Blumenbtättern

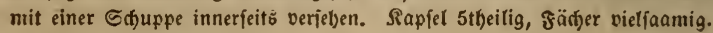

1366. S. anglicum Huds. Fl. dan. 82. 2fuffiteigend, 3lätter zet.

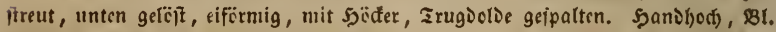
weißrrofa angelaufen. $-2 t n$ alten פRauern. Juni. 4 . 3erwildert. B. Sjaine. roaloe. Reichel. Schwarz. Flach. 18*(1).

1367. S, villosum L. Fl, dan. 24, Sx, 6. Rснв, Fl, gerın, ex-

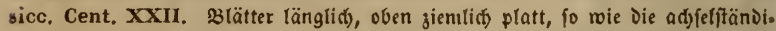

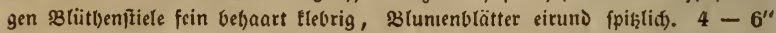
bod, fdjlant, rötblich angclaufen, unten meift mit fterilen, 3reiglein, Blüthen uno

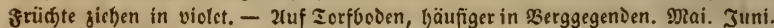

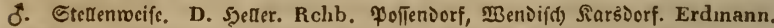
Hoffinann. Blochmann. Misipig. Bok. Z. Fils bei Edjneeberg, Sd)wargen.

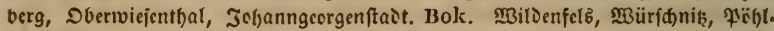

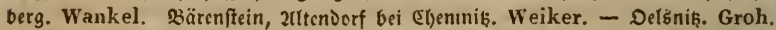
L. Borb̄oorf. Pet. Fl. Lips. Seuba. Diirr. B. Grofbennerboorf, Eoblano, Eei. tenDorf, \&öbau. Kölbing. Burkhardt. ( $\Re$ umburg. G. Rchb.) PL. Diebja unঠ Riešty. Burkhardt. - Borns১orf, Guben, G̈olīen. Rabenhorst. Du.

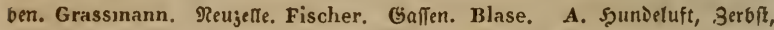

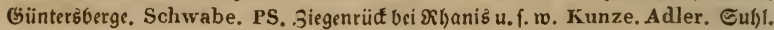

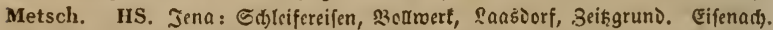

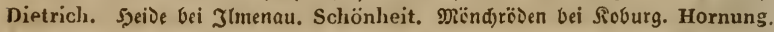

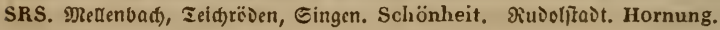

1368. S, album L. Fl, dan, 66. Rсnв. Fl, germ, exsicc. n. 1046.

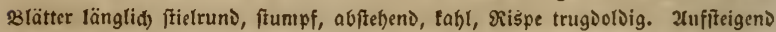

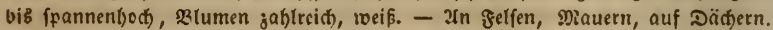
Juni. Juli. 4. (ङigentlid) wild wobl nur bei 3iegentï und $2(\mathrm{rnffndt}$. D. $11 \mathrm{~m}$

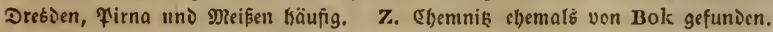
B. Prit/d)nik, Marienftern, (\{̂leiz, Zolleniftein). Kölbing. PL. Sonnenvalde, Piuinen Der MBenientirdye bei Fürtitlidy Drelyna. PS. 3arbn im Farabiefe an Mauern. Scholler. Merfeburg. Biegenriif an Saalfelfon. Adler. Erfurt. Buddensieg. HS, Meimar, Jena. Zenker. SRS. Irnftadt an Zetjen. Buddensieg.

1369. S. sexangulare L. HAYsi Arzneigew. 1. 16. Rснв, Fl. gerın. exsicc. n. 1259. Jufïrigent, Blätter jicutiid walzig, bü̈rig, faft allfredit, an ben jungen Etänmudgen Di 


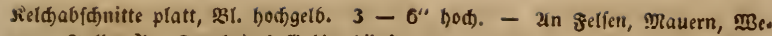
gen. Juli. 4. Durd Das Gebiet bäufig.

1370. S. acre L. Harxe Arzneigew. 1. 15. Rснв. Fl. gernn. exsicc. n. 1048. SBlätter bëđrig eiförmig, jiemli(h) aufred)t, jerfîreut, Irugiolien

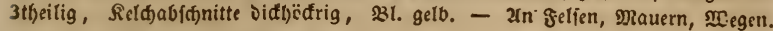
Juni. 4. Durth Das Gebiet läurig.

1371. S. reflexum L. Rснв, pl. crit. III. ic. 459 . Seblaft griin, slätter gerfitreut, unten gelc̈jt, fadenförnig pfriemlid), an Den Eeitenjtämnt(d)en jurüđfgebogen, ant 2 lütbenftengel abftebeno, sweige Der Irugoolse fpäter zurüđ.

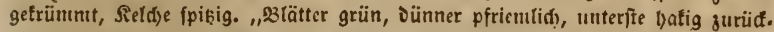
gebogen." Linnée! - In gelien, SRauern bëd) jelten! In Gärten unter Dem Ranten ,Iripmadam". Juti. 4. EuItivirt.

1372. S. rupestre L. DrLLex, Lins. t. 256. Sr. 12. SBäulict grün, Slätter unten gelëff, fpinielfërmig, siemlid) aufred)t, fo vie Die Reldse pfriemenfpişig, an Den Eeitenfänuntóen Diđjt 5reibig, Blumenblätter $6-8$ ab.

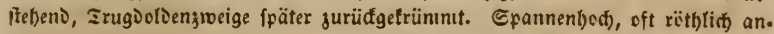
gelaufen, 31. gcl6. - b. recurvatum W. Blätter bïnner, faft ftielrunb, in Der Jugend fd)laff giegelfändig. - 2 n Felfen, Dürren fteinigen 2 (n)

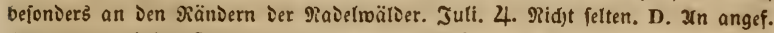

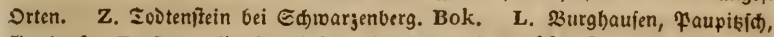

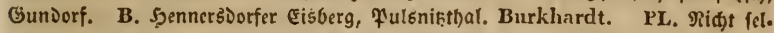

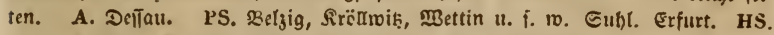
Jena, (Eijenad), Sioburg. SRS. slantenberg, frantenl)aujen, 2(rujtadt.

1373? S. Cepaea L. Crus. p. LXVIII. W. Kir. t. 104. 2ufitei, geno fein bebaart, Blätter flad), unigctel)rt eiruns fpatelförmig uno länglid,

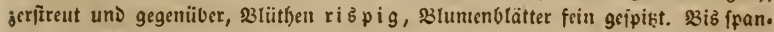
nenbed), 31. meī̄. - 2n fandigen ufern. כuni. Juli. ठ. PS. 2(m falyigen

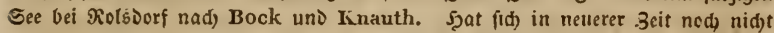
wiever gefunden. Bgl. SPR. Geid). D. Bot. II. S. 47 .

1374. S. Anacampseros L. Bot. Mag. 118. 2rufiteigeno, 33lätter

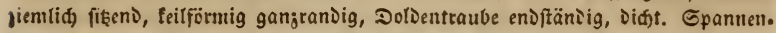
bod), 23l. rofa, MBurjel faferig. - 2luf Mauern. Juli. 2luguft. 4. MBohl nur veriviliert. SRS. Jrantenlyaujen. Hornung.

1375. S. purpureum AndRz. (Teleph. $\beta$. L.) Rснв. pl, crit. ic. 968. Stcif aufred)t, roth angelaufen, silätter frach, jerītreut, cier ju Dreien

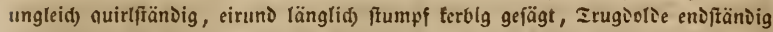

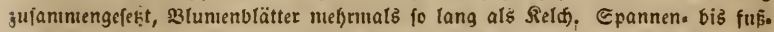

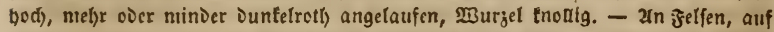

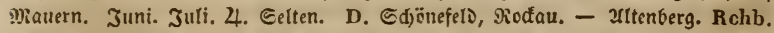
Hübner. G. Rchb. Z. Elonberg. Wankel. 1. Penig. Deline. - B. Rabenhorst. R. Sobenjizein nad) Heinhold.

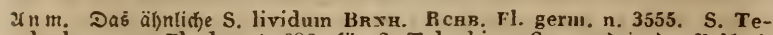
leph. purp. Fl. dan. $t$. 686, für S. Telephiun SM. und in Der \$3eidrei. bung S. purpurascens Kocr in ST. Fl. 83. 8. unterfdeitet fid) Durd) an Der 


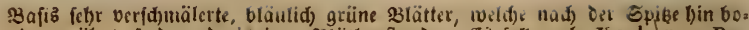
gig gejältht fins uno rispigen sliutbenftano. (E's foll nad) Kioch vont Ra-

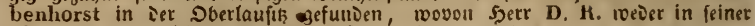

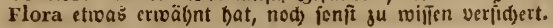

* 1376. S. Telephium $\left(\alpha_{0}\right)$ L. (Fabaria Косн.) Sтоrax S3. 9.

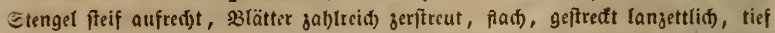
budtig gefägt, Dolientrauke Did)tblütbig beblättert, Blumtenblätter Doppelt fo lang

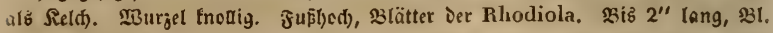
tie in, griintids oder rofa. - Eultivirt uno wie Portulal georaunt. Juni. Juli. 4. 3. \$3. in Erggebirge.

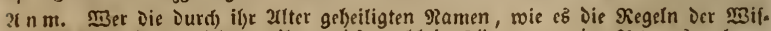
fenf(t)aft foriern, nid)t vertilgt, wiro mobl in Fädell, wo cine 2utt aus mebrern

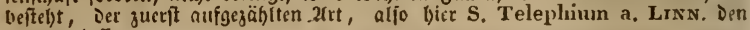
Sianieti laiten.

1377. S. maximum Pers. (Teleph $\varepsilon$. maximum L.) Rснв. pl. crit. ic. 969. 2tufïteigeno, s3lätter hergeiruno, gefägt, gegenüberiłełeno, Irug=

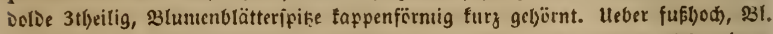

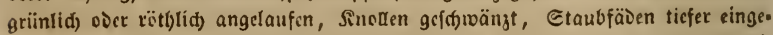
ię̧t. Orf. Rad. hb. Telepluii s. Fabariae. - 2ln Feljen, auf Maurn. Juni. కuli. 4. Sientit(t) häurig.

$x \mathrm{~nm}$. Rhodiola rosea L. A. Mägocfprung nati) Schwabe.

464. Sempervivum L. Sุa

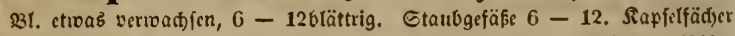
getrennt $6-12$, won einem હd)upfentranje ungeben. - slätter ieifdig, diegelitäncig. 2uธläufer bilden Siofetten.

1378. S. hirtum L. ST. 30. Der Etengel fo mie Die eirund juges ipişten Blätter raud), Blunıcnblätter meift 6 , a ufred) $t$, gefra nft, wei $\bar{F}$. li i) griin, xofetten blätter jufauntengeneigt. S3is fpannenbod). - Xuf Mauern. Juni. Julli. 4. Eclje felten. PL. S'auban. Rabenhorst. -

1379. S. soboliferum SIMs. Bot. Mag. 1457 ! globiferum Rснв. pl, crit. ic, 1131. 23lätter teilfürntig längliç, îpik, tabl, geminıpert, 3lumen. blätter neeift 6, aufred)t, gefranft, gelblid) grïn, אofettenblätter zufanımenge.

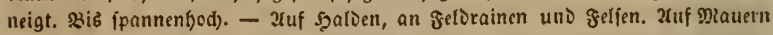
angeprianjt u. vérwilDerni. Juni. Juli. 4. Nur an Den Drten mit Durdfffolfener

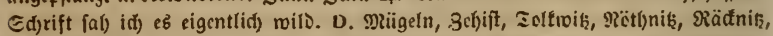
Saik, Meifen. - Dberfrauendorf, Xtenberg, sä̈renftein, sinnmals,

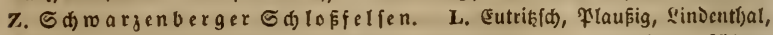
Sileuien, D̈̈lik, zttrannitäot. B. MBeifienberg, Sänik. Dybin, Sittau, \&öbau.

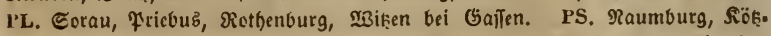
fhau, Mannsfclo, Docrriešborf, Botteniorf, Maulsaujen, Eisleben, Sangerbaujen. Grofinennra, Erfurt. HS. Mellingen bei M̉sintar. Eifenberg.

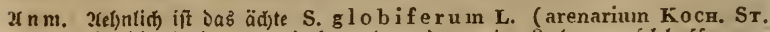

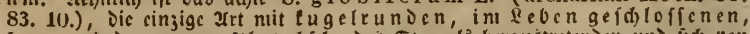

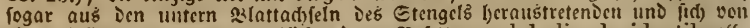
eineu D ïnnen ga Den ablöfenoen Rojetten "globulis decidentibus": Moris. sect. 12. t. 7. f. 18! nur Die Slume ift in Diejer fonjt unvertennba.

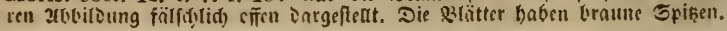


1380. S. tectorum L. HAYNe Arzngew. VI. 14. Die Blätter ber

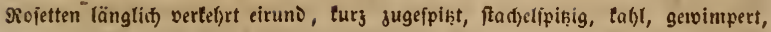

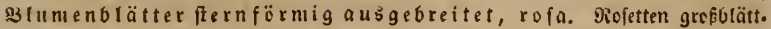

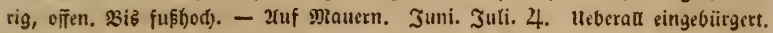

\section{Familie Ribesiaceae, Ribejtaceen.}

- Sectbarienbud) 5. LXV und 160. -

465. Tribes L. Sofannisbeexe, Etadiffeere. Sild

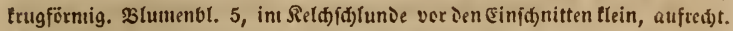

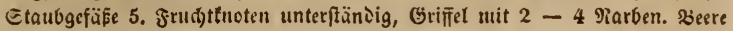
vieliaanig.

1381. R. Grossularia L. Gurmp. t. 23. Sr, 4. Stüthenpticle 1.

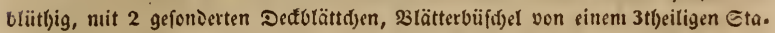

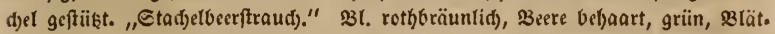
ter 3lappig uno eingeiffnitten, 3 tattftiele oriifentoz, bebaart. - b. R. reclinatum L. nit 3ttheiligen Deffblättdyen, Greiten Blättern, rother sicere, Sweige

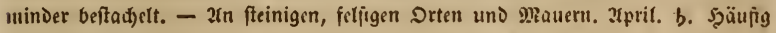
cultivirt und verwildert.

1382. R. "uva-crispa L. Gurmp. t. 24. ST. 44. B(üt)enftiefe 1.

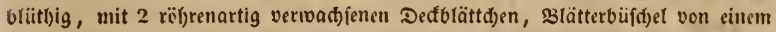

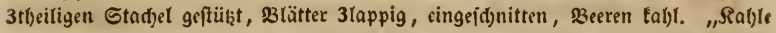

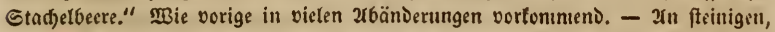
felfigen Drten, Mauern. 2upril. Ђ. Mie vorige.

1383. R, alpinum L. Gurmp. t. 21. St. 51. Irauben aufredtt, Driifig bet)aart, Reldffaum faft fad), fabl, Blumenblätter fpatelfërthilig, Deffblätt.

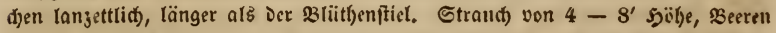

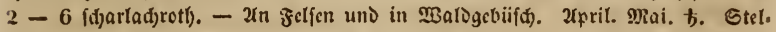
Ienweife, im Eragebirge und Der giedertaufik fel)r felten, um leipjig ferbleno. D.

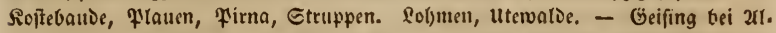
tenberg. Z. Cd)eibenberger Bafalthiibet. B. Dybin, Saufde, Zffornebod, sï.

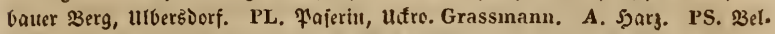

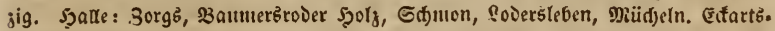
berge. Sinnberg vei Grofmmennra. Guly). HS. Jena. SRS. Irnitait. R. sobenftcin.

1384. R. rubrum L. Sr. 4. SchK. t. 48. Guisp. t. 19. HaYNe

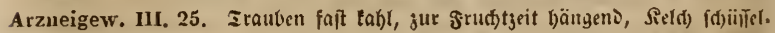

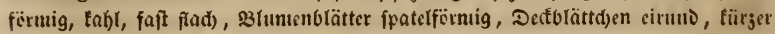

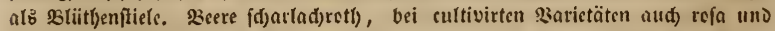
häufiger weiß. $4-5^{\prime}$ hod). Opp. baccae ribis rubri et albi, - 3in sel.

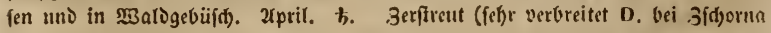
in sinem Ertenmalde. Auerswald.).

1385. R. nigrum L, Guimp, t. 22. Harse Arzneigew. III. 26. 
Irauben meidb bebaart, bängend, Dectblätter pfriemlid, türger als ier Blüthen. fitiel, Blätter unterieitz orüfig punttirt, Beere fd mar $s$, oben ein Mittelraum innerbalb Des Reldyfaunis (roie bei Der Mispel), naft. 4-5' bod). Orp. baccae,

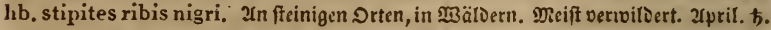

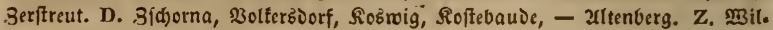

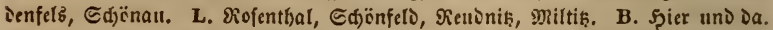

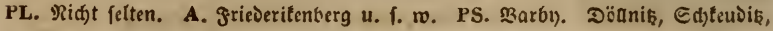
Solzmeipig, Benniorf. Erfurt. HS. Jena. SRS. 2urnitadt.

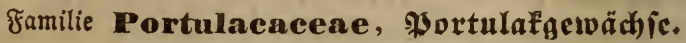

\section{- 5erbarienbud) ธ. LXVI und 161. -}

\section{Seleranthus L. Rnorpelfeld. Sinauel. Reld} glodfig. Caum 5theilig. 231. U. Grudjtinoten cingetwadjien, Grifiel gefpalten. 1U

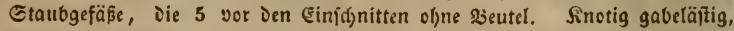
3lätter grgenïber.

1386. S. annuus L. Fl. dan. 504. Die Reld)faumabichnitte fdynal,

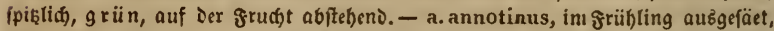
(d)lafiälitig, gegipfelt, 281 . in Den Ibeilungen einjeln. - b. hibernus, in Şerbfte ausgefärt, fteifer, vieljtenglid), BI. Diđt getnäuelt uno gegipfelt. - Xuf Xefern.

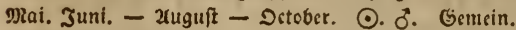

1387. S. perennis L. Sснк. t. 120. Die Rel(t)faunabfd)nitte mit

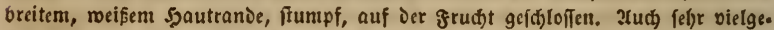
ftaltig nad) Seit und Standort, aud vielleidt Saftarde mit vorigen bitDend. -

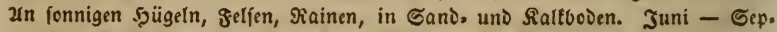
tember. ठ. 4. Jm Gebirge felten, auferden gentein.

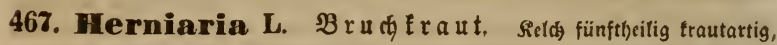

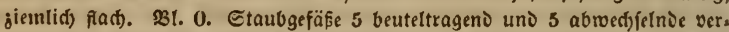

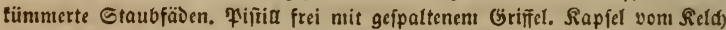
eingejd)loten, 1 faamig, fd)laudartig. Sraut, gabeläjtig, 2(dfelblättd)en un১ Deđtblättd)en fel)r tein.

1388. H. glabra L. Schк. t. 56. Hayns Arzneigew. IV. 37. 3lät。

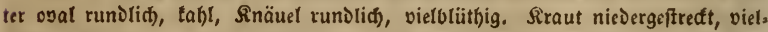

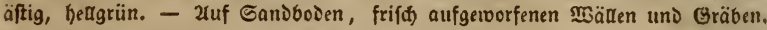
פai, Juni. - Dctober. ठ. 2uggemein verbreitet.

a $n$ nt. H. hirsuta faben roir nod) nid)t allz unfernt Gebiet.

468. Illecebrum L. Inorpelfraut. Sild stheilig, fnor: pelartig, fałpenförmig, pfriemenipikig. 231. U. Gtaubgefäfe 10, Deren' 5 vor Den Reldgeinfdinitten ofne seutel. 2 Rarben. Rapfel im Reldfe, 1faamig, 5fpartig.

1389. 1. verticillatum L. Fl, dan, 335. Sснк. t, 50. Rсв8.

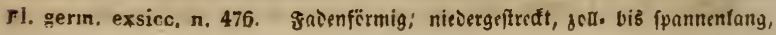


äftig, Blätter Elein, oval, mit 2 2ddfelblättd)en, Blütbcn $10-12$, in Rnäueln quirlartig, nit gegenüberftelgenden Dettolättd)en, ve iß, tnorpela rtig. - 2luf ïberfdroeminten Ganiboden, an इeidufern uno Gräben. Juli - Gept. 4.

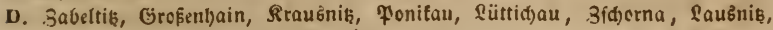

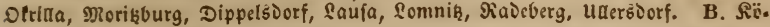

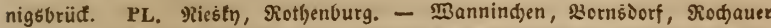

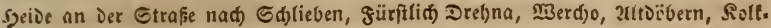

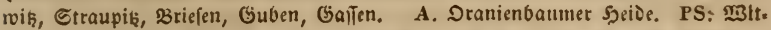
tentirg: Epefte. Seljig. Dïben. Saudbammer bei Drtrano uno Raundorf. HS. Rreujburg bei Eijenad).

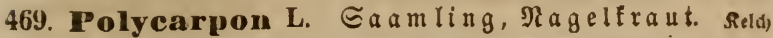

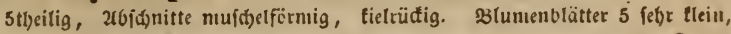
fd) uppenförmig, meift aubgeterbt. Staubgefäse 3-5. Narben 3. Rapfel 3tlappig, 1fäd)rig. Saamenträger in Der Mitte. - U(d)felblättd)en treden. b)äutig.

1390. P. tetraphyllum L. fil. Lam. ill. t. 51, Ronв. Fl. germ. exsicc. n. 1266. Dreimännig, Blätter ungetef)rt eirund fpaltelfürmig, ftengel=

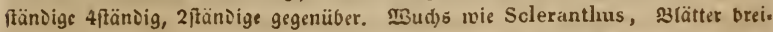
ter, banobod, s2. grün(id), reeiflid) gefäumt. - 2luf Gandooden. 2tuguft October. - Eeljr felten. D. Etedenweife auf Din Graspläţen Der Promenaden son Drebien $18+1$.

470. Alsine L. Ml iere. Sielt) 5tleillg. 23luntenblätter 5 , gang. 10 Etaubgefäßse. Rarben 3. Siapfel 3tlappig, Eaantenträger mittelfänoig 3tantig. - Rievergeftreftt, auffteigeno, tnicbogig, tnotig, häutige 2tafelblät, d)en, Iraube langitielig, frud)tftiele juriidgejdlagen.

1391. A. rubra Crviz. slätter beiserfeits fad), ftad)elfpib̆lg, Gaa. men oreitantig eftig, fein runjelig, 3lume fdjën rofa. 23is ipammenlang. - 2luf trodnem uno feudytem Ganoboden. Jult - Geptember. ๑. Sebr verbreitet, ftedenmeife bäufig.

1392. A. marina (Rтн.) Rснв, Fl, germ, exsicc. n. 477. Bläн

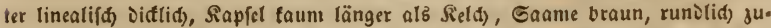
famınengevrïđt, fdärfli đ) gerandet, taun $4-5$ bautrandig. MBuds oer sorigen, Blätter länger, \$lume b I a Deren Şabitus fie vereint, obne ju eincr son beiben gebïren ju fönnen! - 2tuf Ealjboven uno Eumpftriften. Juli - Eeptember. $\delta$. 2tn ien Galinen uni bcl \&ucfau. PL. \&uçau. Rabenhorst. PS. Gtaffurt. Schwabe. Diślau,

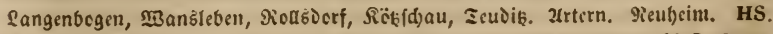
Rreujburg boi (Eifenad). Zenker. Diirr. Couifenballe unmeit Erfurt. SRS. Fran. tenbaufen. Hornung.

1393. A. marginata (Dв C.) Rенв. Fl. germ. exsicc. n. 478.

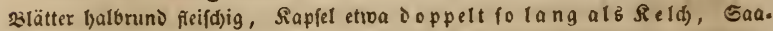

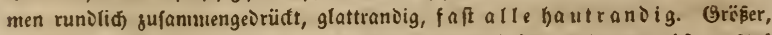

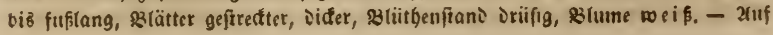


Ealjboden. Juli - Eiptember. $\overrightarrow{0}$. RS. Erieborn, Rolboctf. Wallroth. Klett. Itrtern. Rehb. L. Richb. fil.

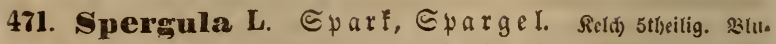
menblätter 5, ganj. Ctaubgefäfé 10) (bei 1394 fino 5 beutellofe.). Frrud)to tnoten balb eingewad)fen, Grififel 5theilig. Sapiel 5ipaltig, Saamenträger

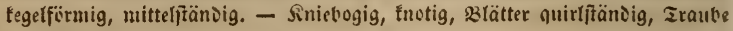
langitielig.

1394. S. pentandra L. Sr. MI. 12. Rснв. Fl, germ. exsicc. и. 1988. Balïtter frielruno pfrimtid), Gaanten platt jufanmengedrüăt, breit baut.

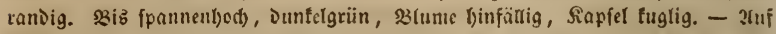
Sanvooden vorgïgfid) in Szeiden und an Saligeln. Xtpril. $\odot$. 2tu geeigncten Drten bäufig; im êrjgebirge bislyer nur $\mathrm{Z}$. bei Edjwargenberg.

1395. S. arvensis L. Rсnв. pl. crit. VI. ic. 704. Fl. germ, ex-

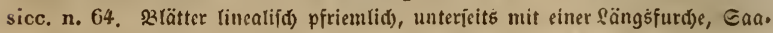
men linfenförmig warjig, tielrandig. Sal)l, l)ellgrün, fol)lanter als folgende, oben

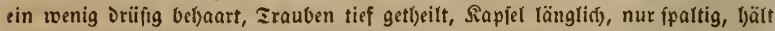
Den Gaamen beifanınten. - 2uf Gantboden, 2Hectern, aud) cultivitt. Juni arıguft. ๑. Gemein.

1396. S. vulgaris BNNGH. Rснв. pl, crit. VII. ic. 705. Fl. germ. exsicc. n. 65. Sil̈tter linealifd) pfriculid), Caamen mit teulenför.

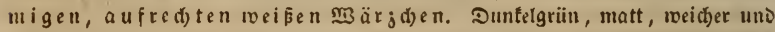

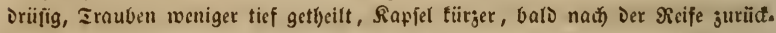

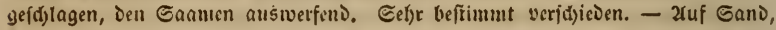

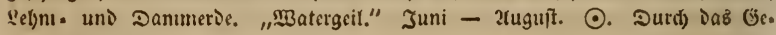
biet nid)t felten.

1397. S. maxima Weiнe, Rchв. pl, crit. VII. ic. 706. Fl, germ.

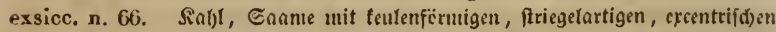

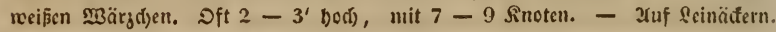

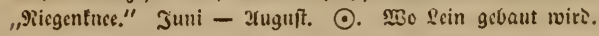

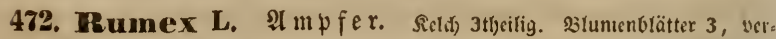
trof́nend. Etaubgefäße $6(-12)$ meift paarig vor Den Sicld)blättern. Pic fitil nit 3 garben. Yiüfisen 3tantig. - NB. Die \$łlumenbrätter werden

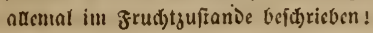

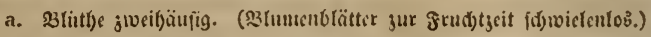

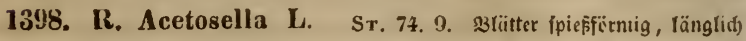
coer lineal rangettlid), \$lunenblätter eifürmig, ganjrandig, obne \$ö̈fer, Feld).

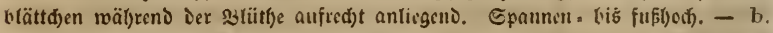
snultifidus L. ST. 74. 10. Sifattor)ren banifürmig getfeilt. - zuf eanifise Den. Mai. 3แmi - Şerb̂R. 4. Gemein.

1399. R. Acetosa L. nayne Xin. 6. Sr. 74. 7. 93lätter pfeil. oocr

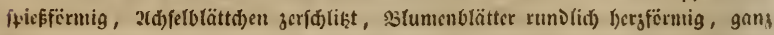

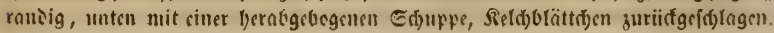


b. intermedius DE C. Blätter ipiesffirmig lineatipi(f) (ängli(t). 2' (jod), aufre(t)t. Tuf Miejen bis auf Die Gebirge. "Eauerantpfer." Mai. Juni - jaerbit. 4. Gemein. Var. b. PS. Erfurt. Hornung.

b. 23 tütlye z̧witterliç.

a. Bluntenblätter fófivielenlos.

1400. R. arifolius AzL. Sт. 74. 6. Rснв, Fl. germ. exsicc. и.

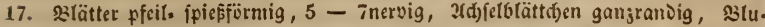

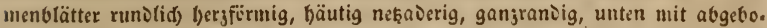

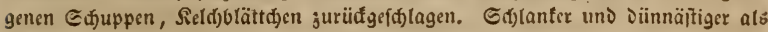
Acetosa, melyr gelblid) grïn, s3lattïl)rdfen abgeruniet. (Jif) jammelte iljn fiden $1 S 17$ in Den Gubeten!) - 2uf Gebirgstriften, an 2uellen. Juli - Eeptember.

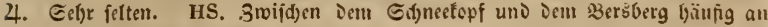
ciner Duelle Der Ġeta. Metsch.

1401. R. scutatus L. BLAKw. t. 306. ST. 74. 5. Siätter bläulid) grün, fpatenfürmig, Blumenblätter bergrundlid, ganjranoig, bäutig, Blïtł́n in 5albquirlen entfernt, blattles. - b. hastifolius M. B. 23\%. an Jen Sciten bud).

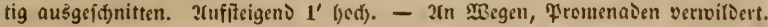
Juni - 2uguft. 4. PL. Sưfau. Rabenhorst, SRS. Frantenlyaujen.

1402. R. aquaticus L. Rchв.pl.crit. IV. 553. Hayxe XIII.4. St.

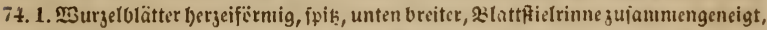
Blunenblätter berjförntig, bäutig, faum gejäl)nelt, Irauben rispig blattlos. Bis

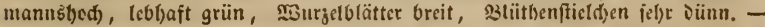
2n Gümpfen uno Gräben. Juni. Juli. 4. Nid)t felten. Serftreut Durd) Das Gebiet.

1403. R. domesticus НАвтм. Rснв. pl. crit. IV. ic. 526. \$3lät, ter langettliđ) und linealijđ, mellenrandig, unterfte fajt berjfïrmig, 33lumenblät, ter faft bergfïrmig, fein geferbt. \$ू心uds von R. crispus. - 2uf Sdutt, be. bautem $2300 \mathrm{cn}$. Juni. Juli. 4. Gel)r felten. Z. Dbergablen\} bei (El)enunik. Weiker.

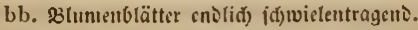

1404. R. maritimus L. Fl, dan, 1208. Sснк. t. 1)(. ST. 73. 1. 3lätter linealifđ) langettlid), Die Quirle beblättert, obere Diđfter, Blumenblätter

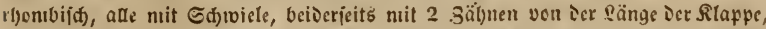
mit lang (anjettliđ), gangrandiger Eqik̨e. Etcif aufređ)t, 1-2' bed), gelogrün,

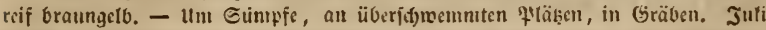

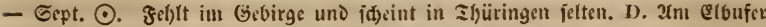

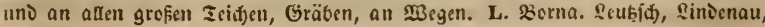

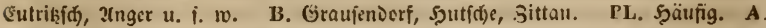

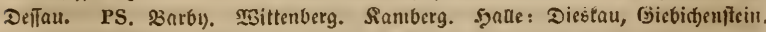

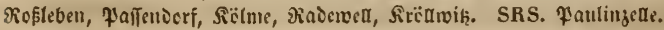

1405. R. palustris SM. Engl, Bot. 1932. ST, 73. 2. stätter $t i=$

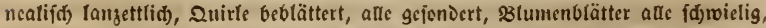

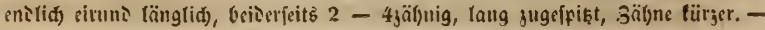


In Eümpfen, Gräben. Juli. auguit. 4. Sctten. L. Strcitboly. Richter. Peteruann. Z. Ebemuniķ. Weiker. PS. Şalle. Sprengel. SRS. Rubfraß̧ boi RuDolftait. Scliönheit.

1406. R. pratensis M.K. Harхs Xu1.2. Sr. 73. 12. Untre \$3lätter

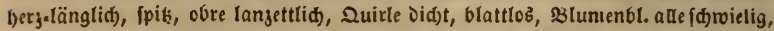

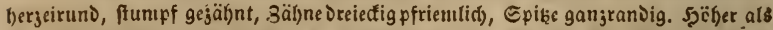
R. obtusifolius, Dem er äl)ntid) ift, \$3lätter nucl)t geftrectt, słlunıenolätter breit

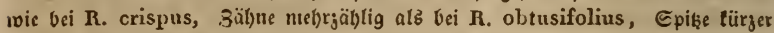

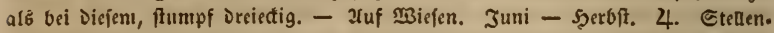

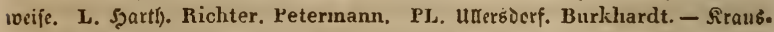

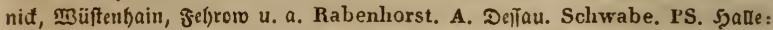
Pettin, Eeben, গaverwell. Erfurt. Doerfäit bei Subl. Metsch. SRS. Eidffelo

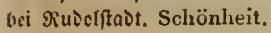

1407. R. obtusifolius L. Rснв, pl, crit. IV.ic.550. HAYNe XIII. 1. Sr. 73. 9. Unterfte Blätter bersförmig, ftumpf, obere ipik, hergförnig u. länglid), oberffe lanjettlidf), Quirle naft, gefondert, słluntenblätter alle fd)wielig, cirund, Dreicđig, neķaderig, unten mit ffriemlid)en 3äl)nen, ๔pike lang, ftumpf, ganjrandig. R. purpureus PoIr, ifit Diefelbe $\mathfrak{F}$ ilange roth angelaufen. - b. R. silvestris Wallr. R R

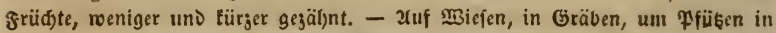
Dörfern. Juti. 2uguit. 4. Şäufig Durd Das Ģebiet.

1408. R. conglomeratus MurR. Rсrв. pl. crit. IV. ic. 352. Nemolapatlıum Енгн. Fl. germ. exsicc. n. 1378. Unterffe 33lätter berg. förmig oder cirund längliđ), obere berglanjettlid, jugefpißst, 3reige faft borizon. tal aus̉gebreitet, Dic 2uirle entfernt, untre beblättert, Blumenblätter alle fobroie. lig, linealif(d) länglidf), ftumipf, gangrandig. Coll nad) Römer u. Schultes u. W. Meyer Der vieldeutige R. acutus Linnées fein. - 2 n Sünıfen, ufcrn, in Gräben. उuli. 2luguft. 4. Gemein Durđ) Das Gicbiet.

1409. R. nemorosus Schrad. Rснв, pl. crit. IV. ic. 551. St.

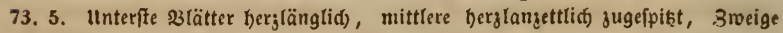
febr Dünn, aufred)t abffel)en〉, nur Die unterften Quirle beblättert, Blumenblätter lineal länglid, ftumpf, ganzrandig, eins fd roielig. Gd)lant und lellgrün, bi̋̈̋cilen nad) cben etwaś rotl) angelaufen. - b. sanguineus L. Sr. 73. 6. untre Slätter viclet geadert, übrigens roth) angelaufen und geffedt. - In \&aub. wälDern an feud)ten Drten. Juli. 2uguft. 4. - b. cultivirt. - Bienilid) ver. breitet Durd) Das Gebiet.

1410. R. crispus L. Rснв. pl. crit. VI. 783. Harxe XIII. 3. Blätter

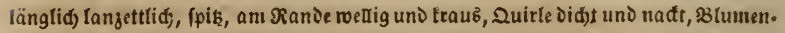
olätter alle ooer nur einz fdorielig, rundidd, ftumpf, gangrandig ooer unten ge. zäbnt. $2-4^{\prime}$ bod, giem(id) einfac). - 2uf \$̇iefen, bebautem Boven, befon. Detร Xeđ̛ern, an Mauern, Planten, 巨dutt. Juti. Xuguft. 4. Genein.

- 1411. R. Patientia L. Scrk. t. 100. Sr. 73. 14. Unterffe Blat.

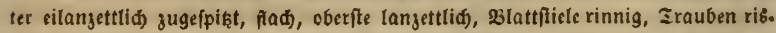
fig, ఇuirle nabe, nadt, slumenblätter bergrunolid, ftunipf, taum gejäbnelt, 


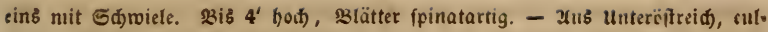
tivirt: "(Gartenampfer". Juli. 2uguft. 4.

1412. R. Hydrolapathum Huds, Rснв. pl. crit. IV. 554. Haxx XIII. 4. Sт. 73.15. Blätter lanzettliđ), beiberfeits seríd)mälert, leidjt wettenrandig,

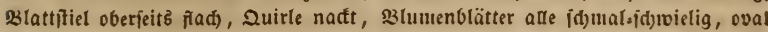
oreiefig, ganjrandig over unten gejäl)nelt. Ueber mannह̈(jod). - In Gümpfen,

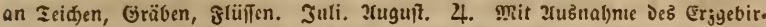
ges Durd ১az Giebict; gentein in 2unfalt und Der Riedetlaujik. D. Elbufer, Fin. niķ, Grofenţain. L. Eđjënfeld, süb̧f́dena. B. Etolpen, Sittau. PL. Eee, Ritfden. - \&udau u. f. w. gentein. A. Gemein. PS. Eceburg, Manbltben,

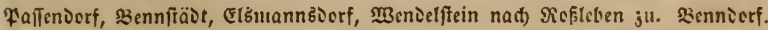
HS. Jena: Runik, M̋̈̈rnik. SRS. Singen.

1413. R. maximus Schreb. St. 73. 16. Btätter fdficf berzeituno,

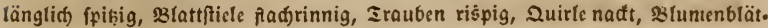
ter alle fdjwielig, bergoreiedig, gejähnelt. lleber mannshod), nur cingelne früß)te bitben fid) auz. - In stufufern. Juti - Eeptember. 4. Gefje felten. PS. In Dex Şelne bei Speringen. Wallroth.

473. Polygonum L. $\mathfrak{R} \mathfrak{n}$ öterị̂. Sield) fünftheilig, farbig. Staubgefäfe 5-6-8, paarig vor Den äufern Seld)abfdnitten, einzeln vor Den

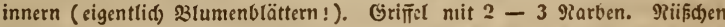
cinfaamig von Der vertrofincten \$lïtbe beieft, feimling wurnifürmig feitlid)

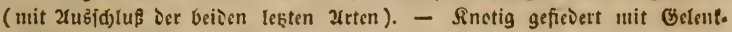
fureiten.

a. Staubgefäfe meift 6 .

1414. P. Hydropiper L. Schк. t. 1)8. Hayxe Arzneigew. V. 20. Rснв, pl. crit. V. ic. 687. 2uffedt, Blätter breit lanjettlid, fangf́pișig,

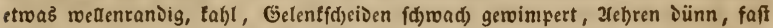

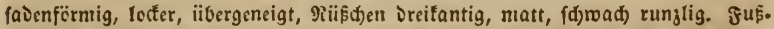

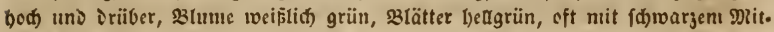
telfiect. Gefdumad pfefierartig beifeno. - b. Blätter unten reeißlid fitgig. OFF. Hb. Persicariae urentis. - .21n feuđten Drten, Flufufern, Gräben, ¥ffii. ben, un Gümpfe, überfd)wenınite Etellen, sorgïglid) in Dörfern. Juli - Eep. tember. - (. Gemein, veríd)riniet jedod, wie alle folgenden, im bëdjiten Ge. birge falt gans.

1415. P. multispicatum G. RCHв. Bzlätter lineal tanzettlid), Ge• lertifdeiden lang gewimpert, Jebren febr jablreid, faienförnig, Didf tolii.

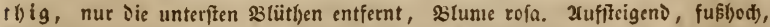

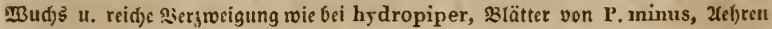
¿eşgl., abet aus ađten 8 lattadfeln, länger un১ etroas geneigt. - Xn einen Ici. be unweit P. hydropiper un১ minus. Juli - Eeptember. $\odot$. Xeuferit frt. ten. D. DRorił̧̨urg 1839, G. Rchb.

1416. P. minus Huds, hays Arzngw, V. 21. Rснв, Fl, gerin. exsicc. n. 285. 3lätter lineal langettlid), Gelenff́delien lang gemimpert, 2teh).

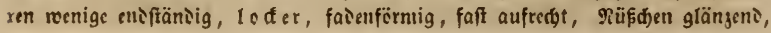


Jlantig. Epannen. bis fusphed), jelbr fittlant, sit. tlein, 5uännig, refa. Sit. bell. griin, feltner mit fdfwargem fled. - b. incanescens Warlr. Silatter unter. feits ıveip̄graupityig. - P. minori-Persicaria BRAUx, eine fterile gittelform,

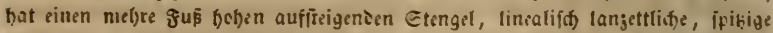

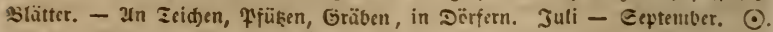
Int Erjgebirge fofor felten, auferien nid)t filten iurdf ¿as Gebiet.

1417. P. laxiflorum Weiнe. Rснв, pl. crit. V. ic. 686. (minus)

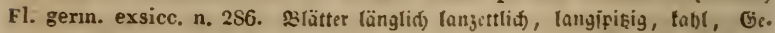

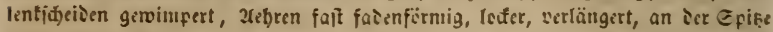

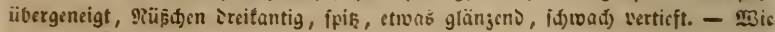
yeriges.

צ $\mathrm{nm}$. Da P. mite P. (hydropiperoides Mcux.) forchl nad) anterilanijithen serliegenien Exentplarin, als aud) nad) ier Diegnefe sirfdieien ift, fo tann unite Pranje Den giamen P. mite SchRK. nidt bebalten, iväbrend Der von WerHe ier unjecitcutige ift.

1418. P. Persicaria L. Haysk Arzneigew. V. 22. Rснв, pl. crit. V. ic. 6St. Fl. gernn. exsicc. n. 773 . Blätter länglid) lanjettlid, tahI,

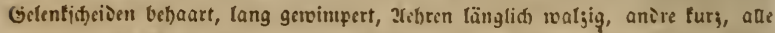

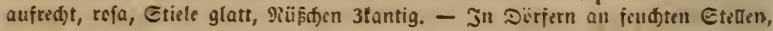

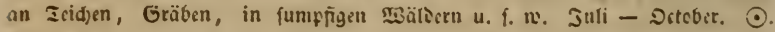
Eel)r gemein.

1419. P. Iaxum Rснв. pl. crit. V. ic. 685. 2uffizeigeno, Blättet

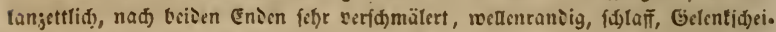

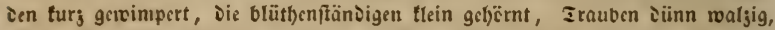

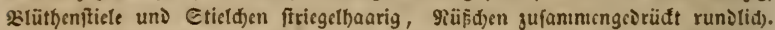

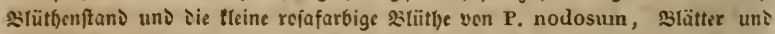
Edjeisen son hydropiper. Edeint ein hydropiperi $\asymp$ nodosum ju icin. -

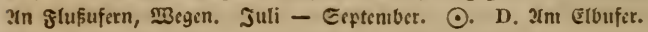

1420. P. lapathifolium Ait. Rснв. pl, crit. V. ic. 68s. צufitei.

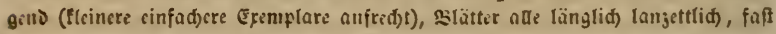

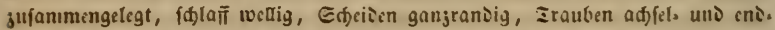

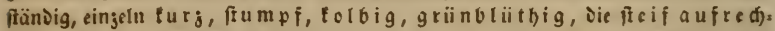
ten Gticle fo roie sic \$lïtben $r a u b j$ riifig. \$is $2^{\prime}$ bed), slätter griin, ungeñeđt, siliitle grë̄̈cr als an aniern, Etautgefäfe $5-6$, eben fo lang. b. slätter unterfeits weifgrau. - In Rartefielfeliern uno ïbcrhaupt auf Redern,

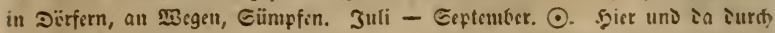
ias Gicbict.

1421. P. lapathifolio $\asymp$ nodosum Rснв. جuffeteigeno, ged,

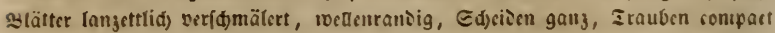

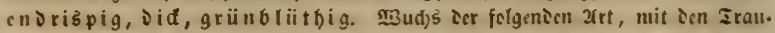
ten uni Bliithen ier verigen. - Unter ien Eltern sercinjelt. Juli - Geptetus ber. ๑./ D. $2 \mathrm{~mm}$ Elfuffer.

1422. P. nodosum Pers. Rchr. pl. crit. V. ic. 689. Fl. gerın.

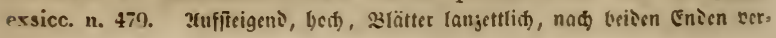


(d)mülert, unterfte lurs oval, fpatelförmig, Sd)eičn gangrandig, 3mifdentnotell. ftüife nad) unten sid angef(f)wolfen, Sranben Didftblütbig, verdünnt, etros iibet, geneigt, riø̄pig sereint, Grifiel auछ̈geipert. $3-4^{\prime}$ bod), Etengel meiftens blut. rotl) punftirt cier roth iberlaufen, Blätter fijöngrün, ier (đ)warje Mittelfet bes

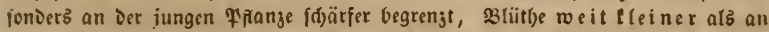

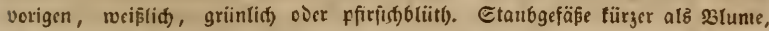

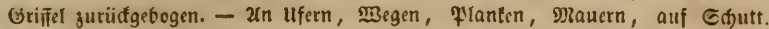
Juli - Septenıber. $\odot$. Bicmlic) gentcin.

1423. P. amphibium L. Fl. dan. 282. Wurgel trię)en〉, \$3lätter

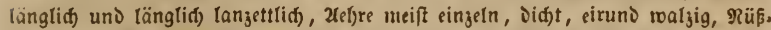

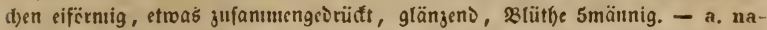

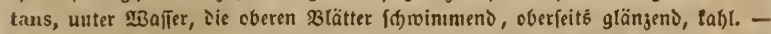

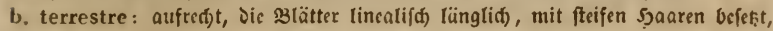
achre Dïnn. $23 i r b$ ein paar SuF lang, 3l, rola. - In కeidjen, Gräben, lang.

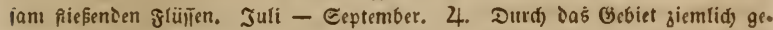

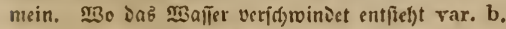

\section{b. Etaubgefäfie nucijt 8,}

1424. P. Bistorta L. Hayse Arzngw. V. 19. Rснв, Fl. germ. exsicc. 480. Etengel einfad), nit ciner Diffwalgigen, Didften Etraufäl)re, sRl. rofa,

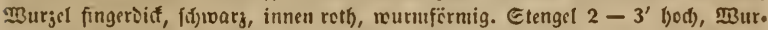

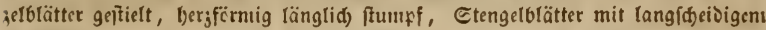
Blattîtiele. - 2uf fcuditen 2Bicfen. Mai - 2uguît. 4. Durd Dab Gebiet, namentlid) in Gebirge und Den Speiben felsr bäufig, oft aud) zur Gewoinnung yen sielbfutter ausgciät. OFr. Rad. bistortae.

1425. P. aviculare L. St, 1. Harse Arzneigew. V. 23. 32tu.

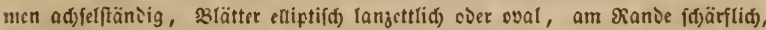

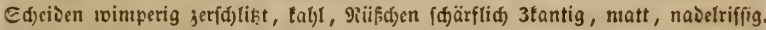
„3el)rgras, 23cgelfnüterig." - b. exectum, gref́blättrig. - c. neglectum, fa.

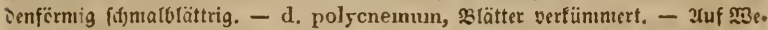

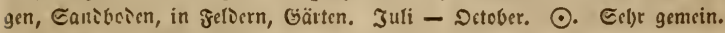

1426. P. Convolvulus L. Fl, dan. 744. Etengel mindens, satät.

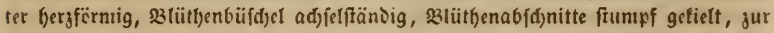

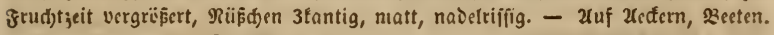
Juli - Eeptember. 4. Gientein.

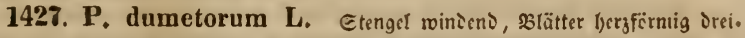

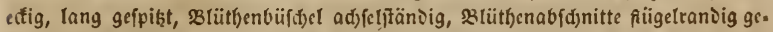

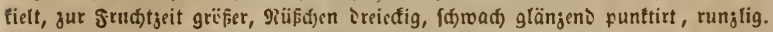
filettert நod). - In Şcden, an Geftiäld) uno Etauden ranteno. Juli - Eep. tember. $\odot$. शidist fitten.

1428. P. Fagopyrum L. St. 18. Haxxz Arzneigew. V. 21.

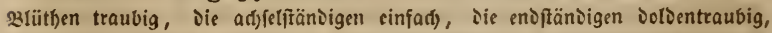

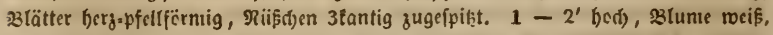

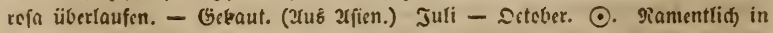

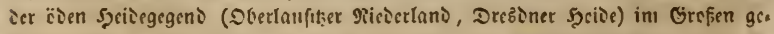

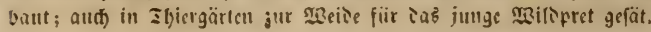


Portulacaceae. - 318 Polygonum.

* 1429. P. tataricum L. Gart. sib. III. t. 13. f. 1. Mriss. rolyg. t. IV. f. S. Frudt. Rснв, Fl. germ, exsicc. n. 481 . \$ie voriges,

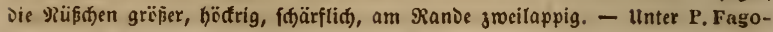
pyrum oft fehr bäuñg. Juli - September.

474. Corrigiola L. Uferling. Seltit 5theilig. 3lume 5.

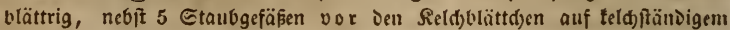
Kinge eingefiigt. Sarben 3. Sd)laud)tapfel 1 faamig, Eaame am berauf. gefficgenen હaantenftrange bängeni. - Blätter jerftreut, mit febr zarten, veif̧bäutigen 2dd)felblättর́)en.

1430. C. littoralis L. Sснк, t. 85. Rснв. Fl, gern. exsicc. $n$. 482. S3eblätterte DolDentrauben, Etengelolätter linealifd) teilfërmig, Stiel ge. itrectt, Stengel ftrablig auşgebreitet, fpannen= biß fuflang, Sraut bläulidg grün,

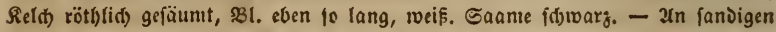
gluşufern. 2uguft. September. ○. D. Jm grofen Gebäge, am Xusfuife Der

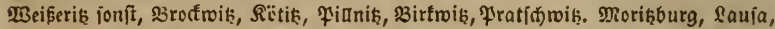
3ídjorna. PL. Steinbad), Priebus. - SB̈̈ftermarte an Der Straße nad) Sd)lie. ben, Duben, Sd) wielungsfee. A. DefTau in Der Dranienbaumer Şeibe, bei Dra. nienbaum, bcim SodjfäDter Ihorbaub, auf Der alten \&eipjiger Strafe. PS.

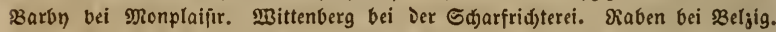

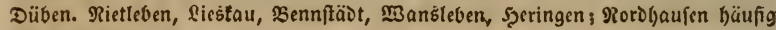
ani Ealten G̈raben.

475. Montia L. Mi ontie. Seld 2tlyeilig bleibens, 5 sslumenofät. ter unten verwadjfen, Deren 3 ff́niäter. 3 Staubgefäpse ifjen angewadjfen. Grifīsl 3t) bilig. Sapiel 1fäd)rig, 3tlappig, 3\{aanig, Eaante tuglig, faft edig, getörnelt.

1431. M. fontana L. Scrк, t. 20. Sr. 11. Sicinç faftigę Siräut. (d)en, tabl, bellgrïn ober roth) angclaufen, 231 . weiß. - a. minor Gx. aufrectit, 1 - 4" (bod), 31. enoftändig. - b. rivularis GM. untergetaud)t, f(d)rinment,

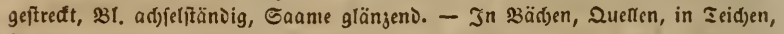
fađben. Januar - Juli. 4. Durd) Das gange Gefiet hier uno Da. Var. b.

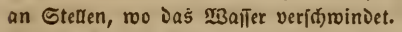

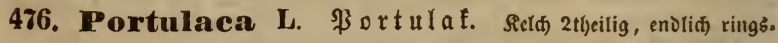
umif́f)nitten abfadeno. 23t. regelniäjig etroas verwadjfen, 4-6blättrig, an

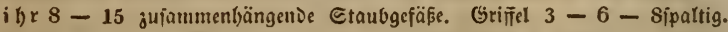
Sapjel fuglig, ringsium aufipringen〉, Saamenträger mittelftän১ig, vieliaa. uig, 巨aanten an langen હträngen aufred)t, nierenfërmig, fd)ärflid). 33(ätter iaftig, ntcift zeriftreut, $\mathbf{B l}$. adjfelftäniig.

1432. P. oleracea L. Schк. t. 138. Blätter länglid) teilförnitg, ab.

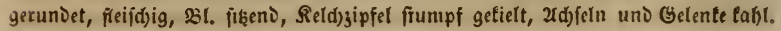
Gabeläftig, niedergeftrect, ifannenlang, roth angelaufen, 23l. gelb. 2uf fettem Boden aud aufred)t: $P$. domestica Loв. ic. 388. - b. aurea Honter. Blätter gelbliđ). - Gebaut un๖ an Megen, Gärten u. f. เo. verwilderno. Juli - Septemiber. $\odot$. 


\section{Familie Azoideae, $\mathfrak{A}_{\mathbf{i}} \mathbf{b}$ ideen.}

- şertarienbud) 5 . LXVII uns 164. -

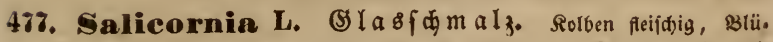
th)en zu Dreien gegenüber eingeienft, ofne Dedfolättthen. Sield bauthig, mit

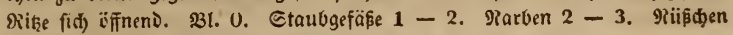

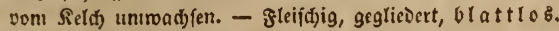

1433. S. herbacea L. Scri. t. 1. Fl, dan. 303. Rснв, FI. gerin. exsicc. Cent, XXII. Getente jufamintengedriaft, aubgeterbt, SGlieder um. gefefrt fegelförmig, folben veroünnt. - a. acetaria PALx. haloph, t. 1. aufo red)t biz (pannenhod). - b. prostrata PALx. t. 3. nicverliegeno, fel)r äftig. -

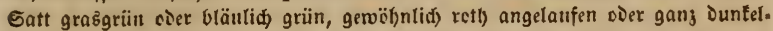

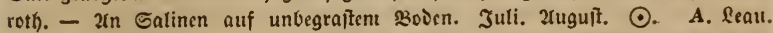
Schwabe. PS. ßaarby, un Die Gradirwerte bei Salja. Scholler. Etaffurt.

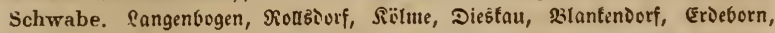

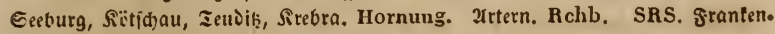
baufen. Rchb. Hornung. L. Rchb. fil.

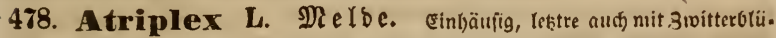
then. Meibl. אe 1 d) 2 fl a pp i g. Männl, ober Sivitterfeld) 3-5theilig. Etaub.

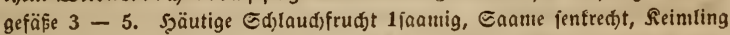

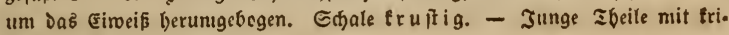
fradbelten łapiden bereift.

a. Schizotheca: einfüufig, olyne switterblütlen.

1434. A. latifolia WahrbG. (patula $S_{\text {Mr. }}$ ) (hastata.) Fl. dan.

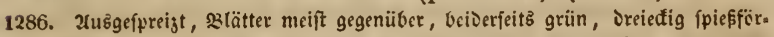
uig, gejälnt, obcre lanjettlid') ganjrandig, Die grudjtteldse Dreiectig, ganjraniig ojer gegäfunelt. - a. microsperma W.K. t. 250). Seld faum grëfer als Бaa.

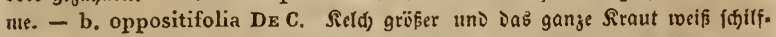

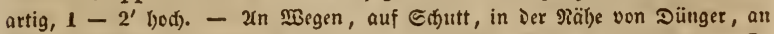
(d)atten, fiud)ten Drten. b. Juf falgigent $230 D e n$. Juli - Septenber. $\odot$. Nidit felten.

1435. A. patula L. Rснв, Fl, germ, exsicc, n, 1379. Engl. Bot, 936. Fl. dan, 1285. hast. Scrk. t. 348. 2užgevreitet tangäftig, Blätter bei.

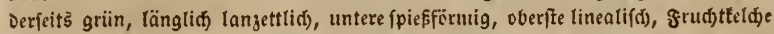

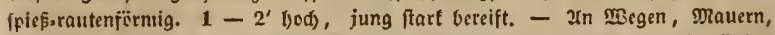

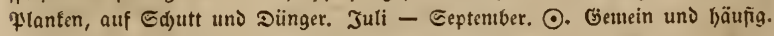

1436. A. tatarica SchK. t. 349. (nicrospenna: W. K. t. 22 I.

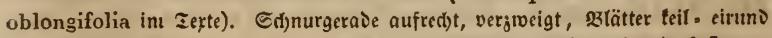

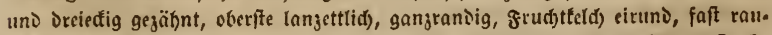
tenförmig gangrandig. $1-4^{\prime}$ lood), graulid) Dumtelgrün, grud)täłre geffreft,

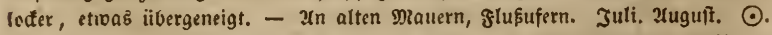

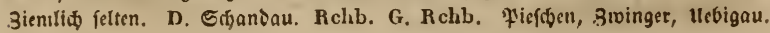


1820. Rchb. G. Rchb. L. Mïđern. Rchb. PS, Sgate. Sprengel. Diirren.

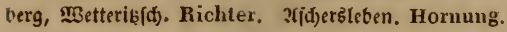

1437. A. hastata L. Rснв. pl. crit. I. ic. 33 . 2ufrentt auşge.

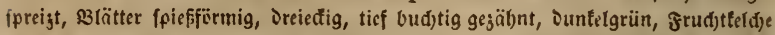
glatt, pfriemlid) lang gezäbnt, Mittclălyn ant längften. $2-4^{\prime}$ bod). - 2(uf Gd)uttbaufen, in Dïrfern. Juli. 2uguft. ๑. Gebr felten. PL. VRidjt felten. Rabenhorst.

1438. A. alba Scop. Rche, Fl. germ, exsicc. n. 661. (rosea L.)

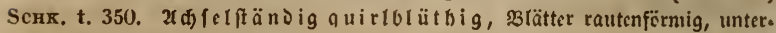

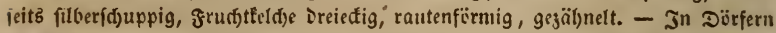

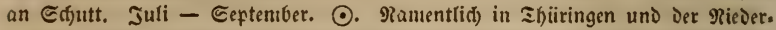
laufik. [D. Rofentl)al nad) Fic. Fl. Dresd. Dafelbit neuerlid) vergeblid ge.

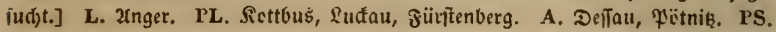

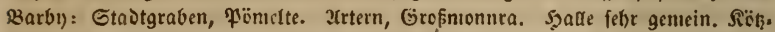

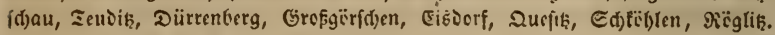
HS. Jena. SRS. 2rmifadt.

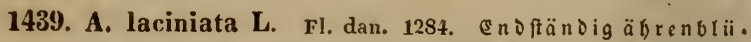

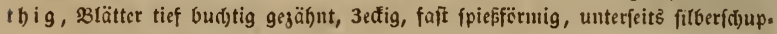
pig, obre länglid), Frud)tfeld) rautenförnig 3lappig, Seitenlałpen abgeftuķt. -

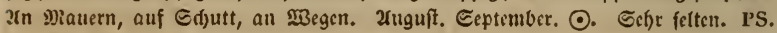

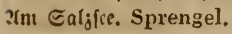

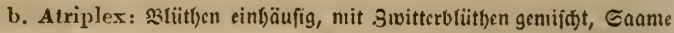
Der tweibl. 331. fenfectft, ier Der 3witter6l. borijontal.

1440. A. nitens Rerent. Rchb, Fl. gern. exsicc. 658. Schr. 1. 348. 2(ufred)t un১ abftclyent over auşgctbrcitet äftig, silätter unterfeits fitber. yrau, obcrfeits glänjens Duntelgrïn, bergförmig Drcieđig, budjtig gczäbnt, obre lanjettlid), frudjtfeld)e ciruno jugcipikt, nekzaicrig, ganjrandig. $2-4^{\prime}$ lyod),

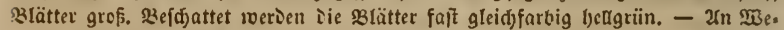

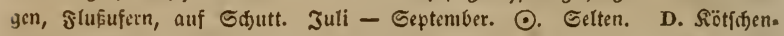

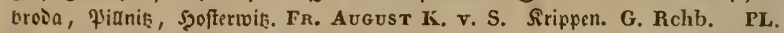

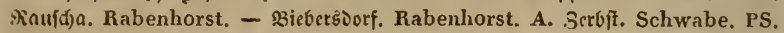

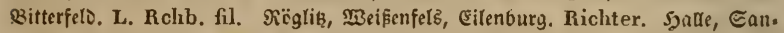
gerbaujen, 3rtern. Erfurt. Hornumg. SRS. Frantent)aufen. Hornung. Ru〉d= ifaot am $\in$ (b)loß̧erg. Schönheit.

1441. A. hortensis L. Sснк. t. 349. 2lufrect)t, Blätter beiderfeits

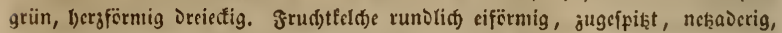
ganjraindig. - b. rubra DEC. gang rett). - Sier und Da gebaut und Daber in Gärten, namentli(i) auf iem Sande, verwildert. Juti. 2ruguft. ๑.

479. Malimug C. Bauh. Wartr. Reilmeloe. Weibr.

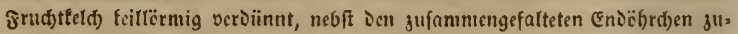

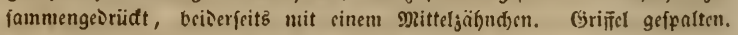

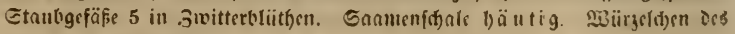
Sicimlings̀ aupifteigent. 
1442. H. pedunculatus WALer. Engl. Bot. 232. Fl, dan. 304. Sснк. 549. Rснв. Fl. germ. exsicc. n. 483. Rrautartig, aufredtt bogig, Blätter umgetel)rt eiruno, gangranbig, weiblid)e stüthe gefticlt, lang teilförmig.

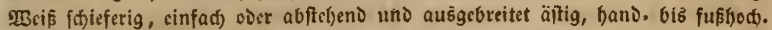
- 2rn Galinen. Juli - Geptember. $\odot$. Eelten, aber fefre gejalig. A. Gröb. jig, \&ecu. Schwabe. PS. Etaffurt. Hornung. 2uttern. Wallroth. Kunze. Rchb. शtumiburg. Sprengel, Hornung.

480. Spinacia L. Spinat. 3reihäufig. Weibt. Seldh 2-3.

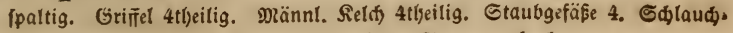

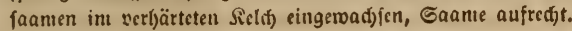

* 1443. S. oleracea L. LAM. ill. t. S14. Btätter elförmig läng. tid, am Grunde faft fpieffïrmig, 23ähnig, grudtteldhe ftadelartig behörnt. Şans grün, $2-4^{\prime}$ yod). -2 ¿us dem Driente. Xngcbaut uno vermilderno: "Minter. fpinat". Nai - Juli. $\delta$.

* 1444. S. inermis M Mch. Scrt. t. 32t. Morts. Sect. v. t.

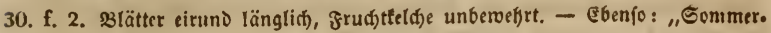

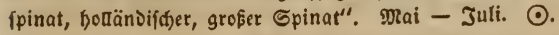

481. Beta L. Niangolb. Reld 5theilig, feifhig wervend, xo.

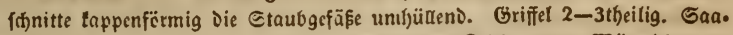

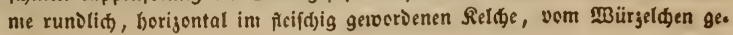
fpi६̨t. - 231. getnäuelt äbrenartig.

* 1445. B. vulgaris L. BLAKW. t. 235. GAERT. t. 75. f. 5.

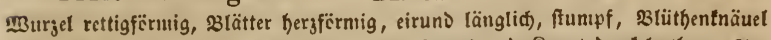

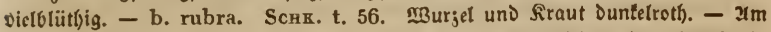

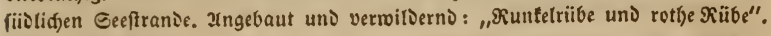
Juli - Septentber. $\delta$.

* 1446. B. Cicla L. Kerny. t. 242. Plenk. t. 170. WBurgel rüben.

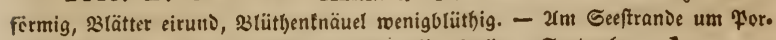

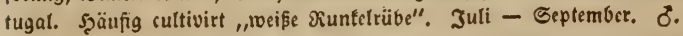

482. Agathophytum Moquin-Taxdon. F̧einridg \&s

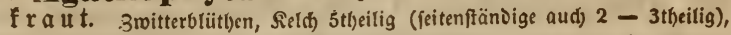
frautartig, Stanfgcfäfe 5 (in Den Geitenblütlen aúd) $1-3$ ). Saame' fruftig, aufred)t (over in den (EnDblititsen borizontal). - 2(rten yon Chenopodiunn bei Linn ée.

1447. A. glaucum (L،) Fl, dan, 1151. Blätter längliḑ, fluniłf, entfernt bud)tig gejäll)nt, unten weifgriin, 2(el)ren blattlos, Saamen glatt. Xuf. red)t ober niebergeftrectit bis über $1^{\prime}$. - 2(n feudsten, überfdrocmmt geroefenen Drten, Düngerpläk̨en, auf Edjutt. Juli - Eeptenber. $\odot$.

1448. A. rubrum (L.) Fl. dan. 1149. 23lätter glänzeno grün, fpleßs.

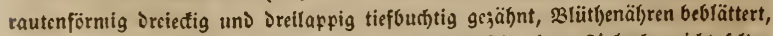
jufammengefotit, Eaame glatt. Xufredt, etreas faftig, $1-2$ ' hod, nidbt felten 


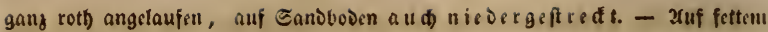
\$ojen, befonters um Düngerpläbe in Dërfern. Juli - Eeptember. ๑. Ju (Erzgebirge fparfam, anferiem jientid) bäufig.

1449. A. Bonus Henricus Moq. TAND. Fl. dan. 579. Schr. 1. 56. Mel)lartig bercift, 2 lätter fpieffëruilg orciectig ganjrandig, Blütlyen in abfele uno endfändigen 2ret)ren. 2uffteigend $1-2^{\prime}$ bod), natt Duntelgriin. auf bebauteni $300 \mathrm{cn}$, auf 5 d)utt, an Mauern, Planten in Dërfern. Jull Septeniber. ठ. Genteil.

483. Blitum L. (5robeerfpinat. 3witterblitt)e. Selt) 5. tbeitig (feitlidje aud) 3tfyeilig), jur grud)tgeit beerenartig, faftig. Gtaubgefäße 4-5 (jeitenitänoige 2 1. Imännig). Grifiel 2theillg. Eaante fruftig, aufredt. grudtfeld) verwad)fen wie giaulbecre. - Durd a b nor.

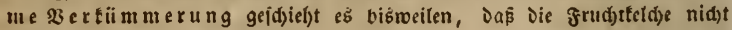
faftig geworden und Die Gattung jum El)aracter Der vorigen l)eraligeftiegen ift.

1450. B. virgatum L. ST, 50. 2. Rchв, Fl, germ, exsicc. n. 1743. Blätter tief gęäl)nt, ađe \$2lütl)en ad)ferftänsig, langäbrig, Saanıe ftumpf

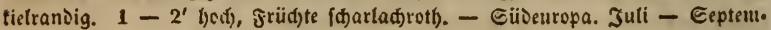
ver. $\odot$. Bei unz cultivirt uno bier und Da verwildert.

1451. B, capitatnm L. Scнк. t. 1. Blätter gejälfut, Blütbentnäuct

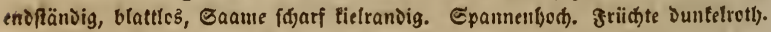
- Mie vorige. Şier und da verroildert.

484. Kochia Roth. Rođíe. Switterblütle. Sicld 5ipaltig, 2(bfd) nitte fäter äusertid) nit einem blumenb(attäl)nlidgen Quer(äppd)en. Staubgefäpe 5. Griffel 2theilig. Gdhlandfaante platt georiiuft, Saanie hoe rigontal, fruftig, Se im ling u

1452. K. scoparia Schrad. Journ. 1801. t. 3. halophyt. t. 1. f. 1. Srautartig, grün, fteif aufre(f)t, bel)aart, 23 tätter lanjettlid) linealif(a), ge=

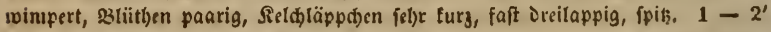

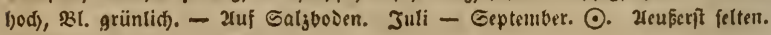
PS. 2lm falzigen Sę. Mü̈kel.

485. Chenopodium L. (5) ä $\mathfrak{n} \mathfrak{f} \in \mathfrak{f} u \tilde{\beta}$. Sivitterblütbe. Seld 5theilig trautartig. Staubgcfäßse 5. Griffel 2tlyeilig. Exanıe linfenförntig berizontal, Ed)ale fruftig. Reimling um Das (Eivcis gefriinumt, - Die jun. gen :lyeile mellig bercift.

- Blüthentnäuel äbrenartig bcifanumen.

1453. C. olidum Curt. Fl, Lond, III. t. 21). Blakw, t. 1(x). Fl. dan. 1152. 33ä̈tter rauten • eifürnig, ganzransig, grauntelylig, Gaaute glän.

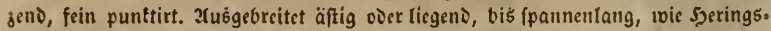
late ftinteno. - 2un bebauten Drten, Maucen, planten. Juti - Eeptbr. $\odot$.

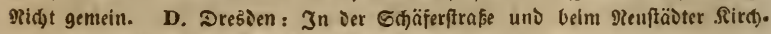

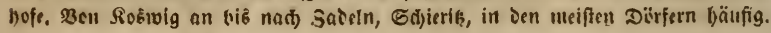




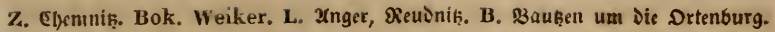

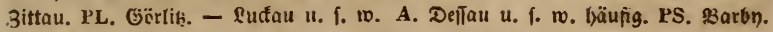
Jalle. Erfurt. HS. Jena, ஐBeintar, Roburg. SRS. 2rnitaot.

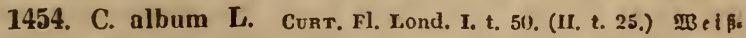

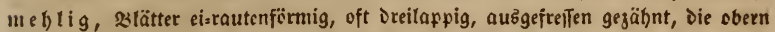
länglid) $u$. lanzettlid) ganzrandig, Snäueläbren a u f $\mathrm{c}$ d) $t$, jiemulid) blattlos, Saa. umen glatt, glänzeno pumftitt. - b. concatenatum Thurs. faĩ alle Blätter ganjrandig Iangettlid, sie tleinen Blüt)entnäuel wie a ngereibet. - 2uf

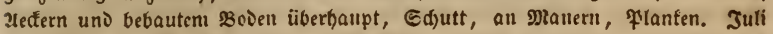
- Eeptember. ๑. Eemein uno gefellig.

1455. C. glomerulosum Rснв. s. viridi $\asymp$ album. Grau. (iđ) grün, Blätter rbontbijđ) eirunt, bud)tig gejägt, obre lanjettlid) ganjrandig,

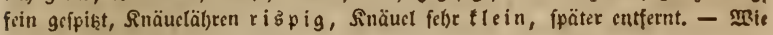
vorigeś, unter den Etanuuältern.

1456. C. paganum Rснв, s. albo $\asymp$ viride. slätter leбbaft

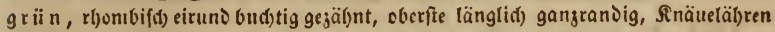

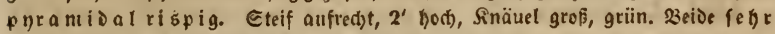

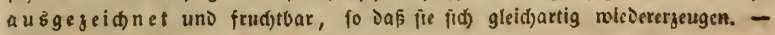

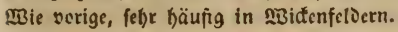

1457. C. viride L. Fl, dan, 1150. Grïn, Blätter themboidifd bud). tig, obre länglid) ganjraniig, Sinäucläl)ten trugooloig gegipfelt. Epan. nen. bizื fǖlyod). - Wie verige.

1458. C. ficifolium Surtr. Engl, Bot. 1724. Dretr. Boruss. V. 298. sBlätter faft (pieff f̈̈rmig Dre irappig, mittellappen sorgejogen länglid) ftunıff, fałt galljrandig, chere lineal lanjettlid) ganjraniig, 厄aante glänzeno, grubig fein funttirt. - $\varkappa_{n}$ äbnlidjen Drten. Juli - Eeptembcr. ○. Siemlid) felten. D. ¥illnik. Fr. Augus T K. v. S. Im votanip̧den Garten. Rehb. Tharandt. Bauer. PS. Şalle. Loderšleben. Wallroth. HS. 2llperftedt. Hornung.

1459. C. opulifolium Scarad. Rсrв. Fl, gerin. exsicc. n. 669. Dretr. Boruss. V. 296. Slätter rautenfïrmig runoli d), ffunţf, fein gefpikt,

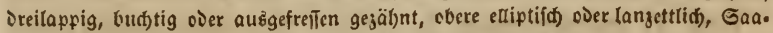
men glatt glänjeno. $1-2^{\prime}$ hod), Dunfelgrïn uno bereift. $-2(n$ älbnlidjen Dr.

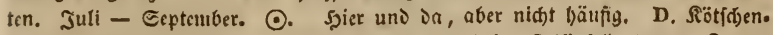

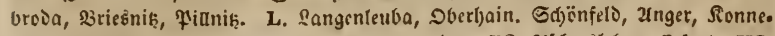
wik. B. Sittaut. Burkhardt. A. Şier uno Da. PS. 2(fiffersleben. Erfurt. HS. orlamünde. SRS. Ehalleben bei frantenlyaufen. Siudolftaot.

1460. C. murale L Engl. Bot, 1722. Curt. II. t. 66, Blätter rau.

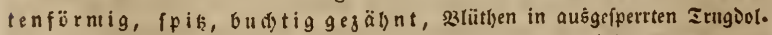
Den, Eaamen matt, tielraniig. Dunfelgriin glä̈ıеn১, $1-2^{\prime}$ bod). -2 n uno

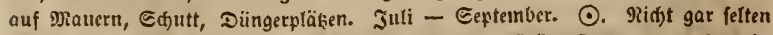

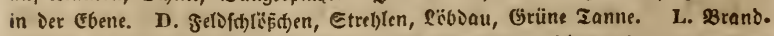
vorwert, Sindenau, 21nger. B. Baruth), Georgsibalise, Riedergurig. PL. Micht 


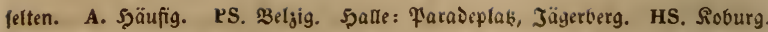
SRS. grantentjaufen.

1461. C. urbieum L. Fl. dan. 1148, Rснв, Fl. germ, exsicc. 11.

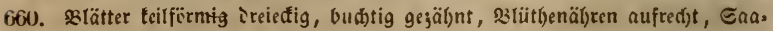
men Didt feingrubig punttirt. - b. rhombifoliun MUenLNв. (urbicun)

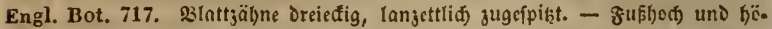
her, weiflid) grün. - Un Şäufern, gRauern, 3üunen, auf હ(jutt. Juli - Eep.

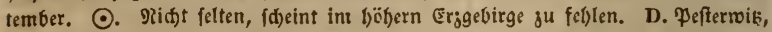

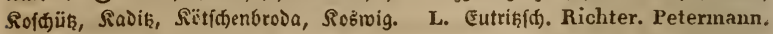

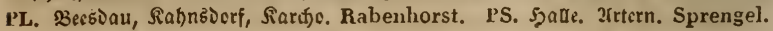
zeublk. Richter. Petermann.

1462. C. hybridum L. 23tätter herjförntig, eđ̛ig gejäl)nt, mit juges ppisten eden, wovon Die nittlere vorgejogen iff, 3zliithen in zrugjolden, Die

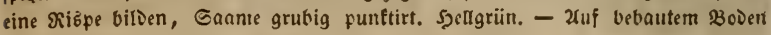
und Eduttland. Juli - Eeptember. $\odot$. Ëntein.

** Blüthentnäuel lë̄en fíd in zrauben coer zrugoolden auf.

1463. C. Botrys L. Haynz Arzueigew, Xill. 14. Rchв, FJ. germ. exsicc. n, 1741. Drüfig weid) bet)aart, Bläster länglich, faft ficverípal.

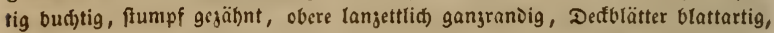

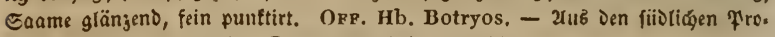
singen. Juni - Xuguit. $\odot$. Sjier und Da verwildert.

* 1464. C. ambrosioides L. HAYNe Arzneigw. XIII, 15. Blät.

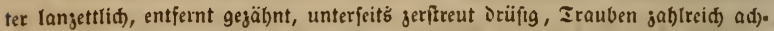
felftändig und beblättert. Etarf rieçend. OPF Hb. Botryos mexicanae. -

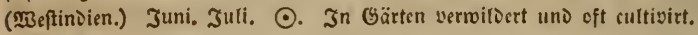

1465. C. acutifolium W. Berl. Schrft. II. t. 5. f. 2. Engl. Bot.

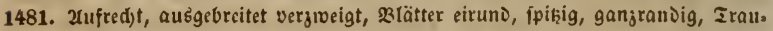

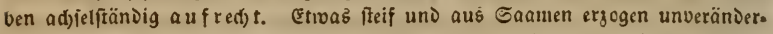
litb, tahl und hedgrün over roth angetaufen. - 2tuf bebautem Sandboden, über.

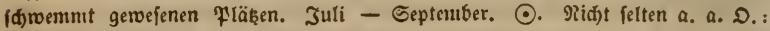

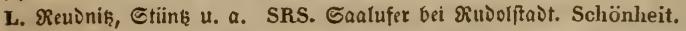

1466. C. polyspermum L. Fl. dan.1153. ¿ícgeno, weitäftig, 23 lätter eiruno ganjrandig, ftumpf, fafi, zrugoolde adjelftänitg a u g gefpreizt, blatt. 108, Saanten glänjent, fein punttirt, im balb ofinem Reldje. - 2luf bebautem Boden, Sdjutt, befonterz an feudten Drten, unı ₹eidje, Gräben. Juti - Eep. tember. ๑. Gemein.

486. Schoberia C. A. MAYER. 〔西oberie. Blütbe guvit.

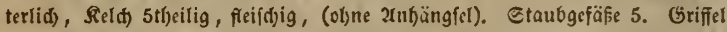

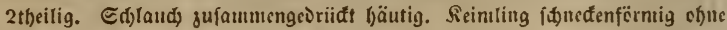
Eimeis.

1467. S. maritima C. A. MAYBR. Fl, dan. 478 . R cri, Fl.

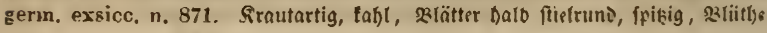


meijt zu ircien adjelitändig, Saame fein punttirt. Spannen. bis fuß̧on, auf. recht mit aufredften 3weigen, oder liegend und meituftig aufíteigeno. Slasigrün, faftig uno faljig. - 2(n Ealinen. 2uguft. Eeftember. ๑. Gelten. PS. Barbin: an Der Ealjta bei Den Ğradirbäujern. Etap̄furt. Schwabe. Rangenbogen, Rül. me, அollsiorf. Urtern. Rchb.

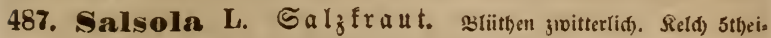

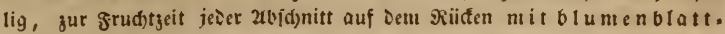

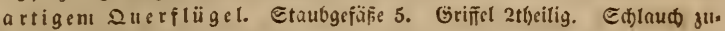

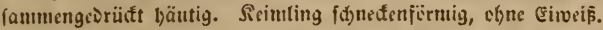

1468. S. Kali L. Fl. dan. 818. Palx. ill. t. 28. f. 2. und t. 29. Rснв. F]. germ. exsicc. n. 485. Sirautartig Duntelgriin, turg und fteiflid) ve.

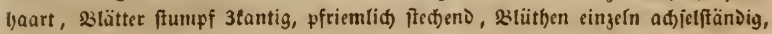
Sielt)iügel abgeruniet zufammentrefent, aus̈gebritet, gröfier als Der turz freifel. förnige Reld), Detien Stadfelipiken fparrig abitelen. - 2uf Sanvboden. Juli.

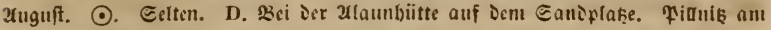
Elbufer. Fr. August K. v. S. Gebäge Desgl, G. Rchb. PS. Sarbt), Dion. plaifir. Scholler. NBittenberg. Nitzsche.

488. Polyenemum L. Rnorpelf $\mathrm{raut}$. Sith ipelgig 5.

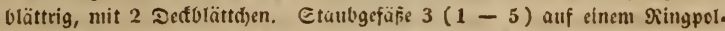
fter. Grifinel jweitbeilig. Edylaudfrudjt mit Decteld)en. Eanme aufa rect)t, truftig.

1469. P. arvense L. Sснк. t. 5. Sт, 44. Rснв. Fl. germ, exs.

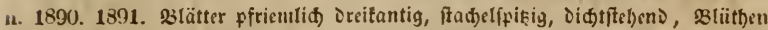

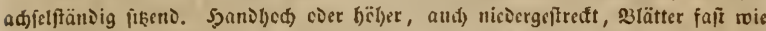

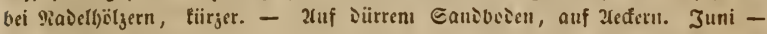

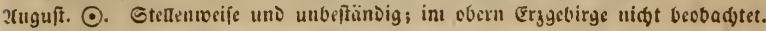

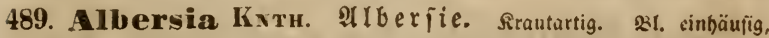
Sicld) 3blättrig (Die wcibl. bei A. polygonoides 5blättrig). Etaulgefäpe

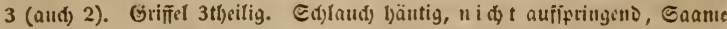
linfellfirmig, zientid) aufred)t.

1470. A. Blitum KNтн. (adscendens 1,огs.) Кснв. pl. crit. V. ic. $664-665$. \$2lätter ei=tautenförmig, ausgeterbt, abgeruniet, \$lüthentnäucs

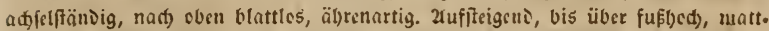

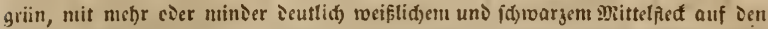

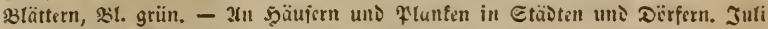
- Eeptentoer. (.) 9idít fetten.

* 1471. A. polygonoides Kхтн. (Blitum :) Rснв, pl. crit. V.

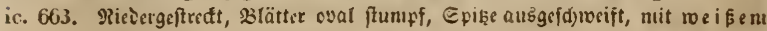
mit tel îe d, roeibl. Ficlde 5theilig, faft glodig, wei seranist. Bis fpan. nenfang. - (2us 2tmerifa.) 2uf bebautem 2icien vermiloert. Juli - Seftem. bir. $\odot$. D. auf Giartentocien.

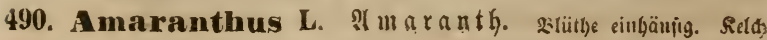




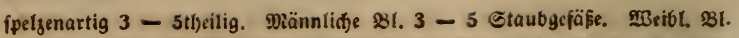
Grificl 3tbeilig. Sapfel pergantentartig rings um a ufforingeno, Ifaa.

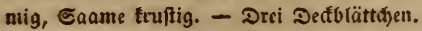

1472. A. hypochondriacus L. Blätter rlyombiī lanzettlid, turs

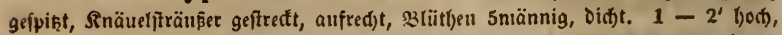
\$lätter mit unrein rotbem Mittelped, aud) Die gauze Pianje rotb) aniaufend. -

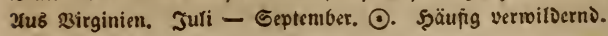

1473. A. retroflexus L. Rснв, pl. crit. V. ic. 669 . Fl, germ. exsicc. 1044. 2ufred)t, 3weige juriiđgebogen, ausgebreitet, fein bebaart, 3 lät. ter eirund toetlig und abgeffumipit, feinfpistion, Deftotätter aus einer Ferbe fte.

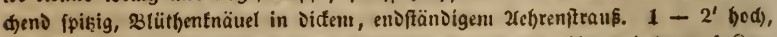
suattgrün, etroš pluntp gebaut. - 2uf bebauten soden, bier uno Da auf Sar. rofielfeltern, auf 巨đutt. Juli - Sept. $\odot$.

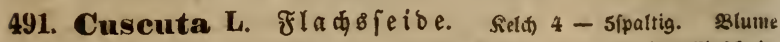
glodig 4 - 5ifaltig, vertrocfneni. Staubgefǟ̄e $4-5$ unter Den Einfáfnitten, unter if)nen ein paar Sduppen. Grififel 2fpaltig. Rapfel pergamentartig, ringsumi oder 2ipaltig alffipringend. Saamen 2, aufredt. Feinlling fifnecten. förnig. - Etengel fadenförmig, blattlos, mit Gaugloärzdjen as anore Pran. jen fid) anfaugeno, 3rt. Inäutlfändig. - Die Drganifation Def Saamens if

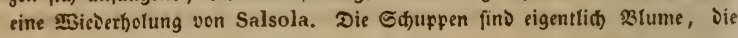
fogenannte Silunie Der field)!

1474. C. Epilinum Weпн, Rснв, pl. crit. V. io, 692. Fl. germ. exsicc. n. 19. Cinfad), s3lumenrïbre $g r$ ü $n$, faft tugelig, Doppelt fo tang als

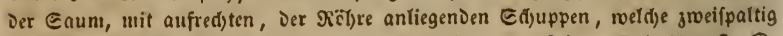
uno gefranjt futo. Jäben grün. - In feinfeloern am Sein. Juli. 2uguft. $\odot$. ג. a. D. nid)t felten.

1475. C. Epithymum L. Rснв. pl. crit. V. ic. 692 . gaft baar.

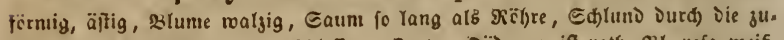

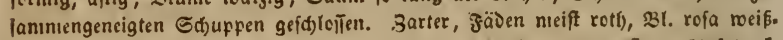

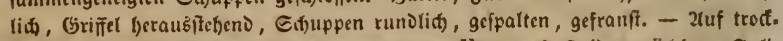
nen ßiefen uno Sjeiden an Thymus Serpyllum uno şeidegenädjen. Juli. auguft. ๑. Ridft felten.

1476. C. europaea L. Rснв. pl. crit. V. ic. 690. 2(ętig, slumen. röl)re waljig, io lang als Der Gaum, mit aufredten Der Rö̈bre anliegenden bani. fpartigen Cd)uppen, Sarben fadenfirmig. Jeftig, Stütl)enlnäuel nit Dectblatt,

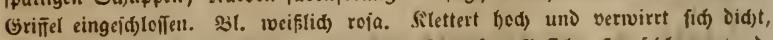

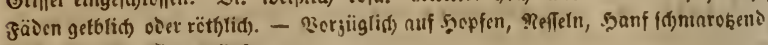

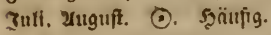




\title{
Eamilie Rosaceae, Roiacen.
}

\author{
- Şerbaricnout) S. LXVII uno 167. -
}

492. Aphanes L. $5 \mathfrak{h} \mathfrak{m} \mathfrak{f r a t}$. Seldfaum thappig 4theilig,

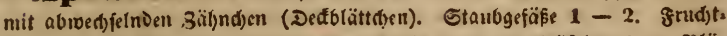

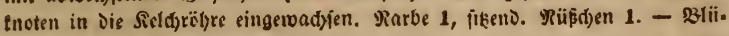
tbentnäuct ađjfelffäntig.

1478. A. arvensis L. Schк. 26. 23 lätter feilf. hanofïrmig Dreiṕpaltig

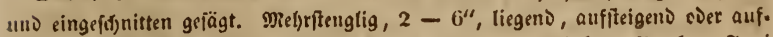

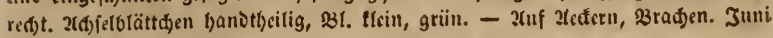

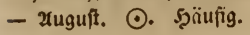

493. Alchemilla L. Sinau, Frauenmantel. Seld).

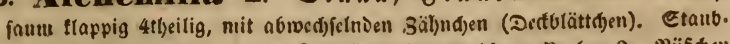

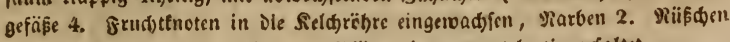
2. - Enofäänige stugovlden. - Blätter jung mantelartig gefaltet.

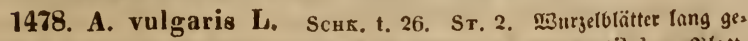
fitiett, nierenfürmig, treißruno, 7 - פlappig gefpalten. - a. aoutiloba: 23 laft. lappen eiruns geftrcft. - b. rolundata: 33lattlappen furz abgermudet. - c. truncata Tsсн. Blattlappen quer abgeftutit. XenDert iibrigens vom tal)len 3u. ifande bis jum Didft weidbeffaarten ab: A. montana W. - 2uf xBiefen uno Grazpläten bis in Die Givbirge. Jprir - Eeptember. 4. Gemein.

494. Sanguisorba L. Wiefenfnopf. Seldfaum anfein.

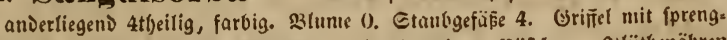

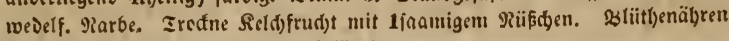

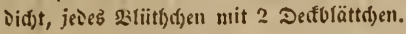

1479. S. officinalis L. Sснк, t. 27. Hayx Arzngew. VII. 22.

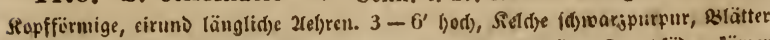

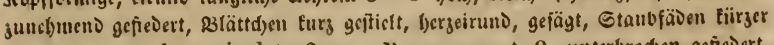
als slume. - b. auriculati ScOP. Bocc. mus, t. 9. unterbrodsen gefievert,

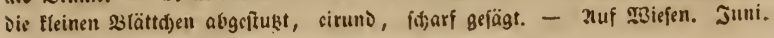
כuti. 4. Şäufig.

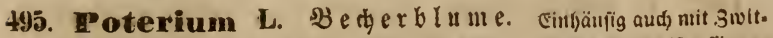

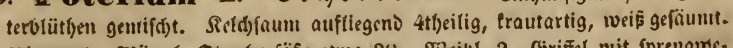

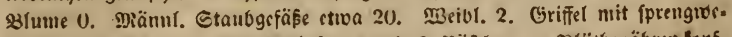

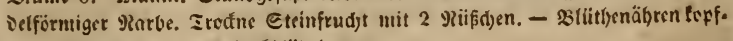

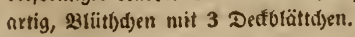

1480. P. Sanguisorba L. Scrk. t. 300. Haxk Arzneigew. 11 .

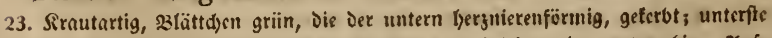

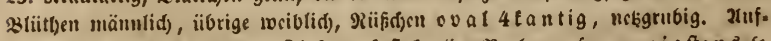

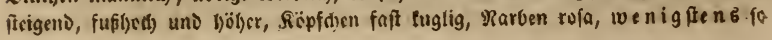


lang a İ Griffel. - Xuf Şügeln, BBegen, gern auf Raltboden. Mai Juli. Şerbft. 4. Dur(t) das Gebiet nid)t folten.

1481. P. glaucescens Кснв. Rrautartig, Blätt(d)en unten bläulió

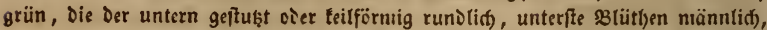
mittlere jroitterlid), oberfte reibliđ), P(üß) grubig. - b. guestphalicum Bxxgr. Dallelbe an Etengel und oen 2 lattfie.

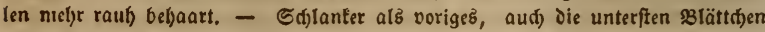
iđ)arf gefägt, bie Der obern 33 lätter teilförnig eirund linealifó, Säl)ne grwijđjen

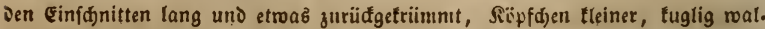
3ig, Rarben tarninretb), veftimnt $t$ iirzer al s (Griffe I, Riifst)en (d)niäler.

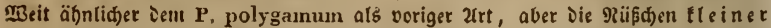
und glatter. - 2uf Şïgeln unD Gelien, meift auf Raltboden. Diai - Juli uno şerbit. 4. 2 . a. D. befonders in stjüringen.

496. Fragaria L. (5 r b beere. Reld sipaltig mit 5 medfein. Den Dedblättchen. $B$ l. 5blättrig. Piftiđe zaflreid), gefondert, Girifiel aus ibrer 2 afib, abfaltend. Frudtboden mirb fleifdig beerenartig. Rüß.

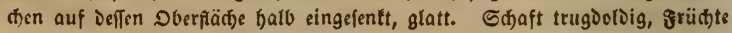

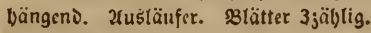

1482. F. vesca L. Scrk, t. 135. St, 2, Hayn Arzneigw, IV. 26. Reld bei Der frudtreife abfteheno, 23tüthenftiele nit abftef)endem slattfiel, mit angeoriidten syaaren. Frud)t faft $\{u g e\lceil r u n D$, unten grüntid), nad) oben Dun. tel (đjarlad)rotb), ober bei einer abänberung reißs. - b. monophylla L. nur

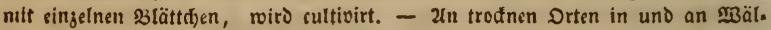
Dern. Frtiibling - Şerbft. 4. Şäufig.

1483. F. semperflorens Duchesx. Hayng Arzneigw. IV. 25. \&rudtkelshabfdnitte und 2 lattffielbaare borijontal, Slütbenftielljaare abftebend

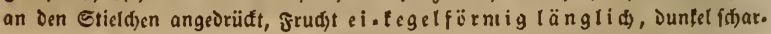

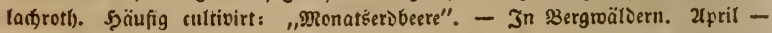
Seroft. 4. Mincer verbreitet alb vorige.

1484. F. elatior Eнвн. Hayns Arzneigew. IV. 27. Reld bei

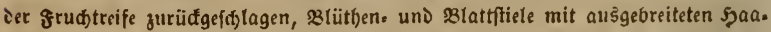
ren, grudt freifelförmig, fuglig, meiffid) grün mit Dunleltoth (arcmatifd)). Ş̈̈.

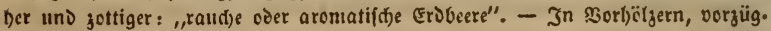
liđb) Der Gebirge. 3pril - Juni. 4. Etellenreife Durdi) Das Gebiet.

1485. F. collina Ehrh. Hayne Arzngw. IV. 30. fructteld) a n. ge D $r$ ü $t$, Şaare Der 23 latt. und 33lütbenftiele ausgebreitet, Die der Etieldjen ab. ftebeno, \$lätter beiDerfeits fein belyaart. Frud)t länglid) tuglig, tarminrotb), fị̦t

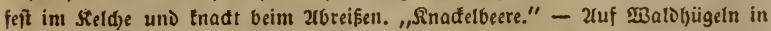
Qchmboden. Mai. Juni. 4. शiđt bäufig. L. Grimma, s3ienik, 3fdjodjer, St. Ibetla. B. SBaukener Dberlan๖. Kölbing. PL. Ş̈̈lenberge hei \&angengraffau. Rabenhorst. A. Deîa nat) Schwabe. PS. Eranau, 3orgg, Siniberg. Er. furt. HS. Jena. Eifenad). Zenker. Grub. Metsch.

z n nt. In Gärten cultivirt man bäufig ১ie Gd)arladjerobcete: F. virginiana

Енан. Rснв. Fl. germ. 3881. Hayse Arzneigw. IV. 28, cann cic $211 n$, 
naberobeere: F. grandiflora Енян. Rснв. Fl. gerin. 3872. HАyлz Arzneigew. IV. 29. und Die Elitierovecte: F. chiloënsis DrLx, clth, t. 120. f. 146. R снв. Fl. germ. 3873.

497. Comarum L $\mathfrak{B} \mathfrak{I}$ ta $\mathfrak{a}$ ge. Reld 5 ipaltig, mit 5 wed).

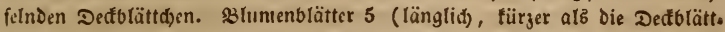

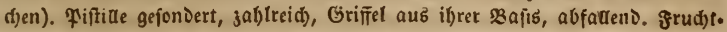

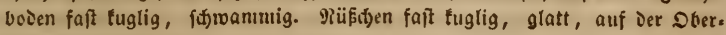
pü̈)e fikeno.

1486. C. palustre L. Scrк. t. 138, Fl. dan. 636. Blätter su 3-7

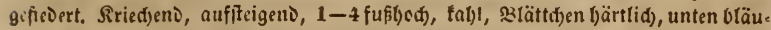

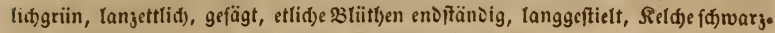
roth), 31. tleik, roja. - In Cümpfen, Mecrboden. Miai - Juli. 4. 3iєntiф

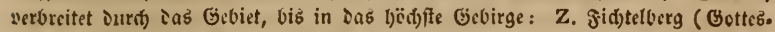
gabe, qlatten.).

498. Potentilla L. $F$ ing $\operatorname{er} \mathfrak{f} \mathfrak{a} u t$. Seld 5 theilig, nit 5 we(t).

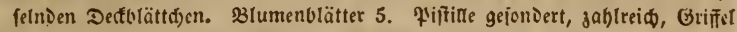

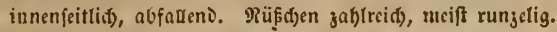

\section{a. Shlunte meißs.}

1487. P. Fragariastrum Eннн. Sснк. t. 135. Dizтr. V. 317. Rснв. Fl. germ. exsicc. n. 1217. Stengel trictrento, nteift 2blütl)ig. Blätt. d)en 3̧äălig, umgetel)rt eiruno uval, eingeidjnitten ge(ägt, Bluntenvlätter länget

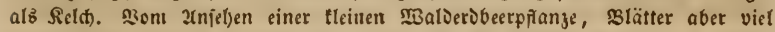

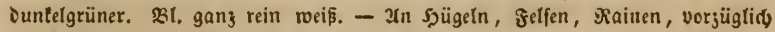

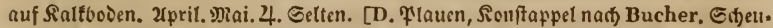

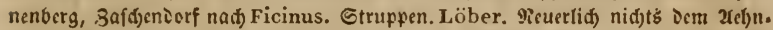

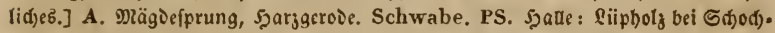

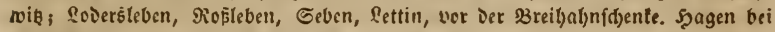

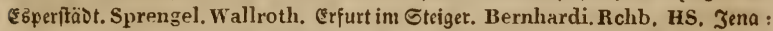

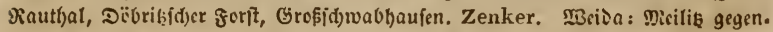
iiber am liuften Elî̃erufir. Rossmässler. R. Gera angeblid).

1488. P. hybrida (fraterna:) WALLR, veieverliegend, 23lättd)en 3jät)lig, umgetef)it eiruno läng(id), nur um ذie Epiąc зufanmengeneigt $5-9$ \{ägejäbnig, unterfeits feciscul)aarig, Die Şaarc Der Mjitteltippe vorjiiglid) lang,

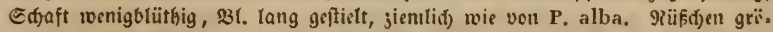

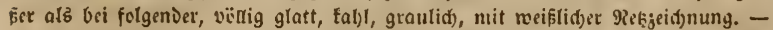

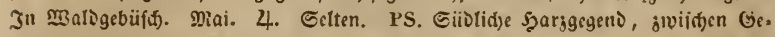
büfd) red)ts ven Der Eteigertfyalfden !mittelmüble. Wallroth. Erfurt im Etciger: wato. Cammerer. Buddensieg.

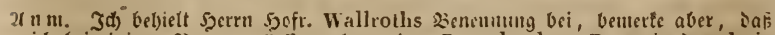
id) bei einigen Siogen wed EFimplaren Der P. splendens RAMr. in Dem bois de Boulogne bei fariś gelammelt, alte die in Der Lisxasa 1840). $.76-$ 81 fuir jene angegebenen פertmale aud) vorimoe. Daß̧ Die Frianje cine gute Zrt ift und nidt, wie Seringe glanbt, zu P. alba gehërt, Darin ftimme id,

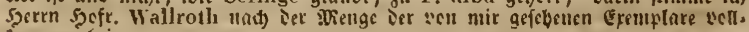

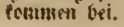


1489. P. alba L. St. 4. Dintr. UI. 166. Rснв, Fl, gerin. ex-

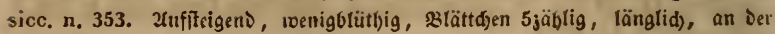

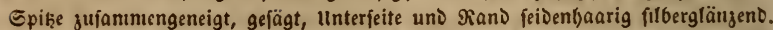

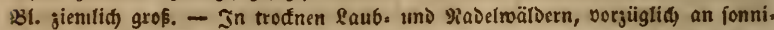
gen 2(nbäben. Nai. Juni. Beniger reidflid) im 2luguft. September. 4. Stels

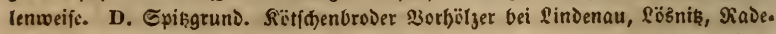

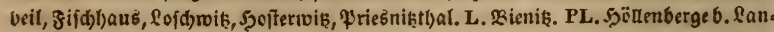

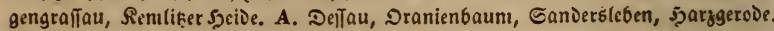

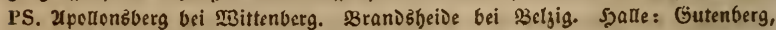
פRittelfol3, SpeiDe. Naumburg. Frei6urg. Norobaujen. HS. Jena: Rospeda,

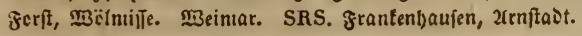

1490. P. rupestris L. JAcQ, austr. t. 114. Dietr. III. 170. RchB, F1. germ. exsicc. n. 287. 24uftecht, oben gabelifpaltig, gipfelbü̈tbig, æ3utzel.

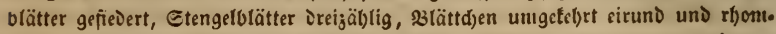

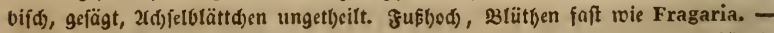

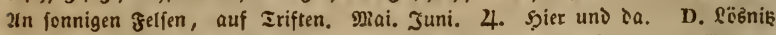
feit Groh. E(j)ieriţ. Mauke, v. Römer. G. Rchb. Papperitz. L. Wuurgen. Schwägrichen. B. STcinwelfe bei Der 3(nftaltకplantage. S3or Der \&agerfd)anje. Kölbing. Burkhardt. PL. Drelnna. Grassmann. Galtettberg; Raltenborn bei GuOen. Rabenhorst. Reujelle. Fischer. A. Darggerode, am yoben ufer Der Mïfter Iorfftedjerei. Schwabe. PS. GnaDau bei \$arby. Scholler. Kützing.

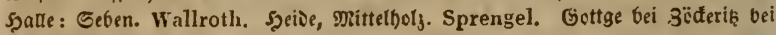
Delisifid). Giittner.

\section{a. Blune gelb.}

1491. P. reptans L. Schx. t. 136. Hays Arzneigew. IV. 32.

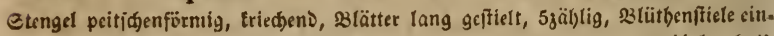

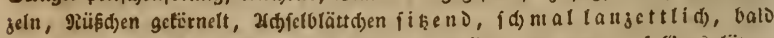

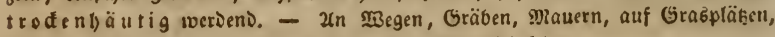
Rainen, ariften. Juni- Eeptember. 4. 9Rirgends falten.

1492. P. mixta Noxte. Rснв, Fl, germ. exsicc. n. 1747. STraut.

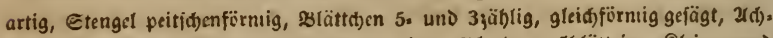

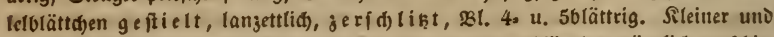
fdglanter als vorige, untre Blätter ftart bel)aart, 2(d)felblättd)en gänylid) verf(d)ie. Den. Bliitje wie Tormentilla, Dajer audj für T, reptans gefbalten. - 2(n

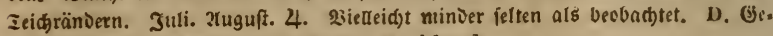

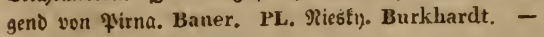

1493. P. verna L. St. 17. Dittr. UI. 168. Rсhв. FJ. germ. ex-

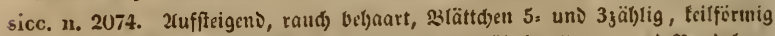

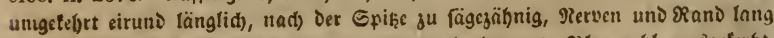
bel)aart, Etengel uno stüt)enffiele a u fredi) t be ba art, Blumenbl. aubgeterbt,

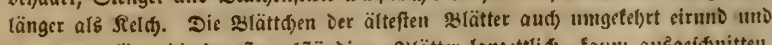
ringšum gefägt, Die Der f̂̉engelifäntigen slätter langettlia), faum auşgef(f)nitten. - b. aestiva ift eine üppige form im Spätjommer aukgebiloct. - c. porrigens 


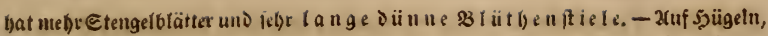

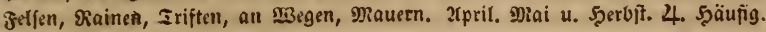

1494. P. cinerea Chaix. JacQ. ic. 491. Dietr. III. 167. Rchb.

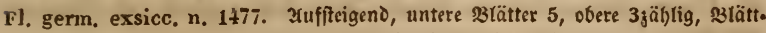
d)en feilförmig, an Der ङpilse geïgt, unterpits liniirt, fit er nf) a a rig graufil gi g.

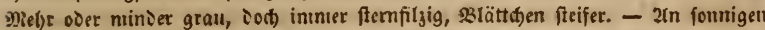

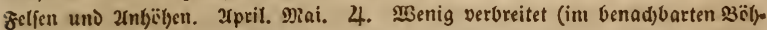

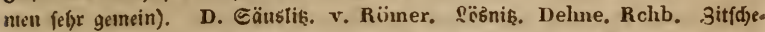
tvig. Dehne. PL. Brans bei $\mathfrak{B a l D o}$. Rabenhorst. PS. Diitrenberg, Reuf(t)= berg. Ieudik. Şalle. Erfurt. Rauntburg. HS. Jena: Joifthen Fiamidorf UnD Benigenjena. SRS. Sialtberge bei frantentbaujen. Hornung.

1495. P. opaca L. Jaç, ic, rar, I. 91. Diktr. III, 169. Rснв. 11. germ. exsicc. n. 2075. sogig aufitcigeno, faienfitmig, borigontal zoto

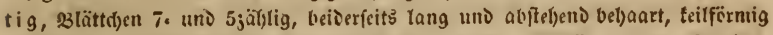

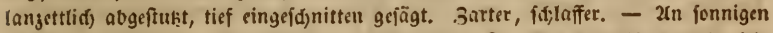

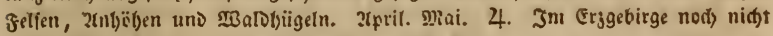
veobad)tet, auferosm all geeiguten Drten mitift felfen.

1496. P. Neumanniana Rснв. \$2ättd)en 7. und 5зӓłlig, tang teilfürnig, ungetefrt cirund, nad) Der Epiḳe hin eingeid)nitten, Die faDenförnrigen nievertiegenien Etengel, Błaft, uno słtïtlenfticle angebrüitt bebaart, Fieldjab.

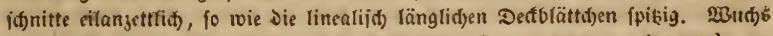
uno anielgen Der P. Opaca, geringe siefleidung Dec P. vema uno patula. Jn Gelfen und Mlauern. 2(pril. Miai. 4. Gel)r filten. D. Dulina. Bauer. G. Reichenbach. ( $3 n$ Böl)nten: Neumam, vergl. Fl. gern. 3836.)

1497. P. thuringiaca BRхн. 2tufiteigeno, gabeläitig, beblättert und locfer rişpenbliitl)ig, abftel)eno bebaart, siättd)en 7 jäl)lig, längliđ), grïn,

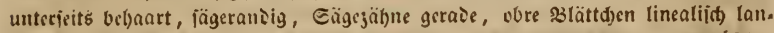

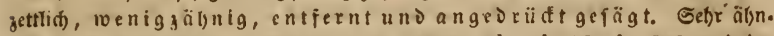
lid) Dec P. intermedia L. Nestr. t. 8. Rскв. pl. crit. VI. ic. 8199. und Der aufredten P. chrysantha Trer. Rche. pl. crit. VI. ic. SuS. und Fl. germ, exsicc. n. 1269. - 2(n Felfen, Bergen, nanentlith anf Forply)r. Mai., 7. Nitur in Iliitingen. PS. Dembery vei Eul)l. Bernhardi. Sauer. Ifoffmann. Metsch. G(j)leujugen nad) Kochs Synopsis. HS. Eiffeld: Engelftein. Hornung. Gleidfberg bei Roburg. Hornung.

1498. P. Wiemanniana Guentheв и. Sснuмm. Lжнм. Pot. t. X. 3uffiłeigent, faienförnig, gaveläftig, Doluentraubig, rišpig, filzig, Blätt.

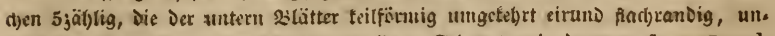

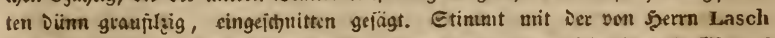

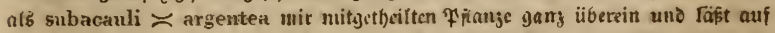

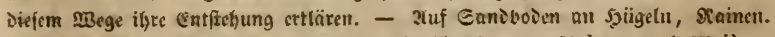
Mai. Jumi. 4. Gebr felten. SRS. Sonderşbaujn. Dr. Edkart nad Weiker.

1499. P. argentea L. Sт. 17. Diктr. 1V. 273. 2uffíteigeni, fitjig, oben Doldentraubig, gabsläftig, slättd)en 5 jäblig, feilförmig, untgetebrt eirun১

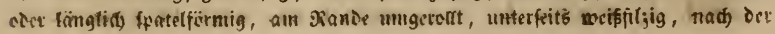




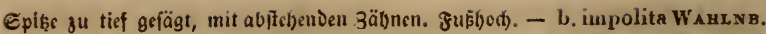
3lättd)en beìerjeitó weiffiljig, tief tammartig eingefd)nitten. - c. tephrodes: slättđ̧)en umgetebrt eiruno fägerandig, oben graue, untelt roeiffilgig. - 2rn get.

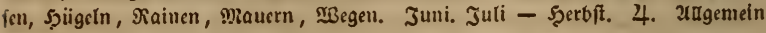
verbreitet.

1500. P. canescens Bess. (recta:) JAcQ. austr. t. 383. Uufrect)t, (d) (ant, weid) bel)art, rotb), 3lätt(t)en 5 zäl)lig, unteríeits graupiljig uno ange: oriift zottig, lanjettlid) fpatelfirmig, gleidförmig tief gefägt, sroeige $r u t b e n$. artiglofergipfelolütlig, Slumenblätter aušgeferbt, etroas länger als

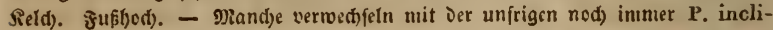
nata VıLs. weld)e gugleid) mit iljr in \$ölymen wäd)it. Bereits Lehınann Mo-

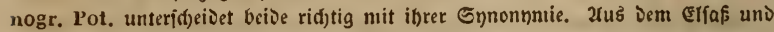
aus Dem bena(f)barten S3̈̈hnten habe i(t) aud) eine argenteo $\asymp$ canescens nit isn tief cingefófuittenen $\$$ lättern Der argentea impolita. - 2ln grajigen geljen,

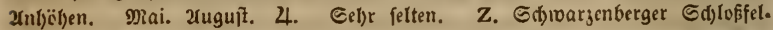
fon. Bok. Rodig. Weiker. Wankel. Rchb. Mildenfelb, Síjoden. Wankel.

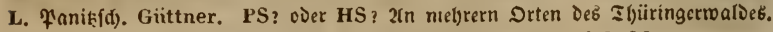
Buddensieg brieflid). R. Pobenitein : Şcinriđfftein nad) Heinhold.

1501. P. recta L. Rснв, pl, crit. IV. ic. 521). Etengel aufrest)t,

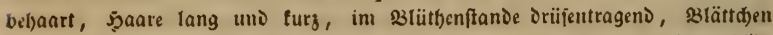
5-7jäl)lig, tcilfïrmig länglicf), grob gefägt, bethgrïn, lang vebaart, 83lumenblät. ter ansgeterbt, bla

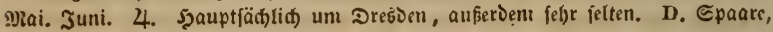

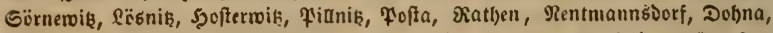

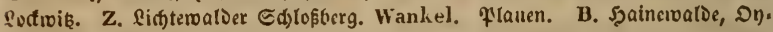

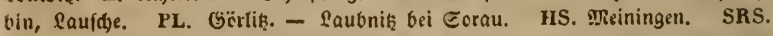
รuvolftaot.

1502. P. obscura W. Balb, ef Nocca Fl. Tic. t. X. Etengel auf. red)t, bel)aart, Şaare fel)r lang, anore turj, Blätt(f)en 5 - 7jäblig, id) mal uno geftrcd́t lanjettlid), tief gefägt, grün, unterfeits jottig, Sluntenblätter bo d) gelb, fo la $\mathrm{ng}$ als Sield). Etengel uno siveige rotb. Blcibt aus Gaamen ergrgen fich

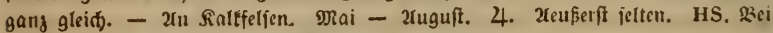
Ziefentbal in Der Gegeno won Gett)a, 3. Juguft 1816. Rchb.

1503. P. norvegica L. Fl, dan, 171. Rснв, Fl, germ. exsicc. n. 457. Xufredt, raud) beljaart, untere 3 lätter felten ju 5 gcfiebert, obcre oreizählig,

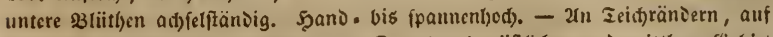

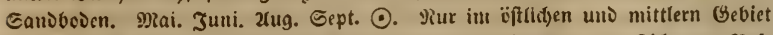
um Ieidje in Speiden; aud) im Gebirge cinmal beobadjtet. D. S(d)orna, 23cl.

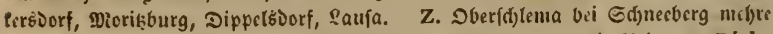
Exemplare. 1839. Scheidhauer. L. S:nifdsn Gresfteinberg uno Grimma. Rich-

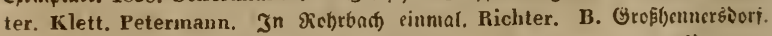

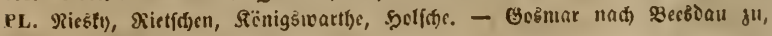
gernstorf, 9rugetle.

1504. P. supina L. Jaç, austr, t. 406. Rснв, Fl, germ. exsice. 
n. 81. Etengel niebergeftredt, aufiteigens, gabclältig, viel vergıcigt, siätter ge. fiedert, sliitl)en einjeln in Den 3reig, und \$Blattadjfeln, Frudjtitiele zuriifgebo. gen. Epannen. bis fuflang, Slättçen länglid) tief gejägt, 3 liitben tlein, felse zal)(reid). Junge uno tleine Pianjen aud) aufred)t. - tm Ieidje, grufufer, auf

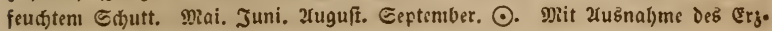
gebirges Durd) Dab Gebiet nidjt jelten.

1505. P. Anserina L. ST, 4. Harar Arzneigw. 1V. 31. Eten.

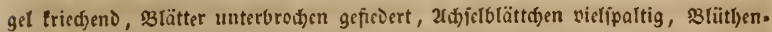
ftiele einzeln, fel)r lang. Slätter Dunfelgrïn, unten jeitenartig bebaart oder beiDerfeits feidenglängent. Orf. Rad. Anserinae. - 2tn feuchten Drtell um Ieidfe,

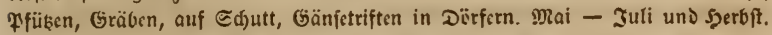
4. Gentein.

499. Tormentilla L. Tormentille. Sield 4theilig, mit 4

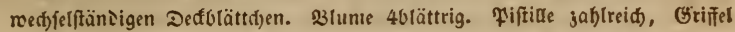

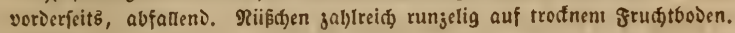
- 81. gelb.

1506. T. erecta L. Schk, t, 136. Harsr Arzneigw. II. 48. Sten.

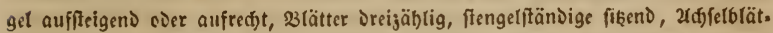

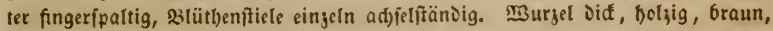
innen roth), etengel faidenfirmig, oft liegent. OrF. Rad. Tormentillae. - 2uf

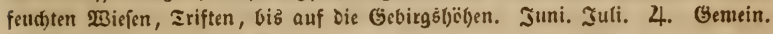

1507. T. reptans L. Engl, Bot, S64. Rснв, Fl. germ. exsicc, $n$. 778. Stengel geffredtt, \$3lätter geffielt, \$lättđ̧en 3. coer 5 jäblig, teilförmig läng.

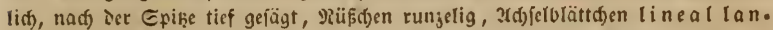
zettli ())! unterfte audi) 2tbeilig. - In Radelwaloungen auf Mlocz. Juni -

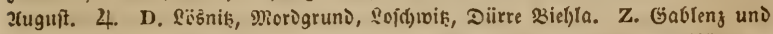

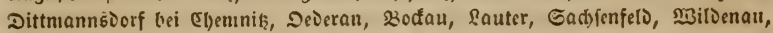
Grünbain, 3wönik, Jobanngeorgenftait, Sdjneeberg, Şartenitein. L. Univer.

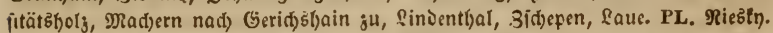
- Reuzelle, Guben. A. Şarjgercie. PS. Dïben. Spede bei Wittenberg. Salte. HS. IInenau. Rufla, Eifenad). R. Sobenftein.

$2 \mathrm{n}$ n. Die vermeintlid)e 56 lättrige Tormentilla (Quorundaun) ift rabridgein.

(idf) Potentilla mixti, f. oben n. 1492.

500. Geum L. Bgenebif tenfraut. Seld 5theilig, 5 ab.

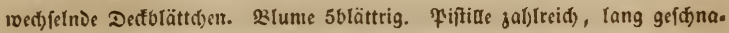
belt, Griffel auf Dem Ganabel eingelentt, abfallend. Frudtboden tegelfirt.

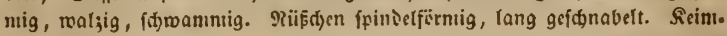
ling aufredjt.

1508. G. rivale L. Hayx Arzneigew. IV. 34. Sснк. t. 137.

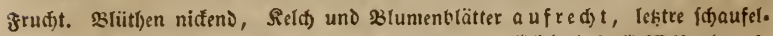
förnig, Tagel lang, Etgnabel unten belgaart, Glies Deb Griffels eben fo lang als Der jettige (Grififel. $1-2^{\prime}$ boct), Duntelrotl) angelaufen, oben orüpig, Tisurgelblätter unterkreden leierfirmig gefieist, Etengetblätter 3theilig, 2xdfel. 


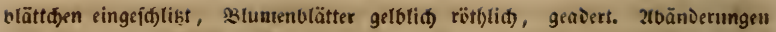
find: b. eglandulosuin Petrers. faft ganj oriifenlos. - c. luxurians, f(t)̈̈ne monftrïfe form, Deren Relchabidynitte blattattig Jupuriren. - Xuf Moor. boven, Im Gebiifd), auf MBiejen. Mal. Juni. 4. Sienlich perbreitet. D. Gr.

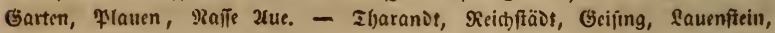

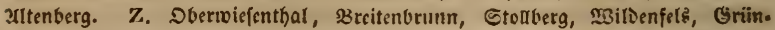

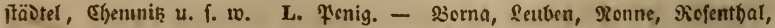

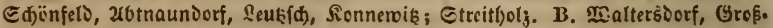

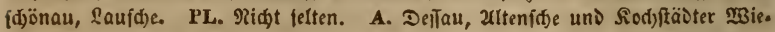
fen, 3erbft. PS. Wittenberg, Samberg. Licbenau, Sd)feudik. HS. Eifenberg.

1509. G. intermedium Енкн. (urbanoこrivale.) Fl. dan. 1874.

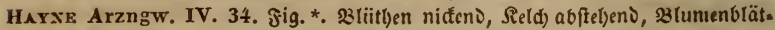

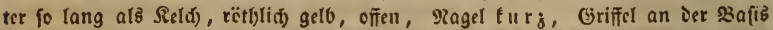

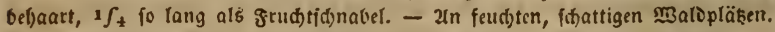

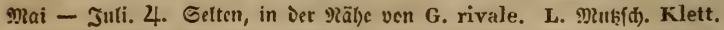

1510. G. rivali $\asymp$ urbanum Rскв. Fl. germ. 387\%. intermed. WrLld. h. Berol. t. 69. Sliitben taum niffello, cīen, Slunicnblätter unige.

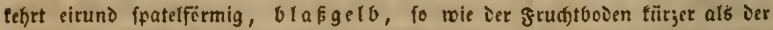
grïne, offne Reld, Є(hnabel bebaart, Grifiel faft tabl. - W3ud)s ven G. urba-

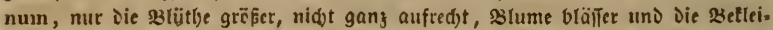
Dung Der Grifiel veridjièen. - In fdattigen Maloungen. Mai - Juli. 4.

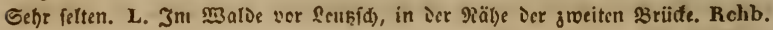
31). 刃aai 1818. Streitbolg bei Connemiş. Petermann.

1511. G. urbanum L. Scri. t. 13i. Harxe Arzneigew. IV. 33.

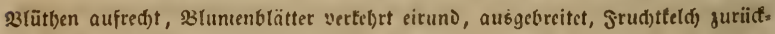
geid)lagen, gruditidnnabel unten fein belsaart, viernal länger als ber Grifel.

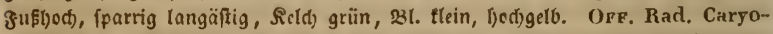

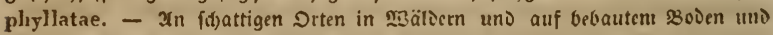
હd)utt in Etäoten uno Dërfern. Maa - Juli uno Şerbft. 4. Ueberall gemein.

501. Tubus L. B̧rombeere, f̧imbeere. Sidd stheilig, dl)ne Deđ̛blättđ)en. 23l. 5blättrig. Fiftitle zals(reid), geben in eingebogene abfallenie Grifel iiber. Frud)tboien tegelfïrmig erbaben. Siernberdfen

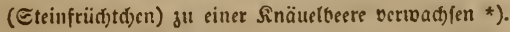

a. 3 - 5jär)lig gefingertblättrige. Sd)ëpilinge $t a \mathfrak{h} l !$

ลa. Blätter grün, Dolientraube gipfelbliitbig.

1512. R. fruticosus L. plicatus Werrk t. I. Eđjöflinge 5tantig,

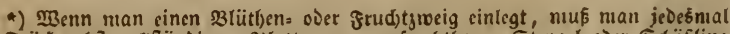

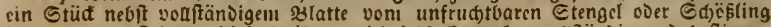

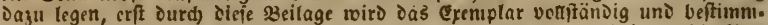
bar. 2rte von nit innerbalb Der Grerigen gefammelte 2utten fino surd) Die şer:

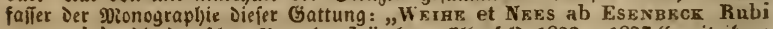

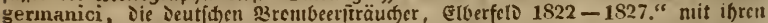
Driginalen verglidben und eigculbänsig mit ibren Bencunungen bejeidinet worden. 
Stadjeln trumm, zerftreut, Blätttifen eiruno rundlid, tängs Der 9erven gefal. tet, oberfeitb talsl, unterfeits fein bebaart, DelDentraube weitläufig, wenig befta.

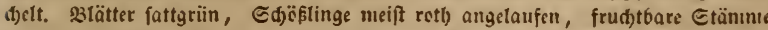

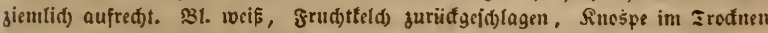

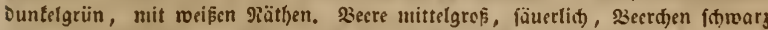

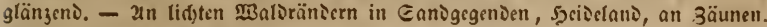
शai. Juni. h. Gemein.

1513. R. suberectus AxDers. Lisv. Transact. XI, 16. Engl. Bot. 2572. fastigiatns Wrrar t. II. Slättden ier Sdjïflinge bergeituno furg.

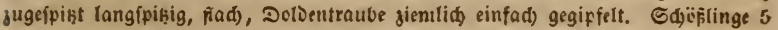
- 15' lang, stantig, aufredt, Dann nicDergebegen, wurgelno, Etad)eln roenig, ctmas getrïnmt, s2lättdsen 5 , felten Das mittlere 3tbeilig, feitlid)e fïrzer gefticlt

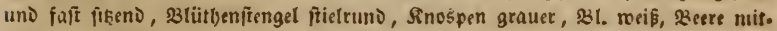

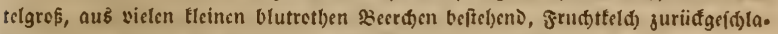

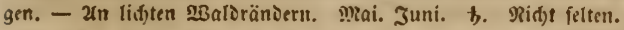

1514. R. affinis WeInE t. III. Rснв, Fl. germ. exsicc. n, $\mathbf{7 8 1 .}$

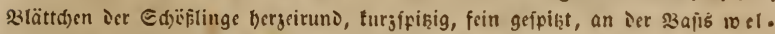
lig, fonft fla d), unten sid)t fein bebaart, $x$ ispe ju fa mu engefe bt, 3lät. ter ant 23 lüthenftengel (Die untern inmer) $5_{j}$ ähtig. Sinospen grauliđ), Stadjeln

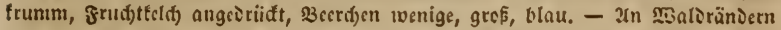

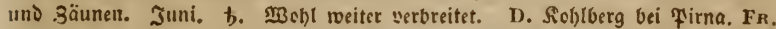
August K. v. S. L. Sindentbal. Rclib. PS. Şalle. Sprengel.

1515. R. nitidus Weihe t. IV. Rchв, Fl, germ, exsicc, n, 783. R. corylifolius (nid)t Sxr.) Harse Arzneigew. III. 31. Guimp. t. IU)2.

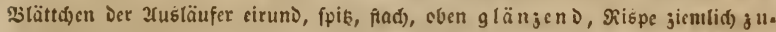

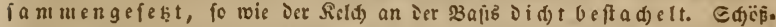
linge bogig $6-10^{\prime}$ lang, 5tantig, wurjelnt, 23 lättd)ent weniger jugeipib̧t, $\mathbf{3 l}$. roeifliot) roja, Becre tleiner, fajt kuglig aus tleinen fidwargrotben Siectden. -

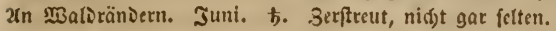

bb. Blätter unten filgig, 3lüthe $r$ is̀ pig.

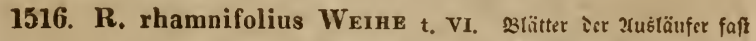
treisruno, unten abgerundet, Fruthtfeld offen. Seb̈ftinge nièergebogen,

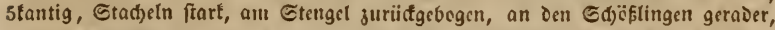

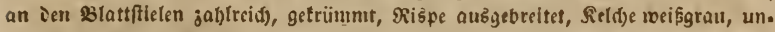

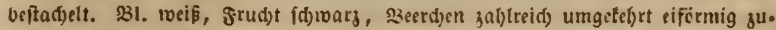

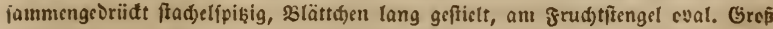
un๖ Dict, 15 - 20' lang. - Ju tref́nen Mäldern. Juni. Juli. b. Ridst felten.

1517. R. candicans WeIhe. fruticosus Wr. $t$. VII. 3tättd)ers

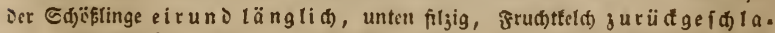
gen. Sdjüflinge nievergebogen, rinnig, 5tantig, tafl, fdjwargbraun, $15-2$ y lang, Blättđjen Der Stengelolätter oval und lanjettlid), aud) ungetebrt eirund,

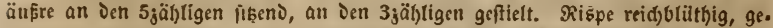
fitređt, unten beblättert, fein behaart filzig. 31 . weis, seere mittelgroßs aus vie. len fleinen id)marzen aromatif́() woblid)medfencen szecr(jen. Stadseln fräftig, 


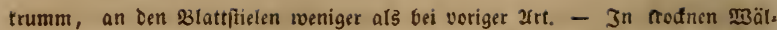
Dern. Juni. Juli. 4. MBobl mel)r verbreitet. D. WBadjwik, Oberpentik̨, Sei. (iț, Dehna, M̉efenftein.

1518. R. tomentosus Borкн, Gurmp, t, 98 . Weine t. viu.

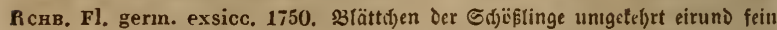

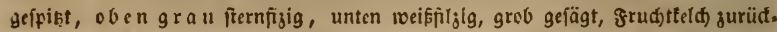
Befd)lagen. Sdjöfling $10-12^{\prime}$, abgebogen 5tantig, fabl, jerftreut oriifenborftig, grünlia), Etad)eln gelblid, turg, Dïnn, zurü̈gebogen, 33lättd)en am Ctengel 3.

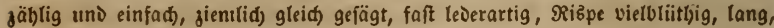

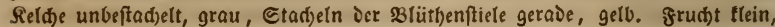
Beerdyen zal)(reid), furwary. R. collinus Dr C. Balb. Nocc. tic. t. IX. bat

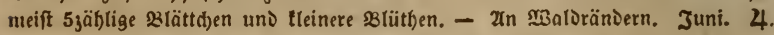

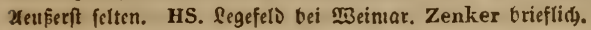

b. 3-5jällig gefingertblättrige, Stjëf́linge bebaart! Staçeln glcidgförmig.

ฉa. Grüne.

1519. R. Sprengelii Wrпнв t. $x$. Rснв. Fl. germ. exsicc, n.

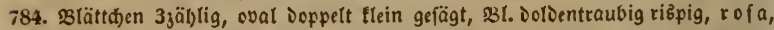
Beere f(d)warg. Ed)ïfling $6-10^{\prime}$, Dünn, rundlid), niederliegend, grünlid), be. baart, trumın beftad)elt, હtengel Dünn und fd)lant, Rispe DolDentraubig aub̆ge.

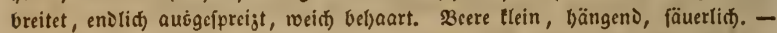

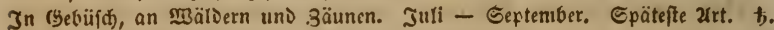
D. fangebrüđ, Scfterwiß, utewalde. MBciter serberitet?

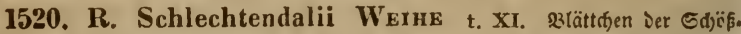

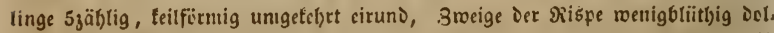
Dentraubig, Etengel ftielrund, raut) bebaart. Gdjëpling nicbergcbogen $10-15^{\prime}$, dicnulid) fficlrund, vcljaart, frum!nt beftadjelt, 3lättdjen groß, obre ftriegelbaarig, unten feidenglänjeno filjig, Etndjeln an Der szafis fefor breit, frumm, Stengel.

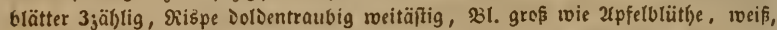

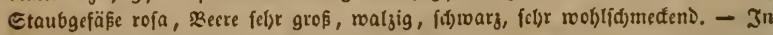
fdattigen Malogebüfd). Juni. Juli. b. Gelten. D. Fianik. Fr, August K. v. S. Shofterwik. Rchb. PS. Şalle. Sprengel.

1521. R. carpinifolius WeIhe t. XuI. Rснв, Fl, germ, ex-

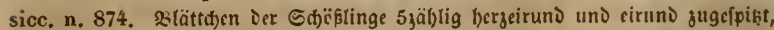

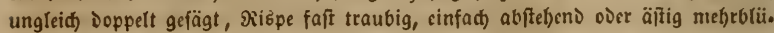
tbig. Cajößling $10-15^{\prime}$, niebergebogen, 5fantig, gefurd)t, grïn und rotb iiber.

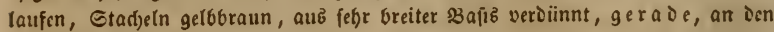

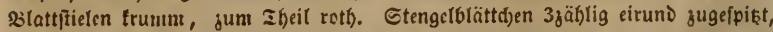

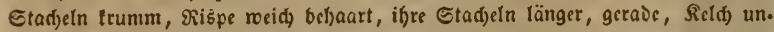

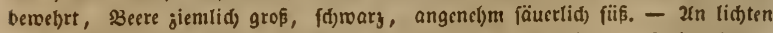

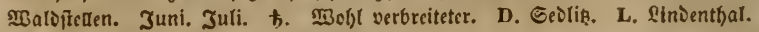

1522. R. vulgaris WEIHE t. XIV. Zriebe tantig, woiß bebaart,

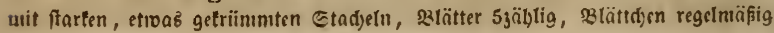




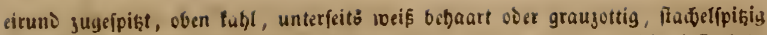

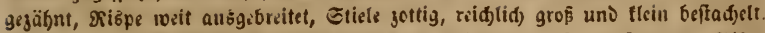

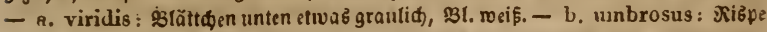

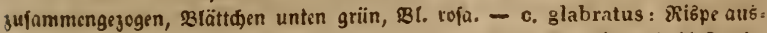

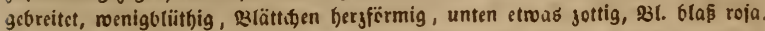

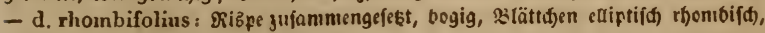

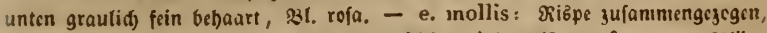

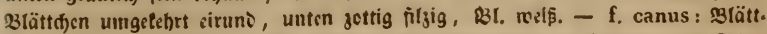
Gen unten graufitgig. - g. bracteosus : mit fururirenien Deffolättern uno Reld).

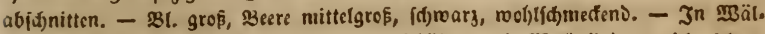

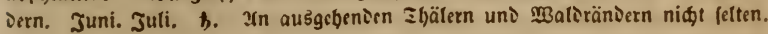

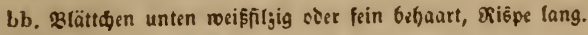

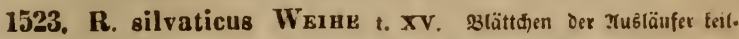
fërnig ungctebrt eiruno fpikig, gleidfarbig, 2rizpe beblättert, abftebeno vet. jreigt. Sdjöfling $12-15^{\prime}$, abftcigeno, etroas tantig, Etadjeln jerftreut, jab)!

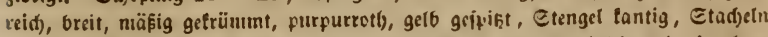

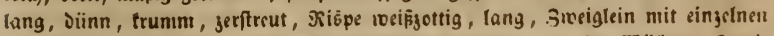

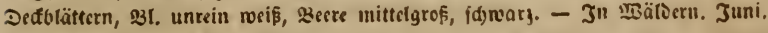
3ull. b. Şier und da jerfitrut.

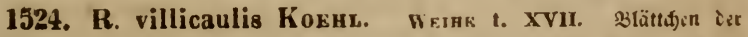

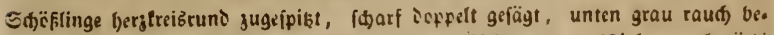

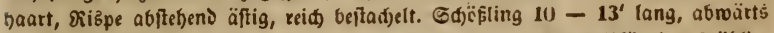
gebogen 5lantig, Etadjein jerîtreut, lang, geraie, brsit, Etingetblättdoen 3jäblig,

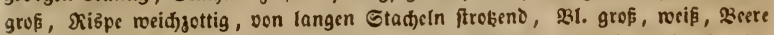

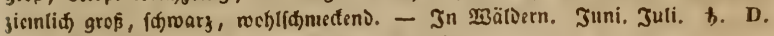

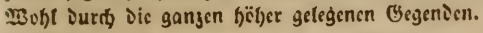

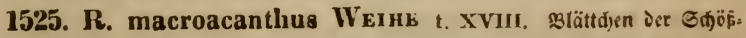

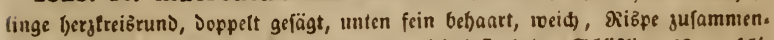
gezogen, sulüt)enftengel zerftreut bebaart, reid) beftađelt. Gdjëfting $12-15^{\prime}$,

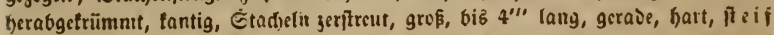
beba a rt, gelboraun ober rëtl)lid, 231. 5, uno mebre 33äblig, 6reit, Stengel

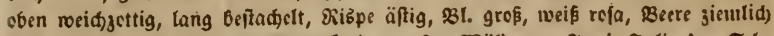

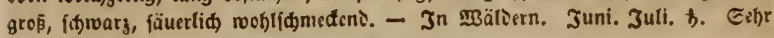
jelten. D. Dbrrpoyriţ. Fr. August K. v. S.

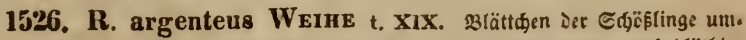

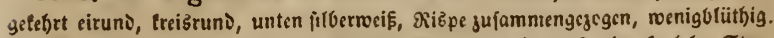
Sdjöfling $15-20^{\prime}$, abgebogen 5tantig, Gtadjeln (ebr gros aber ta b) 1 , Eten.

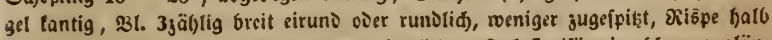

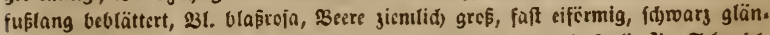

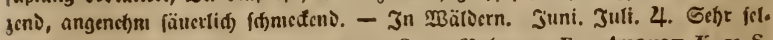

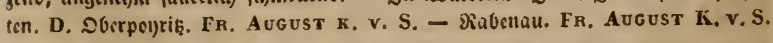

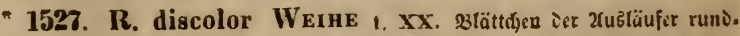

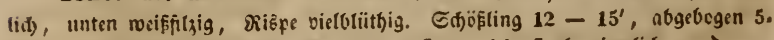
tantig, iunfelroth) angelaufon, Etndfeln jerffreut, febr ftart, giemfidf gerade, alt 
Den S3lattfticlen uno Diippen trunım, Etengel stantig, St. 3jäblig und an Der

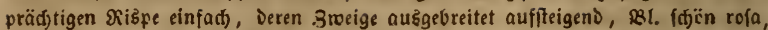

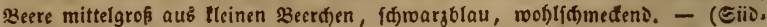
liđjer.) Bei unz nit gefunter Blüthe (R. fruticosus S\$. fl. pleno.) in ₹arts III) Gärten. Juni. Juti. \$.

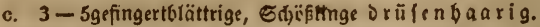

a. Srud)tleld) jurii(tgeid)lagen.

- Grüne, turgriępige.

1528. R. Schleicheri Werne t. XXuI. B(ättd)en Der Ed)ëfllhgs

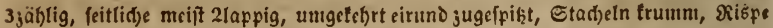
an Der Epişe traubig, Blüthenftiele jerftreut beftadelt. Edös̈ling (d)lant auffreigeno, Etadjeln bäung, größere batig, nad) oben ju tleinere, Diinnere, geraice

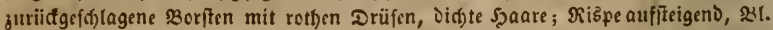

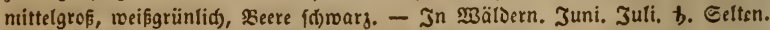
7. Channik. Weiker. L. 2ei Sinientbal. Rchb. 1818.

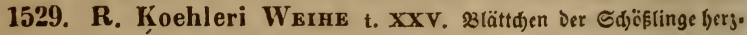
förmig unigetef)rt eiruno, હtadjeln gah)(reid), gerabe, Deftolätter blattartig,

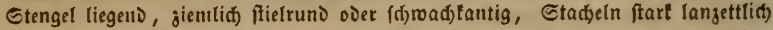

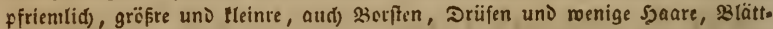
d)en 5 3äblig, breit bergeifïrnig, fpisig, oberfeits tabl, fdjimmerno uno leberartig, Xispe pyramiballfd, ant Grunde beblättert, mit 3 (paltigen, aud) ungetbeilten Blättdfen, Die Etiele abftebeno jottig, mit Drüfen, langen Padeln uno Borften,

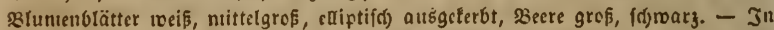
अäldern. Juni. Juli. b. Bon Diefer Gebirgbprange erljielt ids nur: D. Jint utemalder Grunde. Baner. - Galtenljain. Papperitz. 2lltenberg, Geifing. Papperitz. G. Rchb.

1580. R. fuscoater WEIHE t. XXVI. slättofen Der ๔đjïflinge felft

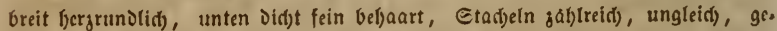
trümınt, Dectolätter lanjettlid), 3-5(paltig, Etengel nicderliegeno tantig. Sd)ös. ling liegend, Diđ, Juntelbraun, હtadjeln gerade, lang borftenförnig, etroas zurïđ. gelruntmt, 5gaare bäupig afd)grau, હtengelblätter 3 jäblig, slättd)en aud breit,

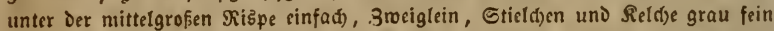
bebaart, borftig Deftadelt, türgere Drüfenborften Dajtbi(d)en, slüthe zicmilit) großs, rofa, 3eere f́froary. - In M̉äliern. Juni. Juli. ち. Eehr felten. L. IIni. verfitätäl)cld, Sgartl). Peternann.

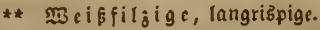

1531. R. vestitus WExнE t. XXXIII. slättd)en ১er Єđäflinge

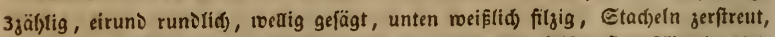

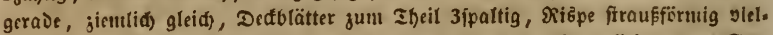
blütbig. Edjëfling berabgebogen, etroas tantig, lyart, afdgraufid) braun, Eta.

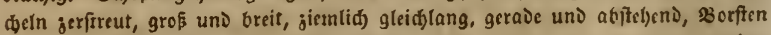

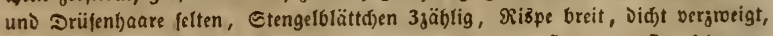
Etadbeln jerftreut, lang, jurïdgebcgen, Driifen ïberall gerftreut, gorften felsr ser. 


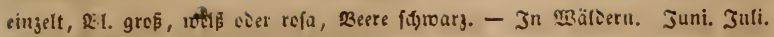
b. Serftrcut, molst Durdi Das Gicbiet.

\section{bb. Frud)tle(d)e aufred)t.}

1532. R. glandulosus Becrardi. (Hirtus:) Trrhs t. XLiII. Rснв. Fl. germ. exsicc. n. 875. Stengel ftielruno, fo mie Die Did)t pistantiol.

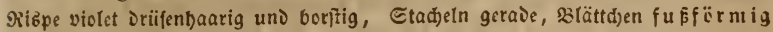

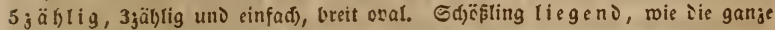
Flianje unrein violet, ficlruno, reid), Etacheln jerftreut, geraie, jurü̈gebrgen,

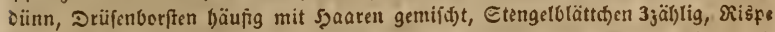

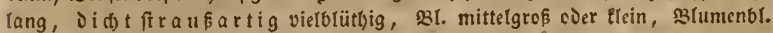

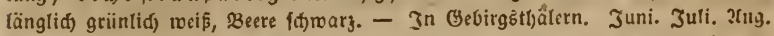
b. In 3erggegenden. D. Pieierwartlja, Fianik. - 2utenberg, Sinnivald. $Z$.

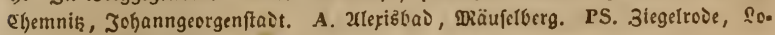
iersteben. HS. MBeimar: in Mibid)t.

1533. R. hirtus Watdst. KIт. t. 141. R. Bellardi Wring t. XLIV. Etengel ftietruno, to wie Die fdllaffe Dotoentraubige $\Re$ Rizpe raud) behaart,

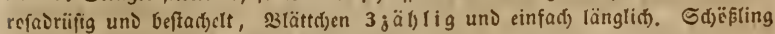

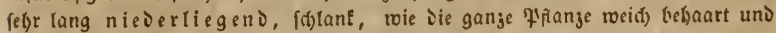
griïn mit rofafarbigen Driijen, Etadjeln felbie borftenartig, länger als Die Drii-

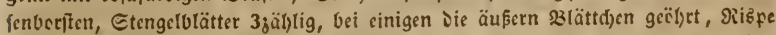

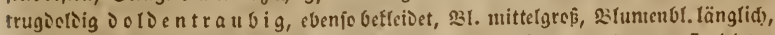

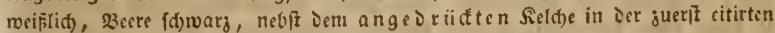

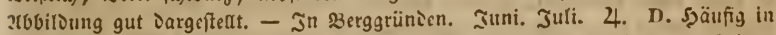

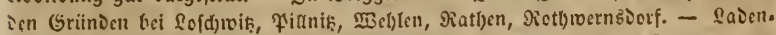

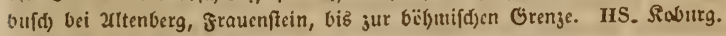

1534. R. corylifolius Sir. nemorosus Hayse Arzngw. MIr.10. Gursxp. t. 101. dunetorun $\alpha$, vulg. WeIHs t. XLV. Blättchen Der fumpf

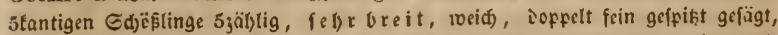

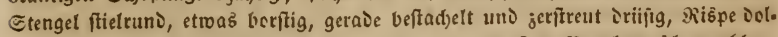
Dentraubig, grudjtteld) a oftehend, sieere aus grofen Beer(f)ell, f(d)warjblaus.

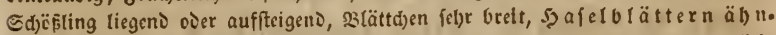
(i id), weid), grün, aud) cinge(d)nitten ooer jertbeilt, variiren aud) unten graulid),

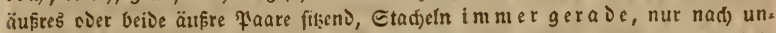

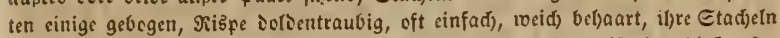

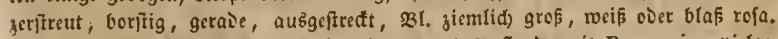

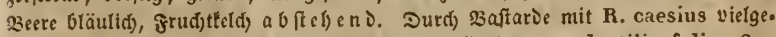

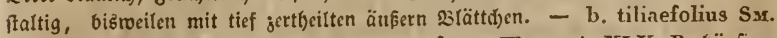
s3lättçen raud)er betjaart uno breiter. - c. ferox WEInE t. XLV. B. häufiger uno iräftiger beł̃achelt. - d. appendiculatus WEIHE. Siişpe reid beblättert,

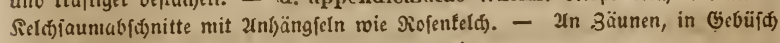
uno \$ä̈loetn. Juni. Juli. b. Siemtid) gemein.

d. 23 creifte, şlättdyen 3jäblig.

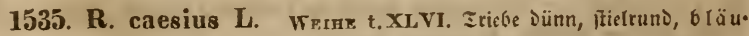
lid) bereift, fein beftad)eft uno benadelt, Blättden eirund rautenfirmig, fein. 


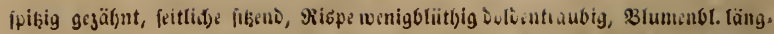

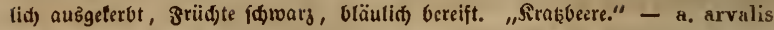
Werhe A. f. 2. uno C. f. 1. 2. Hayne Arzneigew. II. 9. niedultegeno, bär.

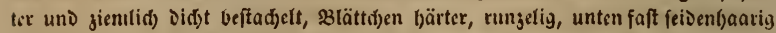
ficin bebaart. - b. umbrosus: febr fdjlant uns jarter, nel)e aufred)t, faft (ab)l,

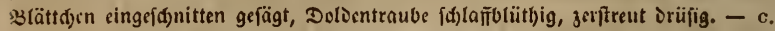
Pseudo-cresius Werne B. f. 1. (el)r jd)lant, fein bebnart, Stad)eln jerftreut

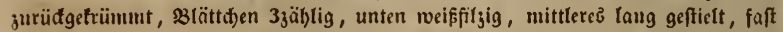

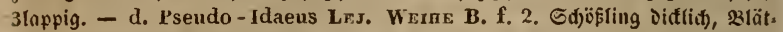
ter 7zäblig gefièert uno 3jäblig. - Xuf 2tefern, in Steinbaufen, Gd)utt, an

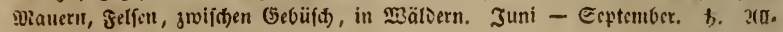
gesuein verbreitct.

\section{e. $\Re$ ofl) $\mathrm{r} \ddot{\mathrm{u}}$ ()) tige !}

\section{aа. S3lätter jufanımengsfę̧t.}

1536. R. saxatilis L. Gưmp. t. 104. Werhe t. IX. હü̈ß̈ling?

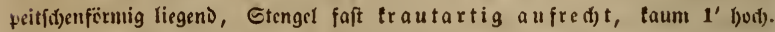
B(ättd)en 3jäblig, untgetel)rt eirund cingefd)nitten gejägt, fein vebaart, SBlüthe

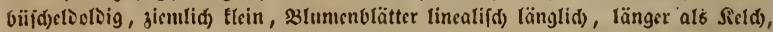

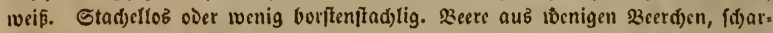

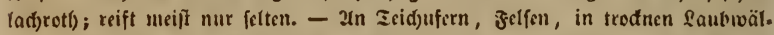
Dern, vorgüglict) auf Siallovien. Mai. Juni. 4. 3erfteut Durd) Das (Sıvict.

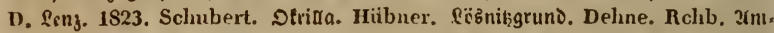

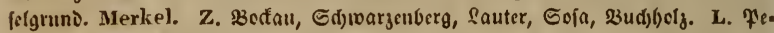
nig. Dehne. Sichren. Dïrr. - Iangenteuba. Dïrr. Gieithain. Seidel. S3ienits

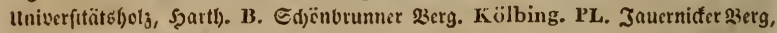

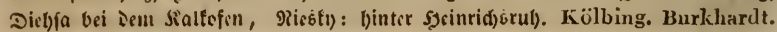

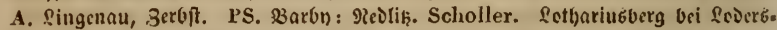

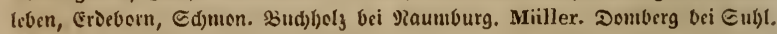
Metsch. Erfurt. Bernhardi. HS. Jena: Dornburg, Juniş. Ed)uląens Gruno bei હifenberg. Weinaar: Etterbberge, Iroiftedt. Zenker. SRS. 2rmftadt. Nicolai.

1537. R. Idaeu L. Hayne Arzneigew. III. 8. Gurmp. t. 97. WEIHE t. XLVII. Etengel ftielruns, aufredt, etwas bereift, slätt(d)en $7 \mathrm{j}$ äh lig gefiedert, unten filjig. MBiro $6-8^{\prime}$ hod), Etadjeln borftenföruig jerftreut,

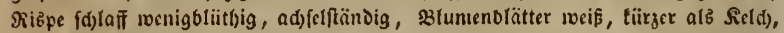
Becee "Sinibcere" weids, furg fein befjaart, blutrotb, in feltnern cultivirten 20 . änderungen meif, aud) gelb. Etacheln Der Edjëflinge nteift fd)warz. OFs. baccae Rubi Idaei - 2un fteinlgen Deten in Mäldern. Mai. Juni. ち. Durd) Das Gebiet.

\section{bb. Brätter niđ)t jufaummengefę̧t.}

1538. R. odoratus L. Bot. Mag. 323. 2fufredt, fiađ)eflos, orïijg

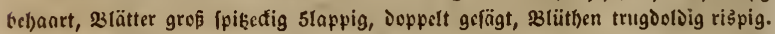
3 - 5' be(t), Blïtbe fef)r grof, Ic(b)aft bläulid) rofa, Becre mittelgref, rotb) (bci

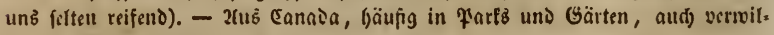
Deriso. Mai - 2uguft. b. 
502. Splraea L. Spiere. Rel(t) 5fpaltig, offen, jienilidf frei.

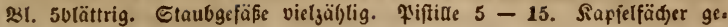
foniert, siemlid) frei berausfetefeno, nel)riaantig.

a. Anencus: Bliithen jweihäufig, grudift abrörtts gebogen.

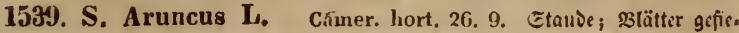

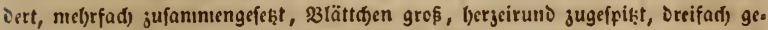

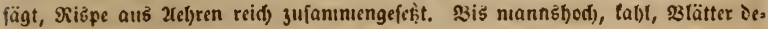
nen ier Angelica etras äfnlid). BReift einige 3witterblütben unternif(d)t. -

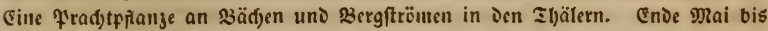

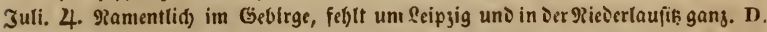

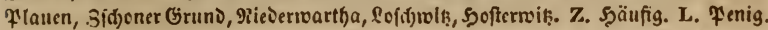

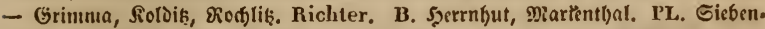

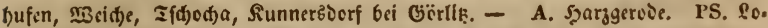
tbariusberg bei Soberśleben. Rauntburg. Erfurt. Euht an ber Lauter und Eteina.

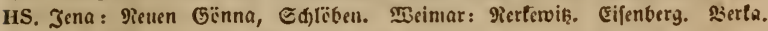

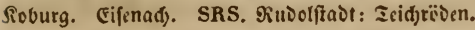

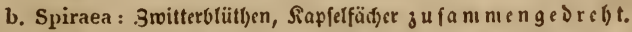

1540. S. Ulmaria L. St. v. 18. Hays Arzneigew. vill. 31.

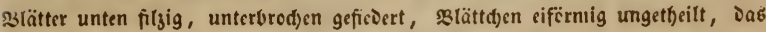
endoftänoige oreilappig, Blüthen Doloentrautig, Sapiel tab). - S. glauca ScHulz.

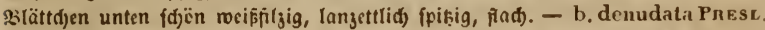

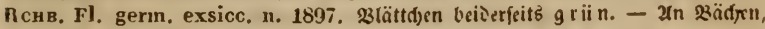

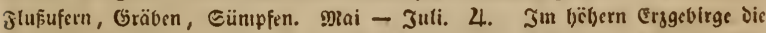

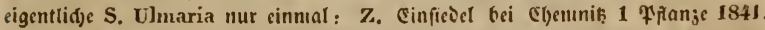

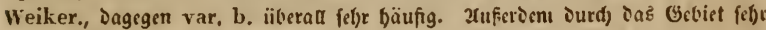
bäufig, var. b. aber neift feltuer.

c. Filipendula HaLx. Srautartig, zmoitterblütfjig, Sapfilfäd)er aufred)t

1541. S. Filipendula L. St. 18. Haysr Arzneigew. ViII. 30. 33lätter unterbro(f)en gefieiert, s3lätt(d)en länglidd), fièerfpaltig elnge(d)nitten, nit

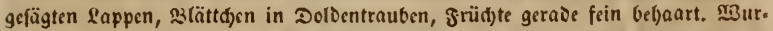

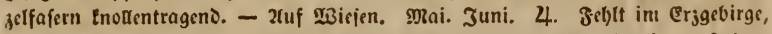
felten in Der Dbertaufib ( ₹iirdjau, Edjönauer Sjutberg, etromberg), nufscien! nid)t felten.

d. Chamaedryon Srr. Etraudjartlg, Sapfelfüdyer nufrentt.

1542. S. salicifolia L. PAxz. ross. I. t. 22. Etraud); 22lättet läng:

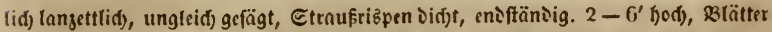

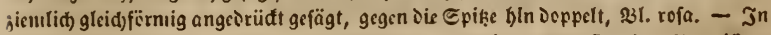

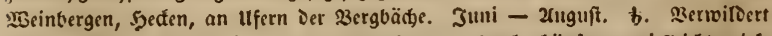
faft überal, nad Kölbing: PS. Siefenfurt am Badje bäufig - vielleidt tvirt. lid) cint)cimifd.

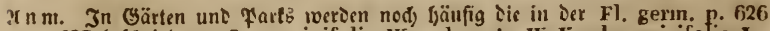
- 627 befdricbenen S. carpinifolia W., obovata W.K., hypericifolia L., acutifolia W. EN., cana W.K., oblongifolia W.K., cliamaedrifolia $\mathbf{L}$., ulmifolia Scor,, crenata $W, \mathbf{K}$, uni opulifolia $\mathbf{L}$. géfogen. 
503. Agrimonia L. Doermennig. Sieldetil)re cben thet. tenartig, હaum 5theilig. 2Bl. 5tättrig. Etauthgefäpe 1U -12 auf Dem

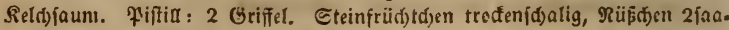

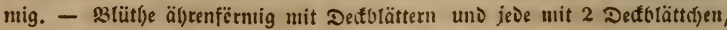
Slätter unterbroden gefiedert.

1543. A. Eupatoria L. Schk. t. 128. Haxws Arzneigw. II. 19. 2Raud) vel)nart, Blättd)en eiruno länglid) uno lanjettlid), ringsum grov einges

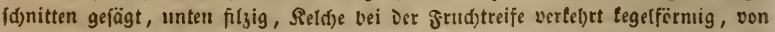

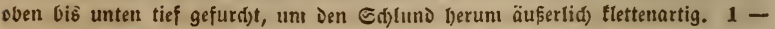

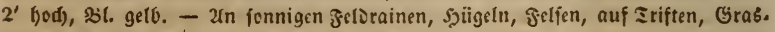
pläzen. Juni. Juli und Sjeroft. 4. angemein פerbreitet.

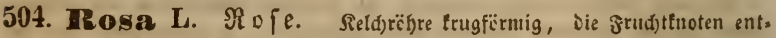

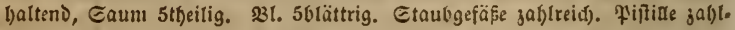

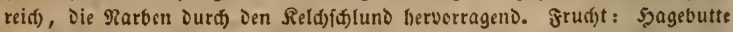

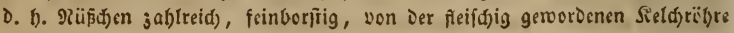
umiffiloten.

Unm. Die vielen nur in Den Gärten cultivirten un๖ ned) nidft verwi(Derten

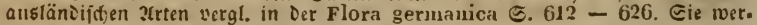

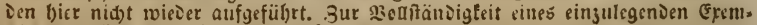

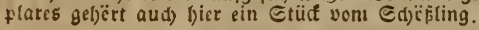

a. Edjëflinge nit geraden Etadieln uno BOrften befeht. aa. Deffulätter fel)len over fino idjulal.

* 1544. R. lutea Mill. Givinp. t. 84. Sruđt tuglig (fpäter fd)ar. Ia(treti)) fo wie ilyr Etiel tabl, Sitdabidnitte eingefditnitten, tiirzer als silunte,

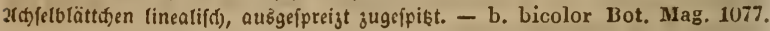

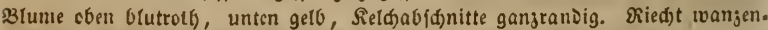

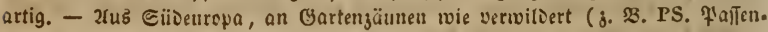

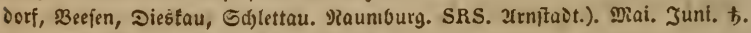

1545. R. pimpinellifolia L. Gurar. t. 86. frut(f) fuglig (ipäter

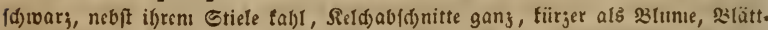
djen $7-9$ runolid), einfarg ferbig gep̈gt (Denen son Poteriun Sanguisorba

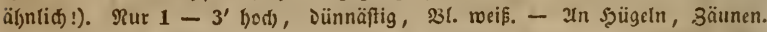

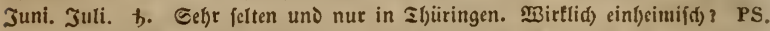
(ErDeborn, Mieśtau uno Gd)lettau an Der Jufnne. Sprengel. HS. Jena: Sorn. berg, Znımerbad). (Eijenad). Zenker. SRS. Xrnitait. Ifultsch. Schünheit.

$\{\mathbf{n} \mathrm{n}$. Die ät)nlid\}e R. spinosissina L. Jat in if)ter urfprünglidfen form eine eiförmige (d)wargrothe \&rud)t, fteif befjaarten Etiel und $7-10$ fidarf Doppsit gefägte ß3lättd)en.

1546. R. alpina L. JAcQ, austr. t. 279. Gurarp, t. 92. Frudjt birnenförntig länglid) fabl, etwas übert)ängeno, Etiel uno s3tattftiele Drürig fteif

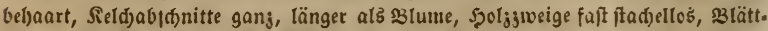

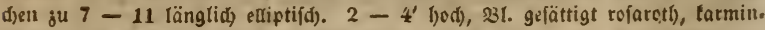

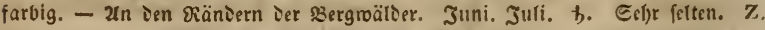
Dzmaligruno bei Mirsenau. Bok. Rodig. 
bb. Detolättır breit.

1547. R. cinnamomen L. Fl, dan, 1214. Gursp. t. 35 . Friidte

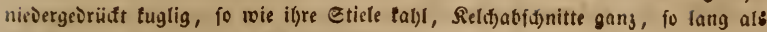
salunte, Ctadjeln an Den 2d)ielolättden gebogen, Blättd)en zu $5-7$ eiruno

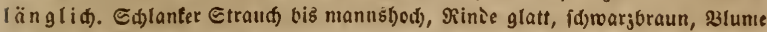

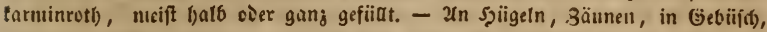
verwildert. Mai. Juni. b. Durd) Dab ganje Gebiet jerftreut. Mirtlid) wilo

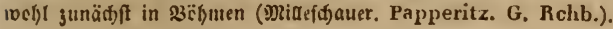

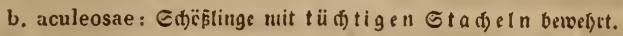

aa, villosae: Ctad)eln ier Ed̈̈̈linge zientlidy gerade, Blätter toeid)filgig.

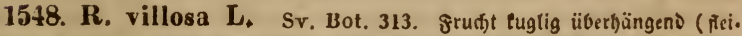

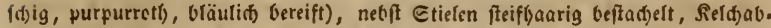
f(j)nitte eingeidonitten fiederifaltig, Blumenolätter orüfig genimpert,

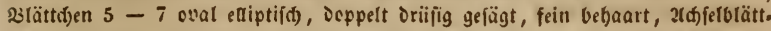

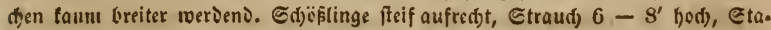

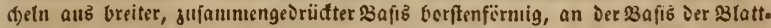
fiiele nid)t filten paarig, slättijen biz 2" lang, unten faum Driifig, Säfine abfte.

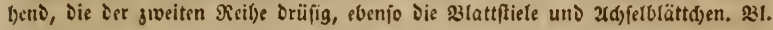
1 - 3 fdj̈̈n refa, fruif)t gres roie tleiner apfel: R. pomifera Heru. - In Berggrgenden aut 2tubgange Der Ibäler. Juni. Juni. b. Sieđeid)t ned) beiter

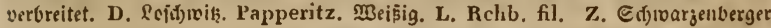
E(j)lopberg. Wankel. B. u. PL. nidjt felten nad) Rabenhorst. PS. Fit. Godula.

1549. R. tomentosa Suith. (R. villosa:) Guisp. t. 88. St. V. 18. Frïd) te faft fuglig aufredit (orangegelb, bart und fpät reifend), ij)r Etiel fteif beljaart, Sicldjabjonnitte länger alb Die Drïfenlofen silumen: blätter, S3lättd)en oval ediftijd), ieppelt abftebend ge(ägt, grau fein bebaart, Eta. d)efn ungleid) ftarf, jujamınengeiriidt, fât gerabe, an Den 2leften jidjelförutig.

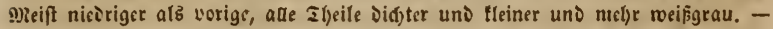

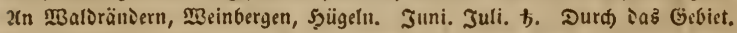

1550. R. farinosa Bechst. Red, ed. Pirole t. 52. frudt luglig

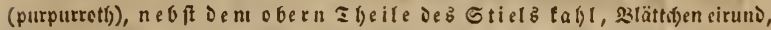
fpishig, f(t)arf Defpelt geägt, beiderfeits ve iffilgig, unten fo wie bie be. ftad)elten Blattfticle o r ïfig, 3(b)clolüttd)en lanjettlid), oriifig gejügt, oben jiem. lidt) talst, unten filzig, Etaifeín geraie. Sileiner uno jarter als iie serigell. -

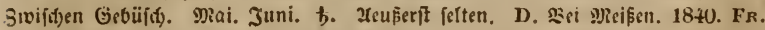
August K. v. S. HS. Grub nat Metsch.

1551. R. cuspidata M. B. (rubiginoso $\asymp$ tomentosa?) ₹runt eiförmig, fo wie Die Dolientraubigen stütbenftiele uno Seld)e fteif bebaart, Gtas

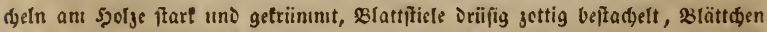

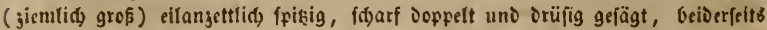

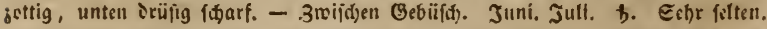
Z. Eilyoargenberg an Icitenititn. Wankel. 
bb. rubiginosae: Stad)eln Dex Edjüß̈linge fiart getrümmit,

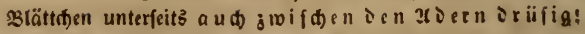

1552. R. rotundifolia ( $\mathbf{R}_{A} \mathrm{v}$ ) grutht faft tuglig, tabt, Etiel ein. Jeln fiftbeno, orüfig feif behaart, Seldabinnitte ficoerfpaltig oriifig, länger als 3luntenblätter, 3lattchen teilförnig rundtid), Deppelt oriinig gefägt, Stađeln am

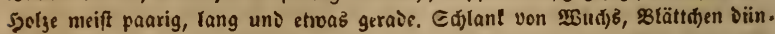

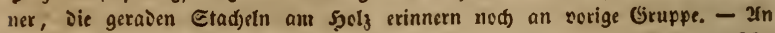

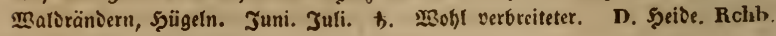
PS. Burgwenien. Rchb.

1553. R. rubiginosa $\dot{L}$. JAc2, austr, t. 50 . ३rudt eiförmig tug. lig, fo roie Dic meift cingelnen Etiele fteif behaart, ßeldjabfonitte lang fièer. fpaltig, fo lang ojer etroas länger aț̇ Die słlumenblätter, Stadeln ftart, jufani.

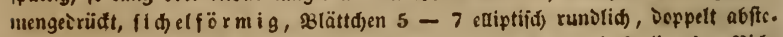

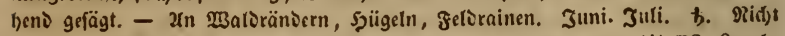

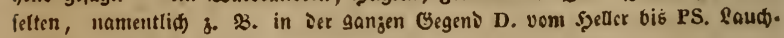
bamuner auffatlen bäufig.

1554. R. micrantha Sm, Engl, Bot. 2490. Fru(t) entipfoidif(t)

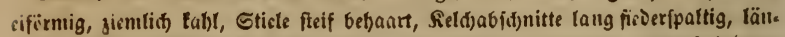

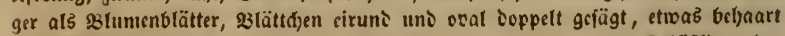

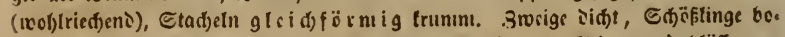
gig, etadjeln zablecio, Setdfaum früber abfattens, sit. tleiner unt bläffer. -

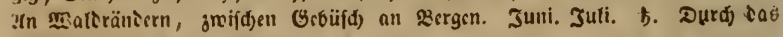
Gisict.

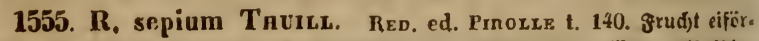
nig, fo mie Dic estiele fal)t, Seld)abfonnitte lang fièserfaltig, länger ats $\mathfrak{B ( u =}$ menblätter, Blättd)en meift $;$ ungctef)rt eitumo lanjettlid, beiberfeitb fpis, Dops welt gefägt, etwas beffaart, unten iiberall rofafarbig oriifig, dic ftärtern Eladjsln trumm, Dic fdwädjern geraice. Sd)lant, 1-5' hod), 3woige

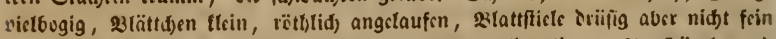

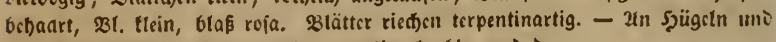

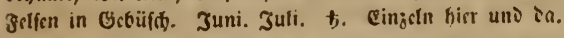

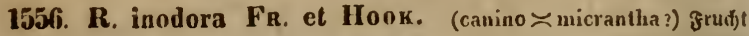

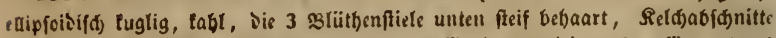

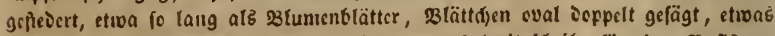
bet)aart (gerud)(os)), Etadef́n gleid)férmig, auz breit f(t)eitenförmiger $B a f i z ~ g e$.

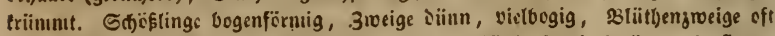

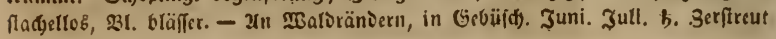

1557. R. caryophyllacea BEss. Frudt unigelet)rt eiförmig, to

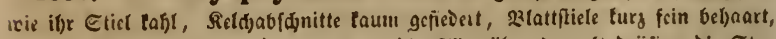

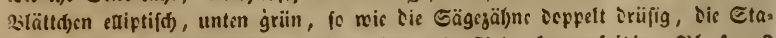

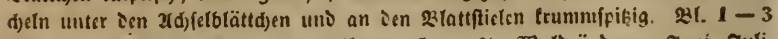

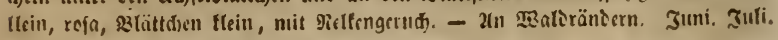
b. rS. Uirgent sen Eubl. Saurer. 


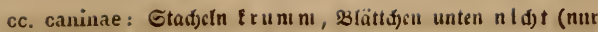
bei einigen an Der Rippe) or üfig, Gteintürntgen in Der Sage. butte etroas gcfitieft.

1558. R. collina JACQ, austr. 11. t. 197. Sr. 34. (villoso $\asymp$ canina ?) fru(t)t tuglig ciförnig, unten fo wie if)r Ctiel uno die slattitiele

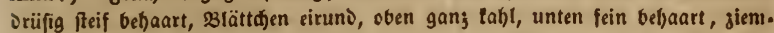

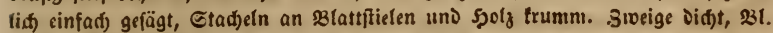
lebljaft rofa. - Xn Şügeln, geloroegen. Mai. Juni. b. Gefr felten. PS. Där. niţ, sölberg, siodtenholg bel sjatle. Wallroth.

1559. R. dumetorum ThusL. fruht eiförmig, tabl, fo wic if $r$ Etiel oben, 23(ättd)en oval fteiflid), oben geftriegelt, unten etıoas bebaart, gleid). farbig, Doppelt oriijig gefägt, Blattficle fein bel)aart uns Drijfig, fo wie Die Srocige beftadselt. $3-6^{\prime}$ bod, aufred)t, Stadjeln Did hatig, bier uns Da Dop.

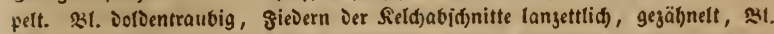
tlein, zart rofa. gon R. canina verf(fieven Durd): 3 (ättden, welde nad) bei.

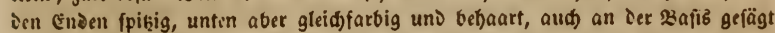
fino, lang frin bel)aarte uni gefticit orüîge Blattfiele, an iber Epike geroin.

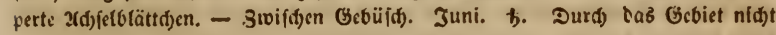
gar felter.

1560. R. umbellata LeERs. Frudyt eifürmig, tabl, Sticle 3fpaltig DofDentraubig, fcin beftadilt fteifbaarig, 33lättđen eiruno, Doppelt gefägt, fciı bef)aart, unten bidst Drüfig, slattfiele etwas belsaart fo wie Die 3weige befta.

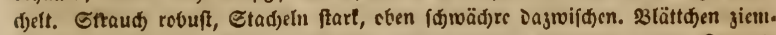

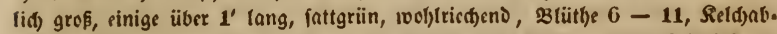
fd)nitte jederfeits etra mit cincr grofen, lanjettlidjen sieder, woldje fteif behaart

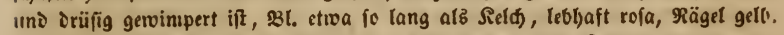
- 3roifden Gebüfd. Maa. Juni. Ђ. Sefre feften. HS. Roburg. Hornung.

1561. R. trachyphylla RAv, (rubiginoso $\asymp$ caninar) gruøt ciförmilg, oben eingefd)nitrt, unten to wic ble angebäuften Etiele ftcif bebanrt, 31veigftad)efn wenige ungleid, frumn, slattficle gerftreut oriifig, etroaz befta. d)eft, $B$ (ättd)en cirums, zicnulid) Drcifad) gefägt, beiberfsits tabl, unter Den Sippen

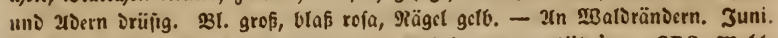
4. Gel)t felten. PS. Edfleufingen nad) פlciningen zu. Külzing. SRS. शrabl. boly bei Gëfrlborn. Schünheit.

1562. R. sylvestris TARERx, (tomentoso $\asymp$ canina?) frud)t

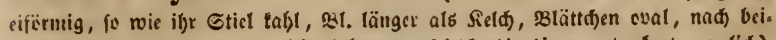
ien Enden (pikig, vciberfeit's fcin bebaart, gleid)farbig (jung getrodnet graulid)), gicmulid) cinfad) ge(ägt, to rois Die 2 (d)fefblättd)en gewimpert, Blattfitiele filgig, et.

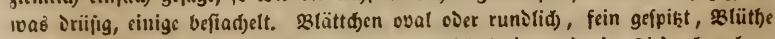

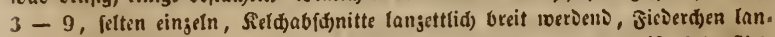

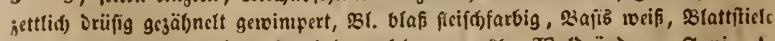

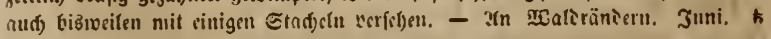
Şicr uno ia jeritreut.

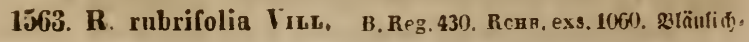


grau bereift, rötblid) angelaufen, grud)t eiförmig (id)arlad)rotb), fo wie Die etıas DolDentraubigen Etiele ealst, Reld)ab(d)nitte faft ganj, länger als slumenblätter, Blattîticle beftad)elt, S3lätt(f)en länglid) (d)arf einfad) jujammengeneigt gefägt tabl, violet geadert, Stad)eln ant 5joly jerftreut, balig. Sd)lanter alb $R$.

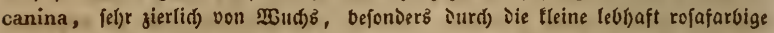

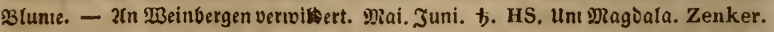

1564. R. canina L. §ruđt länglid) eifïrmig, fo wie il)r Etiel taht,

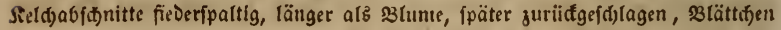
oval, an Der \$3afis ganjrandig, zujanimengeneigt gefägt, fpişig, tal)l, unten

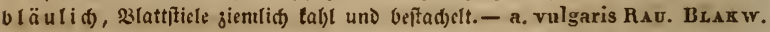
t. 8. Fl, dan. 555. Blattiftiele beftadjelt, ganj fabl, 3(d) jelblättoffen etroas orü. jig gcroimpert, 3lättdjen giem(id) einfad) gejägt. - b. senticosa AchАr. Sr.

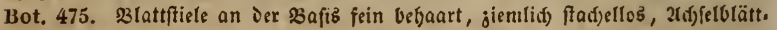

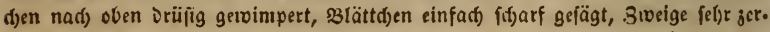
theilt, Did)t. - c. dumalis Bchst. Gurarp. t. 94. Hayne Arzneigew. XI.

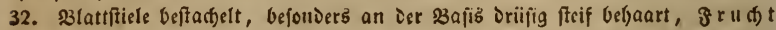
faft fuglig! - d. squarrosa RAv. Sv. Bot. 541. Blattfiele und Mittel. nerv Driifig, Etadjeln felyr groß , faft gerade, Didjt beifaumen, 3lättdjen Dop. pelt or üjig gefägt. OFr. Fructus Cynosbati et Bedeguar: હd)lafapfel.

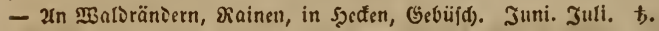

1565. K. alba L. Fl. dan. 1215. Guimp. t. 06. Grud)t eifïrnig, an Der Sajib fo wie Die Blütgenftiele und Reldbe fteif belyaart, Stadjeln alle (tumm, Slättd)en run১lid), unten etroas bcbaart. 21. weiß̄, in (Gärten gefiiat,

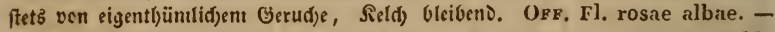

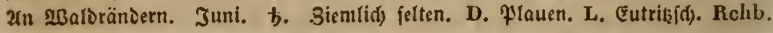

1566. R. Waitziana Rснв, (punilo $\asymp$ canina?) grud)t eifï. ntig, tabl, nur unten, fo wie Der Stiel uno bie cingefd)nitten fieberfpartigen uno gefiederten Seld)abid)nitte unterfcits, fteif ochaart, 3 (ätt(d)en rundlid) cirund, f(b)arf

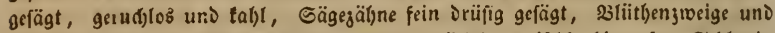
Bilattftiele orïfig, batig beftad)elt. Szlume präd)tig, fieifdfarbig rofa, Gd)lund. politer erljaben. - 2rn Maloräniern. Juni. ち. Eefre jelten. PS. Grofmonnra.

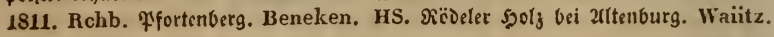

dd. Centifoliae: Staci) eln verfdieden, 3lätter runjeli g.

1567. R. turbinata AIT, JAcQ. Schnbr, t, 415. RED, t. 147.145. polsix. ver. II. t. 1. Frud)t freifelförmig, Şals eingef(f)nïrt, unten fo wie ist Etiel Driifig fteif bel)aart, Reld)abfd)nitte cirund gugefpikt, ganj, Blattfitiele jottig, s3lätt(j)en cirund einfad) gefägt, unten weistid) uno fein beljaart, 33lütlyelt. sweige unbeftad)elt, übrige Stadjeln jerftreut. ŞBiro $8-9^{\prime}$ hod), 23liitbenftiele 1 - 3 mit Defolättern, Reld)abfdnitte graufilyig, sil. gref, pattrig, tarminrotb.

- 2rn Meinbergen verwilbert. Mai. Juni. b.

1568. R. pumila L. Crus. hist. p. 117. JAcQ. austr. t. 198. ST. 1X. 37. Grud)t birnenförnig, to roie Die Stiele Drüfig ftcif bel)aart, Seldab.

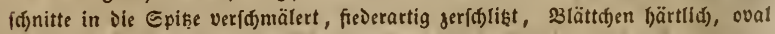

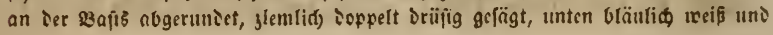


fein bobaart, sitattīicle orüfīg, fo wie isr Etcngel nad) sben jerfitreut ungleid)

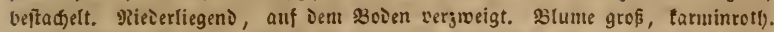

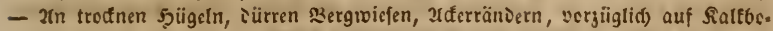

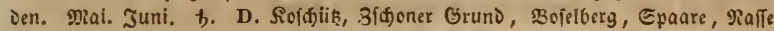

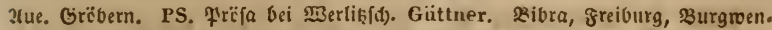

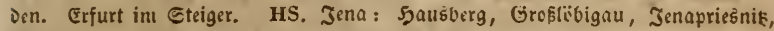

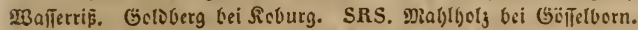

* 1569. R. gallica L. Hayse Arzngew. XI. 30. Frubt tuglig, fo

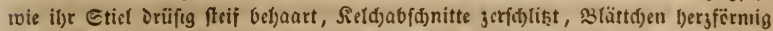

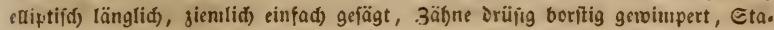
d)eIn uns Drüfenvoriten gerade. 2(ufred)ter Etraut), Blume grof, fiattrig, gi: fättigt rofarctl). Opr. Fl, rosae rubrae. - Eultivirt. Juni. Juli. わ.

1570. R. marginata WALLR. (rubiginoso $\asymp$ pumila ?) รrudt faft luglig, unten nebilt $E$ ticl fteif bel)aart, 3 lättifjen leverartig, ciruno fpiß̨ig,

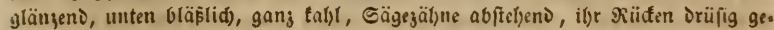
jäl)nelt, 3roeigftad)eln frunım, länger uti Didfter, iie ier \$lïthenjtweiglsin ge. raie. Nur $1-2^{\prime}$ bod), tidft vergroeigt, roth) angelaufen. Reldjabid)nitte eiruno

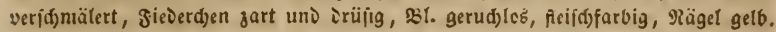
- 2n 2aferräniern. Juni. ち. ๔ebr felten. PS. ßennftäit. Wallroth. HS. Roburg. Hornung.

* 1571. R. centifolia L. II yxr Arzneigew. XI. 29. ร̧ru(f) eiför.

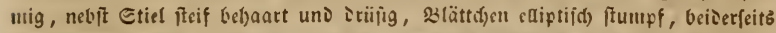
frin belgaart, weid) alijufül)len, orüfig, .Stocige beftadjelt uno oriifenborftig. Die

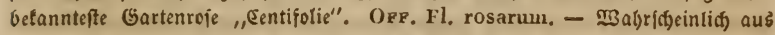
ient Drient. Juni. Juli. b. આeberă in Gärten.

* 1572. R. damascena MILL. RED. t. $84-90$. ङrudt eiförnig aufgetrieben, nebit Eticl fteif bef)aart, Reldjabfojnitte ficierfpaltig, Blättdoen ei. runo jugrifikt, unten fcin bshaart, Etadjeln ant Etengel uno slattfielen bäufig

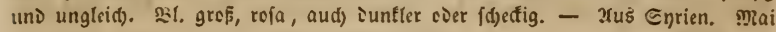
- Şerbft. b. Şäupig cultivirt "Mionatšrofe".

c. nitidae: Slättd)en glänjend glatt, Grififl jufanmentyängens, bet. aušragend.

1573. R. arvensis Huds. Engl. Bot. 188. Fruottlncten fait tug. lig (jung eifïrmig waljig), nebli Dotientraubigen Cticlen taf)l oder menig orüjig, Reld)abfdnitte eiruno, länger als ifre Epişe, roenig fieioripaltig (blaugrau), Blättđjen oval, einfad) gejägt, unten bläulid) weiş. fang iünnjırigig. - 21n

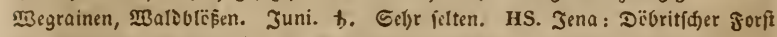

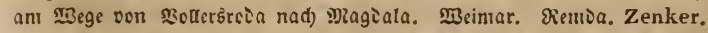

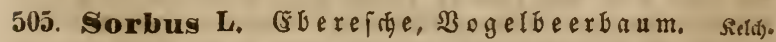
faum 5jäbnig, auf ier frudft bleibeno uno jujanmengeneigt. Blumenblätter 5, runolid. Griñel $3-5$. Grud)t bectenfërmig $3-5$ fäd)rig, fä̈øer 2. faantig. - Bäume, 28t. trugboloig.

1574. S. Aucuparia L. Scrk. t. 332. Bääter geficiert, jung fein 
vefjaart, fpäter faljl, Slätt(jen zicnulid) gleiđ), fpikig geï̈gt, Sinospen flljig, früß)te tugelruno, mennigrotl). Sindet fid) aud) nit Doppelt ge(ägten slättd)en,

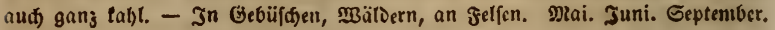
Ђ. Nidt felten, in frudftbaren Sjügelgegenien geniein.

1575. S. domestica L. JAcr, austr, t. 447. GuIMP, t. 68. ST. 34. Rснв. Fl. germ, exsicc, n. r753. Blätter gefiedert, jung feill bebaart, fpäter tabl, slätțiłen längliđf), meift Doppelt gefägt, etroas runjelaierig, Sticle fein bebnart, frudf)t birnenförmig. \$liutben grï̈ser als voriger 21rt. - b. aucupario $\asymp$ domestica, fruntt tuglig. - In Mäloern, befonjers an Faltbergen. Mai. †. 2uud) cultivirt "Speierling". Selje felten. A. Sgarjgerode, MBernige= rove. PS. Gteigertfal, Speringen, Rioffeben. Wallroth. Gropimonnra. Bernhardi, SRS. Grantentjaujen. Hornung.

1576. S. hybrida L. Fl. dan. 301. Blätter nur unten gefie. Dert, ïbrigens längliđ), nađ̆ Der Epişe bin Deppelt gefägt oocr fiederfpaltig, Xofd)nitte (anjettlid), unten ganjrandig. Frud)t mennigrotb) wie von S. aucuparia. - 2(n \$ergen in (jebuijd)en. Mai. Juni. Ђ. Sel)r felten. A. Sanders. leben. Schwabe. PS. Gut)t. Sauer. Ra(t) Metsch nid)t will. HS. Seburg.

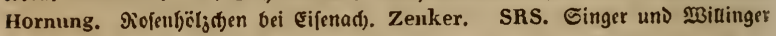
ßerg bei Grieskeim. Jrobnterg. Schönheit.

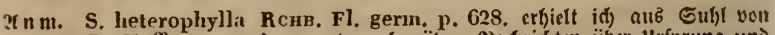
Serru D. Hoffuann uno erwarte nod) näbere Pradyridsten iiber urfprung uno Sorfenumen Diejer viedeid)t ni(b) einbeimif(d)en 2rt.

1577. S. torminalis Cues. Gurve. t. 8). Blätter bergeiruns, fpi(sečtig gelappt, Ecten ungleid) gefägt, untere urbbr abftebend. Junge Iljeile unঠ Inugboloc fein beljaart, frud)t eiförnig, faft orangegelb, braun werisns, jufam. menjielyend, nur nad) Dem Erfricten fïffdmedend: "Elङbeere, Elrike." - In

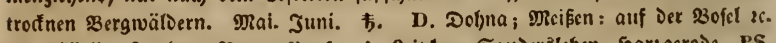

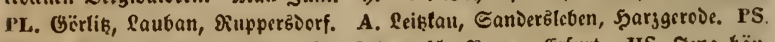

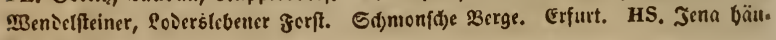
fig. Grub.

1578. S. Iatifolia PERs. slättex breit eiruns, unterfeits tợer firgig,

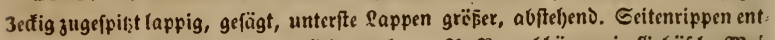

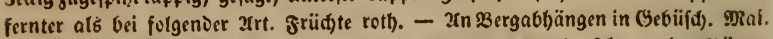
Juni. †. 2teuferft felten. SRS. Billinger Berg bet Gtait Jim mebre szäum. ()) Schöuheit.

1579. S. Aria Crтz. Fl, dan. 302. Blätter umgetiffrt eiruns oval, Doppelt gefägt, unten Diđjt weiffilzig, beiঠerfeitz nit 10-12 Geitennersen. Grofer

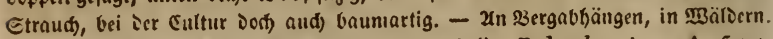
Prai. Juni. わ. Ђ. Cebr felten. PL. Gërliķer Şeide. Rabenhorst. - A. Sar: Scliwabe. PS. Erfurt: Rlettban) am (Eid)berge. Bernhardi. Sulgl. Metsch.

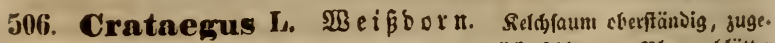

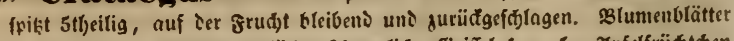

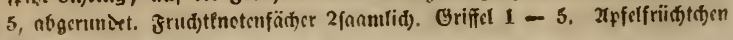




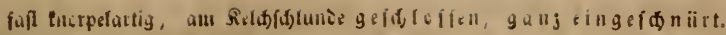
Rerne 1 - 5. - Bivornte Eträudjer.

1580. C. monogyna JAcQ. austr, t. 292. f. 1. Fl, dan. 1162. Gurxp. t. 73. Rснв. Fl, germ. exsico. n. 490 . Slätter tillförmig unigctsh)ıt eiruno, jumal 3-5tbeillg nad Der Epike gefägt, Dolientraube iaumifaarig,

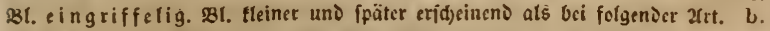

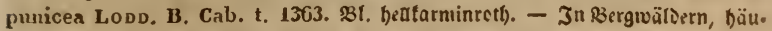
figet auf Ralt. Ende grai. Juni. b. Nidjt gar fetten.

1581. C. Oxyacantha L. Sснк, 132. Gurss. 72. Slätter unige. tebrt eirund, 3-5fpaltig, Sappen brcit, eingejdnitten, Doldentraube tahl, 231 . 3 reigriffelig. - b. oxyacanthoides ThüL. B. Reg, 1128. 231. fcilfïr. mig çal, weniger eingefdnitten, ringsum gefägt. - c. apiifolia Mev. oxyacanthoidi $\asymp$ monogynal tabl, \$l. 3 - 5tl)eilig, \$l. jo gros alb C. oxyac.

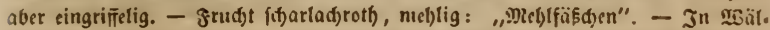

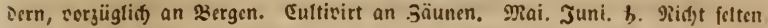

\section{Cotonenster MED. 3 toergmigipel. Polngamilit.}

Sield' treifelformig, Saum a ufred)t 5 jäl)nig. Slumentätter 5 , länglid),

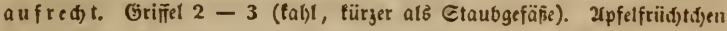
tretfslförnig. Eteinterne $2-5$ jufanmenbängend, coen beraušragenı. -

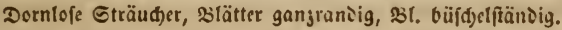

1582. C. vulgaris Lixds, Fl. dan. 112. Gormp, t. 71 . Rснв,

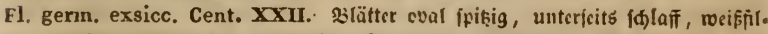

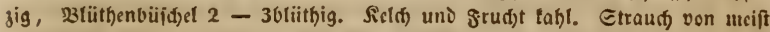

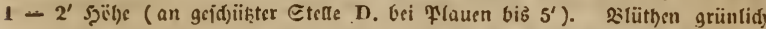

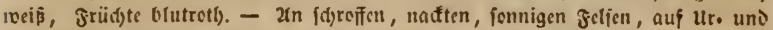
Saltgebirgen. 2tpril. Mai. b. Etellenivcife. D. Flaucn an Den gefäbrlidjiten

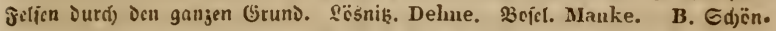

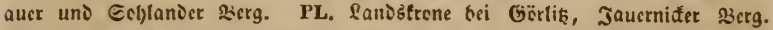
Schunidt. - A. J̧arj. Schwabe. PS. Şatle: Settin, J̧ei১e, Gutenberg. Finn.

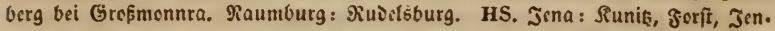

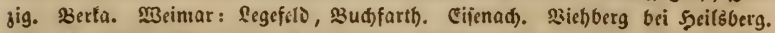

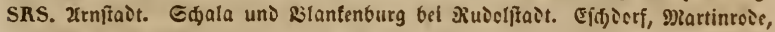
รeid)el. R. SBurgl. Diirr.

508. Aronia Pers. Beermiģel. Reldjaum 5theilig, brei. bent. SBluntenblätter 5 , lanjettlid. Frudttnoten 5 fädbrig, \& ä d) er z we i . fäфrig, 10 Sanmden. Srif̄el $2-5$, unten zufammenbängcn广. Xpfel. früdtden berenartig, $2-5$ Gtrinterne (ofne fergamentartigen (Gr $\mathrm{r}$ p̧). -

1583. A. Amelanchier (Mespilus -) L. Jaç. austr. t. 300. Gurmp. t. 7ł. Rснв. Fl. gerın, exsicc. n. 356. slätter lang gefficlt, oval

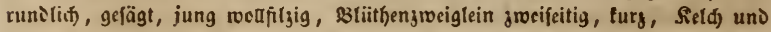
srudft tabl. Etraud) $4-6^{\prime}$ bod), junge sheile woolig umbüut, etroadfencre tabl, slunte gref, weif, ŝruđt geftaltet wie lie son Crat. oxyacantha, aber 


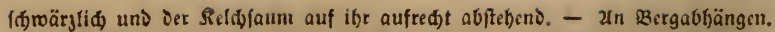
Mal. †. Gelten; nur in meftlidjen Gebiete. A. Sarjgeroie, 2llerisbad. Scliwabe. PS. Bleidfrode. Wallroth. Etempeda. Schünheit. HS. Eaalfelo. Eckart. SRS, Brantenburg. Zenker. Schöuheit. Edjala. Schünheit.

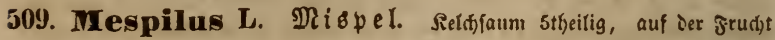
bleibeno und zufammengencigt. Blumenblätter 5, rundlid). Grifiel 2

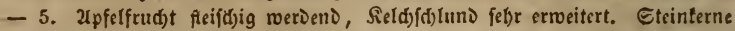
2 - 5, ganj eingcfentt. - Dornig, 33I. an Den 3roeiglcin, enijtändig, reiß̄.

1584. M. germanica L. GurMp. $t, 69$. Blätter lanjettlid), ctraab gejägt, unten filgig. $4-\sigma^{\prime}$ bod), frud(jt wiro nad) Den erften frïften teig und

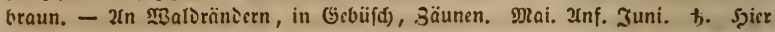
unD Da jetftreut; fdjeint in Den Saufik̨en ju feblen. D. Dofna, giederwartha,

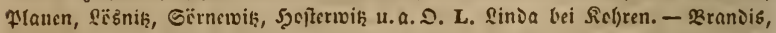

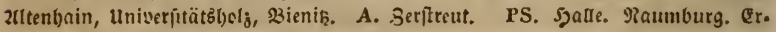
furt. HS. Eijenberg. Jena. SRS. xrnitait.

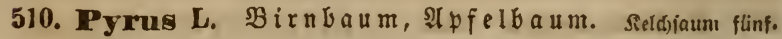
theilig, auf Der frudjt jurüđgeld)lagen un১ vertrođ́nenঠ. Blumenblätter 5 . Grifiel 2 - 5. Jrud)t feifdig, fd)lieft eine perganentartige 5fäd)rige Rapiel

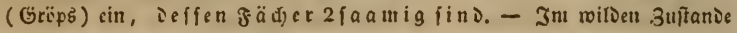
cornige şäume, sil. Dolvenftänvig.

1585. P. communis L. Gurmp. t. 75. Frudt unten nid)t vertieft, Grifiel frei, 3lattitiel fo lang als bie 3lätter. Syäbe bis 40$)-6()-8 U^{\prime}$. 21 . weißs, feltner rëtlliđ) angelaufen. - b. domestica, mit vielen 2lbänDerungen. -

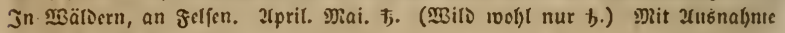
ies bïl)ern Gebirgez nid)t gar felten.

1586. P. acerba (Malus -) Merat. Rснв, Fl, germ, exsicc. n. 1756. Blätter cirun১ jugeipiş, terbig gefägt, nebft Sieldröbre fal)l, jung nux

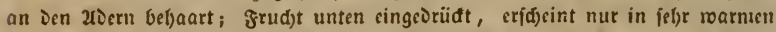
Eomnern. - In MBäldern, vorzïglid) nuf Jelfen. 2pril. Mai. ち. Seljr felten.

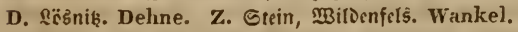

1587. P. Malus L. Scrk, t, 134. HAYNk Arzneigew. IV. 40. Gurmp. t. 78. 3lätter eirun১ fpikig, gefägt, unten filgig, frud)t unten vertieft,

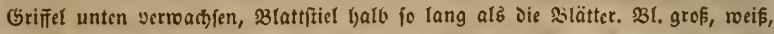
aufen rofa. Jÿ̈be bis $30^{\prime}$. Xp felba um. - siele şarietäten cultivirt. - In

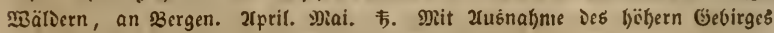
Durch) Das (Gebict nidjt felten. Gefre bäufig cultivirt.

511. Cydomia Juss. Duitte. Seldjaum 5theilig, Glattartig

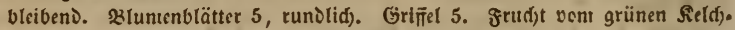
faum getrïnt, innen ein pergnmentartiger, 5fäd)rlger Gröps.. Saamen in den

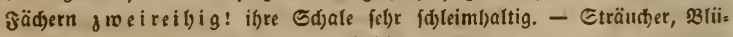
then eingeln, an dett 3reeiglein enditäniig.

1588. C. vulgaris Pres. Gurmp. t. S1. Havse Arzngw. IV.47. 


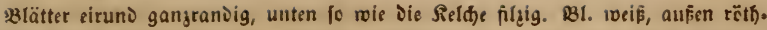
lid), frud)t greß apfelartig, citrongclb, wooblriedend, oder b. pyriformis Gurare. Fig. f. birnenförmig. Fleifo gelblich, fauer jufammenjiebens. - In şecten, au Säunen. Daal. Juni. わ. Berwilbert.

\section{Familie Halorageae, Saloragen.}

- Sperbarienbud) S. LXVIII und 169. -

512. Hippuris L. Tannentoebel. Seldfaum febr tury.-2el.

(). Etrubgefäfe 1. Grudjtencten ganz eingervarffen, Grififl 1, cinfeitig, fa. Denfïrnig einer furdje ies Ctaubbeutels antiegeno. Eteinfrüd)tdyen einfaa.

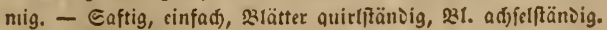

1589. H. vulgaris L. Fl. dan. 87. Schk. t, 1. Drkv, U. HАтxi t. 21. Salätter ju $6-12$ in jeven Quirl, linealifł. $1-3^{\prime}$ bod), über Dent walfer emporrageno, Duntelgriin, meift aufred)t oder feltner aufiteigeno, $-b$.

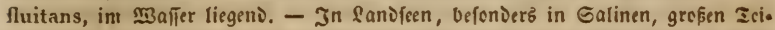

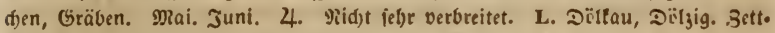

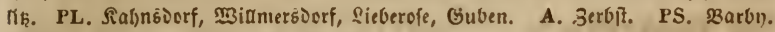

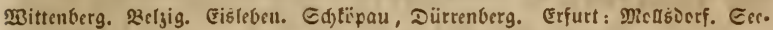

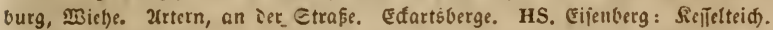

513. MyriophyIIum L. Ta $\mathfrak{a} \mathfrak{e} \mathfrak{n} \delta \mathfrak{b} \mathfrak{l}_{\mathfrak{a}} t \mathrm{t}$. Einbäufig sier

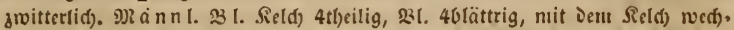

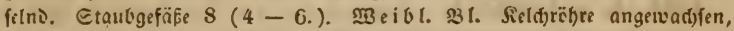
CauII 4ipaltig. 231. (). Siafiel geiondert 4fäđ)rig. - Untergetaudjte Rrüuter, Silätter nur feine 23 lattgeriijte, 231 . ad)felītändig oier quirlährig.

1590. M. spicatum L. Fl. dan. 681. ScrK. t. 296. Deđtütäter ier unteren 2 lïtben singefd)nitten ge्ägt, Die Der oberen ganjrandig, türger als

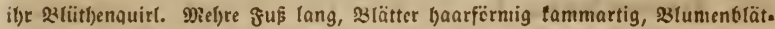

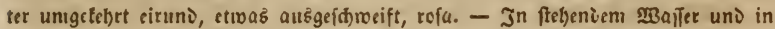

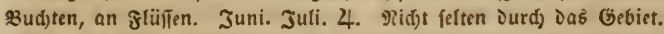

1591. M. pectinatum DE C. Fl. dan. 1046. Blätter, aud) ১ie blü.

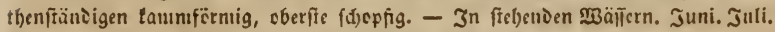
4. Gebr f́lten. D. शiaīe 2ue. Mauke. G. Rclib.

1592. M. verticillatum L. Deđtolätter fämmttid) tanımig fiever. ffaltig, fo lang als Die untergetaud)ten baarförnig gefiecerten. - Jn ftebenien Mäfifern. Juni. Juli. 24. Etrvas feltner als Mr. spicatum. 


\section{Familie Onagracene, gachtferzell. - 5rrbaricnouஞ 5. LXIX und 170. -}

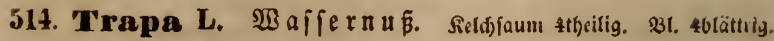
Staubgefäße 4. Srudtfnoten 2fäd)rig, giarbe tepffïrmig. Eteinfrudgt trođen

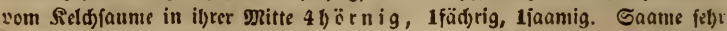

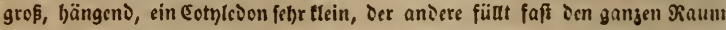

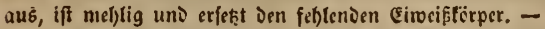

1593. T. natans $L$. Sснк, t. 25. Sт. 31). Rснв. Pl. genn. ex-

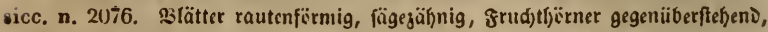
vberfte melje abftebent. Ed)winumt, Etengel gel)t tief in Den Edjlanm uno trägt haarfërnig gefiederte \$lattgeriifte. Die fobminmenten siätter rofettenartig, if)re Blattficle find in Der פRitte fpindelfïrmig vervift unt innen fifroanmig, $\mathbf{3 1}$.

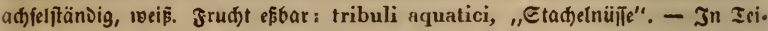

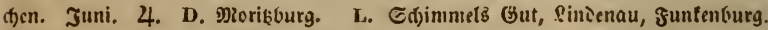

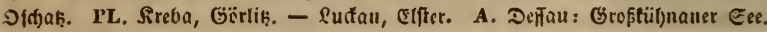
Mörtiḩ. PS. Barbı). Mittenberg. HS. 2ultenturg, 2ionneburg.

515. Isnardia L. $\Im \& n a \mathfrak{r} b$ i e. Reld eifïrnig, Caum theilig,

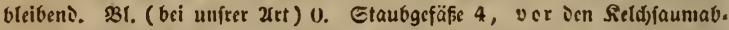

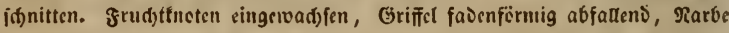

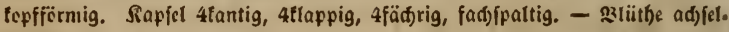
jïänolg.

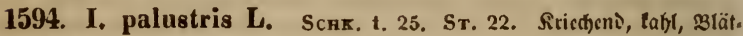

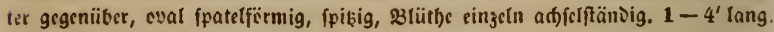

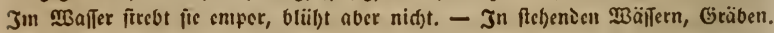

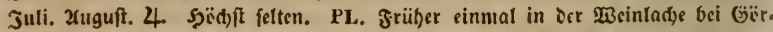

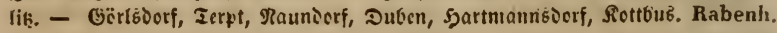

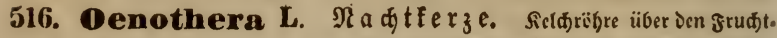
tnoten binaufreidento, an Deflen Epişe abfalleno, Selddfaum tlappig 4theitig,

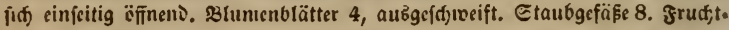
tnoten eingeroadjen, Parbe treuffïrmig. Sapfet 4 fädrig, 4tlappig. Caa. unenträger mit $\mathbf{4}$ vieljaantigen Seiften, Caaute naft. Bilüthen adfelitänıig, bei unjern 2rten gelb.

1595. O. biennis L. Fl, dan. 446. Sr. 4. Etengel etroas gettig,

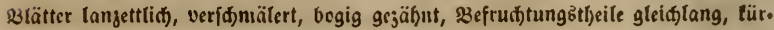
zer als 33lume. - Coll aus \$3irginien im Jabre 1614 nad) Curepa gebrad)t wor.

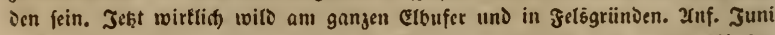

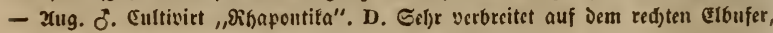

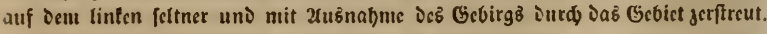

1596. O. muricata L. Murr. Nov. Comın, Gött. VI. t. 1. Fl.

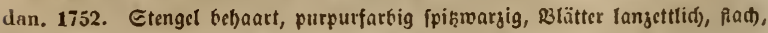
33lumentlätter unigelebrt hersförmig, $\mathrm{n}$ ur fo lang als Etautgcfäfe. Edflanfir 
und fefter, sglätter Durđaus bärtli d) und vodfenimen flad (bei Oe. biennis foblartig reich uns bogig, אänder aufrodrts gebegen), Das ganze Blatt turz

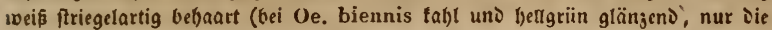
untern unterieits lofer bebaart). Slütbe weit tleiner (bei Oe. biennis soppelt

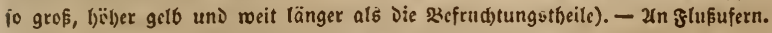

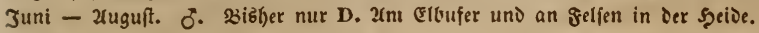

\section{Wpilobium L. Sth ot enmeibrith. Seltffaum regel.} mäfig tlappig 4tbeilig. S3l. 4blättrig. Sapiel lang (iffotenförntig). Saamen

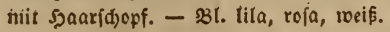

a. Clıaınaeneriun Mхcн. Blume uno Etaubgefäfe regcinıäpig. aa. Tarbe fculenfïrnig.

1597. E. alpinum L. Fl. dan. 322. St. 81. 12. 13. Rснв. Fl. germ. exsicc. n. 1061. Blätter ungetel)rt cirun১, obre länglid) uno langettlid),

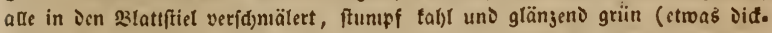
(id)), taum entfernt gejälfnt, Etengel cinfact), stoci zarte Syaarlinien gegeniiber,

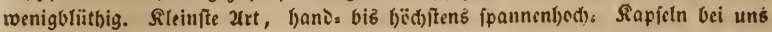

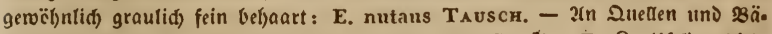

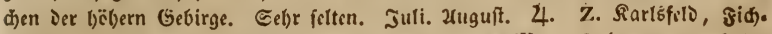
telberg, (Gettesgabe, Flatten). Bok. Wankel. Miiller. Jchanngeorgenftait. Brunner.

1598. E. palustre L. Fl. dan. 1574. Sr. 81. 7. Stengel fitituni,

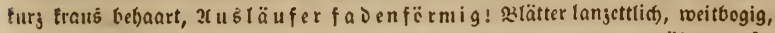
undeutlict) gejäl)nt oder ganzrandig, unten feilfïrmig, untere gegeniiber. - b. hyssopifolium: slättcr linealifa) langettlid), faft gangraniig, Dalfelbe etwas (breitblättriger: Rche. pl. crit. II. ic. 438.439. - pal. turfosun Lasch. nit

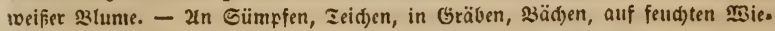
fen. Juli. 2(uguit. 4. Durd) ลas (bebiet bier uns Da nidjt felten.

2r n m. folgende 2 affarie liegen yor mir: roseo $\asymp$ palustre LAsch, montano $\asymp$ palustre LASCH, subpubescenti $\asymp$ palustre LAScH, parvifloro $\asymp$ pahustre HAMPF.

1599. E. tetragonum L. Rснв, pl. crit. II. ic. 340. Fl. germn. exsicc. n. 357. Sт. 81. S. Gtcif aufred)t, rutbenäfrig, S3lätter beltglän.

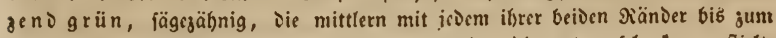

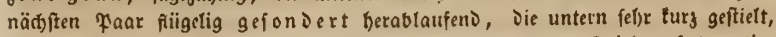
alfo mit geflitgelt $4 \mathrm{fantigem}$ Etengel. 2il. bell lila. Sriebe rofettenartig.

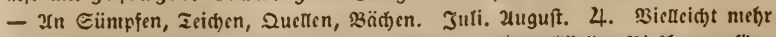

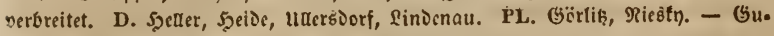
oen, Eprentberg, Eprecmalo, Golifen, Sudfall, Reuzelle.

$x \mathrm{~nm}$. Saftaroc: pubescenti $\asymp$ tetragonum $\mathbf{L A s c r}$, subpubescenti $\asymp$ tetragonum LASCH.

1600, E. obscurum (Chamaeneriun -) Schreb. anno 1771. Rснв. pl. crit. II. ic. 341. Fl. germ. exs, n. 358. virgatun Frrss anno 1828. Sr. 81. 6. Diatt òn telg riin, oben turz graulid bel)aart, von unten 


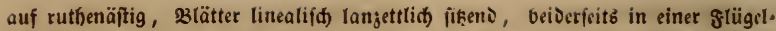
linie berablaufend, weld)e fid) balo vereint. 2rlo von voriger 2rt Durd) Die Dunfle farbe obne Glan; (Dal)er Der game) und Den (nid)t 4riigelig, fondern) 2 flügelig tantigen Etengel und tleine Blïtl)en leidt unteridseisbar, auth) weit mel)r vergiveigt, Dešbalb: virgatun Fr. Iriebe langgeffreft. Die Rarbe fou fpäterlyin 4jpaltig werden, Dod) baben aud Sturm und Koch nut

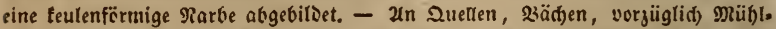

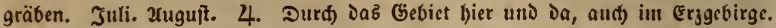

1601. E. roseum Schreb. Rскв, pl. crit. II. ic. 329. Fl, gern. exsicc. n. 359. ST. 81. 9. Stengel abredjfelno 2fantig, Blätter geftielt, länglid), beiberfeitz fpis, ungleiđ) feinfägeran১ig, untere gegenuiber. $1-2^{\prime}$ ober

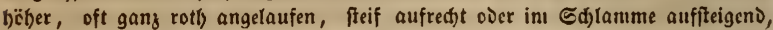
Blätter feft, ru nzelig, Bl. Elein, bla so rofa, faft weiß, mit farminrothen 210ern, giarben fpäter Die Epiben ein wenig gefondert, Dud aufredt! Erfónt faft ganj tabl oder an Den obern zbeilen furz und fein graulid belyaart. - b. unbro-

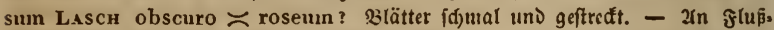

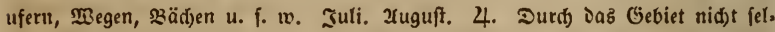
ten, biz ins bobe Gschirge.

\{ $n \mathrm{~m}$. 3aîtarde: fontanum LkJ. (subpalustri $\asymp$ roseum LAsch.), tetragono $\asymp$ roseun RcrB., pubescenti $\asymp$ rosemu LAsch, subpubescenti roseum LAsch.

1602. E. alpestre JAcQ. Rсrв, pl. crit. II. ic. 342. Fl. gernn. exsicc. n. 1757. ST, 81. 10. Steif aufred)t, cinfad), Blätter cirunt (oocr ci, langettlid)), gegeniiber oder meift oreiftä $n$ ১ig, umfaifeno, ungleidffürntig ento

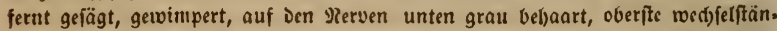
Dig uno fifmäler. $23 i s$ über $2^{\prime}$ bod). - In $2 u e n e n$ in Gebirgen. Juti - Sep: tember. 4. Gebr felten. Z. Unterhalb Der neuen Straße am lobhen fidtelberge vei Doermiefenthal. Rchb. 2. 2ug. 1840.

1603. E, origanifolinm LAM. Rснв, pl, crit. II. ic. 314. Fl.

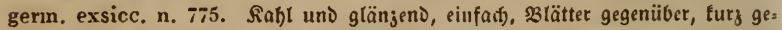
frielt, unterfe ftunipf, iibrige eirund jugefpişt, bogig gezäl)nt. Etengel band. bis

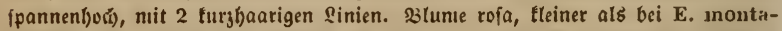

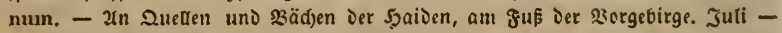
September. 4. Eefre felten. PL. Riešfn. Kölbing Flora 1S42. No. 12. pas.

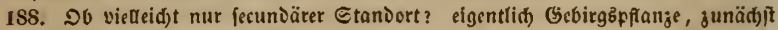
in Den Gudeten, wo idi) es 1817 fammelte.

\section{bb. Narbe 4fpaltig.}

1604. E. persicinum Rснв. Etengel fticlruno, felfr veräffelt, silät. ter geftielt, D ï $n$, jedes beiderfeits in einer Sinie berablaufeno, geptielt, lanzetts

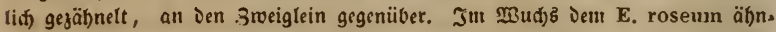
lidb, ađdein Die berublaufenden Sinien find gefoniert, Die Blunte grë̄er, einfarbig

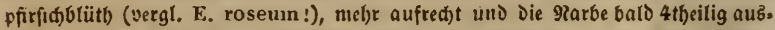
gebreitet. Spannen, biz füflod uno zart. - b. foliosum H. H. bobe fobr bes

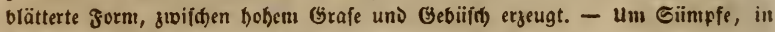

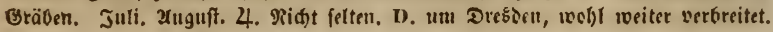


1605. E. montanum L. Rснв, pl. crit. II. ic. 328. Fl. germ.

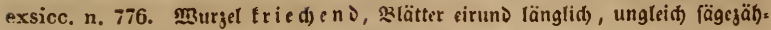
nig, faft tahl, Die untern gegenfä̈ndig uno gefticlt, Etengel ftielrund, fein bes baart. 1 bis üter $2^{\prime}$ bod), 231 . Duntelgrïn glänjend, 231 . Ic(b)aft pfirrfidsblïtb)= rotb. - b. E. collinun Gaf.. Rснв. Fl. germ. exsicc. n. 1893. MBrzel faferig, Etengel aufred)t langäftig, szlätter fel)r gablreid) (tlein, im thmriß faft roie ven Acinos), untre gegenüber, übrige wed)iclitänoig gientid) fitieno, eirund, fägeartig gejäbnt, glänjend uno Diđflid). Jinger, bis fufbed), sat. flein, ticf niffens, rofa. (Gleidjfau Miniaturform ven $\boldsymbol{E}$. inontanun uno eigentlid) nies mals in Daliclbe übergel)end. - In MalDungen, vorjüglid) Der serggegenden, zroifđen Gebüí), Gteinen, an Gelfen. Juli. 2ruguft. 4. Sefreverbreitet. b. 2rn Sü̈geln; Gelfen, Mauern nue in serggegenien. Juli. 2uguft. 4. भidat felten.

1606. E. lanceolatum SEB. MAUR. Fl, veron. t. I. persicino $\asymp$ montanum? Etengel fantenles, słätter lanjettlio) geftredt, bogig fägejät). nig, ade aud) Die cberften wed)felftänذigen geftielt, Blïthenjweiglein un১ Rapfeln grau. Epannenlyod) uno einfad) bis mannshed) uno febr äftig. Die aus̉gegcid). nete Blattform, Die matte Garbe unt Die tleinen Bliithen Des E. persicinum,

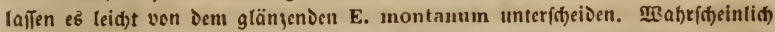
nid)t felten, aber minDer beobadbtet. - 2(n ferudten Drten in \$erggegenDen. Juli. 2tuguft. 4. D. bei Doerau. Rchb.

1607. E, parviflorum Sснвев. St. 81. 5. Diktr. ViII. 572. Rснв. Fl. germ, exsicc. n. 360). 23lätter lanjettlid), geftreftt, fpik, fein ges zäl)nt, Die untern gegeniiber uno furj geftielt, Etengel ftielruno, graulid) weid) bel)aart ober furjjottig. $2-3^{\prime}$ bod), meifît rotb angelaufen. szlunienulätter refa, woal, fpił̧ auछgeferbt. - In Gïnipfen, Gräten. Juti. 2uguft. 4. Durd) Das Gebiet jienulid) verbreitet. D. Mscinbël)la, Niederau, Fianik, Egelfee, Etrchlen,

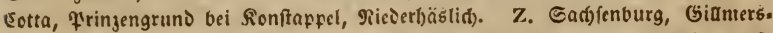

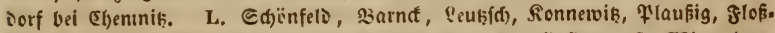

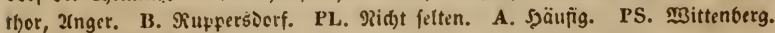
Satue u. f. iv: HS. (Eifenad).

a $\mathrm{nm}$. Baftarde: palustri $\asymp$ pubescens LAscr, intermediun MFRAT (paxviftoro $\asymp$ hirsutum), subtetragono $\asymp$ pubescens LASCH, roseo $\asymp$ pubescens Lasch.

1608. F. hirsutum L. Dretr. VIII. 5i1. Sr. 81. 4. szlätter ges geniiber, unfaffend berablaufeno, länglid) lanjettlid), fägerandig, cucre toedf́fels

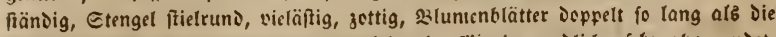
Seld)ab(d)nitte, bell tarninroth), umgetebrt bersförnig rundlid), feb) abgerundet, in Der MRitte fibntal eingef(bnitten, Nagel gelblid). - Biemlid) verbreitet, Den Gtanjort gern to ed) feln $D$, in Gebirge nod) nidit beobadtet. D. Dobna, Briezs.

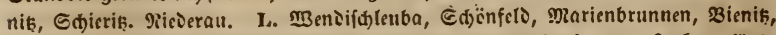

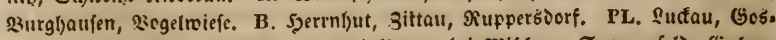

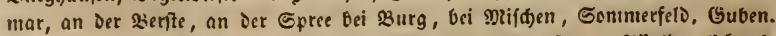

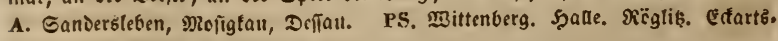
berge. HS. Eifenterg, Eifenad). 


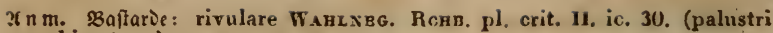
$\asymp$ hirsutum.) -

b. Epilobiun: Slume un` Sefrudytungstbeile unregelmäpig, lestre einfeitig getogen.

1609. F. angustifolium L. Schx, t. 106. Dirtr. VIII. 570. Sx. 81. 3. S3lätter zerftreut, lanjettlid), geaicrt, Blumenblätter ver"ébrt eiruns osal, taum aus̆geterbt, in einem Ragel verfd)mälert, Griffel fpäterbin niçergebo.

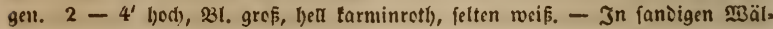

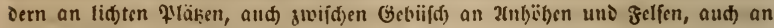
Bäd)en und Fliilien. Juli. 2uguft. 4. 2in gecigneten Etellen ïberall gemein, in Gebirge meift mit Senecio Fuchsii.

518. Circaen L. Şexenfraut. Sildfaum 2tfeilig! Rt. 2 blättrig! Gtrinfrud) birnenförmig, 2fäd)rig, fäd)cr 1faanig. Blïtbe traubig, 81. weiß̄.

1610. C. alpina L. St. 23. Rcrв. Fl. germ. exsicc. n. 77\%. Sabl, Blattitiele fad), bautrandig, Blätter breit eifürmig, tief bergförmig, bogig gejäbnt, Dectblättd)en berftenförnig, słtumenblätter tiiizer als Seld). STeinfte Urt, 2 - $6^{\prime}$ bod), aufiteigent. - In (d)attigen Bergmälocrn, an Bäd)en, 2uel.

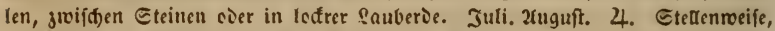

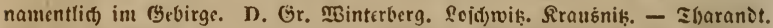

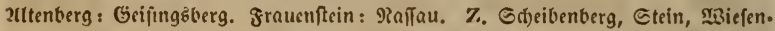

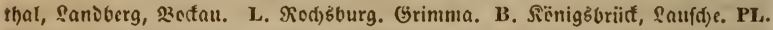
Viešft). - Bornsioerf, Langengraffau, Gebren. A. J̧arjgerode. PS. Mittenberg. Eilenburg: retles 5̧aus. Düben. Gub)l. HS. Jenn: Jenapriesnis, Scisgrunt,

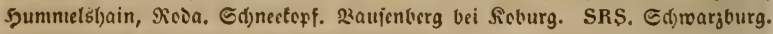

1611. C. intermedia Енян. Fl, dan. 256. Rснв. Fl, germ. ex-

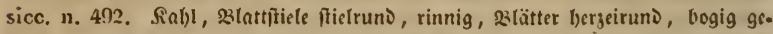
gühnt, Dedulättchen borftenförmig, 33lumenblätter an Der $23 a j t 5$ fpisig, fo lang als Reld). Gejtalt voriger 2art, aber toeit grëfer bis 1'; Gelente verdidt, 231. oft refa angelaufen. - In fidjattigen ミbälern an älbnlidjen Drten. Juli. 2(uguft. 4. -3erftreut Durd) Das Gebiet. D. Picierivartba, Bfíboner Gruno, łlauen. Ute.

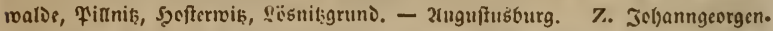

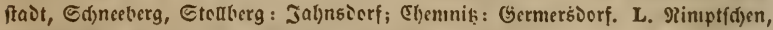

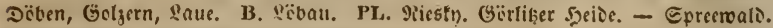

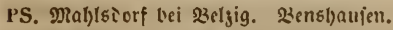

1612. C. Iutetiana L. Fl. dan. 210. Scнк. t. 2. ST, 23. Zsin bebaart, slattfiele ftielruno, etwas rimnig, slätter berzeiruno, bud)tig gejäbnt, Decfolättd)en fel)len, Blumenblätter an ier 23 afis ftumpf, fo lang als Sield). In f(h)attigen feudten Saubiväloern, fowwht in Der Ebene als in Ilyälern. Juli.

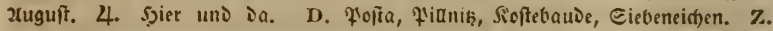

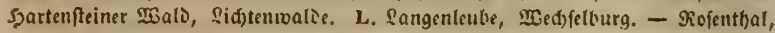
शonne, Streitlyols, Sonnctvih. B. Sottmaršberg bei Scerrnt)ut, Saufd)e. (Eđartsbad,

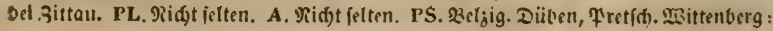


Frobitei, Epecte, Etraube. Şalle: Diestauer Garten, Eđttendif̧. Subl: Dolnmar. HS. Eifenberg. Gleid)berg vei Sioburg. SRS. Ed)warjburg; NGelpersboly bei 2(rnitait.

\title{
Familie Lythrarieae, $\mathfrak{3}$ ciocridhgetwähje.
}

\author{
- Sperbarienbud . S. LXIX uno 172. -
}

519. Elatine $L$. Tånne . Seld $3-4$ theilig. Blumenblättet

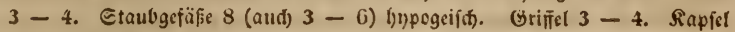
3 - 4fäd)rig, vicliannig. Eaantenträger sentral. Enamen olnne (simeif, meift getrümmt. - Sileine faftolättrige Sräuter, oer Montia nidgt un. äl)nlid), silätter gegenüber, bei leḳter جrrt quirlîtänoig.

1613. E. triandra Sснк, t. 1199. b. Drev, et Harxв t. 71. B. Rснв. Fl. germ. exsicc, n. 11062. 23lïtbon in allen ₹lyeilen 3jäblig, slätter

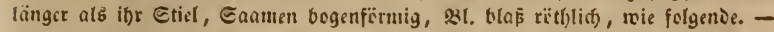

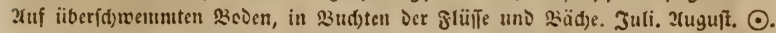

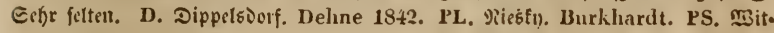
tenberg. Schkihlr. Gutgl vei alloredts el)emalb Metsch.

1614. E. hexandra $D_{\text {E }} C$. Rснв. pl. crit. V. ic. 599. Fl. germ.

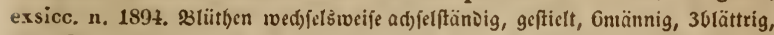

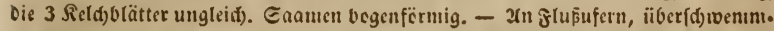

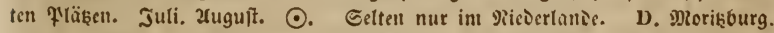

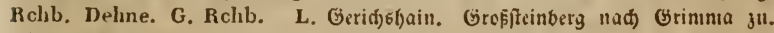
Klett. Richter. Petermann. Caufingt. Miiller. PL. Sitcba, Diengcrsicrf. Burkhardt, -

1615. E. Hydropiper L. Schk, t. 109 a. Drkv, et Haysk t. 71.

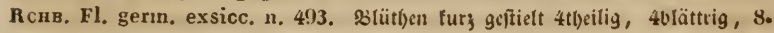
mänuig, B(ätter fpatelfïrmig, Eaamen bufeifenartig jufanmengefrïmmt. - b. Schkuhriana HAYxe. SchK, t. 109 b. (obre E. hydropiper!) Drev. et

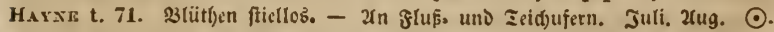

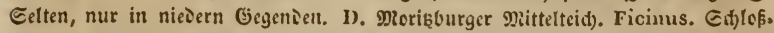
teiđ). Rchb. L. Grimma. Zuteiđ) bei (Geridsblyain. Klett. PL. G̈̈rtiž, Rreba. Burkhardt. - A. Deifau. Schwabe. PS. Mittenberg: 2tngerteid). Schkuhr.

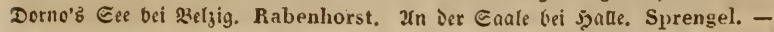
b. Schkuluriana: D. Niale ?ue nad) Fic. Fl. Dresd. L. Qinjenau. Richter. Petermann.

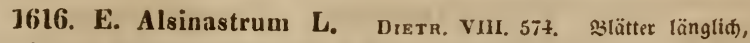

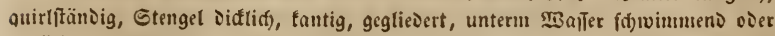

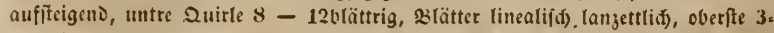
blättrig, if)re 23lätter ciruno. \$2l. grünlid) reeiß, Eaamen gefurd)t, quer gerun.

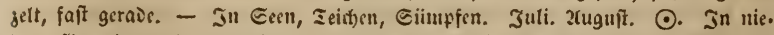
Dern (begenden, nidht gemein. D. Brofivik. Mauke. Mitifidente bei હteinbad

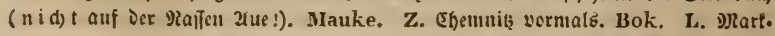

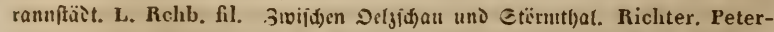

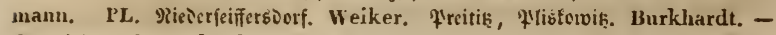
Ed)ivielungoję. Rabenhorst.

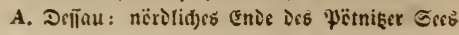


Scliwabe. PS. Mittinverger fađten am Elbufer. Schkuhr. Dbertbau, Ermulib̧, malleniorf. Sprengel.

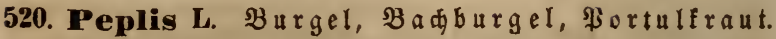
Sield) glotig 12jäl)nig, 6 3ällne türjer juriïgebogen. Slume auf Dem Seld)

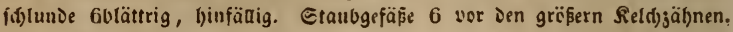
Evifiel turs, garbe tnopffirmig.

1617. P. Portula L. Scrк. t. 99. Sт. 1. B3rätter gegenüber unı

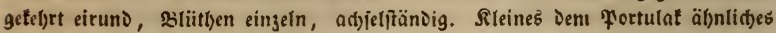
SRraut, 31veige wurzetno. Dieift rotl) angelaufen, 31. weiß. - 2uf unbegrafter feud)ter (Eroe. Juli - Detober. $\odot$. Gemein.

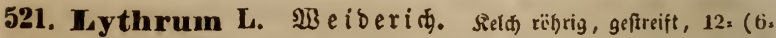

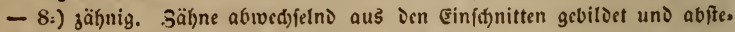
beno, 23r. Gulättrig. Etauligefäß̈e $12(2-6)$. Sapfel 2fäd)rig, vielfaa= nig. - Blumen vlaurotl).

1618. L. Hyssopifolia L. Sснк, t. 12s. Rснв. Fl, germ, ex-

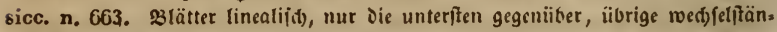

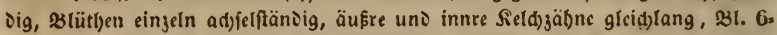

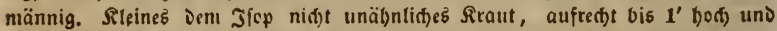
äftig, ooer aud auf ausgotrofnetem Ganobcoen liegeno. - 2uf feudten Xedern,

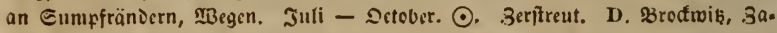

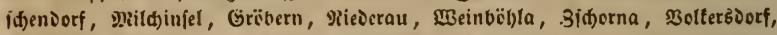
Cberšbad), Piefdjen. L. Bienik, Sileinoëljig, Burghaujen, findentijal, 3weens furth. PL. Mielaune, Sjulithe, Nadibor, Diebfa, Daubik̨, Gee. - Maltersoorf,

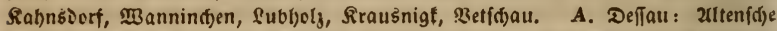

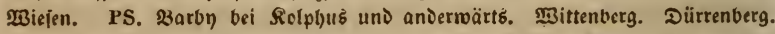
Şalle. SRingleben bei 2rtern. Donnioorf u. a. D. Erfurt: Eteiger, Zue, an Det Gera. HS. Jena nad) Rëtidjau ju. SRS. 2rnftàt.

1619. L. Salicaria L. Schк. t. 128. Haynz Arzneigw. III. 39, 23lätter gegenüber, berjlanjettlid), B(lüthen in enoffänoigen Duirlähren, innere Sield)zät)ne Doppelt fo lang als äufere. $2-4^{\prime}$ over bäh)er, 3toeige aufred)t ab.

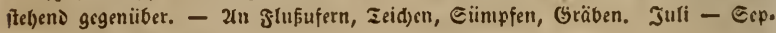
temucr. 4. Gemein.

\section{Fanilie Polygalaceae, Polygalacen.}

- Şrrbarienбu() S. LXX uno 175. -

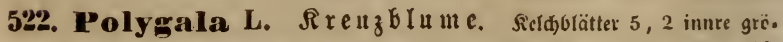
fir, n̂ügclartig (un Dic ganje junge \$liuthe uno grud)t zufanımentlappenoj. Slunic (aus $3-4$ 3lumenblättern verivad)ian) rëbrig 2lippig, Shelm ge. fpaltell, Sippe gefranit ojer gefpalten. Staubgefäfe einbrüDerig vermadjen,

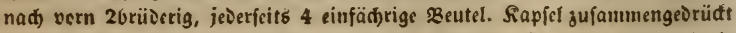
2fäd)rig, Caame in jeiem gad) eingeln, fein behaart, Seimmarje oben, Drcie lappig. 


\section{Polygalaceae. - 359 Polygala.}

a. Polygala : Unterlippe gefranft.

1620. P. uliginosa Rснв, pl. crit. 1, ic, 40. 41. Fl. germ. ex-2vacts

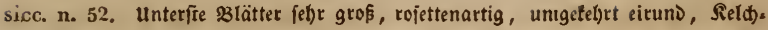

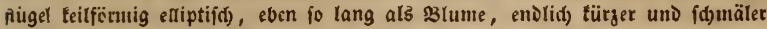

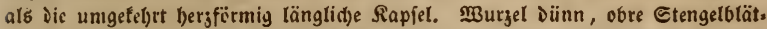

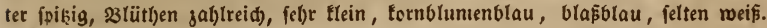

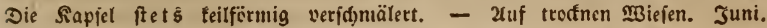
Juli. 4. Serftreut. D. Biebteite nad) Firna angeblid) nad) Fic. Fl. Dresd.

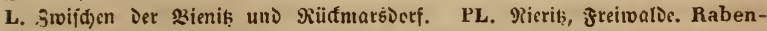
horst. A. Deffau, Moligtau, Berft. Scliwabe. PS. Niaumburg. Scheidhauer. Erfurt. Bernhardi, HS. Großlëbigau. Zenker.

1621. P. amara $J_{A C Q}$, anstr, t. 412. Rснв, pl, crit. 1. ic. 43. 4 .

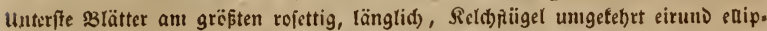

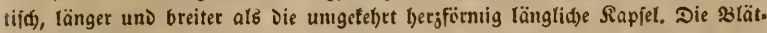

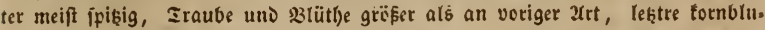

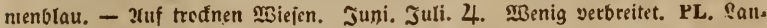
gettgraillau, S̈̈rtftlid) Drebna, Mannindjen, Edjönwalde, Großtubhol;. Raben-

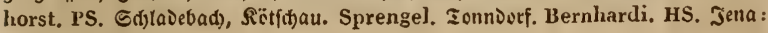
\$B̈̈lntiffe, forft. *)

1622. P. amblyptera Rскв. pl, crit. 1. p. 91. ic. 50. Unterite

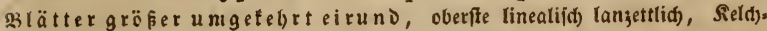

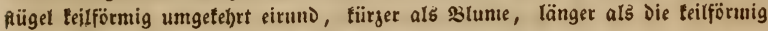
ungetebrt hergförnige etwas breitere Sapfel. Sieldphügel Deutlid) a bgerun. Det und vie $\mathfrak{B}$ lütle fo groß al s Die Dex $\mathbf{P}$. vulgaris, fdän blau. - Zan Saltbergen in Ilyüringen. Juni. Juli. 4. SRS. 2urnjtåt. Lncas.

1623. P. depressa Wenderoth. (serpyllacea Werнe.) Rснв. Fl. germ. exsicc, n. 53. 9tiederliegeno, lang und entfernt getadöffig, Uejtchen fadenförmig, untre 3 lätter oval elliptifd, gegenüber, Die Der Bweige

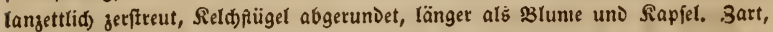

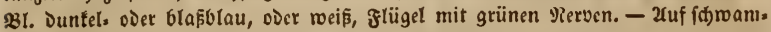

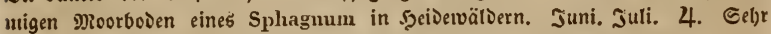
jelten. PS. angeblid) bci હ̈rfurt. Siegentiif. Kunze. HS. Meida binter seid):

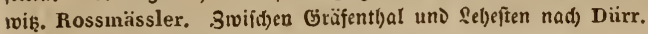

1624. P, vulgaris $L$. Rснв, pl, crit. I. ic. 52. 53. Unterfre 3lätter

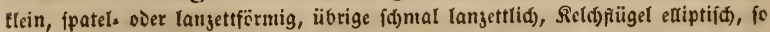

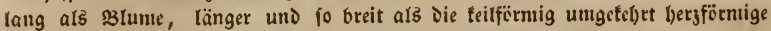

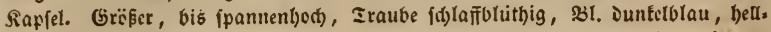
urau, felten weí, an feltenften roja: - b. охурtera Rснв. pl. crit. I. ic. 46

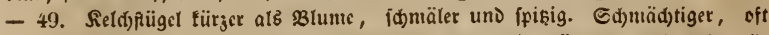
nur bandhod), sal. Duntel = cicr hentlau mit weiß unt griin, oft weiß nit grii=

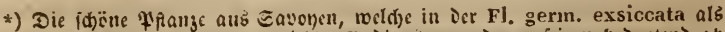
P. annara ausgegeben wourve, weid)t allerdings von Der unjrigen beseuteni ab

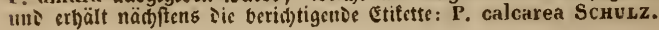




\section{Polygalaceae $\quad 360$ - Polygala.}

nen Merven: r. multicaulis Tsch. felten rofa. - 2uf MBiefen, grafigen Drten in İäldern uno Şciden. Juni. Juli. 4. Siemein.

1625. P. comosa Sснк. t. 194. Rсңв. pl. crit. I. ic. $54-56$.

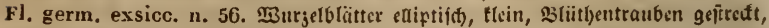
vielblütbig, oberfte Detfblättd)en f(j)pfartig, Eeitennerven Der Relifiügel majdjig geadert. 2(ufiteigeno aufred)t, übcr (panneni)od), ₹raube gebrängt einfeitig, sł. bei unş iumer roja! - 2uf trofenen Biejen, grajigen 2(nl)̈̈ben. Juni. Juti. 4. giid)t fetten Durt) Das Gebict.

b. Chamaebuxus: Unterlippe 4 fpaltig.

1626. P. Chamaebuxus L. JAcQ. anstr, t. 233. St, 13. Rснв. Fl. germ. exsicc. n. 1548. Slein|traudjig, 3lïtljenfitiele ad)fel. uno ensitänoig,

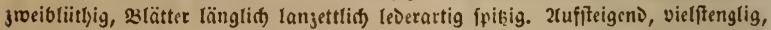

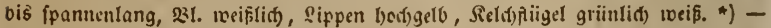

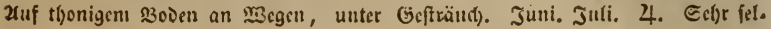
ten; nur ill Boigtlande. Z. - 3wijden seubetba und xiorf angeblid) nadt)

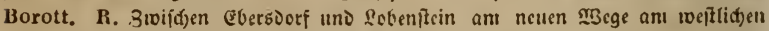

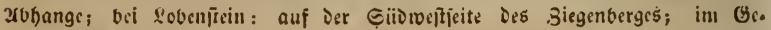
bäge. Hnh.

\section{Fumilie Amygdalacene, S(mygoalacen.}

523. Prunus L. Ririne, Pflaume, Atprifufe. Seld glodig 5ipaltig, ringsum avfpringent. Sil. 5olättrig. Steinfrud)t faftig. Eteinfern nit 2 tielraniigen 9iätl)en.

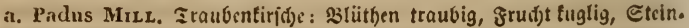
tern foft tuglig.

1627. P. Padus L. Hayar Arzneigew. IV. 40), sziüthentrauben

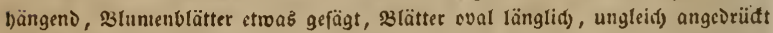
gefïgt, etwos rumgelig, ftautartig, abfallent, furge Blattfiele 2oriifig. Strand)

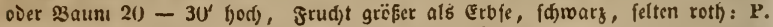
nubra W., over grün: P. chlorocarpos, over veeis: P. leucocarpos. - OPP. Cortex et folia Pruni Padi. - In feud)ten Saubwäliern. 2(pril. Xnf. Mai.

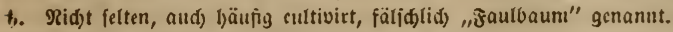

$2 t \| \mathrm{m}$. P. virginiana L., serotina EнRн. und Lauro-Cerasus L., vergl. Fl. gern. 11. 4120 - 4123., toirocu bäufig cultivirt.

b. Cerasus T. Fitrífje: 231. Doldig, frud)t fuglig, glänjento, an iex Safis eingebriidt, Gtcintern bod) gewörivt.

1628. P. Chamaecerasus L. JAc2. ic. 90. Guise. t.61. Dohn

*) Rizbcr nur Diele gärbung bei uns, in Siiden aud) mit fojön rofarotber slume: Fl. germ. exsicc. n. 1685. 
A u y grda laceace $\quad-361-$ Prunus.

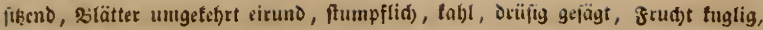

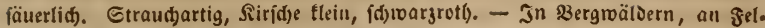
[ell. 2rpril. Mai. b. Eeljr felten. PS. Freiburg givifd)en Der alten uno neuen

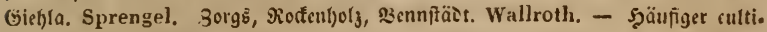
yirt: „Difbeimer Rirf(u)e". -

* 1629. Р. semperflorens Енкн. Siскцев XIV. t. 6. Dolden

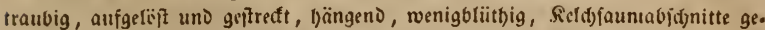

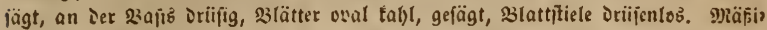
get Baum, fdjlant, aber meift von unten vergıcigt, Jiveige Dïnn rutbenartig.

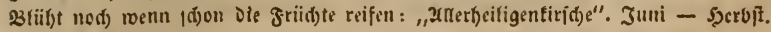
Ђ. In G̈ärten.

* 1630. P. juliana L. s3lätter umgefifyrt eiruno jugcipiķt, jujaumen.

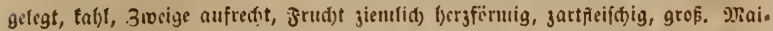
firface: Srck L. II. t. 9. untre Fig. XIII. t. 19. - rotbe Glanjberjtirfde: Sickr, XXII. t. 4. rutbe פiolfentirjd)e XXII. t. 24. - gelbe 5ergfiridje: Sickr.

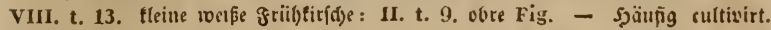
2pril. Maai. t.

* 1631. P. Duracina L. slätter ciruns lang zugefpikt, jufamuten.

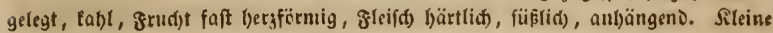

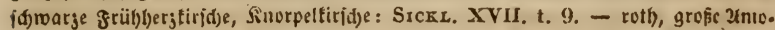
relle: SickL. IV, t. 14. antre vergl. Fl. germ. p. 643. - gelo: punttirte હïßs. firfitfe: Srck, X. t. 19. gelbe Şergtirfd)e. - Şäufig cultivirt. 2łpril. Điai. †.

1632. P. Cerasus L. Haysz Arzneigew. 1V. 42. Guisp. $t .62$. Jnuere Ed)uppen Der 3lütl)entnoह̉pen an Der Epilịe olatttrageno, 3lätter glatt, glänjeno, fpäterbin faft leverartig, Slattfticle oljne Drüjen, \$3แrjel mit 2cusläu.

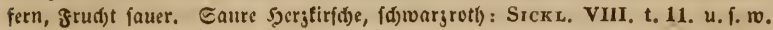
f. Fl. germ. p. 643. - Sileine frïhmoretle, roth) nit blaffem fleifd): Sickx. VIII. t. 11. f, B. - Rid)t felten Durd) Das (jebiet. Freilid) mob)t nid)t ïberad

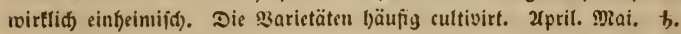

1633. P. avium L. Rert, et ABRE t. 17. KERx, t. 30. 21I! ๔đ)uppen Der 23 (üt)inenfnob̧pen blattlos, Blätter id)wad)runjelig, unterf́eits voeid,

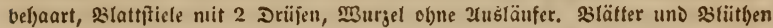
grëperer als bei Den verivaniten Zrten. Sileine \$3alofirid)e, Siogeltirid)e. - Eul. tivirt: tleine fdrbarje runde und lange sogeltirid)e: SrckL. XI. t. 4. - grope

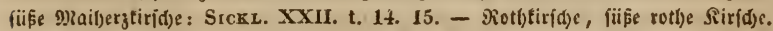
- gitat felten Durd) Das Gebiet, aud) in Der Ebene an Megen. 2upril. Mai. b. جuđ) fchr bäufig cultivirt.

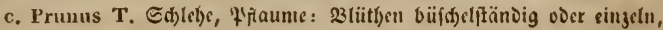
frud)t fuglig over länglid) ofjne cintrut an Der 23afis, bereift, Gtcin. tern minser gemölbt.

1634. P. spinosa L. Schk. t. 132. Hayse Arzngw. 1V. 44. Sinoz.

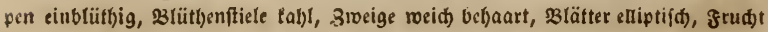

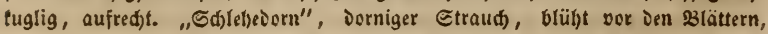
Brüd)te (d)wargblau, blau bereift, reifen im Spätberbft und fdoneden gufammen. 
jielfeno. - b. serotina, Fl. germ. pag. 64t. (fruticans Wвгн.) Rснв. Fl.

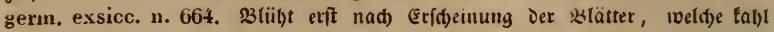

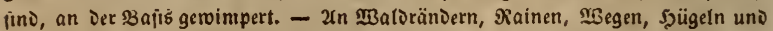

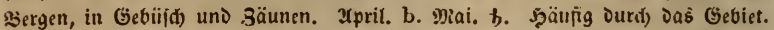

1635. P. insititia L. Gurmp. t. 65. Snospen 26lüthig, 3tütl)enftiele เveid) bel)aart, 3tweige tal)l, 33lätter ediptif(́), Grriid)te länglid) tugelig überbän.

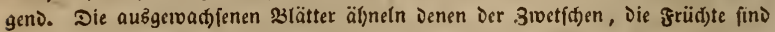

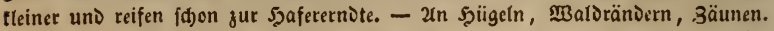
Zpril. Mai. b. פicht gentein. D. Rotta. G. Rchb. Plauen, Totid)appel. Fic.

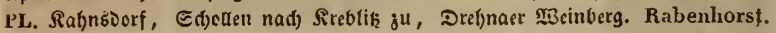

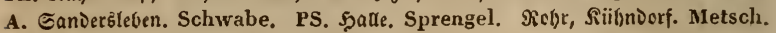
SRS. Yrnftaot. Nicolai.

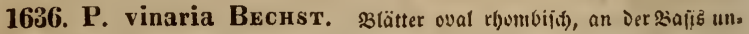

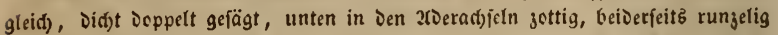
und belsaart, 2 liitl)enftiele paarig ober ju oreien, lang uno talsl, Reldjaumab. fd)nitte gewoimpert, etrab orüfig, 3lumtenblätter runolid), friid)te fuglig, gerieft.

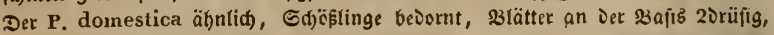
cine Drüfe ain Etiel, \$lütt)e groß wie Sirfd)blütbe, Stiele $2 \int_{3}$.3oll lang, frud)t etroas tleiner als Saberpiaume, rüthlid) marntoritt, blau bereift, jeitig uno füß. - In Doftgärten, Gebägen Der Dörfer in इlüiringen. Beclzstein. 2rpril. Maa. b:

1637. P. Brignola L. slätter lang geffielt, oval, Drüịg gefägt, oben glängeno, tal)l, unten jottig, junge 3reige uno Die paarigen oder eingelnen 23 (ü̈

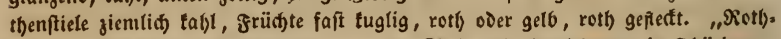

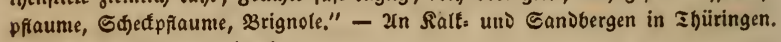
Beclistein. Ipril. Maai. b.

1638. P. Cereola L. slätter eirun১ längtiđ), an Der safỉ 2irüīig,

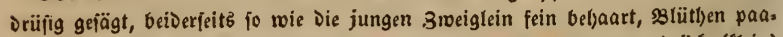
rig, Reldhe etwas bel)aart, früđ)te längliđt) oval, etıas jufammengebrüđt (tkin) gelb. "Der gelbe Epilling" Srcks. VIII, t. 18. - Zuf Raltbergen in Ibii, ringen. Bechstein, 2lprif. Mai. b. Dajelbit aud bäufig in Grasgärten cultivirt.

* 1639. P. domestica L. \$3lütbentnozpen groeiblïtbig, şü̈tbenftiele

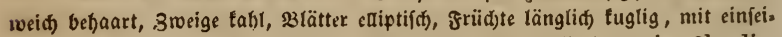

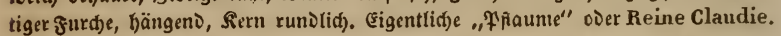
a. blau: Srck . XV. t. 19. 2c. - groffrühtig, roth); rothe cyprifd)e (sierpflaume: Srckl. VII. t. 10. - c. grün: II, t. 13. X. t. 15. - d. gelb: Xprifofen. piaume: SrckL. XVI. t. 11. vergl. Fl. gern. p. 645. - 2ub Dem Driente. यpril. Mai. †. \$̧äufig cultinirt uno verwildert.

- 1640. P. damascena L. szlütbenjtiele meiłz einjeln, salätter oval

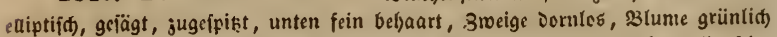

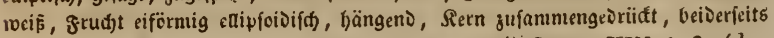
fpisig. - a. Blau bereift: "Deutíd)e blaue 3roetid)e" Srcke. XIII. t. 3. (domestica :) Hayse Arzmeigew. IV. 43. Gurmp. t. 64. - b. rotbe türtifd)e

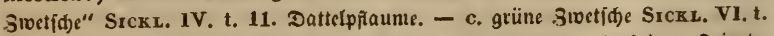

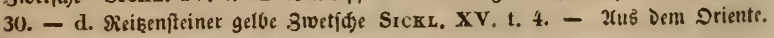
3pril. פaai. Ђ. Şäuñg cultivirt. 
d. Armeniaca, Aprifoje: Slïtlfe eimgeln, faht fticllos, frud)t fajt fug. lig, untin singeoriuct, firjig.

- 1641. P. dasycarpa Енкн. Silïthe ieutliff gễielt, siläter ciruno

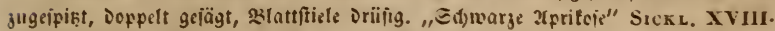

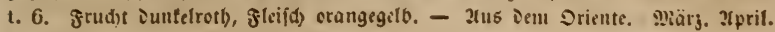
b. Eultivirt.

* 1642. P. Amarella L. slütheniticle singeidilenten, siättir oval,

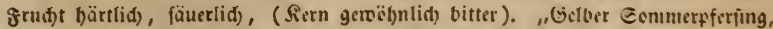
Macreden, 2(morellen." Frudt tlein, ed)ergetb oìr rëtblid). - 2tus Dem Eüien Europas. Märı. 3tpril. b. Euttivirt.

* 1643. P. Armeniaca L. siliutlentiticte eingeidfletion, siätcer faft

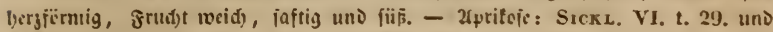

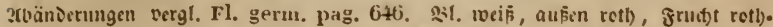
gelb, met)r ober tocniger roth angelaufan, Etcintitn an beisen viätl)en gefurd)t.

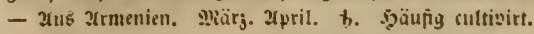

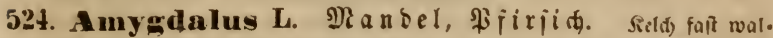
jig coer glođig 5ipaltig, ringsum abipringent. Silume 5blättrig. Etcinfrud)t meî̉ pitżig. Etcintern grubig eingectrüđt. - sl. rofa.

a. Auygdalus T. Sianiel. Eteinfrudt faftles lederartig.

1644. A. nana L. Bot. Mag. 161. Rerb, Fl. genn, exsicc. n.

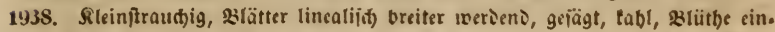

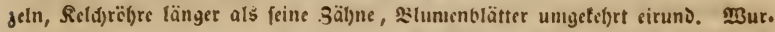
jel tricdent, Siscige 1 - 2' bot). - In Eiiiungarn und Deftreit). 2(prit. Mrai. b. Eingebürgert. SRS. Ed)ladtberg bei frantinbaujen, Hornung.

* 1645. A. communis L. Hayxz Arzngew. IV. 39. Rснв. Fl.

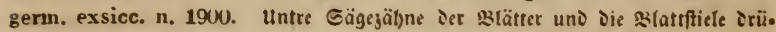

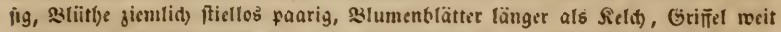
länger als innre Etautfä̈en, Stcinterne febr bart. - $2 \mathrm{~m}$ füDfidgen Siterale. aprit. Mai. わ. Cuttivitt.

b. Persica T. Finjūt). Eteinfudtr jaftig Hei(j)ig.

- 1646. A. Persica L. Harxe Arzneigew. IV. 38. situtter tan.

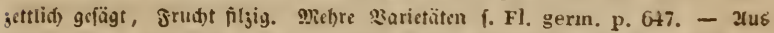
cem Driente. 3pril. Mani. h. Syäung cultivirt und in meinbergen serwiberns.

* 1647. A. Nucipersica C. Bavh. slätter lanzettlid), cinfud) ge.

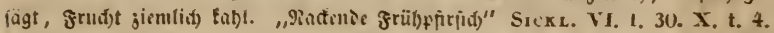

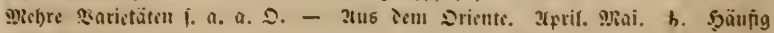
cultixirt. 


\section{T I A I A A N T H A E. $\mathbb{A}$ เ a f f e o e $r$ S $t$ i e - Birgl. 5̧erbarienbud 5. LXX111 min 178. - \\ Fumilie Tetradynamae §ieuzblüthlex. \\ - Şerbarienbud 5. LXXIII uno 178. -}

A. Synclistae, frudtt nifit aufipringent.

525. Neslia Desvaux. Negli e. Seld offen. R2lumentätter

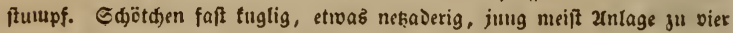
Saamen, Dann 2jaamig, reif Lfaamig, Eotylesonen quer: $011 .-$ Blume fattgelb. -

1648. N. paniculata Desv. Rcrs, Deutschl, Fl. 266bito. 4291. Fl. germ. exsicc. n. 673. Mुurgel Dünn, Etengel ipannen, bis über fuffod),

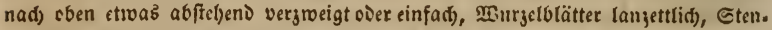

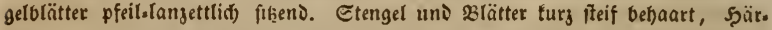
(b) 2, und 3theilig. 23liitben flein dolDentraubig, frudttrauben lang, Etieldjen 3 - 4 Mal to lang als Die tleine grud)t. - 2ruf Xettern unter Gaat unD Ģe. müfen, bäufiget in niesern \$erggegenden, in Sand. uno Raltboden. Nai 3uli - Şerbit. $\odot$. In Den meiften Gegenden gemein.

526. Isatis L. शु̉a í. Ficld) ofien. Edjëtden (büngeno,) länglida,

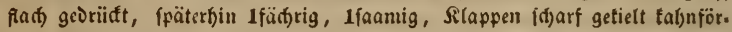
mig, nidjt oder faum abfpringend. Saame bängend, Eotnlesonen guer: $0 / 1$. - Blunie gelb. -

1649. I. tiuctoria L. Trautv. t. II, f. 17. *) (praecox:) Rchr. Deutschl. Fl. 2t6bils. 4178. Sdjötónen teilförmig, länglid), 3 Mal fo lany als breit, abgerundet oder ausgeterbt, tafl, fdfwarg weroenD. Murgel bis tleinfingers.

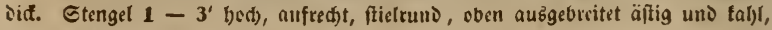

*) Radjoent wir nun enolids cine längft nothwentig gecrefene Moncgrapbic Dicfer Siattung befiben: Thavrvatras de Sameraria et Isatide, fo folge id ieren 23 eptimumungen. 
unten abitebend behaart. Blätter toblartig weiø, bläuliđ grün, untre länglich im Blattftiel ablaufeno, obre ffeilslanjettlic), umfalfend, nur an ber 2 Bajis ge. zäbnt, Blüthen tlein, zarttraubig, riōpig. - 2rn jandigen und taltigen flufufern, Sü̈geln uno ̧eljen. Mai. Juni. $\delta$. Selten. D. 2rm Elbufer unbeftändig, im

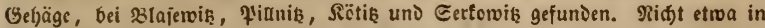

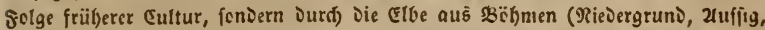

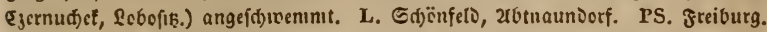
Mälle Erfurts. HS. Şausberg, Jiegenhain น. f. w. bci Jena. Eifenberg.

1650. I. praecox Kiт. Trautv, t. I. f. 12. Rснв, Dentschl. Fl.

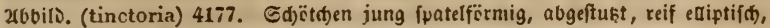
nur joveimal fo lang als breit, 33afis ftumpf, Epiß̨e geftușt, abgeruniet, faum

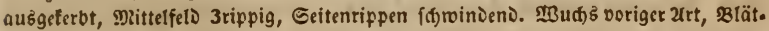
ter alle breiter. - 2un gleid)en Drten wie vorige. Mai. Juni. $\delta$. Gtanjorte nod) sen voriger zu foniern.

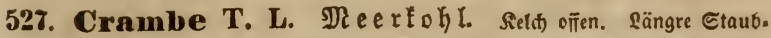

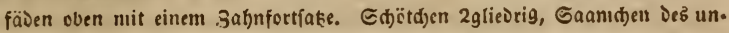
teren Gilicics vertïmmert, Daffelbe wiro Dann ftielartig, Das obere fuglig, einfaamig. Eotyleionen gefaltet: $O \gg$. -3 tunie ve if. -

* 1651. C. maritima L. Rcrв. Dentschl. Fl. 216bilts. 4164. 33lätter runolid), mellenrandig uno aus̈gebud)tet gejäbnt, fo wie Derfteife fingerdide Sten.

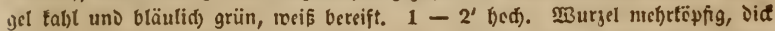

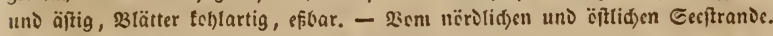
शai. Juni. 4. Eultivirt.

528. Rapistrum BовRн. $\Re a p$ b b

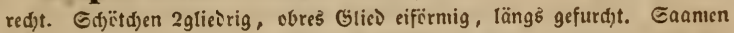
cingeln, im cbern Ğliede aufred)t, in untern bängend, Cotılèonen gefaltet: O $\gg$. - silume gelb. -

1652. R. perenne ALI. Rсвв. Deutschl. Fl, 26b6ils. 4170. 3rocige fât ausgefpreigt, obres frud)tglies eifïrmig, furggrif̄elig, unterfte 8 lätter id)rot. \{ägeförmig, bogig ectig gejäl)nt, cberîte tinealijơ). 1-3' hod). Eteif bel)aart, §ru(t)tgrocige rutbenförntig verlängert. - Bejon๖ers auf Raltboden, an Şügeln,

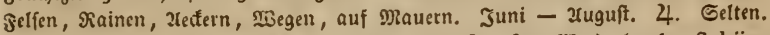
In Il)üringen und 2nbalt. A. Sanderšleben. Schwabe. Merierljaufen. Schön-

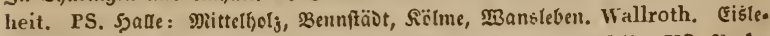
ben. Edtartsberge. Rodig. Dürrenberg, Marfiverben, \$ెeifenfelb. HS. Berfa. Zenker. Etcttinbeini. Bernhardi. SRS. Jrantenl)aufen. Hornung.

1653. R. rugosum ALr. Rснв. Deutschl. Fl. 2r66ils. 4168. 3tweige aufred)t abftelsens, beide frud)tglieder gefurd)t, behaart, Griffel länger als Jab obere Glies, slätter leierfërnig uno tuglig, ftumipf, bcgig gejäbnt. 1 - 2' hoß̣.

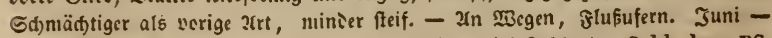
3uguif. 4. Gebr felten. D? 1761 am Elbufer bei Sofdrois. Schkulir. PS. Eđartżterge. Rodig. 


\section{Raphanistrum $T$. Gakrt. Rriebelrettig.} Feld) aufred)t. Glieierid)ote gefd)nabelt, reif perlf(bnurfërmig, Glieber ge. furd)t und abipringeno. Edjeiderwand in Der jungen Sd)ote ned fidtbar,

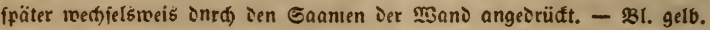

1654. R. arvense ALL, Rснв. Deutschl. Fl, 2obilt. 4172. Fl.

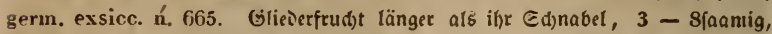

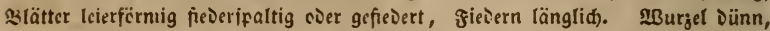
Etengel $1-2$ ' l)ed), freif bebaart roie Die unteren \$lätter. \$2l. gelb. - b. venosuun, Rснв. Fl. germ, exsicc. n. 666 . sBl. grëßer, vlaß̧ odjergelb, 2loern violet. - 2uf 2edern. Juni - Eeptember. ○. Gemein.

530. Taphanus $L_{,} \Re$ et $t i g$. Reld aufredt, Gliederídote (d)roanınig aufgetrieben ofgne äufertid) fid)tbare Gelente, gar nid)t aufiprin. geni. - BI. lita cier weis.

1655. R. sativus L. Rснв, Deutschl, Fl, 2abilt. 4175. ஐBurgel birnenförntig oier Diđ fpindelförmig, gefd)wängt, Etengel aufredit $2-4^{\prime}$ bod,

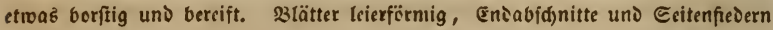
herzfërmig, îtumipf gejä̈hnt, eben meniger gefièert und ganz. 3weige fef)r auf.

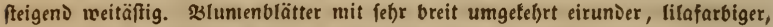
geaderter Flatte. Saame idgrwärylid) braun, d)agrinartig. 2rbänorrungen : $f(d)$ ro a to

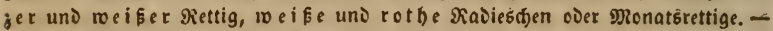
Gebaut uno vertvilDert. Juli. Xuguft. $\delta$.

\section{B. Amphischistae, હdütţen uno @date beiberjeits aufîpringent.}

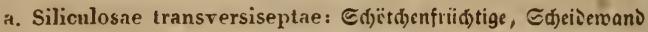
(d)mal, quer.

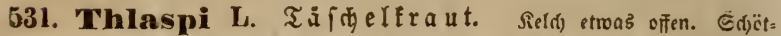
d)er: verîad)t, aug̈geterbt, fllappen tabnfërnnig, mit \&lügelfaum. - Blume mels. Cotylcionen faralat: $0=$.

1656. T. arvense L. Rсnв, Deutschl, Fl, 2ubiro. 4181. Etengci.

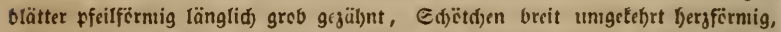
faft treistuno, Eaame ringartig gefurd)t. 1' ober hëher, einfach oder aufred)t äftig. Caamen in jeiem gad) neift 6. Ueppig geroadfen riedt tie t'range wie Sinobtaud). - 2uf 2refern, bebautem sioien überbaupt, Ed)utt uno פauern. april - Sherbft. $\odot$. Semein.

1657. ' $\Gamma$. perfoliatum L. Rcrr. Deutschl. Fl. 26bild, 4183. Fl. gern, exsicc. n. 362. \$3urjelblätter fpatelförmig, Etengelblätter pfeilshersförs, mig, Caamen glatt, fein neşartig. Murget bünn, Stengel $1 \int_{2}-1^{\prime}$ hod), meif von unten an wed)feterweife lange sweige, ganj bläulid) griin, aud) roth ange.

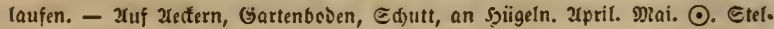

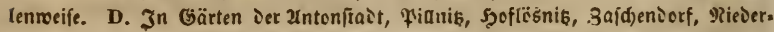
fahre. Soffebanie. Z. Salfgrün. Bok. I. Grimmia. PL. Strefla. Blase. 


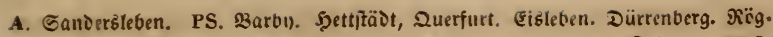

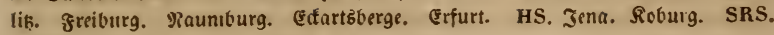
grantenbaujen.

1658. T. alpestre L. Rснв. Dentschl. Fl. 2r6bilo. 4184. Fl. g. exsicc. n. 363. \$3urjelblätter fpatelförnig, Etengelblätter herzförmig, ganjran. Dig, Etengel mefrä̈blig, einfad), Ctaubgefäfe fo lang over länger als slunten. blätter, Seutel violet, ๔d)ëtd)en unigefel)rt hergfërnig, fähber 4-6. (ielten 78.) faantig, Grifiel fel)r furg, flügelfaum oben etroa fo breit als Rlappe. $\mathbb{B}_{\text {Burget }}$

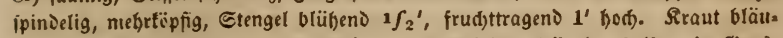

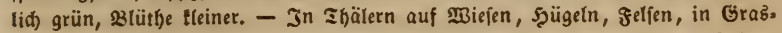

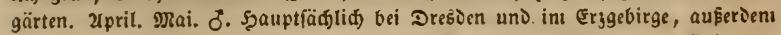
felten. D. giidt felten Surd) Die ganje frudtbate Gegeno. Z. Gemein. L. Grimma: Şohnfä̀t u. f. w. Soldiç. A. Deîau, Gieglişer 3erg, 2btei. PS. Barby. Sjalle: Şornburg und Sittidgenbađ). Sibra. Eilenburg. SRS. SBlantenturg. R. 33urgt.

1659. T. montanum L. Rснв, Deutschl. Fl, 266ils.4157. Mur,

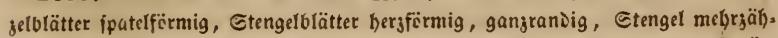

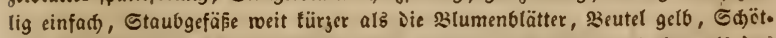

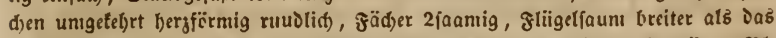
g̊đ), etwas breiter als ১ie Griffellänge. Sd)lanfer, ntinier fteif uno grüner, $\mathfrak{B l}$.

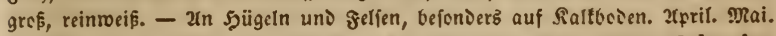

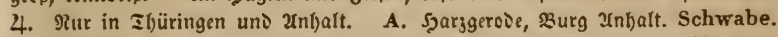
PS. Sreiburg an Єd)lop̄berge, शaunıburg. Miiller. Beneken. Scheidhauer.

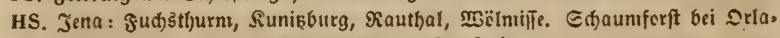
mïnde. Schönheit. SRS. SBlanfenburg. Schönheit.

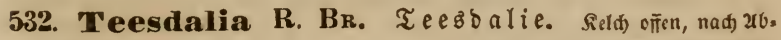

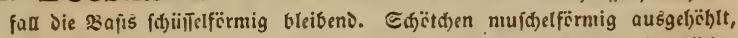

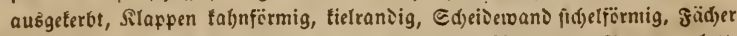
2jaamig. Sï̈rgere Ctaubfäben an Der 2 a jis init säppđen. Sannten glatt. (Eoty)lesonen farallet: $0=-$ slume reis.

1660. T. nudicaulis R, BR. Rснв. Deutschl, Fl. 266ils, 4189.

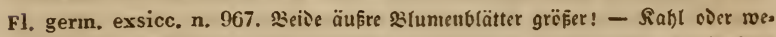
nig bel)aart, Dunfelgrün. $\mathfrak{Z}$ urgelblätter rofettig, erjête fpatelförmig, Die übrigen meift leierfïruig ficberipaltig, ๔d)aft aufred)t $2-4^{\prime \prime}$ bod, Seitenfääfte aufftei,

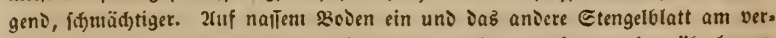
äftelten Єdaft. - 2uf Saniboden in Speiten, 2refern, naftem $300 \mathrm{en}$ überbauft.

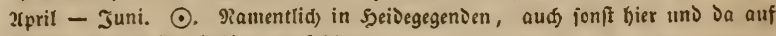
2ecfern, fóseint in Gebirge ju fel)len.

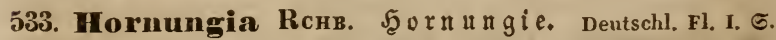

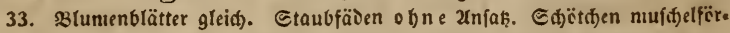

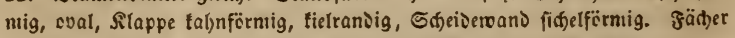
2faanig. 3lume toeißs. Saame glatt. Cotyleionen parallel: $0=$.

1661. H. petraea Rснв. Deutschl. Fl. 266bilo. 4190 . Fl. germ. 


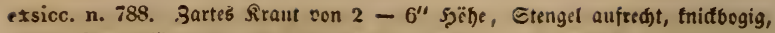

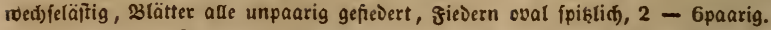

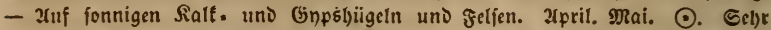
felten. A. Diuloenftein, Merberlyaujen, Güften. Schwabe. xtšleben. Sprengel.

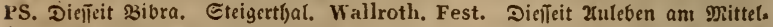
berge. Wallroth. Etcinbađ bci (ङäartsberge. Rodig. Gerbfäbt. Sprengel. SRS. grantenhaujen. Hornung.

534. Hberis L. S๙্le ifenblume. Seld) offen, beioe äufre

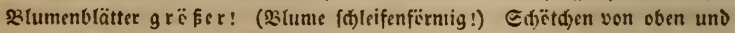

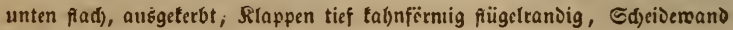
fajicf, fä̈)er ljaanig.

1662. I. amara L. Rснв. Deutschl. Fl. 266bits. 4197. glätter naw

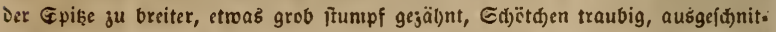

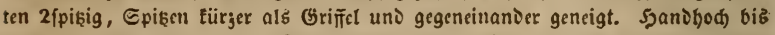

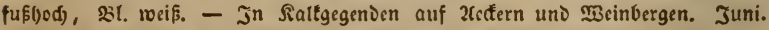

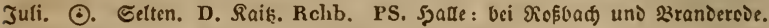
Sprengel. Bei Eitenburg. Binder.

* 1663. I. umbellata L. Rснв. Deutschl, Fl, 266ilo. 4194. Fl. germ. exsicc. n. 195\%. Etengelblätter lanjettlid), meift ganjranذig, Sdjötđjen

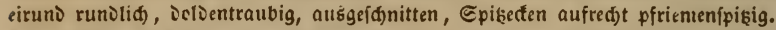

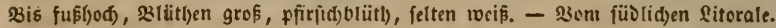

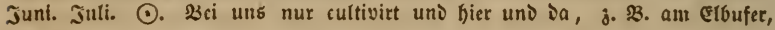
verwildert.

535. Biscutella L. Briflenf ote. Edätden fiad) (brit. (enförmig!), Fäd)er meift treisrumo, cinfaanig, an Der Bafts abjptin. geno, Edeidewano finealiff), geraie. Saame rad), glatt, Eotyledonen pris rattel: $0=$. slume gelb.

1664. B. laevigata L. Rсnв. pl, crit. vil. ic. 837. Deutschl, Fl. abbilo. 4203. Fl. germ, exsicc. n. 4203. 2uşauerno, Slätter länglid fpa. telförmig, grob fägcjäbnig, geffriegelt fteif bel)aart, etengel faft blattlos, (d) $(a \bar{\pi}$.

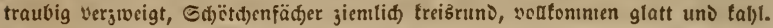

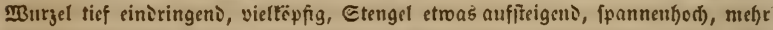

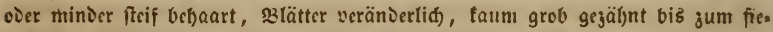
Derfpaltigen, Sontmerblätter roeit grëßst. Frud)t erft fd)ën maigrün, enolid,

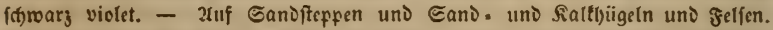

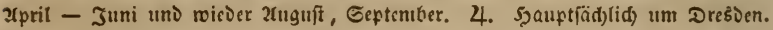

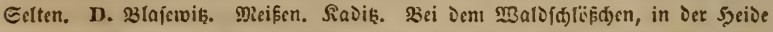
an Dradenberge. A. Deīau, 3erbit. Schwabe. PS. Barb! bei Göoniţ. firc̈n.

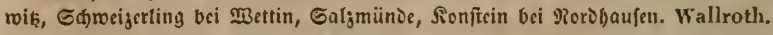

536. Capsella Vext. Scirtentäidgel. Edjötden ungetefrt

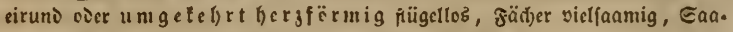
men glatt, (Coty)[coenen quer: 011 . - 23tume rociß̄.

1665. C. procumbens (Lepid. - Lxx.. ) Rсrs. Dentschl. 
FI. 210b. 4221. Fl. germ. exsicc. n. 791. 2uffiteigen๖, fpäter auşgebreitet, fa. ienfërntig verzreigt, 3 lätter alle geftielt, 3 - 5lappig fieverfpaltig, ganzran১ig,

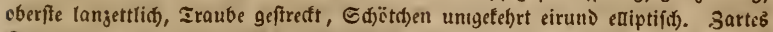

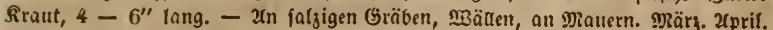
○. Selten. A. Sernourg zroiften ien 2rtemifien. John, PS. Staffurt. John.

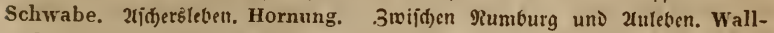
roth. SRS. Franfenfjaufen: bei Der Spitalfirdje u. f. w. Hornung. Richter. Klett.

1666. C. Bursa pastoris Mмсн. Rснв. Deutschl. Fl. 266bild.

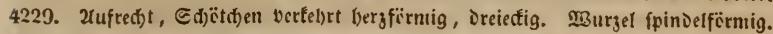
Etengel $1-2^{\prime}$ (jod), einfad) oder abitebeno langäftig, szlätter ounfelgrïn, we.

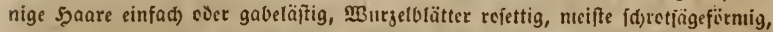
Stengelblätter ninder geipalten, pfcilfïruig, frudtitiele fait horizontal, Sdjët. đ)en 20 - 24jaaınig. - Slattforn veränذerlid), b. integrifolia : 33lätter alte ganjrandig, vergl. 2lobilo. linťs. Micnftrojität: C. apetala Opız. Bluntenblät.

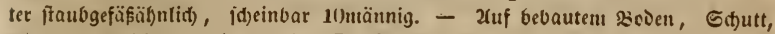

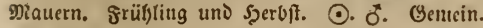

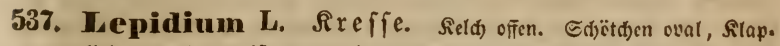
pentiel nad) oben meif̂t etwas piügelartig, fä̈her 1 fanntig, Gaanten glatt. Eot)ledonen quer: $011 .-33$ lume reí.

1667. L. ruderale L. Rcri, Dentschl, Fl, 26bild, 4215. 3mei.

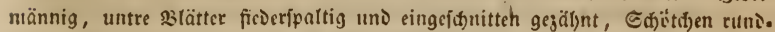

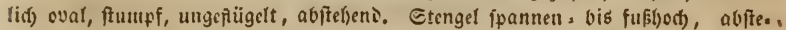
bend vieläftig, zrudjttrauben fel)r ver(ängert ftecif rutlyenartig. sil. febr tlein. Ulebcl.

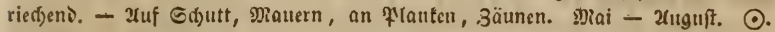
Gentein.

1668. L. sativum L. Rснв. Deutschl. Fl. Wovild, 4212. B(ütl)en

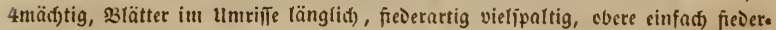

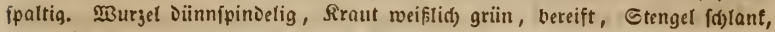

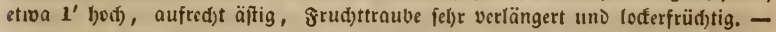

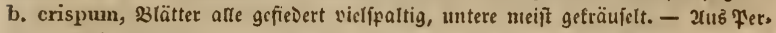
fıen. Mai - Juli. $\odot$. Jn Gärten bäufig cultivirt: "জartentrtsłe", auf be. bautem 300 en und Edyutt verwiroerno.

1669. L. campestre R. BR. Rснв. Deutschl. Fl. આ66ird. 4214. Blätter länglid), untere bud)tig, leier = unঠ id)retfägeförmis, cbere pfeilförmig

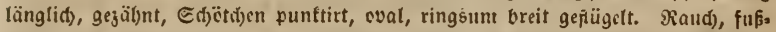

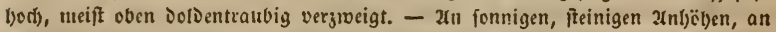

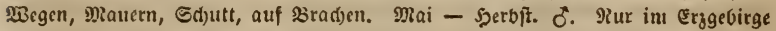
und Der Docrlaujif feltett, auferiem gentein.

538. Cardaria Desvaux. Earbarie. Slume ofien, meif.

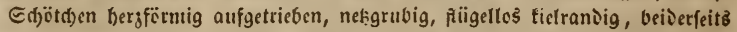

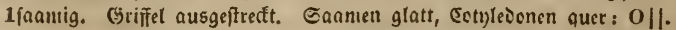

16jo. C. Draba Desv. Renв, Dentschl, Fl, atofiro. 4211. Fl. 


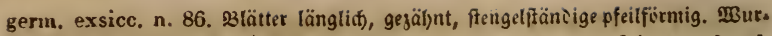
jel biz fingerside, tief einbringend, vielfëpfig, Stengel $1-1 \int_{2}^{\prime}$, etras auf-

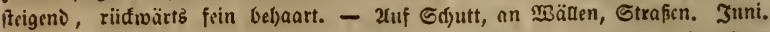
Juli. ટ. 4. Gelten. D. Sicr Den Dobnaifden Cdjlage auf uno an Dex Dro.

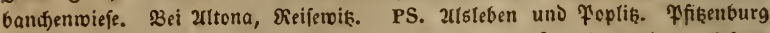
bei (iziorf am Bege nad) Manśleben, nad) Sprengel verf(f)runoen. Exfurt. Buddensieg. HS. Ponifentyanc. Buddensieg. SRS. Yrnftadt. Schönlreit.

539. Senebiera Porr. Senebiére. Sietd) ofen. ๔đät. Ђ̆enfäd)er beide baudjig, netigrubig, einfaamig, an ier Ed)eidemano eingezo.

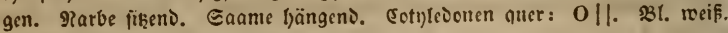

1671. S. Coronopus Porr. Rchs. Deutschl, Fl. W66ild. 4210.

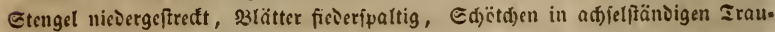
ben, zadenrandig. હpannen= bis fuslang, fef)r äftig, cier vertünmert und furz. 2Ried)t freifenartig. - 2uf bebautem, betretenent 3oven, Gdjutt, an Galinen.

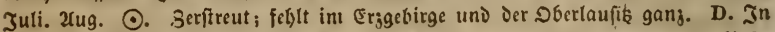

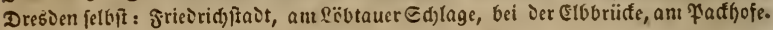

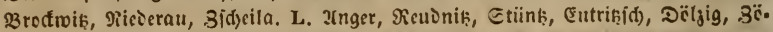

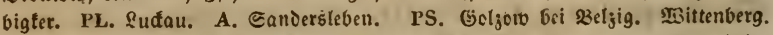

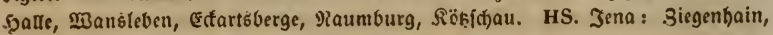

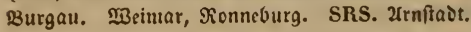

b. Siliculosae paralleliseptae, Sdjütţen tragenic: Sdgeiterwano breit, Den Slappen parallel.

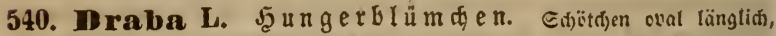
etwar gewïlbt, fäd)er melbraamig, Saamen obue Şautfaum. Eotylebonen paraucl : $\mathrm{O}=$. - \&l. เฉeī̄.

a. Erophila DE C. Blumenblätter cingeterbt.

1672. D. verna L. Rснв. Deutschl. Fl. X6birt. 4234. Murgelblätter refettig langettlid) fpatelförnig, gangranoig ooer wenigjäßnig. S(j)aft blühenঠ

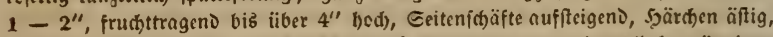
Sd)ötd)en längliơ) oval. - b. Krockeri Axprz, ınjre figur lints, ïppiger, vreitulättriger, S(j)̈̈td)en (d)mäler lanjettlid). - 2uf 2tedfern, bebautem soven, Sanomüften, Şügeln. Mär

b. Draba : \&lumenblätter ganj.

1673. D. muralis L. Rспв, Dentschl, Fl. 犭๖6ilo. 4235. Fl, germ. exsicc. n. 1275. Einjäbrig, 巨tengetblätter cirund jägezäl)nig, 23lumenblätter (weif), umgetebrt cirun১ längliđ). Dünn, bis (pannenlyod), cinfad) òer lang.

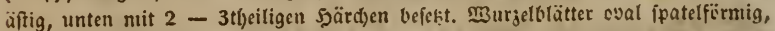

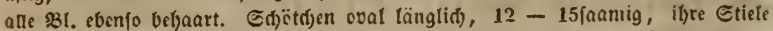

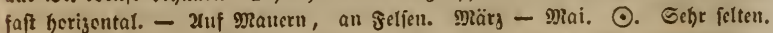
A. Defau in orn Gaalbergen, Gernrobe. Seliwabe. PS. Imtsgartenfelien in Giebidbentein. SRS. Silantenturg. Zenker. 
If $\mathrm{nm}$. Subularia aquatica $20 b$. 4232. nad) Schwabe Fl. Anhalt. A. Def.

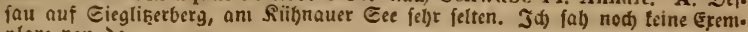
flare son ba.

\section{Alyssum L. Steinfraut. Reld an Der 3afis gleid.} SRlumenblätter cingeferbt. Etaubfäben an ier Bapis mit j̧autfaum cier ein

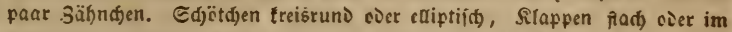
Mittelfeloe gewölbt. Eaamen in jeذcm Fadje $2-4$, rad), meijî hautran.

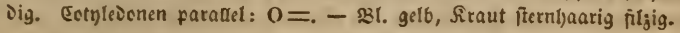

a. Adyseton Scop. Sängere હtaubfä̀en mit Şauträniern, fïrgere mit cin paar jal)n. sDer plïgelartigen 2nfäb̨en.

1674. A. calycinum L. Rснв, Deutschl, Fl, 2r66ild, 4269. Fl. genn. exsicc. n. 2077. 2uffï̌igeno, frautartig, nur iie türjeren Etautgefäß̨e

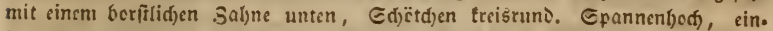

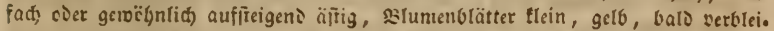

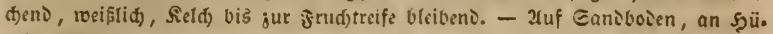

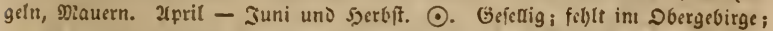

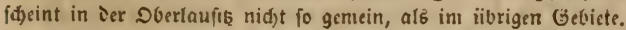

1685. A. montanum L. Rснв, Deutschl. Fl. 2066. 4274. Fl. g.

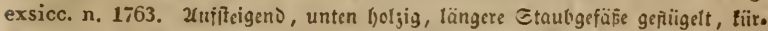

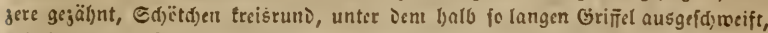
\$31. bodgetb, firaut weisgraul. - b. arenicola (arenariun Gss. nidjt aber Lors.) grëGer, iđflaர̄er, grïner, untre silätter brciter fpatelfïrmig, sil. matter

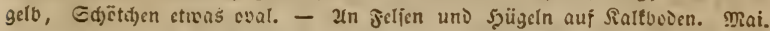

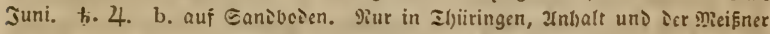

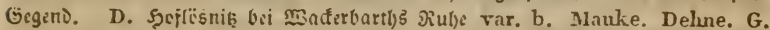
Rchb. Safdeniorf. Mlauke. Cämșlik am etbufit. Fic. Fl. Dresd. A. 23al.

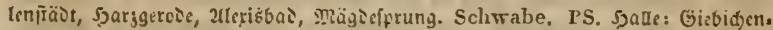
ftein, finter Eberfyaros Garten, Misttin. Fiferta. Miuller. Exțmedenburg bei Erfurt. Bernhardi. HS. Jına: Şaušberg. (ifenad). Dietrich. SRS. franten. baufen. Hornung. Klett. 3unfrait. Nicolai.

b. Anodontea DE C. Sürzere Staubgefäfe nur mit tleinen Drüjigen żnüäken.

16\%6. A. saxatile I. Rсвв. Dentschl, Fl. 2(66its, 42S0). Fl. germ.

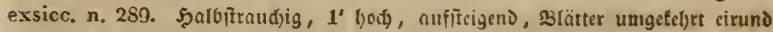

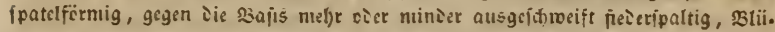

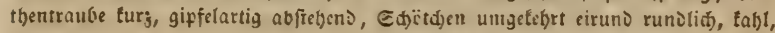
(Srificl $1 \int_{6}-1 \int_{+}$iolang, Eaamen hautrandig, in jeien gad)e 2. Blumen. blätter feid)t alšgeidjnitten, Tebrjaft bod)gelb. Siraut grau. - 2(n Jelfen und

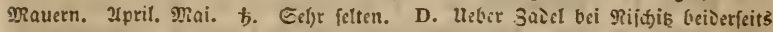

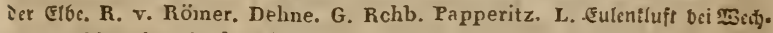
felburg feit Dürr. Groh. Klett.

542. Werteroa Dz C. B̧e $\mathrm{t}$ t e ro auftecht. Blumenblätter paarig beifamıntn, Flatte 2ipaltig. Sürzere Єtaub.

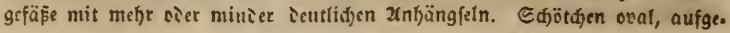




\section{Tetradynamae. $\quad-372-\quad$ Berterea.}

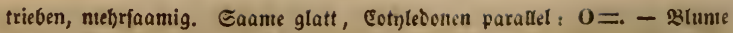
wei $\beta$, Fraut fernbaarig fitgig.

1677. B. incana Dk C. Rcв8. Deutschl, Fl, 2ubils. 4287. Fl. germ. exsicc. n. 1381. Etengel, 2 tätter un১ 巨đütđ̆en graufiłzig, lek̦tre ellip,

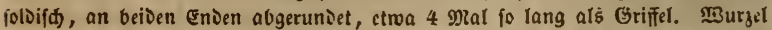
zäbe, einfa(t) over wenigäftig, Etengel aufredft, $1-11 \int_{2}^{\prime}$ bod), Seitenftengel auffeigend, frudtgrweige abftebeno, Saamen in jeiem fad) $6-8$, bei Der Sieife ftumtpfrandig. - Xuf Eanvobien, an IBegen, Felorainen, Siigeln, fteinigeu

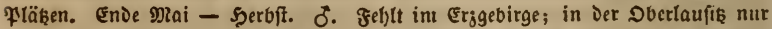

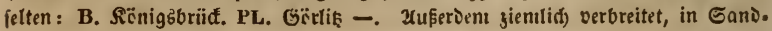
gegenien meift febr gemein.

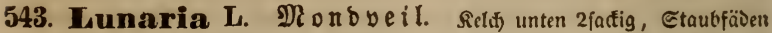

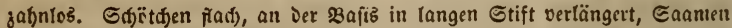
bautrandig, an langem Strang, glatt, Sotyleicnen parallel: $O=-$ slunte lila.

1678. L. rediviva L. Rcrв, Dentschl. Fl. 2366ils. 4290. Fl. g.

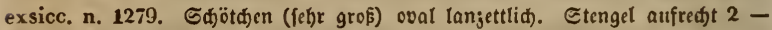
4' hod), (d)lant und (d)wanteno, oben etwas äftig, fein behaart, \$aare abroärts, Blätter alle geftielt, groß, bersfirmig lang zugefpist, oberfte unten eiruno bis teilförnig, atle gefägt, Bähne Der Bafiß tiefer, atle gewintpert, jejer nit Diđer,

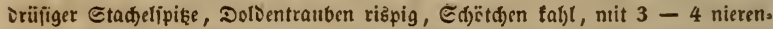

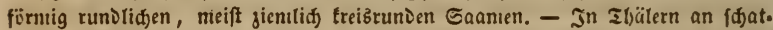

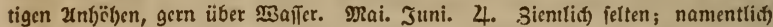

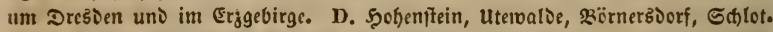

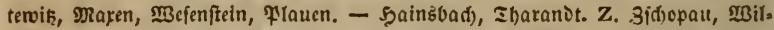

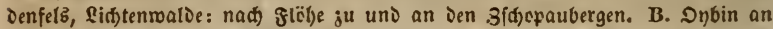

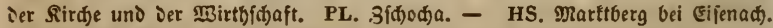
Ehentals am Sd)neefopf, fcit mebrern Jabren gäuglid auşgerottet. R. SBurg! ant Seinridffein.

In n. L. biennis Mxсн. Rснв. Deutschl. Fl. 2rbbiro. 4289. nit feifent

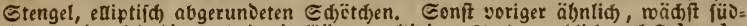
lid)er uno wiro bier uno ia in Gärten cultivirt. Jud angeblid nad Scliwabe

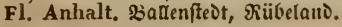

544. Cochlearia L. Löfielf $\mathfrak{a} a$ t. Seld ofien. Blumen, blätter nit umgefebrt eirunder Flatte. Etaubfäben jabnloz, gerabe. Sdjöts कen runolid, fapt fuglig, Flappen mit mittelrippe. Saamen raud getërs. nelt, Cotnlesonen paratel: $\mathrm{O}=$.

* 1679. C. officinalis L. Rснв, Deutschl. Fl. a66ito. 4260). Fl. gerın, exsicc. n. 1452. W3urz̧etblätter lang geffitelt, runoliç, ftengclftänoige

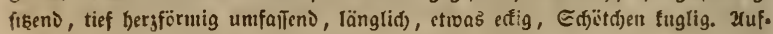

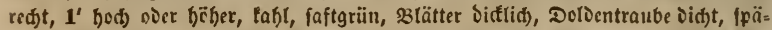
ter lange lodire frudtttraubc. Opp. Hb. Cocldeariae recens. - $\mathfrak{I m}$ Eee,

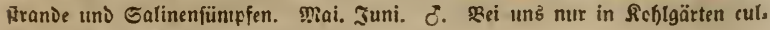
tivitt unt serwitoert. 
Tetradynamae. $\quad-373$ - $\quad$ Armoracia.

545. Armoracia Rupr. Neerrettig. Seld oficn. ङđät. ()en runolid, Slappen bod) getoölbt, faft balbluglig, obne Plittelrippe. Etaubfäben zaljnlos, gerade, Eaame punttirt, Eotyledcuen paradel: $O=$.

1680. A. Rivini Rupr. Fl. Jen. p. 67. (Cochl. Arm. L.) Rснв. Deutsclil. Fl. abbilo. 4262. \$3urjelblätter eirund oval länglid), einge. fđjnitten ftumpf gezäl)nt, Stengelolätter fiederfpaltig, oberfte langettlid), ganj, ranoig. MB Burgel über fustang, walgig. Etmgel $2-4^{\prime}$ bod, Sroeige rutben.

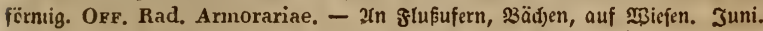

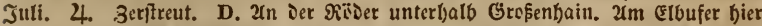
uno Da, namentlid) nad) s3̈̈buten ju. - Sauenftein angeblid). L. Sorna. $\mathfrak{U}_{11}$

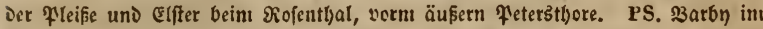
Elbıerder. Nißittenberg. Şalle. Eišleben. Raumburg. HS. Jena: auf ier

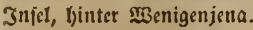

546. Camelina Crantz. Dötter. Sield aufredt. S3lumen.

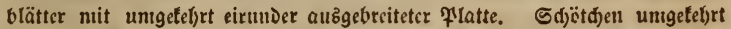
eirun১ birnenförnig, fielranbig, Slappen baudjig, nit gortfak ant Griffel binablaufeno. fä̈d)er vielfaamig, Saamen länglid) ungefäunt. 31 . getb.

1681. C. microcarpa Axprz. Rснв. Deutscll. Fl. 2obiro. 4293. F1. germ. exsicc. n. 1382. Stengelblätter gangrandig, pfeil.langettlid, , fo wie Die gange Pranje Dunfel graugrïn und fart bebaart, Sdjötden breit gefäuut, auf Der untern Şälfte Der Rlappenuitte nit Ripfe, Slappenfortfäßse länger als Der balbe Griffel. 2 bi

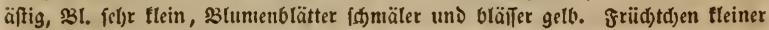

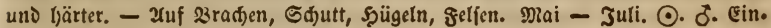
gige urfprïnglid) wilde 2 rt! serftreut.

1682. C. sativa Crantz. Rснв. Deutschl, Fl, 4292. Stengelblät. ter jiemilid) gangranDig, faft Ealsl, pfeilalangettlid), Gdjöttjen auf Der אlappen.

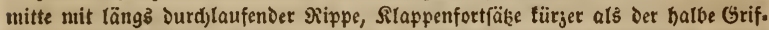
fel. - Mabrid)einliđ aus iem Drient. Xuf Xefern, bäufig gebaut. Mlai. Juni. Sieift im Juli. $\odot$. TRidt felten verwilbert.

1683. C. dentata Pass. Rcrв. Deutschl. Fl. આøbils. 4294. Blät. ter länglid) bud)tig ftuniff gejälynt oder fiederfpaltig, an Der $\$ 3$ afis breiter uno

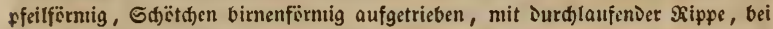

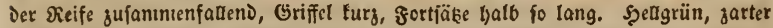
und weidjer, grudt und Eaante Doppelt fo groß , 3lume wie bei C. sativa. -

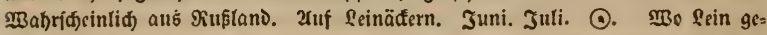
baut mirt.

c. Siliquosae: Edjoten tragenic.

547. Arabis L. (S) ånfefraut. Sidd) aufredt. Sdete linea, lifळ, Rlappen nit Mittelrippe (aud) veräftelt uno mit Seiteurippen). Saa.

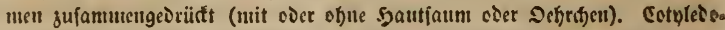
nen paratlel: $\mathrm{O}=$. 231. meift ixcif. 
1684. A. arenosa Scop. Rснв, Deutschl, Fl, 4322. Fl. germ. exsicc. n, 1484. 3meijälrig, vieläjtig einfad) raud)baarig, ßBurzelblätter rojet.

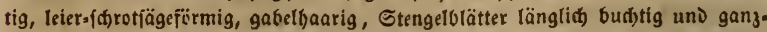

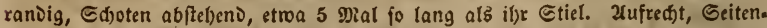

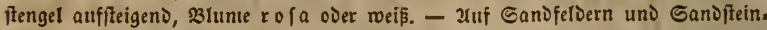
fetten, aud) an Ratebergen. Mai. September. O๋. Gemein nur in Der jädfï. fden Єdweiz, auferdent felten. D. Durd) Die ganze fädfiffde Edfweiz an నua.

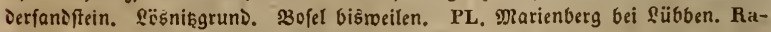

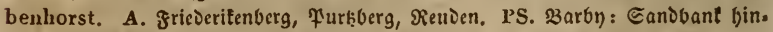
ter Dent Elbwerder. Domberg bei Suft. Mietsch. R. 33urgf. Diirr.

1685. A. Crantziana Енвн. Rснв. Deutschl. Fl. 2r6bilo. 4323.

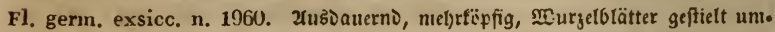
getehrt eiruno ober ediptifo fpatelfürmig, aud leierförmig fipißedig fiecerfpaltig, tabl ooer gabelbaarig, Etengelblätter lanjettlid) fpatelfërnig und faft linealijd) ftumpflid, , fabt, Sdjoten abitebeno, f(j) fdilant, 31. weif, felten rofa. - 2in Ralffeljen. Xpril. Mai. 4. Sehr felten. A. Mägdefprung. Schwabe. PS. Etemipeda in Der Grafictaft Stonberg. Wallroth.

1686. A. Halleri L. Rcre. Deutschl, Fl, arovito, 4326. Fl. germ.

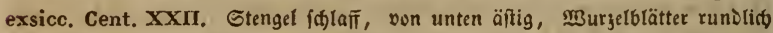

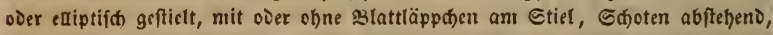
(Durd) Die Saanten) wulffig, Der Dïnne Griffel fo lang ats Die 3 reite Der einner.

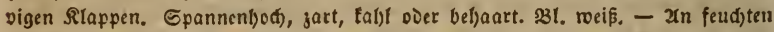

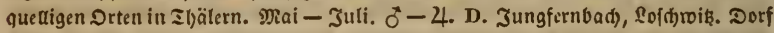

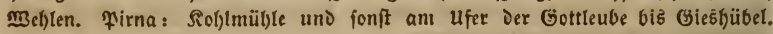
SReinl)arosgrinınta. Dresoen : in pringlid) Jobannfden Garten. Flauen. - Ila. ranot, freiberg. Z. Im Dbergebirge gentein; bäufig an Der æauloe biß Stein,

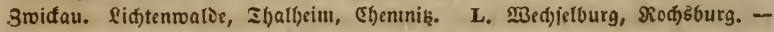

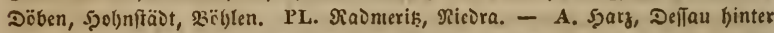

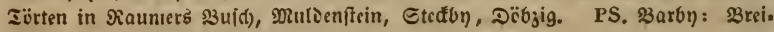
tentjagen. 23itterfeto nad) 2 agulyn ju. R. siurgt.

1687. A. brassicaeformis Walle. R снв, Deutschl. Fl. x6ь. 4333. Fl. germ. exsicc. $n$. 790. Siahl, graugriin, $\mathbb{B} u r$ relblätter rundlid) fpa. telf̈̈rmig, Etengetblätter ticf unıfaffeno, ber

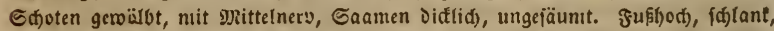
einfađ). S3lätter denen von Bupleur. longifoliunn älyntid). Blumenblätter läng.

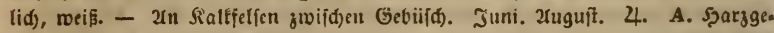
roie. Schwabe. PS. Ed)men, sibra. Un Rraumburg, nantentlidi) auf Dem

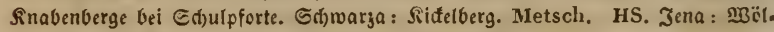

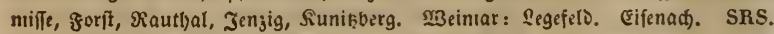
Eoniersilfaufen: Etraußberg. Wallroth. R. Burgt.

1688. A. auriculata Lам. Rснв, Dentschl. Fl, 2666ild. 4334. Fl. germ. exsicc. n. 1281. (Einjälyrig, äpizig, fteif behaart, M̉urzelblätter länglid) f́atelförmig, Etengelolätter tief herjfïrmig, fängliø), Edjoten abftebent, etroas 
gemëlbt, linealifa), Rarbe auf fobr turzem, Difin Grifd, Eaame längliđ́) faum.

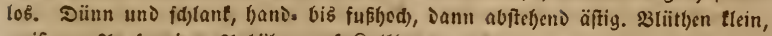

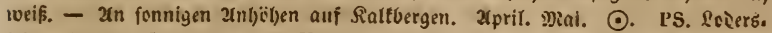
leben. Sprengel. Juleben. Wallroth. HS. Jena : anf Dem Flatcau mitten auf

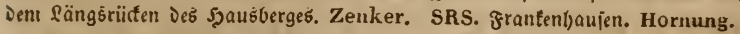

1689. A. hirsuta Scor. Rchв. Dentschl. Fl. 206ilo. 4342. Fl. gern, exsicc. n. 1961. S5aare ant aufred)ten, einfa(t)en Etenget abftebend, ein. fad), Etengelblätter gë̈l)rt, länglid), fo wie die Del)rdjen etroas abftebeno, Edjo. ten platt, felfr f(t)mal, mit vorragendem Siel, Eaamen unpunftirt, unten berun febr fein faumbäutig. C(f)laut, $1-11 \int_{2}^{\prime}$ beds, Iuntelgriin, oft violet angelau. fon. SBlütle giemlid) tlein. Blumenblätter länglid) linealifid in Den geagel ver.

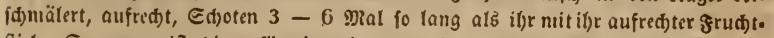
ftiel. Ename meift virnenfïrmig, oer spautjaum verliert fid) gegen iie $\mathbb{B} a f t s$

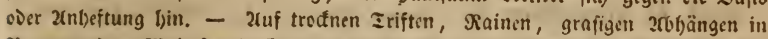
Serggegenden. Diai. Juni. J. Jn Den Iaufiken: B. Dybin. PL. Mefir oder wes niger bäuịg. Rabenhorst. Zū̄erien $A$. felten.

1690. A. planisiliqua ('Pers.) Rснв. Dentschl. Fl. 2666. 4343.

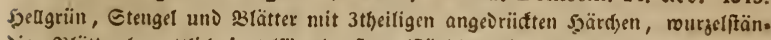

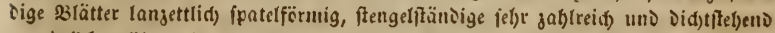

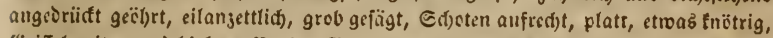
(Sriffel mit r unoli d)er Rarbs, Saanten runolid), punttirt, ftfmal faunbäutig. S(f)nurgerabe über fuphbod), Edjoten etroa 5 Mial fo lang als if)raufredter Stiel.

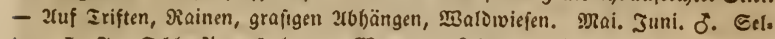

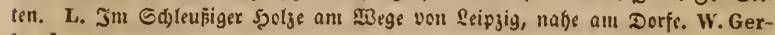
hard. Jm Sicientljale. Petermann.

1691. A. glastifolia Rснв, Deutschl. Fl, 26biro, 43+3. c. tab. XLIII. Gattgrïn, glänjent, wenig veljaart, Şaare einfad) und tïrjere gabel. artig, N3urjelblätter lanjettliç ipatelförnig, entfernt uno gleid) gefägt, Etengel.

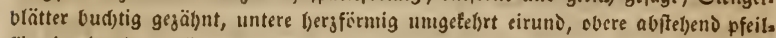
förmig, berjlanjettlid), Gdjote aufrid)t, fed)r fidnnal uno lang, faî 4jeitig, garbe 2lappig, Gaame längliog, faumlos, an ber Gpise mit cinem Dlorfortfab̧e. Ueber fusbod), fel)r fdiant, 3 lumenblätter tlein, fel)e f(d)mal, Griffel gicmlid) fo lang

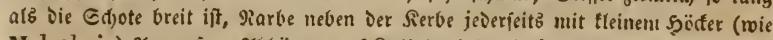

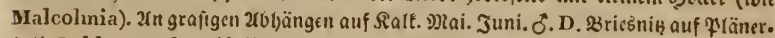
talt, Rchb. - A. longifolia Wallr.? PS. Eteintlippe, 2ulebent. SRS. Etraufuerg.

\section{Turritis Dink. L. Thurmfraut. Sield) idglafi auf.} recht. Sdjote 4 tantig, platteitig. Saame 2reibig, Ectylejonen paradal: $0=$ - Bl. wisip.

1692. T. glabra L. Пснв. Dentschl. Fl. x6biro. $43+6$. Etengel uno Eđboten ffeif aufred)t, \$lätter pfeilfërmig, wurzeljtändige bud)tig gegäl)nt

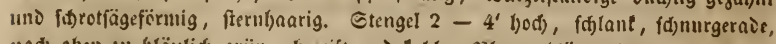
nad) oben ju bläulid) griin, bereift uno talls, s3lumenblätter fdinnal, aufred)t, Saamen faft eiförmig, ungefäunt. - 2u grafigen, fteinigen, felfigen, fonnigen

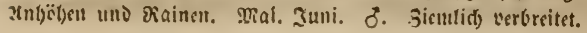


Tetradynamae. $\quad-376-\quad$ Cardamiue.

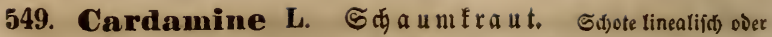
nad) beiden Enden verfdniälert, Slappen ziemulid) rippenlos. Saamen ein. reil)ig. Cotılesonen parallel: $O=$ - Blume weis over rofa. \$3lätter ge. fievert!

1693. C. parviflora L. Rchв. Dentschl. Fl. 2(boirb. 4301. Fl. g. exsicc. n. 1071. Einjär)rig, slätțigen $5-$ Spaarig, (anjettlid) uno linealifd, garizrandig. Zart, bano = bis fpannent)ed), fattgrün, Stengel etwas tniebogig,

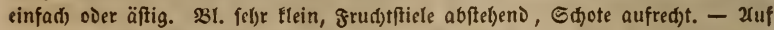

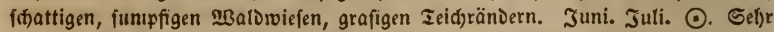
felten; nur in PL. Guben, Epremberg. Ruff. Rabenhorst. Reuzelle. Fischer. Gaffen. Hellwig. PS. Barby) : über Pöberił nady Jđen gu. Scholler Suppl. Schkuhr.

1694. C. Impatiens L. Rснв. Dentschl, Fl, 2abbilo. 4302. Bä̈tt.

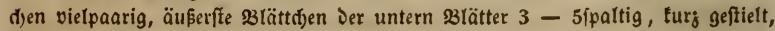
Die obern ganz oder am Ș̦interrande gejäl)nt, B̉lattfitiele nit pfeilförmigen Del)r.

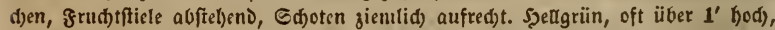
Dann vieläftig, 33l. flein, oft Blunte blattlos (vergl. Die untere Єeitenfigur), Die 6 Staubfäben faft gleid)lang. - Im Sdjatten feudjter Saubwäloer, aud an

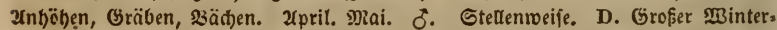

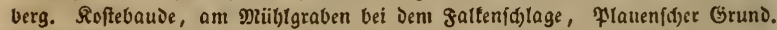

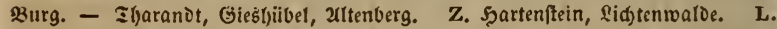

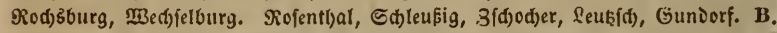
\&aufde. PL. Zränte. - Reuzelle, Guben, Gorfte, Sommerfelo. A. Deitau. PS. Barbn: Zodbeim, Grünberg. \$ittenterg: Probftein, \&ug. \$Biefenburg bei Bels

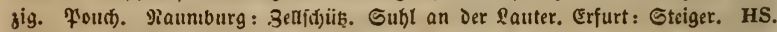
Jena: in Der Brudje, bei Der frïblidjen \$Biedertunft. Edjnepfentbal. R. Burgt. Seta.

1695. C. hirsuta L. Rснв. Deutschl, Fl. 2q6bilo. 4304. Fl. germ. exsicc. n. 1581. Etengel faft blattlos, s3ä̈ttden Der untern runolid), bogig ge: zähnt, Die Der obern lanjettlia), Sirenenblätter Doppelt fo lang als Der Reld), 4 StaubfäDen, Sriffel türjer als Gdjoten breit. Etwas bel)aart oder faft tabl,

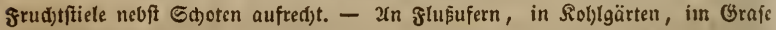
an säđ)en. Miai. Juni. Ђ. Gel)r felten. D? Grüber gefunden: anı Elbufer uns weit Der Saloppe, im Éteinen (Get)äge. Bok. ๔iebeneidjen. Mauke. Z. Bornz,

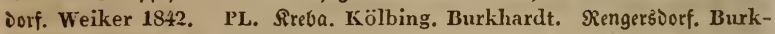
hardt. - Guben. Rabenhorst. Mienzelle. Fischer. PS. આittenberg, Sd)mieve. verg. Schkuhır. Nitzsche. R. @obenftein. Heinhold.

1696. C. sylvatica LrNא. Rснв. Dentschl, Fl. 2(6bilo. 4303. Fl. genn. exsicc. n. 1580. Ctengel bebrättert, Baätthen Der unfern s2lätter run〉,

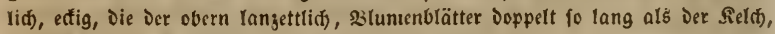
6) StaubfäDen, Griffel fo lang als Die Erjotenbreite. Ettwas beljaart, bogig,

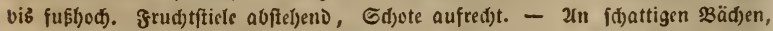

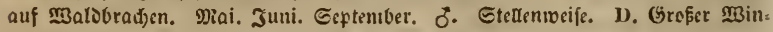
terberg. Dittmarsch, G. Rclıb. Rënigftein. Ficinus. 2tmfflgrunı. Baner. Utt: 
walDe. Rchb. Dreșner Şeios in feudtem Gande. G. Rchb. - 2urtenberg, Il)a.

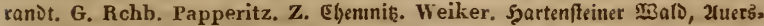

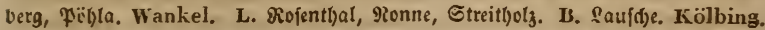
PL. Şainjorfer ફall. Kölbing. - PS. Burg عiebenau. Şinter Sd)teudik̨. Spren-

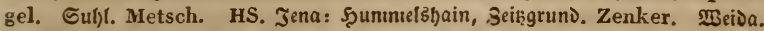
Rossmässler. foburg. Hornung. R. \&obenftein. Heinlıold.

1697. C. amara L. Rснв. Deutschl, Fl. 2166ilo. 4305. Etengel

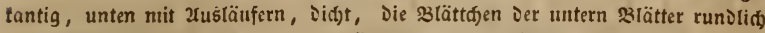
unঠ buđtig gezäbnt, die Der obern längliđ), grob gejäl)nt, Etaubfäben Doppelt und Blumenblätter oxeinal fo lang als Der Reln, 3eutel violet, Grifiel lang, in Der פtitte am Dünnften. Syellgrün, bis iiber fußf(jod), tabl oder fpärlid) bebaart. - b. Opizii Press. Durd)aus weiđ) beljaart. - In feudten WalDungen, an Gräben, Bäđ)en, Queden. 2tpril - Juni. 4. Stellenweife nidt felten. Var. Opizii: L. Unı '́eipjig von Richter beobadtet. A. DeাTau. Schwabe.

1698. C. pratensis L. Rснв. Deutschl. Fl. 266rils. 4308. Etengel röl)rig, runo, nađ) oben geftreift, Die \$lättdyen Der untern \$lätter runDlid, Daš

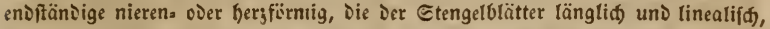
ftumpf, slumenblätter Dreintal fo lang als Der Reld), Grifiel fel)r furz und roal.

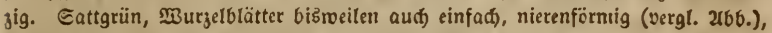

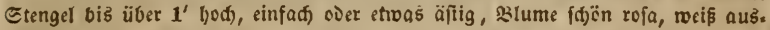

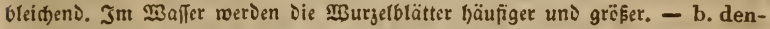
tata Schult. Rснв. Deutschl. Fl. 2ubbils. 430S. b. untre Blätter mit edig gezäbnten Blättden. - 2uf fetten, feud)ten Mुiefen. Xpril, 2)iai. 4. 2xugeurein verbreitit.

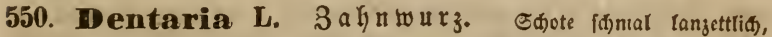
nađ) beiben Enden verid)mälert, Silappen jienulid) rippenlos. Gaamen eins reil)ig, Eotylevonen geftielt: $O=$, fdiefliegend (bei einigen 2(rten Der eine unı

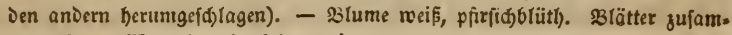
mengefeţt. Nisurjel jahníd)uppig!

1699. D. enneaphyllos L. Rснв. Dentschl. Fl. arobird. 431\%. Fl. germ. exsicc. n. 1280. Drei quirlftändige Dreizäblige 3lätter, Gtaubgefäfe fo lang als Blume. 2ufred)t, ïber 1 ' bod), (ohne Drüife jmifden Den \$lättden,)

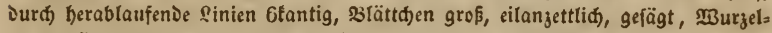
blatt fpäter erf́cbeinen১, Stiel bis̉ iiber fpannenlang, tiefrinnig, feine 3 slätt. den geftielt, bišbeilen unter Der sheilung Enodentrageno, 3lunte groß, odjergelb, Edote bis gegen 2" lang, fafł holjig, Rarbe faum eingeferbt, Saamen jeberfeitz

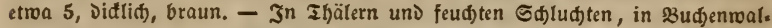
Dungen. 2pril. Mai. Faft 14 氵age früber als folgende. 4 . D. Gr. Minters kerg. G. Rchb. నl. Binterberg. Mauke. Rönigftein. Bauer. Utewalie. Bauer. Hornberger. Papperitz. - ßörners̄oorf. Weigelt. Şirjđiprung. Bucher. Frick. G. Rchb. Papperitz. Z. Şartenjiteiner \$Balo. Bok. Wankel. B. Şod):

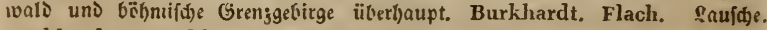
Burkhardt. G. Rchb. PL. Meiferæ๖erf. Burhhardt. -

1700. D. bulbifera L. Rcrs, Deutschl, Fl, 2[btits, 4318, Fl. 
germ. exsiec. n. 1575. Blätter med)ferftändig, untre $5-7$ jäblig, gefiedert, obre 33äblig un১ einfad, Xdffeln mit 3wiebeltnobpen. MBurgelftoct Dünner, Sđ)up. pen angebrïft, Stengel bis $2^{\prime}$ bođ), etwas tantig, tałl, trägt $8-12$ slätter,

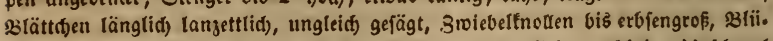
tf)en $3-12$, aud) wolsl ganj verfiimmert, Sdjoten (jelten eríd)eineno) fdjmal

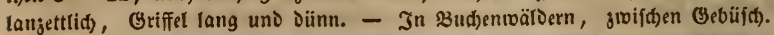

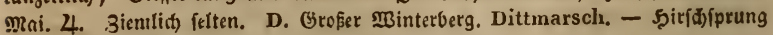
jeit Bucher. Il)aranit. Papperitz. G. Rchb. Kaiser. Z. Shartenfteiner und

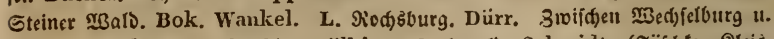

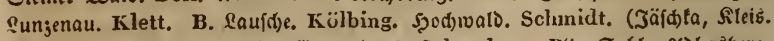

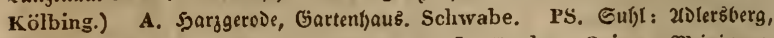
Salthügel. Metsch. HS. Zautenburger forft. Zenker. Geier. Mtiningen. Rauch. Sd)nepfentl)al. Girlanner. R. Burgt. Diirr.

551. Cheiranthus $L$. $\mathfrak{e} a$ ff. Seld angevtriaft aufredist, an ier Sajis 2jactig. Sd)ote 4jeitig, etwas veriad)t. Siappen mit Differ Rittel.

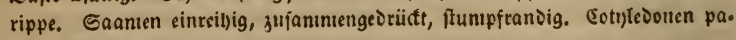
ratiel : $\mathrm{O}=$.

1701. C. Cheiri L. Rснв. Deutschl. Fl. 260bits. 4347. Fl, germ. exsicc. n. 1383. Blatter lanjettlid) fpitzig, gangrandig, faft tal)l, Szeljaarung febr fein genfreut uns anliegend, Edjoten auftedt, grau behaart. Etamm furg,

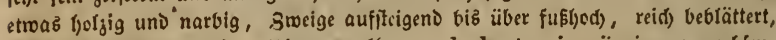
Blätter bärtliç), fattgrïn, silumen gelb. - b. hortensis, iippiger gerwadffen, 231. fäön braunroth), gelb geftreift uno feltner violet. - In Maueripalten. Mai. Juni. J biz 3jäl)rig. Sefre jelten und woljt mur eingebürgert. PS. Jn Şalle.

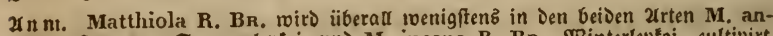
nua SweET., Somimerlevtoi, und M. incana R. BR., MBinterlevfoi, cultivirt. Bergl. unfre abbbiloungen in Deutschl. Fl. 4351 u. 4354.

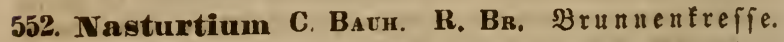
Sdjote waljig sufanmengedrïft roulftig, fpäterbin abwärts gebogen, Saa. men 2reilig, faft fuglig, nefgruvig. - Blume to eif, Staubbeutel getb, \$3lätter gefiedert.

1702. N. officinale R. BR. Rснв. Deutschl. Fl. 2rbbils. 4359.

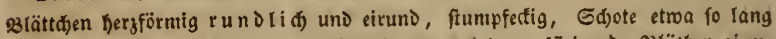
als grudtftiel. Jnt Maffer niederliegeno, wurgelno, aufiteigend, sliitben giem. lid) tlein. Sraut Dunfelgrün, Etengel rül)rig. Opr. Hb. Nasturtii aquatici. - b. microphyllum BNagh. Rснв. Deutsclıl. Fl. 26bild. 4360. in moor.

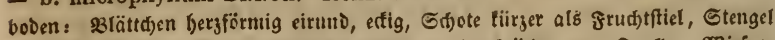

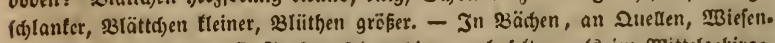
gräben. Juni bis Şerbft. 4. Jmt Dbergebirge nod) feltuer als im Mrittelgebirge; in Der Dberlaufik von Kölbing nur 3. Sieinnelta im \$ad) gegen (d)mod)tits angetroffell; ïberbaupt jwar nidjt felten, aber wolyl faft durdjgängig nidjt fo ge. mein, als angenonmen roiro. b. entfteft an trofinen Etellen.

1703. N. siifolium Rснв. pl, crit, IX. ic, 1132 . Dentschl. Fl. abbtlo, 4361. Fl. germ, exsicc, n, 292. Blättden $7-13$, berg.eilan. 


\section{Tetradynamae. $\quad-379-\quad$ Nasturtiun.}

jettli d) (an Den untern $2-3^{\prime \prime}$ lang), entfernt gefägt, Sđote meift länger ale ibr Stiel. Siefenartig $12-18^{\prime}$ lang, Daumbiff, weitröfrig, 5tantig, tief ge. furdt, Gtengelblätter bis 1' lang, Durd)aus äl)ntiđ) Denen von Simn latifolium, in Defen शä̈le Die Frange wäd)ft. Blütl)e etras gröfer als Die Der vorigen 2rtt. Ju Gräben, an Ieidben. Juni bis 5̧erbft. 4. Sel)r felten. D. Bein Mrod. riser Ieidje über lutiefen feit 15 Jabren jetbft Dann gleid) geblieben, menn Die Pianje ausigerworfen wurde.

553. IRoripa Scor. Ro ri pe. Reț orien. Sthotelänglid (aud

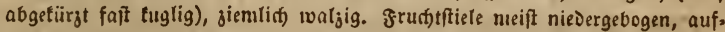
fteigeno. Caamen 2reibig eingeft odi) en punttirt. (Sotyledonen paradtel. Slunie gelo.

1704. R. austriaca (Nasturt. austr. CrTz.) Rснв, Deutschl. Fl. t. LI. 2166ild. 4295 . Fl. gerın. exsicc. n. 674. Sdjötd)en tugelig, in Den ge. püigelten Cticl ver(d)mälert, 3lätter (tunupf, pfeilslangettlid) uno linealif(t), un. terffe unigetelyrt eirund (patelförmig, faft ade ungleid) gefägt. $\mathbb{B}$ urzel faft bolzig, triedtend, Ctengel bis iiber $2^{\prime}$, aufferigend, abfet)eno äftig, Blütt)enftand traubig rispig, 31. tlein, Edjötdjen fo gros als Eenftorn, Grijel etiva halb fo lang, Rarbe runo, Gaamen in jeden ङadje $6-12 .-23 n$ glußufern, auf uferwie. fen. Juni. Juti. 4. Geffr felten. D. 2un Etbufer und auf Den Etbroiefen jefr gefertig.

1705. R. palustris (Sisymbr. pal. LeYs.) Rcrs. Deutschl, Fl. 2u. bild. 4362. Fl. germ. exsicc. n. 680. Eđgoten calpfoidifdy oder längtiđg, wul. ftig, geíd)woden, Blätter leierfürmig fiederfpaltig, 2rbfdnitte ftumıf gezäbnt, SBlu.

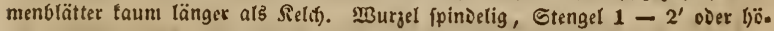

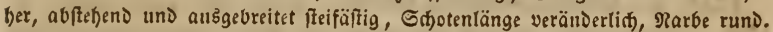
- b. R. rivularis Rchв, pl. crit. VI. ic. 711. Dentschl, Fl. 2606ild. 4305. Sd)oten Dünner, länger als Stiel, abwärtż gebogen, Stengel niederliegenD, 3weige auffteigend, gefurd)t, Blätter unter Den 3roeigen jwillingŝtändig, Jiedern fièer. fpaltig. Edseint eine form int piefenden \$3arbe er;engt oder Baftaro. - 2luf

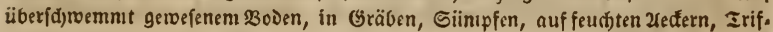

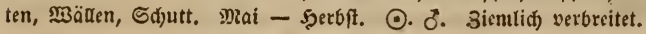

1706. R. amphibia Scop. Rснв. Deutschl, Fl, 2666ils. 4363.

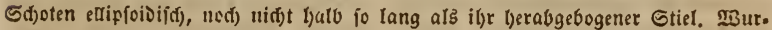

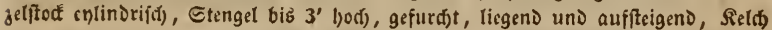
oர̄en, Slumenblätter umgetefrtt eirumD, Doppelt fo lang alß Sett). - a, indivisa : Blätter eiruno länglid), an Gtiele berablaufeno, untre geterbt, obre Dop. pelt fägejätrnig. - b. stolonifera (Press.) Rcris. Deutschl. Fl. 2666ild, 4363. Ed)oten faft fuglig ellipfoidifd), auf 3-4 Mal fo langen Etielen, garbe rund, Blätter ungleid) gejälynt, untere cirund, in Den geäbrten 3 lattftiel berablaufend,

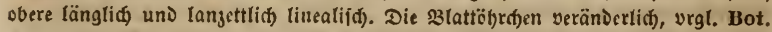
Zeit. 1840. ๑. 710. - c. varifolium DE C. ebcnfo, Die unterften 33lätter abe

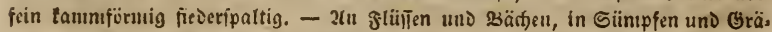

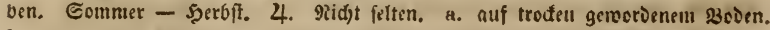
b. an feudften Eteden. co in MBaffer. 
Tetradynamae. $\quad-380-$ Roripa.

1707. R. anceps Rchв. (Sisymbr. - Wнцкв.) Rснв. Deutschl. F1. 26bilo. 4367. F1. germ. exsicc, n. 681 . Sđjoten ellipfoidifd oder läng.

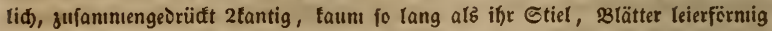
fiederfpaltig uno lanzettlid), Doppelt grob gefägt. Miebrftenglid, auffeigeno, fpan: nen = biß fuङlang, \$lätter mel)r ober ntinjor tief fiederfpaltig, die untern gefie:

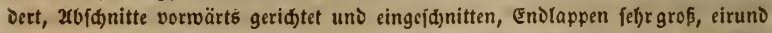

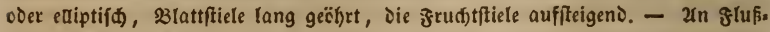
ufern. Mai - September. 4. Selten. D. 2rm હtbufer und auf Den Elbrie: fen unter oen andern 2urten. A. nad) Schwabe. PS. Şalle. Sprengel.

1708. R. silvestris (Nast. - R. Br.) Rснв. Deutschl, Fl. 20. bild. 4368. Fl. germ. exsiccata n. 682. Sdjoten faft fticlrund, nebft il)= ren Stielen aufred)t abftebend, slätter gefiedert und fiederfpaltig, fievern Der untern oval, ringsum gejägt, Stcngelblätter leierförmig uno fieverfpaltig gefägt,

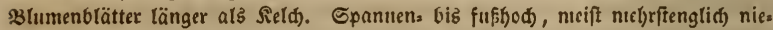
Derliegeno ober auffeigeno, aud) aufred)t, Siveige abftebeno auff́teigeno, slume

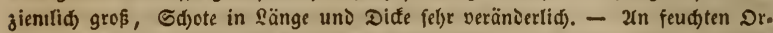

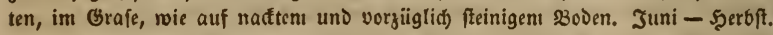
4. Gentein uno bäufig.

1709. R. austriaco $\asymp$ silvestris Rснв. Deutschl, Fl. 2ub6iro. 4366. (Nast. astylon Fl. g.) Sđjoten ellipfoidifđ ober länglid), griffelloz, auf ibren Etielen gerave abftebeno, $\mathfrak{B}$ urgetolätter leierförnig fièerfpaltig, fo wie Die

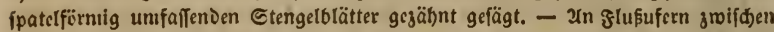
R. austriaca und silvestris. Juni. Juli. 4. Gelten. D. $2 \mathrm{~m}$ Elbufer. Rchb. G. Reichenbach.

1710. R. armoracoides Tavscr. Rehr. Fl, germ. exsicc, n. 1764. ๔d)̈tcjen oval, faum Doppelt fo lang als Griffel, halb ooer ein Drittel fo lang als frudtftiel. Stengel aufred)t, tantig, şlätter fteiflid), ftrieglig, fđärff=

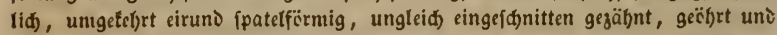
umfaffeno. Selten fino Die Debrd)en unbeulid) und die s3lätter leierförmig. 2n Ğlusufern, auf Biefen. Juni. Juli. 4. Sel)r felten. D. 21n Elbufer. Rchb. G. Rchb.

554. Barbaraea Dod. R. Br, $\mathfrak{B} \mathfrak{a} \mathfrak{b} \mathfrak{a} \mathfrak{a} \mathfrak{f} \mathfrak{r} \mathfrak{a} u t$. Sel(f) aufred)t. Sdjote 4 fantig, 2(d)neidig. Seitenrippen Durd) grofe mafden mit Der Mlittelrippe verbunden. Griffel verdünnt. Saanten einreibig, unge. fäumt, Eotyledonen parallel: $O=$. SBlunte gelb.

1711. B. stricta Andrz. Rchs, Deutschl, Fl, 26boito, 4355. Fl. germ. exsicc. n. 1962. Frudtftiele aufred)t, fammit Den Sdjoten bex גdfe an: georücft, sBluntenolätter balb fo lang alह Der Reld), 3reige aufredt, Seitenlap. pen Der slätter oval. $2-3^{\prime}$ bod), tantig, 8 l. Eleiner, 3 luntenblätter fdjnäler,

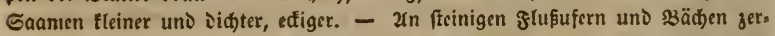

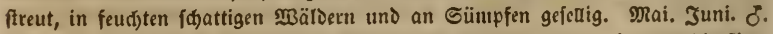
Selten. D. Elbufer. Siebetbaler Girund. Rchb. L. 23ogelıvicfe, Sd)leufiger

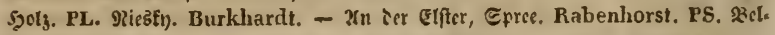
gig. Rabenhorst. 


\section{Tetradynamae. - 381 Barbaraea.}

1712. B, vulgaris R. BR. Rснв, Deutschl. Fl. 2166ird. 4356. Fl. germ. exsicc, n. 678. Blätter leierförmig, Enolappen berzförmig runolid, Sei. tenläppden 2 - 4paarig, oval und lanjettlid, oberfte Blätter ungefel)rt eirund, vogig gejäl)nt obcr fiècrfpaltig, 2 (tiithen Di d)t, 3weige und Die ziemlid) gera. Den Edjoten abftefend, Gaamen rundlid). Niebriger, aber mebr außgebreitet, Blume groß und fdä̈n gelb. Bizmeilen etroas vebaart: B. hirsuta Werhr. Rснв. Fl, gern, exsicc. 1. 679. - 2luf feudtem, befonders fteinigent und fan.

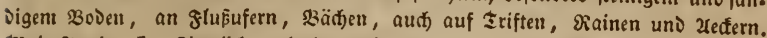

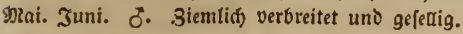

1713. B. arcuata OpIz. Rchв. Dentschl, Fl. 2t66irs. 4357. Fl. gern. exsicc. n. 1963. Blätter leierfïrntig, Endlappen rundlid) oder rboubifd), feitlidje 2 - 4paarig, umgefefrt eiruno, oberfte rbontbiid), bogig gejäl)nt, silï. then lodfer, Ethoten bogenförmig aufifteigend. Bud)5 voriger 2(rt, aber bis $3^{\prime}$ bod), Xefte ntel)r auggebreitet uno anfifteigeno, 23tumen etwaś tleiner und bläîer, હdjoten oft über jealailg, 巨aamen faft waljig. - In Gräbrn. \$lai. Juni.

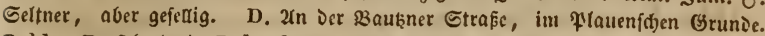

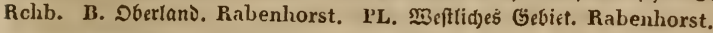

555. Hesperis T. L. I a ditu iole. Sidd unten etrab fadig,

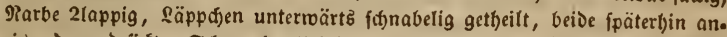
eiriander gevrüftt. Edjote fegelipilig, Gaamen einreibig, Gotylejonen quer: $0 \|$. stume lita cier weis.

1714. H. inodora L. Rсnв, Dentschl, Fl. 266ito. 4378, Fl, gerın, exsicc. $n$. 1577. Heberall fteif bel)aart, Etengelblätter meift geftieft, obre eilan.

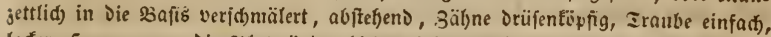

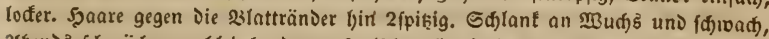

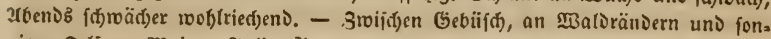
nigen §elīen. Maa - Juli. 4. Sertwildert bier unD Da; 1841 in auffallender

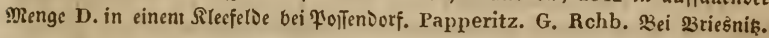

* 1715. H. matronalis L. Rchв. Deutschl. Fl. 2666. 4377. ভten,

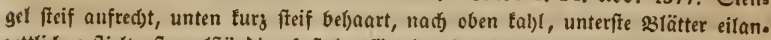
jettlid) geptielt, ftengelftändige faft her,förmig, fisent, lang geftredt, aufredst an.

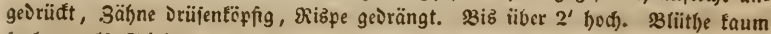

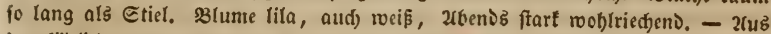

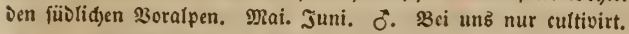

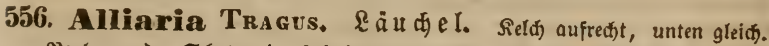
Rarbe runo. Edjote vierfeitig, pfrientenfpisig. Rlappen mebrip. pig uno geadert. Eaamen gefurdit. Sotylsoonen quer: 011 . - situme weiß. -

1716. A. officinalis Axorz. Fснв. Deutschl. Fl. 43\%9. \$3urgel fpinielig, Etengel fteif aufred)t $1-4^{\prime}$ bod). Burzelblätter lang geftielt, tief. bu(j)tig nieren=bersförmig rundlid), ungleiđ) grob geferbt, Stengelblätter fürjer gefitielt, zugeipist. Edjoten jiemlitin) entfernt fferyend, vielmal ränger als ier faft

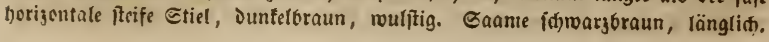


Tetradynamae. - $382-\quad$ Alliaria.

Rraut ried)t mie Rnoblaud. ORP. Hb. Alliariae. - 2luf loderm ober fteinis gem 30 den, gern im હd)atten, in \$B̈̈ldern, Gärten, Meinbergen. 2upril Juni. ठ. Gemein.

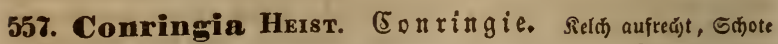
vierfeitig sufammengedrü pfrienenfpisig, Slappen mebr. rippig geabert, Edjeideroand fdjiefmaidjig, Eaame einreihig, ungefäumt, eingeffod)en, punttitt, હotyledonen quer: $0=-$ - Rraut bläulids bereift'

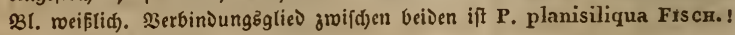

1717. C. Thaliana (Arabis - L.) Rcнв, Deutschl, Fl, arbilo. 4380. Mur ; Etengelblätter länglids, alle féflid) $2-3-4$ ppiķig betbaart, Etengel faden. förntig äftig, faft blattlos, ๔d)oten ein renig geftümunt. W̉utgel Dünn, Etengel

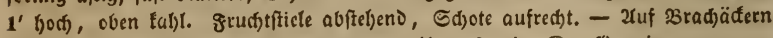
uno bebautem 2ioden, an Berglebnen. 2lpril - Juni. $\odot$. Gemein.

1718. C. orientalis Pers. Rchi, Deutschl. Fl. arbild. 4384. Fl.

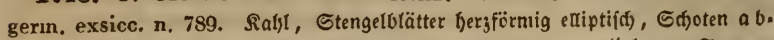
ftebeno: Heber $1^{\prime}$ bod, 33l, weiflith gel6, Edyoten $3-4^{\prime \prime}$ lang, Eaamen

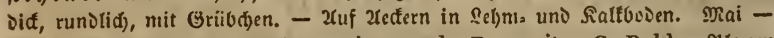
Jufi. $\odot$. ๔elten. D. Meißen. Dittmarsch. Papperitz. G. Rchb. Flauen (eheocm). Hübner. A. 2zernburg, ভandersteben. PS. alzteben, פü̈terborf.

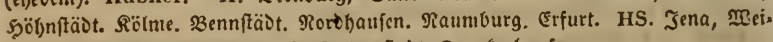

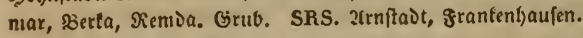

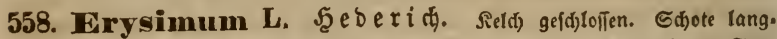
geftreft, viertantig, Slappen mit farfer, e inf a d e r Mitteltippe. Saa. men einteibig, faumtlob, હotylesonen quer: $0=-33$. getb.

1719. E. cheiranthoides L. Rснв. Deutschl. Fl. t, LXII. 260. 4383. Fl. gerın, exsicc. n. 683. Blätter länglidł (anżettlid), entfernt gęälynt,

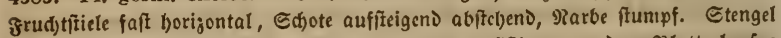
fteif aufred)t $1-2^{\prime}$ hod), cinfad) oier abitebeno äftig, von Dent sBlatte laufen 2 Sinien berab. Spaare 2theilig, angebrüđt. S5aare an Den slättern $2-3$ theis

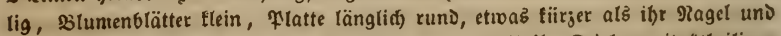
als Der Sicld). Ed)oten etroa $11 f_{2}$ Dial fo lang als iller Eticl, mit 4theiligen Şärdjen befekt, Edjeiderwano nit Mittelnabt. - b. latisiliquun, mit breiten

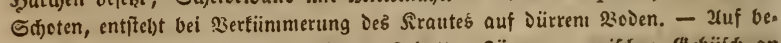

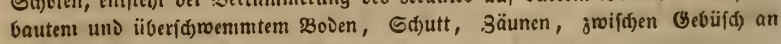
ufern. Juni - Şerbft. $\odot$. Ëemein.

1720. E. repandum L. Rcrb. Deutschl. Fl. 2r6bitb. 4384. slätter

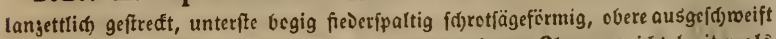
gegäbnt, Sdjoten fit cif borijontal a 3 gebecitet, Stappen nid)t breiter als

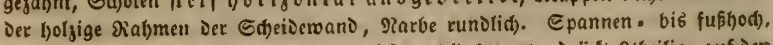
etroas tantig, einfach oder ausgebreitet äftig, Şärchen angebrïđt 2theilig, auf Den Blättern 2 - 3theilig, 8 tiitl)e Eaum Doppelt fo grof als vorige, odsergetb. Ed)o. ten tiber $3^{\prime \prime}$ lang, ftumff 4lantig, etroas bëđrig, Gtiel febr kurs und did, 
Die eifirmigen braungeben Eaamen in Die bolgige Edjeitemano eingebrüdt. zuf Bradyen, Feldern, an Megen. Wini. Juni. ○. Eebr felten; gern unter Triticum monococcum. D. $2 \mathrm{~m}$ meiten Sird)bofe. Rchb. (Sd)eint mit RaIt ialjin georad)t worien ju fein und ift wolst audf roiejer verfifjounien!) PS.

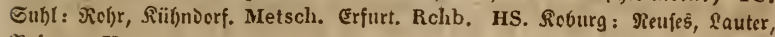
ENofenau. Hornung.

1721. E. crepidifolium Rснв. pl. crit. I. 266ь. 13. Dentschl. F]. 266rilo. 4385. Fl. germ. exsicc. n. 294. Unterfte s3lätter linealijd) (patel. fïrntig, ausిgebu(f)tet un১ fd)rotfägeförmig, obre ränglid fpisig, entfernt gejäbnt

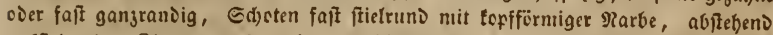

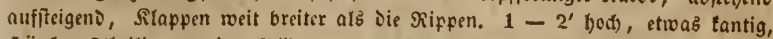

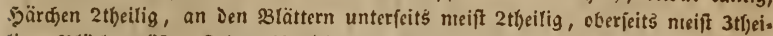
lig. Slütl)e grëser, Edjote bis 3" lang, Sünn, faft runvlid). Gpätlinge bringen

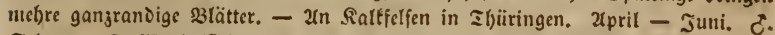
Selten. PS. MBendeliftein, MBttin. Sprengel. Rchb. Raumburg. Miiller. Er.

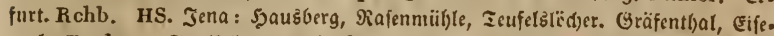
nad. Zenker. Eaalfelo. v. Kiinsberg. SRS. Jranfenbaufen. Hornung. Siu. iolftadt, 2trmftait. Schönheit.

1722. E. durum Prest. Rchi. Dentschl. Fl. 2t66ild. 4387. Fl. germ. exsicc. n. 1964. Steif aufre(t)t, grau, rutljenäjtig, 2alätter langettlió),

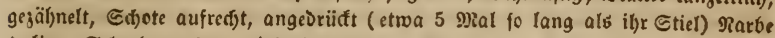
4efig. Gel)r bart, $1-3^{\prime}$ bod'), Şärden 2tbeilig, an Den slättern unten 2 3tfeilig, oberfeits 3theilig, s3lüthe taum grëser als an E. cheiranthoides, forroe.

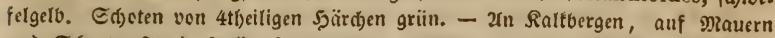
"ni Edbutt. Juni. Juli. Jmuner $2-3$ Bod)en fpäter. (nm 3roinger, Der şoffirdfe uno ies Prinjenpalais, an Wege nad) Friesnik am Elbufer, bei Dieisen. Z. Ebenmis auf ier Gtadtmauer. SRS. Eondersbaufen, Singen.

1723. E. hieracifolium L. Rснв. Deutschl, Fl, 266бirt. 4358. F]. gerın. exsicc. n. 293. S3!ätter grün, länglid) (anz̧ttliđ), entfernt gejäl)nt, Btumenftiele fo lang als Der Reld), હ(t)oten etwa 6 Mal fo lang als ibr Etiel,

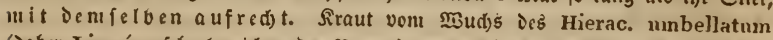
(Daber Linnées feffr bejeidnender giante!), $2-4^{\prime}$ bod), Shärd)en 2tbeilig, auf Den $B$ lättern audi) 3 - 4tbeilig. 3 l. Doppelt fo gres als an E. cheiranthoides, bad)gelb, Edjute grün. - 2n Mauern, in liđten MälDern, jwifd)en Meibenge.

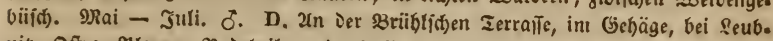

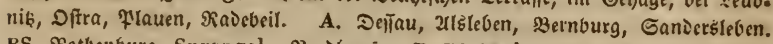
PS. Rotbenburg. Sprengel. Rordijaujin. F. W. Meier.

\section{E. virgatum Rотн. (longisiliquun Sснцегсн.) Rснв.} Dentsch. Fl. 26bбilo. 4389. Blätter (anzettlid), ganzrandig, untere ftumpf,

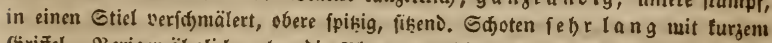
Griffel. Boriger äbntiđ), aber Die 31. ganzrandig, slume grëfer, Sdjoten weit länger. - 2n Mauern uno Felfen, in lid)ten Mäldern. Juni - Septentber. $\delta$. Etellentocife. PS. Erfurt. Schönheit. SRS. Frantent)aufen: an Dem Siffbäufer. F. W. Meyer. 


\section{Tetrad ynamae. $\quad-384-\quad$ Erysinum.}

1725. E. diffusum Eнвн. Rснв, Deutschl, Fl, 206. 4394. 2\{(t). grau grün, Blätter faft linealifif), unteriłe wenig gezäfnelt, oberfte gangranoig,

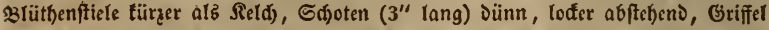

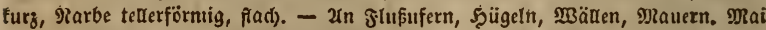

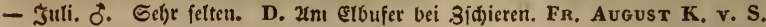
PS. Mangen. Sprengel.

1726. E. lanceolatum R. BR. Rснв, Deutschl, Fl, 2466. 4393.

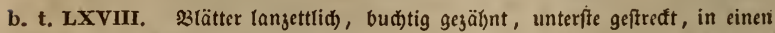
Blattfiel verfdmälert, oberfte fiǩeno, turj gezälynt, Edoten abfteheno, graufilzig, grüntantig, शaarbe 2lappig. $1-2^{\prime}$ hod), fteif, felten äfitig, 3lätterhärdsen vber: feitz 3 - 4theilig, 231. jo groß als an Cheiranth. cheiri. (E. Cheiranthus P. vergl. tab. LXVII. if eine zlpenpĩanje und wiro fälf(lid) für E. lanceolatum gehalten, obwol)t fie nid)ts langettförmiges bat und 4 iff. E. odoratum ЕвRн. vergl. t. LXV. 2r6bild. 4390 . wird aud) mit unferer Fianje verwedselt, weil fie to rie mef)re cinen jarten sjoniggerud) bat.) - 2 (n geffen, auf Bradjen, aud) nuf angefd)metunten glupufern. Juni. Juli. $\delta$. Eetten. D? Bei Eäbri.

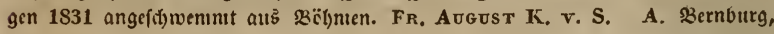
Sandersteben. Schwabe. PS. 3icgenrüđ. Kunze. Rlefpad) bei Erfurt. Hornung. Spohenftein. Wallroth. HS. Zautenburger gorft. Geyer. Soburg: Staf.

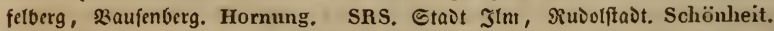
Sd)warzburg. Hornung. Zrnftadt. Nicolai, Buddensieg. R. Robenftein.

559. Sisymbrium L. $\Re$ a uf $e$. Seld) ofien, unten gleid). (Dru. fen an Den Sitappenfeiten paarig.) গarbe einfadj. Sdjote geffrecti, Sfeitig rundtid), Silappen gewëlbt 3nervig. Gaamen einreifig, ungefäumt, punttitt. Eotyledonen quer: O|l. - 31 lume getb.

1727. S. Sophia L. Rсrв. Dentschl. Fl. 4405. 3lätter grau, Drei=

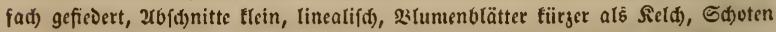

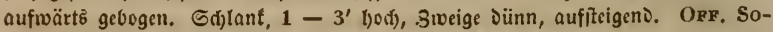
phia Chirurgorun, - 2tuf bebautent $300 \mathrm{cn}$, Gd)utt, MRauern, bäufiger auf

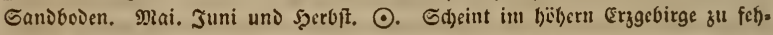
Ien, fonft gemein.

1728. S. officinale Scop. Rchв, Dentsch. Fl. 2666. 4401, 23läte ter fdyrotiägeförntig, 3weige armfïrmig ausecbreitet, Frudgttraube äl)renartig, Sdjoten angebrüđt. $1-3^{\prime}$ bod), meift siolet angelaufen, einfach bel)aart.

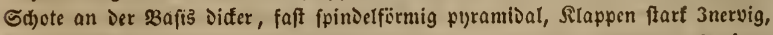

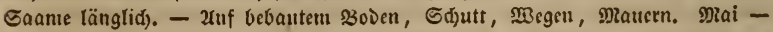
Detober. ๑. Gemein.

1729. S. Loeselii L. Rснв, Dentschl. Fl, 2tbrito. 4409 . Fl. g.

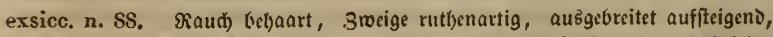
Blätter alle fdifrotä̈geföemig, Die Dïnnen Edjoten mit Den balb fo langen Stielen

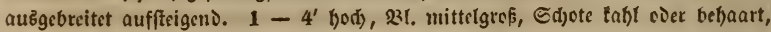
Saamen rïthlid) braun, Evtnle oonen oft f́bief. - 2uf Sdhutt, Mauern, fteinigen

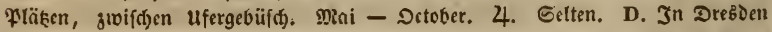
bäufig, in unD um Die Stait auf alten Miauern, am Elbufer. Meifen. A. Bern. 


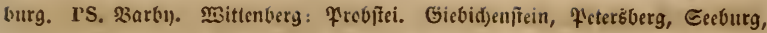
(Eißleben, Ed)raplau, Meniclftein, פeticburg. SRS. Frantenfaufen.

1730. S. multisiliquosum Hofru. Rснв, Deutschl. Fl. 2660

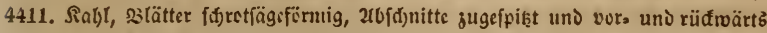

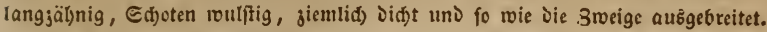

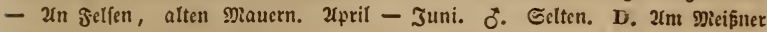

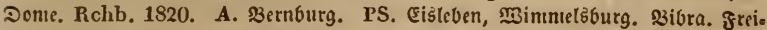

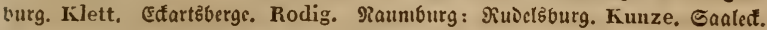
Geser. HS. Samburg, Dornburg. Zenker.

1731. S. Irio L. Rснв. Dentschl. Fl. 2666iro, 4408. 2ưe 23lätter (d) rot ägefërmig, 26bidjnittc gesähnt, Sicld) toenig offen, Blumenplatte fürjer als

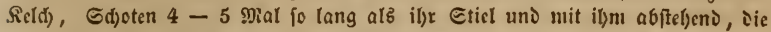

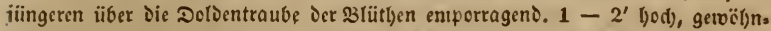

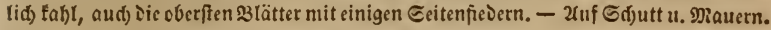

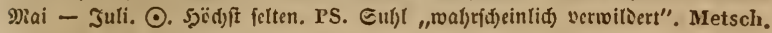

1732. S. strictissimum L. Rснв. Deutschl, Fl. 2r66ils. 4414. Fl. germ, exsicc. n. 685. Blätter geffielt, cirun১ un১ cyal lanjettlich, gejäbnt gë̈̈gt, fein behaart, Ed)oten auf abjetemenen Etielell aufwärts gebegen. 2-4'

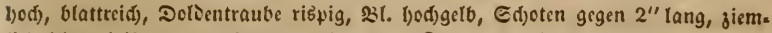
(iid) Did)t beifammen. Canmen länglid). Siraut cft violet angelaufen. - $x_{n}$

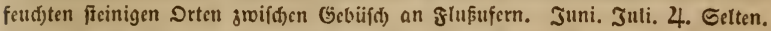

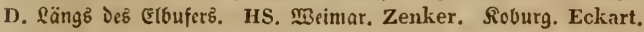

560. Diplotaxis DE C. Rempe. Reld) loder ofien, unten glcidj. Cdjote faft linealifd) gufammengeoriift, mit mittelrippe, ffrienten. frisig. Eaamen auf breiter Edjeideroand zweireifig! Eotylrionen ges faltet: $0 \gg .-$ stume geto.

1733. D. muralis DE C. Rcrв. Deutschl, Fl, abbiro. 4417, Blät.

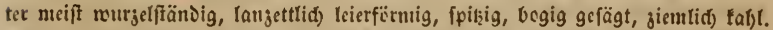
ed)aft auffereigend, silumenblätter feilförmig, Flatte breit a bgerundet.

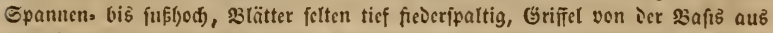
veroift, Narbe breitlidy. - 2uf bebautem $330 \mathrm{den}$, Gd)utt, Mauern. Mai -

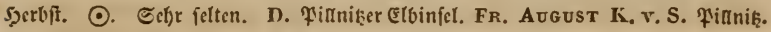
P'apperitz, L. Rchb. fil, G. Rchb. HS. Jena, Zenker.

1734. D. tenuifolia DE C. Rснв, Dentschl, Fl, 266ito. 4t21).

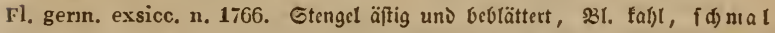

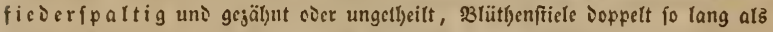

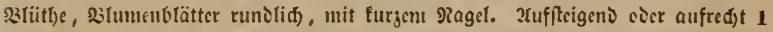

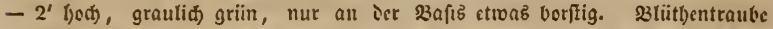

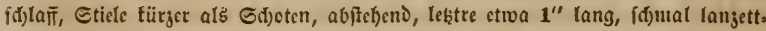

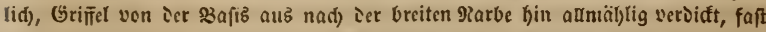
fo lang als Dic siteite Der Sdyote. Eaamen rumblid) jufammengcoriađt, braun, etwaß runjelig. - Xuf wüftem 20icn, Gdjutt, an $\mathfrak{B}_{\mathrm{egen}}$ Mauetn. Juni -

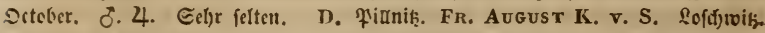

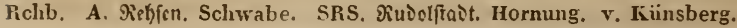


561. Sinapis L. Senf. Relö offen. Sdote fitieltunolid, mul. ftig, Slappen $3-5$ nervig, Eriffel gefd)nabelt. Saame tuglig, cin. reigi g. Cotnlejonen gefaltet: $0 \gg$ 》. -3 lume gelb.

1735. S. nigra L. Hayse Arzneigew. VIII. 46. Кснв. Dentschl.

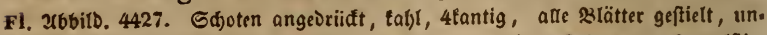
terfte leierförnig, oberfte linealifd). $2-4^{\prime}$ bod), Eabl, Edjote etrob roulftig, jeverfeit? 4 - 6 faamig. OrF. Sem. Sinapios nigrae. - Zuf bebautem 280.

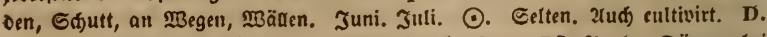

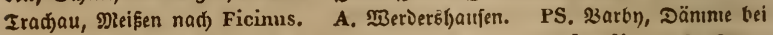
Der Şinterlute. Scholler. Şąe. Sprengel. Erfurt. Bernhardi, HS. Jena. Zenker. Roburg. Hornung.

1736. S. alba L. Haysz Arzneigew. Vill. 39. Rснв. Dentschl. F1. Xobild. 4424. Edoten wulftig, fteif behaart, abftelyend, Slappen 5nervig,

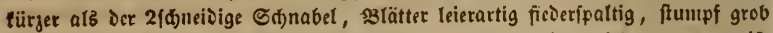
gefägt. $2-4^{\prime}$ hod, weitäftig, fteif behaart. Eaanten jederfeiţ́ $2-4$, weif. (id) gelb. Opr. Sem. Sinap. albae s. Erucae. - 2tuf bebautemi 30 on, Edfutt. Dai. Juni - 2uguft. $\odot$. Eultivirt uns verwildert.

1737. S. arvensis L, Haysr Arzneigw, 11. 14. Rchb. Dentschy. F]. 2rbbild. 4425. Grifel gerade, Edboten fteif, abjtel)eno aubgebreitet, 3roeige aubgeftređtt, Stantig, wulftig aufgetrieben, Rlappen länger als Der greeifd)neioige Sd)nabel, 23lätter oval, ungleid) gébud)tet und gejälint. S(joten bald tafl, balo

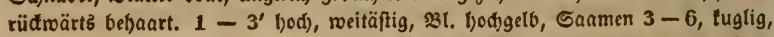

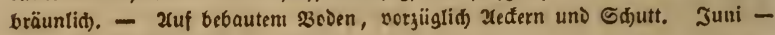
3uguft. $\odot$. Gentein.

1738. S. Schkuhriana RchB. Deutsch. Fl, 4425 b. (S. orientalis Scrx. t. CLXXXVI.) Grifīel Sförnig, Edoten vicltantig, la ng geft $r$ eđ̃t, fpä.

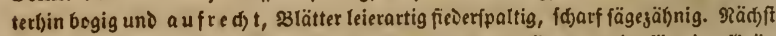

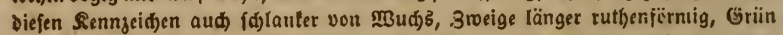
Duntler, $\mathfrak{B l u m e}$ tleiner. Meift nebft Den Edjoten rüđfwärtל fteif bebaart, aber

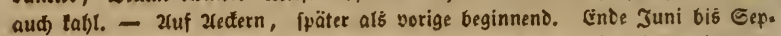

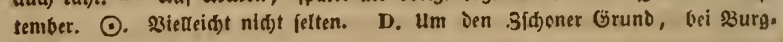
ftäotel. Rchb.

562. Erucnstrum Rснв. $\Re$ a $u$ fe. Fl, gerun. pag. 693. Sitd zientlich offen. Jeberfeitż unter Dem Saamenträger sinc bornförmige Driile. ङळote runotid, etraas gefdnabelt, Rlappe glatt, mit einer Mitteltippe. ङd)nabel meift einfaamig, Saame eiureibig, faft tuglig, sufammenge. orii åt. Cotnledonen gefaltet: $0 \gg .-33$ tume gelb.

1739. E. inodorum (Јон. Bavr.) Rснв. Dentschl, Fl, 2666. 4428. Fl. germ, exs, n. 1967. Etwą fteif bel)aart, Blätter leierartig fièer.

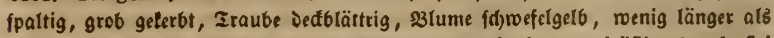

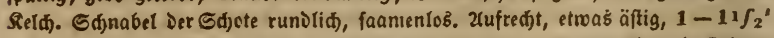
boh, etwas angedrüđt borffig, Duntelgriin, toblartig. - 2uf Eand uni Ed)utt. 


\section{Tetradynamae. $\quad-387-\quad$ Erucastrum.}

Iani. Drai - Şerbft. ๑. Gefre felten. PS. Gigens von şalle. Thilo Irmisch. SRS. 2truftait bei Der rotben Ssiitte angeblid.

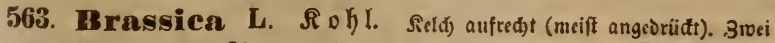
Drüjen unter Den Silappen uno 2 unter ien Gaamenleiften. Edoten rund. lid) pfriemenipişig, Rlappen (bei Der Feife) melyrrippig, Caamen einreifig, tuglig, Eotylevonen gefaltet: $O \gg .-331$. gel6.

1740. B. campestris L. Rüber. Rснв. Deutschl,Fl.2166.4434. Blätter tol)lartig, bläulid) bercift, unterfte ftcif lichaart, Dicfe, jo twie sie mittlern

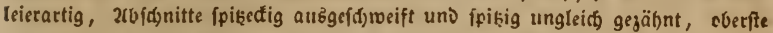

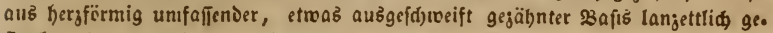
ftreft uno ganjrantig, DolDentraute Di dft georängt! - annua : Conıner. raps, Gomnterriibfell. b. biennis: Minterrapb, Minterrïbfen. Diefe 2trt ift B. campestris LiNN. und SMr. - Eultivirt und verwilbert auf bebautem 230 en. 刃rai. Juni. (.) ర.

1841. B. Napus I. Rofhlrałs. Rcrs. Deutschl, Fl, 2166. 4435. Blaugriin, unterfte \$lätter jung fein bebaart, alt tal)l, obere länglint), h)ergfërmig umifailend, slütbentrauben verlängert, fd laff, Reld balb offen, $2 \int_{3}$ 10 lang alß sie aufliegenion Etaubgefäfe, fru(t)tfiele abftebend, Sdoten aufo

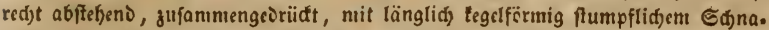

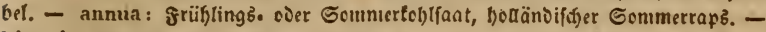

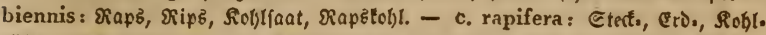
riibe, weife uno rofarothe. Senntlid) sen fern Daran, Daßs Die unterften slïtben tiefer fehen als bie sbern. - Eultivirt und serwildert auf bebautem $230 i \mathrm{cn}$. «pril. פiai. ○.

1742. B. praecox Krт. Rспв. Deutschl. Fl. 4436. Sabl, menig bläulido grün, rourgelftändige und untere Etengelolätter leierartig, oberffe unifaf.

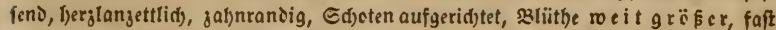
\{affrangelb. Sd)lant, einfad) òer Dünnältig, slättcr fdmmäler uns länger, Saa. men leiner. - Eultivit uno sermiliert auf bebautem 2Boden. 21pril. Rai. ().

1743. 13. Rapa L. Rсrв. Dentschl. Fl. 4437. Unterfte Blätter fteif Gehaart, Duntelgrün, folgende tabl uno bläulid) bereift, leierartig, ftumpflappig, oberfte bergförnig unifaîend, szlïttentrauben gegipfelt, field) fpätetbin ausgebrei. tet abjtebeno, Staubgcfüfe aufiteigend. - annua s. oleifera: Gonımerrüben.

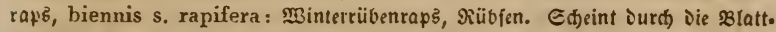

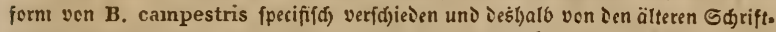
ftellern getrennt rorien ju fein. - 2luf bethautem Bovén, ro Die Frange culti.

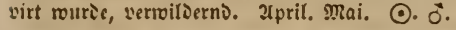

1744. B. oleracea L. Rснв. Deutschl. Fl. 24bbilo. 4438. 23lätter bläulid) grün, unterfte tal)l, oberfte ungeftielt, lüngliđ), slïthentrauten vor bem

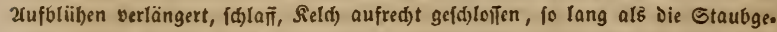
fäfe, etwas türjer als \$iftia, ¥latte Der Glafgelben slumenblätter längli

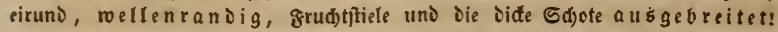
Eultivirte ßarietäten: A. Br. oleracea capitata, אrnut oder Ropftohl, Blätter gu 
Tetrad y nama e. - $388-$ Brassica.

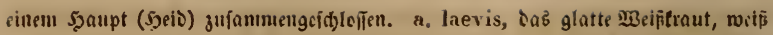
11. violet: violacea. b. bullata (sabauda), słätter loder föpfig, blafıg löớtig:

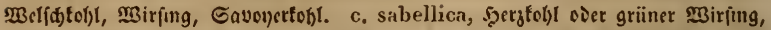
griin und traub. d. pyramidalis MrLs., Spisfriil)ftaut, Minfelftedter Siopfo tol)l, S̈̈pfe länglid), fpikzig, fdjon 2(nf. Juli. B. Br. ol. foliosa : S(atttob).

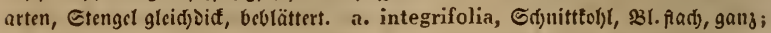

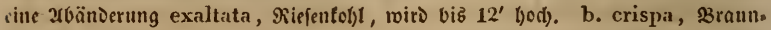

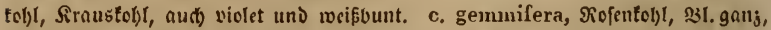

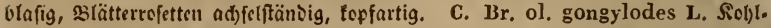
rabi, Etengel in eine Sinolde angcfd'woduen, bläulidygrün oock violst. D. Br. ol.

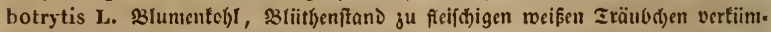

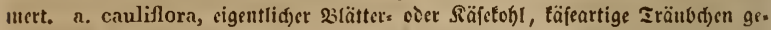
gipfelt. b. asparagoides C. ВАшн. Broccoli, ficif́dige Irauben yerlängert, aứ)

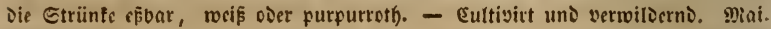
కuni. ठั.

\section{Acroschistae 8, coilocarpicae (Conpect, anno 1828.) Szoblfrübtige, an ber Spize auffpringend.}

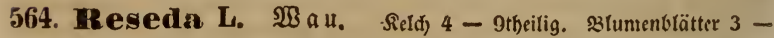

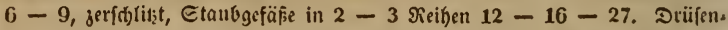
fojild (Driffen Der vorigen vereint). \$iftill 3 - 4narbig. Shoblfrud)t (olyne

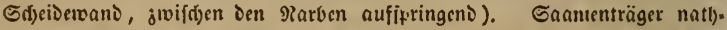

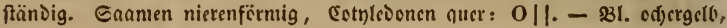

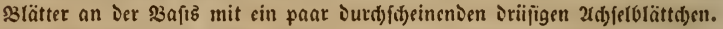

1745. R. Luteola L. Rcis. Dentschl. Fl, 2rbbirs. 4442. 2ruf.

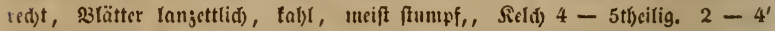

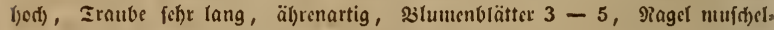

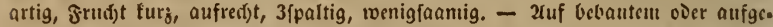

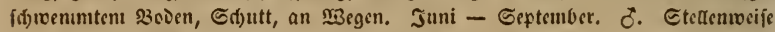

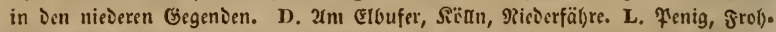

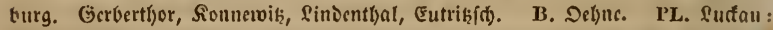

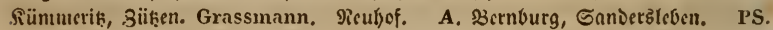

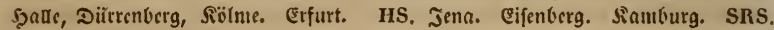
Zunftadt.

1746. R. Iutea L. Rснв. Deutschl. Fl, arbirs. 4446 . Zufiteigens,

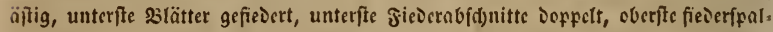

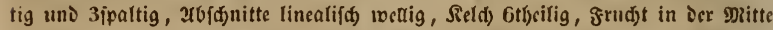

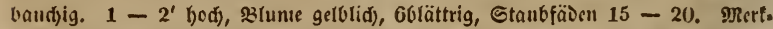

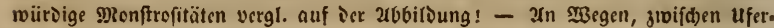
gebiifit). Juni - Geptember. $\delta$. Stcllenweife in Den nievern Gegenden. D.

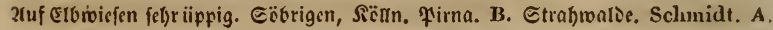

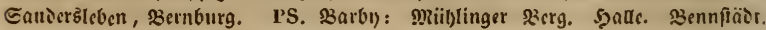

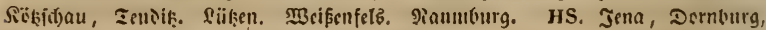
Eifentierg. 
Tetradynamae. - 389 - Reseda.

1747. R. odorata L. Rснв, Deutschl, Fl. w66its. 4t4t. 9iievers

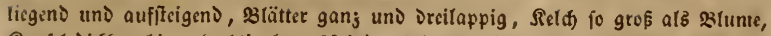
Saffel Didfbandhig, budtig furg 3ipikig, 3luntenblätter $9-11$ ipaltig. Blunte

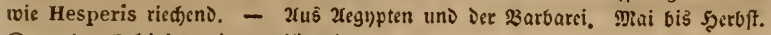
- - b. Eultivirt uni verwilocrno.

* 1748. R. inodora Rснв. Dentschl, Fl. zrobirt. 4445. Fl. germ. exsicc. n. 1969. 2ufte(t)t, untre slätter ganz, obre 3ipaltig, Reld)blätter jo wie

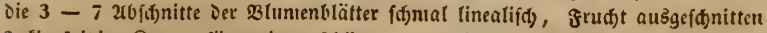

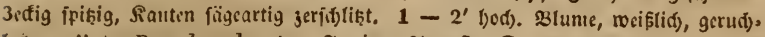
Ies. - Unter Reseda odorata. Juni - Xuguft. ๑. Bcrwirbert.

\section{Familie Papaveracene, Mtohngewäd)ic.}

- Sarbarienbud 5. LXXV uns 18\%. -

A. Fumarieae, (Eroraudigeträchie, Blume radenförmig ver: wartjen, હtaubgefäp̈e 2briberig.

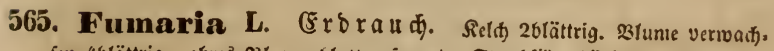
fen 46tättrig, obres 3 tunenolatt geipernt. Staubfäbenbündel 2, jeics mit

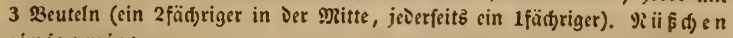
cinja anig : -

1749. F. Vaillantii Lors. Rснв. Deutschl. Fl. 266ils. 4452. Fl.

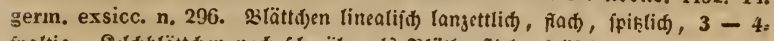

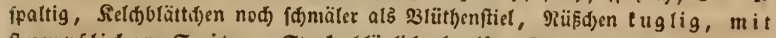
ft umpflidier Epikc. Start bläulid bereift, Irauben Didbt uns vicl. blütbig, \$lütben jart roja, Mïnoung tarninroth), jelten weiß ntit violeter Epilise.

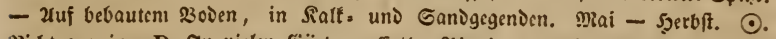

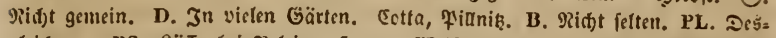

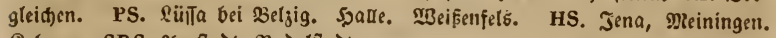
Sioburg. SRS. 2rnftait. Eiudolftadt.

1750. F. media Lors. Rскв. Dentschl, Fl, 266bils. 4453. Slatt=

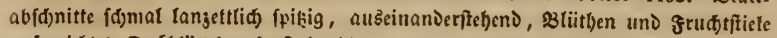

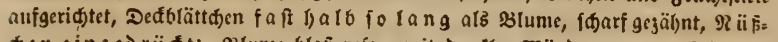

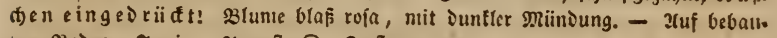
tem 3oden. Juni - 2uguft. $\odot$. Setftrut.

1751. F. officinalis L. Rснв. Deutschl, Fl. 2166its. 4454. Blatt= abf(b)

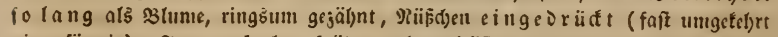

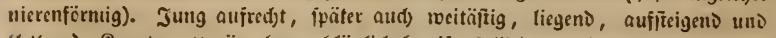
tlettern১, Siraut mattgrïn, taun bläulid) bereift, siliutbentraube uns sitiithe grë: fer, Duntler rett). Opr. Hb. Fumariae. - Inf bebautem Sicicu. Mai Şcrbft. ๑. Şäufig.

1752. F. capreolata L. Rснв, Deutschl, El, ztbiils, $4+56$. Silt: 


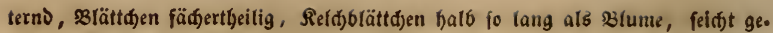

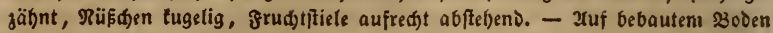
jwifden Gebüfd. 21pril - Juni. ○. Gefr felten. D. In Dres̉den in Ģär. ten in griebridftait. G. Rchb.

566. Corydalis Vent. Şelmbuid, \&erdenfporn.

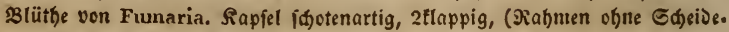
roano,) mebrfaauig. Saanı glänzeno, mit Sieinımarze.

1753. C. fabacea Pers. Rсuв. Deutschl, Fl, I6bils. 4460). Fl. germ. exsicc. n. 1077. Rnolle ausgefült, 3lätter Doppelt 3jäblig, geipalten,

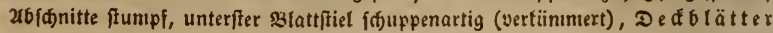
oval, Eporn gefrünımt. शur renige 3olf bod, Iraube nur $2-50$ liitbig, 31 .

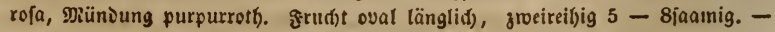
Var. glaucescens WeIKkR: Blüthe roeiß, Rraut niebr bläuliđ angelaufen. -

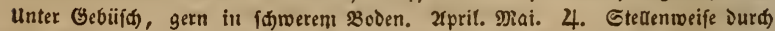
Das Gebiet; in Erzgebirge bis Z. Deveran, MBildenfels, Sintenrwalde; in Der Riederlaufik nur bei Guben uno Eommerfelo. - Var. glaucescens: Z. $\mathfrak{B e i}$ Şelbersiorf alı Ehemınibufer ofjne Die urform, unter wiseidell. Weiker.

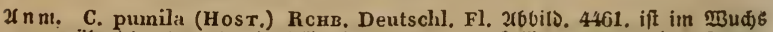
gang äbntid), bat aber banoförmig gefpaltene Defulätter uno getaben Eporn. Biedeiat aud innerbalb unjerce Grenjell vorbanien.

1754. C. digitata Pers. Rснв. Deutschl, Fl. 4462. Fl. germ.

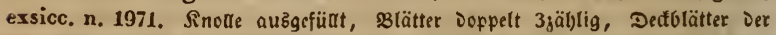
vielblütbigen Iraube b) a noförmig gefpatten, Sporn bogig, Rapfel ges ftreft Iangettlid), einreibig faanig. Epanten. bis fusffod), follant. 23l. rofa,

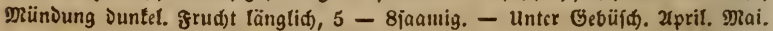
4. Selten. (Bon Ficinus angegeben D. Salfreuth), - am \$adofen bei Şains. berg; an beioen Etetlen neuerlid' auf Das Sorgfältigfte vergebtia gejudt, mie aud) Die theils funtpfige, theils fandige Gegend von Ralfreutb, und Die gang

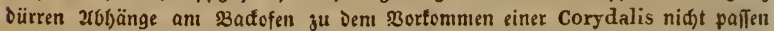
Dürften.) A. DefTau. Richter. Schwabe, Sandersteben. Schwabe. PS. Salle: 3iegelrove, Єteinflippe u. f. w. VRaumburg. Richter. ङfartzberge. Rodig. Dü. ben. Richter. ๔uhl. Sauer. HS. Eijenađ), Dietrich. SRS. Urnftait. Schönheit.

1755. C. bulbosa Pers. Rcri, Deutschl. Fl. 2lobild. 4463. Snolle bobl, Gtenget grbeiblättrig, unten obne Stfuppen, Iraube vielblütbig, Det. blätter oval (ungetlgeilt), Eporn waljig, batig. Gpannen, bis fußbod), \$1. trüb tarminroth). - b. albiflora KIr. meis̄. OFf. Rad. Funariae cavae s. Aristolochiae cavae. - Unter (Sebiifđ), 2upril. Mai. 4. Etellenweife. In Erz. gebirge bis Z. Deveran, (s)enunik, gid)tentwalve.

1756. C. lutea Pers. Rснв. Dentschl. Fl. 2666. 4459. \$ुนtgel unt

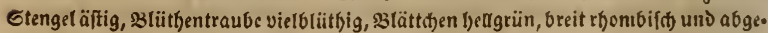
ftumpft oder unigetefrt eirun১, Deđ́flättden bäutig, längliđ), feinf́iłig, ctraa

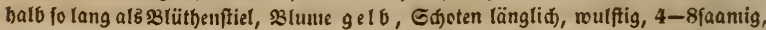

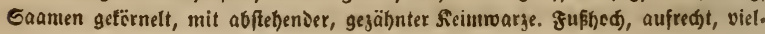


ftenglig bufobig. - 2n altem Eemäuer. Drai - Eeptember. 4. Sefrr felten, vödig eingebürgert. D. In Ibeilen Der alten Seftung: 2In Der \$rüblid)en Ier.

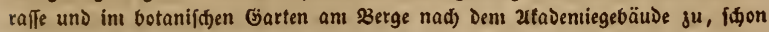
von Bucher beobaditer. In Der Promenade an Der Gartenmauer Desె preupi. fiten Gefautoten beint "Sthallodfe". - 5̧obenftein.

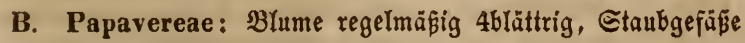 frei, mehrzählig.}

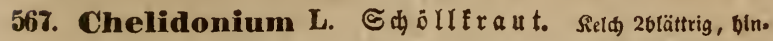

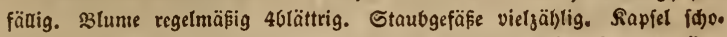
tenartig 2 tlappig, einfädbrig, von unten auढ́ aufipringeno. Saamenträger

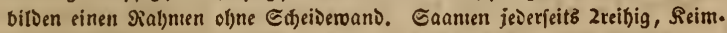
roarge länglid, Did. - Säber, or a ngegelber S a ft. B1. loodgelb.

1757. C. majus L. Rснв, Deutschl, Fl. 266 . 4466. Blätter fieber.

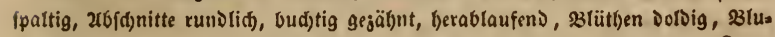
ntenblätter ganj. $2-3^{\prime}$ bod), fitielruns, tnotig, gabeläftig, lang bebaart, Firaut hellgrïn, unterffe giebern geffielt, Gdjotentapfén über $2^{\prime \prime}$ lang. Orp. Rad, et

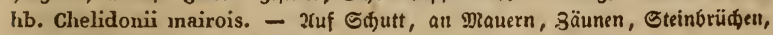

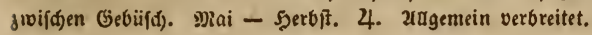

568. Glaucium T. Gaertr. Ş ornmohn. Mie Chelido-

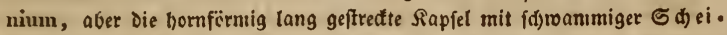
Dewand, an Der Epitae auffpringend. Saauten obne Reimwarge. - Rraut weißlicí grün, Eaft bodggetb.

1758. G. luteum Scop. Rchв, Dentschl. Fl. 266 bilD. 4468. Fl. germ, exsicc. n. 686. Stenget und Die faft gl a tte Grudt tafl, Blume gelb,

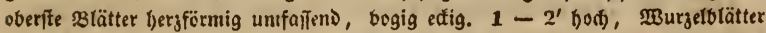

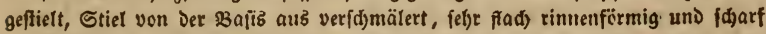

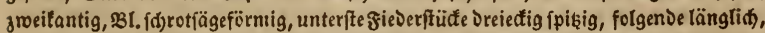
tief ftumpflappig ober fpisectig eingeidunitten, alle befonoerb oberfeits und unten

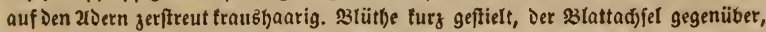
Blumenvlätter großs, faft 3ectig, citronengetb. Tiarbe zufanimengebrüăt 3eđtig,

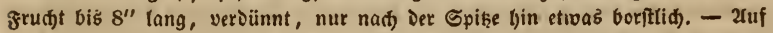

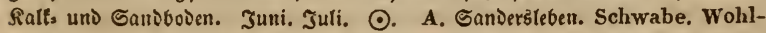
leben. PS. 2Balbeđ. Wohlleben. Şettftäot. Sprengel. ßiłenburg. Schu-

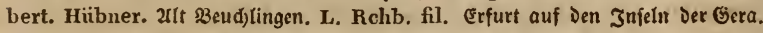
$2 \mathrm{~m}$ ufer berjetben. Binder. Hornung. Botba. Buddensieg.

1759. G, tricolor Bervi. Rсhв, pl. crit. II. ic. 376. Deutschl.

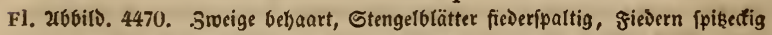

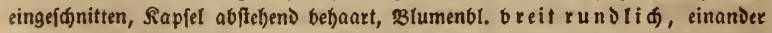

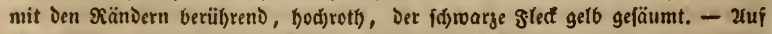

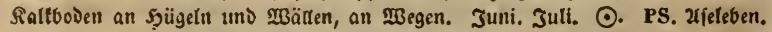

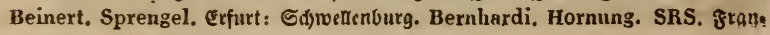
tentbaufen: Sattenburg, zhalleben. Hornung. 


\section{Papaveraceae. $\quad-392-\quad$ Papaver.}

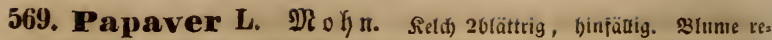

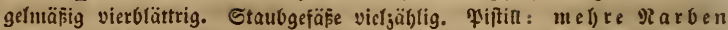
ft $r$ al) lenförmig oberbalo bes frud)tfnotens. Sapjet halb vielfäd)rig (马äs, (j)er nad) Der Mitte frei, unter Den giarben mit Qё(j)ern aufípringenD). Saas men nierenfërntig. - Gaft wäfrig oocr nild)artig, Sinoßppe ničt.

1760. P. Argemone L. Rснв. Dentschl, Fl. 2t66ild. 4473. Stauv.

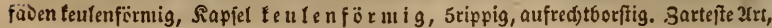

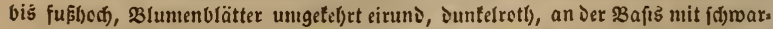
gen verfaufenien gleden. Etaubfäben idfwargblau, szeutel rundidi f́dmusigblau, Marben 5ftralylig. - 2uf bebautem Boien, Jectern, ๔đutt. Juni. Juli. ๑. angemicin verbreitet.

1761. P. hybridum L. Rchr. Dentschl, Fl, 2robilu. 4476. Etaub.

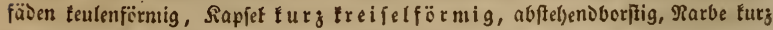
6ftrablig. Etengel $1-2^{\prime}$ bod), aufred)t äptig, angcorïđtborftig, Murgelblättcr

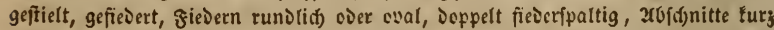
silanjettlid) uno ipişig, Etengelolätter fikent, Doppelt uno einfad) fièerfpaltig,

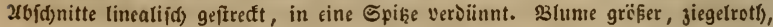

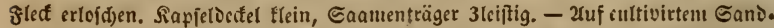

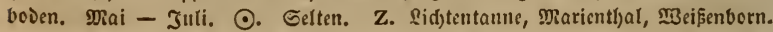
Bok. A. Eanierstıben. PS. Barby) : givijđen Gnadau und Dëben. Granau bei șalls. Erfurt.

1762. P. dubium L. Rснв, Deutschl, Fl, x66. 4477. Staubfäben pfrientlid), Beutel länglid, Die 7 - 10 Sappen Der Narbe gejoniert, Sapfel teu, Lenförmig unten veroünnt, veriđjnuälett, tabt, sie $\mathfrak{B}$ luntenblätter mit turgem $\Re a$.

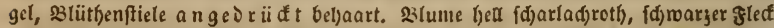

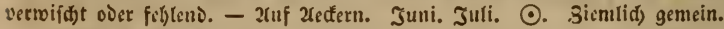

1763. P. intermediun BEскеR. Rснв. Deutschl. Fl, 2robito.

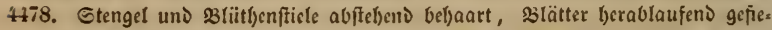

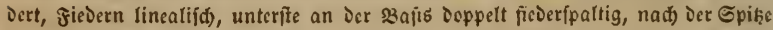

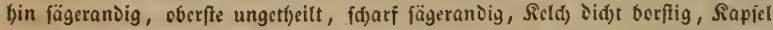

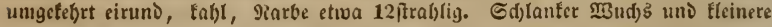

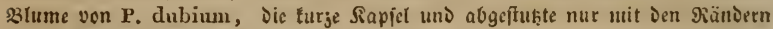
cinanier beriil)renien Deffolättdjen von P. Rhoeas. Die Fapiden der giarbe (nidf)t f(f)warzviolet wie bei Diefom fonঠern nur) bräuntid) (1vic bei P. dubium). Sisn

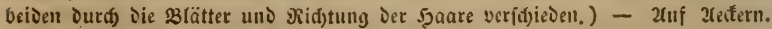
Juni. Juli. ๑. Gchr falten. D. Grroßis Geljäge. Rchb.

1764. P. Rhoeas L. Rchi, Dentschl, Fl, atovito, 4479. Etaubfä,

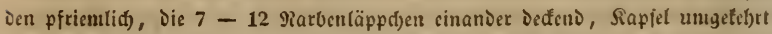

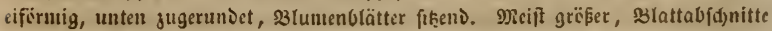

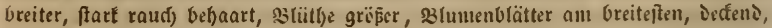

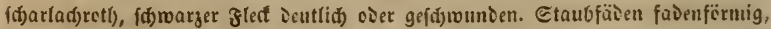

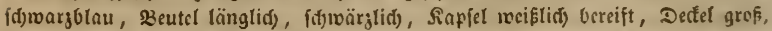

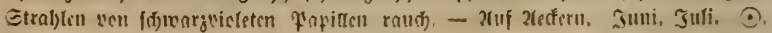
Söufig. 
1765. P. trilobum Wathr, Rснв, Dentschl, Fl. 266its. 4480. Sapfet untgetelyrt eiförnig, fo wie Der äftige Stenget taht, Seld)e und sitattpticle gewimpert, 3lappig, ftumpf (an Des 3lutorz̉ 2lboiloung: fpihig), blaugriin, von

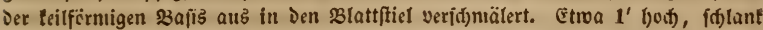
und jart. Blüthentnospe nur erbjengroß, B1. Elein, fatt bod)rett), gearbe Sifrat).

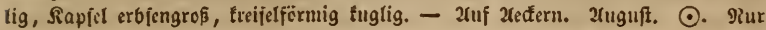

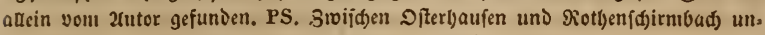
ter Vicia Faba und bei şeringen zmifíten Brassica Napus.

1766. P. somniferum L. Rснв, Deutschl, Fl. 266birs. 4t81. Bläus (id) bercift, neift tal)t, slätter umfailend, eingefd(nitten, Sapfeln faft $t u g l i g$, Viarben vielftrablg, Defel borijontal, Sëd)er offen, Sdjeiderände Dem Mittelpuntte fi d) näberno: 2-4' bod, słtume lita, rotb, weis, in vies Ien Reüancen, fdswarjer fled Dentlid) oder vertofden. Saamen bedtblau. -

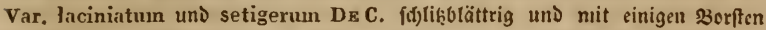
am Etengel, slütlenftielen und Seld. Opr. f. folg. - Zuб Den Drient. Juni - 2uguft. $\odot$. 2ulf bebautem $300 \mathrm{en}$, bäufig verivildert.

1767. P. officinale Guex. Rснв. Deutschl. Fl. Y66ito. 4482.

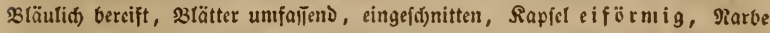

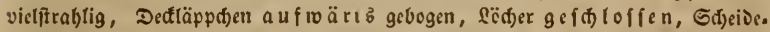
wänie yom DitteIpuntte weit entfernt! $4-6^{\prime}$ hod, 231. weif, glex́

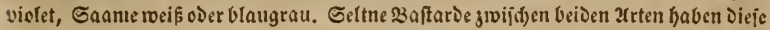

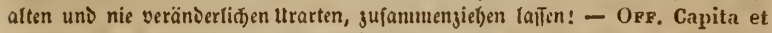

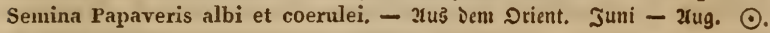

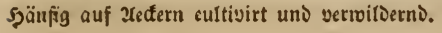

C. Berberideae, Betberib̧en, ๔taubgefäfe beftimmt züblig, Beutel flappig, Blumenblätter y or ben Reldblättern.

570. Epimedium L. So ffe $\mathfrak{b} \mathfrak{b} \mathfrak{u m c}$. Reld) 4b(ättrig mit

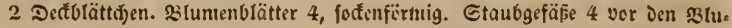

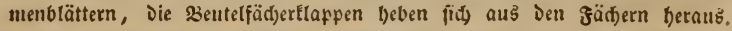
Sapfe1 fđötthenförmig eistriljig, vielfaantig.

* 1768. E. alpinum L. Rcer. Deutschl, FI. 266ito. 4485. Fl, germ. exsicc. n. 1283. Etengelbtatt Doppelt 3jäblig, s3ättd)en ber fiürmig cirund ju= gefpikt, rointperartig gefägt (fpätert)in biß $2^{\prime \prime}$ lang). MBurjelifof faft fnonig,

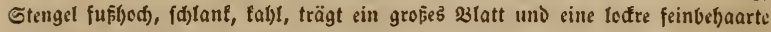

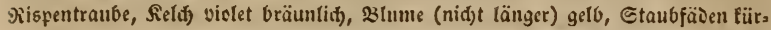

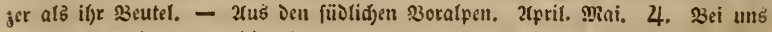
ill F'artś im Grafe verwilderno.

571. Berberis L. B̧erberiţe, Sauerofit. Seld fed)s.

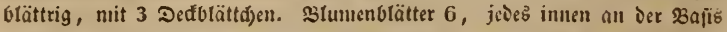

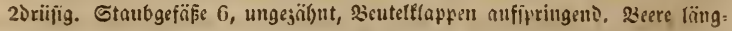
ling, 2 - 3ianmig. - Siliityen uns Enft gett, 


\section{Papaveraceae. $\quad-394-\quad$ Berberis.}

1769. B. vulgaris L. Rснв. Deutschl. Fl. 2u66ilo. 4486, Blätter vertehrt eiruno, mimperartig gefägt, büiffelftänoig, 2ldjelloornen 3theilig, इrau. ben bängen๖. Murzel borsig, innen gelb, Etamm ftraudjartig $6-10^{3}$ bod, Sinie riffig, Blume gelb. Beere fdjatla(t)roth), fauer, Saame ffeinbart, Reim.

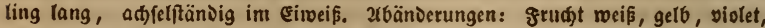

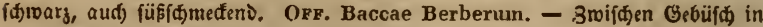

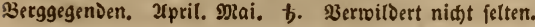

\section{Familie Violaceae, Beildhengewähbie.}

- 5erbarienfuc) ธ. LXXVI und 1S6. -

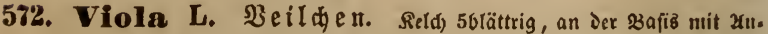
bängfeln. Slume unregelmäßig 56lättrig, untres \$lumenblatt gefpornt. Sapfel 3tlappig, vieliaamig.

a. Dischidiun : Rarbe tappenförmig auzgeföblt, faft 2lappig.

1770. V. biflora L. Rснв, Deutschl. Fl, 2 t6gitb. 4489. Fl, germ. exsicc. n. 687. Stengel 26lättrig, 1-26lüthig, Blätter nierenrunb, fägeran.

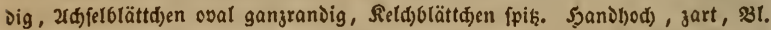

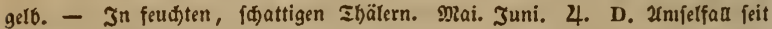
Hasse. Utemaloer Grund. Bauer. Hornberger. PL. ₹afelfingte. Burkhardt. Kölbing. - HS. Infelşerg. Schönheit.

b. Violetta : Ģriffel trompetenförmig. Bergl, Deutfdlan১s హlora II. ธ. 22.

1771. V. palustris L. Rch8. Deutschl. Fl. 2robild. 4491. Sten.

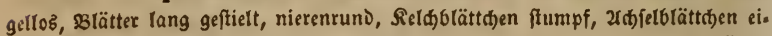

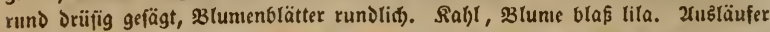
Dünn, lang. Rapfel länglidgrund, ftumpflid). Gaanten heabräunlid, in jever

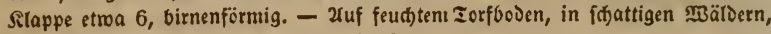
zwifđen feudtent Moofe. Mai. Juni. 4. Nidet felten.

1772. V. uliginosa Schrad, Rснв. pl. crit. 1. 107. Deutschl. Fl. 2666ilo. 4492. Fl, germ, exsicc. n. 68s. Blätter herłförmig Dreiectig läng=

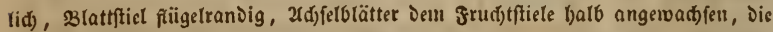

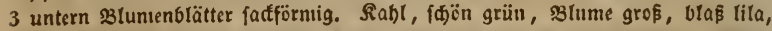
Blumenblätter breit, unten abgerundet, etwas aubgef(d)meift, fd)wad) liniirt. शarbe

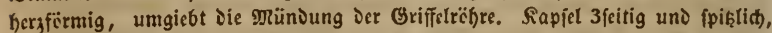
in jeder Slappe 12 - 15 Saamen. - 2uf Moormiefen. März. 2rprit. 4. Set.

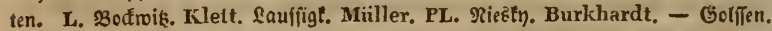

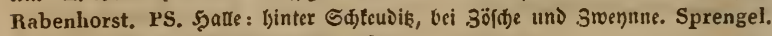
জSicl)e. Wallroth. Gotolauter. Küitzing.

c. Viola: Eriffel balig.

1773. V. hirta L. Rснг. Deutschl, Fl. 2666itd. 4493 . Fl, germ.

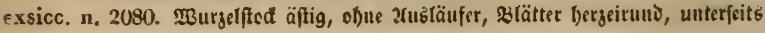




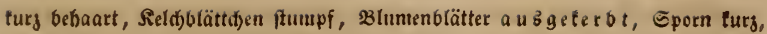
tegelförmig. Blätter fpäterfin febre greß, faft hersförmig länglid), fo roie Die slü. thenffiele roeid) bel)aart. 31 . bla lila, gerud)los. - b. fraterna s. parvula:

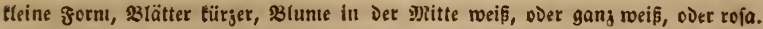

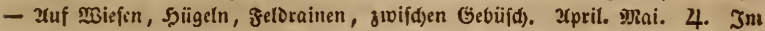

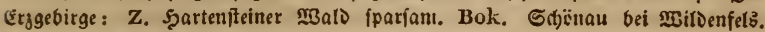
Wankel. Juferienı nidjt felten.

1774. V. collina BEss, Rснв, pl. crit, x. ic. 92. 93. Deutschl. Fl. 266vild. 4497. Fl. germ, exsicc. n. 2081. Etengellos, ol)ne 21usläufer, fein vel)aart, Blätter berjförmig, Eporn taum tïrger als Die ftuntpfen నeld)blättd)en, Blumenblätter länglid, a b ger $u$ n Det, Die nittlern faum gebartet. 28 lunten tlei.

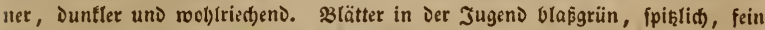
bel)aart, ' im 2ulter Duntelgrïn, faft tabl merient. 2(d)felblättdjen langjäl)nig,

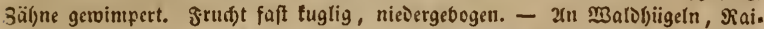
uen. 2pril. Maa. 4. Ueuferft felten. D. Gröbern, G. Rchb, 1841.

1775. V. odorato こ hirta Rснв. Dentschl, Fl. 2166. 4497 b.

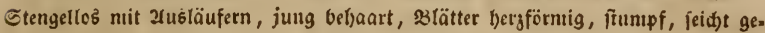
terbt, faft fal)l mervend, Reld)blättd)en fpiblid), B(umenblätter länglid), abge.

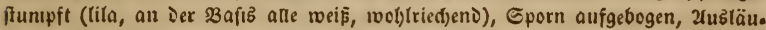

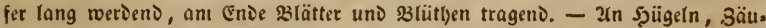
nen. 3pril. Mlai. 4. Єel)r feltell. Z. Bei Mei১a. Rossmäissler.

1776. V. odorata L. Rснв. Dentschl. Fl. 2166ild. 4498. Stengellos mit 3usläufern, fein bebaart, Blätter tief berjförntig, runうliđ, tappenförmig, Seldblätter ftu mı p, Die oberen \$lumenblätter länglid), wenig fdntäler als ১ie

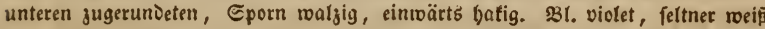
Doer rofa. Epätere Blüthen (vergl. Die abbild.) baben einen zufanumengeneigten

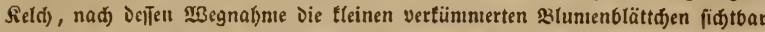
werden, innerijalb Deten Die frudytbaren Staubgefäfse, Der Şonigfporn und Die batige giarbe, endtid) Der Frud)tfnoten, Der fid) ans Diefer slütbe a ltein jur faft tugeltunDen, matt violeten Sapfel entwidelt, Saamen birnenförmig, bräun. liđjgelb nit Differ 9ebelwulift. - Jn Graşgärten, Malotriften. März. 2prit. 4. Sientid) verbreitet, bauptfäd)lid) auf Saltboven, faft auf alden alten Sd)lopber. gen, unt nod) bäufiger cultivirt.

1777. V. arenaria DE C. Rснв, pl. crit. 1. 142-146. Deutschl. Fl. abbito. 4500. Fl. germ, exsicc. n. 1583. Etengel rafenförnig, aus der

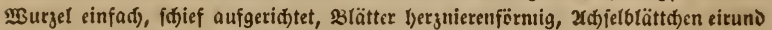
länglid), langjäł)nig ge[ägt, Rel(f)blättd)en fpik, unten ganj, Sporn waljig, Лap. fel fein beljaart, ellipfoidifd) freifelförmig, ipibilid). Sleinfte 3 rt, anfangs ftengel. I08, Blume blaß̧ lila. - 2uf Dürrem Gan১boden. 2xpril. Diai. 4. D. Şeide.

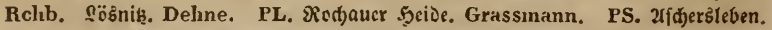

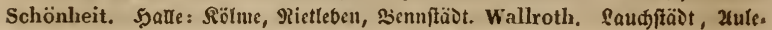
ben. Wallroth, SRS. grautenthaujen. Klett. Hormung.

1778. V. cauina LrNe. Rснв. pl, crit. 1. 150-155. Deutsclit. Fl. 2rbbits. 4501. Fl. gemn. exsicc. n. 297. Stenget fłäterbin auffteigent, 


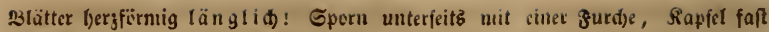
walgig, in seben: a bgeft ut t mit purz aufgejętem Epif̧ben. - H. flatvicornis S.r. (calcarea et sabulosa R.) kleinfte frorm, slätter türjer, Sporn gelb. liđ). - b. ericetorun Schrav. äjtiger uno grïfer, slätter mef́r länglió, Sporn

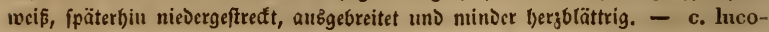
rum: Stengel aufgeridytet, halo bis gan; fubl()od), 33lätter und 23 lütben länger gefticlt, હporn rocifíti. - d. montana L. Fr. Rcнi, Deutschl. Fl. t. XL. (canina $\gamma$. stipulosa PeTrRs.) üppiger, aufïteigeno oder ganj aufredt), slätter uns şü̈tle grëßer, erjtere nidut in Den Etiel berablaufend (DaDurd) von V. Ruppii verfdic১en), aber eben fo wie bei Den übrigen loergeirunb längli d)! X(d)=

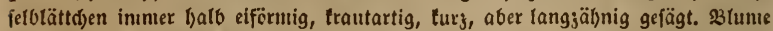

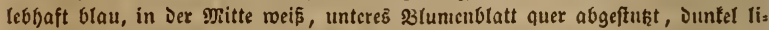

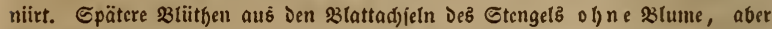
adein tapieltragent. - a. und b. auf jandigen uno fteinigen sriften, trodinen

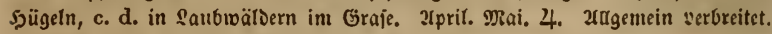
- Sergl. unjer Deutid)l. Flora II. S. 30 - 32.

1789. V. Riviniana Rchв. pl, crit, I. ic. 202. 203. VII. ic. 821 . Deutschl. Fl. abbito. 4502. Fl. germ. exsicc. n. 298. 2ufiteigeno, şätter

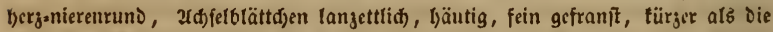
3lattfiele, Sield)blättd)en unten geftust, slumenblätter breitlidb jugerundet, Epoun toaljig, farbloz, unten mit $f u r d$ e! slume am grëften, blas lila oder mild)blau. - In fd)attigen saubwälbern. 2(pril. Mai. 4. 2ugemein verbrei. tet, zuterf von $\mathbf{R}$ iviuus trefflid) abgebiloct uns nie zu verfennen, - Siergl. unire Dcutid)l. Flora H. Є. $32-34$.

1780. V. gylvestris (Dodon.) Lax. Rchв. pl. crit. I. ic. 200. 201. VI. ic. 822. Deutschl. Fl. 26b6ito. 4503. Fl. germ. exsicc. n. 299.

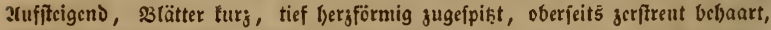

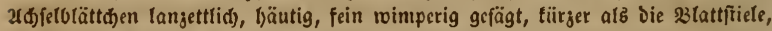

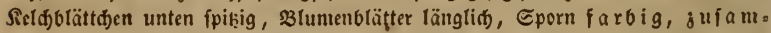

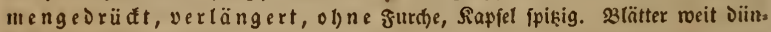
ner, alle Iheile id)lanter, eben fo Die S3lumenbl. geftrefter, Diefe Duntler lila. Sosn

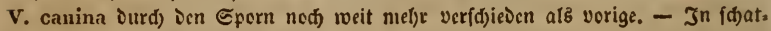
tigen \&aubrälbern. Tpril. शat. 4. 2ugemein werbreitet. - 23ergl. unfere Deutíl. Flora II. G. 34. 35.

1781. V. mirabilis L. Rcrв. Deutschl. F1. xbbils. 4504. Stengel 3tantig, einreibig bchaart, aufred)t, 3lätter jung bütenförnig, nierenrund bergss

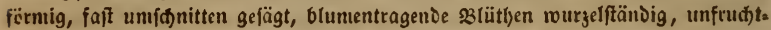
var, ficngelftändige blumenloz, frud)toar, 2d(bfelolättd)en langettlid) fpił gangran.

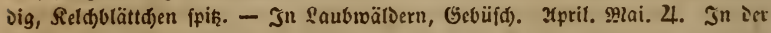

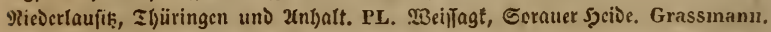

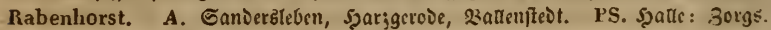

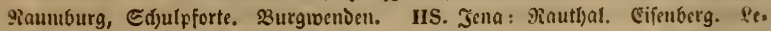

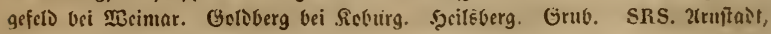
๔d)ala, Mitlinger \$2erg, frebuberg.

1782. V. Ruppii ALL. Rснв, 11, crit. 1, ic. 205. 206. Deutschl. 
Il. 2606. 4505. Fl. germ, exsicc. n. 1770. 2(ufred)t, faft ganz tabl, 3läts

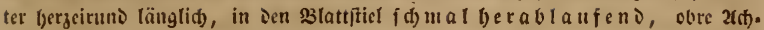
jelblätt(f)el blattartig, eingeid,nitten gefägt, Sporn etiva Doppelt io lang als die

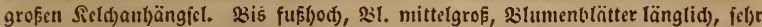

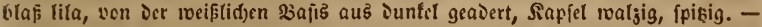
3(n feud)ten, fd)attigen Drten in Sergioäliern. 2(pril - Juni. 4. Sel)r felter.

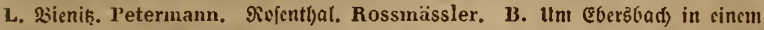

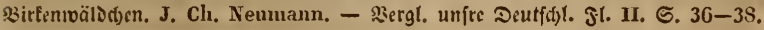

1783. V. lactea Sir. Rснв, pl, crit. I. ic. 20S, Dentschl, Fl, 2fo. vilb. 4507. Fl. germ, exsicc, n. 1080. Gans tabl, Etengel unten viclidjup.

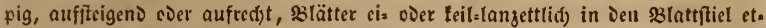

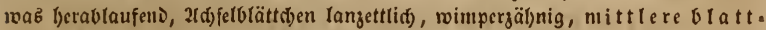
artig, meift balo folangalbif)r 3 lattftiel, Fapfel tlein, ciförmig

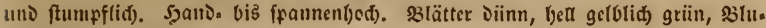

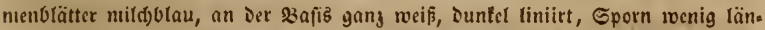

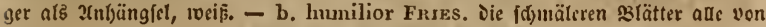

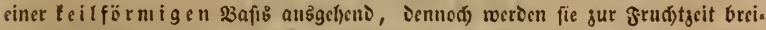
ter. Sie ift V. riphaea Krocker amo 1787 und V. pratensis M.K. anıo 1826. Rснв, Deutschl, Fl, 2ubild. 4507 b. t. XVII. Da隹 Kitaibel cinmal sin frudteremplar Diejer Finange ol)ne 23 lütben, vou tweld)em id a. a. D. sin Stüd abbilse, für neu bictt uno V. stagnina nannte, ift mun wie id) loofie

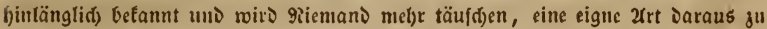

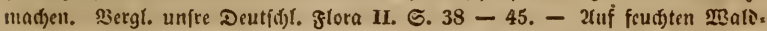

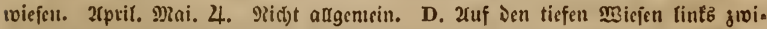

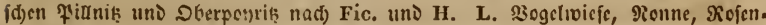

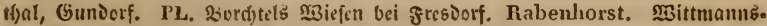

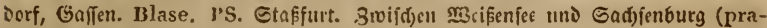

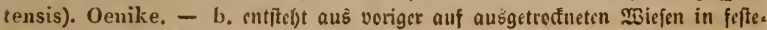

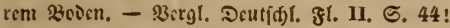

1784. V. persicifolia Scnк, Rснв, pl. crit. I. ic. $209-210$. Deutschl. Fl. 2t6vito. 45(נ). Etengel farf, fteif aufred)t (fufirod)), Blätter ei.

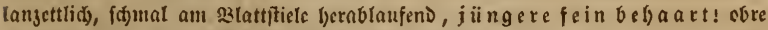

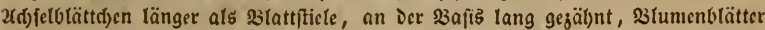

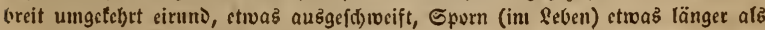

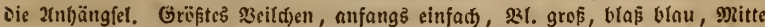

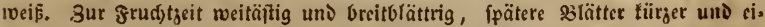

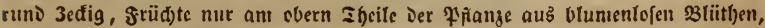

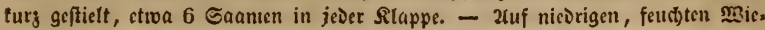
ien, zroifd)en, Gebiifd). Mai. Juni. 4. Gelten. D. 1809 auf Der niestigen Wicfe an zuffecige nad) Striesen. Ficinns. Seitoen ftetz vergeblid) gefudst. L.

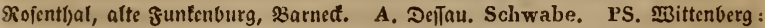

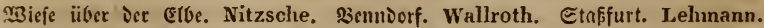

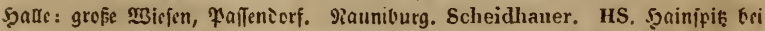
હifuberg. Geyer. Geinitz. 2llperftä̀t. Hornung. 
d. Grameionium Rснв, consp. anno 1828. Etiefmütterden, Rarbe trugfirmig, 2țjelblättdoen meift ficieripaltig. *)

1785. V. tricolor L. Rснв. Dentschl. Fl. 266tito. 451\%. æ3urjel

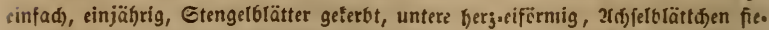
Derfpaltig, Die mittlern 2r6fdnitte verlängert. - a, arvensis MURRAY. $\&$ Iunse toeißlidg gelb, tleiner als Seld. - b. tricolor vulgaris : Dbre Blumenblätter fanımetartig violet, feitlidfe weif, untres gelb, Diefe 3 mit Duntlen finien uno meît violeter Epib̧e. - c. bicolor Hoprsx. alte Blumenbrätter lita cier siolet,

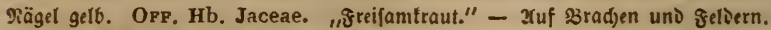
Diärs - Roventber. ๑. Gentein.

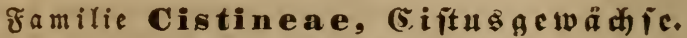

- Sperbarienbud ๔. LXXVII und 188. -

A. Drosereae, Sonnenthaugemädje, Ctaubgefäpe beftimmt= záflig, Erifiel getrennt.

573. Drosera L. Eonnenthau. Seld) 5theilig. Batunte 5.

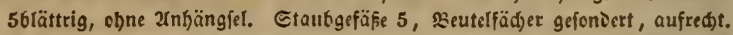
Grī̄el $3-5$, jweitfeitig. Sapfel $3-5$ tlappig, auf ier innern glädje mit Eaamen beiećt. Gaamen bei 1787 uno 1788 nit lecórer Eaament)aut.

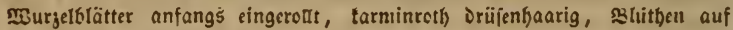

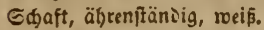

1786. D. intermedia HA Y xE, Rснв, Deutschl, Fl. 4523. Fl. g. exs.

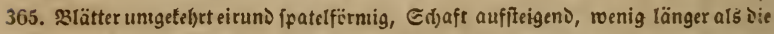
Blätter, Narben ausgeterbt. Siätter uno ๔तुaft wenig ïber gontang. - 2un

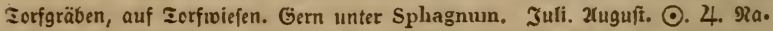
mentliđ im ह̈ftliden und mittlern Gebiet. D. Fonitau, ๔teinbad), Mloriş6urg, Berbisiorf, firayern, Şeller, Saufa, Somnik, Єdjënborn, Dtteniorf, פaunjorf,

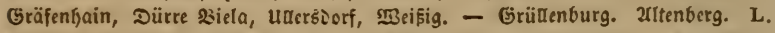

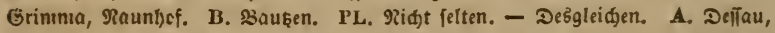
Srieierifenberg, 3erbft, Spunjeluft. PS. \$Bittenberg: Epccte, Sabck. Şalle: Silutegelteid) in Der Speide. Dëlau. Senniorf. Edracenmalo bei Drtrano. ๔ర)leufingen. 3iegenrüđ.

1787. D. longifolia L. Rснв, Deutschl, Fl, 2t6́irs. 4524. Fl.

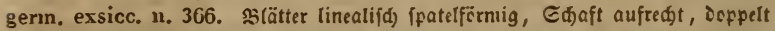

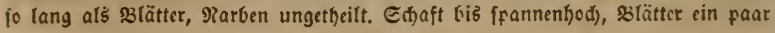

*) Mer Diefe xbthcilung jeht nod) Melanium nennen wollte, miiffe dic alt c Gattung Melanium im mer nod) $n$ i d) t fennen, coer Die 2(ušeinanierfekung, iie id in meiner f̂lora Deutidjlanis II. S. 48. gégeben habe, nicht gelefen ha. ben. - Die fóbinen sarietäten Der fogenannien Pensées in unfern Gärten fammen nidt von V. tricolor, foncern von V. lutea Sar. vergl. Dentschl. Fl. abbilo. 4519. und V. altaica PAxL. B, Reg. 5t. ab. SBcrgl. unfre Deutfdi. ficra iI. Є. 56. 
3ou lang. - In Iorfmooren, Ende Juli. 2uguft. 4. Sefir felten. D. Saufa Ficinus. Rchb. Strinbaต̆. G. Rchı. Dehne. PL. शies̆ty. Burkhardt. -

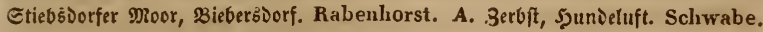
PS. Soderslcbener forft. Wallroth.

1788. D. rotundifolia L. Rcre. Deutschl. Fl.2666.4522. Fl.g. exs.

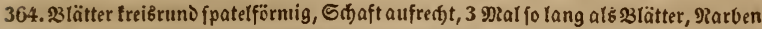
ungetlyeilt. Slä̈tter biß über jollang, Eđaft bis fpannenlang. - 2uf torfigen

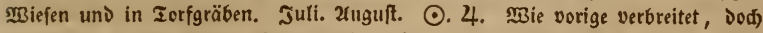
näufiger. D. 22n gleidyen હtellen nit voriger. - Grüllenburg, 2lttenberg, 3inn.

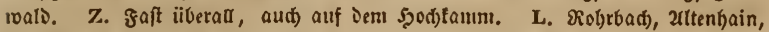
Großbothen, Bodwik, Madjern, Saunt)of. B. SBcrtbelsjorf, Bernftadt, \&ubađau, Sleinwelle. PL. Sebr gemein. - Desgleiden. A. Deflau, Friederitenberg, 3erbft, Sounieluft. PS. Barby: Foleimülyle. Siestau. Єubl. Sdradenmals bei Dr.

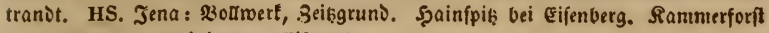
bei alltenburg. Mteiningen. Eifenad).

\section{B. Cisteae, eigentliđje (Eiftusgewäđje, vielmännig, bie 5 Blu= menblätter in ber Rnoz̉pe zujammengefnittert.}

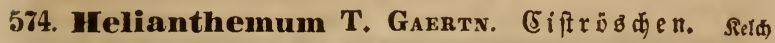
3blättrig, nebft 2 äufern tleinen शebenblättd)en (over Diefe fehlenv). Rapfel

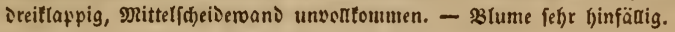

1789. H. guttatum MrLc. Rснв, Deutschl. Fl. 26roilt. 4526. Srautartig, 23lätter gegeniiber, lanjettlid), 3nervig, raud velyaart, wourzelftändige

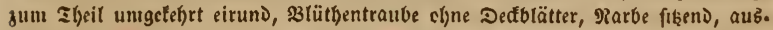

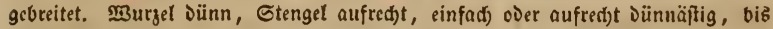

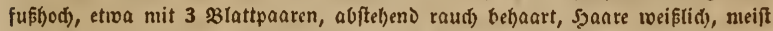

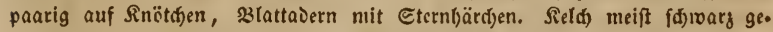

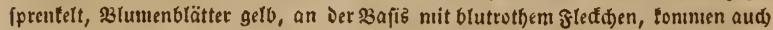
orge Diefe vor und ganzrandig coer ferbrandig. - 2uf Dürtig begraften Eand. l)ügeIn unঠ GanofelDern. Öern mit Calluna, Euphrasia, Ajuga, Spartium

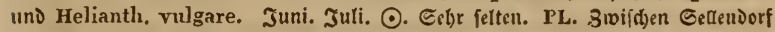

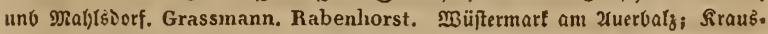

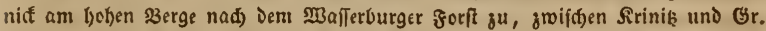
Melyfor. Rabenhorst. A. Purbberg. Schwabe. PS, MBittenberg: unweit

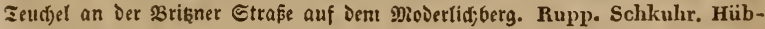
ner. Nitzsche.

1790. H. Fumana Mict, Rchв. Deutschl,Fl, afb6ito.4531, Fl.g.

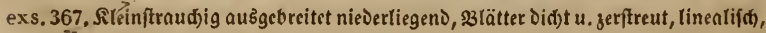

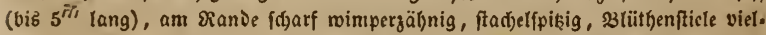

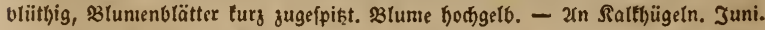

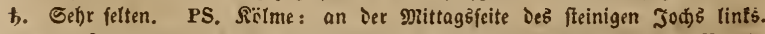
Sprengel. Hübner. Biţenburg zmiffyen 2utrben und 2iotbenburg. Wallroth. SRS. grantenbaufen. Wallroth. Hornung. Fest. 
1791. H. vineale Pers. Rснв. Dentschl, FI. આ66.4533. Fl.g. exs. 368. Siteinftraudjig, auffteigeno, slätter geftieft, ftumpf lanzettlid) oder oval, unten weiffitzig, 33lït)en traubig, \&rudtffiele gerade abftel)eno. 3weige meift roth ange=

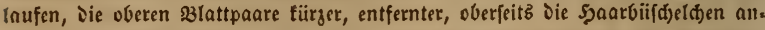

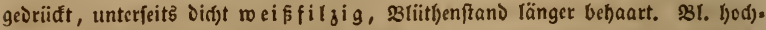
getb, faum länger als Sield), Grifîfl türzer als ber jottige frud)tfnoten. -2 (n

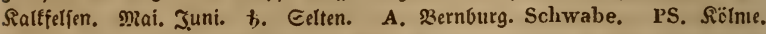

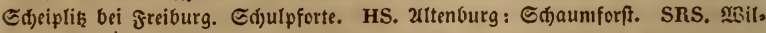
linger \$3erg.' Frohnterg bei Martinrode. Flauifa)er Grund und Eremitage bei żtnjtait.

1792. H. vulgare Gaertev. Rchb. Deutschl, Fl. 2666ird. 4547. Siteinftraudjig, 3weige tang, auffteigend, Blätter gegeniiber, oval elliptija) und länglid), ober(te aud) eilanjettlid), alle tury behaart, getwinipert und am viande

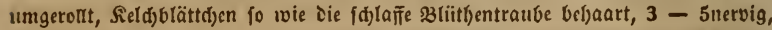

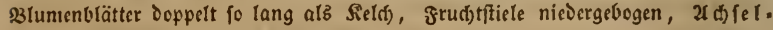

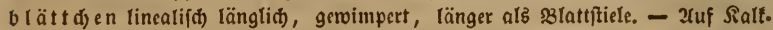

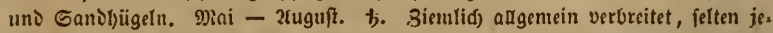
Dod) in bül)ern (Ergebirge: Z. 2(nnaberg. Bok, und in Der Dbertaulfį: B. Gutta, Rlcinţauţen. PL. Jaucrniđ์. -

\section{Familie Ranunculaceae, Rauunfelgewädhie.}

- Sycrbaricnбud) 5. LxXIX uno 190. -

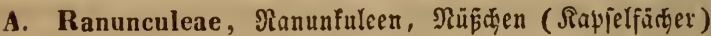 einjaamig.}

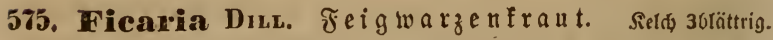

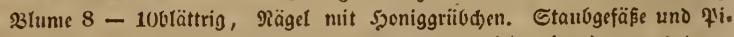
ftide zal)(rcid). Niüsd)en ctwab ffindelförnig ungetef)rt cirund, genabelt. Blune glänjens gelb, $\mathfrak{B} \cap$ fis wie ëlîetig.

1793. F, ranunculoides Мхсн, Rснв, Deutschl. Fl, arobilt.

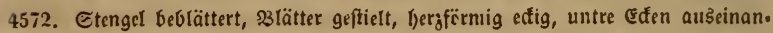

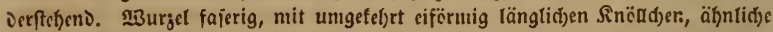

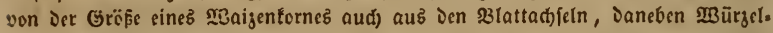

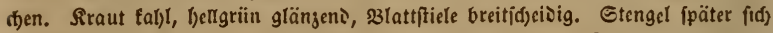

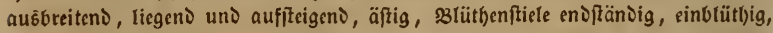
an Der Spişe 5furdjig. - Un f(j)attigen, etwas feudjten Drten, geen in Der Rälye

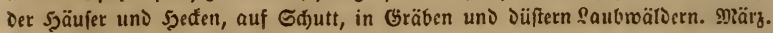

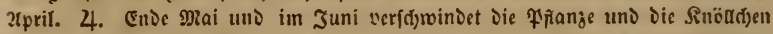

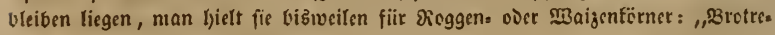
gen": - 2ugentein verbreitet.

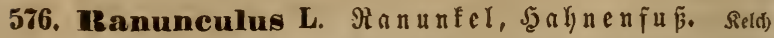

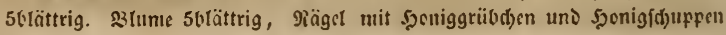


Ranunculaceae. $\quad-401-$ Ranunculus.

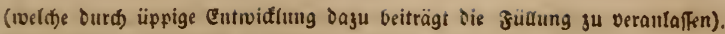

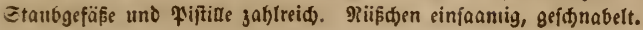

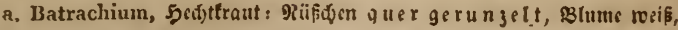
uit gelbem Pingel uno Grübdjen.

1794. R. divaricatus Sснвк. Rснв. Deutschl. Fl, 266t. (circimnatus Sгвтн.) 4575. G(frimmeind, Slätter fte if borftenförmig vieltleillg,

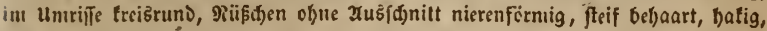

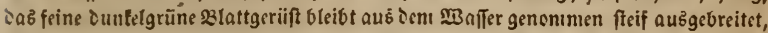

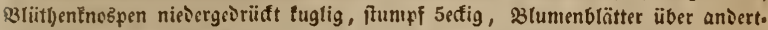

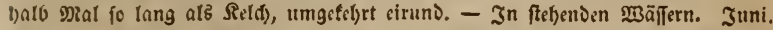

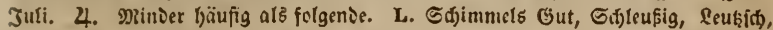

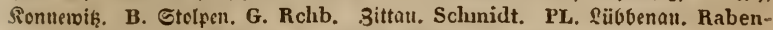
horst. PS. Şatke. Wallroth. SRS. Fautingclle, giubolftaot. Schönheit.

1795. R. aquatilis L. Rснв. Deutschl. Fl. 26б6iro. 4576. бळrims meno, untergetaudte siätter $f$ d) la ff baarartig vieltheilig, idmimmende faft

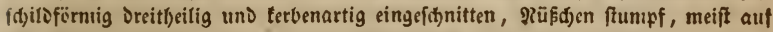

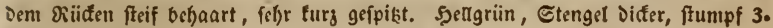
tantig, gabeläftig. Die zarten silattgeriifte falten, aus Dem $\mathbb{3} a \mid j e r$ genonmen, pinfelartig zufammen. Sinespe faft fuglig, nur ১ic Epiķe cin wenig eiförnig ver. Dïnnt, 23 tumenblätter unigetefirt eiruno, $2-3 \mathrm{Mal}$ to lung alb אeldy. 2rbän. Derungen: capillaceus Trumx. ganj untergetaud)t, lauter baartheilige $\mathbf{B}$ lätter. heterophyllus tripartitus uno subtruncatus, subpeltatus, Die fowimimenden Slätter faft 3theilig oder eftig und an ter sajis beinabe quer abgefdnnitten oder

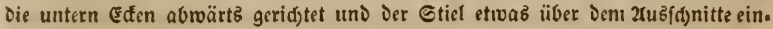
gefügt. - terrestris homoiophyllus : alle 23tätter vielmal gufanmmengefét,t, 216. fdnitte linealif(d) ober nad) Der Epike breiter, terr. heterophyllus : Babei now

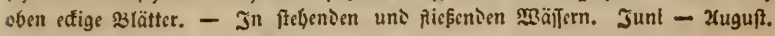
4. 3agentein verbreitet un๖ bäulig.

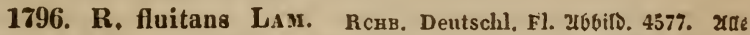
33lätter febr lang baarförmig fd) laff gabelartig parallel gertheilt, Etaub.

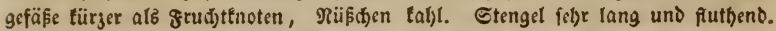

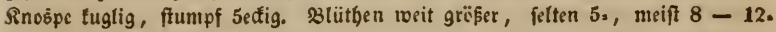

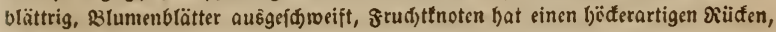

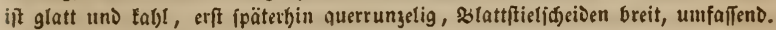

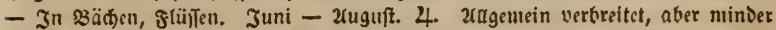
bäufig, an vielen Stellen nur fel)r folten bliibeno.

1697. R. hederaceus L. Rснв, Dentschl, Fl, 2166ito. 4573. Fl. gern. exsicc. n. 1490 . ङ(d)wimment oder trient)end, ale 3 lätter faft nieren. fërnig runDlia), ftumpf 3 - 5lappig, ganjrandig und glatt, Staubgefäße 5 -

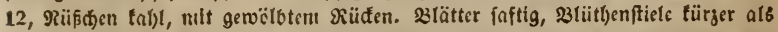

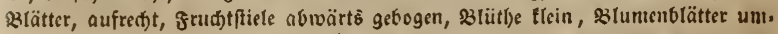

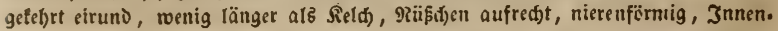

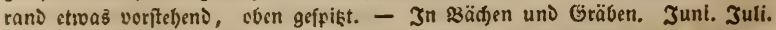

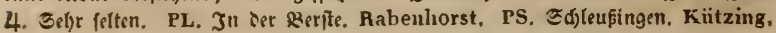




\section{Ranunculaceae. $\quad-402-\quad$ Ranunculus.}

b. Ranunculus : riïđ(t)en glatt.

aа. $\mathfrak{B l u m e}$ reis.

1798. R. aconitifolius L. RснB, Fl. germ, exsiccata n. 1 (s)s. Deutschl. Fl. 26boilo. 4585. $\beta$. platanifolius. Etengel vebfüttert, mel)rblütbig, Blätter bantoförmig $7-5-3$ theilig, zerídlib̨t uno einge[d)nitten, Blütljen

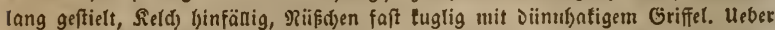

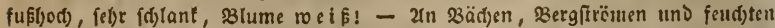
Etetten in Escbirgen. Daai - Eeftember. 4. D. - (3̈̈̈bm. Sinnwald.) 2rl.

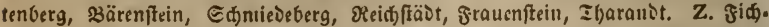
telberg (bis \$latten) uno über Den ganzen Şedtanını; Stein. PL. Syainiorfer

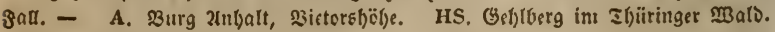
3nfelsberg.

bb. Blunte glänzens gelb.

1799. R. illyricus L. Rснв. Dentscll, Fl, 2666ild. 4587. Fl. gerın. exsicc. n. 887. 24ufreft), 1-3blüthig, 33lätter feiDenartig filberglänzend, erfte lineal langettlid, forgende $3-5$ jäblig gefievert, siedern linealifd) langettlich), Die

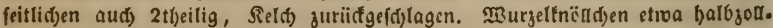

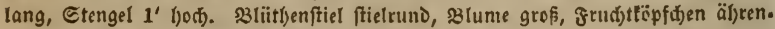
artig. - 2un grafigen Drten auf Candboden. Nai. Juni. 4. Celfr felten. D. Jum grofen Gertäge. Heise. Ficinus 1807. 1SU8. Rchb. 1832. A. Maišorf, Şefflingen. Schwabe. Mzüblingen, am Miïllinger ß̇erg. Scholler. Schwabe.

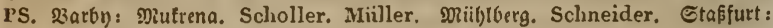
Enten, und Ģalgenberg. Lehmann.

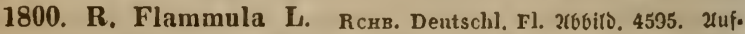

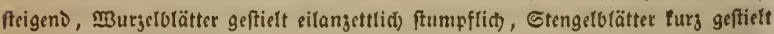

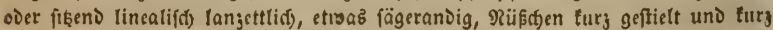

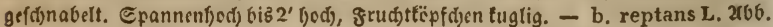
t.X.b. Fl.exs. 1774. Etenget fadenfïrmig bogenartig tried)end, Blätter linealijó,

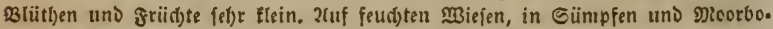

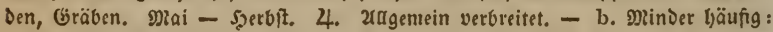

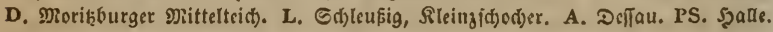

1801. R. Lingua L. Rснв, Deutschl, Fl, 2ubilì. 4597. Fl. gernn. exsicc. n. 1775. Xufredit, Stengel unten an ben Snoten quirtartig murgelnd,

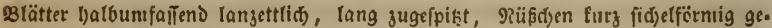

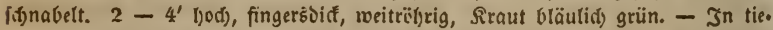

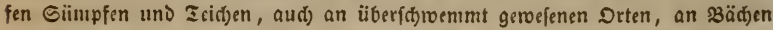

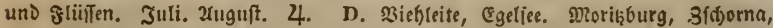

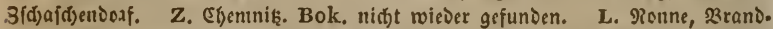

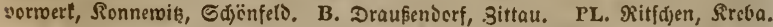
- Nihit felten. A. Berbft. PS. Barbn. W3ittenberg: Speffe, Dobien, Säbelaul. 5alle. Erfurt: ?llad)." Ed)radenwald bel Drtrand. HS. Jena: Gaalthalfiimpfe.

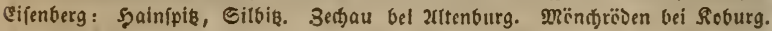

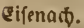

1802. R. sceleratus L. Rcri, Dentschl, Fl. 2robirb. 4598. Sabl, 
fefir äftig, unterfte s3lätter handfërnig 3 - 5theilig, obre gefingert, 2ub/dnnitte

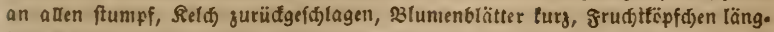

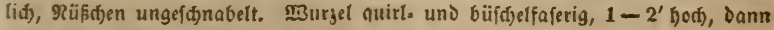
fettitenglig, Blütbenffiele etroas̉ fteif, febr zablteid), roenig behaart, fcin gefurdtst. Blütbe ₹lei $n$, Blumenblätter roenig länger als Reld), längliđ). Sđđarf giftig !

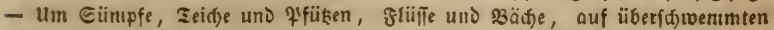

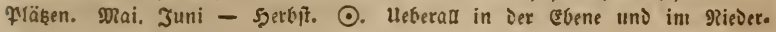
gcbirge.

1803. R. auricomus L. Rснв. Deutschl, Fl. 2666its. 45999. Fl.

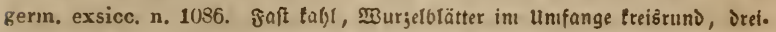
lappig over nteljrtbeilig, felten ungetheilt, geterbt, Etengctblätter fingerförmig aus.

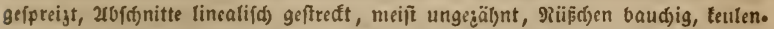
förmig, gefónabelt. \$3urzel faferig, Etengel (pannen, bis fuflyod), s3lütt)enftiel ftielrund, szlume meift tlein, aud nur bie Reldjblättdoen invendig gelb: calycanthus, vergl. beibe ebere figuren, ober Blumenblätter beppelt fo lang als Reld), Dann iie ganje ¥ranje ïppiger und Die હtengelblattabid)nitte eingefdanit. ten: var. incisifolia t. $\mathbf{X}$, untre figur, var. pinguior, nit gröfern, fettern

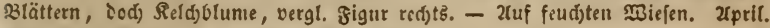
Drai und 5eerbft. 4. 2aggentcin verbreitet.

1804. R. acris L. Rснв. Deutschl. Fl. t. XVI. bis. 2r66ils. 4600.

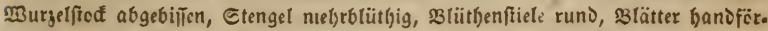
mig 3 - 7theilig, abofdnitte linealifd gerịhliţt, oberfte Ctengctolätter linealifđ)

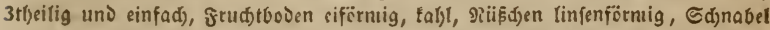

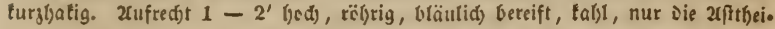

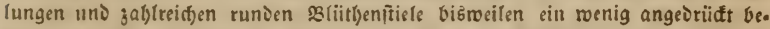

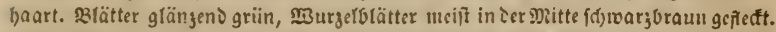
- b ? Stereni Axdrz. 2(66. 4605. NBurjelffecf trictí)cno, Etengel und Die bteiteren

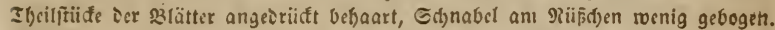

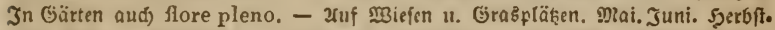
ferm 266. t. XVII. 4606. ๑. 2ugemein verbreitct. - b? neljr in 3erggegenden.

1805. R. polyanthemos LOвEL. Rсвв. Dentsch. Fl, 2666. 4607. य b fteben D raud, \$3urjelblätter baniförnig jertbsilt, 2rofd́nitte linealifd) (an.

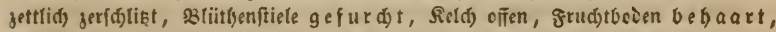

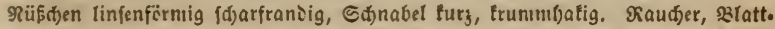

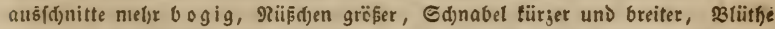
grëßer. - 2uf miefen in Saubwälbern. Mai - Juli. 4. Serîtreut. D. शaîe 2(ue. Sidjenet Gruno, Sedwik, Srcifda, Seuonik, Sotta. L. Seukf(d), 3(d)edjet,

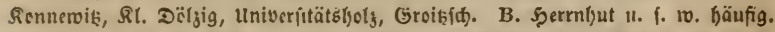

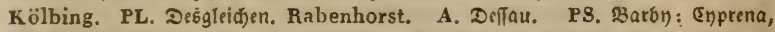

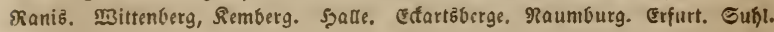
HS. Jena.

1806. R. aureus Schleich, anno 1815! Rcab, pl. crit. II. 252.

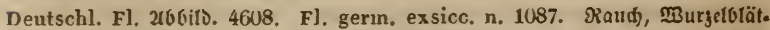

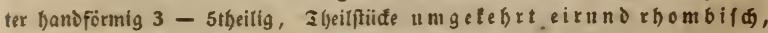

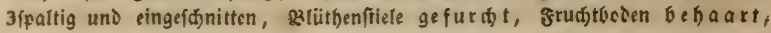




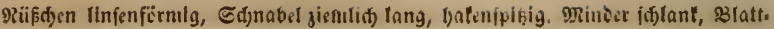
foreioen länger, salattabfit)nitte breiter, in Seben braun geficoft, slätterftiele ftei. fer, szlume melgr bod)gelb, Sdjnabel länger. - Jm bübern Gebirge auf fteini.

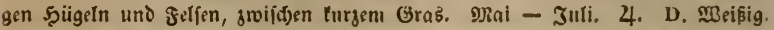
Ficinus, G. Rchb. Z. Sodfau, Sdjrarzenberg, Eibenftof. Rodig. Sdjneeberg, ङtouberg, Mitoenfcls. Wankel. Jol)anngeorgenftabt. Brumner. PL, 3wifden

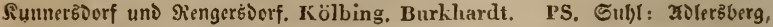

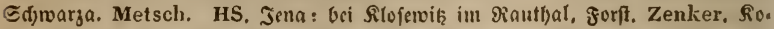
burg. Hornung. Giub. Metsch. SRS. Frantenl)auf(cn. Hornung.

1807. R. lanuginosus L. Rcrв, Deatschl. Fl, 2r6birb, 4609.

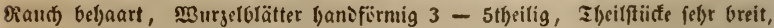
unigefefrt eirund, cingefd)nitten gezäl)nt, jung ctwas feidentbaarig; Stengel viel. blütbig, Etiele ungefurd)t, grudbtboien tabl, räßsten linfenförnig, Sđbnabel ringförmig fpiralig. Leber $2^{\prime}$ bod), roeitäftig, 33lätter (cl)r großß, braun gefiect, oberfte Blätter lanjettlid) einfad). - 2n feudjten Drten fajattiger saubwälder $u$. Tl)äler. 2tpril - Juni. 4. sidjt felten.

1808. R. repens L. Rснв, Dentschl, Fl, 2666. 4610. Ras)l, 21ub.

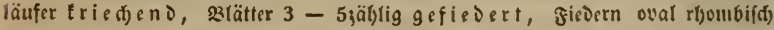

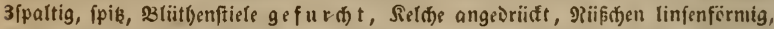
eingeftoden punttirt, Siel 3rippig, હdjnabel jientidi) gerabs. Ctenget bis fus. lang, auffteigeno, bismeilen nad) oben etwaś bel)aart. 2ušläufer an fel)r feuds). ten Drten fefre lang und Dann aud blübend. In Gärten aud flore pleno. 2uf feud)tenı \$zoden, in Gräben, an Dämmen, కeicben, nallen MBiefen und Irif. ten. Mai - Scerbft. 4. 2tgentein verbreitet.

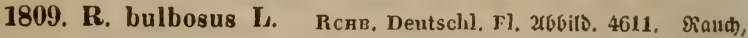
NBurgelblätter Dreigälylig cier Doppelt Dreijählig (audi) Dreitbeilig), slättç)en orci. fpaltigfikend, Stengel unten fnollig angefduvoden, aufred)t, mefrblütljig, satii.

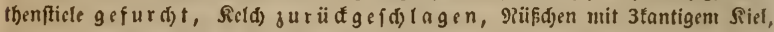
lurjenı, gerabent Sđanabcl. Epannen. bis über fufbod), graulia). - 2uf ₹rif.

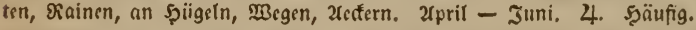

\section{R. Philonotis EнRн. (hirsutus Art.) Rснв. Deutschl.}

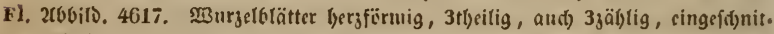
ten geferbt, cberfte (angettlid) 3ipaltig. Stengel allfect)t, vielblütl)ig, 23tüthen.

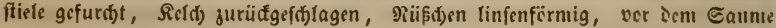
eleinbëcferig. Dem R. bulbosus äl)nlid), aber 1) better grün, 2) oljne 3roiebcl.

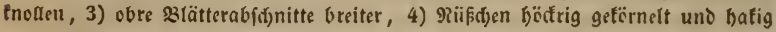
gefdinabelt. - 2in fcudten, fumıfigen, überf(fiocnumten Drten. Mai - Juli.

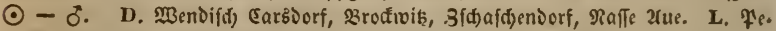

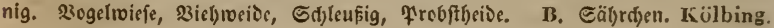
PL. Sucfau. A. Detau, R̈̈tben, Zerbft. PS. Rotbenburg.

1811. R. arvensis L, Rchs. Deutschl, Fl, 2666ild, 461t. W3urgel.

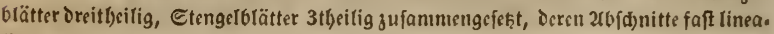

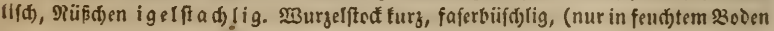
etroas verlängert). Murzelolätter cinfad), andre teilförmig fädjerförmig, eingcfónltten 


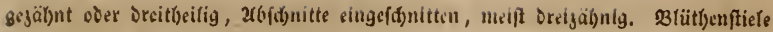
sen slättern gegeniiber ober ticfer, etwaš bet)aart, gur frudgtgeit taum gefurd)t

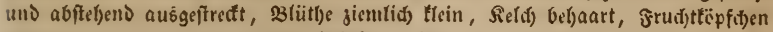

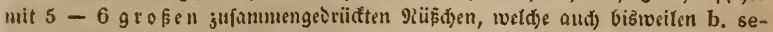
getalis W. K. nur tur' fpiblyëderig, vergl. $266 .$, oder c. leiocarpus : fajt gand böderlos fins. - 2uf 2edern. Mal - Juli. ○. G̈emein. Ju Ëjgebirge: Z, firgtentuarde.

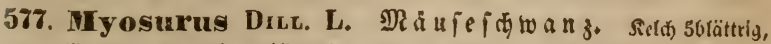

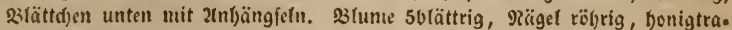

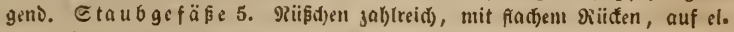

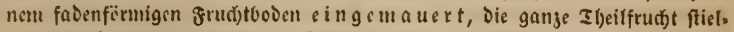
runঠ, f(f)wanzartig verbünnt. Sieimling (Gattung 577 - 583.) rängend.

1812. M. minimus Dicl. Rснв, Deutschl, Fl. 2666ito. 4569. Sd)aft jur 3 lütl)egeit fo lang als ble 3 lätter, Seldganbängiel foft blattartig.

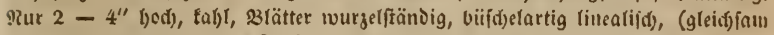
nur Saamenblätter von Adonis!) ctwas breiter weroent, ftumpf, gangrandig, Didflid). S(bäfte aufred)t, etwas veroidt, einblütbig, 231. gelogrün, fru(t)t bis 2" lang, Der lange frud)tboden nod) nekgrubig, Die gï̈s(t)en Did)t verntauert, fpiralig

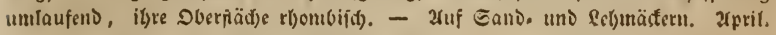

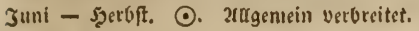

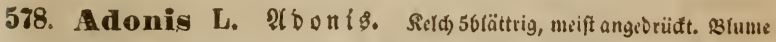

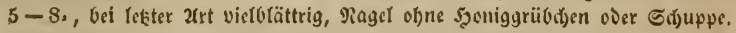

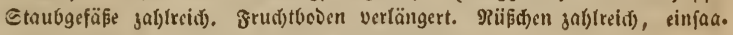
nig, gefớnabelt. - 23ättex foin jufanmengefeșt.

1813. A. aestivalis L. Rснв. pl, crit. IV. 490 - 404 . Deutschl.

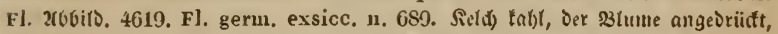

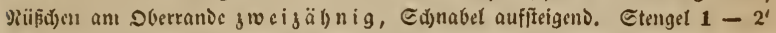
(jod), aufre(b)t, au(b) aufre(j)t äftig, gefurdjt, unten etwas bebaart, Saanienb(ättex (inealifd) geftredt, 3 lätter 3 fad) gefiebert (Denen Der Matricaria Chamomilla äbnli(b)), 33(umenb(ätter meift 8 , aแธ่gebreitet, länglid) ungeffebrt ciruno, mennig. rotl): A. miniata JAcQ. ober ftrolygelo: A. citrina Hoffar, meift au Der $\mathbf{B a f i b}$

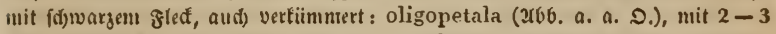
36umenblättern. Frud)t ïber jedlang. - 2uf bebautem Boden, 2leffern, Gd)utt,

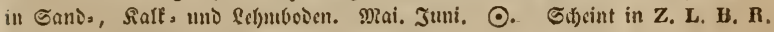
bisher nid)t becbad)tet, allferbum ftellenmeife.

1814. A. flammea JacQ, Rснв, pl, crit. IV, ic. 495. Deutsch.

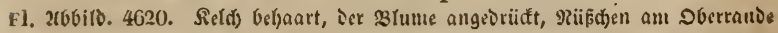

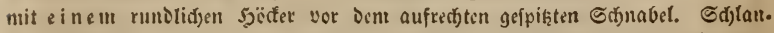
ter, slätter filler (wie bci Clirysanth, inodorum), 3tueige mel)r abftebent, sklu. menblätter meifi 8 , länger, an Der Spişe gegäl)nt, gefättigt jinnobertoth), mit oder (f)ne f(f)wargem gleit, - anomala Warl, Fl. germ, exsicc, n. 8S8., 2166.

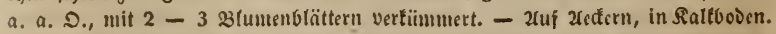

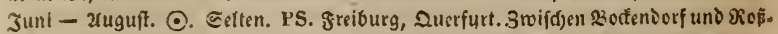
Icten. 2uleben, zilleia. HS, MBeimar, Zena, Roburg. SRS. Grantenlyaufen, Eingen. 


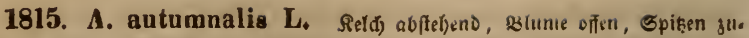
fammengeneigt, Nüßđ)en an Dberrande bogig, Griffel horizontal. Etras robu.

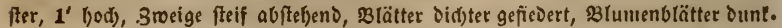

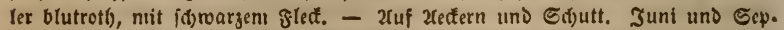
senıber. ๑. Bermiltort. A. Sanderôteben. Schwabe. PS. Şalle.

1816. A. vernalis L. Rснв. Dentschl. Fl. 266bilb. 4622. Fl. germ. exsicc. Cent. XXII. Perennirend, Błumenb(ätter 20 over mefyr, Ianjettlid, an

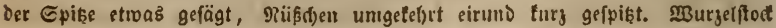

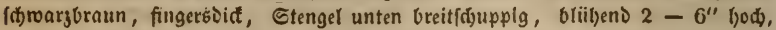

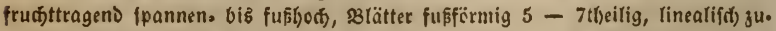
gefpist gefieiert. Bläthe groß, in Durd)meêfer über $2^{\prime \prime}$, ranuntelgelb, anfangs

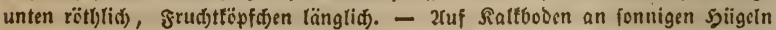

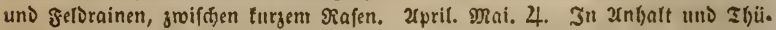
ringen: A. SanderBleben, Bernburg, şarj. PS. Bennftäbt, Rölme, \&angenbo.

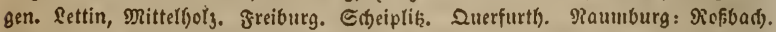
Eđartsberge. Grofmonnra, 3urgmenden. HS. Jena: Forft. Eifenad): Marttberg. Gotha: Eeeberg. SRS. Erentitage bei ximptadt. grantentjaufen.

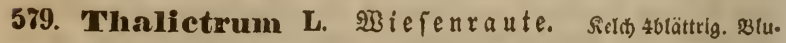
me febrt. Parben berzförmig, Niißsen längśrippig.

1817. T. minus L. Rснв. Deutschl. Fl. 2abbitb. 4627. Etengel

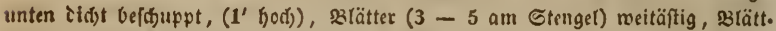
den unterfelts graugriin, Dab äußerfte run১lid), ftumpf 3 - 5terbig, 9iispe blatt.

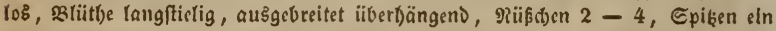
menig zurüđ̆gefrümmt. MBurgel vieffïpfig, Die Etengel unten vielfduppig, orget. pfeifenartig beifammen fteheno, fein gefurd)t, meift bräulid) vereift. Blattid)eiden an Der $\mathfrak{B} a f i s$ nit abgerundeten gezäbnten muf(t)elförmigen Debroben, Blattffie!

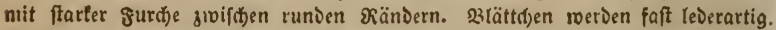

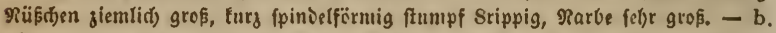
virens, obne פeif, T. uninus JAcQ. austr, t. 419. - c. glandulosun, pubescens ScHL. f. Zl6b. a. a. D., Driilig weid) bel)aart. - Zn fonnigen Şügeln.

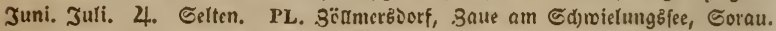
Rabenlıorst. Gnnfen. Blase. PS. Mietteben, Bennftädt, Manbleben, Soofleben,

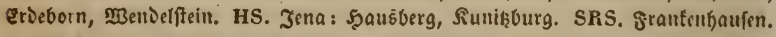

1818. T. flexuosum Berxh. 1815! Ronв. Deutschl, Fl. 2r66. 4628. Ctengel von Der beflätterten 23 afi z anz bogig, siättrien beiberfeitz

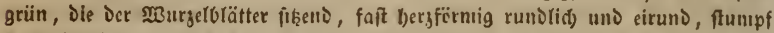

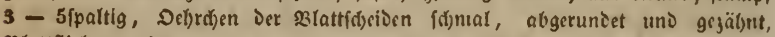

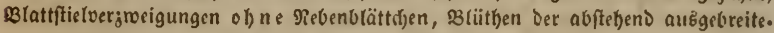

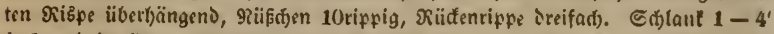
hod) und Darüber, Blattftielfdeiben breitrinnig und rippig, B(attverziveigungen

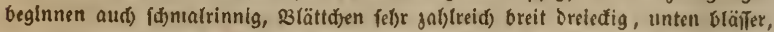

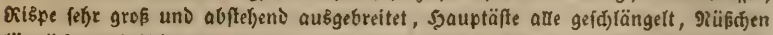

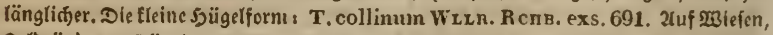

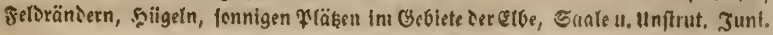




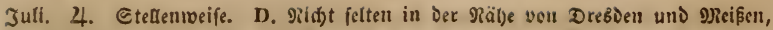
in Menge auf Den El(bricfen, an Elbufer ïberbaupt. L. Stortwi६. Languth.

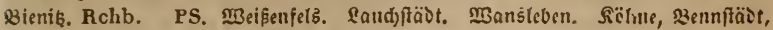
3orgs., 2ulebent. Ëfurt. SRS. Blantenburg, 2irnftait.

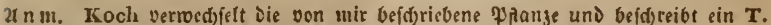

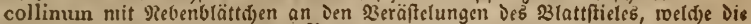

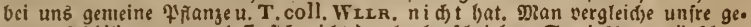
treuen arboitbungen, $u$. Iafle fid) nidht Durd) abgef(jriebene Specialfioren täuidaen.

1819. T. glaucescens W. EN, sppl. Rcrв. Deutschl. Fl. 266 . 4628 b. t. XXIX. Etenget fitetrunb, geftsift, Blütthen follaffrişpig, etıas über.

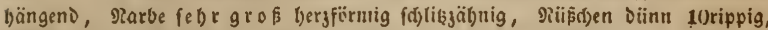

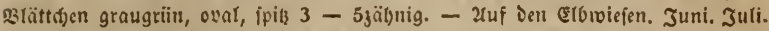
4. 3iemlid felten. D. Bei Drezben u. Firna fettner als T. flexuosum. Bauer.

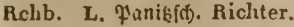

1820. T. majus L. Rcrв, Deutschl. Fl. w66ito, 4629 . Etenger $\left(4-6^{\prime}\right.$ bod) vielbogig, ven unten beblättert, 32latt/tielvergroeigungen olyne 9Re.

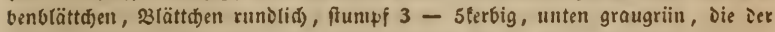

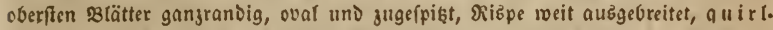

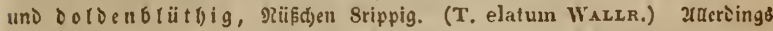

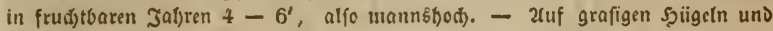

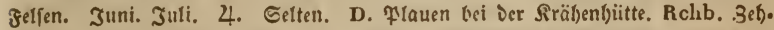
ren. G. Rchb. Papperitz. PS. Şalle: SBijhofsbcrg. Wallroth Ann, bot. Ffortenberg. Beneken.

1821. T. aquilegifoliun L. Rсrв. Deutschl, Fl, 266irt. 4035. Fl. germ. exsicc. n. 1287. B3lattfiefvergweigungen mit bäutigen Błattf(huppen, Blättḑen bersförmig runotid) ftunıpf Dreilappig, einge(d)nitten geterbt, unten graugrïn, Sizppe gegipfelt, siïṕfen $8-15$, geftielt, flïgelartig 3 tan. tig bängen D. Etengel $1-2^{\prime}$ bod), fein gefurdtt, bereift, 2bättrig. Diłpe

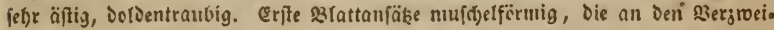

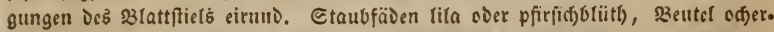

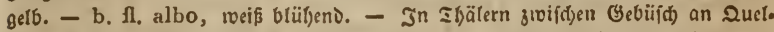

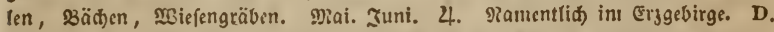

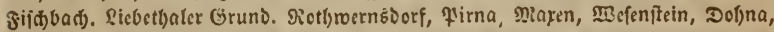

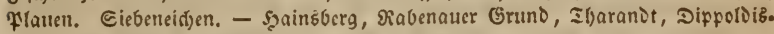
walDe, zlltenberg, Sautuftein, siärenftein, Geifing, Sinnwald. Z. Jmi Docrge. birge altgentein uno lyäufig, aud) bei fid)tenwalde und Stein. Grindelverg bei

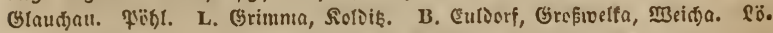

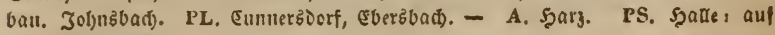
ier grefen Molefe.

1822. T. Bauhini Crantz. Rchs. Deutschl, Fl, Zubito. t. XL.

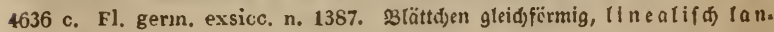
gettlidi, unterfeits feill bebaart, siand umgerollt, sizpe pyra.

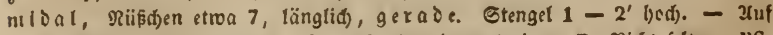

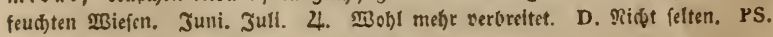

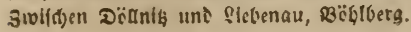




\section{It anunculaceac. $\quad-408-\quad$ Thalictruu.}

1823. T, angustifolium Jacq. Rcri, Deutschl, Fl, 2666ild. 1.

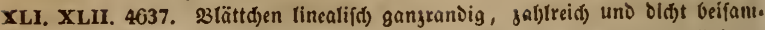

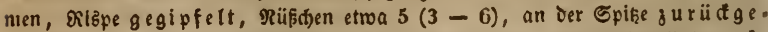

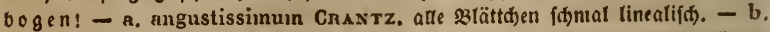
heterophylluun GADD. Blättden unten fein belsaart, an ben untern Blättern lanjettlin) linealijd, nervig, an ben oberften didt beifammen, (inealif() fadenfir.

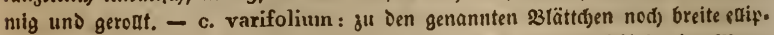

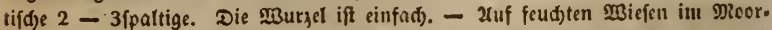
toden, vorgügtidh in Riederungen Der Berggegenien. Juni. Jufi. 4. Nicdtt fet. ten, febtt aber im Erggebirge.

1824. T' nigricans JacQ. Rсrв. Dentschl. Fl, 266 . 4638. Mur.

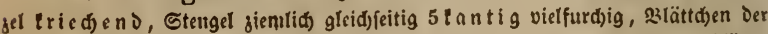
untern Blätter teilförmlg länglld) oreifpaltig, Die ber Stengelbätter

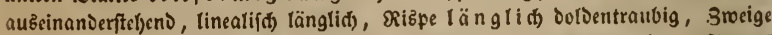

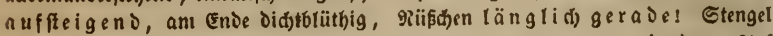

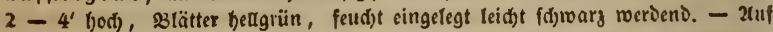

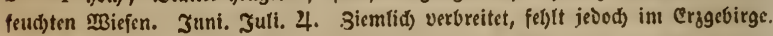

1825. T. flavum L. Rcrs. Deutschl. Fl. 266bito. 4639. Mutrgel

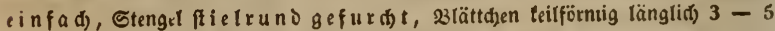
- 7ípaltig, Blattftielverzwelgungen ber untern siätter mit paarigen 23 ta t t.

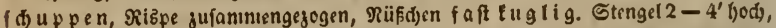
Blätter uno Blättchen groß, lekłtere buntler, ftärfer geabert. - 2luf Sumpfiviefat. 3uni. 3ull. 4. Gelten. L. 23ei Dërsig uno Siebenau. Klett und Richter. PS. Bel Benndorf und bei Dftrau neben Dürrenberg. Klett uno Richter.

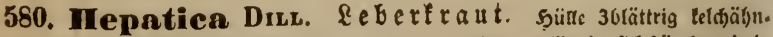

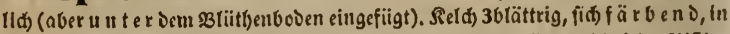

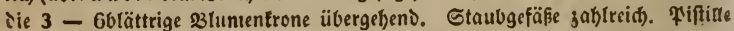

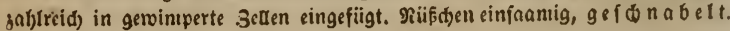

1826. H. nobilis Volkamer Hayne Arzneigew. 1. 21. Rснв. Deutschl. Fl. 2abbito. 4672. Fl, germ. exsicc. n. 693. Blätter herzfërmig, Drellappig, sappen breit eiruno, ganzrandig. Btattfiele und Edjaft zur sititt)ezeit etiva hanobod, feingottig bebaart, Bl. lita, feltner lebbaft rofa ober weif.

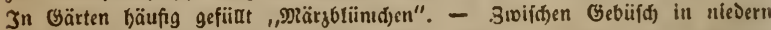

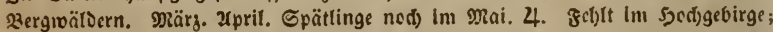
in ber ebene um Seipgig nur: L. Univerfitätzbly. Baumgarten chemals, 18+2 wicorr Wilh. Hofmeister. 2(ufsiden nidt) falten.

581. Anemone L. Haller. 28 i n b b l u me. Reld 30rättrig, jid

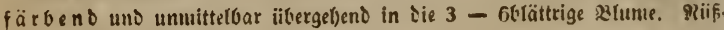
d)en gabfrelds, gefdunabelt. - Sä̈lle blattartig.

A. Anemone, rü̈вden shne Worle.

1827. A. ranunculoides L. RCAB. Dentschl. Fl. $\mathcal{L}$.

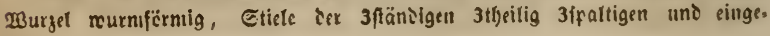




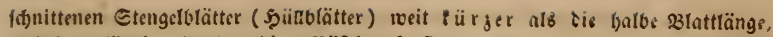
stüthe 5blättrig, bod) gelb, Riifst)en fa ft tuglig, lang bogenfonabelig.

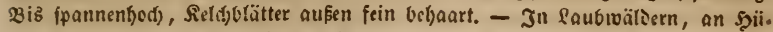

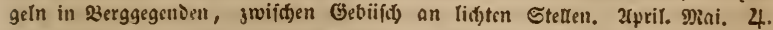
gidat felten, im bëberen Erjgebirge nur: Z. Milbenau, 2nnaberg, 5elbersborf, Draizborf.

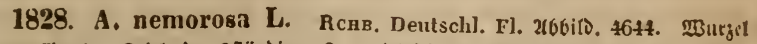
wurmförnig, Sticle orr 3ftänvigen 3 - 5tbciligen, eingeid)nitten gefägten Stelt. gelolätter ( \$üablätter) etroa halb fo lang als bie Blattlänge, Blütben 6blättrig

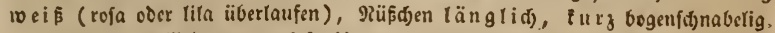
- b. rosea: Blittle ganj rofofarbig. - c. coerulea: Blïtle ganj blau, vrgl. Pritzkl Anem. Rev. p. 92. - d. sulphurea Pritzel, Dicfelbe gand fujwc. folgclb, gleidfam eine ranunculoidi $\asymp$ nemorosa Kuxzr, vergl. unfre Deutid. lanis flora 11. G. 108. uno Pritzel Anein. Rev. p. 92., neigt fid) in ier

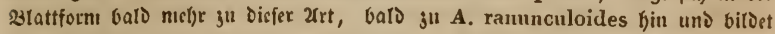

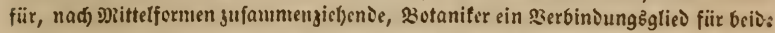
3rteu. Diirfte nad) neucrn Beobad)tungen te in Baftaro fein. - Jn \&aub.

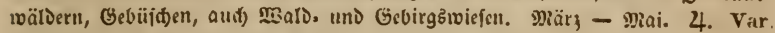
coerulea: D. Edjicrił̧ હin Exemplar G. Rchb. 1S42, - Var. sulphurea: D. 3adel. Kunze. L. బiofenthal. Winkler. Petermann. Pritzel. G. Rchb.

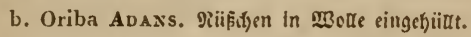

1829. A. sylvestris L. Rснв. Deutschl. Fl. 2666ird. 4651. 2Burgs!.

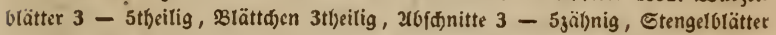

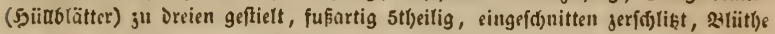

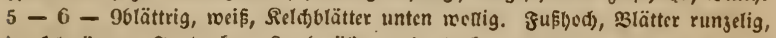

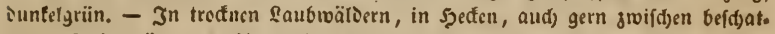
tetem Steingerïlle. april. Diai. Eingeln im Şerbfte. 4. In Ilyüringen niōt felten, auferdem nut vereinjelt. D. Sdjierik au Suftberge Ein Exemplar 1839. r. Römer, L. Rod)liţ. Seidel. PL. Reuzetle. Fischer. - A. Şarggeroie.

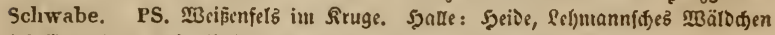

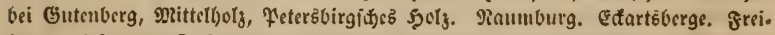
burg. Erfurt. HS. Jena: Pfafinftieg, Dernburg. Berfa. Bcimar: Pegefele,

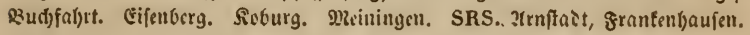

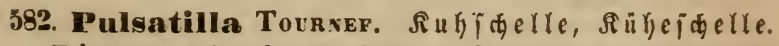

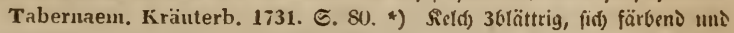

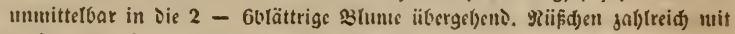
รeverft) wängen. - 3ottig (eahanrt.

1830. P. pratensis L. Rснв. Deutschl, Fl. zкб. 4658. Fl. germ.

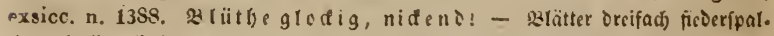

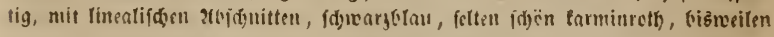

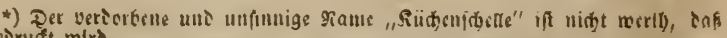
ส georudt mirs. 
lila over weip̄. - b. minor Bess, Rснв. Deutschl. Fl, 2⿲6丨. t. LIII. 4655 b. in alden abeilen t(einer uno follanter. - Sonunt aud) monftr̈̈ vor mit ausgebreite. ter balb ober gan\} vergrünter Blütl)e, vergl. Die 2abviloungen t. LII. - OrF. Pulsatilla nigricantis rad, et berba. - 2uf fandigen Iriften, Miefen, felo. rainen, fteinigen Şügeln. 2upril. Mai. Einzeln im September. 4. Stellenweife.

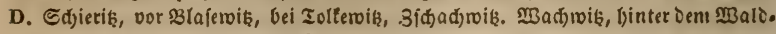

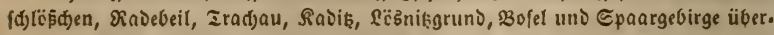

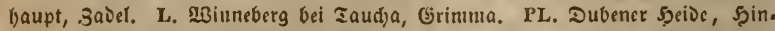
Denberg, Grofraboen, Salfenberg, Giesmannsiorf, Gel)ren, Sottbus, Guben, Gaf. fen, Iriebel, Epremberg bei Dobien. A. Dranienbaun, Deffau. PS. Barby.

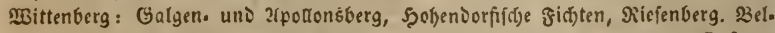
jig. Düben. Raumburg: Gofegt. Şade: Şeice, Gutenberg. - Var. fl. ker-

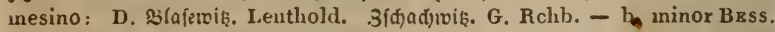

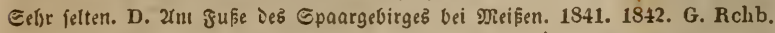

1831. P. vulgaris MrLc. Rснв. Deutschl. Fl. 2660. 4657. 23tiitlle Qufred)t, Blütbenblätter jufanimengencigt over gerave, Beutel eiförmig, MBurzcl.

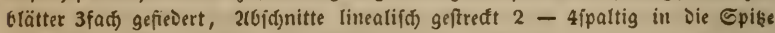

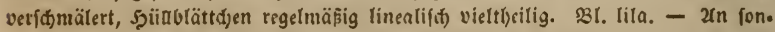

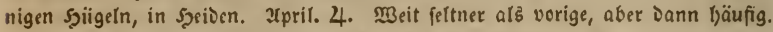

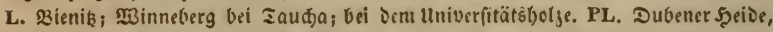
Guben. Rabenhorst. Gaiাen. Blase. A. Deflau, Dranienbaum, 3crbft. PS.

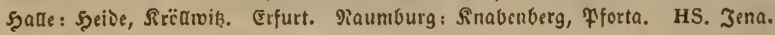
Eifenberg. Grub. SRS. ?trnitaot.

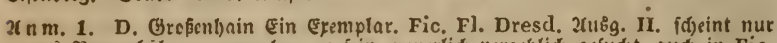

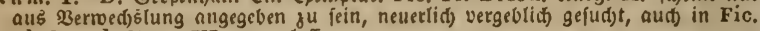
Fl. Dresd. 2115g. III, toeggelaifen.

2f nm. 2. Maan vergleidje of P. Bogenhardiana RchB. Deutschl, Fl. II. S. 115. t. LIII, 26bilto. 4657. uno Pritzex Anem. Rev, p. 31. viedteidit audi) innerbalb Det Grenzen vorfënmt.

1832. P. vernalis MirL. Rснв, Deutschl, Fl. 2666irt. 4660. Fl.

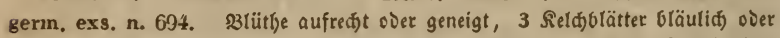

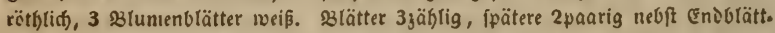

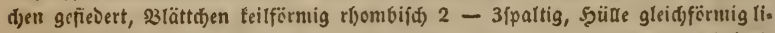

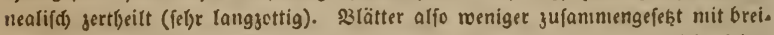

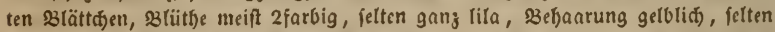

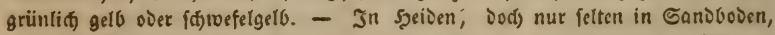
meift in fefter guter brauter Erde. 2(pril. Mai. 4. शramentlid) im \&aufiber *ieierfande, auferdem febr fetten. D. Şeide. 1821 u. 40. Rchb. Saufa 1842. G. Rchb.

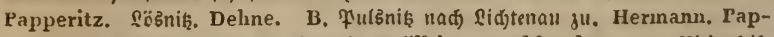
peritz. G. Rchb. Deذernik clyemalb̆. Kölbing. Burkhardt. PL. Riederfeif-

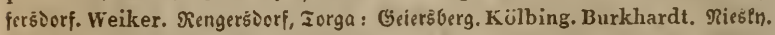

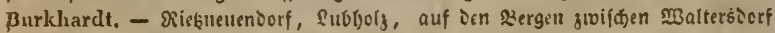

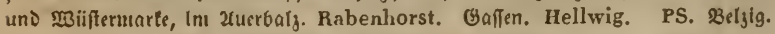
Rabenhorst. 31vifdifen Sprottau uni Grunau bei Eilenburg. Petermann. Zor. gnu. Löber.

1833. P. patens MiLc. Rсяв. Deutschl, Fl, 266tiro. 4661. Fl. 
germ, exsicc, n. 1488. Blïtbe aufred)t vergeitig, meift oblättrig, aubgebreitet, Blätter gefingert ireizäl)lig, Eeitenolättchen 2theilig, (Enıblättd)en 3tbeilig,

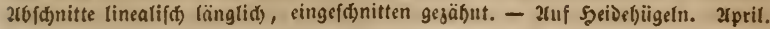
4. Tur: PL. Guben. Grassmann, Rabenhorst.

$21 \mathrm{~nm}$. Man vergl. Die 2robiloungen Der f(t)̈nen mittelfermen Diefer Gattung in

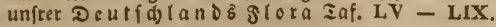

583. Clematis L. 23alb rebe. Sicld) 4-6b(ättrig, fid) fär. beno, llappig! slunte feflt, getiisd)en einfaautig, feberf (t) wängig. slätter gegen ï ber!

1834. C. recta L. Rснв. Deutschl, Fl. 266iro, 4664 . Etengel auf.

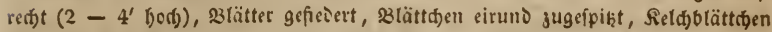
längliđf), ftumipf, aupin ant ranise fein vel)aart. B(ätt(d)en $5-9$, Dreinervig,

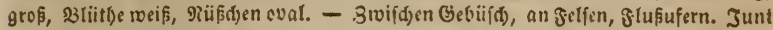

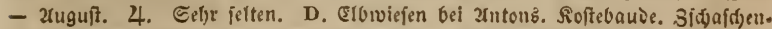
Dorf, Sörnetvik, 23ofel, Epaare. PS. 23arbł). SRS. 2trnftait.

1835. C. Vitalba L. Rснв, Dentschl. Fl. 2660its. 4667. Stetterno,

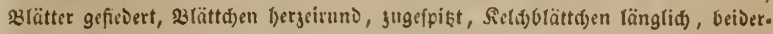
feitz firgig. Die joljigen Dieben bängen fith jiertid guirlandenartig in Bogen

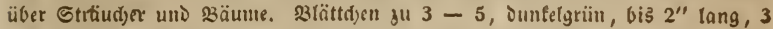
- 5nervig, ganjraniig, oder nit einem oder bem andern 3alyne oder lappig ein.

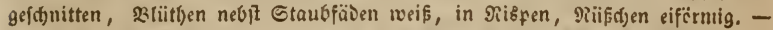
Borgüglid) auf Salteoden an Şägeln, Balorändern, groif(t)en Gebiiid). Juti.

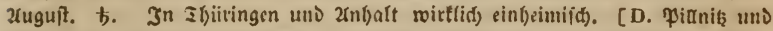

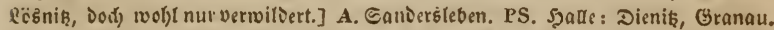
Meifenfels. Taumburg. Eifartšberge. Erfurt. Gdjroarza. HS. Jena: Gorit. SRS. 2 rnftadt.

2 $\mathrm{n} \mathrm{m.} \mathrm{Viticella} \mathrm{deltoidea} \mathrm{Mхсн.} \mathrm{(Clematis} \mathrm{viticella} \mathrm{L.)} \mathrm{Rснв.} \mathrm{Deutschl,}$ Fl. 2rbbirs. 4668. nit grosen violeten 23liithen uno grannenartig gefdenabelten

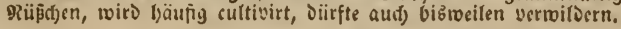

B. Helleboreae: Theilfapfel, fäber gefonbert, viel= jaamig.

584. Aquilegia L. A f e le $i$. selnt 5otättrig, fith färbent, Rzlu. nenblätter 5, bornfürutig, (jobr, jonigtrngend. Etaubgefäfe jablreid), bie

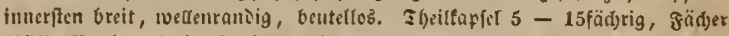
(bülfenfïrmig gejondert) vielfaautig, ธaamen länglíb, glatt, tielraniig. Bliitf) niớnio. -

1836. A. vulgaris L. Rchs. Deutschl, Fl, a66iti. 4729. Fl, germ. exsicc. n, 1590. Die 33 lumenblätter untent einidärtל halig, von Der 2rnfügung

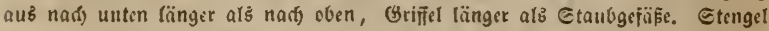

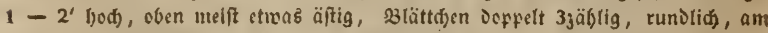
Oberranibe eingeffinnitten geferft, unten bläulíf) grïn, Die Stengetbrätter wenlger

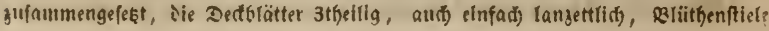




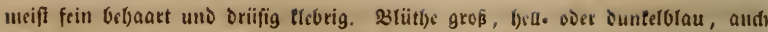

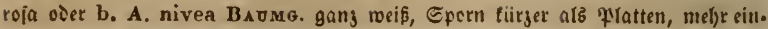
gerout. In Gärten aud) gefülut uno fternbliitl)ig, stellata u. f. to., vergl. unfte Deutfd)lands flora II. S. 148. - 3roifden (Sebiifd), gern auf Saltboden. Juni.

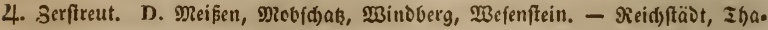

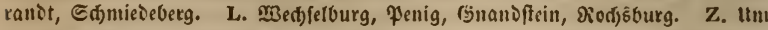
xBirdenfels bäufig. Wankel. B. Sauffse, Dnbin (nur toeifflumig! G. Rclıb.).

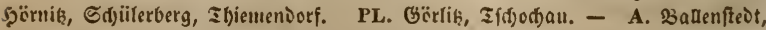

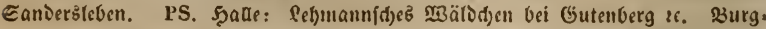
wenien. giaumburg. Eilenburg. Erfurt. HS. Jenn. SRS. 2rmftadt. R. Pobenfteir.

\section{Delphinium L. R it te rff orn. Setd) 5bättrig, fid)}

färbend, obres Blatt gefpornt. S3lume 46lättrig over verwad)fen einblättrig, mit bonigtragendem Fortfahe im Sporn. Frud)tfäder $1-3-5$.

1837. D. Consolida L. Rcus. Dentschl. Fl. 266bils. 4669. Traute

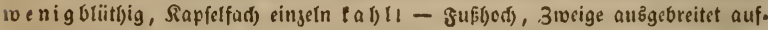
fteigeno, 3lätter fuffërmig linealif(d) vieltbeitig, Blütlyenftiele un১ Sporn länget

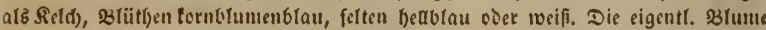
breit 3lappig, beter, in Der Matte weiflid), Eeitenfappen breit abgerundet, פRit.

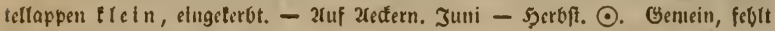
iebod) im bïhern Erggebirge.

- 1838. D. Ajacis L. Rснв. Deutschl, Fl. 266rild. 4670. Zraubs vielorïtbig, Sapielfad) elnzeln fein bebant! Ettngel fteifer $1-2$ ' bod), 3weige auff́teigend, aud) vielblütbig, Irnube länger, wegen Der tiirgern stiithen. ftiele Didter, Blätter äfntid), feiner, türger, Reld leblyaft blau, benblau, rofa,

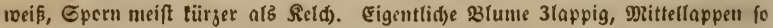
lang alb Seitenlappen, umgetel)rt cirund, eingeterbt uno gejäl)nt, an feiner $23 a f i s$ mit Der mel)r oder minder Deutlidjen కn[d)rift AIA. - 2(us den Giiden, bäufig cultivirt uno verwilbert. Juni - September. $\odot$.

$2 n m$. In Gärten bäufig cultivirt uno viśmeilen verwvilberno: D. elatumn $\mathbf{L}$. D. intermedium AIT. Rснв, Deutschl. Fl, 2ubito. 4676., D. montanum Dк. Rснв. Deutschi. Fl. 206ilo. 4776 b., D. alpinum W. K. Rснв. Deutschl. Fl. 2266irs. 4677.

586. Aconitum L. Sturmhut, Eifenlut. Sield fünf.

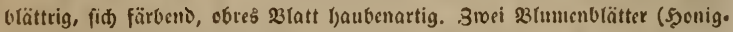
Diiten, Deren gefd)loffene 3 afis nad) oben geridjtet ift und Sporn genannt toird, fortfak ïber Der piünoung nad) unten: \&ippe;) unter ber şaube verborgen, auf langem rinnenföruigen $\Re$ a gel. Rapfelfäd)er $3-5$.

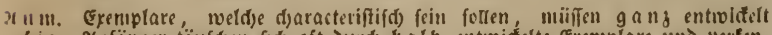
(cin. 2infänger täufdeen fid) cft ourd) balb entroidelte Ercmplare und verfen. uen Daun Die 2irten. 23ergl. unfie Deutíc)l. Flora IJ. S. $125-140$ nebft Deu supfertafeln LXXV - LXXV11., meldie oie ebaraitere aller artent oer cent.

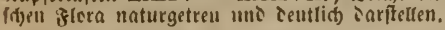

ค. Lycoctonuแ : $\mathfrak{B u r g e l}$ äftig, Şaute margig fegelfirmig.

1839. А. Myoctonum Rcus. Deutschl, Pl, robitt, 4679 uni t 
LXXV. Illustrat. Ac. t. LI. Sporn balbringförntig, an Ifnfak̨r jurïigeoriiat,

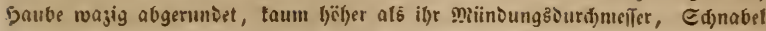
(braun), turz cingebogen. शiur 1 - 2' bod), nad) obenl raud), sklätter jef)r breit. Iappig 5 - 7theilig, eingeffinitten, Bafilarlappen aneinanierliegent. Steinfte

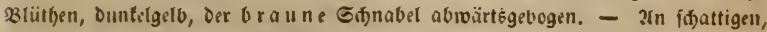
etwas feudten Fläben in Faltgetvirgen im Thüringer Malse. Junl. Juli. 4 Eebr felten, PS. Gegend von Gubl. P. Sauer.

1840. A. Vulparia 3. Cynoctonum Rснв, Deutschl, Fl, 26ub. 4681. Spern ffiralig, Şaube wa l gig fadfö $r$ mig, gegen ben Gruno (Das ober:

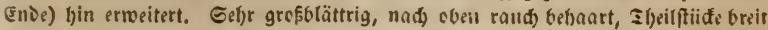

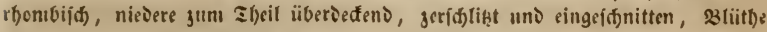

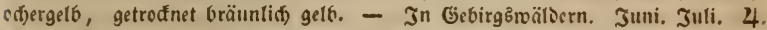
Eelten. Z. Glaudja. v. Künsberg. PS. Surgivenden an Der æendenburg. Fest. Riffelberg bei Sd)warza. Metsch. HS. Jena. Zenker. MBeimar: im 2röod)en

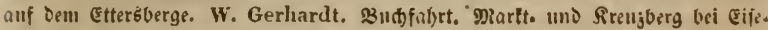
nad). Zenker. SRS. \&udolftait. Zenker.

1841. A. Thelyphonum Rснв, Deutschl, Fl. 266іlo, 4680, и. t LXXV. Eporn fpiralig eingerout, şaube lang legelförmig verengert. Eten. gel 2 - $t^{\prime}$ bod, 3lattlappen breit, aber metjr jugefpişt uno tiefer eingefdlib̧t, Eraube locfer, \$l. bellgclb, Syaube aln büd)iten, febr verengert, böber alb Die 5yo.

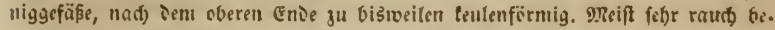
baart. - In Den ₹lälern Der Saltgebirge. Juni. Juli. 4. In ฐ̧üringen uno 2rnbalt. D. 2rngebl. bei Sommaķid) von Dr. Schueider gcfunden. A. Şarjgerode. Schwabe. PS. Riillitt)al bei Siegelrode. Sivifden freilurg und Saudba am Sird)bcrg. Mannbfelo. Raunburg. Beneken, Edjwarja: Sidelbirg. Metsch.

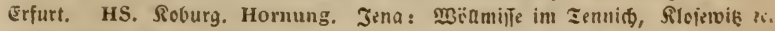
Zautenburger forft. Meimar, Regefelo. Jnjilberg. Zenker.

b. \$urgel tnodig uno fufförmig.

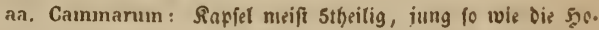
niggefäse a ufred)t.

1842. A. Cammarum Jacq. Rснв, Deutschl, Fl, 2066. 4634 und t. LXXV. Fl. germ, exsicc. n. 8s9. Syaube a ufredt, legelfïmig afgi:

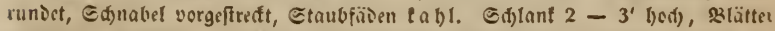

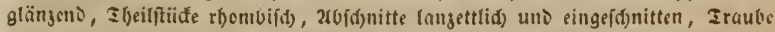

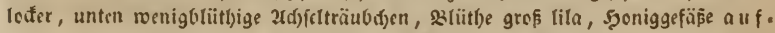

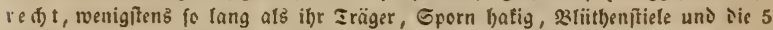
Frudtfüder meift tabl, Gaamen in 2uerriben (ofd)uppt. - Jul ttrgebirge an 2ucden, sä̈t)en, sergifrëuen. Juli - September. 4. Stellenweife. D. Ju Epaargebirge unweit Der 30 fel feit Mauke. Jekt faft ausgerottet! Plaucnfober Grun১. Rchb. Schubert. Hensche. Langefeld. Sivifit)en Dofina und $\mathfrak{B}$ efenifein. Baner. Klotz. - Dslía. Fr. August K. v. S. Börnersborf am Diüblocrg.

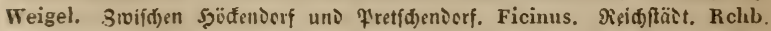
Salnsberg. Rossıässler. Kaiser. Ełaranit. Papperitz. G. Rchb. Eunners. borf. Kaiser, Z. Sd)wargenbirg, Griinftättel, Bok. Gtein. Wankel. Ober. 


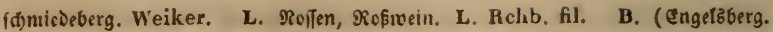

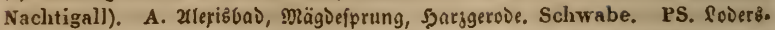
leben bei ber Quede: Golborunnen. Sprengel. Wallroth. HS. Jnfelaberg. Hornung. R. fobellftein.

2 $n$ nı. A. Variegatuun L. Rснв. Deutschl. Fl, 2fb6ilo. 4682. uno t, LXXV.

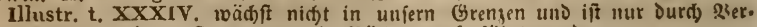

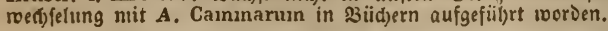

bb. Corythaeolon: Sapfel 3-5tbeifig, jung niten 0 , Rap. felfǟer mit if)ren Spik̨en zufammengeneigt. Şoniggefäpe umgebogen.

1843. A. Stoerkianum RchB. Deutschl. Fl, 2666irt. 4692, und t. LXXVI. Illustr. Ac. t. LXXI. Şaube gerö̈lbförmig, Staubäben be. baart! Etengel $2-4^{\prime}$, ftielruns, Gänfefieldid, beblättert, meift gang fabl. Blätter fattgrün, z̈lglänzens, slatt 7 tl)eilig, Zraube loớer vielblütlbig, unterfte Blüthenftiele 2 - 3blüthig, aud) sunter ifnen Ceitenträubdjen. 231 . violet, zart feidenfdjinimerno, Eporn topfförmig, Sippe umigetel)rt berjförnig, unigerout.

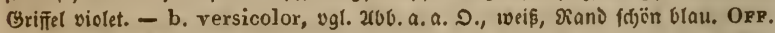

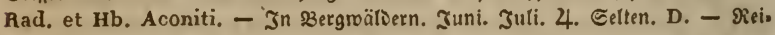
denau. Fr. August K. v. S. PS. Jm Ibüringer \$Balde bei Breitenbad) int Sennebergifđjen. P. Sauer. Metsch. HS. JImeniau: Şc̈utentopf, Sdjurtenthat. Schönlseit. - 2lm bäufigften unter allen 2rrten cultivirt und verwildert.

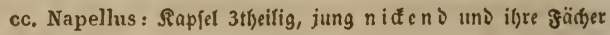
a uzgefpreizt.

1844. A. multifidum Kоосн, Rснв. Deutschl, Fl. 2ubilt. 4636. uno t. LXXVI. Illustr. Acon. t. LXX. Şaube geröilbfërmig gefdjloffen, 23lï. thenftiele aufredyt abftel)ent. Etengel $1-4^{\prime}$ meift $2^{\prime}$ hod), fdjlant, fdinnurgerabe uno einfad), glatt und fabl. Bzä̈ter fuffïrmig 5 - 7 theilig, sheilftide rbom.

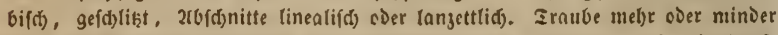
lang, laum merf(id) fein bel)aart, Şärdjen tur uno geftümmt, 231 . mittelgró, ounfelblau, fcltner bentlau, Etaubfäben beba a rt. - In trgebirgstlälern. Juli. 2tuguft. 4. 2teuferft felten. D. - Rebfelo. Tr, August K, v, S.

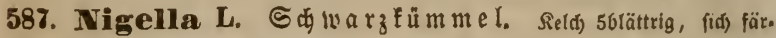
beno, abfallens. 23tumenblätter (Sjonigoüten) 5 - I0. Sapfelfädjer 5 10, an Der Safis gänjlidi) verwad) $[$ en, lang gefdjnabelt. Saamen Dreitantig

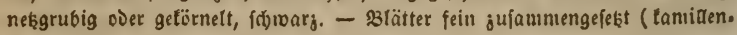
artig).

1845. N. arvensis L. Rспв. Deutschl. Fl. 266бito. 4735. Fl. germ.

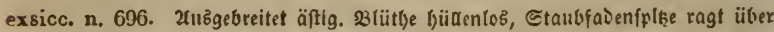
Den 3 Beutel binaus, Die 5 Sapfelfäd)er bals verivadjen, glatt. Tur $3-6^{\prime \prime}$, fel. ten böber, 81 . beublau, Unterlippe Der Şonigoüten gelbgrüntid) mit 3 Duntelgrii. nen Gïrteln. Gtaubgefäfe meif̂t ju 5 in 10 Gruppen. - 2ulf Xectern in Der Qbene uns niebern Gebirgen, auf Rall uns Gant. Jull 2uguft. ○. Stellen.

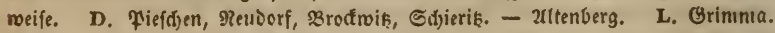

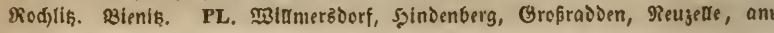


IBege von fübben nadi) altene. A. Säufig. PS. 23arby. Belgig. MBittenberg.

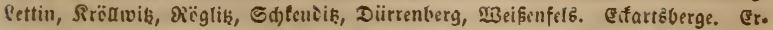
furt. HS. Jena: fidjtenl)ain. Eifenberg. Foburg. SRS. 2frnftait.

1846. N. sativa L. Rсвв. Dentschl. Fl. 2abbilo. 4736. 2(ufredit äfig, Blütbe bïldenlob, Gtauboeutel ungefpikt, Rapieln baudjig, bis oben ver.

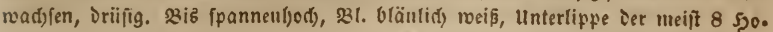
nigoüten geffalten, bel)aart, ïber iem Epaltwintel mit Dunfelblauem Gürtel, carunter 2 grïne Driifen, Etaubgefäse gll 5 in 8 G̈ruppen. - 2rus iem Güien. 3uni. Juli. ○. Eultivirt bejonders in st)üringen und im Boigtlande, aud) bier

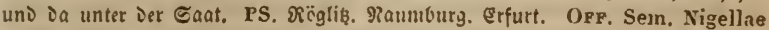
s. Melanthii.

* 1847. N. damascena L. Rснв. Deutschl, Fl. a66itd, 4737. F1.

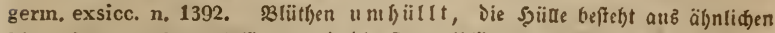

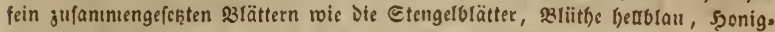
Dïten $5-8$, unterlippe grünlid), borizontal ausgeftreft, 2tbeilig, beljaart, am Ibrilunģ̋winfel 2 grï̈e Driifen. Ctaubgefäße gu 5 in $5-8$ Gruppen. Rapfel

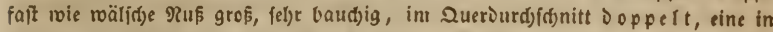

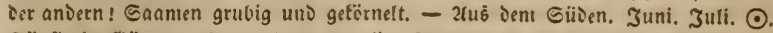
Şäufig in Gärten: "Braut in Şaaren", "నungfer im Grïnnen".

588. Trollius L. T́rollb ( u me. Reld) giegelartlg $5-15$. blättrig, f(đ) färbeno, abfattent. S3lumenblätter (Şonigoliten) tlein, galflteid), zungenförmig. Ibeilfapiel vielfäd)rig, fäd)er roaljig, gel)äuft, vielfaamig, aufipringeno, aufred)t gei(b) abelt. Eaamen gientliळ Dreifeitig, olsne Reint. rarje. - 3liitlye roie Srautfïffden, 3lätter ranunfelartig.

1848. T. curopaeus L. Rснв. Dentschl. Fl. 2666. 4713. Stengel allfređ)r, einulütbig, 3lätter baniförmig 5 - 7tbeilig, 24bfकnitte rautenförntig oreifpaltig, eingefdunitten, \$liitbenblätter $14-15$ zufammengencigt, Blumen. blätter tï̈ger alb Etaubgefäpe. Etengel $1-2^{\prime}$ bođ), stätben bellgelb. - b. hunilis CRAxrz, niebrig, nit Şü̈blättern unter Det 33lütl)e. - 2luf Gumpf. wiefen, jwijdjen Gebüft). Mai. Juni. 2tuguft. 4. Stellenweje. D. Sange.

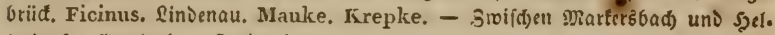
lenDerf; Gettlenbe: Etadtwiejen, an Faljrwege nad) Delia. Geifingsberg uno nedi) auferben bier uno Da bei 2ultenberg, 3. 23. am Mege nad) Bärenburg. Z.

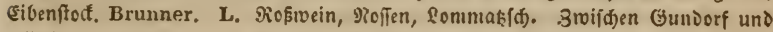
Dülgig. Flaufig. PL. Gorau. A. DeTau, Serbit, Dranicnbaunt, Gandersle. ben. PS. Diepmannsborf bei Belzig. Sennoorf, Gdjentenberg. Şalle: Seben,

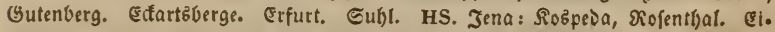

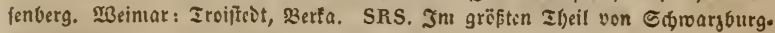
Riuiolfait. - b. L. Bienif. Petermann.

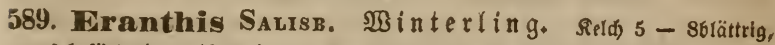
fic) färbeno, abfallent. Blumenblätter (Şonigbüten) $6-8$ diitenförmig, Sippe eingeterbt. Iheilfapfelfäd)er $5-6$, quirlftän Driidt, Durd einen Gtift verbunden. Saamen eiförurig, tuglig, getörnelt. E(h)aft, Şü̈le ftrablig gerid)likt. 
1849. E. hiemalis Sacisb. Rснв, Deutschl. Fl. 366iro. 4714. nßurgeltnode biålin, borizental, Dunfelbraun, langfaferig, MBurzelblatt geftielt

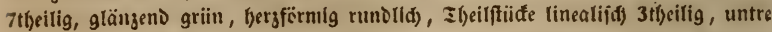

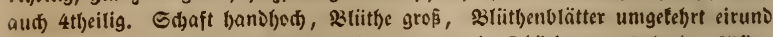

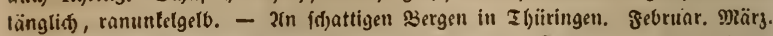

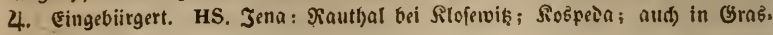
gärten bei Jena.

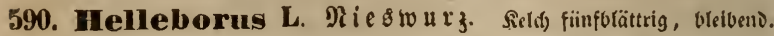

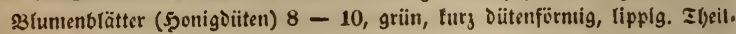

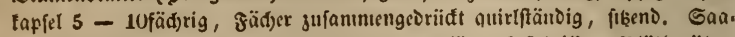

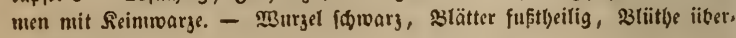
ไ)ängent.

1850. H. viridis L. Rchв, Dentschl, Fl, a66ild, 4718, Fl. germ. exsicc. n, 1390. Stengel 2t)eilig, blatttragende 3tweige 1 - 26tïtl)ig, Blätter fingerartig fuftbeilig, Blättd)en längliđs) lanzettli(h), groß geadert, Doppelt fäge.

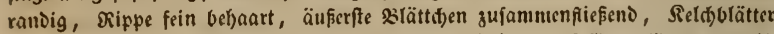

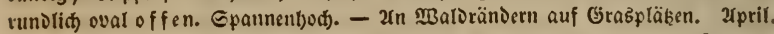
4. Gelten, bier und da nur vermildert. D. Piederivartha. Bucher. $L$. Rchb. fil. G. Rohb. Papperitz. (fid)er wilo). Meisen. Ficinus. Breftwi\&.

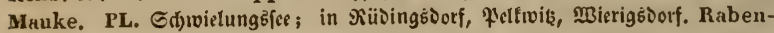
horst. A. Syarz? PS. Jebferidger Şiitten bei \&eltgig. [.3iegelroier 23aumgarten.] HS. [હifenberg in Grą̧gärten.] SRS. 2rnftaot. Buddensieg.

1851. H. foetidus L, Rсrв, Dentschl, Fl, આrgird, 4715. Haye Arzngw.1. 10. Siclit) su famenengene ig t, Etengel vielblütbig beblättert, Sten.

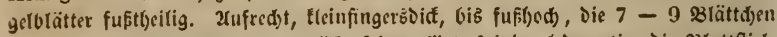
Der Etengelblätter f(s)mal lanzettlid), fcin gefägt, fpișig, leberartig, bie 3lattftiele

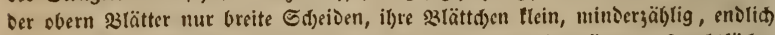

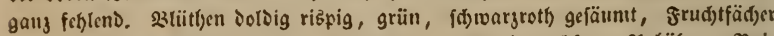

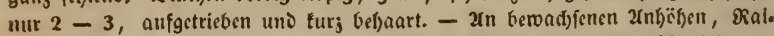

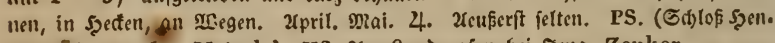
neberg in Franten. Metsch.) HS. ?(m Sanografen bei Jma. Zenker.

591. Caltha L. B ut ter, ober Dotter blume. Seld) 5 . blättrig, fid) (ranuntelgelb) färtbens. Blunte fehtt. Getrennte Sapfelfä̈ber $10-18$, quirlftänঠig, jujantmengedrïđt, vielfaamig, auffpingend. Saamen nit großer, fíbönrother Seinuwarge. -

1852. C. palustris L. Rснв. Dentschl. Fl. 2606irb. 4712. æBätter abgerundet, berz=nierenförmig, geterbt, tabl). $\mathbb{B}$ urzelftod tury, biffdelfaferig, Stengel fumpffantig, aufizeigend $1-2$ ' Inng, räbrig, iaftig, tahl, wenig äftig. Blätter an Der $2 a f i s$ mit fafeloenartigen Del)r d)en zur Seite, Den Gten.

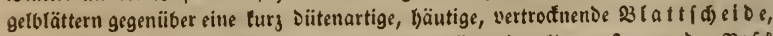

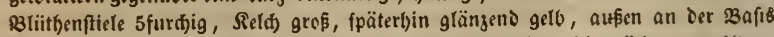
grün blcibeno, zlyeittapiel endlid) fternförmig auzgebreitet, Die fä̈ber von $10-$

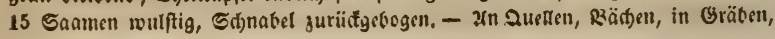


Cïmpfer. Xpril. Nai uno eingelner in syerbft. 4. Gentio. Die Finobpen geben die faljön fiapern.

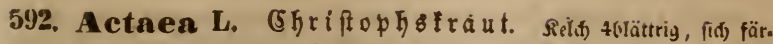
bens, abfadteno. STlumenblätter neift $4(5-6)$, pant), übergebend in sie jablreiden Etaubgefäfe. Gruditfad) einjefn, beerenartig, Eaamen jmei. réílig, glatt.

- 1853. A. spicata L. Rсnв. Deutschl. Fl. 2466iro. 4739. \$Burjel. fted fingersoticf, bräuntiđ, innen weifgelb, ftart befafert. Etengel $1-2^{\prime}$ bod), fticlruno, glatt uno tabl, aนs Sdluppen entfpringeno, trägt $2-3$ entfernte

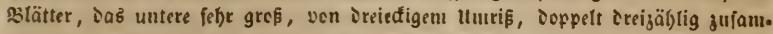

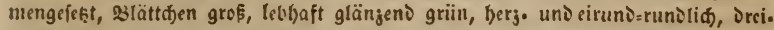
fpaltig und jugefpik̨t, unglcid) cingefd)nitten uno gefägt, iie Der cbern füntälet,

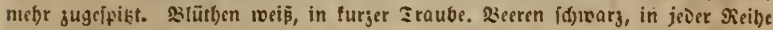

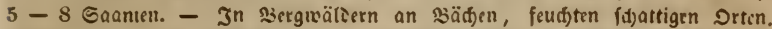
3pril - 3uni. 4. Etillenmeife. D. Rieiermartba, Miloberg, Seftebauie,

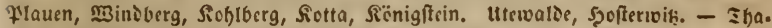
ranit, Şirfdjprung, altenberg. Z. Eibented, હdjeibenberg, Etein, sisitienfils,

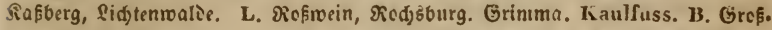

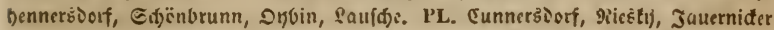
3erg. - Pidjt felten. A. J̧arjgeroie, Eanistšleben. PS. MBittenberg im Edle.

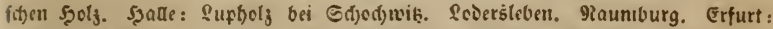

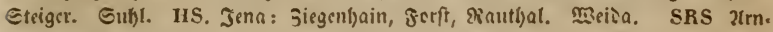
ftrit. R. surgt.

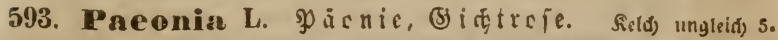
blätrig, faft teicrartig, bleibens. situme $5-10 b$ lättrig. Etaubbeutel

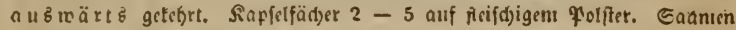
faft kuglig, glatt, einreibig.

* 1854. P. officinalis Retz. Rchr. Deutschl. Fl. 2rubirs. 4it3.

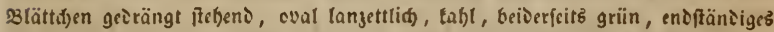

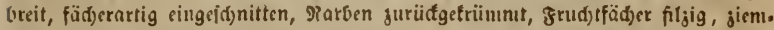
(id) aufred)t, sisurgetfneden sid rettigartig. $1-2^{\prime}$ hod). 23 (. tarntinreth). OPP.

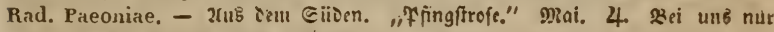
cuttisirt, geroêlyntiat) gefü̈t blibeno.

\section{Familie Rutaceae, Rautengerwäd)}

\section{- Şerbarientru(t) S. LXXIX uno 193. -}

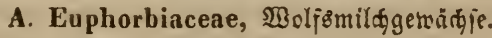

594. Callitriche L. $\mathfrak{B}$ afferfiterm. 310ei Deftolättden. Reld

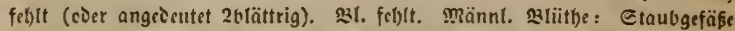

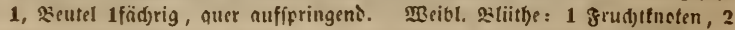

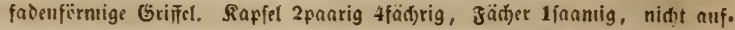




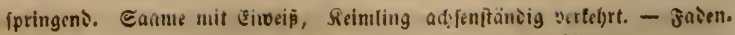
fïrntig, geglieiert, 32lütter gegeniiter, słlütbe einjeln adjfelftäntig.

1855. C. verna L. Rcrв. Dentsch). Fl. 2(6oils. 4746. Die unteren Blätter lincalifa), Die oberen eiruno fpatclförmig, Rapfeln glattrandig, Etaubfa. Den lang, fpäter nicicrgebogen, Grifīel aufrecht, Sapjel tlein, jiculid) fthęens, läng.

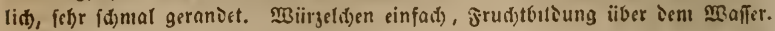
- a. fontana Scop. nur die slifblätter linealifi). - b. stellata HOPPE. obcre 38lätter fpatelförmig, untere linealifक. - c. cespitosa Scнuцz. Etengelbrättir

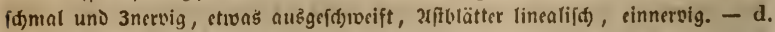
minima HPP. alle 3lätter linealifø) abgeftuk̨t ooer nuzgeterbt. - In fad)en,

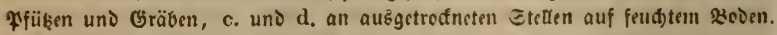
Mai - Juli - Şerbft. 4. Gemein.

1856. C. stagnalis Scop. Rснв. Deutschl. Fl. 2tboils. 4747. 23rätter alle unigefelgrt eirund fpatelfïrnig, etwas auggeid)weift, 5 - 6fad) nervig,

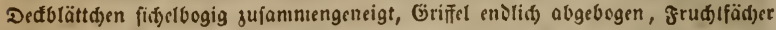
breit piügelrandig treugfä̈ndig. 23lätter Dunfler und fefter, il)r Gtiel breit und

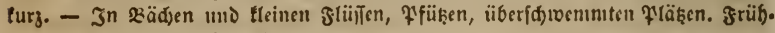
ling - Spätherbft. 4. Girmein.

1857. C. platycarpa Kuetzing. Rснв. Deutsch]. F]. 2ubils.

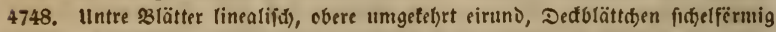
einander treuzend, Griffel fpäter nligebogen, fruditfäiberpiigel paarmeife parallel. Erfd)eint in vielen Barietäten, vergl. pl. crit. ic. 1187 - 1197. uno unfre

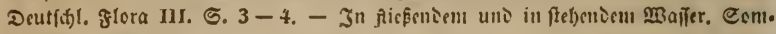
mer. 4. Gentein.

1858. C. hamulata Keetzing. Rcus. Deutschl, Fl, 2666. 4749.

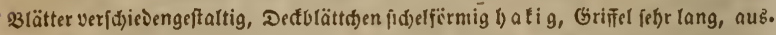

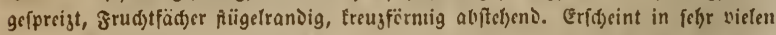
Surmen, vergl. pl. crit. ic. 1201) - 1219. uno unfre Deutid)l. flera III. S. 4

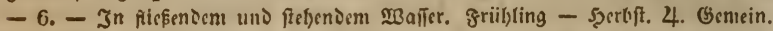

1859. C, autumnalis L. Rснв. Deutschl, Fl, 266, 4749 b. Fl.

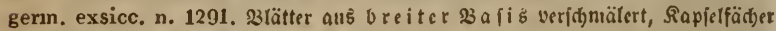

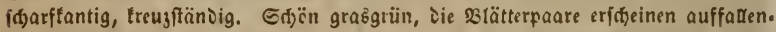

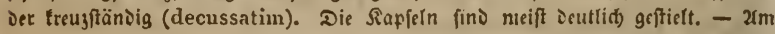

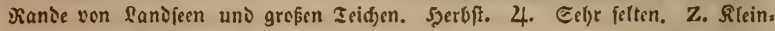

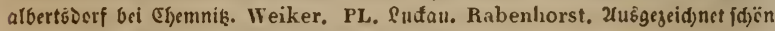
und nit norvifdjen Eremularen genau übereinftimmeno.

595. Euphorbia L. $2 \mathbb{O}$ olf Deren Saum mit $4-5$ blumenblaltartigen Drüfen. sliitben nacti, mef̧rere männlidje befteben aus einem Etaubgefäße auf einem Etield)en eingelentt, roclthes vor einer fpreublattartigen ङd)uppe ftebt , eine weiblidge Blïthe in mittelpuntte auf längerem Stiel, mit tleinen 3lappigen Reld)e, (beftebt aut einem Piftid: Frudttnoten 3fäd)rig, Griffl 3theilig, 2fpaltig. Siapiel 3fäd).

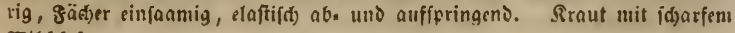
פRildfaft. 
ล. Galarrhoens HAw. Błlumenblattartige Drüfen und Simbrättd)en nierenfïrnig runolid.

1860. F. helioscopia I. Кснв. Dentschl. Fl. 2660ild. 4754. Dorde

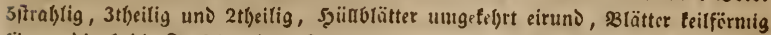
fägerandig tabl, אapfeln glatt, Eaamen nckgrubig. Spannentjod), tabl, 3lätter ungets)rt eirund teilförmig geftieft, über Der 23 afiz fägerandig. - 2uf bebautem

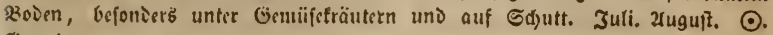
Grmein.

1861. E. platyphyllos L. Rens, Dentschl, Fl. 26biro. 4758. Dolbe 5ftrablig 3theitig grgabelt, Etengels unt syiüblätter langettlid) fägerandig,

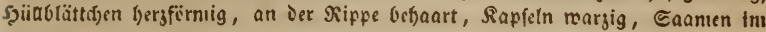

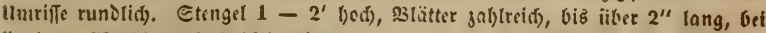

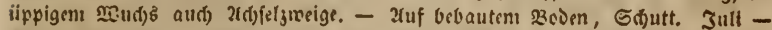

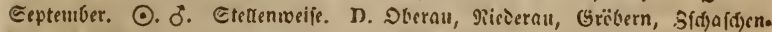

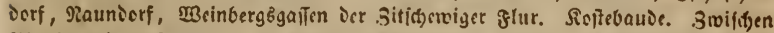

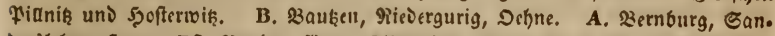

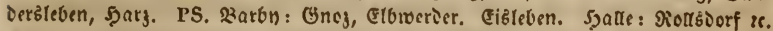

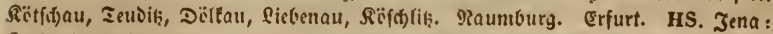
Rlofemils. Eifenberg. WBsimat: 2lltburg. Sioburg: Menfleb. Dieiningen: Sip. persibaufen.

1862. E, solisequa (Esula $\rightarrow$ ) Riv. Rcnв, Deutschl. Fl. r6bits. 4759. Dorbe 5ftrablig, Etrablen 2t)eilig, geraie, sjiuablätter uno s3lättdjen ei. run১ (änglif), gezälynelt, 23lätter unigetebrt cilangettlid) und lanjettlid), nad) Der

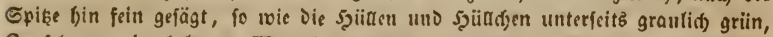

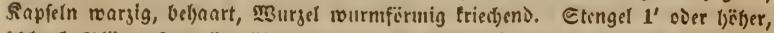
(m)lant, $2 B$ tätter fattgrïn, iiber joulang, Dic Driifen jung grïn (fd)eint E. viridiflora W.K.), fpäter fifyrargreth, Sapfelfitiel geVogen, länger als Sapfel, Diefe in

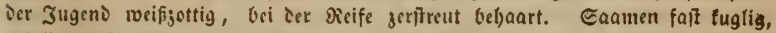

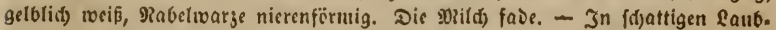

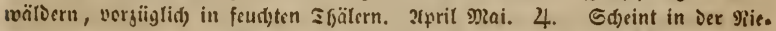

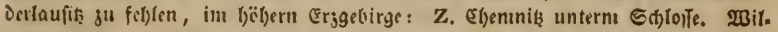

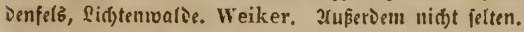

1863. E. dulcis L. Rснв, Deutschl, Fl, 266tirs. 4763. (rerrucosa

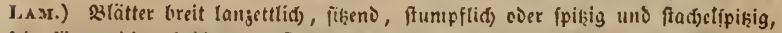

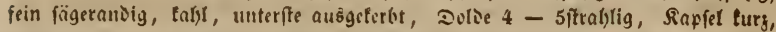

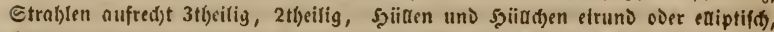

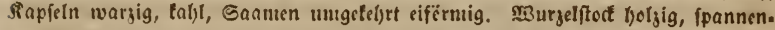

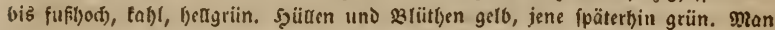
refe in unfrer Deutfitands glora III. 5. 16. - ?n gelbrainen, Dai. Juni. 4. Eelfr felten. HS. Szilohurghaufert. Hoffmann.

2f $n$ un. Daß E. dulcis Ltwx. niđgt Dicfe, foniern Dic $\mathbf{E}$. verrucosa Lans. ift, hat Sunith in ier Flora graeca fidsen yor langer Beit berwicfen. Bergl. unfre Fl. gerin, n. 4iffi3, und unfre Deutfidjl. Flora III. ङ. 16 und 17.

1864. F. palustris L. Rснв, Dentschl. Fl, arbirb. 4771. Dolde 


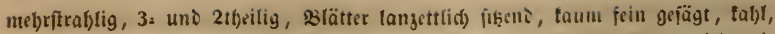

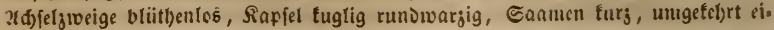
firmig, glatt, fdyvargbraun glängeno. Neurgel bolgig äfrig, etengel aufredt fłu= lensiď, bis iiber $4^{\prime}$ bod). Slätter lanjettlida, ftunipf, ganjrantig, talsl. Dolde

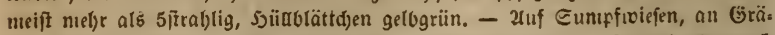

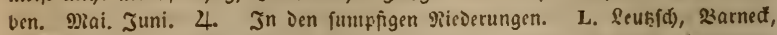
Gunicrf. PL. Guben, Jïrftenberg. A. Deīau, sioffereier fotf̂, MBatDerfee.

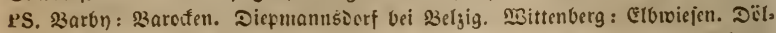

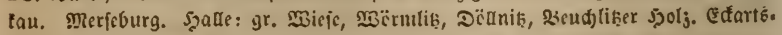
berge. Riaumburg: Eulau, Beiflingen. HS. IIferfteit. Mittclfaufen.

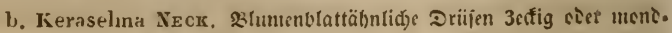

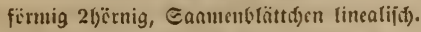

1865. E. Peplus L. Rсне. Deutschl. Fl. 2ubbili, 4773. Dolde 3. ftralslig, mieذertholt $(3-6$ Mal $)$ gabeläftig, \$lätter geftielt, umgefelyrt eiruno

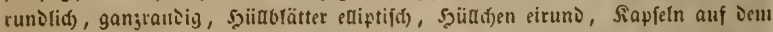

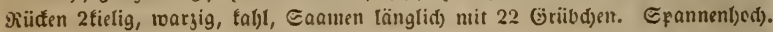
Gaanien glängeno weiß. - Xuf bebautem $\$ 00 \mathrm{en}$, in Gärten, unter Gீ:mï̈feträu. tern, auf હdutt. Juni - Jృerbît. ๑. Gemein.

1866. E. falcata L. Rснв. Deutschl. Fl. 3utils. 4770 . Dolie 3.

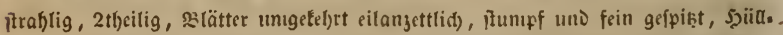

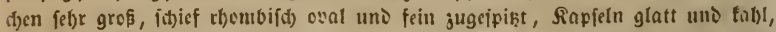

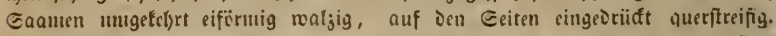

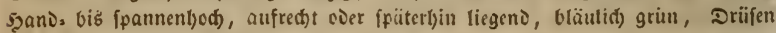

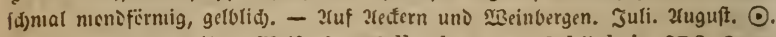
Gebr jelten. PS. B̉ibra, MBifenjee. Wallroth. Erfurt. Schünleit. SRS. grans

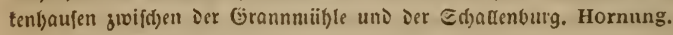

1867. E. exigua L. Rснв. Deutschl. Fl. 266, 4777. Fl. gern.

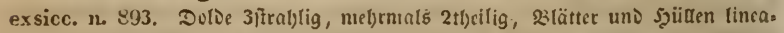

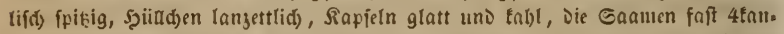
tig, feimwargig. Şanobod bis ffannentang, aufrid)t, fpäterbin aud) liegeno oier aufiteigent. Şethgriu, Drüfen gelblid), હaamen weis̄lid). - b. rubra CAr. Drüfen brauntrtl). - 2uf 2effern, હd)utt. Juli - Eeptember. ๑. Jni Erjo

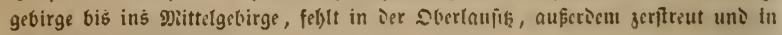
Der (sbene nidit felten.

1868. E. segetalis L. Rснв. Deutschl. Fl, 2466iro. 4781). Dorve

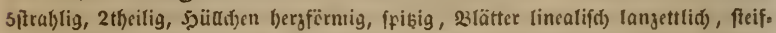
tid), oberite breiter, Drüjen fein ju(felf̈̈rmig, Saanen roeislid), fajt kuglig, neks:

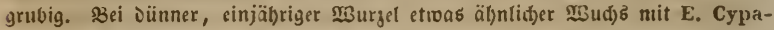
rissias, bis fufib)ed). Slätter nad) beiden Enden (piş, obre breiter, alle abroärţ gerid)tet. Eaamen weî́ bereift, Grübd)en braun. - 2uf 2ređern. Juni. Juli. ๑. Eef)r felten. A. Sobbau, Rathnftein. Scliwabe. HS. Jena: Ziegenfanin, Burgau, Zenker.

1869. E. Lathyris L. Rcнв, Dentschl, Fl. 26tilt. 4738. 3lättir

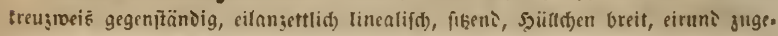


ifiht, Rapicl glatt uno tahl, Eaaunen umg(fel)rt eif̈̈rnig tuglig, rauh), matt uno

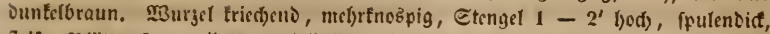
fteif, 33lätter $2-3^{\prime \prime}$ lang, bläulid') grün, meiß geavert. Dolvenftrallen ipan. nenlang, Drüfen fid)elfïrmig, ibre Epişen tëpfdenartig ftumıf. פRildsfaft fel)r reid)lid). OfF. Sem. cataputiae minoris. - 2(uf bebauten $300 \mathrm{cr}$ und Gdutt, nad) Jafbrbunderten wieber teiment. Juni. Juti. 4. Sierwildert.

1870. E. Esūla *) L. Rснв. Deutschl. Fl. 26bitu. 4791. Dolic

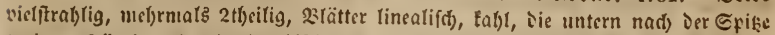

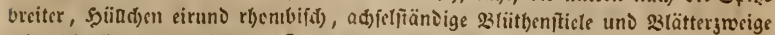

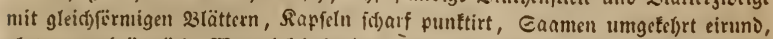

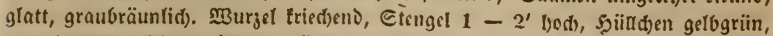
nad) Dem abbliiben grïn, Drïjen rotbbraun, fpisig. - 2in fandigen sriften,

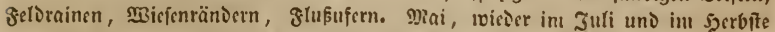
eingelner. 4. Jm bäbern Erggebirge: Z. Stenberg, WBiroenfels. Wankel. 2u. ficrocm nid)t felten, befonders bäufig und groß ant ganjen effufer.

1871. E. Incida W. K. Rснв, Dentschl. Fl. xb6ils. 4797. 2 uf

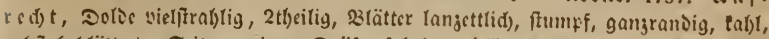

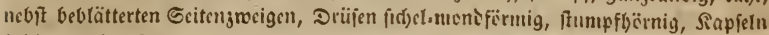
fobl, warjig, Saamen glatt, afd)graubraun. \$3urgel ftarf, Stengel $2-4^{\prime}$ bod), fingersoid, Drüicn $4-5$ ald) $6-7$. Mian leje unfre Deutidilands glora III.

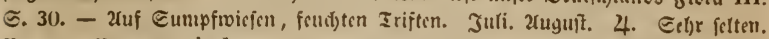
9iur PL. Pieujctle. Fischer.

1872. E. Cyparissias L. Rснв. Dentschl. Fl. 266. 4793. Бஞієf,

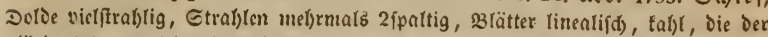

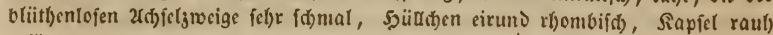
getïmett, Saamen glatt, braun. Burgel fenfres)t, mit tried)enden 2(uşläufern, Etengel fpannen. biö fußf(g)d), (d)icf, Diđ)t beblättert, Şülld)en grïngelb, fpäter rotb) anlaufeno. - b. pinifolia LAs. Dic ïppigere Syerbftform, weit büber, 23lät.

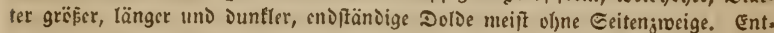

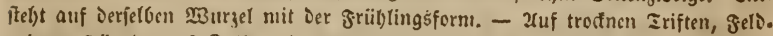

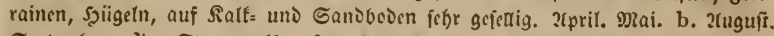
Esptember. 4. Etellenmeife. Im Erggrbirge: Z. Iobtenftein bei Sdwrarzen.

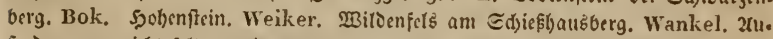
feriem gar nidft felten uno an gecigneten Drten fitrefentweife verbreitet.

1873. E. Gerardiana L. Rсив. Deutschl, Fl. 206iro. 4797 . Fl. germ. exsicc. 11. 497. 2ufred)t, oläulid) bercift, Dolde vielptrablig 2tbeilig, aud)

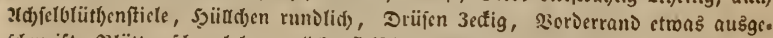

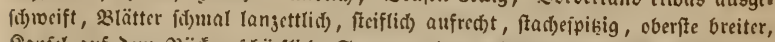
Sapicl auf bem siüdêten id)ärflias, Saamen glast und glanjloz. IBurgel fentred)t

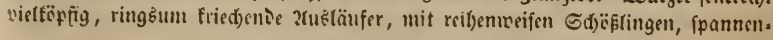

*) PRad)_Borrichrus de lingua pharuacopolorum muf dicjer alte glame is

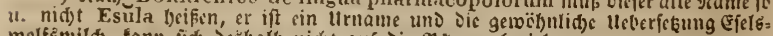

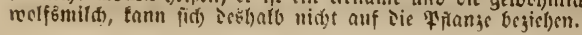




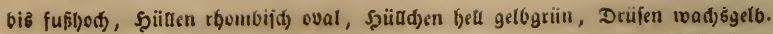

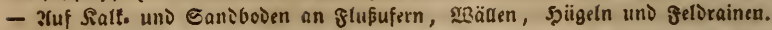

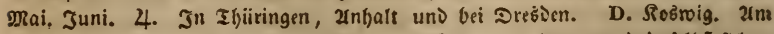

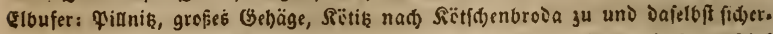
lid) von ier Elbe aub şöbnien (namentlid) von Pobofik, wo fie, narb Ejernufdjet

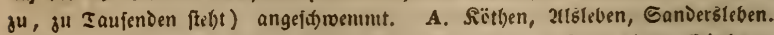

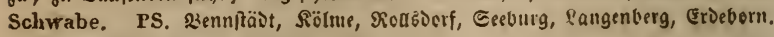

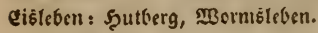

1874. E. amygdaloides L. Rcne. Dentschl. Fl. 266iro. 4793. Fl. germ. exsicc. n. 1591. 2tufferigend, Dolie 5 - 10itrabtig uno fo wie Die

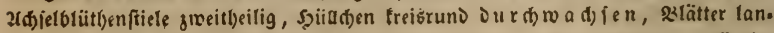

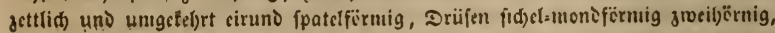
Rapiel fduätflids, tahl, Saamen eiförmig, faft tuglig, glatt uno glanjles. Span. nell. bis fufl)e(b), fdjën grïn, neeift retl) angelaufen, unterfte slätter bis $2^{\prime \prime}$ lang, unten bläuliç) grün, teilfërnig in Den Stiel verfomälert, folgenie Blätter febr

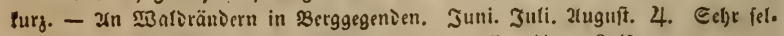
ten. A. Sanierśleben, 5ूarjgercose, Bernburg, Deffau binter Puifium.

596. Mercurialis $L$. B ingelf $\mathfrak{i} a$ ut. 31 . ein. ober zweio bäufig. Reld) 3tl)eilig. Blume 0 . Ctaubgefäße $9-16$. Seutclfäd)er ge. trennt, faft fuglig, in Der roeiblidben stiitbe meift 3 Etaubfäien olyne seutel.

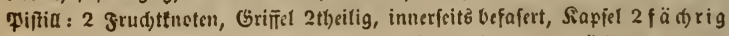
Saamen umgetclyrt ciförmig. - Slättẹt und Swcige gegen ï bcr.

1875. M. annua L. Rснв. Deutschl. Fl. abbilo: 4801. 3wölfmän, nig, einl)äufig, Stengel äptig, Blätter geftielt, eirund länglio, , oberfte langettliđ), gleid)mäfig gefägt uno geminıpert, meiblid)e 21 . fiß̨eno. Stengel 4 tantig, 1 $2^{\prime}$ (jod), einfad) oder äftig, nuännt. s81. in 2(eb)ren, unterbrodben gețäuelt, sveibl.

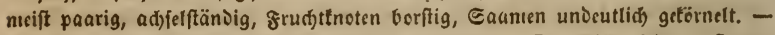
Xuf bebautem soven, 巨d)utt. Juli-December. $\odot$. Nidgt felten, fteden. meife bäufig, bejonders auf Zečern und in Gartentand.

1876. M. perennis L. Rснв. Deutschl. Fl. 2466iro. 4807. शcun.

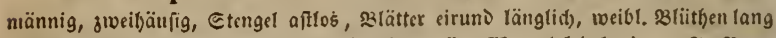
geftielt. Spannens, enDlid) fuflyod), iunfler grïn. I3urgel tried)ent. - In $3 \mathrm{erg}$. walsungen unter Gibüist). 2(pril. פai. 4. 2iid)t felten.

597. Buxus L. $\Re$ ณ

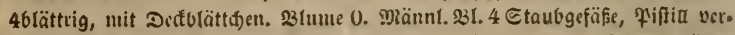

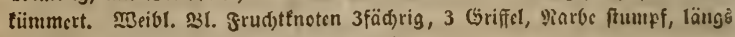

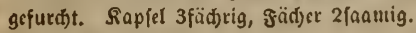

* 1877. B. sempervirens L. Rcub. Deutschl. Fl. atob. 4808. szlät.

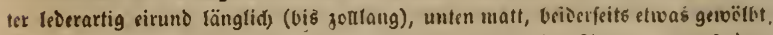

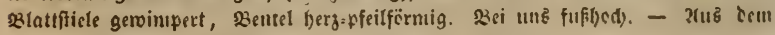

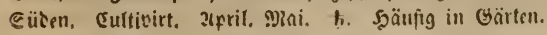




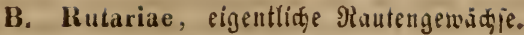

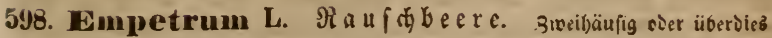

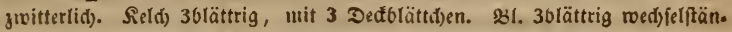

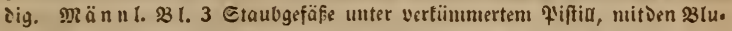

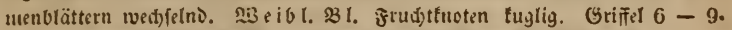

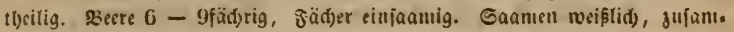
utengsoriiđt. -

1878. E. nigrum L. Rснв. Deutschl. Fl. 2(t6its. 4810. viieder.

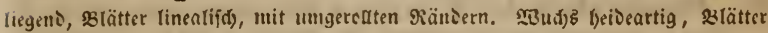
tlein, hart, leierartig, faft jiegelftändig. 33. blaß tarminroth. - 2uf zorfmoo. ren, iagegen audi) an ganj trofinin, freinigen eterten an Felien und an Şalden.

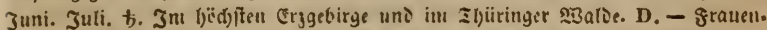
ftein. Schneider. Zlttentirg: Eeifing. Kaiser. Rablenterg. Fic. Fl. Dresd.

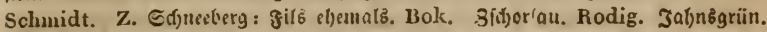
Waukel. Johanngecrgeuffait am Siranidj[er. Bok. Brunner. Sivifdjen Jobann.

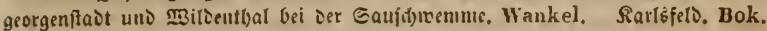
(Sottęggabe. Rchb. Weiker.) HS. Sd)neelepf, Becrborg. Metsch.

599. WR uta L. R a u te. 3it. jwitterlid, aufredt, mittlere suerft

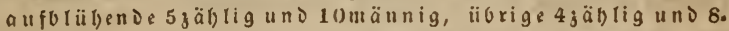
แännig. Sield) $4-5$ tl)gilig. S3lumenblätter $4-5$, muldjelförumig, mit Niagcl, Etantigefäße $8-10$. Griffel an Dex 33 afiz $4-5$ ipaltig. Sapfel

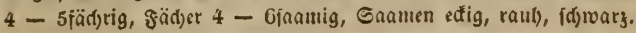

1879. R, graveolens L. Rснв. Deutschl. Fl. 2666ito. 4814.

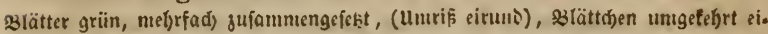

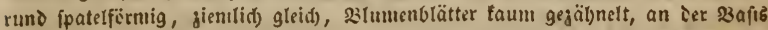

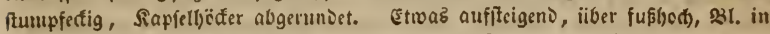
mugoorisger $\Re i$ ispe, gell. Gel)r bitter. OFF. Herba et summitates rutae. -

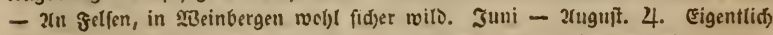
Salbitraud). Eeljr folten. P'S. Grojicnaer Eanifelien, MBeinberge bei greiburg. Beneken.

600. Dictammus L. Diftam. 231. zwitterlid), geneigt. Sield 5tbeilig, abfalleno. s3luntenblätter 5, etwas ungleid). Ctaubgefäfe 10, ab. gelogen auffeigent, Drüfig. (Grifel einfad), Szarbe unabgefekt. Rapfelfädger 5 , gejondert, 1 - 2faanig, હaamen fuglig, glänzend fdjrary.

1880. D. Fraxinella Pers. Rснв, Deutschl. Fl. 266ritb. 4813.

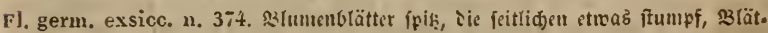
ter cinfad geägt. BBurger bolgig, äftig, weis, Stengel $2-3^{\prime}$ bod), Blätter un.

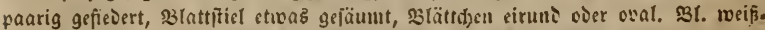
lisf rofa iiberlaufen uno nit farminrotfen Sinien, cier b. albiflos, gauz msif.

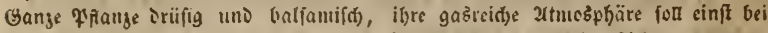
simer warmen beitern gadjt von $L$ in $n$ ées sodjter burd) eine fintianume ent. giintef tooken fein. OFF. Rad. Dictamni albi. - 2 fn fonnigen, beroadfenen 
Saltfelfen. Mai - Juli. 4. In Xnţatt uni şjüringen. A. Sanderšleben,

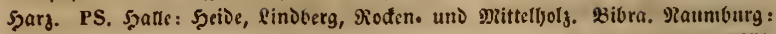

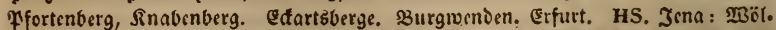
miffe, forft, Runif̨burg, sautljal, 2rniłedt. Zautenburger forft. Meimar: 23 crta. SRS. Raltrfal bei grantenbaufen. 2trnftadt.

\section{Eamilie Snpindacene, Sapinbacen.}

- Şcrbarienoud) ङ. LXX und 175. -

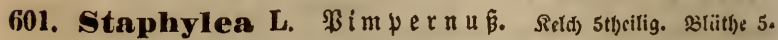
blättrig. Sirugförmiges Driifenpolfter. Ctaubgefäfe 5, nit Den 33 lumenblät. tern abmedffelno. Griffel $2-3$, etwas verwadjen. Sapfel $2-3$ füdjrig, vlafenartig, innen auffiringeno, wenigfaamig. Saamen (grë̄̄er als Erofe)

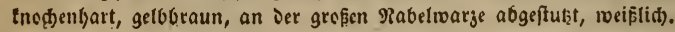

1881. S. pinnata L. Rcrв. Dentschl. Fl. 2666ild. 4823. Fl. germ,

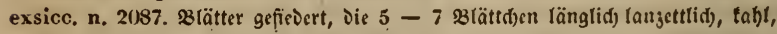

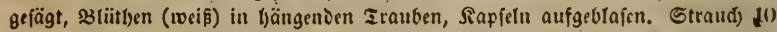

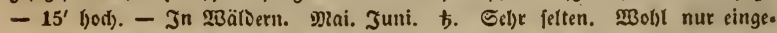
bürgert. Z. Stcuberg. Möller. HS. SRoburg. Hornung. - Şäufịg angepirangt in Ģärten und ૧artร.

602. Acer L. $\mathfrak{A} \mathfrak{G} \circ \mathrm{r} \mathfrak{n}$. $\mathfrak{B l}$. gettennt und grwitterlidf. Reld) 5 theilig. Bl. 5blättrig. Drïfenpoliter giterbt, trägt Die $8(7-9)$ Staubgefäßse. Brvei einfaamige gliigetnüßjen. Suamen fnod)ent)art, an Der Reinuvarge abge. ftußt. - Blätter gegeniiber.

1882. A. campestre L. Rснв. Dentschl. Fl. 2r6birb. 4825. Bäättr herjfërmig 5lappig, J6fidnitte ftumpfectig, unterfte ganjrandig, alte länglid), ftumpf, Doloentrauben aufređt), Fliigel horijontal ausgefpreizt. - b. austriacun Tratt. Dofoentraube menigbliitbig, glügetnïßd)en tal)t, Blattabfd)nitte verfd)mälert, Dann ftumpf. - A. molle Or. Blätter unterfeitz fein bel)aart. A. hebacarpun Tscr. flïgetnififon fein bebaart. - A. microcarpun Tsch.

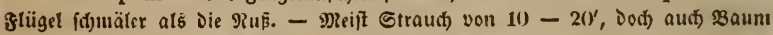

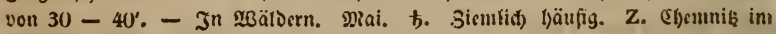

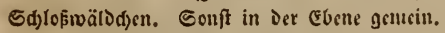

1883. A. platanoides L. Rснв. Deutschl. Fl. ab6 biro. 4S28, 3lät. ter bud)tig 5 - 7lappig, sugefpist edtig, Doldentrauben aufredst, friigel

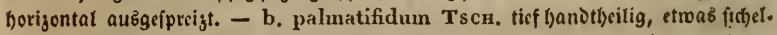
förmig gebogen. - c. laciniatum Du Ror, tief fjanotlfeilig uno fofmal ger.

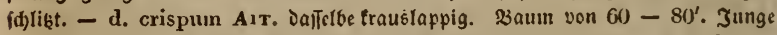

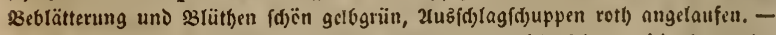
3n Balbungen. 2xpril. Mai. †. Jill zragemeinen nidft felten, jeiod) wenig. ftens im Dbergebirge fparfamer als soriger. (Feb)it in Schwabe Fl. Anhalt.)

1884. A. Pseudo-Platanus L. Rснв. Dentschl, Fl. 2robirs.

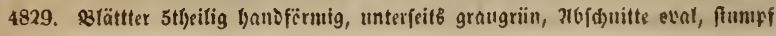




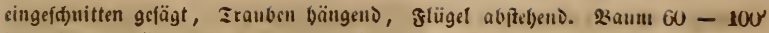
ho(b), junge \$lätter unten filjig, \$lütl)en tlein, grün. - In \$Bälocrn. Miai. b. 3erffreut, nidgt folten.

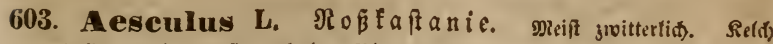
gloufig. Driifenpolĩer geferbt. Blumenblätter $4-5$, untegelmäßig, unten

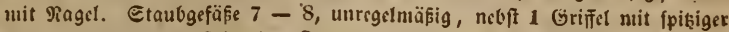
Narbe abgebegen aufîteigend. Rapfel igclftad)lig, jung 3fäd)rig, fä̈ber 1.

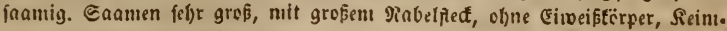

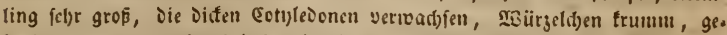

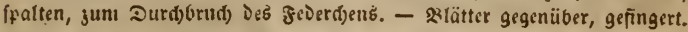

1885. A. Hippocastanum L. Rснв. Dentschl, Fl. 2øbils. 4822.

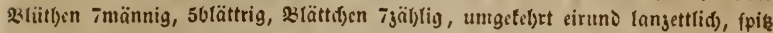

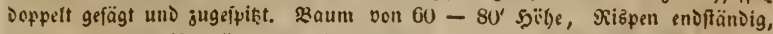
aufred)t. 231. reis, beide obre 33 lumenolätter rola oder mit gelbem glef. Gan. men gum ₹l)sil fellif(t)lageni, oft nur 1 òer 2 ausgebiliet. - Eultivirt und ver. woilorrt. Mai - Eeptember. 4.

\section{Familie IIalvaceae, gia luacell. \\ - Şcrbarienbu() ๔. LXXXI unঠ 199. -}

604. Malva L. $\mathfrak{R}$ alve, $\mathfrak{R} a \mathfrak{f}$ emalve. Reld) 5theilig, mit Drei angerwadjenen Defulättd)en. Sapjelfä̈tjer zaf)(reid), quirtfänoig, ein. \{aauig, fids einjeln abfonderno.

* 1886. M. crispa L. Rснв. Deutschl. Fl, 266iro. 4834. 2(ufted)t,

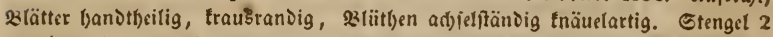

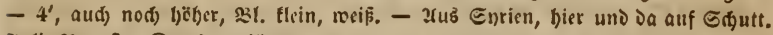
3uli, 2tugujt. ๑). Berwilibert.

1887. M. rotundifolia Lrvv. Fl. suec. et Frirs. Rchr. Deutschl,

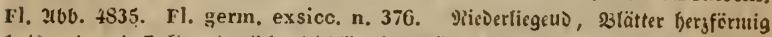

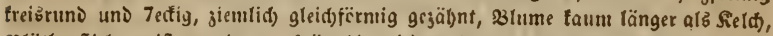

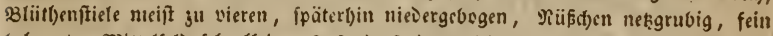

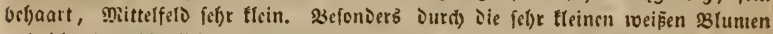

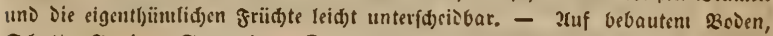

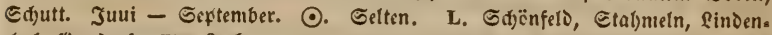

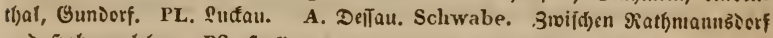
uni 5jobenertleben. PS. Szalle.

1888. M. vulgaris Trag. Fries, (rotundifolia Civ.) Rснв,

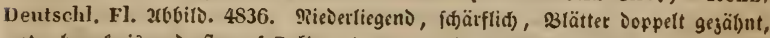
untre bers,freizruno, ftumiff 7eftig, core 5 - 7lappig, stiithenitiele meift paarig,

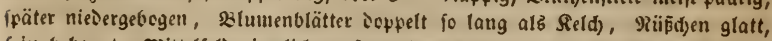

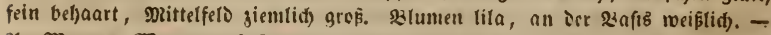
In Mauern, $\mathfrak{B}$ egrn, auf Edgutt. Suli - Geptrmterr. Gimtin. OFF. Hb, et Flores malvae vulgaris, 
1889. M. silvestris L. Rchs, Deutsch1. Fl, uvbils, 4840. $\mathbb{2}$ uryel aubdauterno, Stengel aufredtt, 3lätter freisfërmig, feid)t 5 - 7lappig, oberffe

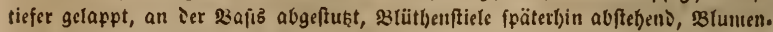

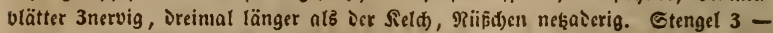
4' hod, teidst bethant, 3 tume lebhaft lita, mit 3 Duntlen Streifen, ober albiflora, Bł. weif. - b. equiua O. Bruxsp. (Wallroth), auf betretenen

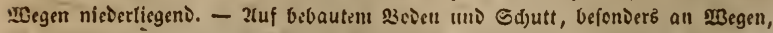

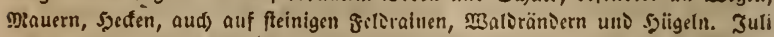
- Septentier. 4. Bentcin.

* 1890. M. mauritiana L. Rснв. Deutschl, Fl. at66iro. 4839.

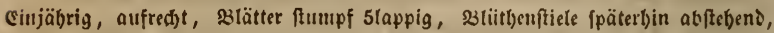

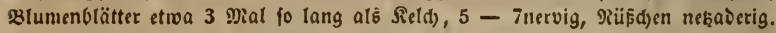
Etengel einzeln, ganj aufred)t, 31. gefättigt lita, viclet 5 - 7iftreifig. - 2xub Der Barbarei uno Eü̇europa. Juli - September. ๑. Berwiliert.

1891. M. moschata L. Rсин. Deutschl. Fl, 2666ilo. 4841 . FI. germ. exsicc. n, 1491. 2(ufredtt, einfach bel)aart, \$Burzelblätter nierenfërntig eingefd)nitten, Etengelblätter fupforrmig 5theilig, ausgefpreigt linea lifd) Doppelt

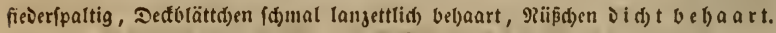

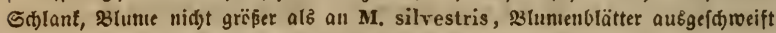
uno ferbig, rofa coer weißs. $1-11 \int_{2}^{\prime}$ hod). - 3(n 2l(ferräntern, fteinigen Şü.

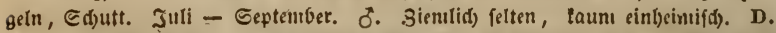

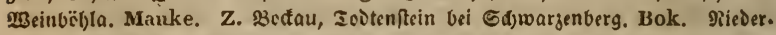
zwönił. Wankel. 13. Etolpen 1840. G. Rchb. A. Şars. Schwabe. PS. Mit,

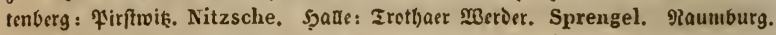
Beneken. HS. Jena: Şaub̆brg. Blantentain, Zenker. SRS. Irnftaot. Schönheit. R. Ebers̄oorf.

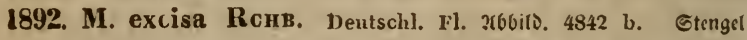

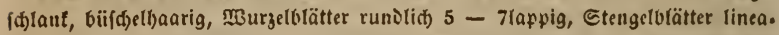
lif́d uno lanzettlid sertheilt, einge(d)nitten gezätht, slumenblätter tief a 1 हg ge.

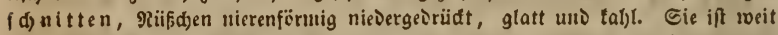

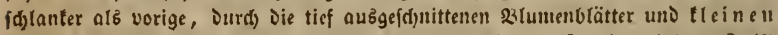

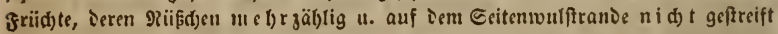

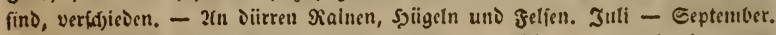

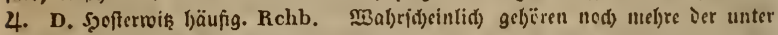
folgender 2art erroälyuten Stanierte bietl)er.

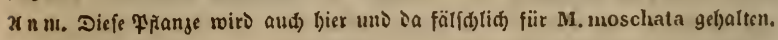

1893. M. Alcea L. Кснв.D. Fl. 206.4942 . Hayse A. 1I. 30. Etengel

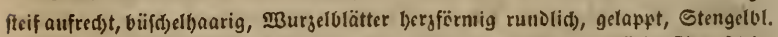

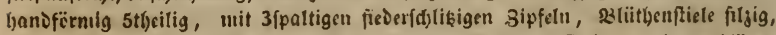

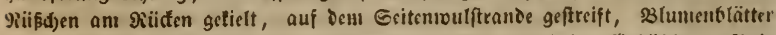

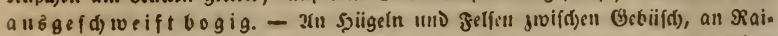
nen, Megen, \$albrändern. Juli - Eeptember. 4. Etellembeife. D. Dber.

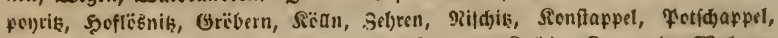

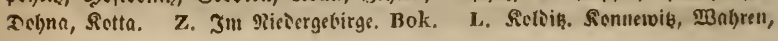


Stabnueln, פöltau. B. Sientlid) verbreitet. PL. De6gleidjen. A. DeT̄au, Eall. derร̇le

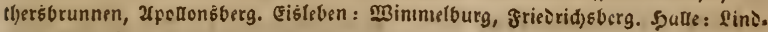

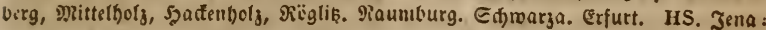
Şallzberg. Eifenberg. ficburg. SRS. Frantenbaufen. R. Gera.

605. Lavatera $L$. Lavatere. Seld 5tbeilig, şiille 3lappig. giüfd)en einfaamig.

1894 L. thuringiaca L. Rснn. Deutschl, Fl, 2rbbild. 485t. Fl. gerı. exsicc. n. 2088. Blätter 5, uno 3lappig, Dittellappen länger, ftumpf,

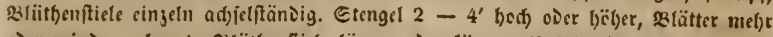
sDer minier gelappt, sitittbenftiele länger oder tiirjer als slattitiel, 28l. giemlit)

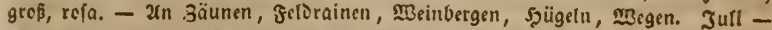

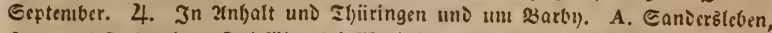

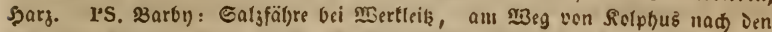

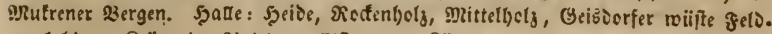

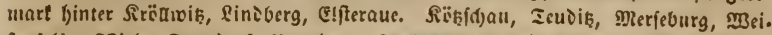

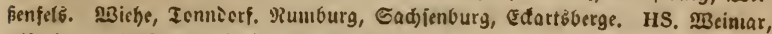
Eijenberg. SRS. Frantenbaufen, Ecchaujen.

a $n$ m. L. trimestris L. Rснв. Dentschl. Fl. xbbirb. 4852. ай iem Güicn, l)äufig in Gärtell cultivitt, vermilsett bier und ia.

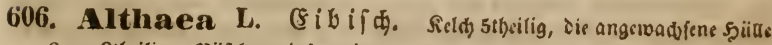
6 - 9tfrilig. riist)en eillfaanig.

1895. A. officinalis L. Rснв, Dentschl. Fl, 2666irs. 4849. 23äts. ter eirund thombifd, meidffiljig, ungleid) grob gefägt und die obern fpiß 5ectig. etengel 2 - 4' èer bäber, 83 . vlafiroja over reiflid). OFr. Rad. hb. et Fl. althaeae. - 2luf feuditen Pläk̨en, gern auf Sandooden. Juli - September.

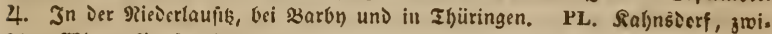

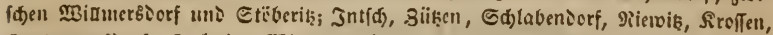

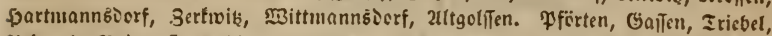
Teik. 4. Rabegaft, Bobban, Mrojigtau, Groftiïnau, Ganieršleben. PS. Barby:

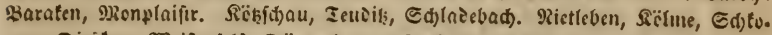

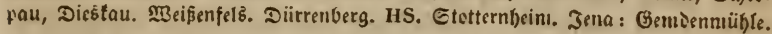

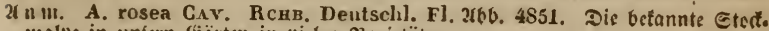
malve in unfern Gärten in viclen \$arictäten.

\section{Familie Geraniaceae, Geraniacen.}

- Saerbarienund G. LXXXII uno 201. -

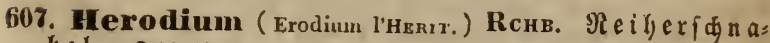
bel. Sield 5blättrig. S2t. 56lättrig, rcgelüäßig. Staubgefäße 10, nur 5 beuteftragend. 5 Sonigoriifon an ier sajis ier frudjtoaren @iaub. fäben. 5 cinfaantige Saffelfädjer fpringen leß und icren tange fortfäłęe orce.

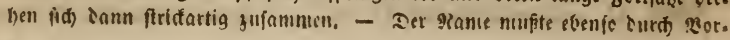


feţung Des feblenden 11 Geridjtigt werben, wie Dics bei Helichrysum, Hecastophyllum u. a. gefífyeben ift. -

1896. H. cicutarium S., Rснв, Deutsch, Fl. 2266. 4864. 2Blï.

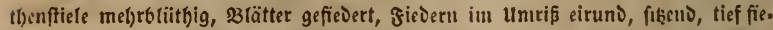
Derfpartig uno eingefdnitten, Staubgefä̧e unten breiter. - pilosun Truixs.

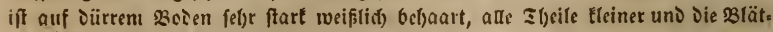

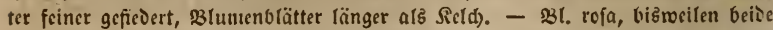

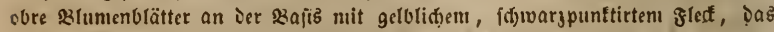

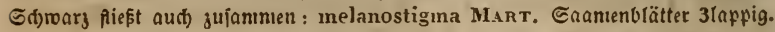

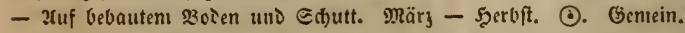

1897. H. pimpinellifolium Sx. Rснв, Dentschl. Fl. 2ro6ilo.

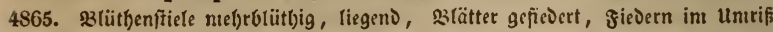

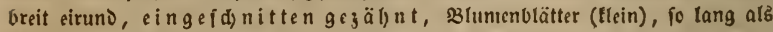
Setđ), ธaantenblätter cinfad), ๔taubfäben in Jer Mitte, etroas tnotig angefd)wol.

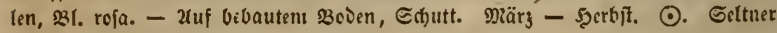
als voriges.

1898. H. moschatum l'Herit. Rснв. Deutschl, Fl. 2666. 4867.

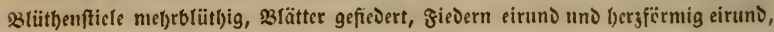

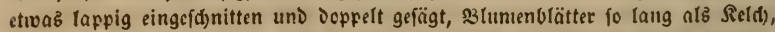
Die frud)tbaren Gtaubfäben unten breiter, zweizälnig. Stengel fpäter liegeno,

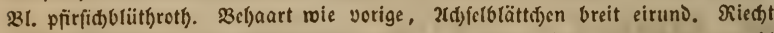

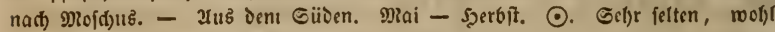
verwitiert. L. Sauffigt. Miiller. PS. Erfurt. Binder.

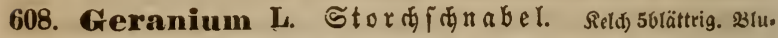

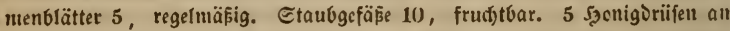

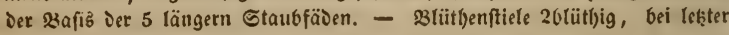
art 1olitithig. -

a. Blumenblätter abgerunoct.

1899. G. Robertianum L. Rснв, Deutschl. Fl. 266bilo. 4871.

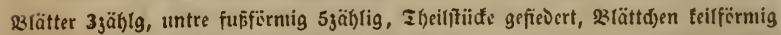
ciruno, fieorig eingefdonitten, grudttllafpen fojief querrunglig, 巨aamen glatt.

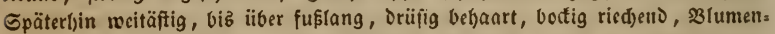

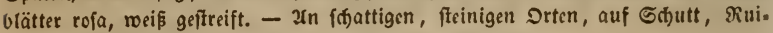

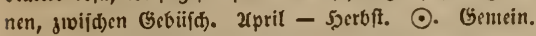

1900. G. lucidum L. Rснв. Deutschl. Fl. 2r6bilo. 4872. Blätter

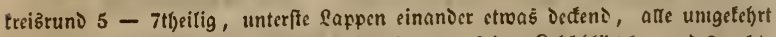

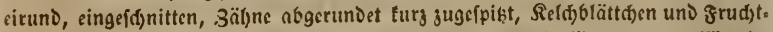
flappen sucr gerungelt, Blumenblätter umigctel)rt eirunt läıglid) fpaterförmig,

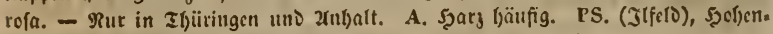

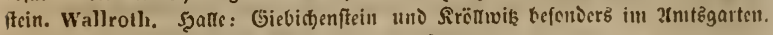

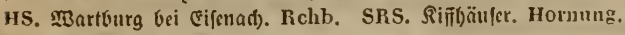

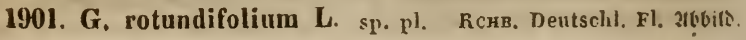


48is. Fl. germ, exsicc. 11. 2091. Silebrig fein bel)aart, auछgefpreigt weitäftig, unterfte 8 lätter nieren=freišruno, Eurj und vreit abgetunost 5 - 7lappig, einge.

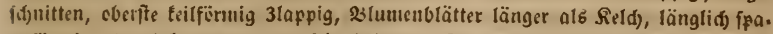
tslfïrnig, fruditklappen glatt, fiin bebaart, Eanmen fiin nekgrubig. \$1. roja. - 2uf 2reftern uno Felorainen. Dai - 2tuguft. ๑. Eelten. \$Burie gefun.

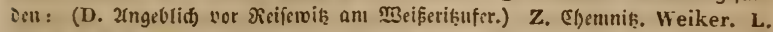
ficnnewik, Dëlik̨, 9ierdjan. A. S3ernburg, Cantersteben in Drängrl.

1902. G. phaeum L. Rснв. Deutschl. Fl. 26бilo. 4591. Fl, germ. exsicc. n. 377. Blätter aubecinanderffebent $5-7$ banitbeilig, eingefdinnitten

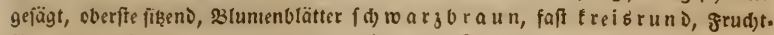
Elappen querfaltig. Fufbod), weid) bel)aart. "Raffecblünıden." - In Ëcbirgs. t)äletn jwif(t)en Gebuifds, im Grafe. Biai. Juni uns wiecte im 2uguft. 4.

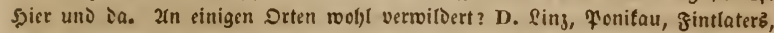

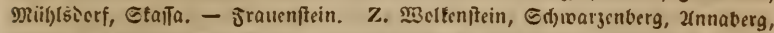

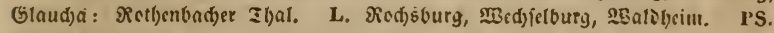
Şalle: Sdjüksengraben, Sibikens 3winger.

1903. G. palıstre L. Rснв. Deutschl, Fl, 2666. 4892. \&lätter 9

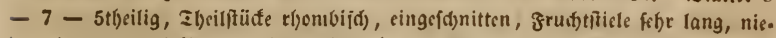
Dergebogen, frudtttlappen glatt, fein bebaart, Saame glatt. Bl. groß́, blauretb).

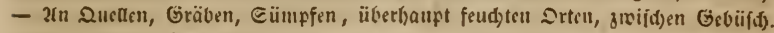
3uni - Eept. 4. 9Rid)t felten.

1904. G. sylvaticum L. Rснв. Deutschl, Fl. 2660. 48s2, Slättet

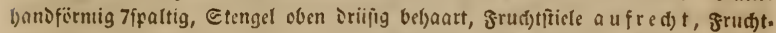

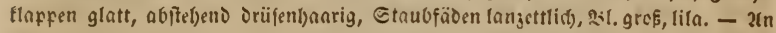
Queden, şäđjen und feudjten Drten iiberbaupt in Ibälern. Juni. Juti. 4. Şier

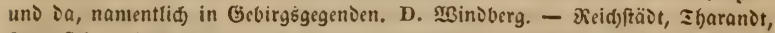
Sallentein, 3rtenberg. Z. In ganzen Dbergebirge. Şartenïtein, Єtein, Milden. fels. L. Grintma. B. (Jäfdt)taberg.) A. Şarjgercie, Dranienbaun, Redlik. PS.

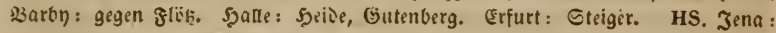

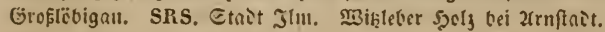

1905. G. pratense L. Rcrв. Deutschl. Fl. 2lbbilo. 4883. Bglätter

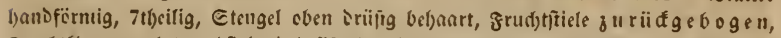
grudttlappen glatt, abitelgeno Drüjenbaarig, Etaubfäben am Grunie freisförmig

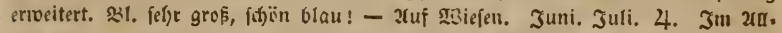

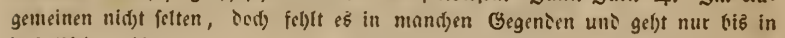

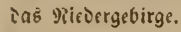

\section{b. S\&lumenblätter cingetrtot.}

1906. G. divaricatum Енкн, Rснв. Dentschl. Fl. 206. 4873.

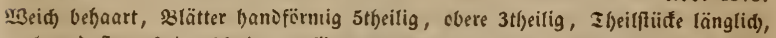
grob und ftumipf eingefd)nitt'n gefägt, grudjtflapfen querrutjeling, હaamen glatt. 2ufred)t, fpäterbin fel)t weitäptig, 2teft lang, oünn, aud) liegeno, sz1. roja. 7. Sdlofferfen (1ci Sthwarzenbrrg. Bok, Rodig. Weiker. Miiller, Wankel. Reichenbach, 
1907. G. bohemicum L. Rснв, Deutschl. Fl. 206. 4874. आ3ein

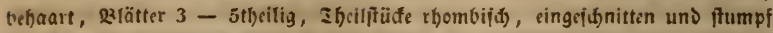

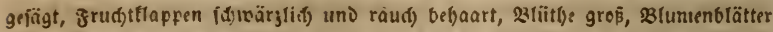

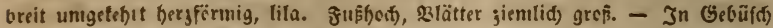

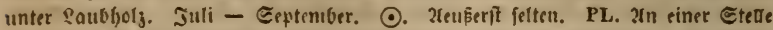

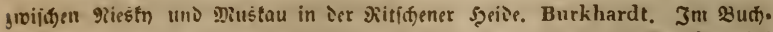

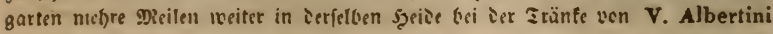
ehcmals gefunien.

1948. G. pyrenaicum L. Rснв. Deutsch,, F], $260.4881 \alpha \cdot$ u. $\beta$.

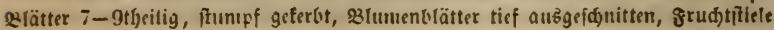
niedergebogen, gruditflappen fein bebaart, Driffenlob. - In fithattigen Dr.

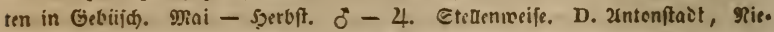

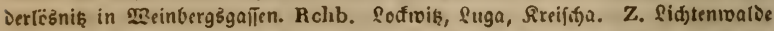

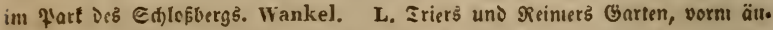

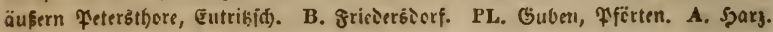
PS. Szatte. Derfeturg. Erfurt. Doniberg bei Eubl. HS. Jena: Relvedere, Seutra. SRS. Frantenţaufen: siotbenburg. - Bl. tila oder reciß, tila geípiąt.

1909. G. molle L. Rснв. Dentschl. Fl, 2t66ito. 4879. Meid) ve. baart, s3ätter nierenfërnig runofid) 7 - 9ipaltig, etengel fefo Diinn veryweigt,

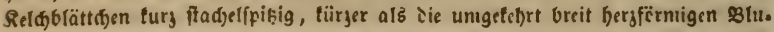

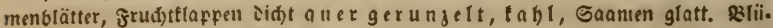
thenftiele firfen meit entfernter und find weit länger als bei bent älinti. ఏen G. pusillum ! Bl. flein, roja. - Zluf bebautem Boien, Sdjutt, an gRauern,

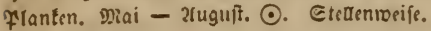

1910. G. pusillum L. $S_{p}$. pl, Rcri, Deutschl. Fl. 2r66ito. 4877. Fl. genn. exsicc. n. 2090. Slätter faft treišrund 6 - 9theilig, Seld furz be. grannt, io lang als situmenolätter, frudtftlappen glatt, veeidt bichaart, Eaanten glatt. Blüthenftiele sidht beif a nt men, 231. flein, roja. zlufredt, fpäter meits,

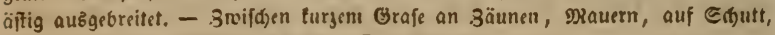
bebautent 2zoien. Diai - 2uguif. $\odot$. Gemein.

1911. G. dissectum L. Rснв. Dentschl. Fl. 2a66ito. 4876. Fl。 germ. exsiccata n. 1592. Blätter 5 - 7theilig, tuit linealióden 26bid)nitten,

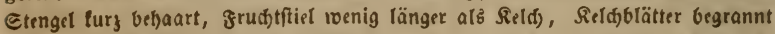
fo lang als slumentlätter, grudttllappen glatt, fein bebaart, Saamen fein nets.

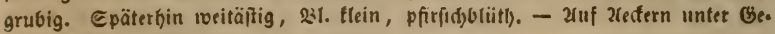
treice, 巨d)utt. Mai. Juni. $\odot$. Semein.

1912. G. columbinum L. Rснв, Dentschl. Fl. 2666ird. 4875. Glänzend, fparfam bebaart, s2lätter 5 - 7theilig, \$3urgelblätter treišund, 210.

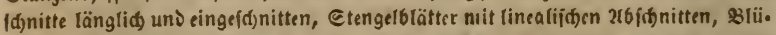
then und grudteffieldsen melbrnals fo lang als Seld), Reldjblätter lang begranne, mit ier Granne fo lang als sie (rofafarbigen) selumenblätter, Frudittlappen glatt

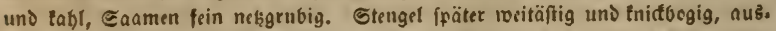

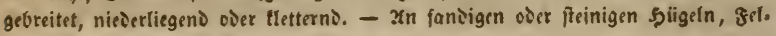

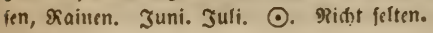




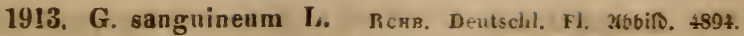

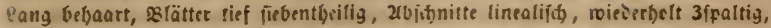

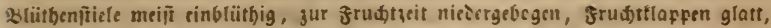

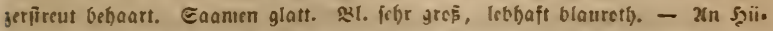
geln und gelfen zmifden Grbuild, vorgïglid) Eani. und Ralfbcien. Juni -

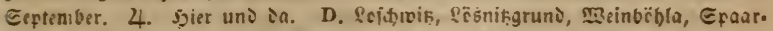

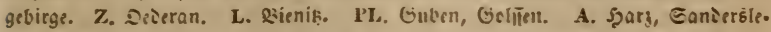

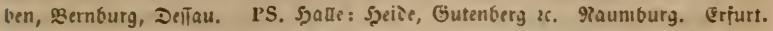

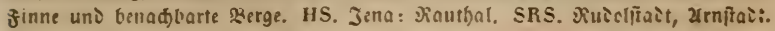

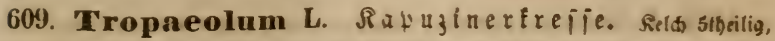
geffornt. S\&lumenblätter 5, mit grägeln, unregelmäßig, 3 untere tleiner (oost

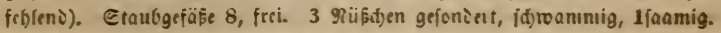

* 1914. T. majus L. Bot. Mag. 23. slätter fơilteirntig freizrund,

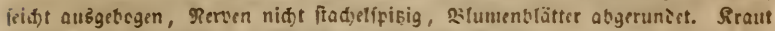

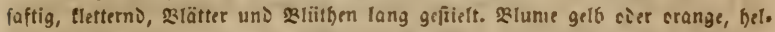

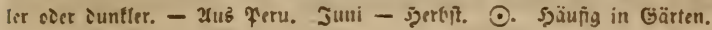

\section{Familie Oxalideae, Eauerflergetwädje.}

\section{- Sgerbatientud ๔. LXXXIII u. 2()3. -}

610. Oxalis L. Gauerflee. sil. regelntäsig. Rith 5uättrig.

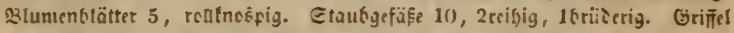

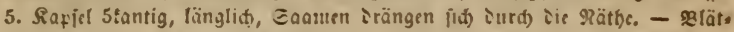

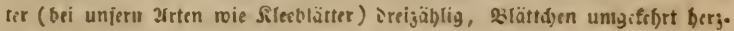
förmig.

1915. O. stricta L. Rснв. Dentschl, Fl. X66ito. 4805. Fl, genn.

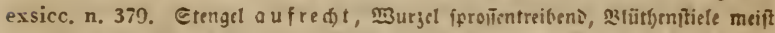

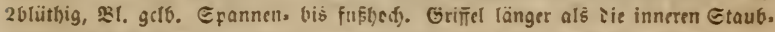
gifäse. Eaanten uner getunjelt. - Juf bebautent sacien und Edfuttland, jroi.

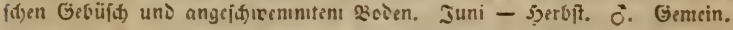

1916. O. corniculata L. Rснв, Dentschl, Fl, x6bils, 4896 . Fl. germ. exsicc. n. 380. Etengel allägeípreizt äjtig, liegeno uno vourgelno,

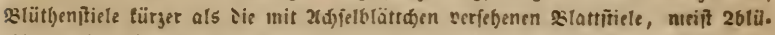

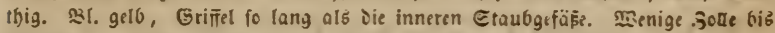
fü̈lang. - Xuf bechauten szcien. Xpril - Eeptemiter. (. Szicr uno ia. D. Mieisen. Ficinus. Rü̈n. L. Rchb. fil. Safdeniorf, Eärnemis. G. Rchb. Z.

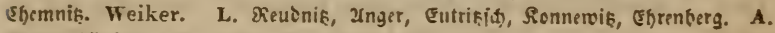

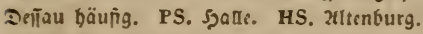

1917. O. Acetosella L. Rсrв. Deutschl. Fl. 266biro. 4598. \$3ur,

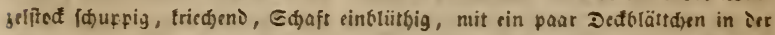
Mitte. S2l. greß, meī̄, lila geadert, felten ganj lita: b. lilacina. Caamen längśriffig. OPf. Hb. Acetosellae s. Lugulae, - In fifattigen £aubwälieṛn. צril. Mai. 4. Ërmein, 


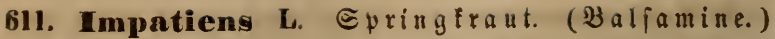

Sielch 40lättrig: 2 Eeitenblättd)en queriiber, cval jugeffiḩt grünlid, ein vor. ceres mufd;elfïrmig, am Sicl krautartig, iibrigenz corchinif(), Das bintere corwlinif̧, tappenfïmig uno geipornt. Blume 20lättrig, 401ättrig verıad). fen, nit nac) ausell georebter łlatte. 5 Etaubgefäfe (fef)r furf). Seutel

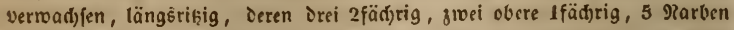
sereint. Siapjel prismatif(t), Die 5 finfpen fpringen los bei szerül)rung uno rwden fitf elaftifd) zujanumen. Sänld)en f(t)mamnig melsraanig, Gaamen rippig.

1918. I. Nolitangere L. Schk. t. 270. ST. 5. Stiithenftiele 2 56lïthig, tiirger als s3latt, unter Dallelbe gebogen, Epern an ter Spiţe etma Sförmig gebogen. Etengel faftig, 1-2' bod), tnotig angefdroodten, fel)r able.

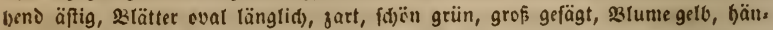
gend, inwendig tarminroth punttirt. Etaubfä̀en grünlid), mit cinem şë̈fer un.

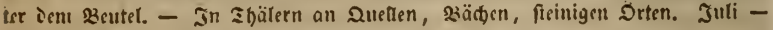
Eeptentber. (. Durd) ias Gebict nidjt felten.

\section{Familie Caryophyllacene, Nelfengewäthje.}

\author{
- Şcrbarientud̆ 5. I.XXXV uno 204. -
}

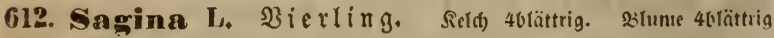
cier 0. Etantigefäpre 4. (jriffel 4. Sapfel 4 flappig, molhraanig.

1919. S. procumbens L. Rсre. Deutschl. Fl. 2606irs. 4959. 2rie.

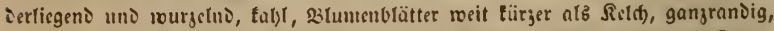
grudtfficle etreas nitteno, Sapiel fo lang als Seld). Zarteb, hellgriines Siraut, Blätter balbrunstid), gefpist. - 2(uf feud)tem 2300 en, aut) on Mauern, Brum. nen. Mai - Dstober. ๑. aldgemein verbreitet bis auf Die Bebirge.

1920. S. ciliata Fr. Rcrib, Dentschl, Fl, 2r6bito, 4956. 2uffitci.

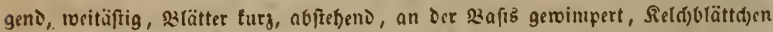
fpifsig, taum iiber balb fo lang als Die reife Sapfet. Bart, ein paar .3oll bod).

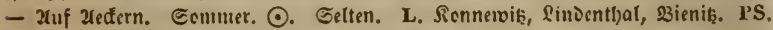
Merfeburg. Dehne.

1921. S. apetala L. Reнв. Deutschl, Fl. 2f66iro. 4958. Fl. gerin. exsicc. n. 68. Sismlid) aufred)t, fein facenfërmig, äftig, bobaart, Bzätter fein. fpişig, grud)tFicle aufred)t, Sicldblättd)en ftumpf, Die beiden äusern mit cin.

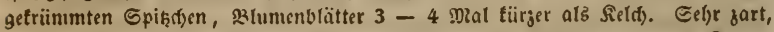
2 - 3". - 2uf Eandboden. Dai - Detober. ๑. Etedtenmeife. L. Ronne.

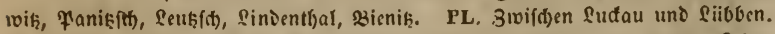

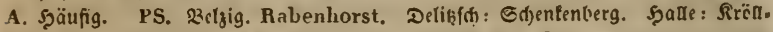
wiş, Geben, Gutenberg. Raumtburg: Slemmingen. Beneken. Erfurt. Hornung. SRS, Singen, Hornung. 
Caryophyllaceae. - 433 - Spergella.

\section{Spergella Rchв. Sperfling. Selti 5theilig, slu.} nenblätter 5, ganzraniig. Staubgefäße 10. Girifel 5. Saffel 5tlappig ge. (palten (fid) ni(đ)t nusbreitent:).

1922. S. subulata (Spergula - Sw.) Rснв. Dentschl. Fl. æa66ilo. 4963. Fl. germ. exsicc. n. 1793. Slätter linealifí) jugefpiķt ftadtelfpikig,

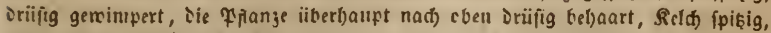
faft fo lang als Sapfel. Ein paar 3oll lang. - 2luf Eaniboien, Bradüätern.

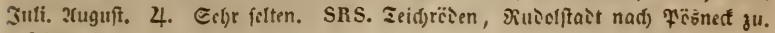
Schönheit.

1923. S. nodosa (Spergula - L.) Rснв. Deutschl. Fl. 2ð66. 4965. Blätter linealifw, die untern jeftr lang, Der Etengel äftig, 3reige vielf notlg,

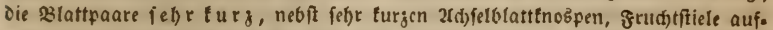

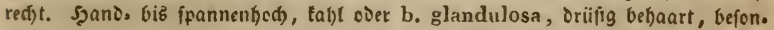
Derb bie cberen zheile. - 2uf feudtent Eandboien. Julli. 2uguft. 4. Sgier uno ia. D. Meinbël)la, Rieverau, Eteinbad), Rreifda. - ₹haranot. Bok. Z. Beid)enbranit. Weiker. L. Edjëufeld, Fortik, Flauffig, Eeegerik, Rleindäljig. B. Berthels̈berf, Onbintbal, Bittau ze. PL. Syäufiger als in B. A. Deffau,

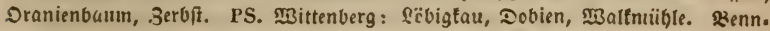
Dorf. Saudbaninter bei Drtrandt. HS. Miseica: surterstorf.

$2(\mathrm{n}$ m. 3 Su 5.311 iff nod) bier nad) zutragen 1390 b.:

1924. Alsine segetalis Schreb. Rсвв. Fl. germ, exsicc. n. 70,

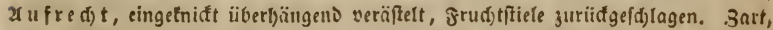
$2-4^{\prime \prime}$ hoch, Seldbuättden trodenthäutig. - 2uf Getreibeäfern. Juni. Juti.

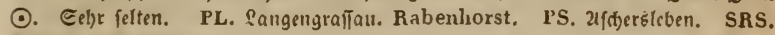
Eingen. Schönheit.

614. Sabulina Rснв. ๔åndłing. Seld 5blätrig, tang u no fein zugcfipikt. Siluntenblätter 5 , länglid) abgerundet, meeift tiurger als

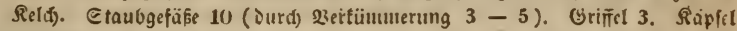
1 fäşrig, halb 3ipaltig. Saainen getörnelt.

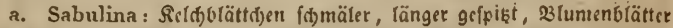
länglid).

1925. S. tenuifolia (Arenaria - L.) Rcнв. Deutschl. Fl. 2r66ils.

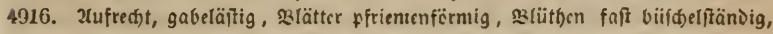
Reld\}blättden für zer als Sapfel. $2-4^{\prime \prime}$ l)od), taftr oder wenig befbart. -

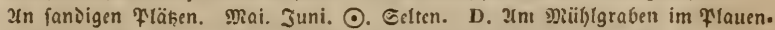
fiffen Grunie früler sinmal. Groh. 2flaunlütte. Ficinus. B. Suttacr @tein. brud\%. Burkhardt. PL. Siroilen, jroifden Solienblatt und İittmiannedorf. A.

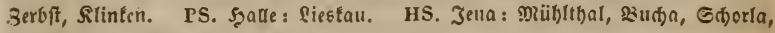
Dicthenftein. SRS. Einger Berg.

1926. S. viscosa (Alsine - Schreb.) RсHв. Deutschl, Fl. 2ub iro. 4917. Fl, germ. exsicc, n. 69 . M̉ie vorige, aber briifig belf)aart und bie

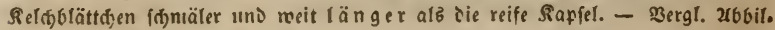




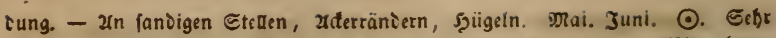

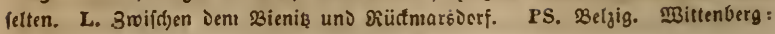
fobenz gegen \$Beifigt. Düben. Sgalle: fie bै a u.

b. Tryphane FExzx. Şärtling *), Seldblätter breiter, (rautartig, bautrandig, Bluntenblätter unten breiter.

1927. S. cespitosa (Arenaria - Eнян.) Rснв. Deutschl. Fl. 2660. 4927. Fl. germ. exsicc. n. 385. S3lätter ffriemlid), ftumpftid), Etengel rispig

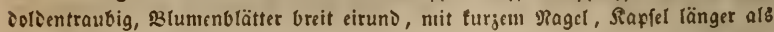

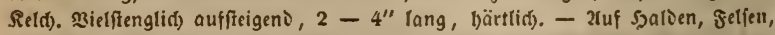

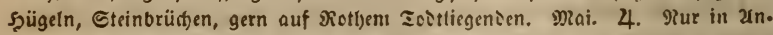
balt, iu Mannbfeltifden uno bei Gingen. A. Syarggerove, Mägiefprung, Ranto

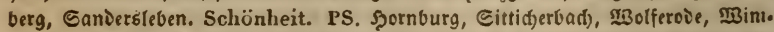
nelburg, Rlofter Mannsfelo, Shetffäit, Eišleben auf Dem Neuftätter Schießplak. SRS. Cinger $22 \mathrm{erg}$. Schönheit.

615. Noehringia L. TR íhringie. Seld 4-5blättrig, Blu. menblätter $4-5$, ganjraniig. Etaubgefäße $8-10$. Rapíel 1fä́)rig, 4 - Gllappig. Eaamen meift 4 , glänzeno glatt, giabelmarze fduppenartig. -

a. Moehringia, viergählig.

1928. M. muscosa L. Rснв, Deutschl, Fl. 206іl). 4900 . Fl.

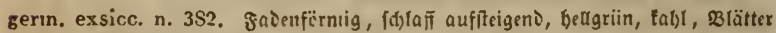

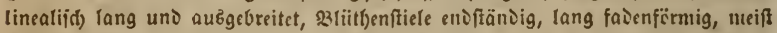

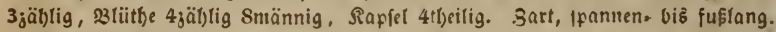
- 2n alten szaumftämmen, auf bentocften @tcinen. Juni - 2ug. 4. 2euferft felten. HS. Jena: in ier M̈̈̈lutile. Graumiiller.

\section{b. Mankea, fünf̧äh)lig.}

1929. M. trinervia Crainville. Rchв. Dentschl. Fl. wobißo. 4943. Blätter eirun১ jugefpișt, 3 - 5ncrvig, Die untern länger geftielt, s3tüthe 5 säblig, 10männig, fapfel Gtljeilig. 2luffteigeno, vieläjtig, fpannenlang. -2 n (d)attigen Drten in tocferm, feuditem Boden. פRai. Juni. ๑. Gemein.

616. Arenaria L. $\varsigma a n$ f $\mathrm{r}$ a ut. Siel(r) 5blättrig, slumenblät. ter 5, gangrandig. 10) Etaubgefäfe. 3 Grifiel. Siapfel 1fädrig, an Der Epike mit meift 6 .3älsuen aufipringeno. Saamen fein quernarbig.

1930. A. serpyllifolia L. Rспв. Deutschl. Fl, 2666. $49+1$. Blätter

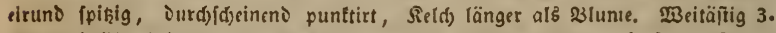
theilig, Drüfig beljaart, unterfte $\mathfrak{B l a ̈ t t e r}$ geftielt, ïbrige fiḩeno. - b. leptoclados

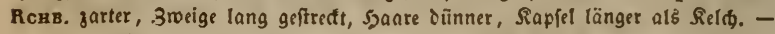
zuf Saniboden, Siigeln, Mauern. Jull - Eeptentber. ๑. Gentein.

") Der Name "2Boldgling" mürie iibel faffon. 


\section{Caryophyllaceae. - 433 - Holosteum.}

617. Holosteum L. ๔purre. Relch 5blättrig. 5 Blumen. blätter, an iex Epilie gefägt. $3-5$ Ctaubgefäße. 3 Grifel. Siapfel 1. fäđrig, vielfaamig, 6jäbnig aufipringend. Saamen fein getérnelt.

1931. H. umbellatum L. Rснв, Deutschl. Fl. 2160. 4901. Błäu. lich griin, band. bis fufbod), aufred; ober feitfidje Etengel auffeigend, tragen

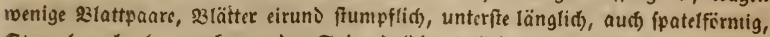

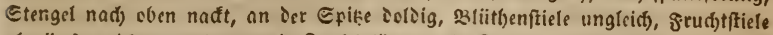
abrö̈rts gerid)tet, 22luue und Siaffel länger als Seld). - Xuf troơnen Xedfern

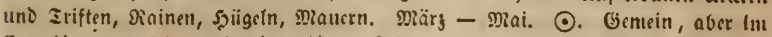

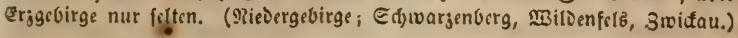

618. Stellaria L. Sternfraut. St. Miere. Sith 5blätt. rig. Blumenbütter 5 , j weitbeilig. 10 Etaubgrfǟe (Durd) Beltiimmerung

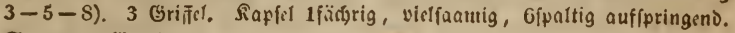
Gaamen getitrnelt. -

1932. S. media ViLL. Rcrs. Deutschl, Fl, 2606ild. 4104. Etengel

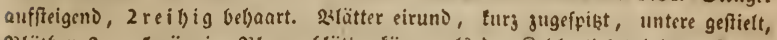
23liitben 3 - 5männig, 23 lumen(tätter fïr länger alל ier Sieldi), 6theilig, Gaamen an ben Esiten gewölbt. - zruf Gebau.

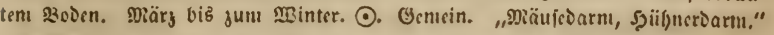

1933. S. neglecta IVвiнe. Renв, Deutschl. Fl, 266tio. 4905. (umbrosa OP.) Fl, germ, exsicc. n. 895. MBe vorige, nber üppiger, Blïtlen 10muännig, Silumenblätter länger, Sapfel Gfpaltig, Eaanın an ien Esiten pad).

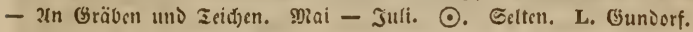

1934. S, nemorum L. Rснв, Deutschl. Fl. 266rild. 4906 . Fl, gerin. exsicc. n. 2093. s2lätter länglid) siformig, Die unteren beryfürmig uno geftielt,

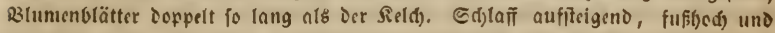

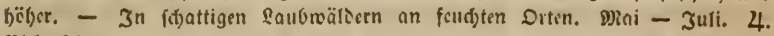
Ridit feiten.

1935. S. Holostea L. Rcri, Deutschl, Fl. 266tis, 4908 , etenget

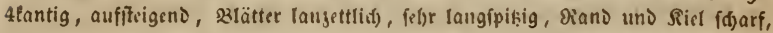

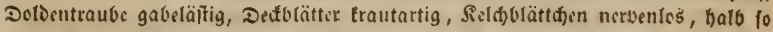
lang als 23lumenblätter und fo lang als Die fuglige Sapfil. 23lätter fteifflid), falz

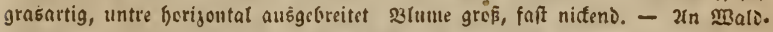

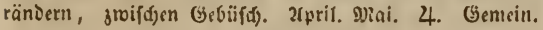

1936. S. glauca Wrтн. Rснв. Dentschl. Fl. 2666ils. 4909. Fl.

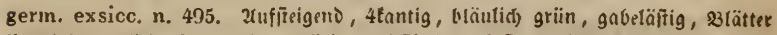

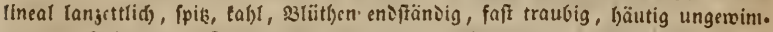

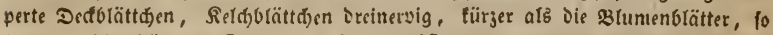

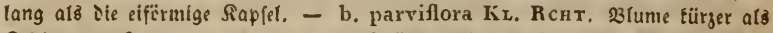

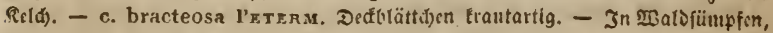
Zeidgen, auf Mloortoiefen. Juni. Jufi. 4. Sgier und da. D. Pratfdrolą, Eallía,

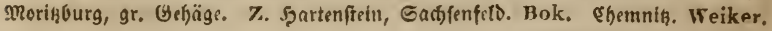




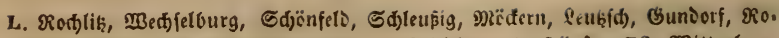
fentbal, Ronne. B. Ridjt felten. PL. Desgleidfen. A. Şäufig. PS. MBittenberg. Salle : Dälnik, Dfenoorf.

1937. S. Iongifolia Fr. (u. Muenunв.) Rснв. Deutschi. F1. 2166. 4912. 2uffteigend, bellgrïn, 4tantig, jełt Diinnäftig, slätter linealif(

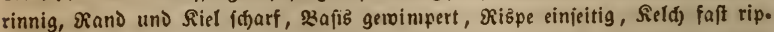
penlob, fo lang als 23 tume, fiirzer alb sie ellipfoisifife Sapisl. - In fdjattigen Märbern. Juni. Juli. 4. 2leuferft felten. PL. Stänte. Burkhardt.

1938. S. graminea L. Rснв. Dentschl. Fl, 260ilo. 4911. 9Rieier.

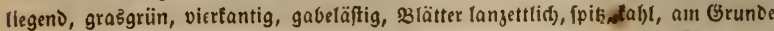

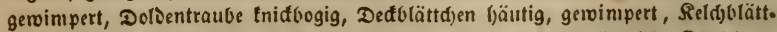
d)en 3nervig, fo lang alछ̇ Die slumenblätter, tïrzer als Die länglidłe Sapfel. b. brevifolia Walr. melyr aufredt, einfadjer, 23lätter türger. 23ergl. 2tobiro.

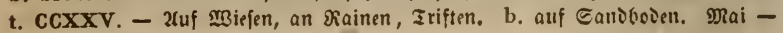
Juli. 4. Gentein.

1939. S. Dilleniana Mксн, Rснв. Dentschl, Fl, 2r6bilt. 4910.

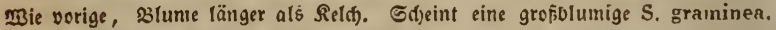
- 2n gleiden Drten unter seriger. Mai. Juli. 4. Etellentoeife.

619. Tanbrea Avg. St. Hru, 2 a tb rea. Field 5tbcitig, un. ten frugförnig. 3luntenblätter 5 , 2theilig, nevfi den 11 Staubgeföpen lel (f) ftänoig. 3 Griffel. Rapfel 6tbeilig.

1940. L. uliginosa (Stellar. - Mивr.) Rснв. Deutsch]. FJ. 266. 3669. F1. germ. exsicc. n. 67. 2tufiłeigent, tfantig, bläulid) griï, 3lätter oval lanjettlid), unten gewimpert, Blïtbenftiele adjfelftändig 3theilig, Dectolätts

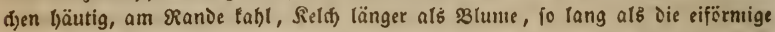
sapfel. \$iś über fpannenlang. (b. bracteata PETERx. f. 1941. Ubänderung?) - In säđ)en, Gräben, an queltigen Drten. Mai - Juli. 4. Pitht felten.

1941. L. bracteata Richт. Rchs. Deutschl, Fl, 2606ilo, 3668. Mie norige, Dedulättofen trautartig. - Mie verige. Geljr felten. L. Burgfan.

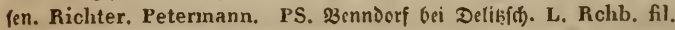

1942. L. crassifolia (Stellar, - Енян.) Rснв. Dentsclil. Fl. 206. 3667. 2tuffteigeno, 4tantig, griïn, s3lätter fib̨ent, längfid) lanjettlid), 23lütben.

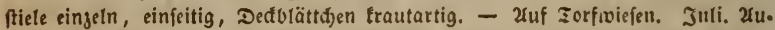
guft. 4. Gcbr felten. PL. MBaltersioorf. Rabenhorst. A. 3erbft, Şunocluft. Schwabe.

620. Moenchia Енrн. Mönt) ie. Reld 46lättrig, aufredt. Blumenilätter 4, gangrandig. 4 Etanbgefäfe. 4 Sriffel. Rapfel walzig, 8 öhnlg auffpringend. Saamen zabltreid), getörnelt.

1943. M. erecta G. M. S. Rснв. Deutschl, Fl. 2rovilo. 4953. Fl. germ, exsicc. n. 386. G(blant, ein paar 30ll bod), tabl, aufredt, Geiten.

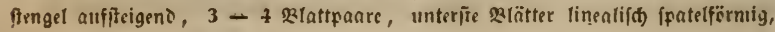


cbire lanjettlid), 31. lang gefticlt, einjeln, over nod) eill adticlitänsiger Etlel, Reld) länger als ذie längliḑen Slumenblätter. - 2uf Eanopläß̨en, Şügeln, Dauern. 2xpril - Juni. ○. Shier und Da. L. Ronneıvis, Sindenall, Bienißs, Et. Ibetla. PL. 2rm mege jwijd)en orr Sd)ludt, ?angengraffau. A. Eaniersleben, 3erbit. PS. Ronneniorf bei

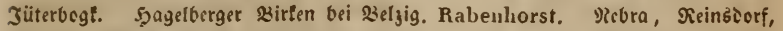

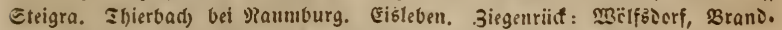

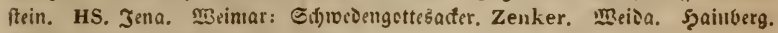
Rossmüssler. SRS. frrantenbaụ๋!.

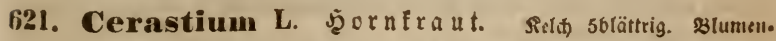
vlätter 5, jreitl)cilig ojer geipalten. 10 Etaubgefüje (Durd) Berfümmerung

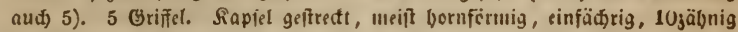
aufipringeno. Caamen geförnclt.

3 ॥ แ. Eine bäuñge Bienftrejitüt ift aud) in Diefer Gattung Das Bergrïnen Der stiitl)an.

\section{a. Cerastium : 23 tune ausggbreitit.}

1944. C. semidecandrum L. Rcri. Deutschl. Fl. 2066iro, 4968. Fl. germ, exsicc. n. 387. Surj bef)aart, aufred)t oder licgeno, slätter eiruno, Defolätt(f) $\xi$ ur 5yälfte bäutig, Frudjtiticle etrea 2 Dial fo lang alb ber Relth), BInnienblätter fo lang oier etwas tiirjer als Reld). Etıva $2-6^{\prime \prime}$ lang,

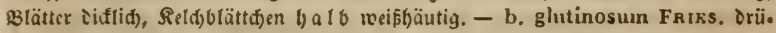
fig bebaart, tlebrig. - c. macilentum Fr. ganj tabl. - Juf janoigen 2teffern. 刃ärj. 3pril. C. Gsumein.

1945. C. pumilum (Curtis?) Boevingh. Rсhв. Deutsch], F1. 366. 4969. Fl. germ, exsicc, 11. 388. Surz bel)aart, aufred)t oder aufo

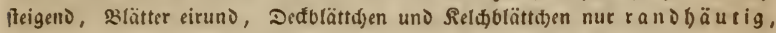
Srudjtfiele 2 - 3 Mal fo lang als Reld). - b. viscidum LK. Orïfig betgaart,

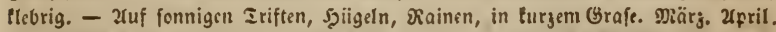
○. Gesvif mef)r serbreitet uno nid)t felten. D. q'Tauen. L. Rleinzfofodjer, Rie.

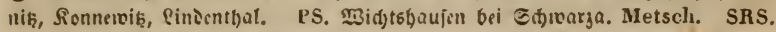
Eingen, Siotteniorị. Schönheit.

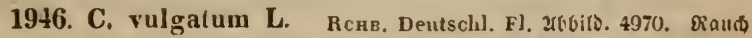
bebaart, aufređ)t cier Eeitenitengel auffteigen১, slätter cval, Deđ́blätter ganı

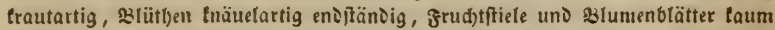
fo lang als Reld), Rapfel hornförnig gebogen. Etwa $2-4^{\prime \prime}$ bod, Duntelgrün.

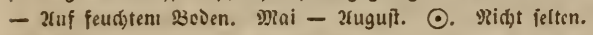

1947. C. brachypetaluin Desportes. Rсrв. Deutsch., Fl. 266olid. 4971. Fl, germ. exsicc. n. 389. Grau behantt, allfredt, slätter oval, Decீ.

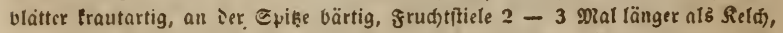
meld)er länger ift als Die slunce, Bib über fpannent)od), Sapíl taum $11 \int_{2}$

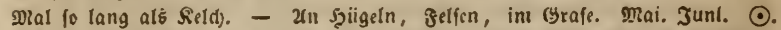
Eelten. D. Iobna. Fr, August K. v. S. Planen. Diirr. Rclib. PS. u/derb. 
Caryophyllaceae. - $438-\quad$ Cerastium.

leten. Schönheit. Rotfenburg. Klett. Raumburg. Beneken, HS. Zena. Zenker.

1948. C. triviale LK. Rснв. Deutschl. Fl. 266ils. 4972. 2rufitei. genv, Eeitenffengel unten rourjelno, słätter länglid), unten in einen \$lattftiel

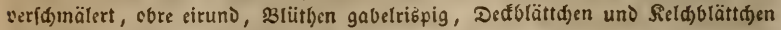

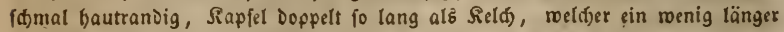
ift als bie Blume. Ein paar Sođ bis̄ fußlod), Dann fel)r äfrig, Duntelgrün. b. holosteoides Fries Rcri. pl, crit. II. 317. faft ganj tal)l u. fdmäritig. - c. uliginosum Schleich. febr üppig gewadjien. - 2luf bebautem socden, Eđ)utt, im Grafe, befonders an Felt. und MBiefeurändern, in Gräben. 21pril Detober. $\odot$ ठ. Gellein'.

b. Leucodonium, Glottennieier: Blune glectig.

1949. C arvense L. Rснв. Deutschl. Fl. 2a66i(o. 4980. 2uffifeigend, Die शebenftengel unten murjelno, meift 3olütbig, Blätter lineal (anjettlids), Deut.

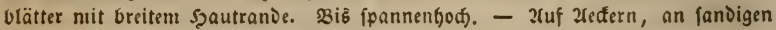
アiainen, Şïgeln. Ifril. Miai. 4. Gemein.

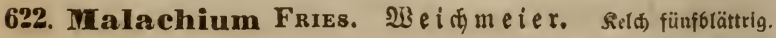
Slumenblätter 5, zroeitbeilig. 10 Etaubgefäse. 5 Griffel. Rapiel eifirmịg, Ifüd)rig, stlappig, R tappen an oer Spike 2 fpaltig. Saa. men getïrnelt.

1950. M. aquaticum Fr. Rснв. Deutschl, Fl. 266tito. 4967. $t$.

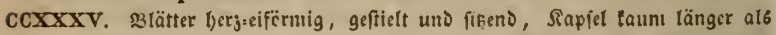

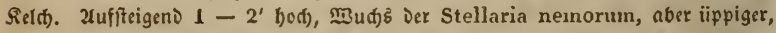

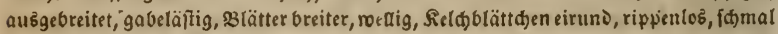
bautrandig, ausen fein bebaart, frtid)titiele etwa 3-4 Mal fo lang als Rapiel,

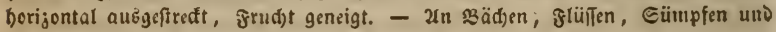
Gräben jroifden Gebïił). Juni - Eept. 4. Ridt felten.

623. Gypsophila L. (5) y 8 f $\mathfrak{x} a$ t. Seld) fiinffpaltig, glo fig, bäutig, nit breiten frautartigen Rippen. Slumenbl. 5, mit langem

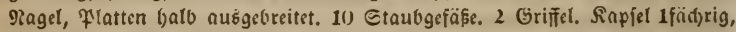

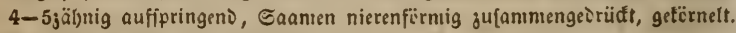

1951. G. muralis L. Rснв. Dentschl. Fl. 2aboild. 4997. Etengel

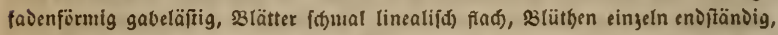

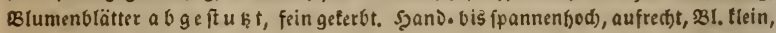
lila. Ganje Franje nicipt unrein violet. - 2uf fonnigem, freinigem Canibo.

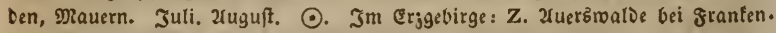
berg, 3roifau. 2ruf̧eriem nidjt filten.

1952. G. serotina Hayxe. Rंснв, Deutschl, Fl, 266. 4998. Fl. gerın, exsicc. n. 72. Etengel fadenförmig äjtig, slätter linealifiob breiter vock.

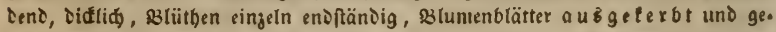
zäbnt, reís, lila geaiert. Gange ¥łiange lebhaft grün. - Mtit roriger an Den. 
folben Drten, alfo nid)t Durd) Stanjort erjengt; bäufiger auf feucbten 23oien.

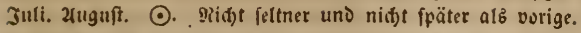

1953. G. repens L. Rсвв. Deutschl, Fl. 26біld. 5000. Fl. germ.

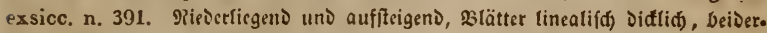

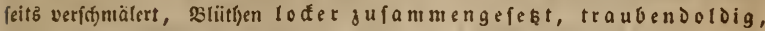
(a b1, 3lumenblätter alıgeferbt, länger alङ Grififel uno Etaubgefäfe. - b. inontana, fd)laffer uno grëfer als Die dipenpilange. 23iz fuflang. 23l. weis,

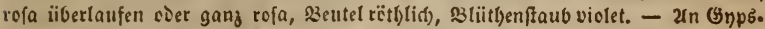

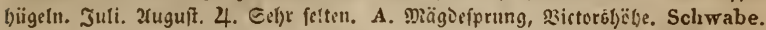
PS. Endfa nad) Sorge gu. W. Meyer Chloris Hannor, Zusatz. æ3alten. rico. Buddensieg.

1954. G. fastigiata L. Rснв. Dentschl, F1. 266bild. 5002. Fl.

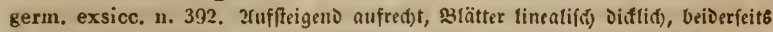

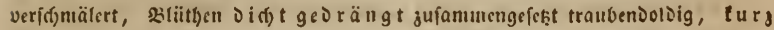
Orïjig bel) a art, 33lumenblätter abgerundet, fürzer als (5jriffel und Staubge.

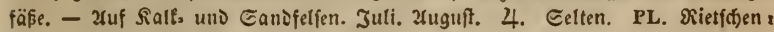
auf Der fandigen, fiislid) gelegenen 2uböbe. Mrodj)olj: auf Dem roeifen \$3erge.

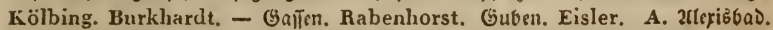
Sclıwabe. PS. SBeljig. Rabenhorst. Rorobau\{en, 2tuleben. Schönheit. SRS. grantenljaufen: Saltberg, Felien linter Dem Galgenberge. Hornung. Fest.

624. Tumica Scop. Fels nelfe. Sield bäutig, 5yälynig, mit breiten frautartigen Sxippen unЬ $2-4$ Ded olättd)en! Slumenolätter 5, utit langeu Niagel, łlatten ausgebreitet. 10 Etaubgefäfe. 2 Grrifel.

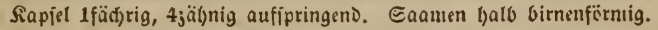

1955. T. rigida (Gypsoph. - L.) Rснв, Dentschl. Fl. 2robird. 5006. Fl. germ. exsicc. n. 393. Fièerliegeno un১ tofer aufifeigeno, slätter alle fel)r turz linealifd) pfriemenfpişig, fein gefägt, Streige gabeläftig 20lütljig,

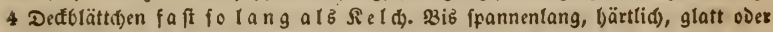

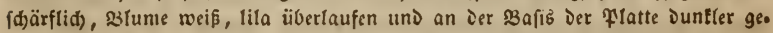
ftreift. Saamen quetmarbig. - 2tuf Dürten, fteinigen und fandigen 5̧ügeln. Mai - Serbft. 4. Egedem felten uno für jeşt greeifellhaft. HS. Meerboorf bel Jena, Dalfer fendcte fie nit Graumuiller in Jalje 1816. PL. 2(ngeblid) Querl, 230llwert.

a $n$ m. Daß̧ Linnées Gypsophila Saxifraga eine ganj Derfđjiedene Prange ift, wat bereits vor langer 3eit Durd) Smith berwicien (vergfeid)e meine Fl. gern. p. 8U2). In neiner Deutf(flanos Jlora t. CCXLVII. $50066 \mathrm{~b}$, ift nun Linnées waljre G. Saxifraga abgebildet uno von Den Murgelolättern an biz jum Eaanten leidit unterfdeibbar. T. rigida ift aber G. Saxifraga Der floriften.

625. Vacearia Dodov. $\mathfrak{R}$ uhatfe. Seldy $\mathfrak{e}$ rugförmlg 5 . tantig, 5jäl)nig, gang trautartig. Blumenblätter 5 , ofne Edjlunofófup. fen. 10 Gtaubgefäfe. 2 Griffel. ßapfel 1fäḑrig, 4 zäbnig aufipringend. Eaamen faft luglig geț̈rnclt.

1956. V. pyramidata G. M. S. Аскв. Deutschl. F1. Robiro. 
4991. t. CCXLV. હ(t)lant, $1-2^{\prime}$ bod), tabl, bedgruin, tnctig, gabeläirig,

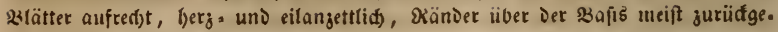
rout, sliitten lang geftielt aus Den xiftbeilungen und am EnDe Dreiftändig. Platte Der stunienblätter abgerundet, pfiritdbliitl). Gaamen etra bis 20. - 2uf Fel.

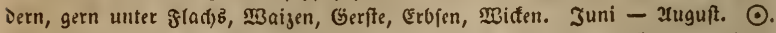

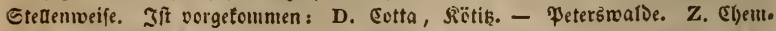
niţ. Weiker. Sranjall 1 Exemplar 1839. Wankel. PL. Mierigsiorf, fres.

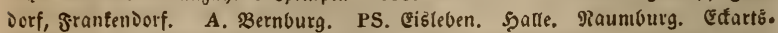
berge. szurgnenoen u. f. 10. faudfiäot. Sulj. HS. Jena. Eifenberg. MBei. nıar. SRS. Irnftait.

626. Saponaria L. Se ifenfrat. Relda wailzig, 5jäb. nig, trautartig und vielnervig. Blumenblätter 5 , mit panrigen vorften.

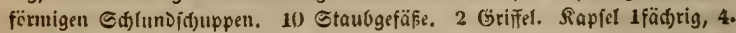

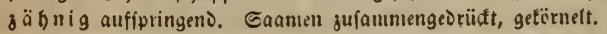

1957. S. officinalis L. Rснв. Deutschl, Fl, 2ubbirs, 4995. Bzlü.

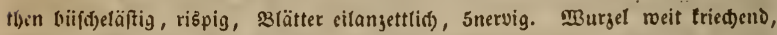

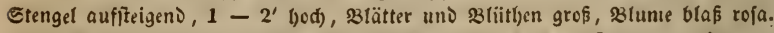
Flatte eingsterbt, Reld) tabl oder furs fein vel)aart. OPr. Rad. Saponariae. -

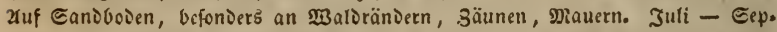
tember. 4. Ueberad jerftreut, in erggebirge aber nur: Z. WBitdenfits. L. 2iodjte burg. - 2ufẹetdem nitgt felten.

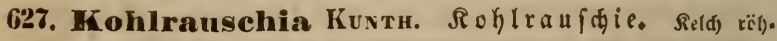
rig, bäutig, nit 5 trautartigen Etreifen. 5 g3tumenbrätter ofjne Edflund.

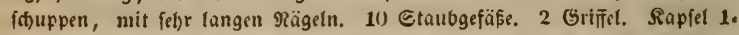

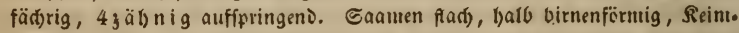
ling gerabe: - S3tïtleentëpfden von großen, trodenbäutigen Ed)uppen umı)üat.

1958. K. prolifera (Dianth. pr, L.) KuхTH. Rснв, D. Fl, 2666. 50 (u)9. 5jüabtättd)en ftumpf. Menige sou bis über fü̈l)od), aufred)t, eingeln over viel. fienglid), 3lä̈ter finealifd), unterfte ftumpf, folgenoe \{pisig, oberfte türzer. Flatte Der 2 (ummenblätter alsgef(d)weift, roja. Gaamen fd)wargbraun, fein getöruelt. b. dininuta (Dianth, diminutus L.) Rcrв. Deutschl, Fl. 2106ilo. 5008. Die

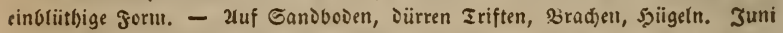

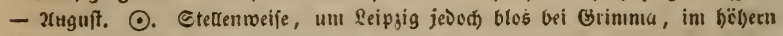
Eragebirge: Z. Dederan, MBitoenfele. Conft nidft felten.

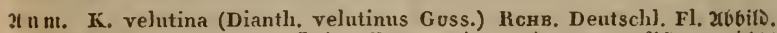
5(1)10. toat einen fel)r unpalienden Mamien, Da an Der ganjen Prianje nidfts

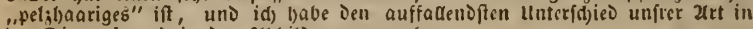
ier Diagnefe uno in ien zoviloungen gegeven.

628. Dianthus L. Si elf e. Seld) röbrig, trautartig, 5jäbnig, un. ten mit 2 ober 1 paar Edjuppen. B3lumenblätter 5 , obne Sdjlundid)uppen,

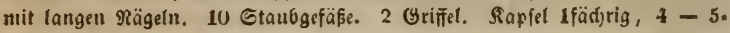
zäbnig, Saamen planconves, Sisimling gerade: 
1959. D. Armeria L. Bснв. Deutschl. Fl. 360. 5u11. t. CCXLIX.

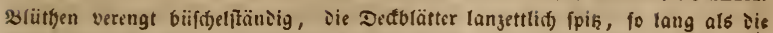
field)rël)re. Etengel $1-2^{\prime}$ bod), fteif gabeläftig, untre Blätter itunipf abge. rundet, oberfte fipisig, Flatte Der 2iJume unigetel)rt eirund länglidi fägerandig, bell tarminroth), suntler punttirt. - 2uf Sanda, Ralt. und styonboden, an for.

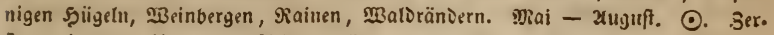

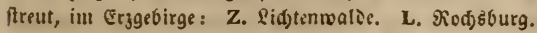

1960. D. Carthusianorum L. Rснв. Deutschl. Fl. 2666. 5019.

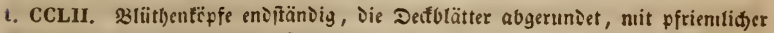

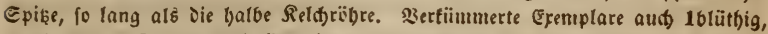

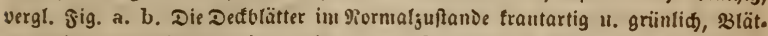
ter breiter uno bäulid) grün, §ig. e. - b. graminicolor, fig. a - d. Die Blätter fd)mäler uno graşgrün, Die Defútütter ganz trođenbäutig uno braun. (Der eigentlidye D. vaginatus VILx. ift t. CCLI. abgebiloet, ourd) Die auzge.

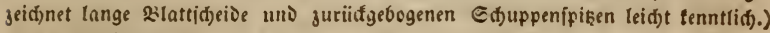
- 2u founigen 2iainen, 2unbäben, Gelfen. Juli - Eeptember. 4. Gemein, feblt im Doer, uno Mittelgebirge.

1961. D. Seguierii Vilx. Rchв. Deutsch]. Fl. Z66ilo. 5023. F1. germ, exsiccata n. 74. Sitütbe einjeln oier zu zroeien, Etiel glatt, Eduupeu

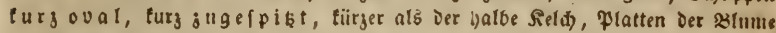
aneinanierliegend, etwa fo lang als Ragel, jugerundet, Deppelt gejäthnt. Epan.

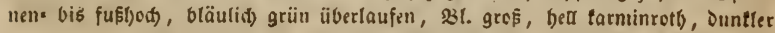

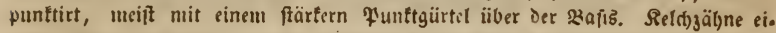

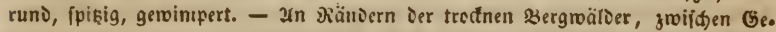
vüj(f) an Belfen. Juni - 2tuguft. 4. etellentwiife. D. Priešnik̨thal. G. Rchb. - 3wifiten Rlappendorf und Geellaujen. H. H. Delia. Fr. August K. v. S. Goitleube. G. Rchb. Börnersoorf, G̈̈pperहiorf. Weigel. altenberg. Rchb. G. Rchb. Papperitz. A. Delīal. Schwake. Singenau, Quateniorf. Naunanu. Scliwabe. PS. Siegentiid. Adler, R. fobenftein. H. H.

1962. D. arenarius L. Rснв. Deutschl. Fl. 2(00. 5026. Fl, germ.

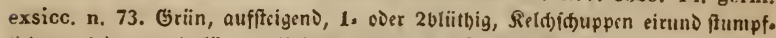

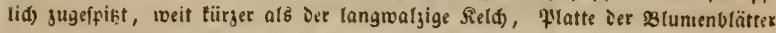

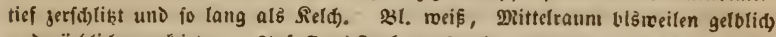
unঠ rëtblid) punftirt. - 2uf Eandftesfen. Juni - 2ugufz. 4. Eeffe felten. PL. Guben, Eenftenberg, Grofradoen, sioderšberg.

1963. D. superbus L. Rснв. Deutschl. Fl. 26bils. 5032. Fl. gern.

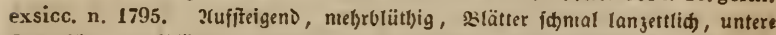

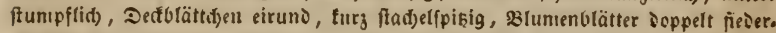
dlikigig, frin gertheilt. Etengel 1-2' hoch, 231. felbr jart, rofa. - Zuf trodnen und feudten $\mathfrak{W}$ Befen, unter (̇efträud) an Bergen. Jufi. 2uguft - Dstober. 4. 9idift gar felten. D. Sdjieril, Sonffappet, Doerwartba, 3[doner uno Fitauen.

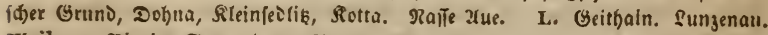
Weiker. Blenis, Sorgenverge, Fegnu, Grimma. B. Draukeniorf, Slefdffelde.

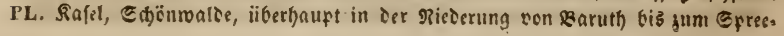




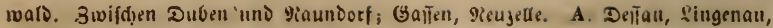
Qualendorf. 3wifd)en Sabel und Frieverifenberg. PS. Belgig. Mittenberg:

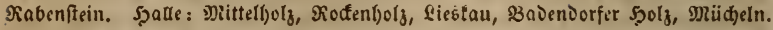
gaumburg. Şcinridss bei Subl. Erfurt. Fiunberg u. i. w. HS. Jena: gorft,

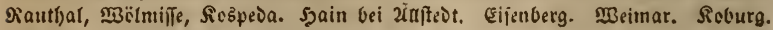
G̈sfniţ bei 2utenbury. SRS. 2rmitadt.

1964. D. deltoides L. Rснв. Deulschl, Fl. 2606iro. 5040, 2ufitci. geno, 23lätter lineal lanzettlid, untere ftumpf abgerundet, 23liitben am Enbe Der

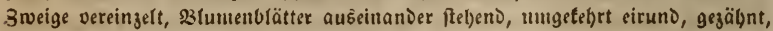

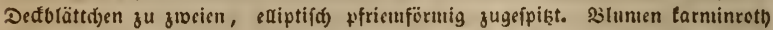
unit weiß̧en Punften unD Duntlerem Rranje, toumen felten aud) reeiß vor: $D$.

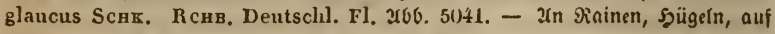
ஐiefen, in Mäldern. Juni - Drtober. 4. Gemein.

If $\mathrm{nm}$. D. Armerio $\asymp$ deltoides Rснв. Fl. germ. p. 809. Deutschl. Fl. rubilt. $50 * 0$ b. ift ju beadjten.

1965. D. caesius Sмiтr. Rснв. Dentschl. Fl, 2166ilo. 50ұt. Fl. gern, exsicc. n. 798. Graugrïn, Etengel meift einoliitbig, şä̈tter ftumpflit), Deftolättdjen oval runolid), ftumpf zugefpikt, na(f) Der Spiß̧e ju 5nervig, s3lu. menblätter tief Doppelt gejäl)nt, an Der $23 a f i s$ etroab̉ bärtig. - 2en maćten, fon. nigen Jerfen. Miai. Juni. 4. Şier und Da. D. Flallenfit)er Grund an Den gefäbrlidjften Gteden nidjt felten, an Den zugängfidjen felfr vermindert. A. 2ltepis. bav. PS. Nieltenftein bei Gul)l. Metsch. P. Sauer. 3iegenrürf. Adler. SRS. Sdroarfourg. Hornung. Blantenturg. Zenker. R. Burgl. Diirr.

$\{\mathrm{nm}$. Die betannten cultivirten D. barbatus, plnmarius und Caryoplyyllus vergl. Rснв. Deutschl. Fl. 2066. 5013, 5030 uno 5051.

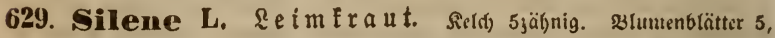
mit langem शagel, (mieiftent:) gefpaltenen Sd)tundfduppen. Siapfel unten 3 - 4fäd)rig, vielfaamig, an Der Epike 6jäbnig allffpringend. Saamen

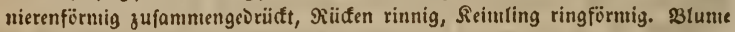
nteift nädttid)! Rraut meift teimig tlebrig.

a. Silene, nit Gd)(uni(d)uppen.

1966. S, silvestris Schотт. Rснв. Dentschl. Fl, 2666ilo. 5055.

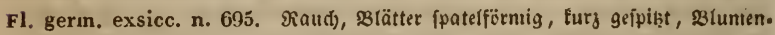
blätter runolid), fein geferbt, 23tüthenäl)re einfeitig, fo wie bie früd)te a ufred)t. Gd)lant, einfad) oder menigäftig, fpannen= bis fus(tod). Blumen. blätter weif́liç) òer blaf́ rofa. - b. quinquevulnera L. Rcri. Deutschl. Fl. 26bbilo. $5(555$ b. wie S. silvestris, Die S\&lumenblätter aber farminroth), blaß geraniet, bleibt wie Die meiften farbenyarietäten aus Caamen ergogen fidf) gleidb), ift aber fonit nid)t zu unterid)eiden. - 2uf 2ectern, gern unter Sommergetreide. 3uli - Dctober. ○. Selten. D. WBetlen, Ittewalde, Rofentbal, Struppen.

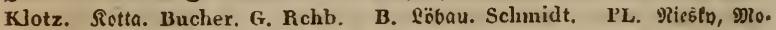
bolz. Burkliardt. WBittnzannsborf, Paferin, Rabel. - PS. MBittenberg. Nitzsohe. - b. quinquevulnern: 2uf 2tedtern, an æBegen uno Bäunen. Geiten. 


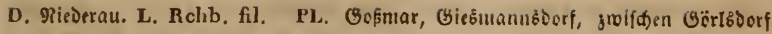
uno MBannindjen, Efremitierg, Ecrall.

$2(\mathrm{nu}$. Die S. gallica L. Rch B. Deutschl. Fl. 26b6ild. 5054. bat, wie fdon Vaillant beweilt, furz zugefpikte situmentiätter uno ith groeipe ob Jemand ein Exemplar Derfilben in sereidbe unjer flera gefelgen bat.

1967. S. conoidea L. Rснв. Deutschl. Fl. 266ito. 5061. Bein be. baart uns tlebrig, Slätter lanjettlid), Fruttteld)e luglig tegelförmig, 30nervig,

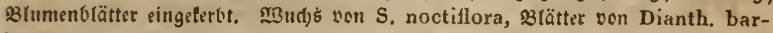
batus, 2B1. reifi oocr refa. - Unter Getreide. Juni. Jufi. ○. 2reuferft felten. PS. Beudblik, Gdjlttau. Sprengel.

1968. S. conica L. Rснв. Deutsclil. Fl. 2166ils. 5062. Graulid lurg bebaart, slätter lanjettli(b), frudtfeld) eifïrnig fegelförnig, 30nervig, s3lu. menblätter 2fpaltig. Siaum biz fpanuenl)cd, einfad) coer utelstitenglig fteif auf. red)t, ¥latten ier \$lumenblätter mel)rntals fürjer als Reld), rofa, Edjlundf(t)u. pen geferbt. - Xuf Sanö̈dern. Diai - Juli. ○. 2rußierft felten. A. Ean. ocrbleten. Schwabe.

1969. S. noctiflora L. Rснв. Deutschl. Fl. U66ito. 5063. Fl. germ, exsicc, n, 1994. Etengel gabeläftig, tlebrig jottig, feld baudjig räbrig, 1Unervig, 3älgne pfriemtid, S3lumenblätter tief 2fpaltig, untre 8 lätter fpatelför.

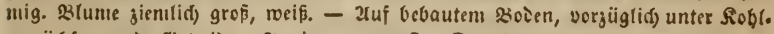
gemädfen unঠ Getreide. Juni - 2uguft. (. Eteltenneifs. Jnt Eragebirge fettner: D. - 2uguf̃ušburg. Z. Erimannsoorf. Eonft nidjt felten.

1970. S. Armeria L. Rciв, Deutschl, Fl. 2166ilo. 5079. Bläulit

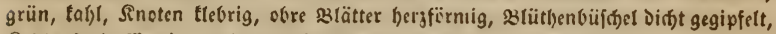
Selde fculenförnig, slumenblätter ausgefdjweift. 1' bod ober bïber, meift et. reas abftebend äftig, s1. bell farminroth, ändert ab rofa und roeis, 3lüthenftaub graublau. - Riđt felten aber unbef̈ändig, auf bebautem Boben. Juni - 2u. guft. (.) 2un einigen Drten toofst nur seriviloert.

1971. S. Otites S.r. Rснв. Deutschl. Fl. 2666ils, 5094. Fl. germ.

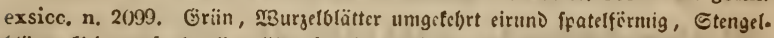
blätter flein, aufred)t, linealiji) läng(iđt), Blütbenjroelglein tabl, faft quirtftän১ig,

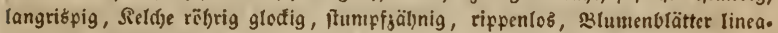

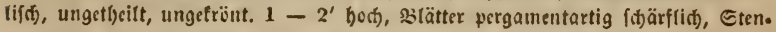

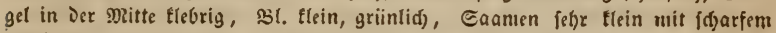

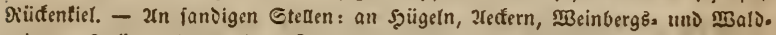
rainen. JuYi - Eeptember. 4. Etelenmeife. D. Grofenljain, Etaija, Rïtik, Meinbëbla, Jriècivalo, sjoflïsnis. PL. Gonnenualoe, Drel)na, Duben, Greß. radoen, \&uđau. A. Şäufig. PS. Sel feil. Raumburg. HS. Jena. Eifenad). SRS. Zrantenbaufen.

1972. S. chlorantha EнRн. Rснв, Deutschl. Fl. 2666ito. 5102.

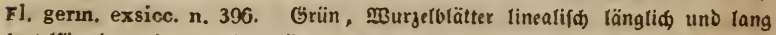
fpatelförmig, rolmperartig gefägt, Rls̈pe lang, einfeitig überljängeno, Blumen.

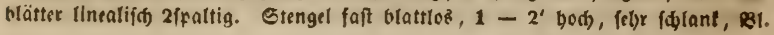


faft von Geftalt ocr folgcnDen, tiirger, fictd weifgrün, 81. gr ii 1. - 2n fandi.

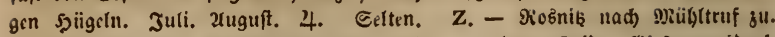

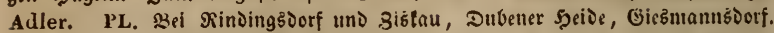
Grassmann. Diablsoorf, Siolien am Drabnsborfer Meinberge, bei ¿ergt nad)

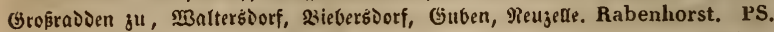
Raben bei Belzig, jroifjen Dïbin und Stgmunborg. Rabenhorst. Reiden. berg. Adler.

1973. S. nutans L. Rснв. Deutschl. Fl. afboiro. 5108. Griin,

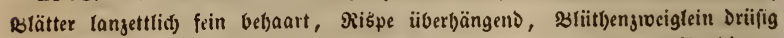

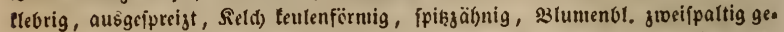
trönt, weißs. b. infracta W.K. t. 213. Rснв. pl. crit. 427. (S. nutans :) Sснк.

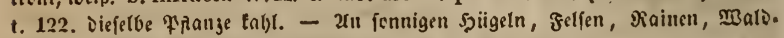
rändern. Mai. Juni. 4. Etencntweife, bis ins Pievergebirge.

1974. S. nemoralis W. K. t. 249. Rснв. pl. crit. 11I. ic. 416. Deutschl. Fl. 26bbito. 5111. Fl. germ, exsicc. n, 300. Fin bel)aart und

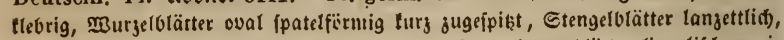

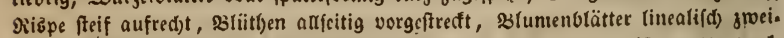

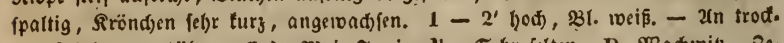

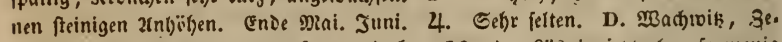
bift, an beiden Drten von Bucher entbect. [J"l Der Sësnik̨ jelżt eben fo wenis su finisn, als Dianth, caesius uno superbus.]

b. Viscago Haller. fcimnelte, olyne Edjlunojd)uppet.

1975. S. inflata SM, Rснв. Deutschl. Fl. 2606iro. 5120. 2fuffeigent, tabl, bläulich griin, nad) oben gabeläftig, slätter lanjettliđ), গRiß̨pe orei. theilig, gegipfelt, überbängeno, నeld) trugförmig aufgeblafen, slumenblätter gee fpalten, ungetrënt, grud)tftiel gernde aubgeftreft, Rapiel faft tuglig, etwa 3 MRal

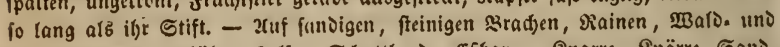

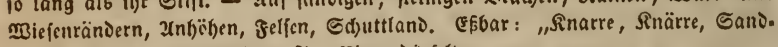
eobl." Juni - September. 4. Rirgends felten.

630. Cucubalus L. Taubentroџf. Reltif frautartig, glortig

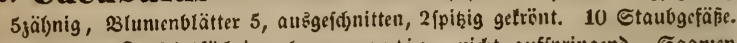
3 Sriffel. Sapfel Ifädjrig, beerenartig, uid)t aufipringend. Saanien grubig punttit.

1976. C. baccifer L. Rснв. Dentschl. Fl. 266bilt. 5122. 2uछge. (preigt, Stengel (f́)rva(̌), weitäftig, tletterno, $2-4^{\prime}$ bod), ftumpf 4tantig, (ó)ärf.

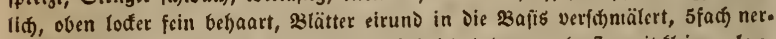
vig, roimperartig gefägt, an Den शerven ftriflid) bebaart, oberfte weit fleiner, lall. gettlid, 3weige 3tbeilig, Blït)en adjfel. unto enoftändig, Reld furg traus bc.

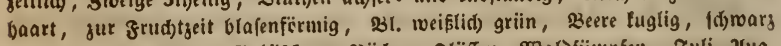

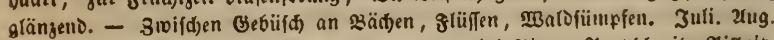

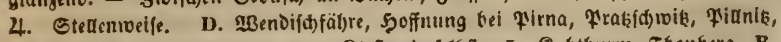
Rötfibenbroia, Bauernik, Meifen, Rlofter infelbft. L. Subthurm, Thonberg. B. 


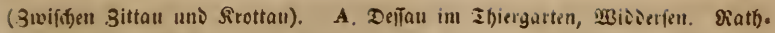

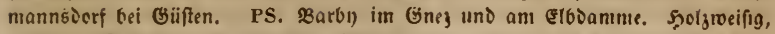
Döanik, Rollenbei. Raumburg: trunıme Ssufe uno an ber Saale. Blegenriite.

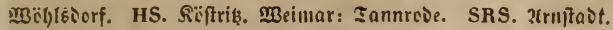

631. Githngo Desf. Ra be. Relíf lederartig sipaltig. slumen.

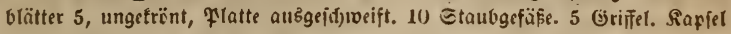
1 ä̈ărig, 53äl)nig aufipringeno. Gaamen zal)lreid), nierenfïrmig, fpiß̧ig ge. fürnelt, Reimling grosinal eingetniđt.

1977. G. 8egetum DEsf. Rснв. Deutschl, Fl. 266t. 5132. ख3urzel uni Etengel einfad), $2-3^{\prime}$ bod), fdblant, weisfitgig, 3weige aufred)t, 33lätter linealifa), Blütben einjeln, fehr lang geftielt, Blumenblätter tarninnotb), ven Der Safiz aub 3ftreifig. - Xuf Getreidefeltern. Juni. Juli. ○. Genein. "Rornrade."

632. Agrostemma L. Bexirnelfe. Mie Githago, Relt. abfd)nitte zufantuengedrebt, Bluntenblätter mit fteif 2 fpisig fted̆)ender Rrone.

* 1978. A. coronaria L. Rснв. Deutschl, Fl. 26б6ilo. 5133. Meif̧. menfilzig, 2' 1)od), allfted)t äftig, sBätter ungetel)rt eiruno ffatelförmig, obre ovar uno eilanzettlio), slütben lang geftielt, szlumenblätter tarntinteth, felten toeib.

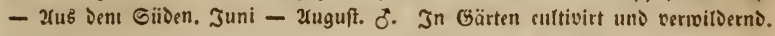

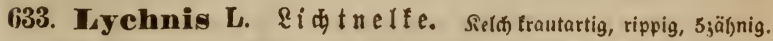
Blunienblätter 5, getrënt. 10 Elaubgefäfie. 5 Griffel. Rapfel 5jälynig, aufípringeno.

a. Coccyganthe Rснв. Rufuf36lume. Szlumendtätter 4tbrilig zer. f(d) lik̨t, field) anticgend, Siapfel tëü(f)rig.

1979. L. Flos-Cuculi L. Rснв, Deutschl, Fl. 20bilo. 5129. Stenget $1-2$ ' bod, (d)lant, fal)l, Sncten rotb), 23lätter lanjettlid), unterffe ftumpf in bie Bafis verf(bniälert, Seld) rotbnervig, Sapicl faft fuglid), Blume refa, feltner weif. - 2uf \$Biefen bis in Die Gebirge. Mai. Juni. Einzeln im Sperbite. 4. Gemein.

b. Viscaria Rrv. Fed)uelte. 23funtenblätter 2ipaltig, fapfel unten 5 fäđ)rig.

1980. L. Viscaria L. Rсnв. Deutschl. Fl. 2ubbilo. 5131. Rlebrig, slütbenbüfd,el sidgtriapig, szluntenblätter ganz. Stcif aufred)t, 1-3' bod, Dunfelgriin, Seldie roth angclaufen, sl. Iebhaft pirfictbliith, filten weißs. In

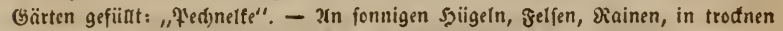

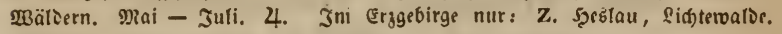
anferbalo gientlid) adgentein verbreitet.

c. Melandryum (Purxri) Cuus. Mièerftō, jıcibäufig, Reld fdlaff, jur Frudtgeit aufgeblafen, Rapfel 1 fäd)rig.

1981. L. diurna Siвтн. Rскв. Deutschl. Fl. 26obilo. 5126. 28lu. 
menblätter rofa, halb 2 paltig, Etengel, Blätter und fild)e jottig, Rapfel trug. förmig, Säbne zur ï đo get $\mathrm{r}$ ü mu t. Etengel $1-2^{\prime}$ bod, Blätter eilangettlid). - In Gefjauen Der Saubrö̈lber, an Gebiif(d), Bäunen, feudten Miefen. Dai und einfelner in Sperbfte. 4. शirgenis felten.

1982. L. dioica L. Havxe Arzneigew. II. 3. Roнв. Deutsch. F1. 2ubbild. 5125. Błumenblätter weiß, balo 2ffaltig, Etengel unten jottig, Die lanjettlidjen s\&lätter uno obern Ibrife irüjig turj beljant, fapfel eiförntig legel.

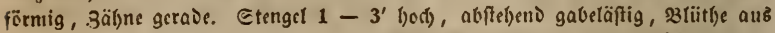
Der zbeilung uno am (5noe ju oreien, ëfinen fid) abenob: L. vespertina Srв rr.

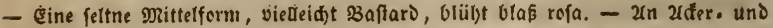
Baloräniern, auf bebautem 23oben. Juni. Juli und Sgerbft. 4. Jut Eragee birge nur int Riebergebirge und 3roifall. Sonjt gemein.

d. Lychnis, Rel(t) eng, faft teulig, Bruntenblätter ausgeterbt oier ges zälint, Rapfel 1fädiłrig.

1982 b. L. chalcedonica L. Rснв. Deutschl. Fl. 260 . 5128. Stelf aufred)t, 23lätter eilangettlid), 3lütben viifdbelartig Didgt topfifändig. $2-4^{\prime}$

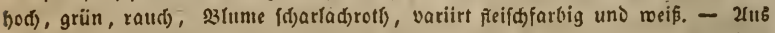
Eibirien uno ¥odolien. Juni. Juli. 4. Şäupig in Gärten uno serwiftert "brennenie Sicbe".

\section{Familie Theaceae, Zheacen.}

- Syerbarienbud) G. LXXXVI u. 207. -

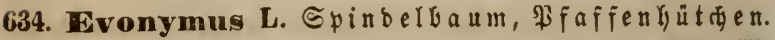
Sildi fradi $4-5-6$ lappig. Slunenblätter $4-5-6$. Etaubgcfäpe 4-5-6 auf feifdigen Folfter. 1 Grifel. Rarbe 3-4-5lappig.

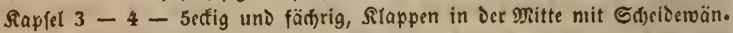
Den, natbipaltig. Eaamen in jedem zad, $1-4$ nit pulpëfem (orangegel. beiii) Mtantel. - Sroeige uno slätter gegeniiber.

1983. E. europaeus L. Sснк. t. 48. Rснв. Deutschl. Fl. 26біils.

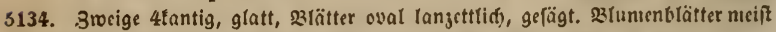
4, längliđa), Sapfeln 4födrig, ungefliigelt, Jer Mantel bedectt Den ganjen Saa. men. Etrauds von $6-8$ over 23autt son $10-3()^{\prime}$ Şöbe. Blütle griinlid).

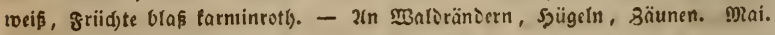
उuni. b. Gemein. Feblt aber in bïchifen Gebirge.

\section{Familie Tiliaceac, Rinoengewähber. \\ - Şerbarienbud) 5. LXXXVII u. 209. -}

635. Tilia L. Rinbe. Sict) 5blättrig, abfaltens. Bfumenulätter 5 .

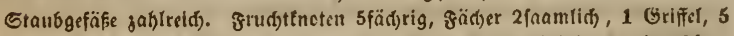
Rarben. Rnpfel leberartig, Durci) Bertiimmerung nur 1fäcffrig, 1 oder 2 fna. 
mig. Eaamenblätter berbfïmig und gerfd) liß̧t! - Grofwerdende, mebre

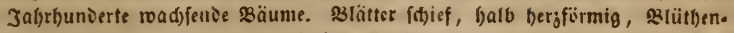
ffiel mebrolütbig, mit berablaufendent Defblats.

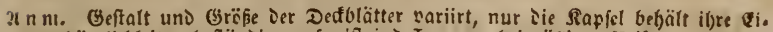
genthïmlid)feiten beftändiger; fie ift inذeiten nur bei vëaiger Reife zu unterfue

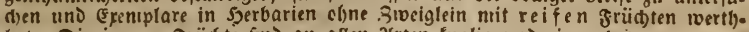
los. Die jungen früd)te fimo an allen atten fuglig uno rippenles.

a. slätter unterfeits bläuli d) grïn, (nur in Den zoeradfeln bärtig) (a hlı

1984. T. parvifolia Енгн. Sснк. t. 141. Hayse Arzneigew.

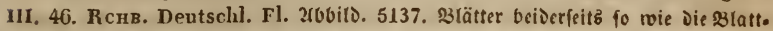

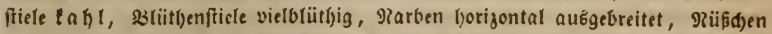
fdief birnenförnig, turs gefónabelt, un oeuttidf fünftantig, slätter fleiner, Dunfter, unterfeits bläulid) grïn, nur Die 2d)feln Der 2tiern bärtig, Etiele länger als ذas balbe 2 latt. $\mathfrak{B}$ äd)ft langfamer, bliilyt 14 zage ffäter, 3weige

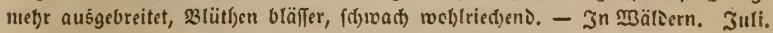

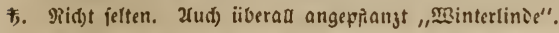

1985. T. europaea L. Rcnв. Deutschl. Fl. a6birs.5138. vulgaris

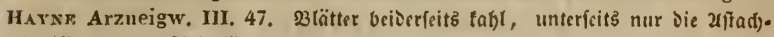

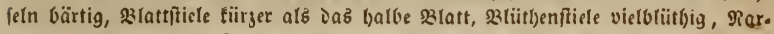

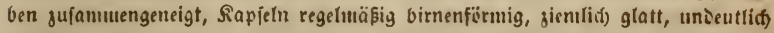
5tantig. S3lütlen ftart woblried)eno. OFF. Flores Tiliae. - \n MBäldern. Juti. ち. शid)t felten. 2u(t) in eragebirge: Z. Ed)marzenberg. Sonft utii Ctäote und Dörfer aud) bäuịg angefrianjt.

$2 \mathrm{n}$ u. Coen fo wie idy in Der Fl, germ. uno fjicr gethan, hat aud Dos in fei. nem grofen $\mathfrak{B}$ erte "General history of the dichainydeous plants vol. $I$.

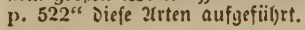

b. Slätter unterjeitŝ grïn, auf bent gangen 2rberneķ be ba a rt.

1986. T. sphaerocarpa Rснв. Dentschlands Fl. 2606. 5138 b.

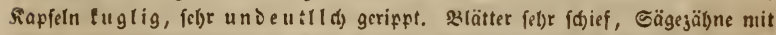
felfr langer Stadfelipike, IInterfeite fo wie Die szlattfiele cberfeitz febr reidslida

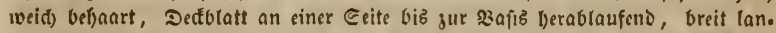
jettlid) abgerundet, 3liitbenitiele 2 - 3otütbig. Sapfeln febr firzig. - 2rnge.

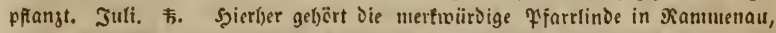

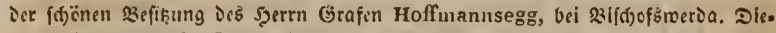
fer wabriftecintid) ältefte uno Didfte 23 aum in Sad)fen, viedcid)t in Deutf(b)lans,

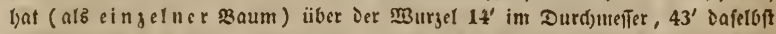
in Itmfange und $371 f_{t}^{\prime}$ ttmifang in einer şïle son $5 \int_{t}$ Eden ïber ier Erie, wobl ein zalter von $S-9(x)$ Jabren uno verjüngt (iid) jäbrlid) Surd) \$3lätter, Blüthen uno frïdte jur Freude Der Bemeinde, Deren Firdbenfiegel er jiert!

1987. T. grandifolia Енвн, Sснк. t. 141. Rснв, Dentschi. Fl. 26bbild. 3139. T. panciflora Hares Arzneigw. III, 48. Rapfefn oft. uenförnilg abgerundet, 5 rippig. Bliitben $2-3$, giemlids groß, gelb, 
10oblried)ent, Rarben aufrect)t. - In Bergroäliern feltner. Juni. \$. Echlägt weit früber ausి "פailinde, Conmmerlinie". Ridgt felten. 2rud) in Errgebirge:

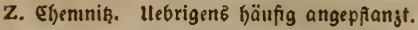

1988. T. turbinata Rскв. Deutschl. Fl. 2robilo. 3139 b. Rapfeln

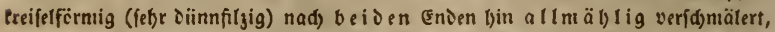
fumpf 4 - 5tantig, Blätter oünn, mattgrïn. Şierber gebïrt T. corallina SM. "viminibus rubris fructu tetragono" Fl. germ. exsicc. n. 1599. menn fie (vorziiglix) in MBinter) torallenrotbe 3tweiglein bat, 4tantige Rapicln fino mon.

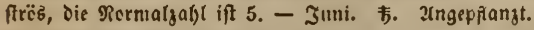

1989. T. oxycarpa Rchi. Dentschl, Fl, 260. 5139 c. Fl, germ. exsicc. Cent. XXII. Rapfeln (grof) tuglig 5 feitig, plyamionl 5 rippig ) ugefpişt. Junge 31veiglein feinjottig, slätter febr menig behaart, Blüthen. fiele 2blütbig. - Juni. Ђ. 2Ingeprangt. Şierljer 3. 2. OL. Die alte Ffart. linde in Dppac. Weiker.

\section{Familie Hyperieineae, Sartheugewäd) fe.}

- syerbarienbud) 5. LXXXVIII แ. 210.-

\section{A. Lineae: 4-5männig, einbrüberig, nekf unfruchtbaren Staulfäben bazmijitien.}

636. Radiola Drut. 3 wergréin. Seld 4tbeilig, 2ubidnitte 2 - 3fpaltig. 4 slumenorätter. 4 frud)thare ๔taubgefäfe. 4 Griffel. Fapfel 8fädjrig, fäd)er 1faamig, Saamen oval, glatt, vräunlidb gclb. -

1990 R. Millegrana Smitr. Rснв. Dentschl. Fl. 2robilo. 5152.

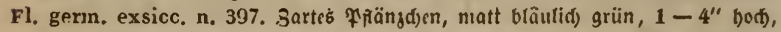
Stengel fadenfërnig, aufredt, gabeläftig, Blätter gegenüber, oval und langettlid), gang oder gegen Die હpik̨e entfernt gefägt, fpik, untere ftunıf, slütbe in Der İbeilung eingeln, aufred)t. Sslumenblätter fo lang als field), fpatelförmig, weiß, bei tleinen Exemplaren faft tnäuelartig beifammen. - 2uf feud)teı Sanovoden

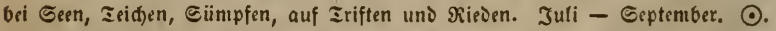

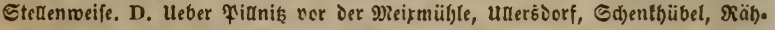

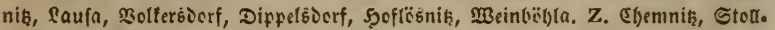

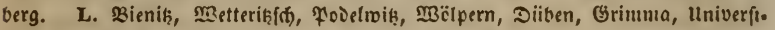

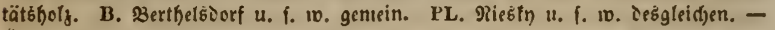

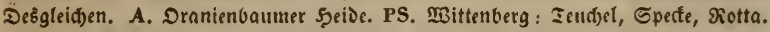

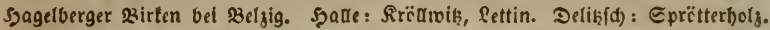

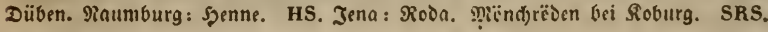
2frnftait.

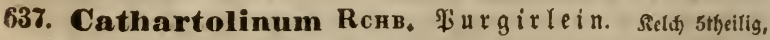

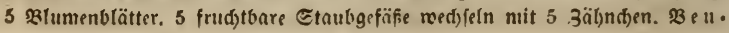


tel a ufredi)t. 5 Grifel, 2 arben fopfförmig. Sapfel 5tlappig, 10, fäßrig, Fäđ)r 1 faamig.

1991. C. pratense Rснв. Deutschl. Fl. 2166ilo. 5153. Limuin catharticum L. Scrk. t. 87. HAvNe Arzneigew. VIII. IS. slätter gegen. ü ber. 3arte Fĩange, $2-8^{\prime \prime}$ hoth, faienförmig, aufrentt, gabeläftig, sstätter alle gegenüber, unigefebrt cilangettlich, szluntenblätter fpișliđb, weißß, gelb liniirt,

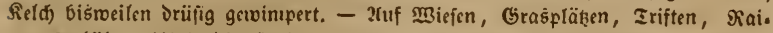

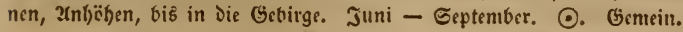

1992. C. tenuifolium (Linmm - L. JACQ. austr. t. 215.) Rснв. Deutschl. Fl. 2Ubild. 5165. Fl. germ. exsicc. n. 1498. Slätter serftreut

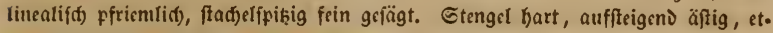

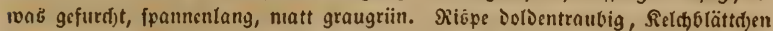
langettlich) zugefpişt, orü fig ge wo impert, szlumenblätter ungctebrt ciruno,

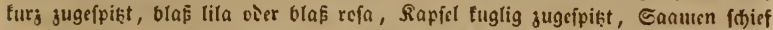
unigetef)rt eirund, gelobraun. - 2 (n fonnigen Gand. uno Raltbügeln. Juni.

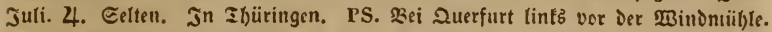
Wallr. Eđtrarza, Diajtäot. Metsch. HS. Drađjenberg bei Mieiningen. Rauch. Grub. Metsch. SRS. 21m Jufrmeg von Sinielbrïd nad) Jrantenbaujen. Hornung. Sdila bei sittiolifait. Schönheit.

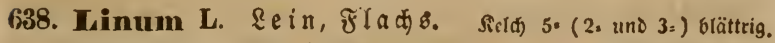
5 Blumenblätter. 5 frud)tbare Staubgefäfe wed)íln mit 5 3äbu(d)en. Bell. tel a lifliegend. 5 Griffel. Viarben teulenförmig. Rapfer 5tlappig,

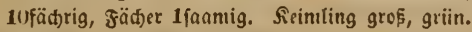

1993. L. usitatissimum L. Sturm VII. 26. Rchв, Dentschl.

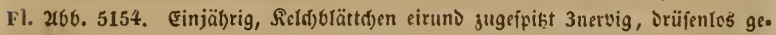
mimpert, fo lang als Die Siaffit, SIlumenblätter abgerundet, getirbt. Etengel

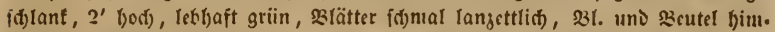
melofau, Eaamen gelobraun, etwaz frunın. Die Fä̇en aus bem હtengel grün, faft fd)war; weriens. - Etammt wobt aus ien Drient. Unter ier Gant. Juni.

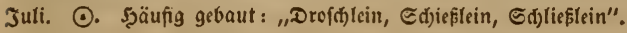

1994. L. humile MrLs. Rснв. Deutschl. Fl. 2166. 5155. L. usi-

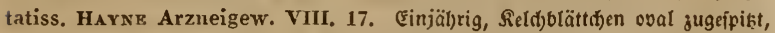
3nervig, fahl, um ein Dritttheil tür jer als Siaffel, 23lumenolätter abgeffuşt aus.

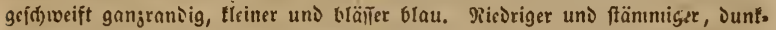
Ier grün, oben Iofer Durbentraubig, siä̈ter breiter, \$eutel Duntler blau, ßapfên grïfere, länger gefficlt, Enamen geraie, foftanienbraun. Eeit Jabrbunderten cigne

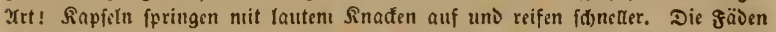

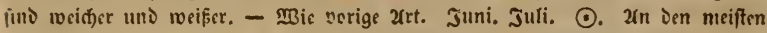

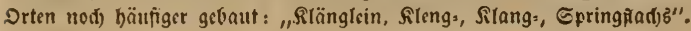


Hypericineae. $\quad-450-\quad$ Hypericum.

B. Hypericeae: :ielmảnnig vieltbrüberig, frracţ flein= vielipamig.

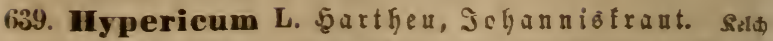
5. (2, und 3.) blättrig. 5 slumenblätter fưfief uni ireh)tnoşpig (gelb, am

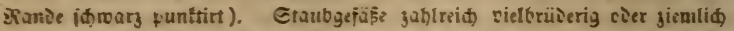
frei, 3 Grif̈ll (bi unjern Xrten!), Rarbon fepffirmig, Rapjel 3füọrig, Jä. Wher vieljaumig, ઉaamen tlein, längliđf, nefgrubig cier gefurdt.

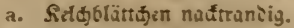

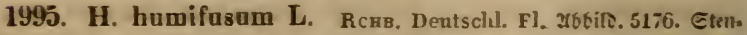

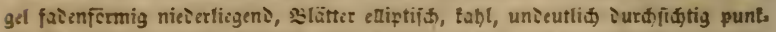

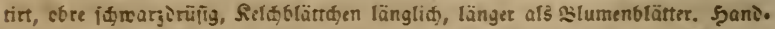

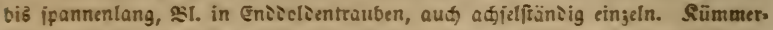
lithe aufredste, sann cft 4 jählig einblütbige Exinţlare find H. Liotardi Vrux. - b. glandnlosum WALlR. (decumbens et serrulatum PETERM.) Iie ven mir Fl. germ. p. 336. angegeigte xbānierung, ieren Reldfblättđen am Rande

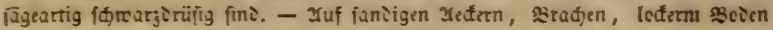
überbaupt. Juli - Eeftember. 2. Gimein.

1996. H. perforatum L. Harxs Arzneigew. VII. 42. Rсnв. Dentschl. Fl. 366ild. 517\%. Etengel aufredt, 2tantig, meifi ärig, slätter

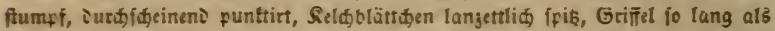

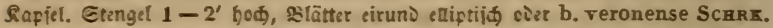

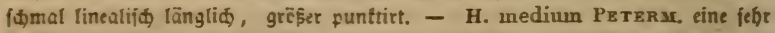

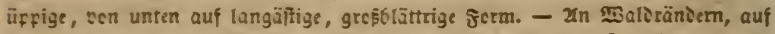

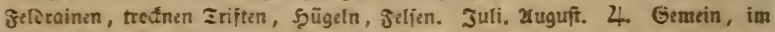
Erggebirge nut: Z. Ebamnis am jeijigral:.

1997. H. quadrangulum L. Sp. pl. I. et Codex 5757. Rснв. Deutschl. Fl. xbbil. 5178. Fl. germ. exsicc, n. 1397. Etingel aufredt,

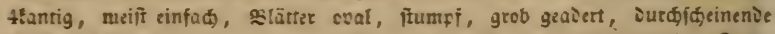
Tuntte gres aber fobr menige cier febleni, slüthen gres, iclientraubig, Relds:

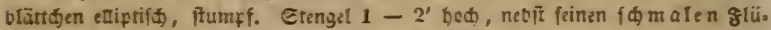

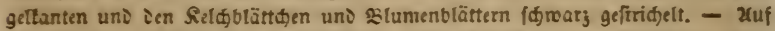

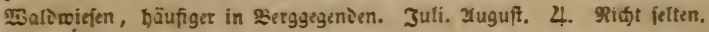

1998. H. tetrapterum Frie8. Rснв. Deutsch, Fl. x66. 5179. Fl. germ, exsicc, n, 1338. quadrangulare Sx. HArse Arzneigw. VII.

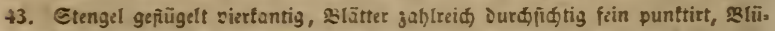

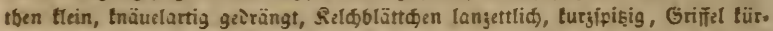

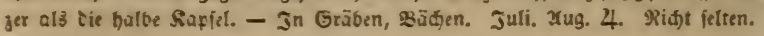

b. Selde geminıert.

1999. H. pulchrum L. Rсвв. pl. crit. III. ic. 477. Deutschl.

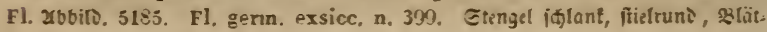




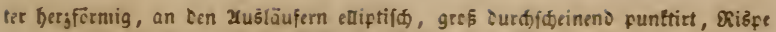

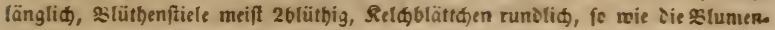

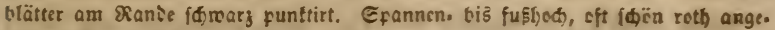
laufen, 28l. fo gré als an $\boldsymbol{H}$. perforatun. - In Scitemäliem. Juni. Juli.

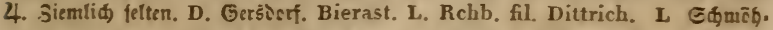

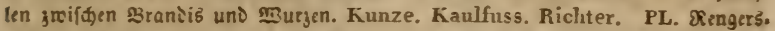
iorf am Geicrb̈brge. Hasse. Burkhardt. - Mäütermarf: im Xuerbalj, am

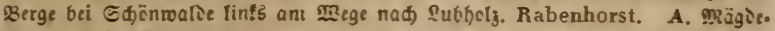
ffrung. Schwabe. PS. Faltenj̄ein. Schwabe. Raumburg: Dīerfelt. Beneken.

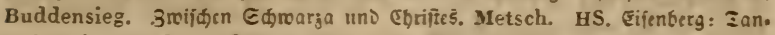

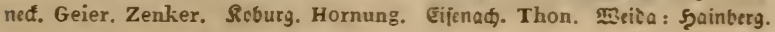
Rossinässler.

2000. H. montanum L. Rснв. Deutschl. Fl, ג66. 5187. Etengel ftielrund, tabl, wenig beblättert, stätter berjseifirmig, am xanie nur

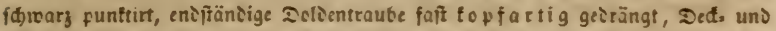

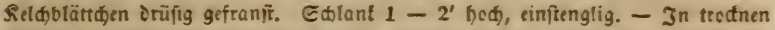

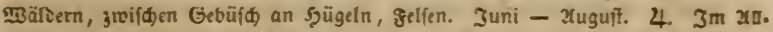
gemeinen nidjt felten. $3 \mathrm{~m}$ Erggebirge nidt a Igemein, fheint in ier Sieierlaujis zu feblen.

2001. H. hirsutum L. Rскв. Deutschl, Fl. xt6. 5159. Fl. genn.

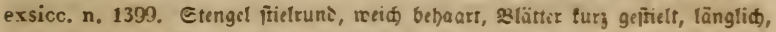

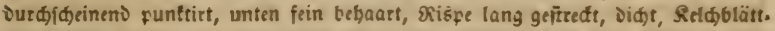

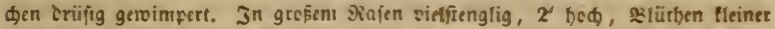

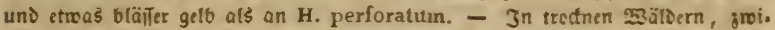

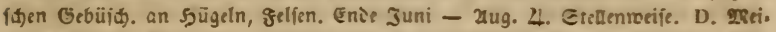

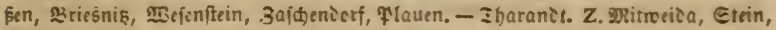

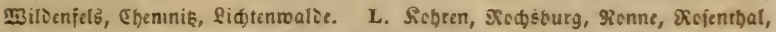

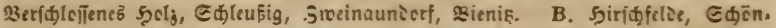

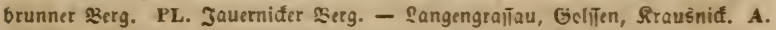

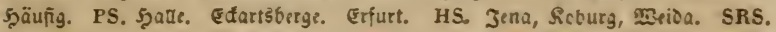
arnftait.

2002. H. elegans SтвPн. Rcrв. pl. crit. III. ic, 443. Deutschl.

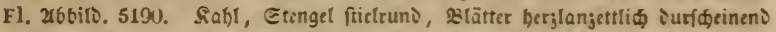

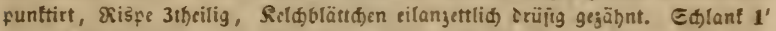

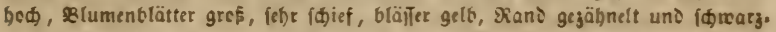

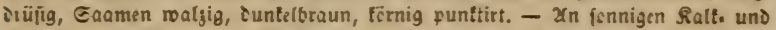

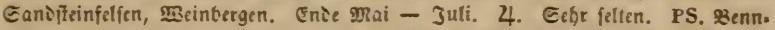

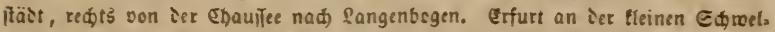

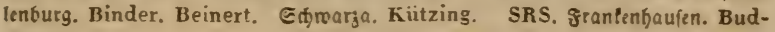
densieg. 


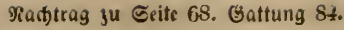

2004. (318b.) I. tenuis WrLev. Shalm fticlrumblich, naớt, an Dir

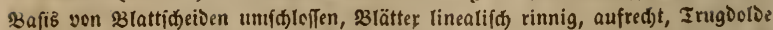

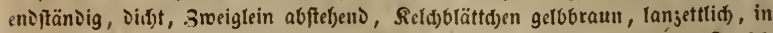
cie Єpik̨e veriđ)mälert, 3nervig, ctroas länger als Die eiförmig längliđłe Sapfet, Staubfäben länger als \$sutel. - Juni. Juli. 4. Şöđ)ft felten (friiber nur in

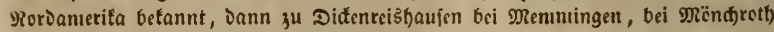
in Bürtemberg und in Der Campine in 236 (gien). PL. 3wifden Sgerrnbut und

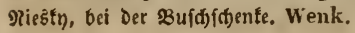

Naळtrag su હeite 122. Gattung $153 \mathrm{~b}$.

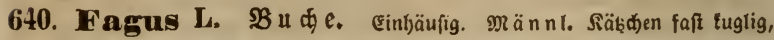

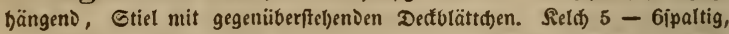
tridterförmig, Staubgefäfe perigynifí) $8-12$. Griffel(pur. $\mathfrak{B}$ сiø I. 221 .

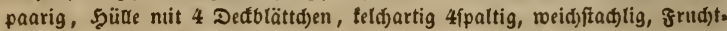

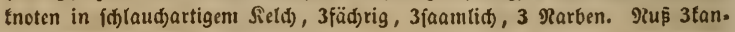
tig, 1 iantig.

2003. (531 b.) F. silvatica L. Schк. 303. Gurmp. 143. 3lätter fobief

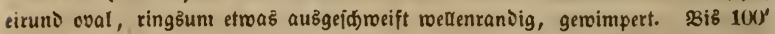

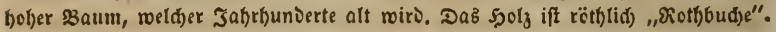

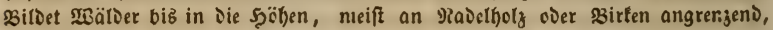

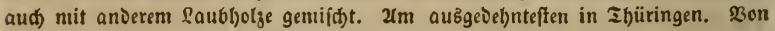

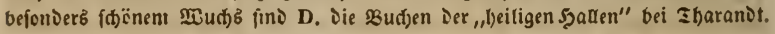
zpril - Juni. h. Gebr verbreitet.

\section{शRadtrag zu ธ. 229.}

1042. Utricularia intermedia. Die erbfengrofen Snoten Diefer

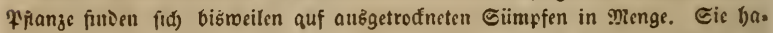
ben eine getblidgräne farbe uno fino fammetglänjent. Sie find Die fpiralig ju.

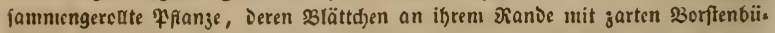

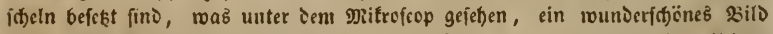

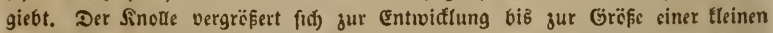

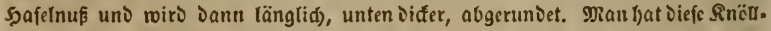
d)en, ifolitt aufgefunien, fdecn für eine 3lge getbalten. sergl, Fl. gern, n. 2621. 


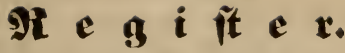

Die mit eincm * verfel)enen Biffern begeid)nen bie 2(rtnamen, allen übrigen iff Die Gattungsnumumer beigefebt.

Abies $1+1$.

Absynthiun $197 \mathrm{~b}$.

Acer 6U2.

Aceras 113.

Achillea 178.

Achyrophorus 235 b.

Acinos 274.

Aconitum 586 .

Acorus 88 .

Actuea 592.

Adonis $57 \mathrm{~s}$.

Adoxa 421.

Adyseton $5+1$ a.

Aegopodiun 384 .

Aesculns 603.

Aethusa 392.

Agathopliytuin 482.

A grimonia 503.

A gropyruin 43.

Agrostemina 632.

Agrostis 16.

aiborn 602.

Aira 22.

Ajuga 285.

attelei 584 .

Ullant 196.

Albersia 489 .

Albucea 104.

Alchemilla 493.

Alectorolophus 310.

Alisma 10.

Alliaria 556.

Allium 100.

Alnus 150.

Alopecurus 26.

2ilplattid) $2(1) 4$.

Alsine 470 uni 1924. *

Althaea 606.

Alyssum $5+1$.

Amarantlius 490 .
Ammophila 18.

Ampelopsis 425.

Impfer 472.

Anygdalus 524.

Anacamptis 109.

Anacyclus 150.

Anayallis 344.

Anchusa 296.

Iniorn 27).

Andromeda 354.

Andropogon 39.

Androrchis 108 b.

Androsace 337.

Anemone 581.

Anethum 406.

Angelica 412.

Anisodontium 270 a.

Anodontea $5+1$ b.

Antennaria 199.

Anthemis 179.

Anthericum 105.

Anthoxanthum 29.

Anthriscus 372.

Anthyllis 453 .

Antirrhinum 313.

Apargia f. 216.

Aparine 172 a.

Apera 16 a.

2(pfelbaum 510.

Aphanes 492.

Apium 381.

Apritofe 1641* - 1643.*

Aquilegia 584.

Arubidopsis f. 171\%."

Arabis 547.

Arbutus f. 355.

Archangelica 413.

Arctiun f. 239.

Arctostaphylos 355 .

Arencuria 616.
Aristolochia 161.

Arıneniaca $523 \mathrm{~d}$.

Anneria 336.

2 (rmleud)ter 131).

Armoracia $5+5$.

A rnica 193.

Arnoseris 213.

Aron 1.

A ronia 508.

Aronsivur 1.

Arrhenatherum 24.

Artemisia 197.

Aruun 1.

A rumcis 5()2 a.

Asarum 162.

Ijit)enlattig 192.

Asclepias 360).

Asparagus 107.

Asperugo 299.

Asperula 173.

Aster 188.

Asterocephalus 163 b.

Astragalus 441).

Astrantia 419 .

Athamanta f. 395 u. 404 .

Atriplex 478.

Atropa 328.

3ugentroft 307.

Avena 23.

Avenaira 22 a.

Avenaria 22 b.

Bad)burgel 520.

Baveftaut 195.

รä̈rent๋ (au 4)s.

Sätentraule 355.

Sörlafp 134.

Särrour 399.

Baldingera $28 \mathrm{~b}$.

sialorian 166.

Billota 269. 
Baljamin: 611 .

Balsamita 183.

Sananenordie 119.

Barbaraea $55 \pm$.

Barbaratraut $55+$.

Barkhausia 233.

Bartgras 39.

Bapilitum 281.

Batrachinin 576 a.

szauernienf i. 53t.

Beermispel 51$) 8$.

sedherblume 495 .

หzifū 197.

Beinned 297.

Bellis 185.

senetiftenfraut $5(x)$.

Berberis 571 .

Berberike 571.

Berteroa $5+2$.

Bettram 182.

Berula 387 b.

Befentyeide 352.

Siéenpfriemen i. 450 .

Beta 451 .

Betonica 268.

Betonie 268.

Betula 149 .

Bidens 207.

Bieneniaug 264.

silientraut 325.

singelfraut 596.

sinie 72 .

Sirnbaum 511.

sirte 149.

Sirnfraut 35).

gifamifraut 421.

Biscutella 535.

Bistorta i. 142t. *

silafenftraud 438 .

Blitum 493 .

Slumenbinfe 11.

Slutauge 437.

Blysınus 73.

sioftsbart 217.

s3otsiorn 331.

sobne 447.

32obnenitraud 452.

Borrago 296.

SBorretid 298.

Sorîtiolie 379 .

\$oritengras 38. 41).

Brachspodium +2 .

Brassica 563.

Braunmur; 318.

Breea 2t) a.

Brenniolis 396.

Brennenie Qicbe 633 d,

Brillenídote 535.

Briza 53.

Brentbeete 501 .

Broiniss 63.

Brutbtraut 467 .
Birunelle 280).

BrunnentreiTe 552.

Bryonia $2+7$.

Bude 641. Geite 452.

Sudisbaum 597.

Buritbobne 1315. *

Bulliarda +62 .

Bungen $3+8$.

Bupleunum 389.

siurge! 521).

Burgsdorfia i. 275.

Butomus 11.

Butterblunie 591.

Buxus 597.

Cacosciadiun 373 a.

Caliunagrostis 17.

Calendula 176 .

Calla 2.

Callistephus i. 6+2.*

Callitriche $59 t$.

Calluna 352.

Caltha 591.

Caunelina $5+6$.

Campanistrum 267 a.

Caunpanula 254.

Eanariengras 87. *

Cannabis 157.

Caprifolium $170 \mathrm{~b}$.

Capsella 536.

Cardamine $5+9$.

Cardaria 538.

Eariebenedicte 210.

Carduus $2+1$.

Carex 66.

Carlina 211.

Carpinus 151.

Carthainus $24 t$.

Caruun 385.

Earpe 385.

Castanea 154.

Catabrosa 52.

Cathartolinuun 637.

Caucalis $37 \%$.

Caulinia 131.

Centaurea 209.

Centunculus $3+2$.

Cepbalanthera 128.

Cerananthe 317 .

Cerastiun 621.

Cerasus 523 b.

Ceratophyllun 133.

Cerinthe 290).

Cervaria $\$ 13$.

Chaerophrllum 373.

Chaetospora i. $67 \mathrm{~b}$.

Cliaeturus 271.

Chamnaedry on 51)2 d.

Chamaeneriun 517 a.

Chamaepitys $285 \mathrm{~b}$.

Chamaesideritis $2 \mathrm{fi}^{\mathrm{i}} \mathrm{b}$.

Cliara 130.

Cheiranthus 551.
Chelidonium 567.

Chenopodium 485 .

Chilochloa 27 a.

Chimophila 351 .

Chondrilla 226.

(5)riftindentraut 195.

(E)riftopl)sfraut 592.

Chrysantlieinuin 181.

Clirysocouna 190.

Chrysosplenium $\$ 59$.

Cicer 444.

Sifforie 214.

Eidocrienfolat 225.

Cichorium 214.

Cicuta 380.

Cineraria f. 19?.

Circaea 518.

Cirsium 241).

(Sifitrïsten 57 .

Cistus 1. 57t.

Cladiun 68.

clematis 583 .

Clinopodium 276.

Cnicus 2 I().

Cnidium 396.

Coccrganthe 633 a.

Cochlearia 544.

Cochlidiosperma 311 a.

Codonoprasum 98.

Coeloglossuun í. 114 und 117.

Colchicuin 87.

Colutea 438 .

Coinarum 497.

Conium 375.

Conringia 557.

Convallaria 91.

Convolvulus 304 .

Conyza 203.

Eoradenwury 121.

Corallorrliza 121

Corianier 370.

Coriandrum 37u.

Cornus 422.

Coronilla 457.

Coronopus f. 539.

Corrigiola $47 \%$.

Corvisartia f. 669.

Corydalis 566 .

Corylus 152.

Corynephorus 21.

Cotoneaster 5117.

Cracea 443 b.

Crambe 527.

Crataegus 5196.

Crepis 231).

Critamus i. 383.

Cruciata 172 ai.

Cucubalus 631.

Cucumis 243

Cacurbita 25i).

Cuscuta 491 . 
Cyanus 706 - 700. Cydonia 511 .

Cymbalaria 312 a.

Cynanchum 359.

Cynoglossum 311.

Cynosurus 59.

(Inpergras 70.

Cyperus 70 .

Cypripedium 129.

Cytisus 452 .

Dactylis $6 \%$.

Daphne $1+5$.

Darrgras 3\%.

Datura 327.

Daucus 415 .

Delphinium 585.

Dentaria 550 .

Deschampsia 22 c.

Dianthus 628.

Dichostylis $73 \mathrm{~b}$.

Dictamnus 6y).

Digitalis 314.

Digitaria 36.

Dill 406.

Diplopappus \{. 186.

Diplotaxis 560.

Dipsacus $16 t$.

Diptam 600.

Dischidium 572 a.

Diftel 241.

Diftelialat 224.

Dïtter $5+6$.

Dofiten 258.

Dotterblumie 591.

Draba $5+0$.

Dradentopf 279.

Dracocephaluun 279.

Dreherdis 123.

Dreigad 7.

Dreizabn 54.

Drosera 573.

Dürrnury 1S7. 203.

Eberéfide 505.

Eberwurs 211.

Ecbaliuun 278.

Echinochloa 37.

Echinops 245.

Echinospermum आN.

Echinu 289.

Ebrenpreis 311.

Eibe 136.

(Eibiji) 616.

(sid) 153.

Einbeere 89.

Eifenhut 586 .

Eijenfraut 288.

Elatine 590 .

Eleocharis it.

Elichrysum i. 20?

(E⿱t口)er 151).

Elrife 1577. *

Elहbeere 1577.*
Elymus 46 .

Empetruun 598 .

Engelwours 413 .

Enodium 1. 56 .

Enjian 363.

Ephemeruun $3+5$.

Eppleu 423.

Epilobiuin 517.

Epinediuu 570.

Epipactis 126.

Eppig 381.

Epipogum 119.

Epitrachys 1*u e.

Equisețun 135.

Eragrostis 4?.

Eranthis 589.

Erbie 441.

Eroäpiel $i(x)$.*

Eribere 496.

Eribeeripinat 483.

Eritraud 565.

Erica 353.

Erigeron 187.

Eriolepis $1 \mathrm{tu}$ f.

Erioplionun i1.

Eriostacliys 207 c.

Erle 15t).

Erobatos i. 1847. *

Erodium f. 60)\%.

Erophila 5+1), a.

Erucastrum 50ใ?

Erse $4+3$ a.

Ervenwürger 324 .

Erruin $4+3$ a.

Eryngium 420.

Erysinum 558.

Erythraea 362.

लide 367.

Esparfette 455 .

Eupatorium 236.

Euphorbia 595.

Euphrasia 3117.

Eurythalia $363 \mathrm{~b}$.

Evonymus 63t.

Faba $4+3$ d.

Fagopyrum 1+28 - 29. *

Fagus 6t1). Eeite 45?.

Falcaria 383.

Fattitaut 193.

Gaulbaun 427.

Fedia 1.165.

fisigwarjentraut 575 .

Freinitrabl 186.

şelsnelte $62 t$.

Findid 393.

istunid 38 .

Jertilfraut 285.

Festuca 62.

Sectheune 4013 .

Jettfraut 316.

Ficaria 575.

ginte $1+1$.
Filago $2(x)$.

Filipendula 5,12 c.

fingergras 36.

fingerbut 314 .

fingertraut 498 .

grlađjsjeice 491 .

flattergras 3t.

glieier 167.

Slctenblume 209.

łlöbjaante 335.

Foeniculum 393.

frlügelīlge $4(x)$.

Fragaria 49 i)

Frangula 427.

Frauenmantel 493.

frrauenniüne 183.

Sraueníd)ub 129.

šrauentbräne 11 s.

Fraxinus 367.

Fritillaria 95.

Froid)biß 13.

Srcidiciñel 10).

Judsidwran; 26 u. 4 .

Juकsiómanjgras 26.

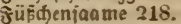

Funearia 565 .

Gänfeblümı)en 18.5.

Gänjefus̃ 485.

Gänfetraut $5+7$.

Gagea 93.

Eagel 140.

Galanthus 80).

Galarrhoeus 595 a.

Galega 436 .

Galeobdolon 265.

Galeopsis 266.

Galinsoga 2000.

Galium 172 .

Gamanier 286.

Garbe 178.

Gatyona 232.

Gaudbeil $3+4$.

Geientemein 34).

Geišrus $38 t$.

Geisraute 436 .

Genista 440.

Gentiana 363.

Gentianella 363 ㄱ.

Geracium 231.

Geranium 6ณ:

Gernter 86.

Gerite 47 .

Geuin 5(x).

Gidtroie 593.

(Gierid) 384.

(豸iftbecte $32 ?$

Gilbuetiel 265.

Ginîter 449.

Githago 631 .

Gladiolus 79 .

Gilanjgraś 28.

Glastraut 156. 
GlaşjthmaI 477 .

Glaucium $56 \mathrm{~s}$.

Glaux $3+0$.

Glechoma 263.

Gileife 392.

Globularia 305.

Gloctenblunie 25t.

Glofenlaud) $9 \mathrm{~s}$.

Glyceria 51.

Gnadentraut 322.

Gnaphalimu 201.

Golobaar 19).

Golorutbe 189.

Goodyera 127.

Gramineionium 572 d.

Grasnelfe 336.

Grasitern 1()4.

Gratiola 322.

Grossularia 1381 - 82. *

(Grunifelte 230.

Grunobeil 4(1)4

(viüif́l 285.

Gundermann 263.

Gurfe 249.

Gyınnadenia 111).

Ginpstraut 623.

Gypsophila 623.

Saargras 46.

Saarftrang t(1)1.

Sabidtstraut 234.

Sä̈ngelippe 114.

Särtling $614 \mathrm{~b}$.

Şab) nenfuß 576 .

Şalynentanin 310.

Shafer 23.

Şaferraigras 27.

Halimus 479.

Shainbud) 151.

Sainfimif 83.

Şanf 157.

Soartgras 50.

Şartl)ell 639.

Spartriegel 369.

ริalcinū 152.

Safetrours 162.

Safenobr 389.

Sajenfalat 229.

5ुaubed el 448 .

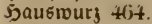

Sedittraut 576 a.

Shetfiame 451 .

Hedera 423.

5ederia) 558 .

Hedysarum i. 458 .

s.eide 353.

Seidelbeere 357.

Scilwur: 395.

Seinridstraut $4 \$ 2$.

Heleocharis $7 t$.

Heleogiton 74 c.

Heliantheınum 5 it.

Heliantluus 21)8.
Helichrysum 202.

Helleborus 590 .

Solmbufit) 566.

JjeInterden 184.

Helminthia 221.

Solmutraut 284.

Helocirsium 2 tu b.

Helosciadium 388.

Heloseris 192 a.

Hemerocallis 1166 .

Hepatica 580.

Heracleun 4108.

Herminium 116.

Herniaria 467 .

Herodium 607:

Herorchis 10s a.

Hesiodea 275.

Hesperis 555.

Serenfraut 518.

(Hibiscus 6r)ib. cult.)

Hieracium 234.

Hierochloa 30 .

Himantoglossum f. 112 .

Szinibeere 1537.*

Hippocrepis 456.

Hippomarathrum f. 1205.*

Hippophaë 143.

Hippuris 512.

Sirífilvury 403 .

Şirie 35.

Şirtentäidjel 536 .

Syoblzabn 266.

Itolcus 31 .

Syollunier 167.

Holoschoenus 575.

Holosteum 617.

Homogyne 204.

Soniggras 31.

Sjopfen 158.

Hordeum 47 .

Sornulatt 132.

5jorntlee 434 .

Sjornmiobn 568.

Sormitraud) 422.

Hornungia 533.

Hottonia 339.

Souilnerbarm 1932. *

Soufeifentlse 456 .

5) uflattig 191.

Humulus 158.

S)

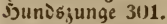

5ungerbliimd)en 5+1).

Hyacintlus f. 111).

Hydrocharis 13.

Hydrocotyle 417 .

Hyoscyanus 325.

Hyoseris f. 213.

Hypericum 639.

Hypochateris 235 .

Hyssopus 260.
Jasione 251 .

Iberis 534 .

Jgelnüid)en 300 .

Jgelstolbe 77.

Jirasekia 343.

lllecebrum 468 .

Jninierid)ön $2(1) 2$.

Jumortelle 202.

Impatiens 611 .

Imperatoria 405.

Inula 196.

Jol)annisbeere 465.

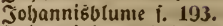

Johannistraut 639.

Iris 78 .

Isatis 526 .

Isnardia 515.

Isolepis 72 b.

Jiop 260 ).

Juglans 428.

Juncus 84. $u$. Seite 452.

Juniperus 138.

Jurinea 238.

Sïlbertropf 373.

Rafíeeblümdhen 1902. *

Siaijerftone 96.

Sialmus 88.

Sanille 179.

Sammigras 59.

Sianını dumiele 58 .

RapujinertreiTe 6U9.

Farien 164.

Siartoinel 1095. *

Raftanie 154.

Siabenninje 262.

Rak̨enpfötd)en 199.

Siakenid)ivan: 271.

Seifmelie 479.

Keraselma 595 b.

Siellerlials f. 4S7. *

Rerbel 371 und 1168. *

Rerbelrübden 1171. *

Siettenblume 222.

fieulengras 21.

Siider 444 .

Siliefer 1+1).

Sienpeft 1.358.

Siridide 523.

Silee 430 .

flitinting 242.

Silette 239.

Rlettenterbel $3 \pi 2$.

Sinabentraut 11)8.

Sinäuelgras 66).

Sinc̈terid) 473.

Sinorpeltelda 466 .

Sinorpelfraut $465 \mathrm{~S} u, 485$.

Sincrpelíalat 226.

Sinotenblume 81.

Snotenfus 9 ).

Kochia 484.

Iioeleria 58. 
hohlrauschia 627.

Siolbenbirfe 106. *

Siobl 563.

Siopfriet 67 .

Kopsia $32 \pm$ b.

fiorntade 197\%. *

Rrapp 17t.

Siraboiftel 2 tu.

Sirebsoiftel 242.

Rrebsid)eere 12.

RretTe 537. 61)9.

Sireujblunte 522 .

Sireujoern 426.

Sirengtraut 194.

Rriebelrettig 529.

Rrombide 457 .

Sirugbliinid)en 317.

Srunınt)als 295.

Siubeidyede 582.

Sïmmel 385.

Sïrbis 250.

Sigelblunte 305.

Rugelriet 75 .

Subborntlee f. 1274. *

Sibnclte 625 .

Subid)elle 582.

Siryftielden 42 .

Situtsolume 633 a.

Sabfraut 172.

Pad 551.

Lactuca 223.

Ladanum 266 a.

\&ämmerialat 213.

Säudid 556 .

९äuf́ftraut 309 .

Iaidtraut 6 .

Lamiopsis $26 t$ a.

Lawuium 264.

Lampsana 212.

Lappia 239.

Lapsana 212.

Larbrea 619.

Larix 142.

Sajer 414 .

Laserpitiuun $41 \%$.

Lathraea 323.

Lathyrus 445 .

Saud 1(x).

Laurocerasus 1627.* annt.

Lavandula 261.

Lavatera 427.

Saveniel 261.

Qebcns̄baum 139.

Seberfiraut 581).

Ledum 358 .

Leersia 33.

Scimfraut 629.

Sein 638.

Qeinblatt 137.

Lemna 3.
Lens 442.

Leontodon 216.

Leomurus 272.

Lepidiun 537.

Lepidotis $134 \mathrm{~b}$.

lercheniporn 566 .

Lencanthemum 181 a.

Leucoiun 81.

Lencorchis 117.

Levisticum 411 .

Libanotis 395.

'lid)tnelte 633.

Diebesgras 49 .

siebficiel 411 .

liejd)gras 27.

ligusticum i. 411 .

Ligustrum 369.

Silat 368.

Silie 97.

Lilium 97.

Limmiris is b.

Limnochloa 72 a.

Limosella 320.

Linaria 312.

sinve 635.

Lindernia 321.

Linnaea 169.

Linosyris f. 190.

Pinje $4+2$.

Linum 637 แ. 638 .

Liparis (fijd)mame!) f. 122.

Listera 125.

Lithosperunum 292.

Littorella 333.

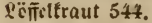

@̈̈wenniaul 313.

sc̈wenzalon 216.

sold) 41.

Lolium 41.

Lonicera 169.

Loroglossuin 112.

Lotopliyllum 430 b.

Lotus 434 .

Lunaria $5+3$.

Lupiums $45 \%$.

Luzulat 83 .

Lyclinis 633 .

Lycium 331.

Lycopodium 134.

Lycopsis 295.

Lycopus 255.

Lysimachia 346 .

Lythrum 521.

Madiat 177.

Mäuje ১arm 1932. *

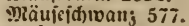

Maianthenum 9:.

Maiblunic 91.

Majorana 258 b.

Mlaib 32.
Malachium 622.

Malaxis 120 .

Malus f. 1586 - 87.

Malva 614.

gianiel 524 .

giangoto 481 .

ganns่tbilo 337.

giannstren $\$ 20$ ).

9)annagras 51 .

פ) Ranngraunengras 24 .

Margaripes 199 b.

Mariendiftel 243.

Miariengras 30 .

פRariení()ui) 129.

Marrubium 270.

Maruta 179 a.

9) Raslicbe 185.

Matricaria isł.

Matthiola 551 2rnm.

Mauerialat 228.

Maukea $615 \mathrm{~b}$.

9) aulberbaum 159.

Dianlblume 312 .

Medicago 433 .

Mieertobl 527.

Meerrettig $5 \neq 5$.

Meifteriour 405 .

Melampyrum 306.

Melaudryun 633 c.

Mretoe 478 .

Melica 55 .

Melilotus 431 .

Melissa 277.

Melittis 278.

Melotentlee 431.

Mentha 256.

Menyanthes 361 .

Mercurialis 596 .

Merf 387.

Mespilus 509.

Meun 399.

Mibora 25.

Microcentron 2t) c.

Miere 470 11. 1924.

giildtraut 340 .

Ditisgras 34 .

Miliun $3 t$.

Minge 256.

gitispel 509.

Diftel $16 \mathrm{~s}$.

Miljtraut 459.

פiç) 415.

Moehringia 615.

Moenchia 620 .

grobn 569.

Diobrriibe f. 415 .

Molinia 56.

Momordica f. $2+8$.

Monoveil 543 .

Moneses $35($ ) a.

Monotropa 349

Montia 475 . 
Dioobauge 350 a. Moosbeere 356.

Morus 159.

Mottentraut 358.

Mulgedium 225.

Muscatbyacintbe 101.

Muscari 101.

Mycelis 228.

Myosotis 297.

Myosnrus 577.

Myrica 146.

Myriophyllum 513.

Mnrrbenterbel 374.

Myrrhis 374.

Radtterfe 516.

Rađtfめatten 332.

Radtricle 555.

Ract́torüfe 11().

Rageltraut 469.

Rajaie 132.

Najas 132.

Narcissus 82.

Nardus 4().

Rarzitie 82.

Nasturtiun 552.

gatternurs 289.

Naumburgia 347.

Relte 628.

Nenuphar f. Nuphar 14.

Neottia 124.

Nepeta 262.

Neslia 525.

Treftel 155.

Reftrours 124.

Reunfraft 205.

Reunfraut 205.

Nicandra 329.

Nicotiana 326.

Riešrourg 590.

Nigella 587.

Rirblume 14.

Nonnea 293.

Nuphar 14.

Rutriet 68 .

Nynphaea 15.

Dofengunge 296.

Ocimuin 281.

Dermennig 503.

Doontite 308.

Odontites $30 \mathrm{~S}$.

Oenanthe $39 \%$ ).

Denothera 516.

Dhmfraut 492.

Ohnblatt 349.

Ohnborn 113.

Omphalodes 302 .

Onobrychis 458 .

Ononis 448.

Onopordon 242 .

Onotrophe 241) d.

Ophrys 118.

Oporinia 216 b.
Opulus f. 581.*

Orchis 108.

Oreoselinum 404.

Oriba 581 b.

Origanuin 258.

Orlaya 416.

Ornithogalum 103.

Ornithopus 455.

Orobanche 324 .

Orobus 446.

Ostericuin 397.

Dfterit 397.

Dfterlu;ei 161.

Oxalis 610.

Oxycoccus 356.

Oxytropis 439 .

Padụs 523 a.

Paeonia 593.

Panicuun 35.

Papaver 569.

Pappel 148.

Parietaria 156.

Paris 89.

Parnassia 365.

Passerina f. 144.

Pastinaca 4(1)7.

Tednelfe $633 \mathrm{~b}$.

Pedicularis 309 .

Peloria i. 312.

Peplis 520.

Periclyınenum f. 578.

Peristylus 114.

Terlgras 55.

Persica 524 b.

Persicaria 473 ค.

Petasites 205.

Peteriltie 382.

Petilium 96.

Petroselinum 382.

Peucedanum 41)1.

Pfar̃enbütónen 634.

Pfaĩenröbrlein 222.

Pfeiltraut 9.

Pferdebohne 1316.*

Fferdegras 31.

Fifingitrofe 593.

Fraume 1635 - 164).*

Pfirfth 1646 - 1647. *

Ffriemen 450).

Pfricniengras 20 .

Tfublbinje 72 ค.

Phalaris 28.

Phaseotus 447.

Tfeifenftraud 461 .

Phellandrium 391.

Philadelphus 461 .

Phleun 27.

Phoenixopus 227.

Phraginites 19.

Physalis 330.

Phytemua 252.

Picris 220.
Timpermus 601.

Pimpinella 386 .

Pinguicula 316.

Pinus 14).

Pippau 230.

Pisum 441.

Plananthus 134 a.

Plantago 334.

Platanthera 115.

Platterbie 445.

Pleurospermuin 376.

Pneumonanthe 363 c.

Poa 48.

Podosperınuun 215.

Polemoniun 343.

Poley 257.

Polinin f. 948.

Polycarnon 469 .

Polycnemum 488 .

Polygala 522.

Polygonatum 91 a.

Palygonuin 473.

Populus 148.

Forken 99.

Porruun 99.

Porcellites 1. 794.*

Portulaca 476 .

Portulat 476 .

Plortultraut 520.

Torft 358.

Poft 358.

Potamogeton 6.

Potentilla 498.

Poterium 495 .

Freifelbeere 1139. *

Prenanthes 229.

Prieftertraufe 181 a.

Prinula 337.

Prismatocarpus 253.

Prunella 280.

Prunus 523.

Psamma f. Ammophila 18.

Psylliun 335.

Ptarmica i. 613.*

Pteroselinum $4(x)$.

Pulegium 257.

Pulicaria 195.

Pulmonaria 291.

Pulsatilla 582 .

Tungen 348.

Furgirlein 637.

Pycrens 69.

Pyrethruun 182.

Pyrola 351).

Pyrus 511).

Quede 43.

ฉuellgras 52.

Quetlriet 73.

Quendel 273.

Ouercus 153.

Quitte 511. 
Kade 631.

Radiola 636 .

ragiour; 116.

Riaigras englifít)es 112 . * = frangöf. 77. * = italiän. 111. *

Rainfarrn 198

Rnintobl 212.

Ramunculus 5 76 .

Rianuntel 576 .

Rapliauistrun 529 .

Raphanus 531).

Rapistrum 528.

Riaps $17+1$.

Rapsö̈tter 528.

Rapüngd)en 165.

Rapunzel 252.

riaute 559. 562 .

Kauf(t)beere 598.

raute 599 .

Rebendolde 3:\%).

Reiberid)nabel 607.

Reitlbgraśs 17.

Renipe 560).

Reseda $56 \%$.

rettig 530 .

Rhamnus 426.

Rhinanthus i. 310 .

Rlodiola f. 2(nm. nad) 1377.*

Rhus 429 .

Rhynchospora 66.

Rhytispernum i. 957.*

Ribes $\$ 65$.

Riemenjunge 112.

Rietgras 66.

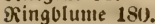

Fingclblume 176 .

Rippniip̄den 376 .

Rispengras 48 .

Ritterfporn 585.

Robinia 437.

Sïtbe $17 \%$.

roggen 45 .

Rohrtolbe 76 .

Roripa 553.

Rosa 504.

Rofe 504.

Rosmarin 283.

Rosınarinus 283.

Reftaftanie 603 .

Roffiimutel 391.

ricthbud)e $2(x) 3$.

Rubia 174.

Rubus 5(1)1.

Rudbgrab 29.

Rübien 1740 - 1743. *

शiüfter 160.

Rub)rfraut 2()1.

Rumex 472 .

Ruppia 5.

Ruta 599.
Rutbenialat 227.

Saamling 469.

Sabulina 61\%.

Sänoling 614 .

Safior 244.

Sagina 612.

Sagittaria 9 .

Salat 223.

Salbei 282.

Salicorivia 477 .

Salix 147.

Salsolit 487.

Salvia 282.

Ealjtraut 487.

Sambucus 167.

Simolius 348 .

Sandoorn 143.

Sandtraut 616 .

Sanorobr 18.

Sanguisorba 4J4.

Sanicula 418.

Sanitel 418.

Saponaria 626.

Saturei 259.

Satureia 259.

Sauerdorn 571.

Snuertlee 6ili.

Saxifraga $46($ ).

Scabiosa 163.

Scandix 371.

Sd)ad)blume 95.

Sd)ärfling 299.

Gibarte 237.

巨d)aftengrute 192.

Eđ)aumitraut 549.

Schedonorus f. 175 176. *

Sclielhaunmeria 65.

Scheuchzeria 8.

Ed)icrling 375 .

Sd)ilfrobr 19.

Sd)immeltraut 2(x).

Schizotheca 475 a.

Sd)!angenfraut 2.

Sd)leifenblume 534 .

Soling(traud) 171.

S(blutte 331).

Sd)lïifelblume 338.

Sd)niele 22.

Sthnabelrict 66.

Sifnedentlee 433.

Sd)nerball 171.

Sd)neeglïdtien 81.

Sd)ncetropfen 80 .

Schoberia 486.

Sđönfraut 567.

Shotenweiberid) 517.

St)uppenrour 323.

Sd)roargtünintel 587.

Sd)weiffd)roinger 61 .

Sdiverter 78.

Stguertlille 78.
Sthivingel 62.

Scilla 1()?.

Scirpus 72.

Scleranthus 466 .

Sclerochloa 50 .

Scordium f. 946 u. 47. *

Scorodonia 287.

Scorzonera 219.

Scrofularia 318.

Scutellaria 284.

Secale 45.

Sedum 463 .

Secblume 15.

Eegge 64.

Seivelbait 145.

Geivenpitange 360.

Seifentraut 626.

Selaginella $13 t$ c.

Selinum 410 .

Sellerie 381.

Sempervivum $46 t$.

Senebiera 539 .

Senecio 194.

cenf 561.

Serapias f. 126.

Serritula 237.

Gefel 394.

Seseli 394.

Sesleria 57.

Setaria 38.

Sherardia 175.

Gidjelvolbe 383.

Sideritis 275.

Siebenftrabl $\mathbf{3 4 1}$.

Siebenzeiten 127\%. *

Sisgıvurs 79.

Silau 398.

Silaus 398.

Silene 629.

Silge 411 .

Silybum 243.

Sinife 84.

Sinapis 561 .

Sinau 493.

Sinngrün 366.

Sisarum f. 1193.*

Sisymbrium 559.

Sium 387.

Sinilacina f. 92.

Solanum 332.

Solidago 189.

Sonchus 224.

Sonuenolume 208.

Sonnentbau 573.

Sorbus 505 .

Sparganiun 77.

Spargel 107.

Spargelerbie 435

Epart 471.

Spartium 450.

Specularia f. 253.

Sperberfenut 231. 
Eperget 471.

Spergella 613.

Spergula 471 .

Spergularia f. 470.

Spertling 613.

Eperrtraut 31)3.

Spiere 502.

Spinacia 480 .

Spinat 480.

Spindelbaum 634.

Spiraea 51$) 2$.

Spiranthes 123.

Spirodela 5.

Spikfal)ne 439.

Spibtlette 246.

Spongostemuna $163 \mathrm{c}$.

Epringtraut 611.

Eprisgurfe 248.

Epurre 617.

Stadelbixie 37.

Stachygynandrun $134 c$.

Stacliys 267.

Staphylea 601.

Statice f. 336.

Staurogeton 6. *

Gted)apfel 327.

Stedrübe 1741. *

Steinbred) 406).

Steifbalu 56.

Steintraut 541.

Steinfaame 292.

Stellaria 618.

Stellera 144.

Stenactis 186.

Gternolume 188.

Gternlyacintbe 10?.

Eterntraut 618.

Sternmiere 618.

Stiefmiutterd)en 1785.*

Stipa 20.

Stipularia f. 470 .

Stordifinabel 6i)s.

Stränoling 333.

Stranonium fo 327.

Stratiotes 12.

Strausigras 2().

Streblidia $67 \mathrm{~b}$.

Streptopus 90.

Sturmbut 586.

Sturmia 122.

Suaeda f. 486 .

Succisa $163 \mathrm{~d}$.

Sumad 429.

Sumpfoolodien 388.

Sumpfrourz 126.

Swertia 364.

Sympliytum 297.

Syringa 368 .

Iänuel 519.

รäid)eltraut 531.

Taglitie 106.

Tanacetum 198.
Sarme 141.

Eammenivedel 512.

Taphrogeton $72 \mathrm{~d}$.

Taraxacuu 222.

Iaubeneflel 264 .

Iaubentropf 630).

saumellold) 110.*

Iaufenoblatt 513 .

Iauienigiildentraut 362.

Taxus 136.

Teesdalia 532.

Seid)rict 74 .

Telmatospluace 4 .

Tephroseris 192.

Tetragonolobus 435 .

Teucriun 286.

Thalictrum $5 \% 9$.

Ibalftern 419.

Thesium 137.

Thlaspi 531 (i. aut) 536.)

Thrincia 215.

Thuja 139.

Eburmitraut 548 .

Shymian 273.

Thymus 273.

Thyrsanthus f. 347 .

Thysanochloa i. 55 a.

Thysselinum 402.

Tilia 635 .

Tillaea f. 462.

Tiniaria f. 1426 u. 27. * Violetta 572 b.

Tithymalus 1. $595 \mathrm{~b}$.

Tofieldia 55.

Ioltirfdee 328.

Tordylimn 4(1)9.

Torilis 379 .

Tormentilla 499.

Iraganth 4 (4).

Tragopogon 217.

Tragoselinum $386 \mathrm{~b}$.

Trapa 514.

Irespe 63.

Traunsteinera 111.

Trichera f. 163 at.

Trichodium $16 \mathrm{~b}$.

Trientalis $3+1$.

Trifolium 430.

Triglochin 7.

Trigonella 432.

Trimorphaea $187 \mathrm{~b}$.

Triodia 54.

Tripoliun 1. 634.*

Trisetum $23 \mathrm{~b}$.

Triticum 44.

Iroublume 588.

Trollius 588.

Tropaeolum 609.

Tryphane $61+\mathrm{b}$.

sürtenbund 97 a.

Tulipa 94.

Eulpe 9t.

Tunica 624.

Vaccinium 357

MâTernuß 514 .
Turgeniat 378.

Turritis $5+8$.

Tussilago 191.

Typha 76.

uferting 474.

Ulex 451 .

Ulmaria f. 502 b.

utlme 160).

Ulumus $16(0)$.

Urtica 155.

Utricularia 315, u. 5.452 .

Uvularia f. 96.

Vaccaria 625.

Valantia i. 5.SS. *

Valeriana 166.

Valerianella 165.

Sieild)en 572.

Ventenita 23 a.

Veratrum 86.

Verbascuu 319.

Verbena 288.

Veronica 311.

Serirnelte 632.

Viburnum 171.

Vicia $4+3$.

sierling 612 .

Vignea 64.

Vince 366 .

Viola 572.

Viscago 1975. *

Viscaria $633 \mathrm{~b}$.

Viscum 168.

Vit is 484 .

Sogeloeerbaum 505.

Vogelia f. 525.

Siogclfuß 455.

Sogelftern 103.

Voglera f. 1341.*

Vulpia 61.

MBađolber 138.

Ma(t)6blume 29 ).

Mad)telıaizen 31$) 6$.

Iิaio 526.

Maizen 44.

IBalberbie $4+6$.

MBalofric oc $3 \$ 5$.

IBalonteifter 173.

IBalorebe 583.

Malovëgelein 128.

Ballnus 428.

Malteraloe 12.

Malierdofte 236.

Mallerfever 339.

Malterlinie 3.

Baffernabel 417.

IBa Terídjierling f. 380t.

T3a)er(d)laud) 315.

IBa Terftern 597.

SBaffertide 11 . 


\section{$-461$}

Mau 564.

Miscgbreit 33t.

Bెegrid) 334.

Bointraut 121). Bcidnucicr 622 .

IBeide 147.

MुseiDerid) 521.

Mुein 424.

Weingaertnera f. 21 .

Meifburbe 151.

Meisoorn $5(1) 6$.

Beifordse 117.

Meištourz 91 a.

Mermutb 197 b.

Wiborgia f. 206.

Mide 443.

Biederftó 633 c.

Miefentnepf 494.

Miefenraute 579 .

Wiggersia f. 1307. *
MBindolute 581 .

MBinde 30$) 4$.

Mindbalm 16.

Bintergrün 351.

Minterling 589.

Mirbelioofte 276 .

M3oblverleil) 193.

Wolfzbol)ne 454.

Molfiffuß 255.

Bolfbutild) 595 .

Molfstrapp 272.

जुolfswur: 586 a.

Mouriet 71 .

Molvertci 191.

झुแ

Biitherid) 380.

Munitlee 453.

Murmiattid) 221.

Xanthium 246.

Xylosteum 170 a. 3aburours 550.

Zamuichellia 4.

Bartrict $72 \mathrm{~b}$.

3aute 91.

Bauntilie 105.

3auntebe 425 .

Zea 32.

3cl)rworg 2.

3 citlofe 87.

Birmet 419.

3ieft 267.

3ittergras 53.

Bottenblume 361.

Sweiblatt 92. 125.

3weigabn 207.

3werife 42.

3werggras 25.

3 merglein 636.

3wergmibpel 507. 


\section{Bor Dem Gebraudhe nöthiße Bertatigungel.}

No. 2 3cile 5 feke bingu: Tal - Eeptbr. 4. - PS. fęe fingu: 23arby, bei Gonmmern.

- $142 \cdot 3$ lies $\mathbf{Z}$ anftatt $\mathbf{L}$.

- $231: 7$ lies Grassmanniana.

- 264 - 5 lies Spr. anjtatt Wallr.

- 331 - 8 lies $4^{\prime}$ anftatt $4^{\prime \prime}$.

- 405: 1 lieb 11 anftatt II.

- 412 - 1 lies innata.

- $642: 5$ lies $\odot$ anftatt 4.

- 723 vorlser lies Oporinia.

- 7912 nnm. lies sabaudun.

- 307 Euphrasia.

- 1034 b. lies vulgaris.

- 1113 lies tenella.

- 1318 ift L. wegjuftreidjen.

- 1336 3eife 5 ties פaai - 2uguft.

- 1356 . 1 liez Tournaf.

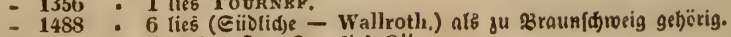
Söttung 557 und 558 anftatt $\mathrm{O}=$ lieह $0 \| 1$. 


\section{it $a$ dो $i$ ch $x$ i f $t$.}

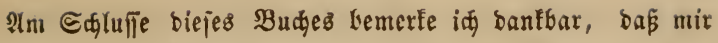

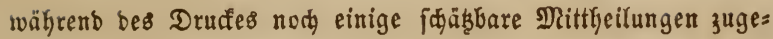
fommen finb, mandife @tanborte finb mir aud ncth zu eigner

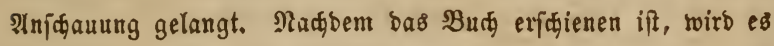
leidit fein, 3ufäkze unb Berbefierungen zu geben, uno wenn id midi redt balb burd bergleiden meitere Dittheilungen erfreut jefje,

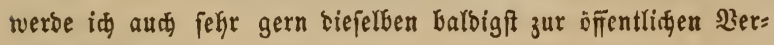
breitung benuk̨en.

$$
\text { Der } \mathfrak{B} \text { erfarfer. }
$$




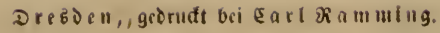






\section{QK314.R42}

Reichenbach, Heinri/Flora saxonica. Die

|| || ||||||||||| || || ||| ||| ||| || |||||||||||||||||||||||||

35185000893717

F 
